


\section{PATHS TO \\ SUSTAINABLE ENERGY \\ Edited by Jatin Nathwani \\ and Artie W. Ng}




\section{Contributors}

Tim Sharpe, Julio Terrados, Gabino Almonacid, Jorge Aguilera, Murat Gokcek, Valentinas Klevas, Marcio Casaro, Denizar Cruz Martins, Niels I. Meyer, Alvaro Montero, Julio Martos, Teresa Magraner, Nicolás Pardo, Javier Urchueguía, Tatyana Bandos, John Fletcher, Jin Yang, Marius Mircea Balas, Calin Musca, Sanda Musca, Alemayehu Gebremedhin, Herschel Specter, Kazuya Watanabe, Artur Pawlowski, Erik Laes, Aviel Verbruggen, Muhammad Bachtiar Nappu, Sridhar Gururaja Rao, Artie Ng, Jatin Nathwani, Chem Nayar, Wuthipong Suponthana, Markson Tang, Miroslav Lazic, Milos Zivanov, Boris Sasic, Branislav Repic, Dragoljub Dakic, Dejan Djurovic, Aleksandar Eric, Seyed Farid Ghaderi, Zahra Tavassoli Hojati, Samuela Vercelli, Nevzat Onat, Sonia Leva, Stefania Guzzetti, Roberto Faranda, Christian Blanc, Alfred Rufer, Kuo-Ing Hwu, Farshid Zabihian, Alan Fung, Chaouki Ghenai, Rongrong Zhai, Yongping Yang, Malti Goel

\section{(c) The Editor(s) and the Author(s) 2010}

The moral rights of the and the author(s) have been asserted.

All rights to the book as a whole are reserved by INTECH. The book as a whole (compilation) cannot be reproduced, distributed or used for commercial or non-commercial purposes without INTECH's written permission.

Enquiries concerning the use of the book should be directed to INTECH rights and permissions department (permissions@intechopen.com).

Violations are liable to prosecution under the governing Copyright Law.

\section{(c) BY}

Individual chapters of this publication are distributed under the terms of the Creative Commons Attribution 3.0 Unported License which permits commercial use, distribution and reproduction of the individual chapters, provided the original author(s) and source publication are appropriately acknowledged. If so indicated, certain images may not be included under the Creative Commons license. In such cases users will need to obtain permission from the license holder to reproduce the material. More details and guidelines concerning content reuse and adaptation can be foundat http://www.intechopen.com/copyright-policy.html.

\section{Notice}

Statements and opinions expressed in the chapters are these of the individual contributors and not necessarily those of the editors or publisher. No responsibility is accepted for the accuracy of information contained in the published chapters. The publisher assumes no responsibility for any damage or injury to persons or property arising out of the use of any materials, instructions, methods or ideas contained in the book.

First published in Croatia, 2010 by INTECH d.o.o.

eBook (PDF) Published by IN TECH d.o.o.

Place and year of publication of eBook (PDF): Rijeka, 2019.

IntechOpen is the global imprint of IN TECH d.o.o.

Printed in Croatia

Legal deposit, Croatia: National and University Library in Zagreb

Additional hard and PDF copies can be obtained from orders@intechopen.com

Paths to Sustainable Energy

Edited by Jatin Nathwani and Artie Ng

p. cm.

ISBN 978-953-307-401-6

eBook (PDF) ISBN 978-953-51-5967-4 


\section{We are IntechOpen, the world's largest scientific publisher of Open Access books.}

\section{$3,250+$}

Open access books available
$106,000+$

International authors and editors

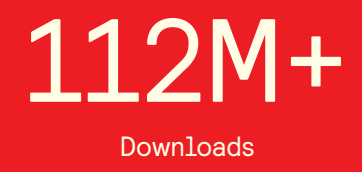

Downloads

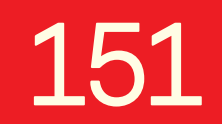 \\ Countries delivered to

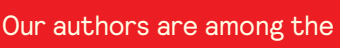

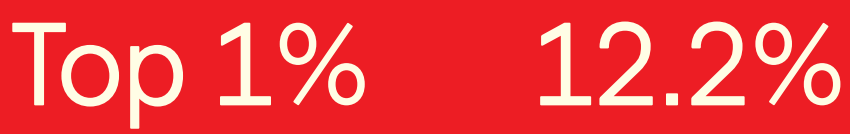 \\ most cited scientists \\ Contributors from top 500 universities}

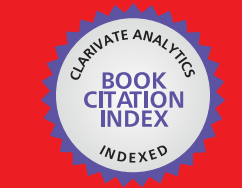

WEB OF SCIENCE ${ }^{\text {M }}$

Selection of our books indexed in the Book Citation Index

in Web of Science ${ }^{\mathrm{TM}}$ Core Collection (BKCI)

\section{Interested in publishing with us? \\ Contact book.department@intechopen.com}

Numbers displayed above are based on latest data collected.

For more information visit www.intechopen.com 



\section{Meet the editors}

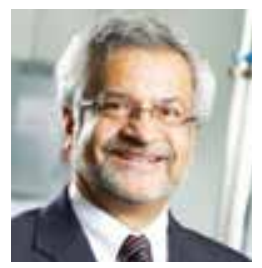

Professor Jatin Nathwani is the Ontario Research Chair in Public Policy and Sustainable Energy at University of Waterloo, in the Faculty of Engineering and the Faculty of Environment. He is the Executive Director, Waterloo Institute for Sustainable Energy (WISE). Dr. Nathwani's experience in the energy sector includes corporate strategy, business planning, policy developments influencing the electricity sector and the planning, design and operation of critical infrastructure. His knowledge of industry practices encompasses regulatory affairs, environmental health and safety issues and drivers of innovation in business practice. Dr. Nathwani serves on several Boards at the provincial and national levels.

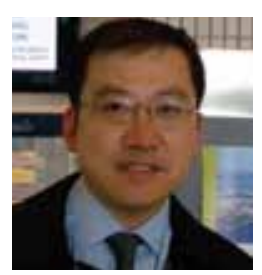

Dr. Artie W. Ng is Research Fellow at Public Policy Research Institute of The Hong Kong Polytechnic University and Senior Lecturer at the School of Professional Education and Executive Development in the same institution. Prior to his academic career, he gained substantial experience in the electricity sector. In his current capacity as an academic, Dr. $\mathrm{Ng}$ is an active researcher of interdisciplinary studies on dynamic management systems, resource allocation for technological innovation as well as the impact of externalities on sustainability policy. 



\section{Contents}

Preface XIII

Part 1 Public Policy and Planning

for a Sustainable Energy Future 1

Chapter 1 Backcasting a Future of Sustainable Energy:

A Public Policy Perspective 3

Jatin Nathwani and Artie W. Ng

Chapter 2 Sustainable Development

vs Environmental Engineering: Energy Issues 13

Artur Pawłowski

Chapter 3 A Call to Action 29

Herschel Specter

Chapter 4 Energy Planning: A Sustainable Approach $\mathbf{5 7}$

Julio Terrados, Gabino Almonacid and Jorge Aguilera

Chapter 5 The Passive Greenhouses 75

Marius M. Balas, Calin B. Musca and Sanda V. Musca

Chapter 6 Decision Support for National Sustainable

Energy Strategies in an Integrated

Sustainability Assessment Framework 93

Erik Laes and Aviel Verbruggen

Chapter 7 Regional Approach for Policies and

Measures Aiming to Sustainable Energy Development 117

Valentinas Klevas

Chapter 8 Identifying Regional Behavior Impacts

of Electricity Generation in Electricity Market

with SSNIP and Granger Test 133

Z. Tavassoli Hojati and S. F. Ghaderi 
Chapter 9 Supporting Psychosocial Processes towards a Sustainable Energy System: The Case of $\mathrm{CO}_{2}$ Geological Storage 155 Samuela Vercelli

Chapter 10 An Advanced Method of Congestion Management for Optimal Energy Pricing 181

Muhammad Bachtiar Nappu and Tapan Kumar Saha

Part 2 Utilization of Solar and Wind Resources 197

Chapter 11 PV Solar Energy Conversion Using the Behavior Matching Technique 199

Marcio Mendes Casaro and Denizar Cruz Martins

Chapter 12 Cost Calculation Algorithm for Photovoltaic Systems 211 İran Güney and Nevzat Onat

Chapter 13 Wind Energy 237

Chaouki Ghenai and Armen Sargsyan

Chapter 14 Introduction to Doubly-Fed Induction Generator for Wind Power Applications 259

John Fletcher and Jin Yang

Chapter 15 The Role of Aesthetics, Visual and Physical Integration in Building Mounted Wind Turbines - An Alternative Approach 279

Tim Sharpe

Chapter 16 New Systems Thinking and Policy Means for Sustainable Energy Development 301 Niels I. Meyer

Chapter 17 Developing Wind Energy in Turkey 315 Murat Gökçek

Part 3 Energy Storage and Efficient Use of Energy 331

Chapter 18 Understanding the Vanadium Redox Flow Batteries 333 Christian Blanc and Alfred Rufer

Chapter 19 Desing of Multiphase Boost Converter for Hybrid Fuel Cell/Battery Power Sources 359 Miroslav Lazić, Miloš Živanov and Boris Šašić

Chapter 20 Non-Isolated High-Gain DC-DC Converter Using Charge Pump and Coupling Inductor 405 Kuo-Ing Hwu and Yeu-Torng Yau 
Chapter 21 Advanced Power Generation Technologies: Fuel Cells 421

Farshid Zabihian and Alan S. Fung

Part 4 Making Fossil Fuels Sustainable 459

Chapter 22 Carbon Capture and Storage Technology

for Sustainable Energy 461

Malti Goel

Chapter 23 CaO-based $\mathrm{CO}_{2}$ Capture Technology and Its Application in Power Plants 483

Rongrong Zhai and Yongping Yang

Chapter 24 MEA-Based $\mathrm{CO}_{2}$ Capture Technology and Its Application in Power Plants 499

Yongping Yang and Rongrong Zhai

Chapter 25 High Renewable Energy Penetration

Diesel Generator Systems 511

Chemmangot V. Nayar

Chapter 26 Facts about Producer Gas Engine $\mathbf{5 3 7}$

G. Sridhar and Ravindra Babu Yarasu

Part 5 Role of Technological Innovations and Emerging Technologies 561

Chapter 27 Electric Power from Rice Paddy Fields $\mathbf{5 6 3}$

Kazuya Watanabe and Koichi Nishio

Chapter 28 Switching from Renewable to Renewable A Case Study from Nordic Perspective $\mathbf{5 8 1}$

Alemayehu Gebremedhin

Chapter 29 Design and Technology for Efficient Lighting $\mathbf{5 9 7}$

R. Faranda, S. Guzzetti and S. Leva

Chapter 30 Ground Coupled Heat Pumps in Mixed Climate Areas:

Design, Characterization and Optimization 621

Álvaro Montero, Tatyana Bandos, Julio Martos, Teresa Magraner,

Nicolás Pardo and Javier Urchueguía

Chapter 31 Development of a Boiler

for Small Straw Bales Combustion 647

Branislav Repic, Dragoljub Dakic,

Dejan Djurovic and Aleksandar Eric 



\section{Preface}

The need for a transformation of the global energy system with a lower environmental footprint is now widely recognized among decision makers in government, political leadership as well as leaders of non-governmental organizations (NGOs), the corporate business sector and the national academies. The United Nations (UN) report on "Energy for a Sustainable Future" (April 2010) is but one of many that call for a drastic realignment of the global energy system on a large scale as an urgent priority to enable a sustainable future for all. The performance of the economic system in harmony with the goals of a cleaner environment remains at the heart of the challenge framed by the growing demand for energy services arising from a combination of demographics and shifting income levels in developing countries. Our reliance on existing sources of energy and their associated detrimental impacts on the environment- whether related to poor air or water quality or scarcity, impacts on sensitive ecosystems and forests and land use - have been well documented and articulated over the last three decades. What is required is a set of credible solutions for both developed and developing countries that strike a balance between economic growth and a sustainable environment. For example, the UN report explains,

"Clean, efficient, affordable and reliable energy services are indispensable for global prosperity. Developing countries in particular need to expand access to reliable and modern energy services if they are to reduce poverty and improve the health of their citizens, while at the same time increasing productivity, enhancing competitiveness and promoting economic growth. Current energy systems are inadequate to meet the needs of the world's poor... For instance, in the absence of reliable energy services, neither health clinics nor schools can function properly. Access to clean water and sanitation is constrained without effective pumping capacity."

The Report of the Interacademy Council, 'Lighting the Way to A Sustainable Energy Future," succinctly summarizes the challenge for the required transition as follows,

"Making the transition to a sustainable energy future is one of the central challenges humankind faces in this century. The concept of energy sustainability encompasses not only the imperative of securing adequate energy to meet future needs, but doing so in a way that (a) is compatible with preserving the underlying integrity of essential natural systems, including averting dangerous climate change; (b) extends basic energy services to the more than 2 billion people worldwide who currently lack access to modern forms of energy; and (c) reduces the security risks and potential for geopolitical conflict that could otherwise arise from an escalating competition for unevenly distributed energy resources." 
The awareness of the urgency to reengineer the overall balance among our accustomed economic development models, life-styles and the use of energy sources is gaining momentum. While there is interest among diverse stakeholders in formulating solutions for energy sustainability, there is a need to focus the collective wisdom to formulate effective solutions. We believe this book provides an open platform to establish and share such intellectual capital among scholars, scientists and engineers from all over the world about various viable paths to a future of sustainable energy.

We hope that this book will provide a bridge for stakeholders with practical guidance to pursue the paths to a sustainable energy future. Success will depend on continuous technological innovation, cross-border knowledge sharing and technology transfer, timely local deployments and implementations. Moreover, the world needs a parallel development of frameworks and policies to reinforce and build on the successes one step at a time over the coming decades. This book is organized into the following five sections:

I. Public policy and planning for a sustainable energy future

II. Utilization of solar and wind resources

III. Energy storage and efficient use of energy

IV. Making fossil fuels sustainable

V. Role of technological innovations and emerging technologies.

Starting with the exploration of the imperatives of public policy and planning for sustainable energy in Section I, scholars from various countries examine the critical issues to be addressed in formulating sustainable energy policies and planning for the future within the electricity sector. Section II collects articles about the increasingly popular utilization of the natural resources that do not generate emissions in their power generating processes, namely solar and wind, to generate electricity. The subsequent Section III and IV provide a platform to share knowledge about the growing interests and uses of energy storage technologies, such as fuel cells, as well as the possible solutions to mitigate the problems with GHG emissions caused by fossil fuels. Section V is a collection of articles that explore other technological innovations and implications for enhancing the development of sustainable energy systems.

Jatin Nathwani

Professor and Ontario Research Chair in Public Policy for Sustainable Energy Executive Director, Waterloo Institute for Sustainable Energy University of Waterloo, Ontario, Canada

Artie W. Ng

Fellow, Public Policy Research Institute Senior Lecturer, School of Professional Education \& Executive Development The Hong Kong Polytechnic University 


\section{Part 1}

\section{Public Policy and Planning \\ for a Sustainable Energy Future}





\title{
Backcasting a Future of Sustainable Energy: A Public Policy Perspective
}

\author{
Jatin Nathwani ${ }^{1}$ and Artie W. $\mathrm{Ng}^{2}$ \\ ${ }^{1}$ Waterloo Institute for Sustainable Energy, University of Waterloo \\ ${ }^{2}$ Public Policy Research Institute / School of Professional Education \& Executive \\ Development, The Hong Kong Polytechnic University \\ ${ }^{1}$ Canada \\ ${ }^{2}$ Hong Kong
}

\section{Introduction}

Although the adoption of renewable energy is perceived as a means to enable delivery of emission-free solutions, its penetration into the energy market has not been timely and significant enough to make a material impact on the structure of the global energy system. Using backcasting as a policy tool for developing a view of a sustainable energy future, this Chapter aims to explore some of the critical hurdles as the policy makers continue to formulate and advance environmentally friendly energy consumption in order to mitigate the impacts of climate change. We illustrate the nature of the challenges to reach a wider adoption of alternative energy resources and build on the need for renewal of the energy "delivery" infrastructure through the "smart grid" as a means for transition to a sustainable economy in the longer term.

While there is now engagement with the public about a sustainable future, alignment of stakeholders' economic interests and absorption capacity of emerging technologies remain as the two main challenges in mitigating the underlying systemic hurdles to be overcome. As the public at large realize the need for a future of sustainable energy despite lack of a global consensus about definitive targets, the policy makers may seek to provide a combination of approaches that build on optimal investment incentives in the near-term, liberalization of the electricity grids in the medium term and a dynamic policy framework that induce continuous technological innovation in the longer term. Observing the current responses to the externalities by the policymakers in a number of jurisdictions we articulate such forthcoming initiatives to mitigate the systemic hurdles embedded in the existing energy infrastructure. We also articulate measures to enable deployment of integrative sustainable energy solutions over a transformed infrastructure, namely smart grid.

\section{Backcasting a future of sustainable energy}

Prior and current studies of energy use have confirmed the problems with the deterioration of air quality and the consequences of lingering reliance of fossil fuels in the modern global economy. The public concern about sustainability of the environment and the ongoing 
issues with climate change remains an important driver of social and political influence. Advocates, mainly from the developed economies have argued for a set clear objectives and targets on emission of Greenhouse Gases (GHG). There is, however, no unanimity and divergent perspectives emerge as at the core of the debates across the globe. Individual countries at different stages of economic development have advocated to jointly limiting their emission to a certain level in response to the adverse effects resulting from climate change. Such an initiative resembles the concept of backcasting for an end point in time with a pre-determined target (Robinson 1982; $\mathrm{Ng}$ 2009). Under such an initiative, a future of sustainable energy with a cap on GHG emission is desired as target.

Such multilateral negotiations have proved to be highly challenging given the complexity of politics involved with respective jurisdictions and the diversity of stakeholders' interests. This was demonstrated in the UN Climate Summit held in Copenhagen December 2009 where multilateral agreements over specific target or cap were attempted but failed inevitably. ${ }^{1}$

\section{Challenges at the policy level}

\subsection{Rethinking the targets and constraints in backcasting}

Although the stakeholders tend to concur on the broad need to deal with issues of climate change and the desire to improve sustainability, there is no coherent plan or a clear road map to a sustainable future. Some argue that there is not sufficient political will among the major players to drive the conclusion of a target at a future point in time (BBC 2009). There are concerns that the un-reconciled targets among the nations would hamper any further progression towards a sustainable future.

In the backcasting methodology, however, it is suggested that while it is critical to have a certain degree of consensus among the key public stakeholders, such a consensus for practical purposes is only around qualitative values. (Robinson 2003). Further development of specific targets would take place at another level on which the local stakeholders might seek more precise sub-optimal targets. In reality, this would be an iterative process with end points and scenarios guiding the process of planning towards the future prior to specific quantifications ( $\mathrm{Ng} 2009$ ).

As reflected in the current public policy formulations among various jurisdictions, the momentum to improve sustainability is still observable despite their respective variations in pace and strategy. Allegedly there are differences in constraints among the political systems as well as in embedded objectives. While some jurisdictions might be accustomed to more explicit and definitive commitments, some might have practical concerns over commitments that could be disagreeable by domestic stakeholders. For instance, the European Renewable Energy Council (EREC) has developed a detailed roadmap and specific renewable energy consumption target of $20 \%$ by 2020 (Zervos and Lins 2010); such a target could be exceeded by another $20 \%$ with reference to the assumption that EU might have even implemented a more ambitious roadmap. Other advanced economies, such as U.S. and Canada however have not developed a national target despite commitment devised by certain states and

$1 \mathrm{BBC}$ (2009) reported on the various reasons for the failure of to reach an agreement with quantifiable measures and noted, "The logical conclusion is that this is the arrangement that the big players now prefer - an informal setting, where each country says what it is prepared to do - where nothing is negotiated and nothing is legally binding." 
provinces. China, another major player in the global economy, has voluntarily to set a target of $15 \%$ by 2020 . The variations in commitment among these major economies is evidence of the differences in pace of economic growth, existing energy portfolio mix and the level of advancement and implementation of renewable energy technologies in the supply mix.
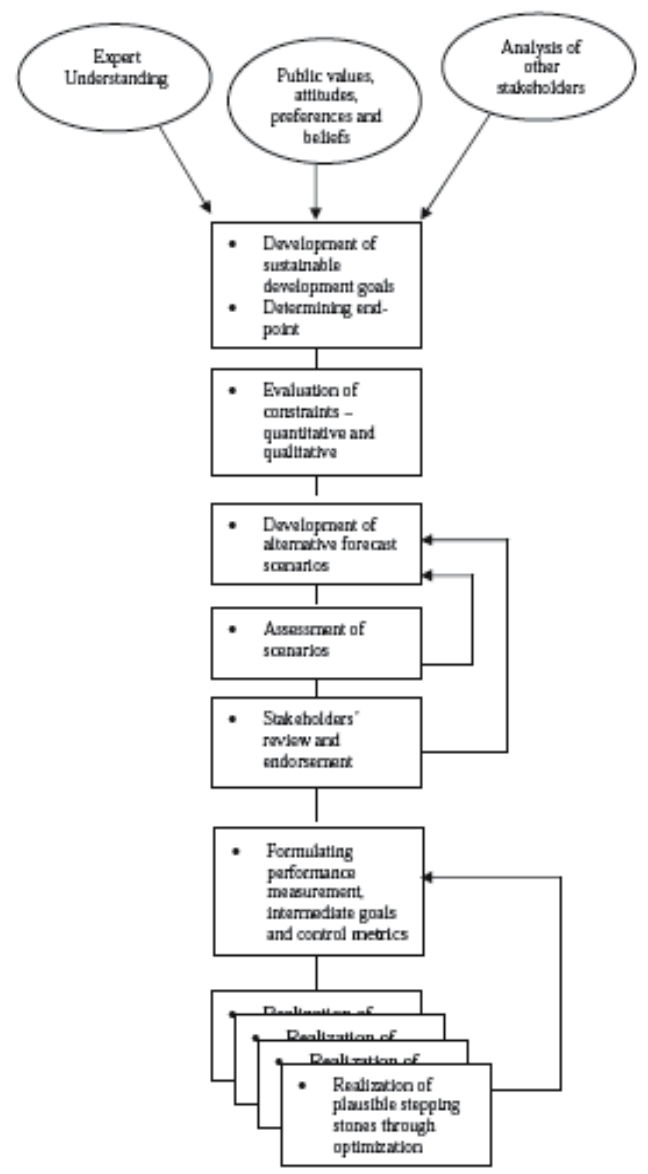

Fig. 1. Backcasting framework for the renewable energy sector $(\mathrm{Ng} 2009)$

\subsection{Optimization under moving targets}

Although there are no confirmed targets set through multilateral agreements, this has not dampened the furthering of policy initiatives to improve the sustainability of energy supply. It is understandable that politicians have difficulties in committing to targets that have short term ramifications on energy supply security, prices and affordability and reliability. Under the preferred voluntary approach, individual countries influenced by both international and domestic political pressures continue to admit their concerns about over reliance on fossil fuels. The public at large has increasingly acknowledged the cost of such externalities to the environment and to the health impacts, which are seen as the common values and constraints agreeable among the human beings. While more resources are being allocated to develop and build capacity of renewable energy, the approach and roadmap to a scenario of 
sustainable energy would still be subject to subsequent transformation of the energy infrastructure as well as technological advancement for renewable energy resources. In other words, the jurisdictions would continue to seek their individual plausible stepping stone through optimization ( $\mathrm{Ng}$ and Nathwani 2010).

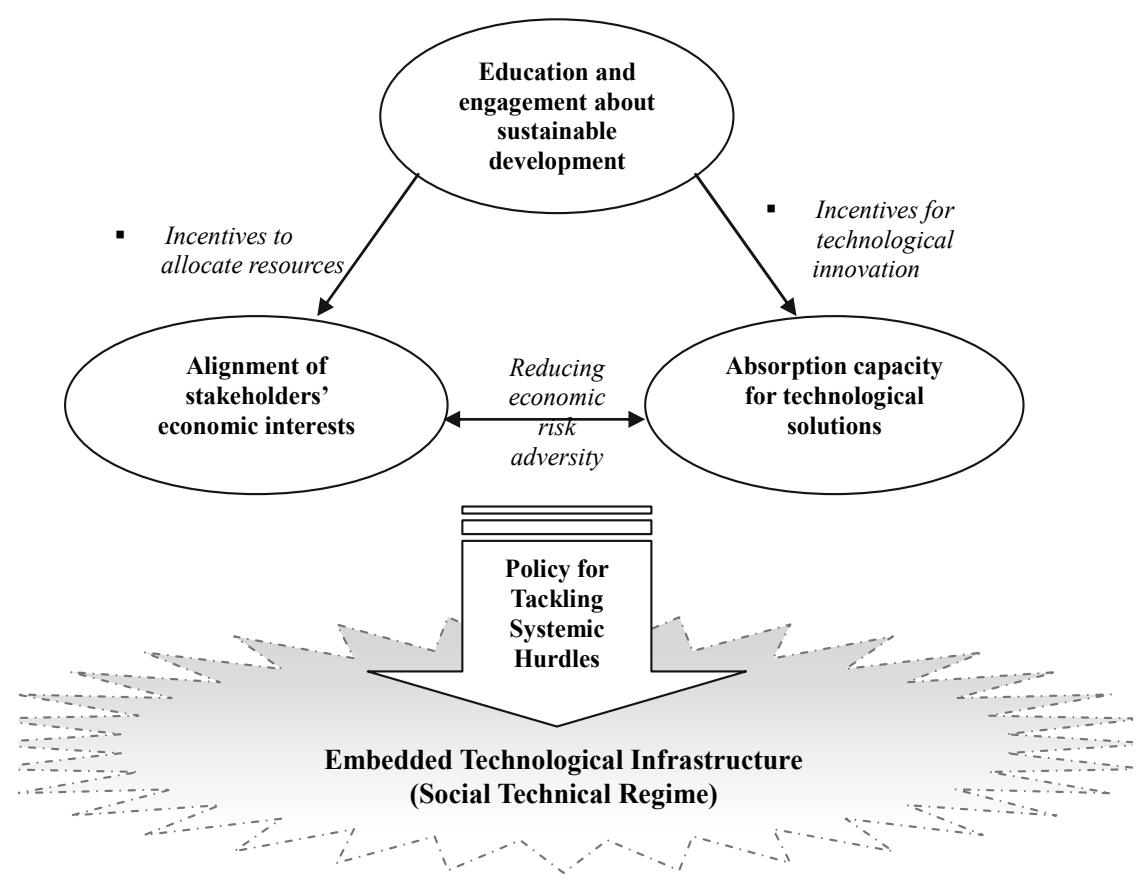

Fig. 2. Dynamic policy development towards a future sustainable energy (Ng and Nathwani 2010)

\section{Emerging country policies to embrace sustainable energy}

\subsection{Inducing multiple sources of renewable and sustainable energy}

As we move into a future of sustainable energy, the dominance of fossil fuels would have to be replaced by a more balanced mix of energy options as suggested by Fanchi (2004). Among the mix, the most convincing sources would seemingly be composed of hydro, solar, wind, geothermal and wave, depending on the geographical dimensions. In order to ensure stability of electricity loading and energy supply, the use of nuclear energy is likely to be maintained and even increased for its complementary characteristics and carbon-free in emission. ${ }^{2}$ Fossil fuels, including natural gas, would still be a likely source for vehicles until a more extensive application of electric and hydrogen-fueled vehicles.

In recent years, policy makers have attempted a number of approaches ranging from command and control through regulations to incentives such as Feed-in Tariffs (FITs) to

\footnotetext{
${ }^{2}$ See Nathwani et al, (1992) and more recently Mackay (2009) in his exploration of a balance sheet of energy production and energy consumption.
} 
Renewable Portfolio Standards (RPS) to promote the development of renewable energy sources through private investments. Stability of a policy framework and the supporting governance models are considered critical to inducing new investments for renewable energy and they will vary from context to context in different countries and political systems. For instance, clean tech ventures are viewed as the next major investment focus among the venture capitalists in the U.S. as the pertinent policy unveiled (Pernick and Wilder 2010). In Canada, the study by Holburn et al. (2010) revealed the influence of pertinent policies to induce initial investments in wind power. On the other hand, emerging ventures have not only expanded in the domestic market but could swiftly tackle international markets where accommodating renewable energy policies are in place as demonstrated in the emerging renewable energy sector in Germany (Jacobsson. and Lauber 2006).

\subsection{Three stages of development}

For further development of renewable energy sources, a stable policy framework is necessary and complementary for the growth and development of an industry that can be stimulated by positive economic incentives. For example, Germany introduced FITs to stimulate the direct investments of solar energy and wind power converted into electricity sold through grids to the end customers giving a boost to early stage development. Such measure enables the nurturing and development of new ventures in renewable energy as well as the growth of pertinent knowledge and technology. The perceived investment risk and cost of capital for such early-stage development by a firm would be reduced as a consequence.

In the next stage of development - the medium term, the policy makers would see the need for the development of an infrastructure that intelligently enhances the supply of renewable energy. For instance, one of the key problems of GHG relating to emissions from fossilfueled vehicles would be mitigated through an extensive adoption of electric vehicles. In particular, the development of a smart grid ${ }^{3}$ would enhance the development and growth of alternative energy sources while providing sufficient electricity supply to extend the use of electric vehicles. The end users will be empowered to choose their choice of energy through an intelligent platform for demand and supply.

In the third stage of development, sustainable and yet competitive industry, emergence of a sustainable and yet would encourage business competitions through a smart grid that is widely open to multiple sources of renewable energy producers as suppliers of energy to the grid. This smart grid system would facilitate the development of a technological regime under which technological innovation will be promoted and efficiency of renewable energy will be further enhanced under an economic model near pure competition (World Economic Forum 2009). For instance, solar energy ventures need continuous technological innovation so as to make solar energy as a viable solution under the current technological regime of the electricity market. In the next decade, the cost of solar panels could be drastically reduced within the next generation of solar energy through technological advancement in efficiency and mass production (Dhere 2007; Pernick and Wilder 2010).

Nonetheless, the combination of other emerging renewable energy sources as well as development of complementary policy and technological infrastructure could perplex the

3 See Report of the Ontario Smart Grid Forum ‘Enabling Tomorrow's Electricity System,' IESO (2009). 
landscape (Johnston et. al., 2005; Johnson and Suskewicz, 2009; Ng and Nathwani, 2010). Reaching this stage of relative market liberalization, an open market for competition through smart grids would, for instance, promote swift development and applications of more efficient solar panels into the electricity markets.

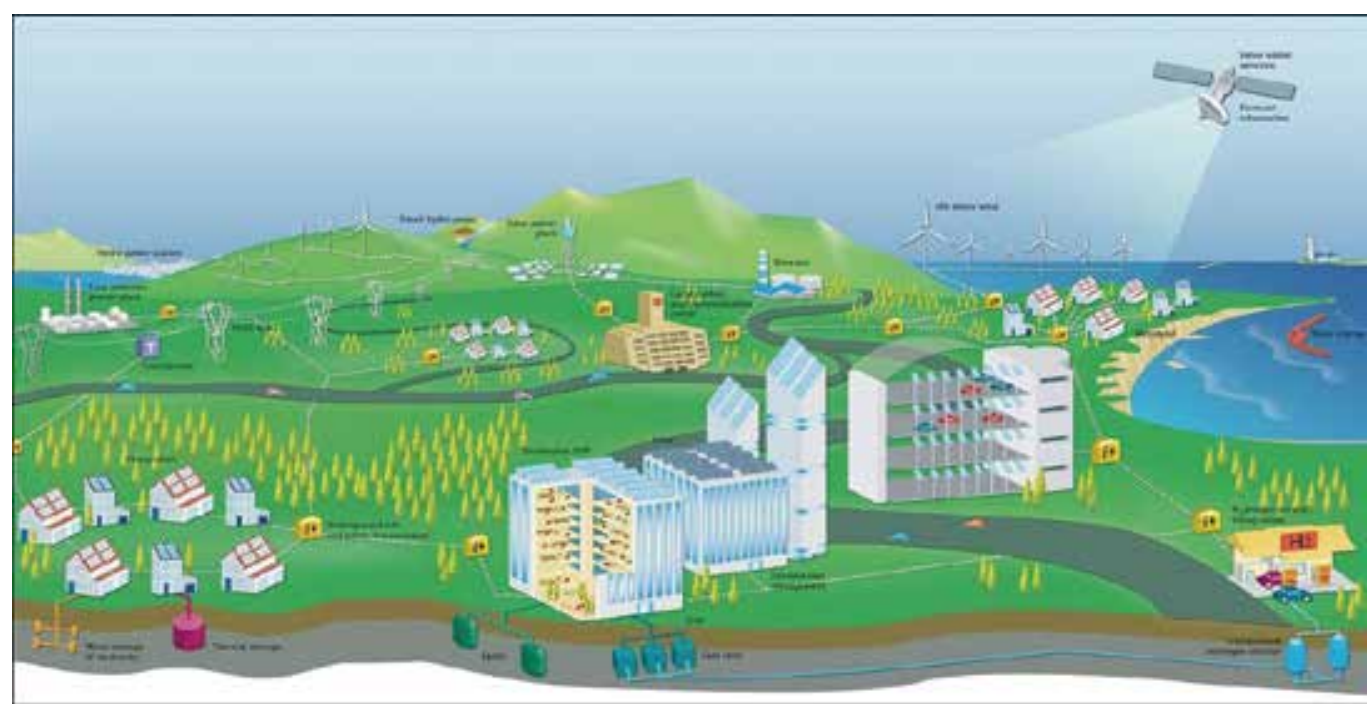

Fig. 4. A scenario of smart grid system in the future ${ }^{4}$

\section{Approaching the medium term - the arrival of smart grid}

\subsection{The significance of smart grid}

As the smart grid technology becomes feasible, the policy makers become increasingly convinced for its complementarity to sustainable energy. Smart grid could help create a landscape for rapid technological innovation envisaged by Grin (2008). The development experience of $3 \mathrm{G}$ networks in the telecom sector and the innovation of smart phones would resemble the potentials of smart grid. Effectively, smart grid would enable consumer empowerment and incentives through real-time information, time-based pricing and utilitybased demand controls. It would also facilitate net metering for consumer-based renewable energy generation through solar and wind, etc. Smart grid in short represents an opportunity to transform the existing infrastructure into one that delivers improved efficiency and optimal capacity utilization as the consumers would ultimately be empowered to choose the most competitive and yet sustainable sources through their smart grid. Remote sources of renewable energy despite issues with their loading stability, including solar and wind, would be extracted and integrated into smart grid so as to maximize their potentials to maximize their potential under a balanced mix of sustainable energy sources.

\subsection{The frontiers from the east and west}

While Fanchi (2004) expressed the potential variations in energy sector development among the various civilizations of the world, differences in the renewable energy development

4 Source: European Technology Platform SmartGrids 
models among countries in the east and west could be assumed. Although it is observed that there are frontiers in the east and west which have commenced their races towards sustainable energy through smart grid developments, there may well be variations in approach, namely between the centralized planning in China and the market-driven ones in the United States. The key initiatives among the frontiers in smart grid from the east and west are summarized in Table 1.

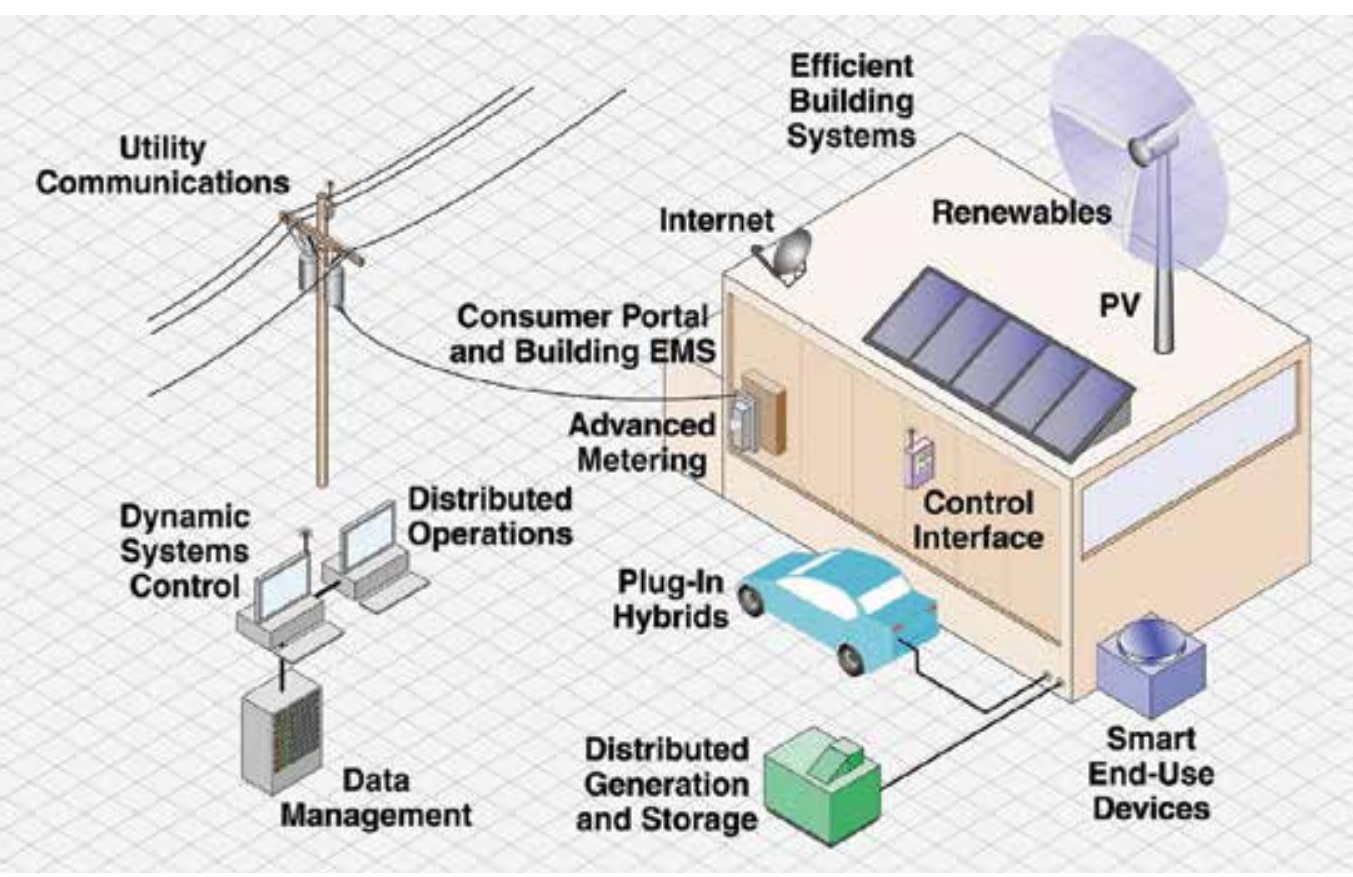

Fig. 4. A schematic of smart grid utilization ${ }^{5}$

\begin{tabular}{|c|c|c|}
\hline East Asia & Europe & North America \\
\hline $\begin{array}{l}\text { China } \\
\text { - } \quad \text { Set forth a } \$ 586 \text { billion stimulus } \\
\text { plan to invest in water systems, } \\
\text { rural infrastructures and power } \\
\text { grids, including a smart grid } \\
\text { system. } \\
\text { Prepared to invest } \$ 7.3 \text { billion } \\
\text { this coming year in smart grid } \\
\text { technology, edging out the } \$ 7.2 \\
\text { billion in U.S. investments } \\
\text { Aim to reduce its overall } \\
\text { energy consumption and make } \\
\text { the power distribution network } \\
\text { more efficient. As part of the } \\
\text { efforts to reduce energy }\end{array}$ & 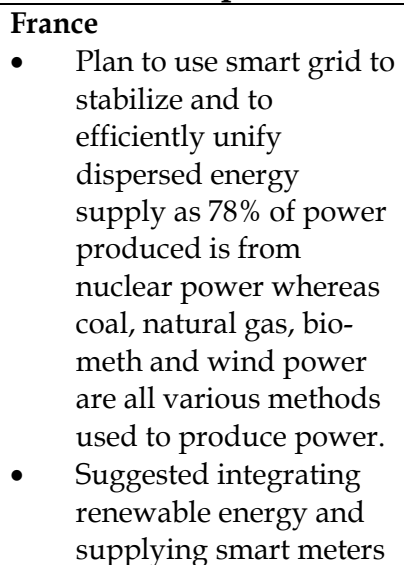 & $\begin{array}{l}\text { Canada } \\
\text { - } \quad \text { National smart grid } \\
\text { implementation will } \\
\text { depend on each } \\
\text { province since the } \\
\text { electricity system is } \\
\text { under provincial } \\
\text { jurisdiction. } \\
\text { Ontario declared } \\
\text { “Green Energy Act as a } \\
\text { comprehensive } \\
\text { government policy } \\
\text { action. Ontario Energy } \\
\text { Board in Canada } \\
\text { mandated a large scale }\end{array}$ \\
\hline
\end{tabular}

5 Source: Electric Power Research Institute 
consumption, smart grid

systems are being considered.

\section{Korea}

- $\quad$ Made a tentative deal with Illinois to jointly develop and test technologies for smart grid. The two parties will set up a pilot program to create smart grid technology at a facility on Jeju Island. Under the plan, technologies that are developed through this partnership and are deemed viable for commercialization will be rolled out both in Illinois as well as in Korean cities. The Korea Electrotechnology Research Institute and other related local centers will collaborate with Illinois' Argonne National Laboratory.

- The Korean government seeks to complete the installment of smart grid in the country by 2030 and establish another 27,000 or more power charge stations for electric cars. A total of 27.5 trillion won will be injected according to the roadmap. The government plans to handle it by developing core technology, new markets, new infrastructure and attracting voluntary investment from businesses.

\section{Japan}

- Announced a national Smart Metering initiative and large utilities companies announced Smart Grid programs to commence in 2010.

- A consortium of well known Japanese companies, formed by Hitachi, Toshiba, Fuji, and Panasonic, plans to construct a working Smart Grid system in New Mexico by 2010. The effort is led by Japan's public research and development organization for environmental to reflect consumer's

demands

- $\quad$ France' energy

environment public

corporation ADME

(Agence de

l'Environnement et de la

Maîtrise de l'Energie)

supports electric vehicle technology-related research and formulated a smart grid roadmap.

- $\quad$ Planning to substitute old fashioned electricity meters by smart meters by 2015 in all households.

UK

- $\quad$ The British Department of Energy and Climate Change (DECC) and the regulator Ofgem published a smart grid route map. A U.K. smart grid could be delivered to contribute to the realization of government carbon targets and endcustomer benefits.

- $\quad$ The route map was developed by the Electricity Networks Strategy Group (ENSG) aiming to realize the U.K.'s smart grid vision.

- $\quad$ Focus on critical smart grid roles for the nation's planned low carbon transition up to 2050, including the integration of inflexible generation, the electrification of transport and heating, as well as integration of distributed energy resources.

- $\quad$ Three high level objectives include carbon reduction, smart grid initiative by upgrading from traditional Automatic Meter Reading (AMR) to Advanced Metering Infrastructure (AMI), a system capable of measuring and analyzing energy usage using two-way communication, throughout the province. The province plans to implement smart meters in all household by 2010 .

- Issues of standardization, security, maintenance and regulation remain a concern while continuing talks between President Obama and Prime Minster Harper implicate a definite movement towards smart grid.

U.S.

- Development of smart grid in the United

States is stimulated by the \$4.5B USD allocated to grid modernization under the American Recovery and Reinvestment Act (ARRA).

- $\quad$ Research in promising technologies for smart grid implementation under the Smart Grid Demonstration Program (SGDP), which allocated $\$ 100 \mathrm{M}$ USD to regional smart grid demonstrations and \$515M USD to energy storage demonstrations. The Smart Grid Investment 


\begin{tabular}{|c|c|c|}
\hline $\begin{array}{l}\text { technologies, NEDO (New } \\
\text { Energy and Industrial } \\
\text { Technology Development } \\
\text { Organization). The Japanese } \\
\text { government is expected to co- } \\
\text { invest between } \$ 20.3 \text { and } \$ 30.4 \\
\text { million in the project composed } \\
\text { of digital monitoring and } \\
\text { distribution of power as well as } \\
\text { solar power generation and } \\
\text { storage. The consortium will } \\
\text { retain ownership of the grid } \\
\text { and control it in large part via } \\
\text { the Internet. }\end{array}$ & $\begin{array}{l}\text { energy security, and } \\
\text { economic } \\
\text { competitiveness and } \\
\text { affordability in } \\
\text { delivering a cost } \\
\text { effective low carbon } \\
\text { transition. }\end{array}$ & $\begin{array}{l}\text { Grant (SGIG) } \\
\text { programs also allotted } \\
\text { \$3.3B USD towards the } \\
\text { quick integration of } \\
\text { proven technologies } \\
\text { into existing electric } \\
\text { grid infrastructure. } \\
\text { Renewable Portfolio } \\
\text { Standards (RPS) for } \\
\text { production of energy } \\
\text { from renewable } \\
\text { sources adopted under } \\
\text { state legislation. }\end{array}$ \\
\hline
\end{tabular}

Table 1. Key policy initiatives for smart grid development in the world ${ }^{6}$

\section{Concluding remarks: towards a scenario of market forces for sustainable energy}

As we look backward from a future scenario of multiple sources of sustainable energy, the world today is posed to upgrade its existing energy infrastructure that would intelligently enable us to embed sustainable policy that benefits the coming generations of the human race. To achieve that scenario, we need to continue to develop policy that enables the electricity and energy industries to undergo a mission-critical transformation. In particular, finances and investments should be stimulated for resources allocation into the development and upgrade of the existing infrastructure at a level of risk that is commensurate with the benefits derived from a safe and secure network that provides delivery at a high level of reliability. At the same time, there ought to be well-planned reform of the existing electricity sector in order to facilitate a comprehensive utilization of the smart grid system. In particular, ownership structure of the pertinent assets should promote sufficient fair competition driving the development of a wide landscape of technological innovation for renewable energy as envisaged by Grin (2008).

New industries for renewable energy and pertinent infrastructure are expected to be built in the coming decades. A strong and stable policy framework plus confidence in the governance of the energy sector will enhance the corresponding value chains development as well as complementary ventures invested and nurtured as a consequence. Given the scale of developments, there will essentially be cross-border collaborations to optimize the strengths of different jurisdictions in building up the value chains for the emerging industries of solar panels, wind turbines and other supplies for building smart grid infrastructures. Nevertheless, the world now needs to learn about these emerging technologies and the knowledge to deploy these intangibles continuously in an innovative manner in order to reach a future of sustainable energy. The positive dynamics among the policy makers, the industry innovators and the general public would need to be engendered swiftly prior to an end point in backcasting.

\footnotetext{
${ }^{6}$ The table is a summary of the recent studies by Korean Smart Grid Institute (2010).
} 


\section{References}

BBC (2009) Why did Copenhagen fail to deliver a climate deal? 22 December 2009, (http://news.bbc.co.uk/2/hi/science/nature/8426835.stm) [accessed 19 August, 2010]

Dhere, N.G. (2007) Toward GW/year of CIGS production within the next decade, Solar Energy Materials and Solar Cells, Vol. 91 No.15-16, pp. 1376-1382.

Fanchi, J. R. (2004) Energy: Technology and Directions for the Future. Elsevier Academic Press, London, UK.

Grin, J. (2008) The multilevel perspective and design of system innovations, In: Managing the Transition to Renewable Energy: Theory and Practice from Local, Regional and Macro Perspectives, Edward Elgar, U.K.

Holburn, G., Lui, K. and Mor, C. (2010) Policy Risk and Private Investment in Wind Power: Survey Evidence from Ontario, Canadian Public Policy, forthcoming.

IESO, Independent Electricity System Operator, Ontario, Canada http://www.ieso.ca/imoweb/marketsandprograms/smart_grid.asp [accessed August 31, 2010]

Jacobsson, S. and Lauber, V. (2006) The politics and policy of energy system transformation - explaining the German diffusion of renewable energy technology, Energy Policy, Vol.34, No.3, pp.256-276.

Johnson, M.A. and Suskewicz, J. (2009) How to jump start the clean-tech economy, Harvard Business Review OnPoint, Spring, pp.88-96.

Johnston, B., Mayo, M.C. and Khare, A. (2005) Hydrogen: the energy source for the 21st century, Technovation, Vol.25, pp.569-585.

Korean Smart Grid Institute: http:/ / smartgrid.or.kr/eng.htm [accessed 18 August, 2010]

Mackay, David, J.P, “Sustainable Energy - Without the Hot Air,” (2009), UIT, Cambridge, England.

Nathwani, J.S, E. Siddall, N.C. Lind (1992) Energy for 300 Years: Benefits and Risks, Institute for Risk Research, University of Waterloo, Waterloo, ON, Canada.

$\mathrm{Ng}$, A. W. (2009) Backcasting performance of the emerging renewable energy sector in China: A strategic optimization approach for policy making, Journal of Technology Management in China, Vol.4, No.1, pp. 53-66(14).

$\mathrm{Ng}$, A.W. and Nathwani, J. (2010) Sustainable energy policy for Asia: mitigating systemic hurdles in a highly dense city, Renewable and Sustainable Energy Reviews, Vol.14 No.3, pp.1118-1123.

Pernick, R. and Wilder, C. (2010) Clean Energy Trends 2010, The Clean-tech Market Authority.

Robinson, J. (1982), Energy backcasting: a proposed method of policy analysis", Energy Policy, December, pp. 337-44.

Robinson, J. (2003), “Future subjunctive: backcasting as social learning”, Futures, Vol. 35, pp. 839-56.

World Economic Forum (2009) Accelerating Smart Grid Investments.

Zervos, A. and Lind, C. (2010) Integration of Renewable Energy Sources, In: Renewable Energy in Europe: Markers, Trends and Technologies, Earthscan, London. 


\title{
Sustainable Development vs Environmental Engineering: Energy Issues
}

\author{
Artur Pawłowski \\ Lublin University of Technology, Nadbystrzycka 40B, 20-618 Lublin \\ Poland
}

\section{Introduction}

Man can't live without environment, one with some strictly specified parameters. Despite this known truth, the relation between man and environment is far from peaceful coexistence. From history's point of view, it can be noticed that mankind have repeatedly caused environmental disasters. At first those were purely local. The primitive nomad usually moved elsewhere in the face of an ecological problem. Later on, the situation became much more complicated. Underestimating the environmental conditions lead to the downfall of the first literate and highly advanced civilization in history, the Sumerians (Ponting, 1993), stabilized as early as 3000 B.C. The area it occupied, between the rivers of Euphrates and Tigris (Lower Mesopotamia), favored agricultural development. The yields were high due to the highly developed irrigating system. A rapid increase in population was observed, along with the increasing demand for food. The increase in yields slowed down however, and depleted systematically, reaching one-third of the maximal yields about 1800 B.C. The signs of crisis were ignored, however, which led to a complete breakdown of the agriculture as well as the entire civilization. Among many causes of the yields' decrease, two deserve a special mention.

- Widespread irrigation favored the increase of soil's salinity (one of the major causes of soil degradation).

- $\quad$ The growing demand for food, along with the increasing populace entailed expanding cultivated area. After utilizing all available farming areas, forests were cut out and the land obtained in this way was cultivated. This resulted in increasing erosion - another important form of soil degradation. Moreover, depletion of plant cover and erosion made way to creating large runoffs and the silting of rivers, which caused floods as a consequence.

Modern technical powers of mankind are much bigger however, than those of the Sumerians. Our pressure on the environment has also increased. Not only can mankind cause its own extinction, but the destruction of the entire biosphere.

Not so long ago it seemed that environmental protection will bring rescue. A breakthrough moment of its development was the U'Thant report in 1969. Although earlier efforts to help the environment were made - the first known act regarding the environment was introduced in China about 1122 B.C. - it was the $20^{\text {th }}$ century and U'Thant's report that made way to large-scale international initiatives. Media publicity, that accompanied the report also helped shape the worldwide society's awareness of the environmental threats. 
Alas, classic environmental protection was not able to stop biosphere degradation. Therefore, the discussion was broadened in 1987, with the formulation of sustainable development concept, merging various problematic groups, including technology, ecology, economics, but also politics, philosophy or social backgrounds.

\section{Discussion over the notion of sustainable development}

The concept of sustainable development refers to a highly popular category of 'development' as such. It plays a major role in economics, especially in the context of economic growth (increasing the elements of a given structure). Apart from that, many other features are assigned to growth, such as: intensiveness, dynamism, rapidity, speed, and on the other hand extensiveness, slowness or durability, sustainability, suspense (Piontek, 2005). It can also be referred to pan-civilizational changes as well as more specific issues, such as science, culture, language, economy or society.

Generally speaking, it can be said that 'progress' is a change of state of a given structure (in a civilizational sense, it would be the whole of a society's activities: aware or unaware) that is thought of as desirable (better, more perfect) in the given conditions, based on a set of criteria (Borys, 2005). Consequently, 'regress' is an undesirable (worse, less perfect) change of state of a given structure, based on the same criteria. At the same time, they need to have a normative character with a very specific axiological aspect. It should include both materialistic as well as spiritual aspects. In both cases it can be assumed that a change for the better is expected. In terms of materialistic values, usually a more complicated state (e.g. improved machines) will be recognized as progressive. In terms of spiritual aspect, it needn't be such - a turn to simplicity may be presented as more desirable (a commonly known slogan: through simplicity toward perfection, the value of ascension). Moreover, the interactions between the two fields are of significance, i.e. 'to have' or 'to be', or maybe 'to have and to be'?

How about sustainable development?

Sustainability is expressed in structural aspect of a given system and means reaching a state of balance between its components, e.g. the actions taken within separate fields of sustainable development must not lead to degradation of the bio-social system.

Sustainability also means durability, whose main characteristic is measured in time. If a given system has been functioning in the past, is functioning now and nothing indicates it could be damaged - that means it is durable in time. Time is also an important factor when it comes to the devastation caused by humans to the environment. In some cases, they are visible almost immediately, but often - especially when it comes to health issues - they become observable after a long period of the so-called 'hibernation'.

Durability also means self-support of the development process, related to the dynamism of life. This includes securing the reserves (energetic among others), that not only would support the present-day status, but also allow taking up new challenges as well as foster creativity, which creates stimuli to further development.

The commonly accepted definition of sustainable development comes from the UN report 'Our Common Future' from 1987. This publication was the result of the research of an independent World Commission on Environment and Development, established in 1983. It was an attempt on a holistic approach to the problems of the modern world. It discouraged from the commonly accepted narrow understanding of the term 'progress' (which only included purely economical development) as well as from an equally narrow term 
'environment'. In the modern world - as pointed out by Donald J. Johnston in the OECD commentary - the environment is not independent from human actions, ambitions nor needs' (Johnston, 2002). Modern crisis situations (in their environmental aspect, as well as developmental, agricultural, social or energetic) are also not independent from each other. It is one global crisis related to man's approach towards the environment, which cannot be resolved within jurisdiction of separate countries.

Sustainable development has been defined in 'Our Common Future' report as such, 'that meets the needs of the present without compromising the ability of future generations to meet their own needs' (WCED, 1987).

Despite a couple of similar proposals and definitions, it was this report that proved to be a breakthrough. Its major achievement was to accept the concept of sustainable development in science as well as in politics and among the broad circles of global public opinion. The definition (referred to as the principle of sustainable development) gained a normative character and is connected with all development strategies presently formulated (Sanchéz, 2008; Redlicft, 2009; Durbin, 2010).

\section{Sustainable development problematics}

Speaking in detail, three problematic fields of sustainable development are distinguished in UN documents and strategies:

- Ecological (natural and artificial environment protection, also spatial planning).

- Social (not only natural environment, but also society may degrade).

- Economic (taxes, subsidies and other economic instruments).

In the journal 'Problems of Sustainable Development' (Problemy Ekorozwoju) no. 1/2006 (Pawłowski, 2006), I have introduced an enhancement to the list, with a couple of other problematic groups. Discussing the multidimensionality of sustainable development, I have pointed to the following additional aspects:

- $\quad$ Ethical layer (human responsibility for nature).

- Technical layer (new technologies, saving raw materials).

- Legal layer (environmental law).

- Political layer (formulating strategies of sustainable development, introduction and control thereof).

Then, in the journal 'Sustainable Development' no. 2/ 2008 (Pawłowski, 2008), and later on in the 'Problems of Sustainable Development' no. 1/2009 (Pawłowski, 2009a), I have proposed a hierarchical order of the layers in question (see table 1.).

\begin{tabular}{|c|c|c|c|}
\multicolumn{1}{|c|}{$\begin{array}{c}\text { Level } \\
\text { I }\end{array}$} & Ethical layer & \multicolumn{1}{|c|}{} \\
\cline { 1 - 1 } $\begin{array}{c}\text { Level } \\
\text { II }\end{array}$ & Ecological layer & Social layer & Economic layer \\
\hline $\begin{array}{c}\text { Level } \\
\text { III }\end{array}$ & Technical layer & Legal layer & Political layer \\
\hline
\end{tabular}

Table 1. Hierarchy of the layers of sustainable development. Author's own work.

The first level, which is the foundation to others, is an ethical reflection. It is one matter when a person makes decisions based on their beliefs or their system of values, and entirely 
different, when those decisions are determined only by the regulations of a legal system in force. It is the ethical justification of important questions like: what values must be accepted, or: why should we act in this way and not otherwise - is the foundation of the whole discussion (Durin, 2008; Laszlo, 2008; Udo, Pawłowski, 2010).

Level two covers ecological, social and economic issues, all treated as equally important.

The third level is an analysis of technical, legal and political details.

The traditional discussion over sustainable development concentrates on the second level. It will be incomplete, however, if not rooted in ethics (level one). On the other hand, without level three, actual practical solutions may escape our mind.

It needs to be pointed out that, despite their hierarchical structure, the layers interpenetrate one with another, which makes it hard to discuss problems characteristic exclusively for any one of them. Even in the case of fulfilling mankind's nonmaterial needs, we cannot avoid associations with the environment. This results from the biological principles of the functioning of the human body, which is in constant need for nourishment and therefore interacts with the environment in this sense at least.

The presented hierarchy proposal offers a new view at the problem of sustainable development. Such a wide range of problems proposed, together with an equally vast variety of changes postulated within individual layers as well as within the actual adopted strategies, allows for making the following assertion: should sustainable development be implemented, it would become a revolution comparable to the breakthroughs in mankind's history, also referred to as revolutions.

In this context, is it not - after the agricultural, scientific and industrial revolutions (Postman, 1995) - the time for a sustainable development revolution (see Table 2)? Or are present environmental problems still part of the industrial revolution? Also, it cannot be ruled out that another stage of human development will go in an entirely different, unsustainable direction (Sztumski, 2007).

\begin{tabular}{|l|l|}
\hline Name of the stage & Time period referred to \\
\hline $\begin{array}{l}\text { Hunter-gatherer } \\
\text { period }\end{array}$ & Upper Paleolithic \\
\hline $\begin{array}{l}\text { Agricultural } \\
\text { Revolution }\end{array}$ & $\begin{array}{l}\text { Began around 9000 years ago in Asia, and approx. 4000 years later in } \\
\text { Europe }\end{array}$ \\
\hline $\begin{array}{l}\text { Scientific } \\
\text { Revolution }\end{array}$ & $\begin{array}{l}1543 \text { - symbolic beginnings with Copernicus' publication of "On the } \\
\text { Revolutions of the Celestial Spheres". } \\
1687 \text { - development period, with I. Newton's publication of "Principia } \\
\text { Mathematica". }\end{array}$ \\
\hline $\begin{array}{l}\text { Industrial } \\
\text { Revolution }\end{array}$ & $\begin{array}{l}1769 \text { - significant improvement to steam engine by Watt. } \\
\text { Further stage (1860-1914): the beginning of oil use (in combustion } \\
\text { engines) and electricity. }\end{array}$ \\
\hline $\begin{array}{l}\text { Sustainable } \\
\text { Development } \\
\text { Revolution }\end{array}$ & $\begin{array}{l}\text { Three crucial dates: } \\
1969 \text { - U'Thant's report. } \\
1987 \text { - sustainable development definition introduced by the UN. } \\
1992 \text { - UN conference in Rio de Janeiro. }\end{array}$ \\
\hline
\end{tabular}

Table 2. Key stages in mankind's development. Author's own work. 
The problem is, the current phase of development has not been clearly defined so far. Industry certainly still plays an important part in the shaping of our civilization, but a number of new phenomena have also appeared. Do these changes bespeak another revolution? Some authors support this and suggest that we are now dealing with a modernization revolution, understood as a conversion from the agricultural society living in the countryside, to a typically urban and industrial society. This process, however, would not be possible without prior scientific and industrial revolutions. These entailed i.a. the development of a new kind of modern urban infrastructure (water supply, waste collection, transportation of people and goods, including food, labor market and health service) that ensures the safe functioning of hundreds of thousands of people living in the same place.

Does mankind's transfer from the countryside to cities deserve the title of a revolution? Certainly, the negative human impact on the planet Earth is associated with urban rather than rural environments; therefore their massive expansion increases human pressure on the environment. However, this does not change the present shape of the relations between man and nature.

Also, there are opinions that we are currently dealing with Informatics Technologies Revolution bound up with the widespread use of the Internet, which is thought of as the next step after the industrial revolution. The Internet is indeed an extraordinary platform that allows accessing and spreading important information, which contributes to the development of an information society. On the other hand, this technology seems to run toward a dead end. In 2008, up to $95 \%$ of e-mails received by the users were the so-called spam messages, namely unwanted material containing brazen advertisement (as recently as 2001 this was only 5\% of the mail). Moreover, the authors of these messages are impersonating well-known institutions and websites for the purpose of fraud and swindling personal data. Furthermore, the Internet has not changed people's approach towards nature, whereas even with their ever-improving ability to communicate, the people did not reduce their pressure on the environment. Informatics technologies are but a tool, which may be utilized in a more general revolution (analogically, a significant improvement to steam engine by Watt was but a symbol of the Industrial Revolution).

If so, what can bring about a desirable change?

In my opinion, sustainable development can be one such thing. Although development of this type has not been introduced yet, many contemporary political, as well as legal, economic and technological initiatives move in that direction.

Assessment of sustainable development revolution is difficult because of the relatively limited time horizon available. Moreover, there is not much we can say about the future, since factors may appear at any moment that could change our previous point of view completely. Just as terrorist attacks of September $11^{\text {th }}$ in New York dispelled the illusion of safety in the modern world, we can experience unexpected ecological catastrophes, resulting from environment pollution caused by humans (such as rapid climate changes). We may as well witness new groundbreaking scientific or technical discoveries that could regard new, efficient energy sources as an alternative to decreasing fossil fuel reserves.

Undoubtedly, current human impact on the biosphere has a global character and calls for a global and balanced immediate response in all areas of human activity. Therefore, intense work is being made on international forums to clarify the basic paradigms of sustainable development, short-, middle- and long-term objectives as well as to search for the tools necessary to achieve the established goals. 
Securing sustainable development is among the most important priorities in the EU politics. It can, therefore, be assumed that securing sustainable development is becoming the most important goal contemporary societies set before them.

\section{Environmental engineering}

Introduction of sustainable development is associated with using the knowledge from the fields of both social and technical sciences. Within the second group, a crucial position is occupied by environmental engineering.

Environmental engineering can be defined as (Pawłowski, 2007) a discipline in the field of technical science, utilizing engineering methods:

- For preserving, rational shaping and using external natural environment (e.g. water resources, waste management, air protection, soil protection),

- For preserving and shaping internal environment of rooms and constructions (devices and installations).

Environmental engineering realizes a wide variety of pro-ecologic activities within the described fields:

- Shapes appropriate conditions and technological methods to uphold proper parameters regarding the human environment,

- Shapes appropriate technical conditions and technological methods to secure the environment's natural biological balance,

- Limits adverse effects of mankind's economic activity,

- Provides technology allowing to reduce the usage of nonrenewable resources (e.g. cleaner production, recycling raw materials from waste),

- Mitigates the effects of natural disasters (floods, droughts, pollution in water, air and soil).

This definition shows how important environmental engineering is for realization of the sustainable development concept. It shapes the conditions of human life; it touches upon the issue of resources, which in turn determines meeting human material needs, both for the present generation and in the future.

Among other detailed problems, energy issues must be pointed out: energy supply, preserving energy carriers and, especially, the usage of fossil fuels.

\section{Energy issues}

Much has been said in recent years about energy security. Within the EU, situation is very diversified (see Table 3). Denmark is in the best position, since it has a surplus of energy reaching almost $40 \%$.

All countries are grappling with the problem, that producing energy out of conventional fuels means an irrevocable loss of those resources.

Estimates say (Salay, 1997) that the world's reserves contain enough coal for about 150-200 years, enough oil for about 40 years and enough natural gas for about 60 years. These periods may actually be slightly longer. Data published in various sources vary from one another, moreover, some authors point at the possibility of exploiting deposits that are uneconomic today, and therefore, prolonging the time of resources availability (e.g. of crude oil by another 20 years). This does not change the main problem, however: world's resources will run out and the time of that disaster is very near. That is not all - it needs to be 
remembered that natural gas and oil deposits are distributed unevenly on our planet. Table 4 characterizes the available gas reserves.

Unquestionable position of the Russian Federation is noteworthy. Beside it, Iran and Qatar have large gas reserves - although half that size. The Russian Federation also has significant coal reserves (2nd to the US).

Another significant issue is that, along with the depletion of natural resources, a demand for energy, required for the processing of the poor resources, rises. E.g. smelting $1 \mathrm{Mg}$ of iron from a $5 \%$ iron ore requires much higher energy input than in the case of a $20 \%$ iron ore.

\begin{tabular}{|c|c|c|c|}
\hline No. & Country & $\begin{array}{c}\text { Total energy } \\
\text { consumption in } \\
\text { millions of tons of fuel }\end{array}$ & $\begin{array}{c}\% \\
\text { of } \\
\text { imported } \\
\text { energy }\end{array}$ \\
\hline 1. & Cyprus & 2.6 & 100 \\
\hline 2. & Malta & 0.9 & 100 \\
\hline 3. & Luxemburg & 4.7 & 98.9 \\
\hline 4. & Ireland & 15.5 & 90.9 \\
\hline 5. & Italy & 186.1 & 86.8 \\
\hline 6. & Portugal & 25.3 & 83.1 \\
\hline 7. & Spain & 143.9 & 81.4 \\
\hline 8. & Belgium & 60.4 & 77.9 \\
\hline 9. & Austria & 34.1 & 72.9 \\
\hline 10. & Greece & 31.5 & 71.9 \\
\hline 11. & Latvia & 4.6 & 65.7 \\
\hline 12. & Lithuania & 8.4 & 64 \\
\hline 13. & Slovakia & 18.8 & 64 \\
\hline 14. & Hungary & 27.8 & 62.5 \\
\hline 15. & Germany & 349 & 61.3 \\
\hline 16. & Finland & 37.8 & 54.6 \\
\hline 17. & EU 27 & 1825.2 & 53.8 \\
\hline 18. & Slovenia & 7.3 & 52.1 \\
\hline 19. & France & 273.1 & 51.4 \\
\hline 20. & Bulgaria & 20.5 & 46.2 \\
\hline 21. & Netherlands & 80.5 & 38 \\
\hline 22. & Sweden & 50.8 & 37.4 \\
\hline 23. & Estonia & 5.4 & 33.5 \\
\hline 24. & Romania & 40.9 & 29.1 \\
\hline 25. & Czech Republic & 46.2 & 28 \\
\hline 26. & United Kingdom & 229.5 & 21.3 \\
\hline 27. & Poland & 98.3 & 19.9 \\
\hline 28. & Denmark & 20.9 & -36.8 \\
\hline
\end{tabular}

Table 3. The characteristic of energy consumption and import dependence of individual EU countries; data from the end of 2008. Source: Europe's Energy Portal, http:/ / www.energy.eu. 


\begin{tabular}{|c|c|c|c|}
\hline No. & Country & $\begin{array}{c}\text { Quantity } \\
\text { (trillions of } \mathrm{m}^{3} \text { ) }\end{array}$ & Graphic presentation \\
\hline 1. & Russian Federation & 43,30 & \\
\hline 2. & Iran & 29,61 & \\
\hline 3. & Qatar & 25,46 & \\
\hline 4. & Turkmenistan & 7,94 & \\
\hline 5. & Saudi Arabia & 7,57 & \\
\hline 6. & USA & 6,73 & \\
\hline 7. & United Arab Emirates & 6,43 & \\
\hline 8. & Nigeria & 5,22 & \\
\hline 9. & Venezuela & 4,84 & \\
\hline 10. & Algeria & 4,50 & \\
\hline
\end{tabular}

Table 4. Countries in possession of the world's largest natural gas deposits, data from the end of 2008. Source: Europe's Energy Portal, http:/ / www.energy.eu.

\begin{tabular}{|l|l|c|l|}
\hline No. & Country & $\begin{array}{c}\text { Quantity } \\
\text { (million tons) }\end{array}$ & Graphic presentation \\
\hline 1. & US & 238308 & \\
\hline 2. & Russian Federation & 157010 & \\
\hline 3. & China & 114500 & \\
\hline 4. & Australia & 76200 & \\
\hline 5. & India & 58600 & \\
\hline 6. & Ukraine & 33873 & \\
\hline 7. & Kazakhstan & 31300 & \\
\hline 8. & South Africa & 30408 & \\
\hline 9. & Poland & 7502 & \\
\hline 10. & Brazil & 7059 & \\
\hline
\end{tabular}

Table 5. Countries in possession of the world's largest coal deposits, data from the end of 2008. Source: Europe's Energy Portal, http://www.energy.eu.

\begin{tabular}{|l|l|c|l|}
\hline No. & Country & $\begin{array}{c}\text { Quantity } \\
\text { (billion barrels) }\end{array}$ & Graphic presentation \\
\hline 1. & Saudi Arabia & 264,1 & \\
\hline 2. & Iran & 137,6 & \\
\hline 3. & Iraq & 115,0 & \\
\hline 4. & Kuwait & 101,5 & \\
\hline 5. & Venezuela & 99,4 & \\
\hline 6. & Un. Arab Emirates & 97,8 & \\
\hline 7. & Russian Federation & 79,0 & \\
\hline 8. & Libya & 43,7 & \\
\hline 9. & Kazakhstan & 39,8 & \\
\hline 10. & Nigeria & 36,2 & \\
\hline
\end{tabular}

Table 6. Countries in possession of the world's largest crude oil deposits, data from the end of 2008. Source: Europe's Energy Portal, http:/ / www.energy.eu. 
Moreover, the growing consumption of fossil fuels is associated with an increasing emission of dust and gases to the atmosphere. The one gas that has drawn scientists' special attention is carbon dioxide, considered to be the main cause of global warming.

Taking into account that $\mathrm{CO}_{2}$ concentration in the atmosphere was $0.0280 \%$ at the beginning of the industrial era, $0.0315 \%$ in 1960 and $0.0385 \%$ at present day, is it possible that an increase in carbon dioxide concentration in the atmosphere by $0.0105 \%$ had such a long-term impact?

Or do other issues play a more significant role here? Cutting out forests - especially tropical forests - can be pointed out. It is no mystery that during the $20^{\text {th }}$ century alone as much as half of them have been cut out (Kalinowska, 1992) about 12 million ha is being cut out every year and about 50 ha every minute (Boc, Samborska-Boc, 2005). Since forests are known to serve as climate stabilizers, cutting out such a large part of the world's forests must have a significant impact on Earth's climate destabilization.

In fact, the issues of the diminishing forest cover and the growing carbon dioxide emission are linked to each other. It is estimated that forests - tropical and subtropical forests in particular - can bind around $25 \%$ of $\mathrm{CO}_{2}$ released to the atmosphere! Moreover, with a proper economy the plant-based binding can be increased before 2050 by another $10-20 \%$ (Nabuurs, Mohren, Dolman, 2000).

Admittedly, the question of connecting climate changes to anthropogenic $\mathrm{CO}_{2}$ emission is being challenged (Russel, 2009; Lendzen, 2010), but we should utilize the attitude of humility. The large emission of various pollutants from our scientific-technical civilization to the environment certainly does no good to the nature. Should our concerns over $\mathrm{CO}_{2}$ turn out to be false, we will bear some costs, but the environment will not deteriorate. And what if our concerns are confirmed? We must remember that drastic climate changes and anomalies may lead to the downfall of our civilization - in this context the example of the Sumerians is a notable warning. Taking remedial action is fully justified.

Table 7 shows $\mathrm{CO}_{2}$ emission in the years 2003-2007 as well as the degree of individual countries closeness to the limit specified in the Kyoto protocol.

The data indicate that 15 of the EU countries (including Poland) have already reached $\mathrm{CO}_{2}$ emission below the limit set by the Kyoto agreement for the year 2012 .

Limiting $\mathrm{CO}_{2}$ and other pollutants' emissions does not change the primary challenge, namely the depletion of the resources. The principle of sustainable development calls for preserving our planet's ability to meet the needs of future generations, and since their access to energy carriers is threatened that means alternative solutions are required.

The progress of nuclear power is one of the possible ways we may choose. Contrary to the popular belief, uranium deposits are limited as well. If only the most popular reactor types are exploited - that is Pressurized Water Reactors (PWR, 60\% of the market) and Boiling Water Reactors (BWR, 24\% of the market) - there should be enough fuel for some 140 years. There are, however, alternative technological solutions. Introducing fast-neutron reactors for exploitation would prolong the time of uranium availability for power production by hundreds of years. The problem is, using fast reactors in civilian technology is associated with facilitated access to materials that might be used for the manufacture of nuclear weaponry. Also, the risk of meltdowns and nuclear disasters is being disputed. Even with the use of the most advanced technology, accidents cannot be ruled out. In September 1999, there has been a major breakdown at a Japanese nuclear power plant Takamura, which could have ended up in disaster. The cause was disregard for safety procedures - as much as 7 times more enriched uranium was added to the container than the technological standard allowed. A chain reaction broke out, but was luckily suppressed. Still, the radiation level jumped to such value that two employees were killed and several hundred 
people have been heavily radiated (Science Daily, 6 Dec. 1999). This incident entailed a series of publications critical towards safety in the supposedly highly advanced Japanese nuclear power plants. Therefore, since erecting new nuclear power plants is probably inevitable, the scientific community must pay special attention to safety issues - there can be no saving here.

\begin{tabular}{|l|c|c|c|c|c|c|c|}
\hline \multicolumn{1}{|c|}{ Country } & 2003 & 2004 & 2005 & 2006 & $\mathbf{2 0 0 7}$ & $\begin{array}{c}\text { Kyoto } \\
\text { limit 2012 }\end{array}$ & $\begin{array}{c}\% \text { below the } \\
\text { Kyoto limit }\end{array}$ \\
\hline Latvia & 10,7 & 10,7 & 10,9 & 11,7 & $\mathbf{1 2 , 1}$ & 23,3 & $+48,07$ \\
\hline Estonia & 21,2 & 21,2 & 20,7 & 19,2 & $\mathbf{2 2 , 0}$ & 40 & $+45,00$ \\
\hline Lithuania & 16,7 & 21,1 & 22,6 & 22,8 & $\mathbf{2 4 , 7}$ & 44,1 & $+43,99$ \\
\hline Romania & - & 60,1 & 153,7 & 53,9 & $\mathbf{5 2 , 3}$ & 259,9 & $+41,40$ \\
\hline Bulgaria & - & 68,9 & 69,8 & 71,5 & $\mathbf{7 5 , 7}$ & 127,3 & $+40,53$ \\
\hline Hungary & 83,3 & 79,5 & 80,5 & 78,8 & $\mathbf{7 5 , 9}$ & 114,9 & $+33,94$ \\
\hline Slovakia & 51,1 & 49,5 & 48,7 & 49,0 & $\mathbf{4 7 , 0}$ & 67,2 & $+30,06$ \\
\hline Poland & 382,5 & 96,7 & 399 & 99,3 & $\mathbf{9 8 , 9}$ & 551,7 & $+27,70$ \\
\hline Czech Rep. & 147,5 & 147,1 & 145,6 & 49,1 & $\mathbf{1 5 0 , 8}$ & 180,6 & $+16,50$ \\
\hline Sweden & 70,9 & 69,7 & 67 & 66,9 & $\mathbf{6 5 , 4}$ & 75,2 & $+13,03$ \\
\hline Un. Kingdom & 658 & 60,4 & 657,4 & 647,9 & $\mathbf{6 3 6 , 7}$ & 678,3 & $+6,13$ \\
\hline France & 560,9 & 556,1 & 553,4 & 541,7 & $\mathbf{5 3 1 , 1}$ & 564 & $+5,83$ \\
\hline Greece & 137,2 & 137,6 & 139,2 & 128,1 & $\mathbf{1 3 1 , 9}$ & 139,6 & $+5,52$ \\
\hline Belgium & 147,6 & 147,6 & 143,8 & 36,6 & $\mathbf{1 3 1 , 3}$ & 135,9 & $+3,38$ \\
\hline Germany & 1024,4 & 1025 & 1001,5 & 980,0 & $\mathbf{5 6 , 1}$ & 972,9 & 1,73 \\
\hline \multicolumn{1}{|c|}{ Country } & 2003 & 2004 & 2005 & 2006 & $\mathbf{2 0 0 7}$ & $\begin{array}{c}\text { Kyoto } \\
\text { limit 2012 }\end{array}$ & $\begin{array}{c}\text { K above the } \\
\text { Kyoto limit }\end{array}$ \\
\hline Netherlands & 215,4 & 218,4 & 212,1 & 208,5 & $\mathbf{2 0 7 , 5}$ & 200,4 & $-3,54$ \\
\hline Portugal & 83,7 & 84,6 & 85,5 & 84,7 & $\mathbf{8 1 , 8}$ & 77,4 & $-5,68 \%$ \\
\hline Ireland & 68,4 & 68,6 & 69,9 & 69,7 & $\mathbf{6 9 , 2}$ & 63 & $-9,84 \%$ \\
\hline Finland & 85,4 & 81,2 & 69,3 & 79,9 & $\mathbf{7 8 , 3}$ & 71,1 & $-10,13 \%$ \\
\hline Slovenia & 19,7 & 19,9 & 20,3 & 20,5 & $\mathbf{2 0 , 7}$ & 18,6 & $-11,29 \%$ \\
\hline Italy & 577,3 & 580,5 & 582,2 & 563,0 & $\mathbf{5 5 2 , 8}$ & 485,7 & $-13,82 \%$ \\
\hline Denmark & 73,6 & 68,2 & 63,9 & 71,0 & $\mathbf{6 6 , 6}$ & 54,8 & $-21,53 \%$ \\
\hline Austria & 92,5 & 91,2 & 93,3 & 91,6 & $\mathbf{8 8 , 0}$ & 68,7 & $-28,09 \%$ \\
\hline Spain & 407,4 & 425,2 & 440,6 & 433,0 & $\mathbf{4 4 2 , 3}$ & 331,6 & $-33,38 \%$ \\
\hline Luxemburg & 11,3 & 12,8 & 12,7 & 13,3 & $\mathbf{1 2 , 9}$ & 9,1 & $-41,76 \%$ \\
\hline Malta & 3,1 & 3,2 & 3,4 & 2,9 & $\mathbf{3 , 0}$ & - & - \\
\hline Cyprus & 9,2 & 9,9 & 9,9 & 9,9 & $\mathbf{1 0 , 1}$ & - & - \\
\hline Table & & & & & & \\
\hline
\end{tabular}

Table 7. Characteristic of the changes in $\mathrm{CO}_{2}$ emission in the chosen countries in the years 2003-2007. Emissions shown in millions of tons of $\mathrm{CO}_{2}$ per year. Source: Europe's Energy Portal, http:/ / www.energy.eu. 
Or should we rely on renewable energy sources (Pawłowski, 2009b)?

In economic policies of the EU action can be observed, leading to combining sustainable development with a well-balanced energy management, including renewables.

Even now one of these sources - water energy - comprises to as much as $20 \%$ of power installed in various power plants around the world (see figure 1). In Europe's scale Norway and Brazil are among water tycoons.

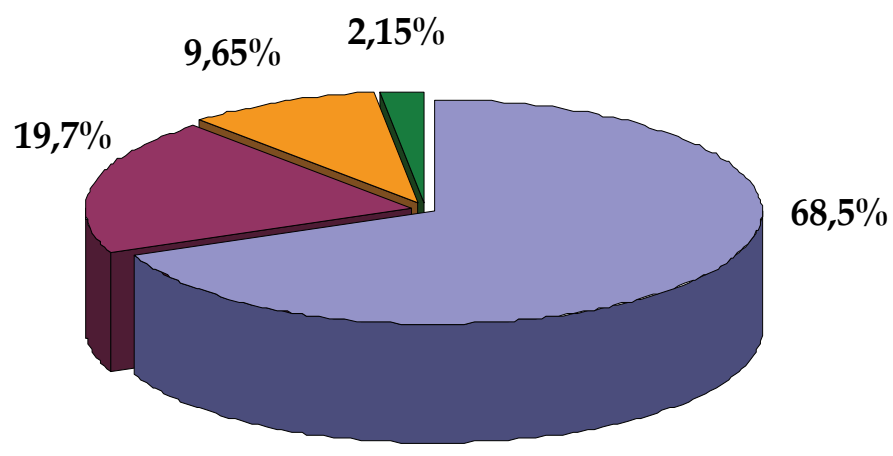

1. Thermal power (coal, oil, gas) $2652269000 \mathrm{~kW}$

2. Hydropower $761863000 \mathrm{~kW}$

3. Nuclear power $374195000 \mathrm{~kW}$

4. Other $83624000 \mathrm{~kW}$

Fig. 1. Total Installed electricity capacity by type. Source: International Energy Annual 2006, Energy Information Administration, Washington 2008.

Still, the largest potential source of energy is the solar radiation. During one year 7500 times more solar energy ( 86000 TW) hit the Earth than the energy consumed by the whole human civilization. Perhaps that is why the EU conducted research over building a 400-billion-Euro solar power plant on the Sahara, which could cover about $20 \%$ of the whole EU's energy demand. This is in accordance to the general policy of the Commonwealth, which postulates that the member countries will gain $20 \%$ of their energy from renewables before 2020 . Table 8 shows the characteristic of renewable energy coverage of individual member countries of the EU.

Developing technologies related to the usage of various energy sources is an important engineering task. The development of energy-saving technologies is just as significant. This is not only the issue of industrial facilities, but also of internal environment. It is a key problem field in environmental engineering, related to heating, ventilation and air conditioning, or - more generally - to public utilities. Its needs consume $17-32 \%$ of the world's total energy consumption. In the EU countries, it came at $26.5 \%$.

This means that there are huge prospects both for energy saving and decreasing fossil fuel consumption in this sector. It is a crucial challenge for environmental engineering! 


\begin{tabular}{|c|c|c|c|c|}
\hline No. & Country & $\begin{array}{l}\text { Share of energy } \\
\text { from renewables } \\
\text { in } 2006\end{array}$ & $\begin{array}{c}2020 \\
\text { objective }\end{array}$ & $\begin{array}{l}\text { Amount } \\
\text { missing }\end{array}$ \\
\hline & EU & $9,25 \%$ & $20 \%$ & $10,8 \%$ \\
\hline 1. & United Kingdom & $1,5 \%$ & $15 \%$ & $13,5 \%$ \\
\hline 2. & Ireland & $2,9 \%$ & $16 \%$ & $13,1 \%$ \\
\hline 3. & Denmark & $17,2 \%$ & $30 \%$ & $12,8 \%$ \\
\hline 4. & France & $10,5 \%$ & $23 \%$ & $12,5 \%$ \\
\hline 5. & Netherlands & $2,7 \%$ & $14 \%$ & $11,3 \%$ \\
\hline 6. & Spain & $8,7 \%$ & $20 \%$ & $11,3 \%$ \\
\hline 7. & Greece & $7,15 \%$ & $18 \%$ & $10,9 \%$ \\
\hline 8. & Italy & $6,3 \%$ & $17 \%$ & $10,7 \%$ \\
\hline 9. & Latvia & $31,4 \%$ & $42 \%$ & $10,6 \%$ \\
\hline 10. & Belgium & $2,6 \%$ & $13 \%$ & $10,4 \%$ \\
\hline 11. & Cyprus & $2,7 \%$ & $13 \%$ & $10,3 \%$ \\
\hline 12. & Germany & $7,8 \%$ & $18 \%$ & $10,2 \%$ \\
\hline 13. & Luxemburg & $1 \%$ & $11 \%$ & $10 \%$ \\
\hline 14. & Malta & $0 \%$ & $10 \%$ & $10 \%$ \\
\hline 15. & Portugal & $21,5 \%$ & $31 \%$ & $9,5 \%$ \\
\hline 16. & Slovenia & $15,5 \%$ & $25 \%$ & $9,5 \%$ \\
\hline 17. & Finland & $28,9 \%$ & $38 \%$ & $9,1 \%$ \\
\hline 18. & Austria & $25,1 \%$ & $34 \%$ & $8,9 \%$ \\
\hline 19. & Lithuania & $14,6 \%$ & $23 \%$ & $8,4 \%$ \\
\hline 20. & Estonia & $16,6 \%$ & $25 \%$ & $8,4 \%$ \\
\hline 21. & Hungary & $5,1 \%$ & $13 \%$ & $7,9 \%$ \\
\hline 22. & Sweden & $41,3 \%$ & $49 \%$ & $7,7 \%$ \\
\hline 23. & Poland & $7,5 \%$ & $15 \%$ & $7,5 \%$ \\
\hline 24. & Slovakia & $6,8 \%$ & $14 \%$ & $7,2 \%$ \\
\hline 25. & Bulgaria & $8,9 \%$ & $16 \%$ & $7,1 \%$ \\
\hline 26. & Romania & $17 \%$ & $24 \%$ & $7 \%$ \\
\hline 27. & Czech Republic & $6,5 \%$ & $13 \%$ & $6,5 \%$ \\
\hline
\end{tabular}

Table 8. A percentage characteristic of the renewable energy share in the energy balance in the EU countries. Source: Europe's Energy Portal, http:/ / www.energy.eu.

Speaking in detail, the main directions of engineers' work for the coming years should include searching energy-saving solutions and new ways to use renewable energy sources in public utilities - the usage of biomass to heat rooms in particular.

In some countries, e.g. in Poland, biomass is already the most popular renewable energy source.

Dry biomass burning for heating purposes in properly fixed ovens (another key design task for environmental engineering) is not the whole thing, however. The ash left over from the process should be used for fertilizing energy plants in plantations (like salix), so that the soils occupied by them would not deteriorate. This is one of the most important directions consistent with the principle of sustainable development, since not only it helps to reduce 
the consumption of nonrenewable energy sources (replaced with the biomass), but also prevents the soil from exhaustion of elements necessary for cultivation.

These positive conditions of 'green' energy do not exhaust the topic, however. The point is that the energy gained from renewable energy sources still is more expensive than that derived from fossil fuels. Adopting appropriate legal and economic mechanisms is the key. There is plenty of possible solutions; we will point to examples regarding biomass burning. In countries like Finland (Nicholls, Monserud, Dykstra, 2009), wider use of biomass as an energy source was achieved by introducing an appropriate tax on fossil fuels. In Austria a similar effect was reached by subsidies for investments making use of biomass. In the case of Netherlands, three separate fiscal instruments were applied: green funds, an energy tax and tax credits (Kwant, 2003). Also, we may expect that EU limits on $\mathrm{CO}_{2}$ emissions will favor the development of renewable energy, including biomass burning.

Moreover, it is noteworthy that the development of new technologies regarding renewable energy sources contributes to a growth of employment level. When it comes to biomass, according to Hillring (Hilring, 2002), each PJ of energy produced with the use of biomass gives from 1.5 (where wood waste is used) to even 113 jobs (in the case of weakly mechanized, rapidly-growing plantations).

\section{Conclusion: Can we secure sustainable development for the future generations?}

When, at the end of the 19th century, gas lamps used so far were replaced by electric lights, the quality of air in the cities improved immediately. Unfortunately, the progress in coal energetics lead to much greater pollution levels in the second half of the 20th century, growing over the urban environment and becoming a global problem. It is a peculiar paradox. A solution, which brought good results at first, turned out to be a threat in the long run (Fox-Penner, 1997).

Research conducted in the field of sustainable development is interdisciplinary, which makes it ideally adapted to coping with the complex challenges of the modern world. There is, however, one phenomenon that escapes control - globalization.

Nowadays globalization is defined as an integrated, global socio-economic system, linked with large corporations, characterized by its transnational diffusion of capital and adopting the principle of free trade in the field of economy - so economic globalization - as well as assimilation of cultural models - so cultural globalization (Gawor, 2006).

Large corporations are an obstacle in the implementation of sustainable development, because they are profit-oriented and because of their transnational, post-national or somewhat anti-national character (Barber, 1995), thus weakening the role, played so far by the authorities of individual countries. If the solutions or strategies adopted by a country or a group of countries (even one like the EU) are seen as adverse, they simply move that part of their activities to other countries, where such actions are acceptable. Moreover, as many economists point out, corporations are able to destroy the progress of nearly any company that does not belong to them (Ikerd, 2005; 2008).

In this context it is worth asking: is sustainable development an alternative to globalization? Suggestions are formulated, that globalization and sustainable development are both two sides of one coin. Just as Duncan French convinces us, globalization organizes the world anew, whereas sustainable development points to the threats brought by this new order, which result from previous mankind's history (French, 2002). 
Note that globalization needs not to rely on the currently dominant egoistic axiology - there also is an eco-humanistic (inclusive) globalization - one that refers to the common good. As John Paul II said in 2001 "globalization is not a priori good or evil. It will by such, as we make it" (the address at the 7th Plenary Session of the Pontifical Academy of Social Sciences, held in Vatican City on 25th-27th April 2001). This line of thought is carried on by Benedict XVI. In his address in 2008 he said that egoistic globalization "is not the synonym of the world order - on the contrary. The conflicts generated by the pursuit of economic primacy and providing for oneself access to energy, water and resource reserves impede the efforts of those who struggle for a world more just and solidary. It became clear that only through adopting a balanced way of life accompanied by serious efforts for equal distribution of goods, a fair and sustainable development is achievable. This requires people who have great hope and great courage (the address from $1^{\text {st }}$ June 2008, made during Epiphany mass). This line of thought has been expanded in the encyclical "Caritas in Veritate" (Benedict XVI, 2009).

Such is the outline of the road towards eco-humanistic globalization, as well as an outline of the road towards sustainable development. It is also the road, which environmental engineers take, providing us with necessary technical tools that would show us how to preserve the environment and use it rationally. It is a challenge, but also a great responsibility in the struggle for our planet's future.

Be it assumed that we are on the threshold of a new revolution - the sustainable development revolution - then our conversion from fossil fuels to new energy sources is one of the most important tasks. Environmental engineering is the one discipline that can achieve this.

\section{References}

Amercian Institute Of Physics (1999). New Details on Japan Nuclear Accident, Science Daily, December 6, 1999, http://www.sciencedaily.com/, retrieved May 27, 2010, ISSN 1521-1878.

Barber, B.R. (1995). Johan vs McWorld, Ballantine Books, ISBN 0-345-38304-4, New York.

Benedict, XVI (2009). Caritas in Veritate, Ignatius Press, ISBN 9781586172800, San Francisco.

Boc, J. \& Samborska-Boc, E. (2005). Z rozwoju koncepcji ochrony srodowiska [Development of the Idea of Protection of the Environment], Ochrona środowiska [Protection of the Evironment], Boc, J. \& Nowacki, K. \& Samborska-Boc, E. (Ed.), Kolonia Limited, ISBN 83-88166-92-1, Wroclaw.

Borys, T. (2005). Wskaźniki zrównoważonego rozwoju [Indicators of Sustainable Development], EiS, ISBN 83-88771-61-2, Warsaw.

Durbin, P.T. (2008). Is There a Best Ethic of Sustainable Development?, Problems of Sustainable Development, vol. 3, no 2, 5-14, ISSN 1895-6912.

Durbin, P.T. (2010). Humanitarian Motives for Sustainable Developments in a Global Economy: An Essay, Problems of Sustainable Development, vol. 5, no 1, 9-13, ISSN 1895-6912.

Energy Information Administration (2007). International Energy Annual 2005, http://www.eia.doe.gov/iea/, retrieved May 27, 2010, Washington. 
Europe's Energy Portal (2010). http:/ / www.energy.eu, retrieved May 27, 2010.

Fox-Penner, P. (1997). Environmental Quality, Energy Efficiency and Renewable Energy, Electric Utility Restructuring, A Guide to the Competitive Era, Public Utility Reports, ISBN 978-0910325677, Vienna.

French, D. (2002). The Role of the State and International Organization in Reconciling Sustainable Development and Globalization, International Environmental Agreements, Politics, Law, and Economics, no 2, 135-150, ISSN 1567-9764.

Gawor, L. (2006). Antyglobalizm, alterglobalizm i filozofia zrównowazonego rozwoju jako globalizacyjne alternatywy [Anti-globalism, Alter-globalism and the Philosophy of Sustainable Development as Global Alternatives], Problems of Sustainable Development, vol. 1, no 1, 41-42, ISSN 1895-6912.

Hillring, B. (2002). Rural Development and Bioenergy Experiences from 20 Years of Development in Sweden, Biomass and Bioenergy 23, 443-451, ISSN 0961-9534.

Ikerd, J.E. (2005). Sustainable Capitalism a Matter of Common Sense, Kumarin Press Inc., ISBN 1565492064, Bloomfield.

Ikerd, J.E. (2008). Sustainable Capitalism: A Matter of Ethics and Morality, Problems of Sustainable Development, vol. 3, no 1, 13-22, ISSN 1895-6912.

Johnson, D.J. (2002). Sustainable Development: Our Common Future, OECD Observer, no 8/2002, http:/ /www.oecdobserver.org/, retrieved January 10, 2010.

Kalinowska, A. (1992). Ekologia - wybór przyszłości [Ecology - the Choice for the Future], Editions Spotkania, ISBN 83-85195-89-0, Warsaw.

Kwant, K., (2003). Renewable Energy in the Netherlands: Policy and Instruments, Biomass and Bioenergy 24, 265-267, ISSN 0961-9534.

Laszlo, C. (2008). Sustainable Values, Problems of Sustainable Development, vol. 3, no 2, 25-29, ISSN 1895-6912.

Lean, G. \& Hinrichsen, D. (1994). Atlas of the Environment, Harper-Perennial, ISBN 9780062733146, New York.

Lendzen, R.S. (2010). Global Warming: The Origin and Nature of the Alleged Scientific Consensus, Problems of Sustainable Development, vol. 5, no 2, 13-28, ISSN 18956912.

Nabuurs, G. \& Mohren, F. \& Dolman, H. (2000). Monitoring and Reporting Carbon Stocks and Fluxes in Dutch Forests, Biotechnology, Agronomy, Society and Environment 4, 308-310, ISSN 1370-6233.

Pawlowski, A. (2006). Wielowymiarowosc zrownowazonego rozwoju [The Multidimensional Nature of Sustainable Development], Problems of Sustainable Development, vol. 1, no 1, 23-32, ISSN 1895-6912.

Pawlowski, A. (2008). How Many Dimensions Does Sustainable Development Have?, Sustainable Development, vol. 16, no 2, 81-90, ISSN 0968-0802.

Pawlowski, A. (2009a). The Sustainable Development Revolution, Problems of Sustainable Development, vol. 4, no 1, 65-76, ISSN 1895-6912.

Pawlowski, A. (2009b). Sustainable Energy as sine qua non for the Achievement of Sustainable Development, Problems of Sustainable Development, vol. 4, no 2, 9-12, ISSN 1895-6912. 
Pawlowski, L. (2007), Slowo wstępne [Foreword], Polska inzynieria srodowiska - informator [Polish Environmental Enginnering - Reference Book, Anielak, A.M. (Ed.), , KIS PAN, 13-16, ISBN 83-89293-41-2, Lublin.

Piontek, F. \& Piontek B. (2005). Kategoria „rozwoj” w alternatywnych koncepcjach jego urzeczywistniania [„Development” Category in Alternative Possibilities of Making it Real], Humanistyczne, ekonomiczne i ekologiczne aspekty kategorii "rozwój" [Humanistic, Economic and Ecological Aspects of "Development" Category], Piontek, F. \& Czerny, J. (Ed.), WSEiA, 30-31, 83-246-0277-1, Warsaw, Bytom.

Ponting, C. (1993). A Green History of the World: The Environment and the Collapse of Great Civilizations, Penguin Books, 9780140176605, New York.

Postman, N. (1993). Technopoly: The Surrender of Culture and Technology, Vintage Books, 9780679745402, New York.

Redclift, M.R. (2009). Sustainable Development (1987-2005) - An Oxymoron Comes of Age, Problems of Sustainable Development, vol. 4, no 1, 33-50, ISSN 1895-6912.

Russel, D.L. (2010). Curmudgeon's Thougts on Sustaiability, Problems of Sustainable Development, vol. 5, no 1, 15-22, ISSN 1895-6912.

Salay, J. (1997). Energy, From Fossil Fuels to Sustainable Energy Resources, The Baltic University Press, ISBN 91-7005-125-9, Uppsala.

Sanchéz, A. (2008). Perspectives and Problems in Sustainable Development, Problems of Sustainable Development, vol. 3, no 2, 21-23, ISSN 1895-6912.

Sztumski, W. (2007). The Mythology of Sustainable Development, Problems of Sustainable Development, vol. 2, no 4, 13-23, ISSN 1895-6912.

Udo, V. \& Pawlowski, A. (2010). Human Progress Towards Equitable Sustainable Development: A Philosophical Exploration, Problems of Sustainable Development, vol. 5, no 1, 23-44, ISSN 1895-6912.

UE (2004). Water, Safe, Strong and Sustainable, Vision on European Water Supply and Sanitation in 2030, Water Supply and Sanitation Platform, 978-92-4-159842 2, Brussels 2004.

WCED (1987). Our Common Future, The Report of the World Commission on Environment and Development, Oxford University Press, ISBN 0-19-282080-X, New York.

Yardley, J. (2007). Under China's Booming North, the Future is Drying Up, New York Times, September 28, 2007, http:/ query.nytimes.com/ retrieved May 27, 2010, ISSN 0362-4331. 


\title{
A Call to Action
}

\author{
Herschel Specter, President \\ RBR Consultants, Inc., \\ United States
}

\section{Introduction}

The United States faces enormous challenges as it attempts to move towards a postpetroleum future. Many measures - a continuing significant dependence on imported oil, high greenhouse gas release levels, depletion of national oil reserves faster than new sources can been found, projected increases in demand for energy from a growing population confirm that the nation has failed to adequately address energy related issues for decades. There is no room to fail again.

There are two energy related pathways that can lead to environmental and human catastrophe. In some ways they seem to be opposites. One threat is the result of insufficient energy and the other threat comes from using energy, specifically from burning fossil fuels which supply about $80 \%$ of the energy used today in the United States and a large percentage of world energy use. Insufficient energy can lead to armed conflict while the overuse of fossil fuels can lead to worldwide damage from climate change effects.

Both of these pathways to environmental and human catastrophe must be dealt with; not one at the expense of the other. However, the sequence of actions selected to overcome these twin challenges is crucial. For the United States, reducing petroleum use and therefore oil imports, should initially have the higher priority. There are environmental, economic, and national security reasons that justify assigning a higher initial priority to reducing petroleum use than emphasizing actions that almost exclusively address climate change concerns.

First emphasis should be on reducing oil imports, including establishing goals and timetables for energy security and for eventual energy independence. This is also essential for the protection of the environment from climate change. A three step energy plan is outlined here which could be used to implement these goals within the suggested time lines. Just as climate change is a global threat, so is the challenge of diminishing oil supplies. The phasing out of petroleum presents a world problem and preventing armed conflict requires world solutions. The U.S. has partially recognized this by attempting to deal with climate change. Now these two issues need to be joined, global agreements must be reached, and actions prioritized. This requires actions beyond the United States and, in particular, a new alliance with China if armed conflict is to be avoided.

In the United States there is an unrecognized, and therefore unresolved, conflict between those that project petroleum use for the next several decades and those that have created Congressional legislation that calls for a significant reduction in the release of carbon dioxide. Energy forecasters, such as the Department of Energy (DOE), the Environmental 
Protection Agency (EPA), and the National Academy of Sciences (NAS) in its report "America's Energy Future" all predict high levels of oil consumption for the next several decades (see Reference 1). The heart of such forecasts is the assumption that the United States will remain a highly car-oriented, gasoline consuming, society. Even factoring in significant improvements in automobile efficiency, these organizations predict little change in oil consumption in the transportation sector for several decades. Vehicular efficiency gains would be offset by a growing population, the assumption that the U.S. will consume even more energy per person in the future, and the slow turnover rate of several hundred million vehicles.

However burning such enormous amounts of petroleum releases gigatons of greenhouse gases (GHG). Analyses show that burning such large amounts of petroleum would be sufficient, by 2030, to exceed the GHG limits that are central to recent Congressional climate change legislation. This 2030 date, when legislated GHG limits begin to be exceeded by the burning of petroleum, was very conservatively arrived at. It was assumed, unrealistically, that there would be no GHG contribution from burning coal and natural gas. All coal and natural gas electric power plants would, in effect, be shut down along with all other natural gas burning end uses. A slightly more realistic scenario assumed that $20 \%$ of the coal and natural gas burned today would be permitted. Burning $20 \%$ of today's coal and natural gas, along with burning all the petroleum projected by DOE, EPA, and NAS, would overcome Congressional legislation about five years sooner, by 2025. At a coal and natural gas burning rate equal to just half of today's and with the GHG contribution from burning high levels of petroleum, Congressional climate change legislation limits would be overcome in less than ten years.

Congressional GHG legislation and projected petroleum consumption are incompatible. Such high levels of petroleum consumption are environmentally unacceptable if climate change is to be moderated.

Attention then turned to economic issues and the cost of burning such huge amounts of oil. An analysis was performed which used the unrealistic assumption that all the oil in these forecasts, through 2035, could be purchased by the United States. This is a business-as-usual type of scenario and the total cost of this oil was estimated to be around \$14 trillion (2008) dollars, i.e., comparable to the U.S.'s present national debt.

As large as this transfer of national wealth to oil producing countries is, it does not tell the full story. It is very unlikely that the United States would "enjoy" decades of a business-asusual situation. More likely there will be frequent and prolonged oil shortage initiated deep recessions, similar to the one the United States is experiencing now. A review of history shows that major oil price shocks have disrupted world energy markets five times since 1973 (1973-74, 1979-80,1990-91, 1999-2000 and 2008). According to studies performed at the Oak Ridge National Laboratory "Most of the oil price shocks were followed by an economic recession in the United States". It has been estimated that over the last 30 years oil market upheavals have cost the United States in the vicinity of $\$ 7$ trillion dollars (1998) dollars. So if the next 25 years, until 2035, is similar to the past 25 years, then the total cost of oil could be in the neighborhood of $\$ 14$ trillion (2008) dollars plus $\$ 7$ trillion (1998) dollars. Very little of this money would remain in the United States. With such an enormous transfer of wealth, would enough money be available to also deal with climate change?

Figure 1, produced by the Oak Ridge National Laboratory, shows the very large economic penalties of oil dependence, particularly during times of oil shortages (see Reference 2). 


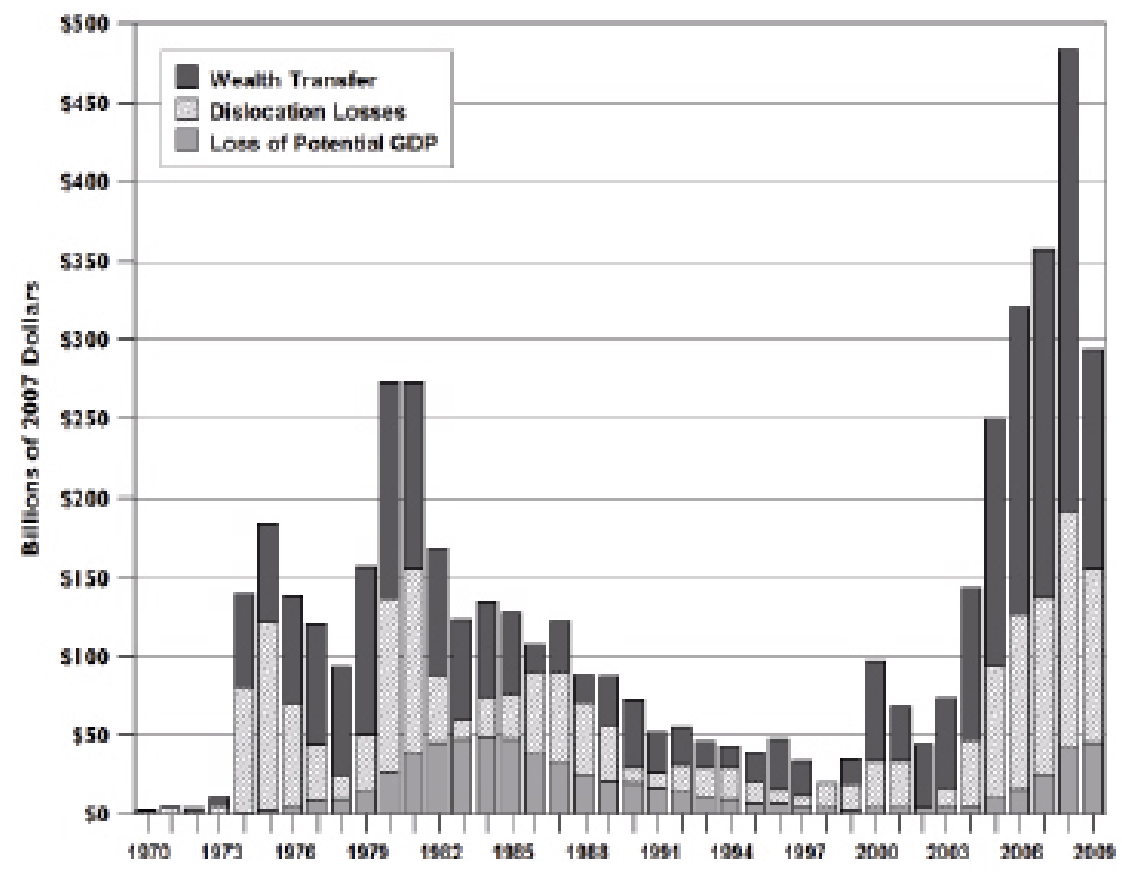

Fig. 1. Costs of Oil Dependence to the U.S. Economy, 1970-2009

Moreover, there are indications that the very nature of oil shocks may be evolving. Reviews of past unbalances between supply and demand, such as the oil embargo in 1973 and the Iranian Revolution in 1979, can be described as politically initiated oil shocks. In the future there could be two causes of oil shortfalls: politically initiated shortfalls, like past oil embargoes, and physically initiated shortfalls whenever demand exceeds supply. There is also the possibility of a political-physical hybrid situation where oil producers favor their best customers with special supply contracts during times when world demand exceeds world supply.

In the past, oil-initiated recessions could end when the political dynamics changed so that full oil flow was again possible, like the end of an oil embargo. In the case of physical shortfalls where demand exceeds supply, it is not clear how they might end. They are materially different from shortfalls initiated by political actions. One can not quickly find new sources of oil and bring that oil to market. Demand can rise far more quickly than creating new supplies. With a limited amount of oil available in the world marketplace, times when demand exceeds supply means that some stronger nations may get less oil than they want while weaker nations will get less oil than they need. Since new sources of oil come on line rather slowly, supply and demand may only come back into a temporary equilibrium when many nations do with less. This new equilibrium would be temporary if demand continues to rise and new supplies can't keep up. Should this occur, back-to-back recessions or even a continuous recession, may happen.

This would be a great hardship for many, but especially for poorer nations, some of whom are already spending more on imported oil than the value of their exports. For example, in Kenya fuel imports exceed their current account balance by $174 \%$. Since food prices correlate closely with energy prices, much higher oil prices, especially during shortfall periods, 
means that many tens of millions of people will not have enough to eat. Higher oil prices and restricted availability of oil means that they may not be able to buy sufficient fertilizers, herbicides, fuel for their tractors or oil to run their irrigation pumps.

Up to now the more severe oil related recessions have been fairly far apart in time with the more recent ones occurring around 1974, then another in 1980-81 and a third in 2008-10 (or longer). In between oil shocks nations often had time to restore their economies. With both politically initiated and physically initiated shortfalls, the time between recessions may shrink. As stated before, there are fewer mechanisms available to recover from a shortfall of oil supply and therefore recessions initiated by physical shortfalls may last longer. In between recessions there could be periods of high oil prices. In 2008, when demand temporarily exceeded supply, the price of oil hit $\$ 147 /$ barrel. Prior to that historic moment there was a run-up on oil prices which rose steadily from $\$ 33.75 /$ barrel in 2003 to $\$ 75.14$ / barrel in 2007 to $\$ 97.26$ in 2008. Prior to 2003 there was considerable margin between the sum of OPEC spare capacity plus world oil production minus oil consumption. This margin largely eroded between 2003 and momentarily disappeared in 2008 as prices reached $\$ 147 /$ barrel. See Figure 2. So a more complete description of the cost of importing oil includes the business-as-usual costs between recessions and the additional costs of recessions.

A closer look at the oil situation around 2008 shows that the margin between world oil production capacity and demand temporarily disappeared, starting the great financial crisis. A margin of about $4 \mathrm{MB} / \mathrm{D}$ has since been established since then, largely because as a result of the recession. U.S. oil consumption in 2009 has decreased to $18.5 \mathrm{MB} / \mathrm{D}$, down from 20.7 $\mathrm{MB} / \mathrm{D}$ in 2007. Figure 2, derived from DOE's Energy Information Administration, displays oil margins between 2002 and 2010.

Unclear at this time is whether a series of shortfalls or back-to-back prolonged recessions would weaken the U.S. economy to the point that the resources needed to achieve long term energy independence or adequately abate GHG releases will not be available. In other words, an economic tipping point could be reached by prolonged or frequent recessions brought on by oil shortages. Back-to-back prolonged recessions puts the economy under great stress. These stresses become far more acute if there is not sufficient energy to meet a nation's basic needs, such as an adequate food supply, and this could lead to armed conflict to secure sufficient oil. In a world filled with weapons of mass destruction, global armed conflict would be the end of civilization as we know it. Global armed conflict must be avoided.

Therefore it is logical to ask "How long might it take before the present margin of about $4 \mathrm{MB} / \mathrm{D}$ would be used up and then what happens?" One energy forecast, predicts a 10 million barrels per day (MB/D) shortfall by 2015 (see Reference 3). Most of the future increase in oil demand will not come from OECD nations or the United States, but from emerging nations like China, India, and Brazil. China is the fastest growing oil market in the world, even though the United States at this time remains the top consumer. The potential demand for oil from China alone is tremendous. Even in the short time since 2007 the oil scene has shifted considerably. Chinese oil consumption has now reached $8.5 \mathrm{MB} / \mathrm{D}$, up from 7.6 MB/D in 2007. By 2011 the number of cars sold in China will be more than double those sold in the U.S. and further demands for oil will come from India with its \$2000 car entering its transportation market. The rise in oil demand from China is reshaping the geopolitics of oil, with Saudi Arabia now exporting more oil to China than to the United States. According to the NY Times "The Chinese military is seeking to project naval power 
well beyond the Chinese coast, from the oil ports of the Middle East to the shipping lanes of the Pacific, where the United States Navy has long reigned as the dominant force, military analysts say." Further evidence of growing energy related friction between China, its neighbors, and the United States recently occurred when the U.S. challenged China on its dispute with its smaller Asian neighbors over a string of islands in the South China Sea. These islands are rich in oil and natural gas deposits.

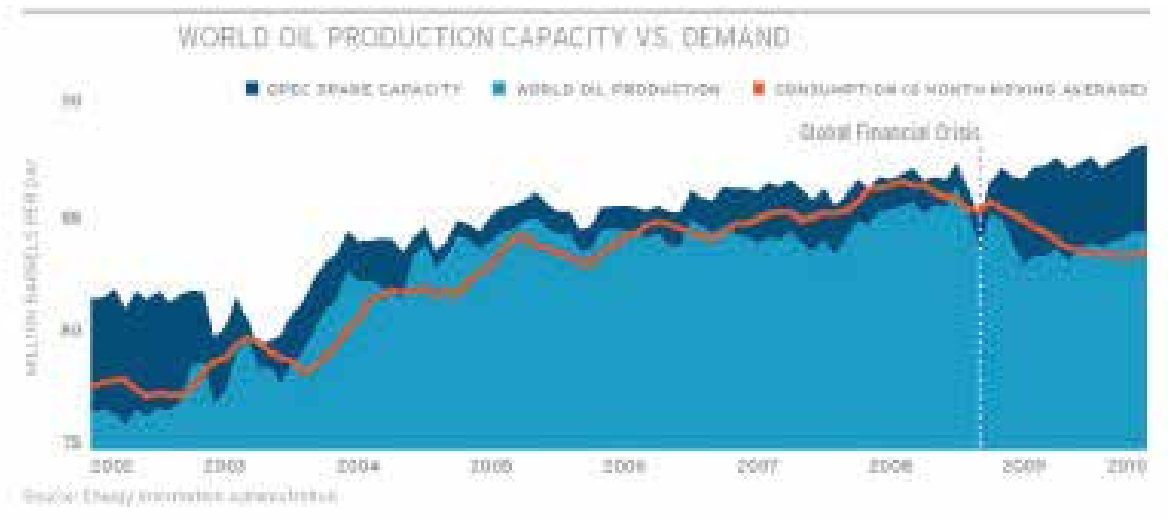

Fig. 2. World Oil Production Capacity vs. Demand

Questions like "How long will it before the world runs out of oil?" and "When will conventional oil production peak?" have spurred debate. Yet these questions may be of secondary importance. Long before the world runs out of oil (conventional plus nonconventional) either a post-petroleum future will be in place or the effects of major climate changes and/or armed conflict over remaining critical resources would have occurred. Nature will not wait for people to cut back their releases of GHG. People and nations will not wait until a critical resource is exhausted before they use force. When or if the world will run out of oil is rather unimportant compared to other oil related issues, like shortfalls.

The precise moment when conventional oil peaks is also rather unimportant. The world has already seen major recessions because of high oil prices. The world has have also seen armed conflict over oil shortages. An oil embargo by the United States on Japan, when the US was a major oil exporter, was a factor in the bombing of Pearl harbor. All of these events have already occurred, well in advance of conventional oil reaching its peak production. Even after the global financial crisis in 2008 world oil production plus OPEC spare capacity continued to gradually increase, demonstrating that peak production has not yet taken place. Conversely, if handled properly through world co-operation, severe consequences might be avoided in a post-peak oil time period.

The time of peak conventional oil production is an interesting moment in history, but other parameters are more important. Perhaps the most important parameter to watch is oil shortfalls with questions like: when might the next shortfall might occur, what is the possible frequency of additional shortfalls, what might be their durations and severity, and which nations would be most affected by them?

The full justification for placing more initial emphasis on imported oil than climate change is therefore:

1. Burning projected amounts of oil releases so much GHG that legislated limits are soon exceeded. 
2. Purchasing vast amounts of oil would transfer so much national wealth it is unlikely that sufficient funds would be available to adequately reduce our GHG releases to protect against climate change or to achieve energy independence.

3. There is a possibility that oil shortfalls could lead to armed conflict much sooner than severe effects of climate change would be felt globally.

In response to these energy challenges a three step energy plan for the United States has been assembled. This plan is guided by the following goals and timetables:

1. By 2015 the U.S. should be able to withstand a sudden and enduring decrease of 5 $\mathrm{MB} / \mathrm{D}$ in imported oil without a loss of any critical function, such as providing adequate food, space heating, and transportation.

2. By 2030, the importation of liquid fuels should be limited to sources from North, South, and Central America, including the Caribbean, and that amount not to exceed $4 \mathrm{MB} / \mathrm{D}$ of gasoline equivalent. Some of this imported gasoline equivalent should be in the form of ethanol.

3. By 2030 the release of GHG should be limited to about $3.6 \mathrm{Gt} /$ year of $\mathrm{CO}_{2 \mathrm{e}}$ which would be consistent with the limits legislated in the House of Representatives bill, H.R. 2454, for that date.

Step One of this plan covers the time period from now through 2020, or so.The purposes of Step One are to put into place a capability to withstand a sudden decrease in imported oil supplies and to lay the groundwork for long term energy independence and the protection of the environment from climate change. Step Two is a much larger endeavor and concentrates on petroleum-displacing actions which would also reduce GHG release rates. It would run between now and 2030 or so and would therefore overlap Step One. At the conclusion of Step Two an assessment would be made to determine if the goal of limiting GHG releases to $3.6 \mathrm{Gt} /$ year had been achieved. Simultaneously, using the science of 2030, a determination would be made to see if the 2050 GHG limits in H.R. 2454 need to be adjusted. Based on these two pieces of information a specific set of actions would be identified to be implemented in Step Three from 2030 to 2050.

\section{Environmental, economic, and national security issues}

\subsection{Introduction}

This section elaborates on the central energy related issues of the impact of energy use and the impact of insufficient energy on the environment, the economy, and on national security.

\subsection{Environmental issues}

Reports by the International Panel on Climate Change and many others have lead to a world-wide concern that rising greenhouse gas (GHG) levels will lead to enormous environmental damage. As climate change occurs, as many scientists predict, it could threaten world catastrophe with huge areas of human habitat flooded by rising sea levels, accelerated loss of species, increased frequencies of category five hurricanes, droughts in some areas and excessive rainfall in other areas, food supply challenges, hundreds of millions of displaced persons, and other severe effects (see Reference 4).

In response to the GHG climate change concern the U.S. House of Representatives passed an energy bill, "American Clean Energy and Security Act of 2009", also known as H.R. 2454. H.R.2454 is quite clear about dealing with the issue of climate change: it presents a timetable by which specific GHG reductions must be achieved. The Environmental Protection Agency 
(EPA) made an analysis of H.R.2454 by analyzing six energy scenarios. In all six scenarios petroleum consumption remained essentially unchanged out to 2050, primarily because of the assumed continued use of gasoline powered vehicles. The EPA is not alone in predicting a high consumption of petroleum for several decades by the United States. Various studies by the Department of Energy (DOE) and the National Academy of Sciences (NAS) also predict continuing high levels of petroleum use. The NAS has published "America's Energy Future" (AEF). To quote AEF's Figure 2.1, "Combining the projected growth in vehicle fleet size with potential savings results in only slightly higher gas (gasoline) consumption in vehicles in 2020 and 2030 than exists today".

However, GHG releases from such predicted petroleum consumption would, by 2030, defeat the goals of climate change legislation, H.R. 2454, even if the energy efficiency of U.S. vehicles were significantly improved and $100 \%$ of the releases of GHG from coal and natural gas were eliminated. A slightly more realistic analysis showed that even if $80 \%$ of today's GHG releases from coal and natural gas were eliminated, the limits set by H.R. 2454 would be overcome would be about five years sooner, by 2025 . If only $50 \%$ of today's GHG releases from coal and gas were eliminated, the limits in H.R. 2454 would be exceeded in less than ten years. Significant expansion of ethanol from biomass in these time frames are estimated to only defer these dates by about one to three years. In effect, the EPA analysis of H.R. 2454 shows that the goals of this climate change energy bill and continued high consumption of petroleum are incompatible. Table 1, below, summarizes the analysis that led to these conclusions, based on projected oil consumption figures from "America's Energy Future"(AEF). Note that the AEF projections already assume significant efficiency improvements for light duty vehicles (LDVs) and heavy duty vehicles (HDVs). It was further assumed that non-transportation uses of petroleum would become less oil consuming and that there would also be a reduction in the release of greenhouse gases that are not based on carbon dioxide molecules.

One important ramification of this analysis is its effect on the policy debate about carbon taxes versus a cap and trade approach to reducing GHG releases from coal and gas electric power plants. Neither policy option has much value unless petroleum use is sharply reduced. Regardless of which policy option or combination of options the nation chooses, if any, it would be overcome in a few years unless petroleum use is simultaneously reduced. Congressional actions limited to only reducing GHG emissions from fossil fueled electric power plants are doomed to fail to adequately address climate change issues.

\subsubsection{Environmental conclusion}

Significant reductions in petroleum use are necessary on environmental grounds in order to meet proposed GHG release limits and moderate climate change.

\subsection{Economic issues}

\subsubsection{A business-as-usual scenario}

A business-as-usual scenario was examined in which it was assumed that adequate oil is available at market prices, at least through 2035. No oil shocks from gaps between supply and demand are considered nor any armed conflict.

The Energy Information Administration (EIA) Annual Energy Outlook for 2010 predicts a cost of $\$ 133 /$ barrel (in 2008 dollars) by 2035 . This would be about $\$ 224 /$ barrel in nominal dollars. Since we have already briefly experienced a peak price of $\$ 147 /$ barrel, the EIA 


\begin{tabular}{|c|c|c|c|}
\hline 1. No Coal or Natural Gas GHG Contribution & $\begin{array}{l}\text { Year } \\
2007\end{array}$ & $\begin{array}{l}\text { Year } \\
2020\end{array}$ & $\begin{array}{l}\text { Year } \\
2035\end{array}$ \\
\hline $\begin{array}{l}\text { From petroleum used in LDVs.(2020 and } 2035 \\
\text { amounts derived from AEF numbers). }\end{array}$ & 1455 & 1686 & 1511 \\
\hline $\begin{array}{l}\text { From petroleum for HDVs.(2020 and } 2035 \\
\text { amounts derived from AEF numbers). }\end{array}$ & 580 & 675 & 605 \\
\hline $\begin{array}{l}\text { From petroleum for non-transportation uses. } \\
\text { (Based on EIA } 2007 \text { petroleum data, with } \\
\text { assumed } 20 \% \text { and } 25 \% \text { reductions by } 2020 \text { and } \\
2035 \text {, respectively). }\end{array}$ & 545 & 436 & 409 \\
\hline $\begin{array}{l}\text { Non- } \mathrm{CO}_{2} \text { greenhouse gases (Based on EIA } \\
2007 \text { data, with assumed } 20 \% \text { and } 25 \% \text { reduc- } \\
\text { tions, by } 2020 \text { and } 2035 \text {, respectively). }\end{array}$ & 1261 & 1009 & 946 \\
\hline Total $\mathrm{CO}_{2 \mathrm{e}}$ from petroleum and non- $\mathrm{CO}_{2} \mathrm{GHG}$. & 3841 & 3806 & 3471 \\
\hline H.R. $2454 \mathrm{CO}_{2 \mathrm{e}}$ limit. & N/A & 5000 & 3000 \\
\hline $\begin{array}{l}\text { Percent of H.R. } 2454 \text { limit, no coal or natural } \\
\text { gas GHG contribution. }\end{array}$ & $\mathrm{N} / \mathrm{A}$ & 0.76 & 1.16 \\
\hline $\begin{array}{l}\text { 2. With a coal and natural gas GHG contribu- } \\
\text { tion equal to } 20 \% \text { of the } 2005 \text { release amount. }\end{array}$ & $\begin{array}{l}\text { Year } \\
2007\end{array}$ & $\begin{array}{l}\text { Year } \\
2020\end{array}$ & $\begin{array}{l}\text { Year } \\
2035\end{array}$ \\
\hline $\begin{array}{l}20 \% \text { of } 2007 \text { 's coal and natural gas GHG } \\
\text { releases. }\end{array}$ & N/A & 680 & 680 \\
\hline $\begin{array}{l}\text { Total } \mathrm{CO}_{2 \mathrm{e}} \text { from petroleum and non- } \mathrm{CO}_{2} \text { gases } \\
+20 \% \text { of } 2007 \text { 's coal and natural gas } \mathrm{GHG} \\
\text { releases. }\end{array}$ & N/A & 4486 & 4151 \\
\hline $\begin{array}{l}\text { Percent of H.R. } 2454 \text { limit with } 20 \% \text { of coal } \\
\text { and natural gas } 2007 \text { GHG releases. }\end{array}$ & $\mathrm{N} / \mathrm{A}$ & 0.90 & 1.38 \\
\hline $\begin{array}{l}\text { 3. With a coal and natural gas GHG contribu- } \\
\text { tion equal to } 50 \% \text { of the } 2005 \text { release amount. }\end{array}$ & $\begin{array}{l}\text { Year } \\
2007\end{array}$ & $\begin{array}{l}\text { Year } \\
2020\end{array}$ & $\begin{array}{l}\text { Year } \\
2035\end{array}$ \\
\hline $\begin{array}{l}50 \% \text { of } 2007 \text { 's coal and natural gas GHG } \\
\text { releases. }\end{array}$ & N/A & 1700 & 1700 \\
\hline $\begin{array}{l}\text { Total } \mathrm{CO}_{2 \mathrm{e}} \text { from petroleum and non- } \mathrm{CO}_{2} \text { gases } \\
+50 \% \text { of } 2007 \text { 's coal and natural gas } \mathrm{GHG} \\
\text { releases. }\end{array}$ & N/A & 5506 & 5171 \\
\hline $\begin{array}{l}\text { Percent of H.R. } 2454 \text { limit with } 50 \% \text { of coal } \\
\text { and natural gas } 2007 \text { GHG releases. }\end{array}$ & $\mathrm{N} / \mathrm{A}$ & 1.10 & 1.72 \\
\hline
\end{tabular}

Table 1. Millions of Tonnes/year of $\mathrm{CO}_{2 \mathrm{e}}$ Released

projected prices may be low. It was assumed that between 2010 and 2035 the time averaged price of oil, in 2008 dollars, would be $\$ 120$ (2008 dollars)/barrel. In 2007 the U.S. imported about 10,000,000 barrels of oil/day or about 3,650,000,000 barrels/year. The AEF report projects that the United States would continue to consume oil, through 2035, at a rate similar to that of 2007. If this rate of imports were continued for 25 years at $\$ 120 /$ barrel, the total cost would be, approximately, $\$ 11$ trillion (2008) dollars. This amount is in the range of the present national debt. 
There are two other major costs that deserve to be considered. There is the U.S. defense costs related to protecting its oil supplies. At a minimum this cost is about $\$ 67.5$ to $\$ 83$ billion (2008) dollars per year not including the costs of actual warfare (see Reference 5). Additionally, estimates have been made by the National Academy of Sciences of the cost of the 2005 health effects caused by our energy system (see Reference 6). These health costs from energy use are estimated to be $\$ 120$ billion /year of which some $\$ 56$ billion/year are attributed to transportation, i.e., to the use of petroleum. The total cost of imported oil, the oil related portion of our national defense effort and transportation (petroleum) related health effects for the next 25 years would, conservatively, come to about \$14 trillion (2008) dollars for the business-as-usual scenario.

\subsubsection{An oil shock scenario}

In the business-as usual scenario, there was a sufficient and stable supply of oil. As stated in Section 1, the business-as-usual scenario is very likely to be interrupted by oil shocks which then lead to recessions. Over the last 30 years oil market upheavals have cost the United States in the vicinity of $\$ 7$ trillion (1998) dollars. So if the next 25 years, until 2035, is similar to the past 25 years, then the total cost of oil could be in the neighborhood of $\$ 14$ trillion (2008) dollars plus $\$ 7$ trillion (1998) dollars. This adds up to about an average of a trillion dollars per year to be borne by a weak economy for about 25 years.

\subsubsection{Economic conclusion}

Dealing effectively with GHG emissions and eventually achieving energy independence may not be possible with such huge transfers of money to oil exporting countries.

\subsection{National security issues}

Oil dependence represents a grave national security issue for the United States. To illustrate how precarious the United States's position is, two tables are presented below. Table 2 lists the top seven countries in terms of oil consumption in 2007. Table 3 lists the 2007 oil and gas reserves. The contrast between Tables 2 and 3 is stark. The United States is, by far, the world's largest consumer of oil, yet American oil companies, ExxonMobil and Chevron, rank 17th and 21st, respectively, in total reserves of oil equivalents. The U.S. has become the Saudi Arabia of consumption.

\begin{tabular}{|l|l|l|}
\hline Rank & Country & Barrels of oil/day \\
\hline 1 & United States & $20,680,000$ \\
\hline 2 & China & $7,578,000$ \\
\hline 3 & Japan & $5,007,000$ \\
\hline 4 & Russia & $2,858,000$ \\
\hline 5 & India & $2,722,000$ \\
\hline 6 & Germany & $2,456,000$ \\
\hline 7 & Brazil & $2,372,000$ \\
\hline
\end{tabular}

Table 2. 2007 Oil Consumption, Top Seven Countries 


\begin{tabular}{|c|c|c|c|c|}
\hline $\begin{array}{l}\text { Rank by } \\
2007 \text { Oil } \\
\text { Equiva- } \\
\text { lent } \\
\text { Reserves }\end{array}$ & Company & $\begin{array}{l}\text { Liquid } \\
\text { Reserves, } \\
\text { Millions of } \\
\text { Barrels }\end{array}$ & $\begin{array}{l}\text { Natural gas } \\
\text { Reserves, } \\
\text { Billions of } \\
\text { Cubic Feet }\end{array}$ & $\begin{array}{l}\text { Total } \\
\text { Reserves (in } \\
\text { Oil Equiva- } \\
\text { lent), Mil- } \\
\text { lions of } \\
\text { Barrels }\end{array}$ \\
\hline 1 & $\begin{array}{l}\text { Saudi Arabian Oil Company } \\
\text { (Saudi Arabia) }\end{array}$ & 259,900 & 253,800 & 303,285 \\
\hline 2 & $\begin{array}{l}\text { National Iranian Oil Com- } \\
\text { pany (Iran) }\end{array}$ & 138,400 & 948,200 & 300,485 \\
\hline 3 & $\begin{array}{l}\text { Qater General Petroleum } \\
\text { Corporation (Qatar) }\end{array}$ & 15,207 & 905,300 & 169,959 \\
\hline 4 & $\begin{array}{l}\text { Iraq National Oil Company } \\
\text { (Iraq) }\end{array}$ & 115,000 & 119,940 & 134,135 \\
\hline 5 & $\begin{array}{l}\text { Petroleos de Venezuela, S.A. } \\
\text { (Venezuela) }\end{array}$ & 99,377 & 170,920 & 128,594 \\
\hline 17 & $\begin{array}{l}\text { ExxonMobil Corpora- } \\
\text { tion (United States) }\end{array}$ & 7,744 & 32,610 & 13,318 \\
\hline 21 & $\begin{array}{l}\text { Chevron Corporation } \\
\text { (United States) }\end{array}$ & 7,087 & 22,140 & 10,870 \\
\hline
\end{tabular}

Table 3. 2007 Oil and Gas Reserves

Back-to-back oil shocks may severely and permanently weaken the U.S. economy. If the U.S. is unable to secure sufficient oil through the market place because its economy can not outbid stronger countries and this results in severe food shortages (mostly due to a transportation system that does not have the fuel to deliver sufficient food) or the loss of other critical functions, then this could lead to armed conflict.

\subsection{Overall conclusion}

Analyses of environmental, economic, and national security issues point to the same conclusion: unless the consumption of petroleum is sharply reduced in the United States on a priority basis, then the goals of limiting the adverse effects of climate change, of achieving energy security or of eventual energy independence, are unlikely to be reached. Achieving these goals largely depends on removing petroleum from our transportation sector. It must also work with other nations, especially China, to co-manage the complicated world transition to a post-petroleum era in a peaceful way.

A three step energy plan directed at addressing the proposed goals in section 1 is presented below.

\section{A three step energy plan}

\subsection{Introduction}

The purpose of this section is to provide a first draft of an energy plan that would address national security issues, economic, and climate change issues. This proposed plan is divided into three steps. The purposes of Step One are to put into place a capability to withstand a sudden decrease in imported oil supplies and to lay the groundwork for long term energy independence while protecting of the environment from climate change. Step One would use mature conservation techniques, like home insulation, to reduce GHG releases. This part of Step One is expected to more than pay for itself. With regard to creating an ability to 
withstand a sudden decrease in imported oil supplies, "no tech" actions, like car pooling, and "low tech" actions, like using more buses and other forms of mass transportation, could be assembled fairly quickly and used to reduce oil consumption and GHG releases. In Step Two other actions both for the near term and for the long term would be initiated. Among such actions would be the creation of different liquid fuel industries based on biomass, coal, and natural gas. The use of energy storage would be greatly expanded. The use of nuclear power would be expanded to first emphasize evolutionary nuclear plants and later the use of high temperature plants for process heat, hydrogen, and electricity. Renewable energy, particularly biomass and windpower, would be encouraged, but a more regional approach would be recommended. Significant investments would be required in this step. Major portions of this investment would come from savings from the U.S. oil import bill.

Step Three is designed to further reduce GHG releases, if shown to be necessary. The time lines of each of these steps are described below.

\subsection{Step One, 2010-2020, or so}

\subsubsection{Non-transportation actions to abate GHG}

Step One calls for the implementation of well known energy conservation actions and is expected to produce a net savings in money. These conservation actions can be implemented rather quickly and with little uncertainty about costs or effectiveness.

Those actions that relate to reducing the release of GHG, but not including a modified transportation future, are displayed in Figure 3 (see Reference 7). The quicker that GHG gases can be abated, the greater the GHG reduction over time. Energy conservation has multiple benefits beyond saving money and reducing the release of GHG. Many conservation actions, like home insulation, are long lasting and would not require further use of resources. Further, conservation actions usually depend on different supply chains and infrastructure support than energy producing actions.

As shown in reference 7, about 1.1 gigatons/year (Gt/yr) of greenhouse gases can be abated by 2020 through actions like home insulation, with a net savings in money. It is estimated that for a $\$ 520$ billion dollar investment, about $\$ 1.2$ trillion dollars in energy costs could be saved, yielding a net surplus of about $\$ 680$ billion dollars. To make further reductions in the release of GHG requires investments that would have a net cost. For the purposes of this report the boundary of Step One is the point at which further investments in GHG abatement would require major construction projects and would have a net cost. Many of these additional investments are to be included in Step Two which also starts in 2010, but would continue on to 2030 or so.

Since current climate change legislation calls for GHG abatement well beyond $1.1 \mathrm{Gt} / \mathrm{yr}$, it is obvious that achieving much larger GHG abatement could require trillions of dollars. For example, the National Renewable Energy Laboratory estimates that to supply $20 \%$ of the nation's electricity with wind power by 2024 would cost $\$ 1.1$ trillion dollars, not including the cost of new dedicated transmission lines, yet this is but a small piece of what has to be done. The most advantageous way of paying for such large investments is to recycle the savings generated by reducing the cost of importing oil.

\subsubsection{No tech and low tech transportation actions to reduce oil consumption}

Recently the United States government increased the fuel efficiency standards of new cars to 35.5 miles per gallon, almost 10 miles per gallon more than the average for new cars today. 


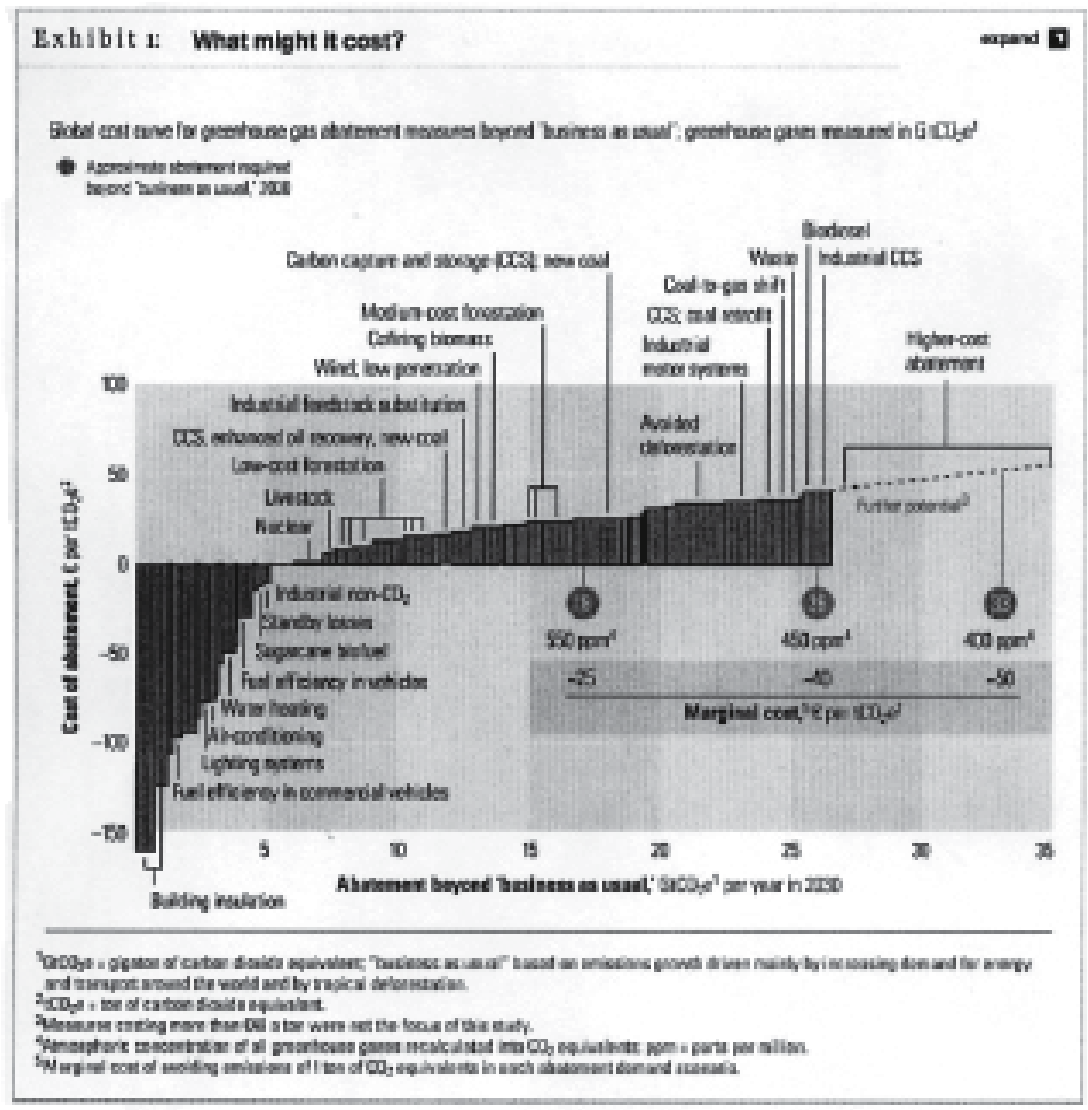

Fig. 3. McKinsey \& Company, Exhibit 1

This significant efficiency improvement, about $38 \%$, will take years to fully implement and is only expected to start within the next six years. Nonetheless, it is a move in the right direction. A requirement to make all new vehicles flex-fuel capable should be implemented as well.

It is going to take many years to build up the kind of infrastructure, like more efficient cars and high speed trains, to begin to reduce both GHG releases and oil imports. As discussed above, a comparatively rapid start can be achieved in reducing GHG releases using mature conservation actions in non-transportation applications. It is also possible to supplement these conservation actions in the transportation sector with activities that are well established and could be implemented rather quickly at comparatively low costs. It is possible to implement near term "no tech" and "low tech" solutions that could reduce GHG and simultaneously reduce oil imports, assuming that U.S. political leaders and policies can create sufficient public support for these approaches.

The least cost trip is the one you didn't have to take. In this regard, working at home or in walk-to short term rental offices with teleconferencing (telecommuting) services would be a true energy and GHG saver. In this digital age of instant electronic communications greater use of teleconferencing is an important tool in reducing oil use and GHG releases. Greater government emphasis needs to be placed on true virtual presence high definition bidirectional video. This means greatly increasing the band width to homes. Other countries in the world are further along on this than the U.S. 
A major example of a "no tech" improvement is higher ridership in individual vehicles using car pools and in public transportation. Table 4, below, adapted from Table 2.12 of ORNL-6984, sheds light on the relationship between ridership (load factor) and energy use for automobiles, buses, airplanes, and trains.

\begin{tabular}{|l|l|l|l|}
\hline Vehicle Type & $\begin{array}{l}\text { Load factor } \\
\text { (persons/vehicle) }\end{array}$ & $\begin{array}{l}\text { Btus per } \\
\text { vehicle-mile }\end{array}$ & $\begin{array}{l}\text { Btus per } \\
\text { passenger-mile }\end{array}$ \\
\hline Automobile & 1.57 & 5,517 & 3,514 \\
\hline Buses & 9.1 & 39,408 & 4,315 \\
\hline Airplanes & 97.2 & 301,684 & 3,103 \\
\hline $\begin{array}{l}\text { One passen- } \\
\text { ger car in an } \\
\text { Amtrak } \\
\text { train. }\end{array}$ & 21.7 & 54,585 & 2,516 \\
\hline
\end{tabular}

Table 4. U.S. Passenger Travel and Energy Use, 2007

One "no tech" practice that could have a very large effect on energy use and GHG releases would be greater use of car pools. If the average number of persons per vehicle were around 3.0 instead of today's 1.57, oil use in individual vehicles would be cut in about half. This exceeds the benefit of increasing average fuel efficiency by almost 10 m.p.g., as mentioned above, and is equivalent to replacing all of our present fleet of automobiles with plug-ins that would have batteries with a range of 27 miles (See Table 6). Of course car pools and more energy efficient vehicles can be used together to further increase energy savings. Public apathy and resistance to forming car pools is expected and political leadership is needed here. Yet car pools might be implemented rather quickly, especially if fuel prices rise sharply through taxation or if people again began to experience gas stations with "out of gas" signs because of oil shortfalls.

As shown in Table 4 the energy use per passenger-mile was the highest for travel by bus. The problem is not with the buses. This is directly attributable to the very low load factor for buses because of our car-oriented society. Travel by air in 2007 had a very high energy use per vehicle-mile, but because the load factor was also quite high, the Btus per passengermile was actually less than those for both cars and buses. If efforts are made to increase bus ridership to an average load factor of, say 70, the Btus per passenger-mile would drop to about 561, or six times better than the efficiency of 2007 internal combustion engine automobiles with its own typically low ridership.

So well before people would be able to use hydrogen based buses or high speed trains, today's ordinary petroleum driven buses could cause a large reduction in gasoline use, provided high ridership is achieved. The U.S. government needs to identify which bus routes would be crucial and create several tens of thousands of new jobs building such a bus system in the United States. All new buses should be flex fuel hybrids with regenerative braking. A steadily increasing tax on imported oil should be levied until gasoline prices resemble those in Europe. Some of the revenues from this import tax should be used to subsidize mass transportation.

Table 4 also shows that increased ridership for Amtrak trains could significantly decrease its energy use per passenger-mile. Mass transportation with high ridership has the potential to reduce oil use far more than all the projected improvements in internal combustion vehicles that are not plug-ins. High speed electric trains would not be part of Step One, but the groundwork for them would fall into Step Two. 
Success in Step One is not a matter of finding a breakthrough in battery technology or discovering a way for algae to produce liquid fuels. All the above increases in ridership were observed during previous oil shortages and just faded away as oil became available again and gasoline prices dropped. Similarly, any of the older technologies (streetcars, buses with overhead power lines, etc.) can be used in the United States to cut oil consumption. What is required here is political leadership that the public has confidence in and policies, such as a tax on imported oil, with the proceeds going to reduce the costs of mass transportation. Perhaps the lesson here is that in the transportation sector is that the U.S. should consider "going backward in time" while working on high tech solutions to go "forward in time". Also note that if Steps Two and Three evolve more slowly than what is envisioned here, car pooling and other Step One practices can continue as long as necessary.

\subsubsection{Use of natural gas to reduce oil consumption}

After many years of decline the reserves of natural gas in the United States has increased dramatically. The reason for this turn around is the ability to extract natural gas from shale using new technologies and the realization that there are vast amounts of shale gas in the country, from Texas to New York.

With regard to transportation, the best use of natural gas is to convert it to methanol which can be distributed through the present petrochemical distribution system, although compressed natural gas can also be used in transportation. The main environmental concerns with regard to shale gas are water management issues and effective disposal of fracture fluids (see Reference 8).

Shale gas offers many important advantages over imported oil. First and foremost it is a domestic energy source. Further, shale gas converted to a liquid fuel produces less GHG than diesel fuel. High fuel use vehicles that use diesel fuel like trash trucks, delivery trucks, buses, etc. are logical candidates to substitute liquid fuels made from shale gas for diesel fuel. With regard to buses, first emphasis on using liquid fuels derived from natural gas should be on those buses that are used for long distance travel, as this is an area not well suited for electric buses or plug-in hybrids and could be implemented well before high speed trains could be put into practice. Further, buses fueled with methanol from natural gas, could travel to any location whereas high speed trains would likely be concentrated in high population density areas. If these buses were also built with a flex fuel platform they could be used in those areas in the country where ethanol from biomass was the dominant oil-displacing liquid fuel and in other areas where methanol was used to displace oil. As indicated in Table 5, the longer average distance traveled in rural areas results in a greater dependence on liquid fuels, such as locally produced ethanol. The shorter average distance traveled and the higher population density of city areas results in greater dependence on electricity in these locations.

\begin{tabular}{|c|c|}
\hline Location & $\begin{array}{c}\text { Average daily distance driven in U.S., } \\
\text { miles }\end{array}$ \\
\hline Rural areas & 40 \\
\hline Suburban areas & 33 \\
\hline Center City areas & 30 \\
\hline
\end{tabular}

Table 5. Average Daily Distance that is Driven in the U.S., Miles

The use of natural gas to displace diesel fuel should start in Step One and continue on through Step Two (2010 to 2030). While an improvement over diesel fuel, natural gas is still 
a fossil fuel and its long term use may be limited by climate change concerns. However, the long term use of natural gas would be an issue for Step Three, which starts around 2030 or so.

The use of liquid fuels from shale gas in buses, preferentially in longer distance intercity travel, would supplement the use of hydrogen/electric buses, described in

Step Two, which would be concentrated in urban and suburban locations. As shown in Table 6 , below, about $38 \%$ of today's passenger car miles are for trips longer than 40 miles, the range of the Chevy Volt, just on batteries. This means that there could be a significant market for liquid fuels of which natural gas derived liquid fuels could be an important contributor.

\begin{tabular}{|l|l|l|}
\hline $\begin{array}{l}\text { Trip Length } \\
\text { (in miles) }\end{array}$ & $\begin{array}{l}\text { Cumulative Percent } \\
\text { of Trips Taken }\end{array}$ & $\begin{array}{l}\text { Cumulative } \\
\text { Percent of } \\
\text { Miles Travelled }\end{array}$ \\
\hline $0-0.9$ & 9.7 & 0.4 \\
\hline $1-4.9$ & 49.7 & 9.5 \\
\hline $5-9.9$ & 71.4 & 23.2 \\
\hline $10-19.9$ & 87.6 & 44.0 \\
\hline $20-49.9$ & 97.3 & 70.9 \\
\hline $50-99.9$ & 99.2 & 82.9 \\
\hline $100+$ & 100.0 & 100.0 \\
\hline
\end{tabular}

Table 6. Trip Length vs. Cumulative\% of Trips Taken and Miles Traveled

It is also possible to generate liquid fuels from biomass and from coal. Having a diversity of liquid fuels is an advantage, especially if the use of shale gas has to eventually be curtailed because of climate change concerns or the need to save shale gas for other applications, such as in residential and commercial space heating and as a chemical feedstock. Ethanol from biomass and methanol derived from coal would be natural supplements to methanol from natural gas, but significant quantities would not be available in Step One.

\subsection{Step Two, 2010-2030, or so}

\subsubsection{Introduction}

Step Two has two purposes: to reduce, by 2030, the U.S. release of GHG to $3.7 \mathrm{Gt} / \mathrm{yr}$ and to limit U.S. oil imports to North, South, and Central America and the Carib-bean. Step Two describes a possible multi-modal transportation future that relies on electrification to further reduce GHG by burning less oil and simultaneously improving the U.S. national security posture. Step Two also describes the use of ethanol from biomass and methanol from coal and natural gas to replace oil in transportation modes where liquid fuel is necessary.

\subsubsection{Reducing oil imports through an electrified transportation future}

Three interrelated modes of electrically driven forms of transportation are envisioned. They are individual vehicles, principally plug-in hybrid cars (mode one); mass transportation in the form of electric buses, light rail, streetcars and subways for local travel (mode two); and high speed long distance electric trains (mode three). These three modes would be interconnected, with further ties to airports and other forms of long distance transportation. 


\subsubsection{Mode One: Plug-in Hybrids and EVs for individual transportation}

Plug-in hybrids are individual vehicles that have the potential to displace a considerable amount of imported oil. These hybrid vehicles are composed of a battery system that can be charged from the electric grid and from small wind turbines or photovoltaic systems principally in rural areas, and a liquid fuel driven engine which enables hybrids to increase their range well beyond the range of the electric only driving. Plug-in hybrids would also use regenerative braking.

The main purposes for plug-in hybrids are to enable local travel in the electric-only mode and to link up with the other modes of travel that use electrified mass transportation. The batteries in plug-in vehicles would be mainly recharged from the 110 volt electric grid at residential locations at off-peak times when the cost for electricity should be lower. Charging times for today's batteries are long, usually several hours. There is interest in level 11 charging, between 208 and 240 volts, to shorten this recharging time. These level II charging outlets would most likely be located in public places. Level III chargers would be capable of providing high voltage to recharge batteries in minutes, not hours. Such chargers might be located along intercity roads to accommodate longer trips (see Reference 9). Long recharging times encourages the recharging of plug-ins in residential settings at night. Since most plug-ins would be recharged at off-peak times, they represent an important step towards a flatter electricity demand profile.

Israel is taking a different approach by establishing many quick electric charge locations throughout the country. This Israeli technology will also be explored in Denmark and Australia. The recharging stands being used in Israel now could be applied to a transportation hub/plug-in hybrid arrangement that would be more closely tailored to transportation needs in the United States. High voltage recharging stands in parking areas at mass transportation hubs could recharge plug-in batteries during the time the drivers were away at work thereby avoiding the inconvenience of waiting for the recharging periods to be concluded.

Recharging stations at transportation hubs would increase the range of plug-ins, up to twice as long. Commuters could drive to the transportation hubs with batteries charged at night at home and return to home with batteries charged at the transportation hubs while they were away at work. Consider the transportation hub as the center of a circle. By doubling the radius which can be totally served by battery power, this increases the fully electrified travel area by a factor of four. Thus, potentially, many more commuting plug-in drivers would be capable of getting to and from these transportation hubs in the electric-only mode if these transportation hubs had recharging stands. Although purchasing electricity at a transportation hub during the day would be more expensive per kilowatt-hour than off peak purchases at home, the cost of electricity per mile traveled is considerably less than paying for gasoline.

Parking buildings near where people work could similarly be upgraded to provide electricity to recharge plug-in batteries during the work day. Such an arrangement has all the benefits of the transportation hub arrangement and could increase the number of miles driven in the electric-only travel mode. A rough estimate can be made of the potential benefits of the recharging station/plug-in hybrid combination by using Table 6 , above. Assume that all plug-ins have a battery system with a 10 mile all-electric range. Based on Table 6 this would be sufficient to travel $23.3 \%$ of our miles in the electric-only mode, leaving $76.8 \%$ of our miles to be traveled using liquid fuels. If the availability of recharging 
stations at transportation hubs and business parking lots doubles the range of the electriconly travel mode, then $44 \%$ of the plug-in miles could be achieved in this manner, leaving $56 \%$ of the plug-in miles to be accomplished by liquid fuels. If half of the trips performed by plug-ins take advantage of recharging stations, then the overall liquid fuel savings would be $(0.50) \times(76.8 \%-56.0 \%) \sim 10 \%$ reduction in national liquid fuel use for the plug-in mode of travel. This simple approximation implies that the cost of building many recharging locations could be offset by a reduced oil import bill.

Additionally, fully charged plug-ins might be available for rent at major mass transportation hubs, again using parking lot recharging stands. Rentals could extend the number of electrically driven miles in a combined electric mass transportation/plug-in hybrid trip. Taxis, which often queue-up waiting for passengers disembarking from trains, could also be plug-in vehicles which are recharged to some degree as they wait for new fares. Level III chargers might be the best match for taxis. Some plug-in hybrid owners, like apartment dwellers, may not have easy access to an electric outlet to gradually recharge their batteries over night. The availability of recharging stands at transportation hubs and at parking areas near work could ease this problem. Apartment dwelling commuters could do the opposite of those commuters that live in private homes and have ready access to an electrical outlet at night. Apartment dwellers might charge their plug-in batteries at a transportation hub or work parking area and then use this stored energy to drive home to their apartments and then back to the transportation hub the following day using their plug-in's electric-only mode.

Federal subsidies for plug-in hybrids might directly be used to reduce the cost of ownership of such vehicles. However, the concept of placing plug-in hybrid recharging stands at transportation hubs and work locations might be a superior way of investing tax dollars.

Plug-in hybrids are also capable of travelling long distances in a liquid fuel mode. The liquid fuel portion of plug-in vehicles should be designed to use a variety of liquid fuels that cover a range of ethanol/methanol/gasoline mixtures, i.e., to be a flex-fuel engine. This capability could be particularly important on longer trips because the type of liquid fuel that might be available could differ from one region of the country to another.

There has been some confusion about the percent of trips that plug-ins can achieve in the electric-only mode and the percent of miles that these trips entail. Table 6, based on light duty vehicle data from the Department of Transportation, can be used to clarify this difference.

Most of our trips are short ranged. A plug-in hybrid with a 20 mile all-electric range would be sufficient for $87.6 \%$ of our trips. However, $56 \%$ of the miles we drive are on trips that are longer than 20 miles. This means that even if all vehicles in the country were plug-ins with a 20 mile battery range, we would still need $56 \%$ of the gasoline, or its energy equivalent, that we consume today, unless we also use other modes of electrified mass transportation to a much greater degree. A plug-in hybrid like the Chevy Volt with its 40 mile range in the electric-only mode would be capable of accomplishing $94.1 \%$ of our trips, but $38 \%$ of the miles would still remain to be accomplished through liquid fuels for the remaining $5.9 \%$ of our trips. To put this into perspective, 38\% of the oil the U.S used in 2007 is $7,858,400$ barrels per day, of which about two thirds was used for transportation, or about 5.2 million barrels per day. In 2007, France, the UK, and Italy, combined, consumed about 5.4 million barrels of oil per day for all purposes; transportation and otherwise. Even if a 100 mile battery could be developed at an acceptable cost, weight, and size, some $17.1 \%$ of the miles to be travelled would need liquid fuels. Unless there are additional modes of electrically driven 
transportation, e.g., electrically driven mass transportation, completely replacing present internal combustion engine vehicles with plug-ins would still require vast amounts of liquid fuel.

At this time the cost for batteries in plug-in vehicles is high. As reported by the National Research Council the Chevy Volt with its 40 mile battery system will cost about $\$ 18,000$ more to manufacture than a similar-sized conventionally powered vehicle (see Reference 10). The plug-in version of Toyota's Prius will cost an estimated $\$ 6600$ dollars more than a conventionally powered car and is expected to have an all-electric range of 13 miles. There have been interesting proposals that might lower these costs. One thought is that people who plan to go on an occasional long trip rent a special small trailer that carries additional batteries to supplement the normal plug-in batteries.

The need to have batteries with higher energy densities and other improvements is clearly recognized. The present U.S. administration has allocated $\$ 2.4$ billion dollars into developing and subsidizing next generation plug-in hybrids (PHEVs) and fully electric vehicles (EVs).

With recharging stands at transportation hubs plug-in hybrid purchasers might more frequently opt for lower cost plug-ins with the smaller batteries because this transportation hub arrangement would significantly increase their electric-only range when commuting. This in turn would encourage a more rapid market penetration of the lower cost plug-in version. A more rapid market penetration of lower cost plug-ins would serve the national interest by more rapidly reducing the amount of oil that need be imported. Electric Transportation Engineering Corporation was recently awarded a stimulus grant of nearly $\$ 100$ million to build 12,800 charging stations in five different states.

Although much of the discussion about plug-ins centers around battery technology, it is important to seek high efficiencies in the liquid fuel mode of travel. To very effectively reduce national petroleum consumption, one might combine plug-in hybrids with car pools. Although plug-ins would not completely solve future transportation needs, it is clear that plug-in vehicles should be part of the U.S. multi-modal transportation future. In this analysis no credit is given to EVs, all electric vehicles. It is assumed that their very high battery costs will limit their impact on reducing petroleum use in the Step Two time frame, i.e., between now and 2030. However, as discussed earlier, some plug-in hybrids used by commuters may, in effect, act like EVs when combined with recharging stations.

\subsubsection{Availability of resources}

\subsection{Introduction}

Two of the most important resources in implementing a post-petroleum transportation future are electricity and non-oil liquid fuels.

\subsection{Electricity}

Today only about one percent of the U.S. passenger miles is accomplished electrically. If future U.S. transportation had but half of its passenger miles accomplished electrically, that would require a 50 fold increase in this form of travel compared to today; a huge undertaking. How much electricity might be needed to supply the needs of a postpetroleum transportation future? The answer to this question requires that we know how large Mode 2 is. Nonetheless, some initial information is at hand.

The U.S. present electrical system has the potential to produce far more electricity than it does today using the same power plants and transmission grids. This is because this 
electrical system is designed to handle the large diurnal swings in electricity demand that are experienced between business hours and nighttime and weekends. In addition to the diurnal variations in electricity demand there are seasonal variations and to prevent blackouts or brownouts electrical systems require enough capacity to meet peak demands, like on a hot summer day, with a reserve margin in case a plant unexpectedly drops off the grid. It has been estimated that, on an annual average, this electrical system only produces about $46 \%$ of the kilowatt-hours it could produce if it ran $100 \%$ of the time, less outages for maintenance. To get a more precise understanding of this unused capacity than taking an annual average, one has to compare supply and demand on an hour-by-hour basis throughout the whole year to determine the time dependent amount of excess capacity. A partial answer to this question can be found in a study by Pacific Northwest National Laboratory (PNNL) which analyzed the impact of plug-in hybrid vehicles on the U.S. power grid (see Reference 11).

PPNL made a stylized load shape for one day during the peak season, as reproduced below in Figure 4. Here the area labeled "valley filling" provides opportunities to extract more electricity from our present electrical system without needing to increase the number of power plants or make nationwide improvements to the trans-mission grid for the purpose of supplying electricity to plug-in hybrids.

The PPNL analysis concluded that about 73\% of the nation's 2007 stock of about 235 million light duty vehicles (LDVs) could be replaced by plug-in hybrids without requiring additions to our electricity production capabilities. However, in order to achieve the $73 \%$ figure, the plug-ins would have to have access to the grid's underutilized capacity 24 hours a day. Using an assumption that would better match likely plug-in recharging times, from 6:00 P.M. to 6:00 A.M., PPNL calculated that the percentage of present LDVs that could be replaced by plug-ins without expanding our electrical system for that purpose would be $43 \%$. The PPNL analysis is based on plug-ins with a battery system capable of travelling 33 miles in the electric-only travel mode. This percentage would increase if regional energy transfers over an improved grid system made more electricity available in the 12 hour time span listed above. If high voltage recharging stands were placed at transportation hubs and elsewhere, they might be energized during time periods between 6:00 A.M. to 6:00 P.M. With the use of recharging stands, plug-ins could replace somewhere between $43 \%$ and $73 \%$ of the nation's LDVs during the most limiting day, i.e., during peak demand time periods. Other future energy storage applications would also shift the shape of the valley areas in Figure 4 and these would have to be accounted for in a systematic way. Energy storage, which makes better use of the existing electricity system, might enable an even higher percentage of use by plug-ins than PPNL's 73\%.

If $43 \%$ of today's LDVs were replaced by plug-ins, this would require about 100 million plug-ins. Even if the cost of batteries decreased significantly, it would take many years before such a large number of plug-ins were on the road. In a recent National Research Council (NRC) study an optimistic plug-in penetration of 40 million plug-ins might be achieved by 2030 out of 300 million vehicles expected at that time. A different NRC scenario, thought to be more realistic, places the plug-in penetration at 13 million by 2030. This means that for quite some time before electrical capacity to operate Mode Two type mass transportation vehicles would be a constraint. Electricity demands from plug-ins, under a range of NRC scenarios, appear to be well within the electrical capacity of our present electrical system. These PPNL data and the NRC study imply that all three modes of electric 
transportation could expand in parallel without running into electrical capacity limits for many years, particularly if extensive energy storage is used.

However, it is possible that the NRC estimates are too low. As discussed elsewhere in this paper, combinations of plug-ins and "outside" sources of electricity such as charging stations, embedded power strips in roadways, the use of rapid charge capacitors/battery combinations, etc., may make the smaller, 10 mile range, lower cost battery closer to the minimum cost size, using today's technology. This would have the effect of having a more rapid ramp up for plug-ins. Because plug-ins displace oil and, as already shown, the cost to the U.S. for imported oil is staggering, plug-ins and rechargers might justifiably receive a significant subsidy.

The demand for electricity for high speed trains should be based on data from France, Spain, Japan, or China rather than Amtrak data in Table 4. These data are not available at this moment. Although it is expected that most of the demand for electricity for Mode Three travel will occur between 6:00 A.M. and 6:00 P.M., there may be ways of meeting some of this demand through energy storage of electricity made in off peak hours. If more generation capacity needs to be added to the system to meet the daytime demands of Mode Three transportation, this would potentially also increase the supply of electricity during off peak times.

In conclusion, it would take many years before the present electrical capacity was insufficient to meet the demands of Modes Two and Three. As more high speed trains come into service additional electric generation capacity may become necessary. There should be ample time to construct this new capacity. If significant electricity generating capacity is

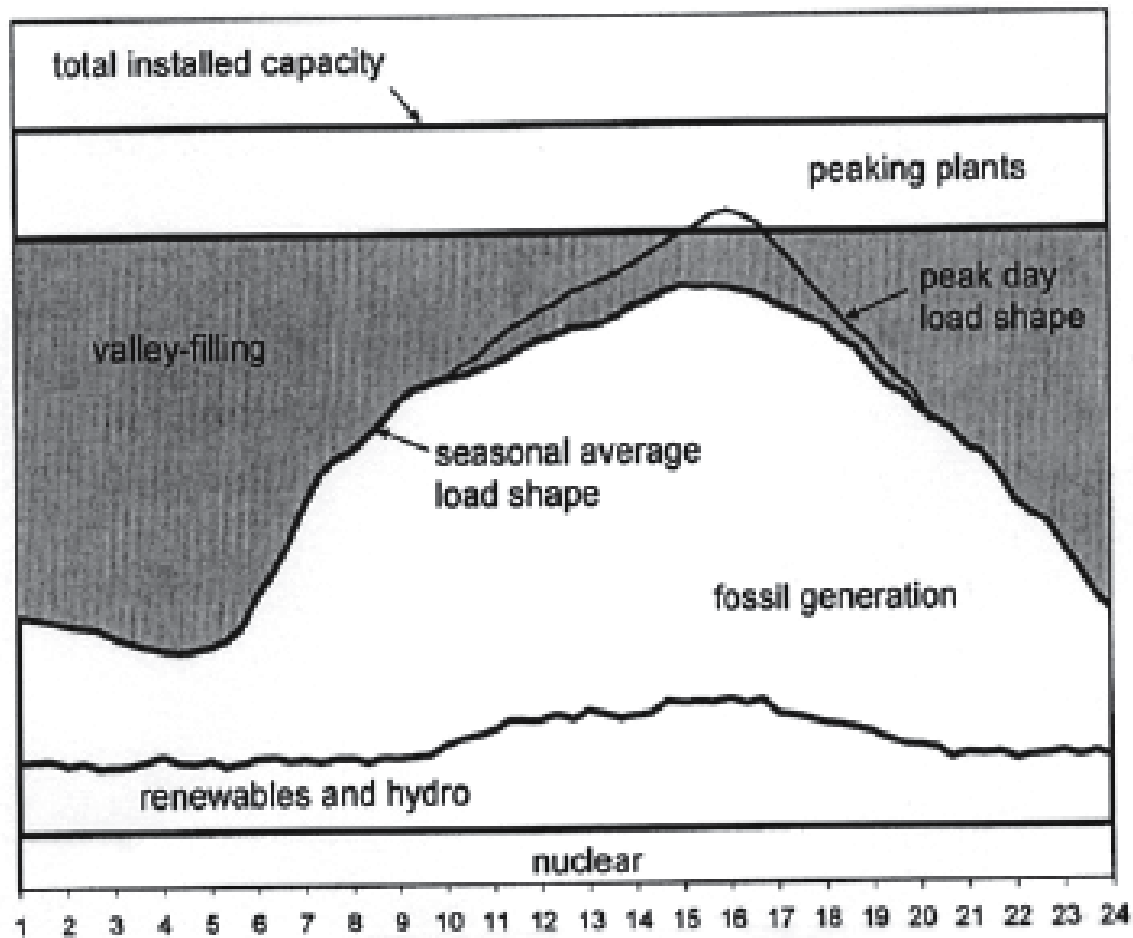

Fig. 4. PNNL - One Day Load Shape During Peak Season 
removed by shutting down older coal plants, new low carbon sources of electricity would have to be added. The pace of building this new low carbon electrical capacity would have to be sufficient to replace the shut down coal plants, meet the demands of a growing population, and meet the demands of an increasingly electrified transportation sector. If the pace of adding new electrical capacity is not rapid enough it could slow down the rate at which oil is displaced by electricity in transportation.

In the long term, 2030 to 2050, other major sources of electrical energy may begin to become available such as from breeder nuclear power plants, from fusion, from geothermal energy, and various forms of renewable energy. Any one of these energy sources could supply electrical energy for millennia. This report stresses the use of electrically driven end uses as a means of reducing oil consumption and abating the release of greenhouse gases. However, there is another major benefit of having electrified end uses. As these long term new sources of electricity enter our electrical system, the end use devices they would power would already be in place. This arrangement supports having flexibility built into our energy future.

\subsection{Liquid fuels from biomass}

The main contributors to the America's Energy Future (AEF) biomass liquid fuels are cellulosic plants, corn stover, and woody biomass. Using the information in AEF's Figure 2.11 , a potential supply of 0.5 million barrels of gasoline equivalent per day was forecast for 2020 and 1.7 million barrels by 2035. However it may be possible to significantly exceed these projected production amounts. Perhaps the most promising way to increase the biomass contribution to liquid fuels is a basic rethinking of how land is used. Some $85 \%$ of the land used for agriculture in the U.S. does not directly go into making food for humans. Rather, this land is used to make food for animals which are later consumed in our food chain. If however, we could feed cows more digestible grass or crop residues and less grain, the land formerly devoted to feeding them grain can grow grass for biofuels and animal feed. Other means to increase the amount of biomass is to use double cropping. The presence of a double crop would permit the removal of corn stover plus the additional biomass from the double crop. Finally, a larger contribution from biomass would entail increasing the grass yield from pasture land from 3 tons per acre to about 6 . Achieving this increase in pasture yield is considered to be plausible based on the fourfold increase in the yield of corn over the past 50 years which was accomplished by better seeds and better agronomic practices. It is estimated that this approach would require about 280 million acres of land and might produce about 100 billion gallons of ethanol per year after accounting for losses in the biorefineries, about half of the energy equivalent of today's gasoline used in transportation in the United States. In addition to growing biomass for liquid fuels in the United States, energy farms might be encouraged in other locations, like Central America.

The pace at which liquids from biomass enter the transportation market might not be set by the ability to grow the requisite amount of biomass, but more by the time it takes to build the accompanying infrastructure. Estimates are that it would take decades to build enough biorefineries to convert the biomass into 100 billion gallons of ethanol per year. One estimate is that about 1000 biorefineries might be needed. Even if a new biorefinery became operational every week, it would still take about 20 years to build 1000 refineries. Some other aspects of this infrastructure issue are discussed below. 
Transporting biomass can present infrastructure issues. The energy density of many biofuels before processing, like switchgrass, is low. This limits the range over which vehicles, like trucks, can gather up these energy sources. At some point the energy it takes to drive the truck on a round trip will exceed the energy content of the biomass in the truck. This zero net energy point is the maximum distance that the truck should travel from the biorefinery. Because of energy density considerations, steps are taken to densify the biomass near its point of origin, i.e., near the fields themselves. Work is underway to accomplish this localized densification of biomass (see Reference 12).

Unlike methanol, once out of the refinery the resultant ethanol can not be transported in unused petroleum pipelines as presently configured, according to the AEF report: "Ethanol is currently transported by rail or barges and not by pipelines, because it is hygroscopic and can damage seals, gaskets, and other equipment and induce stress-corrosion cracking in high-stress areas". Two suggestions are offered. First, it would be better to use ethanol at locations nearest the point where they are produced/refined, that is in rural areas/farms. Present day farm equipment is sold with flex-fuel engines that could use ethanol blends. Second, it might be worthwhile to investigate methanol/ethanol blends that could be used in flex-fuel vehicles and capable of being transmitted through unused petroleum pipelines. If this were possible, then methanol would be piped into a biorefinery where it would be blended with ethanol and the resultant mix piped out through available petroleum pipelines. Some energy experts take a different view on using pipelines to ship ethanol. Their views are that once the tonnage gets high enough, pipeline companies will come up with ways to avoid ethanol/water interactions and that the pipes themselves would be protected from stress induced cracking conditions. As the tonnage of petroleum shipped by pipeline decreases there is an incentive for the pipeline industry to make this petroleum infrastructure "ethanol friendly". Technical conferences on this very subject have been conducted this year.

There are important insights that support the concept of a more regional approach to using renewable energy, such as biomass. Similar arguments have been presented for wind power, such as emphasizing off shore wind power with its higher average wind speeds and in locations closer to electrical load centers rather than attempting to transmit wind power over great distances and seek permits from multiple states and local jurisdictions.

Table 5 describes the average daily distance driven in the U.S. as a function of location. This simple table supports the idea that electrified transportation is a better fit for higher population density areas. For example, in city and suburban areas a higher percentage of the trips will fall into the range of plug-ins, especially if they are supplemented by strategically placed fast recharging stations. Other forms of electrified mass transportation also make more economical sense in the more densely populated areas. Further, electrified transportation would greatly improve air quality conditions in city and urban areas and the resultant health benefits would save large sums of money each year. In rural areas, many trips would be beyond the range of affordable present batteries and electrified mass transportation is likely to be uneconomical in such low population density areas. Therefore the fraction of the miles that would be driven using liquid fuels is likely to be higher in rural areas than in the more densely populated areas. This suggests that the first priority for liquid fuels from biomass should be to meet the needs of rural areas. The whole pipeline/ethanol issue may not need to be a consideration until after all the liquid fuel needs of rural areas are met. 
This regional approach to our transportation future emphasizes the need to require that all new LDVs have a flex-fuel design. The U.S. could take a lesson from Brazil in the use of flexfuel vehicles. Open Fuel Standard legislation should be supported.

In conclusion, some experts believe that over several decades a large fraction of today's liquid fuels could come from biomass by emphasizing the use of grass fed animals over grain fed and other land use improvements. It seems appropriate to test this important idea by demonstrating that the projected biomass yields can be economically obtained in a sustainable way that does not create water shortages, cause soil degradation, create a net increase in GHG, or reduce the amount of food the nation now produces. Since making liquid fuels from biomass should be able to be accomplished in a way that decreases the release of GHG in transportation, biomass derived liquid fuels could be an important mechanism to meet the long term GHG limits proposed in H.R. 2454. A significant demonstration project of appropriate scale seems to be justified.

\subsection{Coal-to-liquid processes}

All the various proposed ways to meet long term liquid fuels needs have economic, environmental, and technological uncertainties. This encourages the use of diversity of long term liquid fuel supplies so that there would be a higher assurance that the liquid fuel will be there as needed. The use of natural gas in transportation is already covered in section 3.2.3. Here the use of coal to make liquid fuels is discussed and converting biomass into ethanol as described in section 3.3.2.2.3.

Converting coal into a liquid fuel (CTL) is a long established technology. Coal can be converted to alcohols, ethanol and methanol, through a gasification process. Coal is used to make syngas which, after passing through a catalyst, becomes methanol. This is existing technology and the cost per gallon of methanol is comparatively low. Another advantage of methanol is that it could use petroleum pipelines as part of its distribution system without further modification. Coal supplies in the United States are very large and the cost per barrel of gasoline equivalent from coal is attractive. A shown in AEF's Figure 2.14, CTL would be competitive with gasoline if oil prices remain above $\$ 65 /$ barrel (2007 dollars).

One major drawback to CTL is in the GHG it produces. In some CTL processes today coal is used both as a heat source and as a feedstock. GHG are emitted when coal is burned as a heat source and more GHG are emitted when the liquid fuel, such as methanol, is burned in transportation. A number of alternative CTL processes have been suggested that would prevent GHG from entering the environment during the heat addition step. The AEF report identifies two such schemes: Using biomass instead of coal as the heat source and using a carbon capture and storage (CCS) process to capture coal's GHG releases when used as a heat source. The AEF report correctly points out that using biomass as a heat source is not attractive in that this same biomass might be used to make ethanol. This then would leave the CTL process completely dependent on a successfully developed CCS process, which has considerable technical challenges of its own. If CCS is not feasible then the amount of domestic liquid fuels the U.S. would be left with would be limited to ethanol from biomass, methanol from natural gas, plus a minor amount of domestic oil.

An alternative to using coal with CCS as the heat source is to use some non-carbon heat source. Several scientists have written papers on using nuclear power in a CTL process, either as a source of hydrogen or as a high temperature heat source (see References $13,14,15)$. High temperature nuclear power plants have the additional advantage over the CCS approach in that it would stretch out coal reserves. The AEF report, on page 66, 
estimates that to supply 3 million barrels of gasoline equivalent/day would require huge amount of coal, up to $50 \%$ of the coal we extract today, assuming coal is both the heat source (with CCS) and the feedstock. Forsberg has studied coupling a nuclear hydrogen plant with a coal liquefaction plant and concludes that this would convert almost all of the carbon in the coal to liquid fuels and eliminate carbon dioxide from the coal liquefaction plant (see Reference 16). Up to three times as much liquid fuel would then be produced per ton of coal. It would be prudent to develop both CCS and high temperature nuclear technology to have greater assurance that liquid fuels will be available when needed.

\subsubsection{Conclusions on Plug-in Hybrids}

A review of plug-in hybrids concludes that there would be ample electricity and liquid fuel from biomass, natural gas, and coal CTL processes to run 100 or more million plug-in vehicles with the present electric power system, depending on the ranges of their batteries. The bulk of the GHG emissions from plug-ins would came from the electric power plants that supply them, and that it is important to build these vehicles to have flex- fuel capabilities and engines with high liquid fuel efficiencies. Battery cost appears to be the major determinant of plug-in market penetration. However, combining plug-ins with charging stations at transportation hubs and in parking garages near work sites, might enable owners to purchase smaller battery designs that could be quite adequate. This, in turn, would lower overall costs and accelerate market penetration of these vehicles. In some cases these recharging stations would enable some drivers who live within a certain range to, in effect, use their plug-ins as EVs, total electric vehicles. Advances in battery technology may lower costs and a new approach to subsidizing technological development, based on its oil-displacing potential, may reduce plug-in purchase costs.

Plug-ins should play a major part in our energy future, but the public will need other means of electrified transportation to supplement the plug-in contribution. This last conclusion places more emphasis on Mode Two and Three electrified mass transportation, particularly those forms that do not rely on huge numbers of lower cost batteries.

\subsubsection{Mode Two: local electrified mass transportation}

Mode Two mass transportation vehicles can be divided into two types: those that follow a fixed route and those that have the capability to alter their route, as necessary. In the latter situation, some form of stored energy within the Mode Two vehicle is necessary to give it the flexibility to alter its route.

There is no question that Mode Two electrified mass transportation can be accomplished. It has been done for many decades using old technology, such as with subways, electric streetcars, and buses which draw electricity from fixed position sources of electricity like overhead electric power lines. Fixed route vehicles generally do not have stored energy onboard. Whereas electrified mass transportation without on-board energy storage is simpler, less costly, and can be accomplished with mature technologies, following a fixed route is a series process: an interruption along the route that can not be by-passed might cause a whole route to be shut down until the cause of the interruption is removed. Further, fixed route Mode Two electrified mass transportation is usually limited to one function: moving people. Mass transportation electric vehicles with on-board stored energy might be put to use in two functions: moving people and moving goods.

In addition to long established Mode Two forms of electrified mass transportation like streetcars, there are modern variations of this. In Seoul, Korea there is now a short distance 
electric tram system that draws its electricity from power strips imbedded into the road (see Reference 17). In between these power strips this electric tram uses on-board batteries.The use of imbedded power strips reduces the need for on-board batteries by $80 \%$. It is thought that this form of electric vehicle travel might be a model for much wider use in urban areas.

China is experimenting with a different kind of electric bus called a capabus. Instead of using batteries these vehicles store electricity in electrical double layered capacitors (EDLCs). Capacitors have some distinct advantages over batteries. They can be very quickly recharged and discharged. They have a long life and can be put through far more charge/ discharge cycles than ordinary batteries (millions or more compared to 200 to 1000 for most commercially available batteries). These characteristics make capacitors ideally suited for the stop-and-go of city buses and streetcars that use regenerative braking. As a capabus goes from stop-to-stop it can be quickly recharged under what is called an "electric umbrella". In 2006 two commercial bus routes began to use EDLCs, one of which is in Shanghai.

Brazil uses "Bus Rapid Transit" or a BRT system that appears to be very cost effective. Capital and infrastructure costs are extremely low compared to rail and subway systems and utilization has been high. BRT systems use "transit stations" in place of bus stops. These are elevated platforms where passengers pay to enter the transit station or use passes to enter, thereby eliminating any waiting for fare collection. These buses have wide doors to speed up passenger entry and exit times. Because the BRT system uses supercapacitors, these buses can be quickly recharged at the transit stations. Similar BRTs have also been used in the United States and in Europe, however the user-friendly transit stations seem to be predominantly in South America.

There may be some Mode Two designs that would be particularly attractive to the United States because it would build upon two existing infrastructures: the electric power system and the petroleum distribution system. This U.S. design would use supercapacitors and could operate under both a fixed route and variable route conditions and would be pollution free at the point of use.

One design would use solid oxide fuel cells (SOFCs).These fuel cells are considered impractical for cars and light trucks because they only operate at high temperatures. However, SOFCs might be useful in heavy trucks and in buses. With good insulation these SOFCs could be kept hot continuously. The fuel could be hydrogen from renewable energy sources or nuclear power or it can be natural gas or volatile hydrocarbons; it could even be de-mineralized coal or wood charcoal feeding an on-board gasifier. Such fuel cells would be combined with supercapacitors, regenerative braking and possibly some energy storage in batteries for prolonged power on uphill grades or prolonged braking on downhill grades.

Use might be made of present gasoline stations, as they would take on a somewhat different role in the future. These stations are ubiquitous, have or could have 220 volt electrical service or higher and already have underground storage tanks used to hold gasoline or diesel fuel. In the future many of these gas stations could be transformed to serve future vehicles. A portion of the underground storage at these stations would hold liquid fuels, such as methanol, ethanol, or any petroleum-like product that comes from biomass, coal, or natural gas. This liquid fuel would be for vehicles, like plug-in hybrids and buses, that need liquid fuel for longer distance trips. The remaining underground storage would be for hydrogen where large pressurized tanks would replace former gasoline storage tanks. Since this underground hydrogen storage tank would be stationary, its heavy weight would not be a problem. The technology for storing and handling hydrogen seems to be well advanced 
in Germany. There the Linde Group has opened a hydrogen filling station for zero emissions fuel cell passenger ships (see Reference 18). The hydrogen in this former gasoline station system would be generated by electrolysis of water using lower cost off-peak electricity. Such highly dispersed hydrogen storage depots could be used to put electricity back on the grid during peak demand periods to avoid blackouts or to supply energy to emergency vehicles. Since these energy depots would be decentralized energy storage systems, but located close to end use devices they service, their stored energy would be less vulnerable to terrorist acts. Such hydrogen energy storage depots could be shared by all sources of electricity, including nuclear and wind power.

\subsubsection{Mode Three: long distance electrified transportation}

Because of its great emphasis on individual automobiles the United States has fallen far behind Europe and other countries in the use of high speed trains. China recently became the world leader in manufacturing high speed electric trains. China has 42 high-speed trains recently opened or set to open by 2012 with an average speed of 215 miles per hour. The State of California which plans to build its own high speed rail system. This has gained widespread interest in that China, Japan, Germany, South Korea, Spain, France, and Italy have approached California to build this train system. Of particular interest is China's offer. China is not just offering to build a railroad in California, but to help finance its construction. "We are the most advanced in many fields, and we are willing to share with the United States" said Zheng Jian, the chief planner and director at China's railway ministry (see Reference 19). Such an arrangement would be beneficial to both countries. Much like what the auto industry has done, foreign countries can create large industries in the U.S. employing many American workers. As China helps to reduce U.S. petroleum consumption through advanced technology and creative financing, it helps to moderate world oil prices and sustain a margin between supply and demand. With China's increasing appetite for petroleum, actions that help to moderate world oil prices saves China vast sums of money.

If the nation were to build a substantial high speed rail system it should look for routes that might have the greatest impact on reducing gasoline usage as rapidly as possible. For example, a high speed route between Richmond, Virginia and Portland, Maine could well be a top choice because of the high population density in this important area.

Significant liquid fuel savings, as well as reductions in GHG emissions, may be achieved by modifying our ground freight shipments. Liquid fuel consumption in the ground freight transport system could be reduced by $80 \%$ by the combination of electrification of railroads, as in Europe, and large scale intermodal rail truck systems. Most of the long distance truck transport would be replaced by containerized freight that travels long distances by rail, with local delivery by truck. Modifying ground freight transport by using electrified trains is estimated to reduce America's petroleum demand by 5\%. To accomplish this Forsberg estimates that 50,000 megawatts-electrical would be required or about 30-35 large nuclear power plants (see Reference 20).

Forsberg also points out "In the 1970s, the French Government decided to build an electrified high-speed super train system to connect major metropolitan areas and to reduce consumption of liquid fuels. The system has demonstrated that high-speed trains can replace air travel for distances up to 500 miles because of lower costs, higher point-to-point speeds and greater comfort. Simultaneously, rail stations have been built at major airports to provide point-to-point transport." 
Greater use of such trains have secondary benefits, as well. Almost half of the aircraft flight delays in the country were directly or indirectly a result of the three New York and two Washington, D.C. airports. If one wants to fix the U.S. airline system, including long taxi lines that burn jet fuel, high speed rail is a requirement for the east coast corridor to unload those airports. This would reduce the release of GHG, lower air pollution, reduce the use of oil, and increase customer satisfaction.

\subsection{Step Three, 2030-2050, or so}

The purpose of Step Three is to assess what additional efforts, if any, need be taken to further reduce the release of GHG and to establish a plan to implement such efforts. Step Three would start around 2030. By that time many GHG reducing efforts should have already become operational. Further, the science of climate change should have advanced with more data and more sophisticated computer models.

One area that might receive closer attention is the 2050 GHG release limit as presently spelled out in H.R. 2454 which is very low at about $1 \mathrm{Gt} / \mathrm{yr}$. Since many of the easier GHG actions would presumably been taken by around 2030, implementing this final reduction could be quite difficult. The science available at 2030 should be better able to inform us of the environmental consequences if the world's carbon sinks come into equilibrium with GHG releases at a level that is higher than $1 \mathrm{Gt} / \mathrm{yr}$. The higher the acceptable point of GHG equilibrium, the more likely that it can be achieved. If it turns out that a $1 \mathrm{Gt} / \mathrm{yr}$ release rate is appropriate, the implementation of Steps One and Two would match the release rate called for in H.R. 2454 so no time would have been lost in addressing climate change.

\section{References}

[1] “America's Energy Future”, National Academy of Sciences, 2009.

[2] “Transportation Energy Data Book: Edition 28-2009”, pg 1-9,ORNL-6984.

[3] Joint Operating Environment, United States Joint Forces Command, pg 28, February 18, 2010.

[4] "Storms of My Grandchildren", Dr. James Hansen, 2009.

[5] "Imported Oil and National Security" Rand Corporation, 2009, page 71.

[6] "Hidden Costs of Energy-Unpriced Consequences of Energy Production and Use", National Academy of Sciences, 2009.

[7] “Reducing Greenhouse Gases-How Much at What Cost?”, McKinsey \& Company, 2007.

[8] "The Future of Natural Gas, An Interdisciplinary MIT Study", 2010.

[9] "Electrification Roadmap", pg.15, Electrification Coalition, November, 2009.

[10] "Transitions to Alternative Transportation Technologies-Plug-in Hybrid Electric Vehicles", National Research Council, Prepublication Copy, March, 2010.

[11] "Impact Assessment of Plug-in Hybrid Vehicles on Electric Utilities and Regional U.S. Power Grids, Part:1 Technical Analysis", Michael Kintner-Meyer, et al, Journal of EUEC, Volume 1, 2007.

[12] "Technical and Financial Feasibility Analysis of Distributed Bioprocessing Using Regional Biomass Pre-Processing Centers", J.Coralan, S. Joshi, and B. Dale, Journal of Agricultural \& Food Industrial Organization, Volume 5, Article 10, 2007. 
[13] “Meeting U.S. Liquid Transportation Needs With a Nuclear Hydrogen Biomass System", Forsberg, C.W., American Institute of Chemical Engineers, Manuscript Number 85370, September 7, 2007.

[14] "Sustainable Fuel for the Transportation Sector", R. Agarwal, et al, Proceedings of the National Academy of Sciences, Vol.104, March 20, 2007.

[15] "Producing Transport Fuels with Less Work", D. Hildebrandt, et al, Science,vol.323, March, 2009.

[16] "Nuclear Energy For a Low-Carbon-Dioxide Emission Transportation System with Liquid Fuels", C.W. Forsberg, Nuclear Technology, Vol.164, December, 2008).

[17] “In Seoul, Green Transit is Mayor's Pet Project", Choe Sang-Hun, NY Times, March 27, 2010.

[18] "The Linde Group Opens First Hydrogen Filling Station for Fuel Cell Passenger Ships", Marketwatch, August 29, 2008.

[19] "China Again Hopes to Drive U.S. Rail Construction”, Kenneth Bradsher, NY Times, April 7, 2010).

[20] Personal communication, Professor Charles Forsberg, MIT, April 6, 2010. 


\title{
Energy Planning: A Sustainable Approach
}

\author{
Julio Terrados, Gabino Almonacid and Jorge Aguilera \\ IDEA Research Group, \\ University of Jaén \\ Spain
}

\section{Introduction}

Energy system is currently based on a large fossil fuels dependence. It is a centralised model that have allowed a strong economic development in the last century, but that is showing a number of inconveniences which are turning it more and more unsustainable. Fossil fuels depletion, environmental damage and territorial unbalance caused by centralised energy model are significant factors to change energy structure, integrating new resources and modifying the way we use them. It is necessary to make compatible socio-economic development with a sustainable energy model, environmental respectful and that could generate local wealth. The key issue is to address current model towards a more balanced system based on the exploitation of renewable resources.

Therefore, planning decisions concerning energy system cannot be consider under one specific criterion. Different implications, apart from energetic, such as environmental or socioeconomic matters, derived from changes on energy development and from the seek of sustainability, make it unavoidable to use tools and techniques that could take into account such multiplicity.

In this way, this chapter summarizes current trends in energy planning when social and environmental issues have to be considered. This kind of approach have to be set in order to foster renewable energies development, mainly at regional level, by establishing strategies to reach, in the long term, an energy system more sustainable and mainly based upon autochthonous resources.

Current energy planning models, related to sustainable development processes, are described and analyzed. The importance of multicriteria decision techniques, Delphi surveys and SWOT analysis, which are the most referred approaches on literature, is highlighted, and a deep review of such methodologies is presented.

Successful combinations of these methods are also enlightened. Hybrid models as those using SWOT analysis and Delphi techniques, or Delphi techniques as a support of a Multicriteria Decision Making analysis, are specified and best examples are shown. Finally, a number of best practices are also presented, looking into their main drawbacks and advantages.

\section{Sustainable approach to energy planning}

Energy sector configures a strategic area inside territorial socio-economic system. On one side, energy supply constitutes a basic service for citizen's daily life and, on the other hand it represents a fundamental item on progress and economic development. This is the reason 
why energy policies and planning process have traditionally intended to assure energy supply on optimal conditions of security, quality and price.

In the past, national energy planning aimed to determine the infrastructure investment program to be carried out in a defined time period. However, on the new legal frame, most of the energy planning is recommended, being respectful with private enterprise, and reserving as binding planning only great energy transport infrastructures.

In spite of above mentioned, inconveniences derived from current energy model imply the need to drive energy system toward more sustainable levels, establishing strategies to encourage energy diversification and solid commitment with renewable energies. In this context, planning processes became essential to fix European, national and even regional targets and to foster the involvement of public and private actors in objectives attainment.

Following this philosophy, the European Commission issued on 1997 the communication called "Energy for the future: renewable sources for energy. White Paper for a community strategy and action plan" establishing a European target of 12 percent for the contribution of renewables on year 2010 (Comision Europea, 1997). Attainment of this target at European level required strategies and commitments at national level, as they were established in the Spanish Renewable Energies promotion plan in 1999 (IDEA, 1999), subsequently revised as the new Spanish Renewable Energies Plan in 2005 (IDEA, 2005), and is definitely requiring strategies and actions at regional level.

As the "planning chain" is deployed, new energy planning models have to be developed. It must be taken into account that decisions concerning energy system cannot be consider any longer under one specific criterion. Different implications, energetic, environmental or socioeconomic, derived from changes on energy development make it unavoidable to use tools and techniques to deal with such multiplicity.

\section{Renewable energy planning methodologies: basic tools}

Different techniques have been traditionally used for renewable planning purposes at regional level. In this section, techniques currently used for energy planning purposes are analysed, focusing on those ones related to sustainable development processes and regional level scope. As we will highlight, multicriteria decision techniques, Delphi surveys and territorial energy planning constitutes the most referred approaches on literature.

\subsection{Multicriteria decision techniques}

Multicriteria decision techniques were developed profusely in the 60's. Classic methods come from that decade, when Goal Programming and ELECTRE (Elimination and choice translating reality) method were proposed. On the 70's new methods and refinements of existing ones were developed, and finally on the 80's support from computer sciences has allowed a fast growth in applications and results from multiple criteria decision making (MCDA) techniques (Barba-Romero \& Pomerol, 1997).

In general, all multicriteria decision aid techniques are based on the identification of a number of alternatives (A1, A2, ..., Am); the selection of assessment criteria, $(\mathrm{C} 1, \mathrm{C} 2, \ldots, \mathrm{Cn})$; and determination of results of the assessment of each alternative, Ai, for each one of the criteria. Resulting matrix, [aij], common to all MCDA methods, is usually called Decision Matrix (Fig.1).

MCDA techniques are being successfully used in many different planning processes. Although there are many different MCDA methods (optimisation, goal aspiration or outranking models), steps to be followed are similar in all of them: 
1. Problem definition

2. Identification of alternatives

3. Criteria selection

4. Decision matrix elaboration

5. Weights assignment

6. Prioritization, and

7. Decision making

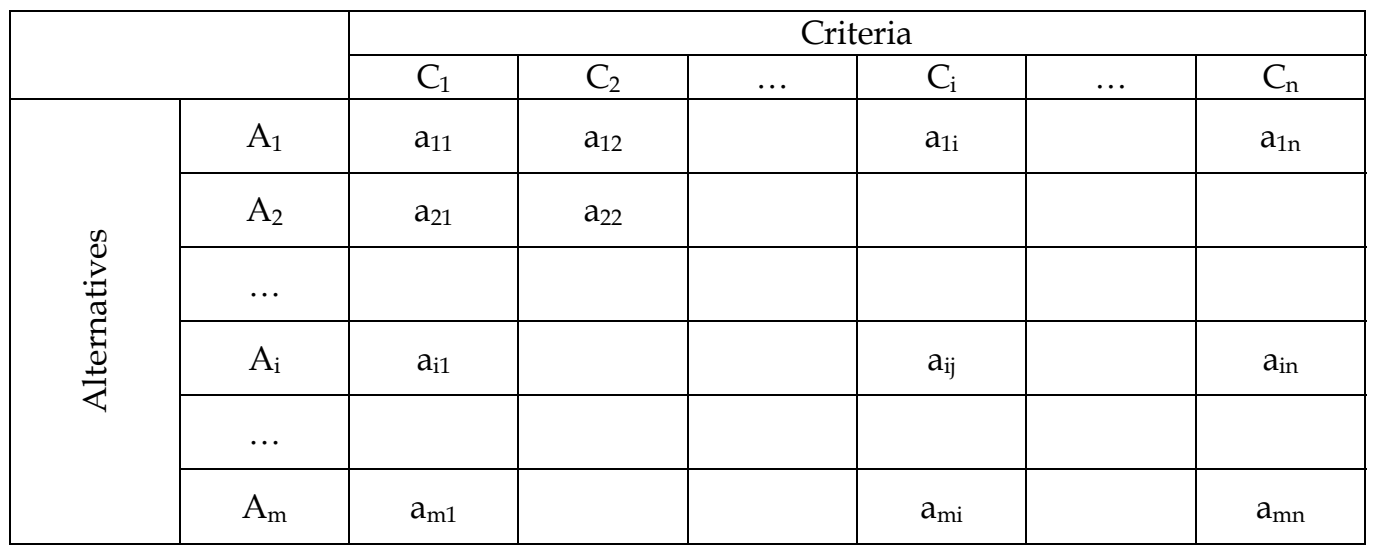

Fig. 1. Decision Matrix diagram in a MCDA process

This kind of methodology is often currently used by different environmental Agencies in the US and Europe to tackle planning processes implementation (Linkov et al. 2004). The authors reveal that, despite of the fact that decision process implementation is often based on physical modelling and engineering optimisation schemes, Agencies are beginning to implement formal decision analytical tools, especially multicriteria decision analysis, in environmental decision making. They also highlight the relation between MCDA general steps, as described above, and general planning processes.

Under energy scope, the need to consider environmental, technological and social factors on energy planning has encouraged the use of multicriteria decision techniques. Among different MCDA techniques, AHP (Analytical Hierarchy Process), PROMETHEE (Preference ranking organization method for enrichment evaluation) and ELECTRE method have been widely used in energy planning, in accordance with data compiled and published in mid 2000's (Pohekar and Ramachndran, 2004).

ELECTRE method is based on the outranking relations established between each pair of alternatives. Concordance matrix and discordance matrix are then elaborated to generate a selection or a ranking of the different alternatives. It has been successfully used for renewable energy planning (Beccali et al. 2003). An action plan was assessed for the diffusion of renewable energy technologies at regional scale, using a multicriteria approach with twelve evaluation criteria

ELECTRE has also been utilised to elaborate a new energy strategy for Crete Island (Georgopoulou et al. 1997). It is advocated by these authors the use of MCDA techniques to select alternatives energy policies at regional level, mainly on high renewable resources regions. MCDA tools utilisation allows, in these cases, to take into account the environmental dimension, as well as technical, economical and political criteria. However, it is also emphasized the fact that we are dealing with "decision aid" techniques far from 
"decision making" techniques and, in this sense, the application of one of these methods only represents one of the steps to follow.

Other authors take advantage of AHP as community decision support on energy projects implementation (Nigim et al. 2004). MCDA has been used by a workgroup in Canadian Waterloo region, to determine priorities among five different renewable energy projects by means of six criteria that assessed both impacts and project feasibility. A process based upon group participation was developed, and results were successfully compared with those generated by a linear programming tool. Nigim et al. analyse the strong dependency between decision aid methods used, and expert opinion made to assess the hierarchy elements weight. They consider that, finally, MCDA tools have to depend on intangible aspects and subjective opinions of involved people, and they propose the use of objective criteria, as net project value, to minimise this point.

On the other hand, the use of PROMETHEE methodology is also rising. Cavallaro presents a multicriteria integrated system to assess sustainable energy options that has PROMETHEE technique as the basis of its development, and applies it to the Italian Messina region (Cavallaro, 2005). It is important to highlight that, in this case, net flow (defined as difference between positive and negative flow) is used to reach a complete outranking among alternatives.

Furthermore, a combination of MCDA methods, either in parallel or sequentially applied, may also be a proper selection in energy planning. Different combination uses that include AHP along with PROMETHEE; AHP along with TOPSIS (technique for order preference by similarity to ideal solutions); and AHP along with GP (goal programming) are described in research literature (Loken, 2007). Loken also advocates the suitability of MCDA methods as planning tool in local energy system, where several energy sources and several energy carriers are involved.

A recent review of the published literature on sustainable energy decision-making (Wang et al., 2009) shows a great applicability of MCDA methods for sustainable energy decisionmaking. The review concludes that AHP is the most popular comprehensive method among MCDA techniques and that fuzzy set methodology has been increasingly applied to deal with qualitative criteria and vagueness inherent to the information. Referring to criteria selection, it has been observed that efficiency, investment cost, $\mathrm{CO} 2$ emission and job creation are the most common criteria in the technical, economic, environmental and social scenarios. The investment cost locates the first place in all evaluation criteria and $\mathrm{CO} 2$ emission follows closely because of more focuses on environment protection.

\subsection{Delphi techniques}

Delphi techniques have also been a popular tool for preparing forecasts and planning purposes. Landeta acknowledges that, since its first application up to current applications in a huge diversity of fields such as higher education, public health, information systems, production sector analysis or political options assessment, the technique has been refined and adjusted to different uses (Landeta, 1999).

In recent years, it is being used as an effective method in long term planning related to sustainable development. In this sense, it is suggested the use of two scenarios constructed by means of a Delphi expert-based survey (Shiftan et al. 2003). Other authors propose the utilisation of Delphi, assisted by a web-based survey, combined and supported by a geographical information system (GIS) to promote sustainable development in development countries (Popper and Dayal, 2002). 


\subsection{Territorial and rural energy planning methods}

Participatory approaches for energy planning implementation are been extensively used in rural areas and development countries. P.M. Williams reflected on the use of traditional strategic planning methods for designing sustainable development strategies, and advocated changing the model to "strategic architecture" instead of "strategic plan", in order to plan the things to be done today to modify the future (Williams, 2002). He also emphasized the process more than contents and actors more than the structure.

Participation is an essential item in these processes. In this sense, a paradigmatic example is the rural energy development planning in India that has been referred by Neudoerffer et al., who verify that energy programmes launched by Indian government have got a limited success due to the lack of mechanism to assure the implication of final users, and present the main conclusion of a research project to develop planning methodologies and tools to facilitate public participation (Neudoerffer et al. 2001). Other authors also highlight the importance of participation techniques to implement, in a successful way, energy plans and projects at rural areas (Anderson and Doig, 2000).

The case of Jaén province (Terrados et al. 2007), also confirms the suitability of this kind of approaches when society implication is essential. Authors conclude that management tools used in territorial strategic planning processes, especially SWOT (Strengths Weaknesses Opportunities and Threats) analysis, can be successfully used by public administrations as proper tools to search and select strategies that may help them in the redesigning of the regional energy system.

\subsection{Other techniques}

Apart from above mentioned techniques, optimisation methods such as EFOM (energy flow optimisation model) have been used to support planning processes (Cormio et al. 2003). In this case, authors executed several simulations on the Apulia region energy system, in Italy, to prove the suitability of combined cycle installations, wind energy and biomass exploitation as environmental friendly technologies to be promoted.

Other techniques, concerning energy model generators, are being currently used for the purpose of strategic energy planning and decision making. This is the case developed at Basilicata region, in Italy, where a MARKAL models generator was used to obtain mediumterm strategies and climate protection policies (Pietrapertosa et al. 2003 and Salvia et al. 2004). They implemented a MARKAL model specific for the region in order to assess the contribution of local energy systems to the achievement of national targets.

\section{Renewable energy planning methodologies: combined models}

Combination of SWOT analysis and Delphi techniques has been successfully used in planning processes related with local and regional development. L.V. Zwaenepoel proposes an approach based in an initial SWOT analysis and a later use of the Logical Framework analysis that make use, as inputs, of SWOT analysis outcomes. The process includes, inside SWOT methodology, an expert survey in order to reach a consensus prior to launch the Logical Framework analysis (Zwaenepoel, 2005).

We can also consider as a combined model the one presented by Carlos Benavides who applies it to Strategic Planning at Universities. In this case, a round of talks to experts is utilised as a support process in SWOT matrix elaboration (Benavides \& Quintana, 2004). 
There are other hybrid models using Delphi techniques as a support of a Multicriteria Decision Making analysis. It can be highlighted contributions by Aragonés, called PRES II Multiexpert methodology (Aragonés, 1997), and also by Curtis, who proceeded with an eighty experts Delphi panel to assign weighs on twenty attributes of an ecosystem that was evaluated by means of MCDA (Curtis, 2004).

Another type of combination arisen in the last year $s$ is the integration of fuzzy methodologies with expert opinion and MCDA techniques. Recently it has been presented the case of the renewable energy planning for Istanbul by using an integrated fuzzy-AHP methodology (Kaya \& Kahraman, 2010). In this methodology, the weights of the selection criteria are determined by pairwise comparison matrices of AHP, and fuzzy logic is successfully applied to model the uncertainty and vagueness of the judgments of expert and decision makers who are unable to provide exact values for the criteria.

\section{Best practices}

In this section a selection of three best practices of sustainable energy planning applications is presented.

The first one is related to regional energy planning through classical strategic planning tools and shows the advantages of the use of SWOT analysis in the design of a new energy system. The second one is an application of Multicriteria decision techniques (MCDA), based on Electre III procedure, to assess an action plan for renewables diffusion in Sardinia. And the third one is an application of a combined methodology, using SWOT, Delphy and Promethee techniques, for sustainable energy planning in the south of Spain.

\subsection{The strategic plan for Jaén province}

Elaboration of the Strategic Plan for Jaén province began with the commitment of the Provincial Government in the project. On 1997, Provincial authorities formally approved the proposal to elaborate an Strategic Plan to foster territorial development. Since this proposal, a negotiation process started, among most relevant institutions, in order to shape the initial idea, to establish the structure and to define organization and project terms.

Both, Provincial Government and University of Jaén, took the lead of the project and created a Foundation called "Strategies for economic and social development of Jaén province" that took charge of the whole project management. This was the starting point for most relevant institutions at provincial level to join to the newly created Foundation and collaborate in the ambitious project of territorial strategic planning.

A sequentially phased program was established (Figure 2), trying to assure on one hand the technical consistency of the Plan and, on the other hand, the massive participation of provincial community. Technical consistency was pursued trough a diagnosis phase based upon expert working groups, and the implication of the community was addressed by means of a collective participation phase specifically designed to encourage participation in working tables. Political implication and commitment was also pursued. In this way, an approval phase, where each political institution assumed its compromise with plan execution, was finally carried out.

At the beginning of the Diagnosis Phase, a series of technical expert groups were appointed in each of the technical areas to be addresses by the Strategic Plan. One of these groups was responsible to analyse territory status within the area of Infrastructures, Energy, Urban Development and Environment. It was constituted in December of 1998, including 
representation from University, Energy Agency and Provincial Government. Group members maintained up to twenty two working meetings along the whole process and they elaborated first, during four months, an initial report that was issued and presented publicly.

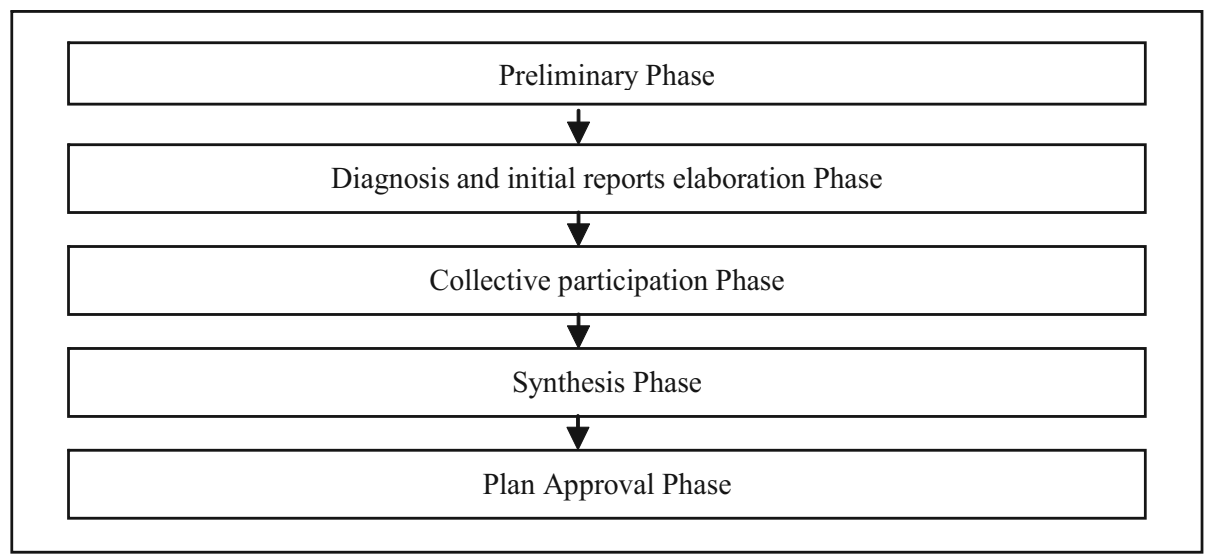

Fig. 2. Strategic plan development phases

Afterwards a Collective Participation Phase began, and the technical report was put under later discussion to allow collaborators, who voluntarily had become involved in the reflection process, to analyze it and to contribute new ideas to the debate. Finally the technical group reprocessed the initial report, collecting the contributions and the suggestions of the collaborators, incorporating new proposals, clarifying some of the existing ones, and omitting those that were not considered pertinent. The final document concerning the energy area was approved in the month of March of 2000.

It is important to emphasize that the work sessions followed an interdisciplinar method, where ideas exposed by anyone of the group members were submitted to different scientific and/or technical interpretations from any other scope. In this way, results were enriched by the manifold approaches under which the proposals were analyzed.

The diagnosis of the energy system was structured through a SWOT matrix (Figure 3), in which were shown the weaknesses, strengths, threats and most relevant opportunities than must be faced by the provincial energy system. This kind of analytic tool is often used in participatory planning approaches, although it was originally developed for strategic planning in business and marketing purposes. It must be taken into account that SWOT is only a tool, and has to be based on a sound knowledge of the present situation and trends.

SWOT analysis for energy allowed to establish, as the following step, problems that had to be faced by the energy area, as well as the suitable strategies that could overcome such problems. For this purpose, a problems tree was elaborated, arranging in form of family tree the main weaknesses of the provincial energy system, grouping them under the headline of: "Centralized energy system, incomplete, hardly respectful with the environment and with scarce autochthonous resources utilization".

Directly derived from that problems tree, it was depicted an objectives tree that allowed the obtainment of strategies and performance lines routed to the solution of detected problems. This objectives tree structured strategies under the general mission of: "To improve the energy efficiency and the energy supply conditions as local development and environment 
conservation element". Finally, in third place, they were presented each one of the strategic projects designed to reach the previously outlined objectives.

Despite of the fact that the most usual tools in energy planning are based on multicriteria decision analysis techniques, that have demonstrated their effectiveness in a significant amount of situations, the use of SWOT analysis in the development of the Strategic Plan permitted a correct comprehension of the provincial energy situation and served as a basis for objectives and strategies proposal. In fact, the use of SWOT analysis encouraged the discussion and criteria contrast among group members in the elaboration process of the sectors of the matrix as well as in the subsequent review for the development of the problems tree and objectives tree. This quality, already commented by some authors (Pickton \& Wright, 1998), favoured the elaboration of the diagnosis and the interdisciplinar coherence.

\section{STRENGTHS}

F.1 High solar radiation

F.2 Large amount of agricultural and industrial biomass

F.3 High exploitation of hydroelectricity in Guadalquivir river basin

F.4 Great tradition in solar energy research and development

F.5 Existence of the Energy Management Agency of Jaén province

F.6 High value of natural heritage, that favours clean energies development

OPPORTUNITIES

O.1 Existence of industrial sectors suitable for installing Cogeneration processes

O.2 Suitable climate for the successful application of bioclimatic criteria

O.3 Existence of applicable funds to invest in Energy System development

O.4 Existence of susceptible areas for wind energy development

O.5 Existence of subsidies to electricity production with Renewable sources in the new Spanish electrical market

\section{WEAKNESSES}

D.1 Lack of fossil energy resources

D.2 Limited installed power for electrical generation

D.2 Insufficient infrastructure for natural gas distribution

D.4 Low sensitiveness to energy saving

D.5 There is no individual awareness for Renewable Energy utilisation

D.6 Buildings are not constructed with bioclimatic criteria

D.7 Renewable energy business sector is weak

D.8 Low quality of electricity on determined areas

D.9 Absence of financial mechanisms to endeavour RES penetration

D.10 Dependency of an unique high voltage injection to the provincial electricity network

THREATS

A.1 Progressive environmental deterioration A.2 Excessive dependency on fossil fuels

A.3 Risk of energy resources price increase

Fig. 3. SWOT matrix for energy

Along the Synthesis Phase, the Strategic Plan was structured as a deployment of Promotion Programs, Performance Lines and Strategic Projects. Project definition included, in most of the cases, the quantification of the objective goals (Table 1). Among these objectives it can be highlighted the followings: the installation of $100 \mathrm{MW}$ of power in plants electrical generation with biomass; to reach $1 \mathrm{MW}$ of PV grid connected installed power; to obtain the annual installation of $10.500 \mathrm{~m} 2$ of thermal solar panels; or to reach $50 \mathrm{MW}$ installed in Wind Energy systems. 


\begin{tabular}{|l|c|}
\hline \multicolumn{1}{|c|}{ STRATEGIC PROJECTS } & Goal to meet \\
\hline 015. Extension of Natural Gas transport and distribution network & $\begin{array}{c}80 \% \text { of } \\
\text { population }\end{array}$ \\
\hline $\begin{array}{l}\text { 016. To increase the capacity of the high and medium voltage electricity } \\
\text { grid, to guarantee supply and industrial development }\end{array}$ & - \\
\hline $\begin{array}{l}\text { 019. Exploitation of biomass resources for the installation of electricity } \\
\text { generation plants }\end{array}$ & $100 \mathrm{MW}$ \\
\hline $\begin{array}{l}\text { 020. Installation of cogeneration plants in thermal energy consuming } \\
\text { industrial sectors }\end{array}$ & $130 \mathrm{MW}$ \\
\hline $\begin{array}{l}\text { 021. Establishing of the necessary structures for the complete } \\
\text { exploitation of agricultural and forest residues }\end{array}$ & $\mathrm{Y} / \mathrm{N}$ \\
\hline $\begin{array}{l}\text { 022. Establishing of the necessary structures for the energy exploitation } \\
\text { of residues from cattle raising and industry }\end{array}$ & $\mathrm{Y} / \mathrm{N}$ \\
\hline 023. Wind energy planning of Jaén province & $50 \mathrm{MW}$ \\
\hline 024. Promotion of solar photovoltaic grid-connected systems & $1 \mathrm{MW}$ \\
\hline 025. Promotion of energy crops in marginal lands & - \\
\hline $\begin{array}{l}\text { 121. Legal normative to encourage domestic solar water heating systems } \\
\text { in new buildings }\end{array}$ & $10.500 \mathrm{~m}{ }^{2}$ \\
\hline $\begin{array}{l}\text { 122. To increase the use of isolated PV systems for the electrification of } \\
\text { rural housings and facilities }\end{array}$ & $\mathrm{Y} / \mathrm{N}$ \\
\hline 123. Application of energy saving and efficiency criteria in buildings & - \\
\hline 124. To encourage the recovery of small hydraulic plants & Rehab. Plan \\
\hline 125. To transform AGENER into the Provincial Energy Agency & $\mathrm{Y} / \mathrm{N}$ \\
\hline $\begin{array}{l}\text { 145. Installation of a second 220 kV injection to electricity transport grid } \\
\text { 146. Improvement of the electrical distribution grid to increase supply } \\
\text { quality }\end{array}$ & $\mathrm{Y} / \mathrm{N}$ \\
\hline $\begin{array}{l}\text { 154. Diffusion and training campaigns in energy saving and Renewable } \\
\text { energies }\end{array}$ & $\mathrm{TIEPI} \mathrm{=} \mathrm{2,11}$ \\
\hline $\begin{array}{l}\text { 155. Research and technological development institute dedicated to } \\
\text { exploitation and conservation of natural resources }\end{array}$ & $\mathrm{Y} / \mathrm{N}$ \\
\hline
\end{tabular}

Table 1. List of strategic projects and goals defined

The quantification, in terms of energy, of the specifically set Strategic Plan goals, lead us to foresee an electricity yield of $1.226 \mathrm{GWh}$ from renewable sources. It is interesting to check that this figure match with the extrapolation to provincial level, using the population as extrapolation ratio, of the Spanish and Andalusian objectives set by the respective energy plans.

The energy diagnosis of the Plan (Almonacid et al. 2000), concluded fixing as long-term high-priority items the energy diversification, fundamentally based in Natural Gas and autochthonous Renewable Resources, the improvement of gas and electricity networks, the political and social awareness to drive an environment-respectful energy development, and the research and education on Renewable Energy matters.

\subsection{Application of the ELECTRE method to assess an action plan for RES diffusion.}

In this best practice, presented in 2003 by Professors M. Becalli, M. Cellura and M. Mistretta (Becalli et al. 2003), an application of the multicriteria decision-making methodology is used 
to assess an action plan for the diffusion of renewable energy technologies at regional scale. They consider that this methodological tool gives the decision-maker considerable help in the selection of the most suitable innovative technologies in the energy sector, according to preliminary fixed objectives, and they show the results of a case study carried out for the island of Sardinia.

The aim of such case study is to select the most suitable technologies in a Renewable Energies diffusion plan for the Sardinia region. They have previously selected a set of technologies of energy conversion and saving, which are associated with their diffusion in Sardinia, and afterwards Electre III method is use to. In this method, the criteria of the set of decisional alternatives are compared by means of a binary relationship, defined as 'outranking relationship', are more 'flexible' than the ones based on a multi-objective approach.

\section{Selection of alternatives (actions)}

A total amount of fourteen actions were initially selected. The list comprised actions related to solar energy, wind energy, hydraulics, biomass, animal manure, energy saving and CHP.

\section{Definition of evaluation criteria}

Twelve evaluation criteria were defined to deal with technical, political, economics and environmental aspects, as follows:

1. Target of primary energy saving at regional scale

2. Technical maturity, reliability

3. Consistence of installation and maintenance requirements with local technical know-how

4. Continuity and predictability of performance

5. Cost of saved primary energy

6. Sustainability according to greenhouse pollutant emissions

7. Sustainability according to other pollutant emissions

8. Land requirement

9. Sustainability according to other environmental impacts

10. Labor impact

11. Market maturity

12. Compatibility with political, legislative and administrative framework

\section{Definition of three decisional scenarios}

Selected criteria were weighed in accordance with three different scenarios: the 'environmental-oriented' scenario (with a preference toward actions generating the lowest environmental impacts); the 'economy-oriented' scenario (with a preference toward actions involving the highest economical and social benefits); and the 'energy saving and rationalization' scenario (with a preference toward actions addressed to energy saving and a rationalization of global energy system).

\section{Outranking with Electre III procedure}

Finally, the outcome of the Electre III procedure gives us the final order for each decisional scenario. In each order a best actions area is defined as the area within which the best alternatives are placed for both distillations. These alternatives represent the actions that fulfil the objectives that the decision-maker has fixed.

In the environmental scenario, actions concerning domestic solar water heaters; wind energy; hydro plants in existing water distribution networks; Building insulation; High efficiency lighting; and High efficiency electric, belong to such area. 


\subsection{Application of a combined methodology for regional energy planning at a Spanish} region

On the basis of the analysis of planning techniques already made in previous sections, it can be deduced that all of the three methodologies have significant advantages and useful contributions for the sketching of strategies and action lines for renewable energies development. Therefore, we can infer that a combination of those methods, in order to take advantage of their positive characteristics, will lead us to strengthen the effectiveness of the results, complementing their main virtues.

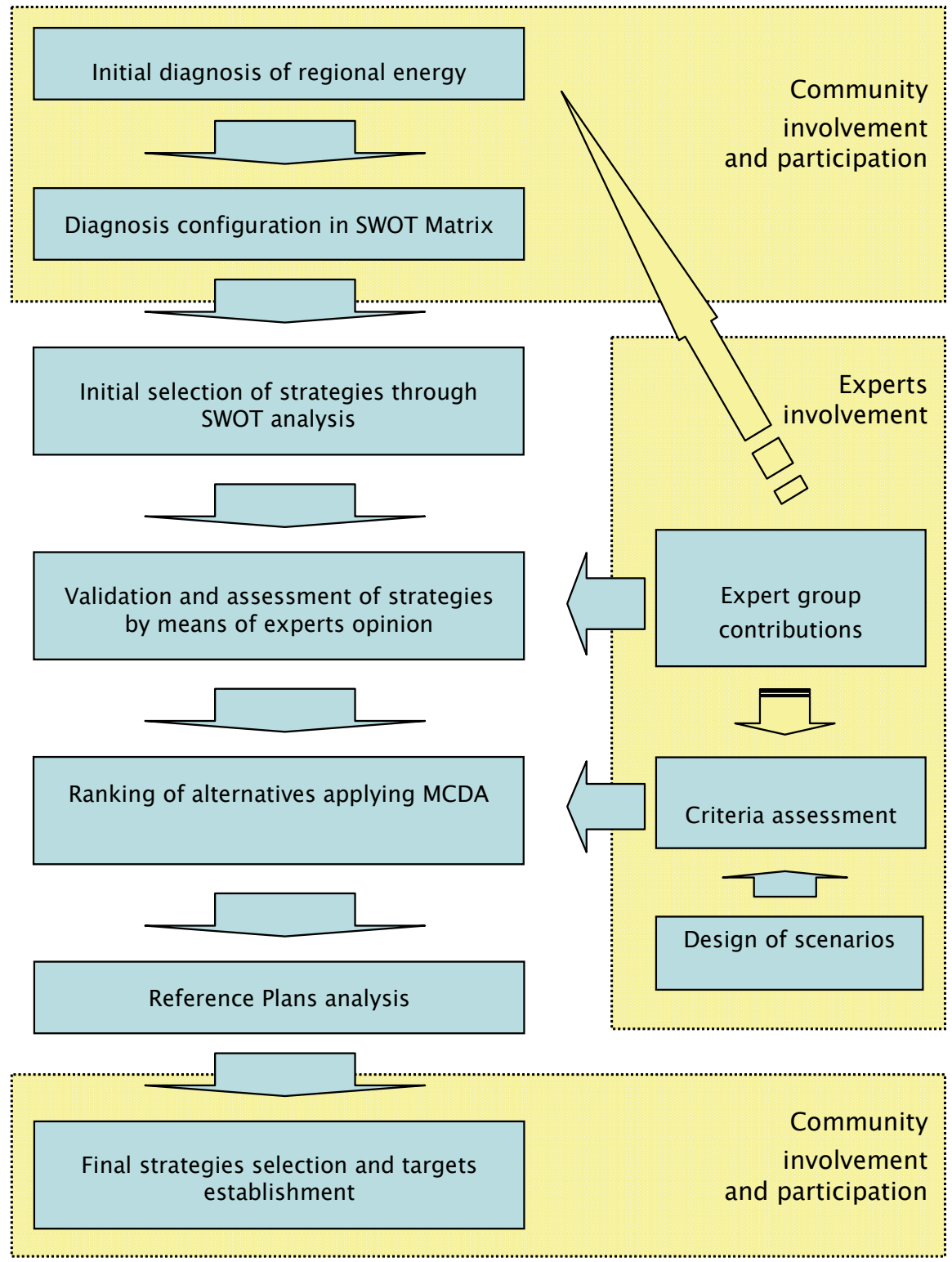

Fig. 4. Scheme of proposed RES planning process 
The new approach, proposed by Terrados et al., combines advantages from the three techniques commonly used in regional energy planning: multicriteria decision techniques, expert opinion and SWOT analysis.

For this, the basic structure consists of seven phases:

1. Initial diagnosis of regional energy system

2. Diagnosis configuration as SWOT Matrix

3. Initial selection of strategies through SWOT analysis

4. Validation and assessment of strategies by means of experts opinion

5. Ranking of alternatives applying MCDA

6. Reference Plans analysis

7. Final strategies selection and targets establishment

This scheme is also useful to assure the involvement of stakeholders in the planning process. Figure 4 illustrates the whole framework and shows by means of dark lines the main path, and by means of dotted lines the expected contributions of experts and social community.

The methodology has been applied to Jaén province, a southern Spanish region whose energy system is currently mainly dependant on fossil fuels (Terrados et al. 2009). It was pursued the definition of a series of strategies for renewable energies development and the establishment of energy targets to be achieved in year 2010.

\section{SWOT analysis}

First of all, a diagnosis of the provincial energy system was accomplished. Such diagnosis was structured through a SWOT matrix where strengths, weaknesses, opportunities and threats were identified. Deployment of SWOT analysis, comparing the different sectors of the matrix, allowed us to define a set of possible strategies that were segregated on 28 defined actions.

\section{Delphi survey}

Following SWOT analysis application, an expert survey, based on Delphi technique, was performed. In this case the number of experts to participate was limited by the characteristics of the matter to study. We needed to contact experts on renewable energies in general, and who should also know about provincial reality. Such limitation would meant to reject Scientifics who were specialized only on a determined renewable resource and were unable to develop a forecast on the rest of sources and, on the other hand it also would meant to reject renewable energies researchers who were unaware of our regional situation.

Thirteen experts were initially selected, and nine of then finally got committed in the process. They represented the main Institutions, Organizations and Enterprises connected with provincial energy field (University, Energy Administration, Provincial Energy Agency, Electrical distribution Company, Andalusian Energy Agency, Andalusian Institute of Renewables, Andalusian Development Institute and Ecologist Associations).

The questionnaire sent in the first round considered twenty eight actions to be executed, and experts were required to assess, in one hand, the relevance of those actions for renewable energies development and, on the other hand, to estimate the target to be met by the action (power installed, number of installations, ...) by year 2010. They were also required to propose additional actions.

As a result arising from the first round, all of the actions were judged very positively with ten alternatives above four points (on a 1 to 5 scale) and another fifteen alternatives above three points. A high degree of consensus was also achieved. Referring to the estimation of targets, discrepancy among experts was higher. A second round was then accomplished. 
Consensus among experts was increased both in valuation of alternatives and in target estimation. Variation factor decreased, in a widely manner, and consensus suitable level was judged as appropriate.

\section{Multicriteria analysis}

Finally, a Multicriteria analysis was performed in order to fix priorities among alternatives. A set of ten criteria were initially defined to be assessed in each of the alternatives. Later, an eleventh criterion was added to incorporate results from Delphy analysis into MCDA. In this way, assessment provided by experts survey was consider as an additional criterion.

\begin{tabular}{|c|c|c|c|c|c|c|c|c|c|c|c|c|}
\hline \multicolumn{13}{|c|}{ Criteria } \\
\hline & & 1 & 2 & 3 & 4 & 5 & 6 & 7 & 8 & 9 & 10 & 11 \\
\hline \multicolumn{2}{|c|}{ Type } & MÁX & MÁX & MÁX & MÁX & MIN & MIN & MIN & MÁX & MIN & MAX & MÁX \\
\hline \multirow{28}{*}{ 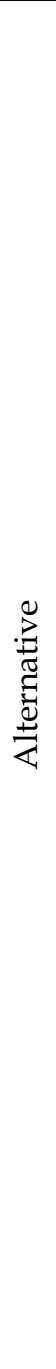 } & 1 & 2,107 & 4 & 2 & 5 & 50,1 & 0,08 & 4 & 1,75 & 1442 & 4 & 4,52 \\
\hline & 2 & 2,107 & 4 & 2 & 4 & 50,1 & 0,08 & 4 & 1,75 & 1442 & 4 & 4,09 \\
\hline & 3 & 2,007 & 3 & 1 & 4 & 50,1 & 0,08 & 3 & 1,75 & 1442 & 3 & 4,27 \\
\hline & 4 & 2,007 & 3 & 1 & 5 & 50,1 & 0,08 & 3 & 1,75 & 1442 & 3 & 3,76 \\
\hline & 5 & 2,007 & 2 & 2 & 5 & 73 & 0,61 & 3 & 1,75 & 1503 & 3 & 3,45 \\
\hline & 6 & 2,007 & 3 & 2 & 4 & 73 & 0,61 & 3 & 1,75 & 1503 & 3 & 3,19 \\
\hline & 7 & 2,007 & 3 & 2 & 4 & 73 & 0,61 & 3 & 1,75 & 1503 & 3 & 3,42 \\
\hline & 8 & 2,007 & 3 & 2 & 4 & 73 & 0,61 & 3 & 1,75 & 1503 & 2 & 3,39 \\
\hline & 9 & 0,076 & 4 & 3 & 4 & 25 & 0,04 & 2 & 1,75 & 240,9 & 3 & 3,67 \\
\hline & 10 & 0,096 & 4 & 3 & 4 & 25 & 0,04 & 2 & 1,75 & 151,4 & 3 & 3,77 \\
\hline & 11 & 0,076 & 4 & 3 & 4 & 25 & 0,04 & 3 & 1,75 & 62,02 & 3 & 4,1 \\
\hline & 12 & 0,344 & 5 & 1 & 3 & 11,6 & 0,025 & 4 & 0,30 & 601 & 1 & 3,33 \\
\hline & 13 & 0,502 & 5 & 2 & 3 & 9 & 0,1 & 2 & 0,30 & 1202 & 3 & 3,69 \\
\hline & 14 & 0,502 & 5 & 2 & 3 & 9 & 0,1 & 2 & 0,30 & 1202 & 4 & 4,11 \\
\hline & 15 & 0,416 & 5 & 5 & 4 & 75 & 0,4 & 1 & 1,02 & 13222 & 3 & 3,91 \\
\hline & 16 & 0,416 & 5 & 5 & 4 & 75 & 0,4 & 1 & 1,02 & 13222 & 3 & 4,29 \\
\hline & 17 & 0,416 & 4 & 5 & 4 & 60 & 0,4 & 2 & 1,02 & 6611 & 4 & 3,38 \\
\hline & 18 & 0,416 & 4 & 5 & 4 & 60 & 0,4 & 2 & 1,02 & 6611 & 4 & 3,74 \\
\hline & 19 & 0,416 & 4 & 4 & 4 & 60 & 0,4 & 2 & 1,02 & 6611 & 3 & 2,97 \\
\hline & 20 & 0,143 & 5 & 5 & 4 & 17,98 & 0,147 & 1 & 1,12 & 729,8 & 3 & 4,63 \\
\hline & 21 & 0,143 & 4 & 4 & 4 & 17,98 & 0,147 & 1 & 1,12 & 472,2 & 3 & 4,81 \\
\hline & 22 & 0,143 & 4 & 4 & 4 & 17,98 & 0,147 & 2 & 1,12 & 472,2 & 3 & 4,91 \\
\hline & 23 & 0,143 & 3 & 3 & 4 & 17,98 & 0,147 & 2 & 1,12 & 472,2 & 3 & 4,31 \\
\hline & 24 & 0,645 & 2 & 1 & 4 & 26 & 0,19 & 3 & 1,12 & 2524 & 3 & 3,57 \\
\hline & 25 & 0,631 & 4 & 3 & 3 & 18,06 & 0,08 & 2 & 0,30 & 871,5 & 3 & 3,21 \\
\hline & 26 & 0,631 & 5 & 2 & 3 & 18,06 & 0,08 & 5 & 0,30 & 871,5 & 3 & 4,09 \\
\hline & 27 & 2,007 & 3 & 2 & 3 & 27,36 & 0,94 & 4 & 1,75 & 1442 & 3 & 2,89 \\
\hline & 28 & 2,007 & 2 & 1 & 3 & 27,36 & 0,94 & 3 & 1,75 & 1442 & 3 & 2,89 \\
\hline
\end{tabular}

Table 2. Decision matrix of MCDA phase 
Therefore, up to eleven criteria were defined, grouping them in four different categories:

Technological criteria

1. Total primary energy saved

2. Maturity of technology

3. Technical know-how of local actors

4. Continuity and predictability of resource

Environmental criteria

5. Sustainability according to $\mathrm{CO} 2$ emissions

6. Sustainability according to other emissions (SO2, NOx)

7. Sustainability according to other impacts (noise, visual impact, landscape, ...) Socio-economic criteria

8. Job creation

9. Financial requirements

10. Compatibility with local, regional and national policies

Delphi criterion

11. Expert valuation

Each of the alternatives was quantified in every one of the criteria to obtain the Decision Matrix (table 2), and PROMETHEE method was selected to perform muticriteria decision analysis. Incoming (positive) and outcoming (negative) fluxes were calculated and priorisation of alternatives was established in three different scenarios. Flux diagram concerning environmental scenario is presented in fig 3.

Multicriteria analysis allowed us to establish three different priority levels. Fourteen alternatives were set as A priority, six were set as B, an eight were set as C.

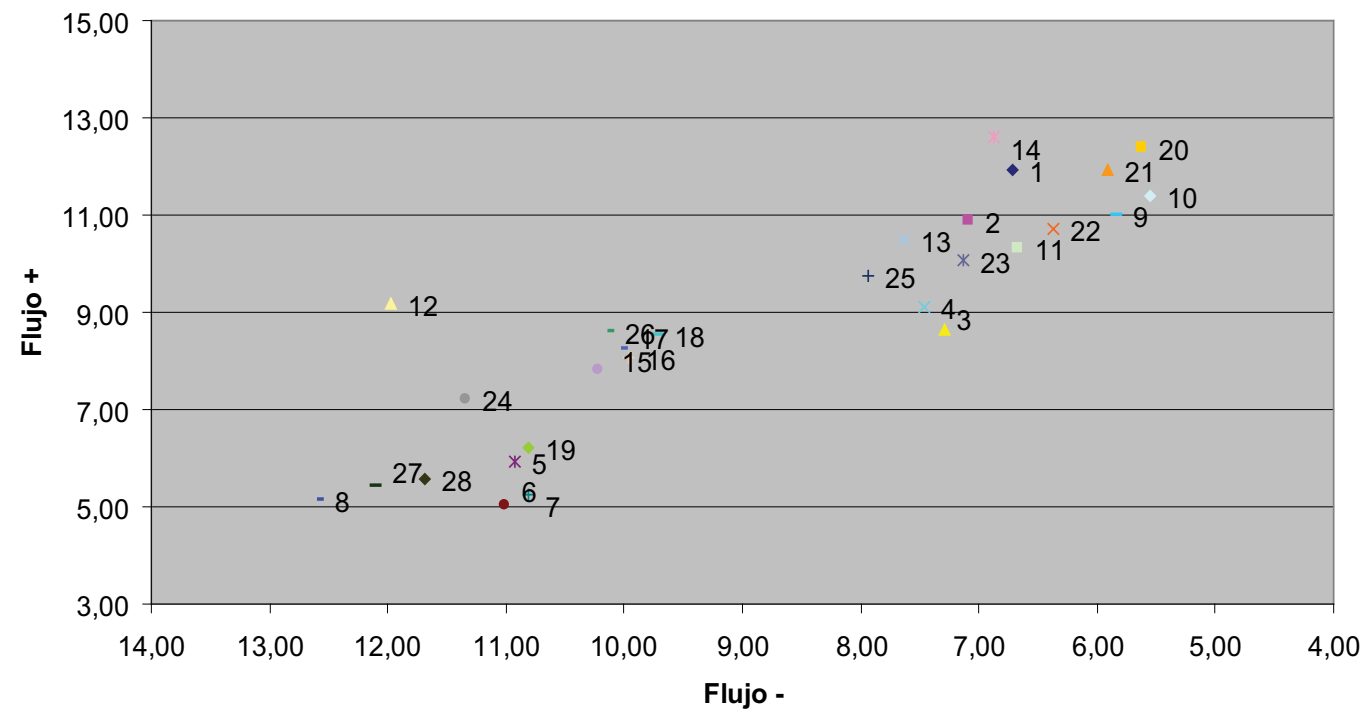

Fig. 5. MCDA process: flux diagram for environmental scenario

\section{Strategies selection and targets establishment}

Final actions selected and energy targets to be met are shown on table 3. For the purpose of the energy plan, the whole set of twenty eight strategies was selected including the group of alternatives that were worse appreciated and that should become lower level priority actions. 


\begin{tabular}{|l|c|}
\hline \multicolumn{1}{|c|}{ Action } & 2010 Target \\
\hline Installation of comb. cycle pw. stat. (10-15 MW) fuelled by Olive oil industry res. & $75 \mathrm{MW}$ \\
\hline Installation of comb. cycle pw. stations (10-15 MW) fuelled by Olive pruning res. & $30 \mathrm{MW}$ \\
\hline Installation of gasification-based pw. stat. (10-15 MW) fuelled by Olive prun. res. & $20 \mathrm{MW}$ \\
\hline Installation of gasification-based pw. stat. (10-15 MW) fuelled by wood ind. res. & $8 \mathrm{MW}$ \\
\hline Installation of Biogas plants fuelled by Olive oil industry residues (5 - 10 MW) & $10 \mathrm{MW}$ \\
\hline Installation of Biogas plants fuelled by cattle wastes (5 - 10 MW) & $6,5 \mathrm{MW}$ \\
\hline Installation of CHP plants for the exploit. of water treat. station biogas (0,5-2MW) & $1,5 \mathrm{MW}$ \\
\hline Installation de Biogas plants fuelled by urban residues (1-5 MW) & $2,5 \mathrm{MW}$ \\
\hline Installation of biomass domestic heating systems & $980 \mathrm{Unit}$ \\
\hline Installation of biomass heating systems at educational centres & $60 \mathrm{Unit}$ \\
\hline Installation of biomass heating systems at industry and services & $510 \mathrm{Unit}$ \\
\hline Hydro plants on existing and future dams (10 - 30 MW) & $160,0 \mathrm{MW}$ \\
\hline Small hydro plants on waterfalls and watercourses (0,5 - 10 MW) & $58,5 \mathrm{MW}$ \\
\hline Refurbishing of old hydro plants (0,25 - 5 MW) & $7,0 \mathrm{MW}$ \\
\hline Domestic isolated PV systems (2 - 5 kW) & $0,5 \mathrm{MW}$ \\
\hline Isolated PV systems in farming applications (2 - 5 kW) & $0,6 \mathrm{MW}$ \\
\hline Domestic grid connected PV systems (2 - 5 kW) & $0,50 \mathrm{MW}$ \\
\hline Grid connected PV systems at comp. and public administrations (30 - 100 kW) & $3,00 \mathrm{MW}$ \\
\hline Large grid connected PV systems (200 kW - 1000 kW) & $2,00 \mathrm{MW}$ \\
\hline Single-family domestic solar-thermal heating systems installation & $10.500 \mathrm{Unit}$ \\
\hline Communities domestic solar-thermal heating systems installation & $10.200 \mathrm{Unit}$ \\
\hline Solar-thermal heating systems installation at Hotels and services sector & $11.300 \mathrm{Unit}$ \\
\hline Solar-thermal heating systems installation at Industry & $5.500 \mathrm{Unit}$ \\
\hline Solar-thermal gas hybrid installations (2 - 20 MW) & $12,0 \mathrm{MW}$ \\
\hline Low-power isolated wind systems (5 - 250 kW) & $2,0 \mathrm{MW}$ \\
\hline Wind farms (5 - 30 MW) & $70,0 \mathrm{MW}$ \\
\hline Energy crops exploitation in combustion cycles & $2,5 \mathrm{MW}$ \\
\hline Biofuel generation through energy crops & 2,89 \\
\hline
\end{tabular}

Table 3. List of actions selected and energy targets

Final result of such process presents 472 MW of power installed in year 2010, by means of twenty strategies concerning electricity generation with renewable resources, leading to an annual production of $1.630 \mathrm{GWh}$ out of the region. Concerning thermal production, target is fixed in 253,46 ktep through eight strategies mainly focused on biomass and solar thermal.

\section{Conclusions}

Energy planning processes under sustainable development criteria have made extensive use of Multicriteria Decision techniques, where environmental criteria have been incorporated 
in the assessment, and also experts' opinion methods and techniques derived from territorial strategic planning.

The analysis of these methodologies and tools is useful to highlight their main advantages and to harness them in the proposal of combined planning methods involving different approaches.

Multicriteria decision analysis (MCDA) tools utilisation allows, in the case of sustainable energy planning processes, to take into account the environmental dimension, as well as technical, economical and political criteria. However, it is important to consider the fact that we are dealing with "decision aid" techniques far from "decision making" techniques and, in this sense, the application of one of these methods only represents one of the steps to follow.

Delphi techniques, that imply the participation of a number of experts, have also been a popular tool for planning purposes. In most of the cases expert opinion has been part of a broader methodology. The use of multicriteria decision analysis combined with expert judgement provides us with a sounder result, strengthening subjective group opinion with objective data analysis. Furthermore, current software applications are allowing planners to perform simulations and sensibility analysis in a quicker and easier way. This characteristic can be useful to value the result robustness.

Finally, methodology based on SWOT analysis for the diagnosis of the energy system assured a comprehensive outline of regional energy situation and a complete set of strategies deployment. SWOT methodology will allow us to arrange energy system diagnosis in accordance with a matrix basis (strengths, weaknesses, opportunities and threats) and will also be used to generate strategies for improving current situation.

These methods allow us to establish development strategies concerning mainly renewable resources, quantifying and ranking them. And, on the other hand, these methods are easily interrelated with collective participation techniques that may assure, as a key factor to success, the involvement of the community in regional planning process. Three issues can be highlighted as the most important for planning success purposes: community participation, interdisciplinarity and SWOT methodology.

\section{References}

Lima, P.; Bonarini, A. \& Mataric, M. (2004). Name of Book in Italics, Publisher, ISBN, Place of Publication

Almonacid, G; Quesada Moya, F.M.; Rey Zamora, P., et al. (2000). La Energía. In: Martín Mesa, A. (dir.). Plan Estratégico de la provincia de Jaén. Jaén: Fundación “Estrategias para el desarrollo económico y social de la provincia de Jaén"; p. 129-142.

Anderson T, Doig A. (2000). Community planning and management of energy supplies international experience. Renewable Energy. 2000;19: 325-331.

Aragonés P. (1997). Aproximación a la Toma de Decisiones Multicriterio en Proyectos. Implementación de una Metodología Multicriterio y Multiexperto: PRES II. Tesis Doctoral. Valencia: Universidad Politécnica de Valencia.

Barba-Romero S, Pomerol, J C. (1997). Decisiones Multicriterio. Fundamentos Teóricos y utilización Práctica. Madrid: Servicio de Publicaciones de la Universidad de Alcalá.

Beccali M, Cellura M, Mistretta M. (2003). Decision-making in energy planning. Application of the Electre method at regional level for the diffusion of renewable energy technology. Renewable Energy. 2003; 28: 2063-2087. 
Benavides C, Quintana C. (2004). Proceso y fases de la dirección estratégica: aplicación a la gestión de la Universidad. In: Planificación Estratégica y mejora de la Calidad en las Universidades, Murcia: Dirección General de Universidades. Consejería de Educación y Cultura de la Región de Murcia, 2004 p. 47-89.

Cavallaro F. (2005). An integrated Multi-Criteria System to Assess Sustainable Energy Options: An Aplication of the Promete Method. Nota di Lavoro 22.2005. Milan: Fundazione Eni Enrico Mattei. Web availabe: www.feem.it.

Comisión Europea. (1997). Libro Blanco "Para una estrategia y un plan de acción comunitarios: Energía para el futuro: Fuentes de Energías Renovables" COM (97) 599 final, de 26 de noviembre de 1997.

Cormio C, Dicorato M, Minoia A, Trovato M. (2003). A regional energy planning methodology including renewable energy sources and environmental constraints. Renewable and Sustainable Energy Reviews. 2003.; 7 (2): 99-130.

Curtis A. 2004. (2004). Valuing ecosystem goods and services: a new approach using a surrogate market and the combination of a multiple criteria analysis and a Delphi panel to assign weights to the attributes. Ecological Economics. 2004; 50:163-194

Georgopoulou E, Lalas D, Papagiannakis L. (1997). A Multicriteria Decision Aid approach for energy planning problems: The case of renewable energy option. European Journal of Operational Research. 1997; 103: 38-54

IDAE. (2005). Plan de Energías Renovables en España. Madrid: Instituto para la Diversificación y Ahorro de la Energía - IDAE -; 2005.

IDAE. (1999). Plan de fomento de las energías renovables en España. Madrid: Instituto para la Diversificación y Ahorro de la Energía. Madrid: Instituto para la Diversificación y Ahorro de la Energía - IDAE -; 1999.

Kaya T , Kahraman C. (2010). Multicriteria renewable energy planning using an integrated fuzzy VIKOR \& AHP methodology: The case of Istanbul. Energy 35 (2010) 2517e2527

Landeta, J. (1999). El método Delphi. Una técnica de previsión para la incertidumbre. Barcelona: Editorial Ariel S.A. ; 1999.

Linkov I, Varghese A, Jamil S, Seager T P, Kiker G Bridges T. (2004). Multi-criteria decision analysis: a framework for structuring remedial decisions at contaminated sites. In: Linkov I, Ramadan A, editors. Comparative Risk Assessment and Environmental Decision Making, Kluwer, 2004, p. 15-54

Loken E. (2007). Use of multicriteria decision analysis methods for energy planning problems. Renewable and Sustainable Energy Reviews. 2007; 11: 1584-1595.

Neudoerffer RC, Malhotra P, Ramana PV. (2001). Participatory rural energy planning in India - a policy context. Energy Policy. 2001; 29(5): 371-381.

Nigim K, Munier N, Green J. (2004). Pre-feasibility MCDM tools to aid communities in prioritizing local viable renewable energy sources. Renewable Energy. 2004; 29: 1775-1791

Pickton, D.W. and Wright, S. (1998). What's swot in strategic analysis?. Strategic change. 1998: 7; 101-109.

Pietrapertosa F, Cosmi C, Macchiato M, Marmo G, Salvia M. (2003). Comprehensive modelling for approaching the Kyoto targets on a local scale. Renewable and Sustainable Energy Reviews. 2003; 7: 249-270. 
Pohekar SD, Ramchandran M. (2004). Application of multi-criteria decision making to sustainable energy planning - a review. Renewable and Sustainable Energy Reviews. 2004; 8: 365-381.

Popper R, Dayal A. (2002). Environmental Foresight: Use of online Strategy-Delphy Surveys (SDS) with Geographic Information Systems (GIS). Ponencia en el Seminario "Knowledge, education and territorial development in Central and Eastern European Countries. Triestre, 2002.

Salvia M, Pietrapertosa M, Cosmi C, Cuomo V, Macchiato M. (2004). Approaching the Kyoto targets: a case study for Basilicata region (Italy). Renewable and Sustainable Energy Reviews. 2004; 8: 73-90.

Shiftan Y, Kaplan S, Hakkert S. (2003). Scenario building as a tool for planning a sustainable transportation system. Transportation Research . 2003; Part D. 8: 323-342.

Terrados J, Almonacid G, Hontoria L. (2007). Regional energy planning through SWOT analysis and strategic planning tools. Impact on renewables development. Renewable and Sustainable Energy Reviews. 2007; 8: 365-381

Terrados J, Almonacid G, Perez-Higueras, P. (2009). Proposal for a combined methodology for renewable energy planning. Application to a Spanish region. Renewable and Sustainable Energy Reviews 13 (2009) 2022-2030

Wang J-J, Jing Y-Y, Zhang C-F, Zhao J-H. (2009). Review on multi-criteria decision analysis aid in sustainable energy decision-making. Renewable and Sustainable Energy Reviews 13 (2009) 2263-2278

Williams P M. (2002). Community strategies: mainstreaming sustainable development and strategic planning?. Sustainable Development. 2002; 10: 197-205.

Zwaenepoel, L.V. (2005). Swot Methodology and Regional Development Planning. 2005. Documento disponible en Web : http:/ /odmec.zrc-sazu.si 


\title{
The Passive Greenhouses
}

\author{
Marius M. Balas' ${ }^{1}$ Calin B. Muscaㄹ and Sanda V. Musca ${ }^{2}$ \\ ${ }^{1}$ Aurel Vlaicu University of Arad, \\ ${ }^{2}$ Politehnica University of Timisoara (PhD student), \\ Romania
}

\section{Introduction}

We are living in a great Greenhouse: our planet, the Earth. This sustainable system is almost closed, except the radiative energy received from the Sun. Understanding and respecting its principles is the only guaranty for a safe future of our species. The Greenhouse effect is a process by which a part of the incident solar energy is trapped by the lower atmosphere due to the action of some atmospheric gases, called greenhouse gases. A part of the Earth's surface infrared radiation, which would be otherwise lost into the space, is redirected back by the greenhouse gases and the clouds, so the temperature of the lower atmosphere becomes higher than it would be if direct heating by solar radiation was the only warming mechanism (IPCC, 2007). This effect has a certain similarity with the overheating of a proper greenhouse, which works by isolating warm air inside a transparent building, by reducing the convection heat flow.

The greenhouses were developed in order to cultivate plants under controlled conditions. They offer high productivity and efficiency, and remove much of the risks caused by the inappropriate weather and climate. A certain greenhouse surface can feed five to ten times more people than the same conventional agricultural terrain. That is why greenhouses are used from more than two millenniums, as we know from the Plinius the Elder reports on the culinary habits of the Roman emperor Tiberius, who was already aware of the vegetarian regimes' advantages (Janick, 2007). His favorite cucumbers were planted in wheeled carts, put in the sun daily and then taken inside at night. The cucumbers were stored under frames or in special houses covered with oiled cloth or with sheets of selenite. The first modern greenhouse structures were built in the 13th century at the Vatican in Rome. Along centuries the greenhouses issued a powerful industry, which nowadays is supporting powerful economies, like in the case of the Netherlands.

Although from the technological point of view greenhouses are well covered, they have to cope with the continuously increasing costs of the energy. Their main asset, the direct use of the solar energy, is not able to constantly ensure the temperature constraints demanded by plants, because of the hardly predictable weather conditions. That is why most greenhouses have to be connected to conventional energetic infrastructures: electricity, gas, warmed water, etc. Our purpose is to investigate a fundamental improvement of the greenhouse concept, with a huge potential to improve our lives: the Passive Greenhouses. 


\section{Greenhouses - the state of the art}

\subsection{The greenhouses of the third millennium}

A greenhouse is nowadays a relatively complex technical system. Essentially they are built of glass or transparent plastic panels, single layered or double layered, sustained by a metallic structure. Controllable ventilation fans and/or opening roofs as well as vaporization devices are common features. Removable curtains are deployed over the plants when the solar radiation is too strong, in order to avoid the overheating produced by the greenhouse effect or during cold nights. Unconventional constructive solutions may be also found, as the convertible open-top greenhouses for example, which are using rolling flexible transparent films as covers (Richel, 2004). Very often the plants are cultivated on artificial soils, sand or perlite for instance. The water and the nutrient solutions are conducted towards the roots of the plants by special watering installations, which are dosing the fertilizers, mixing, dropping and re-circulating them. Specific devices can be used in order to furnish the necessary treatments against fungus, insects or diseases. The following photos were taken at the experimental greenhouse of the Southern University of Toulon-Var (see §2.2).

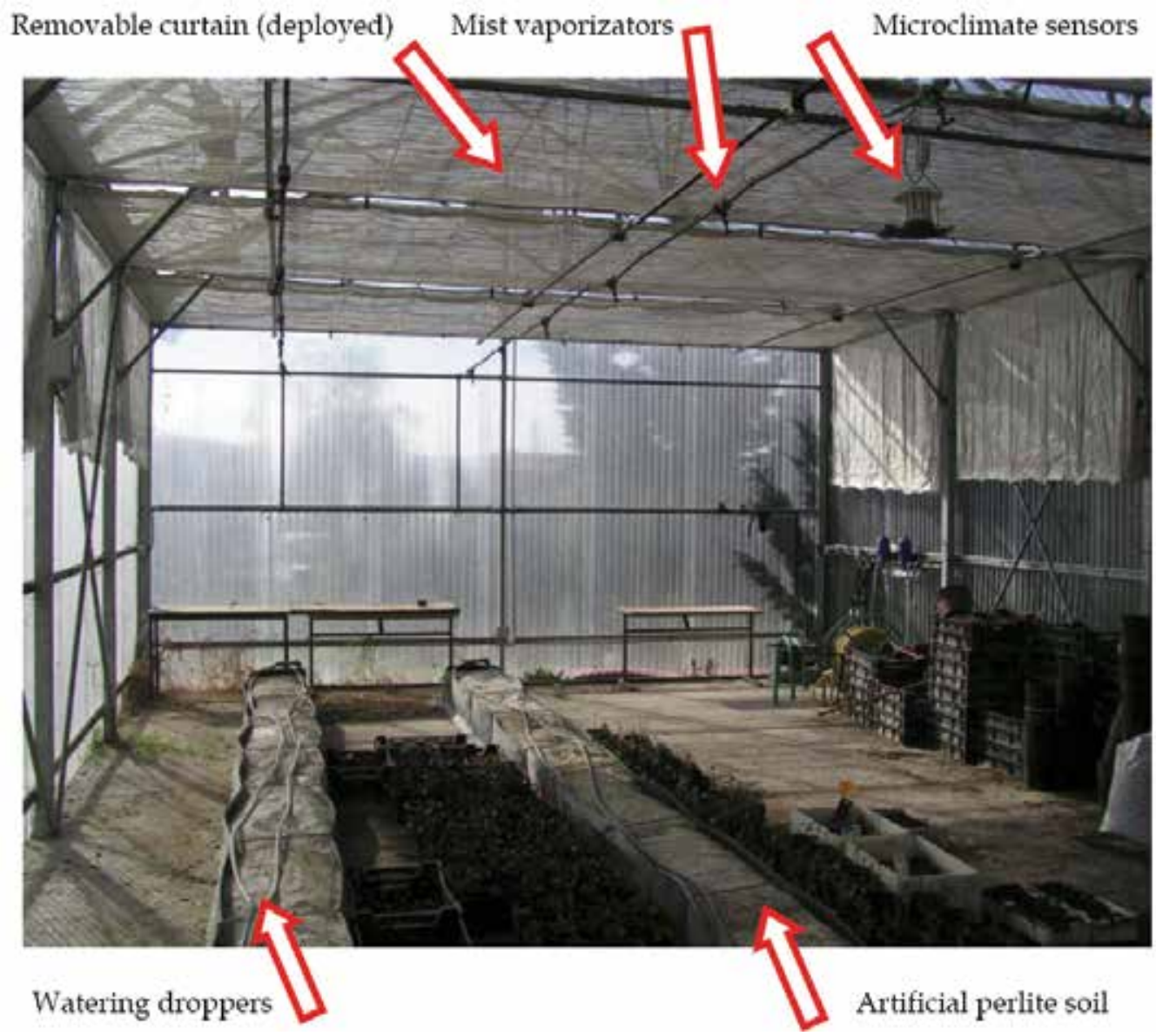

Fig. 1. The Toulon experimental greenhouse 


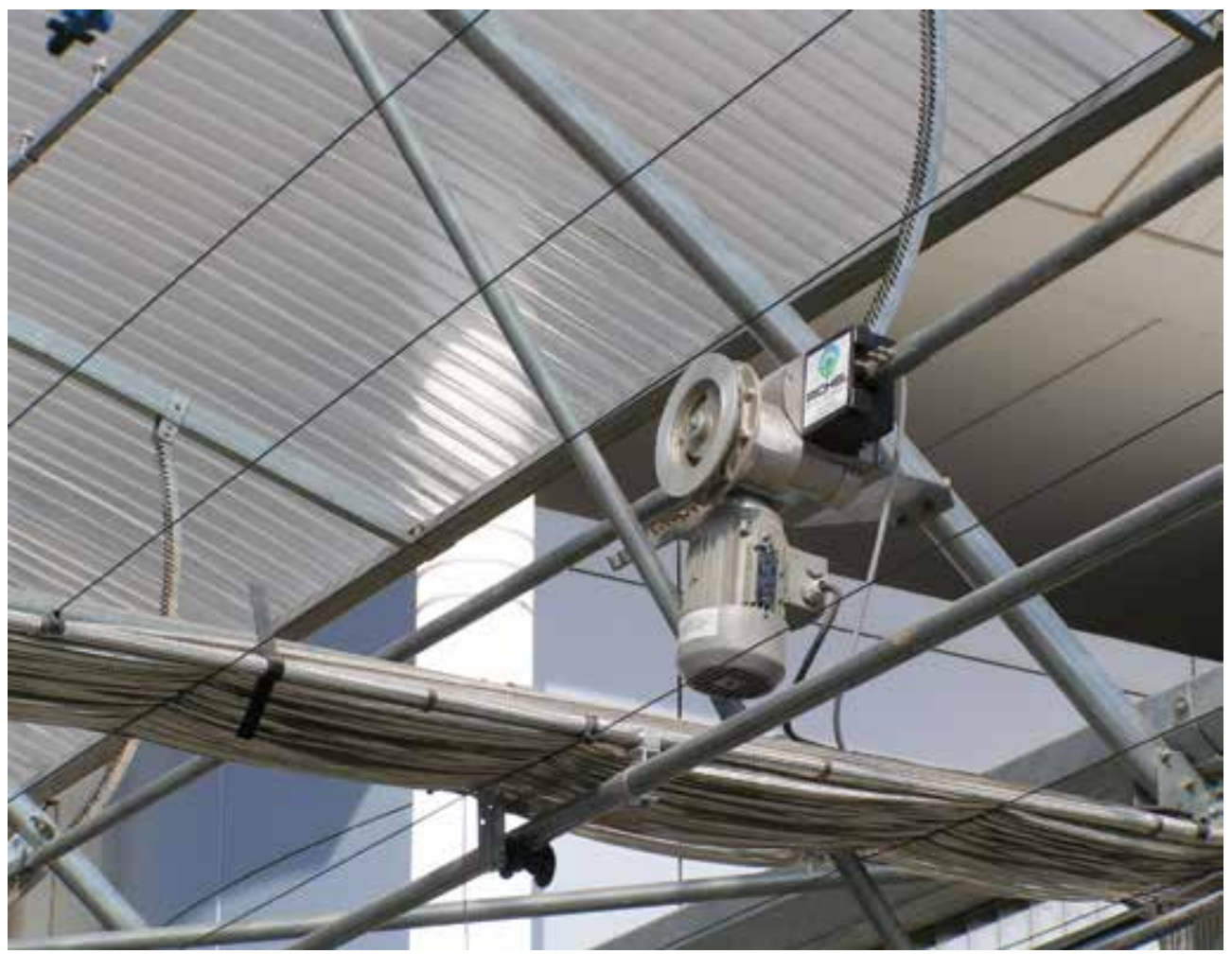

Fig. 2. Opening roof and removable curtain (removed)

The artificial illumination and the carbon dioxide generators are also contributing to the economical efficiency of the greenhouses. Since photosynthesis converts carbon dioxide into organic compounds using the energy of the light, increasing the duration of the illumination and the carbon dioxide concentration in the air is substantially increasing the crop.

A wide range of control, monitoring, surveillance and telecommunication equipment is currently installed or connected to greenhouses. The typical greenhouse control is sequential, implemented by PLCs (Programmable Logic Controllers). Dedicated sensors are monitoring the main parameters of the microclimate and of the environment: the inside and outside air temperature and humidity, the soil temperature and humidity, the wind speed and direction, the solar illumination, etc.

The damages caused to the plants by the insects can be detected in very early stages by bioelectronic noses (Biologically Sensitive Metal-Oxide-Semiconductor Field-Effect Transistor BioFET). For example the sensitive antenna of a Colorado beetle (Leptinotarsa decemlineata) may be connected to a MOS-FET. Thanks to the quasi-infinite impedance of the MOS-FET input gate, each electric impulse induced into the insect antenna by the odorant molecules emanated by the damaged plants may be amplified and measured (Schutz et al., 2000). However, the essential components that decide the performance and the efficiency of the greenhouses are the heating/cooling installations. They use different conventional energy sources: electricity, gas, liquid fuels, coal or wood, as well as renewable energy sources such as hot geo-thermal waters. 
Although the greenhouse is able in principle to directly use the sun energy for heating, this feature is not at all reliable, depending of the day-night cycle, the changing weather and the technical condition of the greenhouse. For example, when personnel work inside, the greenhouse system is changing a lot its parameters. That is why usual greenhouses still need a great deal of conventional energies. During the last decades the increasing energy price has affected the greenhouse industry in many parts of the world.

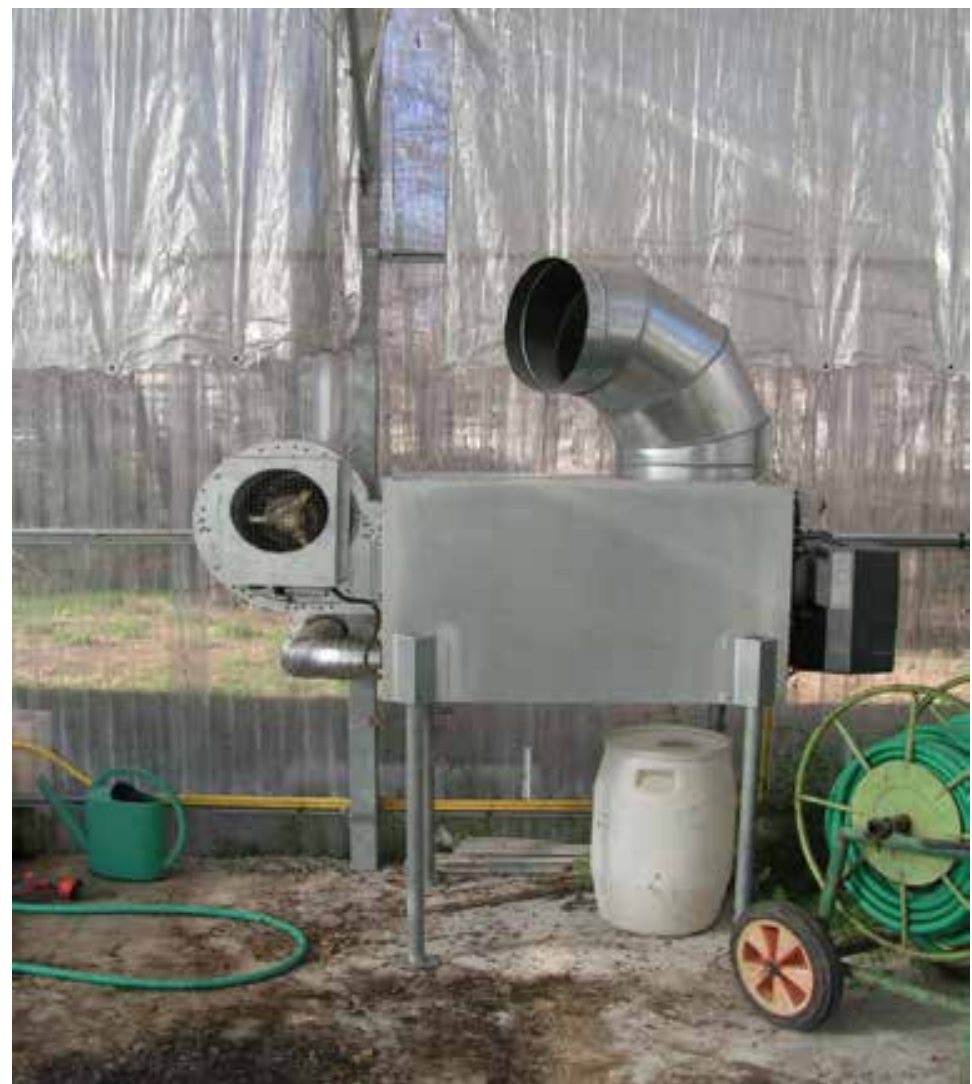

Fig. 3. A 55kW gas heater: extremely effective, but the gas is expensive and polluting

The scientific and technological research is continuously investigating different ways to increase the performance of the greenhouses:

- Constructive improvements concerning the materials, the shapes, the dimensioning of the components, etc.

- Improvements concerning the automate control: optimizations of the algorithms, smart/ intelligent features, embedding knowledge concerning the weather, the crop, etc.

- The elaboration of mathematical and computer models for the greenhouse system, able to assist the constructive dimensioning, the automate control, the automate diagnosis, etc.

- Introducing different renewable energy sources, in order to reduce the energy cost.

The following sections will illustrate some of the relevant achievements of the domain. 


\subsection{The experimental greenhouse of Toulon}

The LSIS team (Laboratoire des Sciences de l'Information et des Systèmes) of the Southern University of Toulon-Var France initiated almost twenty years ago a project that issued a great deal of data and knowledge concerning greenhouses. Professor Gilles Enéa and his colleagues Jean Duplaix, Jean-François Balmat and others, built an experimental greenhouse

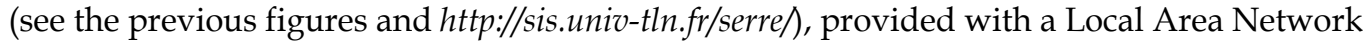
control and monitoring system. More than twenty sensors measure the most important environmental and technical parameters. This platform and its Internet compliant technology supported numerous researches dedicated to the identification and the intelligent control of the greenhouses.

Both synthetic and structural models were approached. The synthetic modeling - neural networks, genetic algorithms, etc. proved to be very precise and efficient when dealing with very specific operating regimes: sunny or cloudy days, still or windy nights, etc. but encountered fundamental obstacles when trying to cover the overall greenhouse's performance (Lafont \& Balmat, 2001; Bouchouicha, 2002). In other words, the synthetic models extracted from a sunny day recorded data are not properly working when applied for a cloudy day data. This is due to the complexity and high nonlinearity of the greenhouse system, and the only way that eventually produced good results was the fusion of several sub-models, each one aiming a particular operating regime: night, sunny day, cloudy day, rain, etc. The most comprehensive and precise synthetic model was obtained by a multi-model system supervised by HFL - Hierarchical Fuzzy-Logic (Pessel et al., 2009). The sub-models are implemented by neural networks. Although the synthetic modeling is a popular option nowadays, especially when the physical structure of the investigated process is unknown, such models are opaque; they are hiding any explicit knowledge about the system we are focusing on.

That is why, starting from 2003, the authors of this chapter engaged themselves on the other fundamental modeling strategy: the structural one. A structural identification is trying to catch the essential functional constraints that are governing the time evolution of the physical parameters. The complexity and the nonlinearity of the greenhouse as a mathematical item forced us to choose the simplest possible solutions, which are approximating rather roughly the reality. We avoided any computational complications: for instance, the inside greenhouse temperature was modeled by a first order differential equation (the Newton's law of cooling), with time varying coefficients and dead time, avoiding a partial differential equation system, that would have been the recommendable solution. Each coefficient of this key equation was determined on behalf of specific experimental tests, which were possible thanks to the experimental features of the Toulon greenhouse:

- The coefficient of the heat transfer through the walls was determined using the recorded data of a still night;

- The influence of the wind on the heat transfer issued out of a windy night data;

- The greenhouse effect was determined assuming that the heat transfer through the walls, previously determined for night conditions, will not change during daytime. The essential data for the identification of the greenhouse effect was recorded during a sunny day, keeping the greenhouse strictly closed, in order to avoid air changes with the exterior.

We can define two stages of the structural modeling:

- The elaboration of a "first guess", based on the theoretical analyze of the process and on training data;

- The optimization of the first guess model, based on validation data. 
We applied this method mostly for the identification of the influences of the wind (Balas et al., 2008) and of the sun (Balas \& Balas, 2008a). Our optimizations were carried on with the help of the genetic algorithms, but other choices are also legitimate.

The lack of precision of this method is largely compensated by its robustness, versatility and efficiency in terms of computational resources and developing time. Consider just the case of a new application, the synthetic modeling has to start from the scratch, while the structural one has only to be adapted and optimized for the validation. Of course, the greenhouse system is rather tolerant for the temperature variations, which is facilitating our task.

As a conclusion, the Toulon experimental greenhouse offered us the necessary conditions to elaborate a valid structural mathematical and computer model of a generic greenhouse. This model served us to explore new heating and cooling architectures for greenhouses, since the nature of the energy sources has a small impact on it.

\subsection{The Wageningen solar greenhouse}

The Netherlands plays a leading role in the greenhouse industry and horticulture. The scientific research that is supporting this industry is mainly located at the Wageningen University and it is inspired and supervised by Professor Gerrit van Straten. The Dutch Government promoted a fundamental research project dedicated to solar greenhouses and their optimal adaptive control (Dutch, 1999a \& b), which was accomplished at Wageningen. This project was finalized by a doctoral thesis (van Ooteghem, 2007), that from our point of view, represents a milestone in the field. Here one can find the most detailed and complete structural model of a generic solar greenhouse, including the model of its developing crop. The Wageningen Solar Greenhouse, shown in Fig. 4, aims to minimize the fossil fuel consumption.

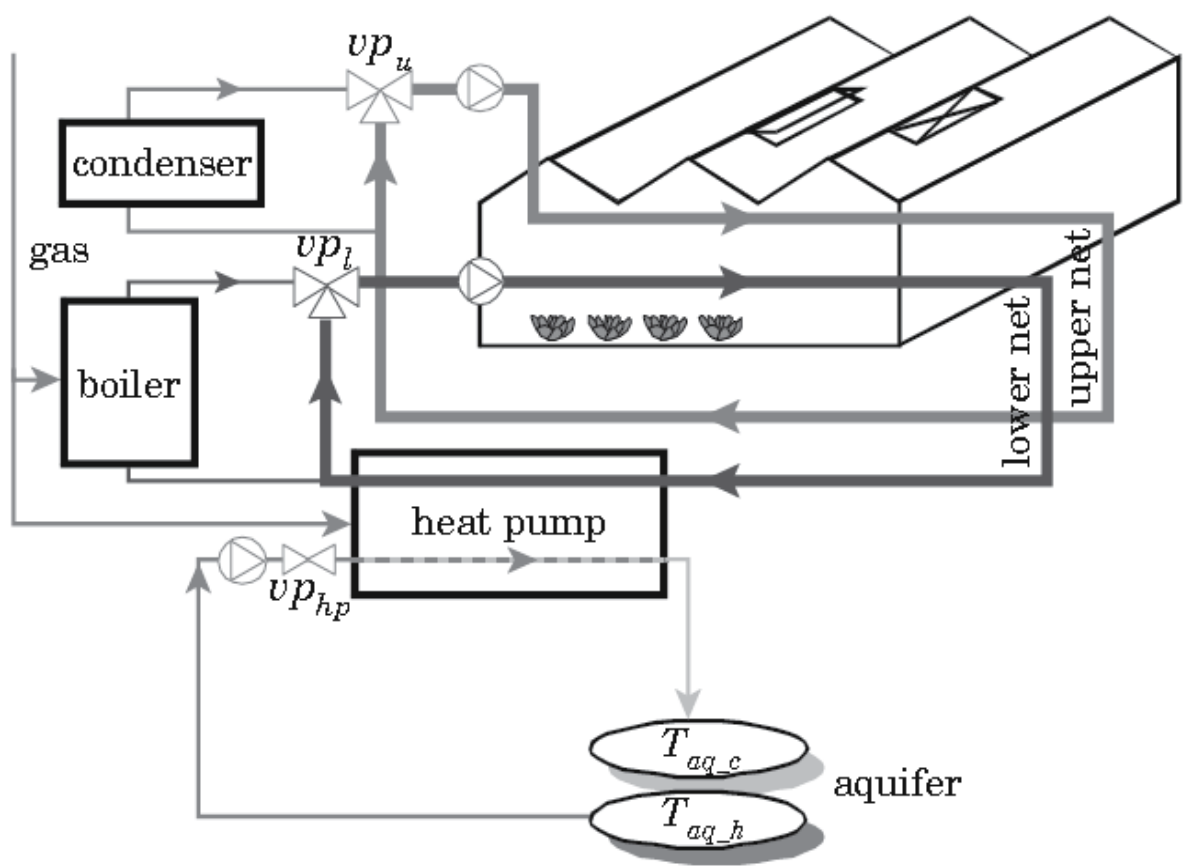

Fig. 4. The Wageningen solar greenhouse 
Besides the solar effect, the greenhouse is warmed by a system consisting of a cold water heat pump, a gas boiler and a condenser. The heat pumps are able to extract energy from low temperature waters or air, by means of an external water circuit, and to inject it into an internal closed water heating installation. The energy is provided by the thermal radiation of the earth. Obviously this type of energy is available everywhere on the surface of the earth, it is free of any costs, it is very constant and it has no predictable time limits. The external circuit may be closed (pipes) or open. The open circuit needs an aquifer system with two water wells: a warm one (say $16^{\circ} \mathrm{C}$ ) and a cold one (say $10^{\circ} \mathrm{C}$ ).

Heat pumps need 15-20\% of their nominal energy for the recirculation of the water. The heat pump of the Wageningen greenhouse is fired by gas. The heat pump can heat the lower net up to $330 \mathrm{C}$ while the boiler can heat it up to 900C.

Besides the warming system, the greenhouse is provided with a cooling heat exchanger, also connected to the aquifer and to its own upper cooling net.

The optimal adaptive predictive control is essential for the process (van Ooteghem, 2007). The predictive features are created with the help of the mathematical model that simulates over a time period of 6 days the effects of the disturbances: control actions (valve positions, ventilation windows aperture, etc.) and weather forecast. The model takes account of the crop growth effects. The receding horizon optimal control (RHOC) has been implemented. A goal function is formulated to minimize fossil energy use and maximize crop yield. With the goal function the costs are calculated based on the predicted process dynamics and the control inputs are altered to find the minimum costs.

The van Ooteghem model is the most comprehensive model communicated so far. All the greenhouse components and the associate physical effects are treated in a detailed manner: inside temperatures (air, walls, soil, etc.), curtain's effect, ventilation, heating and cooling, as well as the developing crop: evapotranspiration, photosynthesis, respiration, etc.

Although heat pumps can produce much higher temperatures, the gas boiler is still needed because the heat pump is highly inertial, unable to perform a fast control action. As in the case of the Toulon greenhouse, a powerful gas heating device is considered necessary.

\subsection{The closed greenhouse and the watergy}

Persons living in temperate or cold climate consider greenhouses mainly as energy manipulation technical items. However greenhouses can do much more than this. The management of the water resource - the Watergy - becomes essential in hot and arid regions that require large quantities of water for irrigation. The Closed Greenhouse, a concept of TerraViva Tec S.L., excludes the external aeration, preserving the initial water supply (TerraViva, 2004).

A tower with an internal cooling duct is placed into the centre of a greenhouse. Heated air humidified by the plants rises to the tower driven by natural buoyancy. From the upper end of the duct, the air is constantly cooled down by a heat exchanger. As it becomes colder, the air falls down through the tower and back into the greenhouse. This generates in the same time cooled and dehumidified air and condensed water. Besides the food production, closed greenhouses can turn wastewater or saltwater into irrigation and even drinking water.

Obviously, the Closed Greenhouse may become an Advanced Life Support item, making possible the habitation of remote areas like the desert and the polar regions and even the long term journeys in space. 


\section{The Passive Greenhouse}

\subsection{What is a Passive Greenhouse?}

Starting from 2004 we began to investigate a new concept: the Passive Greenhouse (Balas et al., 2004). This term stems from Passive House, which defines a building with a reduced ecological footprint. Although this might open some controversies, we decided to consider the term passive in the sense of free of conventional energy, relying exclusively on sustainable energy.

A Passive Greenhouses is independent of any conventional energetic infrastructure (gas, hot water, electricity, etc.) The concept is close to the Solar Passive Greenhouse, which uses only solar radiation and natural ventilation (Bellows, 2003). If provided with renewable energy sources as geo-thermal water, wind, photovoltaic, etc. a Solar Passive Greenhouse becomes a Passive Greenhouse. We can appreciate a Passive Greenhouse as a radicalization of the Wageningen Solar Greenhouse, in the sense that we renounce at any sort of conventional energy - gas and even electrical network. As we are about to see, although from the constructive point of view a Passive Greenhouse is not much more than a Passive House, major difficulties appear because of the intrinsic characteristics of the renewable energy sources: the geo-thermal energy is highly inertial while the sun and the wind are inconstant and not reliable. That is why we will be forced to replace the idea of the optimal adaptive predictive control with the expert adaptive predictive control. We can afford to drop the optimization constraint because of the strategic advantage of the Passive Greenhouses: the zero cost energy!

The construction of a Passive Greenhouse is quite banal; all its components have already developed their own markets. On the other hand, putting together several renewable energy devices, with contradictory technical and economical constraints, gives birth to a new systems engineering item, with unexpected and promising interdependences and synergies.

Before describing the Passive Greenhouse, we prefer to discuss its potential impact on our future. This way the readers interested rather in ecology or economics will not be forced to bear the technical details. Anyway, the technological support of the Passive Greenhouses is expected to constantly change for the better, what is really essential is to understand the principle and to assume its consequences.

\subsection{The Passive Greenhouse sustainable agricultural system}

For the time being conventional greenhouses have to be located near the existing infrastructures of our towns or villages. Assuming solved the technical problems, besides their free energy, the essential feature of the Passive Greenhouses is the full independence of any conventional energetic infrastructure. They can be installed virtually anywhere we dispose of natural or even artificial aquifers. Thanks to this feature, the extensive use of Passive Greenhouses offers us the opportunity to reconsider the global structure of the agricultural terrains (Balas, 2008; Balas et al., 2009a).

The Passive Greenhouses could be concentrated into remote locations, out of other immediate interest. Such sacrificed arias will look perhaps as the ugly mountainous zones that are currently occupied by solar greenhouses near San Remo, Italy (see Fig. 5). However these unpleasant looking greenhouses, located on artificial terraces, are producing the splendid flowers that are decorating the Italian Riviera! Inspired by this image, we will borrow a chess strategy: sacrificing a humble pawn - passive greenhouse concentration regions - for the final victory: a global ecological reconstruction of our environment.

The reason standing behind this idea is simple: a certain greenhouse aria can feed five to ten times more people than the same conventional agricultural terrain. The unshackled surfaces 
resulted after replacing a great deal of the agricultural terrains by Passive Greenhouses can be ecologically reconstructed and converted into natural environments: forests, pastures, orchards, pounds, etc. and all the consequent benefits.

Our alimentation is accomplished by two basic food chains:

a. A three level trophic chain: plants $\rightarrow$ animals $\rightarrow$ humans

b. A two level trophic chain: plants $\rightarrow$ humans

Much energy is lost into the environment at each transfer from one trophic level to another. That is why the food chain a) needs much more agricultural surfaces and energy than the food chain b). If, as a consequence of the extensive use of Passive Greenhouses, the animal growing will turn over the use of natural pastures instead of the actual cereal feeding, we can count on a significant bias of the trophic chains balance in the favor of the food chain b).

Besides any theoretical speculations, replacing conventional agricultural terrains by greenhouses has a doubtless carbon offset effect. We know that the $\mathrm{CO}_{2}$ consumption of trees is much higher than for cereals (Tuzhilkina, 2006). The $\mathrm{CO}_{2}$ consumption in a greenhouse is similar to a forest (Voican, 1998; Horgos, 2003), due to the high density of the plants and to the ideal growing conditions. So, in the end, more greenhouses means less $\mathrm{CO}_{2}$ in our air.

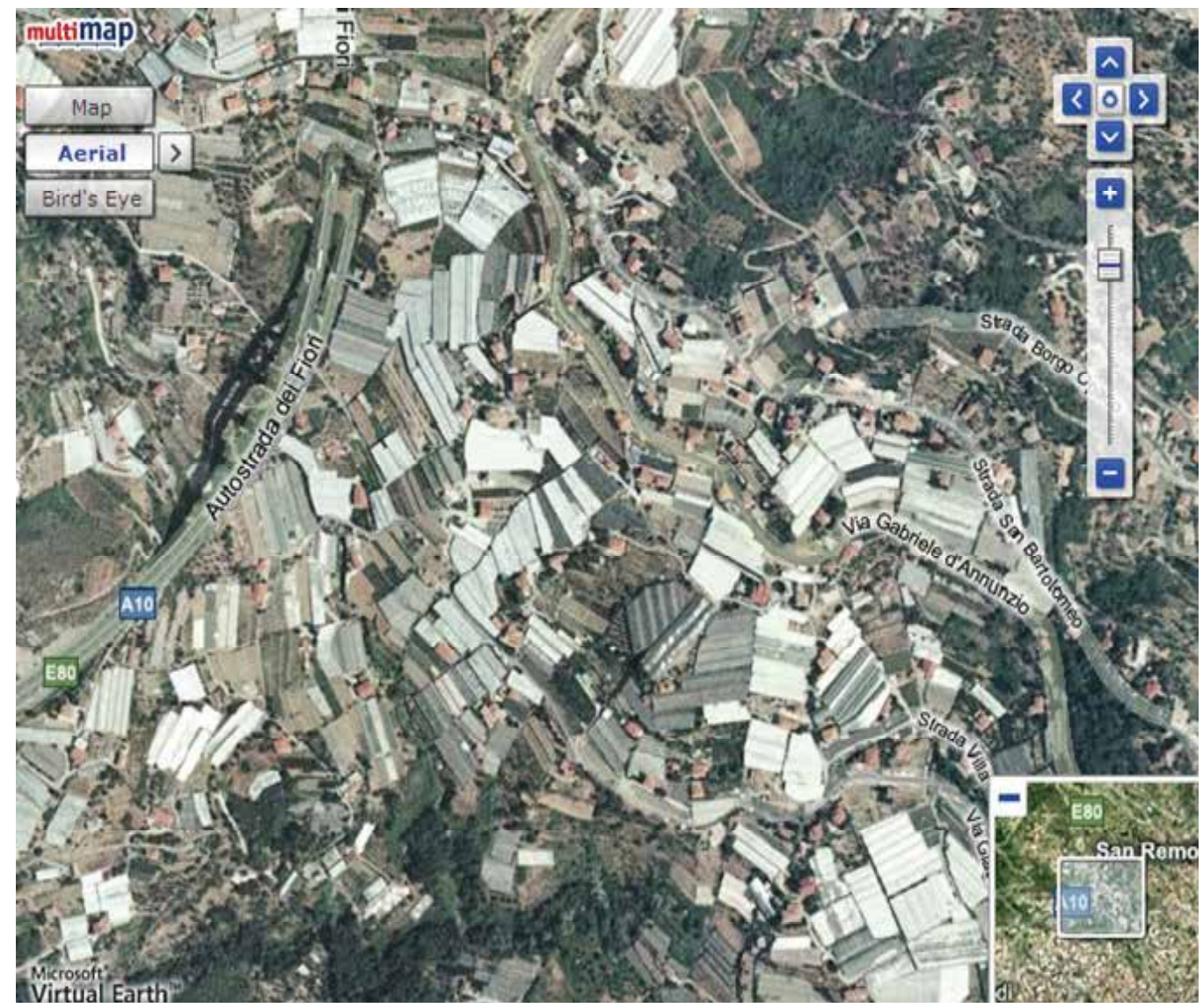

Fig. 5. Greenhouse concentration near San Remo, Italy (satellite view) 


\subsection{The Passive Greenhouse generic structure}

In our previous papers (Balas et al. 2004; Balas \& Duplaix, 2008d) we proposed a generic passive greenhouse structure that aggregates three renewable energy sources: a cold water heat pump (Ochsner; Olivier, 2001), a dc wind generator (NREL, 2006; IEC, 2006; SECO, 2008; Texas, 2010) and a matrix of orientable photovoltaic panels (Bradford, 2006; Texas, 2010). The roles played by the components of the Passive Greenhouse are the following:

$m$ The heat pump is the main heating/cooling device;

$\Rightarrow$ The wind generator produces the energy needed by the heat pump for recirculation;

The orientable photovoltaic panels produce recirculation energy for the heat pump and also replace the removable curtain, shading the plants when the solar radiation is excessive; this idea might seem too expensive, but the panels' prices are constantly decreasing.

\ The dc accumulator stocks wind and photovoltaic energy in order to supply the electric recirculation pump of the heat pump and also to supply all the control, driving and communication systems needed by the greenhouse.

The aggregation and the stocking of the disposable energy amounts in the accumulator are our first weapons against the energetic unreliability of the wind and the sun.

Another item that can help the renewable energy sources aggregation during exceptional cold weather is a supplementary gas/bio-gas burner. Since such extreme weather periods are rather seldom, this is a good method to reduce the investment costs, avoiding the overdimensioning of the other energy sources. Gas burners are anyway useful in greenhouses in order to increase the carbon dioxide concentration in the air. The electric energy of the accumulator can be used as well for heating for short periods, in emergency cases.

Comparing to the Fig. 4 greenhouse, we need only the lower net, used for both heating and cooling. The low position of the heat exchanging net is normal for heating but may appear as inadequate for cooling. However, we must recall that the overheating greenhouse effect is produced essentially at the ground level, so cooling the soil is very effective, not to mention the cost reducing. The heating-cooling switching of the heat pump is not a critical issue.

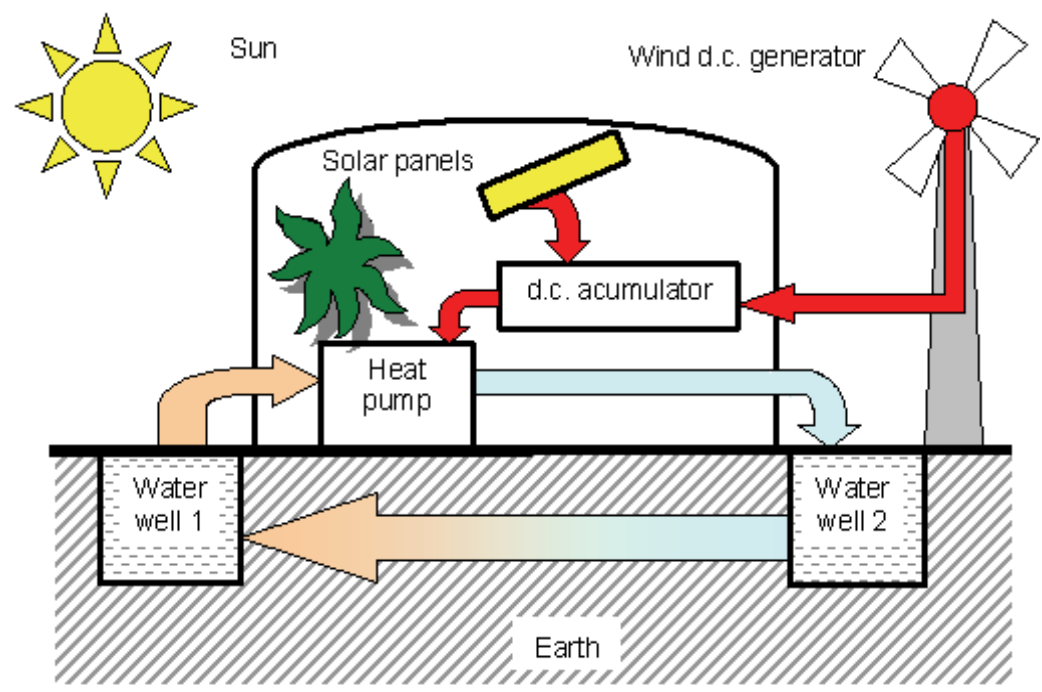

Fig. 6. The generic Passive Greenhouse 


\section{Modeling the Passive Greenhouses}

Although all its parts are wide spread industrial products, the Passive Greenhouse is a novel product by its functionality and is not materialized yet. A pilot Passive Greenhouse has to be built as soon as possible. For the time being our research tool is a structural mathematical model enabling us to perform any theoretical task concerning the design and the development of the Passive Greenhouse. However this model resulted just by replacing the power of the gas heater of the Toulon experimental greenhouse with the power developed by the previously described renewable energy sources assembly, so we have no reasons to doubt the conclusions of the research. The model is tuned for the Toulon greenhouse but as a structural model, it can be adapted to any other greenhouse, after the experimental or theoretical identification. The model is essential for the Passive Greenhouses development because it can be easily adapted for different purposes.

One future application of this model is intended to address and the essential issue of the investment costs. Simulations performed after relevant scenarios may help us to optimize the energy sources balance that minimize the costs but ensures the desired operation.

\subsection{The structural model of the Passive Greenhouse}

According to the purpose of the future simulations we can use different arrangements for the greenhouse mathematical model. For the Passive Greenhouse our interest is to emphasis the contribution of each energy source over the overall internal temperature $\mathrm{T}_{\mathrm{I}}$ :

$$
\frac{d T_{I}(t)}{d t}=\frac{d T(t)}{d t}+\frac{d T_{P C}(t)}{d t}+\frac{d T_{W}(t)}{d t}+\frac{d T_{E S}(t)}{d t}
$$

The detailed elements of the model are the following:

a. $\quad \mathrm{T}(\mathrm{t})\left[{ }^{0} \mathrm{C}\right]$, the basic inside temperature due to the environment influence, embedding the effects of the heat flow through the walls and of the natural or forced ventilation:

$$
\frac{d T(t)}{d t}=\left[k_{a}(t)+k_{V} \cdot F(t)\right] \cdot\left[T_{E}(t)-T_{I}(t)\right]
$$

where $k_{a}(t)\left[s^{-1}\right]$ is the coefficient of the heat flow through the walls, $k_{v}\left[m^{-3}\right]$ the ventilation coefficient, $\mathrm{F}(\mathrm{t})\left[\mathrm{m}^{3} / \mathrm{s}\right]$ the ventilated air flow and $\mathrm{T}_{\mathrm{E}}\left[{ }^{0} \mathrm{C}\right]$ the external temperature. $\mathrm{k}_{\mathrm{a}}(\mathrm{t})$ is a nonlinear parameter, embedding several functional influences: constructive (shape, dimensions, material of the walls), of the wind, etc. The model considers the two major physical effects characterizing the heat flow through the walls, the radiation and the convection, by two specific coefficients, $\mathrm{k}_{\mathrm{aR}}\left[\mathrm{s}^{-1}\right]$ and $\mathrm{k}_{\mathrm{aC}}\left[\mathrm{m}^{-1}\right]$ :

$$
\mathrm{k}_{\mathrm{a}}=\mathrm{k}_{\mathrm{aR}}+\mathrm{k}_{\mathrm{aC}} \cdot \mathrm{V}_{\mathrm{W}}
$$

where $V_{W}[\mathrm{~m} / \mathrm{s}]$ is the speed of the wind. The ventilation coefficient $\mathrm{k}_{\mathrm{v}}$, which is considered constant for the moment, could also be treated as nonlinear, influenced by the shape and the dimension of the ventilation fans, the wind, etc.

b. The equation of the heat pump is:

$$
\frac{\mathrm{dT}_{\mathrm{PC}}(\mathrm{t})}{\mathrm{dt}}=\mathrm{k}_{\mathrm{PC}} \cdot \mathrm{P}_{\mathrm{PC}}
$$

with $\mathrm{T}_{\mathrm{PC}}(\mathrm{t})$ the temperature amount added to $\mathrm{T}(\mathrm{t})$ by the heat pump, $\mathrm{k}_{\mathrm{PC}}\left[{ }^{0} \mathrm{C} \cdot \mathrm{s}^{-1} \cdot \mathrm{W}^{-1}\right]$ the heat pump coefficient, and $\mathrm{P}_{\mathrm{PC}}[\mathrm{W}]$ the power of the heat pump. 
c. The equation of the wind generator is:

$$
\frac{\mathrm{dT}_{\mathrm{W}}(\mathrm{t})}{\mathrm{dt}}=\mathrm{k}_{\mathrm{W}} \cdot \mathrm{P}_{\mathrm{W}}
$$

where $T_{W}(t)$ is the temperature amount added to $T(t)$ by the wind generator if connected to the electric heating device, $\mathrm{k}_{W}\left[{ }^{0} \mathrm{C} / \mathrm{m}\right]$ the wind coefficient and $\mathrm{P}_{W}$ the power supplied by the wind generator. We are considering a generic wind generator modeled by the following equation (Iowa):

$$
\mathrm{P}_{\mathrm{W}}(\mathrm{t})=0.5 \cdot \eta_{\mathrm{W}}\left(\mathrm{V}_{\mathrm{W}}\right) \cdot \rho \cdot \Pi \cdot \mathrm{r} \cdot \mathrm{V}_{\mathrm{W}}{ }^{3}
$$

where $\eta_{w}$ is the efficiency coefficient of the wind generator, $\rho\left[\mathrm{kg} / \mathrm{m}^{3}\right]$ is the density of the air and $\mathrm{r}[\mathrm{m}]$ is the radius of its helix.

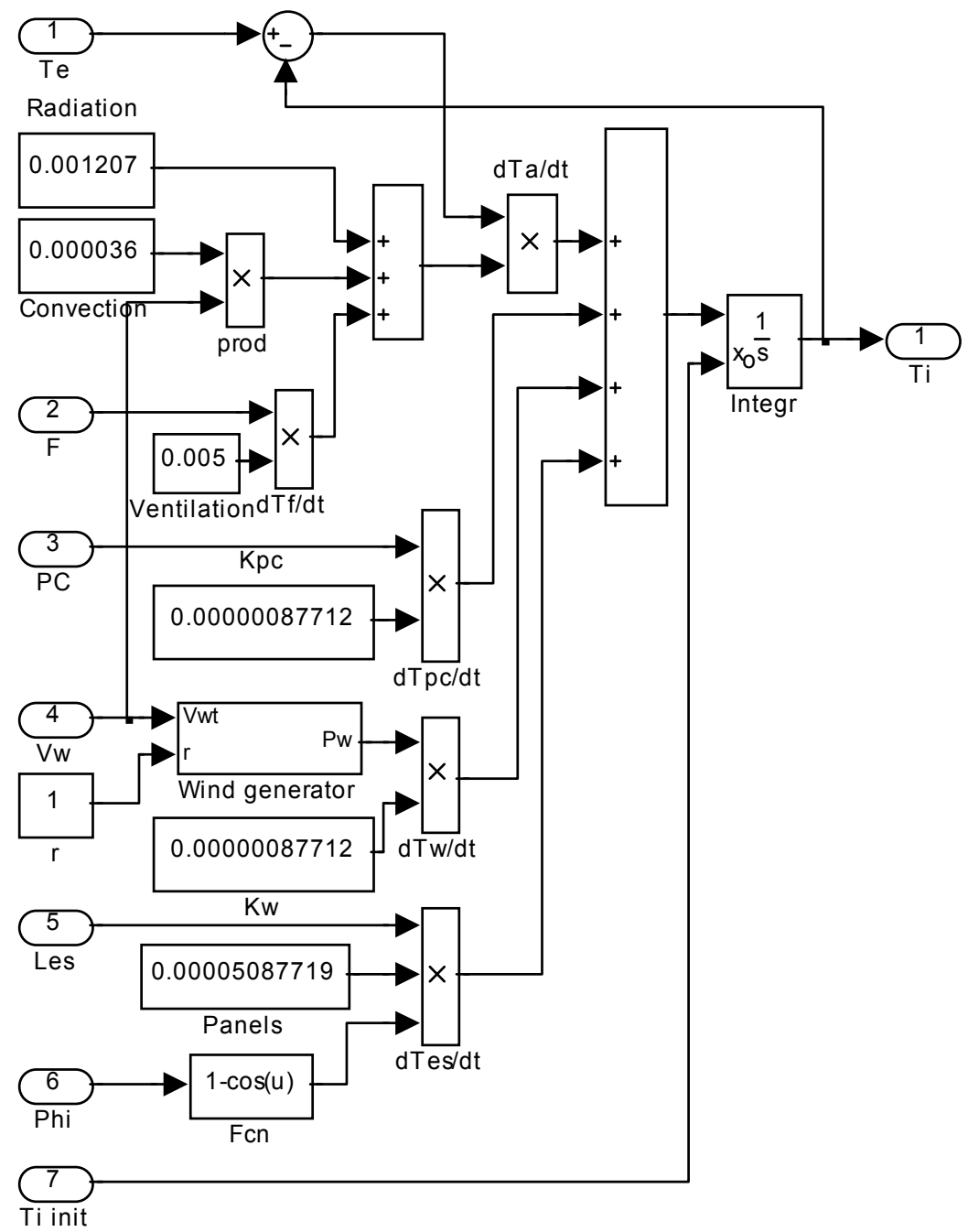

Fig. 7. The Simulink-Matlab implementation of the Passive Greenhouse model 
d. The equation of the greenhouse effect is:

$$
\frac{\mathrm{dT}_{\mathrm{ES}}(\mathrm{t})}{\mathrm{dt}}=\mathrm{k}_{\mathrm{ES}} \cdot \mathrm{L}_{\mathrm{S}}
$$

where $\mathrm{T}_{\mathrm{ES}}(\mathrm{t})$ is the temperature amount added by the sun, $\mathrm{k}_{\mathrm{ES}}\left[{ }^{0} \mathrm{C} \cdot \mathrm{m}^{2} \cdot \mathrm{s}^{-1} \cdot \mathrm{W}-1\right]$ the greenhouse effect coefficient and $\mathrm{L}_{S}\left[\mathrm{~W} / \mathrm{m}^{2}\right]$ the intensity of the solar radiation (Balas \& Balas, 2008a).

The coefficients $\mathrm{k}_{\mathrm{aR}}, \mathrm{k}_{\mathrm{aC}}, \mathrm{k}_{\mathrm{PC}}, \mathrm{k}_{\mathrm{W}}$ and $\mathrm{k}_{\mathrm{ES}}$ are tuned according to the results obtained in the previous papers concerning the Toulon greenhouse. For $\mathrm{k}_{\mathrm{V}}$ experimental data are missing so far and we use a plausible value. The numeric values of the parameters used for the simulations to find in the next section are the following:

$$
\left\{\begin{array}{l}
\mathrm{k}_{\mathrm{aR}}=0.001207 \mathrm{~s}^{-1} \\
\mathrm{k}_{\mathrm{aC}}=0.000036 \mathrm{~m}^{-1} \\
\mathrm{k}_{\mathrm{V}}=0.005 \mathrm{~m}^{-3} \\
\mathrm{k}_{\mathrm{PC}}=(250 \cdot 4560)^{-1}=0.87712 \cdot 10^{-6} \mathrm{~W} \cdot \mathrm{oC} \cdot \mathrm{s}^{-1} \\
\mathrm{k}_{\mathrm{W}}=(250 \cdot 4560)^{-1}=0.87712 \cdot 10^{-6} \mathrm{~W} \cdot \mathrm{c} \cdot \mathrm{s}^{-1} \\
\mathrm{k}_{\mathrm{ES}}=50.87719 \cdot 10^{-6} \mathrm{~m}^{2} \cdot \mathrm{oC} \cdot \mathrm{s}^{-1} \cdot \mathrm{W}^{-1}
\end{array}\right.
$$

The Simulink-Matlab implementation of the model is presented in Fig. 7.

\subsection{Direct applications of the model}

a. The assistance of the design and the optimization of the nominal parameters of the energy sources. The simulations are helping us to verify the sizing of the constructive components according to different simulation scenarios specified by the users.

Consider the following situation: we want to install a Passive Greenhouse identical to the Toulon experimental greenhouse in a region where the lowest winter temperature is $-20{ }^{\circ} \mathrm{C}$, the mean winter temperature is $0{ }^{\circ} \mathrm{C}$, and the mean wind speed is $5 \mathrm{~m} / \mathrm{s}$. Which heat pump should we choose if we want to keep a minimum $\mathrm{T}_{\mathrm{I}}$ of $10{ }^{\circ} \mathrm{C}$ ? A simulation for $\mathrm{T}_{\mathrm{E}}=-20{ }^{\circ} \mathrm{C}$, shows that we need $47 \mathrm{~kW}$ to stabilize $\mathrm{T}_{\mathrm{I}}$ at $10{ }^{\circ} \mathrm{C}$. The same simulation for $\mathrm{T}_{\mathrm{E}}=0{ }^{\circ} \mathrm{C}$ indicates only $16 \mathrm{~kW}$. Since the extreme temperatures are very seldom, we can choose a 16-20 $\mathrm{kW}$ heat pump and an emergency gas burning device.

b. A simulation performed over a certain time horizon, using the current input data, extrapolates instantly the current evolution of the system. This kind of predictors can help us to avoid the damaging of the crop (freezing or overheating) or to diagnose damaged walls.

Let us consider the following situation: $\mathrm{P}_{\mathrm{PC}}=15 \mathrm{~kW}, \mathrm{~T}_{\mathrm{E}}=0 \circ \mathrm{C}$, initial $\mathrm{T}_{\mathrm{I}}=20{ }^{\circ} \mathrm{C}$ and $\mathrm{L}_{\mathrm{S}}=10$ $\mathrm{W} / \mathrm{m}^{2}$ (a cold night, with no ventilation). We measure a $-0.02{ }^{\circ} \mathrm{C}$ decrease of the temperature per minute. A simulation over two hours starting with this input data is indicating that $\mathrm{T}_{\mathrm{I}}$ will stabilize at $8{ }^{\circ} \mathrm{C}$. If the greenhouse's crop consists for instance of tomatoes we can accept this situation, taking into account the fact that the plants can tolerate such short time cool periods. If we cultivate tropical flowers that are not tolerating low temperatures, we must take appropriate measures to avoid the damage, for instance to burn biogas until morning, when the sun will begin to heat the greenhouse. The power of the gas burner can be tuned as well with the help of the model.

Imagine now, that for the same conditions, the walls are damaged, resulting a $0.5 \mathrm{~m}^{3} / \mathrm{s}$ air flow. After two hours, $\mathrm{T}_{\mathrm{I}}$ would stabilize at $3.5{ }^{\circ} \mathrm{C}$ that is not tolerable. The decreasing of $\mathrm{T}_{\mathrm{I}}$ 
in $60 \mathrm{~s}$ is this case is $-0.056^{\circ} \mathrm{C}$. Since this value is significantly exceeding the normal $-0.02{ }^{\circ} \mathrm{C}$ decrease we are usually measuring in these conditions, we are able to diagnose the damaged walls after just one minute, and we can produce immediately the necessary interventions.

\section{The expert adaptive predictive control of the Passive Greenhouses}

Controlling the Passive Greenhouse is not a trivial task, because of the extremely slow action of its main energy source, the heat pump, comparing to a conventional energy source (Balas \& Duplaix, 2008d; Balas et al., 2009b). The control algorithm may cope with this strong inertial behavior only by strong predictive features. This kind of applications (highly nonlinear, demanding Artificial Intelligence elements, but with no strong accuracy constraints) may be conveniently treated with the expert control. The expert control is a control application involving expert systems. An expert system is a software that attempts to provide an answer to a problem the same way as a human expert would do it. An expert controller is essentially composed by a control rule base and an inference method. The control rules are elaborated by experts. If the control rules are modeled by fuzzy sets and the inference uses the fuzzy logic we obtain fuzzy expert systems. The fuzzy control was previously applied for the natural ventilated buildings (Dounis et al., 1996). The fundamental advantage of the intelligent control (fuzzy expert included) over the conventional/ optimal control is that the control rules may be formulated by experts in horticulture with absolutely no IT skills but having a deep understanding of the greenhouse system.

Our personal approach relies on the fuzzy-interpolative expert systems that may be implemented by look-up tables with linear interpolations, or with any other software or hardware interpolative networks (Koczi et al., 2005). Some of the control rules we used in our simulations for the Passive Greenhouse control may be linguistically described as follows:

1. IF outside is cold THEN the heat pump is turned ON (heating regime).

2. IF outside is cold AND inside is colder than desired THEN the ventilation is OFF.

3. IF outside is not cold AND inside is too warm THEN the ventilation is on.

4. IF the wind is strong AND the accumulator is not loaded THEN the wind turbine is loading the accumulator.

5. IF the accumulator is not loaded AND there is sun THEN the solar panels are ON.

6. IF the solar light is weak THEN the solar panels are OFF (let the light get to the plants).

7. IF outside is cold AND inside is cold AND the wind is strong THEN the wind turbine is directly heating the greenhouse. This is an emergency situation.

8. IF outside is cold AND inside is cold AND the accumulator is loaded THEN the accumulator is heating the greenhouse, etc.

Our simulations are clearly proving the efficiency of this approach, as the following case study is pointing (Balas \& Balas, 2008b). Consider a very bright day, when the greenhouse effect would produce overheating. Fig. 8 presents the Toulon experimental greenhouse data recorded between 7 a.m. and 19 p.m. in 2004.02.09. One observes that the internal temperature $T_{I}$ is reaching $38{ }^{\circ} \mathrm{C}$ while the external temperature $T_{E}$ is less than $22{ }^{\circ} \mathrm{C}$. We need to avoid overheating and to maintain $\mathrm{T}_{\mathrm{I}}$ around $20{ }^{\circ} \mathrm{C}$. We try to control $\mathrm{T}_{\mathrm{I}}$ by only two energetic passive control actions:

- The natural ventilation. We considered a typical $3 \mathrm{~m}^{3} / \mathrm{s}$ mean ventilated air flow that can be switched between two positions: ON and OFF.

- The shading of the plants. The orientable photovoltaic panels can be switched between two positions: $\mathrm{ON}$ when the plants are shaded and the panels are charging the accumu- 
lator and OFF when the panels are parallel to the solar radiation and the plants are in full light.
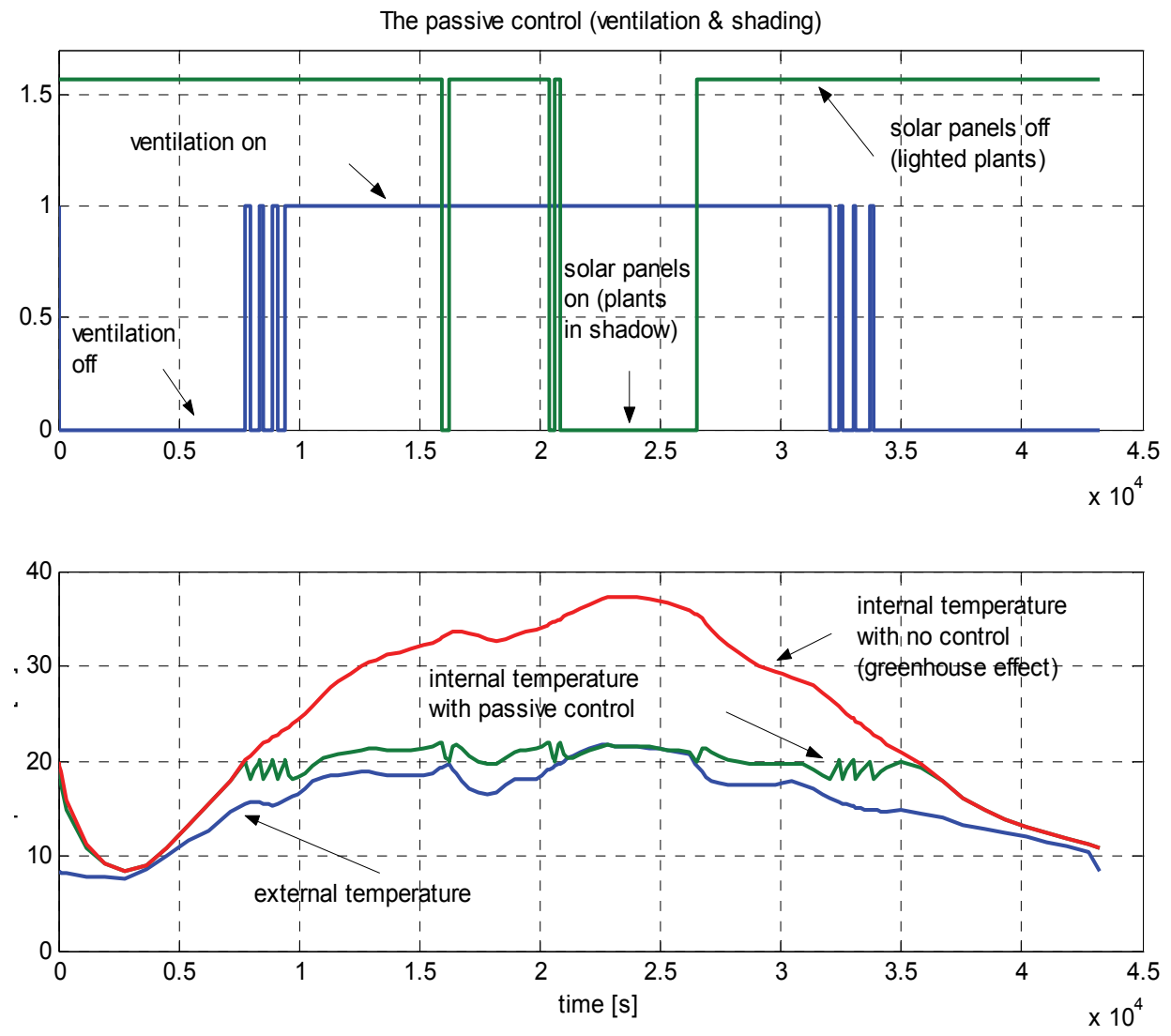

Fig. 8. Expert control performed by energetic passive actions: ventilation and shading

As shown in Fig. 8, our control problem can be easily solved, simply by setting appropriate numerical values at the fuzzyfication block of the controller.

During the first half of the day, when $\mathrm{T}_{\mathrm{E}}<20^{\circ} \mathrm{C}$, the natural ventilation is able by itself to cool the greenhouse. When $\mathrm{T}_{\mathrm{E}}$ is exceeding $20^{\circ} \mathrm{C}$ the shading of the plants interferes as well. For much higher external temperatures the intervention of the heat pump, in the cooling regime, becomes necessary. Meanwhile the solar panels are not just controlling the temperature but also charging the accumulator!

Due to the high flexibility and adaptivity of the expert control, other situations, even contradictory or needing predictive decisions, can be conveniently handled by the same controller. For example, if we are aware that during cold mornings the greenhouse is naturally heated by the rising sun, by a small number of appropriate rules we can save about $20 \%$ of the daily energy consumption. Such control rule clusters can be addressed to any operating regime.

A particular constraint that is associated with the Passive Greenhouse is the remote control and monitoring. We performed experimental tests with a general use Programmable Logic Controller, able to control a generic greenhouse, which was connected to an Internet Ethernet network, with excellent results. 


\section{Conclusions and future research}

This Chapter introduces the Passive Greenhouses, free of burned fuel energy and of conventional energetic infrastructures, and relying exclusively on renewable sustainable energies. We defined a generic Passive Greenhouse structure and proposed a corresponding mathematical model. This model adapts renewable energy sources (a cold water heat pump, a wind generator and a matrix of orientable photovoltaic panels) to a previous valid model of an experimental greenhouse, existing in Toulon.

Passive Greenhouses benefit of free energy and can be installed virtually anywhere we can find or build aquifers. They have the potential to reconvert a great deal of the existing agricultural terrains and give us the chance to ecologically reconstruct our environment.

This approach continues some existing concepts, as the Wageningen solar greenhouse, and relies exclusively on already existing renewable energy sources and technologies. The novel contribution of the work is the reconsideration of the solar greenhouse way of operating. Providing solar greenhouses with a sustainable aggregation of renewable energy sources they can become fully independent of any energy infrastructure.

The main technical difficulty to be coped is the extremely slow action of the heat pump. We can deal with this problem with the help of the expert adaptive predictive control, as our simulations are showing.

However the main obstacle against the Passive Greenhouses development is the high investment costs. We address this problem by optimizing the energy sources balance that can be performed by relevant simulations.

The Passive Greenhouses research project need a lot of future work:

- The refining of the mathematical model, applicable to any virtual or existing greenhouse;

- The development and the implementation of a comprehensive control algorithm;

- The study of the Internet remote monitoring and control of the greenhouse;

- The elaboration of a dedicated data base, with key information on Passive Greenhouses: materials, renewable energy sources (heat pumps, wind generators, photovoltaic solar panels) and accessories (accumulators, electronic converters), with technical data, prices and purchasing information;

- The elaboration of a design method able to optimize the investment costs;

- The implementation of a Internet site, containing our knowledge on greenhouses, a software able to assist a user at the dimensioning of its own Passive Greenhouse, tutorials, and other related information;

- The development of a Computer Aided Design application for greenhouses, etc.

Most of all, we need to build an experimental passive greenhouse!

\section{References}

Balas, M.M.; Cociuba, N. \& Musca, C. (2004). The energetic passive greenhouses. Analele Universitatii "Aurel Vlaicu" din Arad, pp. 524 - 529, Arad, 2004.

Balas, M.M. \& Balas V.E. (2008). Modeling Passive Greenhouses - The Sun's Influence. 12th IEEE International Conference on Intelligent Engineering Systems INES'08, pp. 71-75, Miami, 2008.

Balas, M.M.; Duplaix, J.; Bouchouicha, M. \& Balas, S.V. (2008). Modeling the Wind's Influence over the Heat Flow of the Greenhouses. Journal of Intelligent E Fuzzy Systems, Vol. 19, No. 1, pp. 29-40, 2008. 
Balas, V.E.; Balas, M.M. and Putin-Racovita, M.V. (2008). Passive Greenhouses and Ecological Reconstruction. 12th IEEE International Conference on Intelligent Engineering Systems INES'08, pp. 77-81, Miami, 2008.

Balas, M.M. \& Duplaix, J. (2008). Les serres passives et la reconstruction écologique. Conference Internationale Francophone d'Automatique CIFA'08. pp. 1289-1297, Bucharest, 2008.

Balas, M.M.; Balas, V.E.; Mnerie, C.; Falcan, O. \& Toader, D. (2009). A Sustainable Agricultural System for Our Future: The Passive Greenhouse. Proceedings of IEEE SOFA'09, pp. 233-238, Szeged-Arad, 2009.

Balas, M.M. \& Balas V.E. (2009). The Fuzzy Interpolative Control for Passive Greenhouses. In: Intelligent Systems and Technologies H.-N. Teodorescu, J. Watada, and L.C. Jain eds. Vol. 217, pp. 219-231, 2009.

Bellows, B. (2003). Solar greenhouses. ATTRA National Sustainable Agriculture Information Service, Fayetteville, North Carolina, 2003. http://www.attra.org/attrapub/solar-gh.html.

Bouchouicha, M.; Lafont, F. \& Balmat J.F. (2002). Neural networks, Fuzzy logic and Genetic algorithms for greenhouse identification. $2^{\text {nd }}$ International Conference - Tunisian Conference on Electro-Technical and Automatic Control JTEA, pp. 356-362, 2002.

Bradford, T. (2006). Solar Revolution: The Economic Transformation of the Global Energy Industry. MIT Press, Cambridge, Massachusetts, 2006.

Bialasiewicz, J.T. (2008). Renewable Energy Systems With Photovoltaic Power Generators: Operation and Modeling. IEEE Transactions on Industrial Electronics, Vol. 55, No. 7, pp. 2752-2758, 2008.

Dounis, A.I.; Bruant, M.; Santamouris, M.; Guaracino, G. \& Michel, P. (1996). Comparison of Conventional and Fuzzy Control of Indoor Air Quality in Buildings. Journal of Intelligent \& Fuzzy Systems, John Wiley \& Sons, Vol. 4, No. 2, pp. 131-140, 1996.

Dutch Government, (1999). Optimal adaptive control design for a solar greenhouse. Research Program on Ecology, Economy and Technology. 1999. http://www.onderzoekinformatie. nl/en/oi/nod/onderzoek/OND1298882/1999-2007.

Dutch Government, (1999). Solar Greenhouse Project. Research Program on Ecology, Economy and Technology. 1999. http:/nt1.aenf.wau.nl/mrs/Projects/SolarGreenhouse/index.html.

Horgos, A. (2003). Legumicultură specială. Ed. Agroprint, 2003,Timisoara.

IEC, (2006). Wind Energy Manual. Iowa Energy Center. http://www.energy.iastate.edu/Renewable/wind/wem/windpower.htm.

IPCC, (2007). Climate Change 2007: Synthesis Report. Contribution of Working Groups I, II and III to the Fourth Assessment Report of the Intergovernmental Panel on Climate Change. Pachauri, R.K \& Reisinger, A. eds. IPCC, Geneva, Switzerland, 2007.

Janick, J.; Paris H.S. \& Parrish D.C. (2007). The Cucurbits of Mediterranean Antiquity: Identification of Taxa from Ancient Images and Descriptions. Annals of Botany, Oxford University Press, doi:10.1093/aob/mcm242, 2007.

Koczy, L.T.; Balas, M.M.; Ciugudean, M.; Balas, V.E. \& Botzheim, J. (2005) On the Interpolative Side of the Fuzzy Sets. Proceedings of IEEE SOFA'05, pp. 17-23, Szeged-Arad, 2005.

Lafont, F. \& Balmat, J.F. (2001). Modélisation floue itérative d'une serre agricole. Actes des Rencontres Francophones sur la Logique Floue et ses Applications (LFA), pp. 281-288, 2001.

Mirecki, A.; Roboam, X. \& Richardeau, F. (2007), Architecture Complexity and Energy Efficiency of Small Wind Turbines. IEEE Transactions on Industrial Electronics, Vol. 54, No. 1, pp. 660-670, 2007. 
NREL, (2006). Wind Turbine Design Cost and Scaling Model. National Renewable Energy Laboratory. Technical Report NREL/TP-500-40566, 2006. http://www.nrel.gov/docs/fy07 osti/40566.pdf.

Olivier, C. (2001). Ground source heat pump in France in the residential. International Summer School on Direct Application of Geothermal Energy, 2001, Skopje. http://www.geothermie.de/tag-ungkongresse/vortrag-sprogramm_igd_2001.

van Ooteghem, R.J.C. (2007). Optimal Control Design for a Solar Greenhouse. Ph.D. thesis, Wageningen University, 2007. http://library.wur.nl/wda/dissertations/dis4110.pdf.

Pessel, N.; Duplaix, J.; Balmat, J.F. \& F. Lafont (2009), A Multi-structure Modeling Methodology. In: Soft Computing Based Modeling in Intelligent Systems and Technologies, Balas, V.E.; Fodor, J. \& Várkonyi-Kóczy, A.R. eds., Vol. 196, pp. 93-114, Springer, 2009.

Richel - Serres de France. www.richel.fr.

Schutz, S. et al. (2000). An insect-based BioFET as a bioelectronic nose. Sensors and Actuators B 65, pp. 291-295, Elsevier, 2000.

SECO, (2008). Small Wind Systems. State Energy Conservation Office. Texas. http://www.seco. cpa.state.tx.us/re_wind_smallwind.htm.

TerraViva, (2004). Watergy ${ }^{\circledR}$, a system for water treatment, building climate control and food production. http://www.terravivatec.com/eng/TVTProductsEng5001.html.

Tuzhilkina, V.V. (2006). Carbon dioxide exchange in the photosynthetic apparatus of trees in a mature spruce phytocenosis of the northern taiga subzone. Ekologiya, pp. 95-101, No. 2, 2006, Moscow.

Voican, V. \& Lacatus, V. (1998). Cultura in sere si solarii. Ed. Ceres, 1998, Bucharest. 


\title{
Decision Support for National Sustainable Energy Strategies in an Integrated Sustainability Assessment Framework
}

\author{
Erik Laes ${ }^{1,2}$ and Aviel Verbruggen ${ }^{2}$ \\ ${ }^{1}$ Flemish Institute for Technological Research (VITO), \\ ¿University of Antwerp (UA), \\ Belgium
}

\section{Introduction}

\subsection{A new context for knowledge production}

Though apparently very straightforward, each concept figuring in the title of this chapter is actually quite problematic considering the nature of contemporary energy system governance. First, the concept of 'decision support' seems to suggest that 'supporting' a decision can be delineated sharply from actually 'taking' a decision - with the first task being safely entrusted to 'scientists' who provide the 'facts' (i.e. the solid grounds) on which a decision is to be based; the second task belonging to 'decision makers' with authority, power and legitimacy to take decisions in pursuing 'societal values'. This mechanistic separation is to be rejected because value-based arguments and decisions inevitably enter the phase of constructing 'facts' (Latour, 2004), also in energy policy decision making (Kraus, 1987). Second, the aspect 'national' energy strategy is challenged by an increasingly globalised energy economy, a fortiori in many Western countries where energy markets are liberalising and responsibilities for energy system governance are moving up to international institutions, down to regional organisations, and/or out to non-state actors (Rhodes, 1996). Further, economic and governance activities impinging on energy system development are unstructured and complex and cannot be an object of calculation, management, or governance by any form of 'centralised' authority. Instead such practices are oriented to subsets of energy-economic relations that have been discursively and often organisationally and institutionally fixed as objects of intervention (Miller \& Rose, 1990). Third, 'integrated sustainability assessment' suggests a resemblance to 'environmental impact assessment'. Although the latter is a streamlined procedure imposed in many jurisdictions on the development of energy infrastructures (Petts, 1999), the former still remains ambiguous and contested. A coherent body of knowledge and/or practical guidance are still missing (Jordan, 2008).

No component of 'decision support for national sustainable energy strategies in an integrated sustainability assessment framework' is readily available. This challenges policy makers and analysts alike, because our energy systems must evolve to a more 
sustainable direction. This necessitates reliable assessment tools for monitoring progress and commanding the 'best available science'. Even with the nation state's steering capacities in energy policy diminishing since the 1960/70s, national states remain critical actors in international negotiations on climate and energy policy (Lesage et al., 2010), and key sites of political accountability and public legitimacy (Gamble, 2000). 'Decision support for national sustainable energy strategies in an integrated sustainability assessment framework' is an important issue, but the key components require rephrasing as follows:

- 'Scientific decision support' is necessary for providing explanatory knowledge about energy systems - i.e. knowledge about socio-economic activities, future demand for energy services, energy supply and demand technologies and the resulting impacts. But such knowledge cannot be considered as 'objectively given'; it should be 'negotiated' in the course of the sustainability assessment process. In addition to traditional objective selectors for explanatory knowledge like controllability, reproducibility and nonambiguity, subjective and inter-subjective selection criteria have to be made explicit (for playing a role). The latter criteria refer to the suitability of knowledge to be internalised by individuals (criteria like utility, simplicity, etc.). They also refer to the degree of acceptance of an idea within a group (criteria like collective utility, expressiveness, authority of the knowledge source, etc.);

- In the likely absence of a generally accepted blueprint for a sustainable energy system, formulation of national sustainable energy strategies must emerge from interactive and inclusive processes of social dialogue and reflection. The processes are guided by orientation knowledge of justification arguments used by different (sets of) stakeholders;

- Integrated sustainability assessment is not only a scientific methodology, but also a 'value-articulating institution' (Stagl, 2009). Because (sustainability) valuation methods determine inter alia who participates in the valuation process, how they participate and in what capacity (e.g. as citizen, consumer, expert, stakeholder), what counts as trustworthy data, and which data processing and aggregation procedures are used, the outcomes of such methods go beyond a rational selection of the 'best possible option' in two senses. First, outcomes are influenced by how participants are invited to contribute to the valuation, information is provided and questions are stated. Different stakeholders may exhibit different 'rational choices' in a given situation, and there are no neutral grounds to identify the 'best option'. Second, the outcomes of valuation processes can actually influence the behaviour of those participating in the valuation. In this sense, valuation processes (such as integrated sustainability assessment) can be regarded as institutions. Therefore, sustainability assessment methods also need to be reflexive and sensitive to the processes of knowledge production. Society and policy makers not only need action-guiding knowledge, but also need to develop an awareness of how to interpret knowledge including the inevitable uncertainties. Reflexivity should extend to the functioning of 'traditional' decision support tools (such as energy system models, multi-criteria decision aiding techniques, or cost-benefit analysis) in an institutionally-anchored sustainability assessment framework. Reflexive governance will also create a better understanding of the nation state's role in devising sustainable energy strategies. 


\subsection{The SEPIA project}

This chapter presents reflections on an innovative national energy policy decision support architecture based on experiences gained from the SEPIA project ${ }^{1}$. SEPIA investigates decision support methodologies, procedures, structures and tools for a sustainable energy policy with a focus on stakeholder involvement. It combines participatory fuzzy-set multicriteria analysis with narrative scenario building and (quantitative) energy system modelling using the LEAP model ${ }^{2}$. The goal of SEPIA is to develop and discuss the feasibility of the main components of sustainability assessment in the Belgian energy policy context. Identifying elements of consensus and of dissent across stakeholder groups about possible designs of sustainability assessment provides a basis for an sustainability assessment procedure adapted to the Belgian energy governance, particularly embedded in a multi-level governance structure. SEPIA explicitly acknowledges socio-political and normative backgrounds of participants in the debate on energy issues and choices, including sustainable energy.

The project encompasses 4 phases, running over three years (Jan. 2008 - Dec. 2010): i) methodological reflections on sustainability assessment (Jan. 2008 - June 2008); ii) participatory construction of long-term sustainable energy futures and a value tree including sustainability criteria (July 2008 - June 2009); iii) deliberation on these futures with the aid of a fuzzy-set multi-criteria decision support tool (July 2009 - June 2010); and iv) reporting and dissemination of results (July 2010 - Dec. 2010). Sustainability assessment of long-term energy scenarios using qualitative and quantitative data and multi-criteria decision tools requires both a 'holistic' and a 'partial' assessment (i.e. an assessment of both the 'whole picture' presented by a scenario storyline as well as the different dimensions of sustainability). Also stakeholders must accept the assessment as methodologically sound and legitimate. Since SEPIA is still ongoing at the time of writing this contribution, we cannot present definite results. This chapter discusses from a conceptual and methodological perspective the challenges in providing explanatory, orientation and reflexive knowledge in a new context of knowledge production. We proceed from an overview of the 'state-of-the-art' of sustainability assessments (Section 2.1), (energy) foresight (Section 2.2) and multi-criteria analysis (Section 2.3). Next, we show how SEPIA combines the three domains by a detailed account of the methodological choices made in the course of the project (Section 3). The chapter ends with conclusions and observations and offers reflections on future research needs (Section 4).

\footnotetext{
${ }^{1}$ SEPIA stands for 'Sustainable Energy Policy - Integrated Assessment'. The SEPIA project is carried out by 5 partners: the University of Antwerp (UA, acting as the co-ordinator), the Free University of Brussels (VUB), the University of Liège (ULg), the Flemish Institute for Technological Research (VITO) and the Belgian nuclear research centre $(\mathrm{SCK} \cdot \mathrm{CEN})$. It is funded by the Belgian office of science policy. Further details can be found at the project website <www.ua.ac.be/sepia>.

2 LEAP stands for 'Long range Energy Alternatives Planning system'. LEAP is an integrated modelling tool that is used to track energy consumption, production and resource extraction in all sectors of an energy economy. More information on LEAP is available at <www.sei-international.org/leap-the-longrange-energy-alternatives-planning-system $>$.
} 


\section{Methods for strategic decision making on sustainable energy development}

\subsection{Integrated sustainability assessment \\ 2.1.1 Planning, networking and 'futuring'}

Integrated assessment in the context of sustainability is necessarily predicated (to a greater or lesser extent) on 'foresight' abilities, i.e. of thinking, shaping or debating the future. This is quite clear on an intuitive level: despite the obvious uncertainties inherent in any attempt at 'foreseeing' the future, some form of future anticipation is simply implied in human decision making of all sorts, as is evident in associated notions of intentionality, accountability, responsibility, etc. which are all necessarily predicated on assumptions of a (certain degree of) anticipation. More specifically, according to Meadowcroft (1997: 429-431) foresight in integrated sustainability assessment relates to a mix of planning, networking, and futuring activities:

- Planning is needed because it is generally assumed that sustainable development (in any field) is unlikely to be achieved by spontaneous social processes, or as the 'unintended consequences' of seeking other ends (e.g. maximising profits in markets). Therefore, sustainable development requires the explicit attention and intervention of some 'governing agency'. The foresight component of planning relates to exploring possible futures or developing visions for the future, identifying possible impacts of certain policy measures, testing the robustness of policy measures under different imaginable futures, etc.;

- Networking is needed because governments alone cannot bring about the sweeping changes needed for a (more) sustainable development, but depend on a host of other actors (e.g. business, labour unions, NGOs, the media, etc.) (cf. Section 1.1). The foresight component of networking relates to deepening dialogue on problem framings, mapping different problem definitions and checking for societal support, looking for future possibilities to surpass or reconcile conflicting views, etc.;

- $\quad$ Futuring (defined as the ensemble of methodologies or support tools to help reflecting on the future) is needed because the realisation of sustainable development requires 'methodological attitudes' to deal with an uncertain future, since governments must act in a consistent way over time to realise policy objectives.

Integrated sustainability assessment involves different types of knowledge flows within each activity and across activities, therefore different types of information, audiences and processes are expected, as illustrated in the next section (Section 2.2).

\subsection{2 'Policy as calculus' and 'Policy as discourse'}

The different approaches to integrated sustainability assessment can be illustrated further by situating them within the wider governance framework in which these assessment processes play a role. Paredis et al. (2006) make a useful distinction between two idealtypical governance 'styles' - called respectively "Policy as calculus" and "Policy as calculus". These "styles' illustrate the two extremes of a spectrum of choices available to policy makers interested in setting up governance mechanisms for sustainability. They see sustainable development as a wider process of change engaging with an entire network of (policy, commercial, civil society, etc.) actors, institutions, technical artefacts, etc. However, both perspectives differ in the way they approach the generation of strategic (i.e. explanatory, orientation and reflexive) knowledge needed for steering this change process in the direction of a sustainable future. Put very briefly, 'Policy as calculus' represents a 
'closed' process heavily predicated on expert input and agreement, whereas 'Policy as discourse' 'opens up' to a wider range of actors, disciplines and concerns. Both perspectives are compared on a number of attributes in Table 1. A SWOT analysis is made in Table 2.

"Policy as calculus" assumes that knowledge-based decision support - and the decision processes built on this support - can be conceptualised separately from its 'socio-technical object' (e.g. the energy system). For recommending how to steer socio-technical change in more sustainable directions, expert analysts should 'step outside' the system to objectify its workings. Governance is characterised in terms of exogenous 'mechanistic' interventions. In all of this, an important role is attributed to 'expert input'. This does not exclude stakeholder involvement for providing 'inputs' to the assessment process. But separate stakeholders are assumed of holding a 'jigsaw puzzle' piece that experts collect and layout to compose a picture of the 'socio-technical object'. As such stakeholders are no more than 'carriers' of policy alternatives, information, and value judgements. It is assumed that all stakeholders observe 'the same' object, but they each tend to prioritise or focus on a limited set of aspects related to this object. Once the relevant pieces of the puzzle are collected (i.e. e.g. objectives are clearly defined and agreed upon, all necessary data are available, cause-effect relations are established, etc.), the 'solution' to the governance problem follows 'logically' from aggregating the different perspectives by using for example economic optimisation models, multi-attribute utility theory, etc. The appraisal process 'closes down' on the single socio-technical object - i.e. it is about "...finding the right questions, recruiting the appropriate actors (actors with 'relevant' insights), highlighting the most likely outcomes and therefore also defining the best options..." (Smith \& Stirling, 2007: 6). Once the appraisal procedure has aggregated all relevant information, the instruments for intervening in the dynamics of socio-technical objects follow mechanically (e.g. when economic evaluation finds nuclear power as 'best option' policy instruments must clear the 'barriers' of a full nuclear deployment). Politically this approach implies that 'relevant actors' bring their commitments in line with the recommendations from the appraisal. The alignment job is left to the political decision makers, in devising appropriate tools to persuade, entice or simply force actors to realize the path set out by 'the experts'.

\begin{tabular}{|l|l|l|}
\hline & \multicolumn{1}{|c|}{ Policy as calculus } & \multicolumn{1}{c|}{ Policy as discourse } \\
\hline $\begin{array}{l}\text { Role of sustainability } \\
\text { assessment }\end{array}$ & $\begin{array}{l}\text { Sustainability assessment as a } \\
\text { tool for selecting the best } \\
\text { alternatives in order to reduce } \\
\text { negative sustainability } \\
\text { impacts }\end{array}$ & $\begin{array}{l}\text { Sustainability assessment as a } \\
\text { framing process of deliberation on } \\
\text { ends and means }\end{array}$ \\
\hline $\begin{array}{l}\text { What matters for } \\
\text { political planning? }\end{array}$ & $\begin{array}{l}\text { Uniform solutions based on } \\
\text { technical and economic } \\
\text { expertise }\end{array}$ & $\begin{array}{l}\text { 'Framings', deliberation, } \\
\text { perspective-based testing of } \\
\text { hypotheses involving a wide range } \\
\text { of disciplines (including but not } \\
\text { limited to economics and } \\
\text { engineering) }\end{array}$ \\
\hline $\begin{array}{l}\text { Leading actors } \\
\text { (networking)? }\end{array}$ & $\begin{array}{l}\text { Context-dependent, with a } \\
\text { focus on academics (with } \\
\text { demonstrable expertise in the } \\
\text { relevant scientific disciplines) } \\
\text { and government actors }\end{array}$ & $\begin{array}{l}\text { Context-dependent, with a focus on } \\
\text { experts (e.g. academics, } \\
\text { professionals with experience in } \\
\text { relevant fields, etc.), stakeholders } \\
\text { (representative of the different }\end{array}$ \\
'problem framings'), and \\
government actors
\end{tabular}




\begin{tabular}{|c|c|c|}
\hline Foresight methods? & $\begin{array}{l}\text { Mostly quantitative (i.e. } \\
\text { modelling), explorative trend } \\
\text { analysis (based on 'what if' } \\
\text { reasoning) } \\
\text { Government actors and/or } \\
\text { stakeholders as 'clients' }\end{array}$ & $\begin{array}{l}\text { Mostly qualitative (i.e. sociological) } \\
\text { analysis (based on 'what is } \\
\text { desirable' reasoning) with } \\
\text { quantitative analysis as a support } \\
\text { Government actors and/or } \\
\text { stakeholders providing crucial } \\
\text { inputs }\end{array}$ \\
\hline $\begin{array}{l}\text { Methods and tools } \\
\text { (futuring, planning, } \\
\text { networking) }\end{array}$ & $\begin{array}{l}\text { 'Standard' scientific methods, } \\
\text { e.g. mathematical models, } \\
\text { cost-benefit analysis, cost- } \\
\text { effectiveness analysis, } \\
\text { checklists, matrices }\end{array}$ & $\begin{array}{l}\text { Deliberative methods (e.g. scenario } \\
\text { workshops, expert panels, focus } \\
\text { groups, etc.) with 'standard' } \\
\text { scientific methods as supportive }\end{array}$ \\
\hline What is maximised? & $\begin{array}{l}\text { Planning - i.e. simple anwers } \\
\text { to complex problems, clear- } \\
\text { cut recommendations about } \\
\text { specific proposals }\end{array}$ & $\begin{array}{l}\text { Networking - i.e. interdisciplinary } \\
\text { scientific knowledge, participation, } \\
\text { deliberation, individual and societal } \\
\text { learning effects }\end{array}$ \\
\hline $\begin{array}{l}\text { Procedurally } \\
\text { effective if... }\end{array}$ & $\begin{array}{l}\text { The optimal alternative has } \\
\text { been identified } \\
\text { Trade-offs are based on } \\
\text { scientifically tested } \\
\text { methodologies } \\
\text { The proposal is of better } \\
\text { quality (in the sense that } \\
\text { negative impacts are avoided } \\
\text { or mitigated) after the } \\
\text { realisation of the assessment }\end{array}$ & $\begin{array}{l}\text { Ideally, the deliberative process } \\
\text { produces consensus by actually } \\
\text { changing minds through reasoned } \\
\text { argument } \\
\text { A political community has been } \\
\text { created around an issue } \\
\text { Decision-making culture and } \\
\text { practice have changed } \\
\text { Sustainability assessment is iterative } \\
\text { and fully integrated within the } \\
\text { policy process, giving adequate and } \\
\text { timely inputs to policy formation } \\
\text { Transformative effect - acceptance } \\
\text { of new goals and guiding principles } \\
\text { for the energy transition }\end{array}$ \\
\hline $\begin{array}{l}\text { Procedurally } \\
\text { efficient if... }\end{array}$ & $\begin{array}{l}\text { A solution is found with } \\
\text { minimum expenditure of } \\
\text { available resources (time, } \\
\text { money) and expertise (state- } \\
\text { of-the-art knowledge) for the } \\
\text { sustainability assessment }\end{array}$ & $\begin{array}{l}\text { The sustainability assessment is } \\
\text { carried out according to a clear and } \\
\text { achievable timetable, giving enough } \\
\text { time and resources for preparation } \\
\text { of the process and stakeholder } \\
\text { engagement }\end{array}$ \\
\hline Procedurally fair if... & $\begin{array}{l}\text { The recommended } \\
\text { alternative(s) are justified by } \\
\text { established expert authority, } \\
\text { e.g. accredited research } \\
\text { institutes, peer review, } \\
\text { lauded academics, etc. }\end{array}$ & $\begin{array}{l}\text { No legitimate point of view is } \\
\text { excluded a priori from the } \\
\text { assessment } \\
\text { Power differentials between social } \\
\text { actors are neutralised }\end{array}$ \\
\hline
\end{tabular}

Table 1. Two different views on governance for sustainability (based on Paredis et al., 2006; Smith \& Stirling, 2007) 


\begin{tabular}{|c|c|c|}
\hline & Policy as calculus & Policy as discourse \\
\hline Strengths & $\begin{array}{l}\text { Practical instrument resulting in } \\
\text { univocal recommendations from } \\
\text { a 'narrow' framing perspective } \\
\text { Part of the existing decision- } \\
\text { making process in many } \\
\text { countries }\end{array}$ & $\begin{array}{l}\text { Sustainability raised as a } \\
\text { collective concern } \\
\text { Improved decision-making } \\
\text { process }\end{array}$ \\
\hline Opportunities & $\begin{array}{l}\text { Political demand for this kind of } \\
\text { exercises } \\
\text { Use of existing knowledge and } \\
\text { know-how } \\
\text { Practical experience with similar } \\
\text { exercises (Environmental Impact } \\
\text { Assessment, Regulatory Impact } \\
\text { Assessment) }\end{array}$ & $\begin{array}{l}\text { Can build on existing } \\
\text { participatory arrangements } \\
\text { Scientific and political } \\
\text { momentum in favour of } \\
\text { sustainable development; } \\
\text { acceleration of global change } \\
\text { signals calls for ambitious } \\
\text { action }\end{array}$ \\
\hline Weaknesses & $\begin{array}{l}\text { Attempt to include all aspects of } \\
\text { sustainability in quantitative } \\
\text { models faced with difficulties: } \\
\text { unavailable data, uncertainties, } \\
\text { etc. } \\
\text { Environmental, governance and } \\
\text { equity concerns are marginalised } \\
\text { Acceptance of unlimited } \\
\text { substitutability implies 'weak } \\
\text { sustainability' }\end{array}$ & $\begin{array}{l}\text { Representativeness of involved } \\
\text { and missing stakeholders } \\
\text { Potential to yield practical } \\
\text { recommendations in due time } \\
\text { Difficult to institutionalise } \\
\text { Additional (and } \\
\text { multidisciplinary) expertise, } \\
\text { data, tools and time required } \\
\text { compared to 'policy as calculus' }\end{array}$ \\
\hline Threats & $\begin{array}{l}\text { Technocracy and bureaucracy } \\
\text { Reductionist perspectives are } \\
\text { encouraged } \\
\text { Risk of imbalance towards } \\
\text { incremental approaches and } \\
\text { consequent marginalisation of } \\
\text { long-term sustainable } \\
\text { development objectives }\end{array}$ & $\begin{array}{l}\text { Lack of practical experience in } \\
\text { conducting sustainability } \\
\text { assessment exercises, leading to } \\
\text { unrealistic expectations } \\
\text { Manipulative interventions by } \\
\text { some participants, eventually } \\
\text { ending in demagogy } \\
\text { Resistance against potentially } \\
\text { transformative power of the } \\
\text { sustainability assessment }\end{array}$ \\
\hline
\end{tabular}

Table 2. SWOT of 'Policy as calculus' and 'Policy as discourse'

"Policy as calculus" starts from the premise that there is no unique 'objectively rational' position from which a 'socio-technical object' (e.g. the energy system) can be observed. System boundaries, interrelations between system components, opinions on what causes change, etc. (in short: 'framings') vary according actor perspectives, and may change during various stages of the appraisal. Because different 'framings' imply different methodologies for arriving at 'relevant' knowledge about the 'socio-technical object', input to the sustainability assessment cannot be 'imposed' but has to be negotiated. The same applies for the criteria guiding the 
sustainability assessment, which have to be checked for legitimacy and acceptance. Assessment does not identify the 'best possible' pathway for the evolution of the 'sociotechnical object', but rather tests its evolution under the different 'framings' brought to the table by stakeholders. As a consequence, no unique set of ideal policy instruments can be identified; recommendations will always be much more 'conditional' (e.g. 'option $x$ is the preferred option under framings $a$ and $b$, but does not score well under framing $c$ ', 'option $y$ scores rather well under all framings, and can therefore be considered as a robust option', etc.).

The difference between 'policy as calculus' and 'policy as discourse' should not be conceived along the lines of a stark dichotomy between "...established, narrow, rigid, quantitative, opaque, exclusive, expert-based, analytic procedures tending to privilege economic considerations and incumbent interests..." and the "...new, relatively unconstrained, qualitative, sensitive, inclusive, transparent, deliberative, democratically legitimate, participatory processes promising greater emphasis on otherwise marginal issues and interests such as the environment, health, and fairness..." (Stirling, 2008: 267). To support this point of view, Stirling points out some examples of 'bottom-up participatory initiatives' by design which in their practical implementation and outcomes are better understood as 'top-down exercises in legitimation', and conversely also of 'expert-based analytic processes' which are more conducive to enhanced social agency than their participatory counterparts. In other words, according to Stirling (2008) the detailed context and implementation of a particular governance approach are more important factors to understand what happens in practice. Instead of an illustration of the opposition between an 'expert-based' and a 'deliberative' governance approach, the difference between 'policy as calculus' and 'policy as discourse' should be seen as illustration of how assessments and/or commitments can be 'closed down' (in the case of 'policy as calculus') or 'opened up' (in the case of 'policy as discourse') in an institutional environment which is structured and pervaded by power relationships. If appraisal is about 'closing down' the formation of commitments to policy instruments or technological options, then the aim of the assessment is to assist policy makers by providing a direct means to justify their choices. If, on the other hand, the assessment is aimed at 'opening up' a process of social choice, then the emphasis lies on revealing to the wider policy discourse any inherent indeterminacies, contingencies or capacities for action. Of course, expert-based analytic approaches such as cost-benefit or cost-effectiveness assessment are frequently practiced as part of a 'policy as calculus' approach, but these techniques might equally lend themselves to an 'opening up' philosophy (Stagl, 2009).

In order to define adequately which features of both 'philosophies' SEPIA adopts, a thorough analysis of the existing energy policy context and the institutional landscape is a prerequisite. In practice, the dominant approach in Belgium to decision support in energy policy has followed more or less the 'policy as calculus' philosophy. Therefore, we consider there is both in academic discussion as in policy practice some scope for a more symmetrical interest in processes for 'opening up' the debate on long-term sustainable energy strategies. SEPIA had to find an adequate balance between moment of 'opening up' and 'closing down' assessments, and choose the appropriate methods accordingly. These methodological choices are explained further in section 3.

\subsection{Foresight methodology}

The term 'futuring' (section 2.1.1) refers to the ensemble of scientific tools used to support foresight, for example forecasting techniques, envisioning workshops, modelling tools, 
brainstorming sessions, etc. Broadly speaking, futuring activities aim at deliberate and systematic thinking, debating or shaping of the future. In practice, futuring approaches come in many different shapes and forms (van Notten et al., 2003). A first distinction is between predicting and exploring the future. Earlier attempts at forecasting (prediction) have proven to be largely unsuccessful (particularly in the case of long-term energy foresight) and are increasingly being abandoned by foresight practitioners - although expectations of correct prediction on the part of policy makers are still apparent. Next, there is the difference between quantitative (modelling) and qualitative (narrative) traditions with the former prevailing in the field of energy. Hybrid approaches combine narrative scenario development with quantitative modelling. Also are distinguished descriptive or exploratory futuring approaches describing possible developments starting from what is known about current conditions and trends, from normative, anticipatory or backcasting approaches constructing scenario pathways to a desirable future. Neither approach is 'value free', since both embody extra-scientific judgments, for example about 'reasonable' assumptions. But the objectives of the scenario development exercise determine the choice between exploratory and anticipatory approaches. Exploratory (or 'what-if') analysis articulates different plausible future outcomes, and explores their consequences. Prioritising technological choices, technical and economic experts perform the analysis in a relatively closed process, with government actors mostly assuming the role of client (they 'order' the analysis). Anticipatory scenarios represent organised attempts at evaluating the feasibility and consequences of achieving certain desired outcomes or avoiding undesirable ones. Finally, trend scenarios based on extrapolations of (perceived) dominant trends, differ from peripheral scenarios focusing on unexpected developments and genuine 'surprising' events. Several choices on the suitable foresight methodology are to be made. The SEPIA choices are elucidated in section 3.1.

\subsection{Multi-criteria decision support}

The multi-dimensional nature of sustainability imposes that public plans or strategic decisions are evaluated with procedures explicitly integrating a broad set of (possibly conflicting) points of view. Hence, multi-criteria evaluation is a most appropriate decision framework (Kowalski et al., 2009). A variety of multi-criteria decision support tools can be used in sustainability assessments under both the 'policy as discourse' and the 'policy as calculus' philosophy. Each analysis method is based on specific assumptions and supports only a certain type of analysis. The preference for one particular tool must follow from its fitness for the problem characteristics and the desired scope/features of analysis. A promising start for reflection on the application of multi-criteria decision support in sustainability assessment is provided by Munda (2004) and Granat and Makowski (2006). For complex decision-making problems Munda (2004) developed the 'social multi-criteria evaluation' technique, applied to wind farm location problems by Gamboa \& Munda(2007). Granat and Makowski (2006) find as required properties of a multi-criteria decision analysis tool for a stakeholder evaluation of energy technologies and scenarios at the European level:

- the multi-criteria method can handle criterion scores of a different nature ('crisp' scores, stochastic scores, 'fuzzy' scores, etc.);

- in general, simplicity is a very desirable characteristic of the multi-criteria decision process - i.e. the number of ad hoc parameters used should be limited (preferably only information on weights and on scores should be used as exogenous inputs); 
- criterion weights should be seen as 'importance coefficients' (and not as numerical values allowing for full compensability between criteria or as indicators of a 'trade-off' between different criteria);

- information on all possible rankings for each actor should be given (and not only on the 'optimal' one, since taking into account second-best or third-best options can reveal a space for compromise solutions compared with other actors' rankings);

- the multi-criteria appraisal should include a 'conflict analysis' (i.e. an analysis of the 'distance' between the different actor perspectives, revealing possible groupings into major 'world-views'). As win-win situations are not always achievable, some trade-offs will have to be made. These trade-offs will then appear in the discussions on values stimulated by the use of the multi-criteria appraisal and will give normative input to consequences of selecting one alternative over another. Mathematical models can then be of assistance in the selection of the most consensual alternative, regroup alternatives according to the results of the conflict analysis, etc.

Section 3.2 gives more details on the SEPIA approach.

\section{Towards an integrated sustainability assessment for devising sustainable energy strategies: the Belgian case}

\subsection{Foresight methodology}

Corresponding to SEPIA's 'opening up' logic, the foresight methodology explicitly acknowledges the possibility of different 'framings' of the energy system (the 'sociotechnical object' under consideration) and of the factors that cause long-term changes in this system. Narrative scenario-building is particularly well-suited for 'opening up' the system description to, and for exploration of, fundamental complexities and uncertainties (Bunn \& Salo, 1993). The construction of scenarios for exploring alternative future developments under a set of assumed 'driving forces' has a long tradition in strategic decision making, especially in the context of energy policy (Kowalski et al., 2009). Exploratory scenariobuilding is criticised for its propensity to limit the space of the possible to only a few probable 'storylines' (Granger Morgan \& Keith, 2008). The backcasting approach is more suited for long-term and complex problems - such as sustainable development - requiring solutions which shift society away from business-as-usual trends. Backcasting is however often criticised for defining utopian futures with little value for decision makers in the 'real world'.

For combining the strengths of explorative and (traditional) backcasting methodologies SEPIA developed a 'hybrid backcasting' approach. 'Traditional' backcasting starts from future visions - i.e. a quantitative and qualitative interpretation of a 'sustainable energy system' in 2050. From this, we worked backwards to define the pathway that links the 'here and now' (i.e. the energy system in 2009-2010) to the 'there and then' (i.e. the energy system in 2050). Pathways were built with rather traditional scenario-building methods. A 'scenario' resulted from the combination of a vision and a pathway.

Scenario building (following a hybrid backcasting approach) takes place starting from a systematic exploration of futures, by studying many combinations resulting from the breakdown of the energy system. The process of 'breaking down' the system implies the definition of a set of factors, which could each influence the development of the energy system into different directions. These possible developments are formulated as 'hypotheses' or 'possible configurations'. The total number of combinations represents a 
'morphological space', which must then be reduced to a number of coherent sets by formulating transition conditions ('exclusions' and 'compromises') congruent with reaching the sustainability visions. For this process, we proceeded in a number of separate steps (cf. Fig. 1). These steps are explained in sections 3.1.1 - 3.1.6. The scenario-building phase relied on qualitative in-depth deliberative workshops with the scenario builders group (SBG), and the SEPIA team acting as 'scientific secretariat', delivering input materials for the workshops (e.g. information sheets) and processing the outcomes. Scenarios were reviewed by the stakeholder panel (SHP).

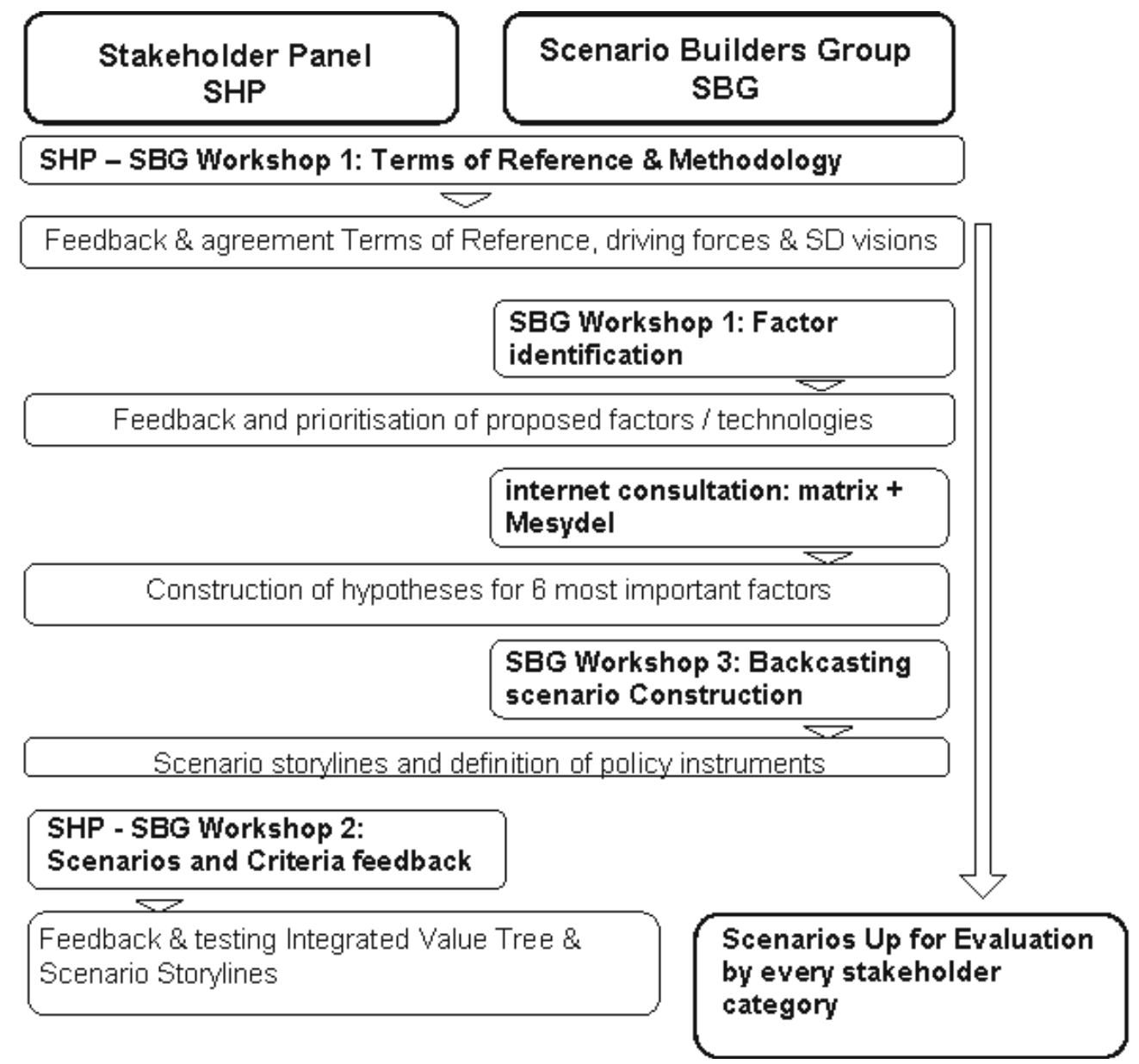

Fig. 1. Scenario-building steps in the context of the SEPIA project

Social mapping was used for composing the SBG and SHP groups respecting the following criteria:

- $\quad$ Scenario Builders Group (SBG): The SBG is responsible for developing the long-term energy scenarios describing the different possible visions on a sustainable energy future (horizon 2050) and the pathways (including policy instruments) needed to realise those visions. We expected from each participant to contribute their expertise and personal experience to the discussions. The Scenario Builders were asked to participate on 
personal title and not as a representative of the organisation in which they are active. The participants were generally willing to engage in an open, creative, non-judgemental foresight process. Members of the SBG are contacted by the SEPIA team and submitted for approval to the steering committee.

- $\quad$ Stakeholder Panel (SHP): The SHP is mainly responsible for evaluating the long-term energy scenarios developed by the SBG; though they will also be given an important role in setting the general directions for these scenarios and providing feedback on scenario assumptions before the LEAP-modelling will take place. This group aims to be representative of the 'stakes' in the Belgian energy sector. Therefore, it was important to ensure that all the potential social groups with a current or potential interest in the problem had the possibility of being included in the process. When deciding on the composition of groups taking part in participative processes, inclusiveness refers to ideas of representativeness, although not in a statistical sense. Rather, participants should be selected to represent constituencies that are known to have diverse and, especially, opposing interests. No stakeholder group should be composed of a preponderance of representatives who are known to have a similar position or who have already formed an alliance for common purpose. In the case of experts - who are presumed not to have constituencies but ideas - they should be chosen to represent whatever differing theories or paradigms may exist with regard to a particular task.

\subsubsection{SHP-SBG workshop_1: Terms of reference \& methodology}

It is clear that before starting to formulate sustainable energy strategies, policy makers and/or relevant stakeholder groups will already have some general ideas about the possible alternative solutions. Before entering the multi-criteria assessment phase (in which a decision about the significance of the possible impacts of the alternatives in terms of furthering the sustainable development agenda has to be made), these general ideas will already have to be worked out to a greater level of detail. It is only as a result of the detailed 'scoping' of the sustainability assessment that the decision alternatives will take on their definitive shape - that is, the 'scoping' provides the necessary consensual ground rules for deciding what counts as a 'reasonable' alternative, the range of alternatives to be taken into account, the level of detail needed to explore each alternative, etc. Scoping is therefore an essential part of the sustainability assessment, and should form the basis of a negotiated 'contract' between the project team, stakeholders, experts and steering committee involved in the project. This 'contract' is called the 'Terms of Reference' (TOR). The SEPIA Terms of Reference were thoroughly discussed in a full-day workshop ${ }^{3}$. Since the (hybrid) backcasting approach adopted in the project essentially relies on normative inputs for the development of desirable end points, the first workshop was for a large part devoted to finding a consensus on sustainability principles.

An integrated value tree was developed which discusses the sustainability goals specific to the development of energy systems in more detail. A value tree identifies and organises the values of an individual or group with respect to possible decision options. It structures values, criteria, and corresponding attributes in a hierarchy, with general values and concerns at the top, and specific attributes at the bottom. For the purposes of the SEPIA

3 The final version of the SEPIA TOR can be downloaded from the project website $(<w w w \cdot u a \cdot a c \cdot b e /$ sepia $>)$. 
project, the integrated value tree integrates fundamental sustainable development (SD) objectives, scenario pathway SD principles, SD (sub-)dimensions and SD indicators.

Fundamental SD objectives are objectives which have to be aimed for ultimately in each long-term energy scenario (though not necessarily by 2050). They are considered to be fundamental to the notion of sustainability and of equal standing. However, because of different interpretations of these objectives, different views on priorities, and the inherent uncertainty of long-term societal evolutions, choices will have to be made. These choices are made apparent in the different visions. In order to establish a consensual list in line with the broad political debate, the fundamental SD objectives referred to widely shared objectives (embedded in international treaties and constitutions, e.g. article 2 of the UNFCCC or the Millennium Development Goals). In other words, they are derived as much as possible from international commitments subscribed to by the Belgian state.

For the purposes of the SEPIA project, we used the following list of fundamental sustainability objectives related to energy system development. These were inspired by the objectives defined by the Belgian federal council on sustainable development (FRDO/CFDD), by the federal planning bureaus' 'Sustainable Development Goals'4 and international commitments (cf. Table 3).

Scenario pathway SD principles are five Rio principles most often used by Belgian governments which have to be respected on the pathway towards the SD visions:

- Global responsibility;

- Integration of all dimensions of development (social, institutional, environmental, economic);

- Inter- and intragenerational equity;

- Precaution;

- Participation of civil society in decision making.

However, these principles are formulated in a rather general way and are subject to divergent interpretations in the different long-term energy pathways.

SD (sub-)dimensions are the constituent dimensions of sustainability covering all possible areas of interest related to sustainability assessment of long-term energy scenarios (for some of which fundamental SD objectives are defined). The top-level dimensions relate to the economic, ecological, social and institutional dimensions of SD.

SD indicators are the measurable variables resulting from a decomposition of SD into its (sub-) dimensions. SD indicators will be used to score the different long-term energy scenarios.

As mentioned before, the SEPIA integrated value tree incorporates all the previously mentioned sustainability dimensions. In practice, the value tree supported both the construction of long-term energy scenarios by the 'scenario builders group' and the evaluation of these scenarios by the 'stakeholder panel'. Different interpretations/prioritisations of fundamental SD objectives and scenario pathway SD principles lied at the basis of different visions on the long-term future of the Belgian energy system and the pathways needed to get there. Using a backcasting approach, the consequences of different long-term sustainability visions (horizon 2050) were explored using foresight methods for the near (e.g. 2012), mid(e.g. 2020/2030) and long-term (2050) future. The more detailed development of these

${ }^{4}$ Taken from Belgium's fourth federal report on sustainable development. 
fundamental objectives into a hierarchy of (sub-)dimensions (attributes) and associated indicators will guide the stakeholder evaluation process (cf. Section 3.2).

\begin{tabular}{|c|c|c|}
\hline 8 ultimate objectives of the FRDO/CFDD & SDG's $4^{\text {th }}$ SDR & $\begin{array}{l}\text { International } \\
\text { commitments }\end{array}$ \\
\hline $\begin{array}{l}\text { 1. To provide an effective answer to the challenge of } \\
\text { climate change consistent with Article } 2 \text { of the UN } \\
\text { Framework Convention on Climate Change } \text {. }^{5} \\
\text { During the first SEPIA workshop (17 Nov. 2008), a } \\
\text { consensus on an } 80 \% \text { GHG emission reduction target for } \\
\text { Belgium by } 2050 \text { (reduction by the Belgian economy with } \\
\text { the exclusion of offsets) was reached. }\end{array}$ & SDG 13 & UNFCCC Art 2 \\
\hline $\begin{array}{l}\text { 2. To provide access for all to basic energy services and by } \\
\text { doing so contribute to the improvement of living } \\
\text { conditions and the creation of wealth and jobs. }\end{array}$ & SDG 1, 2, 3 & $\begin{array}{l}\text { JOPI 9,9a,g 10.b; } \\
\text { Rio 92 Principle } \\
\text { 5, MDG } 1 \\
\end{array}$ \\
\hline $\begin{array}{l}\text { 3. Pursuing the use of (almost) non-depletable natural } \\
\text { resources. }\end{array}$ & SDG $13,15,16$ & JOPI 9a, 15. 20c \\
\hline 4. Pursuing demand side management & SDG 11,14 & JOPI 9a \\
\hline 5. Characterised by an optimal energy-efficiency & SDG 11,14 & JOPI 9a, 15 \\
\hline $\begin{array}{l}\text { 6. Causing a minimal health impact on mankind and } \\
\text { ecosystems }\end{array}$ & SDG 7,11, 12 & JOPI 7.f, 15 \\
\hline 7. Owning a high standard of reliability & & JOPI 9.e,f, 20e \\
\hline 8. Implying an affordable cost & & $\begin{array}{c}\text { UNFCCC Art } 3.3 \\
\text { JOPI } 20 \mathrm{~b}, \mathrm{e}\end{array}$ \\
\hline
\end{tabular}

JOPI = Johannesburg Plan of Implementation

Rio 92 = Rio Declaration on Environment and Development

SDG $=$ Sustainable Development Goal (defined by Federal Planning Bureau)

SDR $=$ Sustainable Development Report (written by Federal Planning Bureau)

UNFCCC $=$ United Nations Framework Convention on Climate Change

Table 3. Fundamental sustainability objectives used in the context of the SEPIA project

\subsubsection{SBG workshop_1: Factor identification}

For the first SBG workshop, the SEPIA project team developed brief explanations and 'fact sheets' for about 50 major factors (trends, tendencies) / technological developments expected to have an impact on long-term Belgian energy system development. A 'factor' was defined as anything that could influence energy system development in the long run. This workshop was meant to explore the possible factors of change without pronouncing an

\footnotetext{
${ }^{5}$ The ultimate objective of this Convention and any related legal instruments that the Conference of the Parties may adopt is to achieve, in accordance with the relevant provisions of the Convention, stabilization of greenhouse gas concentrations in the atmosphere at a level that would prevent dangerous anthropogenic interference with the climate system. Such a level should be achieved within a time-frame sufficient to allow ecosystems to adapt naturally to climate change, to ensure that food production is not threatened and to enable economic development to proceed in a sustainable manner.
} 
opinion on the desirability of certain evolutions. Only in the later process steps possible factor evolutions were connected with desirable visions on the long-term energy future. During the workshop comments, suggestions and remarks on current state, predictability, possible states (hypotheses) and time horizon of change (slow evolution vs. sudden change) of different factors were elicited.

T8 Advances in energy storage technologies
P2 EU internal energy market policy
T1 Competitiveness of energy conservation technologies for stationary end uses
Ex3 Structural changes to the Belgian economy in a globalised environment
Ex13 Location
P1 EU energy vulnerability strategy
P3 EU energy RD\&D strategy
P4 Price instruments to internalise externalities
T13 The 'hydrogen economy'
T6 Advances in renewable energy technologies
T14 The 'electric economy'
Ex 11 Ecological and health constraints
T10 ICT technology innovations
B5 Active public involvement in environmental issues
Ex 12 Market environment
Ex 9 Energy price dynamics
P9 Land use policies
B6 Risk perception and evaluation
B8 Shifts in demands for housing and living space/comfort
P8 Stranded assets \& Lock in
P7 Importance of social policy
T2 Energy efficiency of various transport modes: technological progress

Table 4. List of 22 factors selected during SBG-W1

The afternoon session of the workshop continued with the identification and selection of about 20 most important factors rated according to their impact on reaching sustainable development objectives in 2050. The results of the individual point allocation (green and red dot stickers) as well as the bailout points (blue dot stickers) resulted in the definition of the guiding factors for the SEPIA exercise. The participants agreed on selecting 22 factors instead of 20 as to avoid wasting valuable time in discussions. The final list of 22 factors was accepted after the question "Do we all agree on this?" (cf. Table 4).

\subsubsection{Internet consultation: Matrix exercise}

The list of 22 factors with a likely influence on energy system development was consequently submitted to the SBG in an internet consultation in order to perform a crossimpact analysis of interdependencies between factors. The cross-impact analysis was performed by asking the members of the SBG to fill in a $22 \times 22$ matrix with the 22 factors 
represented in the rows and columns of the matrix. Each cell of the matrix represented the impact of the factor in the row on the evolution of the factor in the column (score between 0 and 3; $0=$ no impact; $3=$ high influence). By adding together the scores of all members of the SBG, factors could be classified into the following groups:

- Determinants: factors with a high influence on the development of other factors, without being influenced much in return. In other words, these factors act as 'motors' or 'restraints' for the development of energy systems;

- Strategic variables: factors with both a high influence and dependence on other factors. These factors are likely candidates for the development of broad strategic actions plans, provided they can be 'steered' by political interventions;

- Regulatory variables: factors with both a mid- to low influence and dependence on other factors. These factors can be taken into consideration when designing specific policy instruments, provided they can be 'steered' by political interventions;

- Dependent variables: factors which are highly dependent on the evolution of other factors. These factors can be likely candidates for monitoring efforts;

- Autonomous variables: factors which evolve largely independently of other factors.

Based on this matrix exercise, 6 factors were selected ( 3 determinants and 3 strategic variables) that would serve as the 'backbone' for the scenario storylines (developed in SBG-W3):

- Ecological \& health constraints;

- Energy price dynamics;

- Market environment;

- Use of price instruments to internalise externalities;

- EU energy RD\&D strategy;

- $\quad$ EU energy vulnerability strategy.

\subsubsection{Internet consultation: Mesydel}

At the start of the second phase of the internet consultation, the project team developed 2-3 hypotheses with regard to the long-term evolution for each of the 6 most influential factors. These hypotheses were submitted to deliberative feedback by members of the SBG with the aid of the 'Mesydel' tool'. With Mesydel, questions are encoded on a central computer and an access to the software is given to each expert. At any time they could come back to the software and amend or augment their answers. The mediator, for his part, has access to a series of answers classification tools: ability to mark the answer's relevance, to note if he will or will not work later on the question, to comment on the answers (these comments are for his exclusive use) and - the most interesting feature - to give "tags" (keywords) to answers. These tags could then be classified according to topics selected by the mediator. These classification tools allow the mediator a huge flexibility in his work and help optimising his results by allowing him finding very quickly all relevant messages on a given topic. The 'Mesydel' round thus resulted in amended versions of the hypotheses developed for each of the factors.

\subsubsection{SBG workshop_3: Backcasting scenario construction}

Starting from the processed results of the internet consultation (priority factors, short description of possible alternative hypotheses for their evolution), the members of the SBG

${ }^{6}$ For more information, see <http://www.mesydel.com/mesydel.php>. 
developed three scenario 'skeletons' composed of factor hypotheses and technological developments congruent with the logic of reaching the 8 sustainability objectives (cf. Section 3.1.2). This can be done by a formal consistency check; however - in view of the highly resource-intensive mathematical character of this procedure (and the need for supporting software) - we chose a more intuitive method. Starting from a certain factor, a hypothesis was selected and then connected to other hypotheses (for the other factors) that were deemed to be consistent with the initial hypothesis. This combination of hypotheses could then be regarded as an alternative 'solution' to the problem of moving towards the attainment of the 8 sustainability objectives in 2050. These combinations were then taken as a basis for the construction of a scenario, and the procedure was repeated until the SBG felt that they had covered the range of possibilities with their scenarios.

For each of the scenario skeletons (which both enable and constrain certain developments), the SBG group had to explore in which other factors (taken from the original list resulting from SBG-W1, cf. Section 3.1.2) - i.e. technologies, behavioural changes, broad policy choices etc. - 'critical' changes had to be achieved (compared to now) in order to achieve a certain vision on a Belgian energy system in 2050 which is supportive of the 8 sustainability objectives. They also had to indicate an approximate timing of the changes needed in the 'critical' factors. Finally, in order to complete the pathways, the SBG group had to backcast the necessary policy interventions needed on the Belgian level for reaching the 8 sustainability objectives, given a certain combination of a vision and pathway elements as the policy context. The backcast had to give an answer to the question: "What is needed at the Belgian (i.e. federal and regional) level in order to realise the changes in the factors within the timeframe indicated by a particular pathway?". Although the workshop discussions lead to many interesting suggestions, we did not succeed in constructing pathways in sufficient detail in order to serve as an input to the LEAP energy system model. A detailed backcast also proved to be too demanding a task, mainly due to the rather low attendance. A lot of decisions still had to be made. As a consequence, the project team decided to change the format of the final workshop to some extent, dedicating it also to the further construction of scenarios storylines.

\subsubsection{SHP-SBG workshop_2: Feedback on scenario storylines and criteria}

The last workshop, which combined inputs from the SHP and SBG, served a dual purpose: deliberation and feedback on a draft value tree as proposed by the project team (with 'fact sheets' unequivocally explaining each indicator, potential data sources and possible measurements (e.g. quantitative/qualitative), taking into account uncertainties); and feedback and further development of the 'scenario skeletons' developed by the SBG in the previous workshops. The value tree was modified according to the feedback received7. Deliberative feedback on the scenario skeletons resulted in more needed specifications on the scenarios to serve as an input into the LEAP modelling exercise; however, a lot of 'room for interpretation' was still left for the project team. At the time of writing this chapter, the SEPIA scenarios were still under development. Therefore, for the time being we can only give a qualitative description of the three scenario storylines serving as an input for further modelling.

A first storyline called "Global consensus" starts from the assumption that climate change concerns dominate energy system development, in the sense that early and drastic emission

${ }^{7}$ The final version can be downloaded from the project website (<www.ua.ac.be/sepia>). 
cuts are called for (e.g. an EU target of $-30 \%$ in 2020 compared to 1990). Energy RD\&D spending on the EU level is increased substantially and is geared towards realising a common European vision - a low-carbon energy system with maximum penetration of renewable and distributed energy sources. RD\&D focuses on technological 'breakthroughs' for the achievement of the common energy system vision (e.g. advances in ICT, large offshore wind parks, smart grids, energy storage technologies, nanotechnology etc.). Those solutions mostly require big investments in new supply technology and/or new infrastructures (cf. the 'Supersmart grid') ${ }^{8}$. Technologies that are labelled as 'risky' encounter strong public and political opposition. A combination of low public acceptance and unresolved waste, safety and proliferation issues leads to a rejection of the nuclear option: without public backing, investments in new nuclear power plants simply become too risky for private investors. Existing plants are shut down as they reach the end of their projected lifetime, and lifetime extensions are not considered. Public support for carbon capture \& storage (CCS) is also reluctant. By 2050, energy supply is largely based on renewable energy sources.

In the "Oil shock(s)" storyline, the oil (and possibly also the gas) market goes through a series of crises in the period 2010-2030, caused by physical (peak production or refinery capacities are surpassed) or political factors (e.g. crisis in the Middle East), resulting in sudden and unpredictable price increments. Leading powers try to control the remaining resources by engaging in strategic alliances, as energy policy is to a large extent dictated by foreign policy and security considerations. Energy security is the main concern over the short to mid-term, leading to a focus on energy efficiency (on the demand side) and on available technologies that alleviate the dependence on imported oil \& gas (on the supply side): renewables (mainly wind energy and biofuels), coal (later equipped with carbon capture and storage) and prolonging the lifetime of existing nuclear power plants. Thanks to these measures, energy security concerns are alleviated over the period 2030-2050, allowing the climate change agenda to take over as a priority issue.

Finally, the "Confidence in $R D \mathcal{E} D$ " storyline stands for a scenario where a combination of high oil (and gas) prices, climate policy and competitive energy markets decisively influence the pace of transition to a low-carbon energy future in the OECD countries. In the EU the Lisbon agenda (and possible successors) carries high priority. The EU protects and expands its previous economic achievements, including the internal energy markets. However, governments are still heavily involved in securing their external energy supplies (this goes for 'government' as well on the EU as on the national level in Europe), albeit in a more subtle and indirect way than in the "Oil shock(s)" scenario. In general, market forces determine the investments choices made by energy industry between renewables, 'clean coal' or nuclear power, but public and/or political perceptions sometimes lead to targeted interventions. The use of the nuclear option is especially closely associated to national preferences. Independently from the developments in the fields of nuclear, Europe is on its way to a smooth and accelerated transition towards renewable energy. The process is quite similar to the one described in "global consensus", although the share of renewable energy sources is smaller. Large off-shore wind farms are the most important renewable source for electricity production and biomass playing a major role in heating or cogeneration. In addition, because of the higher demand, highly efficient gas- and coal-fired power plants with CCS are needed in this scenario. Decentralised power generation is a growing trend in

${ }^{8}$ More information on the 'Supersmart grid' concept can be downloaded from <www.supersmartgrid.net>. 
the coming 50 years. The increase in energy efficiency is also determined by market forces as new energy end-use technologies emerge in electricity use, space heating, 'smart' decentralised energy systems and transportation.

\subsection{Fuzzy-set multi-criteria decision support}

As mentioned in the introduction to this chapter, the scenarios developed for the SEPIA project have not been evaluated yet with the aid of the multi-criteria decision support tool. To claim the motivation of the use of fuzzy-set multi-criteria analysis, we briefly introduce the reader to the principles of fuzzy logic and the particular advantages of using a fuzzylogic multi-criteria group decision support tool named DECIDER, which was chosen for the evaluation of the energy scenarios by the stakeholder panel in the context of the SEPIA project based on earlier experiences (Ruan et al., 2010).

\subsubsection{Fuzzy logic}

Fuzzy logic deals with reasoning that is approximate rather than precise. In fuzzy logic the truth degree of a statement can range between 0 and 1 and is not constrained to the two truth values \{true, false\} or \{yes, no\} as in classic binary logic. And when linguistic variables (Zadeh, 1975) are used (as is the case in the DECIDER tool), these degrees are modelled by specific mathematical functions (e.g. membership functions in fuzzy logic as shown in Fig. 2). The difference between 'classic' and 'fuzzy' logic can be illustrated by the example of a 100-ml glass containing $30 \mathrm{ml}$ of water. We may consider two concepts: 'Empty' and 'Full'. In classic logic, the phrase "the glass is empty" can only have one 'truth value' (i.e. true or false). In fuzzy logic, the meaning of 'empty' or 'full' can be represented by a certain fuzzy set. One might define the glass as being 0.7 empty and 0.3 full. Clearly, the concept of 'emptiness' is subjective and would depend on the observer or designer. Another observer might equally well consider the glass to be 'full' for all values down to $50 \mathrm{ml}$. It is essential to realise that fuzzy logic uses truth degrees as a mathematical model of the vagueness of human judgement which is quite simply prevalent in all kinds of decision situations.

To illustrate the use of linguistic variables, consider the example of the temperature of the liquid contained in the glass. Each function maps the same temperature value to a truth value in the 0 to 1 range. These truth values can then be used to determine e.g. whether the liquid is too hot or too cold to drink.

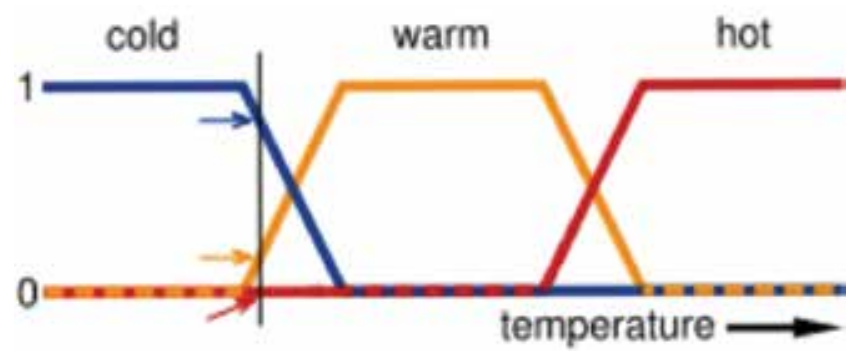

Fig. 2. Illustration of membership functions

In this image, the meaning of the expressions cold, warm, and hot is represented by functions mapping a temperature scale. A point on that scale has three 'truth values' - one for each of the three functions. The vertical line in the image represents a particular temperature that the three arrows (truth values) gauge. Since the red arrow points to zero, 
this temperature may be interpreted as "not hot". The orange arrow (pointing at 0.2) may describe it as "slightly warm" and the blue arrow (pointing at 0.8 ) "fairly cold".

\subsubsection{Application of fuzzy logic to sustainability assessment}

It is fair to say that some clear measures or, at least, indicators of sustainability exist, but the overall effectiveness of policies towards a goal of sustainability cannot be assessed. Attempts have been made to measure sustainability using the economical, the ecological, or a combined ecological-economic approach, but the results still lack universal acceptance (Laes, 2006). For the sake of analysis, researchers have broken down sustainability into a large number of individual components or indices whose synthesis into one measure appears to be next to impossible. As pointed out in the literature, it is not so much that environmental and socio-economical information is lacking but the fragmentary, often qualitative, and very detailed nature of this information hampers its direct usefulness in policy making. Not only are there no common units of measurement for the indicators of sustainability, but quantitative criteria for certain values are lacking. A systemic method based on a reliable scientific methodology, which combines multidimensional components and assesses uncertainty, is needed. In reality, the border between sustainability and unsustainability is most of the time not sharp but rather fuzzy. This means that it is not possible to determine exact reference values for sustainability, and a scientific evaluation of uncertainty must always be considered in the procedure of sustainability assessment. For this reason, the use of natural language and linguistic values based on the fuzzy logic methodology (Munda et al., 1994) seems more suitable to assess sustainability.

Multi-criteria analysis with linguistic variables, commonly known as fuzzy-set multi-criteria decision support, has been one of the fastest growing areas in decision making and operations research during the last three decades. The motivation for such a development is the large number of criteria that decision makers are expected to incorporate in their actions and the difficulty of expressing decision makers' opinions by crisp values in practice. Group decision making takes into account how people work together in reaching a decision. Uncertain factors often appear in a group decision process, namely with regard to decision makers' roles (weights), preferences (scores) for alternatives (scenarios), and judgments (weights) for criteria (indicators) (Lu et al., 2006). Moreover, multi-criteria analysis aims at supporting decision makers who are faced with making numerous and conflicting evaluations. It highlights these conflicts and derives a way to come to a compromise or to illustrate irreducible value conflicts in a transparent process. Firstly, as decision aiding tools, such methods do not replace decision makers with a pure mathematical model, but support them to construct their solution by describing and evaluating their options. Secondly, instead of using a unique criterion capturing all aspects of the problem, in the multi-criteria decision aid methods one seeks to build multiple criteria, representing several points of view. In particular, fuzzy-set multi-criteria decision support respects the principles of the 'policy as discourse' approach as set out in Section 2.3. Lack of space in the context of this chapter hinders us to give a full demonstration; we will illustrate however how DECIDER is able to deal with different types of information.

\subsubsection{Handling different types of information with the DECIDER tool}

Quantitative and qualitative information (or data) used in the evaluation of scenarios will be of very different nature; it may be heuristic or incomplete or data that is either of unknown 
origin or may be out of date or imprecise, or not fully reliable, or conflicting, and even irrelevant. In order to allow an adequate interpretation of the information from the stakeholder evaluation, the DECIDER tool was further modified in order to deal with various uncertainties that result in various data formats in practice. For application in the context of sustainability assessment it was considered advantageous to have a sound and reliable mathematical framework available that provides a basis for synthesis across multidimensional information of varying quality, especially to deal with information that is not quantifiable due to its nature, and that is too complex and ill-defined, for which the traditional quantitative approach (e.g., the statistical approach) does not give an adequate answer.

Within the SEPIA project, we the following data formats can be handled by DECIDER:

1. Information (data) presentation with different formats

Type A. Numerical Value - It is the most common way of indicating information scale. Any information a takes values in a $[0, \mathrm{C}]$ interval, where 0 is the lowest and predetermined $C$ value is the highest level of possible judgments. $C=1$ and $C=100$ cases are the most frequently used ones.

Type B. Interval Value - any interval of $[0, C]$ may give sufficient information.

Type C. Linguistic Value - It is sometimes more appropriate to indicate information with linguistic terms (fuzzy sets) instead of numerical values. In this type, a takes values from a predetermined linguistic terms set. Let $S=\{S i\}, i=\{0, \ldots, m\}$ be a finite and totally ordered term set. Any label, si, represents a possible value for a linguistic variable. The semantics of the finite term set $S$ is given by fuzzy numbers defined in the $[0,1]$ interval, which are described by their membership functions. For instance, $S=\{\mathrm{Si}\}$, $\mathrm{i}=\{0, \ldots, 6\}$, in which the following meanings to the terms are assigned - S0: none, S1: very low, S2: low, S3: medium, S4: high, S5: very high, S6: excellent.

Type D. 2-tuple (Continuous linguistic value) - When it's hard to make information with discrete linguistic terms, then one can indicate some information between S2 and S3 below.

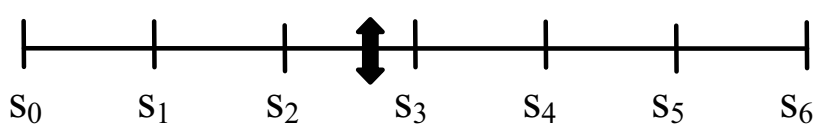

Type E. Distribution over linguistic values

A belief structure could be used as for instance to represent general belief of the information with a given situation. Such that, to evaluate a performance of scenarios vs. criteria, for example, an expert may state that he is $20 \%$ sure it (the relationship between scenario $x$ and criterion y) is S1, 50\% sure it is S2, and 30\% sure it is S3. In this statement S1, S2, and S3 are linguistic evaluation grades and percentage values of $20 \%, 50 \%$, and $30 \%$ are referred to as the belief degrees, which indicate the extents that the corresponding grades are assessed to.

2. Information aggregation with various certain and uncertain theories

After having obtained all formats of information, one can transfer all information from the types A, B, C, and D to the type E. Thus all well-known theories such as set theory, probability theory, possibility theory, fuzzy set theory, and evidence theory can be selected and applied depending on the nature of uncertainty of the information. 
Different aggregation techniques can be also applied for different needs of the decision analysis support.

3. Final decision support scenarios

By using the type E-based approach in (I), one can deal with efficient uncertain information, especially, when missing information appears during the decision analysis within the project. Typically, missing information could be (a) stakeholders don't know/understand the information; (b) stakeholders don't have any information; (c) stakeholders think the information is irrelevant. Most traditional approaches would have some difficulty to deal with such missing information.

\section{Concluding observations}

Sustainability assessment of energy policy strategies is performed at the interface between scientific theory-building and political practice. Therefore, practical sustainability assessments are judged by criteria like scientific soundness, political legitimacy and practicability (in a real political setting). In this chapter, we offered a reflection on how such criteria can be met, based on experiences from the SEPIA project. Indeed, presumes that deciding on an appropriate (i.e. sustainable) long-term energy strategy is at least a suitable 'test case' for a more deliberative (discursive) governance arrangement, ergo that it is not $a$ priori better handled by alternatives such as (a combination) of free market competition, lobbying and/or direct government regulation (top-down 'government' as opposed to bottom-up 'governance'). Further in-built presuppositions include that some particular composition of actors is thought to be capable of making decisions according to (voluntarily accepted and consensually deliberated) rules, that will resolve conflicts to a maximum extent possible and (ideally) provide the resources necessary for dealing with the issue at hand. Moreover - next presupposition - that the decisions once implemented will be accepted as legitimate by those who did not participate and who have suffered or enjoyed their consequences. Also different from standard science practice, foresight knowledge is non-verifiable, since it does not give a representation of an empirical reality. All together, substantiating the quality of the SEPIA approach is challenging, in theory and in practice, as documented by the following observations.

The SEPIA methodology aligns with theory-building in ecological economics, decision analysis, and science and technology studies, favouring the combination of analytical and participatory research methods in the field of 'science for sustainability'. This view is motivated by sustainability problems being multi-dimensional (thus limiting the use of only monetary cost-benefit analysis), of a long-term nature (thus involving significant uncertainties) and applying to complex socio-economic and biophysical systems (thus limiting the use of mono-disciplinary approaches). SEPIA shows the advantages of combining a (hybrid backcasting) scenario approach with a (fuzzy logic) multi-criteria decision aiding tool. Scenario exploration allows taking into account the (socio-economic and biophysical) complexities of energy system development so that uncertainties on the long term can be explored. Multi-criteria methods, and especially those based on fuzzy-set theory, are very useful in their ability to address problems that are characterised by conflicting assessments and have to deal with imprecise information, uncertainty and incommensurable values. Both methods are supported by a large body of scientific literature, ensuring that an effective check of 'scientific soundness' can be made through the peer review process. However, the application of these methods, and especially their 
participatory nature, are challenging in practice. For instance, the combination of narrative scenario building and quantitative modelling in theory necessitates the need for a deliberative consensus on all parameters used in the model, which in practice turns out to be impossible to organise (the LEAP model requires hundreds of inputs). The scenario development phase as it was already turned out to be time intensive for stakeholder participants. We struggled with non-participation and dropouts of stakeholders; without proper investigation we for the time being cannot explain why participation fluctuated as it did. However, at least part of the explanation can probably be found in the general impression that the potential players in the Belgian energy system transition landscape how limited their number may be - are rather scattered. In Belgium (as in many other countries), energy problems cross a varied set of policy domains and agendas, such as guarding the correct functioning of liberalised energy markets, promoting renewables, environmental protection, climate policy etc. These are dealt with by different administrative 'silos' and analysed by separate groups of experts and policymakers. As a result of this fragmentation, a lot of the key players struggle with overloaded agendas, organisation specific expectations and performance criteria and hence find no time for explicit reflective/exchange moments in the context of a scientific project not directly connected to any actual decision-making process. There may be many contacts on the occasion of events and by communication means, but there is not a structured exchange of experiences, knowledge and mutual feedback ('structured' in the sense of embedded in a culture of working methods). This impression of fragmentation sharply contrasts with the high priority assigned to institutionalised networks and collaboration in the context of 'transition management'. Perhaps the best way to sum up the findings so far is: assessing scenarios in the form of transition pathways towards a sustainable energy future with the aid of a participatory fuzzy-logic multi-criteria decision aiding tool certainly has the potential to support a more robust and democratic decision-making process, which is able to address socio-technical complexities and acknowledges multiple legitimate perspectives. However, these methods are time- and resource intensive and require the support of adequate institutional settings for a proper functioning in real political settings. Participation in integrated energy policy assessment should therefore not be taken for granted. We hope that the experience gained so far in the context of the SEPIA project will allow future initiators of similar participatory projects to level the project objectives, the participants' expectations and the political backing with each other, a prerequisite for successful participation in foresight exercises.

\section{References}

Bunn, D. \& Salo, A. (1993). Forecasting with scenarios. European Journal of Operational Research, Vol. 68, No. 3, 291-303.

Gamble, G. (2000). Politics and Fate, Polity Press, Cambridge.

Gamboa, G. \& Munda, G. (2007). The problem of windfarm location: A social multi-criteria evaluation framework. Energy Policy, Vol. 35, No. 3, 1564-1583.

Granat, J. \& Makowski, M. (2006). Multicriteria methodology for the NEEDS project. NEEDS project deliverable T9.2 - RS2b, International Institute for Applied System Analysis (IIASA), Laxenburg, Austria. 
Granger Morgan, M. \& Keith, D. (2008). Improving the way we think about projecting future energy use and emissions of carbon dioxide. Climatic Change, Vol. 90, No. 3, 189215.

Jordan, A. (2008). The governance of sustainable development: taking stock and looking forwards. Environment and Planning C: Government and Policy, Vol. 26, No. 1, 17-33.

Kowalski, K., Stagl, S., Madlener, R. \& Omann, I. (2009). Sustainable energy futures: Methodological challenges in combining scenarios and participatory multi-criteria analysis. European Journal of Operational Research, Vol. 197, No. 3, 1063-1074.

Kraus, M. (1987). Energy forecasting. The epistemological context. Futures, Vol. 19, No. 3 (June 1987), 254-275.

Laes, E. (2006). Nuclear Energy and Sustainable Development. PhD Thesis, KULeuven (University of Leuven), Leuven, Belgium.

Available at: https://lirias.kuleuven.be/handle/1979/461

Latour, B. (2004). The Politics of Nature: How to Bring the Sciences into Democracy, Harvard University Press, Cambridge, Massachusetts.

Lesage, D., Van de Graaf, Th. \& Westphal, K. (2010). Global Energy Governance in a Multipolar World, Ashgate, London.

Meadowcroft, J. (1997). Planning for sustainable development. Insights from the literatures of political science. European Journal of Political Research, Vol. 31, 427-454.

Miller, P. \& Rose, N. (1990). Governing economic life. Economy and Society, Vol. 19, No. 1 (February 1990), 1-31.

Munda, G. (2004). Social multi-criteria evaluation: Methodological foundations and operational consequences. European Journal of Operational Research, Vol. 158, No. 3, 662-667.

Munda, G., Nijkamp, P. \& Rietveld, P. (1994). Qualitative multicriteria evaluation for environmental management. Ecological Economics, Vol. 10, 97-112.

Paredis, E. et al. (2006). Methodology and feasibility of sustainability impact assessment. Case: Federal policy making processes. Final report of a BELSPO project, Belgian Science Policy, Brussels.

Petts, J. (Ed.) (1999). Handbook of Environmental Impact Assessment, Blackwell, Oxford.

Rhodes, R. (1996). The new governance: governing without government. Political Studies, Vol. 44, 652-667.

Ruan, D., Lu., J., Laes, E., Zhang, G., Ma, J., \& Meskens, G. (2010). Multi-criteria group decision support with linguistic variables in long-term scenarios for Belgian energy policy. Journal of Universal Computer Sciences, Vol. 15, No. 1, 103-120.

Smil, V. (2003). Energy at the Crossroads, MIT Press, Massachusetts.

Smith, A. \& Stirling, A. (2007). Moving inside or outside? Objectivation and reflexivity in the governance of socio-technical systems. Journal of Environmental Policy and Planning, Vol. 8, Nos. 3-4, 1-23.

Stagl, S. (2009). Value articulating institutions and changing social preferences. REFGOV Working Paper Series GPS-11, Centre for Philosophy of Law, Université Catholique de Louvain, Louvain-La-Neuve.

Stirling, A. (2008). 'Opening Up' and 'Closing Down'. Power, Participation, and Pluralism in the Social Appraisal of Technology. Science, Technology and Human Values, Vol. 33, No. 2, 262-294.

van Notten, Ph., Rotmans, J., van Asselt, M. \& Rothman, D. (2003). An Updated Scenario Typology. Futures, Vol. 35, 423-443. 


\title{
Regional Approach for Policies and Measures Aiming to Sustainable Energy Development
}

\author{
Valentinas Klevas \\ Lithuanian Energy Institute \\ Kaunas University of Technology \\ Lithuania
}

\section{Introduction}

It is widely accepted that integrated complex of environmental, social and economic policy measures is easier to implement in towns and regions scale because of "bottom up" approach permit to achieve more than one goal of sustainable development. Municipalities may have significant role in promotion of sustainable development as local authorities have more functions in energy sector, and such opportunities should be used. They may implement policies and measures, such as diversification of energy supply system, using a mix of fuel types from a range of sources and a variety of supply options by using renewable energy sources. The threat of energy supply interruptions can be minimized through the maintenance of energy infrastructure, reliable plant and effective back-up systems. Encouraging energy efficiency among consumers to reduce overall demand, and the effective management of demand to reduce the difference between peak and low energy use assists in reducing the threat of short term interruptions in energy supply that can be caused by high demand.

Prospective organizational and financing forms for sustainable energy development are local/regional energy programs. Integration of energy projects into local development process may create an external positive effect concerning environmental and other national sustainable development goals. The examples of EU-15 countries (United Kingdom, Austria, The Netherlands etc.) implementing their sustainable energy development and climate change mitigation policies on local level can be successfully applied in Lithuania and other countries.

However, integration of sustainable energy projects, e.g. renewable energy sources (RES) technologies may be successful after reliable methodological assessment of positive effect of such projects for solving social, economic, rural development problems in regional development context.

Scientific problem is to define the economic background for policies and measures aiming to sustainable energy development. All support schemes must form single, systematic and blameless economic whole.

Methodology of analysis is devised both for identifying and for quantifying energy market distortions that lead to inefficient resource allocation. Methodology of cost-benefit analysis of the positive or negative effects of increasing energy supply security, social, environmental, economic impacts was applied. 
Methodology of municipal energy development has been elaborated which can link National sustainable development policy to local relevant issues. Local energy development scenario starts from a clear strategic idea which establishes links between strategic national and local goals. Municipal energy development enables the municipality to give shape to sustainable, realistic aims within a clearly defined structure. Establishing a local or major regional market rather than separate renewable energy projects could help to ensure a market of a sufficient size and enhance competition. In addition, a regional approach could be an important element in the Kyoto follow-up work.

\section{The problems of formation uniform sustainable energy policy}

\subsection{The problems of redirecting urban areas development towards formation sustainable energy}

The need for formation of single energy policy including support system for renewable energy sources (RES) as one of compounds is notified for several years already. It is impossible without single attitude to the perspectives of the use of separate types of fuels and sorts of energy in making strategic decisions as well as in implementing them.

Creation of competitive energy market is favorable for the increase in economic growth, however, security of energy supply, mitigation of environmental impact and energy affordability are the targets of sustainable energy development which can be achieved only by the implementation of wise energy policy by the Government. Therefore, the main role of the Government is reorienting energy policy towards the sustainable development. The problem certainly does not lie with the intrinsic goals being pursued as part of the completion of a competitive market. Development of RES and combined heat and power, implementation of climate change policies, improvement of energy efficiency and security of energy supply are all the necessary elements of sustainable energy future that will not be delivered by market forces alone. "The problem lies with current inconsistencies, lack of market integration and frequent absence of a least-cost approach. A patchwork of policies, burdens and new regulations, keeps building up without sufficient coherence, balance or properly thought-out economic assessment. As a result, the essential aims of regulatory consistency, avoidance of market distortions and use of least cost solutions are far from being met" (EURELECTRIC, 2004).

The concept of sustainable energy development can't be separated from the understanding of additional positive socio-economic effect of sustainable energy projects (energy efficiency measures, use of renewable energy sources). Implementation of sustainable energy projects has positive impact on security of energy supply, provides financial economies and improved comfort and has multiplier effect for new jobs, involving small and medium size enterprises. Therefore integration of sustainable energy projects into regional development process may create external positive effect concerning increased energy security and other regional development goals (reduction of unemployment, reduction of environmental impact etc). The examples of EU-15 countries implementing their sustainable energy development and climate change mitigation policies on local level can be successfully applied in Lithuania. Methodological problems is related with integration of sustainable energy projects into regional development procedures and provide guidelines, ensuring that energy elements may compile integral uniformity in terms of regional goals.

The main issue is that the sustainable energy development would be treated as a set of separate good practice case studies or the quantitative jump would be performed in 
organizing the implementation of sustainable energy development process. The exchange of practices, based on sustainable energy aspects, is the key to promote the development of projects at the local level, satisfying the requests of the programme level.

An INTERREG IIIC Programme project RUSE (Redirecting Urban areas development towards Sustainable Energy) has been launched in order to transfer experience of EU15 to the New Member States (NMS) in the field of sustainable energy projects, financed by the Structural Funds. In this project the exchange of experiences represent a very important European Added Value.

Since 2004, the Structural Funds are available in the New Member States and are an opportunity for linking sustainable energy and urban development by creating and stimulating the integration of energy issues in urban development policies, including all its impacts on the environment. Experience has already been gained in the EU15. Sometimes this has been a bad one, for instance when the Structural Funds have not been used in the best way by promoting infrastructure projects, without taking into account their impact on natural resources or climate issues. There are environmental impact assessment (EIA) regulations available in all EU member states, however, standard EIA procedures are not always able to assess all impacts on human health and natural resources provided by infrastructure projects.

On many other occasions it has been a good experience, for example, when energy issues have been considered from the point of view of energy demand and promotion of local renewable resources rather than simply from that of the supply side via investment in grids and trans-national networks. This experience must be used by new Member states to avoid the same mistakes and to integrate these aspects in the preparation of the projects, as requested by the rules of European Regional Development Funds.

However, practices which should be the standard often still are the exception, and a majority of new infrastructure or building projects, as well as major renovation schemes, are still carried out without any consideration being given to their energy impact, in spite of the EU defined priorities for the control of energy demand and for limiting $\mathrm{CO}_{2}$ emissions.

Energy issues are not the most visible part of local planning, compared to the construction or even to the renovation of infrastructure and buildings. Energy efficiency and energy saving measures are Community priorities, which should be automatically included in the requisites of projects applying to a support from the Structural Funds.

The RUSE operation was aimed at improving the use of Structural Funds and other financial resources by municipalities and other stakeholders in charge of urban development issues in New Member States and candidate countries, thus progressing towards a better integration of sustainable energy issues (energy efficiency, renewable and distributed generation) in their projects.

To achieve the improvement of the use of Structural Funds, the RUSE operation had the following main objectives:

- to make municipalities and related bodies in New Member States and third countries more aware of existing Structural Funds related experience in European countries by disseminating information, promotion good practice and exchanging experience;

- to improve capacity building on energy issues in both individual bodies (municipalities) and collective structures (city networks, agencies, etc.);

- $\quad$ to prepare municipalities so that they can design projects dealing with their powers and responsibilities in a sustainable manner and to enable them to submit successful 
proposals under European Regional Development Fund programmes (incl. INTERREG IIIA, URBAN, etc.). In other words, to help them integrate the concept of sustainable energy in urban plans and put them into practice;

- $\quad$ to influence national decision makers regarding the integration of energy issues in their programmes from the point of view of energy demand and the promotion of renewable energy, both of which are good methods for promoting local development.

"The new legislation allowed the integration of energy efficiency as eligible measure in the Structural Funds 2007-2013. Because of co-financing requirements, it is important to convince those behind the Community Support Frameworks in the NMS that energy efficiency and RES go hand-in-hand with traditional structural and cohesion targets, such as increased employment, improved competitiveness, improved local environments, and improved infrastructures. Investments in energy efficiency in buildings, for example, are extremely cost effective. They are often cost-free because the cash flow from reduced energy consumption pays off the investment long before the technical lifetime of the investment. This cash can then be re-invested locally and regionally. These investments use much unskilled as well as semi-skilled, and skilled labour. There are similar examples in industry and transport." (RUSE Newsletter, No.1, 2005).

\subsection{The possibilities to solve the problem of increasing RES demand}

The main trends of investigations related to RES economic support policy are as follows:

- Analysis of various financing related risks and barriers which suspends wider development of RES sector.

- Assessment of external costs and including them into costs price, caused by use of traditional energy sources - oil and oil products, natural gas, coal.

- Analysis of the problem exhaustibility of resources, which participate in economic process and reflection of this feature in economic estimations.

- Investigating of issues, related to the use of developed technologies of RES, e.g. hybrid wind-hydrogen plants, tri-generation and many others.

- Creating of organizational management forms, which permit assessment and financing in wider scale.

- Creating of innovative financial tools and mechanisms, enabling RES financing

Our research was based on general hypothesis that it is possible to give correct justification to projections of the use of energy resources in economic expression of various aspects. This would be the background on one hand to evaluate various types of fuel and energy, and on the other hand to define social benefit of types of fuel and energy. The need to support RES is defined by the shortcomings of the market, which make not equal conditions for comparability and competitiveness of various types of fuel and energy.

It is necessary to separate two main support groups concerning RES:

a. Energy producers and suppliers, which must integrate into operating energy system to compete with main types of fuel - natural gas, oil (heavy oil fuel), coal.

b. Energy consumers to whom RES without additional support and establishment of infrastructure cannot afford most demand defining factors - acceptable price and security of supply.

However, the use of RES is related to additional public benefit, which is not evaluated in individual business decision making. RES accumulates the following main qualities: 
- $\quad$ RES means that the problem of the exhaustibility of their use doesn't exist, which means possibility to supply future generations with energy sources;

- Technological progress is directed towards harmony of human activity with natural processes;

Scientific problem is to define the economic background for support. It is necessary to analyze economic support forms for creation and mastering of RES technologies to make them competitive with technologies of traditional fuels and make them sensible according to actual purpose, need and possible effect. All support schemes must form uniform, systematic and blameless economic whole. In principle meaning this support scheme must make RES demand conditions the same but not protect them against other sorts of energy and technologies. Finally they all must have one or another uniform systematic whole.

From the attitude of RES supply support tools for technology creators and suppliers means compensation of social RES production costs as traditional resources are not evaluated correctly because of market errors.

From the attitude of RES demand one should investigate correct evaluation of social benefits, which may show those advantages, which are not seen in investment solutions, e.g. inexhaustibility and possibility to ensure energy resources for future generations. As some RES technologies, e.g. use of biogas in animal farms, also solve environmental problems, thus can be additionally funded from other sources.

The background of the research is the following conceptual statements:

- prices of all energy resources must be based on social costs with assumption that methodologically possible to justify all aspects in the use of fuel and energy - security, environmental, social and renewability;

- $\quad$ RES benefit can be assessed according to real benefit now and in future, which is not fixed in investment efficiency with assumption that various sustainability criteria may have single denominator on single methodological background;

- justification of RES support measures is based on comparison of fuel and energy resources used by energy system, on competitivity while assessing various sustainable development aspects by single criterion;

- $\quad$ RES competitivity is evaluated in specific territorial environment till certain optimal level, where marginal costs and marginal benefit of all types of energy become equal;

- the support to RES business is considered as correction of market shortcomings to solve sustainable development problems;

With regard to define the guidelines for sustainable energy development in economic understanding, first we should clearly evaluate current or necessary infrastructure, related to the used type of fuel.

The most suitable tool for redirecting urban areas towards sustainable energy could be local programs. Municipalities have policy instruments and means to implement them and, moreover, they are in direct contact with citizens and business. Sustainable energy policy linked to specific national measures could contribute to reducing and managing energy and environmental problems in general and greenhouse gases in particular. A very interesting example is the experience of Netherlands. Municipal climate policy has been operating since 2001 in Netherlands. Since then, more than 150 municipalities have made a start. Dutch municipal climate policy is based on a covenant between central government and representative bodies from the municipalities and provinces. The tasks are clearly defined: broadly speaking, central government focuses on identifying the climate objectives, including basic standards, furthermore, acts as a facilitator, while the municipalities will be 
the ones that actually do the work. The Ministry of Housing, Special Planning and the Environment makes subsidies available so that municipalities can release an extra capacity for implementing the policy. The level of these subsidies is linked to the degree of ambition and the actual results achieved. A total of 37 million euro has been made available for the coming years.

The underlying principle for climate policy implementation is therefore that municipalities decide for themselves the topics on which they will focus their policy. They, better than anyone else, know where the best chances of success lie. They can build on previously developed environmental and other measures. And they understand how to make the policy fit local circumstances and needs. Each municipality chooses its own theme(s): municipal buildings and installations, sustainable energy. Before a municipality can get to work on one or more themes, it attaches a level of ambition to it. This serves to indicate how far the municipality wants to take this theme. Distinctions are made between an active policy, a leading policy and an innovative policy. Based on the outcome, the municipality establishes its policy for the next five years. This policy is then implemented by means of a phased plan, which is also provided by the municipal climate policy program.

RES are a wide group of energy resources and the assessment of those resources is one-tomany depending on the potential, secure and sufficient supply, environmental and renewable character and impact to solving of social problems.

\section{Methodological approach of investigations}

The classical approach to solving methodological problems above presents applied welfare analysis. Efficient resource allocation occurs in the way energy is priced. At any time, the price of the energy resource should reflect its marginal social cost. This implies that any divergence between social and private cost arising as a consequence of the market failures (for example, public goods or externalities) should be corrected by internalizing such external costs. To assure the equivalence of price and marginal costs, a competitive market framework is required. Monopoly elements are to be eliminated if prices are not equal to marginal costs. Applied welfare analysis allows to quantify the welfare loss associated with any given market failure. This enables policy makers to focus on the market distortions. But even though a policy change leads to an aggregate welfare gain, certain groups may suffer deleterious income distribution loss. Again this implies need to create welfare system to redress burdens on the poor as a consequence of an efficiency generating policy change.

All market based mechanisms provide possibility for efficient resource allocation just under perfect competition which is not available in reality. "An urge for a liberalization of global trade has been sweeping anonymous over the world without any public debate and without even asking what are the benefits. Indeed a market economy is excellent on a certain scale. But when it leads to ever larger production and trade companies it is a threat to the environment as well as to democracy. It is no longer a free market. From a democratically controlled market we have then moved to a market controlled by the big market forces themselves. The criteria behind the economic theories of the advantages of a free market no longer exist "(Norgard, 2001).

Even worse that the negative effects of decreasing energy supply security, social, environmental, economic impacts are treated not as externalities but as normal commodities. The following theoretical considerations reflect this problem: "A common logical error is to identify a source of pollution and automatically conclude the existence of a 
market failure and thus a welfare loss. Recall that externalities exist when private valuations of costs or benefits differ from social valuation of costs and benefits. Voluntary agreements between the polluters and affected parties can achieve the socially optimal outcome. Even when private transactions are not capable of equilibrating private and social valuations, governmental policies may. Critical policy question is not whether pollution exists but rather whether it occurs at socially optimal level. The economic approach to pollution control is to view clean air and water as commodities like gasoline and air conditioning, to be provided according to the Standard criteria applied to all goods. The last unit of clean air or water should confer a marginal social benefit just equal to the marginal social cost of providing it" (Griffin \& Steele, 1986).

This problem is transferred into problem of national accounting. Growth of GDP indicates the constant progress. However the investigation of economic growth and valuation of environment corrects the optimistic result provided by constant national income and GDP growth in developed economies (Van Ireland et al, 2001). Environmental accounting is still in development stage, and its concepts, tools, processes and the potential benefits to both Lithuanian industry and government are not clearly recognized. Close collaboration of academic, research institutions and environmental organizations will be an important factor in environmental accounting development and implementation. International organizations such as the United Nations and the European Union perform increasingly important role in international exchange of information and experience, and establishment of guidelines and standards (Gouldson\&Roberts, 2000).

For formation of economic policy at state scale one needs to used non-standard approaches, which allow to synthesize various researches, which test theoretical hypotheses and define assumptions for various RES development scenarios for long term perspective of several decades. This will be performed using quantitative and analytic tools, which will define best future technologies, enabling implementation of EU environmental and energy policies. Technologies sustainability assessment, which will be performed during the project, will help to define future energy generation technologies.

The movement of sustainable development means balance of all resources or optimization. Such attitude requires guidelines of economic theory, how and why it is possible. Practical idea has created the approach, which is called Integrated Resources Planning (IRP). This approach permits to avoid partial optimization. The main idea of IRP is that the whole systems and not separate units are to be optimized.

The main problem is avoiding shortcomings of partial optimization via using integrated resource planning approach. To certain extend energy system is rather efficient as any investment must give economic pay-back. This does not mean a separate investment project, no matter how large it is, it may be insufficiently optimized or have some shortcomings. However, optimization is possible from the attitude of total costs, including external costs, such as environmental and correction of market errors.

The main methodological tool for economic assessment of specific energy resource is the price of energy resource, based on social marginal costs. Price value is market signal for consumers to react, i.e. to choose more or less energy consuming technologies, appliances, less heat consuming households or, etc. This is also the most important expression of social aspect in energy consumption.

With regard to evaluate the project efficiency for any type of RES, for separate project or on national scale, extended economic analysis is applied, supplemented with environmental 
indicators, which define project implementation impact to environment or evaluate external energy generation costs. Emissions of pollutants into atmosphere have the most important impact to the value of external electricity generation costs (Markandya \& Longo, 2005). Evaluating the monetary expression of the value of main emissions, external energy generation costs are achieved, which enable to supplement classic cost-benefit analysis with environmental indicators. Environmental indicator would allow showing that RES projects are more efficient comparing to traditional sources without regard to high capital investment necessary to implementation of such projects.

For assessment of various economic aspects we use universal approach, enabling reliable estimation of various aspects with single denominator in comparable and clear form, which has direct link to pricing. This is the approach used for levelised energy costs estimation via extended economic analysis. Levelised energy costs are not just guideline for prospective planning, but also a good tool for consumers, which will define the demand.

\section{Integration of sustainable energy projects into regional development process}

\subsection{Implementation of National sustainable development strategy via local energy development program}

The main long-term planning document - Long-term Lithuanian Economy Development Strategy was approved in 2002. It comprises 15 branch strategies (MoE, 2002).The main principles of sustainable development are integrated in these strategies. Some of these branch strategies are directly aimed at interaction between sectors (the factors of social development and economic factors of employment, economic factors of environmental protection, tourism development, etc.). Despite a great integrity of the certain strategies, there is a lack of clear relations between the aforementioned 15 strategies. In order to solve this problem the National Strategy of Sustainable Development was adopted in 2003. This strategy includes 6 branches of economy (transport, industry, energy, agriculture, household, tourism), 4 environmental sectors (air, water, biodiversity and waste), 4 main social aspects (employment, poverty and health, education, cultural identity) and regional development issues. All these economic, social, environmental and regional development issues are presented in close integrity. Sustainable development indicators for economic, social and regional development and state of environment are selected in the strategy for the monitoring of sustainable development however this system of indicators were not applied for the analysis of trends and only some targets of sustainable development were set using these indicators (Ciegis \&Streimikiene, 2005).

Energy is the priority sector in economic development because energy is closely connected with social, economic development, quality of life. Production and consumption of energy has the significant impact on environment.

Methodology of integration of sustainable energy projects into local/regional development programs has been elaborated as a key to integrate sustainable energy projects into the regional deployment level (Klevas \& Antinucci, 2004). Methodological approach is suitable for sustainability assessment using regional social-economic-environmental indicators, as increasing of security of energy supply, new jobs, new enterprises, additional economic product, greenhouse gas reduction.

It must be taken into account that each country has its own problems, which are to be solved according to the situation in a particular country. Following the Netherlands' experience of 
climate policy management, an overall framework of the sustainable energy strategy could be presented as follows:

- municipal sustainable energy policy should be based on a covenant between government and representative bodies.

- $\quad$ local sustainable energy plans must be based on the National sustainable development strategy.

Implementation of National sustainable development strategy should be supported by sharing the tasks on the increased share of RES and energy efficiency improvements between regions and authorities (Klevas \& Minkstimas, 2004). Moreover, the Structural Funds programming period 2007-2013 is crucial for the implementation of sustainable energy into practice. It should be focused on the regional and local sustainable energy programmes

The fact that municipalities can link their climate policy to their own local problems, makes climate policy to be defined as vivid. This removes the risk of vagueness and the feeling that it has no relevance to local issues. Improved traffic situations, sustainable business parks, healthier houses and less pollution: these are the points that enter the picture thanks to climate policy. Municipal climate policy is then easy to sell and it continues to working because of its supporting base and image. Climate policy brings benefits for a municipality. Municipal climate policy works according to a model of policy options. This enables the municipality to give shape to sustainable, realistic aims within a clearly defined structure.

Establishing a regional market rather than local renewable energy market could help to ensure a market of a sufficient size and enhance the competition.

In the Netherlands, wind energy parks and biomass power plants are often implemented on a regional scale. For individual municipalities, however, local opportunities also present themselves. The purchase of green power for their own buildings, constructing new buildings with an optimum sun-facing position, supporting the marketing of solar energy: all these things are within the reach of every municipality and contribute substantially to reducing $\mathrm{CO}_{2}$ in built-up areas.

Municipalities occupy a key role when it comes to energy saving in existing housing. They are involved right from the beginning in renovation and restructuring plans and have a decisive contribution to make to energy saving and energy provision. They can make agreements with housing associations about the quality of energy in the rental sector. The municipality can also exert its influence on individual homeowners. This will enable homeowners to make responsible choices from the available measures to both save energy and increase their own comfort.

However, there is a need to support this process, and the most feasible solution could be based on the local programming approach.

The main methodological problem is to integrate energy efficiency and RES projects into regional/local development procedures, so that energy elements may compile an integral uniformity in terms of regional/ local goals. The most difficult problem is to have municipal officials that are willing and cooperative. A very important issue is to define a possible external positive effect of energy project in the framework of local/regional policy directions (financed by SF), and summarize these effects as a total input of energy projects' implementation.

An additional positive effect on energy saving, energy efficiency measures and RES most often compile with the local and regional development objectives: 
- $\quad$ RES, being indigenous sources of energy improve the security of energy supply and diversity of the fuel mix.

- $\quad$ RES have advantages for regions, in which power and heat supply costs are considerably higher than average costs in the country. Thus the use of RES - electricity and heat in small isolated systems can also help to avoid or delay expensive extensions to the grid.

- $\quad$ Some RES are a labour intensive form of industry and create jobs especially at location sites in rural areas.

Method of evaluation of the above named advantages to be included into the evaluation process in feasibility studies is under elaboration. The methodological approach for solving this problem and consequently integrating energy projects into a regional/local development process has been drafted by (Klevas \& Antinucci, 2004).

Therefore, the preparation of financial perspectives for 2007-2013 is crucial, and regional development must be energy sustainable. Many resources of Structural Funds (SF) resources are to be used in a most sustainable way, which means that economic, social and environmental aspects should be accounted for. The tools (multi-criteria decision aiding based on sustainable value added etc.) for the selection of the best sustainable energy projects should be applied in decision making.

The concept of sustainable energy development can't be separated from the understanding of additional negative and positive social - economic effect of energy efficiency measures, energy savings, implementation of renewable energy sources. For example, projects on energy efficiency improvements allow to save energy costs and have the multiple effects on new jobs places creation, disperse across the community both socially and spatially, involving small and medium size enterprises. The indicators to be used describe the contribution of energy projects to a sustainable economic development, the medium- and long-term trends and the inter-relationship between them and the typical energy indicators (saved toe, improved energy efficiency, percentage of RES).

The energy service level is here used to indicate the aspects of economic development, which are relevant to the energy system. This service level can be indicated by different physical parameters like the dwelling size available per capita or the amount of cement produced per year. For a country as a whole is often used the GDP, which has earlier been described as quite insufficient to indicate the development of people's well-being.

\subsection{Framework of regional energy programs}

Sustainable development requires that economic growth contributes to social progress and respects the environment, that energy policy shores up economic performance and that environmental policy makes economic sense. There are lot of good practice case studies developed in European cities however the use of these examples projects is complicated in New Member States. The additional measures are necessary which would allow to strengthen the role of cities by implementing sustainable energy development strategy and to create methodological framework for this (Bacchus guidelines, 2003).

Sharing the tasks between regional (countries) and local authorities are to be solved as well. Implementation of National sustainable energy strategy should be supported by energy efficiency policy.

The main economic policies and fiscal measures having impact on renewable energy sources are: pollution taxes, fuel taxes, value added tax and excise tax allowances for RES, feed-in prices for electricity produced from renewable energy sources, greenhouse gas emission and 
green certificate trading schemes which can be voluntary or obligatory. However these fiscal measures do not provide sufficient initiatives for the sustainable energy development because deal just with one market failure - negative externalities of pollution however other market failures (positive externalities of innovations and diffusion of environmentally friendly technologies and asymmetry of information) are also need to be dealt. Therefore it is necessary to develop and implement policies aiming directly at encouraging the development and diffusion of environmentally friendly technologies. Public support is necessary for technology innovation and diffusion.

The most applicable approach is implementation of RES in frame of climate policy (United Nations Environment Program, 2005). The fact that municipalities can link their climate policy to their own local themes makes climate policy by definition vivid. This removes the risk of vagueness and the feeling that it has no relevance to local issues. Improved traffic situations, sustainable business parks, healthier houses and less pollution- these are points that enter the picture thanks to climate policy. Municipal climate policy is then easy to sell and continues to work because of its supporting base and image. Climate policy brings benefits for the municipality. Municipal climate policy works according to a model of policy options. This enables the municipality to give shape to sustainable, realistic aims within a clearly defined structure.

Establishing a regional market rather than local renewable energy market could help to ensure a market of a sufficient size and enhance competition. In addition, a regional approach could be an important element in the Kyoto follow-up work.

In the Netherlands, wind energy parks and biomass power plants are often implemented on a regional scale. For individual municipalities, however, local opportunities also present themselves. The purchase of green power for their own buildings, constructing new buildings with an optimum sun-facing position, supporting the marketing of solar energy: all these things are within the reach of every municipality and contribute substantially to reducing $\mathrm{CO}_{2}$ in built-up areas.

However there is need to support this process and the most feasible solution could be based on local programming approach.

The main methodological problem is to integrate energy efficiency, energy saving, RES projects into regional/local development procedures, so that energy elements may compile integral uniformity in terms of regional / local goals.

The most difficult problem is to define possible external positive effect of energy project in framework of local/regional policy directions (financed by SF) and summarize these effects as total energy projects implementation input.

Additional positive effect to energy saving, energy efficiency measures and RES most often compile with local and regional development objectives:

- $\quad$ RES, being indigenous sources of energy improve the security of energy supply and diversity of the fuel mix.

- RES have advantages for regions, in which power and heat supply costs are considerably higher than average costs in the country. Thus use of RES - electricity and heat in small isolated systems can also help to avoid or delay expensive extensions to the grid.

Some of RES are a labour intensive form of industry and create jobs especially at location sites in rural areas.

Above named advantages are to be included into evaluation process in feasibility studies. 
Sustainable energy investment projects, characterised by a positive local environmental development impact, can be brought up to the level of implementation, using contribution from Structural Funds or other regional public resources. However SF resources are to be used in a most sustainable way, which means that economic, social and environmental aspects should be accounted for.

The main problem is concerned to financing of RES implementation. Different risks and bariers disturbe development of RES implemetation in different stages. In the point of view of financial risk in the short and medium period RES are not competitive as compared with traditional energy sources. Moreover RES demand increases investment costs and takes lover income rate. This is reason why most investors are not ready to finance RES implementation or makes investments in unfourable conditons. Such a situation is often observable in developing countries where financial sources are hardly available and amount of financing depends on purposive subsidies.

The process of financing promotion of technological innovations comprises the stages as follows research and development $(R \mathcal{E} D)$, demonstration activities, pre-commercial and commercial stages. Two main forces "Technology push" and "Market pull" are involved in this process.

We may state that financing gap in the process arises in the middle of demonstration phase and continues all the pre-commercial phase. New innovative financing mechanisms are being created for efficient financing RES.

\subsection{Examples of integration sustainable energy projects into regional development programs}

Integration of energy projects into regional development process may create external positive effect concerning environmental and other regional development goals. The examples of EU-15 countries (United Kingdom, Austria, Netherlands) implementing their sustainable energy development and climate change mitigation policies on local level can be successfully applied in Lithuania and other countries.

\section{The Energy vision of Murau}

In the district of Murau (Austria), the regional energy program was established trough a bottom-up process. The participation process was started in 2002 when regional energy actors defined an energy strategy for the district of Murau, and called it "Energievision Murau" the energy vision of Murau.

The main goal of the energy vision is to establish an energy self sufficient district where the energy supply is based on $100 \%$ renewable energy sources in thermal energy and electric energy sector. During the last years the energy vision became a strong guideline for the whole district and for the people living there.

To reach of the common objectives and the main goal, the energy self sufficiency by 2015, ideas for implementing a strategy were developed by the participants themselves in moderated energy conferences. After summarizing the project ideas; 5 main focuses emerged - wooden biomass, thermal solar systems, thermal sanitation, passive houses and green electricity production. By intensive work programme, innovative new projects and products within these four main focuses, the energy self sufficiency should be reached.

An important topic that becomes visible in all four focuses is the awareness creation for renewable energies in common and especially for regional available energy sources. 


\section{The sustainability of renewable energy for commercial and industrial buildings in Cornwall}

The project aims to develop three interlocking initiatives to significantly speed up the introduction of renewable energy installations in Cornish industrial buildings, through:

1. Helping develop planning guidelines in all local planning authorities for $\mathrm{R} E$ in all new industrial buildings;

2. Developing a grant scheme to assist with the capital costs of installation;

3. Development of training courses for R.E installers.

As some new industrial 50 buildings are developed in Cornwall each year, the proposed programme would save some $443,000 \mathrm{MWh} \mathrm{p} / \mathrm{a}$ of oil, gas and electricity, saving around $175,000 \mathrm{t} \mathrm{p} / \mathrm{a} \mathrm{CO}$.

This part of the programme is evaluating the overall sustainability of the technical and organisational solutions.

\section{Municipal climate policy in the Netherlands}

Municipal climate policy in the Netherlands has been operational since 2001. Since then, more than 150 municipalities have made a start. We are in no doubt that there is a long way to go before we achieve our goals, but neither are we in any doubt about the major contribution the efforts of local authorities can make to achieving the Kyoto objectives.

Municipal climate policy in the Netherlands is based on a covenant between central government and representative bodies from the municipalities and the provinces. The tasks are clearly defined: broadly speaking, central government focuses on identifying the climate objectives - including basic standards and furthermore acts as a facilitator, while the municipalities will be the ones to actually do the work. The Ministry of Housing, Special Planning and the Environment makes subsidies available so that municipalities can release extra capacity for implementing the policy. The level of these subsidies is linked to the degree of ambition and the actual results achieved. A total of 37 million euro has been made available for the coming years.

The strict environmental requirements have conditioned the development of biogas production in all EU countries. The biogas received during anaerobic decomposition of the organic waste can be utilized as energy source for electricity and heat generation or as gas fuel. The one of the main raw material sources for biogas production in Lithuania may be organic waste in stockbreeding sector. Therefore the development of the biogas energy sector is related to the current conditions and future of the country's stockbreeding.

In frame of IEE(Intelligent Energy Europe) project SEIPLED (Sustainable energy investments promoting local economic development) the study of biogas utilization in stockbreeding sector was performed. The study has analysed the possibilities to produce energy from live stock waste and food industry. Based on feasibility studies performed for farm complexes in Vilnius, Jonava and Silute districts the recommendations for the further biogas utilization for energy purposes in Lithuanian were developed in the study.

The huge amounts of waste at the stockbreeding farms must be properly handled and usefully utilized. The organic waste can be used for feeding, digesting. Also the waste can be burned or ploughed in the fields or processed into bio-fuel or bio-gas. The study in frame of SEIPLED has analysed the possibility to process the organic waste from pig farms and butchery to the bio-gas. 
The Lithuanian case study analyses the possibilities to produce energy from live stock manure and food industry. The different biogas studies indicate considerable theoretic potential. It should be possible to generate more than $3000 \mathrm{GWh}$ of energy if overall amount of organic waste is processed. However according assessment of the real possibilities of processing and economical indicators the potential, by using $30 \%$ of livestock manure, corresponds to the production of $50 \mathrm{mln} \mathrm{m} 3$ biogas, with calorific value of $300-400 \mathrm{GWh}$ of energy. Currently 4 biogas plants are processing live stock manure and waste from food industry with total energy production of $7.4 \mathrm{GWh}$.

It is important to ensure that these farms would dispose manure and use for fertilization according to the requirements of Nitrates directive. Presently the pig farms face severe problems regarding the environmental requirements for developing farms operation, limiting the increase of the number of pigs. Following the requirements of EU directives and Lithuanian Republic laws, the pig farms must have appropriate area of farmland, depending on the number of pigs at farm, where the slurry could be watered. This demand is related with the nitrogen amount and concentration limit to the piece of land area.

The biogas production partly shall solve this problem because, after the anaerobic process in the biogas reactor, the liquid fraction of the waste is separated from the solid and the nitrogen amount is reduced. Such processed slurry can be watered in larger amounts to the same area of the land, comparing with the slurry coming directly from the pig farms. Therefore there appears to be a possibility to increase the number of the pigs at the farm. The farm will receive an additional income if it utilizes the waste collected from internal or external butcheries.

The main environmental problems related with manure and animal products waste accumulations are the increase in GHG (mainly $\mathrm{N}_{2} \mathrm{O}$ and $\mathrm{CH}_{4}$ ) emissions and $\mathrm{NH}_{3}$ emissions. The share of ammonia is $88 \%$ ammonia and the one of methane $22 \%$. The likely evolution of GHG emissions without implementation of biogas plants is based on the forecast of the number of cattle from 2004 to 2013 made by the Lithuanian Institute of Agricultural Economics.

The biogas plant development switches from fossil fuel to renewable energy sources and reduces GHG emissions from fuel combustion and $\mathrm{CH}_{4}$ and $\mathrm{N}_{2} \mathrm{O}$.

Seeking to reduce the negative impact of pollution from stationary pollution sources and to avoid the transferring of pollution from one environment to another the IPCC system encompassing water, air and land protection and waste disposal measures is implemented. The Directive 96/61/EC requires to avoid waste accumulation and if such waste is generated it should be used if technically possible and economically efficient.

Based on IPCC directive requirement the stockbreeding and poultry farms, butcheries and food industry enterprises of certain size should obtain IPCC permits. This group of enterprises includes various enterprises of agriculture, food industry and waste disposal.

In Best Available Technologies (BAT) bureau information bulletins there are recommendations the biologically degradable waste to reprocess in biogas plants. The Directive 96/61/EC require member states to prepare the BAT information bulletins presenting the technologies and practices technically and economically acceptable for the specific country conditions. The preparation of such information bulletins would promote pollution reduction and rational use of local energy resources and development of new biogas plants. 
The nature and composition of raw materials determines the utilization possibilities of reprocessed mass. Microbiologically dirty waste needs to be processed before utilization. Various technologies for raw materials necessary reprocessing increase the costs of technology for biogas utilization for energy purposes and biogas plant becomes not economically attractive for energy production. Therefore in this case the biogas plant can increase its value because of anaerobic utilization of waste and environmental pollution reduction and enhanced quality of fertilized land.

\section{Conclusions}

- The interplay of new technologies and the environment involves the interaction of two sets of market failures. The result of these interactions is that the rate of investments in environmentally friendly technologies including use of RES is below the socially optimal level because of absence of the public policy. Environmentally friendly technologies are doubly underpowered by markets: non integrated external costs of pollution and non integrated external benefits of innovation and diffusion of new technologies.

- Emission fees or caps on total pollution, with tradable emission permits, are examples of ways to internalize the costs of pollution, increasing competitiveness of RES. However environmental policies restricting pollution and implementing economic tools do not overcome all market failures hampering development of RES and additional measures to promote investments in environmentally friendly technologies are needed.

- Integration of energy projects into regional development process may create external positive effect concerning environmental and other regional development goals. The examples of EU-15 countries (Austria, UK, Netherlands) implementing their sustainable energy development and climate change mitigation policies on local level can be successfully applied in Lithuania.

- Regional/local programmes have to start from a clear strategic idea, avoiding the simple distribution of money rain-like, by open calls for projects, which typically satisfy the political aspirations but do not achieve any stable development change

- Environmental accounting is still in development stage, and its concepts, tools, processes and the potential benefits to both Lithuanian industry and government are not clearly recognized. Close collaboration of academic, research institutions and environmental organizations will be an important factor in environmental accounting development and implementation. International organizations such as the United Nations and the European Union perform increasingly important role in international exchange of information and experience, and establishment of guidelines and standards.

- $\quad$ The data of research will provide background for long-term economic state policy for RES mastering in wide scale from the attitude of security of supply, regional energy development

- The originality of the research is the development of the attitude to RES mastering as organically linked to economic, social, environmental public development

- The research will enable:

- $\quad$ to assess energy problems on the basis of single economic theory and is the input into development of Lithuanian's economic science. 
- evaluate the statements of currently dominating economic theory in the context of energy economics and possibilities to measure adequately the quality of inexhaustibility of energy resources;

- $\quad$ to justify state organizational and financial support role by whole positive effect (positive shift of foreign trade balance, improvement of purchasing power of population, etc.), which would be provided by practical use of defined and available to implement energy conservation potential

\section{References}

Ciegis, R. \& Streimikiene, D. (2005). Integration of sustainable development indicators in development programmes, Engineering economics, No 2: p.p. 28-41

EURELECTRIC (2004). Closing the circle of competitiveness: the need to reorient European electricity policy

Gouldson, A. \& Roberts, P. (2000). Integrating environment and economy strategies for local and regional government, Routledge, London and New York

Griffin, J. M. \& Steel, H. B.(1986). Energy Economics and Policy, Academic Press, Orlando

Klevas, V. \& Antinucci, M. (2004). Integration of national and regional energy development programs in Baltic States. Energy Policy, No. 32: 345-355

Klevas, V. \& Minkstimas, R. (2004). The guidelines for state policy of energy efficiency in Lithuania. Energy Policy, vol. 32, p. 309-320

Klevas, V.; Streimikiene, D. \& Kleviene, A. (2009). Sustainability assessment of the energy implementation in regional scale, Renewable and Sustainable Energy Reviews, Vol. 13.No.1, p. 155-166

Markandya, A. \& Longo, A. (2005). “Identification of Options and policy Instruments for the Internalization of External Costs of electricity Generation". Social Science Research Network Electronic Paper Collection: http:/ / ssrn.com/abstract=729704

Ministry of the Environment of the Republic of Lithuania, (2002). National Sustainable development strategy, Vilnius

Norgard, J.S. (2001). "Sustainable energy future - Nordic perspective". Keynote at PanEuropean NGO Sustainable Energy Seminar, Denmark

RUSE Newsletter (2005). No. 1. www. ruse_europe.org

Sustainable energy and the Structural Funds (2003). BACCHUS guidelines

United Nations Environment Programme. Public Finance Mechanisms to Catalyze Sustainable Energy Sector Growth. (2005)

Van der Ireland, E. C.; van der Straaten, J. \& Vollebergh, H. (2001). Economic Growth and Valuation of the Environment, Edward Elgar, Cheltenham, Northampton 


\title{
Identifying Regional Behavior Impacts of Electricity Generation in Electricity Market with SSNIP and Granger Test
}

\author{
Z. Tavassoli Hojati ${ }^{1}$ and S. F. Ghaderi ${ }^{2}$ \\ ${ }^{1}$ Socio-Economic Systems Engineering, University of Tehran, Tehran, Iran \\ ${ }^{2}$ Department of Industrial Engineering, College of Engineering, University of Tehran, \\ Tehran, Iran
}

\section{Introduction}

A brief glace at the electricity market and considering the methods of supervising its exploitations in different countries illustrate that this market had been managed monopolistically by governments for several years. Regarding restructuring and evolution in the electricity markets happened in many countries in recent years, it is necessary to achieve methodologies in which some trends like market power could be analyzed (Heydari K. 2003). Then decision makers can easily make some decision to prevented unfair behaviors in electricity market and direct it to a pure competitive condition.

A competitive market is characterized as:

1. When a quantity of production of a producer reduced, simply, another producer could replace that. It means that there is an appropriate reservation in the network.

2. New producers could enter to the market easily.

3. The numbers of competitors are enough. It means that they sell their production according to the market price and it also mean that it is them that put the price and no company could change the price by changing the quantity of its production.

4. Market and production information are available as free for sellers and buyers.

Although the attempt to achieve a completely competitive market has not been succeed but it improved the condition of this market considerably. In this way presenting the proper definition of the market, recognizing present markets and relationship between these markets is necessary. Without it, any assessment regarding the market power and changing prices could result confusion in market activities. Furthermore because of particular characteristic of electricity to be non-storable product in large scale, electricity market has to be controlled and monitored by the governments to detect and prevent exercising any market power. In order to achieve this goal, there are some controls and antitrust activities which are done inside and outside of electricity market. A group of techniques are also employed for analysis of prices relation and model design for finding market's boundaries by Granger and SSNIP test.

In this chapter, the conceptions concerning market definition, market power, SSNIP test (as a mechanism for market defining and a good tool for those who provide prices in order to identify related markets they are engage it) and granger test (as a statistical technique using for defining dependent and independent markets and relations between these markets) are 
presented and then the market definition and identification for the related markets in a sample Electricity market are discussed. Presented models as the prediction mean in electricity market are evaluated; finally the results of SSNIP test are compared with the real electricity market database.

\section{A review on function of Iran's electricity market}

Iran's electricity market has been established in 1382 as a wholesaler market. According to electricity market rule, "market adjusting board", "market manager" and "center" constitute three main organs of Iran's electricity structure.

Market manager do electricity transaction, in other words daily administrating energy's market. National network leading and searching center or its assistance (national dispatching) is responsible for leading country's electricity network, also it should make sure that using this network would be safe and secure.

Market adjusting board lead and control electricity market to facilitate economic exchanges as well as solving disputes among market's main members. So market adjusting board can be labeled as Iran's electricity market lawmaker organ. Importance of responsibilities and jurisdiction, necessitate independency of this organ from market's members.

However, the following reasons (especially when the numbers of producers are limited) generally cause the prevention of establishment of competitive market in the field of electricity:

1. Impossibility of electricity storage in mass extent

2. Impossibility of flow power control to desirable course

3. Not balanced distribution (based on the principle of production and consumption) in comparing to other competitive markets:

In a complete competitive market, despite some limitations, usually production is done in the nearest distance from consumption market. But in electricity market production takes place in an area that primary facilities such as primary source of energy and work force are available and there be no environmental issues.

4. Absence of balanced transfer and distribution power system establishment:

Limitations in quantity of transfer lines and distribution of power and also impossibility of new line establishment (because of no economic value or environmental issues) are considered as some other factors which restrain competition in electricity market.

5. Other technical difficulties:

Some difficulties such as limitations power voltage resistance etc could be categorized in the section.

Iran's electricity market programs is indeed about output and input of units, provided that by received information from electricity seller companies some limitations are removed. The input information of this program which is within market manager's jurisdiction is as follows:

- $\quad$ Unit's megawatt and suggested rate of produced energy

- Forecasting network bar: electricity market would have bar information for the whole next day. This includes forecasting bar of national network for 24 hours, forecasting regional electricity companies peak bar hour and regional peak bar hour. In addition, the rate of foreign interchange is known for hour by hour of the next day. The total model of Iran's electricity market is shown at figure 1. 
- Network's limitations: it includes limitations of interchanging among regions, maximum and minimum power stations daily energy, units which should be out and on and identification information of power station units.

The general policy of electricity market program is as follows:

The program starts to solve a non-linear optimization case regarding the information which it has received from seller companies.

After solving optimization case, the program produces a series output. The most important part of them is market production arrangement and average accepted price at each hour. The sellers would announce their proposal to market for each power station unit and for each day by the hour in maximum 10 steps. The information related to forecasting buyers needed service (regional electricity companies) would be announced to market daily and by hour too.

For handling electricity market, there should be received technical information from network leading assistance, including power stations produced energy, information of interchanging lines, production and code of unit status and peak hour, capability by unit and power station, forecasting regional electricity companies bar, frequency fall and rate of black-out and the amount of power stations lack of co-operation with control center.

Figure 1 shows Iran's electricity market model comparing to standard market (Setayesh Nazar M. et al. 2007) Parts who have no boarders has not yet set in motion.

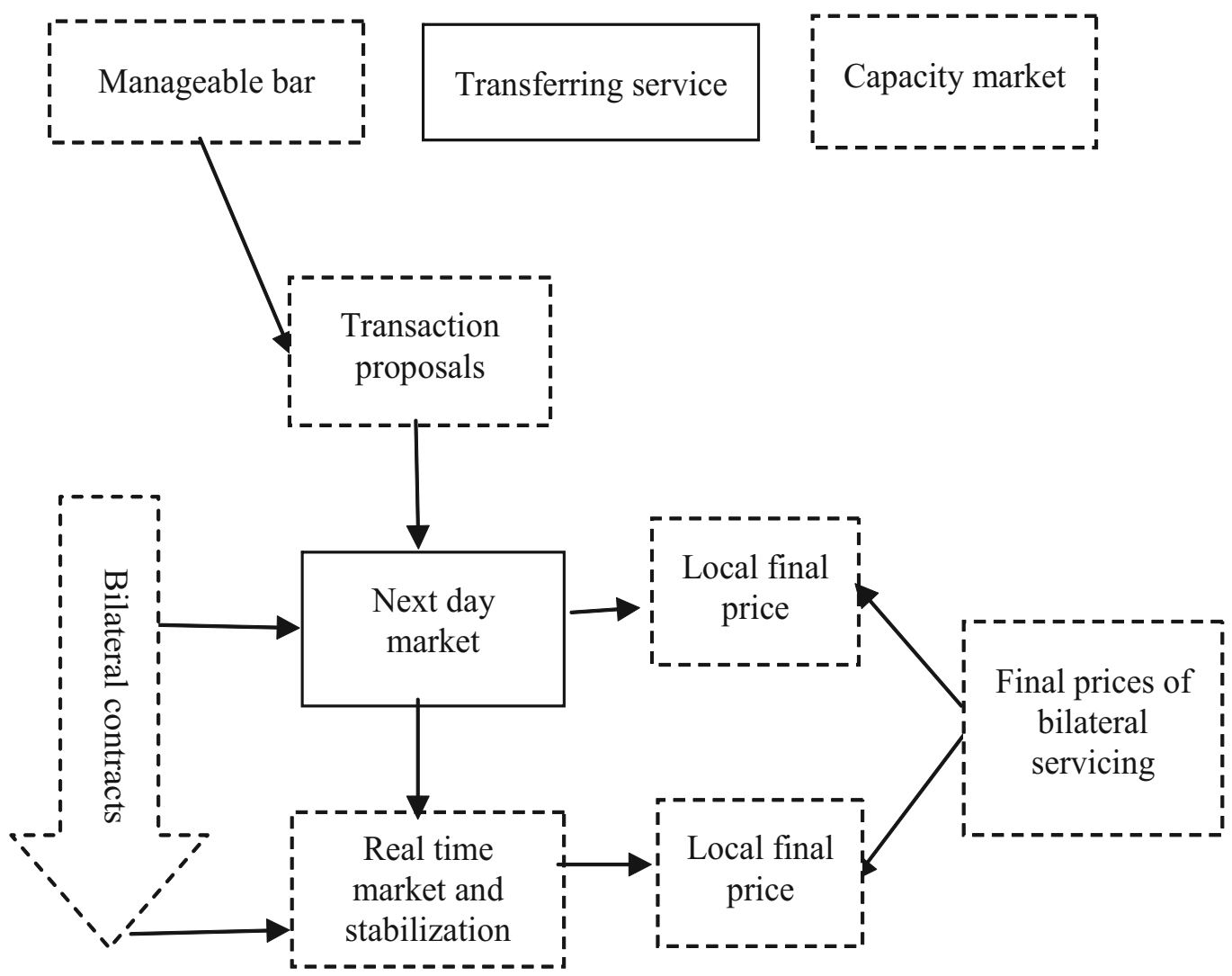

Fig. 1. Iran's electricity market model comparing standard market 


\section{Ways of market's exercising of authority}

After privatization and changing market's structure to new ones, usually there would exist a phenomenon named "market's power". In this phenomenon, seller can change prices to gain more benefit than to competitive prices. In U.S. Department of Justice (DOJ) market power means ability in stabilizing prices at a level upper that competitive level at a known time span. So some factors are used to control market power in U.S. electricity market like short-term administrating of non-elastic demand (supply and demand in short -term span are not elastic, and sometimes this cause privatization and power of market), and preventing privatization expenses, etc. So an operating central market is used for interchanging in network and rate of access to fuel. Here are listed some key factors which prevents market power:

1. Definition of market and parameters which affect on it

2. Test on market potential power and evidences about misusing by market power

3. Enforcing a restriction against those who can exercise authority

To gain this goal, there are some controls and antitrust activities that are done inside and outside of electricity industry, a series of techniques are also employed for analysis of prices relation, economic studies and model design for finding market's boundaries by Granger test and SSNIP.

Main ways of exercising authority by market are:

1. Physical or quantity restriction which needs intentional reduction of suggesting power station unit in market, even if its output be sold higher than final price. This restriction can be done by lack of suggestion, reduction of output level or announcement of unit output.

2. Financial or economic restriction which necessitate proposals with prices higher than competitive prices.

3. Transferring system strategies, which involve existing or intensifying transferring system repletion for increasing market prices in special regions.

Electricity markets have a special structure, so just the above mentioned items do not confirm existence of market power. Market power in electricity industry means ability of restriction for reduction of some units for increasing market prices and more benefit of other units. This definition, however, should be revised when we encounter electricity network boundaries or lack of mitigation. A company can reduce production of some units and cause changes in market prices, so gain more benefits from production of its other units. This is possible by output restriction as well as over production of some units (to exercise transport limitations) to be benefited by higher prices for other units output. There are some other matters which can cause high prices or produce energy for units whose capacity is under normal level and total shortage of reservation.

There are some standards like HHI which are used to recognize existence of market power. Lack of suitable definition on market or dependant markets can lead to wrong recognition of market power. The standards can be employed in market in two ways:

1. ex ante: the time of market's exercising authority

2. ex post: finding out when market power use its ability in disturbing market.

These standards should be limited and reduced to control market power. In U.S. these limitations are placed according to maximum price and limited prices, but none of them had been successful so far (Frayer J et al. 2004). This problem cause producers do not tend to produce electricity. Totally, employing limitation to all producers in market is not suitable; 
it should be done just about those who are able to exercise authority on market and not for producers of dependant markets.

\section{Definition of market}

There are many techniques for defining market which are used for analysis of each market according to its characters. These definitions are offered according to key economic roles of each market.

A separate market enjoys a competitive boarder which separates it from other markets. Finding out market's geographical boarder is possible by estimating whether there is any potential for imaginary market power or not. This is done by SSNIP test which is explained in next parts in details.

In economic discussions the way of refracting imaginary monopoly via substituting from two views is brought up:

- How one product beneficiary would react against changing price of different products? This discussion is named demand-side substitution. Cross-price elasticity of demand which is shown in figure 2 is used to reply this question.

Px: Price in Spot Markets

(Product X)

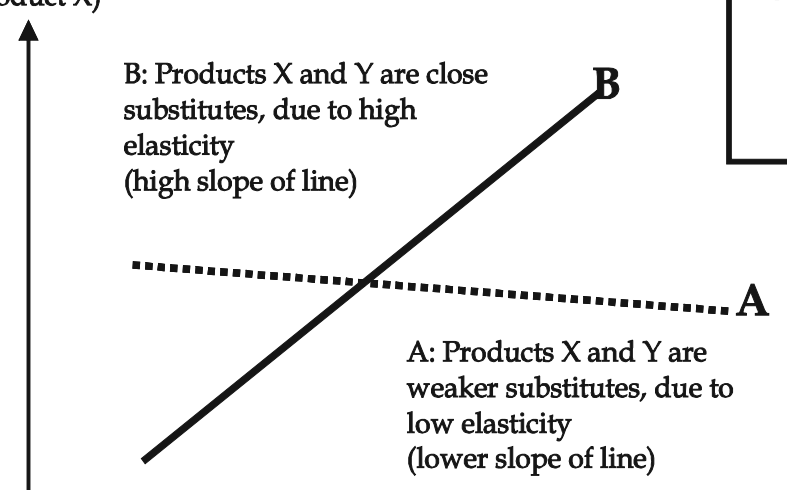

Cross-Price Elasticity of Demand:

$$
\frac{\Delta Q_{Y}}{\Delta P_{X}} \times \frac{P_{X}}{Q_{Y}}
$$

All substitutes will have positive cross-price elasticity.

Qy: Quantity of Forward

Contracts (Product $Y$ )

Demanded

Fig. 2. An example of estimating cross-price elasticity of demand

- How the strategy of other suppliers would change by changing one supplier price? The concept of this question is brought up under the title of supply-side substitution too. This question can be replied by the concept of cross-price elasticity of supply.

Now it is possible to define dependent and independent markets by above mentioned concepts.

- Distinct market is a market including a competitive environment different from other kinds, so it is impossible to eliminate market power by market exercising authority which employs substitution processes. Practical estimation of this market's geographical aspects is done by application of conjectural monopoly policy and SSNIP test.

- Relevant market includes one or more competitive goods. In this market goods can compete and be replaced. Even though the monopolist can increase his price to gain 
benefit but existence of goods which substitute monopoly ones he cannot .This cause products to have little cross-price elasticity of demand. A relevant market compound geography and product aspects and define the result as follows:

- A relevant market compares all products and services which can be substitute by consumer because of characteristics of product, its price or way of consumption.

- A relevant market compare field which companies are worry about offering the products or services.

A traditional definition of market is done based on definition of four aspects of market which is shown in fig. 3 .
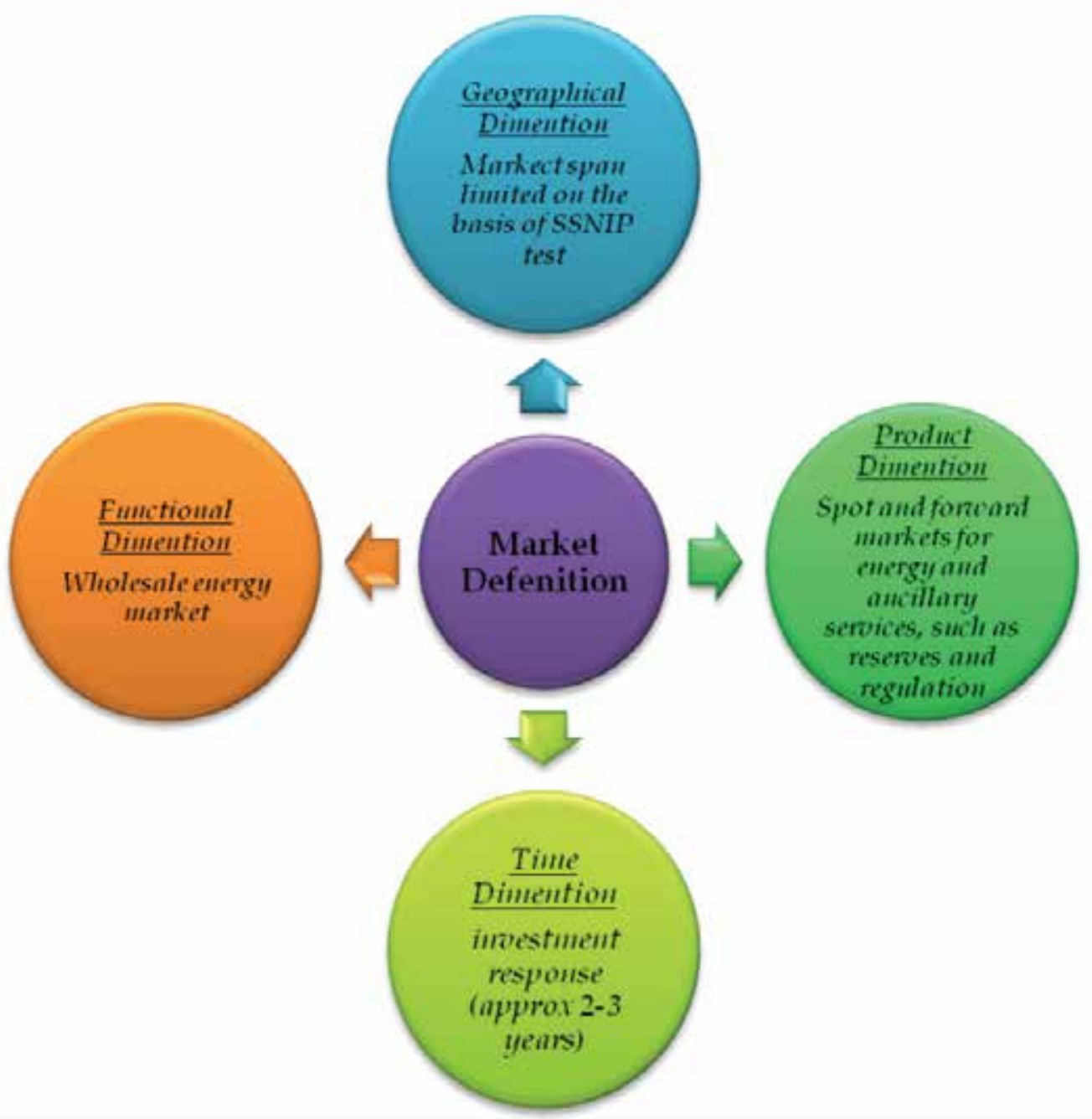

Fig. 3. Four effective aspects in market definition

Local aspect is determined by distinguishing physical boarders of market. In electricity market this aspect is specified by expansion of transport network which is determined by market physical boarders. In market, inter connection among generators do not necessarily 
mean uniform market, but it depends on connective lines between supplier generators in that regions. Geographical aspect can be done by SSNIP test.

Product aspect is determined based on type of that product or service. For example, wholesale in electricity market includes various products and services which has been provided by generators and suppliers of transport service and is necessary for energy wholesale and delivering to consumers. These products can be represented via short-term and long-term contractors or sale -point market daily or without delay. Another discussion here is about peak hours of electricity production and other hours which are not at peak, and whether it is possible to have a separate market for peak hours. For example, lack of correlation in supply diagram in electricity market which is shown in three parts in figure 4 as base load, mid-merit and peak have different offer prices and can show different markets.

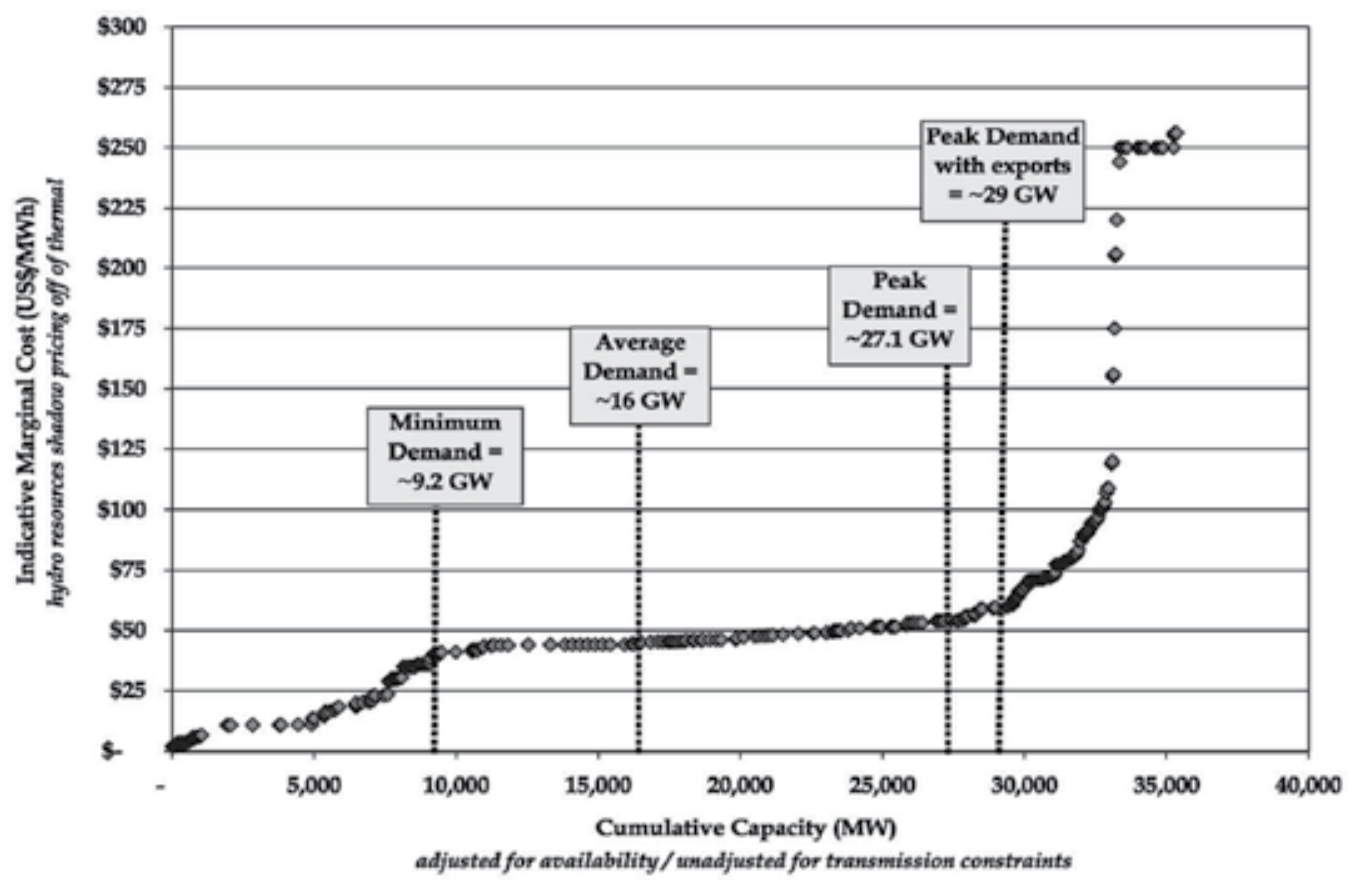

Fig. 4. Supply diagram in US electricity market

Time concept among different products of energy indicates the state of transition in these markets. Although energy is transported by hour and is measured in little profits, but this does not mean market time aspect is one hour or point market (by hour or by five minutes) is a separate market. Point markets are not separate ones because monopoly has not effect on it and consumers can substitute products which they buy form.

In markets throughout the world, a remarkable amount of energy wholesale is done by contacts of bilateral contracts until three years. This can prevent employing a suitable time aspect.

\section{SSNIP test}

In the field of competition rules, before deciding about necessity of companies exercise authority and government interference, SSNIP test is done for determining relevant market 
to a large extent (KATZ M. 2002). This test analyze potential market exercising authority, by analysis of substitute products which are determinative in relevant markets. In addition, competition in market controls market authority. Effective antitrust factors prevent market refraction too, by similar industries alliance, group monopoly and goods monopoly.

Market power is effective when:

1. consumers do not substitute product

2. other suppliers do not increase their supply

This test is used to specify producers who can exercise authority on market or to determine relevant markets boarders, somehow means as "something worth monopolizing". At every market there is a list of products which can be substituted. Each list is monopoly value. This means if there is only one producer for a product, it can increase its price without ability of substituting product by the consumer. This test specifies every relevant market which supposed monopoly or collusion of industry owners which can increase prices effectively. This test results are more useful than Granger's test (Frayer J. et al. 2004) and has been used in electricity market extensively.

\subsection{SSNIP test history}

This test has been directly defined in 1982 by DOJ as a new method for defining markets and a way of measuring market's power.

SSNIP test has been used for the first time in 1992 in UN and in 1997 in European commission to define relevant market.

\subsection{Method of SSNIP test}

This test is done as follows:

1. Offering a definition from supposed market based on product, geography, time and operation aspects

2. Making a model from supposed market including a complete definition of relations in relevant markets which can exist and describe input, supply and demand of possible substitutions at that market

3. Testing the effect of supposed monopoly by little increasing of price ( 5-10 percent)

Using short-term models in this market is a remarkable point of this test in electricity market, so considering time aspect is necessary too. In total, the test limitations (Ogzera 2005) are as follows:

1. considering just competition of prices, ignoring other aspects like quality

2. not being suitable for various kinds of products

3. possibility of mistake based on base point if market be not symmetrical

4. Reduction in production rate do not necessarily means its substitution, it may be because of not consuming by consumers

5. In analysis of competition within product A market, just increasing A price would be considered. For analysis of monopoly state between A and B (both of them in the same market) considering A market is enough.

6. Consideration of market power is considered as competitive pressure of B on A. The controversy of situation is not necessarily true.

\subsection{Measuring results of SSNIP test}

For consideration gained results following items are used: 
1. By practical estimation of critical demand elasticity and comparing it with compounded demand elasticity ( final price would be enough for linear demand function)

2. If demand elasticity cannot be measured, a substitute method would be used named "critical loss" (Katz M. 2006). Critical loss is maximum wasting of a sale which can increase prices effectively. Increasing of prices would be effective when possible loss be lesser than critical loss.

In SSNIP the gained results would be considerable by increasing prices and comparing it with base circumstances, and in the same circumstances with base state, increasing transport price in lines or exercising time aspect in the base environment.

\section{Granger test}

Granger in 1969 proposed a time-series data based approach in order to determine causality. In the Granger-sense $x$ is a cause of $y$ if it is useful in forecasting $y$. In this framework "useful" means that $\mathrm{x}$ is able to increase the accuracy of the prediction of $\mathrm{y}$ with respect to a forecast, considering only past values of $y$.

In doing economic analysis, sometimes, we would like to know whether changes in a variable will have an impact on changes other variables. To use this phenomenon more accurately, we need to learn more about Granger Causality Test. For more information about the mathematical basis of this test, (Gujarati N. 1995) is suggested.

The Granger price test belongs to a genre of statistical techniques used to measure market integration and includes more simplified analysis such as correlation and more sophisticated techniques such as co-integration analysis and error correction models. The base of such tests is derived from Marshallian economic theory, which holds that in open markets (prices encapsulate and characterize all supply and demand dynamics).

Furthermore the Granger causality test takes the analysis of price relationships one step further. Suppose you have a regression model explains the current price of a product by fitting a curve to the historical prices in time series format of that product ex. electricity. Granger's idea explores whether you could significantly increase the descriptive power of this regression analysis for the price of one product by including the price of another product. Formally, Granger causality is said to be not present when the relationship between two variables, $X$ and $Y$, when: $f\left(X_{t} / X_{t_{-} 1}, Y_{t_{-} 1}\right)=f\left(X_{t} / X_{t_{-} 1}\right)$.

There are three possible deductions from the econometric analysis:

- Unidirectional Granger causality from Y to X (or vice versa)

- Feedback or Bilateral Granger causality

- Independence

Granger causality test has also has applied in antitrust cases in the U.S. for the purpose of delineating Electricity market boundaries, on a product, geographical, and functional dimension by (Frayer J et al. 2004). This test also used for identifying of causality of California's electricity and natural-gas (Chi-Keung W. et al 2006), Electricity consumption and economic growth (Yemane W. 2006) and many other cases.

\section{Implementation in Iran electricity market}

By considering and administrating Iran electricity market to model it, a complex solution should be modeled like transport system limitations and its special circumstances on 
market. This matter causes analysis and exact simulations. Limitations which controls market should be considered completely in its model, otherwise, gained results from simulation would not be trustful (Tabei S. M. 2005). Iran's electricity market have 7 regions which each of them enjoys some region regional electricity which is shown in regions (table 1), in regional electricity (table 2) and in network graphical show in Iran electricity market.

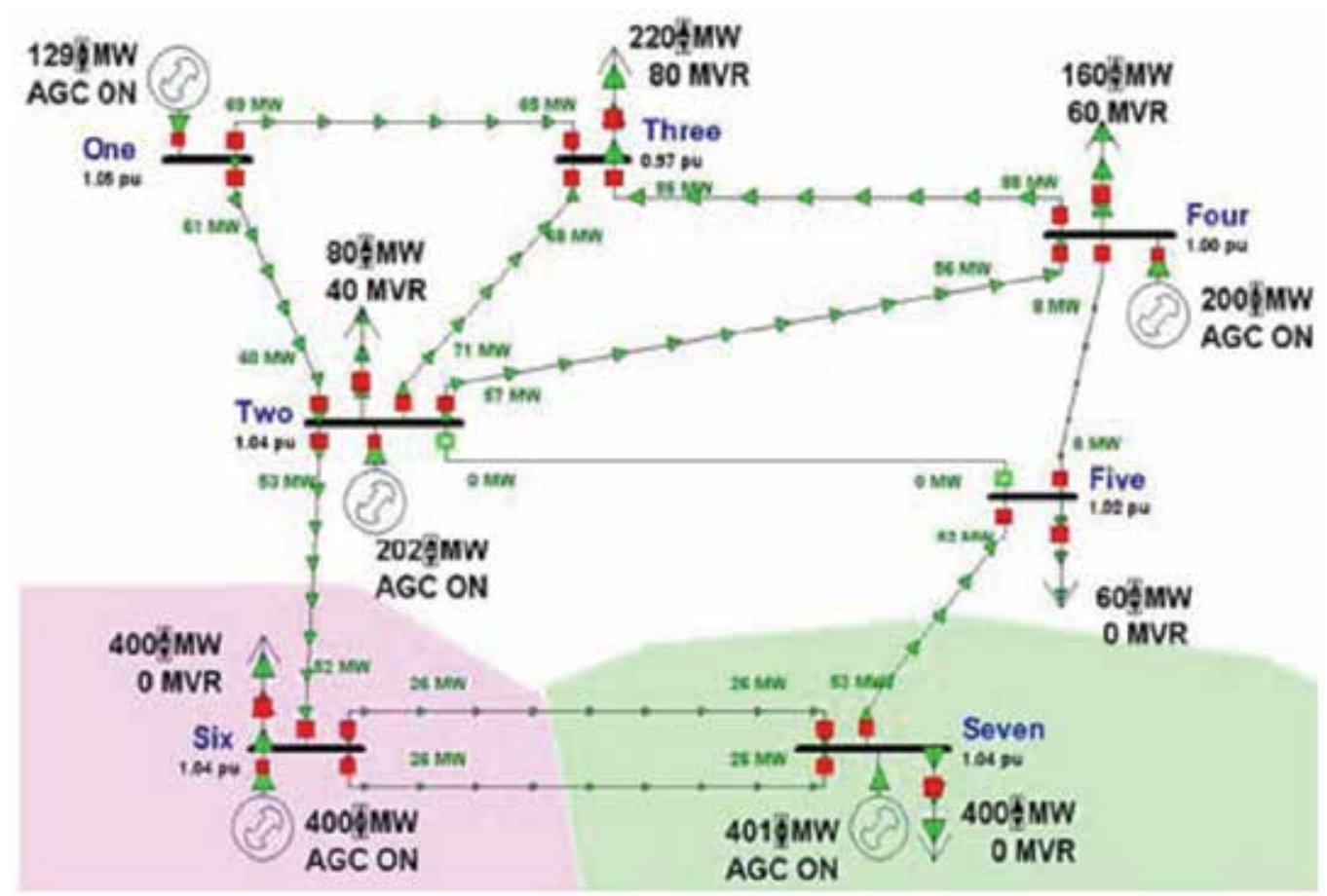

Fig. 5. Graphical show of considerable network

\begin{tabular}{|c|c|}
\hline Region's number & Region's name \\
\hline 1 & Azarbaijan \\
\hline 2 & Markazi \\
\hline 3 & Shomal \\
\hline 4 & Khorasan \\
\hline 5 & Sistan \\
\hline 6 & Gharb va bakhtar \\
\hline 7 & Jonobe shargh \\
\hline
\end{tabular}

Table 1. Regions of Iran's electricity market

Electricity cannot be saved by vast scale and electricity production and distribution management should schedule for utilization and optimal investment according to comparison of supply with energy demand. Therefore for future projects, foresight of bar 
have a special importance and its fault rate should be decreased as possible. Therefore, by initiating electricity market in Iran network, regional electricity companies should anticipate and give whole included network hour by hour consumption needs. This anticipation has been done in Iran electricity market by three states:

1. Anticipation normal days according to finding out similar days

2. Anticipation special days according to finding out similar days

3. Anticipation days after special day according to finding out similar days

\begin{tabular}{|c|c|c|}
\hline Region's number & Region's name & $\begin{array}{c}\text { Number of } \\
\text { related region }\end{array}$ \\
\hline 1 & Azarbaijan & 1 \\
\hline 2 & Esfehan & 2 \\
\hline 3 & Bakhtar & 6 \\
\hline 4 & Tehran & 3 \\
\hline 5 & Khorasan & 4 \\
\hline 6 & Khozestan & 2 \\
\hline 7 & Zanjan & 3 \\
\hline 8 & Semnan & 3 \\
\hline 9 & Sistan and balochestan & 5 \\
\hline 10 & Gharb & 6 \\
\hline 11 & Fars & 2 \\
\hline 12 & Kerman & 7 \\
\hline 13 & Gilan & 3 \\
\hline 14 & Mazandaran & 3 \\
\hline 15 & Hormozgan & 7 \\
\hline 16 & Yazd & 7 \\
\hline 17 & Kish free region & \\
\hline
\end{tabular}

Table 2. Regional electricity of Iran's electricity market

According to analysis done on Iran network bar inputs, bar behavior diagram is different during the weak and is similar in back-to- back weeks. Results of anticipation for Iran cross country network bar inputs and comparison with nerves network anticipation alongside with master phase system has been shown in figure number 6 till 11 (Vahabi A. et al. 2007). According to electricity market rule, hours are distributed according to warm and cold months as well as consumption capacity as following table.

\begin{tabular}{|l|c|c|c|}
\hline & Low bar hours & Normal hours & Peak hours \\
\hline Warm months & $1-8$ & $9-20$ & $21-24$ \\
\hline Cold months & $\begin{array}{c}1-5 \\
21-24\end{array}$ & $6-17$ & $18-21$ \\
\hline
\end{tabular}

Table 3. Hours distribution based on consumed bar according to electricity market rule 


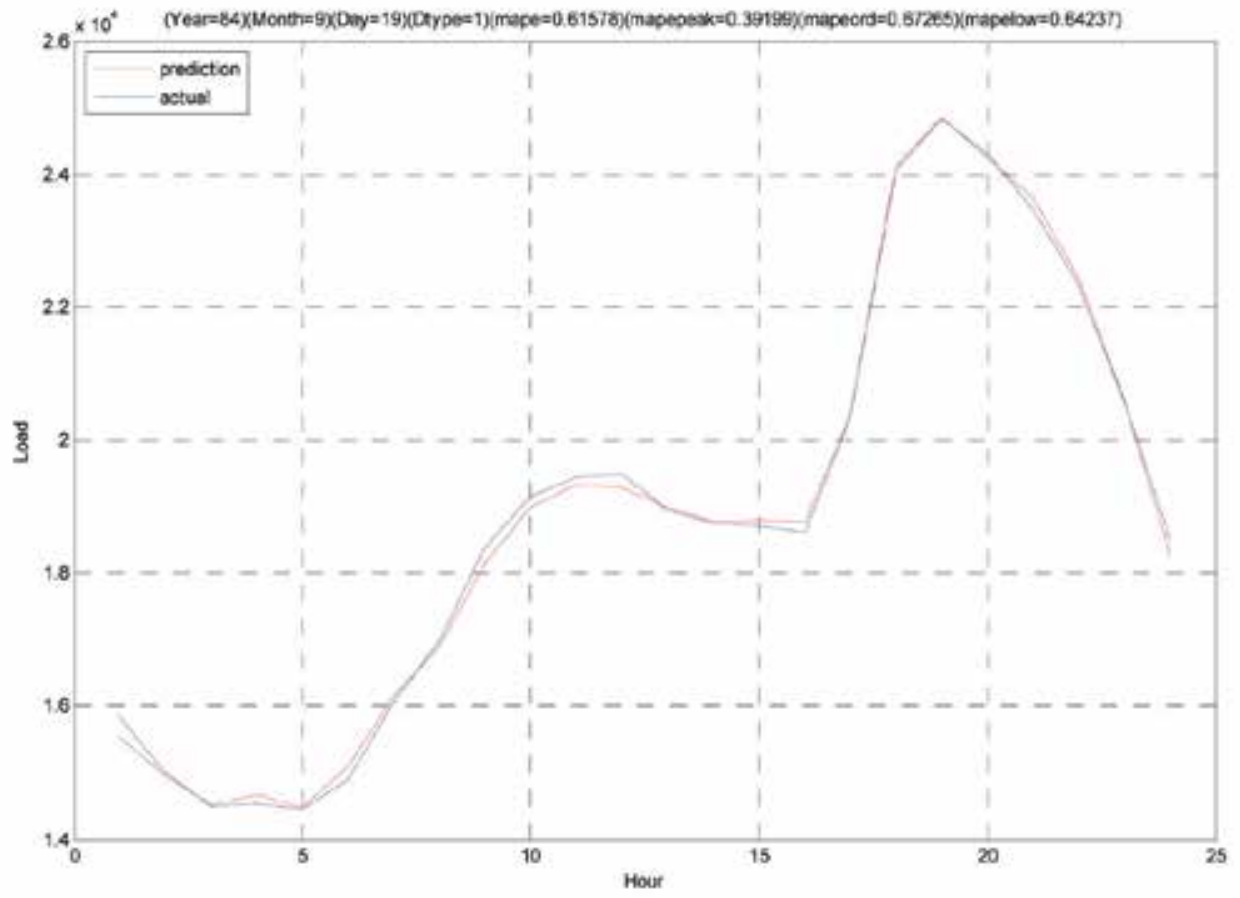

Fig. 6. Anticiption diagram and real bar curve for Saturday

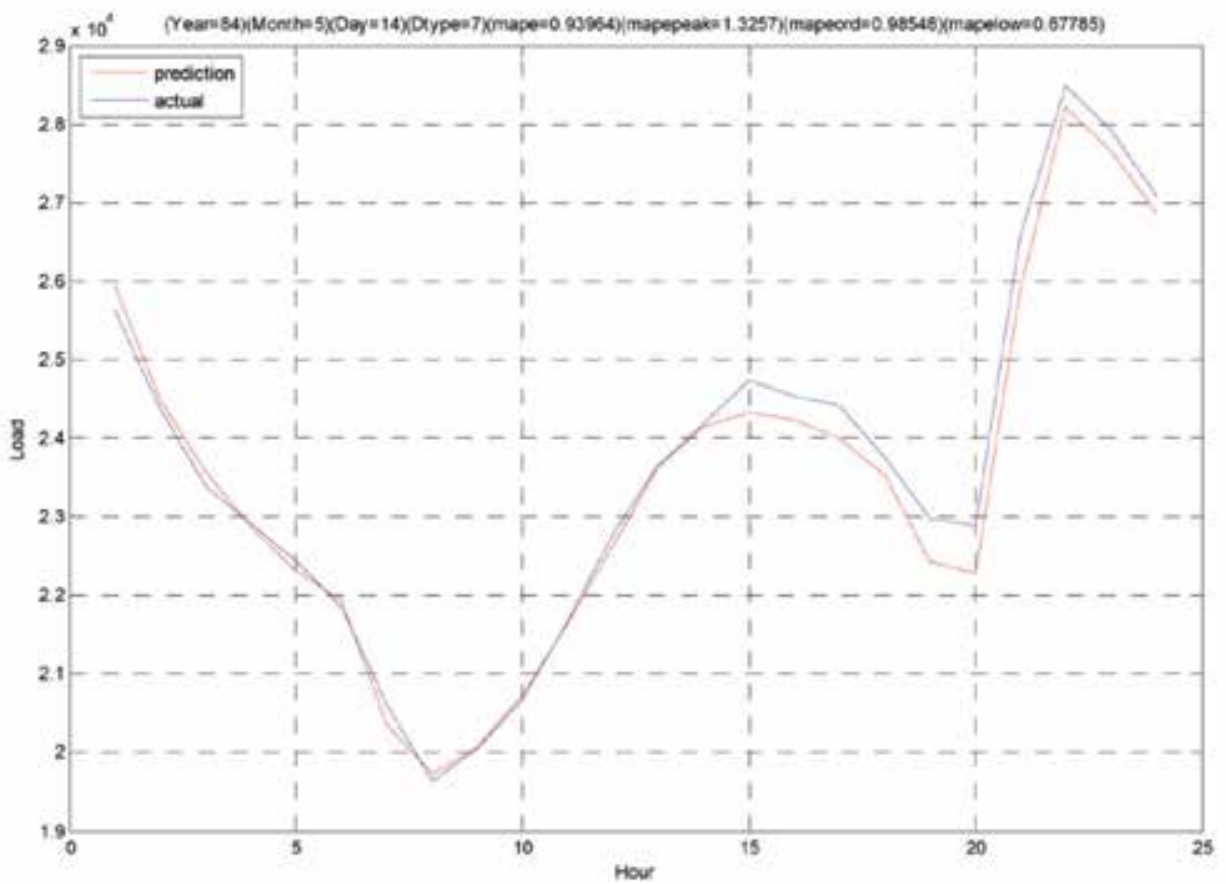

Fig. 7. Anticiption diagram and real bar curve for Friday 


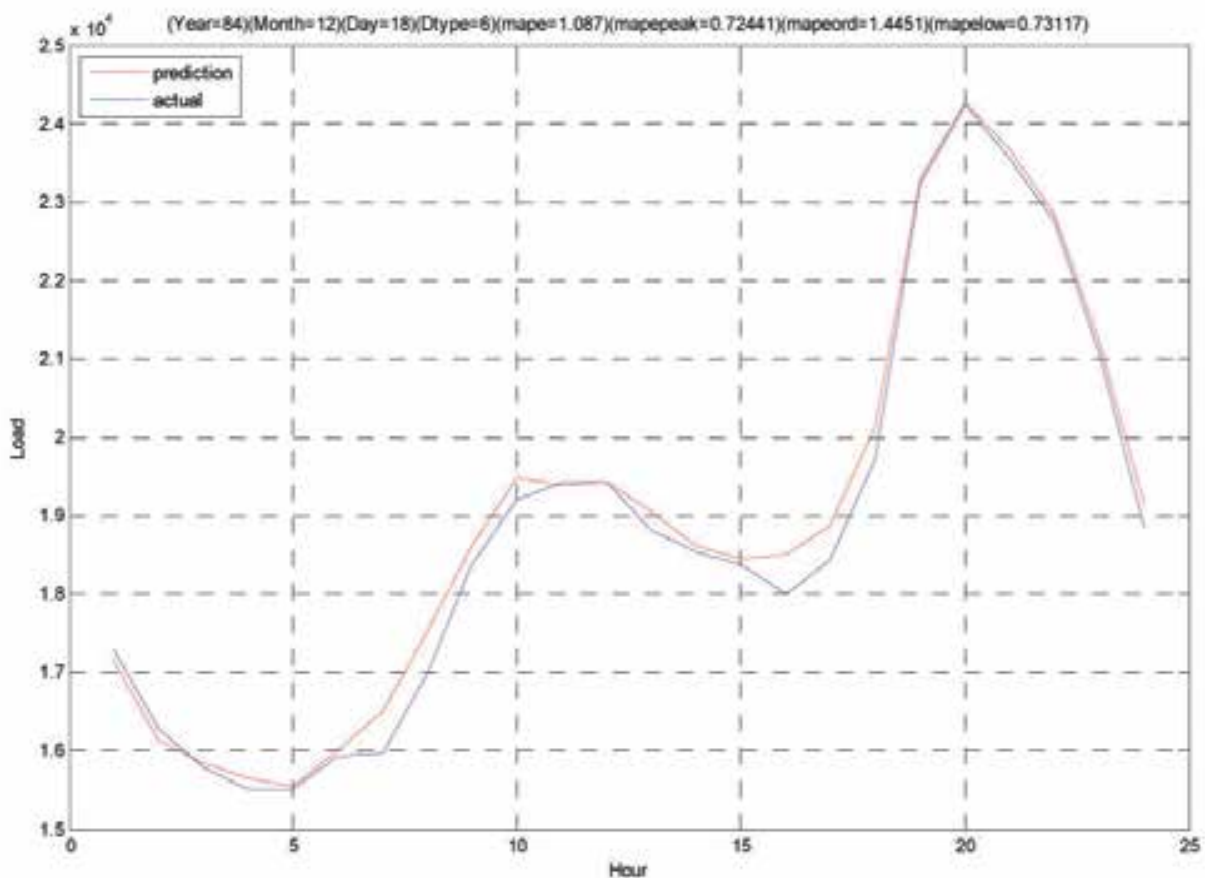

Fig. 8. Anticiption diagram and real bar curve for Thursday

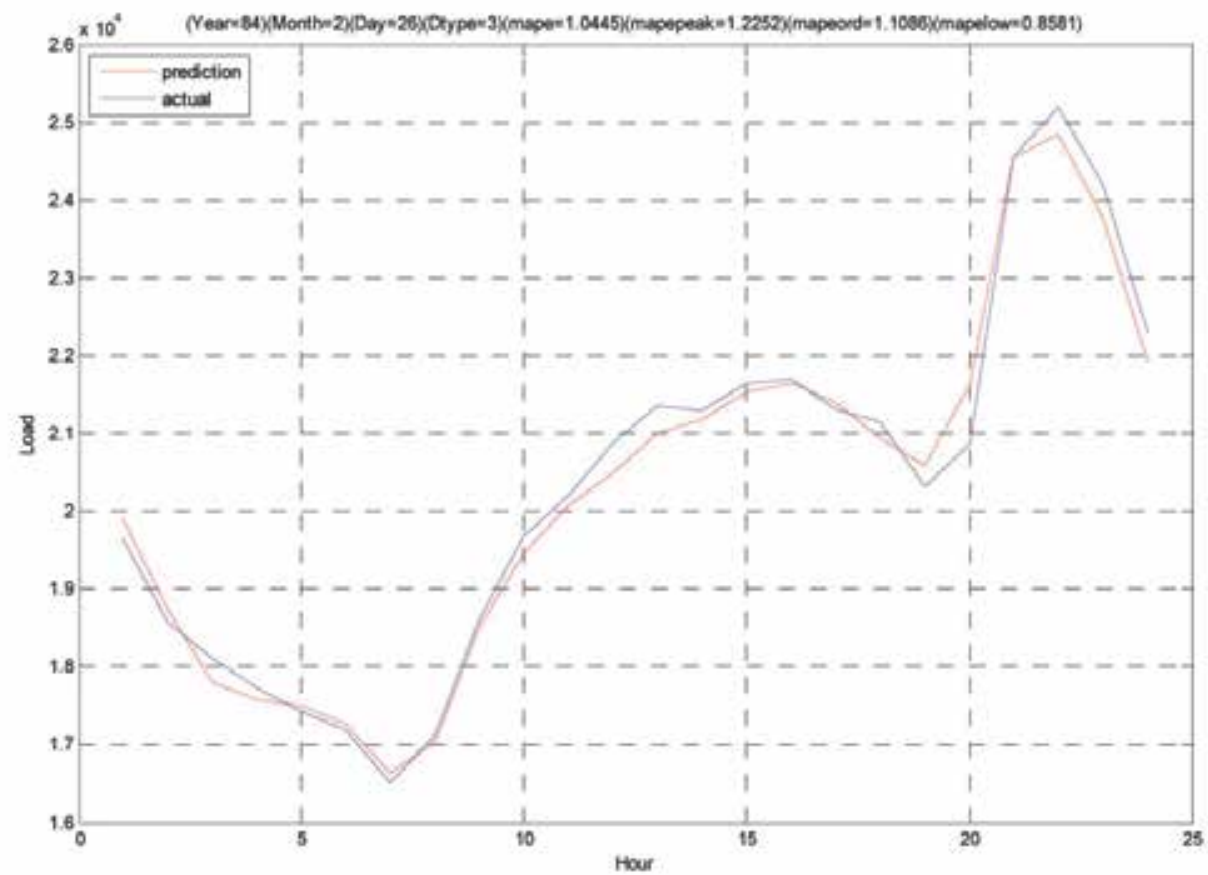

Fig. 9. Anticiption diagram and real bar curve for Monday 


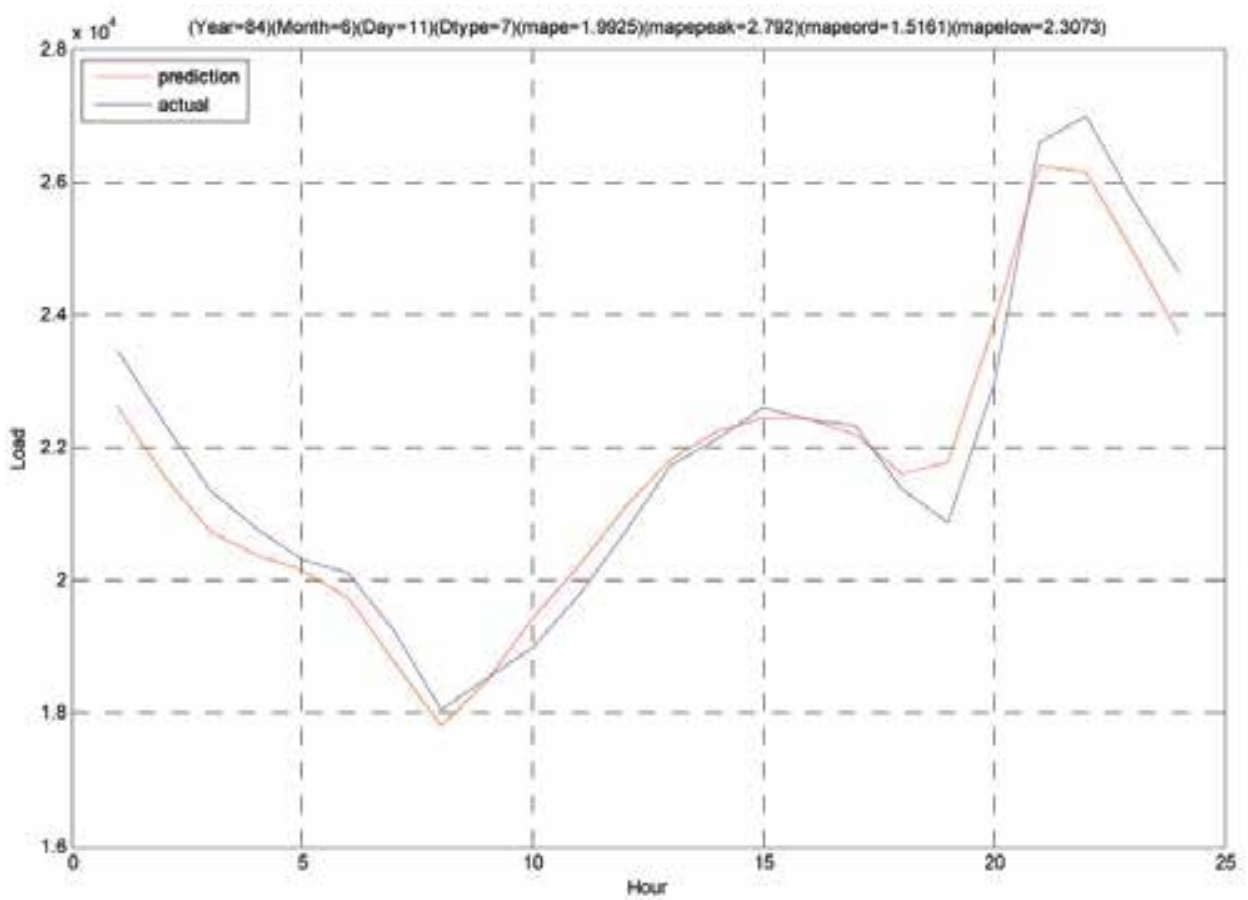

Fig. 10. Anticiption diagram and real bar curve for special lunar day

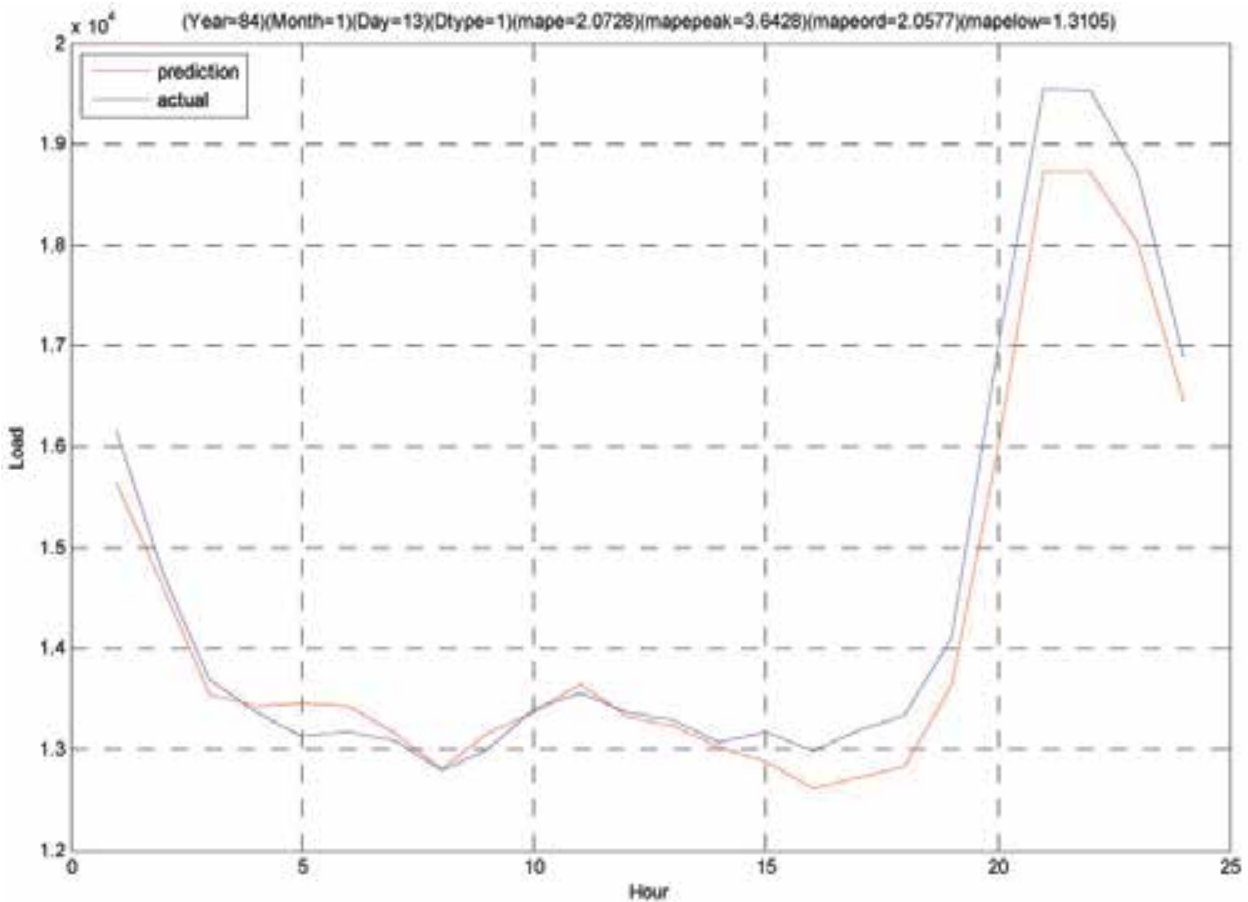

Fig. 11. Anticiption diagram and real bar curve for special solar day 
Network has been distinguished with three different colors as is shown in figure 5. In this figure each bas indicate a region in market. A simple network has been simulated by a Microsoft (Setayesh Nazar M. et al. 2007), and it has been tried to analyze production and lines capacity, their effects on network, and electricity power potential in various states. The results show Iran electricity network includes two parts in north and south. After considering possibility of market exercising authority and its indicators in each region, some ways about reduction of market power in Iran electricity market has been brought up as follows:

1. management of interrupted bars

2. increasing number of power stations

3. increasing of transport lines

4. accumulation management

In another simulation model (Izadi F. \& Puyan S.A. 2002) done in Iran electricity market, at first final expense of each operator is calculated as follows.

$$
S(p)=\frac{1}{2 c}(p-b)=m_{s}\left(p-p_{\min }\right)[M W]
$$

With considering and simulating whole network and each operator behavior, the gained benefit of operators would be calculated. In a complete competitive market, it had been proved that optimal state of a producer is final proposal as production strategy. This simulated model has 5 bas and 4 operators. It has shown at the end that whole market's benefit is decreased when exercising limitations. In addition, the way by which benefit is distributed has had considerable changes and operator has removed others from market.

In another model (Kashani Zade B. et al. 2006) it has been tried to simulate procedure strategies, using play theories and considering each operator role on market price. Considering this effect on price, supply and benefit of each operator in market comparing states lack of limitation between lines and considering lines limitations would be next step.

Goal of all operators of electricity production in competitive environment is increasing production benefit, so procedures would not take any role for consumer. This situation necessitate changing market to a competitive one by exercising policies to prevent monopoly in market and effect prices based on a special strategy of a procedure.

\section{A review on results on Iran electricity market}

Considering information get from offered prices and each region's production and demand, we would examine above results in Iran electricity market. As mentioned before, consumption need do not differ in different month days and in similar hours. Figures 12-18 show price, production and demand for four Mondays (4 weeks) from Tir, 1387 on 3 pm (based on anticipation at local maximum level for Mondays) for all 7 electricity market region.

1. Just region number 6 and 7 can produce at a rate more than their demand for all four days. In other regions production exceeds demand.

2. In region number 6 and 7 , fluctuation of prices has not been effective on production and demand rate, so market can exercise authority.

3. In regions number 6, especially 7 , fluctuation of production and demand is considerable, but in other five regions production and demand volume had little changes during those four weeks. 
Paths to Sustainable Energy

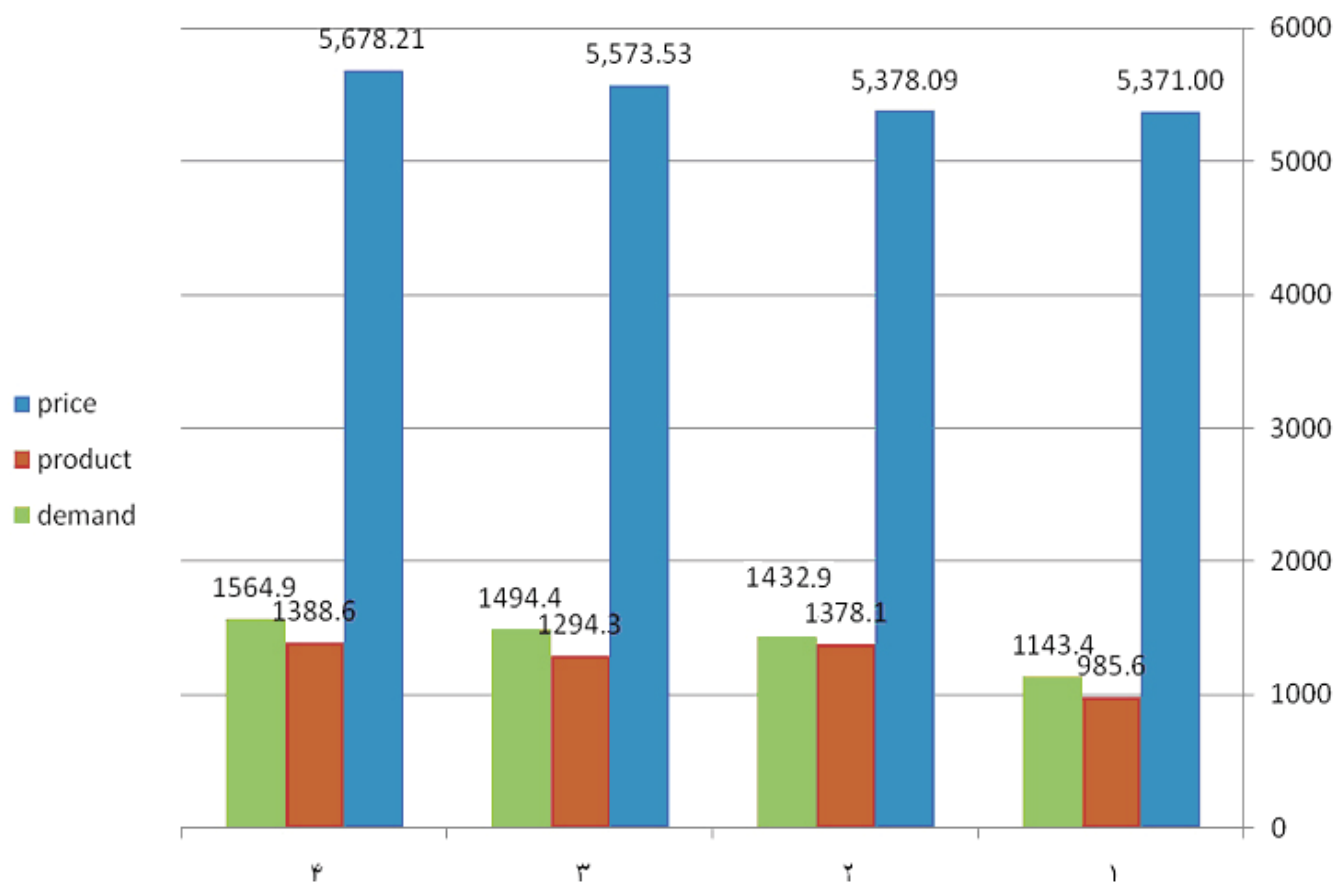

Fig. 12. Comparing three factors in region 1

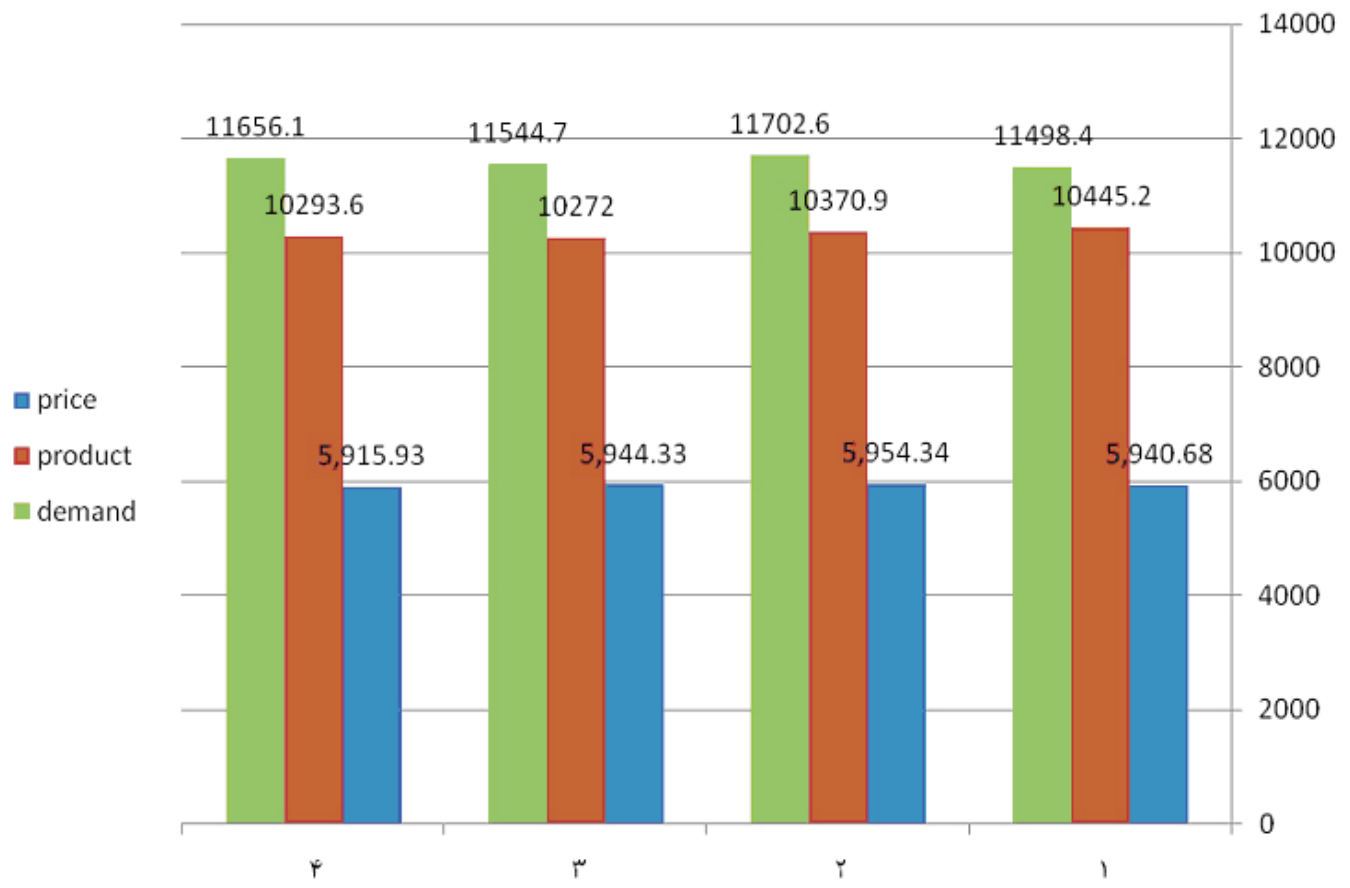

Fig. 13. Comparing three factors in region 2 


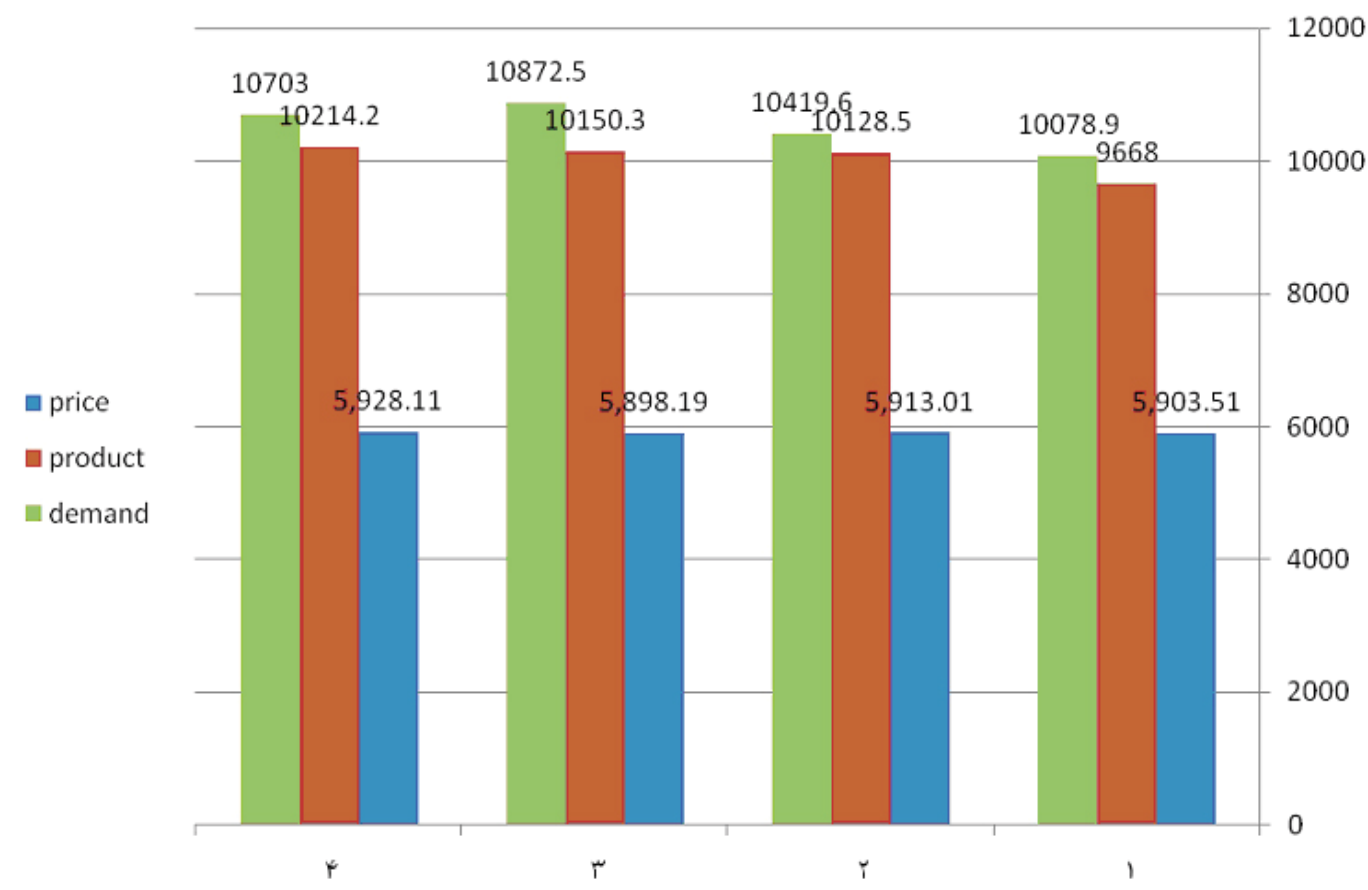

Fig. 14. Comparing three factors in region 3

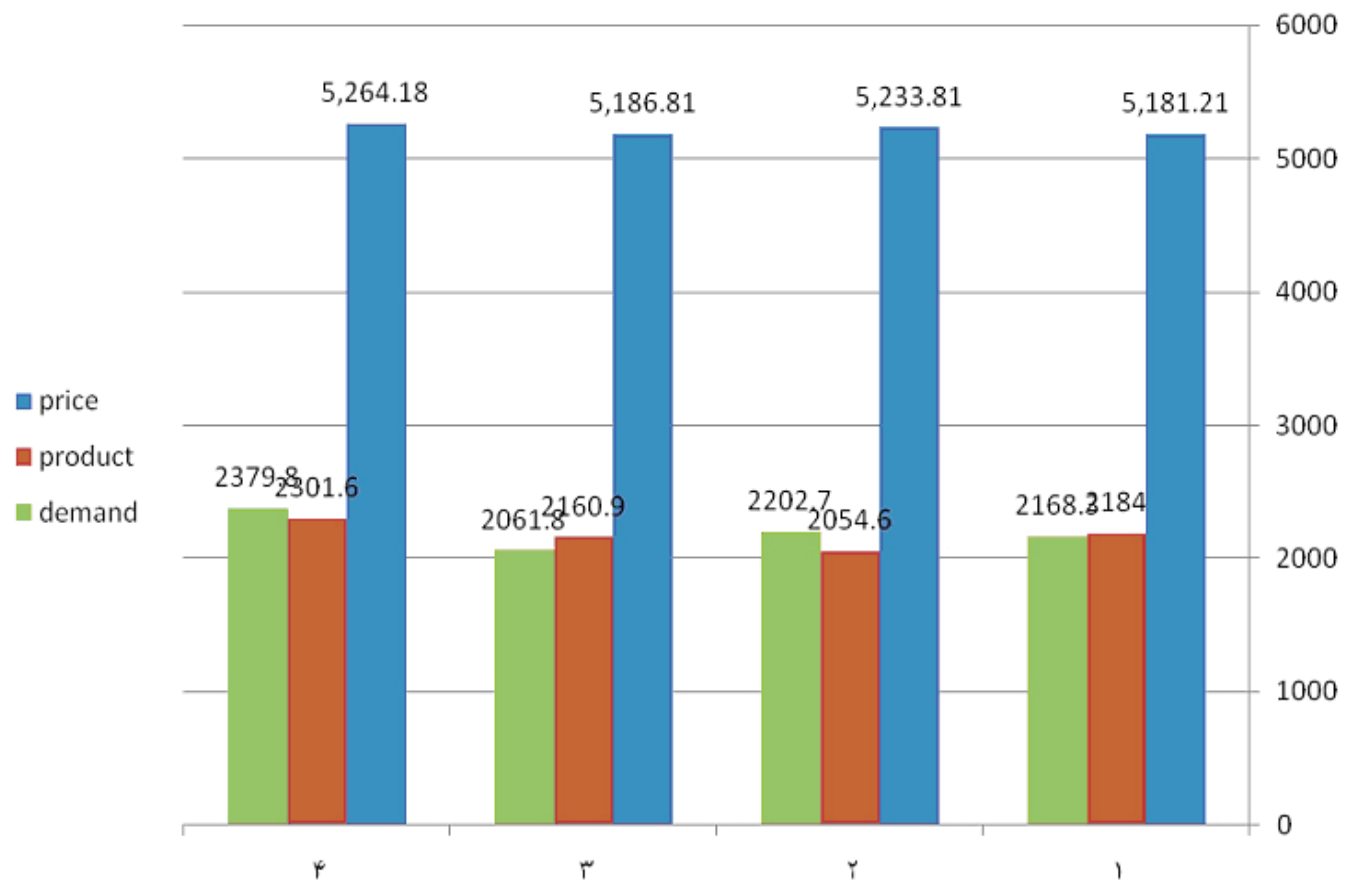

Fig. 15. Comparing three factors in region 4 
Paths to Sustainable Energy

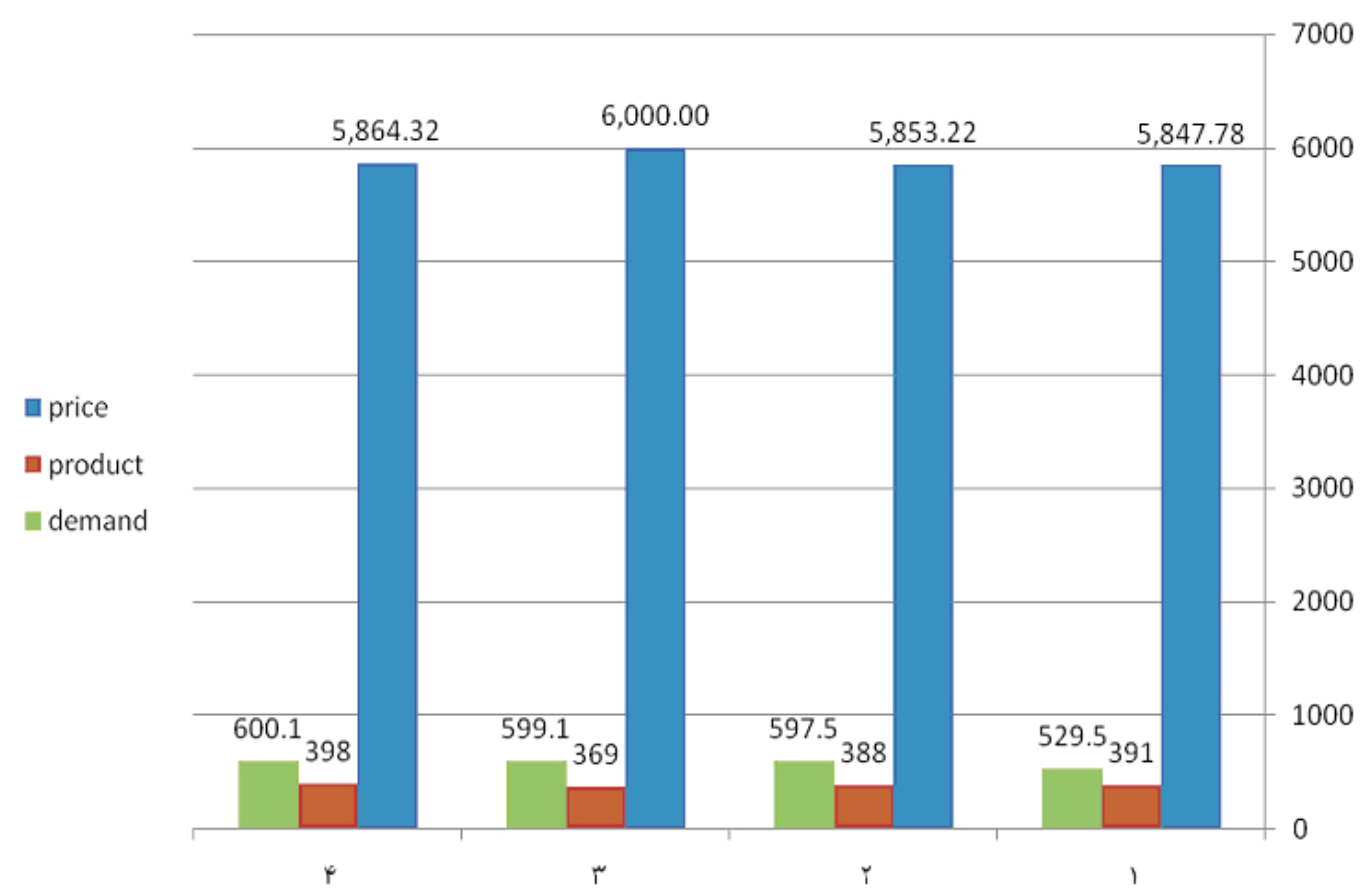

Fig. 16. Comparing three factors in region 5

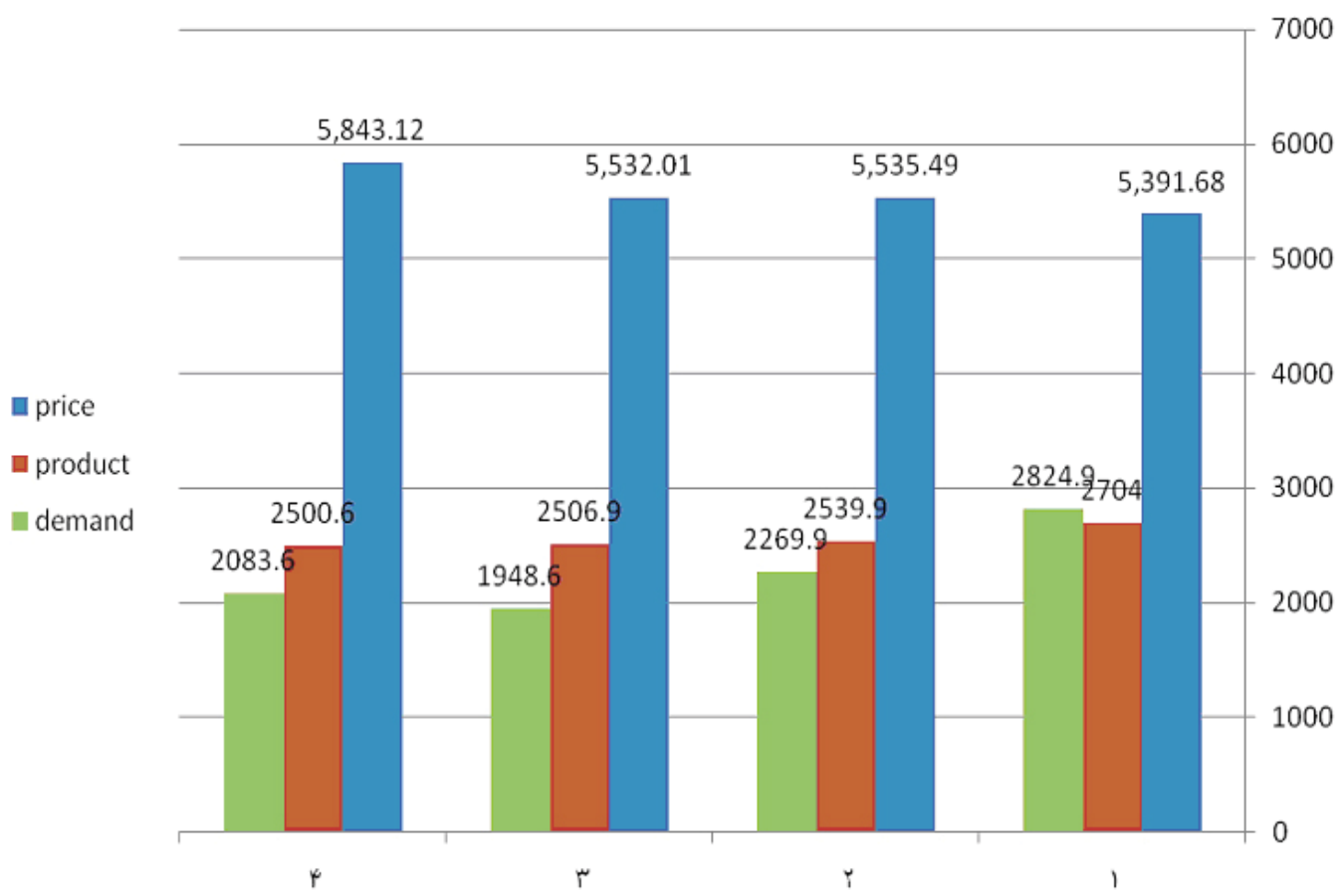

Fig. 17. Comparing three factors in region 6 


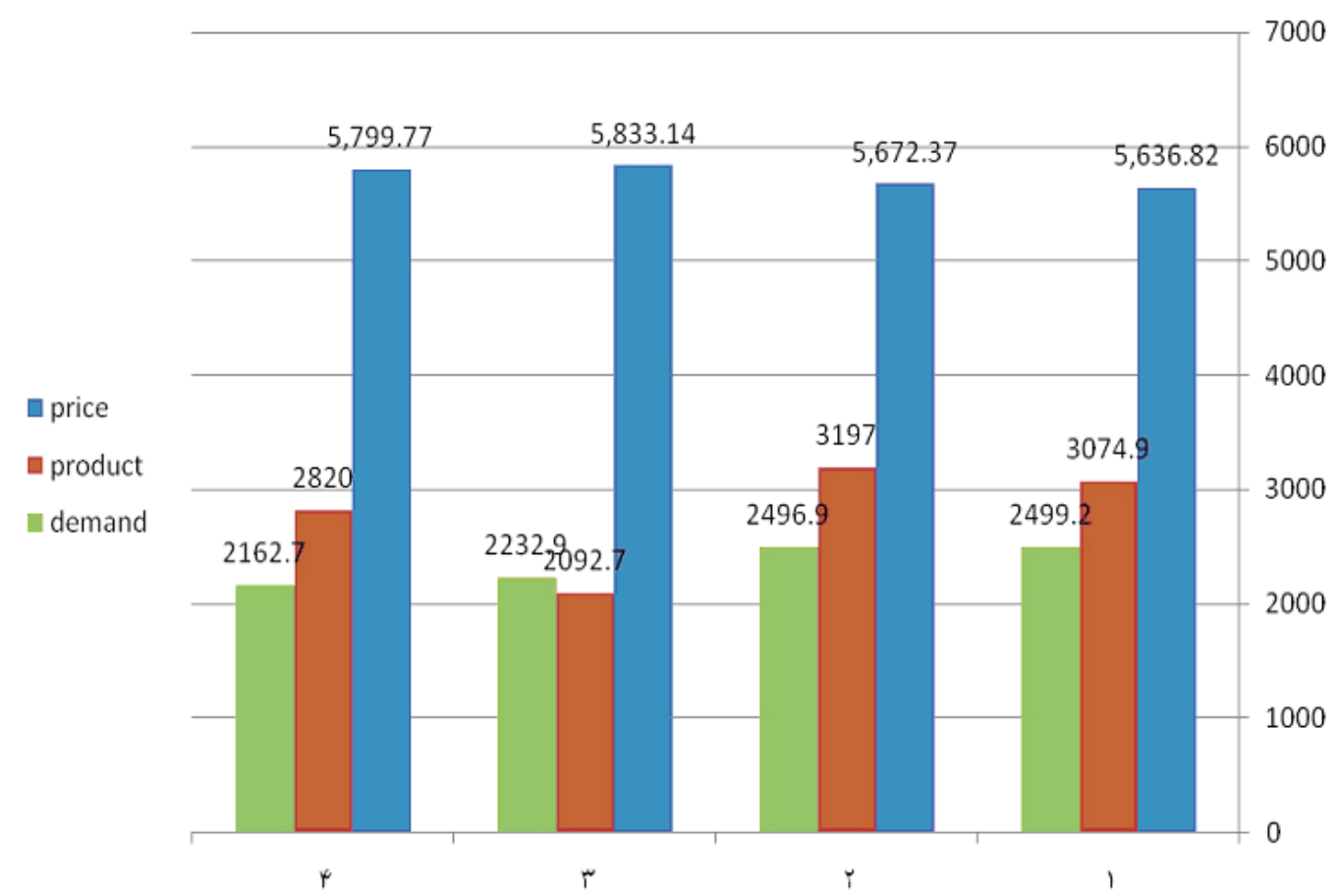

Fig. 18. Comparing three factors in region 7
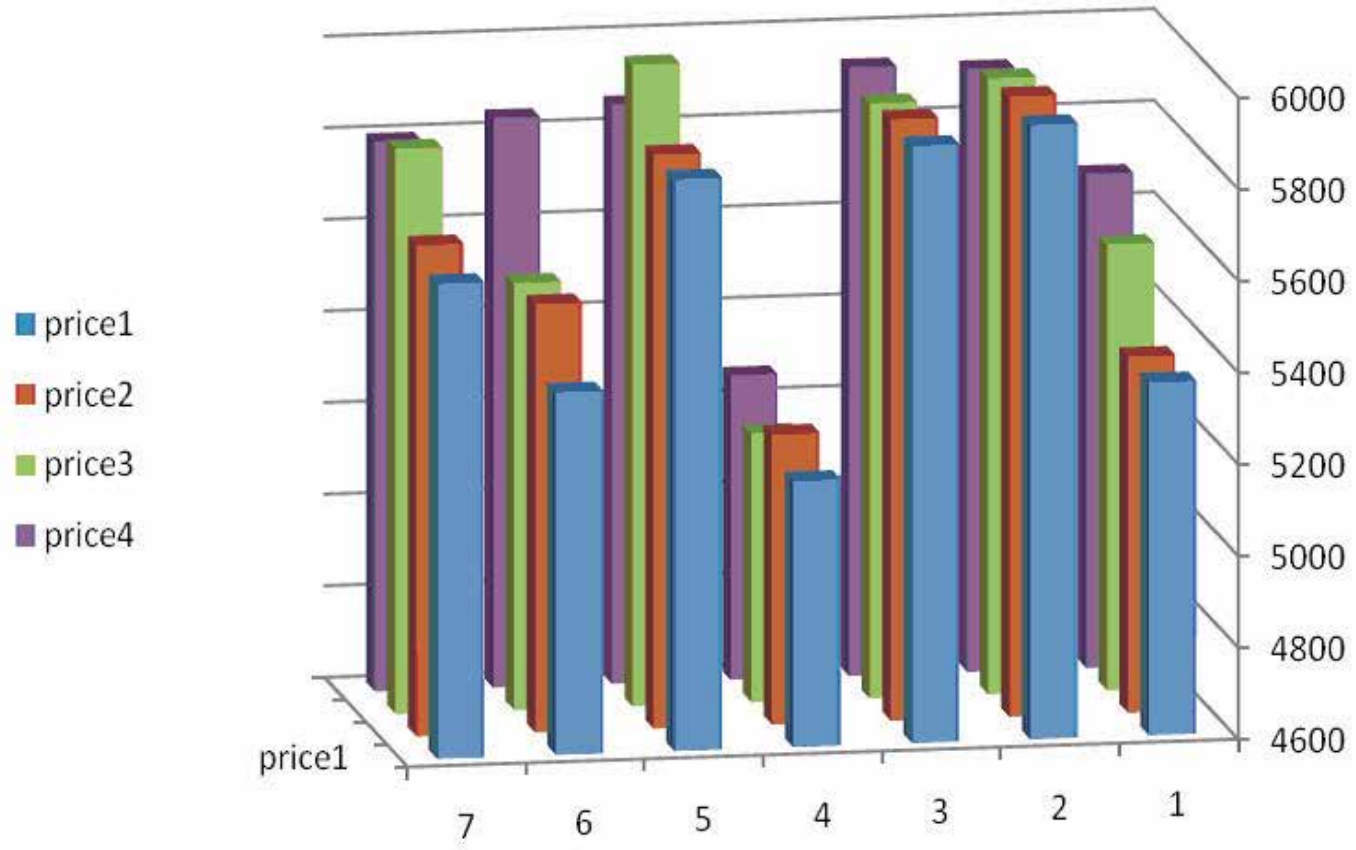

Fig. 19. Comparing price of four weeks in 7 regions 


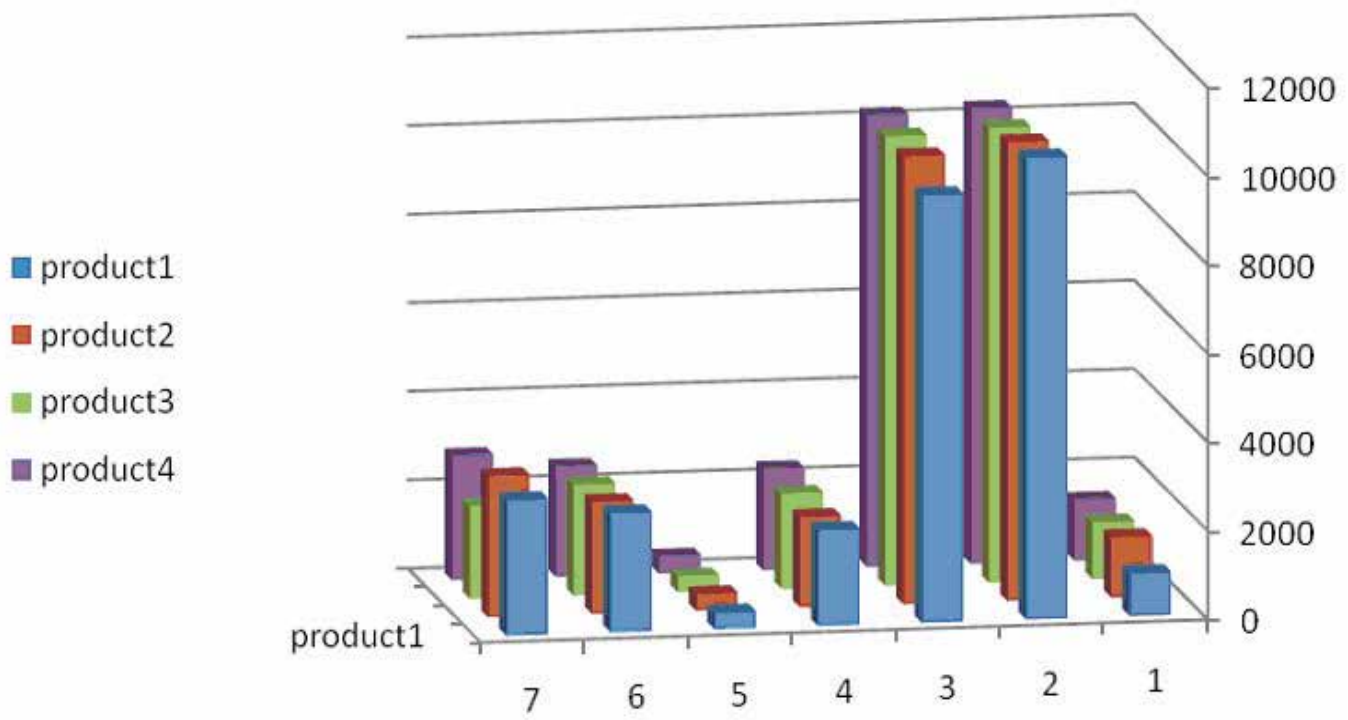

Fig. 20. Comparing production of four weeks in 7 regions

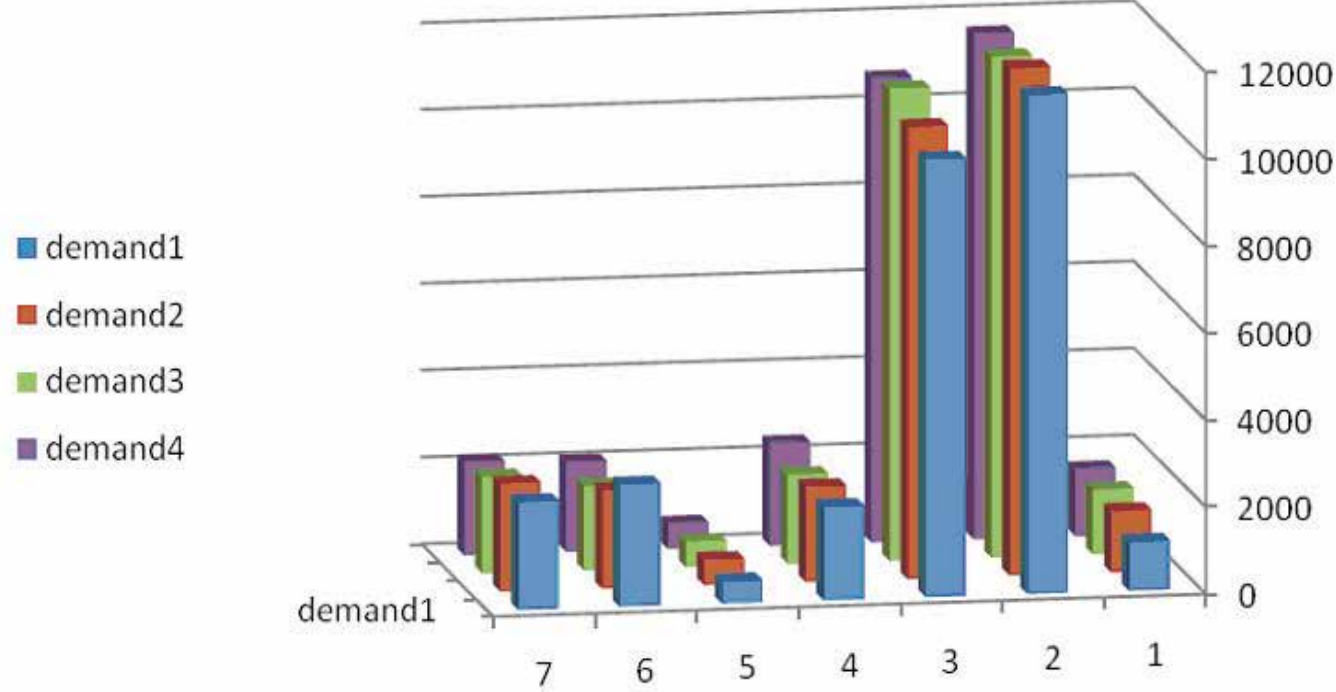

Fig. 21. Comparing demand of four weeks in 7 regionsResults of diagrams 12-18 show:

In figures number 19-21 changes of each price indicator, production and demand is shown separately in 7 regions in 4 days. Diagram 19 shows that highest prices alongside with lowest fluctuation of regions 2 and 3. Region 4 enjoys lowest price and regions 6 and 7 are growing with relatively high fluctuation.

Production and demand changes in figures 20 and 21 shows coordination between production and demand in regions. As seen in these two diagrams just regions number 6 and 7 can produce at a level higher than region demand, price offered in that regions is at a 
low level comparing adjacent regions. These factors show these two regions have potential for market exercising authority.

\section{Results}

Limiting market power is a necessary parameter for power evolution. For doing this at first an exact definition of market helps to recognize existing market power or items which market can exercise authority on.

In this article, SSNIP test has been introduced as a mechanism of defining market, recognizing market boarders and potentials for market exercising authority.

Considering electricity network in Iran and simulated models in Iran electricity market, shows potential exercising authority of market. Iran electricity market has 7 regions, from which according to information in data base, dependant regions number 6 and 7 can do market exercising authority in Iran electricity market. In other five regions recognized as dependent markets, providing demands needs presence of other producers in the region. Offered price in regions number 2 and 3 is at its highest level comparing others because of high demand in those regions.

According to above results, offering some solutions to prevent market exercising authority is necessary. Interrupted bars can decrease system demand in critical circumstances as an operation reservation for a short time. These bars can have role in intensifying competitive circumstances by growth of system margin and decrease of transport lines accumulation. A solution can be growth of power station units as well as departing larger units to smaller ones. Lines accumulation is one factor which can motivate market exercising authority. Planning for re-production and bar cuts are some ways of lines management.

\section{References}

Chi-Keung W. et al, (2006). Bi-directional causality in California's electricity and natural-gas Markets. Energy Policy, 34, 2060-2070

Frayer J., Uledere N. and Lovick S. (2004). Beyond market shares and cost-plus pricing: Designing a horizontal market power mitigation framework for today`s electricity markets. The electricity journal, 1040-6190.

Gujarati D. N. (1995).Granger test, In: Basic Economic. ISBN: 964-03-9330-4, University of Tehran.

Heydari, Kiyomarth (2003). Reform in the Iranian electricity market. 18 th electricity conference, 98-f-sea-416.

Izadi, Farhad; Puyan, Seyed Ali (2002). Electricity market simulation, considering transport system limitations. Tehran regional electricity.

Kashani zade, Babak; Ehsan, Mahdi (2006). A review on effects of producers' strategies on electrical energy market price. The first international management and planning energy conference.

Katz M. (2002). Recent Antitrust Enforcement Actions by the U.S. Department of Justice: A Selective Survey of Economic Issues. Review of Industrial Organization, 21: 373-397.

Katz M. (2006) . The Year in Review: Economics at the Antitrust Division, 2005-2006. Review of Industrial Organization, 29:305-326.

Ogzera website (2005). The SSNIP test: some common misconceptions. 
Setayesh Nazar, mehrdad; Saber, Hamze; Javidi, Hosein (2007). Considering effects of interrupted bars on electricity market power mitigation. Sixth National energy Conference, Khordad 1386 (2007), 22 and 23, 98-f-eec-362.

Tabei, Seyed Mohammad Hadi (2005). A new way of calculation of potential transport in electricity market. 20 th international electricity conference, 98-f-ptl-179.

Vahabi, Abd-al-Hossein; Barghi Niya, Saeedeh; Vafadar, Naser; Berahmand Por, Homayon (2007). A suggestion for anticipation of short-term bar based on finding out similar days. 22 th international electricity conference, 98-f-pss-610.

Yemane W., (2006). Electricity consumption and economic growth: a time series experience for 17 African countries. Energy Policy 34, 1106-1114. 


\title{
Supporting Psychosocial Processes towards a Sustainable Energy System: The Case of $\mathrm{CO}_{2}$ Geological Storage
}

\author{
Samuela Vercelli \\ University of Rome "La Sapienza"- CERI \\ Italy
}

\section{Introduction}

\section{Technology and society: what are the keys to thinking and feeling?}

When we think about sustainable energy... what do we think? Do we think it is possible...or impossible? Can it be done now, or is it for the future? How can we bring it about? Is it a dream, or is it really feasible? Is there anything I can do? What can I do? It's up to industry, it's up to politicians, it's up to environmentalists... The list continues with many other examples of thoughts and feelings which might emerge when we turn our minds to the topic of sustainable energy. These thoughts and feelings will be crucial in moulding our relationship with environmentally friendly ways to produce energy. New inventions and possible solutions and choices will have to come to terms with what is in the minds and hearts of people. Producing a scientific understanding of people's thoughts and feelings can thus support the implementation of new technological solutions and ultimately our ability to develop a more sustainable energy system. From this perspective, psychosocial change processes need just as much attention and care as technological development processes, otherwise the gap between technology and society could hamper the exploitation of available technologies and solutions. This is quite an innovative approach, since the relevance of people's thoughts and feelings usually comes to the fore only when troubles arise, such as so-called "public acceptance" issues. The idea that, if we really want a sustainable energy system, we need to work on our thoughts and feelings and thus stimulate the sharing of new visions and perspectives, is not common. There are a number of activities which are conducted on a social level to facilitate the adoption of new technologies or to improve the way society reaches consensus over critical environmental decisions (Flynn \& Bellaby, 2007). But it is mostly an effort to formulate appropriate policies that can be implemented without too much resistance, or an effort to engage in effective public communication. Also, the so-called participative processes often pertain more to the realm of negotiation than to the acquisition of new common perspectives. Work on thoughts and feelings, which find expression both at individual and collective levels, can instead contribute to the co-creation of meaning, which in turn facilitates decision making both at the individual and social level. This approach to social processes is still to be discovered but we already know that it can affect ongoing change in society: first of all empowering people to direct that change; secondly, allowing the development of new shared representations (Carli, 1972; Carli \& Paniccia, 1981; Carli \& Paniccia, 2002). 
But what are the keys to thoughts and feelings? How can we gain understanding of energy issues by studying them? Here we will propose some experiences which might shed a light on possible pathways forward. Our approach recognises first of all the need to provide conditions that allow their expression. Secondly the importance of the presence of someone who is there to listen to them and who gives start to an elaboration process which can bring new insights and stimulate other thoughts and feelings and so on. Thus, in the long jouney towards a sustainable energy system, social processes, which also involve changing choices and habits require study and attention. In this context the dynamics of knowledge management and dissemination and the related issue of knowledge and technology awareness are of particular interest. Scientific and technological developments can reach the stage of exploitation only when they find full support at a social level. Studying and facilitating the emergence of the meaningfulness of specialized knowledge in our society can be crucial. What is really being done? What is its importance for society? How can this technology contribute to our quality of life? The answers to these questions cannot be taken for granted, they will be formed via an ongoing interaction within our society at all levels. How can we help this interaction? What occurs in our society that allows for a better understanding of a new technology, of how we can decide whether to deploy it or not, to support or reject it? Here we will relate some experiences in the field of $\mathrm{CO}_{2}$ Geological Storage (CGS) on how these processes can be approached and possibly facilitated.

\section{A technology to be discovered}

\subsection{What is carbon capture and storage}

The $\mathrm{CO}_{2}$ emitted when burning fossil fuels in power plants and heavy industry can be captured and stored back in the underground. We call this technology Carbon Capture and Storage (CCS).

CCS is considered one of the technologies with the biggest potential for the reduction of greenhouse gases and in particular for the abatement of $\mathrm{CO}_{2}$ emissions (IPCC, 2005; Stangeland, 2007; IEAGHG, 2008).

\subsection{CCS is mostly unknown}

Nevertheless, such an important technology is still mostly unknown to the wider public (Eurobarometer, 2006; Reiner et al., 2006; Ashworth et al., 2006; Ha-Duong et al., 2009); also among relevant stakeholders, such as authorities at national or local levels, or other policy makers, knowledge about the technology and awareness about its potential concerning climate change is still limited (Johnsson et al., 2010; Shackley et al., 2007; Shackley et al., 2009; Stephens et al., 2009).

\subsection{CCS communication}

Studies have been conducted to understand the public's perception of CCS and communication issues (Shackley \& Evar, 2009; Ashworth et al., 2009b; Reiner 2008; HaDuong et al., 2009) and guidelines have been prepared to support public communication of CCS projects (DOE-NETL, 2009; WRI, 2009; Desbararts et al., 2010). Still, much remains to be understood about how people will structure their own response to the challenges posed by the adoption of this new technology.

We can distinguish two main levels for further investigation: 
- $\quad$ understanding of the place CCS might take in our general culture as a climate change mitigation option, whether it will be recognized as a relevant technology and supported in its deployment

- understanding of the specific issues which might be raised in relation to specific contexts of application

It has to be said, that in the case of CCS, as it has been the case for prior technologies, social awareness of the technology is far behind technological development; for many social researchers (personal communications) it is difficult to comprehend the great delay in starting public consultation and communication, since social research and experience clearly show the high risks connected to lack of communication with the public.

\subsection{The role of education}

A specific issue for CCS is that, given the generally low level of education with regard to geology, it might be difficult for many people to get a good understanding of $\mathrm{CO}_{2}$ Geological Storage, or, given the limited knowledge on energy production processes, it might be difficult for them to comprehend the $\mathrm{CO}_{2}$ capture processes.

\subsection{The role of stakeholders}

Numerous studies have been focused on stakeholders already acquainted with the technology and on the important role they play both for the deployment of the technology and for the communication of information about the technology itself (Shackley et al., 2007; Vercelli \& Tambelli 2005; Heiskanen et al., 2007; Johnsson et. al., 2010; Terwel et al., 2009; Malone et al., 2009, 2010; Fischedick et al., 2009; Ter Mors et.al., 2009). The importance of these stakeholders cannot be underestimated, as stakeholders such as scientists and industrial operators constitute the sources of information on the technological process, while regulators and policy makers will be the sources of information on the rules for the technology's application. It will therefore be of interest to understand how they perceive and actualize their own role within the wider social context. At the same time, the impact of stakeholders' communication will vary depending on the cognitive and emotional substrate to be found in the social context. The way people will receive new information on the technology will be in relation both to the characteristics of the input and to the characteristics of people's culture and education. It thus appears useful to enquire both on stakeholders' perceptions and awareness and on the cultural representations existing in our society which could be relevant when getting acquainted with the new concept.

\subsection{The research}

Here we report on the research we have conducted to explore both the level of specialized stakeholders - a scientific community, $\mathrm{CO}_{2} \mathrm{GeoNet}$ Network of Excellence, created to integrate and develop scientific knowledge on $\mathrm{CO}_{2}$ Geological Storage - and the level of the people, with a study that look place in the primary school involving teachers, children and their families.

\section{The demand analysis approach (DAA)}

\subsection{The social researcher as the locus for incubating mutual understanding}

One of the big issues of our time is the great fragmentation of knowledge and, at the same time, the rare emergence of ideas or ideals that have the strength to bring people together. Knowledge production seems sometimes to loose touch with what really matters to people. 
It is thus critical for social science to find ways to get back in touch with the uncertainties and challenges which lay behind the complex solid structures of our society. These structures are reflected in the highly complex theoretical background of social researchers and in the major part of our work very often condemning it to social irrelevance. To reflect real life and get back to people and society we have experimented an approach which does not focus on the needs of theoretical and academic coherence and procedures, even though it relies on solid scientific foundations (mainly the psychoanalytically oriented "Demand Analysis" theory, the "Social Representations" theory and McClelland "Motivational" theory) but rather focuses on the heuristics of interactive activities carried on by the social researcher. The social researcher, in this perspective, becomes the medium where fragments of knowledge and of opinions come together, in the presence of theoretical structures, and undergo an elaboration process which will inevitably be seasoned with the spontaneous, 'here and now' life experience, feelings, thoughts and the unique perspective of the researcher herself. Valuing and focusing on the unique experience of the researcher herself we get on track to value and focus on the unique experience of each and every individual in our society and therefore we improve the possibility of reaching the experience of individuals to better understand their perceptions, their choices and their participation or resistance to processes of change, such as the one we are interested in with regard to energy production.

\subsection{Intersubjectivity and the co-creation of meaning}

In the field of psychoanalysis there has been a profound evolution which has brought us to recognise more and more the role of subjectivity and intersubjectivity in our relationship to reality and to others (Orange et al., 1997; Stolorow et al., 1987; Stolorow \& Atwood, 1992). The therapeutic relationship has come to be completely reshaped on this basis and furthermore it deals with the task of "making sense" together. Whereas more traditional forms of psychoanalysis are based on the dominant role of interpretation, which of course will be based on previously developed theoretical assumptions and on their elaboration by the psychoanalyst in relation to the present situation, more recent approaches focus on the continuous inter-subjective exchange between the therapist and the patient, who work together to find shared meanings for what they share and experience within their relationship. It is possible to note that what has become so relevant in psychoanalysis and also in many other psychotherapeutic approaches, namely subjectivity and the possibility of co-creating meaning, is also showing its importance more and more in the socio-political arena. The need to understand the richness of subjective perspectives of the multiple stakeholders on a given issue and the need to find ways to make sense of all this complexity thus providing satisfactory solutions for all, is growing fast. The Demand Analysis Approach (DAA) (Carli, 1987; Carli \& Paniccia, 2003) has been developed precisely to help establish contexts for relationships at both individual and collective levels, where subjectivity can find expression and the social process can develop to produce shared meanings. These meanings will shape in the form of social representation, a "form of knowledge that is socially processed and shared, which has a practical goal and concurs to the construction of the common reality of a social community.(...) Generally it is thought that social representations, because they are systems of interpretation that support our relationships with the world and with others, orient and organize behaviours and social communication. Similarly, they intervene in various processes, such as the diffusion and assimilation of knowledge, individual and collective development, the definition of personal and group identities, group expression and social transformation."(Jodelet, 1992). 
The DAA is interested to social change processes which can improve the well-being of individuals and communities and thus is not interested in finding general criteria or laws for human behaviour but rather in working on problems which might be present in the community; hence the focus on the "demand" coming from the community which will be the point of reference for understanding what will happen in the relationship between the community and the researcher. The Demand Analysis provides a valid framework for working on thoughts and feelings in that it is centred on the understanding of the relationship between the investigator and the investigated. This understanding, which proceeds recursively and reciprocally, is functional to the identification of relevant representations that the investigated and the investigator bring into the relationship in relation to the object or objective of the relationship itself, and finds its foundation in the elaboration of the emotional experience considered in terms of the unconscious system mode (Matte Blanco, 1981). The Demand Analysis thus offers the possibility to study the emergence of possible social representation dimensions, keeping in touch with both the individual and the social dimension of emotions, avoiding the risk of purely intellectual and detached understanding which inevitably doesn't manage to reach people.

\subsection{State of the art of CCS social research}

Studies conducted up to now have been oriented mostly to surveying public attitudes towards CCS or to engaging with the public in relation to some CCS projects (for a review see Shackley \& Evar, (2009)). Although the outcomes are fairly homogeneous, showing moderate like or dislike of the technology, it still appears quite difficult to account for the variability and in particular to understand if and how public perception might grow towards more radical positive or negative positions. Surveys and other activities such as focus groups, have been greatly conditioned by the fact that a limited or very limited number of people in our society have any knowledge about CCS. Many studies have thus enquired about informed stakeholders' opinions or perceptions or have tried to bypass scarcity of knowledge by providing prior information to the subjects involved, for example with an "informed choice questionnaire - ICQ" (De Best Waldhober et al., 2009). This has been only partly successful since the respondents' evaluation of the technology proved to be based only partially on the expert information provided. Also, the effort to identify the specific aspects of the technology, benefits and consequences etc. which could influence people's evaluation produced limited results as "none of the aspects or consequences sticks out as a major predictor of the evaluation" (De Best-Waldhober et. al., 2009, p.331). These results might not be surprising when we think that the topic has multiple binds to a number of controversial themes such as energy policy, energy production, climate change, siting of big industrial installations, the use of fossil fuels, etc. In addition, it might be argued that the current status of such issues in our culture is highly undefined, making it difficult for people to formulate coherent thoughts and for the experts to formulate appropriate questions; what seems to be missing is not the information but rather the criteria for making sense of the available information or for looking for missing information. In other terms, we could say that social representations (Moscovici, 1961, 1976; Jodelet, 1992) on these topics are still forming and that we have not yet developed a sufficiently common thought to orient us in our understanding and behaviour. Maybe this is one reason why, in the great majority of studies, the questionnaires and the other material for activities such as focus groups, have been prepared on the basis of the researchers' assumptions on what issues could be at stake based on materials provided by experts in the field. While a lot of information has thus been gathered on CCS perception by a number of stakeholders, it must be said that the way the questionnaires have been structured, the 
questions asked and the choice of the issues addressed, have provided information to the interviewees which would condition their input and limit it to the representation of the topic already given by the researchers. This way of proceeding presents some risks, with regard to the study of an area which has both new technological content and undiscovered social meaning. The way different publics and stakeholders might appropriate themselves of such a new technological concept could lie outside what the researchers might imagine or foresee on the basis of their own information and representation. In addition, it might be very difficult to understand what people are really thinking and feeling, without establishing a direct relationship with them. A direct relationship would instead allow to collect not only answers to our questions but, even more precious personal input, impressions, and spontaneous considerations which can help us get a "feel" of what's really going on and give us useful cues on which issues are in people's hearts. Therefore, in our attempt to understand what could be the way for people to relate to CCS and make sense of it, we have chosen to adopt a theoretical approach coherent with the need to set the conditions for people to express their own original perspectives, for detecting their own choice of issues and questions, reducing the influence of the researchers' structured thoughts to a minimum.

The proposed approach differs from that of the previous studies in at least three main aspects:

1. rather than starting with the social researchers choosing issues and questions, it sets the conditions for both the children and the researchers to raise their own issues and questions, in relation to learning about the topic for the children, and in relation to spreading the knowledge, for the researchers. This approach implies a trusting attitude towards whatever issues people might raise and recognizing their importance independently from the level of their specific competence

2. it values the direct relationship to the people as a fundamental tool for gaining realistic understanding of the issues at stake

3. it emphasizes the need to produce a deep understanding of what could prevent the dissemination and exploitation of available technological resources; what we mean by "deep understanding" is a holistic knowledge that guides us through the hurdles of complex socio-political contexts, when the application of well tested analytical guidelines might not suffice. This need implies remaining open and available to any emerging social meaning.

In adopting this approach we intend to favour the possibility of getting involved in the social processes which produce social representations. Thus we might identify the representational aspects that have the potential for guiding our society in making appropriate and sustainable choices.

\subsection{Providing insight}

From this perspective, it has to be considered that our objective is not to demonstrate or prove what people actually think and feel but rather to provide useful insights on how we can all advance, in our pathways towards sustainability, when we take into account our own as well as other people's thoughts and feelings.

\section{Being immersed in the social processes}

We propose reflecting on the social processes that we have studied with researchers and children and which gave us firsthand information on individual and collective thoughts and feelings that can arise when work is done on the processes of knowledge transmission. We 
will try to illustrate the journey we shared within the scientific community in relation to the challenges of creating a network capable of internal and external communication of scientific research. We will also discuss some of the adventures and data from the study in the school. Both these experiences seem to have more than a subtle link with one another and with the difficult path towards sustainability.

\subsection{CO2GeoNet - The European Network of Excellence for the Geological Storage of $\mathrm{CO} 2$}

In regards to the case of $\mathrm{CO}_{2}$ Geological Storage, our study is part of the research carried on within $\mathrm{CO}_{2} \mathrm{GeoNet}$ Network of Excellence, a European network of 13 research institutes, among which Sapienza University of Rome, which was promoted by the European Commission for the creation of a pan-European virtual lab to develop research on $\mathrm{CO}_{2}$ geological storage in an integrated manner (Czernichowski et al., 2009). The big gap between the advanced stage of scientific progress on $\mathrm{CO}_{2}$ Geological Storage and the very low awareness about it amongst the public and other stakeholders, was the starting point of the work. How could we disseminate knowledge? How could we efficiently communicate complex and highly specific geological concepts which explain the functioning of $\mathrm{CO}_{2}$ Geological Storage? Several aspects of the issue appeared relevant, some of them more difficult than others to approach methodically. The role of the scientific community in clarifying CGS, what it is about and its feasibility, was of course a fundamental one.

It is well known that although scientists hold a high level of credibility by the public, as is confirmed by surveys such as those of Eurobarometer (2006) about credible information sources on energy issues, nevertheless communication between scientists and the public is not so easy due to many factors, among which the considerable differences in language and cultural background. This situation, which is quite common in our society, indicates that the work on information itself, to be effective, needs to be part of a wider process; the need to communicate has to be understood in light of the numerous points of view and requests arising from scientists, the public or other more specialised stakeholders. Following this line of reasoning, a process was started within the network, through dedicated sessions and workshops, to understand the specific perspective of the researchers in their effort to disseminate knowledge and to facilitate the definition of what they actually wanted to disseminate.

Our work within the Network has been carried on in the area of the Spreading of Excellence activities, which comprised different forms of dissemination (training, workshops and conferences, a website, the media). The community of researchers, which was forming under the auspices of the European Commission, needed to coordinate its own development as an integrated network of scientific institutes and at the same time was invested with the task of communicating research on $\mathrm{CO}_{2}$ Geological Storage to other stakeholders and the wider public. It was a situation that was rather engaging and difficult to sort out: both the process of integration and the process of dissemination involved psycho-social dimensions about which the researchers - geologists, engineers, biologists, etc. - were mostly inexperienced and/or unaware. Our institute was then involved, thanks to the presence of social researchers in the research team, to support the performance of Spreading of Excellence activities through initiatives for raising awareness in the Network about $\mathrm{CO}_{2}$ Geological Storage communication issues. The work of raising awareness, following the Demand Analysis Approach, has been characterised by the exploration of communication needs, through the organization of facilitating situations and contexts and then by working with the researchers on what emerged. This process has been part of the life of the Network 
articulating itself complementarily with all the other activities for research, management, communication, etc.

A number of workshops and seminars have been conducted, for different levels within the organization, starting with the Management Board, then the high-level representatives in the Assembly, the network's governing body, and then more extensively for all the researchers. This first phase has subsequently given rise to a number of internal and external communication activities, which reflected a greater definition of communication objectives and the effort to dialogue and find an appropriate language for different stakeholders. Throughout this process a number of issues had to be faced and elaborated:

- $\quad$ the reasons for the existence of the Network and its objectives

- clarification of the context for the Network's operation: EC mandate, CCS community, wider social context, etc.

- clarifiying the relationship of the research work to its practical application, and for planning it in relation to society's needs and the requests of industrial operators or regulators

- defining the role of the single research disciplines in the framework of $\mathrm{CO}_{2}$ Geological Storage

- establishing the fundamental role of multidisciplinary integration since complementarity of knowledge is essential toward building a comprehensive framework for a solid scientific foundation of $\mathrm{CO}_{2}$ Storage

- consequently, establishing relevance of internal communication activities - not just the presentation of one's own work but also more interactive activities facilitating discussion and exchange

- examining specificity of external communication, developing an understanding of possible information needs of other stakeholders and developing communication skills.

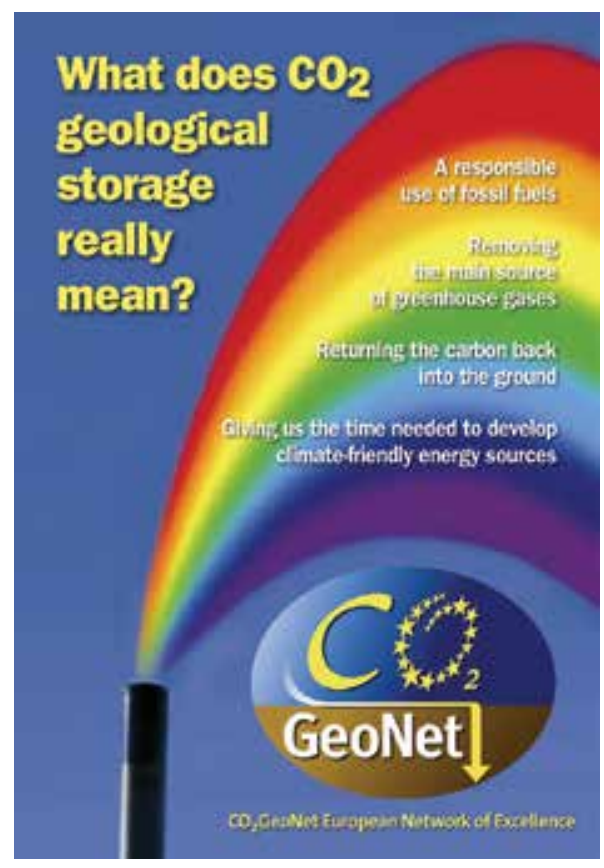

Fig. 1. Cover of $\mathrm{CO}_{2} \mathrm{GeoNet}$ brochure on $\mathrm{CO}_{2}$ geological storage 
These issues emerged gradually as the analysis of the social process developed, based on the Demand Analysis, and just as gradually, increased the awareness of the researchers about their own role beyond the production of scientific data: the need to make sense of this data, to link the data of different disciplines, and to enable accurate comprehension of the research outcomes. This implied first of all, an in-depth understanding of one another's work, thus high-intensity and high-level sharing and exchange and secondly the capacity to explain the meaning implicit in the data, which was developed through the effort to communicate externally. A number of specific activities were conceived and became the opportunity to materialize this process, or we could say, this progress. A milestone, in particular, was the Training and Dialogue Workshop on "What does $\mathrm{CO}_{2}$ Geological Storage really mean?" which took place in Paris in the Autumn 2007. The idea for this workshop, the way it was developed, the method for integration and communication of knowledge which we practiced together were the fruit of the work on social processes within the Network. They were the outward manifestation of a new awareness about the role of researchers in a wider social context, in relation to a new emerging social representation (Vercelli \& Lombardi, 2009). Further developments of the Paris workshop have led us to produce, thanks again to the coordinated efforts of a multidisciplinary team of researchers, a scientific brochure with the same title (fig. 1). This brochure is not just a comprehensive explanation of the scientific foundations of $\mathrm{CO}_{2}$ Geological Storage, it is an example of integrated knowledge production and dissemination; it is an example of how very specialized scientific research can be made available and accessible: the brochure is downloadable from $\mathrm{CO}_{2} \mathrm{GeoNet}$ website www.co2geonet.eu and is already available in 10 languages thanks to the collaboration on the translation, of a number of other entities outside the Network.

What is new and good is that the synergy between the European Commission mandate for building the Network and promoting integration, high level scientists, attention and work on social processes has given us the possibility to experiment new ways for knowledge production and dissemination. What we learned during this process is the importance of direct exchange and discussion in a safe environment.

In our case, the rise of strong personal relations and a trusting atmosphere, together with strong achievement motivation, played a central role. We will see below what we intend for achievement motivation and how it relates to the work we did with children.

\subsection{The primary school project}

The way energy issues are represented in our society will be reflected in what children learn at school and absorb from the social environment they live in. At the same time, the structuring of thoughts and cultural dimensions in children is still very plastic, children are much quicker at learning new things and usually more open and curious towards new ideas and practices. This is why we considered working with children particularly interesting for gathering information on the psycho-social challenges linked to the introduction of a new technology such as CCS. Last but not least, today's children are the adults of tomorrow: they will be the ones who will be involved in the deployment of new technologies.

\subsubsection{Contact with the children}

It is well known that we learn best when we are enjoying ourselves; also self-expression is encouraged by activities which we take pleasure in. For these reasons, because the topic we wanted to communicate about was quite technical and intellectual, we tried to communicate 
it in a simple, enjoyable and playful way. The scope was to support full learning and full self-expression and thus maximise the value of reciprocal exchange with the children. How would they learn about CCS? Would they be interested?

\subsubsection{The activities}

The study took place in three Roman primary schools and was dedicated to understanding how the children would build their own relationship to the proposed topic, how they would learn about it and interact with regard to the dynamics of problems and solutions. The study continued in the time frame of two subsequent school years. One fundamental criterion in building the context for our work with the children and the teachers, was the establishment of a collaborative and enjoyable relationship. This relationship was the main source of information for the social process that was activated during the research and for the introduction of scientific concepts. The production of materials such as drawings or written texts is part of this relationship which also accounts for their significance. Much care was thus given to avoid a frontal teaching setting and to creating as equal relationship as possible where the children could express themselves freely, wouldn't worry about making mistakes, would feel free to explore, and would ask questions and experiment. Of course this was long, and intensive task, meeting 13 classes for 7 sessions (for 2 hour sessions), plus: one "meeting a scientist" session (a dialogue setting, where a geology researcher was available to answer all sorts of questions); one visit to our Fluid Chemistry Lab (where the children were shown how we take gas samples, measure $\mathrm{CO}_{2}$, and were allowed to do some gas and water experiments themselves); a final event with the families (where the children explained to their parents and relatives what they had learned during the project with the help of posters they had previously prepared); preparatory meetings with the teachers.

\subsubsection{Questions: the relationship with the children}

When we worked with children in the classroom we were interested in observing spontaneous imagination and thought processes evoked in children on the topic of energy and pollution. It is very important from a psychological point of view, that spontaneous contents and reactions can find room for expression (so they can be observed), since they will be the real determinants for related behaviour. We had prepared the teachers to support our work, for example, accepting whatever the children said without criticism. But very often a situation would arise where the children expressed concepts, which in the eyes of the teacher, were "wrong", and so the teacher would intervene and "correct" the child. In this context it was difficult to introduce new concepts; since both the children and the teachers were very worried about what was right or wrong, and little room was left for adventuring into new areas of knowledge, for experimenting, or for asking questions... But whenever we managed to create a relaxed situation in the classroom and the teachers tolerated free selfexpression, the children would raise many questions and engage in in-depth discussions. Then the topics proposed became an opportunity for exploring and expressing all sorts of doubts and curiosities. In any case, the sessions were pleasant and lively and the children showed a lot of enthusiasm for the subject and all the activities done together. The opportunity to interact with University researchers in an open setting was perceived as precious particularly when, through play activities, we could talk and "discover" new things. The feeling was, that there was never enough time for this kind of exchanges, the ones which were more satisfactory. Just as in our work within $\mathrm{CO}_{2} \mathrm{GeoNet}$, the value of 
establishing a safe environment where everybody could feel free to express oneself emerged. This was new and good and not only the children but most of the teachers appreciated the difference in their everyday learning/teaching experience. Protecting the children from criticism and judgement wasn't easy because the teacher's themselves felt exposed to criticism and judgement when the pupils were not, in their eyes, up to the task. The understanding that the freedom to be wrong would enhance the capacity to explore, to be creative, and to find solutions, even though it was recognized, was very difficult to practice. We wonder how much of our ability to solve problems is sacrificed by the need to be right... This thought and this feeling have accompanied us all throughout the work in the schools and with it, the thought of how important it would be to free human resources to be able to stand up to issues such as those of energy and pollution. Further on this path, today we would reinforce the emphasis on creating an environment where the children could feel free to explore and set their own learning agenda. Although during the project all the contents were proposed in an interactive mode, through dialogue and experiments, and adjusted to answer the requests coming from the children, we now think that on the level of content, the process of appropriation would have been much more efficient if the children had taken the lead in the choice of topics, following their own interests. We would now try to overcome the limits created by the fact that we proposed set material, which had been decided for research reasons. It would probably have been much more efficient to work with a different approach, starting from the problem and then just supporting the children in finding information rather than providing it for them. Of course this would have been much more difficult to handle from a research point of view and in due regard to the teachers, who already found the adopted setting very innovative.

\subsubsection{The drawings}

For this publication we have taken into consideration some of the results regarding the drawings produced at the beginning and at the end of the study in year one and in year two. The children were in $4^{\text {th }}$ and $5^{\text {th }}$ grade (9-11 years old) and produced a total of 650 drawings. We asked the children to make the first drawing the very first time we met them, to survey their representation before the work to be done together started; after spending some time getting acquainted we had a short interaction connecting them to the topic of interest. We asked them if they knew what energy is, how it is produced and what are the consequences on the environment; the children were encouraged to say without any input on our part. After these questions and answers we asked them to please make a drawing on this issue and/or its possible solutions.

The second drawing was done at the end of the first year, after having introduced new concepts about geology, gas, special characteristics of $\mathrm{CO}_{2}$, energy production, the issue of greenhouse gases, and possible solutions for reducing $\mathrm{CO}_{2}$ emissions including CCS. The third drawing was done after one year, having been refreshed through dialogue and play on what had already been done together. For some examples of the drawings see figure 2, 3, 8 .

\subsubsection{Drawings codification}

The drawings have been classified for a number of variables. The ones we will consider here are "Motivation need" and "Relationship to pollution".

For the "Motivation need" variable, we refer to the theory of human motivation of David McClelland, who identifies three major needs driving human behaviour: the need for 
Affiliation, when the main concern is for establishing, maintaining or restoring a positive affective relationship with another person or persons; the need for Power, which pushes people towards controlling or influencing other people's behaviour or towards influencing the environment around them and the need for Achievement, which carries out the function of guiding man's behaviour toward the search for a solution to individual and social problems. For a complete description of the three motives see McClelland (1987).

To apply McClelland motives to the drawings' codification some specific criteria have been formulated to facilitate the identification of the motivational disposition of the child in relation to the topic of the drawing (see Table 1).

\section{Need for Affiliation}

- The problem is experienced at a community level without seeking a solution

- Powerlessness regarding pollution that leads to stasis or delegation

- The problem is present, the question of whether it should be addressed is not asked, but social dimensions are recoverable, at times with negative connotations (even though the relationship can generate anxiety, it is the solution to the problem)

- Absence of attribution of cause or fault

- Presence of the problem and the active remedial action but it is tautological

\section{Need for Power}

- One is an active part in the polluting process (power over...)

- Presence of causative factors with negative effects, but in the drawing potential solutions are excluded

- Pollution controls and determines certain phenomena

- Pollution is held responsible of a (people's, animal's or other entity's) problem, pollution has the power to condition people's life

- Powerlessness. The cause (in terms of whose fault it is) is identified and no potential solutions are foreseen

- Powerlessness regarding pollution, that leads to a request for help

\section{Need for Achievement}

- Solutions are proposed

- The subject is actively engaged in the process for finding solutions

- The pollution process is described

- Presence of causes, not faults

- The process is described even if only partially. If the process is described highlighting powerlessness, it is need for power

Table 1. Criteria for the codification of "Motivation need" in the drawings

The "Relationship to pollution" variable is defined here as the emotional relationship towards the pollution issue reflected by the dominant point of view in the drawing. After an initial screening of the drawings, we have identified five criteria: 1) acting, 2) witnessing, 3) being subjected to, 4) blaming, 5) being constructive, 6) other. See table 2 for codification criteria. 
Acting (code 1)

- If the subject (in the description) pollutes or damages the environment, we consider it "acting" also if there is somebody subjected to it. If it is the main subject to be subjected, it will be classified with code 4

- It is not the subject that acts but an element of the drawing (a factory, a car, a house, etc.). The intention to pollute is expressed in the written description of the drawing

- Elements that pollute or degrade the environment are personified. If there is no personification, it will be codified as a description (code 2)

- An action that generates a negative consequence

- The form -ing is utilized to explain an action taking place. E.g. "They are polluting" is an action taking place at that moment, it is different from "pollutes": one who observes the process in a detached way (code 2)

\section{Witnessing (code 2)}

- A situation is "objectively" described, an external point of view is assumed

- A person or a personification is present that is actively polluting but it is only one of the elements in the drawing. The person and the other inanimate elements are present in the drawing with a similar function. E.g. a child that pollutes in a city with cars, factories and airplanes that pollute. The subject is in the position of the observer

- When a subject is present that pollutes and there is one who is suffering, if none of them predominates (acting or being subjected to) it is code 2

\section{Blaming (code 3)}

- Rules are dictated to avoid polluting behaviour, presence of punishment for the polluter

- Presence of bans in the drawing e.g. posters or warnings present in the description

\section{Being subjected to (code 4)}

- The drawing focuses on a factor that is actively polluting and a person /personification/animal that suffers the consequences

- Feeling ill due to someone / something

- Presence of animals or people that suffer the effects of pollution or damage to the environment

- Planet Earth suffers the effects of pollution or other activities that bring damage to it. Presence of elements that refer to a condition to passivity. E.g. Planet Earth cries

- Powerlessness and stasis (delegation) or request for help, not knowing what to do

- The fact that the subject is being subjected to pollution is present in the description

\section{Being constructive (code 5)}

- An active role in the process of environmental improvement. E.g. recycle, separate, turn off light

- Presence of a clear solution to pollution problems

- Proposal of solutions even if bizarre or not feasible

- The text describes what should be done to face pollution even if in the drawing it is not detectable

- Constructive elements are not present in the drawing but in the description

Other (code 6)

- Not clearly classifiable in the previous categories

Table 2. Criteria for the codification of the "Relationship to pollution" in the drawings 


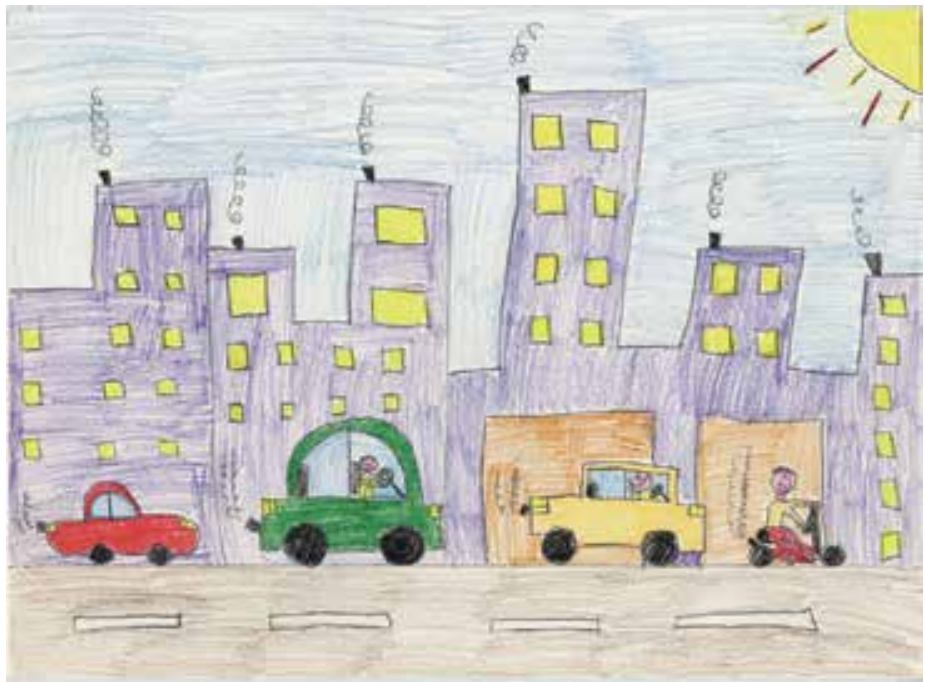

Fig. 2. "I drew polluted Rome. Air pollution" (Affiliation/Witnessing)

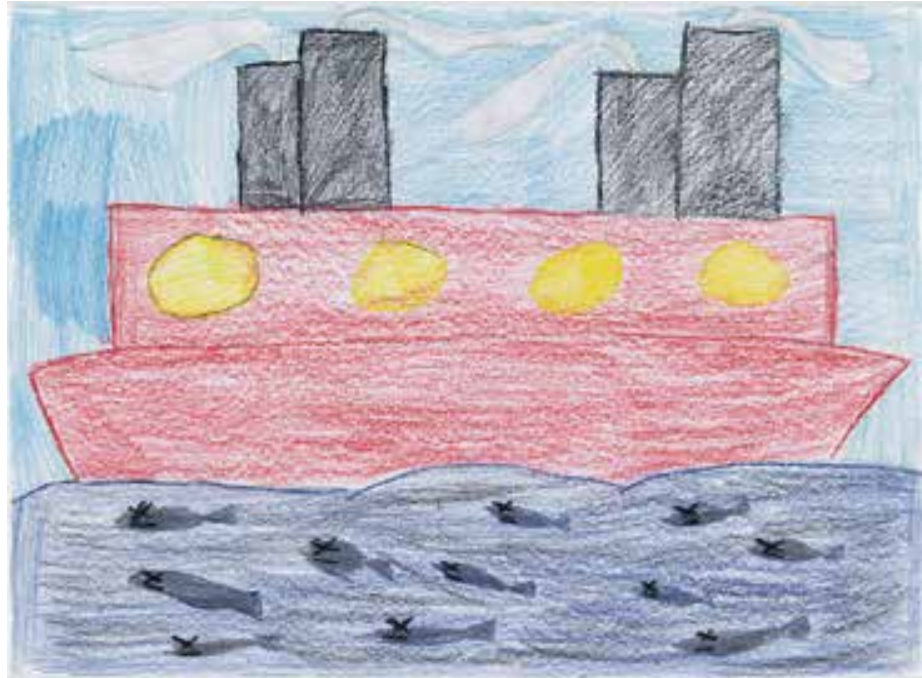

Fig. 3. "I drew an oil tanker that pollutes the sea and makes fish die“ (Power/Being Sub. to)

\subsubsection{Results}

The majority of the drawings present a motivational dimension of Achievement $(55,5 \%)$, followed by Affiliation (30,8\%) and Power (13,7\%) (Table 3). Clearly, most of the children are driven to the issue of energy and pollution in terms of problems/solutions. It is interesting to note that the Achievement motive increases over time, while the Affiliation motive diminishes (Table 3, Figure 4).

When we look at the second variable (Table 4), the Relationship to pollution, we can see that the majority of children express a position of Witnessing $(51,8)$, followed by Being constructive $(18,2 \%)$, Being subjected to $(10,6 \%)$, Acting $(9,2 \%)$, Other $(7,8 \%)$ and Blaming $(2,3 \%)$. (Table 4$)$. 


\begin{tabular}{|c|c|c|c|c|c|c|c|c|}
\hline \multicolumn{10}{|c|}{ Motivation needs } \\
\hline & \multicolumn{2}{|c|}{ I drawing } & \multicolumn{2}{|c|}{ II drawing } & \multicolumn{2}{|c|}{ III drawing } & \multicolumn{2}{c|}{ Tot } \\
\cline { 2 - 10 } & $\mathrm{N}$ & $\%$ & $\mathrm{n}$ & $\%$ & $\mathrm{n}$ & $\%$ & $\mathrm{n}$ & $\%$ \\
\hline Need for Affiliation & 83 & 34,6 & 86 & 35,4 & 31 & 18,6 & 200 & 30,8 \\
\hline Need for Power & 37 & 15,4 & 34 & 14,0 & 18 & 10,8 & 89 & 13,7 \\
\hline Need for Achievement & 120 & 50,0 & 123 & 50,6 & 118 & 70,6 & 361 & 55,5 \\
\hline Total & 240 & 100 & 243 & 100 & 167 & 100 & 650 & 100 \\
\hline
\end{tabular}

Table 3. Motivation needs, evolution over time and totals

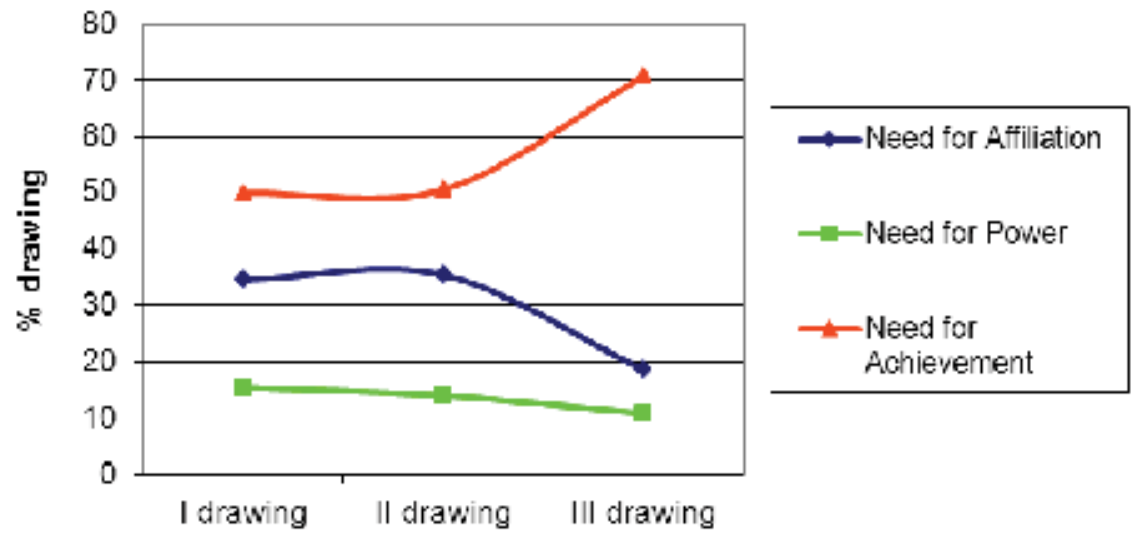

Fig. 4. Motivation needs: evolution over time

It can be noted that the high Achievement need does not correspond to a high Being constructive relationship with pollution.

If we look further in detail we can see that throughout the project Being constructive has a sharp increase, from $10,8 \%$ at the stage of the first drawing to $31,1 \%$ at the third drawing. Acting and Being subject to, show a tendency to decrease (from $11,3 \%$ to $2,4 \%$ and from $15 \%$ to $9 \%$ respectively) (Table 4 , Figure 5). This is quite comforting since the presence of a number of drawings expressing the active will to pollute was rather alarming.

If we take only the drawings which have been rated as Achievement need, we can see that in this case the number of children who express a Being constructive attitude is much higher from the beginning and further increases in time. In this group we also find lower Acting, Blaming and Being subjected to attitudes (Table 5, Figure 6).

Finally, if we compare the Relationship to pollution found in the three sub-groups, interestingly we can see that the drawings rated for Affiliation present the highest rate of Witnessing and a dominant one. The drawings rated for need for Power present high rates for Acting and Being subjected to. While the drawings categorised as Achievement present high rates of Witnessing and Being constructive (Table 6, Figure 7).

All the data are here considered as trend indicators, not for their statistical significance. 


\begin{tabular}{|c|c|c|c|c|c|c|c|c|}
\hline \multicolumn{10}{|c|}{ Relationship to pollution } \\
\hline & \multicolumn{2}{|c|}{ I drawing } & \multicolumn{1}{|c|}{ II drawing } & \multicolumn{2}{|c|}{ III drawing } & \multicolumn{2}{c|}{ Tot } \\
\cline { 2 - 10 } & $\mathrm{N}$ & $\%$ & $\mathrm{n}$ & $\%$ & $\mathrm{n}$ & $\%$ & $\mathrm{n}$ & $\%$ \\
\hline Acting & 27 & 11,3 & 29 & 11,9 & 4 & 2,4 & 60 & 9,2 \\
\hline Witnessing & 128 & 53,3 & 125 & 51,4 & 84 & 50,3 & 337 & 51,8 \\
\hline Blaming & 3 & 1,3 & 8 & 3,3 & 4 & 2,4 & 15 & 2,3 \\
\hline Being subjected to & 36 & 15,0 & 18 & 7,4 & 15 & 9,0 & 69 & 10,6 \\
\hline Being constructive & 26 & 10,8 & 40 & 16,5 & 52 & 31,1 & 118 & 18,2 \\
\hline Other & 20 & 8,3 & 23 & 9,5 & 8 & 4,8 & 51 & 7,8 \\
\hline Total & 240 & 100 & 243 & 100 & 167 & 100 & 650 & 100 \\
\hline
\end{tabular}

Table 4. Relationship to pollution over time and total

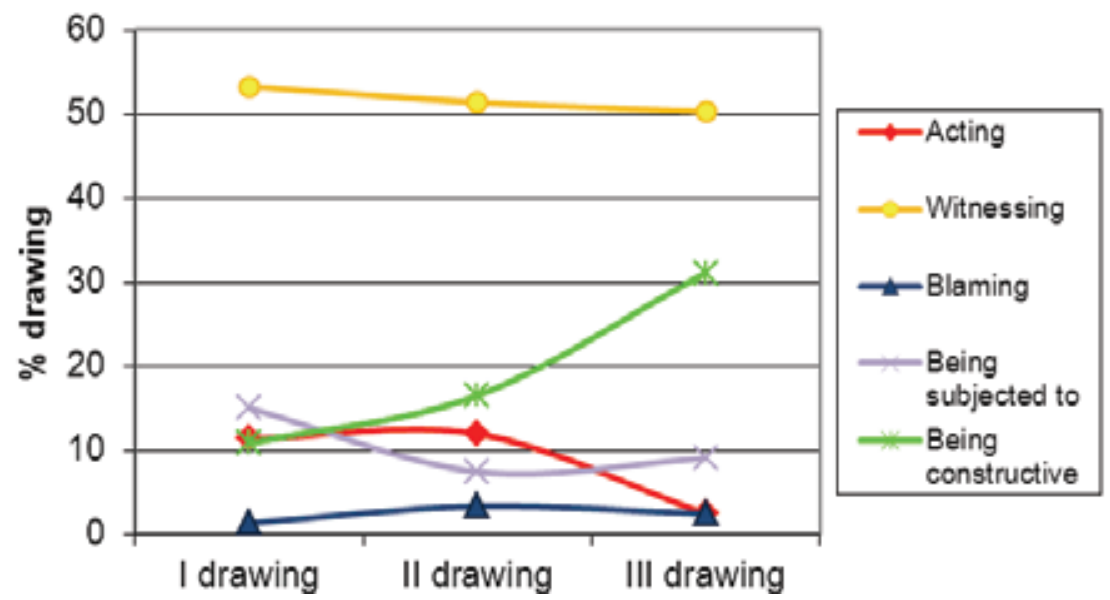

Fig. 5. Relationship to pollution over time

\begin{tabular}{|c|c|c|c|c|c|c|c|c|}
\hline \multicolumn{10}{|c|}{ Need for achievement/Relationship to pollution } \\
\hline & \multicolumn{2}{|c|}{ I drawing } & II drawing & \multicolumn{1}{|c|}{ III drawing } & \multicolumn{2}{c|}{ Tot } \\
\cline { 2 - 10 } & $\mathrm{n}$ & $\%$ & $\mathrm{n}$ & $\%$ & $\mathrm{n}$ & $\%$ & $\mathrm{n}$ & $\%$ \\
\hline Acting & 10 & 8,3 & 7 & 5,7 & 1 & 0,8 & 18 & 5,0 \\
\hline Witnessing & 72 & 60,0 & 71 & 57,7 & 63 & 53,4 & 206 & 57,1 \\
\hline Blaming & 2 & 1,7 & 2 & 1,6 & 2 & 1,7 & 6 & 1,7 \\
\hline Being subjected to & 10 & 8,3 & 4 & 3,3 & 5 & 4,2 & 19 & 5,3 \\
\hline Being constructive & 25 & 20,8 & 36 & 29,3 & 47 & 39,9 & 108 & 29,8 \\
\hline Other & 1 & 0,9 & 3 & 2,4 & - & - & 4 & 1,1 \\
\hline Total & 120 & 100 & 123 & 100 & 118 & 100 & 361 & 100 \\
\hline
\end{tabular}

Table 5. Need for Achievement/Relationship to pollution over time and totals 

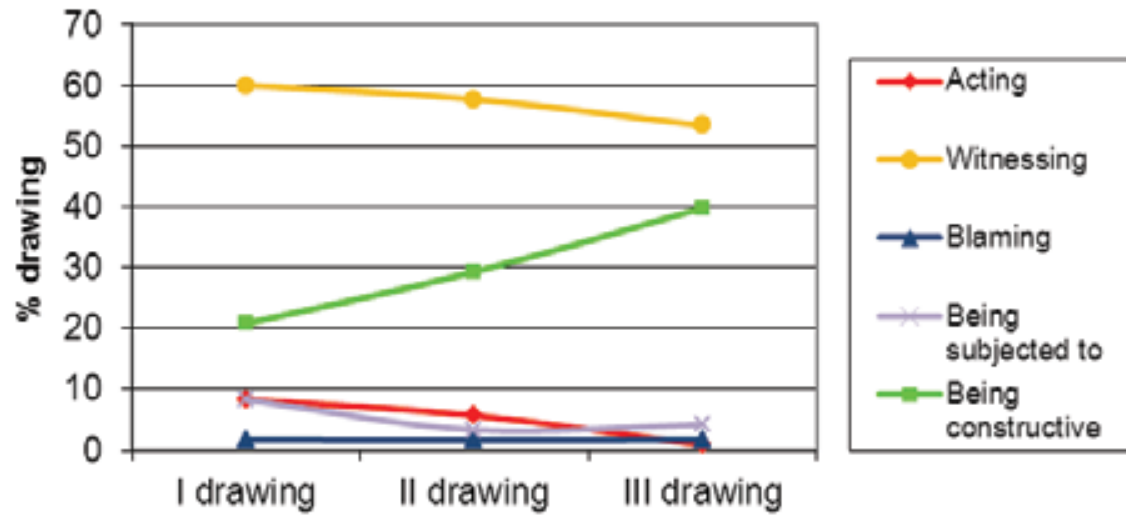

Fig. 6. Need for achievement/Relationship to pollution over time

\begin{tabular}{|c|c|c|c|c|c|c|}
\hline \multicolumn{7}{|c|}{ Motivation Needs/Relationship to pollution } \\
\hline & Need for Affiliation & Need for Power & \multicolumn{2}{c|}{ Need for Achievement } \\
\cline { 2 - 7 } & $\mathrm{n}$ & $\%$ & $\mathrm{n}$ & $\%$ & $\mathrm{n}$ & $\%$ \\
\hline Acting & 11 & 5,5 & 31 & 34,8 & 18 & 5,0 \\
\hline Witnessing & 119 & 59,5 & 12 & 13,5 & 206 & 57,1 \\
\hline Blaming & 6 & 3 & 3 & 3,4 & 6 & 1,7 \\
\hline Being subjected to & 12 & 6 & 38 & 42,7 & 19 & 5,3 \\
\hline Being constructive & 6 & 3 & 4 & 4,5 & 108 & 29,8 \\
\hline Other & 46 & 23 & 1 & 1,1 & 4 & 1,1 \\
\hline Total & 200 & 100 & 89 & 100 & 361 & 100 \\
\hline
\end{tabular}

Table 6. Motivation Needs/Relationship to pollution

\subsubsection{Discussion}

What appears as the most interesting result, is that the topic of energy and pollution generates Achievement motivation in the majority of the children, that is, it is seen as a problem to which a solution needs to be found. But when we look at the way the children relate to the problem, then we can see that the majority of them cannot envisage a positive and active behaviour towards the solution. Only a minority of the children can think and feel that something can be done; this group increases over time and actually triples by the end of the study. It can be observed that the increase in the "being constructive" attitude corresponds to a decrease in the "acting" and "being subjected to" categories, as if negative behaviour and/or situations could be abandoned once the possibility of constructive behaviour, through the project's experience, becomes a real option. There is, instead, only a slight shift in the number of children who look at pollution without taking any active negative or positive attitude; the "witnessing" attitude decreases, but the actual reduction is very small (Table 4 ).

But when is the "being constructive" attitude found? If we look at Table 6, we can see that when the Achievement motive is not activated, it is very unlikely that the children manifest a constructive attitude in their relationship to pollution (Table 6). This attitude is overwhelmingly linked to the Achievement motive. The importance of how to support the 


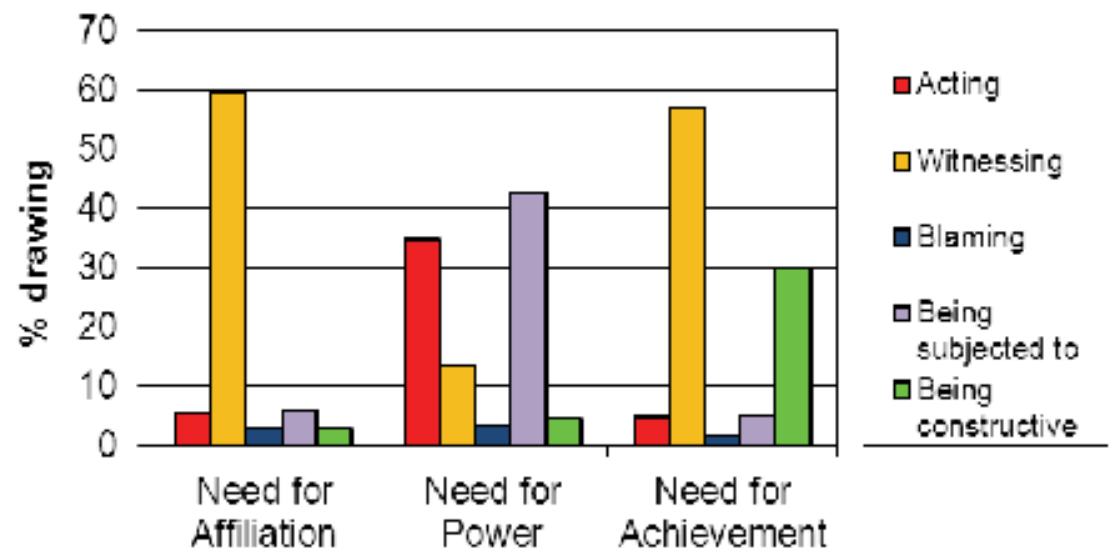

Fig. 7. Motivation Needs/Relationship to pollution (totals)

children in the development of this motivational dimension stands out. Going into further detail (Table 5), we can see that the children whose drawings were classified in the Achievement motivation category made interesting changes in the course of time: the category "Acting", which corresponds to the representation of the will to pollute, practically disappears and "Being subjected to" is halved, while being constructive nearly doubles (see also figure 6); also "Witnessing" has an interesting decrease. Nevertheless, the presence of such a high "Witnessing" percentage lends itself to speculation: why so many of the children, notwithstanding their Achievement motivation, do not express a problem solving attitude? We will not try to give an answer since more research is certainly needed here, but at least it can be pointed out that the project's activities seem to have produced a higher coherence between the Achievement need and the way the children relate to pollution. Further analysis of this data together with the data from the written texts collected will be carried out to make some hypotheses for future studies regarding which factors can be identified to explain and possibly to promote this change. Concerning future research, it would be useful to test if a similar mechanism is activated with adults, particularly when they come into contact with new technologies or solutions; is Achievement motivation as important for the adult population and can the same gap with one's own personal relationship to the problem be found? If such outcomes were obtained in a privileged context, where there was full willingness to collaborate, to learn and to get involved, what can we expect in more difficult conditions, when in addition a number of other factors, such as vested interests will be playing a role?

Another outcome that appears problematic, is that for all the children who fall within the two other motivation categories, Affiliation and Power, the access to a constructive attitude is very restricted (Figure 7, Table 6). The attitude of children classified for Affiliation is overwhelmingly passive rather than active, and the opposite can be found when Power motivation is present. In this case, though, it is only rarely a positive kind of action: the children classified as Power seem to be trapped between two negative sorts of relationships with pollution: either actively polluting or being subjected to pollution. Again, it would be interesting to understand if these results would also be indicative for the adult population. These data, especially the ones relating to the Power motive might be related to a problem that arises regularly when issues about the introduction of new technologies are discussed, the idea that there will be people who will be opposed in any case, independently from any reasonable argument. We got the same feeling in the classroom, when sometimes a child 
would ask for explanations and then would refuse them, as though we had entered a dimension of "trying to convince". Looking at these data, the hypothesis can be made that when such a situation occurs, we are in the presence of a problem which is not being approached with a problem-solving attitude because those involved get trapped in the dynamic of a Power motive, which does not allow reciprocal listening and understanding, which the Achievement motive would instead support. The "profoundly perceived trust in one's ability to accomplish" (Carli, 1972) which is characteristic of the Achievement motivation would probably support a more trusting relationship to the other and its reasons. If this were the case new, interesting considerations could be investigated to support the development of such difficult situations.

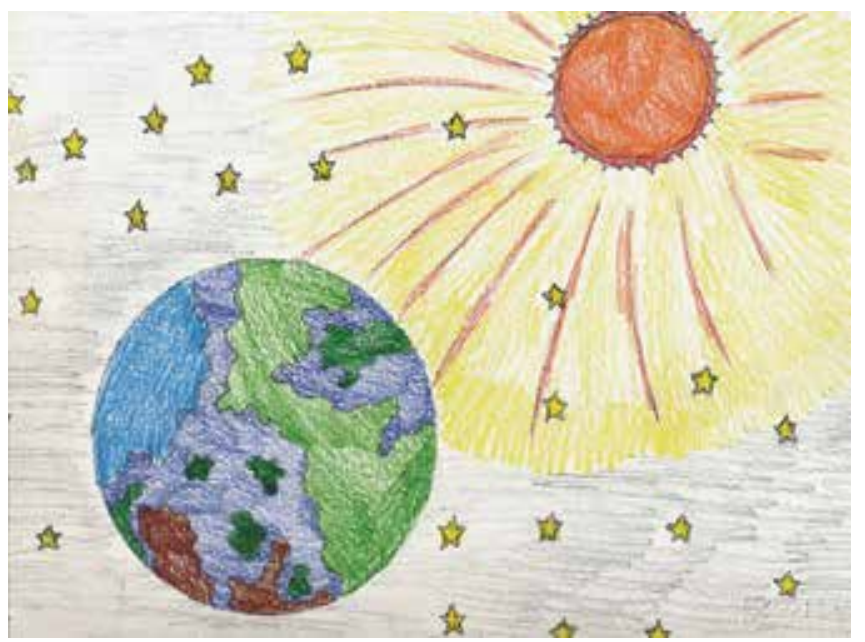

Fig. 8. "I drew the greenhouse effect: the sun illuminates and warms the earth with its rays. Carbon dioxide is represented in grey and lots of stars. The sun's rays go into the earth but can't get out and so the greenhouse effect is created."

We will now take into consideration these data and draw them together, as they build a comprehensive picture and reflect on the possible social representation of the issues related to energy production and pollution. We can see, first of all, that the major trend to be found corresponds to not feeling actively involved or interested (high "Witnessing" score in all the sample) while in the same time there are others who create the problem ("Acting") or are victimised of it ("Being subjected to") or are trying to find solutions ("Being constructive"). In other words, the direct and practical relationship of these issues with the life of each and every one is not obvious. So, the idea is, that we have a problem, which we can somehow deal with (dominance of the Achievement motive), but it is unclear who and how, it can be solved.

When we consider change processes, we see that at the end of the project the predominance of the Achievement motive $(70 \%$, Table 3 Figure 4$)$ goes together with the increase of the Being constructive attitude $(31,1 \%$, Table 4, Figure 5). At the same time the increase of the Achievement motivation goes together with the decrease of the Affiliation motive while the Power motive is reduced but rather stable. This last data seems to reinforce the impression that the shift towards a more realistic representation of the issues at stake will take advantage of a perspective where energy, pollution and the deployment of new technologies can be seen as a problem to which everyone can give a contribution. This aspect was greatly 
emphasized in the work with the children and the children gave us researchers a great contribution to understanding dissemination and communication issues about the technology and also a more comprehensive view of the problems linked to energy production. Our thoughts on CCS were completely transformed after the experience in the school, for example it was of great help in integrating our views on geological storage, which we were specialized in, along with all the other aspects of the technology, of energy production, etc. At the end of the project we can predict a different social representation, where the weight of Witnessing becomes less important as Being constructive is much more present and thus the motivation to Achieve is more solidly experimented.

\section{General discussion}

The data regarding the drawings match our experience with the teachers and in the classroom. Just as we found high Achievement motivation and low Being constructive rate in the drawings, we found high willingness to collaborate but a lot of limitations and powerlessness when proposing collaborative approaches to learning and when exploring new concepts. Very often, it is as though the teachers or the children would like to do it differently or to explore new paths, but don't know they can, or consider some of the possible pathways to be "wrong". We have met the same kind of difficulties when working with the researchers. It is possible to say that they also presented a high Achievement motivation, but when it came to making sense of their experience or communicating it to the outside world, their awareness about their potential and about possible ways for being constructive was low. In both cases work on the social process, following the Demand Analysis Approach and thus bringing attention to subjectivity, giving respect and listening before proceeding to subsequent interpretative actions, which could support the ongoing social processes in relation to the respective objectives, produced interesting changes. While $\mathrm{CO}_{2} \mathrm{GeoNet}$ research community found the way to a number of satisfactory communication actions, children and teachers started to enjoy the work on difficult scientific topics, made new experiences and discovered they were important, just as the scientists, for solving energy problems. Particularly interesting, from this point of view, was the final activity held with the participation of the children's families where the children became their parents' teachers, explaining to them what they had experienced and learned during the project. We remember how exciting and moving these moments were, not only for the children but for all of us involved, and how meaningful it was to see the children take courage and explain difficult issues and terms.

So, this appears as the first part of the problem, raising awareness of what each and everyone can do and setting the conditions for free experimentation, so that people can find out if certain paths are "really" wrong. Freedom to experiment means more tolerance for mistakes and allowing more time to discover, that is, lower efficiency expectations. Just one example: it was very hard and it took a considerable amount of time and patience to introduce interactive communication activities in the research community meetings and conferences. Although each time this was done these activities would prove more and more productive and satisfactory, nevertheless a lot of experimenting was necessary to overcome the idea that it was just a "waste of time" or that it was not appropriate to the context, etc. In the same way, it was not easy to get the support of the teachers for letting the children express "wrong" thoughts or ideas without immediately correcting them.

Awareness grew in a context of a trusting environment and trust appears in fact as another important part of the problem, one which certainly needs more research. In this respect, 
both experiences show the relevance for the subjects of having a direct experience of the effects of a trusting relationship and of a supportive environment: this definitely seems to have a very positive impact. An aspect that needs more investigation are the conditions and the institutional, organizational arrangements, outside of experimental research conditions such as the ones we have experienced, that could support the creation of trusting environments which can favour the development of the Achievement motivation and its practical application. It would certainly be a major accomplishment to identify such organizational conditions, since, as Carli well explains: "Cooperation, in fact, more than the result of (a difficult) generic voluntarism, appears rather like the result of an automation of the need for achievement, of a profoundly perceived trust in one's ability to accomplish, and therefore an action that takes place on the basis of an elevated probability of success."(Carli, 1972).

Paradoxically, to develop such trust we need a trusting environment where we are not concerned about making mistakes. In fact, the biggest problem encountered in creating the conditions for the work on the social process was overcoming everybody's needs to protect themselves from criticism, because criticism would be destructive. This remains a major challenge to be overcome, making confrontation accessible, which in turn is useful for solving problems.

Another aspect that seems part of the social representations that condition our perception of energy issues is the idea that we should not take pleasure in what we do: enjoying ourselves when working or studying is seen just as a possible "plus" to what we do, not as an important requirement. This aspect seemed to account for some portion, for example, of the relatively low Being constructive rate in the drawings; sometimes the children seemed to find it very hard to engage the process of problem-solving, but this was not surprising if we considered that the teachers would try to make something "serious" out of what was done, or were too concentrated on final results and not interested in the process of getting there. This is also a conspicuous problem in the research community, where the pressure for efficiency and good use of time, for example in the organization of meetings, doesn't leave much room for a more pleasurable dimension which would probably foster more creativity and increase the ability to reach substantial results. This is especially true in the CCS community, where the feeling of urgency and magnitude of the problems to be solved is very high: the impending climate change challenge and the large scale of the possible solutions make it difficult for people to keep in touch with the overall process with a real feeling of competency and achievement.

\section{Conclusions}

The research performed on social processes within the framework of the Demand Analysis Approach has produced some interesting insights on the social issues that might condition the introduction of new energy technologies and particularly CCS:

1. The first area of interest that emerged concerns the opportunities of appropriate contexts and conditions for exchange and discussion. Both in the case of the scientific community and in the case of school children, what seemed to be most problematic was the lack of time and situations for sharing, for discussion and having time to think about problems within a trusting social environment. This is quite understandable if we think of the complexity of energy issues, of how difficult it is for people to orient themselves on these problems and to the fact that in order to face them, everyone's contribution not just that of specialized stakeholders, is essential. It will be useful to 
consider that, although we apparently live in a world where communication is intense and simple, the opportunities for people to meet and take time to discuss issues of common interest have become greatly reduced. So this might be the case, but only one aspect of it. Another aspect is the competence needed to make these exchanges profitable: what emerges from the study indicates the need to develop both personal skills and social structures that can facilitate these exchanges.

2. The second area concerns the representation of the energy issue in terms of "a problem to be solved". The high presence in the school sample of the Achievement motive (and the high motivation to Achieve found in the research community) give us interesting information on the direction psycho-social processes can take when appropriately supported. Diffused and competent exchange activities of people driven by the Achievement motive could probably accelerate progress towards sustainability. What is critical though, is the gap between the frequency of the Achievement motive and the representation of oneself as a positive actor; this aspect needs to be better understood. Both the experience in the school and with researchers seem to point to the importance of specific social experiences that enable the subjects to relate personally in a more satisfactory (meaningful and practical) way to the energy or technology issue. Nevertheless it will be interesting to see the results that emerge from the written texts collected in the school, as to whether there are factors specific to the energy theme which influence the low Being constructive rate or if it is a more general factor of social competence that is influential.

3. The experience within $\mathrm{CO}_{2} \mathrm{GeoNet}$ Network of Excellence indicates that $\mathrm{CO}_{2}$ Geological Storage communication issues are strongly related to the quantity and the quality of the work necessary to produce effective scientific information material and events. In addition to the specific characteristics of the topic - multidisciplinarity, the necessity of a geological educational background, long term time frames, etc.- also the fact that the CCS community is of recent formation, can explain the difficult task of dissemination, since no common representations have been developed yet and even among the experts there is a great need of exchange of information on the various aspects of the technology. Again, it is not just gathering information, but rather providing opportunities for processing it and unveiling its meaning in terms that can be meaningful both for specialized and non-specialized stakeholders. The project has shown that the DAA work can be effective in empowering the researchers in finding congenial ways to achieve the communication goal.

4. The importance of information in supporting the psycho-social processes towards sustainability appears in itself quite limited. If we consider the work with the researchers we can see that the preparation of meaningful information to be disseminated is subsequent to the empowerment of researchers, and comes from sharing and discussion. In the same way, in the school, the information could be better examined and listened to when a positive and trusting environment had been created. Information is an essential part of the process but maybe we need to remind ourselves that information undergoes a continual process of transformation while it is being exchanged and more often than not, this process is far more important than the content itself.

5. The application of the DAA in the school has proven to be a heuristic tool, not only for research goals but potentially for educational goals too; although this was not the primary focus of the work, it is true that the role of the educational system cannot be underestimated in the effort towards sustainability. As Bangay states: "If the role of 
education is to help learners of all ages to develop the knowledge, skills and capacities which enable them to think critically, to solve problems, and to address uncertainty, then the focus of climate change interventions should not simply be on new inputs/ content (although these are also necessary), but also on more holistic ways of addressing climate change through high quality teaching and learning." (Bangay \& Blum, 2010, p.9). Our research confirms the importance of placing new information in an appropriate context of high human quality.

6. It clearly appears that the processes implied in the adoption of a new technology do not concern just the examined technology. They involve a number of other technically related content as well as wider social and personal processes and perspectives. This needs to be taken in account when planning communication activities which will also inevitably communicate what is not explicitly said, to ensure that what is or might be meaningful to people is not left out. A good and probably unique example of the public engaging in activities on energy issues that addresses this aspect, comes from the work carried on in Australia by Peta Ashworth and colleagues (Ashworth et al., 2009a). The framework they designed to support a large group process met, in many respects, both the need for appropriate environments for sharing and the need to contribute to solutions that emerge from research.

In conclusion, if we want a "more sustainable" energy system we need "more sustainable" settings for learning and working; settings that increase the possibilities for people to explore and discover their potential, to submit their contribution at all levels, towards solving energy issues. New settings are also needed in the context of social research to improve our capacity to support our society's change and transformation towards common goals. The approach we have experimented is proposed as a form of a new "hybrid" mode of knowledge production, which tries to be more functional to the need of interaction-based knowledge and hopes to give support for counteracting the "hubris" intrinsic in many of our technological problems (Hard \& Jamison, 2005). We would like to point out that there is something special each one of us can contribute with our thoughts and our feelings and that we need to include them in science for the benefit of all: "New ways of thinking and new ways of looking at things are desperately needed today. Children who have had the opportunity to think for themselves, to discover and explore the world at their own pace may grow up to be adults who are able to find new insights into old problems"(Layne, 2000). As it is shown by the work in the school, the potential for Achievement needs to be liberated...

\section{Acknowledgements}

The present work was conducted within the framework of $\mathrm{CO}_{2} \mathrm{GeoNet}$ European Network of Excellence for the Geological Storage of CO2, Project no. SES6-CT-2004-502816. Funding from the EC is gratefully acknowledged.

The author would like to thank the research community of $\mathrm{CO}_{2} \mathrm{GeoNet}$ Network of Excellence: a special thank to the scientists who accepted the challenge of confrontation and in particular to Salvatore Lombardi, Isabelle Czernichowski, Nick Riley and Sergio Persoglia.

Thank you to the teachers and the children of the Roman primary schools Mazzini, Manzoni and XX Settembre for their enthusiastic participation and collaboration: we learned a lot from you. 
Thank you to Francesco Zarlenga, Manuela Errante, Anna Baccani, Aldo Annunziatellis, Monia Coltella, Jonathan Anderlucci, Laura Antinucci, Stan Beaubien, Giancarlo Ciotoli, your contribute has been very much appreciated.

\section{References}

Ashworth, P., Pisarski, A. \& Littleboy, A. (2006). Social and Economic Integration Report: Understanding and Incorporating Stakeholder Perspectives to Low Emission Technologies in Queensland, Centre for Low Emission Technology.

Ashworth, P., Carr-Cornish, S., Boughen, N. \& Thambimuthu, K. (2009a). Engaging the public on carbon dioxide capture and storage: Does a large group process work?, Proceedings of the 9th International Conference on Greenhouse Gas Control Technologies (GHGT-9), Energy Procedia, Vol. 1(No.1), Washington DC, USA, pp. 4765-4773.

Ashworth P., Boughen, N., Mayhew, M. \& Millar, F. (2009b). An integrated roadmap of communication activities around carbon capture and storage in Australia and beyond, Proceedings of the 9th International Conference on Greenhouse Gas Control Technologies (GHGT-9), Energy Procedia, Vol. 1(No. 1), Washington DC, USA, pp. 4749-4756.

Atkinson, J. W., Heyns, R. W. \& Veroff, J. (1954). The effect of experimental arousal of the affiliation motive on thematic apperception, Journal of abnormal and social psychology, Vol.49(No.3): 405-410.

Bangay, C. \& Blum, N. (2010). Education responses to climate change and quality: Two parts of the same agenda?, International Journal of Educational Development, Vol. 30(No.4): 359-368.

Carli, R. (1972). Fenomenologia dell'adattamento sociale, in L. Ancona (ed.), Nuove questioni di psicologia, La Scuola, Brescia, pp.51-72.

Carli, R. (1987). L'analisi della domanda, Rivista di Psicologia Clinica 1:38-53.

Carli, R. \& Paniccia, R.M. (2003). Analisi della domanda. Teoria e intervento in psicologia clinica, Il Mulino, Bologna.

Carli, R. \& Paniccia, R.M. (1981). Psicosociologia delle organizzazioni e delle istituzioni, Il Mulino, Bologna.

Carli, R. \& Paniccia, R.M. (2002). L'analisi emozionale del testo. Franco Angeli, Milano.

Czernichowski-Lauriol, I., Arts, R., Durand, D., Durucan, S., Johannessen,P., May, F., Olivier, M.-L., Persoglia, S., Riley, N., Sohrabi, M., Stokka, S., Vercelli, S. \& VizikaKavvadias, O. (2009). CO2GeoNet, the unique role of the European scientific body on CO2 geological storage, Proceedings of the 9th International Conference on Greenhouse Gas Control Technologies (GHGT-9), Energy Procedia, Vol.1(No. 1), Washington DC, USA, , pp. 2043-2050.

De Best-Waldhober, M., Daamen, D. \& Faaij, A. (2009). Informed and uninformed public opinions on $\mathrm{CO} 2$ capture and storage technologies in the Netherlands, International Journal of Greenhouse Gas Control, Vol. 3(No. 3): 322-332.

Desbararts, J., Upham, P., Riesch, H., Reiner, D., Brunsting, S., Best-Waldhober, M. de, Duetschke, E., Oltra, C., Sala, R. \& McLachlan, C. (2010), Review of the public participation practices for ccs and non-ccs projects in europe. Near C02 project Work Package1.2 http:/ / www.communicationnearco2.eu/fileadmin/communicationnearco2/user/ docs/WP1.2_Final_report.pdf

DOE-NETL (2009). Public outreach and education for carbon storage projects. (DOE/NETL2009/1391).http://www.netl.doe.gov/technologies/carbon_seq/refshelf/BPM_Pu blicOutreach.pdf 
Eurobarometer (2006). Attitudes towards energy, Special Eurobarometer 247/Wave 64.2 TNS Opinion and Social.

http://www.managenergy.net/download/ebs_247_en.pdf

Fischedick, M., Pietzner, K., Supersberger, N., Esken, A., Kuckshinrichs, W., Zapp, P., Lin[ss]en, J., Schumann, D., Radgen, P., Cremer, C., Gruber, E., Schnepf, N., Roser, A. \& Idrissova, F. (2009). Stakeholder acceptance of carbon capture and storage in Germany, Proceedings of the 9th International Conference on Greenhouse Gas Control Technologies (GHGT-9), Energy Procedia, Vol. 1(No. 1), Washington DC, USA, pp. 4783-4787.

Flynn, R. \& Bellaby eds. (2007). Risk and the public acceptance of new technologies, Palgrave Macmillan, New York.

Ha-Duong, M., Nadaï, A. \& Campos, A.S. (2009). A survey on the public perception of CCS in France, International Journal of Greenhouse Gas Control, Vol.3(No.5): 633-640.

Hard, M. \& Jamison, A. (2005). Hubris and hybrids : a cultural history of technology and science, Routledge, New York.

Heiskanen, E., Hodson, M., Raven, R. Feenstra, Y., Alcantud, A., Bauknecht, D., Brohmann, B., Fritsche, U., Fucsko, J., Jolivet, E., Maack, M., Mourik, R.M., Onsizk-Poplawska, A., Poti, B.M. \& Schaefer, B. (2007), Factors influencing the societal acceptance of new energy technologies: metaanalysis of recent European projects, Work Package 2 report of the Create Acceptance Project, FP6-2004-Energy-3, SUSTDEV-1.2.8. http: //www.createacceptance.net/fileadmin/createacceptance/user/docs/E07058.pdf.

IEAGHG, (2008). Carbon Capture and Storage. http://www.ieaghg.org/docs/general _publications/GHGT9\%20Reports\%20CD.pdf.

IPCC, (2005). IPCC special report on Carbon Dioxide Capture and Storage. Prepared by working group III of the Intergovernmental Panel on Climate Change. Cambridge University Press, Cambridge, United Kingdom and New York, NY, USA.

Jodelet, D. (1992). Le rappresentazioni sociali: un campo in espansione, in D. Jodelet (ed.), Le rappresentazioni sociali, Liguori, Napoli, pp.43-76.

Johnsson, F., Reiner, D., Itaoka, K. \& Herzog, H. (2010). Stakeholder attitudes on Carbon Capture and Storage--An international comparison, International Journal of Greenhouse Gas Control, Vol.4(No.2): pp. 410-418.

Layne, M. (2000). Learning at home: mother's guide to homeschooling, Sea Change Publications, Victoria.

Malone, E. L., Bradbury, J.A. \& Dooley, J.J. (2009). Keeping CCS stakeholder involvement in perspective, Proceedings of the 9th International Conference on Greenhouse Gas Control Technologies (GHGT-9), Energy Procedia, Vol. 1(No. 1), Washington DC, USA, pp. 4789-4794.

Malone, E.L., Dooley, J.J. \& Bradbury, J.A. (2010). Moving from misinformation derived from public attitude surveys on carbon dioxide capture and storage towards realistic stakeholder involvement, International Journal of Greenhouse Gas Control, Vol.4(No.2): 419-425.

Matte Blanco, I. (1981). L' inconscio come insiemi infiniti : Saggio sulla bi-logica. Einaudi, Torino.

McClelland D. C. (1987). Human Motivation. Cambridge University Press, London.

Moscovici, S. (1961,1976). La psychanalyse : son image et son public, Puf, Paris.

Orange, D.M., Atwood, G.E. \& Stolorow, R.D. (1997). Working intersubjectively: Contextualism in psaychoanalytic practice. Analytic Press, Hillsdale.

Reiner, D., Curry, T., de Figueredo, M., Herzog, H., Ansolabehere, S., Itaoka, K., Akai, M., Johnsson, F. \& Odenberger, M. (2006). An international comparison of public 
attitudes towards carbon capture and storage technologies, Proceedings of GHGT-8, 8th International Conference on Greenhouse Gas Control Technologies, Trondheim, Norway.

Reiner, D.M. (2008). A looming rhetorical gap: a survey of public communications activities for carbon dioxide capture and storage technologies, Electricity Policy Research Group Working Papers, No.0801, University of Cambridge, Cambridge. http:/ / www.eprg.group.cam.ac.uk/wp-content/uploads/2008/11/eprg08012.pdf.

Shackley, S., Waterman, H., Godfroij, P., Reiner, D., Anderson, J., Draxlbauer, K. \& Flach, T. (2007). Stakeholder perceptions of CO2 capture and storage in Europe: Results froma survey, Energy Policy, Vol.35(No.10): 5091-5108.

Shackley, S., Reiner, D., Upham, P., de Coninck, H., Sigurthorsson, G. \& Anderson, J. (2009). The acceptability of $\mathrm{CO} 2$ capture and storage (CCS) in Europe: An assessment of the key determining factors: Part 2. The social acceptability of CCS and the wider impacts and repercussions of its implementation, International Journal of Greenhouse Gas Control, Vol. 3(No. 3): 344-356.

Shackley, S. \& Evar, B. (2009). Public Understanding, Engagement and Communication Efforts on CCS: A Review for the IEA CCS Roadmap, IEA, Paris.

Stangeland, A. (2007). A model for the CO2 capture potential, International Journal of Greenhouse Gas Control, Vol.1(No.4): 418-429.

Stephens, J.C., Bielicki, J. \& Rand, G.M. (2009). Learning about carbon capture and storage: Changing stakeholder perceptions with expert information, Proceedings of the 9th International Conference on Greenhouse Gas Control Technologies (GHGT-9), Energy Procedia, Vol.1(No.1), Washington DC, USA, pp. 4655-4663.

Stolorow, R.D., Atwood, G.E. \& Brandchaft, B. (1987). Psychoanalytic treatment: an intersubjective approach. Analytic Press, Hillsdale.

Stolorow, R.D. \& Atwood G.E. (1992). Context of being. The intersubjective foundation of psychological life. Analytic Press, Hillsdale.

ter Mors, E., Weenig, M. W. H., Ellemers, N., Daamen, D.D.L. \& de Best-Waldhober, M. (2009). Public information: On why and when multiple information sources are more effective than single information sources in communication about CCS, Proceedings of the 9th International Conference on Greenhouse Gas Control Technologies (GHGT-9), Energy Procedia, Vol.1(No.1), Washington DC, USA, pp. 4715-4718.

Terwel, B.W., Harinck, F., Ellemers, N., Daamen, D.D.L. \& De Best-Waldhober, M., (2009). Trust as predictor of public acceptance of CCS, Proceedings of the 9th International Conference on Greenhouse Gas Control Technologies (GHGT-9), Energy Procedia, Vol. 1(No.1), Washington DC, USA, pp. 4613-4616

Vercelli, S. \& Tambelli, R. (2005). Stakeholders acceptance and understanding of CO2 geological storage, in S.Lombardi, L.K.Altunina, S.E.Beaubien (ed.), Advances in the geological storage of carbon dioxide. International approaches to reduce anthropogenic greenhouse gas emissions, Kluwer Academic Publishers, New York: 345-358.

Vercelli, S. \& Lombardi, S. (2009) CCS as part of a global cultural development for environmentally sustainable energy production, Proceedings of the 9th International Conference on Greenhouse Gas Control Technologies (GHGT-9), Energy Procedia, Vol. 1(No.1), Washington DC, USA, pp. 4835-4841.

World Resources Institute (WRI), (2009). Guidelines for community engagement regarding carbon dioxide capture and storage (CCS) projects. August 2009 draft for stakeholder review. 


\title{
An Advanced Method of Congestion Management for Optimal Energy Pricing
}

\author{
Muhammad Bachtiar Nappu ${ }^{1,2}$ and Tapan Kumar Saha ${ }^{2}$ \\ ${ }^{1}$ Hasanuddin University \\ ${ }^{2}$ The University of Queensland \\ ${ }^{1}$ Indonesia \\ ${ }^{2}$ Australia
}

\section{Introduction}

As one of the electricity infrastructure, a robust power network is needed to support the sustainability of energy supply. Compared to other common customer goods, electric energy has some unique features that require specific consideration. Unlike most products, electricity cannot be stored in large amounts in an economical manner. Accordingly, electricity has to be simultaneously produced and distributed on demand. Transmission and distribution network systems are then used to deliver the power. The operating capability of generation, transmission and distribution systems must be adequate to meet the fluctuating demands of the customers. As illustrated in Figure 1, a simple configuration of an interconnected power system has basically three important parts, namely: generator as source of the electrical energy, transmission line for transmitting power to remote areas and the load which consumes the power.

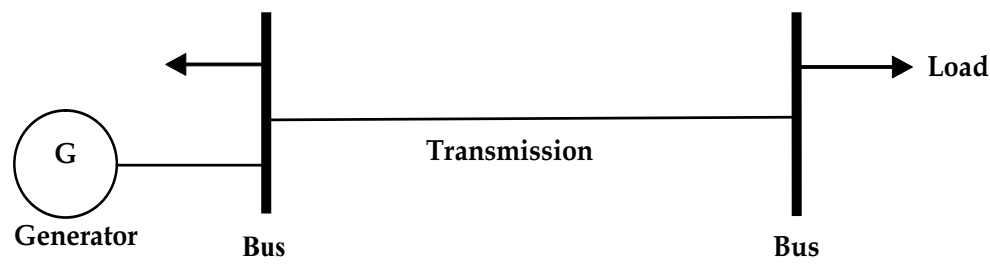

Fig. 1. A simplified interconnected power system

Tie lines are utilized to make interconnection of the transmission networks in order for utilities to either exchange power or share spinning reserves between one and another. A fundamental issue for an interconnection system as shown above is how to minimize the cost of production. Because the energy may come from different resources such as fossil fuel, gas, water, coal, tidal, geothermal, sun power and radioactive, the alternative option of one or the other is based on economic, technical or geographic points of view.

Hence an efficient, low-cost and reliable operation of a power system by adjusting the available electricity generation resources to supply demand of the system is needed to 
ensure economic plant dispatching. The main idea of the importance of economic dispatch is to minimize the total cost of generation while meeting the operational constraints of the available generation resources. Economic dispatch is the process to allocate generation levels to the generating units in the mix, so that the system load may be supplied entirely and most economically (Chowdhury \& Rahman, 1990). It is performed as an optimization problem in terms of minimizing the total fuel cost of all committed plant while satisfying both losses and demand. In addition, it determines a set of active power delivered by the committed generators to satisfy the required demand subject to the unit technical limits and at the lowest production cost at any time. Consequently, this problem should be solved as fast and precisely as possible.

Locational Marginal Prices (LMP) is the key factor to identify the spot price and to manage transmission congestion (Ristanovic \& Waight, 2006; Sun, 2006). LMP methodology has been implemented or is under implementation at some independent system operators, for example: California ISO, PJM, New York ISO, ISO-New England, Midwest ISO, ERCOT, etc (Jun, 2006; Litvinov, 2006; Xie et al., 2006; Yong \& Zuyi, 2006). Reference in (Gedra, 1999) gives a tutorial review of the use of optimal power flow approximation to calculate optimal locational prices and congestion costs.

Many researchers have proposed various methodologies to assess locational marginal pricing under a competitive market. Nevertheless, the determination of energy price, and transmission cost seems to be rigid and are based on many assumptions such as: ignored network losses, power pool operation is carried out on one-sided bidding, and market price is cleared in separated calculation. Furthermore, transmission management is required to ensure sufficient control over producers and customers to maintain the security level of power system while maximising market efficiency.

Independent system operators (ISOs) usually observe the transactions and control the state of the system, take a part in handling the network congestion management (Stamtsis \& Erlich, 2004; Lin et al., 2006). ISOs are being challenged to develop a set of regulations to control the security level of power systems and ensure they are at an acceptable level while keeping the efficiency of the power market high (Conejo et al., 2006; Xusheng et al., 2006). This implies that market operators should alleviate network congestion; maintain the security and efficiency of power system operation (Kumar et al., 2004) in order to ensure all market participants have the same rights to access a transmission system without any discrimination (Shirmohammadi et al., 1998). Congestion levels typically determine the security of a power system, which would have further consequences on market transaction and energy prices.

Market operators have been using the DC-OPF for dispatching power and clearing energy (Farmer et al., 1995; Hogan, 1998; Singh et al., 1998; Karaki et al., 2002; Niimura \& Niu, 2002; Fonseka \& Shrestha, 2004; Hamoud \& Bradley, 2004; Dan et al., 2006) to determine the LMP due to its speed and robustness, particularly in market simulation and planning (Wu et al., 2004; Junjie \& Tesfatsion, 2007; Li \& Bo, 2007). Generally, the DC-OPF is used for security constrained economic dispatch and redispatch when controlling transmission congestion while maximising the economic power transfer capability of the transmission system without violating its constraints (Kafka, 1999; Yajing et al., 2006; Gomes \& Saraiva, 2007; Rodrigues \& Silva, 2007). However, DC-OPF does not consider the network losses. Consequently, when the DC-OPF is modified by incorporating the line losses, the linearity 
and superposition features of the LMP model, which is advantageous for the simplicity, robustness and efficiency are no longer exist anymore due to the non-linear, quadratic relationship between line loss and line current.

Therefore the authors in this paper introduce schemes for incremental cost-based energy pricing model to deal with congestion including losses and transmission usage tariff, but simplify the method and have acceptable transparency so that it may correctly generate economic signal to the market participants. In this manuscript, a new scheme is presented to briefly review the main idea behind the LMP calculation, and further discuss the techniques used to incorporate transmission usage tariff into the model. This would be a comprehensive approach in which pricing of transmission service is implemented together with short-term nodal pricing or LMP, which represents energy price, network losses cost, and transmission congestion cost. Findings of this research are expected to be useful to support developing standard market design in transmission networks, which promotes economic efficiency, lowers delivered energy costs, maintains power system reliability and mitigates exercising market power.

\section{Dispatch methodology}

The rules of dispatch methodology must be robust, fair and transparent (Christie et al., 2000). It should also encourage load elasticity and mitigate the application of market power (Niimura \& Niu, 2002). This is because congestion will influence all market participants and may allow suppliers or generators to exercise market power. This action usually occurs during the congestion period or peak load hours to gain more profits, which in turn results in an expensive price at the customer node. Furthermore, economic signals have to be generated in the dispatch process to ensure the sustainability and security of the electricity market. Transmission pricing as the output of dispatch should not only be transparent and stable, but also promote optimal transmission system development and be able to avoid being overinvested (Farmer et al., 1995; Yamin, et al., 2004; Kaymaz et al., 2007). For that reason, economic optimality should be conducted in the dispatch mechanisms. This means transmission pricing associated with network constraints is required to send the correct cost signal of service to generators, suppliers and customers to avoid cross subsidy among different nodes at different times of usage.

Shift factor (SF) methodology is employed in order to perform congestion-based nodal price model through optimal power flow approach. It is used with the intention to maintain the linearity and superposition features of the LMP model while still able to account for both congestion and losses cost (California-ISO, 2005). The shift factor helps to determine the power flow over a given transmission line from the source node (generation) to the sink node (load). It is characterized by four attributes, namely; a reference node, a particular node, a particular line with reference direction, and the value of the shift factor.

Shift factor values depend on network topology and line impedance. Once these two variables change, the value of shift factor will change as well. Basically, the shift factor can be formulated through three stages based on dc load flow network model approach:

- Stage 1: Making sensitivity equation of phase angles as the function of node injections.

- Stage 2: Making sensitivity equation of branch flows as a function of phase angles.

- Stage 3: Substitution the result of stage 1 into stage 2. 


\section{A new LMP-TUT model for optimal energy pricing}

In the author's previous proposed dispatch model (Nappu et al., 2008), two schemes were introduced to formulate energy pricing for both neglecting and considering network losses. The first scheme ignores the losses, called LMP-losssless, while the second scheme which takes network losses into account is named as LMP-loss.

$$
\begin{gathered}
\mathrm{LMP}_{\text {lossless }}=\mathrm{EP}+\mathrm{CR} \\
\mathrm{LMP}_{\text {loss }}=\mathrm{EP}+\mathrm{CR}+\mathrm{LC}
\end{gathered}
$$

Dispatch model discussed in this paper encompasses energy price (EP), transmission congestion revenue (CR), and transmission losses cost (LC). Embedded cost in terms of transmission usage tariff is also added into this formulation. Basically, the model in this scheme is equal to LMP-loss model, namely it encompasses three components: energy price, transmission congestion revenue and transmission losses cost. However, an embedded cost, transmission usage tariff (TUT) is added in to this formula. In fact, market operators use different approaches to account for this tariff, such as: postage stamp rate method, contract path method, MW-mile method, unused transmission capacity method or counter-flow method (Perez-Arriaga et al., 1995; Shahidehpour et al., 2002; Shu \& Gross, 2002).

So far, pricing for transmission services using such methods above are still separately accounted for from the energy market price calculation. With the intention of having efficient, transparent and effective pricing due to transmission network usage services, LMPs' model in this scheme is formulated to take into account a tariff for transmission usage and is referred to as LMP-TUT model. By incorporating this component, the scheme is expected to simplify the method and have acceptable transparency so that it may send an economic signal correctly to the market participants (Luonan et al., 2002; Fonseka \& Shrestha, 2006).

Accordingly, the formula for this model will be:

$$
\mathrm{LMP}_{\mathrm{TUT}}=\mathrm{EP}+\mathrm{CR}+\mathrm{LC}+\mathrm{TUT}
$$

\subsection{Objective function}

Total transmission usage tariff is written as:

$$
T_{m}\left(P_{G i}\right)=\alpha_{m} \text { flow }_{m}
$$

In this scheme, the objective function is to minimize the total social cost and transmission usage tariff to decide the power supply and required demand.

$$
\operatorname{Min} \sum_{m=1}^{M} T_{m}\left(P_{G i}\right)+\sum_{i=1}^{n_{G}} C_{i}\left(P_{G i}\right)-\sum_{j=1}^{n_{D}} B_{j}\left(P_{D j}\right)
$$

where:

$T_{m}:$ total transmission usage tariff $(\$ / \mathrm{h})$

$\alpha_{m}:$ transmission charge rate for line $m(\$ / \mathrm{MWh})$

flow $_{m}$ : power flow on line $m(\mathrm{MW})$

$C_{i}$ : production cost function $(\$ / \mathrm{h})$

$B_{j}$ : costumer benefit function $(\$ / \mathrm{h})$ 


\section{Constraints}

- Bus power balance with network power losses

$$
\sum_{i} P_{G i}-P_{L}\left(P_{G i}\right)=\sum_{j} P_{D j}
$$

- Generator power output

$$
P_{G i}^{\min } \leq P_{G i} \leq P_{G i}^{\max }
$$

- Active power demand

$$
P_{D j}^{\min } \leq P_{D j} \leq P_{D j}^{\max }
$$

- $\quad$ Power transfer capability

$$
\text { flow }_{m}^{\min } \leq \text { flow }_{m} \leq \text { flow }_{m}^{\max }
$$

Thus, the Lagrange function may be formulated as:

$$
\begin{aligned}
L\left(P_{D j}, P_{G i}, \lambda_{i}, \mu_{i}\right)= & \sum_{m=1}^{M} T_{m}\left(P_{G i}\right)+\sum_{i=1}^{n_{G}} C_{i}\left(P_{G i}\right)-\sum_{j=1}^{n_{D}} B_{j}\left(P_{D j}\right)+\lambda_{i}\left(\sum_{j} P_{D j}-\sum_{i} P_{G i}-P_{L}\left(P_{G i}\right)\right) \\
& -\sum_{j} \mu_{\min , D j}\left(P_{D j}-P_{D j}^{\min }\right)+\sum_{j} \mu_{\max , D j}\left(P_{D j}-P_{D j}^{\max }\right) \\
& -\sum_{i} \mu_{\min , G i}\left(P_{G i}-P_{G i}^{\min }\right)+\sum_{i} \mu_{\max , G i}\left(P_{G i}-P_{G i}^{\max }\right) \\
& -\sum_{m} \mu_{\min , \text { flow }, m}\left(\text { flow }_{m}-\text { flow }_{m}^{\min }\right) \sum_{m} \mu_{\max , \text { flow }, m}\left(\text { flow }_{m}-\text { flow }_{m}^{\max }\right)
\end{aligned}
$$

After obtaining the first order optimal condition of Karush-Kuhn-Tucker, Locational Marginal Prices or LMPs for both suppliers and customers can be formulated as follows:

\section{LMPs for suppliers}

$$
\begin{aligned}
& \rho_{i}=\frac{\partial T_{m}\left(P_{G_{i}}\right)}{\partial\left(P_{G_{i}}\right)}+\frac{\partial C_{i}\left(P_{G_{i}}\right)}{\partial\left(P_{G_{i}}\right)}-\mu_{\min , G_{i}}+\mu_{\max , G_{i}} \\
& =\lambda\left\{1-\sum_{i^{\prime}=1}^{I} G_{L n-n^{\prime}}\left(\sum_{i \in I\left(i^{\prime}\right)} P_{G_{i}}-\sum_{j \in J\left(j^{\prime}\right)} P_{D j}\right)\right\}+\sum_{m} \mu_{\min , f l o w, m} \cdot S_{m, n} \\
& -\sum_{m} \mu_{\max , \text { flow }, m} \cdot S_{m, n}-\sum_{m} \alpha_{m} \frac{\text { flow }_{m}\left(P_{G_{i}}\right)}{\mid \text { flow }_{m}\left(P_{G_{i}}\right)} \cdot S_{m, n}
\end{aligned}
$$




\section{LMPs for customers}

$$
\begin{aligned}
\rho_{i}= & \frac{\partial B_{j}\left(P_{D j}\right)}{\partial\left(P_{D j}\right)}-\mu_{\min , D j}+\mu_{\max , D j} \\
= & \lambda\left\{1-\sum_{i^{\prime}=1}^{I} G_{L n-n^{\prime}}\left(\sum_{i \in I\left(i^{\prime}\right)} P_{G i}-\sum_{j \in J\left(j^{\prime}\right)} P_{D j}\right)\right\}+\sum_{m} \mu_{\min , f l o w, m} \cdot S_{m, n} \\
& \left.-\sum_{m} \mu_{\max , \text { flow }, m} \cdot S_{m, n}-\sum_{m} \alpha_{m} \frac{\text { flow }}{\mid \text { flow }_{m}\left(P_{G i}\right)} \cdot S_{G i}\right) \mid
\end{aligned}
$$

Merchandizing surplus which contains congestion revenue, cost of losses and the transmission usage tariff will be:

$$
M S=\lambda P_{L}\left(P_{G i}\right)+\sum_{m} \mu_{\max , \text { flow }, m} \cdot \text { flow }_{m}-\sum_{m} \mu_{\min , \text { flow }, m} \cdot \text { flow }_{m}+\sum_{m} \alpha_{m}\left|f l o w_{m}\left(P_{G i}\right)\right|
$$

\subsection{Basic tasks of the improved method}

The methodology of this research comprises several basic objectives and is divided into 5 tasks.

1. Identification of primary data

2. Assessment of branch power flow and branch loss

3. Modeling of LMP Schemes

4. Developing optimization tools

5. Examining the most efficient reference node

In order for the proposed method to obtain appropriate reference node and to perform the lowest overall cost, the following iteration process needs to be taken:

1. select any arbitrary node as reference prior to running simulation

2. choose particular node which performs the lowest nodal price, and

3. re-run the simulation after fixing that node as the reference node.

\subsection{Conceptual flowchart of the schemes}

In a brief snapshot, problem identification represents the basic tasks is illustrated in Figure 2 , which figures out all the basic objectives described in this section.

\section{Results and analysis}

\subsection{Implementation of the proposed methodology}

The LMP models formulated in Section 3 are implemented in software. An optimization tool has been successfully developed through MATLAB technical programming. The tool for assessing LMP using optimal power flow based on shift factor methodology, SF-OPF, covers all the schemes. In addition, another optimization tool using conventional DC optimal power flow methodology is also created.

Since the perspective of employing this approach was originally only appropriate to the LMP-lossless, then it should be modified in such a way so that it suits with the LMP-loss and LMP-TUT schemes as well. The main intention of making this second tool is to validate the 
results of the proposed method, the SF-OPF. By running the tools, their outputs are evaluated and compared to each other with the aim of finding the best results.

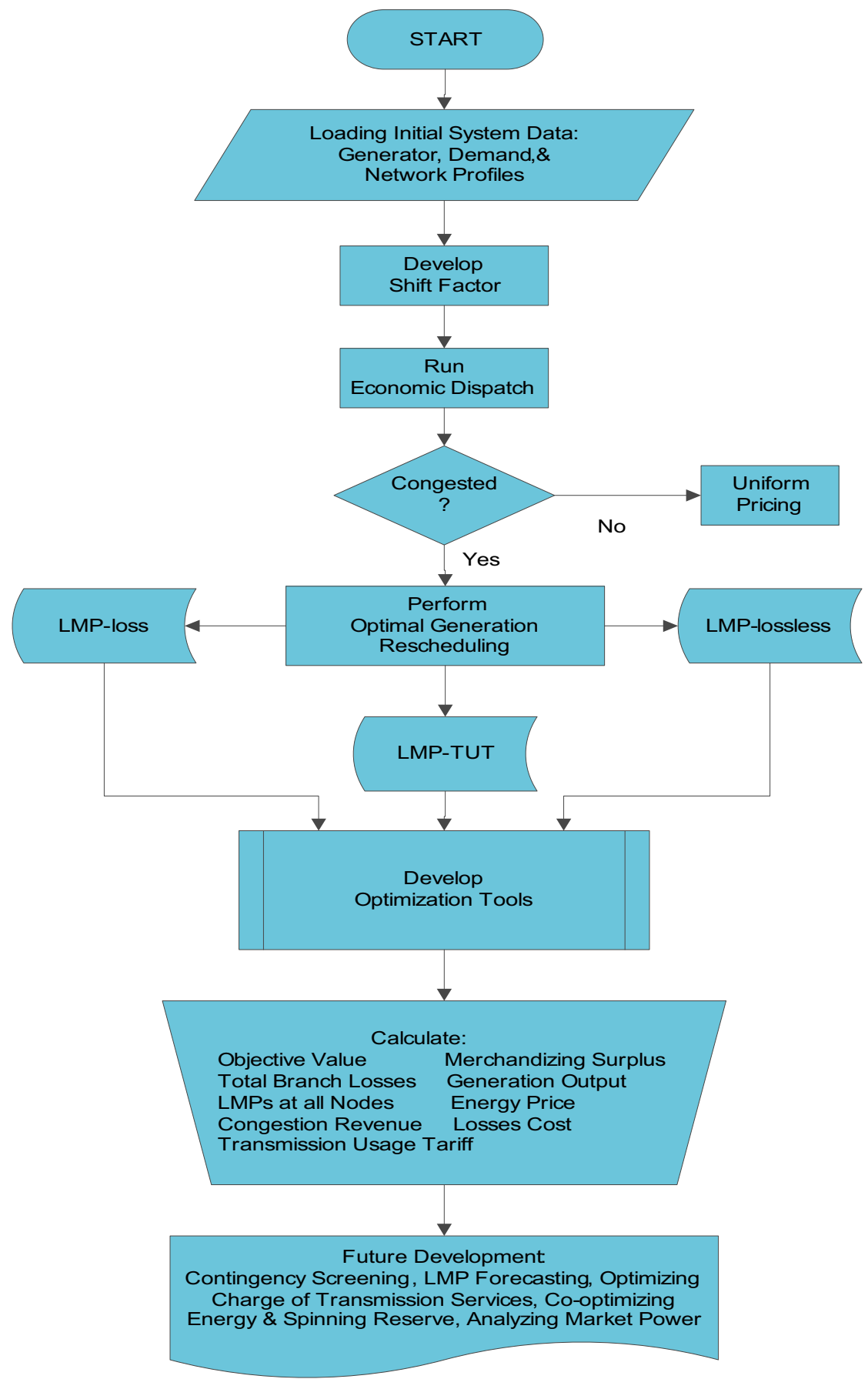

Fig. 2. Flowchart of the LMP schemes improvement 


\subsection{Illustrative example of simple 3-Bus system}

The proposed method is implemented with a simple 3-bus system. Some important characteristics are evaluated to describe benefit features of the method. System details consisting of generation and branch profiles are given in Table 1.

\begin{tabular}{|c|c|c|c|c|c|c|}
\multicolumn{7}{|c|}{ Generator Profile } \\
\hline & $\begin{array}{c}\mathrm{b}_{\mathrm{i}} \\
(\$ / \mathrm{MWh})\end{array}$ & \multicolumn{2}{c|}{$\begin{array}{c}\mathrm{m}_{\mathrm{i}} \\
\left(\$ / \mathrm{MW}^{2} \mathrm{~h}\right)\end{array}$} & $\begin{array}{c}\min \mathrm{G}_{\mathrm{i}} \\
(\mathrm{MW})\end{array}$ & $\begin{array}{c}\max \mathrm{G}_{\mathrm{i}} \\
(\mathrm{MW})\end{array}$ \\
\hline $\mathrm{G}_{1}$ & 20 & \multicolumn{2}{c|}{0.015} & 150 & 600 \\
\hline $\mathrm{G}_{2}$ & 18 & \multicolumn{7}{|c|}{0.015} & 50 & 400 \\
\hline \multicolumn{7}{|c|}{ Branch Profile } \\
\hline & $\mathrm{n}^{\prime}$ & $\mathrm{n}^{\prime \prime}$ & $\begin{array}{c}\mathrm{r} \\
\text { p.u. }\end{array}$ & $\begin{array}{c}\mathrm{x} \\
\text { p.u. }\end{array}$ & $\begin{array}{c}\text { cap } \\
(\mathrm{MW})\end{array}$ & $\begin{array}{c}\mathrm{a}_{\mathrm{m}} \\
(\$ / \mathrm{MWh})\end{array}$ \\
\hline L1 & 1 & 2 & 0.0134 & 0.1335 & 200 & 2 \\
\hline L2 & 1 & 3 & 0.0067 & 0.0665 & 550 & 1 \\
\hline L3 & 2 & 3 & 0.0084 & 0.1002 & 350 & 1.25 \\
\hline
\end{tabular}

Table 1. 3-bus system generator and branch details

Results obtained are recapitulated and shown in Table II. From the table, it can be observed that the minimum cost is achieved when node- 2 is selected as the reference node. This option causes minimum power supply for network losses at $24 \mathrm{MW}$, compared to the other option; 24.06 MW and 25.53 MW for node-1 and node-3, respectively. Although node-1 and node-2 tending to have the same network losses supply, selecting node-2 as reference node gives a minimum objective value as well. This is comparable to the results of model without adding embedded cost, LMP-loss.

However, LMPs obtained under this LMP-TUT model are diverse because the component of the LMP now has additional cost that is transmission usage tariff. As a result, notwithstanding all generators output and the total of branch loss in LMP-loss and LMPTUT models are the same, yet objective value, cost of losses and merchandizing surplus are dissimilar. The relationship between objective value and merchandizing surplus relative to the selection of reference nodes is given in Figures 3 and 4.

Illustration about the change of branch flow for different reference node can be found in Figures 6(a)-6(d). It is apparent that branch flow over transmission line 2-3 decreases when node 2 is selected as the reference node. This means transmission congestion may be avoided since power flowing on this line is only $344.42 \mathrm{MW}$, which is lower than $350 \mathrm{MW}$ as the maximum loadability of the line 2-3. In addition, by selecting node 2 as the reference node, it allows the network power loss to be supplied from node 2 which has the lowest nodal price. Meanwhile in DC-OPF method, compensation for network losses must be distributed to all generators in such a way to ensure the power flow in the line does not exceed network thermal limit. This fact causes adding up of the total cost compared to the proposed SF-OPF method, which needs a specific bus as injection point for the network power loss compensation. 


\begin{tabular}{|c|c|c|c|c|c|c|c|c|c|c|c|c|}
\hline \multicolumn{13}{|c|}{$\begin{array}{c}\text { SF-OPF } \\
\text { (Proposed Method) }\end{array}$} \\
\hline $\begin{array}{l}\text { Ref. } \\
\text { Node }\end{array}$ & $\begin{array}{l}\text { Obj. } \\
\text { Cost1 } \\
(\$ / h)\end{array}$ & $\begin{array}{l}\text { Loss } \\
(\mathrm{MW})\end{array}$ & $\begin{array}{l}\text { G-1 } \\
(\mathrm{MW})\end{array}$ & $\begin{array}{c}\mathrm{G}-2 \\
(\mathrm{MW})\end{array}$ & $\begin{array}{c}\rho 1 \\
(\$ / \mathrm{MWh})\end{array}$ & $\begin{array}{c}\rho 2 \\
(\$ / \mathrm{MWh})\end{array}$ & $\begin{array}{c}\rho 3 \\
(\$ / \mathrm{MWh})\end{array}$ & $\frac{\lambda}{(\$ / \mathrm{MWh})}$ & $\begin{array}{l}\text { TUT } \\
(\$ / h)\end{array}$ & $\begin{array}{c}\mathrm{LC} \\
(\$ / \mathrm{h})\end{array}$ & $\begin{array}{c}\mathrm{CR} \\
(\$ / \mathrm{h})\end{array}$ & $\begin{array}{l}\text { MS } \\
(\$ / h)\end{array}$ \\
\hline 1 & 19223 & 24.06 & 435.52 & 388.54 & 26.53 & 25.04 & 28.74 & 26.53 & 964.58 & 638.29 & 1061.29 & 2664.16 \\
\hline 2 & 19177 & 24.00 & 424.00 & 400.00 & 25.15 & 25.06 & 26.62 & 25.06 & 949.25 & 601.45 & 0.00 & 1550.70 \\
\hline 3 & 19299 & 25.53 & 449.71 & 375.82 & 27.35 & 25.45 & 30.11 & 30.11 & 964.67 & 768.78 & 1445.55 & 3179.00 \\
\hline \multicolumn{13}{|c|}{$\begin{array}{c}\text { DC-OPF } \\
\text { (Conventional Method) }\end{array}$} \\
\hline $\begin{array}{l}\text { Ref. } \\
\text { Node }\end{array}$ & $\begin{array}{l}\text { Obj. } \\
\text { Cost2 } \\
(\$ / h)\end{array}$ & $\begin{array}{l}\text { Loss } \\
(\mathrm{MW})\end{array}$ & $\begin{array}{l}\text { G-1 } \\
(\mathrm{MW})\end{array}$ & $\begin{array}{c}\mathrm{G}-2 \\
(\mathrm{MW})\end{array}$ & $\begin{array}{c}\rho 1 \\
(\$ / M W h)\end{array}$ & $\begin{array}{c}\rho 2 \\
(\$ / M W h)\end{array}$ & $\begin{array}{c}\text { p } 3 \\
(\$ / \mathrm{MWh})\end{array}$ & & $\begin{array}{l}\text { TUT } \\
(\$ / h)\end{array}$ & $\begin{array}{c}\mathrm{LC} \\
(\$ / \mathrm{h})\end{array}$ & $\begin{array}{c}\text { CR } \\
(\$ / h)\end{array}$ & $\begin{array}{l}\text { MS } \\
(\$ / h)\end{array}$ \\
\hline 1 & 19238 & 24.53 & 436.88 & 387.64 & 26.55 & 23.81 & 29.53 & & 964.62 & 673.41 & 1155.64 & 2793.68 \\
\hline 2 & 19238 & 24.53 & 436.88 & 387.64 & 26.55 & 23.81 & 29.53 & & 964.62 & 673.41 & 1155.64 & 2793.68 \\
\hline 3 & 19238 & 24.53 & 436.88 & 387.64 & 26.55 & 23.81 & 29.53 & & 964.62 & 673.41 & 1155.64 & 2793.68 \\
\hline
\end{tabular}

Table 2. 3-bus system results

In view of that, there is no congestion revenue, and merchandizing surplus only contains the cost of network losses, which is the lowest cost of losses for this scheme. Therefore merchandizing surplus and objective value in this option are about half the value of other selected reference nodes, as shown in Figures 3-4. Normally, merchandizing surplus comes with congestion revenue component as the major element.

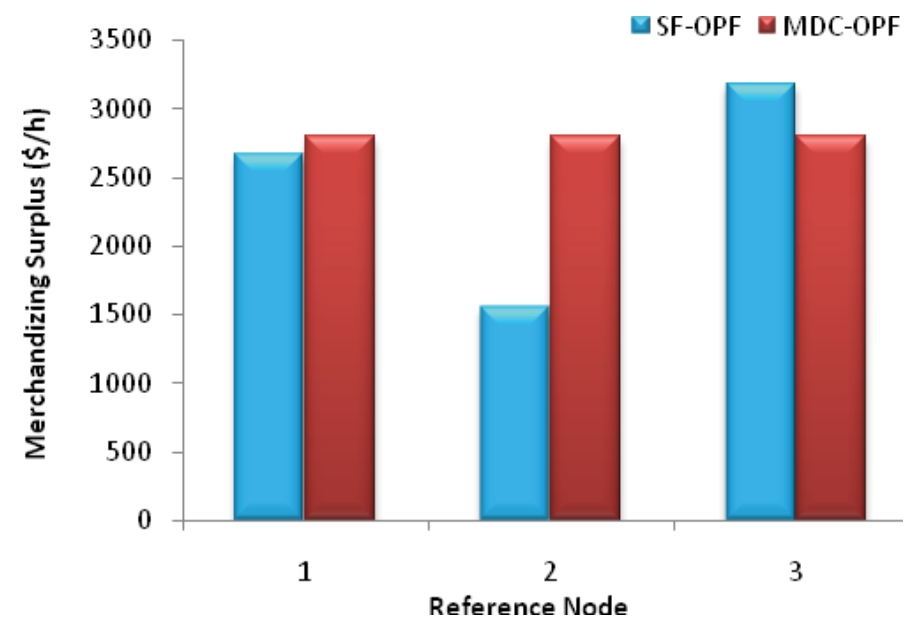

Fig. 3. Output of the optimization tools: Merchandizing Surplus vs. Reference Node

The behavior of the transmission usage charge formulated over this scheme can be analyzed in Figures 7(a)-7(b), in particular when demand is increased to 850 MW. Figure 7(a) 
describes how the composition of the transmission revenue component changes as the network charge rates are raised. As shown by Figure 11(b), employing the SF-OPF method is able to save costs of about $\$ 1000 / \mathrm{h}$ compared to the modified DC-OPF results.

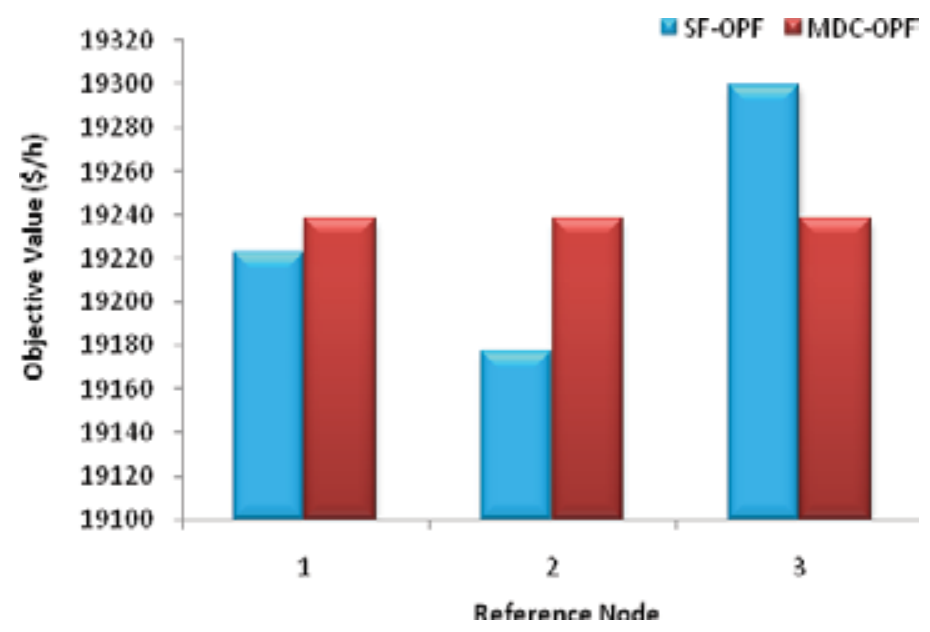

Fig. 4. Output of the optimization tools: Objective Value vs. Reference Node

The transmission usage tariff has a converse correlation with the transmission congestion revenue. As the network charge rate increases, it causes the transmission usage tariff to increase in value. Transmission congestion revenue then decreases while the total transmission cost, in this case merchandizing surplus remains constant. Thus, the total amount of transmission revenue is kept constant to the entire time subject to network charge rate. This condition will keep away market participants from the possible monopolistic price raised by transmission owners during peak load hours when the lines are more likely to be congested or exceeding the thermal limit. This is the main feature of the LMP-TUT scheme that can be useful to protect both generators and customers as the network users.

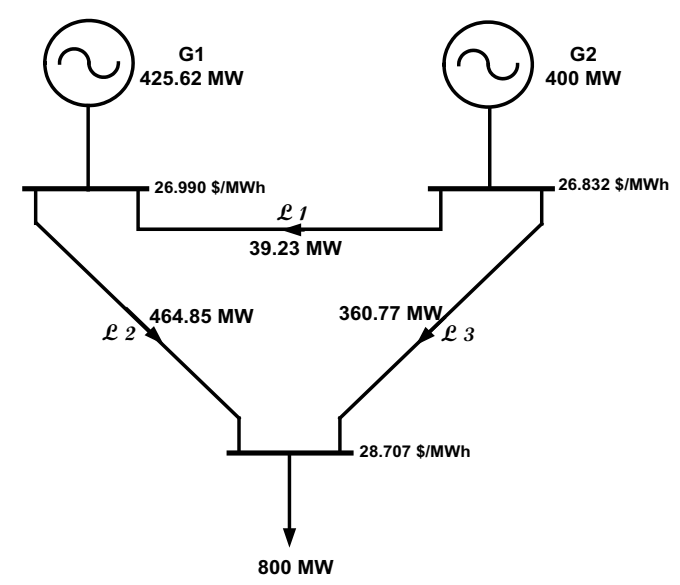

Fig. 5. Un-constrained branch flow of the 3-bus system 


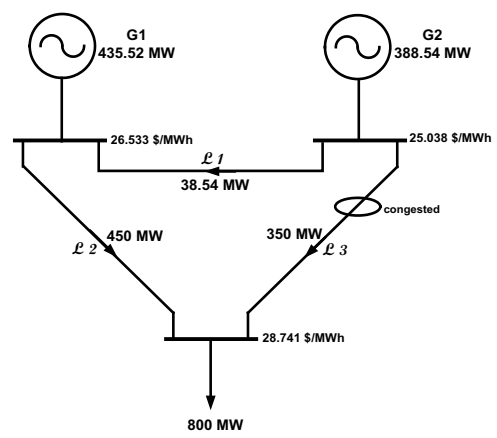

(a) SF-OPF with ref. node \#1

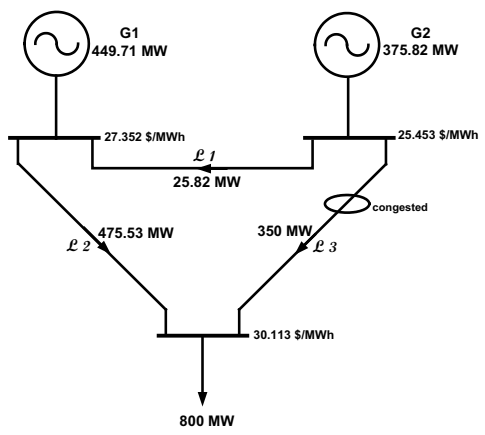

(c) SF-OPF with ref. node \#3

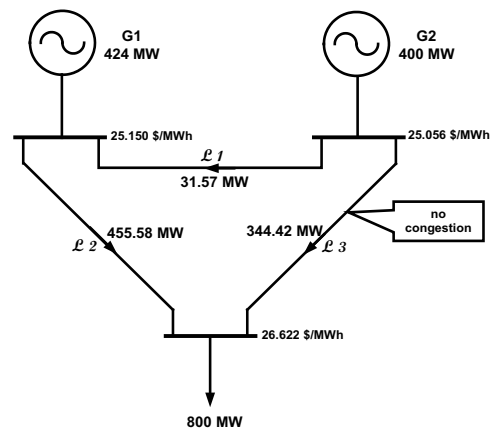

(b) SF-OPF with ref. node \#2

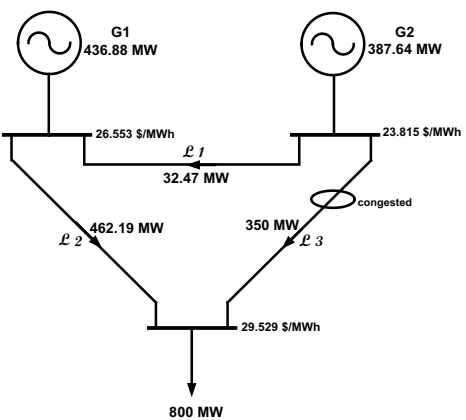

(d) DC-OPF with any ref. node

Fig. 6. The comparison of constrained branch flow with different reference node

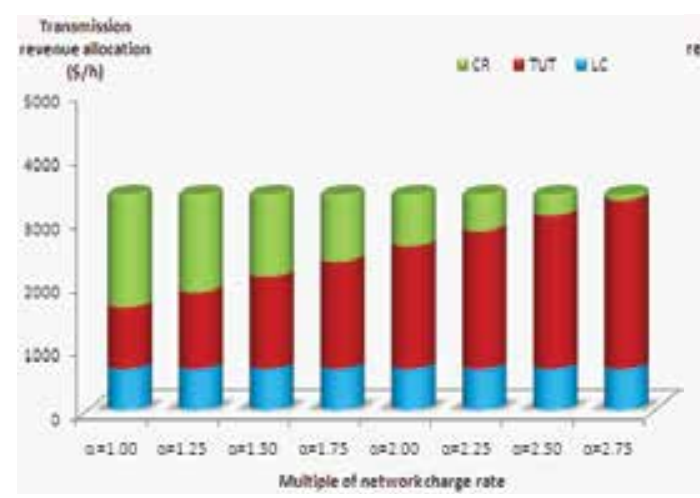

(a) SF-OPF method

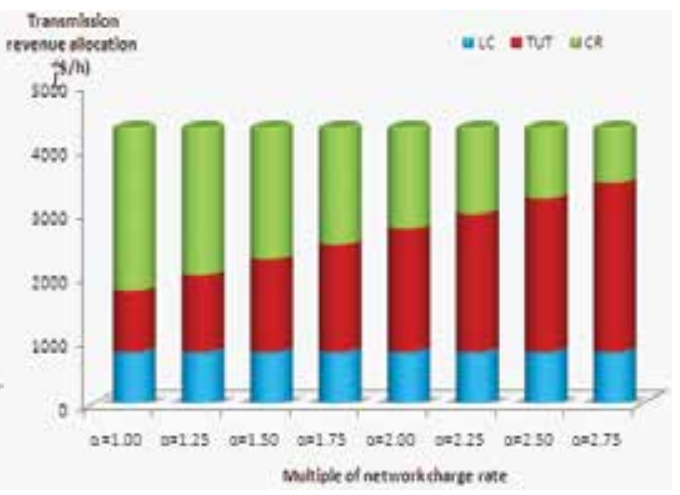

(b) DC-OPF method

Fig. 7. Transmission revenue component vs. multiple of network charge rate with different approach

\section{Conclusions}

An effective congestion-based nodal price modeling is the key factor in determining optimal pricing, which could generate economic signal especially as congestion happens. Therefore a comprehensive tool for congestion-based nodal pricing has been developed to encourage 
transparent and competitive price but still be able to address the issues surrounding transmission management.

Locational marginal prices formulated under the LMP-TUT model have an additional cost called transmission usage tariff. The SF-OPF and modified DC-OPF methods are used to simulate this third scheme of the author's proposed schemes. Market efficiency obtained by the SF-OPF method proves that this approach is much better than the conventional DC-OPF method.

In addition the results show that there is a reverse relationship between transmission usage tariff and transmission congestion charge. As the network charge rate increases, usage tariff also increases but congestion revenue decreases automatically. This particular scheme advantages market participants because it incorporates the usage tariff while keep the amount of total transmission charges to be constant.

By applying this scheme for managing transmission congestion, accordingly, it would be able to avoid network users from the drawback of potential monopolistic network charge rates increased arbitrarily by transmission owners, especially during the peak load period in which the lines are most probably exceeding their thermal limits.

\section{Future research}

From the study conducted in this project, there are a number of future research issues for further development as illustrated in Figure 2. Some of them are as follows:

\subsection{The effect of transmission congestion on market power}

The main concern of non-competitive participants in the deregulated power market, particularly the generation companies is when market power is exercised, since it may impede competition in power production, service quality and technological innovation (Shahidehpour et al., 2002). Furthermore, market power in electricity markets are more complicated than those in other markets because of the characteristic of the electricity (Peng et al., 2004). Market power can be exercised intentionally or unintentionally. When a generation company offers large amounts of generation to the market, by committing more expensive generating units to maintain system reliability while cheaper units could have been committed, this is called an intentional practice of market power. Nonetheless, market power can be the cause of transmission congestion that limits the transfer capability in a certain area, this is unintentional market power. Congestion phenomenon can prevent particular generating units that could be cheap from supplying power. On the other hand, transmission congestion can permit certain units to escalate market prices by offering expensive units.

The impact of transmission congestion on market power can be explored with long term dynamic simulation (Allen \& Ilic, 2000). The research should be focused on the effect of transmission congestion on a generator's settlement prices, incomes and benefits. Simulation is continued by examining the charge of transmission services to discover the optimal pricing, which could meet revenue requirements of the assets and may stimulate third parties (investor) to build new transmission lines and generating capacity in optimal locations, in order to enhance efficiencies in the power market.

\subsection{Co-optimization of energy and spinning reserve}

Another area for research to be conducted is to analyze co-optimization of energy and spinning reserve. The spinning reserve is one of the most important ancillary services that 
must have full attention paid to it in a markets management and operation. Thus, establishing an efficient market structure for spinning reserve services has become crucial (Allen \& Ilic 2000; Bautista et al., 2006; Wong \& Fuller, 2007). In addition, spinning reserve can be used to manage system contingencies (Jie et al., 2003). In this way, the research should focus on proposed scheduling and pricing algorithms, which provides LMP as a possible market signal tool of reserve supply. To analyze system security, simulation can be done in the presence of a network outage due to contingency screening. A co-optimization is performed in terms of minimizing the expected costs of energy and reserves while meeting system load and transmission constraints and maintaining certain grid security (Marwali \& Shahidehpour, 2000; Shangyou \& Shirmohammadi, 2002). This determines the optimum patterns of energy dispatch and reserves.

\subsection{LMP forecasting}

Since the introduction of restructuring and competition into the power system, the electricity price has become the center of all activities in the power market. Therefore shortterm price forecasting is vital for market players to manage their price risk (Mandal et al., 2009). Nowadays, electricity has been considered as a commodity in various markets. Nevertheless, electricity has distinct characteristics that distinguish it from other commodities. Its characteristics are that electricity cannot be stored economically for long periods of time and transmission congestion in a power system may prohibit exchange among control areas. As a result, electricity price movement can demonstrate major volatility. Hence the price forecasting methods prevalent in other commodity markets cannot be applied to forecast the electricity price.

Research that could be conducted in a technical aspect of transmission congestion management is to investigate a framework for short-term LMP forecasting. Transmission congestion that occurs when power flow in a transmission line exceeds its thermal limit can cause different LMP or bus prices. Even though LMP is very volatile, they are not random. Thus certain patterns and rules concerning market volatility can be recognized. Because a high volatility of LMP is resultant during the congestion period, LMP forecasting is now holding a significant part in establishing proper economical operation (Valenzuela \& Mazumdar, 2005; Li et al., 2007). Therefore it is crucial to predict the congestion rigorousness for LMP forecasting. The effect of line flow and line limit will be calculated on price to find out the relationship between congestion and the LMP.

\section{References}

Allen, E. H. and M. D. Ilic (2000). "Reserve markets for power systems reliability." Power Systems, IEEE Transactions on 15(1): 228-233.

Bautista, G., V. H. Quintana, et al. (2006). "An oligopolistic model of an integrated market for energy and spinning reserve." Power Systems, IEEE Transactions on 21(1): 132142.

California-ISO (2005). Shift Factors: Methodology and Example. CAISO Market Operations: [online] Available: http://www.caiso.com/docs/2004/02/13/200402131609438684.pdf.

Chowdhury, B. H. and S. Rahman (1990). "A Review of Recent Advances in Economic Dispatch." IEEE Power Systems, IEEE Transactions on 5(4): 1248-1259. 
Christie, R. D., B. F. Wollenberg, et al. (2000). "Transmission management in the deregulated environment." Proceedings of the IEEE 88(2): 170-195.

Conejo, A. J., F. Milano, et al. (2006). "Congestion management ensuring voltage stability." Power Systems, IEEE Transactions on 21(1): 357-364.

Dan, Y., A. Hallam, et al. (2006). Optimal Bidding Strategy for Financial Transmission Right. Power System Technology, 2006. PowerCon 2006. International Conference on.

Farmer, E. D., B. J. Cory, et al. (1995). "Optimal pricing of transmission and distribution services in electricity supply." Generation, Transmission and Distribution, IEE Proceedings- 142(1): 1-8.

Fonseka, P. A. J. and G. B. Shrestha (2004). Network expansion under the frameworks of regulated monopoly and merchant transmission. Power System Technology, 2004. PowerCon 2004. 2004 International Conference on.

Fonseka, P. A. J. and G. B. Shrestha (2006). A Study on the Pricing of Network Services. Power System Technology, 2006. PowerCon 2006. International Conference on.

Gedra, T. W. (1999). "On transmission congestion and pricing." Power Systems, IEEE Transactions on 14(1): 241-248.

Gomes, B. A. and J. T. Saraiva (2007). Calculation of Nodal Marginal Prices Considering Load and Generation Price Uncertainties. Power Tech, 2007 IEEE Lausanne: 849-854.

Hamoud, G. and I. Bradley (2004). "Assessment of transmission congestion cost and locational marginal pricing in a competitive electricity market." Power Systems, IEEE Transactions on 19(2): 769-775.

Hogan, W. W. (1998). Independent System Operator: Pricing and Flexibility In A Competitive Electricity Market. C. f. B. a. Government. Cambridge, Massachusetts, John F. Kennedy School of Governement, Harvard University: 52.

Jie, C., J. S. Thorp, et al. (2003). Locational pricing and scheduling for an integrated energyreserve market. System Sciences, 2003. Proceedings of the 36th Annual Hawaii International Conference on.

Jun, Y. (2006). Locational marginal pricing in ERCOT market. Power Engineering Society General Meeting, 2006. IEEE.

Junjie, S. and L. Tesfatsion (2007). Open-Source Software for Power Industry Research, Teaching, and Training: A DC-OPF Illustration. Power Engineering Society General Meeting, 2007. IEEE: 1-6.

Kafka, R. J. (1999). OPF for economic control of transmission congestion. Power Engineering Society Summer Meeting, 1999. IEEE.

Karaki, S. H., H. T. Chahine, et al. (2002). Congestion management and pricing in the restructured power system of Lebanon. Power Engineering Society Summer Meeting, 2002 IEEE.

Kaymaz, P., J. Valenzuela, et al. (2007). "Transmission Congestion and Competition on Power Generation Expansion." Power Systems, IEEE Transactions on 22(1): 156-163.

Kumar, A., S. C. Srivastava, et al. (2004). "A zonal congestion management approach using real and reactive power rescheduling." Power Systems, IEEE Transactions on 19(1): 554-562.

Li, F. and R. Bo (2007). "DCOPF-Based LMP Simulation: Algorithm, Comparison With ACOPF, and Sensitivity." IEEE Transaction On Power Systems 22: 1475-1485.

Li, G., C. C. Liu, et al. (2007). "Day-Ahead Electricity Price Forecasting in a Grid Environment." Power Systems, IEEE Transactions on 22(1): 266-274. 
Lin, Y., G. A. Jordan, et al. (2006). "Economic Analysis of Establishing Regional Transmission Organization and Standard Market Design in the Southeast." Power Systems, IEEE Transactions on 21(4): 1520-1527.

Litvinov, E. (2006). LMP implementation in New England. Power Engineering Society General Meeting, 2006. IEEE.

Luonan, C., H. Suzuki, et al. (2002). "Components of nodal prices for electric power systems." Power Systems, IEEE Transactions on 17(1): 41-49.

Mandal, P., A. K. Srivastava, et al. (2009). "An Effort to Optimize Similar Days Parameters for ANN-Based Electricity Price Forecasting." Industry Applications, IEEE Transactions on 45(5): 1888-1896.

Marwali, M. K. C. and S. M. Shahidehpour (2000). "Coordination between long-term and short-term generation scheduling with network constraints." Power Systems, IEEE Transactions on 15(3): 1161-1167.

Nappu, M. B., T. K. Saha, et al. (2008). Investigation on congestion-based optimal energy price for competitive electricity market. IEEE International Conference on Sustainable Energy Technologies, Singapore, 24-27 November.

Niimura, T. and Y. Niu (2002). Transmission congestion relief by economic load management. Power Engineering Society Summer Meeting, 2002 IEEE.

Peng, W., X. Yu, et al. (2004). "Nodal market power assessment in electricity markets." Power Systems, IEEE Transactions on 19(3): 1373-1379.

Perez-Arriaga, I. J., F. J. Rubio, et al. (1995). "Marginal pricing of transmission services: an analysis of cost recovery." Power Systems, IEEE Transactions on 10(1): 546-553.

Ristanovic, P. and J. Waight (2006). Locational marginal prices in practice: a vendor's perspective. Power Engineering Society General Meeting, 2006. IEEE.

Rodrigues, A. B. and M. G. D. Silva (2007). "Probabilistic Assessment of Available Transfer Capability Based on Monte Carlo Method With Sequential Simulation." Power Systems, IEEE Transactions on 22: 484-492.

Shahidehpour, M., H. Yamin, et al. (2002). Market Operations in Electric Power Systems. New York, John Wiley \& Sons, Inc.

Shangyou, H. and D. Shirmohammadi (2002). "Congestion management with ex ante pricing for decentralized electricity markets." Power Systems, IEEE Transactions on 17(4): 1030-1036.

Shirmohammadi, D., B. Wollenberg, et al. (1998). "Transmission dispatch and congestion management in the emerging energy market structures." Power Systems, IEEE Transactions on 13(4): 1466-1474.

Shu, T. and G. Gross (2002). "A congestion-management allocation mechanism for multiple transaction networks." Power Systems, IEEE Transactions on 17(3): 826-833.

Singh, H., S. Hao, et al. (1998). "Transmission congestion management in competitive electricity markets." Power Systems, IEEE Transactions on 13(2): 672-680.

Stamtsis, G. C. and I. Erlich (2004). "Congestion analysis and participants' behaviour in a pool market." Generation, Transmission and Distribution, IEE Proceedings- 151(1): 127131.

Sun, D. (2006). Experiences with LMP implementation. Power Engineering Society General Meeting, 2006. IEEE. 
Valenzuela, J. and M. Mazumdar (2005). "A Probability Model for the Electricity Price Duration Curve Under an Oligopoly Market." Power Systems, IEEE Transactions on 20(3): 1250-1256.

Wong, S. and J. D. Fuller (2007). "Pricing Energy and Reserves Using Stochastic Optimization in an Alternative Electricity Market." Power Systems, IEEE Transactions on 22(2): 631-638.

Wu, Z. Q., Y. N. Wang, et al. (2004). "Continuous integration congestion cost allocation based on sensitivity." Generation, Transmission and Distribution, IEE Proceedings151(4): 421-426.

Xie, K., C. M. Jiang, et al. (2006). Application of the Locational Marginal Pricing Model in North China Grid: A Preliminary Study. Power System Technology, 2006. PowerCon 2006. International Conference on.

Xusheng, Y., S. Wanxing, et al. (2006). A New Solution for Multi-Region Transmission Congestion Management. Intelligent Systems Design and Applications, 2006. ISDA '06. Sixth International Conference on.

Yajing, G., Z. Ming, et al. (2006). Sequential Monte Carlo Simulation Based Available Transfer Capability Calculation. Power System Technology, 2006. PowerCon 2006. International Conference on.

Yamin, H., S. Al-Agtash, et al. (2004). "Security-constrained optimal generation scheduling for GENCOs." Power Systems, IEEE Transactions on 19(3): 1365-1372.

Yong, F. and L. Zuyi (2006). Different models and properties on LMP calculations. Power Engineering Society General Meeting, 2006. IEEE 


\section{Part 2}

\section{Utilization of Solar and Wind Resources}





\title{
PV Solar Energy Conversion Using the Behavior Matching Technique
}

\author{
Marcio Mendes Casaro ${ }^{1}$ and Denizar Cruz Martins ${ }^{2}$ \\ ${ }^{1}$ Federal University of Technology - Paraná, Ponta Grossa \\ ${ }^{2}$ Federal University of Santa Catarina, Power Electronics Institute \\ Brazil
}

\section{Introduction}

This chapter presents the Behavior Matching technique (Casaro \& Martins, 2007; Casaro \& Martins, 2008). It is based on DC-DC converters' input I-V characteristics. When a DC-DC converter employs the technique, its duty-cycle and frequency are optimal fixed values. It don't use a control loop for MPPT, but the maximum power point is fastest tracked for rapid solar irradiation changes. A minimal amount of sensors and only one microcontroller are required for PV system operation. There are many options of technique-compatibles DC-DC converters to achieve high frequency isolation and high efficiency. To continue, a brief explanation about how a DC-DC converter can be inserted in a PV system is introduced.

\subsection{PV systems}

Distributed PV generation systems use switching inverters to extract the maximum power of photovoltaic modules and inject this energy into grid. Grid-current control and MPPT are carried out by inverter in different ways. The following topics explain the state of the art about inverters topologies (Carrasco et al., 2006).

- Single-stage inverter: in one processing stage, MPPT and grid-current control are handled.

- Dual-stage inverter: a DC-DC converter performs the MPPT and a DC-AC one is responsible for the grid-current controlling.

- Multistage inverter: various DC-DC converters are used for the MPPT and only one DC-AC converter takes care of the grid-current control.

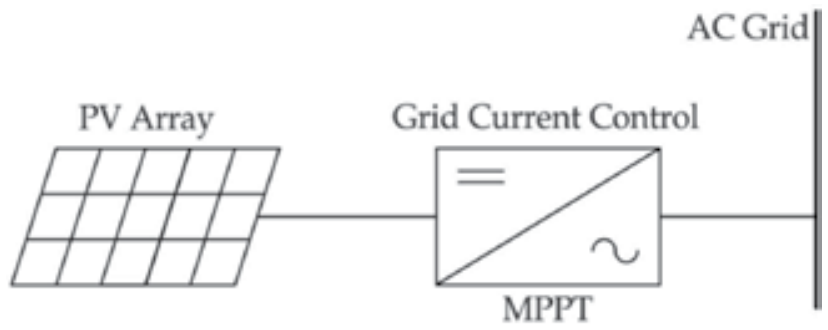

Fig. 1. Inverter without a DC-DC converter. 


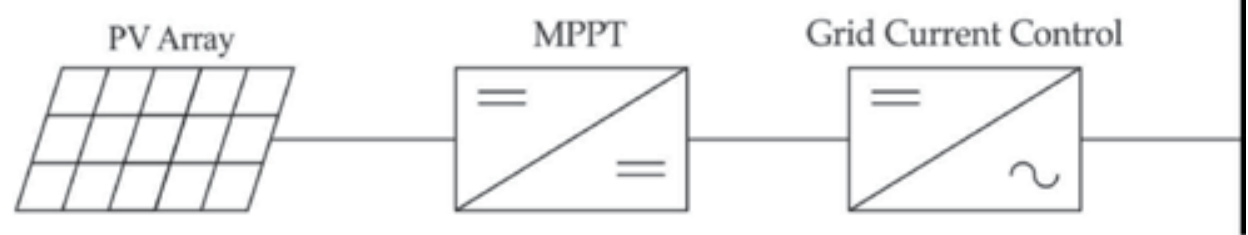

Fig. 2. Photovoltaic energy flowing through two conditioning converters.

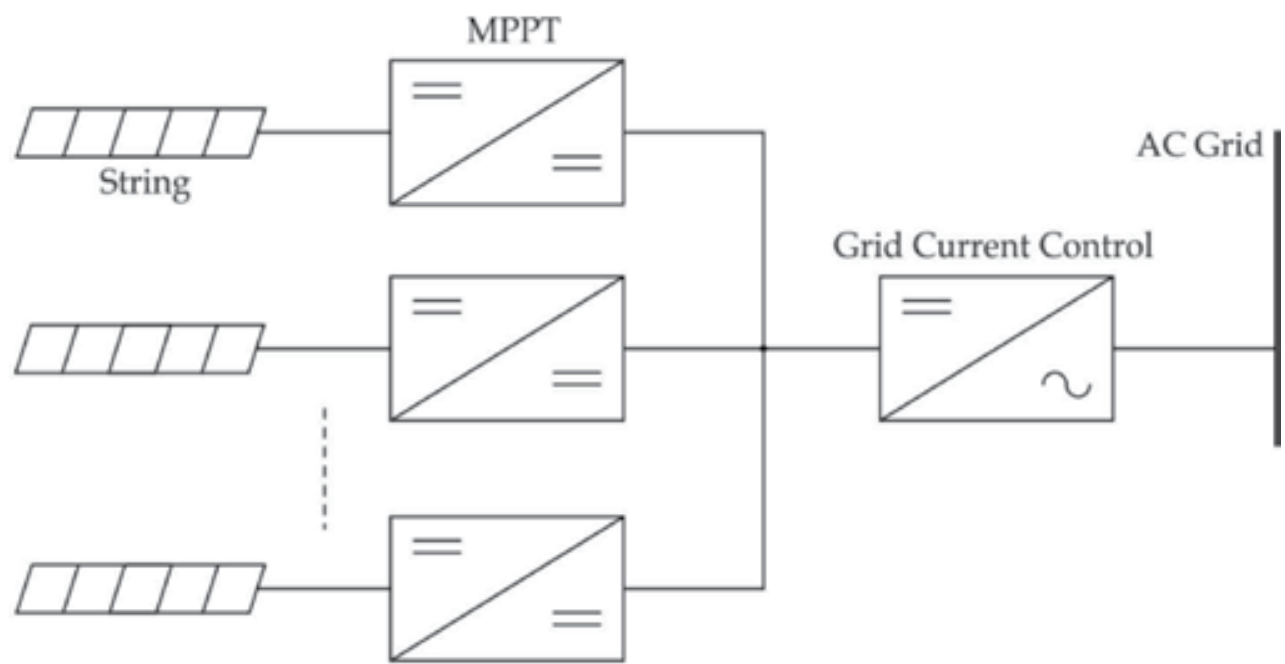

Fig. 3. Low power DC-DC converters connected to strings and one large DC-AC in the grid interface.

The inverters previously showed give an idea about the control and the DC-DC converters' application. It is worth discuss in more details how the PV modules are connected with inverters and these are connected with the grid. There are four configurations commercially accepted:

- Central-plant inverter: usually a large inverter is used to convert DC power output of PV array to AC power. In this system, the PV modules are serially string and several strings are connected in parallel to a single DC bus. A single or a dual-stage inverter can be employed. Fig. 4. illustrates this configuration.

- Multiple-string DC-DC converter: each string has a DC-DC converter, which can be galvanically isolated. There is a common DC link, which feeds a transformerless DC-AC converter. As Fig 5., only the multistage inverter can implement this configuration.

- Multiple-string inverter: several modules are connected in series on the DC side to form a string. The output from each string is converted to AC through a small individual inverter. Many such inverters are connected in parallel on the AC side. A single or a dual-stage inverter can be employed, as Fig. 6.

- Module-integrated inverter: each module has a small inverter. Once more, a single or a dual-stage inverter can be used. Fig. 7. shows this configuration. 


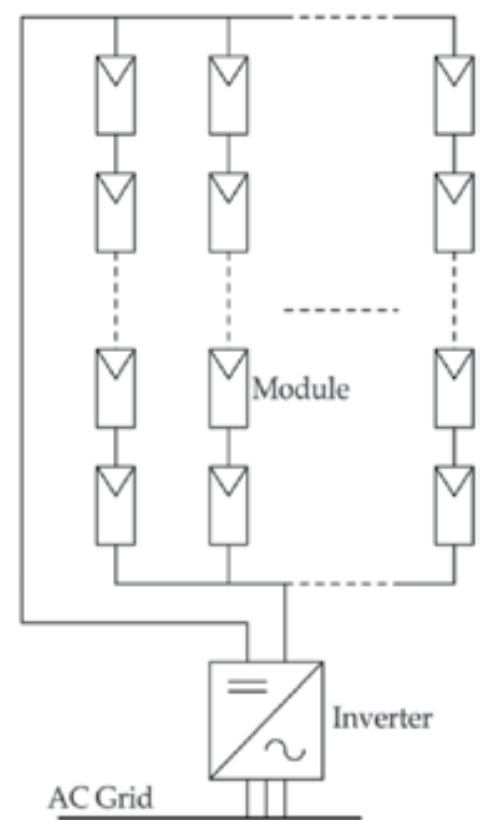

Fig. 4. Central-plant inverter.

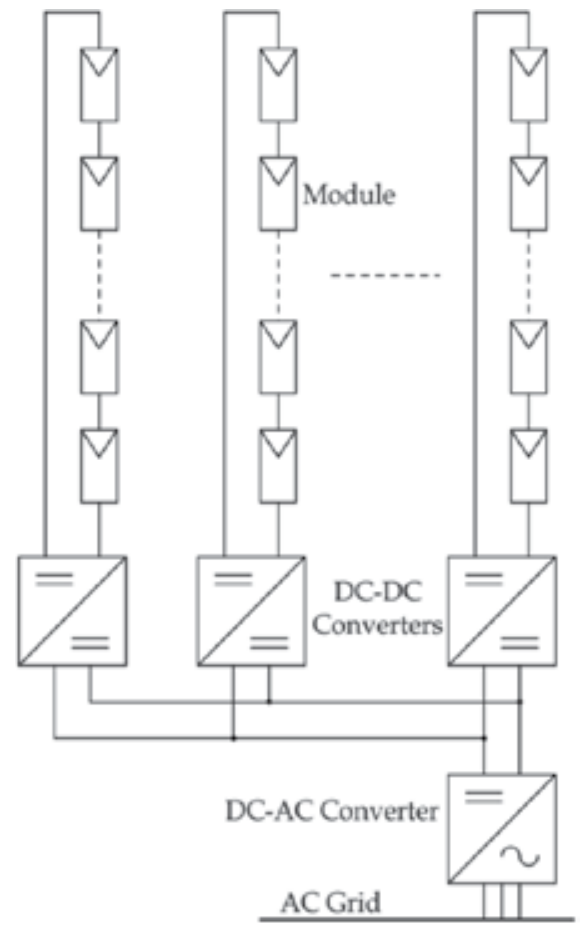

Fig. 5. Multiple-string DC-DC converter.

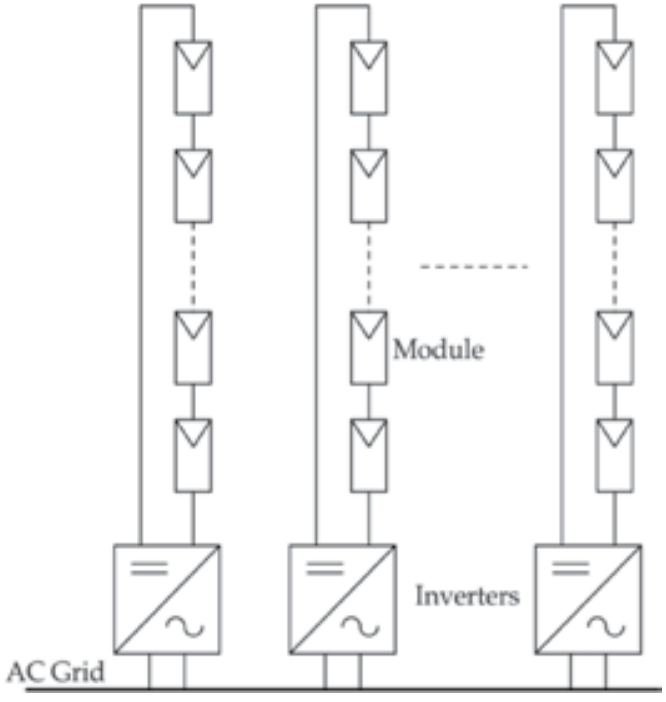

Fig. 6. Multiple-string inverter.

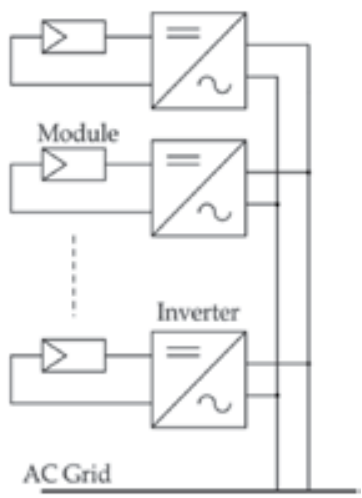

Fig. 7. Module-integrated inverter.

\subsection{Considerations}

The high efficiency is one of the most important characteristics of a PV inverter. Thus, whenever possible, these inverters are nonisolated electronic circuits, since a transformer 
imposes an efficiency drop. This efficiency drop is $2 \%$ larger for a low than for a highfrequency transformer (Yuan \& Zhang, 2005.). Hence, when grid-isolation is mandatory, the incorporation of a high-frequency transformer is a trend (Carrasco et al., 2006.).

As important as high efficiency, it is the inverter cost. Carrasco et al. (2006.) indicate the centralization of inverter for reduced cost, according to plant showed in Fig. 4.

To satisfies the previously argumentation, the dual-stage inverter configured in a centralplant is the solution. However, the MPPT will not be carried out by DC-DC stage. The system will be more cost-effective if it is able to track the MPP using the variables already available for the grid-current control. Some sensors would be avoided. Fig. 8. illustrates this simple idea. This implementation is discussed in the next section.

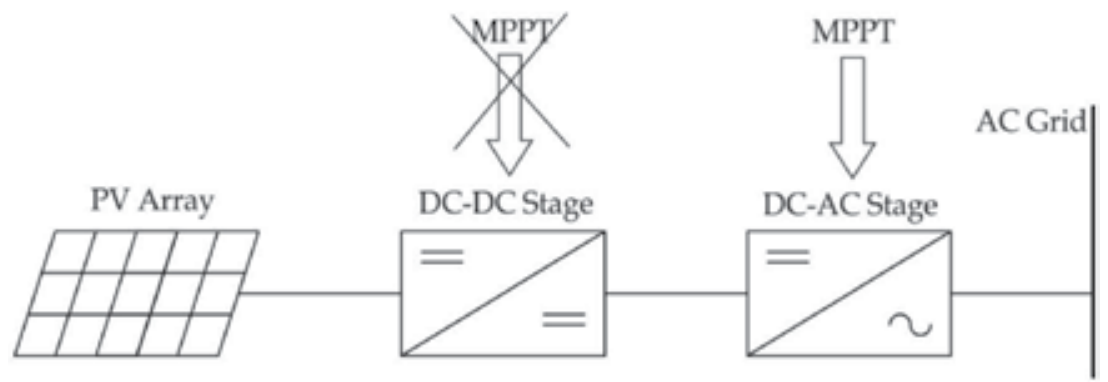

Fig. 8. Modified dual-stage inverter.

\section{Behavior matching}

The Behavior Matching Technique's purpose is to take a dual-stage inverter to perform the MPPT in the DC-AC stage, so that the control structure is simplified and the MPPT is improved. Normally, the DC-DC stage performs the MPPT in this type of PV inverter topology. From a didactic intent, the buck converter, showed in Fig. 9., is adopted to constitute the DC-DC stage. However, applying the Behavior Matching technique, all switch $S$ parameters are constants. Therefore, duty cycle and switching frequency don't change during normal operation conditions.

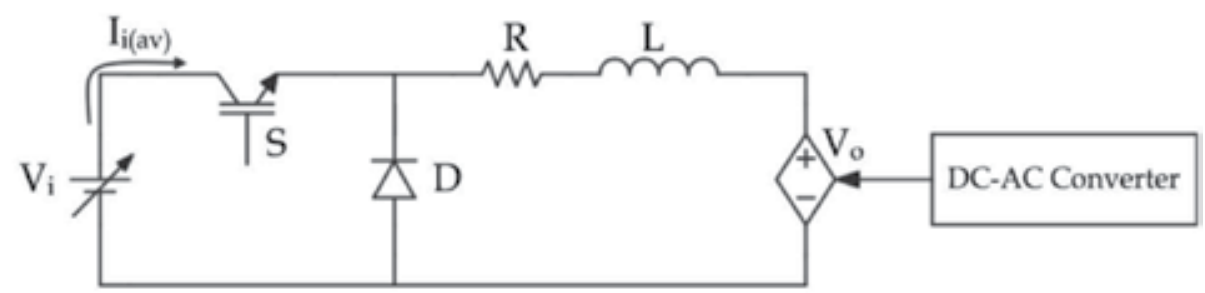

Fig. 9. DC-DC Buck converter.

The DC link voltage, $V_{o}$, is regulated by DC-AC stage. The feedback from $V_{o}$ is compared with a reference defined by the MPPT algorithm. Hence, the controlled variable by the MPPT strategy is the DC link voltage.

It is well known that the ideal static gain of the Buck converter is given by $V_{o}^{\prime}=D \cdot V_{i}$. Being $V_{o}$ constant and $V_{i}$ variable, the input average current, $I_{i(a v)}$, goes to infinite when $D \cdot V_{i}>V_{o}$. For realistic input I-V characteristic, all Buck losses were represented by resistance $R$. Then, 
this input I-V characteristic become inclined, as presented in Fig. 10. PV module's typical curves are in the background. For each irradiation level there is a MPP locus.

The DC-DC converter input I-V characteristic can fall together with MPP loci at various solar irradiation levels. Then, the convergence time of conventional MPPT algorithms is accelerated for rapid changes on insolation conditions. At the limit, no control action would be needed.

As noted in Fig. 10, a control action can shift the DC-DC converter input I-V characteristic for left or right, keeping its shape. Then, temperature variations of the PV module can be compensated with adjusts of the $V_{o}$ value.

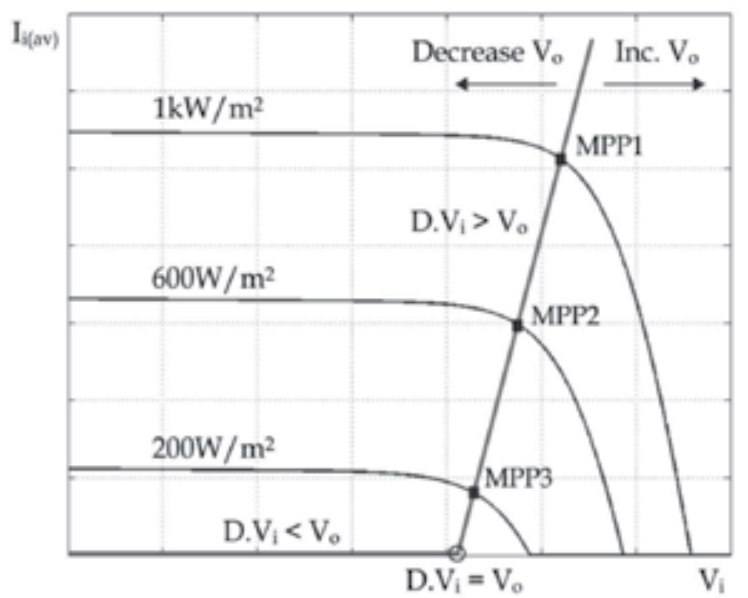

Fig. 10. DC-DC Buck converter input I-V characteristic on PV module curves.

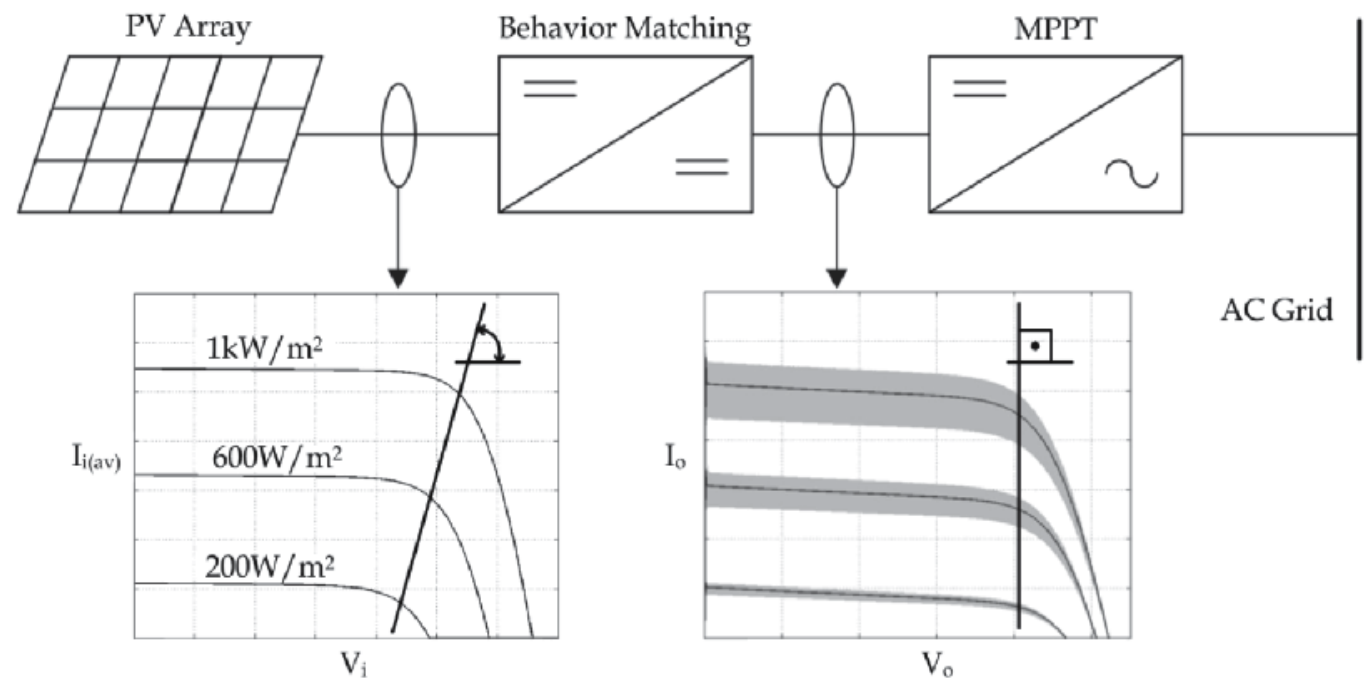

Fig. 11. Behavior Matching principles.

Fig. 11. shows simulation results where it can be seen that the PV array behavior, represented by $I_{i(a v)} \times V_{i}$, is reproduced on the DC-DC stage output terminals, represented by 
$I_{o(a v)} \times V_{o}$. From the controller point of view, $I_{o(a v)} \times V_{o}$ is similar to $I_{i(a v)} \times V_{i}$. Thus, MPPT task is to extract the maximum power of the DC link, or, to inject the maximum power in the grid. The strategies are different, but the result is the same: both tune the DC-DC stage input I-V characteristic to the PV array MPP.

The Behavior Matching Technique brings significant advantages for the PV system always that the DC-DC converter input characteristic curve lies on closest the MPP loci, for all MPPT range. Step-down DC-DC converters with similar input Buck behavior are eligible to integrate a modified dual-stage inverter.

\section{DC-DC stage}

The isolated ZVS Full-Bridge is usually used at power levels above 750W (Carrasco et al., 2006). Commonly, its efficiency ranges from $92 \%$ to $93 \%$ under a $45 \%$ to $100 \%$ load condition. With a nonisolated version, this efficiency can be increased within $96 \%$ to $98 \%$ (Lee et al., 2008). As an alternative to single-phase Full-Bridge based converters, the threephase conversion has some advantages (Ziogas et al., 1988), such as:

- $\quad$ Reduced switching stresses of the power semiconductor devices.

- $\quad$ Reduced size and ratings of associated reactive components.

- Better transformer copper and core utilization.

The topic of this chapter focuses on the application of the three-phase isolated DC-DC series resonant converter (SRC3), proposed by Jacobs et al. (2004), in a dual-stage inverter. Despite the galvanic isolation, the measured efficiency of this DC-DC converter was above $97 \%$ under a $45 \%$ to $100 \%$ load condition.

The SRC3 topology is presented in Fig. 12. This three-phase DC-DC converter was evaluated about its efficiency in different input power levels, components number, EMI emission, performance under unbalanced conditions and power range. It seems to relate the best characteristics among others converters with soft commutation.

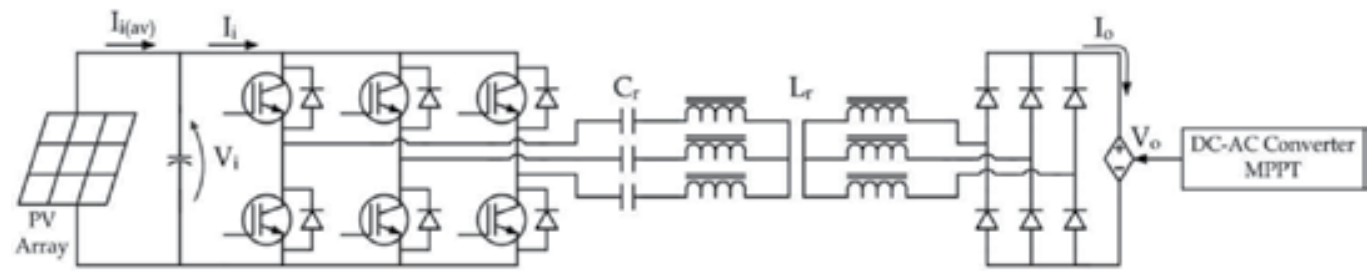

Fig. 12. Three-phase DC-DC Series Resonant Converter connected to a photovoltaic array.

The switches are gated by six phase-shifted signals. Neglecting the deadtime between two switches in each inverter leg, all switches are turned on exactly half a period.

When the switching frequency, $f_{1}$, is equal to the resonance frequency, $f_{r}$, the converter operates in ZCS mode. If $f_{1}>f_{r}$, the converter operates in ZVS. In this condition, the efficiency is much reduced for low-power transfer. Then,

$$
\begin{gathered}
f_{1}=f_{r}=\frac{1}{2 \cdot \pi \cdot \sqrt{L_{r} \cdot C_{r}}} \\
I_{i(a v)}=\frac{6}{\pi^{2} \cdot R_{\text {loss }}} \cdot\left(V_{i}-V_{0}^{\prime}\right)
\end{gathered}
$$


Where:

$L_{r}$ - leakage inductance of the transformer;

$C_{r}$ - resonant capacitor;

$V_{o}^{\prime}$ - output voltage of the three-phase bridge rectifier, referred to the primary side;

$R_{\text {loss }}$ - takes all losses into account: conduction and switching losses of the switches and diodes, the dielectric losses of the capacitors, the copper and iron losses of the three-phase transformer and the conduction losses of wires and connections.

The turns ratio transformer can be defined by : $N=N_{2} / N_{1}$.

The efficiency of the SRC3 strongly depends on the implemented deadtime and switching frequency. Beyond the designed values for them, the efficiency abruptly decreases. Consequently, these variables should not vary. Thanks the Behavior Matching, this is exactly the operation condition imposed to the converter.

The PV array consists of two parallel strings, each with ten KC200GT modules from Kyocera. Its nominal power is $P_{i}=4 \mathrm{~kW}$, with $V_{i}=263 \mathrm{~V}$ and $I_{i}=15.2 \mathrm{~A}$. The estimated efficiency for the DC-DC stage is $\eta_{1}=97 \%$. The switching frequency of the SRC3 is $f_{1}=$ $40 \mathrm{kHz}$. The grid has $220 \mathrm{~V}$ of phase voltage.

The three-phase transformer is constructed with three single-phase transformers, in wye connection. The measured leakage inductances were $L_{r}=3.6 \mu \mathrm{H}$. These result in resonant capacitors of $C_{r}=4.4 \mu \mathrm{F}$, for ZCS operation. Polypropylene capacitors were adopted.

The nominal DC-link voltage is calculated with (3) and the converter losses with (4).

$$
\begin{gathered}
V_{o}^{\prime}=\eta_{1} \cdot V_{i}=255 \mathrm{~V} \\
R_{\text {loss }}=\frac{6}{\pi^{2} \cdot I_{i(a v)}} \cdot\left(V_{i}-V_{o}{ }^{\prime}\right)=0.32 \Omega
\end{gathered}
$$

The voltage $V_{o}^{\prime}$ is raised to $V_{o}=816 \mathrm{~V}$ by $N=3.2$. This turns ratio keep the DC-link voltage above $600 \mathrm{~V}$ for all MPPT range.

A SK20GD065 Semikron IGBT module was used. The diode bridge was made with six ultra fast recovery rectifiers FFPF05U120S, of 1200V and 5A.

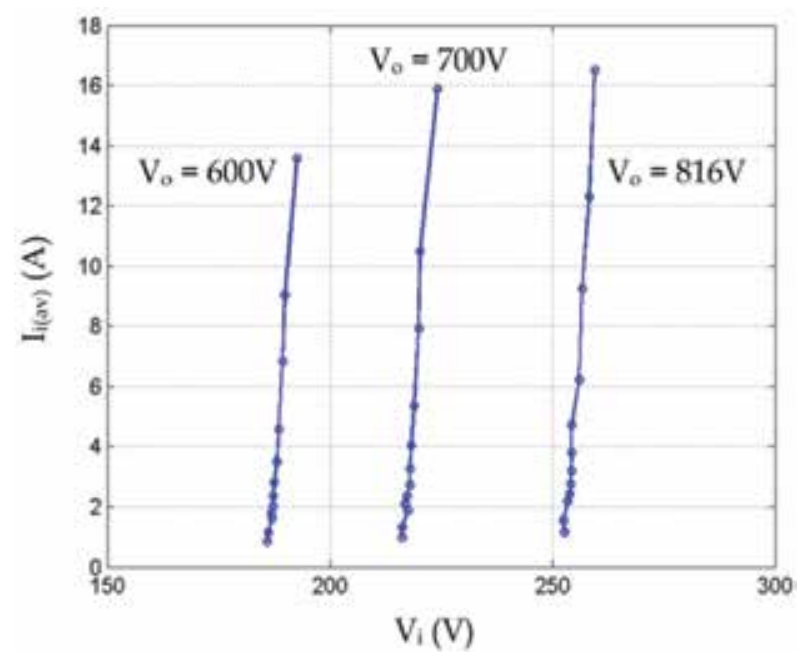

Fig. 13. DC-DC converter's input I-V characteristics. 
The inclination of the SRC3 input I-V characteristic, for all Vo operation range, is given by (5), obtained from (2). Fig. 13. shows experimentally measured points of SRC3 prototype input I-V characteristic.

$$
\frac{d I_{i(a v)}}{d V_{i}}=\frac{6}{\pi^{2} \cdot R_{\text {loss }}}=1.9 \frac{\mathrm{A}}{\mathrm{V}}
$$

The DC-DC converter's input characteristic has a propitious behavior to MPPT algorithm. Putting Fig. 13. $\left(V_{o}=816 \mathrm{~V}\right)$ on the PV array I-V characteristic curves, the proximity between the DC-DC converter's input characteristic and the MPP loci can be established, as shown in Fig. 14. This collaborates with the MPPT performance for fast changes in atmospheric conditions.

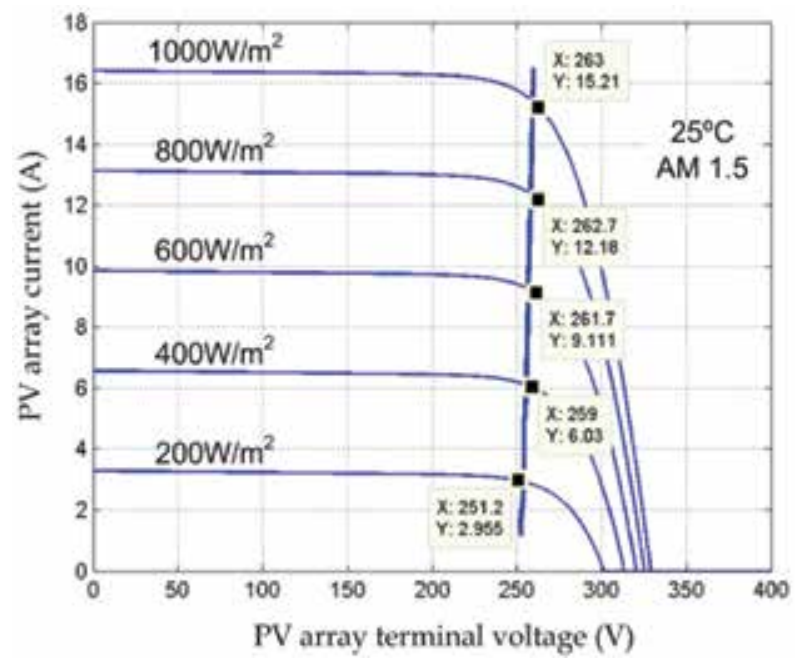

Fig. 14. Crossing between SRC3 and PV array characteristic curves.

\section{Performance of the adopted DC-DC converter}

A compare unit pertained to a peripheral of the Texas TMS320F2812 controller was configured to generate six gate pulses for SRC3, with duty cycle of $50 \%$ and deadtime of 640ns. The same DSP carried out the grid-current control and the MPPT.

Fig. 15. shows the resonant currents. Obviously, the leakage inductances of each phase are not exactly the same. These unsymmetries cause small differences in resonant currents amplitudes. However, this has a negligible impact on the SRC3 operation.

Figs. 16. and 17. present the DC-DC stage input and output currents for different power conditions. These currents have a low ripple and a frequency of six times that of the switching frequency, resulting in a continuous power flux. These features are not common among three-phase DC-DC converters and lead to reduced filter devices. The PV array parallel capacitor is of only $680 \mathrm{nF}$, for example. The voltage ripple on it is showed in Fig. 18 . This ripple was produced by the current $I_{i}$ of Fig. 17. It has a negligible impact above PV array efficiency.

The ZCS commutation is shown in detail by Fig. 19. Unfortunately, the commutation losses drastically increase at low power levels, according to Fig. 20. Fig. 21. shows the SRC3 efficiency. 


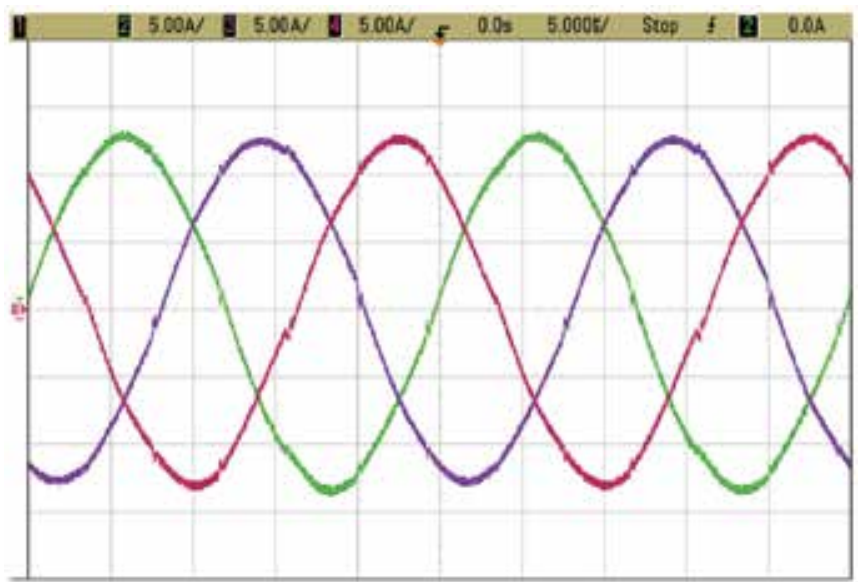

Fig. 15. Resonant currents under nominal conditions.

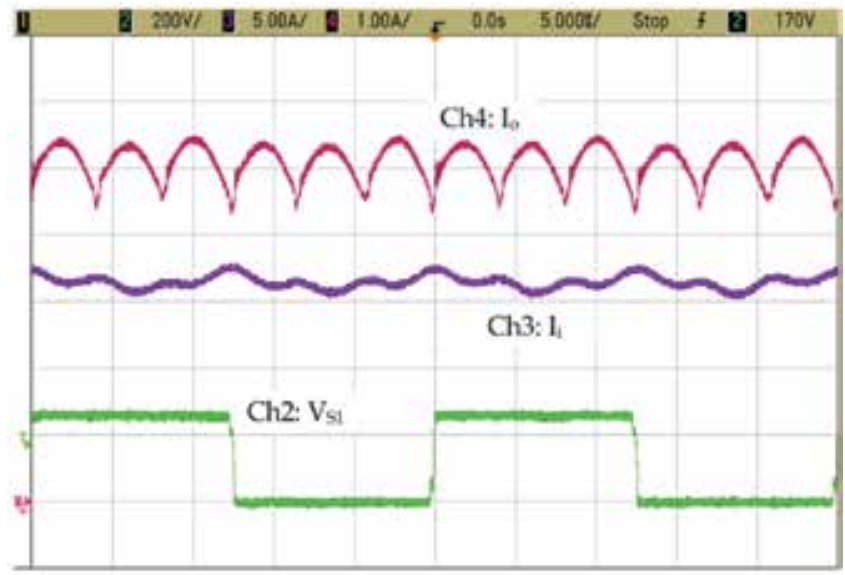

Fig. 16. DC-DC stage input and output currents and collector-emitter voltage, under nominal conditions.

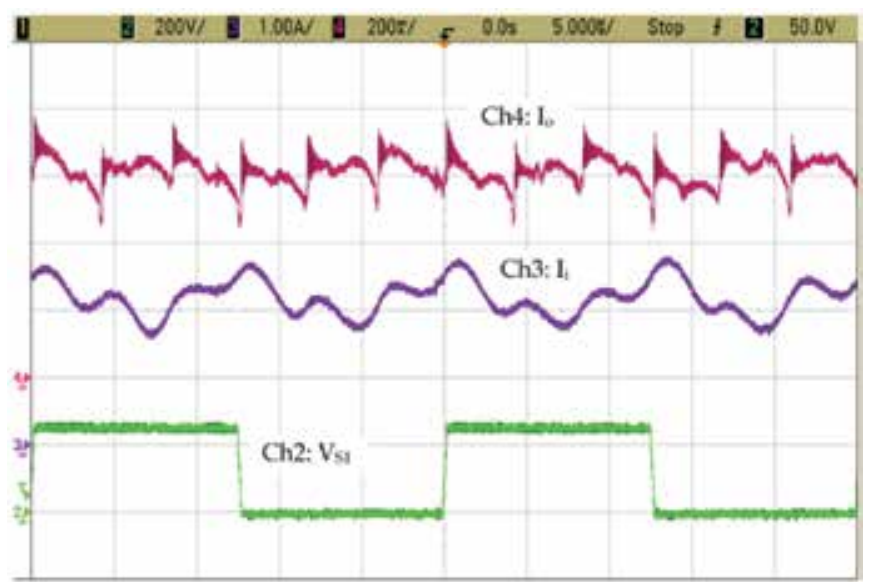

Fig. 17. DC-DC stage input and output currents and collector-emitter voltage, with $P_{o}=500 \mathrm{~W}$. 


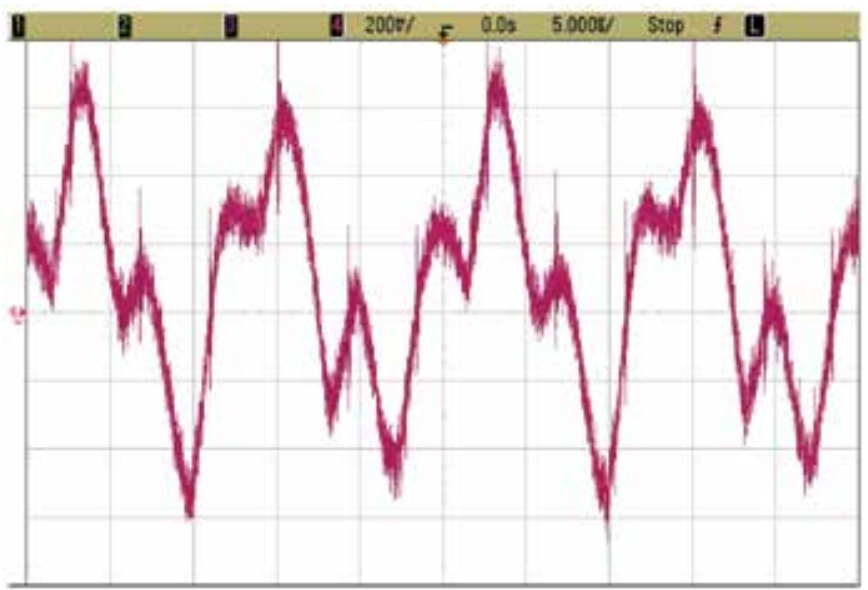

Fig. 18. PV array output voltage for $P_{o}=500 \mathrm{~W}$.

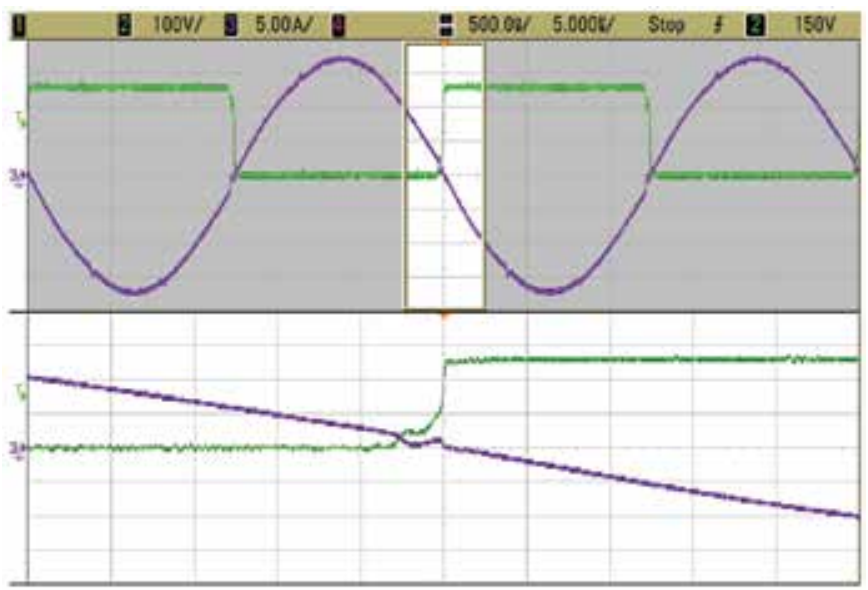

Fig. 19. Resonant current and collector-emitter voltage, under nominal conditions.

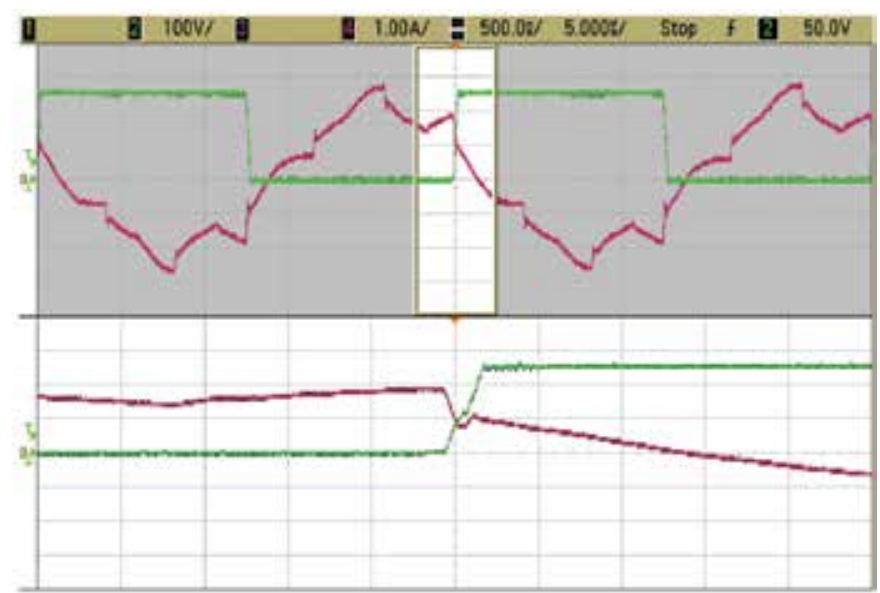

Fig. 20. Resonant current and collector-emitter voltage, for $P_{o}=500 \mathrm{~W}$. 


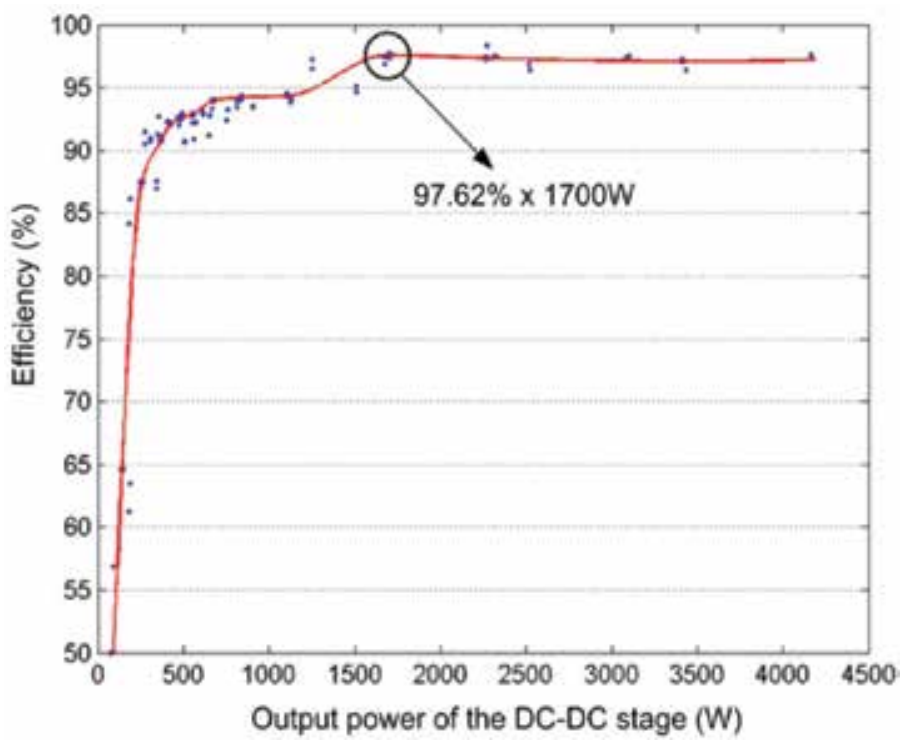

Fig. 21. SRC3 efficiency.

The impact of voltage harmonic components on the resonant current depends on the resonant circuit quality factor, presented in (6).

$$
Q=2 \cdot \pi \cdot f_{r} \cdot \frac{L_{r}}{R_{\text {loss }}}
$$

The requirement of large impedance for frequencies that are different of the resonant frequency is fulfilled when the quality factor $Q$ is high. The value of $Q$ is high in nominal conditions, such as Fig. 19. On the other hand, for low SRC3 output power rate, the $Q$ value is low too, according to Fig. 20. This occurs due increasing of $R_{\text {loss }}$ for output powers below of approximately $1700 \mathrm{~W}$. Fig. 21 points to decreasing of efficiency below this power. Larger $L_{r}$ could reduce the power from which $R_{\text {loss }}$ rises. The efficiency would be more flat.

\section{Conclusion}

This chapter proposed the Behavior Matching technique applied to grid-connected photovoltaic systems composed of dual-stage inverters. A dual-stage inverter contains DCDC stage and DC-AC stage. Through the Behavior Matching, the DC-DC stage operates with constant frequency and duty cycle and the DC-AC stage becomes responsible for the maximum power point tracking and grid-current control. The I-V characteristic of PV array was reproduced at output of the DC-DC stage, without any control. Some sensors could be avoided because the grid-current control apparatus produces the variables needed for the MPPT. In addition, only one digital controller can generate gate pulses for all transistors of PV system, which results more simple and cheaper. It was demonstrated if a propitious converter composes the DC-DC stage, the MPPT convergence remains faster for rapid changes in solar irradiation power. Among various soft switching three-phase DC-DC converters, the Series Resonant was selected for practical analysis. It added a lot of advantages for PV system. Its efficiency is highest for a specific frequency and its duty cycle 
cannot change. Thus, Behavior Matching optimized it along all operation range. This input I-V characteristic matched with MPP loci, without any control action. The converter can switch with high frequencies, $100 \mathrm{kHz}$ or more, becoming very compact, i.e., its transformer and capacitors. An insignificant capacitor was used on implementation of PV array parallel filter. Two factors mainly contributed with this advantage: the continuous current flux with low ripple and the barrier formed by the resonant circuit to electrical perturbations on DC link, that did not affect the primary side voltage bus. Finally, the Series Resonant Converter features a robust operation under unbalanced conditions.

\section{References}

Casaro, M.M. \& Martins, D.C. (2007). New Method of MPPT Application for Dual-Stage Inverters, 9th Brazilian Power Electronics Conference, pp. 676-681.

Casaro, M.M. \& Martins, D.C. (2008). Behavior Matching Technique Applied to a ThreePhase Grid-Connected PV System, IEEE International Conference on Sustainable Energy Technologies, pp. 17-22.

Carrasco, J.M.; Franquelo, L.G.; Bialasiewicz, J.T.; Galván, E.; Guisado, R.C.P.; Prats, M.A.M.; León, J.I. \& Moreno-Alfonso, N. (2006). Power-Electronic Systems for the Grid Integration of Renewable Energy Sources: A Survey. IEEE Transactions on Industrial Electronics, Vol. 53, No. 4, August 2006, pp. 1002-1016.

Jacobs, J.; Averberg, A. \& De Donker, R. (2004). A Novel Three-Phase DC/DC Converter for High-Power Applications, IEEE Power Electronics Specialists Conference, pp. 18611867.

Lee, J.; Min, B.; Kim, T.; Yoo, D. \& Yoo, J. (2008). A Novel Topology for Photovoltaic DC/DC Full-Bridge Converter with Flat Efficiency Under Wide PV Module Voltage and Load Range. IEEE Transactions on Industrial Electronics, Vol. 55, No. 7, July 2008, pp. 2655-2663.

Yuan, X. \& Zhang, Y. (2005). Status and Opportunities of Photovoltaic Inverters in Grid-Tied and Micro-Grid Systems, $15 \mathrm{~h}$ International Photovoltaic Science \& Engineering Conference, pp. 226-227.

Ziogas, P.D.; Prasad, A.R. \& Manias, S. (1988). Analysis and Design of a Three-Phase OffLine DC/DC Converter with High Frequency Isolation, Proceedings of IEEE Industry Applications Society, pp. 813-820. 


\title{
Cost Calculation Algorithm for Photovoltaic Systems
}

\author{
İrfan Güney ${ }^{1}$ and Nevzat Onat ${ }^{2}$ \\ ${ }^{1}$ Acibadem University, \\ ${ }^{2}$ Marmara University \\ Turkey
}

\section{Introduction}

The electric energy is directly correlated with vital elements for countries of today's world. These elements can be divided into four sub-titles of production, national income, health and education. It is almost impossible for countries that lack of electric energy to ensure positive developments in such parameters. It is known that, even these days, at least 1.6-2 million people not to consume electricity in the world. Besides, in some countries, there exist great differences between the poor and the rich in obtaining energy (Belfkira et al., 2008).

In that situation, the most benefit in the future of electricity generation sources, expected to be renewable energy sources especially solar and wind. It is also expected that the technical, economic, social and political barriers of widespread use of these resources will decline over time and these resources will own a very important share in the production of electricity at the end of this century. In this chapter, features of sustainable energy production and sustainability parameters of photovoltaic (PV) systems are summarized. This chapter focused on a life cycle cost analysis (LCCA) method that used in PV system design. In this point, apart from conventional cost analysis, calculable "external costs and benefits" are taken into account. In addition, effect of the capacity utilization (CU) on unit energy cost is explained particularly in stand-alone PV systems. Thus, detailed analysis of life cycle and unit energy costs -which the most disadvantaged parameter of PV within the parameters of sustainability- was, carried out. The topics discussed are supported with sample applications at the end of chapter.

\subsection{Expectations for the future of energy production}

Energy plays a very important role for the peace of world, in addition to its role being an element that effects development of a country. For this reason, the World's Energy Council has resolved to act with understanding of "energy for people, energy for peace". Electric energy demand is increasing very rapidly with each passing year. According to the forecasts of the International Energy Agency, the energy need of world will increase two times in 2020 when compared to 1997 (WEC Handbook, 2004).

World Energy Council (WEC) has been forecast over the various scenarios related to the amount of future energy consumption and energy production technologies. These scenarios are divided into two classes as A and C group characteristically (Table 1).

In these scenarios, it is estimated the world population will be 10.2 billion in 2050 . According to the A-group scenario, economic growth and energy demand of the world will 
increase because of globalization. It is also expected the annual energy consumption that was $420 \mathrm{EJ}$ in 2000 , will be $1040 \mathrm{EJ}$ in 2050 . In addition, it is indicated that using of the world's fossil energy sources will continue in a high percentage, so the annual carbon dioxide $\left(\mathrm{CO}_{2}\right)$ emissions will rise up form 6.4Gt to 9-15Gt. C-group scenarios suppose in a highly unusual that the international community will focus on ecological protection and international equity and as a result of this energy consumption will reduce. According to the scenario, primary energy consumption will be 600EJ in 2050. Especially small power, reliable and advanced technology production nuclear reactors and renewables will be used in electrical production and as a result the annual carbon dioxide emissions will fall from 6.4Gt to 5Gt. Fossil fuels will be used only as a transitional fuel. The said scenarios are divided into subgroups among themselves that differ in some respects. For example, in A-1 scenario it is forecast that percentage of fossil fuels will be high in energy production, will not be a major advance in coal and nuclear energy technologies, trend of technological development will focus on oil and natural gas systems, in particular these two fossil fuels will be preferred instead of coal in $21^{\text {st }}$ century. In another scenario (scenario A-3), is proposed to especially biomass, renewables and new-generation nuclear energy technologies will have the largest share in electrical energy production (WEC Report, 2004).

\begin{tabular}{|c|c|c|c|c|c|}
\hline \multicolumn{2}{|c|}{ PARAMETER } & \multicolumn{2}{|c|}{ SCENARIO -A- } & \multicolumn{2}{|c|}{ SCENARIO -C- } \\
\hline \multicolumn{2}{|l|}{ DATE } & 2000 & 2050 & 2000 & 2050 \\
\hline \multicolumn{2}{|c|}{ World population [billion] } & 6.2 & 10.2 & 6.2 & 10.2 \\
\hline \multicolumn{2}{|c|}{$\begin{array}{l}\text { The world's economic assets (GWP) } \\
\text { [trillion } \$]^{*}\end{array}$} & 30 & 110 & 30 & 84 \\
\hline \multicolumn{2}{|c|}{$\begin{array}{c}\text { Primary energy consumption } \\
\text { [Exa Joule] }\end{array}$} & 420 & 1040 & 420 & 600 \\
\hline \multirow{2}{*}{ Resource availability } & Fossil & High & High & High & Low \\
\hline & Renewable & High & High & High & High \\
\hline \multirow{2}{*}{ Technology intensity } & Fossil & High & High & High & Medium \\
\hline & Renewable & Low & High & Low & High \\
\hline \multicolumn{2}{|c|}{ Net Carbon Emissions [Gigatonnes] } & 6.4 & $9-15$ & 6.4 & 5 \\
\hline
\end{tabular}

Table 1. Change expectations in parameters that affect the world's energy needs

In all of these scenarios, particularly in the residential-office and transportation the use of coal will be completely abandoned, and the share of petroleum products is projected to decline to $10 \%$ of today's level. From these knowledge has clearly emerged to invest in alternative energy sources is to make investment in the future of the countries

\section{Sustainable electrical energy production}

The environmental impacts of energy development scenarios should be very well explained and focused on the sustainable energy production applications to guide future investments. 
Fig. 1. shows that distribution of resources used for electric energy production of the world in 2007. "Other renewables" term includes energy sources except hydropower such as wind, photovoltaic, geothermal. It is known that coal has the highest emissions of $\mathrm{CO}_{2}$ and other pollutants per $\mathrm{kWh}$. However, because of low cost and easily accessible, coal dominated energy market and is standing against the principles of sustainability. If these trends continue, the number of coal power plants will increase and only the developing countries will be producing carbon dioxide much more than the sum of all OECD countries since 2030. Here, a cost term has emerged that usually cannot measured clearly. These costs are expressed with the "external costs" term. In a study was made by Sovacool in 2009, has suggested that coal (19cents/kWh), oil (12cents/kWh) and nuclear (11cents/kWh) power plants are in the first three rows respectively in terms of the highest ranking of the negative costs. These values were calculated as 6-7cents/ $\mathrm{kWh}$ for natural gas and biomass power plants and 5cents/kWh for hydroelectric power plants. Wind, geothermal and solar plants have been identified as the most advantageous systems because of $1 \mathrm{cent} / \mathrm{kWh}$ and below external cost (Sovacool, 2009).

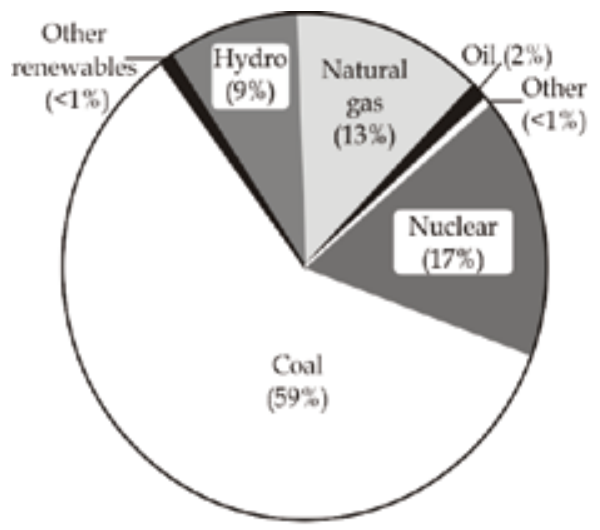

a-) State agencies (Total: 2504GWh)

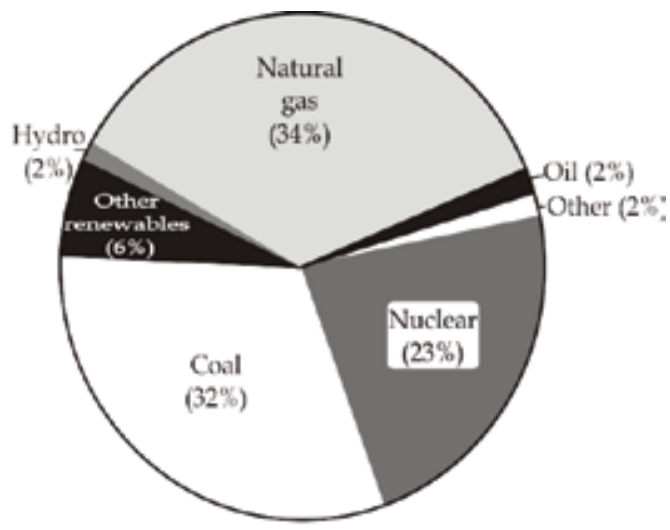

b-) Private sector (Total: $1653 \mathrm{GWh}$ )

Fig. 1. Distribution of resources used for electric energy production of the world in 2007 (EIA, 2007)

Environmental effects of an energy production system is a process in which various stages such as mining and processing of mineral, to the amount of direct and indirect emissions, reuse or recycling of waste facilities. Assessment of each stage of this process, main indicators should be identified to measure possible impacts. These indicators will be some values such as environmental and social impacts, greenhouse gas emissions, consumption of raw materials, availability and economical benefits of renewable energy resources. Measurement of external costs will greatly reduced the problem of high costs which is the most important parameter adversely affecting the competitiveness of renewables.

\subsection{Sustainability ranks of PV systems}

There are many important parameters that must be taken into account in the sustainability analysis of energy generation technologies. The effects of power generation should not be considered with the traditional method only results in environmental and climatic conditions. Social and economical environment of community using generated energy also 
significantly affects the choice of production method. Due to the increasing worldwide communication and information sharing, public awareness of the environmental and climatic changes rapidly increases. This awareness is manifested in the field of energy production as in all areas. According to the analysis of the WEC, since 2030 the amount of energy derived from renewable sources will increase rapidly and have a large share of world energy markets at the end of this century. As shown in Fig. 2., electricity generation will be met largely from renewables and especially PV systems (approximately 60\%) in 2100. Today, this estimate may be perceived as utopian. However, remember that developments in nanotechnology and semiconductor technology have put innovation into our lives which recognized the utopia just 20 years ago. In the PV module industry, hot-carrier and quantum dots based cells which are product of nanotechnology are seen as the most competitive technologies in terms of sustainability (Manna \& Mahajan, 2007; Azzopardi \& Mutale, 2010).

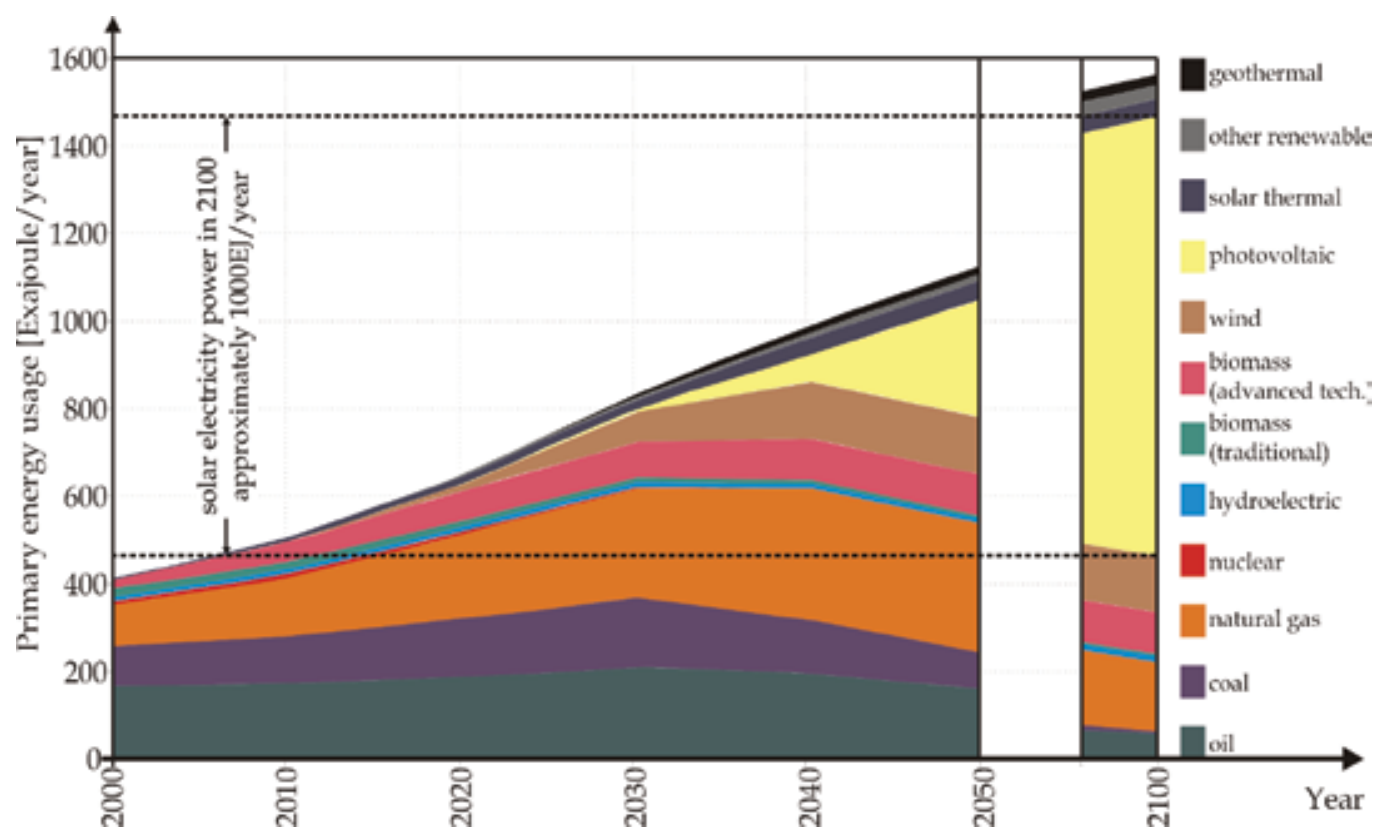

Fig. 2. Change expectations of WEC for usage of primary energy in electricity generation (WEC Report, 2007)

Comparing of PV systems in terms of sustainability parameters is given in Table 2. As seen, PV systems have important advantages to compete with other energy generation systems for sustainability such as availability, $\mathrm{CO}_{2}$ emission, land use, fresh water consumption, social and environmental impacts. However, especially high initial and unit energy costs are major disadvantages although decreases with each passing year as a result of technological developments and investment (Varun et al., 2009). It is expected that the unit cost of PV energy will be half of present day value until 2025 that decline is quite high compared to other renewable systems (Fig. 3.) (Winkler et al., 2009).

Especially, the unit energy cost of a stand-alone PV plant quite varies depending on life cycle and capacity utilization of the system. This issue will be discussed again in later sections. 


\begin{tabular}{|c|c|c|c|c|c|c|c|}
\hline $\begin{array}{l}\text { Production } \\
\text { Technology }\end{array}$ & $\begin{array}{l}\text { Unit Energy } \\
\text { Cost }[\$ / \mathrm{kWh}]\end{array}$ & $\begin{array}{c}\mathrm{CO}_{2} \text { Emission } \\
{[\mathrm{g} / \mathrm{kWh}]}\end{array}$ & Availability & $\begin{array}{c}\text { Efficiency } \\
{[\%]}\end{array}$ & $\begin{array}{c}\text { Fresh Water } \\
\text { Consumption } \\
{[\mathrm{kg} / \mathrm{kWh}]}\end{array}$ & $\begin{array}{l}\text { Land Use } \\
{[\mathrm{km} 2 / \mathrm{GW}]}\end{array}$ & $\begin{array}{c}\text { Social and } \\
\text { Environmental Effects }\end{array}$ \\
\hline Nuclear & $0.0172-0.0273$ & $10-50$ & $\begin{array}{c}280 \text { years } \\
\text { (99\% of all world reserves are } \\
\text { within boundaries only } 10 \\
\text { countries) }\end{array}$ & $30-45$ & $30-100$ & $1-4$ & $\begin{array}{l}\text { - Danger of radioactive leaks } \\
\text { - Public reaction } \\
\text { - Nuclear waste issues }\end{array}$ \\
\hline Coal & $<0.1$ & 1000 & $\begin{array}{c}185-260 \text { years } \\
\text { (50\% of all world reserves are } \\
\text { within boundaries of only } 3 \\
\text { countries }) \\
(26 \% \text { USA, } 16 \% \\
\text { Russia and } 11.5 \% \text { China })\end{array}$ & $30-45$ & $15-30$ & $10-20$ & $\begin{array}{l}\text { - High toxic gas emissions } \\
\text { - The public's negative perception } \\
\text { - The effects of environmental } \\
\text { pollution and greenhouse gas } \\
\text { - Mining difficulties }\end{array}$ \\
\hline Natural Gas & $<0.1$ & $500-600$ & $\begin{array}{c}120 \text { years } \\
41 \% \text { of total reserves are } \\
\text { within Middle East and } \\
27 \% \text { are within Russia } \\
\text { boundaries) }\end{array}$ & $45-55$ & $15-30$ & $1-4$ & $\begin{array}{l}\text { - Be imported fuel for many countries } \\
\text { - The public's negative perception } \\
\text { because of dependence on foreign } \\
\text { sources } \\
\text { - High CO2 emissions }\end{array}$ \\
\hline Wind & $0.4-0.5$ & $10-50$ & Infinite & $24-54$ & $<1$ & $50-100$ & $\begin{array}{l}\text { - Noise pollution } \\
\text { - Visible pollution (minor) } \\
\text { - Adverse effects on wildlife (bird } \\
\text { deaths) } \\
\text { - Positive public perception } \\
\text { - Low CO2 emission }\end{array}$ \\
\hline Hydroelectric & $0.1-0.3$ & $1-100$ & Infinite & $>90$ & $65-70$ & $75-750$ & $\begin{array}{l}\text { - Climate change } \\
\text { - Major land use and because of its } \\
\text { negative effects on natural } \\
\text { environment }\end{array}$ \\
\hline Photovoltaic & $0.8-1.2$ & $15-100$ & Infinite & $12-22$ & $<1$ & $28-64$ & $\begin{array}{l}\text { - The toxic waste created during the } \\
\text { module production } \\
\text { - Visible pollution (minor) } \\
\text { - Positive public perception } \\
\text { - Low CO2 emission } \\
\text { - Quiet operation }\end{array}$ \\
\hline
\end{tabular}

Table 2. Sustainability indicators of energy generation systems (Evans et al., 2009; Meier, 2002; Green, 2005; Fthenakis \& Kim, 2009; Kaygusuz, 2009; Abdeen, 2008)

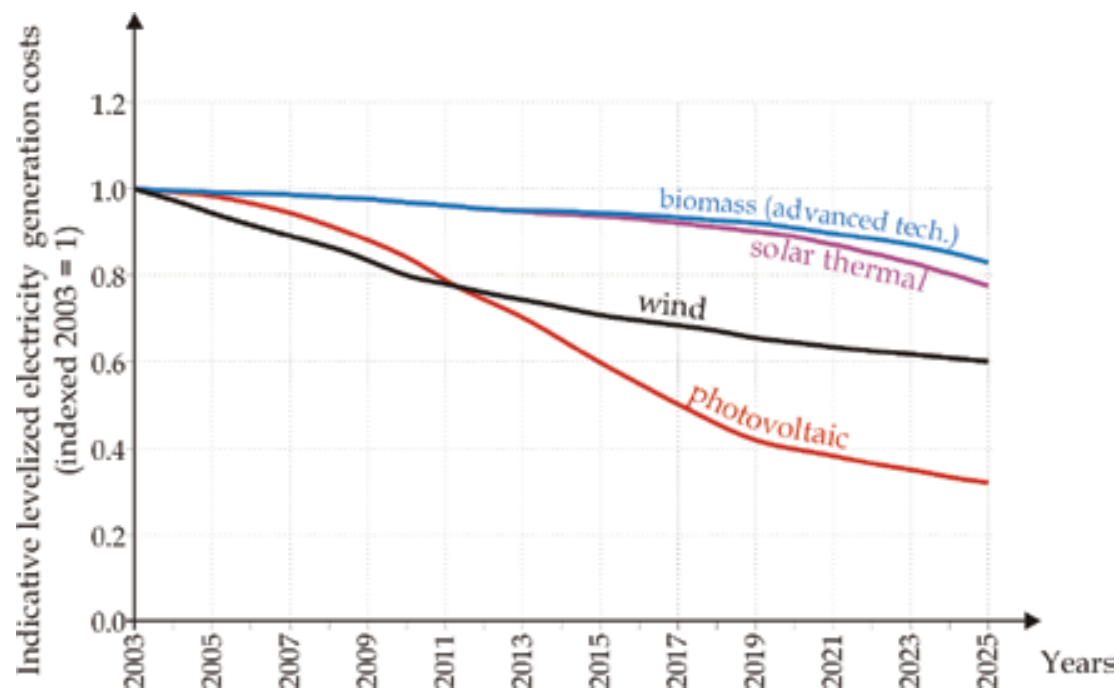

Fig. 3. Unit energy cost estimations of advanced energy generation technologies

According to the International Energy Agency (IEA) reports, changing of the installed PV power in member countries of IEA Photovoltaic Power System Programme (PVPS) between 
1992 and 2008 is given in Fig. 4. Growth rates in recent years are particularly noteworthy. While the amount of the total installed power is 105MW in 1992, it has been increased by 127.8 times until 2008 and reached 13425MW. The total installed capacity of 7866MW in 2007 increased $71 \%$ in only one year. By the end of 2008, the share of stand-alone PV Systems (that are shown as black columns in Fig. 4) in total installed power was realized as 5.5\% (741MW).

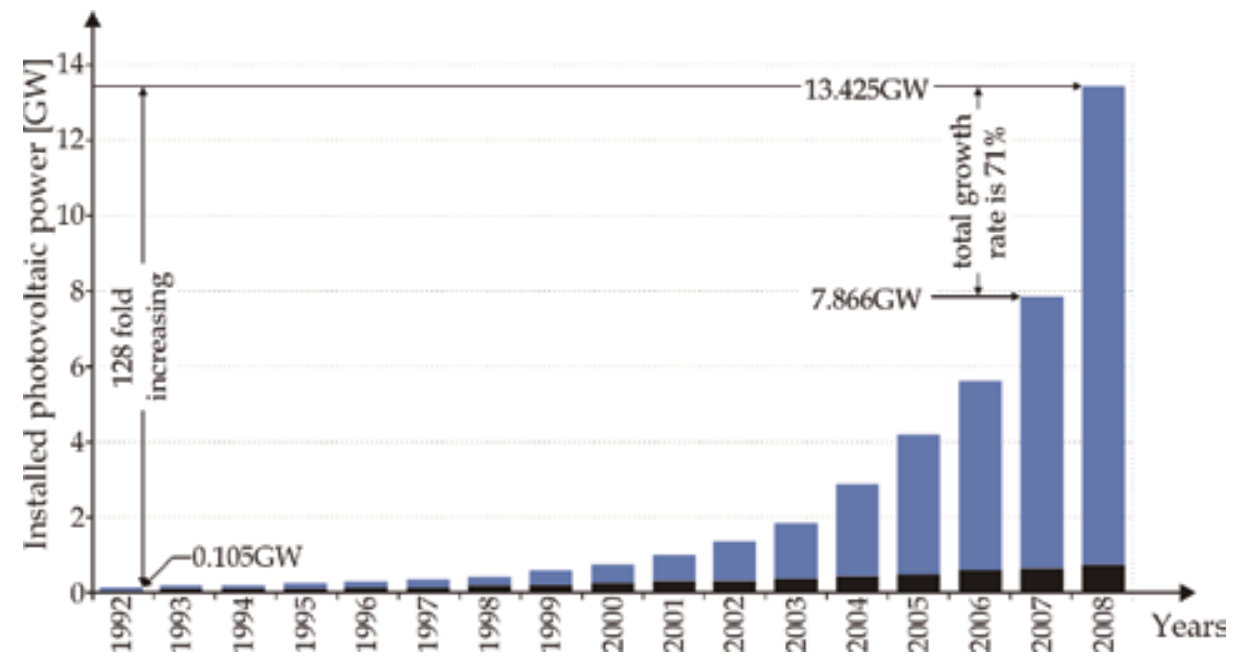

Fig. 4. Cumulative installed grid-connected and off-grid PV power in IEA_PVPS countries (IEA, 2010)

\section{Photovoltaic system design}

The sun actually constitutes the source of all energy in the world. Sun power converts to other energy sources in various ways. These relationships are seen in Fig. 5. But, only PV systems which convert solar energy directly into electricity are entered into the topic of this section.

Modular structures of PV systems provide a great flexibility in terms of many parameters. The power spectrum ranges from a few miliwatts for wristwatches or scientific calculators, to kilowatt systems in remote area power supplies, for example, for mountaineering lodges or water pumps, to large central PV power stations in the megawatt range (Presier, 2003). PV cells are generally considered to be an expensive method of electricity production. However, in off-grid situations photovoltaics are very often the most economic solution to provide the required electricity service (Hongbo et al., 2009). The growing market all over the world indicates that solar electricity has entered many areas in which its application is economically viable. Additionally, the rapidly growing application of PV systems in gridconnected situations shows that photovoltaic's are very attractive for a large number of private people, companies and governments who want to contribute to the establishment of a new and more environmentally being electricity supply system.

PV systems may contain different components and specifications by use. In Fig. 6., block diagrams of stand-alone and grid-connected PV systems are shown. Battery groups are used in both systems. If desired, grid-connected systems can be designed without batteries. However, stand-alone systems as usually include storage units (Chaar, 2006). In following sections, design processes of a PV system are investigated. 


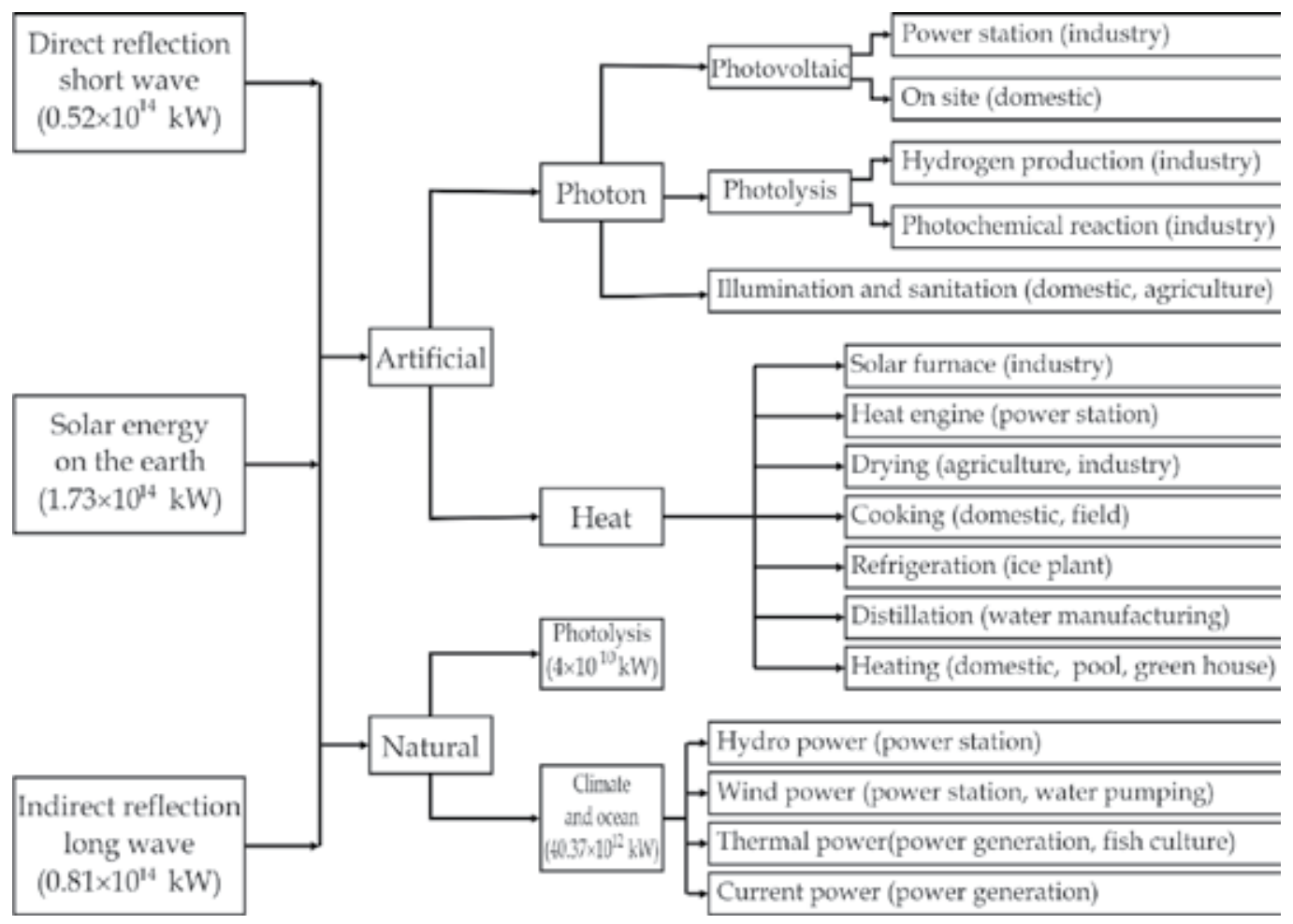

Fig. 5. The relationship between solar energy and other energy sources (Sen, 2004)

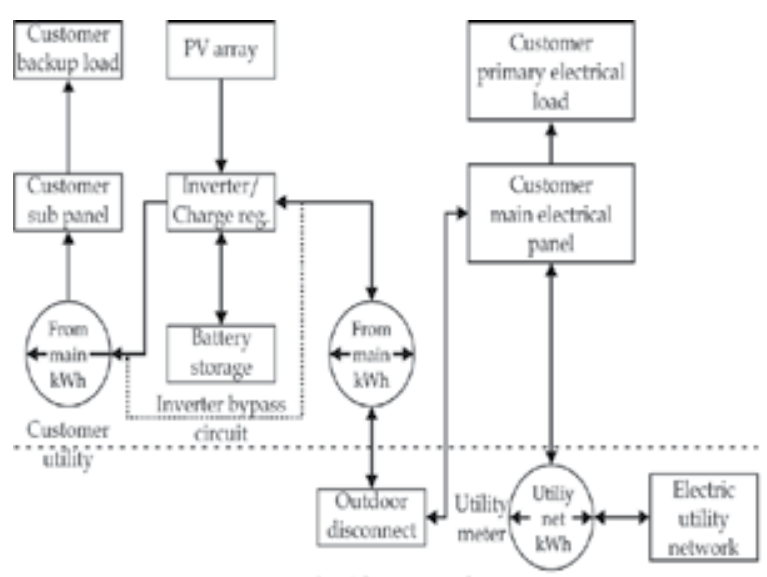

a-) grid-connested

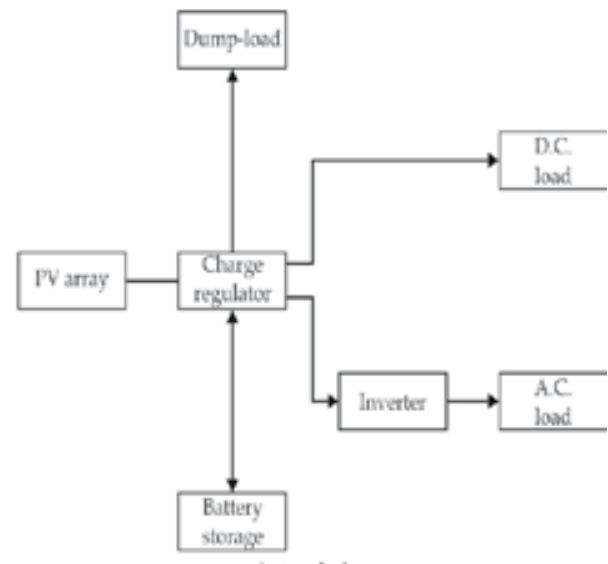

a-) stand-alone

Fig. 6. Block diagram of PV systems with battery storage

\subsection{Determination of the load amount}

Load determination is the first and most important stage of PV system design. Generally, storage capacity is given as ampere-hour (Ah). Therefore, the amount of energy demanded by load must be denominated in this unit. Correct identification of load is crucial to the reliability of the system. For this purpose, all loads are supplied from the PV panel should 
be defined and power, current, operating voltage, and especially the daily working hours of each load are determined. In some cases, load amount may be varied as seasonal, monthly or daily and should be recalculated for each change period. For an accurate result, the amounts of AC loads in watts and DC loads in $\mathrm{Ah}\left(\mathrm{W}_{\mathrm{AC}}\right.$ and $\left.\mathrm{W}_{\mathrm{DC}}\right)$ must be calculated separately. At the next stage the total amount of load is determined by adding of these two values. Inverter sizing should be made for AC loads. Wire sizing is realized for each load by using their power. At this stage, a precise voltage drop calculation can be made if required. However, wiring efficiency can be assumed as a constant value such as 0.98 in most cases. Efficiencies of other components (inverter and charge regulator) also must be known. Finally, if the system contains a battery group, battery losses that occur during charging and discharging events must be taken into consideration. Thus the total current demand from the PV panels would be designated. Following equations can be written for load sizing.

$$
\begin{gathered}
\mathrm{L}_{\mathrm{AC}}=\mathrm{W}_{\mathrm{AC}} \cdot\left[\frac{1}{\mathrm{~V}_{\mathrm{ii}}} \cdot \frac{1}{\eta_{\mathrm{i}}} \cdot \frac{1}{\eta_{\mathrm{w}}} \cdot \frac{1}{\eta_{\mathrm{b}}} \cdot \frac{1}{\eta_{\mathrm{ch}}}\right] \\
\mathrm{L}_{\mathrm{DC}}=\mathrm{W}_{\mathrm{DC}} \cdot\left[\frac{1}{\eta_{\mathrm{w}}} \cdot \frac{1}{\eta_{\mathrm{b}}} \cdot \frac{1}{\eta_{\mathrm{ch}}}\right] \\
\sum \mathrm{L}=\mathrm{L}_{\mathrm{AC}}+\mathrm{L}_{\mathrm{DC}} \quad[\mathrm{Ah}]
\end{gathered}
$$

Here, $\eta_{\mathrm{i}}, \eta_{\mathrm{w}}, \eta_{\mathrm{b}}$ and $\eta_{\mathrm{ch}}$ shows inverter, transmission line, battery group and charge regulator efficiencies respectively. $V_{i i}$ is the value of $D C$ input voltage of inverter. If the operating voltage of the load is different from system voltage, a convertor circuit should be added to the system. The efficiency of this element should be also added to the equation (Messenger \& Ventre, 2000). In some cases, to calculate the amount of load, practically total power values of the loads multiplied by a constant coefficient after being converted to Ah. This coefficient varies between 1.1 and 1.5. Designer must be taken in to account all system parameters correctly to obtain this coefficient (Chel et al., 2009).

\subsection{Determination of storage capacity and battery number}

PV systems usually include a storage system because of modules produce energy in the only daytime hours. Storage systems typically consist of rechargeable batteries. In addition to energy storage, batteries also undertake additional tasks, such as to pause the system when overload times, to provide voltage regulation and to be a current source.

Location of PV systems is significantly effect on the performance. Depending on location, less storage may be required even during the worst season of year. If the minimum peak sun hours value $\left(\mathrm{T}_{\min }\right)$ of system location is known during the operation times of load, autonomous day number (D) calculates by using of the equations (4) and (5).

$$
\begin{gathered}
\mathrm{D}_{\text {critic }}=-1.9 \cdot \mathrm{T}_{\text {min }}+18.3 \\
\mathrm{D}_{\text {noncritic }}=-0.48 \cdot \mathrm{T}_{\text {min }}+4.58
\end{gathered}
$$

Here, $\mathrm{T}_{\min }$ value is daily sunshine duration and measured as meteorological data. These equations are only valid for regions where $T_{\min }$ value is at least one hour in a day. If the sun does not appear, $\mathrm{D}$ value should be also more than these values (18.3 for critical loads, 4.58 for noncritical loads) (Messenger \& Ventre, 2000). Total battery storage (B) is calculated with equation (6) using the D value obtained from above formulas. 


$$
\mathrm{B}=\sum \mathrm{L} \cdot\left(\frac{\mathrm{D}}{\mathrm{D}_{\mathrm{T}} \cdot \mathrm{D}_{\mathrm{ch}} \cdot(\text { disch })}\right)
$$

In this equation, $\mathrm{D}_{\mathrm{T}}$ represents the capacity reduction of batteries depending on temperature and discharge amount. If the load current will exceed the specified discharge rate for more than 10 minutes, additional correction factor should be applied to B value. This factor is called as charge-discharge correcting factor and represented with $\mathrm{D}_{\mathrm{ch}}$. The amount of discharge expressed as a fraction has been identified with (disch) symbol. Practically, assuming as $\mathrm{D}_{\mathrm{T}} \cdot \mathrm{D}_{\text {ch }} \cdot($ disch) $\cong 0.8$ provides sufficient accuracy (Messenger and Ventre, 2000). In studies that realized by Chel et al. for India-New Delhi and Able-Thomas and Hill for Gambia, D value was assumed as three days practically (Chel et al, 2009; Able-Thomas \& Hill, 1996). In a similar study, Deshmukh has indicated that this value could be two or three days (Deshmukh \& Deshmukh, 2008). This approach is applicable for location where not too many climate change during year. After this stage, to calculate the number of batteries $\left(\mathrm{N}_{\mathrm{B}}\right)$ is sufficient to know capacity value the selected battery (Ah). Number of batteries in parallel $\left(\mathrm{N}_{\mathrm{B}}\right)$ is obtained by equation (7). If required, this value multiplied by battery numbers that connected in serial.

$$
\mathrm{N}_{\mathrm{B}}=\frac{\mathrm{B}}{\mathrm{Ah}}
$$

A no integral quantity is found as a result of this calculation. The exact number obtained by rounded of this value up or down. Other factors in the battery selection are additional connection requirements in case of too many battery using and additional maintenance times. Increasing the number of connections increases the risk of failure. On the other hand, insufficient number of batteries may require more outages in case of a fault. In addition, weight and commercially availability of batteries must be taken in to account for a good choice. Battery unit is usually the second biggest part of the total cost of PV system after modules. Storage costs are closely related to the life of selected battery. According to a detailed study by Jossen et al., if battery life is less than 3.5 years, storage units are becoming the most expensive element of PV systems due to increased replacement costs (Jossen et al., 2004).

\subsection{PV panel array sizing}

After making the calculation about amount of load, photovoltaic array (panel) can be sized. In that phase, to provide the aim of minimum PV module usage, appropriate tilt and number of parallel modules are determined. If the system voltage is greater than the chosen module's output voltage, additional modules can be needed for series connection.

The main thing is working of the system under the worst conditions (Messenger \& Ventre, 2000; Able-Thomas \& Hill, 1996). In that case, calculation can be made like that separate for every day or every month, in addition to that if the system will work during the whole year or whole month just for the worst conditions the current taken from the PV module (IPV) and number of modules $\left(\mathrm{N}_{\mathrm{M}}\right)$ can be determined. The number of modules needed for the system is determined after taking into consideration of modules' dirty surface due to usage or depreciation loss, total design current is divided to one module's current. Especially crystalline modules are more sensitive to dirty surface and slope of sunshine than 
amorphous modules. Besides, the temperature changes on surface during the daytime also affect the efficiency of module (Gregg et al, 2005). For this reason, a correction factor is implemented to that calculated module current. To choose that value as 0.9 is enough to provide accuracy (Messenger \& Ventre, 2000). According to chosen number of modules multiplication of the power of module $\left(\mathrm{P}_{\mathrm{M}}\right)$ and number of modules gives the power of the installed PV $\left(\mathrm{P}_{\mathrm{PV}}\right)$ panel.

$$
\begin{gathered}
\mathrm{I}_{\mathrm{PV}}=\frac{\sum \mathrm{L}}{\mathrm{T}_{\text {min }} \cdot 0.9} \\
\mathrm{~N}_{\mathrm{M}}=\frac{\mathrm{I}_{\mathrm{PV}}}{\mathrm{I}_{\mathrm{M}}} \\
\mathrm{P}_{\mathrm{PV}}=\mathrm{P}_{\mathrm{M}} \cdot \mathrm{N}_{\mathrm{M}}
\end{gathered}
$$

If the tilt of the panel can be changed monthly or seasonally, a new table that gives the optimum design current can be made. To form that table, a database should be made according to tilt for every month. But in that case module save can be failed because the system is designed for the worst conditions. This method provides the calculation of the extra energy produced from the PV modules and this energy can be consumed by additional consumers.

\subsection{Selection of inverter and charge controller}

Under the nominal working conditions the necessary inverter power to feed the A.C. load can be chosen the $110 \%$ of PV panel power. However if the system feeds a motor load, the choice should meet the start up and maximum load current. According to an experimental study made by Onat et al. in 2009, especially start up currents of A.C. machines such as induction motor and transformers have some important effects on PV systems. According to the study, induction motor has been the most compelling electrical machine for PV system that has demanded a startup power that is 2.14 times higher than nominal power value. In addition, such demand for quite high power (transient operation period) has lasted for a long time of 8.2 seconds. On the other hand, startup power of transformers has been 1.3 times higher than nominal value. Moreover, the time required to complete transient operation has been $5.3 \mathrm{sec}$. However, if the startup current is not taken into consideration, particularly in the systems that are frequently connected and disconnected, high power drawn may result in overheating of the modules and decrease of the efficiency of the photovoltaic system (Onat et al., 2009).

In charge controller selection, generally simple ones are preferred. Some safety problems can be occurred because of complexity. Charge controller should keep the battery current that comes from the panels equal to the load current. In that case inverter power $\left(P_{\text {inv }}\right)$ and controller current $\left(\mathrm{I}_{\mathrm{ch}}\right)$ can be found by following formulas.

$$
\begin{gathered}
\mathrm{P}_{\text {inv }}=\mathrm{P}_{\mathrm{PV}} \times 1.1 \\
\mathrm{I}_{\mathrm{ch}}=\frac{\mathrm{P}_{\mathrm{PV}}}{\mathrm{V}_{\mathrm{b}}}
\end{gathered}
$$

In that formula, $\mathrm{V}_{\mathrm{b}}$ shows the battery group's D.C. output voltage. In the selection of inverter and controller the efficiency affects the system's working directly and that has been 
stated in the design phase of load determination. In the selection of those equipments, the efficiency cost relation should be checked. Especially in inverter market, simple, cheap but it creates until the $10 \%$ loss, additionally expensive but working with $98 \%$ efficiency models are also available (Gregg et al., 2005).

\subsection{Auxiliary components (BOS) and assembly}

Wire sizing must be made separately for every part of the system. Generally, panel-battery, battery-controller, or inverter and controller-load are the main parts. But this can be extended according to the specifications of the load and system. In consideration with maximum current of every part and line length, voltage drops can be calculated.

In the selection of fuse, generally standard fuses that have as a current value $125 \%$ of the nominal line current are preferred. All fuses that are going to be used in DC should be suitable for that type current.

Switches and breakers in the system that makes the on-off operations should be suitable for the maximum current values controlled by them. Besides they should be suitable for the current type (AC or DC) that used for. In inductive currents, sudden current interruption may cause high voltage in switches. If the controlled load is inductive, they should be durable to high voltage and arcs that are formed when the circuit is interrupted.

Sub components of the systems, such as plugs, fuse clips, protection systems, ground rods, battery cabins, electric boards...etc should be considered in design phase.

These equipments' cost is named as BOS (Balance of System). In practical calculations, this cost is taken as $10 \%$ of the total panel cost (Messenger \& Ventre, 2000). However, if enough data is available this calculation can be made in more detail. Besides, the assembly cost also should be considered in the design phase. Assembly costs change according to land conditions and system characteristics.

\section{Cost calculation of PV systems}

Costs in photovoltaic systems include purchase, operating, maintenance and change costs. If the firm should borrow money to buy a property, then this cost also should be added to this cost. In most of the cases, to meet all cost of the first purchase from the capital stock is not economical. Especially, for an accuracy cost calculation of PV systems, considering of external costs is important. External cost is generally not measurable and does not have direct relation with the system. For example many people know that acid rains are occurred due to sulphur emission from the factory chimneys. Also acid rains cause damages in buildings and this is also known. But the cost of this damage does not paid directly by the companies that cause the emission (Messenger \& Ventre, 2000). External cost value can also be negative. For example, if the system has a benefit that is not directly have a positive effect on the system, this value can have an effect to decrease the total system cost. Generally when to determine the cost the following four methods are used.

1. Heuristic or experience based method; In that method estimated cost is determined by experienced people.

2. Analogical method; this method includes stereotypes about cost estimation systems and structures.

3. Parametric method; uses equations to define the relation between a system's measurable aspects and its cost.

4. Analytical method; is also called as detailed model. Every step in construction phase of the system is included in cost. Like labor force rate, labor force time, material amount 
and price. This method also called as bottom-up method (Du et al., 2009). In Table 3. these methods' implementation parts are seen.

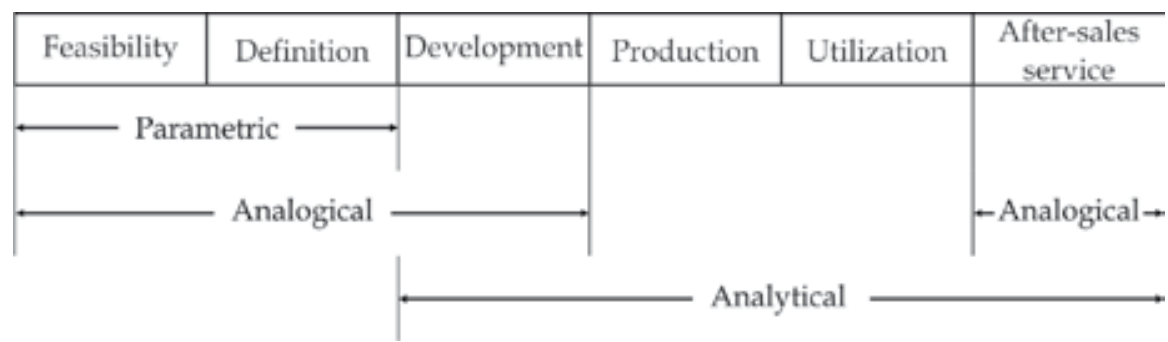

Table 3. Use of cost calculation methods and application areas

\subsection{Life cycle cost analysis (LCCA) of PV systems}

Purchase of any properties or construction of a facility, the first and most important step is creating the design project. Design steps of photovoltaic systems are focused in previous parts. In some situations, the aesthetic and ergonomic characteristics of the design are also examined in this scope. Second step is to determine how the design can be carried out. "How long does it take to set up the system?" and "What is the first cost in construction phase?" are this step's two important questions and should be answered after the first step. The third step is calculation of the total cost of purchase/construction during the life of the system. This information also includes operating, maintenance, replacement and disposal (salvage) costs in addition to the first setup and design costs and especially affects the investors' decision. Many effective methods are developed to calculate this value before the construction phase by the use of economic theories with computer technologies (Mearig et al., 1999). LCCA is generally used to compare a few different project alternatives. PV systems can also be including these different alternatives. For example, like a PV system working separately or a hybrid PV/Wind system's preference, to chose one of the load from two loads those make the same work, to compare the module and battery options those are going to be used in PV systems according to their costs for the different options as a result of LCCA well decisions can be made. In electric producing systems, the other aim of LCCA is to determine the energy cost per unit. This value can affect the system's set up preference. This also gives clue in determination of sales cost of the produced electrical energy.

\subsection{Stages of LCCA}

In litterateur, different implementation methods are developed for LCCA. Barringer explained the 11 steps to complete the LCCA. According to this study, "the basic tree for LCC combines acquisition and sustaining costs as shown in Fig. 7. Acquisition and sustaining costs are not mutually exclusive. If you acquire equipment, you must sustain the acquisition, and you can't sustain without someone having acquired the item. Acquisition and sustaining costs are found by gathering the correct inputs, building the input database, evaluating the LCC and conducting sensitivity analysis to identify cost drivers" (Barringer \& Barringer, 2003).

According to the study of Jeromin et al, LCC analysis includes there main stages as investment, operating and recycling. In addition to that the information, for every stage which costs are calculated, is also included in detail (Jeromin et al., 2009). Some parameters used in LCCA have been explained below. 


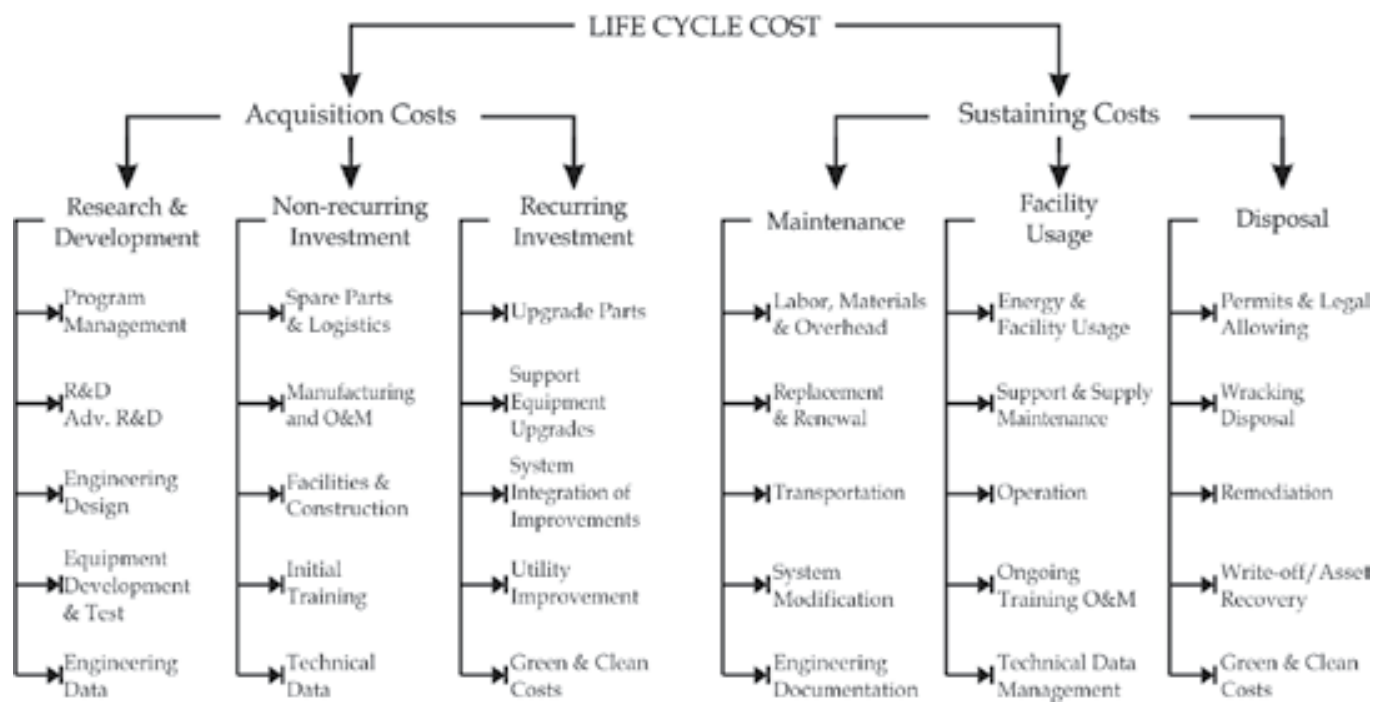

Fig. 7. Main components of LCC

\subsection{The monetary Impact of time}

Life cycle cost (LCC) of an item includes the sum of operating and trading costs during the life time. Some of these costs occur in the purchasing period, while others engaged in next time. To compare two similar products which taken at different times and at different costs is a convenient way to reduce all costs to purchasing time. This process is known as the "present worth method". The two events will determine the value of money over time.

Inflation rate (i) is a measure of the decline in the value of money. For example, in a country where annual inflation rate of $5 \%$, then the items will cost more than $5 \%$ next year. So that, more money will be required to buy the same product. In fact, there is decreasing the value of cash. Beside this, the inflation rate is valid for any product does not have to equal to the general inflation rate. Annual price increase on certain products may be too high or low according to the average value.

Interest (discount) rate (d) is associated with the amount of profit that obtained from saving capital. If the money is being deposited in a bank account, interest rate of that is a positive value. The -n- year's later value of a currency lent at interest annually at a $d \%$ rate is calculated by (13).

$$
\mathrm{N}_{\mathrm{n}}=\mathrm{N}_{0}(1+\mathrm{d})^{\mathrm{n}}
$$

Therefore, the amount of money in cash will increase. However, incoming money $\left(\mathrm{N}_{\mathrm{n}}\right)$ will not be equal to initial value $\left(\mathrm{N}_{0}\right)$ in terms of purchasing power by reason of changes in the inflation rate. Inflation increases the purchasing cost of a product. For this reason, the purchase cost of an item -n- years later will be:

$$
\mathrm{C}_{\mathrm{n}}=\mathrm{C}_{0}(1+\mathrm{i})^{\mathrm{n}}
$$

In this case, if the cost of an item increases more than incoming money from bank account, it may be profitable to buy the product immediately. If the opposite that inflation rate lower than discount rate then should wait before making the purchase. However, this purchasing 
manner is not valid often because of cannot be benefit from the item until it is purchased. Finally, in the purchasing period of an item economy may not always be in the forefront. Only needs or personal requests may be reasons of purchase. If the initial purchasing cost and investment cost are equal to each other $\left(\mathrm{C}_{0}=\mathrm{N}_{0}\right), \mathrm{C}_{\mathrm{n}} / \mathrm{N}_{\mathrm{n}}$ ratio is a dimensionless value. This ratio determine the present worth coefficient $\left(P_{R}\right)$ of money. Accordingly, $P_{R}$ of an item that will purchase -n- year later is;

$$
P_{R}=\left(\frac{1+i}{1+d}\right)^{n}
$$

Thus, the present value of the item ( $\left.\mathrm{P}_{\text {Worth }}\right)$ is calculated by following equation.

$$
\mathrm{P}_{\text {Worth }}=\mathrm{P}_{\mathrm{R}} \cdot \mathrm{C}_{0}
$$

In the calculation of $P_{\text {Worth }}$ of recurring expenses in each or certain years such as operating and maintenance costs $(\mathrm{O} \& \mathrm{M})$ or replacement costs etc., above equation (16) is rewritten for each purchasing year and their sum is taken as in equation (17).

$$
\mathrm{P}_{\text {Worth }}=\mathrm{C}_{0}+\mathrm{C}_{0}\left(\frac{1+\mathrm{i}}{1+\mathrm{d}}\right)+\mathrm{C}_{0}\left(\frac{1+\mathrm{i}}{1+\mathrm{d}}\right)^{2}+\mathrm{C}_{0}\left(\frac{1+\mathrm{i}}{1+\mathrm{d}}\right)^{3}+\ldots .+\mathrm{C}_{0}\left(\frac{1+\mathrm{i}}{1+\mathrm{d}}\right)^{\mathrm{n}-1}
$$

If assumed that $x=\left(\frac{1+i}{1+d}\right)$, equation (17) can be written as follows (Messenger \& Ventre, 2000; Kolhe et al., 2002).

$$
\mathrm{P}_{\text {Worth }}=\mathrm{C}_{0}\left(1+\mathrm{x}+\mathrm{x}^{2}+\ldots .+\mathrm{x}^{\mathrm{n}-1}\right)
$$

\subsection{Calculation of life cycle cost}

Life cycle cost (LCC) is defined as the sum of present values of all components in the system. Basically, the calculated LCC should be included purchasing, replacement, maintenance, fuel and operating costs of each component. Additionally, if there is a sales value of the system at the end of the operating life, this fee will be added as a negative cost to LCC. In some cases, destruction, transportation or disposal expenses may also be required. These values should be added as a positive life costs.

In this study, fossil fuel saving amounts that obtained by the use of PV systems are taken into consideration. This value can be determined by the calculation of required fossil fuel to produce the energy equal to PV system. Here, lower heating value $(\mathrm{H}[\mathrm{kcal} / \mathrm{kg}])$ of used fossil fuels and efficiency of power plant $\left(\eta_{\ddot{u}}\right)$ should be known. In this case, to calculate the saved fuel amount $\left(\mathrm{M}_{\mathrm{F}}\right)$, following equation can be used.

$$
\mathrm{M}_{\mathrm{F}}=\frac{1}{\mathrm{H}}\left(\sum_{\mathrm{i}=1}^{\mathrm{t}} \frac{\mathrm{X} \cdot \mathrm{Y}_{\mathrm{i}}}{\eta_{\ddot{u}}}\right) \text { [tonnes] }
$$

Here, $X$ indicates power of the system (MW) and $Y_{i}$ represents the percentage value of solar power in total during lifetime (Amit et al., 1995). If PV provides all power consumption of load, then assumed $Y_{i}=1$. " $t$ " is the total time (hours) of the system in operation. Another point to note here that the fossil fuel consumed during the production of solar cells or the carbon dioxide emissions is taken into account. With the adding of these values in the calculations more accurate results are obtained. In a detailed study realized by Stoppato, 
recycling period of toxic gas emissions that occur during the PV module production was calculated. Recycling period was obtained as 3.5 and 4.91 years for two different systems which have 28 year lifetime and 10MW power (Stoppato, 2008). These values correspond to the $13.5 \%$ and $17.5 \%$ of total module life respectively. So, for accurate calculation of $-\mathrm{t}$ - in equation (19), system life should be assumed lower than approximately $15 \%$ of real value. In this case, saving the cost of fossil fuels $\left(\mathrm{C}_{\mathrm{F}}\right)$ can be easily calculated by multiplying the calculated value in (19) by the unit price of fuel ( $\left.\mathrm{C}_{\text {fuel }}\right)$ (Amit et al., 1995).

$$
\mathrm{C}_{\mathrm{F}}=\mathrm{M}_{\mathrm{F}} \cdot \mathrm{C}_{\text {fuel }}
$$

As a result, data needed to write a comprehensive LCC equation can be obtained. LCC value will be the sum of present worth of the costs detailed above.

$$
\mathrm{LCC}=\mathrm{C}_{0}+\mathrm{C}_{\mathrm{O} \& \mathrm{M}_{\mathrm{PW} \text { orth }}}+\mathrm{C}_{\mathrm{R}_{\mathrm{PW} \text { orth }}}-\mathrm{C}_{\mathrm{S}_{\mathrm{PW} \text { orth }}}-\mathrm{C}_{\mathrm{F}_{\mathrm{PWOrth}}} \quad \text { [c.u.] }
$$

Here, $C_{0}, C_{O \& M}, C_{R}, C_{S}$, and $C_{F}$ represent the sum of initial purchasing, operation and maintenance, replacement, salvage and fuel costs respectively. All the values are calculated in currency unit (c.u.) of purchase. In grid-connected PV systems, selling value of produced electricity is also added to LCC. Depending on the size of the system, design and construction phase may take one or two years. This period is the stage of initial purchasing at the same time. Fig. 8. shows cash flows of a sample system that's total life is 27 year (including the design and installation period) (Whisnant et al., 2002). Note that, cost of saving fuel has participated in the seventh year to LCC as stated above.

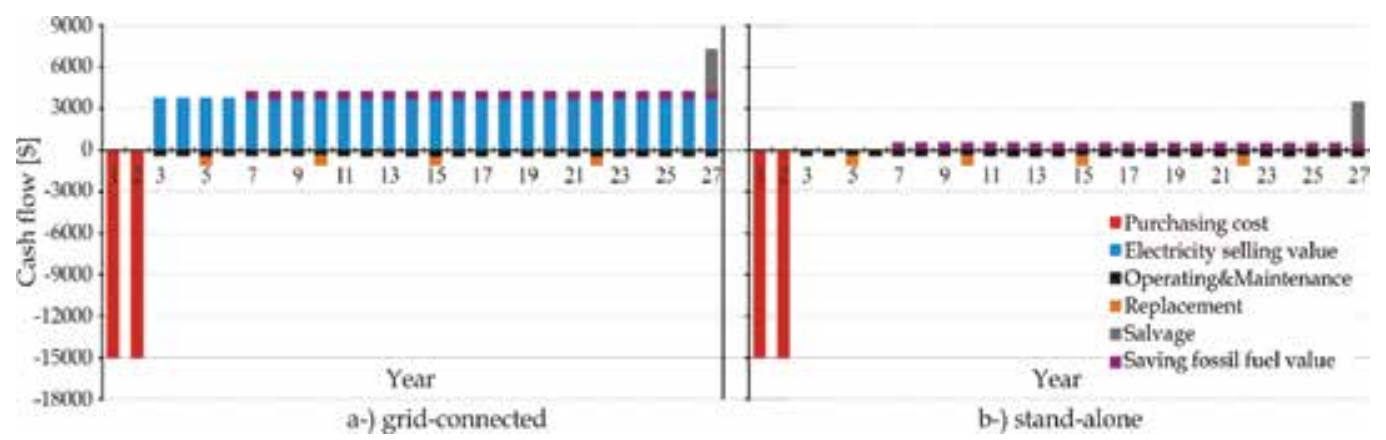

Fig. 8. Sample cash flows of PV systems

Finally, the choice to be made between different alternatives, a table is prepared containing LCC values of all components and options for a healthy comparison. Thus, LCCA is completed. But generally the unit cost of energy is also calculated in power systems. Especially in stand-alone systems, knowing of unit energy cost provides important advantages.

\subsection{Unit energy cost calculation}

The unit energy cost $\left(\mathrm{C}_{\mathrm{E}}\right)$ can be calculated as simple dividing by annual life cycle cost (ALCC) to annual energy consumption of loads feeding by system. Here, total energy consumption of loads $(\Sigma \mathrm{E})$ during life time of the system is obtained by multiplying $\Sigma \mathrm{L}$ that calculated by equation (3) and total time ( $t$ ) of the system in operation. Equation (23) is used to calculate ALCC value (Chel et al., 2009). In this case, annual energy production and unit energy cost of PV system are founded from equation (24) and (25) respectively. 


$$
\begin{gathered}
\sum \mathrm{E}=\sum \mathrm{L} \cdot \mathrm{t} \quad[\mathrm{kWh}] \\
\text { ALCC }=\mathrm{LCC} \cdot\left[\frac{\left((1+\mathrm{d})^{\mathrm{n}} \cdot \mathrm{d}\right)}{\left((1+\mathrm{d})^{\mathrm{n}}-1\right)}\right] \quad[\mathrm{CU} / \text { year }] \\
\mathrm{E}=\frac{\sum \mathrm{E}}{\mathrm{n}} \quad[\mathrm{kWh} / \text { year }] \\
\mathrm{C}_{\mathrm{E}}=\frac{\mathrm{ALCC}}{\mathrm{E}} \quad[\mathrm{CU} / \mathrm{kWh}]
\end{gathered}
$$

ALCC re-calculated for each system, but it is a constant value. Therefore, according to the equation (25), the most effective way of reducing the unit cost of energy is increase the load as possible as feeding by system.

\subsection{Other parameters that affect LLC and the unit energy cost of PV systems}

In the calculation of LCC and unit energy cost can be various positive and negative factors in addition to the above-mentioned parameters. Capacity utilization rate $(\mathrm{CU})$, the loan has been received and not received (credit use) to meet the initial investment cost, conditions and amount of borrowed money, incentives and subsidies given by the state or otherwise applied additional taxes can be considered as the most important ingredients that create these effects. These parameters are described briefly below.

\subsubsection{Capacity utilization rate}

Capacity utilization (CU) is one of the most important parameters that directly affect the unit cost of PV energy systems. CU is a measurable value depending on consumed percentage of total generated energy and changes with technical, geographical and climatic parameters in PV systems. However, in grid-connected wind and PV systems, depending on the region's conditions if the $\mathrm{CU}$ rate is above $20 \%$ is considered suitable for investment (EIE, 2009).

$\mathrm{CU}$ rate is largely depending on amount of load feeding from PV system. System design should be made taking into account the worst conditions in operating period of the load. Otherwise, reliability problems and loss of load probabilities will arise. Panel sizing and storage unit calculations are also made according to the worst climatic data as given previous sections. So, resulting in usage of excess energy is important in the better climatic conditions when the system is in operation. Usually, excess energy is wasted with dump loads or some modules are disabled. However, these methods do not make a positive impact on unit energy cost. If the excess energy uses to feed other loads or it is possible to sell to the real consumers, unit energy costs can be reduced greatly in (Eltawil \& Zhao, 2010). In a sample application realized by Ersöz and Onat for İstanbul-Turkey, effect of CU on unit energy cost was calculated. According to this paper, CU of a PV system designed for a load that is in operation whole year was determined as $2.48 \%$ in case of only load feeding. Unit energy cost is $1.16 \$ / \mathrm{kVAh}$. In case of only $5 \%$ of excess energy consumed in a useful way, unit energy cost decreases approximately three times and is $0.394 \$ / \mathrm{kVAh}$ (Ersöz \& Onat, 2010). The relationship between capacity utilization rate and the unit cost of energy is seen in Fig. 9. 


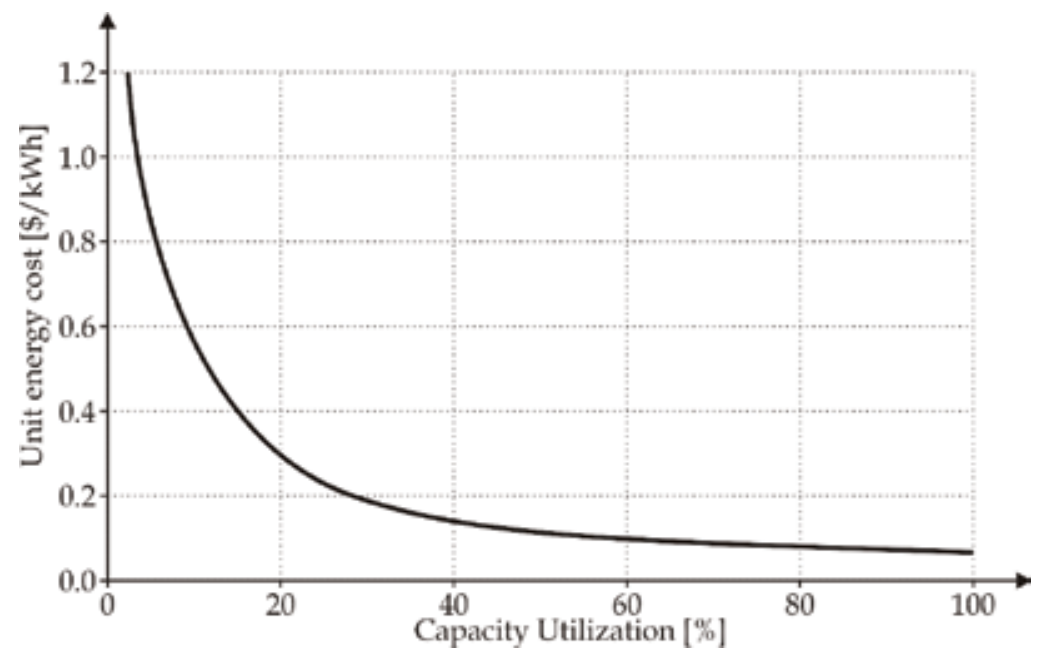

Fig. 9. Changing of unit energy cost with capacity utilization

\subsubsection{Borrowed money (credit usage)}

Sometimes do not enough money in hand to get a desired product. In this case, often borrowing is taken from banks and other credit institutions. So, the amount of borrowed money and interest on borrowings is also important and affects the cost of items. If bank loan will be used to buy a product, it must be known how will affect the LCC of the product. To do so, tables would prepare showing the annual repayment of borrowed money. This process has become very easy with computer technology.

If enough money is available for any purchase, it is really easy to decide whether spending or saving. Otherwise if the money is not available, the only option is to borrow. Even if the money is available, it should be taken into consideration that interest of the borrowing is lower or higher than bank account interest. In some cases, credit usage may be more advantageous (Messenger \& Ventre, 2000).

\subsubsection{Subsidies (incentives) and taxes}

Additional factors that should be taken into consideration in cost analysis are effects of subsidies (government aids) in various ways. While some of subsidies are included into the cost directly, others occur as external costs. Today, in most countries various subsidy mechanisms have been established to encourage the use of renewable energy sources. Rarely, some governments are taking some extra taxes during the installation of the system or over produced energy. Therefore, effects of these taxes and subsidies on LCC vary between countries. For example according to the law on "Use of Renewable Energy Resources for Production of Electric Energy" dated May 10, 2005 in Turkey;

- For the energy to be produced from renewable energy resources by companies that fulfill the conditions given in the regulation, a purchasing guarantee will be ensured.

- In case the natural and judicial persons establish plants with maximum 1MW installed power to meet their own needs, regardless of whether it is a network supported or individual system, for the projects of which definite project, planning, master plan, preliminary survey or first study are prepared by the General Directorate of State Hydraulic Works (DSI) or (EIE), no service fee will be charged. 
- The necessary plant investments to establish such systems, supplying of electromechanic systems domestically as production, research and development (R\&D) and production investments to be made under scope of electric production systems that use solar cells and focusing units and R\&D plant investments related to electric energy or fuel production by using biomass resources will be benefit from incentives,

- In case immovable assets under property of the forestry and treasury departments or disposition and jurisdiction of the state are used to make electric energy production from renewable energy resources under scope of law, the required usage permits for such lands will be given and in case of leasing; various tax deductions will be awarded (Official Gazette of Turkish Republic, 2005).

After all these steps LCC analysis are completed. Designer should try to make an accurate calculation as possible using all of or only necessary steps above-mentioned, depending on economic, social and geographical conditions of the country.

\section{Examples}

\subsection{Sample application-1}

For a PV system planned in İzmir-Turkey, cost-effective option will be chosen from among alternatives in Table 4. Duration of the project and installation of the system is given as one year. Operating cycle is determined as 25 years duration of the project except. Let's calculate LCC and unit energy cost of each alternatives.

\begin{tabular}{|r|c|l|}
\hline System Location & $:$ & İzmir - TURKEY \\
\hline Life Cycle of System & $:$ & 25 year \\
\hline Inflation Rate & $:$ & $5 \%$ \\
\hline Interest Rate & $:$ & $10 \%$ \\
\hline Operating and Maintenance Cost & $=$ & $150 \$ /$ year \\
\hline Balance of System Cost (BOS) & $=$ & $10 \%$ of module cost \\
\hline Assembly Cost & $=$ & $5 \%$ of module cost \\
\hline Salvage Value & $=$ & $15 \%$ of total initial purchasing cost \\
\hline
\end{tabular}

\begin{tabular}{|c|c|c|c|}
\hline $\begin{array}{l}\text { Component } \\
\text { Alternatives }\end{array}$ & Specifications & Price $[\$]$ & Life [Year] \\
\hline $\begin{array}{l}\text { Load - } 1 \text { (AC Load) } \\
\text { (fan motor) }\end{array}$ & voltage: $220 \mathrm{VAC}$, daily power consumption: $2 \mathrm{kWh} /$ day & 150 & 15 \\
\hline $\begin{array}{l}\text { Load - } 2 \text { (DC Load) } \\
\text { (fan motor) }\end{array}$ & voltage: 24VDC, daily energy consumption: 100Ah/day & 250 & 10 \\
\hline Module & voltage: $12 \mathrm{~V}$, power: $120 \mathrm{~W}$, current: $10.84 \mathrm{~A}$ & 638 & $=$ system life \\
\hline Battery - 1 & voltage: $12 \mathrm{~V}$, capacity: $210 \mathrm{Ah}$, efficiency: $90 \%$ & 313 & 10 \\
\hline Battery - 2 & voltage: $12 \mathrm{~V}$, capacity: $102 \mathrm{Ah}$, efficiency: $90 \%$ & 153 & 15 \\
\hline Inverter & voltage: 24VDC-input / 220VAC-output efficiency:95\% & 500 & 10 \\
\hline Charge Regulator & Input voltage: $24 \mathrm{VD}$, efficiency: $95 \%$ & 145 & 5 \\
\hline Wiring & efficiency: $98 \%$ & BOS includes & $=$ system life \\
\hline
\end{tabular}

Table 4. System specifications for sample application 


\subsubsection{Solution}

Let us first determine the amount of the system daily load. Using equations (1) and (2), L values are determined as below.

For AC load, $\quad \mathrm{L}_{\mathrm{AC}}=104.68 \mathrm{Ah} /$ day, $\quad$ and $\mathrm{DC}$ load, $\quad \mathrm{L}_{\mathrm{DC}}=119.35 \mathrm{Ah} /$ day

According to the average of 30 years meteorological data measured by Turkish State Meteorological Service, the peak sun hours of Izmir are given in Table 5.

\begin{tabular}{|c|c|c|c|c|c|c|c|c|c|c|c|c|}
\hline Months & January & February & March & April & May & June & July & August & September & October & November & December \\
\hline $\begin{array}{c}\text { Peak sun hours } \\
\text { [h/day] }\end{array}$ & 4.3 & 5.1 & 6.6 & 7.4 & 9.6 & 11.8 & 12.2 & 11.6 & 10.0 & 7.5 & 5.3 & 3.8 \\
\hline
\end{tabular}

Table 5. Average peak sun hors of Izmir for each month

The worst time-slot of average daily sunlight duration for İzmir is stated as December $3.8 \mathrm{~h} /$ day. Voltage of PV module is half of load voltage. Therefore, two modules should connect in serial. Accordingly, demanded current, number of modules and power of PV panel are calculated by taking twice of values determined from equations (8), (9) and (10).

$$
\begin{array}{lll}
\mathrm{I}_{\mathrm{PV}(\mathrm{AC} \text {-load })}=27.552 \mathrm{~A}, & \mathrm{~N}_{\mathrm{M}(\mathrm{AC}-\text { load })}=5.08 \Rightarrow 6, & \mathrm{P}_{\mathrm{PV}(\mathrm{AC} \text {-load })}=720 \mathrm{~W} \\
\mathrm{I}_{\mathrm{PV}(\mathrm{DC} \text {-load })}=31.41 \mathrm{~A}, & \mathrm{~N}_{\mathrm{M}(\mathrm{DC} \text {-load })}=5.78 \Rightarrow 6, & \mathrm{P}_{\mathrm{PV}(\mathrm{DC} \text {-load })}=720 \mathrm{~W}
\end{array}
$$

Note that, total module number $\left(\mathrm{N}_{\mathrm{M}}\right)$ can not be odd number because of parallel connection requirements. Autonomous day number is calculated as $D=2.756$ days, by using of the equation (5). From equation (6), total battery capacity is determined as, $B_{\mathrm{AC}-\text { load }}=360.62 \mathrm{Ah}$ and $\mathrm{B}_{\mathrm{DC}-\mathrm{load}}=411.16 \mathrm{Ah}$. In this case, numbers of batteries for each option are calculated by using equation (7). (The battery number will be doubled and $\mathrm{N}_{\mathrm{M}}$ can not be odd number).

$$
\mathrm{N}_{\mathrm{B}(1) \mathrm{AC} \text {-load }}=4, \quad \mathrm{~N}_{\mathrm{B}(2) \mathrm{AC}-\text { load }}=8, \quad \mathrm{~N}_{\mathrm{B}(1) \text { DC-load }}=4, \quad \mathrm{~N}_{\mathrm{B}(2) \text { DC-load }}=8,
$$

In battery selection, consideration of only initial purchase cost does not give accurate results. To make an acceptable choice, LCC analysis must be realized for two batteries given in the problem. By the use of inflation and interest rates, " $x$ " value is found as $x=0.9545$. Accordingly, the cost calculation results are given as outlined in Table 6. Despite containing

\begin{tabular}{|c|c|c|}
\hline Cost [\$] & Battery - 1 & Battery - 2 \\
\hline Initial & 1252 & 1224 \\
\hline $\begin{array}{l}\text { Pworth of } 10^{\text {th }} \text { year } \\
\text { replacement }\end{array}$ & 785.89 & \\
\hline $\begin{array}{l}\text { Pworth of } 15^{\text {th }} \text { year } \\
\text { replacement }\end{array}$ & & 608.72 \\
\hline $\begin{array}{l}\text { Pworth of } 20^{\text {th }} \text { year } \\
\text { replacement }\end{array}$ & 493.31 & \\
\hline TOTAL LCC & 2531.2 & 1832.72 \\
\hline
\end{tabular}
more connection, Battery-2 $(12 \mathrm{~V}, 102 \mathrm{Ah})$ should be preferred that is advantageous approximately $28 \%$ in terms of total LCC.

Table 6. LCCA of battery alternatives

Inverter power is calculated as approximately $400 \mathrm{~W}$ from equation (11). Current value of charge regulator is also determined as $15 \mathrm{~A}$ by the use of equation (12). After these stages, 
LCC calculation can be realized. For this, showing of all calculations in a table is a preferred way. In this study, Table 7 . has been established using the same method.

\begin{tabular}{|c|c|c|c|c|c|c|c|}
\hline \multirow{2}{*}{\multicolumn{2}{|c|}{ Component }} & \multicolumn{3}{|c|}{ AC - LOAD } & \multicolumn{3}{|c|}{ DC - LOAD } \\
\hline & & $\begin{array}{c}\text { Purchasing Cost } \\
{[\$]}\end{array}$ & $\begin{array}{c}\text { Present } \\
\text { Worth [\$] }\end{array}$ & $\begin{array}{l}\text { Per. of in the } \\
\text { LCC [\%] }\end{array}$ & $\begin{array}{l}\text { Purchasing } \\
\text { Cost }[\$]\end{array}$ & $\begin{array}{c}\text { Present } \\
\text { Worth [\$] }\end{array}$ & $\begin{array}{l}\text { Per. of in the } \\
\text { LCC [\%] }\end{array}$ \\
\hline \multicolumn{8}{|c|}{ Initial Investment Costs } \\
\hline \multicolumn{2}{|l|}{ Load } & 150 & 150 & 1.63 & 250 & 250 & 2.94 \\
\hline \multicolumn{2}{|l|}{ Module } & 3828 & 3828 & 41.6 & 3828 & 3828 & 45.1 \\
\hline \multicolumn{2}{|l|}{ Batteries } & 1224 & 1224 & 13.3 & 1224 & 1224 & 14.4 \\
\hline \multicolumn{2}{|c|}{ Charge Regulator } & 145 & 145 & 1.58 & 145 & 145 & 1.71 \\
\hline \multicolumn{2}{|l|}{ Inverter } & 500 & 500 & 5.44 & & & \\
\hline \multicolumn{2}{|l|}{ BOS } & 382.8 & 382.8 & 4.16 & 382.8 & 382.8 & 3.00 \\
\hline \multicolumn{2}{|l|}{ Montage } & 191.4 & 191.4 & 2.08 & 191.4 & 191.4 & 4.51 \\
\hline \multicolumn{3}{|c|}{ Total Initial Investment Costs } & 6421.2 & 69.85 & 6021.2 & 6021.2 & 71 \\
\hline \multicolumn{8}{|c|}{ Operating and Maintenance Costs } \\
\hline \multicolumn{2}{|c|}{$\begin{array}{l}\text { Yearly Operating\& } \\
\text { Maintenance Costs }\end{array}$} & 100 & 1542.92 & 16.78 & 100 & 1542.92 & 18.2 \\
\hline \multicolumn{8}{|c|}{ Replacement Costs } \\
\hline $5^{\text {th }}$ Year & Charge Reg. & 145 & 114.88 & 1.25 & 145 & 114.88 & 1.35 \\
\hline \multirow{3}{*}{$10^{\text {th }}$ year } & Load & & & & 250 & 156.93 & 1.85 \\
\hline & Inverter & 500 & 313.86 & 3.41 & & & \\
\hline & Charge Reg. & 145 & 91.02 & 0.99 & 145 & 91.02 & 1.07 \\
\hline \multirow{3}{*}{$15^{\text {th }}$ year } & Batteries & 1224 & 608.72 & 6.62 & 1224 & 608.72 & 7.17 \\
\hline & Load & 150 & 74.60 & 0.81 & & & \\
\hline & Charge Reg. & 145 & 72.11 & 0.78 & 145 & 72.11 & 0.97 \\
\hline \multirow{3}{*}{$20^{\text {th }}$ year } & Load & & & & 250 & 98.51 & 1.16 \\
\hline & Inverter & 500 & 197.01 & 2.14 & & & \\
\hline & Charge Reg. & 145 & 57.13 & 0.62 & 145 & 57.13 & 0.67 \\
\hline \multicolumn{2}{|c|}{ Total Replacement Costs } & \multicolumn{2}{|c|}{1529.33} & 16.64 & \multicolumn{2}{|c|}{1198.82} & 14.13 \\
\hline & Salvage Cost & \multicolumn{2}{|c|}{300.68} & 3.27 & \multicolumn{2}{|c|}{281.95} & 3.32 \\
\hline \multicolumn{3}{|c|}{ Life Cycle Cost (LCC) } & 9192.77 & 100.0 & \multicolumn{2}{|c|}{8481.5} & 100.0 \\
\hline
\end{tabular}

Table 7. LCC calculation details of two load alternatives

Looking at the LCC values obtained seems to be very close to each other. The difference between the two systems is below $10 \%$. In such a case, the design engineer may also decide which option is more appropriate by looking parameters other than cost. For instance, a load may be preferred that require fewer battery or module. Sometimes, because of market conditions in the country, availability or being domestic production may be preferred for a system. In this application, only the life cycle costs will be considered only. In this case, to choose the DC load is obviously necessary. If accepted, this selection is made; the unit cost of energy can be calculated. From equation (22), useful amounts of energy will be produced by the system is determined as $26137.65 \mathrm{kWh}$ in 25 years. Note that, it should also be considered in this calculation that system voltage is $24 \mathrm{VDC}$. By the substituting of this value in equation (23), ALCC is obtained as 934.4\$/year. (24) After the calculation of E value as $1045.5 \mathrm{kWh}$ /year from equation (24), unit energy cost $\left(\mathrm{C}_{\mathrm{E}}\right)$ can be determined using of the equation (25) as $0.894 \$ / \mathrm{kWh}$. 


\subsection{Sample application-2}

In this application, we calculate the system's capacity utilization rate selected in previous example. In addition, we determine the amount of produced excess energy and show the effect of consuming $5 \%, 15 \%, 25 \%$ and $35 \%$ of this excess energy on unit energy cost.

\subsubsection{Solution}

The amount of produced PV energy can be calculated for each month. PV panel consist of three parallel circuits with two modules in serial connection as calculated above. The current of each circuit is $10.84 \mathrm{~A}$. In this case, for instance, according to $\mathrm{T}_{\min }$ value is $4.3 \mathrm{~h}$ for the month of January, produced energy in this month can be calculated as $E_{\text {January }}=3^{*} 4.3^{*} 10.84^{*} 31=4334.92 \mathrm{Ah}$. Table 8 . is formed from similar calculations made for other months.

\begin{tabular}{|c|c|c|c|c|}
\hline Months & $\begin{array}{c}\text { Peak sun } \\
\text { hours [h/day] }\end{array}$ & $\begin{array}{l}\mathrm{I}_{\mathrm{PV}} \\
{[\mathrm{A}]}\end{array}$ & $\begin{array}{c}\text { EpV }_{\mathrm{PV}} \\
{[\mathrm{Ah} / \text { month] }}\end{array}$ & $\begin{array}{c}E_{\text {Load }} \\
{[\mathrm{Ah} / \text { day] }}\end{array}$ \\
\hline January & 4.3 & \multirow{12}{*}{32.52} & 4334.92 & 3699.85 \\
\hline February & 5.1 & & 4643.86 & 3341.8 \\
\hline March & 6.6 & & 6653.59 & 3699.85 \\
\hline April & 7.4 & & 7219.44 & 3580.5 \\
\hline May & 9.6 & & 9677.95 & 3699.85 \\
\hline June & 11.8 & & 11512.08 & 3580.5 \\
\hline July & 12.2 & & 12299.064 & 3699.85 \\
\hline August & 11.6 & & 11694.192 & 3699.85 \\
\hline September & 10 & & 9756 & 3580.5 \\
\hline October & 7.5 & & 7560.9 & 3699.85 \\
\hline November & 5.3 & & 5170.68 & 3580.5 \\
\hline December & 3.8 & & 3830.856 & 3699.85 \\
\hline \multicolumn{3}{|c|}{ Yearly Total [Ah/year] } & 94353.528 & 43562.75 \\
\hline \multicolumn{3}{|c|}{25 years TOTAL [Ah] } & 2358838.2 & 1089068.75 \\
\hline \multicolumn{3}{|c|}{ Capacity Utilization } & \multicolumn{2}{|c|}{$\% 46.17$} \\
\hline
\end{tabular}

Table 8. Produced energy and CU values of the system for each month

As shown in Table 8 . during the total life cycle (25 years), approximately $1270 \mathrm{kVAh}=30480 \mathrm{kWh}$ excess energy will be produced in case of feeding DC load only. Useful consumption of this amount in rates of given in the problem, then the following results are obtained.

$\begin{array}{lllll}5 \% \text { is consumed; } & \Rightarrow & \mathrm{E}=1106.44 \mathrm{kWh} / \text { year } & \Leftrightarrow & \mathrm{C}_{\mathrm{E}}=0.84 \$ / \mathrm{kWh} \\ 15 \% \text { is consumed; } & \Rightarrow & \mathrm{E}=1228.39 \mathrm{kWh} / \text { year } & \Leftrightarrow & \mathrm{C}_{\mathrm{E}}=0.76 \$ / \mathrm{kWh} \\ 25 \% \text { is consumed; } & \Rightarrow & \mathrm{E}=1350.3 \mathrm{kWh} / \text { year } & \Leftrightarrow & \mathrm{C}_{\mathrm{E}}=0.69 \$ / \mathrm{kWh} \\ 35 \% \text { is consumed; } & \Rightarrow & \mathrm{E}=1472.23 \mathrm{kWh} / \text { year } & \Leftrightarrow & C_{\mathrm{E}}=0.63 \$ / \mathrm{kWh}\end{array}$

Unit cost of energy has fallen by increasing of the capacity utilization.

\subsection{Sample application-3}

Let's calculate the amount of fuel consumption and its financial value and let's draw a cash flow diagram. Low heating value and unit price of diesel are given as $\mathrm{H}_{\text {diesel }}=10000 \mathrm{kcal} / \mathrm{kg}$ and $C_{\text {diesel }}=2000 \$ /$ ton. Efficiency of diesel power plant will be accepted as $35 \%$. 


\subsubsection{Solution}

First we calculate the amount of fuel saving with equation (19). LCC of the system assumed as $15 \%$ lower than actual value as mentioned under heading $4.4 \quad(25 \cdot 0.85=21$ year $)$. According to utility energy amount that will be produced by the PV panel is $26137.65 \mathrm{~kW}=26.14 \mathrm{MW}$, saving diesel fuel amount is calculated as

$$
\mathrm{M}_{\text {Diesel }}=\frac{1}{\mathrm{H}_{\text {Diesel }}}\left(\sum_{\mathrm{i}=1}^{\mathrm{t}} \frac{X \cdot Y_{\mathrm{i}}}{\eta_{\text {diesel }}}\right)=\frac{26.14 \cdot 1}{10000 \cdot 0.35} \cdot 21=2.184 \text { tonnes . }
$$

By dividing of this value to life of the system, annual saving amount is obtained as $103.8 \mathrm{~kg}$. In this case, present worth of saving can be calculated. For this, by the using of " $x$ " value that have already calculated before as $x=0.9545$, Table 9 is formed. Here, unit price of diesel $(2 \$ / \mathrm{kg})$ should be taken into account. Although, purchasing cost of diesel in first year is $2 \cdot 103.8=207.6 \$$, calculation should start from $5^{\text {th }}$ year.

\begin{tabular}{|l|l|l|l|c|c|c|c|c|c|c|c|c|c|c|c|c|c|c|c|c|c|c|c|c|c|c|}
\hline Years & 1 & 2 & 3 & 4 & 5 & 6 & 7 & 8 & 9 & 10 & 11 & 12 & 13 & 14 & 15 & 16 & 17 & 18 & 19 & 20 & 21 & 22 & 23 & 24 & 25 & Total \\
\hline $\mathbf{M}_{\text {diesel }}[\mathbf{k g}]$ & & & 103.8 & 103.8 & 103.8 & 103.8 & 103.8 & 103.8 & 103.8 & 103.8 & 103.8 & 103.8 & 103.8 & 103.8 & 103.8 & 103.8 & 103.8 & 103.8 & 103.8 & 103.8 & 103.8 & 103.8 & 103.8 & 2179.8 \\
\hline $\left.\mathbf{C}_{\text {diesel }} \mathbf{\$} / \mathbf{k g}\right]$
\end{tabular}

Table 9. LCC analysis of fuel savings

Here, the calculated value of $\$ 2255.1$ in the amount of savings is the only measurable benefit. It does not include the environment and human health benefits. Even considering of this value only, the calculated value of LCC in example- 1 decreases to the $6226.4 \$$. Finally, annual LCC and unit energy cost are calculated as $685.95 \$ / \mathrm{kWh}$ and $0.656 \$ / \mathrm{kWh}$ respectively. As a result of these calculations, cash flow diagram is also seen in Fig. 10.

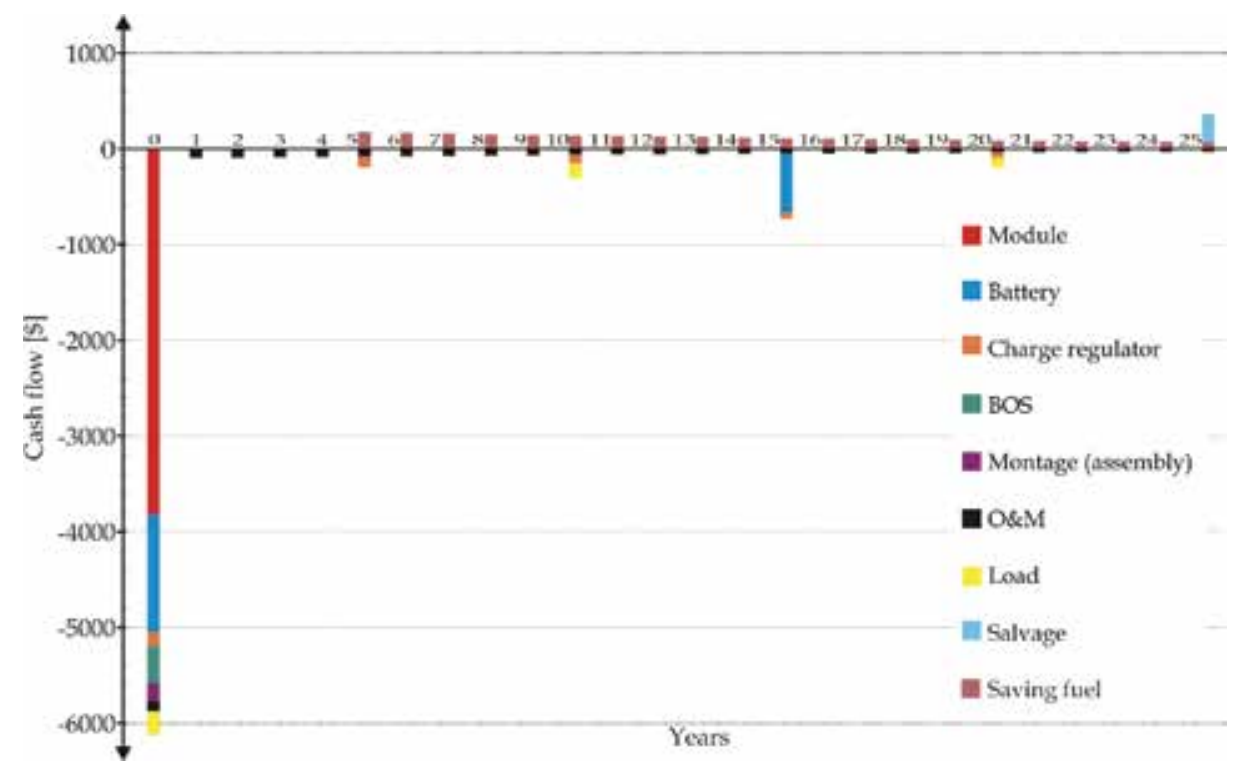

Fig. 10. Cash flow diagram of PV system with DC load 


\section{Conclusions}

In this chapter, it has been supported by the results of various researches that PV systems should take place within the sustainable energy policies. This is an accepted fact by international energy agencies that PV systems will have an important share in the second half of $21^{\text {st }}$ century especially.

In today's economic conditions, cost is the most disadvantaged sustainability parameter of PV systems. This negativity can be reduced by taking into account the external benefits in cost calculations. In this chapter, PV system design processes are described in detail. All necessary parameters are also defined to make an accurate LCC calculation. In addition, the impacts of capacity utilization and fossil fuel savings on the LCC are discussed and methods of calculating these values are added to the topics.

Other important disadvantage of PV system in terms of sustainability is power quality depending on the reliability problems. Both high cost and short life span of batteries used to reduce the reliability problems are emerging as negative barriers. Low efficiencies of commercial PV modules (between $12 \%$ and $20 \%$ ) are also an important technical drawback. Depending on technological developments on these issues, the share of PV system in electrical energy production will increase substantially.

\section{References}

Abdeen, M. O. (2008). Energy, environment and sustainable development. Renewable and Sustainable Energy Reviews, Vol.12, No.9, (December 2008), 2265-2300, ISSN: 13640321.

Able-Thomas, U. \& Hill, R. (1996). Techno-economic comparison of PV and diesel systems for telecommunications and aviation navigational aids, Proccedings of $25^{\text {th }}$ Photovoltaic Specialists Conference, pp.1481-1484, ISBN: 0-7803-3166-4, May 1996, Washington, D.C.

Amit, J.; Tripathy, S. C. \& Balasubramanian, R. (1995). Reliability and economic analysis of a power generation system including a photovoltaic system. Energy Conversion and Management, Vol.36, No.3, (March 1995), 183-189, ISSN: 0196-8904.

Azzopardi, B. \& Mutale, J. (2010). Life cycle analysis for future photovoltaic systems using hybrid solar cells. Renewable and Sustainable Energy Reviews, Vol.14, No.3, (April 2010), 1130-1134, ISSN: 1364-0321.

Barringer, H. P. \& Barringer, P. E. (2003). A Life Cycle Cost Summary, Maintenance Engineering Society of Australia, a Technical Society of the Institution of Engineers, Australia.

Belfkira, R.; Nichita, C.; Reghem, P., \& Barakat, C. (2008). Modeling and optimal sizing of hybrid renewable energy system, Proceedings of Power Electronics and Motion Control Conference, pp.1834-1839, ISBN: 978-1-4244-1741-4, Poznan, September 2008, Univ. of Le Havre, Le Havre.

Chaar, L. (2006). Solar power conversion, In: Power Electronics Handbook, Muhammad H. Rashid, (Ed.), 661-672, Academic Press, ISBN: 0120884798, USA. 
Chel, A.; Tiwari, G. N. \& Chandra, A. (2009) Simplified method of sizing and life cycle cost assessment of building integrated photovoltaic system. Energy and Buildings, Vol.41, No.11, (November 2009), 1172-1180, ISSN: 0378-7788.

Deshmukh, M. K. \& Deshmukh, S. S. (2008). Modeling of hybrid renewable energy systems, Renewable and Sustainable Energy Reviews, Vol.12, No.1, (January 2008), 235-249, ISSN: 1364-0321.

Du, L.; Wang, Z.; Huang, H. Z.; Lu, C. \& Miao, Q. (2009). Life cycle cost Analysis for design optimization under uncertainty, Proceedings of International Conference on Reliability, Maintainability and Safety, pp.54-57, ISBN: 978-1-4244-4903-3, Chengdu, July 2009, China.

Eltawil, M. A. \& Zhao, Z. (2010). Grid-connected photovoltaic power systems: Technical and potential problems-A review. Renewable and Sustainable Energy Reviews, Vol.14, No.1, (January 2010), 112-129, ISSN: 1364-0321.

Energy Information Administration (EIA), (2007). Electric Power AnnualReport 2007, pp.16-17, USA.

Ersoz, S. \& Onat, N. (2010). Effects of Turkey's solar energy potential distribution on PV system costs, Proceedings of $5^{\text {th }}$ International Ege Energy Symposium and Exhibition, Denizli, June 2010, Turkey.

Evans, A.; Strezov, V. \& Evans, T. J. (2009). Assessment of sustainability indicators for renewable energy technologies. Renewable and Sustainable Energy Reviews, Vol.13, No.5, (June 2009),1082-1088, ISSN: 1364-0321.

Fthenakis, V. \& Kim H. C. (2009). Land use and electricity generation: A life-cycle analysis. Renewable and Sustainable Energy Reviews, Vol.13, No.6-7, (August-September 2009), 1465-1474, ISSN: 1364-0321.

Green, M. A. (2005). Silicon photovoltaic modules: A brief history of the first 50 years. Progress in Photovoltaics: Research and Applications, Vol.13, No.5, (April 2005), 447455, ISSN: 1062-7995.

Gregg, A.; Parker, T. \& Swenson, R. (2005). A "real world" examination of PV system design and performance, Proceedings of Photovoltaic Specialists Conference, pp.1587-1592, ISBN: 0-7803-8707-4, January 2005, USA.

International Energy Agency (IEA). (2010). Photovoltaic Power Systems Programme Available: http:/ / www.iea-pvps.org/, access date: June 2010.

Jeromin, I.; Balzer, G.; Backes, J. \& Huber, R. (2009). Life cycle cost analysis of transmission and distribution systems, Proceedings of IEEE PowerTech 2009 Conference, pp.1-6, ISBN: 978-1-4244-2234-0, Bucharest, June 2009, Romania.

Jossen, A.; Garche, J. \& Sauer, D. U. (2004). Operation conditions of batteries in PV applications. Solar Energy, Vol.76, No.6, 759-769, ISSN: 0038-092X.

Kaygusuz, K. (2009). Environmental impacts of the solar energy systems. Energy Sources, Part A: Recovery, Utilization, and Environmental Effects, Vol.31, No.15, (January 2009), 1376-1386, ISSN: 1556-7230.

Kolhe, M.; Kolhe, S. \& Joshi, S. C. (2002). Economic viability of stand-alone solar photovoltaic system in comparison with diesel-powered system for India. Energy Economics, Vol.24, No.2, (March 2002), 155-165, ISSN: 0140-9883. 
Manna, T. K. \& Mahajan, S. M. (2007) Nanotechnology in the development of photovoltaic cells, Proceedings of International Conference on Clean Electrical Power ICCEP'07, pp.379-386, ISBN: 1-4244-0632-3, Capri, May 2007, Tennessee Tech Univ., Cookeville.

Mearig, T.; Coffee, N. \& Morgan, M. (1999). Life Cycle Cost Analysis Handbook, State of Alaska Department of Education \& Early Development, Education Support Services/Facilities, 1st Edition, Juneau, Alaska.

Meier, P. J. (2002). Life Cycle Assessment of Electricity Generation Systems and Applications for Climate Change Policy Analysis, Publication of Fusion Technology Institute University of Wisconsin; UWFDM-1181, Madison Wisconsin.

Messenger, R. A. \& Ventre, J. (2000). Photovoltaic System Engineering, CRC Press LLC, Boca Raton, Florida, USA.

Official Gazette of Turkish Republic. (2005). Number: 25819, 18 May 2005, Ankara, Turkey.

Official web site of General Directorate of Turkish Electrical Power Resources Survey and Development Administration (2009). http:/ / www.eie.gov.tr.

Onat, N.; Kiyak, I. \& Gokmen, G. (2009). Experimental wavelet transient-state analysis of electrical machines directly feeding by photovoltaic cells. WSEAS Transactions on Circuits and Systems, Vol.8, No.8, (August 2009), 719-728, ISSN: 1109-2734.

Preiser, K. (2003). Photovoltaic systems, In: Handbook of Photovoltaic Science and Engineering, Antonio Luque, Steven Hegedus, (Ed.), 753-798, John Wiley \& Sons Ltd, ISBN: 0471-49196-9, England.

Ren, H.; Gao, W., \& Ruan, Y. (2009). Economic optimization and sensitivity analysis of photovoltaic system in residential buildings. Renewable Energy, Vol.34, No.3, (March 2009), 883-889, ISSN: 0960-1481.

Sen, Z. (2004). Solar energy in progress and future research trends. Progress in Energy and Combustion Science, Vol.30, 367-416, ISSN: 0360-1285.

Sovacool, B. K. (2009). Rejecting renewables: The socio-technical impediments to renewable electricity in the United States. Energy Policy, Vol.37, No.11 (November 2009), 45004513, ISSN: 0301-4215.

Stoppato, A. (2008). Life cycle assessment of photovoltaic electricity generation. Energy, Vol.33, No.2, (February 2008), 224-232, ISSN: 0360-5442.

Varun, N.; Prakash, R. \& Bhat, I. K. (2009). Energy, economics and environmental impacts of renewable energy systems. Renewable and Sustainable Energy Reviews, Vol.13, No.9, (December 2009), 2716-2721, ISSN: 1364-0321.

Whisnant, R. A.; Johnston, S. A. \& Hutchby, J. H. (2002). Economic analysis and environmental aspects of photovoltaic systems, In: Handbook of Photovoltaic Science and Engineering, Antonio Luque, Steven Hegedus, (Ed.), 971-1003, John Wiley \& Sons Ltd, ISBN: 0-471-49196-9, England.

Winkler, H.; Hughes, A. \& Haw, M. (2009). Technology learning for renewable energy: Implications for South Africa's long-term mitigation scenarios. Energy Policy, Vol.37, No.11, (November 2009), 4987-4996, ISSN: 0301-4215.

World Energy Council (WEC), (2004). Renewable Energy Projects Handbook, ISBN: 0-94612112-15, London. 
World Energy Council (WEC), (2004). Energy End-Use Technologies for the 21st Century, ISBN: 0-946121-10-90-946121-15-X, London.

World Energy Council (WEC), (2007). “2007 Survey of Energy Resources, Chapter:10, Solar Energy, 381-382, ISBN: 0-946121-26-5, London. 


\title{
Wind Energy
}

\author{
Chaouki Ghenai and Armen Sargsyan \\ Ocean and Mechanical Engineering Department, \\ College of Engineering and Computer Science, Florida Atlantic University \\ Boca Raton, Florida, \\ U.S.A.
}

\section{Introduction}

\subsection{Sustainable energy systems}

Sustainable energy is to provide the energy that meets the needs of the present without compromising the ability of future generations to meet their needs. Sustainable energy has two components: renewable energy and energy efficiency. Renewable energy uses renewable sources such biomass, wind, sun, waves, tides and geothermal heat. Renewable energy systems include wind power, solar power, wave power, geothermal power, tidal power and biomass based power. Renewable energy sources, such as wind, ocean waves, solar flux and biomass, offer emissions-free production of electricity and heat. For example, geothermal energy is heat from within the earth. The heat can be recovered as steam or hot water and use it to heat buildings or generate electricity. The solar energy can be converted into other forms of energy such as heat and electricity and wind energy is mainly used to generate electricity. Biomass is organic material made from plants and animals. Burning biomass is not the only way to release its energy. Biomass can be converted to other useable forms of energy, such as methane gas or transportation fuels, such as ethanol and biodiesel (clean alternative fuels).

In addition to renewable energy, sustainable energy systems also include technologies that improve energy efficiency of systems using traditional non renewable sources. Improving the efficiency of energy systems or developing cleaner and efficient energy systems will slow down the energy demand growth, make deep cut in fossil fuel use and reduce the pollutant emissions. For examples, advanced fossil-fuel technologies could significantly reduce the amount of $\mathrm{CO} 2$ emitted by increasing the efficiency with which fuels are converted to electricity. Options for coal include integrated gasification combined cycle (IGCC) technology, ultra-supercritical steam cycles and pressurized fluidized bed combustion. For the transportation sector, dramatic reductions in $\mathrm{CO} 2$ emissions from transport can be achieved by using available and emerging energy-saving vehicle technologies and switching to alternative fuels such as biofuels (biodiesel, ethanol). For industrial applications, making greater use of waste heat, generating electricity on-site, and putting in place more efficient processes and equipment could minimize external energy demands from industry. Advanced process control and greater reliance on biomass and biotechnologies for producing fuels, chemicals and plastics could further reduce energy use and $\mathrm{CO} 2$ emissions. Energy use in residential and commercial buildings can be substantially 
reduced with integrated building design. Insulation, new lighting technology and efficient equipment are some of the measures that can be used to cut both energy losses and heating and cooling needs. Solar technology, on-site generation of heat and power, and computerized energy management systems within and among buildings could offer further reductions in energy use and $\mathrm{CO} 2$ emissions for residential and commercial buildings.

The development of cleaner and efficient energy technologies and the use of new and renewable energy sources will play an important role in the sustainable development of a future energy strategy. The promotion of renewable sources of energy such as wind energy and the development of cleaner and more efficient energy systems are a high priority, for security and diversification of energy supply, environmental protection, and social and economic cohesion (International Energy Agency, 2006).

\subsection{History about wind energy}

The use of wind as an energy source begins in antiquity. Mankind was using the wind energy for sailing ships and grinding grain or pumping water. Windmills appear in Europe back in $12^{\text {th }}$ century. Between the end of nineteenth and beginning of twentieth century, first electricity generation was carried out by windmills with $12 \mathrm{KW}$. Horizontal-axis windmills were an integral part of the rural economy, but it fell into disuse with the advent of cheap fossil-fuelled engines and then the wide spread of rural electrification. However, in twentieth century there was an interest in using wind energy once electricity grids became available. In 1941, Smith-Putnam wind turbine with power of $1.25 \mathrm{MW}$ was constructed in USA. This remarkable machine had a rotor $53 \mathrm{~m}$ in diameter, full-span pitch control and flapping blades to reduce the loads. Although a blade spar failed catastrophically in 1945, it remains the largest wind turbine constructed for some 40 years (Acker and Hand, 1999). International oil crisis in 1973 lead to re-utilization of renewable energy resources in the large scale and wind power was among others. The sudden increase in price of oil stimulated a number of substantial government-funded programs of research, development and demonstration. In 1987, a wind turbine with a rotor diameter of $97.5 \mathrm{~m}$ with a power of 2.5MW was constructed in USA. However, it has to be noted that the problems of operating very large wind turbines, in difficult wind climates were underestimated. With considerable state support, many private companies were constructing much smaller wind turbines for commercial sales. In particular, California in the mid-1980's resulted in the installation of very large number of quite small (less than $100 \mathrm{KW}$ ) wind turbines. Being smaller they were generally easy to operate and also repair or modify. The use of wind energy was stimulated in 1973 by the increase of price of fossil-fuel and of course, the main driver of wind turbines was to generate electrical power with very low $\mathrm{CO}_{2}$ emissions to help limit the climate change. In 1997 the Commission of the European Union was calling for 12 percent of the gross energy demand of the European Union to be contributed from renewable by 2010. In the last 25 years the global wind energy had been increasing drastically and at the end of 2009 total world wind capacity reached 159,213 MW as shown in Figure 1. Wind power showed a growth rate of $31.7 \%$, the highest rate since 2001. The trend continued that wind capacity doubles every three years. The wind sector employed 550,000 persons worldwide. In the year 2012, the wind industry is expected for the first time to offer 1 million jobs. The USA maintained its number one position in terms of total installed capacity and China became number two in total capacity, only slightly ahead of Germany, both of them with around 26,000 Megawatt of wind capacity installed. Asia accounted for the largest share of 
new installations (40.4\%), followed by North America (28.4 \%) and Europe fell back to the third place (27.3\%). Latin America showed encouraging growth and more than doubled its installations, mainly due to Brazil and Mexico. A total wind capacity of 203,000 Megawatt will be exceeded within the year 2010. Based on accelerated development and further improved policies, world wide energy association WWEA increases its predictions and sees a global capacity of 1,900,000 Megawatt as possible by the year 2020 (World Wide Energy Association report, 2009). The world's primary energy needs are projected to grow by $56 \%$ between 2005 and 2030, by an average annual rate of 1.8\% per year (European Wind Energy Agency, 2006).

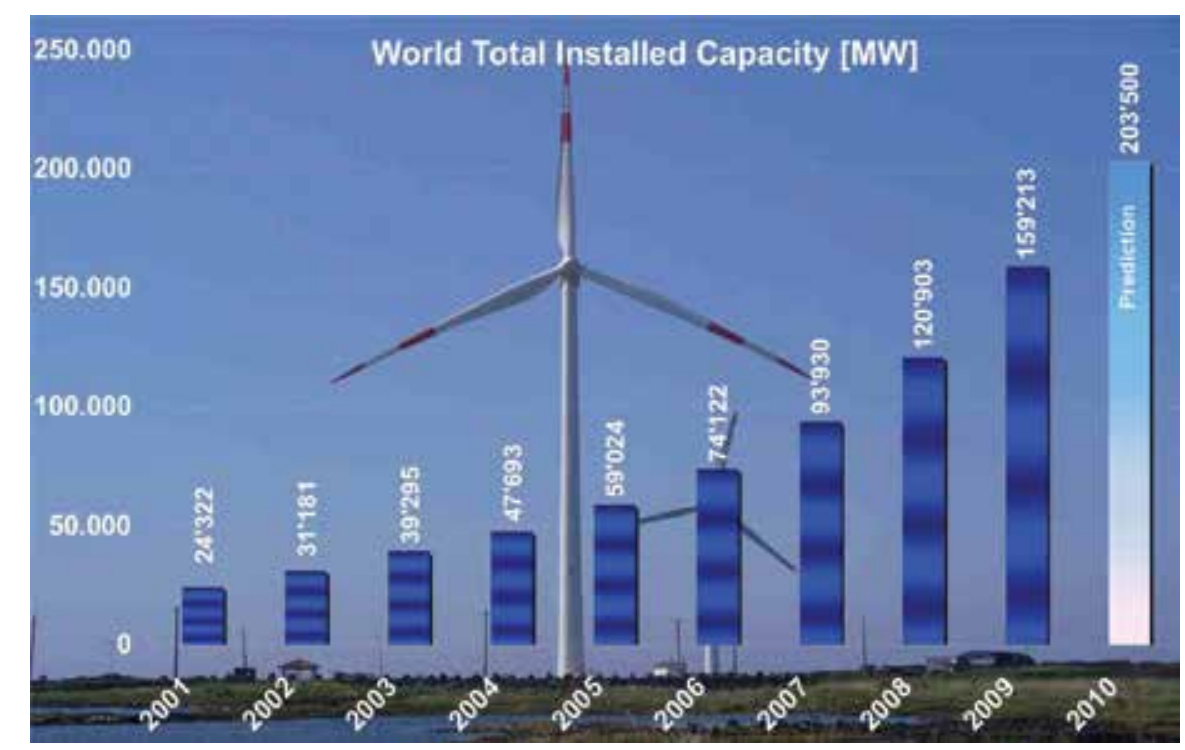

Fig. 1. World total installed capacity by the end of 2009 - Data source: wwea.org

\subsection{Fundamental concepts of wind turbine systems 1.3.1 Type of wind turbines}

A wind turbine is a rotary device that extracts the energy from the wind. The mechanical energy from the wind turbine is converted to electricity (wind turbine generator). The wind turbine can rotate through a horizontal (horizontal axis wind turbine - HAWT) or vertical (VAWT) axis (See Figure 2). Most of the modern wind turbines fall in these two basic groups: HAWT and VAWT. For the HAWT, the position of the turbine can be either upwind or downwind. For the horizontal upwind turbine, the wind hits the turbine blade before it hits the tower. For the horizontal downwind turbine, the wind hits the tower first (See Figure 2). The basic advantages of the vertical axis wind turbine are (1) the generator and gear box can be placed on the ground and (2) no need of a tower. The disadvantages of the VAWT are: (1) the wind speeds are very low close to ground level, so although you may save a tower, the wind speeds will be very low on the lower part of the rotor, and (2) the overall efficiency of the vertical axis wind turbine is not impressive (Burton et al., 2001). 


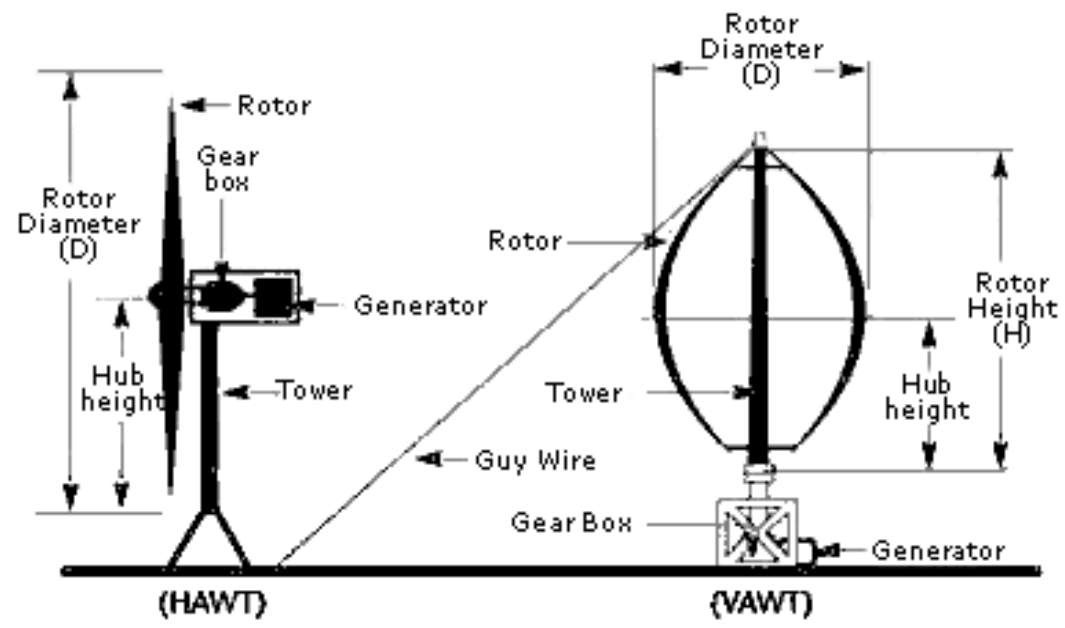

Fig. 2. Horizontal and vertical wind turbines

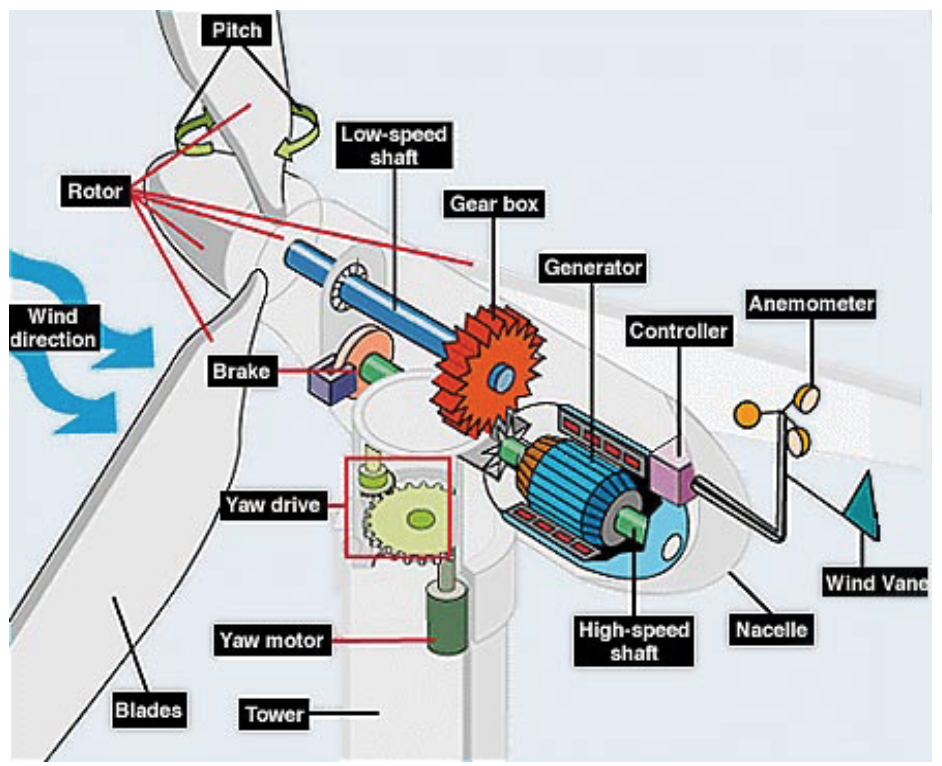

Fig. 3. Wind turbine parts

\subsubsection{Wind turbine parts}

The main parts of a wind turbine parts (see Figure 3) are:

- Blades: or airfoil designed to capture the energy from the strong and fast wind. The blades are lightweight, durable and corrosion-resistant material. The best materials are composites of fiberglass and reinforced plastic.

- Rotor: designed to capture the maximum surface area of wind. The rotor rotates the generator through the low speed shaft and gear box.

- Gear Box: A gear box magnifies or amplifies the energy output of the rotor. The gear box is situated directly between the rotor and the generator. 
- Generator: The generator is used to produce electricity from the rotation of the rotor. Generators come in various sizes, relative to the desired power output.

- Nacelle: The nacelle is an enclosure that seals and protects the generator and gear box from the other elements.

- Tower: The tower of the wind turbine carries the nacelle and the rotor. The towers for large wind turbines may be either tubular steel towers, lattice towers, or concrete towers. The higher the wind tower, the better the wind. Winds closer to the ground are not only slower, they are also more turbulent. Higher winds are not corrupted by obstructions on the ground and they are also steadier.

\subsubsection{Wind turbine design}

During the design of wind turbines, the strength, the dynamic behavior, and the fatigue properties of the materials and the entire assembly need to be taken into consideration. The wind turbines are built to catch the wind's kinetic energy. Modern wind turbines are not build with a lot of rotor blades. Turbines with many blades or very wide blades will be subject to very large forces, when the wind blows at high speed. The energy content of the wind varies with the third power of the wind speed. The wind turbines are build to withstand extreme winds. To limit the influence of the extreme winds and to let the turbines rotates relativelly quickly it is generarlly prefer to build turbines with a few, long, narrow blades.

- Fatigue Loads (forces): If the wind turbines are located in a very turbulent wind climate, they are subject to fluctuating winds and hence fluctuating forces. The components of the wind tubrine such as rotor blades with repeated bending may develop cracks which ultimately may make the component break. When designing a wind turbine it is important to calculate in advance how the different components will vibrate, both individually, and jointly. It is also important to calculate the forces involved in each bending or stretching of a component (structural dynamics).

- Upwind/Downwind wind turbines designs: The upwind wind turbines have the rotor facing the wind. The basic advantage of upwind designs is that one avoids the wind shade behind the tower. By far the vast majority of wind turbines have this design. The downwind wind turbines have the rotor placed on the lee side of the tower.

- Number of blades: Most modern wind turbines are three-bladed designs with the rotor position maintained upwind using electrical motors in their yaw mechanism. The vast majority of the turbines sold in world markets have this design. The two-bladed wind turbine designs have the advantage of saving the cost of one rotor blade and its weight. However, they tend to have difficulty in penetrating the market, partly because they require higher rotational speed to yield the same energy output.

- Mechanical and aerodynamics noise: sound emissions from wind turbines may have two different origins: Mechanical noise and aerodynamic noise. The mechanical noise originates from metal components moving or knocking against each other may originate in the gearbox, in the drive train (the shafts), and in the generator of a wind turbine. Sound insulation can be useful to minimise some medium- and high-frequency noise. In general, it is important to reduce the noise problems at the source, in the structure of the machine itself. The source of the aerodynamic sound emission is when the wind hits different objects at a certain speed, it will generally start making a sound. For example, rotor blades make a slight swishing sound at relatively low wind speeds. 
Careful design of trailing edges and very careful handling of rotor blades while they are mounted, have become routine practice in the industry.

\subsubsection{Wind turbine power}

The Wind turbines work by converting the kinetic energy in the wind first into rotational kinetic energy in the turbine and then electrical energy. The wind power available for conversion mainly depends on the wind speed and the swept area of the turbine (see Figure 4):

$$
P_{W}=\frac{1}{2} \rho A V^{3}
$$

Where $\rho$ is the air density $\left(\mathrm{Kg} / \mathrm{m}^{3}\right)$, A is the swept area $\left(\mathrm{m}^{2}\right)$ and $V$ the wind speed $(\mathrm{m} / \mathrm{s})$.

Albert Betz (German physicist) concluded in 1919 that no wind turbine can convert more than 16/27 (59.3\%) of the kinetic energy of the wind into mechanical energy turning a rotor (Betz Limit or Betz). The theoretical maximum power efficiency of any design of wind turbine is 0.59 (Hau, 2000 and Hartwanger and Horvat, 2008). No more than $59 \%$ of the energy carried by the wind can be extracted by a wind turbine. The wind turbines cannot operate at this maximum limit. The power coefficient $C_{p}$ needs to be factored in equation (1) and the extractable power from the wind is given by:

$$
P=\frac{1}{2} C_{P} \rho A V^{3}
$$

Example: Given the following data: Blade length $1=52 \mathrm{~m}$, wind speed, $\mathrm{V}=12 \mathrm{~m} / \mathrm{s}$, air density $\rho=1.23 \mathrm{Kg} / \mathrm{m}^{3}$ and power coefficient $C_{P}=0.4$. Calculate the power converted from the wind into rotational energy in the turbine?

The swept area $\mathrm{A}=\pi \mathrm{r}^{2}=\pi \mathrm{l}^{2}=3.14 * 52^{2}=8495 \mathrm{~m}^{2}$

The available power $\mathrm{P}=1 / 2 \mathrm{C}_{\mathrm{P}} \rho \mathrm{A} \mathrm{V} \mathrm{V}^{3}=1 / 2 \times 1.23 \times 8495 \times 12^{3} \times 0.4=3.6 \mathrm{MW}$

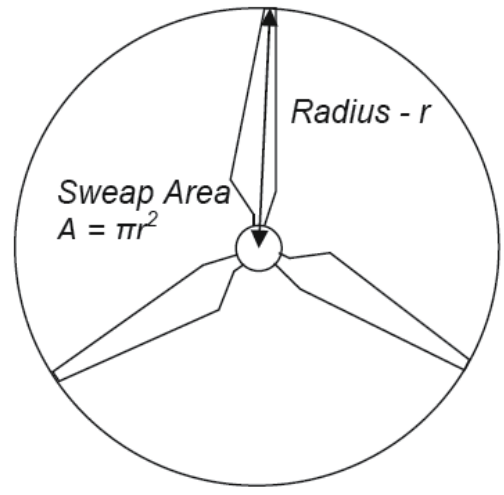

Fig. 4. Swept area of the wind turbine

\subsubsection{Power coefficient $\mathrm{Cp}$}

The $\mathrm{Cp}$ value is unique to each turbine type and is a function of wind speed that the turbine is operating in. In real world, the value of $C_{p}$ is well below the Betz limit (0.59) with values of $0.35-0.45$ for the best designed wind turbines. If we take into account the other factors in 
a complete wind turbine system (gearbox, bearings, generator), only $10-30 \%$ of the power of the wind is actually converted into usable electricity. The power coefficient $C_{p}$, defined as that the power extracted by rotor to power available in the wind is given by:

$$
C_{p}=\frac{P}{\frac{1}{2} \rho A V^{3}}=\frac{\text { Power Extracted by Rotor }}{\text { Power Available in the Wind }}
$$

The power coefficient $C_{P}$, defined as extracted power over the total available power can be similarly defined in terms of axial induction factor $a$ (Hansen, 2000 and Hartwanger and Horvat, 2008) as:

$$
C_{p}=4 a(1-a)^{2}
$$

The axial induction factor $\mathrm{a}$ is the fractional decrease in wind velocity between the free stream (Position 1) and rotor plane (Position 2) as shown in Figure 5. The axial induction factor can be expressed as:
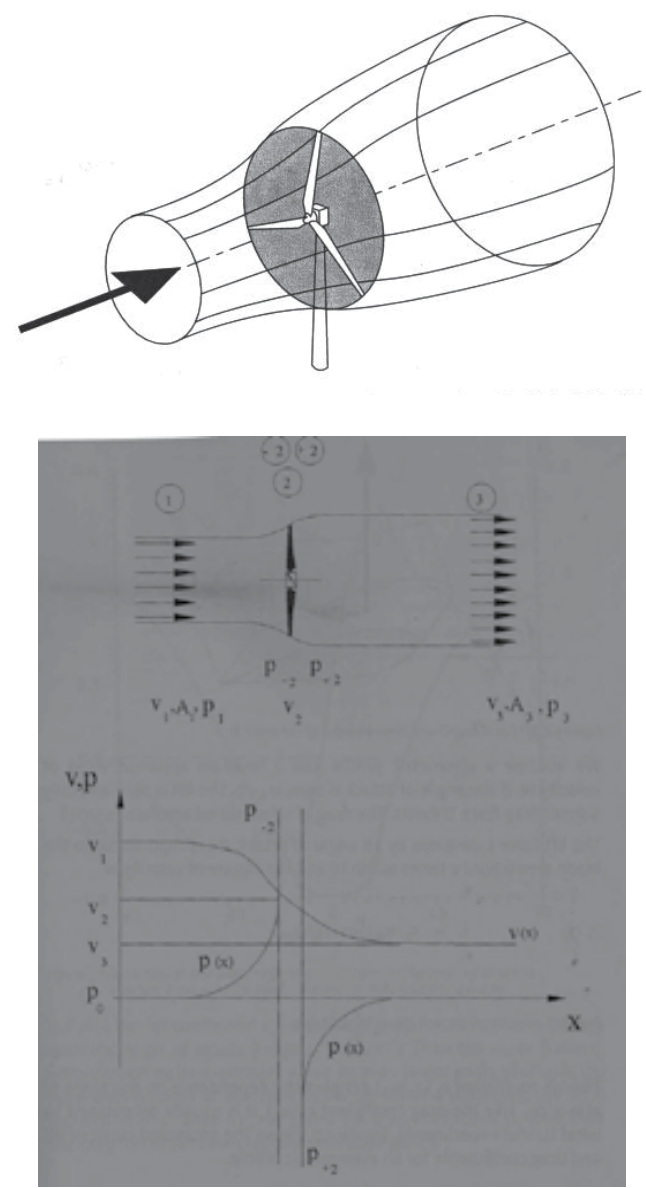

Fig. 5. Velocity and pressure distribution 


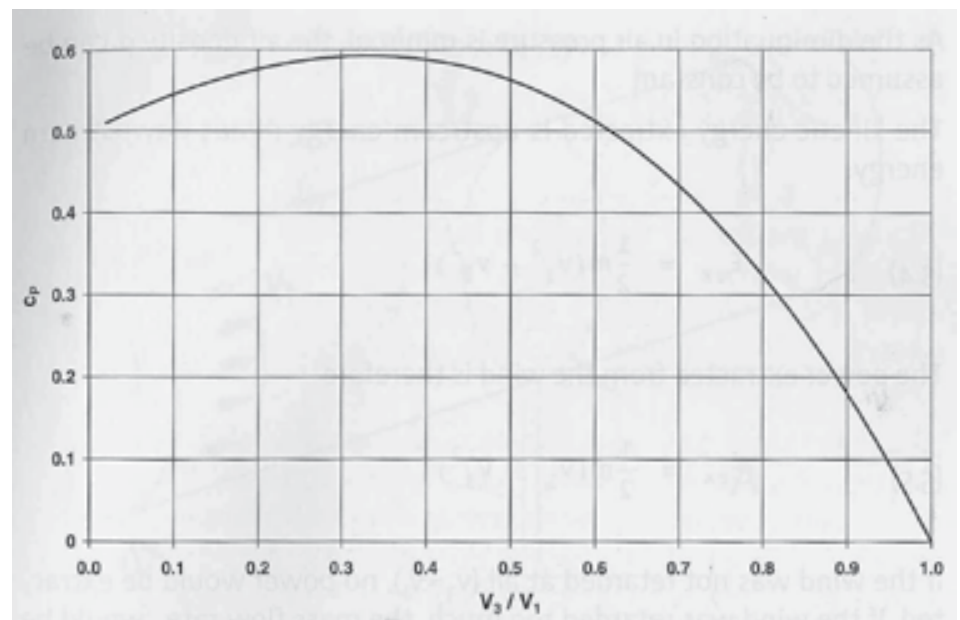

Fig. 6. Power coefficients $\mathrm{Cp}$ versus V3/V1 ratio

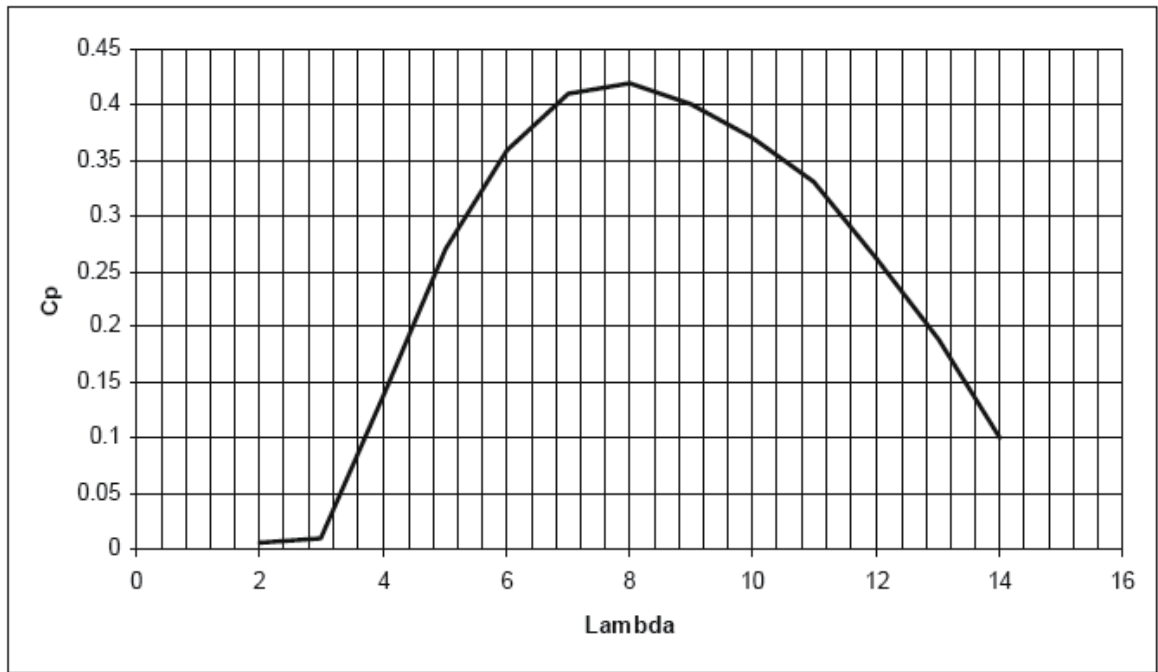

Fig. 7. Power coefficient $\mathrm{Cp}$ curve versus $\lambda$

$$
a=\frac{V_{1}-V}{V_{1}}
$$

The velcoity $\mathrm{V}$ is defined by:

$$
V=\frac{1}{2}\left(V_{1}+V_{3}\right)
$$

The variation of the power coefficient $C_{P}$ versus the velocity ration V3/V1 is shown in Figure 6 . The power coefficient $C_{P}$ is not a static value. It varies with the tip speed ratio of the turbine (TSR or $\lambda$ ) as shown in Figure 7. The tip speed ratio is defined by ratio between the tip speed (tangential velocity) and the undisturbed wind speed $V_{1}$ entering the turbine: 


$$
\lambda=\frac{\Omega r}{V_{1}}
$$

Where $\Omega$ is the rotational speed of the turbine and $\mathrm{r}$ is the length of the blade. The variation of the power coefficient $C_{P}$ versus the tip speed ratio is shown in Figure 6.

\subsubsection{Torque}

The wind turbines extract power from the wind in mechanical form and transmit it to the load by rotating shafts. The shaft must be properly designed to transmit this power. When power is being transmitted through a shaft, a torque $T(\mathrm{~N} . \mathrm{m} / \mathrm{rad})$ will be present. This torque is given by:

$$
T=\frac{P}{\Omega}
$$

$\mathrm{P}$ is the mechanical power and $\Omega$ is the rotational speed or the turbine or the angular velocity $(\mathrm{rad} / \mathrm{s})$.

\subsection{Characteristics of wind: wind power density, wind shear and turbulence}

Wind resource evaluation is a critical element in projecting turbine performance at a given site. The energy available in a wind stream is proportional to the cube of its speed, which means that doubling the wind speed increases the available energy by a factor of eight. With a wind speed of 8 meters per second we get a power (amount of energy per second) of 314 Watts per square meter exposed to the wind (the wind is coming from a direction perpendicular to the swept rotor area). At $16 \mathrm{~m} / \mathrm{s}$ we get eight times as much power, i.e. $2509 \mathrm{~W} / \mathrm{m}^{2}$. Further more the wind speed also varies with the time of day, season, height above ground, and type of terrain. Proper sitting in windy locations, away from large obstructions, enhances a wind turbine's performance. In general, annual average wind speeds of 5 meters per second (11 miles per hour) are required for grid-connected applications. Annual average wind speeds of 3 to $4 \mathrm{~m} / \mathrm{s}$ (7-9 $\mathrm{mph}$ ) may be adequate for nonconnected electrical and mechanical applications such as battery charging and water pumping. Wind resources exceeding this speed are available in many parts of the world. The Wind Power Density (WPD) is a useful way to evaluate the wind resource available at a potential site. The wind power density, measured in watts per square meter, indicates how much energy is available at the site for conversion by a wind turbine. Classes of wind power density for two standard wind measurement heights are listed in the Table 1 below. Wind speed generally increases with height above ground. In general, sites with a wind power class rating of 4 or higher are now preferred for large scale wind turbines.

The wind shear is the sudden, drastic change in wind direction or speed over a comparatively short distance. Most winds travel horizontally, as does most wind shear, but under certain conditions, including thunderstorms and strong frontal systems, wind shear will travel in a vertical direction. With its sharp shifts in wind direction and relative wind speed, it can cause a reduction of wind turbine performance and may also cause damage to the wind turbine blades. The wind turbine must never be located such that it is subject to excessively wind shear and turbulent air flow. Light turbulence will decrease performance since a turbine cannot react to rapid changes in wind direction, while heavy turbulence may 
reduce expected equipment life or result in wind turbine failure. Turbulence may be avoided by following a few basic rules: (1) the wind turbine should be mounted on a cleared site free from minor obstructions such as trees and buildings and (2) If it is not possible to avoid obstructions, tower height should be increased to a value of approximately 9 meters greater than the height of obstructions, and (3) A good "rule of thumb" is to locate the turbine at a minimum height of three times that of the tallest upwind barrier.

\begin{tabular}{|c|c|c|c|c|}
\cline { 2 - 5 } \multicolumn{1}{c|}{} & \multicolumn{2}{c|}{10 meters } & \multicolumn{2}{c|}{50 meters } \\
\hline $\begin{array}{c}\text { Wind Power } \\
\text { class }\end{array}$ & $\begin{array}{c}\text { Wind power } \\
\text { density }\left(\mathrm{W} / \mathrm{m}^{2}\right)\end{array}$ & Speed $(\mathrm{m} / \mathrm{s})$ & $\begin{array}{c}\text { Wind power } \\
\text { density }\left(\mathrm{W} / \mathrm{m}^{2}\right.\end{array}$ & Speed (m/s) \\
\hline 1 & $<100$ & $<4.4$ & $<200$ & $<5.6$ \\
\hline 2 & $100-150$ & $4.4-5.1$ & $200-300$ & $5.6-6.4$ \\
\hline 3 & $150-200$ & $5.1-5.6$ & $300-400$ & $6.4-7.0$ \\
\hline 4 & $200-250$ & $5.6-6.0$ & $400-500$ & $7.0-7.5$ \\
\hline 5 & $250-300$ & $6.0-6.4$ & $500-600$ & $7.5-8.0$ \\
\hline 6 & $300-400$ & $6.4-7.0$ & $600-800$ & $8.0-8.8$ \\
\hline 7 & $>400$ & $>7.0$ & $>800$ & $>8.8$ \\
\hline
\end{tabular}

Table 1. Classes of wind power density at two different wind measurements heights

\subsection{Aerodynamics, flow structure in wind turbine wake and wind farm}

Wind turbine aerodynamics of a horizontal-axis wind turbine (HAWT): The air flow at the blades is not the same as the airflow further away from the turbine. The very nature of the way in which energy is extracted from the air also causes air to be deflected by the turbine. Flow Structure in wind turbine wake: The near region immediately downstream of the rotor, vortex sheets, associated with the radial variation in circulation along the blades, are shed from their trailing edge, and roll up in a short downstream distance forming tip vortices that describe helical trajectories (near wake region). When the inclination angle of the helix is small enough, the layer, in which the tip vortices are located, can be interpreted as a cylindrical shear layer which separates the slow moving fluid in the wake from that on the outside. Because of turbulent diffusion, the thickness of the shear layer increases with downstream distance. Most of the turbulence that makes the wake diffuse is, at this stage, created by the shear in the wake, mainly in the shear layer. However, the shear in the external atmospheric flow also plays an important role, at least in the redistribution of the generated turbulence. At a certain distance downstream about two to five diameters, the shear layer reaches the wake axis. This marks the end of the near wake region. After the near wake region, there is a transition region leading to the far wake region, where the wake is completely developed and, in the hypothetical absence of ambient shear flow, it may be assumed that the perturbation profiles of both velocity deficit and turbulence intensity are axisymmetric, and have self-similar distributions in the cross-sections of the wake. This property of self-similarity is the basis of the kinematic models describing wind turbine wakes.

Wind Farm: A wind farm is as a cluster of wind turbines that acts and is connected to the power system as a single electricity producing power station. Generally it is expected that a wind farm consists of more than three wind turbines. Modern wind farms may have capacities in the order of hundreds of megawatts, and are installed offshore as well as on 
land. Modern wind farms generally are connected to the high voltage transmission system, in contrast to the early application of wind energy for electricity production with wind turbines individually connected to the low- to medium-voltage distribution system. Hence, modern wind farms are considered power plants with responsibilities for control, stability, and power balance. Most of the other technical issues with wind farms are associated with the close spacing of multiple turbines. The close spacing implies that extraction of energy by wind turbines upwind will reduce the wind speed and increase the turbulence, which may cause reduced efficiency and higher loads on downwind turbines. Another technical issue for large wind farms is the grid connection and the integration into the power system. Large wind farms are very visible, especially at land and in coastal areas and this together with a number of environmental concerns, such as possible disturbance of migrating birds and bats, play an important role in the wind farm planning process and can result in selection of sites with less than optimal wind conditions.

\subsection{Commercial wind turbines}

Commercial wind farms are constructed to generate electricity for sale through the electric power grid. The number of wind turbines on a wind farm can vary greatly, ranging from a single turbine to thousands. Large wind farms typically consist of multiple large turbines located in flat, open land. Small wind farms, such as those with one or two turbines, are often located on a crest or hill. The size of the turbines can vary as well, but generally they are in the range of 500 Kilowatts to several Megawatts, with 4.5 Megawatts being about the largest. Physically, they can be quite large as well, with rotor diameters ranging from $30 \mathrm{~m}$ to $120 \mathrm{~m}$ and tower heights ranging from $50 \mathrm{~m}$ to $100 \mathrm{~m}$. The top ten wind turbine manufacturers, as measured by global market share in 2007 are listed in Table 2. Due to advances in manufacturing and design, the larger turbines are becoming more common. In general, a one Megawatt unit can produce enough electricity to meet the needs of about 100200 average homes. A large wind farm with many turbines can produce many times that amount. However, with all commercial wind farms, the power that is generated first flows into the local electric transmission grid and does not flow directly to specific homes.

\begin{tabular}{|c|c|c|c|c|c|}
\hline \multirow[b]{2}{*}{1} & \multirow[b]{2}{*}{ Vestas } & \multirow{2}{*}{$\begin{array}{c}\text { Model } \\
\text { V90 }\end{array}$} & \multicolumn{3}{|c|}{ Power rating $[\mathrm{kW}]$ Diameter $[\mathrm{m}]$ Tip speed $[\mathrm{m} / \mathrm{s}]$} \\
\hline & & & 3,000 & 90 & 87 \\
\hline 2 & $\begin{array}{c}\text { GE } \\
\text { Energy }\end{array}$ & $2.5 X \mathrm{X}$ & 2,500 & 100 & 86 \\
\hline 3 & Gamesa & G90 & 2,000 & 90 & 90 \\
\hline 4 & Enercon & E82 & 2,000 & 82 & 84 \\
\hline 5 & Suzlon & S88 & 2,100 & 88 & 71 \\
\hline 6 & Siemens & 3.6 SWT & 3,600 & 107 & 73 \\
\hline 7 & Acciona & AW-119/3000 & 3,000 & 116 & 74.7 \\
\hline 8 & Goldwind & REpower750 & 750 & 48 & 58 \\
\hline 9 & Nordex & N100 & 2,500 & 99.8 & 78 \\
\hline 10 & Sinovel & 1500 (Windtec) & 1,500 & 70 & \\
\hline
\end{tabular}

Table 2. Top ten wind commercial wind turbines manufactures in 2007 


\section{Three dimensional modelling of flow field of Horizontal Axis Wind Turbine (HAWT) using RANS method}

Full three-dimensional computations, employing the Reynolds averaged Navier Stokes (RANS) equations, have been carried out by Kang and Hirsh (2001), focused on 3-D effects on a HAWT. They have used the EURANUS/Turbo solver with either algebraic and k- $\omega$ turbulence models for closure. Several numerical investigations were carried out on HAWT, using in-house Navier-Stokes solver EllipSys2D/3D, and dealing with overall performances, loads, design of rotors and blade sections (Sorensen, 2002, 2004 and 2005). Commercial CFD package Fluent was used to perform a detailed analysis of HAWT flow (Carcangiu, 2007). The steady flow field around an isolated rotor of a middle-sized HAWT was predicted in a non-inertial reference frame, using both the Spalart-Allmaras turbulence model and the $\mathrm{k}-\omega$ SST model, and specifying a constant axial wind velocity at the inlet. The classical BEM method was adopted for the design of a first turbine model, extending the active part of the blade close to the hub. This blade region is aerodynamically redesigned following the tendencies of modern wind turbines (Rohden, 2004). Several 2D and 3D simulations were carried out, to yield information on the different aspects involved by this problem, ranging from performance calculations to wake development.

The principal objective of this computaional fluid dynamics (CFD) analysis is to investigate the flow field around a horizontal axis wind turbine rotor and to determine the turbine's power over a full range of operating conditions (wind speed and rotational speed of the turbine). A three dimesional CFD analysis was performed in this study using Reynolds Averaged Navier Stokes (RANS) method. Due to periodicity of the wind turbine, only one third of the turbine rotor was modeled, and a single moving reference frame system (SMRF) was used in this study. The turbulnece was modeled using k- $\varepsilon$ turbulene model. The governing equations of mass, mometum and turbulence equations were solved using finite volume method. The numerical results of the wind turbine coefficient of performance were compared to the experimetal data for the validation of the model. The results of the CFD analysis include the velocity field ( $x$-velocity, $y$-velocity, z-velocity, and velocity magnitude), pressure distribution around the wind turbine blades, turbulent wake behind the wind turbine and the power coefficient $C_{p}$.

\subsection{Governing equations}

The mathematical equations describing the aerodynamics of wind turbines are based on the equations of conservation of mass and momentum together with other supplementary equations for the turbulence. The standard k- $\varepsilon$ turbulence model is used in this study. The equations for the turbulent kinetic energy $\mathrm{k}$ and the dissipation rate of the turbulent kinetic energy $\varepsilon$ are solved. The time averaged gas phase equations for steady turbulent flow are:

$$
\frac{\partial}{\partial x_{j}}\left(\rho u_{i} \Phi\right)=-\frac{\partial}{\partial x_{i}}\left(\Gamma_{\Phi} \frac{\partial \phi}{\partial x_{i}}\right)+S_{\Phi}
$$

Where $\phi$ is the dependent variable that can represent the velocity $u_{i}$, the turbulent kinetic energy $k$, and the dissipation rate of the turbulent kinetic energy $\varepsilon$.

\subsubsection{Continuity equation}

The equation of conservation of mass or continuity equation is given by: 


$$
\frac{\partial}{\partial x_{j}}\left(\rho u_{i}\right)=0
$$

\subsubsection{Momentum equation}

The Momentum equation is given by:

$$
\frac{\partial\left(\overline{\rho u_{i} u_{j}}\right)}{\partial x_{j}}=-\frac{\partial \bar{P}}{\partial x_{i}}+\frac{\partial\left(\overline{t_{i j}}+\overline{\tau_{i j}}\right)}{\partial x_{j}}
$$

Where, $\bar{t}_{i j}$ is the viscous stress tensor defined as:

$$
\bar{t}_{i j}=\mu\left[\left(\frac{\partial \overline{u_{i}}}{\partial x_{j}}+\frac{\partial \overline{u_{j}}}{\partial x_{i}}\right)-\frac{2}{3} \frac{\partial \overline{u_{k}}}{\partial x_{k}} \delta_{i j}\right]
$$

Where $\delta_{\mathrm{ij}}=1$ if $i=j$ and $\delta_{\mathrm{ij}}=0$ if $i \neq j$

$\bar{\tau}_{i j}=-\overline{\rho u_{i}^{\prime} u_{j}^{\prime}}$ is the average Reynolds stress tensor defined as:

$$
\overline{\tau_{i j}}=\mu_{t}\left[\left(\frac{\partial \overline{u_{i}}}{\partial x_{j}}+\frac{\partial \overline{u_{j}}}{\partial x_{i}}\right)-\frac{2}{3} \frac{\partial \overline{u_{k}}}{\partial x_{k}} \delta_{i j}\right]-\frac{2}{3}\left(\overline{\rho k \delta_{i j}}\right)
$$

Where, $\bar{k}=\frac{1}{2} \overline{u_{i} u_{j}}$ is the average turbulent kinetic energy, $\mu_{t}=c_{\mu} \frac{\overline{\rho k^{2}}}{\bar{\varepsilon}}$ is the turbulent eddy viscosity, $c_{\mu}$ is constant $\left(c_{\mu}=0.09\right)$ and $\bar{\varepsilon}=v \overline{\frac{\partial u_{i}^{\prime}}{\partial x_{j}} \frac{\partial u_{i}^{\prime}}{\partial x_{j}}}$ is the average dissipation rate of the turbulent kinetic energy.

\subsubsection{Transport equations for $\mathrm{k}$ and $\varepsilon$ :}

The standard k- $\varepsilon$ model is a semi-empirical model based on model transport equations for the turbulence kinetic energy $\mathrm{k}$ and its dissipation rate $\varepsilon$ :

\subsubsection{Turbulent kinetic energy equation:}

$$
\rho \frac{\partial\left(\overline{k u_{j}}\right)}{\partial x_{j}}=\frac{\partial\left[\left(\mu+\frac{\mu_{t}}{\sigma_{k}}\right) \frac{\partial \bar{k}}{\partial x_{j}}\right]}{\partial x_{j}}+G_{k}-\overline{\rho \varepsilon}
$$

Where, $\sigma_{k}=1$ and $G_{k}$ is the production of turbulent kinetic energy defined as:

$$
G_{K}=\mu_{t}\left[\left(\frac{\partial \overline{u_{i}}}{\partial x_{j}}+\frac{\partial \overline{u_{j}}}{\partial x_{i}}\right)\right] \frac{\partial \overline{u_{i}}}{\partial x_{j}}-\frac{2}{3} \frac{\partial \overline{u_{i}}}{\partial x_{j}} \delta_{i j}\left[\mu_{t} \frac{\partial \overline{u_{k}}}{\partial x_{k}}+\overline{\rho k}\right]
$$




\subsubsection{Dissipation of kinetic energy}

$$
\rho \frac{\partial\left(\overline{\varepsilon u_{j}}\right)}{\partial x_{j}}=C_{\varepsilon 1} \frac{\bar{\varepsilon}}{k} G_{k}+\frac{\partial\left[\left(\mu+\frac{\mu_{t}}{\sigma_{\varepsilon}}\right) \frac{\partial \bar{\varepsilon}}{\partial x_{j}}\right]}{\partial x_{j}}-C_{\varepsilon 2} \frac{\bar{\rho} \frac{\overline{\varepsilon^{2}}}{k}}{k}
$$

Where $C_{\varepsilon_{1}}=1.44, C_{\varepsilon_{2}}=1.92, \sigma_{\varepsilon}=1.3$

\subsection{Geometry, mesh, boundary conditions and numerical method}

The equation of fluid flow is usually solved in stationary (or inertial) reference frames. However, there are many fluid flow problems that require the equations be solved in a moving (or non-inertial) reference frames. Rotating rotor of wind turbine is such case. There are two types of moving frames: multiple reference frames (MRF - different regions in the computational domain are rotating with different speed) and a single reference frame (the entire computational domain is rotating with the same speed). The single reference frame is used in this study. Table 3 shows the wind turbine blade characteristics used for this study. The wind turbine has three blades and a turbine rotor diameter of $6 \mathrm{~m}$. The foil series which was used for the blade design was the NACA 638xx. The computational domain is extended in axial direction roughly 2 diameter upstream and 5 diameters downstream of the rotor (See Figure 8). In the vertical plane of the rotor, the cylindrical domain diameter is 1.5 times of the rotor diameter. ANSYS ICEM CFD 12 was used to build a tetrahedral mesh with approximately 870,000 volume elements. Periodic section of the hub and the blade was modeled. By applying periodicity, high number of mesh elements are used for $1 / 3$ sector of the computational domain (See Figure 9), which will produce more accurate results.

\begin{tabular}{ll} 
Rotor radius & $3 \mathrm{~m}$ \\
Blade length & $2.625 \mathrm{~m}$ \\
Hub radius & $0.375 \mathrm{~m}$ \\
Number of blades & 3 \\
Twist & 15 degree \\
Foil Type & NACA 638xx \\
\hline
\end{tabular}

Table 3. Characteristics of the investigated turbine

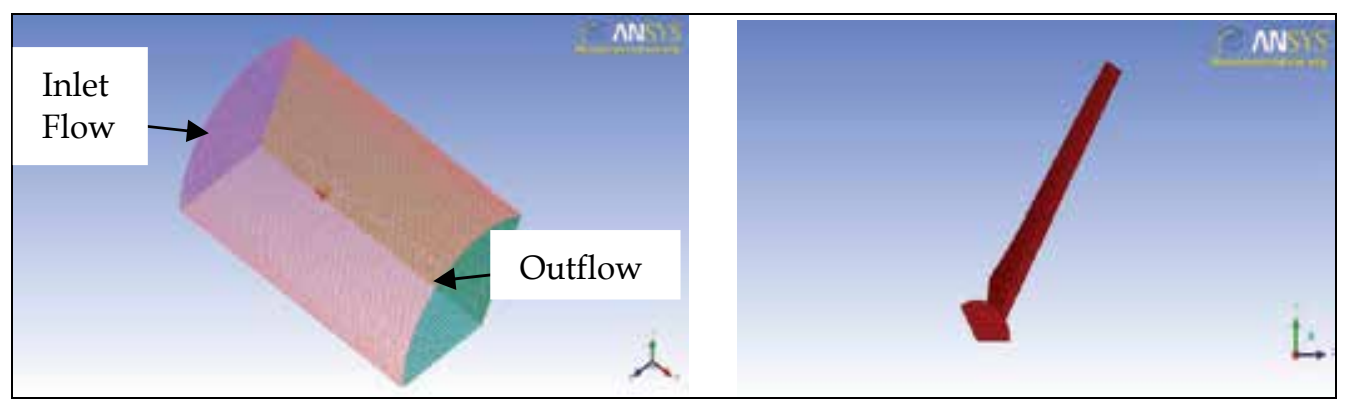

Fig. 8. Three dimensional computational domain and blade model 


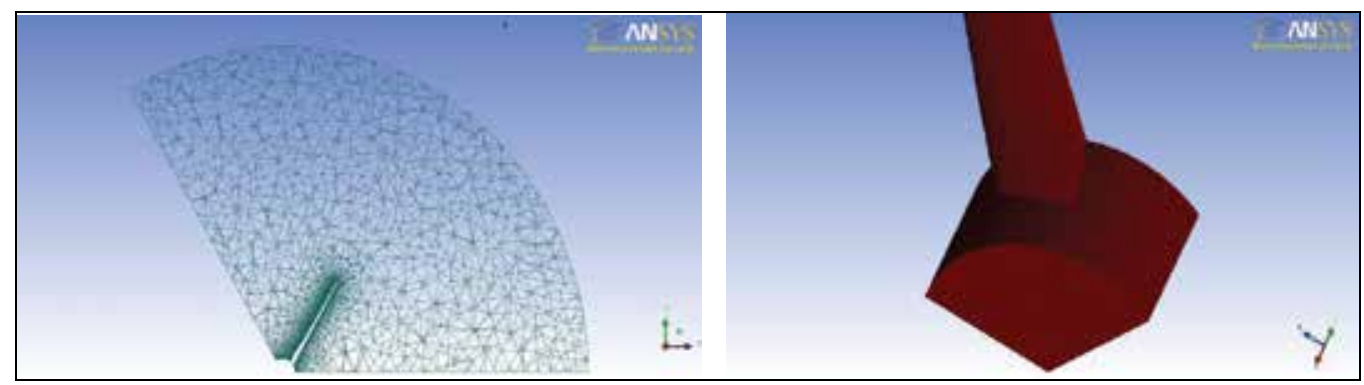

Fig. 9 Mesh generated (a) 2-D view of the mesh generated for the computational domain and (b) mesh created on the surface of the blade and hub

After creating a 3-D geometry model and generating the mesh, the flow boundary conditions (BC) have to be specified as shown in Figure 10. It is a very critical for simulation, that these boundary conditions are specified appropriately: (1) Wall (no-slip) boundary conditions are used for the blade surface and hub, (2) Velocity-inlet: This BC is used to specify the air flow velocity, (3) Outflow: Outflow boundary condition is used to model flow exits (the mass flow rate through the inlet $\mathrm{BC}$ should be the same as the flow arte through the outflow BC), (4) Symmetry: symmetry boundary conditions (zero flux of all quantities across the symmetry boundary) are used for the outer diameter of the cylindrical region representing the limit of the computational domain), (5) periodic: periodic boundary condition is used since only one third of the turbine blade is modeled. Periodic boundary conditions are used when the physical geometry of interest and the expected pattern of the flow/thermal solution have a periodically repeating nature. By using a periodic boundary the number of grids can be reduced enabling finer grids. Figure 10 shows the two dimensional views (the full blade and $1 / 3^{\text {rd }}$ of the turbine blade) of the wind turbine with the corresponding boundary conditions. The velocity inlet and outflow boundaries are shown in Figure 8.

For the numerical method, the finite volume method and the first order upwind method were used to solve the governing equations. The convergence criteria were set to $10^{-3}$ for the continuity, momentum, turbulent kinetic energy, and dissipation rate of the turbulent kinetic energy.

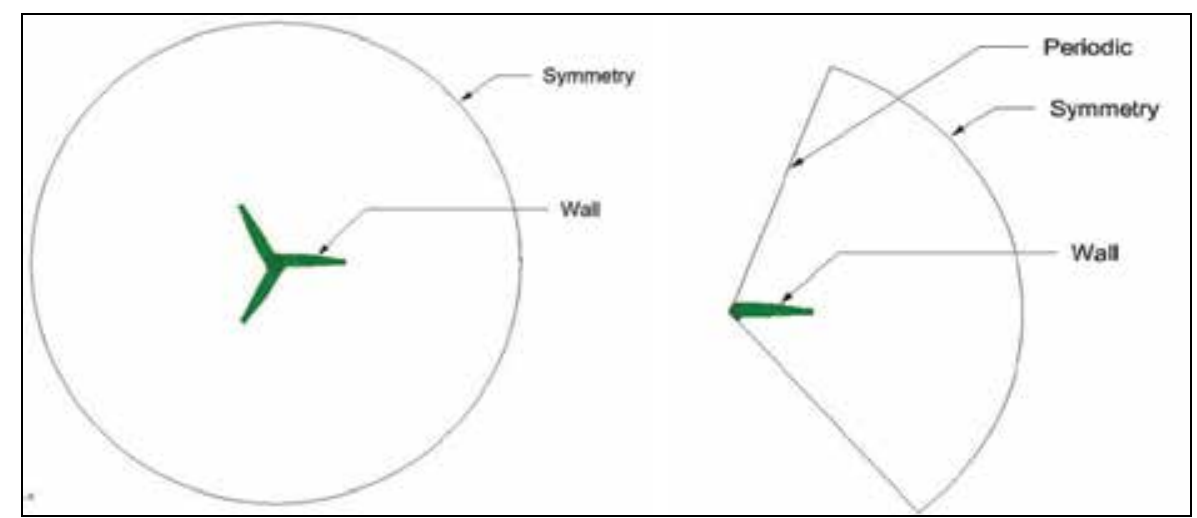

Fig. 10. Two dimensional views of the wind turbine, computational domain and boundary conditions 


\subsection{Results}

The flow field around the wind turbine was predicted for a tip speed ratio TSR $=7$, inlet wind speed of $10 \mathrm{~m} / \mathrm{s}$ and the blade rotational speed of $26.66 \mathrm{rad} / \mathrm{s}$. The axial, radial and tangential velocity contours are obtained at different sections along the $x$ axis (flow direction). Figure 11 shows the normalized axial velocity $(\mathrm{Vx} / \mathrm{Vo})$ contours at different axial positions $x / d=-1$ to 3 . The contours are plotted by taking clipped surface from the center of the hub to a radially outward distance of $4 \mathrm{~m}$. This allows visualizing the contours close to near-blade region. The results show that the wind speed velocity decreases as the flow approaches the rotor because of the backflow effect. According to actuator disk theory axial velocity is reduced at the rotor plane (due to induction factor) in the presence of the rotor and it is confirmed in $\mathrm{x} / \mathrm{d}=0$ contour.

Figure 12 shows the wake expansion along the flow at $y=0$ inclined plane, which cuts through the turbine blade at angle of $60^{\circ}$ to the z-axis. As flow moves downstream, it can be seen that wake expands along the direction of the flow. However, magnitude of velocity decreases within the stream tube. Green area right after the turbine indicates very low and even negative velocities because of hub bluntness. Light yellow area corresponds to velocity magnitude of about $6.17 \mathrm{~m} / \mathrm{s}$ at the outflow, which kept at distance of 5D after the rotor. The wake field boundary shows a smoother gradient and the far wake is dominated by diffusion phenomena, so that the wake is forced by external flow. It is of interest to know the turbulence characteristics in wind farms in order to predict the mechanical loads on the wind turbines and their performances and to evaluate the velocity deficit created in the wind stream by the drag of the turbines. A distinct division can be made into near and far wake region. The near wake is taken as the region just behind the rotor, where the properties of the rotor flow can be noticeably discriminated, roughly up to one rotor diameter downstream. In this region the presence of the rotor is visible because of the aerodynamic perturbation created by the blades, including stalled flow, three dimensional effects and tip vortices. The near wake survey is focused on the physical process of energy conversion. The far wake is the region beyond the near wake, where the focus is put on the mutual influence of wind turbines in farm situations. The main research interest is to study how the far wake decays down-stream, in order to estimate the effects produced on the downstream turbines, i.e. lower velocity and higher turbulence intensity, which make the power production decrease and the unsteady loads increase. This observation is helpful in means of positioning next turbine when wind farm considered and it is clear that $5 \mathrm{D}$ distances is not enough. More deep far wake studies are required for such determination.

Figure 13 shows the normalized axial velocity plots at various $x / d$ locations taken at radial lines inclined at the angle of $60^{\circ}$ to the z-axis. Here also it can be observed the fact that axial velocity gets reduced before the turbine and geometry of the hub (bluntness) also accounts for zero or sub-zero velocities downstream of the rotor. The expansion of the wake can be visualized where velocity reaches the stream velocity $\mathrm{V}_{0}$ and shifts further outward radially as the flow advances.

Figure 14 shows the contours of the normalized tangential velocities. As it can be observed from the contour plots, variations of tangential velocity vectors starts about at $x / d=-0.05$ to $\mathrm{x} / \mathrm{d}=0.5$. It is also noted that the tangential velocity at the tip of the blade reached a value of $72.4 \mathrm{~m} / \mathrm{s}$. Negative value of the tangential velocity indicates that tangential velocity acts in the opposite direction to that of the blade rotation. Figure 15 shows the pathlines colored by the velocity magnitude. Both the front and the isometric views are shown. 


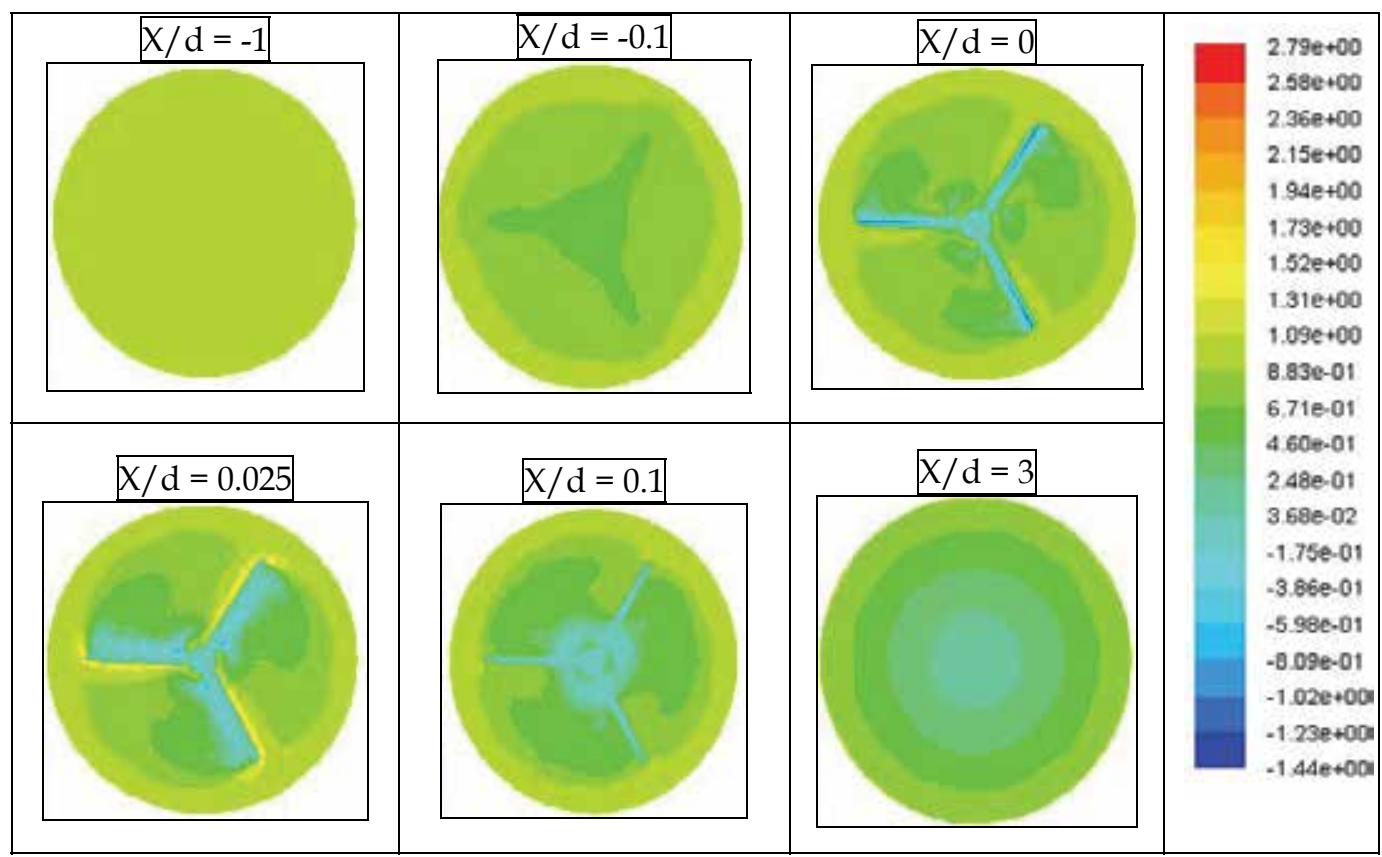

Fig. 11. Normalized axial velocity $(\mathrm{Vx} / \mathrm{Vo})$ contours at different $\mathrm{x} / \mathrm{d}$ locations $-\mathrm{TSR}=7$ and stream velocity $\mathrm{V}_{0}=10 \mathrm{~m} / \mathrm{s}$

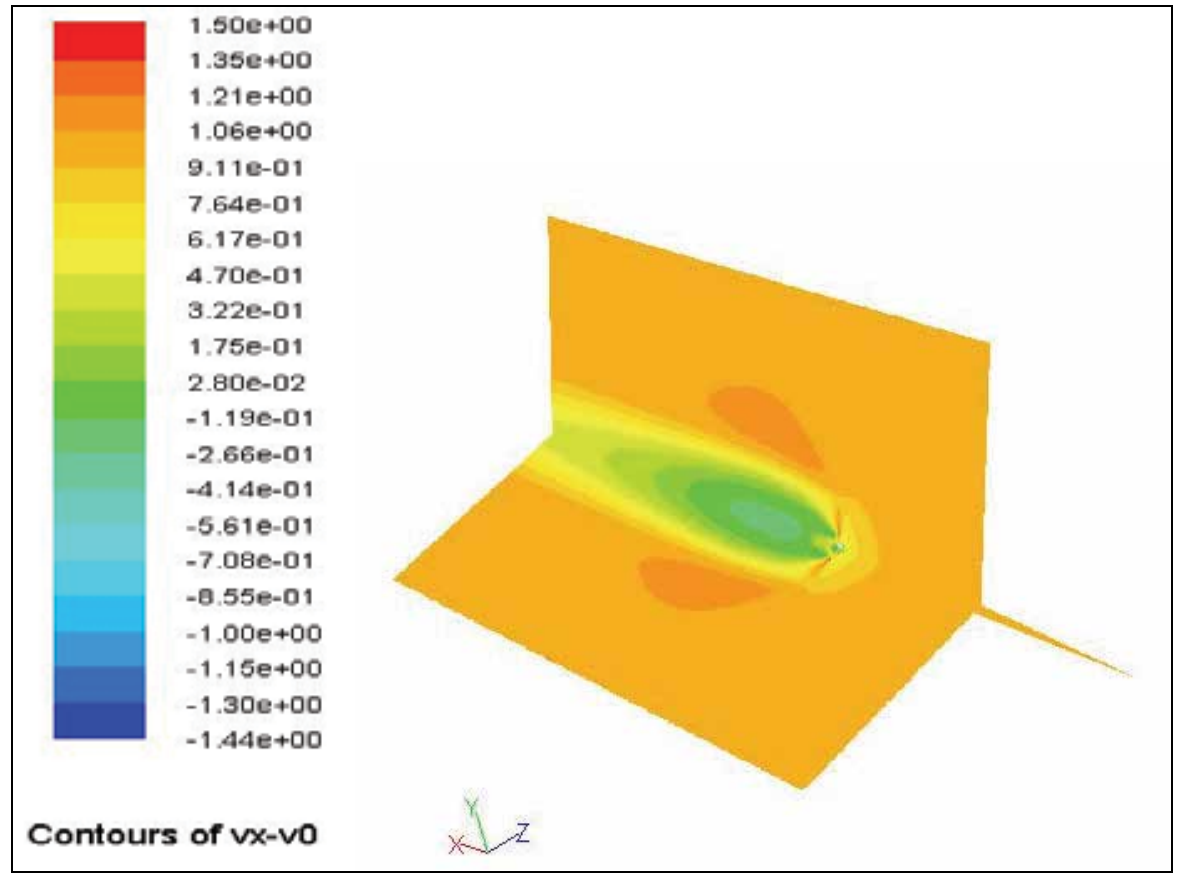

Fig. 12. Wake expansion along the flow at $y=0$ inclined plane, which cuts through the turbine blade at angle of $60^{\circ}$ to the $\mathrm{z}$-axis. 

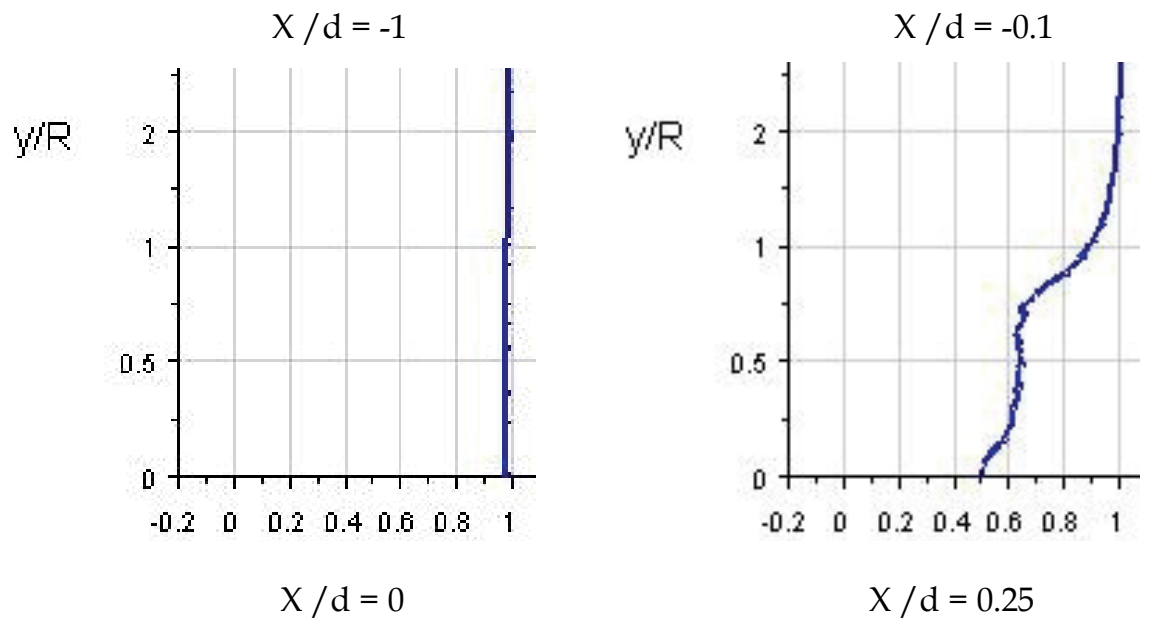

y/R
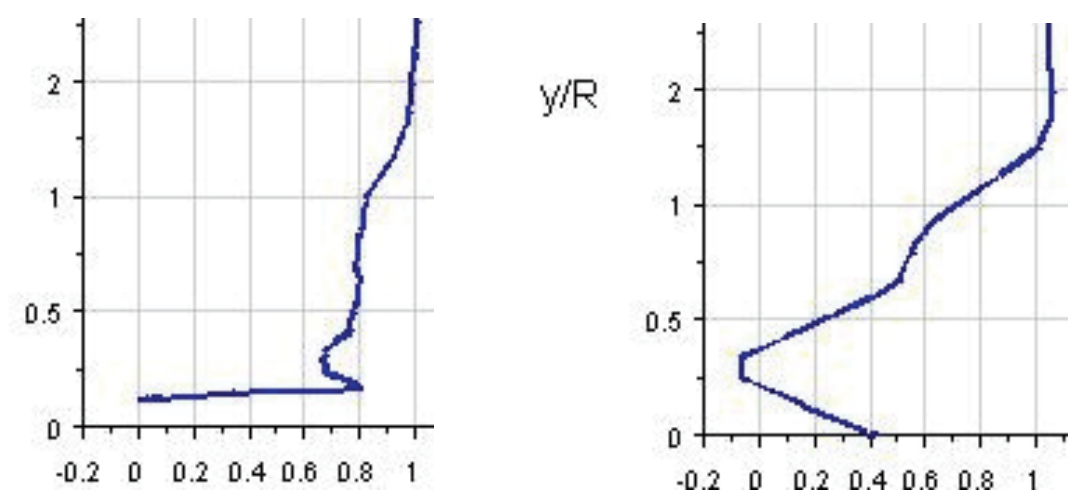

$$
X / d=0.5
$$

$$
\mathrm{X} / \mathrm{d}=3
$$

$y / R$
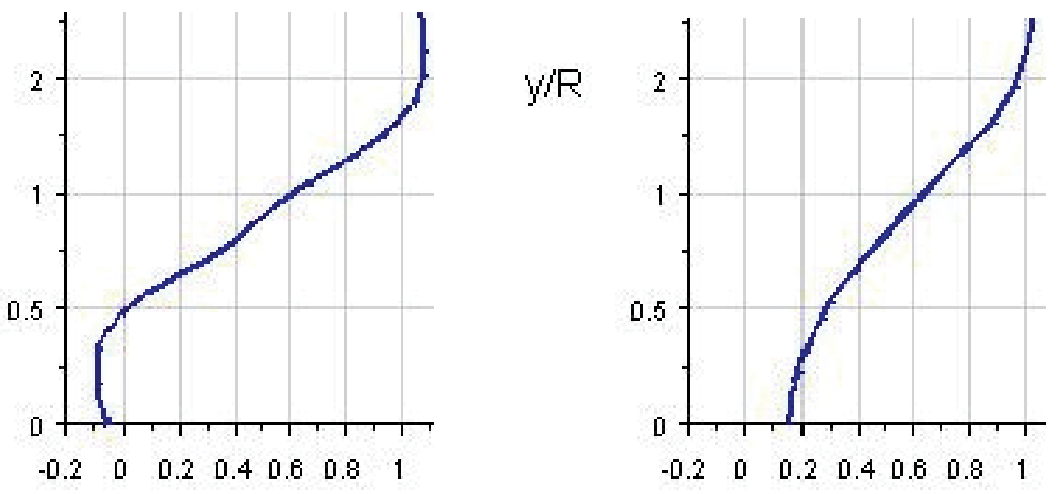

VWO

WNO

Fig. 13. Normalized axial velocity (VX/Vo) plots along the flow direction 


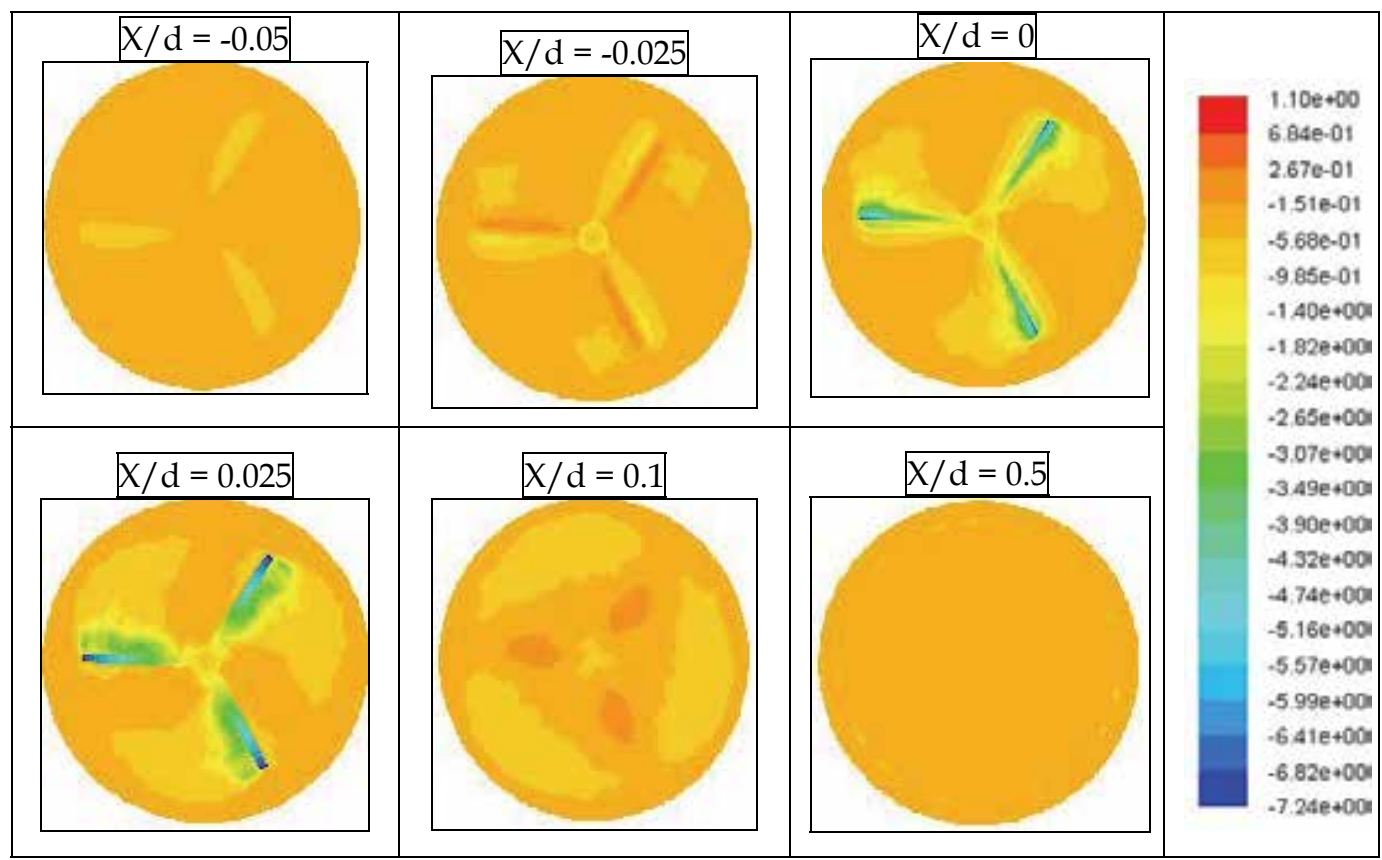

Fig. 14. Normalized tangential velocity contours at different $\mathrm{x} / \mathrm{d}$ locations $-\mathrm{TSR}=7$ and stream velocity $\mathrm{V}_{0}=10 \mathrm{~m} / \mathrm{s}$

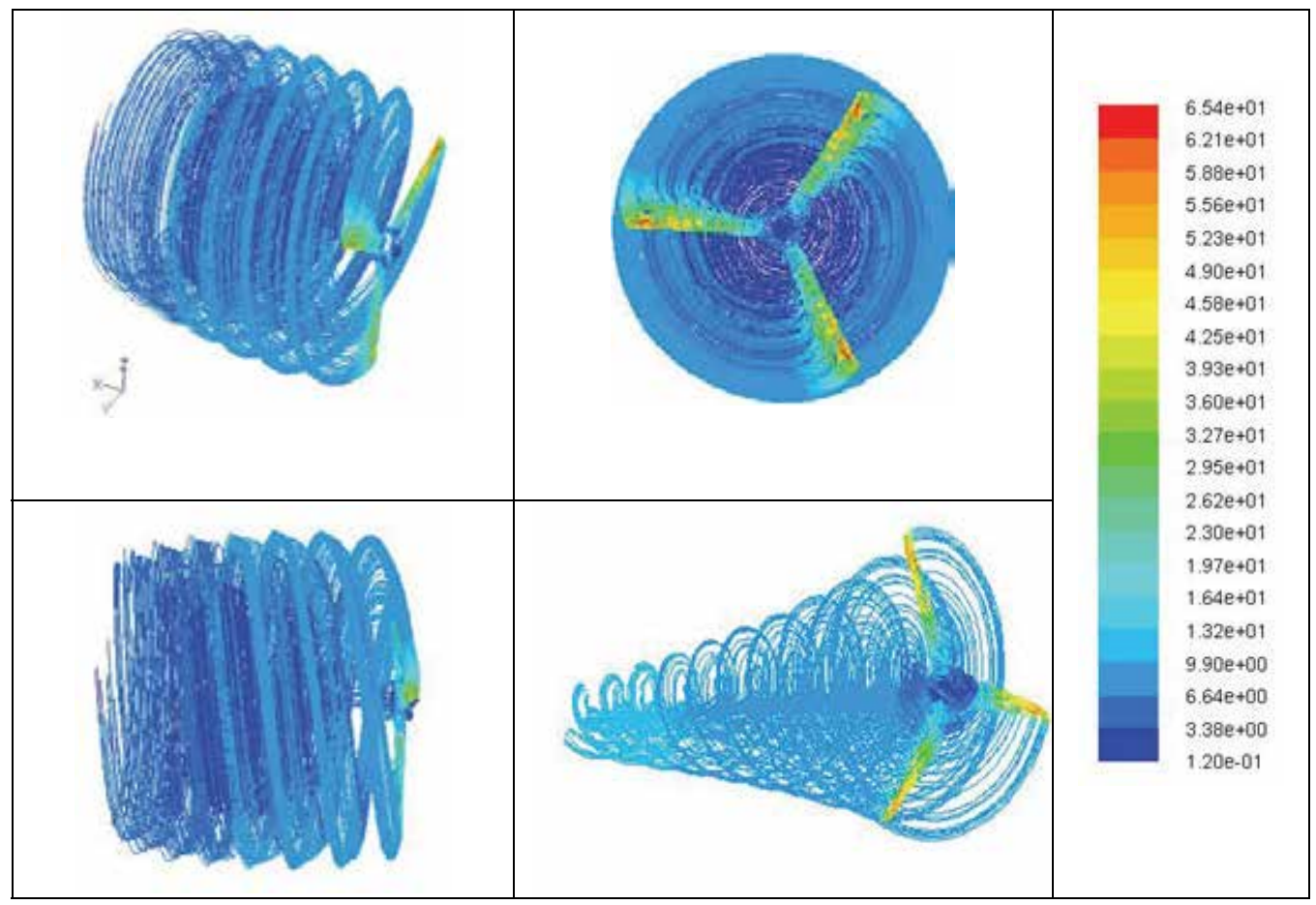

Fig. 15. Pathlines colored by the velocity magnitude $(\mathrm{m} / \mathrm{s})$ - Isometric and front views 
The power coefficient was determined using the induction factor a. The induction factor was first determined from the velocity profiles before and after the wind turbine and then the power coefficient was calculated. The results of the variation of the power coefficient with the tip speed ratio are presented in Figure 16. The CFD results of the power coefficient were compared to the NREL Unsteady Aerodynamics Experimental data (Acker and Hand, 1999). It is noted that the results presented in Figure 16 are obtained with a normalized TSR value between 3 and 9 . The value of the normalized TSR was increased by keeping the wind speed constant at $10 \mathrm{~m} / \mathrm{s}$ and increasing the rotational speed of the wind turbine or the angular velocity $\Omega(\mathrm{rad} / \mathrm{s})$. The CFD results shows that the maximum value of power coefficient is $40 \%$ with a normalized value of TSR $=7$. At this condition the wind turbine will produce approximately $7 \mathrm{KW}$ of mechanical shaft power. For the experimental study the turbine achieves a pick efficiency of approximately $36 \%$ at tip speed ratio of approximately 5.5 in controlled wind tunnel environment. The simulated power coefficient curve has a similar trend like other typical turbines. The results also show a good agreement with the experimental data.

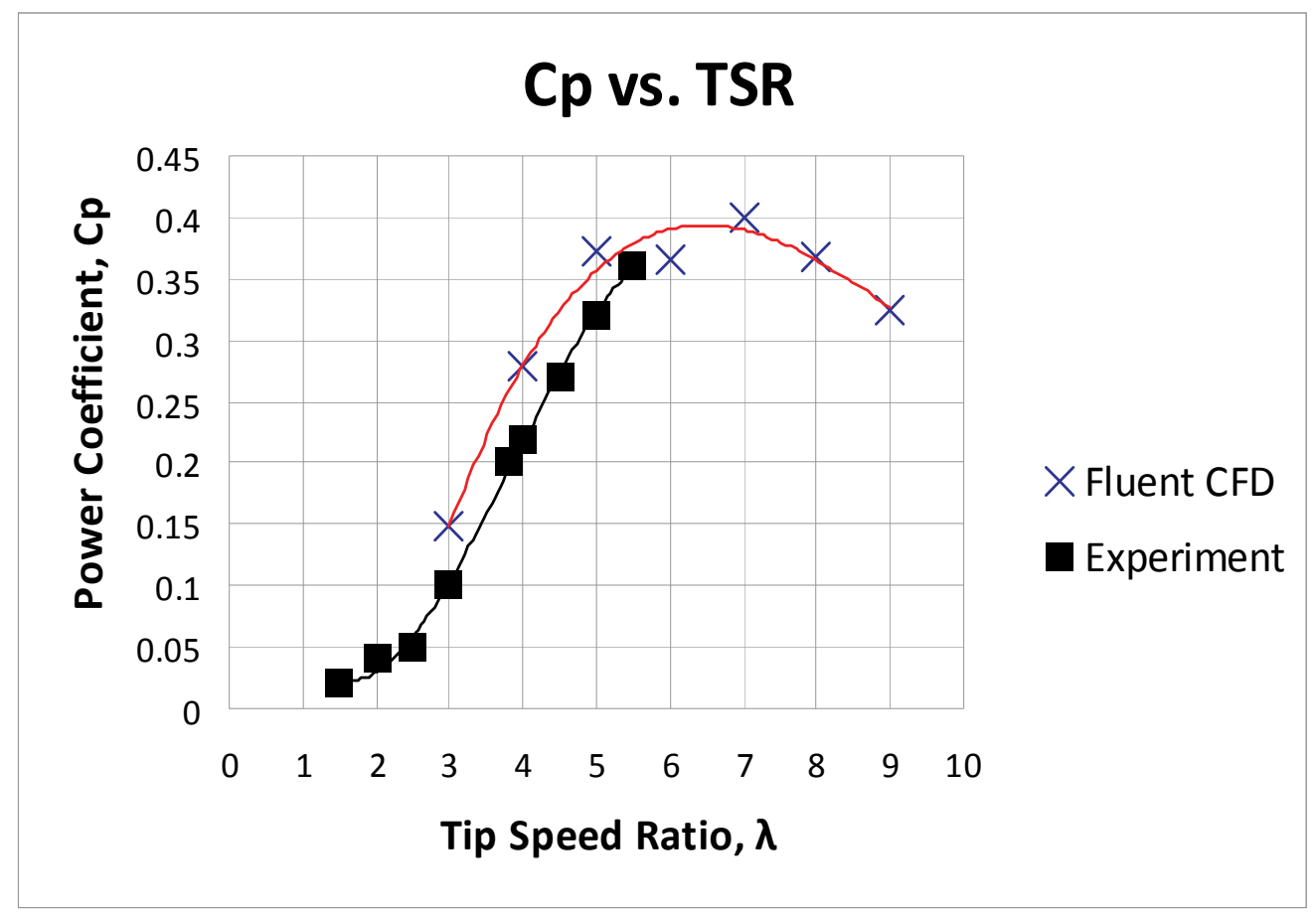

Fig. 16. Variation of the power coefficient with the tip speed ratio - Comparison of the CFD results with experiment

\section{Conclusions}

This chapter is divided in two parts: the first part is a review of wind energy in general and the second part concerns the use of CFD Reynolds Average Navier Stokes simulations to get better understanding of wind turbine blades aerodynamics and to determine the wind turbine power coefficient. Several issues were addressed in the first part of this chapter 
including the role of wind energy in the development of sustainable energy systems and the reasons for switching to renewable energy sources; the fundamental concepts of wind turbines systems (type of wind turbines, wind turbine components, the design of wind turbine, wind turbine power, power coefficient of performance, energy and torque); the wind characteristics such as wind power density, wind shear and turbulence and their effect of wind turbine performance; the flow structure in the near and far wake; design of wind turbines, wind farm and information data about top commercial wind turbines.

The second part if this chapter presents a three dimensional modeling of fluid flow around horizontal axis wind turbine using Reynlolds Average Navier Stokes method. Due to periodicity, only one third of the turbine rotor was modeled in the moving reference frame. The simulations were performed using the k- $\varepsilon$ turbulence model and finite-volume method. The axial, radial and tangential velocity contours, pressure distribution on the turbine blades, near and far wake characteristics, turbulence intensity and the power coefficient were obtained in this study. The results from the computations were quite satisfactory and they can represent a good foundation for future work. The results obtained will help better understanding of the flow field past the rotating blades, the pressure distribution on the wind turbine blades, flow structure in the near and far wakes, determine the power extracted from the wind power and to optimize the performance of the wind turbines. The CFD results for the power coefficient versus the normalized tip speed ratio were compared to experimental data and found to be in good agreement. The CFD-RANS method can be used as a CFD tool for computing performances and loads on wind turbine blades and as analysis tool for single turbine and wind farm design.

Future works should include higher performance computers in order to create much more elements in the computational grid, use more sophisticated meshing techniques to create hexahedral elements and refinement of boundary layer for achieving more accurate results, use k- $\omega$ SST turbulence model for RANS method and perform more extensive unsteady computation analysis using large eddy simulations (LES).

\section{References}

Acker, T.; Hand, M., "Aerodynamic Performance of the NREL Unsteady Aerodynamics Experiment (Phase IV) Twisted Rotor", AIAA-99-0045, Prepared for the 37th AIAA Aerospace Sciences Meeting and Exhibit, Reno, NV, January 11-14, 1999, p. 211-221.

Burton T., Sharpe D., Jenkins N. and Bossanyi E, Wind Energy Handbook, John Wiley \& Sons Ltd: Chichester, 2001.

Carcangiu, C.E., Sorensen, J.N., Cambuli, F., Mandas, N., CFD-RANS analysis of the rotational effects on the boundary layer of wind turbine blades, Dansk Vindkraftkonference 2007, Trinity, Snoghoj, Fredericia, 25- 27 April 2007

European Wind Energy Agency, VV.AA. Annual report. Technical report, EWEA, European Wind Energy Agency, 2006

Hansen M.O.L, Aerodynamics of Wind Turbines. Rotors, Load and Structures. James \& James: London, 2000.

Hartwanger, D. and Horvat, A., 3D Modeling of a wind turbine using CFD, NAFEMS UK Conference, Cheltenham, United of Kingdom, June 10-11, 2008

Hau E, Wind turbines. Springer: Berlin, 2000.

Kang S. and Hirsch C, Features of the 3D flow around wind turbine blades based on numerical solutions. In Proceedings of EWEC 06: Copenhagen, 2001. 
Rohden R, Revolutionary blade design. Wind Blatt, the Enercon Magasine, 03, 2004

Sorensen J.N. and Shen W.Z, Numerical modeling of wind turbine wakes. Journal of Fluid Engineering, 124:393-9, 2002.

Sorensen N.N. Johansen J. and Conway S, CFD computations of wind turbine blade loads during standstill operation. KNOW-BLADE Task 3.1, Technical Report R-1465, Riso National Laboratory Roskilde - DK, June 2004.

Sorensen N.N. et al. Tip shape study. Technical Report R-1495, Riso National Laboratory Roskilde - DK, January 2005.

International Energy Agency, VV.AA, Wind energy annual report, Technical report, IEA, International Energy Agency, 2006.

World Wind Energy Association (WWEA), World Wind Energy Report, 2009, http://www.wwindea.org 


\title{
Introduction to Doubly-Fed Induction Generator for Wind Power Applications
}

\author{
Dr John Fletcher and Jin Yang \\ University of Strathclyde, Glasgow \\ United Kingdom
}

\section{Introduction}

This chapter introduces the operation and control of a Doubly-fed Induction Generator (DFIG) system. The DFIG is currently the system of choice for multi-MW wind turbines. The aerodynamic system must be capable of operating over a wide wind speed range in order to achieve optimum aerodynamic efficiency by tracking the optimum tip-speed ratio. Therefore, the generator's rotor must be able to operate at a variable rotational speed. The DFIG system therefore operates in both sub- and super-synchronous modes with a rotor speed range around the synchronous speed. The stator circuit is directly connected to the grid while the rotor winding is connected via slip-rings to a three-phase converter. For variable-speed systems where the speed range requirements are small, for example $\pm 30 \%$ of synchronous speed, the DFIG offers adequate performance and is sufficient for the speed range required to exploit typical wind resources.

An AC-DC-AC converter is included in the induction generator rotor circuit. The power electronic converters need only be rated to handle a fraction of the total power - the rotor power - typically about 30\% nominal generator power. Therefore, the losses in the power electronic converter can be reduced, compared to a system where the converter has to handle the entire power, and the system cost is lower due to the partially-rated power electronics. This chapter will introduce the basic features and normal operation of DFIG systems for wind power applications basing the description on the standard induction generator. Different aspects that will be described include their variable-speed feature, power converters and their associated control systems, and application issues.

\section{Steady-state operation of the Doubly-Fed Induction Generator (DFIG)}

The DFIG is an induction machine with a wound rotor where the rotor and stator are both connected to electrical sources, hence the term 'doubly-fed'. The rotor has three phase windings which are energised with three-phase currents. These rotor currents establish the rotor magnetic field. The rotor magnetic field interacts with the stator magnetic field to develop torque. The magnitude of the torque depends on the strength of the two fields (the stator field and the rotor field) and the angular displacement between the two fields. Mathematically, the torque is the vector product of the stator and rotor fields. Conceptually, the torque is developed by magnetic attraction between magnet poles of opposite polarity where, in this case, each of the rotor and stator magnetic fields establish a pair of magnet 
poles, Fig 1. Clearly, optimum torque is developed when the two vectors are normal to each other. If the stator winding is fed from a 3-phase balanced source the stator flux will have a constant magnitude and will rotate at the synchronous speed.

We will use the per-phase equivalent circuit of the induction machine to lay the foundations for the discussion of torque control in the DFIG. The equivalent circuit of the induction machine is shown in Fig.2.

The stator side has two 'parasitic' components, $R_{s}$ and $L_{s}$, which represent the resistance of the stator phase winding and the leakage inductance of the phase winding respectively. The leakage inductance models all the flux generated by current in the stator windings that does not cross the air-gap of the machine, it is therefore not useful for the production of torque. The stator resistance is a natural consequence of the windings being fabricated from materials that are good conductors but nonetheless have finite conductance (hence resistance).

The magnetising branch, $L_{m}$, models the generation of useful flux in the machine - flux that crosses the air-gap either from stator to rotor or vice-versa.

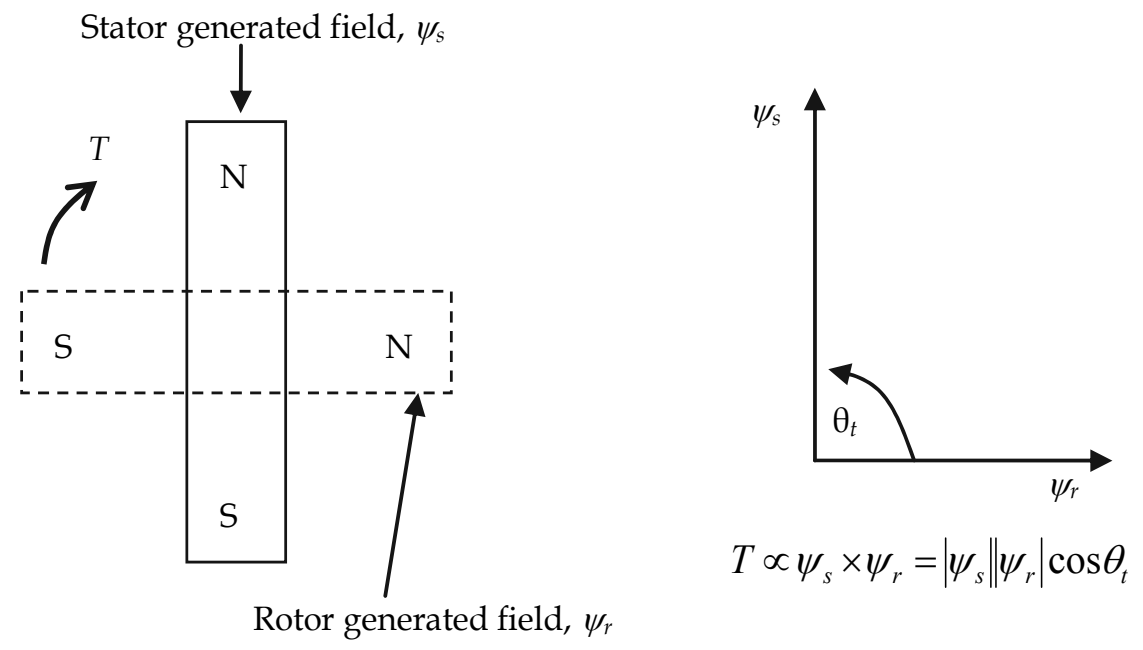

Fig. 1. Magnetic pole system generated by currents in the stator and rotor windings. The stator and the rotor field generate a torque that tends to try and align poles of opposite polarity. In this case, of rotor experiences a clockwise torque.

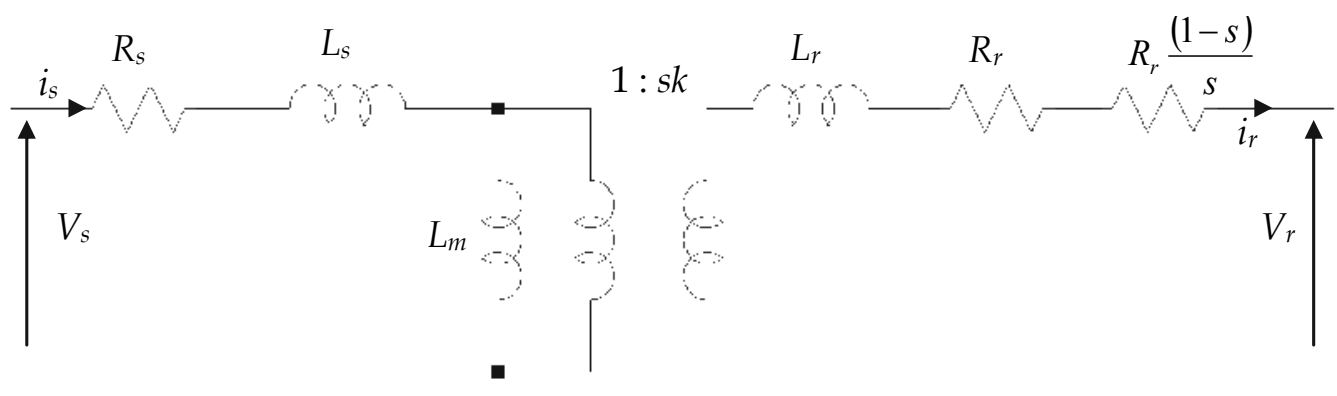

Fig. 2. Per-phase equivalent circuit of an induction machine. 
Like the stator circuit, the rotor circuit also has two parasitic elements. The rotor leakage reactance, $L_{r}$, and the rotor resistance $R_{r}$. In addition, the rotor circuit models the generated mechanical power by including an additional rotor resistance component, $R_{r}(1-s) / s$. Note that the rotor and stator circuits are linked via a transformer whose turns ratio depends on the actual turns ratio between the stator and rotor (1:k), and also the slip, $s$, of the machine.

In an induction machine the slip is defined as

$$
s=\frac{n_{s}-n_{r}}{n_{s}}
$$

where $n_{s}$ and $n_{r}$ are the synchronous speed and the mechanical speed of the rotor respectively. The synchronous speed is given by

$$
n_{s}=\frac{60 f_{e}}{p} \mathrm{rpm}
$$

where $p=$ number of pole pairs and $f_{e}$ is the electrical frequency of the applied stator voltage. We will first consider the operation of the machine as a standard induction motor. If the rotor circuit is left open circuit and the rotor locked (standstill), when stator excitation is applied, a voltage will be generated at the output terminals of the rotor circuit, $V_{r}$. The frequency of this output will be at the applied stator frequency as slip in this case is 1 . If the rotor is turned progressively faster and faster in the sub-synchronous mode, the frequency at the output terminals of the rotor will decrease as the rotor accelerates towards the synchronous speed. At synchronous speed the rotor frequency will be zero. As the rotor accelerates beyond synchronous speed (the super-synchronous mode) the frequency of the rotor voltage begins to increase again, but has the opposite phase sequence to the subsynchronous mode. Hence, the frequency of the rotor voltage is

$$
f_{r}=s f_{e}
$$

No rotor currents can flow with the rotor open circuit, hence there is no torque production as there is no rotor field $\psi_{r}$, Fig 1 . If the rotor was short circuited externally, rotor currents can flow, and they will flow at the frequency given by (3). The rotor currents produce a rotor magnetic field, $\psi_{r}$, which rotates at the same mechanical speed as the stator field, $\psi_{s}$. The two fields interact to produce torque, Fig. 1.

It is important to recognise that the rotor magnetic field and the stator magnetic field both rotate at the synchronous speed. The rotor may be turning asynchronously, but the rotor field rotates at the same speed as the stator field.

The mechanical torque generated by the machine is found by calculating the power absorbed (or generated) by the rotor resistance component $R_{r}(1-s) / s$. This is shown to be

$$
P_{\text {mech }}=3\left|i_{r}\right|^{2}\left(\frac{1-s}{s}\right) R_{r}
$$

In an ideal induction machine, we can ignore the rotor and stator phase winding resistance and leakage inductance. The per-phase equivalent circuit then becomes simple, Fig. 3 . The phasor diagram for the machine is shown. Note that the stator generated flux component is normal to the rotor current (hence rotor flux) phasor giving the optimum conditions for 

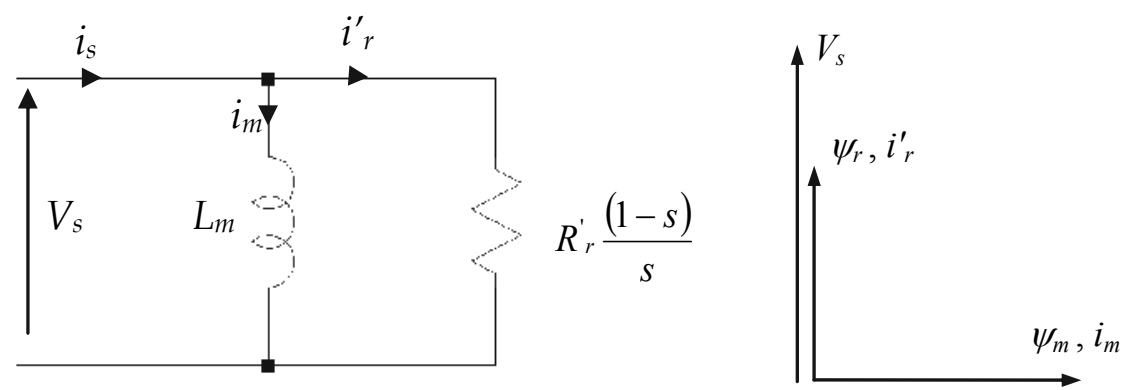

Fig. 3. Simplified equivalent circuit of the induction machine assuming low values of slip and negligible stator and rotor leakage reactance. Phasor diagram demonstrates optimal orientation of magnetising current and rotor current.

torque production (note this is true for low values of slip only). Using this simplified circuit diagram, the mechanical torque production is then:

$$
\begin{gathered}
T_{\text {mech }}=3\left|i_{r}^{\prime}\right|^{2}\left(\frac{1-s}{s}\right) \frac{R_{r}^{\prime}}{\omega_{m}} \\
\text { As } \omega_{m}=\frac{(1-s) \omega_{m}}{p} \text { and } \psi_{m}=L_{m} i_{m}=\frac{V_{s}}{\omega_{s}}=\frac{\left|i_{r}^{\prime}\right| R_{r}^{\prime}}{s \omega_{s}}
\end{gathered}
$$

Then

$$
T_{\text {mech }}=3\left|i_{r}^{\prime}\right|^{2}\left(\frac{1-s}{s}\right) \frac{R_{r}^{\prime}}{\omega_{m}}=3 p \frac{\left|i_{r}^{\prime}\right| R_{r}^{\prime}}{s \omega_{s}}\left|i_{r}^{\prime}\right|=3 p \psi_{m}\left|i_{r}^{\prime}\right|
$$

The key point in this development is to show that the developed torque is controlled by the combination of the stator generated flux, $\psi_{m}$, and the rotor current magnitude, $i_{r}^{\prime}$, if the two vectors are maintained in quadrature, Fig. 1 . In the DFIG system, torque is controlled by calculating the physical position and magnitude of the stator generated flux (by monitoring the position and magnitude of the applied stator voltage which in this case is imposed by the grid voltage magnitude, frequency and phase) and regulating the rotor currents such that they are normal to the stator flux with a magnitude that will generate the desired torque.

The DFIG system therefore has to control the magnitude, frequency and phase of the applied rotor current. Most DFIG systems utilise closed-loop current control using a voltage-source inverter (VSI). At this stage, the voltage source inverter can be viewed as a three-phase voltage source whose magnitude and phase can be altered instantaneously - this will be illustrated in Section 2. Therefore, the VSI can be used to regulate the rotor current. In order to properly position the rotor current knowledge of the physical position of the rotor is required using a mechanical position sensor, for example. In such a way, the rotor current (hence flux) can be oriented optimally with respect to the stator flux to generate the desired torque.

\section{Rotor power converters}

This section will detail the AC-DC-AC converter used on the rotor which consists of two voltage-sourced converters, i.e., rotor-side converter (RSC) and grid-side converter (GSC), 
which are connected "back-to-back." Between the two converters a dc-link capacitor is placed, as energy storage, in order to keep the voltage variations (or ripple) in the dc-link voltage small. With the rotor-side converter it is possible to control the torque or the speed of the DFIG and also the power factor at the stator terminals, while the main objective for the grid-side converter is to keep the dc-link voltage constant regardless of the magnitude and direction of the rotor power. The grid-side converter works at the grid frequency (leading or lagging in order to generate or absorb a controllable magnitude of reactive power). A transformer may be connected between the grid-side inverter or the stator, and the grid. The rotor-side converter works at different frequencies, depending on the wind speed.

The back-to-back arrangement of the converters provides a mechanism of converting the variable voltage, variable frequency output of the generator (as its speed changes) into a fixed frequency, fixed voltage output compliant with the grid. The DC link capacitance is an energy storage element that provides the energy buffer required between the generator and the grid.

The back-to-back inverter-converter arrangement

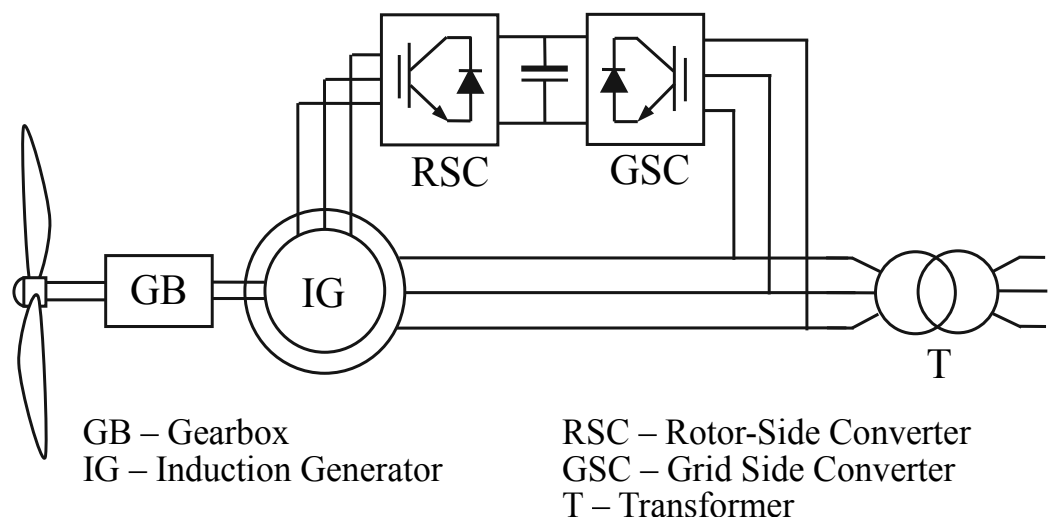

Fig. 4. Typical back-to-back arrangement of inverter and converter circuits to control power flow.

At the current state of development, most DFIG power electronics utilise a two-level sixswitch converter, Fig. 4. Two-level refers to the number of voltage levels that can be produced at the output of each bridge leg of the converter. A two-level converter can typically output zero volts or $V_{d c}$, where $V_{d c}$ is the voltage of the dc link. Fig. 4 shows two such converters connected in a back-to-back arrangement with a DC link between the two converters. The switching elements in higher power converters are likely to be Insulatedgate Bipolar Transistors (IGBTs). The six-switch converter can synthesise a three-phase output voltage which can be of arbitrary magnitude, frequency and phase, within the constraint that the peak line voltage is less than the DC link voltage. The converter is capable of changing the output voltage almost instantaneously - the limit is related to the switching frequency of the pulse-width modulated switching devices, and delays introduced by any filtering on the output (typical on the grid-side converter). The converter switches are switched ON and OFF with a fixed frequency but with a pulse-width that is varied in order to control the output voltage. 


\section{The voltage source inverter}

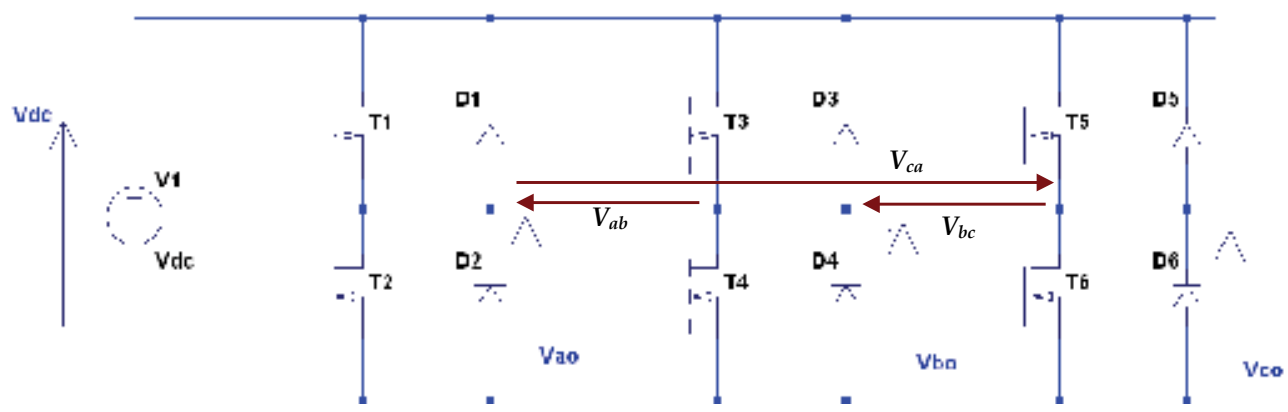

Fig. 5. Six-switch voltage source inverter circuit.
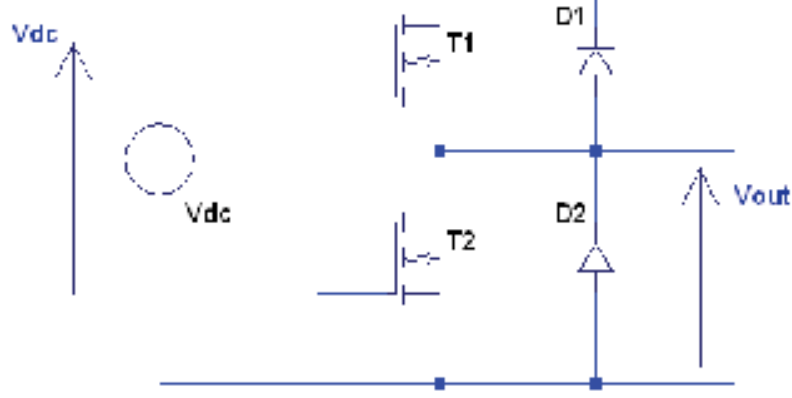

Fig. 6. One bridge leg of a voltage source inverter circuit.

Fig. 5 shows a six-switch inverter topology. It comprises three bridge legs in parallel. Fig. 6 shows one bridge leg. When switch $\mathrm{T} 1$ is $\mathrm{ON}$, the output voltage, $V_{\text {out }}$, is $V_{d c}$. When switch $\mathrm{T} 2$ is $\mathrm{ON}$, the output voltage is zero. (Note that both switches are not turned on at the same time). If the output is periodically switched between these two states, the output voltage, $V_{\text {out }}$, averaged over each switching period, can be controlled between zero volts and $V_{d c}$. The switching cycle is usually fixed, and the width of the pulse of $V_{d c}$ adjusted in order to change the output voltage. Fig. 7 shows an example of a pulse-width modulated signal and indicates how the width of the pulse can be varied by comparing the modulating waveform with the carrier waveform - this is now mainly performed digitally but is also easy to implement in analogue electronics. The average output voltage, at the terminals of the bridge leg, $V_{\text {out }}$, is given by

$$
V_{\text {out }}=V_{d c} \frac{t_{1, o n}}{T_{s w}}
$$

Where $T_{s w}$ is the switching period, and $t_{1, \text { on }}$ is the on time of the switch T1. We define the duty cycle, or modulation index, $m$ as

$$
m=\frac{t_{1, o n}}{T_{s w}}
$$




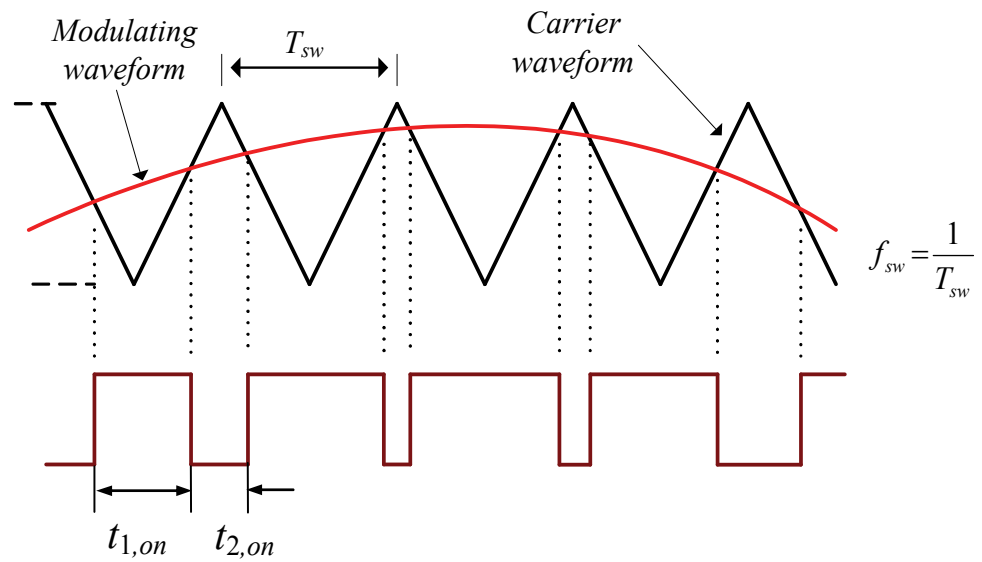

Fig. 7. Example of carrier-based pulse-width modulated signal generation.

Hence

$$
V_{\text {out }}=m V_{d c}
$$

where $m$ must be between 0 (T2 on continuously) and 1 (T1 on continuously). The modulation index, $m$, can be varied in time, therefore any desired voltage and frequency can be generated at the output terminals (within the bounds fixed by the switching frequency and $V_{d c}$ ).

In the three-phase converter shown in Fig 5, there are three phase legs, hence three modulation indices, $m_{a}, m_{b}$ and $m_{c}$. The voltages between the mid-point of each phase leg and the $0 \mathrm{~V}$ node of the dc link are

$$
\left\{\begin{array}{l}
V_{a o}=m_{a} V_{d c} \\
V_{b o}=m_{b} V_{d c} \\
V_{c o}=m_{c} V_{d c}
\end{array}\right.
$$

Now if each modulation index varies sinusoidally according to

$$
\left\{\begin{array}{l}
m_{a}=\frac{1}{2}+m \sin (\omega t) \\
m_{b}=\frac{1}{2}+m \sin (\omega t-2 \pi / 3) \\
m_{c}=\frac{1}{2}+m \sin (\omega t+2 \pi / 3)
\end{array}\right.
$$

Then the resultant output line voltages will take the from

$$
\left\{\begin{array}{l}
V_{a b}=V_{a o}-V_{b o}=\sqrt{3} m V_{d c} \sin \left(\omega t-\frac{\pi}{6}\right) \\
V_{b c}=V_{b o}-V_{c o}=\sqrt{3} m V_{d c} \sin \left(\omega t-\frac{5 \pi}{6}\right) \\
V_{c a}=V_{c o}-V_{a o}=\sqrt{3} m V_{d c} \sin \left(\omega t+\frac{\pi}{2}\right)
\end{array}\right.
$$


These are three-phase, balanced output line voltages, whose magnitude is controlled by $m$ and whose output frequency and phase can be regulated by the frequency and phase of the modulating waveform. The modulating waveforms can be manipulated digitally using high-performance microcontrollers or digital signal processors.

The VSI is capable of generating any voltage with arbitrary frequency and phase (within the limits of dc link voltage and switching frequency). Therefore, the VSI can be viewed and modelled as an ideal controllable voltage source whose bandwidth is usually much higher than the required excitation frequency required by the system. For example, Fig. 9 shows a single line diagram of a grid-connected inverter. In this case the inverter is simply modelled as an ideal voltage source that is generating a balanced set of three-phase voltages whose magnitude and phase can be controlled relative to the grid voltage. This provides the capability to control the flow of real and reactive power to the grid as will be discussed later. Note that synchronisation to the grid frequency is assumed.

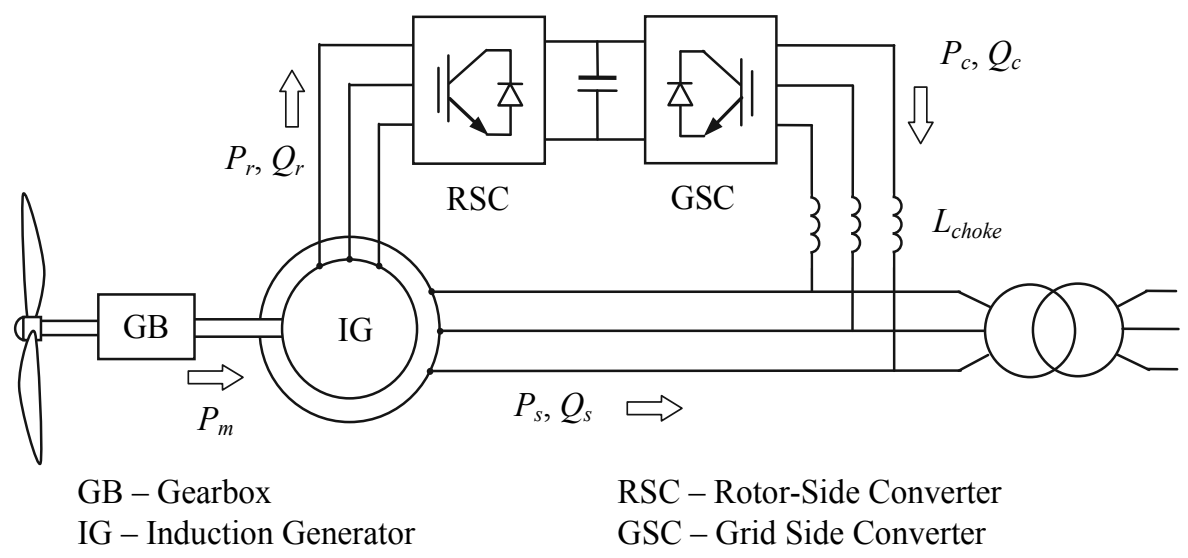

Fig. 8. Doubly-fed induction generation system power flows.

In steady-state at fixed turbine speed for a lossless DFIG system, the mechanical power from the wind turbine applied to the shaft is $P_{m}=P_{s}+P_{r}$. It follows that:

$$
P_{r}=P_{m}-P_{s}=T_{m} \omega_{r}-T_{e m} \omega_{s}=-T_{m}\left(\frac{\omega_{s}-\omega_{r}}{\omega_{s}}\right) \omega_{s}=-s T_{m} \omega_{s}=-s P_{s}
$$

where $s$ is defined as the slip of the generator: $s=\frac{\omega_{s}-\omega_{r}}{\omega_{s}}$.

Therefore if the maximum slip is limited, say to 0.3 , the rotor winding converters can be rated as a fraction of the induction generator rated power. This is typically around $\pm 30 \%$ for DFIG in wind power generation systems gives a slip range of \pm 0.3 . This is one key advantage of the DFIG system over fully-rated power electronic systems.

From the above relationships, the stator and rotor power are $P_{s}=P_{m} /(1-s)$ and $P_{r}=-s P_{m} /(1-$ $s)$, respectively. To consider the mechanical power change during different rotor speeds, the following analysis is carried out with all terms in per unit values. The slip is assumed to vary from a sub-synchronous value of +0.35 to a super-synchronous valua of -0.35 . The per unit output power from wind turbine is 


$$
P_{m}=C_{p_{-} p u} V_{w i n d_{-} p u}^{3}
$$

Here we use the example wind turbine model in MATLAB (The Mathworks Inc., 2008): $C_{p}(\lambda, \beta)=c_{1}\left(\frac{c_{2}}{\lambda_{i}}-c_{3} \beta-c_{4}\right) e^{\frac{-c_{5}}{\lambda_{i}}}+c_{6} \lambda, \frac{1}{\lambda_{i}}=\frac{1}{\lambda+0.08 \beta}-\frac{0.035}{\beta^{3}+1}$, with the coefficients as $c_{1}=$ 0.5176, $c_{2}=116, c_{3}=0.4, c_{4}=5, c_{5}=21$ and $c_{6}=0.0068 . \lambda=\frac{\omega_{r} R}{V_{\text {wind }}}$ is the tip-speed ratio.

The maximum value of $C_{p}$ is 0.48 when $\beta=0$ for $\lambda=8.1$. These are defined as base values for per unit calculations. Here base wind speed is $12 \mathrm{~m} / \mathrm{s}$, gear ratio is 10 , rotor radius is $5.16 \mathrm{~m}$. When $s=-0.2, C_{p}$ is 0.48 then $P_{m}$ is 1.0 p.u. ideally. Hence for 2 pole-pair generator, $s=\frac{\omega_{s}-\omega_{r}}{\omega_{s}}, \omega_{r_{-} p u}=1-s, \lambda=\frac{\omega_{r} R}{V_{\text {wind }}}=(1-s) \frac{5 \pi \times 5.16}{12}=6.751(1-s)=c_{7}(1-s)$.

Then at the base wind speed, the expression of $P_{m}$ in terms of slip $s$ is

$$
P_{m}=\frac{C_{p}}{0.48}=\frac{1}{0.48}\left[c_{1}\left(\frac{c_{2}}{\lambda_{i}}-c_{4}\right) e^{\frac{-c_{5}}{\lambda_{i}}}+c_{6} c_{7}(1-s)\right], \frac{1}{\lambda_{i}}=\frac{1}{c_{7}(1-s)}-0.035
$$

The above analysis is carried out in MATLAB programming, with the power flow results shown in Fig. 9. Fig. 9 shows how the rotor and stator power vary as the rotor slip changes from sub- to super-synchronous modes. The speed of the rotor has to change as wind speed changes in order to track the maximum power point of the aerodynamic system. Slip, $s$, therefore is related to incident wind speed. In this case, a slip of -0.2 occurs with rated wind speed $\left(12 \mathrm{~ms}^{-1}\right)$. As wind speed drops, slip has to increase and in this case has a maximum value of 0.35 .
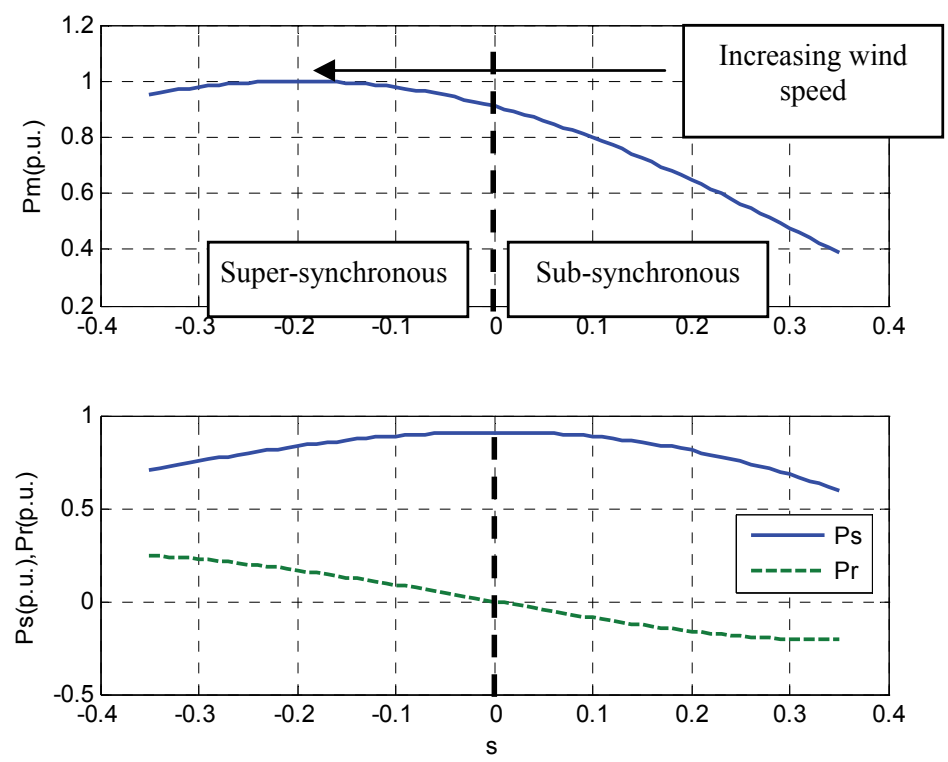

Fig. 9. Doubly-fed induction generation system power flows. 
It is clear that the mechanical power, $P_{m}$, reaches its peak at super-synchronous speed when $s=-0.2$. When rotating at the synchronous speed $(s=0)$, the DFIG supplies all the power via the stator winding, with no active power flow in the rotor windings and their associated converters. Note that at $s=0$, the stator power is maximum. As the wind speed increases, the rotational speed must also increase to maintain optimum tip-speed ratios. In such circumstances, the machine operates at super-synchronous speeds $(s<0)$. The mechanical power flows to the grid through both the stator windings and the rotor windings and their converter. For example, at $s=-0.2, P_{s}$ is $0.8 \mathrm{pu}$ and $P_{r}$ is $0.2 \mathrm{pu}$ giving a total generated power of $1 \mathrm{pu}$. At lower wind speeds, the blades rotate at a sub-synchronous speed $(s>0)$. In such circumstances, the rotor converter system will absorb power from the grid connection to provide excitation for rotor winding. For example, at $s=0.2, P_{s}$ is $0.8 \mathrm{pu}$ but $P_{r}$ is $-0.2 \mathrm{pu}$ giving a total generated power of $0.6 \mathrm{pu}$. With such a control scheme it is possible to control the power extracted from the aerodynamic system such that the blade operates at the optimum aerodynamic efficiency (thereby extracting as much energy is as possible) by adjusting the speed of rotation according to the incident wind speed.

\section{The Rotor-Side Converter (RSC)}

The rotor-side converter (RSC) applies the voltage to the rotor windings of the doubly-fed induction generator. The purpose of the rotor-side converter is to control the rotor currents such that the rotor flux position is optimally oriented with respect to the stator flux in order that the desired torque is developed at the shaft of the machine.

The rotor-side converter uses a torque controller to regulate the wind turbine output power and the voltage (or reactive power) measured at the machine stator terminals. The power is controlled in order to follow a pre-defined turbine power-speed characteristic to track the maximum power point. The actual electrical output power from the generator terminals, added to the total power losses (mechanical and electrical) is compared with the reference power obtained from the wind turbine characteristic. Usually, a Proportional-Integral (PI) regulator is used at the outer control loop to reduce the power error (or rotor speed error) to zero. The output of this regulator is the reference rotor current $i_{r q}$ ref that must be injected in the rotor winding by rotor-side converter. This $q$-axis component controls the electromagnetic torque $T_{e}$. The actual $i_{r q}$ component of rotor current is compared with $i_{r q}$ ref and the error is reduced to zero by a current PI regulator at the inner control loop. The output of this current controller is the voltage $v_{r q}$ generated by the rotor-side converter. With another similarly regulated $i_{r d}$ and $v_{r d}$ component the required 3-phase voltages applied to the rotor winding are obtained. The generic power control loop is illustrated in the next section.

\section{The Grid-Side Converter (GSC)}

The grid-side converter aims to regulate the voltage of the dc bus capacitor. Moreover, it is allowed to generate or absorb reactive power for voltage support requirements. The function is realized with two control loops as well: an outer regulation loop consisting of a dc voltage regulator. The output of the dc voltage regulator is the reference current $i_{c d}{ }^{\text {ref for }}$ the current regulator. The inner current regulation loop consists of a current regulator controlling the magnitude and phase of the voltage generated by converter from the $i_{c d} d^{r e f}$ produced by the dc voltage regulator and specified $q$-axis $i_{c q}$ ref reference.

\section{Converter losses}

The losses of the converters can be divided into switching losses and conducting losses. The switching losses of the transistors are the turn-on and turn-off losses. For the diode the 
switching losses mainly consist of turn-off losses, i.e., reverse-recovery energy. The turn-on and turn-off losses for the transistor and the reverse-recovery energy loss for a diode can be found from data sheets. The conducting losses arise from the current through the transistors and diodes. The transistor and the diode can be modeled as constant voltage drops, and a resistance in series. The switching losses of the transistor can be considered to be proportional to the current, for a given dc-link voltage. For a given dc-link voltage and switching frequency, the switching losses of the IGBT and diode can be modeled as a constant voltage drop that is independent of the current rating of the valves (Petersson, 2005).

\section{DC-link model}

The dc-link model describes the dc-link capacitor voltage variations as a function of the input power to the dc-link (Ledesma \& Usaola, 2005). The energy stored in the dc capacitor is

$$
W_{d c}=\int P_{d c} d t=\frac{1}{2} C V_{d c}^{2}
$$

Where $C$ is the capacitance, $V_{d c}$ is the voltage, $W_{d c}$ is the stored energy, and $P_{d c}$ is the input power to the dc link. The voltage and energy derivatives are

$$
\frac{d V_{d c}}{d t}=\frac{P_{d c}}{C V_{d c}}, \frac{d W_{d c}}{d t}=P_{d c}
$$

The $P_{d c}$ is calculated as $P_{d c}=P_{\text {in }}-P_{c}$. Where $P_{i n}$ is the input power from rotor-side converter and $P_{c}$ is the grid-side converter output power. The dc-link voltage varies as $P_{d c}$ and is a constant when $P_{d c}=0$.

\section{Basic Control of Real and Reactive Power using the RSC}

The grid side converter is used to partly control the flow of real and reactive power from the turbine system to the grid. The grid-side converter feeds the grid via a set of interfacing inductors. Figure 9(a) shows the single phase equivalent circuit of the system. As previously shown, the grid-side converter (a voltage source inverter) can generate a balanced set of three-phase voltages at the supply frequency and that the voltage, $E$, can have a controllable magnitude and phase. Load angle control is used to illustrate the basics of real and reactive power control, though in practise, a more sophisticated control is used which provides superior transient response. Load angle control mimics the operation of a synchronous generator connected to the network. Essentially, load angle control uses the angle, $\delta$, between the voltage generated by the grid-side converter, $E$, and the grid voltage, $V$, Figure $11(b)$, to control the real power, $P$, injected on to the grid. Likewise, reactive power, $Q$, is controlled using the magnitude of the voltage generated by the grid-side converter. The steady-state equations governing the real and reactive power flow from the grid-side converter to the grid are

$$
P=\frac{V E \sin \delta}{X_{s}} \text { and } Q=\frac{V^{2}}{X_{s}}-\frac{V E}{X_{s}} \cos \delta
$$

where $X_{s}$ is the reactance of the interfacing inductance. If $\delta$ is small the equations can be simplified to 


$$
P=\frac{V E \delta}{X_{s}} \text { and } Q=\frac{V^{2}}{X_{s}}-\frac{V E}{X_{s}}
$$

Showing that $P$ can be controlled using load angle, $\delta$, and $Q$ can be controlled using the magnitude of $E$. Interfacing inductance must be used to couple the output of the grid-side converter shown in Figure 8 to the grid. The inductor is sized according to the rating of the converter. Typically, the system will have a transformer on the turbine side of the point of common coupling (PCC). In addition, at the point of connection there is usually the need for a substation which includes whatever equipment is required by local network codes, for example, plant to disconnect the turbine under fault conditions.

The combination of control and power electronics enables the grid-side converter to produce the necessary voltage magnitude, $E$, and load angle, $\delta$, in order to meet a required $P_{c}$ and $Q_{c}$ demand set by the main system controller. The controller has to be able to synchronise to the grid frequency and phase, in order to connect and supply power. This is typically carried out using some form of phase-locked loop.

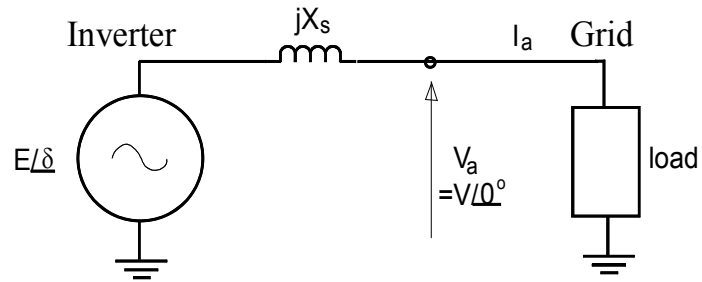

(a)

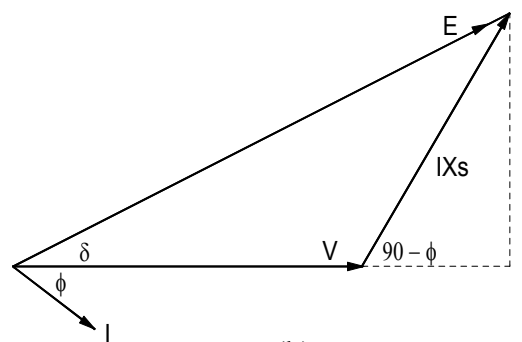

(b)

Fig. 10. (a) Single line diagram of steady-state generator-side converter connected to the grid and (b) phasor diagram demonstrating load angle control of the grid-side converter to establish exported real power and control of reactive power

At any instant, the power exported by the GSC is determined by the state of the DC link voltage. The grid-side converter controller monitors the DC link voltage. If the DC link voltage rises, the grid-side converter can export more real power by increasing the load angle in order that the DC link voltage moves back towards it nominal value. If more power is being exported by the GSC than is currently being generated by the RSC, the DC link voltage will fall below its nominal value. The grid-side controller will then reduce the exported real power to allow the DC link voltage to recover to its nominal value. In essence the DC link voltage indicates power flow balance between the generated energy and the exported energy in the rotor side. If the input and output power to the dc link capacitor do not match then the dc link voltage will change.

The quality of the energy supplied to the network must meet basic requirements and these will be set by the 'Grid Code' in force at the connection point. The grid code specifies many performance indicators of the quality of the energy supplied by the grid-side converter, along with other important issues such as fault levels, anti-islanding and disconnection. The relevant grid code(s) in operation must be determined prior to tendering for work on the turbine power electronics and control.

The grid code has important implications on the control system of the turbine. One main concern in many turbine systems is what to do if the turbine system loses its mains 
connection, say, for example, because of a network fault. Without a mains connection the turbine is unable to export energy. If the generator-side controller continues to generate power, the DC link capacitance will be over charged. Therefore, a grid fault will require the generator to stop generating energy, which then means that there is no longer a restraining torque to control the blade speed. In a wind turbine, a loss of supply will cause an overspeed condition, as the blade system will accelerate due to the aerodynamic torque produced by the blades. Shorting resistors, or a crowbar circuit, are often switched across the rotor circuit of the generator in order that the energy generated by the blade system can be absorbed and the over-speed condition controlled to a safe and manageable level. In addition, there are often aerodynamic (pitch control) and mechanical braking mechanisms included in wind turbines as an additional over-speed safety measure.

\section{Control system}

Nomenclature

$\begin{array}{ll}\vec{v}, \vec{i}, \vec{\psi} & \text { Voltage, current and flux vectors. } \\ R_{s}, R_{r} & \text { Stator, rotor winding resistances. } \\ L_{s}, L_{r}, L_{l s}, L_{l r} & \text { Stator, rotor winding self- and leakage inductances. } \\ L_{m} & \text { Magnetizing inductance. } \\ \omega_{s,}, \omega_{r}, \omega_{s l i p} & \text { Synchronous, rotor and slip angular frequencies. } \\ P, Q & \text { Active and reactive power. } \\ s, r & \text { Stator and rotor subscripts. } \\ g & \text { Grid-side value subscripts. } \\ c & \text { Converter value subscripts. } \\ d, q & d \text {-axis and } q \text {-axis component subscripts. } \\ n & \text { Nominal value subscript. } \\ r e f & \text { Reference value superscript. }\end{array}$

This section will detail the vector-control techniques used for the independent control of torque and rotor excitation current in the DFIG and decouple control of the active and reactive power supplied to the grid. The vector control for the generator can be embedded in an optimal power tracking controller for maximum energy capture in a wind power application. By controlling the active power of the converter, it is possible to vary the rotational speed of the generator, and thus the speed of the rotor of the wind turbine. This can then be used to track the optimum tip-speed ratio as the incident wind speed changes thereby extracting the maximum power from the incident wind. The grid-side converter control gives potential for optimising the grid integration with respect to steady-state operation conditions, power quality and voltage stability.

\subsection{Rotor-side converter control}

The rotor-side converter (RSC) provides the excitation for the induction machine rotor. With this PWM converter it is possible to control the torque hence the speed of the DFIG and also the power factor at the stator terminals. The rotor-side converter provides a varying excitation frequency depending on the wind speed conditions. The induction machine is controlled in a synchronously rotating $d q$-axis frame, with the $d$-axis oriented along the stator-flux vector position in one common implementation. This is called stator-flux orientation (SFO) vector control. In this way, a decoupled control between the electrical 
torque and the rotor excitation current is obtained. Consequently, the active power and reactive power are controlled independently from each other.

There are other options for directional rotating frames. Orientation frames applied in traditional vector control of induction machines such as rotor-flux orientation and magnetizing-flux orientation, can also be utilised (Vas, 1990). Additionally, the statorvoltage orientation (SVO) is also commonly-used in DFIG vector controller, as contrast with SFO (Muller et al., 2002).

To describe the control scheme, the general Park's model of an induction machine is introduced. Using the motor convention in a static stator-oriented reference frame, without saturation, the voltage vector equations are

$$
\begin{gathered}
\vec{v}_{s}=R_{s} \vec{i}_{s}+\frac{d \vec{\psi}_{s}}{d t} \\
\vec{v}_{r}=R_{r} \vec{i}_{r}+\frac{d \vec{\psi}_{r}}{d t}-j \omega \vec{\psi}_{r}
\end{gathered}
$$

where $\vec{v}_{s}$ is the stator voltage imposed by the grid. The rotor voltage $\vec{v}_{r}$ is controlled by the rotor-side converter and used to perform generator control.

The flux vector equations are

$$
\begin{aligned}
& \vec{\psi}_{s}=L_{s} \vec{i}_{s}+L_{m} \vec{i}_{r} \\
& \vec{\psi}_{r}=L_{m} \vec{i}_{s}+L_{r} \vec{i}_{r}
\end{aligned}
$$

where $L_{s}$ and $L_{r}$ are the stator and rotor self-inductances: $L_{s}=L_{m}+L_{l s}, L_{r}=L_{m}+L_{l r}$. Under stator-flux orientation (SFO), in $d q$-axis component form, the stator flux equations are:

$$
\left\{\begin{array}{l}
\psi_{s d}=L_{s} i_{s d}+L_{m} i_{r d}=\psi_{s}=L_{m} i_{m s} \\
\psi_{s q}=0
\end{array}\right.
$$

Defining leakage factor $\sigma=1-\frac{L_{m}^{2}}{L_{s} L_{r}}$ and equivalent inductance as $L_{o}=\frac{L_{m}^{2}}{L_{s}}$. The rotor voltage and flux equations are (scaled to be numerically equal to the ac per-phase values):

$$
\begin{aligned}
& \left\{\begin{array}{l}
v_{r d}=R_{r} i_{r d}+\sigma L_{r} \frac{d i_{r d}}{d t}-\omega_{s l i p} \sigma L_{r} i_{r q} \\
v_{r q}=R_{r} i_{r q}+\sigma L_{r} \frac{d i_{r q}}{d t}+\omega_{s l i p}\left(L_{o} i_{m s}+\sigma L_{r} i_{r d}\right)
\end{array}\right. \\
& \left\{\begin{array}{l}
\psi_{r d}=\frac{L_{m}^{2}}{L_{s}} i_{m s}+\sigma L_{r} i_{r d} \\
\psi_{r q}=\sigma L_{r} i_{r q}
\end{array}\right.
\end{aligned}
$$

where the slip angular speed is $\omega_{\text {slip }}=\omega_{s}-\omega_{r}$. 
The stator flux angle is calculated from

$$
\left\{\begin{array}{l}
\psi_{s \alpha}=\int\left(v_{s \alpha}-R_{s} i_{s \alpha}\right) d t \\
\psi_{s \beta}=\int\left(v_{s \beta}-R_{s} i_{s \beta}\right) d t
\end{array}, \theta_{s}=\tan ^{-1}\left(\frac{\psi_{s \beta}}{\psi_{s \alpha}}\right)\right.
$$

where $\theta_{s}$ is the stator-flux vector position.

The control scheme of the rotor-side converter is organised in a generic way with two series of two PI-controllers. Fig. 11 shows a schematic block diagram for the rotor-side converter control. The reference $q$-axis rotor current $i_{r q}{ }^{*}$ can be obtained either from an outer speedcontrol loop or from a reference torque imposed on the machine. These two options may be termed a speed-control mode or torque-control mode for the generator, instead of regulating the active power directly. For speed-control mode, one outer PI controller is to control the speed error signal in terms of maximum power point tracking. Furthermore, another PI controller is added to produce the reference signal of the $d$-axis rotor current component to control the reactive power required from the generator. Assuming that all reactive power to the machine is supplied by the stator, the reference value $i_{r d}{ }^{*}$ may set to zero. The switching dynamics of the IGBT-switches of the rotor converter are neglected and it is assumed that the rotor converter is able to follow demand values at any time.

The control system requires the measurement of the stator and rotor currents, stator voltage and the mechanical rotor position. There is no need to know the rotor-induced EMF, as is the case for the implementation with naturally commutated converters. Since the stator is connected to the grid, and the influence of the stator resistance is small, the stator magnetising current $i_{m s}$ can be considered constant (Pena et al., 1996).

Rotor excitation current control is realised by controlling rotor voltage. The $i_{r d}$ and $i_{r q}$ error signals are processed by associated PI controllers to give $v_{r d}$ and $v_{r q}$, respectively.

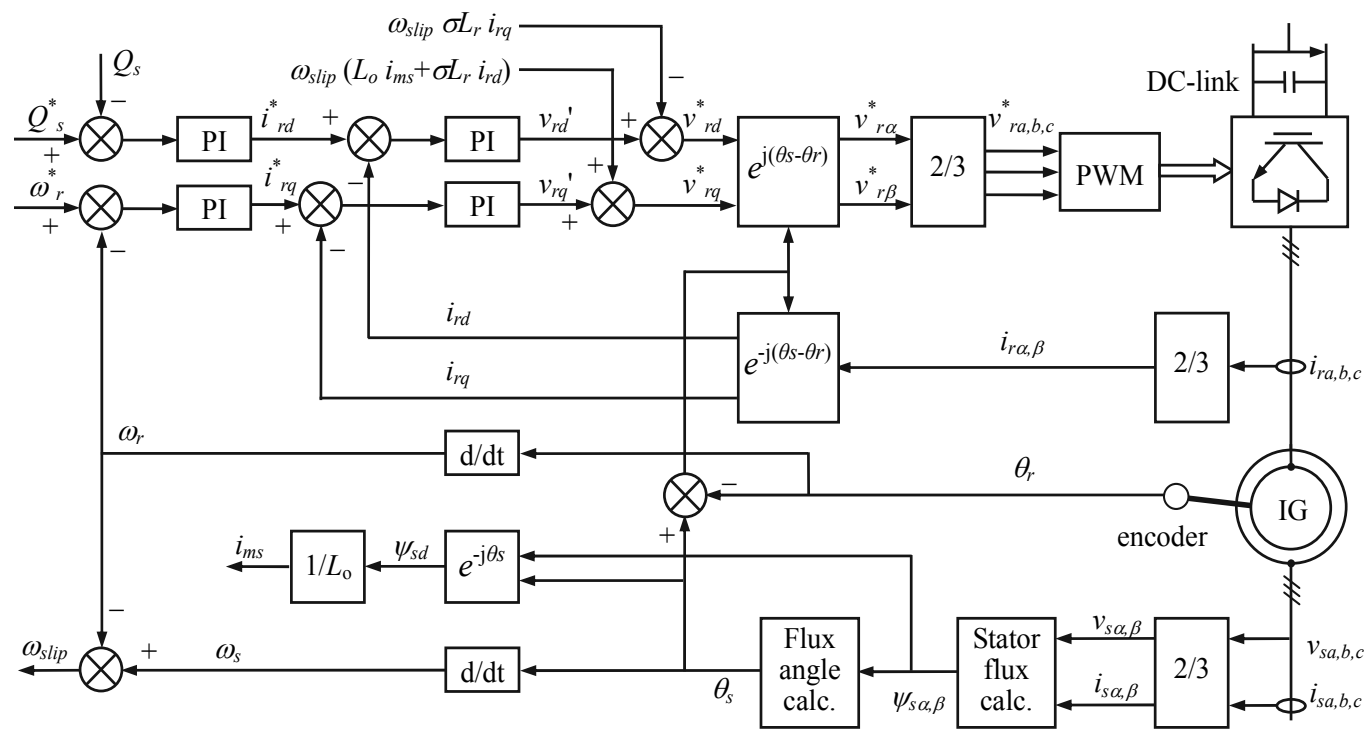

Fig. 11. Vector control structure for rotor-side converter. 
From the rotor voltage equations (26) define

$$
\left\{\begin{array}{l}
v_{r d}^{\prime}=R_{r} i_{r d}+\sigma L_{r} \frac{d i_{r d}}{d t} \\
v_{r q}^{\prime}=R_{r} i_{r q}+\sigma L_{r} \frac{d i_{r q}}{d t}
\end{array}\right.
$$

To ensure good tracking of the rotor $d q$-axis currents, compensation terms are added to $v^{\prime} r d$ and $v_{r q}^{\prime}$ to obtain the reference voltages $v_{r d}{ }^{*}$ and $v_{r q}{ }^{*}$ according to

$$
\left\{\begin{array}{l}
v_{r d}^{*}=v_{r d}^{\prime}-\omega_{\text {slip }} \sigma L_{r} i_{r q} \\
v_{r q}^{*}=v_{r q}^{\prime}+\omega_{\text {slip }}\left(L_{m} i_{m s}+\sigma L_{r} i_{r d}\right)
\end{array}\right.
$$

The electromagnetic torque is

$$
T_{e}=-\frac{3}{2} p \operatorname{Im}\left\{\vec{\psi}_{s} \vec{i}_{r}^{*}\right\}=-\frac{3}{2} p L_{o} i_{m s} i_{r q}
$$

For the stator-voltage oriented control the above equation is an approximation. However, for stator-flux orientation, the stator flux current $i_{m s}$ is almost fixed to the stator voltage. For torque mode control, since it is difficult to measure the torque, it is often realised in an open-loop manner. The torque can be controlled by the $q$-axis component of the rotor current $i_{r q}$. Therefore, the $q$-axis reference current, $i_{r q}$ ref can be determined from the reference torque $T_{e}{ }^{r e f}$ as

$$
i_{r q}^{r e f}=-\frac{2 T_{e}^{r e f}}{3 p L_{o} i_{m s}}=-\frac{2 T_{e}^{r e f}}{3 p \psi_{s}}
$$

\subsection{Grid-side converter control}

The grid-side converter controls the flow of real and reactive power to the grid, through the grid interfacing inductance. The objective of the grid-side converter is to keep the dc-link voltage constant regardless of the magnitude and direction of the rotor power. The vectorcontrol method is used as well, with a reference frame oriented along the stator voltage vector position, enabling independent control of the active and reactive power flowing between the grid and the converter. The PWM converter is current regulated, with the $d$-axis current used to regulate the dc-link voltage and the $q$-axis current component to regulate the reactive power. Fig. 12 shows the schematic control structure of the grid-side converter.

A similar analysis for the control of the $d q$ currents carried out for the grid-side converter can likewise be done for the control of the converter $d q$ currents. The voltage equations in synchronously rotating $d q$-axis reference frame are:

$$
\left\{\begin{array}{l}
v_{c d}=R i_{c d}+L_{c h o k e} \frac{d i_{c d}}{d t}-\omega_{e} L_{c h o k e} i_{c q}+v_{c d 1} \\
v_{c q}=R i_{c q}+L_{c h o k e} \frac{d i_{c q}}{d t}+\omega_{e} L_{c h o k e} i_{c d}+v_{c q 1}
\end{array}\right.
$$


The angular position of the grid voltage is calculated as $\theta_{e}=\int \omega_{e} d t=\tan ^{-1}\left(\frac{v_{c \beta}}{v_{c \alpha}}\right)$

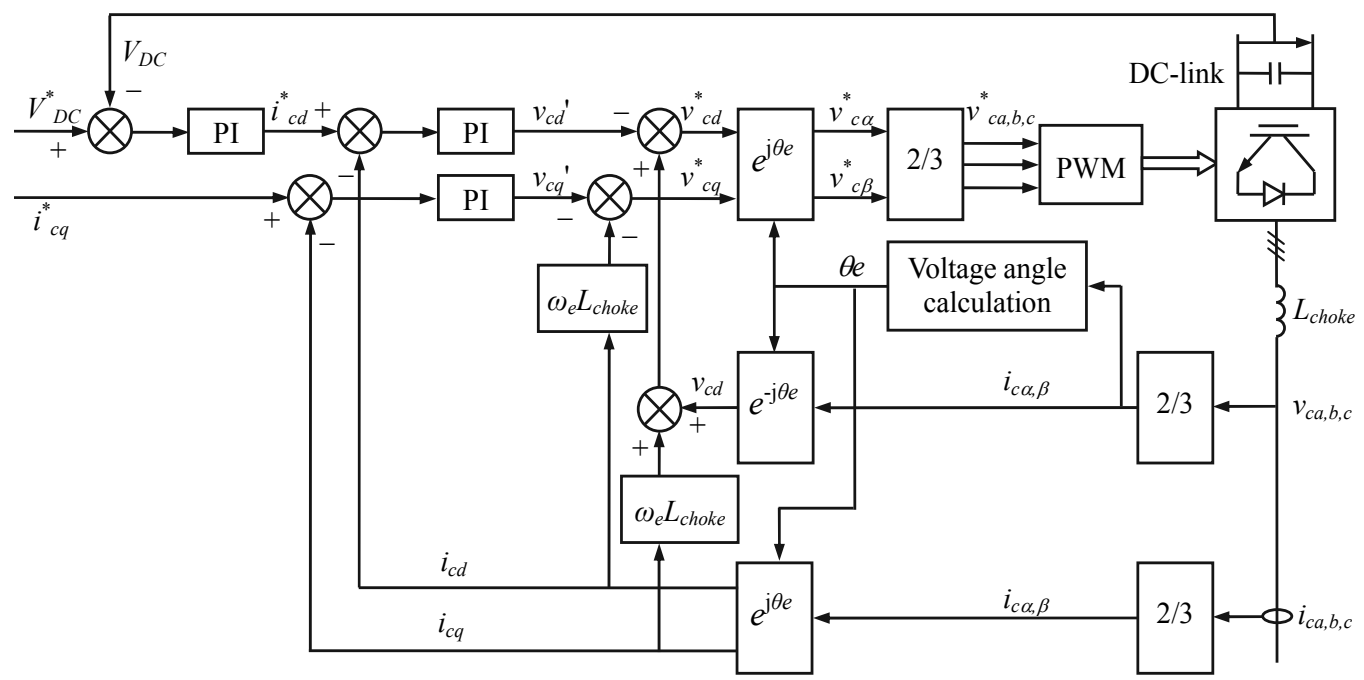

Fig. 12. Vector control structure for grid-side converter.

where $v_{c \alpha}$ and $v_{c \beta}$ are the converter grid-side voltage stationary frame components.

The $d$-axis of the reference frame is aligned with the grid voltage angular position $\theta_{e}$. Since the amplitude of the grid voltage is constant, $v_{c q}$ is zero and $v_{c d}$ is constant. The active and reactive power will be proportional to $i_{c d}$ and $i_{c q}$ respectively.

Assume the grid-side transformer connection is star, the converter active and reactive power flow is

$$
\left\{\begin{array}{l}
P_{c}=3\left(v_{c d} i_{c d}+v_{c q} i_{c q}\right)=3 v_{c d} i_{c d} \\
Q_{c}=3\left(v_{c d} i_{c q}+v_{c q} i_{c d}\right)=3 v_{c d} i_{c q}
\end{array}\right.
$$

Which demonstrates that the real and active powers from the grid-side converter are controlled by the $i_{c d}$ and $i_{c q}$ components of current respectively. To realise decoupled control, similar compensations are introduced likewise in equation (30):

$$
\left\{\begin{array}{l}
v_{c d}^{*}=-v_{c d}^{\prime}+\left(\omega_{e} L_{c h o k e} i_{c q}+v_{d}\right) \\
v_{c q}^{*}=-v_{c q}^{\prime}-\left(\omega_{e} L_{c h o k e} i_{c d}\right)
\end{array}\right.
$$

The reference voltage $v_{c d}{ }^{*}$ and $v_{c q}{ }^{*}$ are then transformed by inverse-Park transformation to give 3-phase voltage $v_{c a b c}{ }^{*}$ for the final PWM signal generation for the converter IGBT switching.

\section{Application issues}

\subsection{Industrial applications}

The DFIG system costs more than fixed-speed induction generators without converters. However, the performance and controllability are excellent in comparison with fixed- 
speed induction generator systems; they capture more wind energy, they exhibit a higher reliability gear system, and high-quality power supplied to the grid. It saves investment on full-rated power converters, and soft-starter or reactive power compensation devices (fixed-speed systems). Modern wind farms, with a nominal turbine power up to several MWs, are a typical case of DFIG application. Besides this, other applications for the DFIG systems are, for example, flywheel energy storage system, stand-along diesel systems, pumped storage power plants, or rotating converters feeding a railway grid from a constant frequency utility grid.

\subsection{Braking systems}

Braking systems for a wind turbine generation system must be able to reduce the speed of the aerodynamic rotor during abnormal scenarios, such as over speed, maintenance or fault conditions. Wind turbine design standards require two independent brakes which must be capable of reducing the wind turbine to a safe rotational speed in all anticipated wind speeds and fault conditions (Craig et al., 1998). There are usually combined conventional mechanical shaft (disk) brakes and aerodynamic brakes (for example, pitching mechanisms) for wind turbine brake systems. For a rapid response, electrodynamic braking can be used but only in the event that the electrical systems are operational. However, it has to be used in combination with a mechanical parking brake in cases when the rotor cannot be allowed to idle at a low rotational speed. Moreover, it cannot hold the rotor at standstill.

\subsection{Converter protection systems}

The prevalent DFIG converter protection scheme is crowbar protection. A crowbar is a set of resistors that are connected in parallel with the rotor winding on occurrence of an interruption. The crowbar circuit bypasses the rotor-side converter. The active crowbar control scheme connects the crowbar resistance when necessary and disables it to resume DFIG control. A braking resistor (DC-chopper) can be connected in parallel with the DC-link capacitor to limit the overcharge during low grid voltage. This protects the IGBTs from overvoltage and can dissipate energy, but this has no effect on the rotor current. It is also used as protection for the DC-link capacitor in full rated converter topologies, for example, permanent magnet synchronous generators. In a similar way to the series dynamic braking resistor, which has been used in the stator side of generators, a dynamic resistor is proposed to be put in series with the rotor (series dynamic resistor) and this limits the rotor over-current (Yang et al., 2010). Being controlled by a power-electronic switch, in normal operation, the switch is on and the resistor is bypassed; during fault conditions, the switch is off and the resistor is connected in series to the rotor winding. The rotor equivalent circuit is shown with all the above protection schemes in Fig. 13.

\section{Summary}

The DFIG system applied to wind power generation has gained considerable academic attention and industrial application during the past 10 years. In practical applications, power levels are currently reaching $3-5 \mathrm{MW}$ and the DFIG is gradually maturing as a 


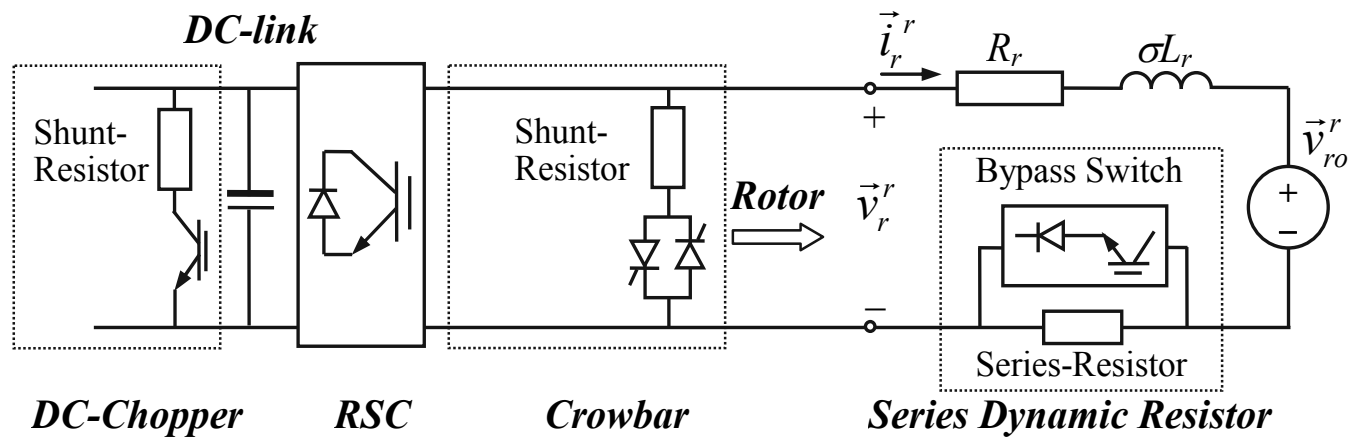

Fig. 13. DFIG rotor equivalent circuit with all protection schemes shown.

technology for variable-speed wind energy utilisation. In this chapter, the steady-state induction machine operation, back-to-back converter system and basic vector-control techniques are summarised, with practical application issues briefly summarised. Although topologies of new systems with improved performance are emerging both in academia and industry (Chen et al., 2009), DFIG is the most competitive option in terms of balance between the technical performance and economic costs.

\section{References}

Chen, Z.; Guerrero, J.M. \& Blaabjerg, F. (2009). A review of the state of the art of power electronics for wind turbines, IEEE Trans. Power Electron., Vol. 24, No. 8, August 2009, 1859-1875, ISSN 0885-8993

Craig, L.M.; Saad-Saoud, Z. \& Jenkins, N. (1998). Electrodynamic braking of wind turbines, IEE Proc.-Electr. Power Appl., Vol. 145, No. 2, March 1998, 140-146, ISSN

Ledesma, P. \& Usaola, J. (2005). Doubly fed induction generator model for transient stability analysis, IEEE Trans. Energy Conver., Vol. 20, No. 2, June 2005, 388-397, ISSN 0885-8969

Muller, S.; Deicke, M. \& De Doncker, R.W. (2002). Doubly fed induction generator systems for wind turbines, IEEE Ind. Appl. Magazine, Vol., No., May/June 2002, 26-33, ISSN 1077-2618/02

Pena, R.; Clare, J.C. \& Asher, G.M. (1996). Doubly fed induction generator using back-to-back PWM converters and its application to variable-speed wind-energy generation, IEE Proc.-Electr. Power Appl., Vol. 143, No. 3, May 1996, 231-241, ISSN

Petersson, A. (2005). Analysis, modeling and control of doubly-fed induction generators for wind turbines, Chalmers University of Technology, Goteborg, Sweden, 2005.

The Mathworks Inc. (2008). MATLAB (R2008a), Product Help.

Vas, P. (1990). Vector Control of AC Machines, Oxford University Press, ISBN 019859370 8, Oxford, UK. 
Yang, J.; Fletcher, J.E. \& O'Reilly, J. (2010). A Series-dynamic-resistor-based converter protection scheme for doubly-fed induction generator during various fault conditions, IEEE Trans. Energy Conver., Vol. 25, No. 2, June 2010, 422-432, ISSN 0885-8969 


\title{
The Role of Aesthetics, Visual and Physical Integration in Building Mounted Wind Turbines - An Alternative Approach
}

\author{
Dr. Tim Sharpe \\ Mackintosh Environmental Architecture Research Unit, Glasgow School of Art \\ Scotland, UK
}

\section{Introduction}

There context for addressing energy use in the built environment includes: the climate change agenda; concerns about peak oil supply; increasing fuel costs; costs of de-carbonising grid supply; and security of supply for certain regions. All of these highlight the value and need for renewable energy supplies. The context for the increased development of renewable energy is clear. The balance of evidence coming from the scientific community concerning the threats and impacts of anthropogenic climate change is now widely accepted (IPCC 2007). This had led to an economic analysis of the actions needed to address these problems (Stern 2007), which identify the benefits of early action. In addition to the climate change agenda, other drivers in the form of concerns about peak oil supply in turn leading to scarcity and increasing fuel costs, the costs of decarbonising grid supply, and security of supply for certain regions all highlight the value and need for renewable energy supplies.

To address these problems, a range of policies and technologies are being developed to reduce consumption and to provide a greater generating capacity of low carbon and renewable energy. This requires action at a range of scales and across industries, from national generators to individual consumers.

The built environment has particular responsibilities with respect to its demand for energy and resources. The majority of the population live in urban environments and buildings account for about $50 \%$ the UK energy consumption, and housing produces $27 \%$ of $\mathrm{CO}_{2}$ emissions (Boardman 2007). Furthermore, the need for a national grid to serve the built environment, which also results in transmission losses, is also a factor.

Energy consumption is based on both space and water heating, and electrical use for lighting, appliances, etc. These demands can be reduced by measures such as improved insulation and air tightness, and this is typified through approaches such as Passivhaus design, which aims to reduce fabric and ventilation losses to a minimum. Further reductions can be made through the use of efficient appliances and controls, but even with these measures residual electrical loads remain.

Wind energy is one of the most mature renewable technologies. The development of large scale wind farms both onshore and latterly offshore, provides a significant proportion of the UK renewable energy generation capacity. It is also one of the most visible, and thus in some quarters, contentious generators. However, the use of wind generation in urban environments has increased in scale in recent years and provides significant potential. This chapter discusses the policy drivers and approaches that are forming this market at present. 


\section{Policy}

Despite an inability of the global community to reach an accord at the Copenhagen summit, many governments are committed to action to address these problems. Both the UK and Scottish Governments have identified targets to reduce both energy and carbon reduction and these are supported through both legislation and incentives. The targets identified with the UK Climate Change Act 2008 aim for an $80 \%$ reduction in carbon emissions by 2050, with interim target of $34 \%$ by 2020 (DECC 2009). The Scottish Government Climate Change (Scotland) Act 2009 has the same 2050 target, with an interim target of $42 \%$ by 2020 (Scottish Government 2009).

Many of these targets will be achieved through reductions in demand and the decarbonisation of energy supply through both carbon reducing energy generation technologies and largescale renewable generation such as wind farms, tidal and nuclear. Nevertheless, there is considerable potential for energy production from localised, distributed, small scale systems, (generally referred to as micro generation), produced on or near buildings using a range of technologies such as photovoltaics, combined heat and power, micro-hydro and wind. An Energy Savings Trust micro generation study (Energy Saving Trust 2005) estimated that micro generation could produce up to $30-40 \%$ of electricity demand by 2050 .

Small, distributed renewable generators are extremely well placed to help achieve Government targets (A.S. Bahaj, L. Myers, 2007). Early reports such as the DTI Microgeneration strategy (DTI 2005) and the Scottish Executive Energy Efficiency and Micro-Generation Bill proposal (Boyack 2005) highlighted the potential benefits of this approach, which is now included in the Climate Change legislation. The current UK coalition government have recently opened consultation on a new Micro-generation Strategy (DECC 2010), which aims to further develop this area.

The targets set in the Climate Change legislation and also associated instruments such as the UK Low Carbon Transition Plan and the UK Renewable Energy Strategy also impact on other departments, so for example, planning authorities are also required include policies in their development plans that require a percentage of the energy in new developments to come from on-site renewables (ODPM 2004)

In order to enable businesses and consumers to take steps to meet these targets, a number of schemes for assistance, in the form of advice and financial support have also been provided. These include support for advisory organisations such as the Energy Savings Trust, and the Carbon Trust and until 2010 these organisations also administered major financial incentives in the form of grants for energy saving and renewable measures, including wind turbines.

However on the 1st April 2010 Feed-in-Tarrifs were introduced across the UK, which provides payments for the generation of electricity from small-scale renewables including Micro-Hydro turbines, Photovoltaics, Micro Combined Heat and Power, and Small Wind Turbines (UK Government 2010). The principle of FIT's is that the owner is paid a tarrif per $\mathrm{kWh}$ of renewably generated energy that offsets demand on the grid. This significantly reduces the running costs and payback periods of systems, making them financially attractive to householders and building owners.

FITs cover use of Photovoltaics (PV), small scale combined heat and power (CHP), smallscale hydroelectricity and small scale wind (up to $15 \mathrm{~kW}$ ). While all of these may be viable depending on the site location and building form, there are some key differences.

Photovoltaics are easily sited and integrated on buildings, but location, angle and orientation are very site specific, requiring good solar access and suitable weather 


\begin{tabular}{l|l|l|l|} 
Technology & Scale & Tariff level p/kWh) & Tariff lifetime (years) \\
\hline Solar electricity (PV) & $\leq 4 \mathrm{~kW}$ (retro fit) & 41.3 & 25 \\
\hline Solar electricity (PV) & $\leq 4 \mathrm{~kW}$ (new build) & 36.1 & 25 \\
\hline Wind & $\leq 1.5 \mathrm{~kW}$ & 34.5 & 20 \\
\hline Wind & $>1.5-15 \mathrm{~kW}$ & 26.7 & 20 \\
\hline Micro CHP & $\leq 2 \mathrm{~kW}$ & 10.0 & 10 \\
\hline Hydroelectricity & $\leq 15 \mathrm{~kW}$ & 19.9 & 20 \\
\hline
\end{tabular}

Table 1. Feed in Tarrifs

conditions. PV is a developing technology and although economies can be made through displacement of other building components costs such as cladding and roofing, they remain an expensive option. Although micro CHP makes efficient use of fuels, these are fossil fuels, such as gas or oil. At present systems using low carbon fuels such as biomass are either very expensive, or not available at a sufficiently small scale. Micro-hydro is very site specific and very uncommon in urban environments.

Of these wind is the most mature. However wind systems have tended to be in rural situations, and the emerging question is whether wind can be a viable and cost effective means of generating electricity on or near buildings. FIT's makes the economics of wind turbines more attractive in general, and provided turbines are well sited, they can give good power outputs and payback periods, but the potential confounding factors become more complex when considering turbines in urban environments.

\section{Urban wind systems}

Over the past 20 years there have been major advances in the technology and efficiency of large-scale wind turbines. The relatively recent use of small turbines in urban areas has remained peripheral to the mainstream wind energy industry and remains an under researched area.

However, use of this type of installation has increased in recent years, due to increasing interest in renewables amongst building owners, users and designers, combined with stimulus from grant aid. The introduction of FITs is likely to further increase demand.

There are some potential advantages to mounting turbines on buildings. The energy generated is renewable, zero carbon and localised, and can contribute to carbon reduction and micro generation strategies. It can be utilised directly by the building, and will be eligible for FIT's, making it a more economically attractive option. It also raises the profile of energy generation and use and there is some evidence that this can help to raise awareness of consumption among building users.

There are also possible benefits to be derived from the theoretical augmentation of wind flow around buildings, (Mertens, 2002 and 2003) and this research has been developed in relation to building forms (Taylor 2998) (Steemers et al 1996), (Lu and Ip 2007). This has also led to research into the use of ducted wind systems on buildings (Dannecker \& Grant 2002), (Watson el at 2007).

As a result of these factors the small wind $(>15 \mathrm{~kW})$ market has achieved major expansion over the past 5 years with generating capacity increasing from $2.47 \mathrm{GWh}$ in 2005 to $35.8 \mathrm{GWh}$ in 2009, resulting in carbon savings of 1558t in 2005 to 22,000t in 2009 (Renewable UK, 2010).

Several areas of growth within this are noted. Firstly, the majority of installed turbines are freestanding with a cumulative total of 11483 machines installed in 2009. However, the 
number of building mounted turbines has increased from 2 in 2005, to a total of 2432 in 2009. The vast majority of turbine systems are Horizontal Axis (HAWT) turbines (97\% in 2009), but in recent years there have been an increasing number of Vertical Axis (VAWT) turbines emerging on the market.

At present there are over $20 \mathrm{UK}$ and many more overseas companies active in the UK market. In 2009 there were over 3280 different turbine types rising from only 1163 in 2005.

Overall the picture of the small wind market is that is steadily increasing and all the indications are that the introduction of FITs will provide a significant boost. Indications are that the number of grid-connected systems will increase.

Although the indications are that the number of building mounted system may increase, the projected percentage increase is not great and it is apparent that this type of application is at something of a crossroads. Difficulties have been encountered with building mounted systems and the Warwick Wind Trials in 2009 (Encraft 2009) examined the operation of 26 building mounted wind turbines from five manufacturers across the UK during 2007-2008. These turbines were mounted on sites ranging from theoretically poor (single storey urban buildings) through to theoretically excellent ( $45 \mathrm{~m}$ tall exposed flats in isolated settings on hilltops).

The study found wide discrepancies in performance and output from the varying turbines and sites, and only those system on tall buildings produced useful amounts of energy. Predictions of power generation, particularly on low-rise sites were very inaccurate, due in part to poor predictions of wind speeds, but also inaccurate power curves from some manufacturers. Despite attempts to improve this by tools such as $\mu$-Wind (Bahai et al 2007), subsequent research has shown that performance remains highly site-specific (Peacock et. Al 2008).

Thus while there is a potential market for building mounted machines there is increasing evidence that mounting turbines on to or near buildings has been detrimental to performance (Carbon Trust 2008) resulting in relatively poor cost-effectiveness (Mithraratne, 2009). The possible exception to this is turbines mounted on tall buildings, which have been demonstrated to have greater effectiveness (Phillips et al 2007).

\section{Technical barriers}

Mounting turbines onto buildings presents a number of technical and aesthetic challenges. The additional cost of installation is also proving to be a significant barrier to building mounted systems (Sharpe 2008). Most systems require a bespoke adaption to a generic ground fixing system and this requires additional design and fabrication as well as statutory permissions such as planning permission and building warrant. Furthermore, the costs of installation and later maintenance, for example crane hire, road closure and costs associated with working at height, particularly on high or exposed parts of buildings, compromise their cost-effectiveness.

As well as the principle issues of performance, several other issues arise when considering building integrated systems:

\subsection{Structure and construction}

The structure of the building needs to provide sufficient lateral stability due to increased wind loading, and be able to accommodate fixing points for the turbine itself. These will be 
at the highest points of the building, typically at gable ends and eaves on smaller buildings and at roof level on multi-story buildings. While the additional lateral loads to the building as a whole are not likely to be large, the point loads produced by the fixings may be substantial, and this can be problematic for smaller buildings with weaker structures. Larger turbines may also require an additional bespoke fixing system, depending on the nature of the underlying construction, size of turbine and method of assembly and maintenance.

\subsection{Installation}

Free-standing turbines incorporate a simple base fixing system, generally a concrete pad and can be assembled at ground level. For building mounted systems, fixing has to be at height and this can require the use of machinery for lifting, increasing cost and complexity. This is particularly the case for tall buildings, which will require a crane.

\subsection{Maintenance}

There is need for safe access for maintenance of the turbines. This is typically an annual inspection. For smaller buildings this may be possible by ladder access, or cherry picker but for larger turbines on taller buildings, the roof space must enable access and some arrangement is required to access to the generator and blades. A common method is a hinged base to allow the turbines to be tilted flat. The orientation and mechanism for this requires further consideration in relation to the roof design. Flat roofs make this straightforward, but more detailed consideration would be required for sloping and curved roof forms.

\subsection{Service requirements}

In order to be effective the provision should make the best possible use of existing service provision. Minimal additional requirements would include an inverter and associated switchgear will require space within the building.

\subsection{Safety}

Safety is a primary concern with the use of turbines in urban, populated environments. There are four main identified concerns: failure or the turbine or fixings leading to collapse, proximity to people; blade shedding; ice formation and shedding. While there have been no recorded incidents of these problems, the installed base is small and the need to evaluate and undertake risk assessment contributes to the complexity and cost of the installation.

\subsection{Environmental Impact}

Noise and vibration are major concerns associated with turbines. Smaller turbines are quieter and generally do not require gearing mechanisms as the rotor is coupled directly to the generator, which is the main source of noise. In addition the ambient noise in urban contexts also provides some masking of turbine noise. In general noise has not been found to be a major issue, however there are some examples where complaints by residents have led to turbines being removed.

The risk of vibration may be present if transmitted directly to the structure and this may require the use of damped bearings. Other environmental concerns include visual flickering, radio, TV and telephone interference, aircraft safety, and bat and bird life. 


\section{Aesthetic barriers}

When considering the use of turbines in the urban environment, their appearance becomes a key issue. Consideration would include the appearance from a distance, shadow casting (especially of moving blades), integration with building form and the actual turbine design. Whilst technical issues can be investigated and solved, the question of appearance and visual integration is harder to address. The majority of turbines are unmodified HAWT systems, designed from a cost and utilitarian standpoint and these have not been designed to be integrated visually with buildings. The majority of installations consist of a conventional turbine, mounted on a mast, which is fixed to the host building.

However there have been systems coming onto the market that have been developed specifically for the urban environment in which their appearance is an important factor. This has resulted in several commercially available turbines that are marketed for the built environment as evidenced in their product literature, for example, Swift "is the first quiet rooftop wind turbine" (www.swiftwindturbine.com). Of particular interest is the development of VAWT systems for building integration such the Quiet Revolution produced by $\mathrm{XCO} 2$ "designed in response to increasing demand for wind turbines that work well in the urban environment" (www.quietrevolution.co.uk), and Turby "especially designed for use in the built-up environment (urban areas) on the rooftop of high buildings" (www.turby.nl). VAWT turbines have the advantage they do not need to rotate to face wind direction, and are visually more suited to being building mounted, but in general are not as efficient as HAWT installations.

A critical issue in regard to building integrated turbines is the impact that appearance and integration can have on planning consents. Until recently, the relative novelty of building integrated turbines meant that planning departments had difficulty dealing with such applications, and this led in many cases to delays, requests for further information, or problematic conditions, for example, mounting turbines below the roofline.

In England and Scotland, changes to permitted development rights for renewable technologies introduced on 6th April 2008 and 12th March 2009 respectively, have lifted the requirements for planning permission for most domestic microgeneration technologies, however this legislation does not yet extent to small wind.

Accordingly small wind energy installations still require planning permission and local consultation with relevant stakeholders, such as neighbours. Deciding factors include environmental considerations, access to the site, noise and visual effect. Overall, national planning policies support the development of small-scale wind energy, and the introduction of Planning Policy Statement 22 (PPS22), (ODPM 2004), sets out a clear national policy framework on renewable energy for planning authorities to ensure that the Government's renewable energy targets are met. Under PPS22 regional and Local Planning Authorities should recognise the full range of renewable energy sources, their differing characteristics, locational requirements and the potential for exploiting them subject to appropriate environmental safeguards. PPS22 introduces a new policy area for small systems by encouraging Local Planning Authorities to require that new developments should supply a percentage of their energy needs from onsite renewable energy sources.

Similar proposals exist in Scotland with the Planning Advice Note 45 'Planning for Micro Renewables' and at present there is a consultation on permitted development rights for microgeneration equipment on non-domestic properties. This consultation invites views on what the thresholds might be for microgeneration equipment on non-domestic properties. 
Introducing the proposals would remove the need for a planning application to be submitted for the equipment falling within the thresholds.

Although this guidance may assist the planning process, the issue of visual integration remains a critical issue in respect of building owners and occupiers.

\section{Architectural Integration}

It is a fundamental tenet of architectural design that the form and appearance of the building is critical. Issues of context, site and materials are used within the design process to determine an architectural approach to a particular building and place. The ability of renewable systems to be effective visually integrated within a design concept is therefore a critical concern. A distinction may be drawn here between installations on new and existing buildings, which can have very different approaches.

\subsection{New buildings}

With new buildings, the ability to make the building energy efficient through its fabric performance, form, orientation and mechanical systems provides the greatest scope for energy and carbon reduction. However, in most cases residual energy demands, particularly electricity remain and this demand can potentially be met through building integrated renewable energy generation. With a new building design, the capacity to incorporate turbines into the overall building form is greater. An early demonstration of this concept was the ProjectWEB project (Campbell \& Stankovic 2001), and whilst several building concepts incorporating integrated turbines have been publicised, for example Bill Dunsters Flower Tower (http://www.zedhomes.com/html/about/options/skyzed/) and more recently the Dynamic Revolutions project (www.dynamicarchitecture.net), It is only relatively recently that this approach has now been realised with high profile buildings such as the Bahrain World Trade Centre (www.bahrainwtc.com), and in the UK the Strata development (ww.stratalondon.com).

The difficulty with this approach is that it requires a particular building form to concentrate air flow and accommodate the turbine system, both of which will compromise the plan and plot ratio of the building. These issues may not be critical for one-off, high specification landmark buildings, but it does limit their potential replicability. Approaches such as Strata in which the installation is at roof level minimise this, but nevertheless, such bespoke arrangements will necessarily be expensive.

The other key question is how efficient these turbines are in practice in terms of power output, and environmental impacts such as noise and vibration, but to date there is not sufficient results from these projects. This type of installation requires one-off turbine systems, which will be expensive, and accurate predictions of power curves and outputs will be difficult to calculate. Cost effectiveness will also be limited, although this is likely to be a secondary consideration for these types of development.

\subsection{Existing buildings}

The use of wind turbines on existing buildings is perhaps a more important consideration. To return to the context for a moment, it is estimated that up to $87 \%$ of the homes that will exist in 2050 have already been built, (Boardman 2007) and 85\% of this was built before 1985 (Gaterell \& Mcevoy 2005). 


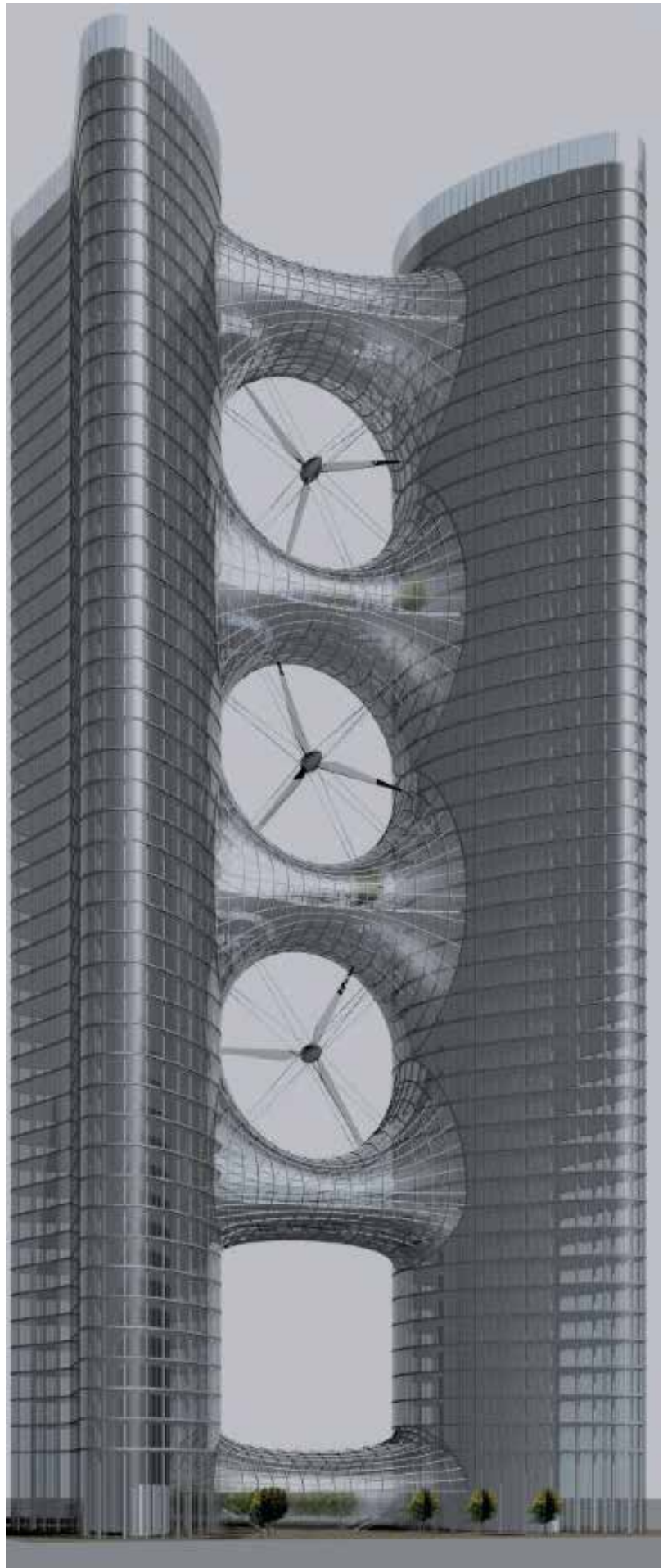

Fig. 1. Project Web: Wind Energy For The Built Environment proposal 


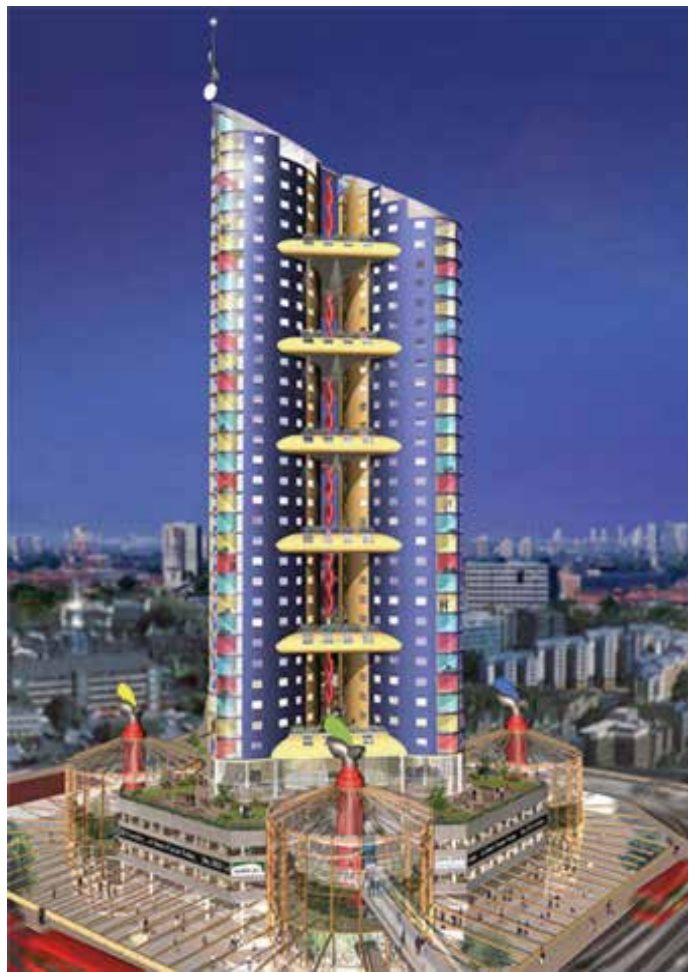

Fig. 2. SkyZED proposal

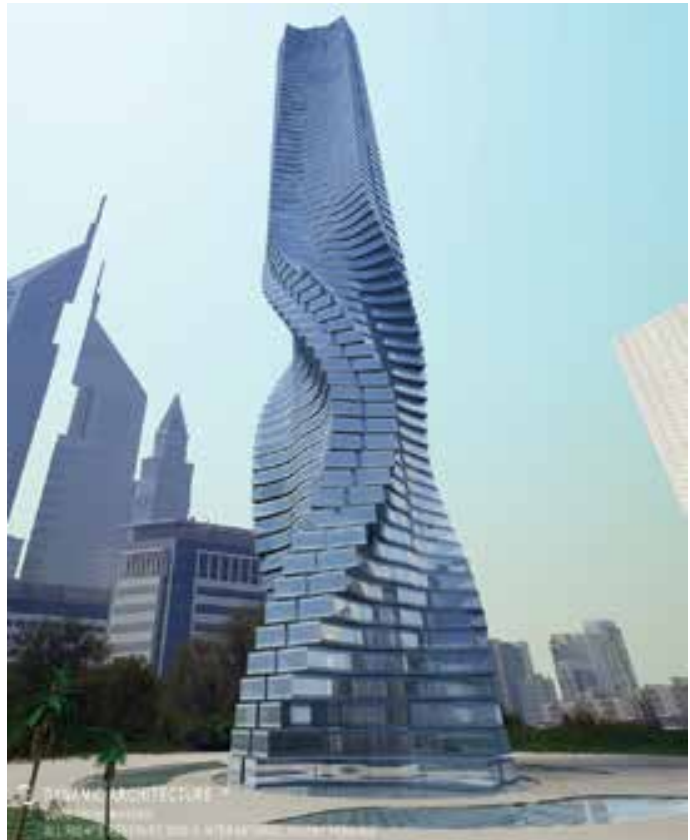

Fig. 3. Dynamic Architecture 


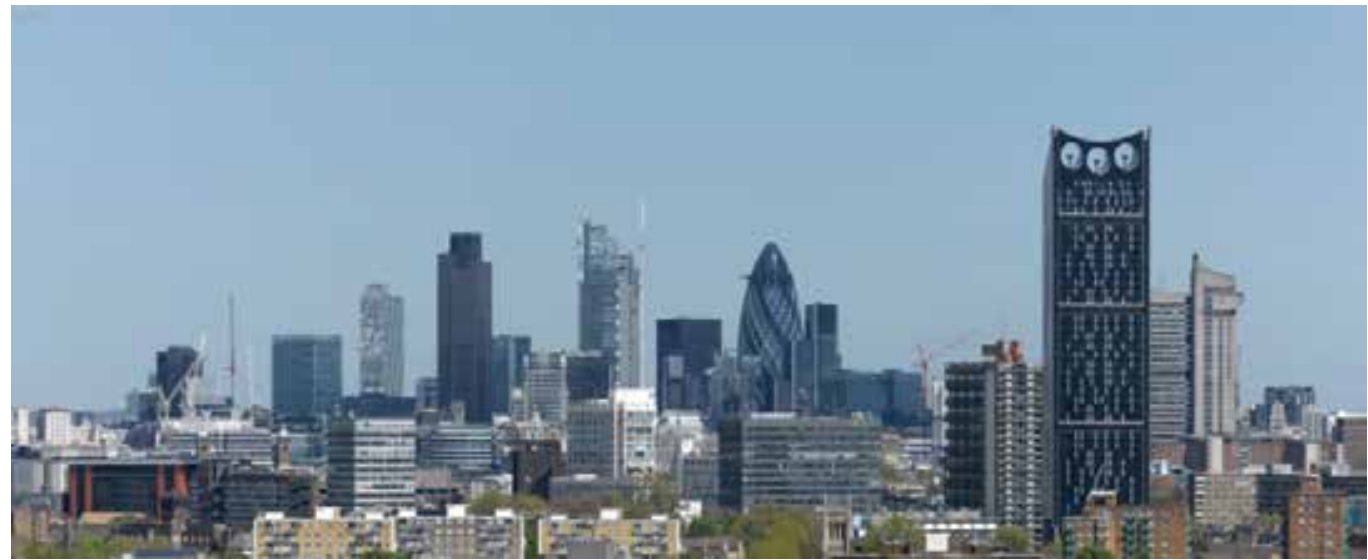

Fig. 4. The Strata Building, London.

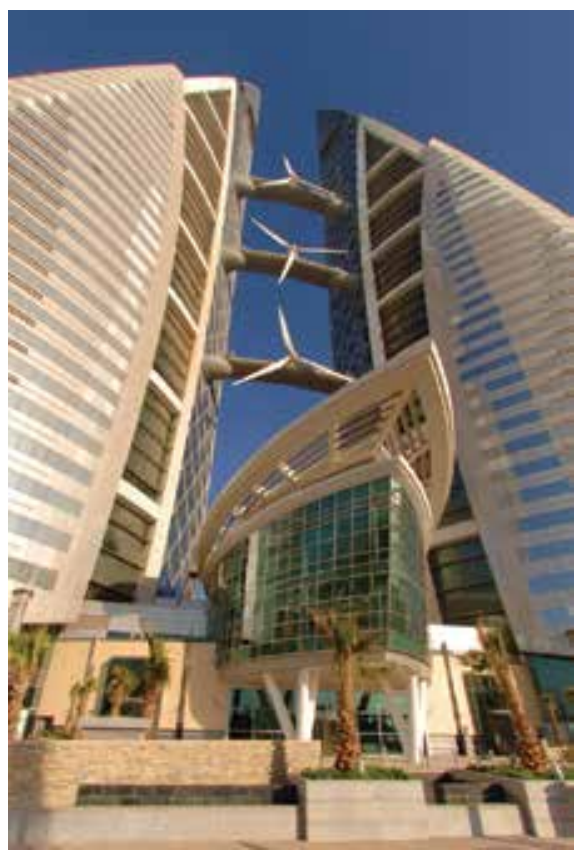

Fig. 5. Bahrain World Trade Centre

As existing buildings were built to lower standards and are far less thermally efficient, their carbon production is far more problematic. At the same time, reductions in demand through refurbishment are technically harder to achieve due to existing construction and materials and accordingly are more expensive. Retrofit of insulation cannot generally meet the standards of new construction, and the existing layout will also tend to compromise other energy saving measures.

For existing buildings then, even with improvements in performance, residual electrical loads are likely to be higher. This can increase the attractiveness of renewable generation in terms of carbon reductions, but at the same time limitations through the building form, 
orientation, exposure and construction compromises the type size, placement and utilisation of the systems.

In situations where turbines have been installed on existing buildings, the prevalent condition is the use of an existing turbine system, which has been mounted on the building, generally at roof level. The majority of monitored data has come from this type of installation, and as indicated in the Warwick Wind trials, the overall performance has been disappointing.

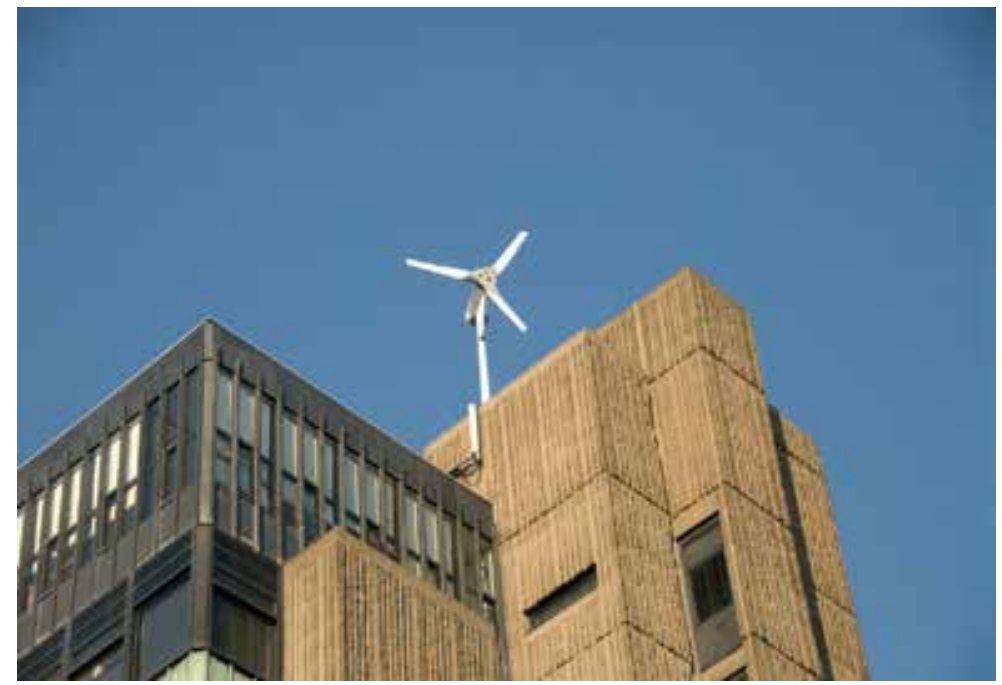

Fig. 6. Roof mounted turbine

Well-sited turbines can be effective, but the additional installation and maintenance costs undermine their overall economic viability. Although it can be demonstrated that there are economies of scale that can improve pay-back, the most effective technique for improving output - use of larger turbines - is not visually or technically feasible on buildings. There are four reasons for this.

1. Large turbines would generate significant loads on the host building. These are generally not problems of the lateral stability of the building itself, but more localised loads onto the connection points.

2. The ability to access the turbine for maintenance or repair would be difficult and expensive.

3. Potential environmental factors such as noise and vibration may become more apparent, especially when the generator becomes large enough to require a gearing mechanism.

4. The relationship of the size of the turbine to the building itself. Although larger buildings could accommodate larger turbines, the overall proportion would limit what was visually acceptable.

In the case of existing buildings, there is very little scope for the form of the building to be adapted to aid integration. Alterations to the building form will be technically difficult and therefore expensive. The primary mechanism therefore to improve appearance resides with the turbine design itself, and appears to be a viable tool in the marketing and implementation of urban turbines. It is interesting that promotion of these types of systems 
has primarily been through their aesthetic performance, rather than any direct benefit of being building mounted.

Thus there exists a dichotomy with regards to visual appearance of turbines on buildings. On the one hand, improved appearance and integration can improve the attractiveness of this option, leading to a greater installed capacity. On the other hand, there is a danger that this type of installation may be used as a visual signifier of sustainability, and if these installations do not perform well, the market may become undermined.

The fact that the popularity of some turbine forms is not based solely on their generating capacity illustrates the value placed on the appearance of devices that will be visible to the public. While attractive appearance may be a useful driver to adoption of this technology, there is some inherent risk in this if the rationale is driven by public profile, rather than a realistic assessment of energy production. The term 'eco-bling' has been used to describe ostensible, but ineffectual devices by Professor Doug King, and this is evidenced to some extent by the developer of the Strata project: "The brief we gave to Hamilton's Architects was we wanted a statement, we wanted to create benchmarks for sustainability and urban living. We wanted something bold, we wanted remarkable." (Black 2010)

The evidence presented so far would lead to the conclusion that small wind is generally not viable in urban situations, but this may not be a true picture. Firstly, it is apparent that many turbines are not well sited, either in terms of geographical location, or placement on the building. This is hampered by difficulties in accurate prediction of performance, both through reliable manufacturers data, and predictions of wind at particular sites. Many efficient systems are not visually attractive and are difficult to visually integrate onto buildings.

However, in situations where efficient turbines have been well sited, marked improvements in performance are recorded (ENCRAFT 2009), and certain building forms, such as high-rise buildings can deliver good performance.

In summary, whilst there are policy and economic drivers leading to an increasing demand for urban turbines, the current state of the art has not produced an effective building integrated turbine. At present it seems unlikely that a solution will emerge from a conventional HAWT, which in general are designed for mast mounting in unobstructed areas. In considering the shortfalls of existing systems, the following desirable characteristics emerge:

- $\quad$ Building integrated for visual performance.

- Building integrated for augmented flow.

- Scalable and economic.

- Good power output in turbulent and gusting sites.

- Ease of installation.

- Applicable in a wide variety of locations.

\section{Crossflex}

To address these issues an concept originally developed by Proven Energy and further developed by MEARU, proposes an alternative turbine for use in the urban environment. 'Crossflex' is based on a Darrieus turbine, but includes a number of innovations to improve its performance and applicability in the built environment.

Crossflex takes the basic Darrieus form but mounts it within a frame with the shaft held at either end. The blades incorporate low solidity and low mass materials, which being flexible, can assume a natural troposkein shape at speed, Control of rotor speed and 
overspeed protection is proposed by means of passive twisting of the blades. The design concept is a system that is modular rather than scalable. Based on a $1 \mathrm{~kW}$ unit, increased capacity is derived from a greater number of units (Sharpe \& Proven, 2010).

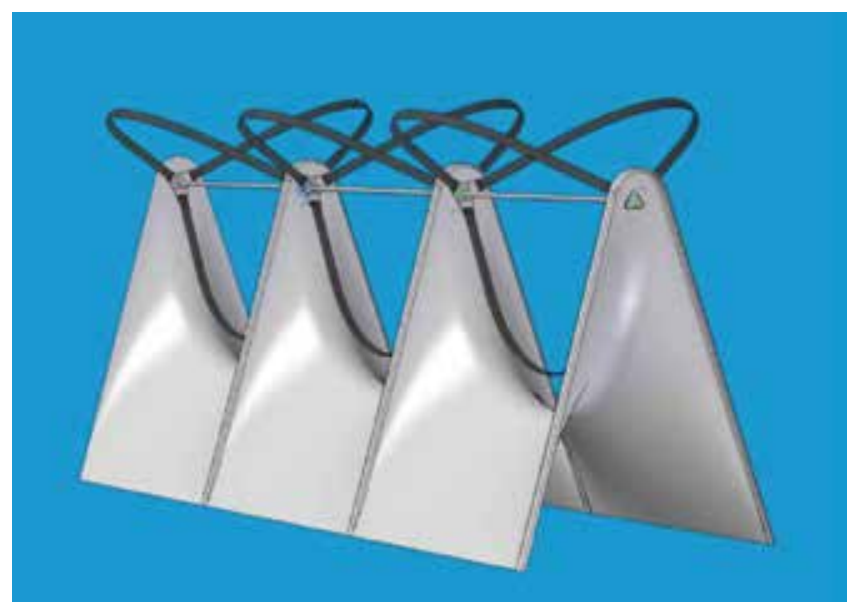

Fig. 7. Crossflex concept

The research to date has examined a number of issues related to the theoretical performance, particularly those relating to the blade design. Work has also been undertaken on the potential for building integration.

\subsection{Technical innovations}

The critical design issues include the variable twist aerofoil sections, the pitch control mechanism, aeroelastic stability issues and noise and vibration control. These have been examined using a theoretical model developed from the multiple streamtube momentum balance approach first developed by Strickland (Strickland 1975) and later improved by Paraschivoiu (Paraschivoiu 2002) for more specific purposes such as analysing self starting capabilities, assessing toe-in/ toe-out angles, factoring for downwind losses and crucially, investigating the potential for passive over speed control via blade pitch control. Analysis has been based on a turbine with the following specifications: Rotor height $=2.73 \mathrm{~m}$, radius $=2.436 \mathrm{~m}$, chord $=0.07 \mathrm{~m}$, blade length $=3.55 \mathrm{~m}$, blades $=3$, swept area $=4.44 \mathrm{~m} 2$ ). The provisional power curve is shown in Fig. 8.

Several configurations of blade cross-section are under consideration. As very little bending is experienced, there is greater scope for use of anisotropic materials, or composites to provide the section shape, with various configurations of ropes or wires providing the principal tensile strength.

Small toe-in and toe-out angles are required to smooth the torque peaks of the upwind and downwind sections. However the variation of toe-in and toe-out angles with wind speed are roughly linear, so could be configured with a spring to gradually increase the magnitude of the negative pitch angle with increasing rpm (via centrifugal force).

Consideration of the rotational speed of the rotor is also required. Limiting the rotor rpm is important when considering the generator coupled to the rotor shaft, as most generators operate most effectively within a fairly narrow ratio of maximum to minimum rpm, usually about 4-to-1. 


\section{Power vs rpm with increasing wind speed}

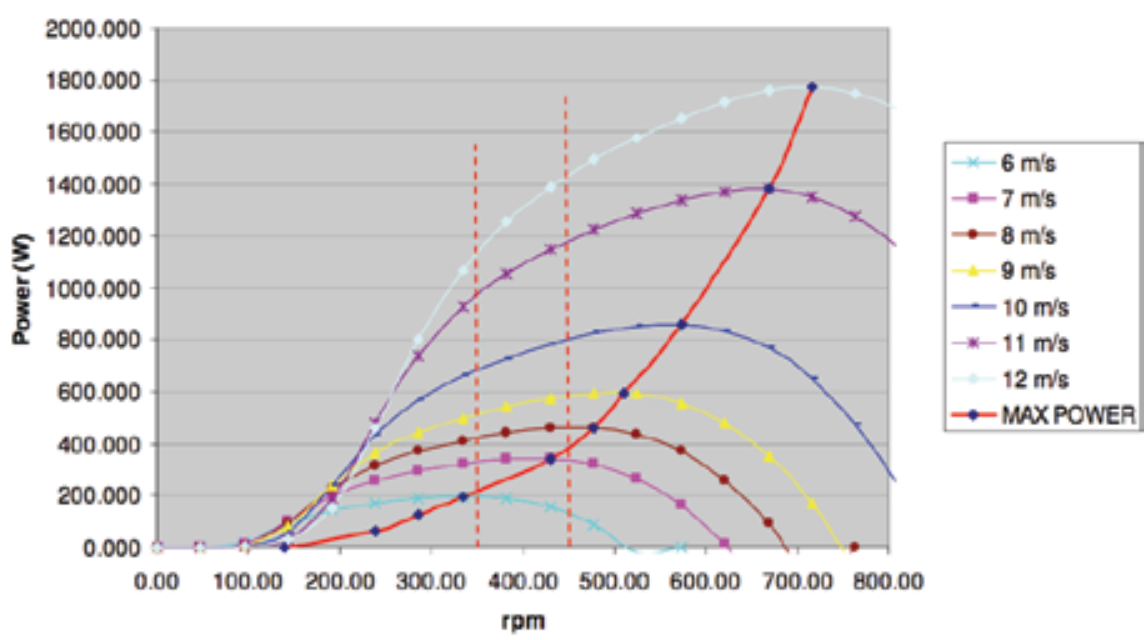

Fig. 8. Power vs rpm with increasing wind speed

Most turbines operate at fixed rotational speeds except when starting and stopping and this is beneficial when using synchronous generators in parallel with the utility grid. However, this means that the maximum coefficient of performance $\mathrm{Cpm}$ is available only at one particular wind speed. A lower coefficient of performance is observed for all other wind speeds, which reduces the energy output below that which might be expected from variable speed operation.

This indicates that if fixed speed operation is required, then $450 \mathrm{rpm}$ is a good choice of operating $\mathrm{rpm}$ for sites with a high percentage of winds between 6 and $10 \mathrm{~m} / \mathrm{s}$ since the turbine can deliver nearly the maximum possible shaft power over this wind speed range.

Analysis of the turbine torque versus the load torque indicates that a variable speed turbine is technically possible. There is a possibility of simplified construction and lower costs and also a possibility of greater energy production from a given rotor. Fixed speed systems will probably dominate where induction or synchronous generators are used to supply power to the grid, but variable speed systems may find a role in stand-alone situations.

Although a generator with a suitable load characteristic can limit the rotor speed, a further limiting device is required should the generator either fail or provide insufficient counter torque in gusty conditions. Ideally this other speed limiting device will take the form of a passive mechanism which induces a pitch change at a specific rpm and so drastically reduces the aerodynamic performance of the blades in order to limit the rotor torque above that rpm. Possible models being examined include twisting of the blade, either through feathering or stalling. This will depend on the blade material and construction, and also the nature of the fixing at the blade root. The use of dampers at these points, either at one end or both ends, seems the most promising approach.

The power density based on the streamtube analysis is promising, indicating a power output of up to $1 \mathrm{~kW}$ and a power density $0.196 \mathrm{~kW} / \mathrm{m}^{2}$. However this analysis does not take into account induced velocities. Allowing for this but also modifying the toe-out angle indicated a figure of $0.79 \mathrm{~kW}$, but work on ducted and augmented systems suggests that additional enhancements are possible through the form of the cowling. 


\subsection{Visual integration}

This form has several advantages with regard to building integration and may help to over come a number of the problems that existing systems have encountered. The shaft is supported at either end and therefore is in simple bending, as opposed to a cantilever in a conventional Darrieus system, and so the loads on the fixings, shaft and bearings are distributed significantly reduced and smaller, lighter elements can be used.

The cowling also provides a much greater range of potential fixing points to the host structure. Not only does this distribute the loads imposed onto the host structure, it also enables a degree of adaption to varying underlying forms. Thus fixing points can be positioned, within certain limits, to suit the structural system of the host structure. This is a critical aspect in relation to the application to existing buildings, in which the structure is varied, and generally cannot be altered. For example, a building with steel trusses at $2400 \mathrm{~mm}$ centres section may only require four fixing points on two trusses, but one with weaker timber trusses at $600 \mathrm{~mm}$ centres may accommodate up to ten fixings over five trusses.

The shape of the cowl has the potential to augment and concentrate airflow over the blades. One of the variable factors in the urban environment is the presence of turbulent airflows and vortex shedding around buildings. As buildings are not generally designed to accommodate this, some adaption is necessary to help smooth airflow into the turbine path, and the benefits of this have been identified in previous work (Aguilo et al 2004), (Wang et al 2008)

The cowl will also be the main visual element of the system and the choice of material, colour and texture can be varied to suit the host structure. This has the advantage that the host structure does not require any adaption to aid physical or visual integration.

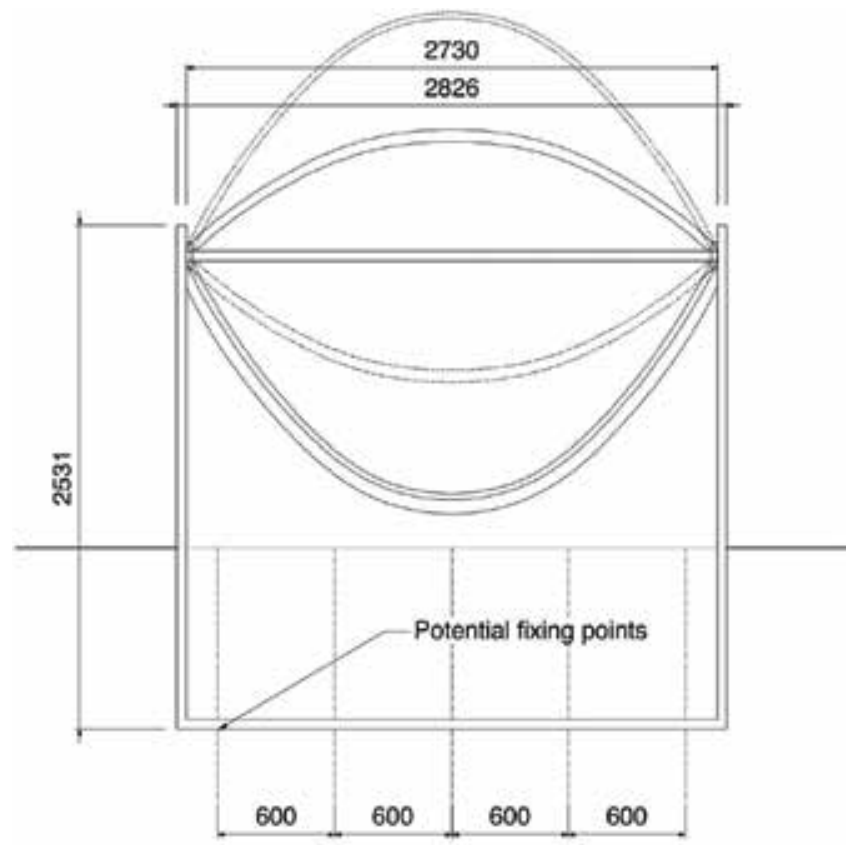

Fig. 9. Overall dimensions and fixing points 


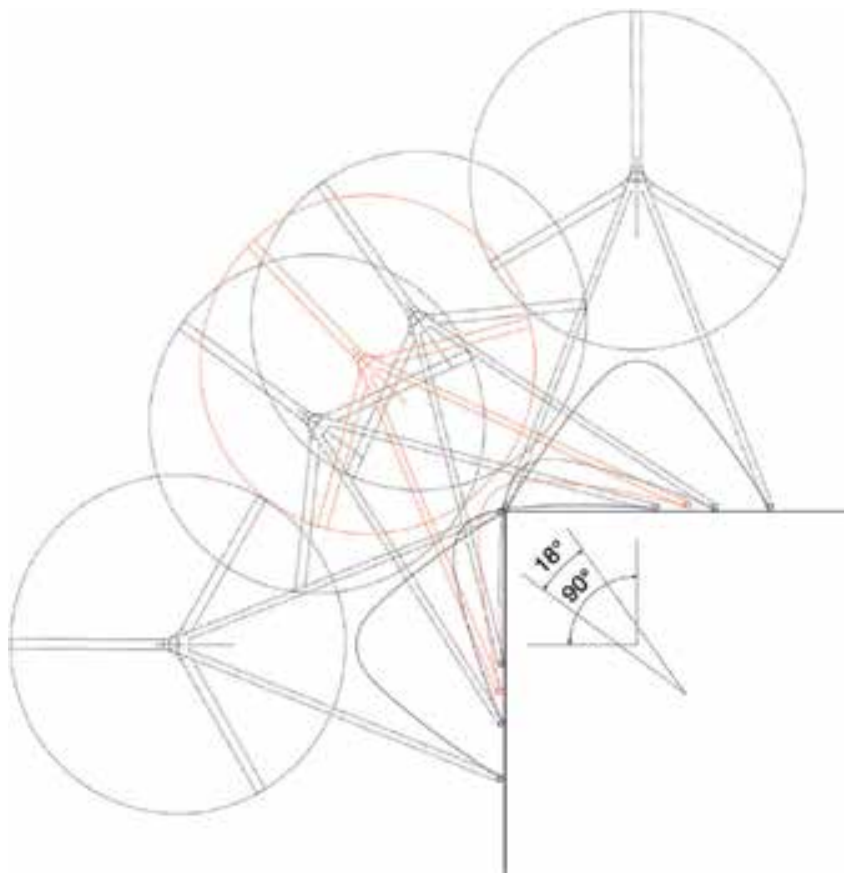

Fig. 10. Geometric arrangements for locations.

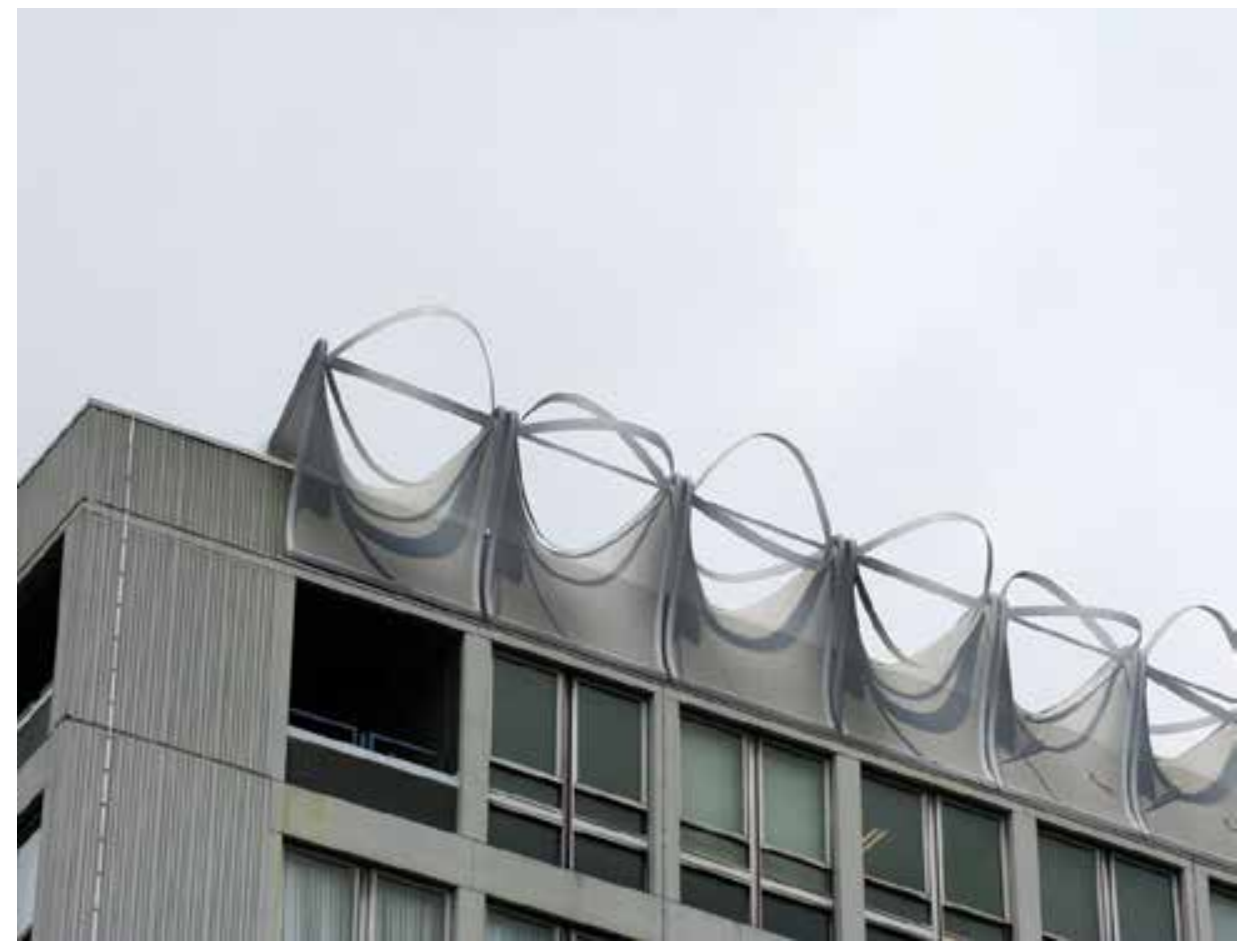

Fig. 11. Horizontal Arrangement 


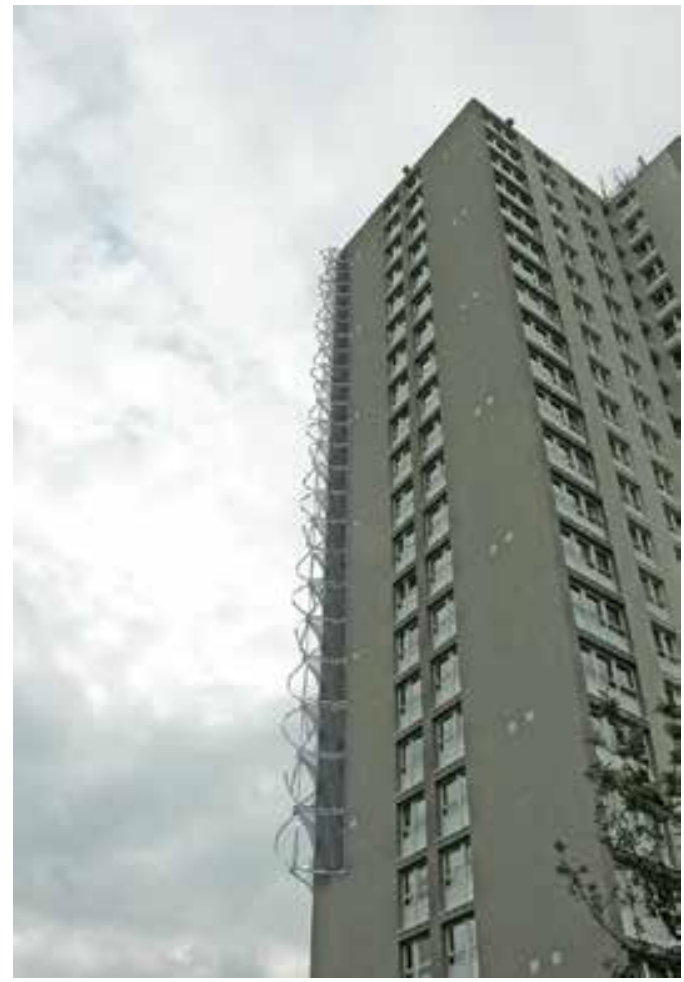

Fig. 12. Vertical Arrangement

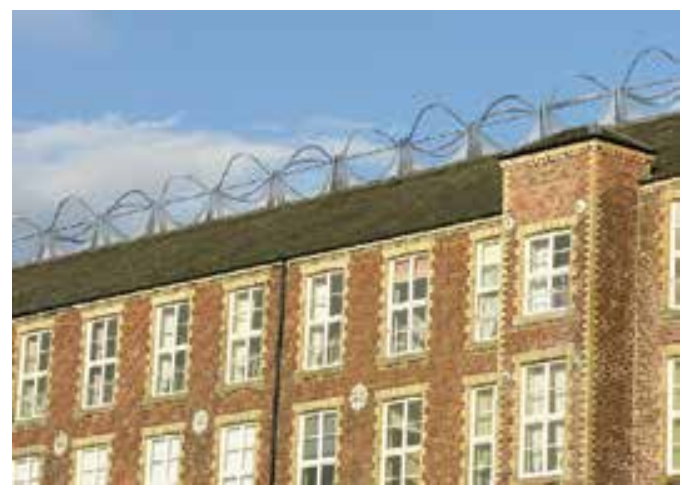

Fig. 13. Pitched roof mounting.

There are a number of possible materials that may be used to form the cowl, the most obvious being composite materials such as glass or carbon reinforced plastics. This may provide the opportunity for the cowl to act as a monococque structure. However, the localised loads at the shaft connection may be difficult to accommodate, and issues of vibration would need to be analysed.

The alternative strategy would be to provide a steel structural frame, with a very lightweight skin. The required shape of the cowl naturally produces an anticlastic form and this allows the use fabrics and films. As well as being very lightweight, these can also 
potentially provide some degree of transparency to reduce its visual impact and aid visual integration, as well as being be easily replaceable.

A key aspect of the proposal is that of modularity. As previously discussed, conventional turbine development has attempted to provide efficiency and capacity though increased scale. In the built environment market there are limitations to the size of turbine that can be accommodated both technically in terms of loads, and visually in terms of scale and integration.

The intention behind Crossflex is to produce a relatively small, but potentially modular device. Keeping the turbine small helps to minimise and distribute structural loads, reduces vibration to the host structure, and reduces the scale of plant required for installation.

A modular system can use a larger number of units to increase capacity. This is an especially important characteristic in relation to corner and edge mounting on tall buildings whereby installation capacity is significantly greater. This can be illustrated in Fig. 14, which shows a comparison of the visual impact of a $6 \mathrm{~kW}$ VAWT turbine with 6 Crossflex turbines on the Newbery Tower, a campus building at GSA.

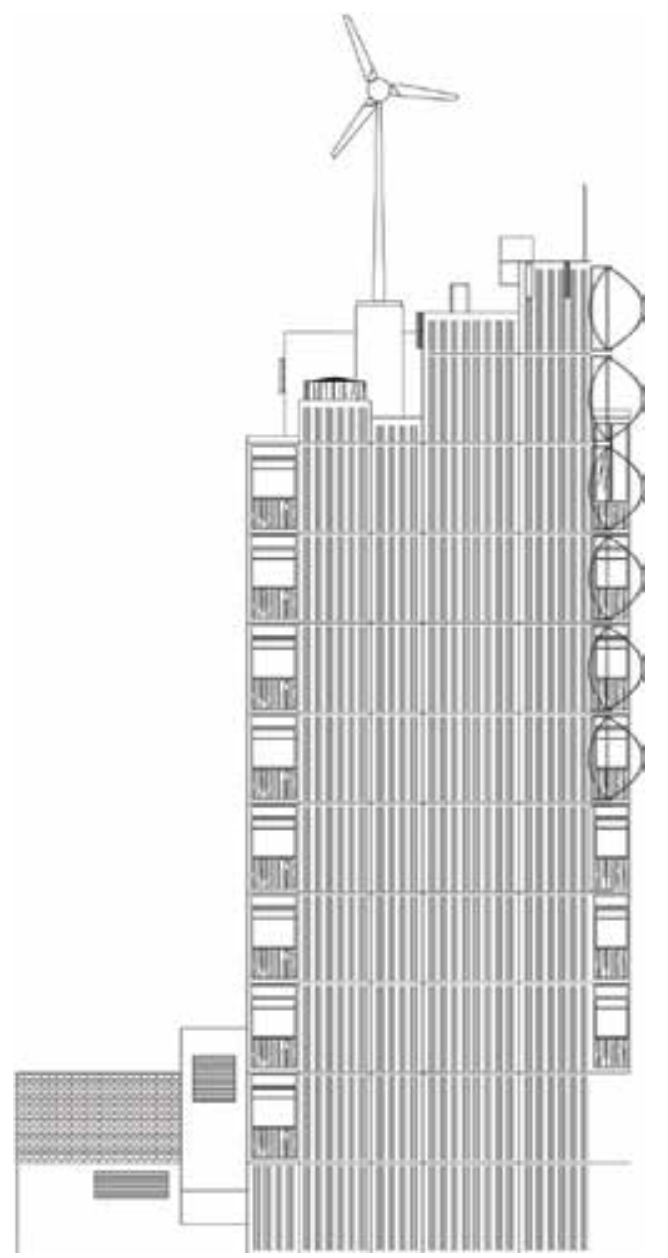

Fig. 14. 6kW Proven VAWT vs 6 No $1 \mathrm{Kw}$ Crossflex 
The use of Crossflex provides a far more disbursed model and there are also fewer localised structural point loads. Although there are a larger number of fixings, these will be taking much smaller loads, so can more rapidly installed bolt or anchor systems. In this example, installed capacity could be between a factor of 4 or 6 times greater if all possible mounting locations where used.

Modularity also leads to economies of scale derived from reduced manufacturing costs and generic fixing and installation systems. It enables interchangeable components for maintenance or change in appearance (for example material or colour or the cowl). Conventional building mounted installations have significant installation costs and technical difficulties, for example structural loads, and installing a larger number of units need not necessarily increase these. Indeed modularity can also assist with the feasibility of installation if components can be kept small enough to be easily handled and assembled insitu with the minimum of plant.

\section{Conclusion}

Although there is both an existing market and further potential for small wind generation in the built environment, experience to date has shown that there are considerable challenges in exploiting this potential.

Although well-sited, efficient and well-integrated turbines can make a valuable contribution, there has been a rush to market of conventional machines that are not designed for use in urban environments. This has led to situations where performance is poor.

The fact that turbines are a very visible manifestation of renewable technology on buildings presents some conflicting challenges. Conventional turbines can be unattractive and this can lead to problems of planning, and acceptability by building users and designers. However, addressing this issue can then lead to systems which are less efficient, or that are used inappropriately.

The built environment is more complex than rural installations, with a number of compound interactions involving clients, specifiers, designers, the public, legislatory and statutory bodies, as well as technical issues such as turbulence, installation, safety and environmental impacts. It is therefore critical that devices for this market need to be designed with these factors in mind. Urban turbines do have the potential to contribute to carbon savings, provided they can utilise design features that make them economically viable.

Given the diversity of the urban environment, it is unlikely that a single form will become dominant. There are major differences in applications between bespoke turbines for newbuild developments and manufactured systems for existing buildings. This suggests a number of niche markets are possible, but whether these are of sufficient scale to justify commercial development is unclear, but does indicate a role for further research.

\section{Acknowledgements}

Fig. 2. Kind permission of The Zedfactory Ltd

Fig. 3. Kind permission of Dynamic Architecture

Fig. 4 Kind permission Brookfield

Fig. 5 Kind permission Atkins 


\section{References}

Aguilo, A.; Taylor, D.; Quinn, A.; Wiltshire, R. (2004). Computational Fluid Dynamic Modelling of wind speed enhancement through a building augmented wind concentration system, European Wind Energy Conference 2004

Bahaj, A.S.; Myers, L. (2007). Urban energy generation: Influence of micro-wind turbine output on electricity consumption in buildings, P.A.B. James, Energy and Buildings 392007 154-165

BERR (2010). Microgeneration Strategy consultation www.decc.gov.uk/en/content/cms/consultations/microgen_strat/microgen_strat .aspx

Black, (2010). London landmark building will generate $8 \%$ of its energy needs, The Guardian, Sunday 14 March 2010 www.guardian.co.uk/environment/2010/mar/14/razor-tower-windturbines?intcmp=239

Boardman, B. (2007). Home Truths: A low Carbon Strategy to reduce UK Housing emissions by $80 \%$ by 2050 .

http://www.eci.ox.ac.uk/research/energy/downloads/boardman07hometruths.pdf University of Oxford ISBN 1874370435

Boyack, (2005). The Energy Efficiency and Micro-Generation Bill Proposal (2005 http://www.scottish.parliament.uk/business/bills/pdfs/mbconsultations/microg eneration.pdf

Carbon Trust, (2008). Small scale wind energy - Policy insights and practical guidance (CTC738), http://www.carbontrust.co.uk/Publications/pages/PublicationDetail.aspx?id=CT C738

Campbell, N.S.; Stankovic, S. (2001) Wind energy for the Built environment - Project WEB. A report for Joule III Contract No JOR3-CT98-01270 2001

Dannecker, R.K.W.; Grant, A.D. (2002) Investigations of a building-integrated ducted wind turbine module, Wind Energy Vol 5 No 1 pp 53-71 2002

DTI (2005). DTI, Potential for Microgeneration: Study and Analysis, Department of Trade and Industry, November 2005, <http:/ / www.berr.gov.uk/files/file27576.pdf

Encraft (2009). Warwick Wind Trials Project. http://www.warwickwindtrials.org.uk/2.html

Energy Savings Trust (2007). Generating the Future: An analysis of policy interventions to achieve widespread micro generation penetration.

http:/ / www.energysavingtrust.org.uk/

Gaterell,; McEvoy (2005), The impact of climate change uncertainties on the performance of energy efficiency measures applied to dwellings, Energy and Buildings Volume 37, Issue 9

Lu, L.; Ip, K.Y. (2007). Investigation on the feasibility and enhancement methods of wind power utilization in high- rise buildings of Hong Kong, Renew Sustain Energy Rev (2008), doi:10.1016/j.rser.2007.11.01

Mertens, S. (2002). Wind description for roof location of wind turbines; a design guideline or the required height of a wind turbine on a horizontal roof of a mid- to high-rise building, Global Windpower, Paris, France, Fig 5. 20 
Mertens, S. (2003). The wind conditions at flat roofs for small wind turbines, EWEC 2003, Madrid. Spain.

Mithraratne, N. (2009). Roof-top wind turbines for microgeneration in urban houses in New Zealand, Energy and Buildings, Volume 41, Issue 10, October 2009, Pages 10131018, ISSN 0378-7788

ODPM (2004). Planning Policy Statement 22: Renewable Energy, ISBN 978011739242 http://www.communities.gov.uk/documents/planningandbuilding/pdf/147444. pdf

Paraschivoiu, I. (2002). "Wind Turbine Design With Emphasis On Darrieus Concept", Polytechnic International Press

Peacock, A.D. ; Jenkins, D. ; Ahadzi, M. ; Berry, A. ; Turan, S. (2008). Micro wind turbines in the UK domestic sector, Energy and Buildings, Volume 40, Issue 7, 2008, Pages 1324-1333, ISSN 0378-7788

Phillips, R.; Blackmore, P.; Anderson, J.; Clift, M.; Aguilo-Rullan, A.; Pester, S. (2007). Microwind turbines in urban environments - an assessment Nov 30, 2007 ISBN 978-184806-021-0

Renewable UK (2010) Small Wind Systems UK Market Report, http://www.bwea.com/small/index.html, April 2010

Scottish Government (2009). The Climate Change (Scotland) Act 2009, www.scotland.gov.uk/Topics/Environment/climatechange/scotlandsaction/climatechangeact

Sharpe, T. (2008). Building Mounted Wind Turbines on Existing Multi-Storey Housing, Open House International, September 2008, 0168-2601

Sharpe, T. (2010) CROSSFLEX: Concept and early development of a true building integrated wind turbine Energy and Buildings Article in Press, Accepted Manuscript, Elsevier B.V.

Solomon, S.; Qin, D; Manning, M.; Chen, Z.; Marquis, M.; Averyt, K.B.; Tignor, M. and Miller, H.L. (eds.) (2007). Contribution of Working Group I to the Fourth Assessment Report of the Intergovernmental Panel on Climate Change, 2007 Cambridge University Press.

Steemers, K.; Baker, N.; Crowther, D.; Nikolopoulou, M; Clocquet, R. (1996), 'Project ZED, Modelling environmental characteristics of urban forms,' Solar Energy in Architecture and Urban Planning, H. S. Stephens, Bedford, pp. 4-7,

Stern, N. (2007). The Economics of Climate Change, The Stern Review, Cabinet Office - HM Treasury ISBN-13: 9780521700801

Strickland, H. (1975). “The Darrieus Turbine: A Performance Prediction Model Using Multiple Streamtubes", Sandia Laboratories Energy Report 1975

Taylor, D. (1998), Using buildings to harvest wind energy, Building Research and Information, Volume 26, Number 3, 1 May 1998 , pp. 199-202

UK Government (2009). The Climate Change Act (2008). http://www.decc.gov.uk/en/content/cms/legislation/en/content/cms/legislatio n/cc_act_08/cc_act_08.aspx

UK Government (2010). The Feed-in Tariffs (Specified Maximum Capacity and Functions) Order 2010, STATUTORY INSTRUMENTS 2010 No. 678, Electricity. 
Wang, F.; Bai, L.; Fletcher, J.; Whiteford, J.; Cullen, D. (2008). Development of small domestic wind turbine with scoop and prediction of its annual power output Renewable Energy Volume 33, Issue 7, July 2008, Pages 1637-1651

Watson, S. J. ; Infield, D. G.; Barton, J. P. ; Wylie, S. J. (2007). Modelling of the Performance of a Building-Mounted Ducted Wind Turbine. Journal of Physics: Conference Series 75 (2007) 012001 doi:10.1088/1742-6596/75/1/012001 


\title{
New Systems Thinking and Policy Means for Sustainable Energy Development
}

\author{
Niels I. Meyer ${ }^{1}$ \\ Technical University of Denmark, 2800 Lyngby, \\ Denmark
}

\section{Introduction}

Mitigation of the present global warming is a central challenge for a sustainable energy development. A major part of the global warming and the resulting climate change is due to combustion of fossil fuels with emission of $\mathrm{CO}_{2}$ as a dominating greenhouse gas (GHG).

The Intergovernmental Panel on Climate Change (IPCC) is analyzing the global climate changes and its findings have been published in a series of reports since 1991. Each report takes several years of preparation and the consequences of global warming have turned out to appear faster than foreseen in the latest report [IPCC 2007]. Several experts are estimating that irreversible "tipping points" are only few years ahead [Hansen et al. 2008, Kopp et al. 2009]. As a consequence they propose that the goal for the future $\mathrm{CO}_{2}$ concentration in the atmosphere should be as low as 350 ppm compared to the value in 2009 of about 387 ppm. A recent report from the National Research Council in the US has pointed out that the global warming will continue for several hundred years even if the GHG concentration is stabilized at the present level [National Research Council 2010].

So far, strategies for mitigation of global warming have mostly focused on technological solutions e.g. promotion of renewable energy sources (RES) on the supply side and energy efficiency on the demand side. Less attention has been given to potential contributions from changes in lifestyle and alternative economic, institutional and social systems.

Despite long and tedious preparations for COP15 in Copenhagen in December 2009, the final result [Copenhagen Accord 2009] lacked concrete commitments for reduction of GHGs after 2012 when the Kyoto Protocol expires. Moreover, the Copenhagen Accord is only an offer of co-operation that individual nations can choose to support. A specified goal of maximum 2 degrees increase in global mean temperature was included in the Copenhagen Accord but concrete policy means to attain the goal were missing. Recent analyses indicate that this goal will require that about half of present fossil reserves, especially coal, should remain under ground [Meinshousen et al. 2009 ]. No reference to such a requirement was included in the Copenhagen Accord.

For simplicity, this chapter focuses on $\mathrm{CO}_{2}$ emission from fossil fuels as a dominant contributor to climate change, but $\mathrm{CO}_{2}$ from deforestation as well as emission of methane $\left(\mathrm{CH}_{4}\right)$, laughing gas $\left(\mathrm{N}_{2} \mathrm{O}\right)$ and a number of industrial GHGs should be included in a more comprehensive analysis.

\footnotetext{
1 nim@byg.dtu.dk
} 
If the global energy supply system including fuels for the transport sector was completely based on RES a significant part of the problems in relation to climate change could be eliminated. However, even the most optimistic energy experts do not expect this to be the case before the second half of this century, if then. This may well be too late to avoid serious disruptions of the global climate system, likely to be accelerated by exceeding the so-called "tipping points" with positive feed-back effects and irreversible consequences. One example is the release of large quantities of the potent GHG methane $\left(\mathrm{CH}_{4}\right)$ now frozen in tundras in arctic areas. New data refer to an accelerating increase in the $\mathrm{CH}_{4}$ concentration in the atmosphere since 2007 [Dlugokencky and Nisbet 2010].

It should be added that in practice the global potential of RES for energy supply is not unlimited and not without environmental impact. With a growing world population and a growing demand for energy services the practical potential for supply systems based on RES will eventually meet its limits [Trainer 2001]. Furthermore, even if a clean and infinite energy source became available, this might lead to an unrestricted exploitation and pollution of nature with significant losses of natural habitat and biodiversity.

This chapter will address both technological strategies for mitigation of climate change and policy questions such as economic systems, limits to growth, population policies, national and international equity, and alternative employment policies.

The chapter is focusing on developments in affluent countries, such as those in OECD, with the aim of leaving more environmental space for the less developed countries, where growth in material living standard is often a more pressing goal.

\section{Main factors behind climate change}

The main factors behind the present climate change are the growing world population, the material consumption per person and the eco-impact per unit of this consumption. This may be described by the following simple equation:

$$
\mathbf{I}=\mathbf{P} * \mathbf{A} * \mathbf{T},
$$

where I denotes the Impact on the environment, $\mathrm{P}$ is Population, A is Affluence in the sense of general consumption per person, and $\mathrm{T}$ is a Technological factor representing the ecoimpact per consumption provided [Ehrlich \& Holdren 1971]. These factors are the basis for mitigation of the climate change.

Growth in any one of these three factors will tend to push upwards the total impact, while a decrease will have the opposite effect. In affluent countries solutions are almost as a rule sought in the T-factor, while the two other factors are ignored or even encouraged to grow. A number of theoretical and practical policy concerns for mitigation of global warming are summarized in the following and more details are given in [Daly 2007 and Meyer et al. 2010].

\subsection{Limits to growth and sustainable development:}

Over the last century, development of economics as a discipline has increasingly, with few exceptions, been dominated by a perception of living in an unlimited world with unlimited resources and pollution drains. Resource and pollution problems in one area were supposed to be solved by moving production or people to cleaner and more resource rich parts of the world. The very hint of an overall global limitation as suggested in the report "The Limits to Growth" [Meadows et al. 1972] has generally been met with disbelief and rejection by 
businesses and most economists. However, this rejection was mostly based on false premises as further discussed below.

An early case of concern for sustainable development is published by John Stuart Mill in his chapter "Of the Stationary State" [Mill 1900]. In contrast to most of his contemporary economic colleagues he welcomed and defended the stationary state: "It is scarcely necessary to remark that a stationary condition of capital and population implies no stationary state of human improvement". This line of thought is reflected in to-days controversy between economic schools where ecological economists distinguish between growth and development while the dominating neoclassical school of economics typically uses the two concepts as near synonyms both related to growth in GDP. This is elaborated in more detail in the following.

It has been a barrier for a rational and enlightened discussion that the concepts of growth and sustainable development are used in different and often somewhat conflicting ways. While neoclassical economists typically focus on growth in GDP, modern ecological economics is concerned with physical throughput in economics. In relation to sustainability neoclassical economists require that the utility of future generations is to be non-declining while ecological economists claim that throughput should be sustained. A detailed description of the conflicting use of the concepts is given by Herman Daly in a series of papers [Daly 2007].

Through the 1960s a number of studies revealed the hitherto ignored human and environmental costs of the GDP growth, and in the early 1970s several reports questioned the net blessings of continuing this path [e.g. Schumacher 1973, Goldsmidt et al. 1972]. One of the more extensive studies was initiated by The Club of Rome, resulting in the 1972 report The Limits to Growth (LtG) [Meadows et al. 1972]. The study's results are based on an aggregated computer model, simulating the global development in population, food production, use of non-renewable resources like fossil fuels, industrial output, and in pollution such as the emission of $\mathrm{CO}_{2}$. A key feature of the model is the interactions between these parameters and the delays in the consequences.

The basic conclusion of the LtG report was that continuation of the growth policies in population, industrialization, pollution, food production, and consumption of nonrenewable resources would most likely lead to some kind of collapse during the 21th century, due to resource scarcity, over-pollution, and over-population. Although this catastrophic growth scenario got most attention, alternative scenarios were also presented in the report, including one, which illustrates that it is possible to change course and reach an environmentally sustainable development path, at the same time satisfying all people's physical needs. Finally, the report stressed that due to delays in natural and man-made systems, it is essential for achievement of sustainability that global society acts before the environment undergoes irreversible changes and forces undesired changes upon us.

Many critics of the report focused exclusively on the growth and collapse scenario, and stated in the 1990s that the collapse had failed to materialize. However, this scenario in LtG finds the collapse to occur decades later [Nørgård et al. 2010]. The recent recognition of global warming from increasing $\mathrm{CO}_{2}$ concentration in the atmosphere and an approaching peak in oil supply fits rather well with the growth scenario in LtG. Thus, the real developments in the main parameters in LtG have followed quite closely the main trends in the report's standard scenario, which leads to collapse around 2040 [van Vuuren 2009, Turner 2009]. This underlines the fact that the basic structure and drivers of the global economy have not changed. Not surprisingly, recent environmental reports have presented concepts and warnings similar to those in LtG [Rockström et al. 2009]. Thus, in today's debates on strategies for sustainable development it would be wise to revisit the analysis of the original 1972 version of LtG and its two later revisions [Meadows et al. 1992, Meadows et al. 2004]. 


\subsection{Standard neoclassical economics versus ecological economics:}

Standard neoclassical economics (SNE) is based on an isolated economic system with circular flow of production and consumption. In contrast to this, ecological economics (EE) considers economy as an open subsystem of a finite, non-growing biosphere that is closed with respect to matter but open to a (non-growing) flow of solar energy. A detailed analysis of the differences between the two economic schools has been given by Herman Daly [Daly 2007]. A summary of the main features related to sustainable development follows.

SNE is primarily focused on efficient allocation of resources with minor attention to distribution and typically no attention to scale. EE focuses first on the sustainability of the economic scale and its material through-put. Second priority is given to a just distribution while efficient allocation is positioned lower as a third priority.

SNE is mainly concerned with the variation of a narrowly defined GDP where depletion of natural capital and a number of pollution effects are not included as costs in the accounting. EE points out that growth in GDP may result in uneconomic growth due to depletion of natural capital and pollution effects. The tendency to uneconomic growth is already observed in some OECD countries [Daly 2007].

In recent times a number of studies by economists and other researchers have revealed that in societies where citizens' basic needs are met, further income and consumption seems not to increase people's satisfaction and happiness [Jackson 2009, Jackson 2005, Nørgård 2006]. In other words, in affluent parts of the world, continued growth in GDP is not necessary for a good life. Two Nobel laureates in economics, Joseph Stiglitz and Amartya Sen, stated in their key message in a commission report to the French President Nicolas Sarkozy that "the time is ripe for our measurement system to shift emphasis from measuring economic production to measuring people's well-being" [Stiglitz et al. 2009]. Such a policy shift would be a constructive step in the promotion of sustainable development.

SNE favors global economic integration based on free trade and free capital mobility with reference to the classical argument of "comparative advantage". EE points out that the classical model did not include free capital movement and that internalization of environmental costs tends to be given low priority in a global competition to cut costs and attract capital.

An important sustainability question is related to the concern for intergenerational balance. In standard macroeconomic modeling this is often settled by introducing discount factors for future economic events. However, discount factors of $4 \%$ or higher mean that the welfare of future generations is given low priority. Nevertheless, a number of governments in OECD countries have officially announced discount factors in this range. EE points out that intergenerational balance cannot be satisfied by such a simple technical factor in economic models. The intergenerational distribution problem is a complex one and should take into account that different generations have different goals and priorities. The focus should not be on efficient allocation but on keeping flexible choices and opportunities open for future generations.

The above examples of the differences between SNE and EE should make it clear that the dominating economic school (SNE) is a serious barrier for the promotion of sustainable development. A change in economic policy is required where the principles of ecological economy are given much higher priority. This is not a sufficient condition for sustainable development but a necessary condition. 


\subsection{Population growth:}

Over the last five decades world population has grown from about three to around seven billion. Most of this growth has occurred - and still occurs - in countries with a low $\mathrm{CO}_{2}-$ emission per person. However, in a future where people in these countries are expected to improve their material welfare, the number of people will play a significant role in global environmental problems. According to official UN estimates, world population with no new measures is projected to grow to around 9 billion by 2050 [The Population Council 1998].

In many parts of the Western world population is slowly declining. Government policies in these densely populated, high $\mathrm{CO}_{2}$ emitting, countries often encourage higher birth rates rather than lower, however. Most of the global population growth will, nevertheless, take place in the developing world where current energy consumption per capita is much lower than in industrial countries. In recent decades a number of developing countries, especially in the Asian region, have successfully reduced birth rates to around 2.0 or below [UN Population Div. 2008, Mason 2001]. In general this has been associated with a better material standard of living and better education of the female part of the population.

Fortunately the development of world population is characterized by a large flexibility in options over the long term. Population control is, however, a sensitive issue, and coercive policies often conflict with basic principles of personal freedom. Similarly, birth control may conflict with traditions and religious beliefs. Nevertheless, population policy should be part of any climate change policy

\subsection{Economic and social equity:}

Lack of economic equity nationally and between nations is an important driving force for economic growth. A general argument is that economic growth is needed in order to create more equity, in spite of the fact that in many countries economic growth has actually resulted in less equity.

Economic growth in its present form creates a number of problems for sustainability as described above. At the same time, as expressed by the historian Tony Judt: "It is the growing inequality in and between societies that generates so many social pathologies" [Judt 2010]. Thus, the goal of more equity should be decoupled from the general policy of economic growth and solved by redistribution of wealth and social rights. This will tend to acknowledge and promote economic satiation in affluent societies.

Recognition of a world with limited natural resources will make demands for equal right to the use of these resources more morally and politically legitimate. The complex coupling between inequity, economic growth and sustainability is often overlooked in international negotiations concerning sustainability.

\subsection{Liberalized markets:}

Commercial markets typically have relatively short time horizons e.g. demanding less than five years pay-back time for investments. In contrast to this, desired radical changes of the energy supply systems require planning horizons of 50 years or more. If this is not taken into account, short-sighted investments based on market competition may block necessary long-term solutions. Investments in new coal plants without carbon capture and storage (CCS) and in oil production from tar sand are examples of this.

New systems thinking is needed, in some cases requiring that planning and promotion of investments in vital sectors are transferred from the commercial market to government institutions. This applies in particular to an energy sector which has a goal of sustainable development. 


\subsection{Fear of unemployment:}

One of the main arguments for continued economic growth is based on the experience, that in OECD countries the productivity in the production sector, and to a certain degree also in the service sector, generally increases by about $2 \%$ or more per year. The assumption is that without economic growth this would create more unemployment. This assumption overlooks the flexibility of the employment concept. Rather than considering a lower demand for the workforce due to increased labor productivity as a problem, it should be considered as a blessing due to its associated possibility for an increase in general welfare. A constructive solution to the unemployment problem may be a paid work- sharing program with fewer working hours per week or more vacations.

Other studies focusing on how little labor is needed to provide a decent material standard of living, typically conclude that one or two days of work per week is sufficient (e.g., Gorz 1983). Flexible parameters in this connection are the weekly working hours, the length of vacations, the system of sabbatical leave and the concept of basic income or citizens salary [Meyer et al. 1981].

\section{Energy supply based on renewable energy sources}

In the time perspective of centuries the sustainability criteria require that global energy supply is based on renewable energy sources (RES). However, as mentioned in the Introduction, the transition to an energy supply based on RES cannot wait for centuries due to global climate change from combustion of fossil fuels and to the approaching "peak oil". Thus, if the precautionary principle is taken seriously, this transition should take place before the middle of the present century. This represents an enormous technological challenge requiring new kinds of systems thinking especially in relation to systems based on intermittent RES like solar, wind and waves etc. This section is focused on wind power as one of the significant intermittent global sources for electricity production.

Denmark is used as case study based on its position as a pioneering country in the promotion of modern wind power. One important aspect is the long historical development of the sector in Denmark, which may be traced back to the 1890s [Rasmussen 1987, Grubb and Meyer 1993, Meyer 1995]. This period culminated with the Danish $200 \mathrm{~kW}$ Gedser Mill, in operation from 1959 to 1967 [Rasmussen 1987]. The operation was successful, and the Gedser Mill became the mother of modern Danish wind turbines in the 1970s characterized by three blades on a horizontal axis in an upwind position.

This concept was further developed by a number of small Danish industrial entrepreneurs from the mid-1970s, starting with small turbines (typically rated at about $22 \mathrm{~kW}$ ). While most of these small firms were economically weak a few of them survived and ended up as global leaders of wind turbine production, e.g. the Danish company Vestas. A comparison between wind power penetration in different European countries has shown that the existence of a national wind turbine production is an important factor [Meyer 2007].

The Danish wind power development had early support from acknowledged institutions like the Danish Academy of Technical Sciences (Danish Academy 1975, 1976] and from government programs. This included a test and certification facility. The Danish utilities were generally skeptical about the prospects of Danish wind power but were involved in a few programs in the 1970s.

In the mid-1970s, Danish government commitment to rapid introduction of nuclear power led to significant debate about alternatives. The debate on nuclear energy versus renewable continued for about a decade [Beuse et al. 2000], but was terminated in 1985, when the 
Danish parliament decided that nuclear energy should not be an element of the country's future energy supply. At this time, Danish energy policy was getting ripe for more focus on RES in the electricity system.

\subsection{Danish energy policies and targets}

The Danish strategy for promotion of wind power in the period from the mid seventies to the mid nineties has combined a number of different elements:

- long-term government support for research, development and demonstration;

- national tests and certification of wind turbines;

- $\quad$ government sponsored wind energy resource surveys (wind atlases);

- $\quad$ subsidies, feed-in tariffs and regulations;

- local ownership of wind turbines and careful selection of sites.

These elements will be discussed in more detail in the following.

The shift in the focus of Danish energy policy after 1985 was confirmed by new official energy plans in 1990 [Danish Ministry of Energy 1990] and 1996 [Danish Ministry of Environment and Energy 1996]. Now, the overall goal of Danish energy policy was to create a sustainable energy system and reduce GHG emission. Policy strongly promoted the development of RES and the expansion of electricity generation based on renewable energy sources. The specific target for RES in these plans was 12-14\% of primary energy by 2005 and $35 \%$ coverage by 2030.

Wind power was given an important role in these plans with targets for installed capacity of around $1500 \mathrm{MW}$ in 2005 and $5500 \mathrm{MW}$ in 2030, covering $10 \%$ and up to $50 \%$ of Danish electricity consumption, respectively. The 2030 target includes $4000 \mathrm{MW}$ of offshore wind capacity.

In practice, the 2005 target was exceeded by a factor of two by 2003, with installed wind power capacity of around $3000 \mathrm{MW}$. This corresponds to nearly $19 \%$ of Danish electricity consumption. Since then, the growth of installed wind capacity has stagnated due to a change in energy policy. The mechanisms behind this development of growth and subsequent stagnation are analyzed in more detail in the following.

\subsection{Research, development and resource assessment}

A marked feature of Danish wind power development is its "safe" technical path, with a gradual increase in turbine size based on improvements of the same basic design, starting with typical rated powers of about $20 \mathrm{~kW}$ in the mid-1970s and leading to MW capacities today. Establishing market credibility was integral to this approach. A machine-testing program was established at Risø National Laboratories in 1978. About a year later, a formal certification procedure was added. This program has been essential in preventing substandard technologies from being marketed both at home and abroad, presenting a marked contrast with California in the early 1980s, where early expansion born of generous financial incentives foundered on the poor reliability of the machines installed [van Est 1999].

A further component to Denmark's supportive developmental context was the publication in 1981 of a wind atlas for Denmark, based on the pioneering work of E. L. Petersen and co-workers at Risø National Laboratories [Petersen et al. 1981]. Computational procedures described in the atlas made it possible to estimate the wind distribution over heterogeneous terrain and to map the wind energy resource with higher accuracy than from general meteorological data. This enabled an extensive national assessment study on sites for wind turbines to be conducted from 1981 to 1986 by Danish authorities [Danish Energy Authority 1986]. 
In 1982 a government committee was established for promoting energy systems based on RES, including wind, solar and biomass. In the late 1980s, the committee promoted new programs of offshore wind farms in order to overcome the foreseen obstacles for land-based turbines (see below).The total funding for RES from the committee during its nine years of operation amounted to about 30 million $€$.

\subsection{Economic support schemes}

From 1979, private citizens who installed certified wind turbines were reimbursed $30 \%$ of the turbine's purchase price by the Danish government. As wind power economic improved during the 1980s, the investment subsidy was gradually reduced to $10 \%$. In 1989, it was finally eliminated after a total investment subsidy of about 280 million DKK (37 million $€$ ) contributing to the installation of about $300 \mathrm{MW}$ rated wind power.

After a number of disagreements between utilities and wind power producers over conditions for grid connection and tariffs, regulations were introduced by the Danish government in 1992. This included a feed-in tariff which was fixed at $85 \%$ of the utility production and distribution costs. On top of the feed-in tariff from the utilities, the private wind power producers would receive a tax refund ("environmental premium") of 0.27 DKK per $\mathrm{kWh}$ (3.6 eurocents per $\mathrm{kWh}$ ). After a drop in the yearly growth of wind capacity in the early 1990s, this initiated a strong growth in land-based wind capacity in the last part of the 1990s (Figure 1).

\section{Yearly growth in number of turbines and capacity in Denmark}

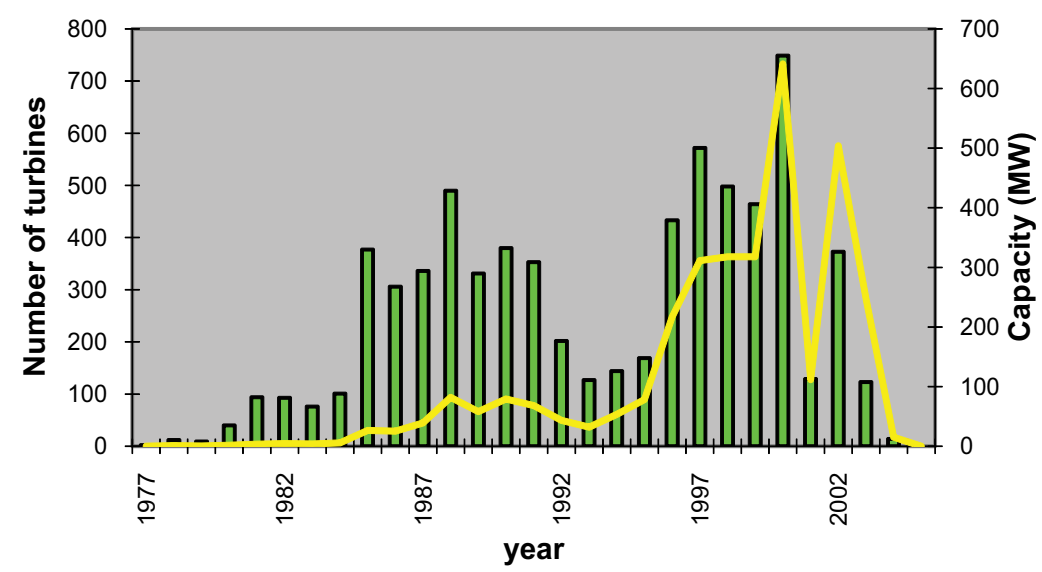

Fig. 1. Yearly growth in number of turbines in Denmark (bars) and annual installed capacity (line) from 1977 to 2005 (Danish Energy Authority). From 2005 to 2010 the net annual increase in capacity has been close to zero due to a change in government policy.

The success of wind power in Denmark and other European countries like Germany and Spain is mainly due to the so-called Feed-In Tariffs (FITs) where owners of wind turbines are guaranteed a favorable tariff on a long term basis, often combined with priority access to the grid. The same type of scheme may be used for other intermittent RES like PV and wave power. Flexibility may be introduced by yearly reductions in the tariffs for new plants as the technology matures [Bechberger \&Reiche 2007]. 
A competing scheme in Europe is called Trading of Green Certificates (TGC) with certificates issued to individual wind power producers in accordance with a specified government target for the total national wind power production and with sanctions to utilities if the target is not fulfilled. In the US this scheme is called Renewables Portofolio Standard (RPS). A comparison of the European and the US experiences may be found in [Rickerson \& Grace 2007].

Neither the FIT nor the TGC operates in accordance with traditional market principles. In the case of FIT the price of the wind electricity is fixed while the volume is decided by the market; the opposite applies to TGC. A number of variations of these two schemes may be found in different countries e.g. in the US [Schreurs 2007]. The advantages and problems of the FIT and TGC schemes have been discussed by Hvelplund and Meyer [Hvelplund 2001a, 2001b, 2005, Meyer 2003]. It is concluded that the FIT so far has been most efficient for promotion of wind power as illustrated by the wind power development in Denmark, Germany and Spain [Meyer 2003].

It is not relevant to force intermittent RES like wind power into the traditional market system, when the main goal is to accelerate its penetration into the electricity supply system. After the investment has been made in a wind turbine, there is no way that the investor can compete more efficiently by cutting running costs or improving the production efficiency. It all depends on the wind. This also supports the priority for the FIT scheme and its general application in a system with priority for establishing a sustainable energy supply.

The political opposition to the FIT has mainly been based on economic complaints that the favorable tariff combined with priority for wind results in higher electricity prices for the consumers compared to electricity from e.g. coal plants. However, it should not be overlooked, that wind power in many cases provides lower consumer prices on the electricity market by outcompeting power sources with high marginal prices. The least cost-effective power plants close down when the wind blows. An analysis of the Danish power market from 2005 to 2008 has shown that the cost of power to the consumer (excluding taxes and transmission and distribution tariffs) would have been 5 to $10 \%$ higher if wind had not been contributing to power production [Munksgaard \& Morthorst 2008, Wind Directions 2010].

\subsection{Local ownership of wind turbines and careful planning of sites}

Social acceptability is widely recognized as an important factor influencing wind energy deployment. Public attitude surveys of wind power in the 1990s generally showed that around $80 \%$ of the Danish population supported wind power [Danish Wind Industry Association 1993, Damborg 1999]. However, that this general support translated into local acceptance of specific projects can be attributed largely to the fact that most Danish turbines were owned by private households based on neighbouring cooperatives. About 150,000 Danish households were registered as owners of shares in wind in 2001. It is easier to accept some extra noise and the view of a turbine if it reminds you of the fact that the turbine gives you money when the wind blows. Such externalities have, in any case, been reduced by more modern turbines, minimum separation distances from dwellings, and careful attention to turbine siting and design.

Strict rules for investors were another factor promoting local accept of wind turbines. Thus, owners of wind turbines in a community had to live in this community or in a neighboring community. When this restriction was cancelled in 2000 local opposition to wind turbines were growing in Denmark. 


\subsection{Offshore wind farms in Danish waters}

Offshore wind farms were proposed as a promising solution in relation to onshore site constraints by the Danish governmental RES committee in the late 1980s. Subsequently, the first offshore wind farm in the world became operational in September 1991 at Vindeby - a site northwest of the Danish island Lolland in the Baltic Sea. A second offshore wind park became operational in October 1995 at Tunø Knob between Jutland and the island of Samsø. A special investigation concerning the impact on bird habitats has been carried out in connection with this project. This problem has turned out to be negligible. Since then, a number of Danish offshore wind farms have been installed (see Table 1).

\begin{tabular}{|c|c|c|c|}
\hline Year & Place & $\begin{array}{c}\text { Number of } \\
\text { turbines }\end{array}$ & $\begin{array}{c}\text { Total capacity } \\
\text { (MW) }\end{array}$ \\
\hline 1991 & Vindeby & 11 & 5 \\
\hline 1995 & Tunø Knob & 10 & 5 \\
\hline 2001 & Middelgrunden & 20 & 40 \\
\hline 2002 & Horns Reef 1 & 80 & 160 \\
\hline 2003 & Nysted & 72 & 166 \\
\hline 2003 & Rønland & 8 & 17 \\
\hline 2003 & Samsø & 10 & 23 \\
\hline 2009 & Sprogø & 7 & 21 \\
\hline 2009 & Horns Reef 2 & 91 & 11 \\
\hline 2010 & Avedøre Holme & 3 & 207 \\
\hline 2010 & Rødsand & 90 & 400 \\
\hline 2012 (planned) & Anholt & To be decided & \\
\hline
\end{tabular}

Table 1. Offshore Danish wind farms.

Some of the Danish offshore wind farms have been installed based on a tender procedure including conditions in relation to grid connections and tariffs. The first tender for a second 200 MW wind farm at Horns Reef in the North Sea in 2006 resulted in a tariff of 0.53 $\mathrm{DKK} / \mathrm{kWh}$ (7.1 eurocents/kWh). The latest tender (2010) for a $400 \mathrm{MW}$ wind farm at the island of Anholt resulted in a tariff of 1.06 DKK (14 eurocents/kWh). There was only one bidder and the high tariff is partly due to stringent conditions and partly influenced by high international offshore tariffs, e.g. favorable government conditions for offshore farms in the UK.

\subsection{Impact of government policy}

A striking illustration of the influence of national energy policy is given in Fig. 1, most dramatically by the stagnation of the wind power development after a change of government in November 2001. The new conservative-liberal government cancelled most of the previous support for RES and replaced it by a reliance on commercial market forces. Danish wind producers have received the lowest unit price among the old 15 member states of EU under the new government that is still in power in 2010.

As a consequence the net increase in installed wind power in Denmark has been close to zero since 2003. The major contribution to increased capacity on land has been re-powering of existing wind turbines with higher capacity turbines, rather than opening up of new sites. At the same time there has been a growing local opposition to new wind turbines as the government has cancelled geographical restrictions on investors resulting in reduced economic advantages to the local community. 


\subsection{Grid system balance}

Coverage by intermittent wind power of more than $20 \%$ of the total electricity consumption gives rise to new regulation problems, especially in combination with a high percentage of heat-bound co-generation like in Denmark. One solution is to expand the transmission capacity to neighboring countries but this may not be the optimal solution as discussed in the Danish CEESA project [CEESA 2010]. An alternative solution may be based on coordinated production between wind turbines and distributed and flexible Combined Heat and Power (CHP) plants. A project along these lines is taking place in Western Denmark involving the development of a "Cell Architecture" for decentralized grid management of semi-autonomous cells with well-defined local functions and system-wide coordination capabilities [Lund et al. 2006].

In a longer time perspective, the transport sector should be included in a comprehensive energy system, where electric cars can play a significant role as storage element in the electric supply system [Lund 2010, CEESA 2010].

\section{Conclusions}

The process of international climate negotiations from Bali to COP15 in Copenhagen has illustrated the need for new and supplementary schemes for mitigation of climate change. This chapter presents proposals for new strategic thinking to overcome present barriers and promote efficient schemes for sustainable energy development. The chapter's main conclusions are summarized as follows:

- A new economic paradigm is needed with less attention to GDP and more attention to sustainability and welfare. This involves, among other things, a shift in the present balance between societal planning and commercial market principles to the advantage of long range societal planning. Economic science should give high priority to the development of market constructs that leads to sustainable development.

- The level of the global population is an important factor in relation to global warming and demand for energy. Thus, regulation of birth rates should not be a taboo subject.

- Lack of economic and social equity is a serious barrier for sustainable development. More equity globally and within nations is needed.

- Limits to growth on a finite planet should be recognized. It is necessary to change the institutional market conditions in which households are embedded.

- Present employment policies promote material growth. The alternative is sharing of paid work and more free time. Introduction of a general citizens salary (basic income) may be worth pursuing.

- Stronger promotion of renewable energy and energy conservation is needed.

- Important factors for the penetration of wind power in a country (besides the wind potential) are the existence of a national turbine production, official government targets, favorable feed-in tariffs and favorable conditions for grid connections.

- In order to avoid local opposition to land-based turbines, the rules should secure economic advantages to local communities in connection with new wind parks.

- Wind power should not be included in traditional commercial market systems. The penetration of wind power can be promoted by flexible feed-in systems.

- New distributed and flexible systems in combination with storage in electric cars can allow high coverage of wind power in the supply system. 


\section{Acknowledgements}

Thanks are due to my colleagues, professors Jørgen S. Nørgård and Frede Hvelplund for valuable discussions, especially on the subjects of limits to growth and neoclassical economics. Parts of the work behind this chapter have been supported economically by the research project Coherent Energy and Environmental System Analysis (CEESA), partly financed by The Danish Council for Strategic Research

\section{References}

Bechberger M and Reiche D (2007) "Diffusion of Renewable Feed-in Tariffs in the EU-28", chapter in "Green Power Markets", edited by Lutz Mez, pp. 31-50, Multiscience Publishing, UK.

Beuse E, Boldt J, Maegaard P, Meyer NI, Windeleff J and Østergaard I (2000) "Renewable Energy in Denmark - History of 25 Years of Growth 1975 to 2000" (in Danish), OVE Publishers. Aarhus, Denmark.

CEESA (2010), www.ceesa.dk

Copenhagen Accord (2009), www.un.org/climatechange.

Daly HE (2007) "Ecological Economics and Sustainable Development", in Advances in Ecological Economics, Edward Elgar Publishers, Northhampton, MA, USA.

Damborg S (1999) "Public Attitudes Towards Wind Power" (in Danish), Danish Wind Industry Association. www.windpower.dk

Danish Academy of Technical Sciences (1975) "Wind Power" (in Danish), Copenhagen, Denmark.

Danish Academy of Technical Sciences (1976) "Wind Power 2 - Proposal for an Action Programme" (in Danish), Copenhagen, Denmark.

Danish Energy Authority (1986) "Large Windmills in Denmark", Copenhagen, Denmark.

Danish Ministry of Energy (1990) "Energy 2000 - A plan of Action for Sustainable Development", Copenhagen, Denmark.

Danish Ministry of Environment and Energy (1996) “Energy 21 - The Danish Government's Action Plan for Energy". Copenhagen. Denmark.

Danish Wind Industry Association (1993) "Attitudes on Wind Power" (in Danish), Ringkøbing, Denmark.

Dlugokencky E and Nisbet E (2010) “Global Atmospheric Methane in 2010: Budget, Changes and Dangers", presented at the Royal Society, London, UK, February 2010.

Erlich P and Holdren JP (1971) "Impact of Population Growth". Science, New Series, Vol. 171, No. 3977, pp 1212-1217.

Goldsmith E, Allen R, Allaby M, Davoll J and Lawrence S (1972) “A Blueprint for Survival”, The Ecologist, 2, no 1 (1972).

Gorz A (1983) “Les chemins du Paradis, L'agonie du Capital”, Edition Galilée, Paris, France.

Grubb MJ and Meyer NI (1993) “Wind Energy: Resources, Systems, and Regional Strategies", in Renewable Energy: Sources for Fuels and Electricity, edited by T.B. Johansson, H. Kelly, A.K.N Reddy and R.H. Williams. Washington D.C. Island Press: pp. 157-212.

Hansen J, Sato M, Karecha P, Beerling D, Berner R, Masson-Delmotte V, Pagani M, Raymo M, Royer DL and JC Zachos (2008): Target Atmospheric CO2: Where Should Humanity Aim? Open Atmospheric Science Journal. arXiv:0804.1126v2 [physics.ao-ph]. 
Hvelplund F (2001a) "Renewable Energy Governance Systems", Department of Development and Planning, Aalborg University, Denmark. http://www.windorks.org/FeedLaws/ARTsGovernance.html

Hvelplund F (2001b) "Political prices or political quantities?: A comparison of renewable energy support systems", New Energy, No. 5.

Hvelplund F (2005) "Renewable energy: Political prices or political quantities" in: Switching to renewable power: a framework for the 21 ${ }^{\text {st }}$ century/red Volkmar Lauber. London: Earthscan, pp. 228-245.

IPCC (2007) “Climate change 2007: The physical science basis. Contribution of Working Group I to the fourth assessment report of the Intergovernmental Panel on Climate Change". [Solomon, S., D. Qin, M. Manning, Z. Chen, M. Marquis, K.B. Averyt, M. Tignor and H.L. Miller (Eds)]. Cambridge, UK and New York, USA, Cambridge University Press.

Jackson T (2006) "Live better by consuming less? Is there a 'double dividend' in sustainable consumption?", Journal of Industrial Ecology, 9 (1-2), pp. 19-36.

Jackson T (2009) "Prosperity without Growth - Economics for a Finite Planet". Earth Scan, London, UK.

Judt T (2010) "Ill fares the land", Penguin Books, UK.

Kopp RE., Simons FJ, Mitrovica KX, Maloof AC and Oppenheimer M (2009) "Probabilistic assessment of sea level during the last interglacial state", Nature 462, pp. 86-867.

Lund H (2010) "Renewable Energy Systems", Elsevier, Amsterdam, the Netherlands.Layard, R (2006). "Happiness - Lessons from a New Science", Penguin, London, UK.

Lund P, Cherian S and Ackermann T (2006) "A Cell Controller for Autonomous Operation of a $60 \mathrm{kV}$ Distribution Area, International Journal of Distributed Energy Resources 2, pp. 83-100.

Mason A ed. (2001) "Population Policies and Programs in East Asia", East West Center, Occasional Papers. Population and Health Series, No. 123.

http://www.eastwestcenter.org/fileadmin/stored/pdfs/POPop123.pdf

Meadows DH, Meadows DL, Randers J and Behrens III WW (1972) “The Limits to Growth", Universe Books, New York, USA.

Meadows DH, Meadows DL and Randers J (1992) "Beyond the Limits", (Earthscan Publications Limited, London, UK).

Meadows DH, Randers J \& Meadows DL (2004) "Limits to Growth. The 30 Years Update", Chelsea Green, White River Junction, Vermont, USA.

Meinshausen M, Meinshausen N, Hare W, Raper SCB, Frieler K, Knitti R, Frame DJ and Allen MR (2009) "Greenhouse-gas emission targets for limiting global warming to $2^{\circ} \mathrm{C}^{\prime \prime}$, Nature, 458 (7242), pp. 1158-1162.

Meyer NI (1995) “ Danish Wind Power Development”, Energy for Sustainable Development 2: pp.18-25.

Meyer NI (2003) "European Schemes for Promoting Renewables in Liberalised Markets", Energy Policy, 31, pp. 665-676.

Meyer NI (2007) "Learning from Wind Energy Policy in the EU: Lessons from Denmark, Sweden and Spain", European Environment 17, pp. 347-362.

Meyer NI., Petersen KH and Sørensen V (1981): "Revolt from the Center", Marion Boyars Publishing, London, UK.

Meyer NI, Hvelplund F and Nørgård JS (2010) "Equity, Economic Growth and Lifestyle", chapter in Energy Sustainability and the Environment: Technology, incentives, behavior, F. Sioshnsi Ed., Elsevier, the Netherlands, forthcoming. 
Mill JS (1900) "Principles of Political Economy" (original version published in 1848). Revised edition, Vol. II, Colonial Press, New York, USA.

Munksgaard J and Morthorst PE (2008) "Wind power in the Danish liberalised power market - Policy measures, price impact and investor incentives", Energy Policy 36, pp.3940-3947.

National Research Council (2010) “Climate Stabilization Targets: Emissions, Concentrations, and Impacts over Decades to Millenia", The National Academic Press, Washington D.C:, USA.

Nørgård JS. (2006) “Consumer efficiency in conflict with GDP growth”, Ecological Economics, 57, pp. 15-29.

Nørgård JS, Peet J and Ragnarsdóttir KV (2010). "The history of The Limits to Growth", Solutions, vol 1, No 2, March-April, pp. 59-63. http://www.thesolutionsjournal.com/node/569.

Petersen EL, Troen I, Frandsen S and Hedegaard K (1981) "Wind Atlas for Denmark", Risø National Laboratory. Roskilde, Denmark.

Rasmussen B (1987) “ Power Production from the Wind", in "Wind Energy in Denmark", report from the Danish Ministry of Energy, Copenhagen, Denmark.

Rickerson W and Grace RC (2007) "The Debate over Fixed Price Incentives for Renewable Electricity in Europe and the United States: Fallout and Future Directions", A White Paper prepared for the Heinrich Böll Foundation, Berlin, Germany.

Rockström J et al.(2009) “A safe operating space for humanity”. Nature, 461, 472, 24. Sept.

Schreurs MA (2007) "Renewable Energy Politics in the United States", in Green Power Markets: Support Schemes, Case Studies and Perspectives", edited by Lutz Mez, Multiscience Publishing, UK, pp. 227-250.

Schumacher EF (1973) "Small is Beautiful - a study of economics as if people mattered", Blond \& Briggs, London, UK.

Stiglitz JE, Sen A and Fitoussi J-P (2009) “Report by the Commission on the Measurement of Economic Performance and Social Progress", Paris, France, www.stiglitz-senfitoussi.fk

The Population Council (1998) “UN World Population Projections to 2150". The Population Division of the United Nations Population Secretariat. Population and Development Review,24, No 1 (March, 1998), pp. 183 - 189. http:/ / www.jstor.org/stable/2808146.

Trainer FE (2001) "Natural Capitalism Cannot Overcome Resource Limits", http://www.mnforsustain.org/trainer_fe_simon_lovins_critique.htm.

Turner GM (2009) "A Comparison of the 'Limits to Growth' with 30 Years of Reality", Global Environmental Change, http:/ / www.csiro.au/files/files/plje.pdf.

UN Population Division (2008) "World Population Policies 2007", Department of Economic and Social Affairs. United Nations, New York, USA. http://www.un.org/esa/ population/publications/wpp2007/Publication_index.htm

van Est R (1999) "Wind of Change - A Comparative Study of the Politics of Wind Energy Innovation in California and Denmark", Dr. Thesis, University of Amsterdam, the Netherlands.

van Vuuren DP and Faber A (2009) "Growing within Limits - A Report to the Global Assembly 2009 of the Club of Rome", The Netherlands Environmental Assessment Agency. Bilthoven, The Netherlands. http://www.rivm.nl/bibliotheek/rapporten/500201001.pdf.

Wind Directions (2010) "Wind: lowering electricity prices", European Wind Industry Magazine, 29, no.2, pp. 18-19. 


\title{
Developing Wind Energy in Turkey
}

\author{
Murat Gökçek \\ Niğde University, Department of Mechanical Engineering \\ Turkey
}

\section{Introduction}

An important portion of the world's electrical energy requirement in today has been supplied by thermal power plants that use fossil fuels. The increasing negative effects of fuels based on carbon that are non-renewable in recent years have forced the scientists to draw attention to clean energy sources that are both environmentally more suitable and renewable such as wind, solar, biomass, and geothermal energy. Actually, the wind power has played a long and important role in the history of civilization. Wind energy has been utilized by mankind for thousands of years. Since earliest recorded history, wind power has been used to drive ships, pump water and grind grain. However, the use of wind turbines to generate electricity can be traced back to the late nineteenth century with windmill generator constructed in the US. In spite of technical advances and the enthusiasm, among others, there was little sustained interest in wind generation until the price of oil rose dramatically in 1970s. The sudden increase in the price of oil stimulated a number of substantial research, development and demonstration. The wind technology was gradually improved since the early 1970s. By the end of the 1990s, wind energy has re-emerged as one of the most important renewable energy resources (Burton et al, 2001). The cost of wind electricity production cost has been gradually decreasing with improving technology.

At present, wind energy has been widely used to produce electricity in many countries in America, Asia and especially Europe Continent. According to 2009. data, total installed wind power capacity in the world is reached 160,084 MW by increase $31 \%$ compared to 2008 year. US, $22 \%$ of the global wind capacity, is worldwide the leading wind energy country. US have $35159 \mathrm{MW}$ installed capacity. Electricity generation from wind power is projected to reach $4.5 \%$ of total electricity generation in 2030 . worldwide, compared with less than $1 \%$ in 2007. Wind power is projected to soon become the most significant source of renewablesbased electricity after hydropower, ahead of biomass (World Energy Outlook, 2009.).

Turkey as a bridge between Europe and Asia Continent has been developing both economically and technologically day-by-day. Electrical energy in Turkey is mainly produced by thermal and hydroelectric power plants. Because of limited energy sources, Turkey is heavily dependent on imported oil and gas. The primary energy consumption of Turkey is about 90.1 million tons of equivalent oil (Mtep) according to 2009. records (BP Statistical Review of World Energy, 2010.). Utilization of renewable energy as indigenous source in the electricity generation is an important fact for Turkey in terms of both security of energy supply and environmental concerns. When it comes to Turkey's situation pertaining to wind energy exploitation, it can be seen that Turkey is rather unsuccessful in using its potential (Gökçek et al., 2007.). Technical potential in Turkey in terms of wind 
power is about $83,000 \mathrm{MW}$. In spite of this potential, Turkey' $\mathrm{s}$ wind energy installed capacity was about $802 \mathrm{MW}$ at the end of 2009. (TWEU, 2010). Considerable wind source in Turkey must be used by taking into account both environmental and economic concerns.

In this study, the wind-electricity status in Turkey is investigated and according to the recent developments on wind utilization in the world, the wind Turkey' $s$ wind energy potential is considered. In addition, a case study was carried out for both wind characteristics and wind energy production.

\section{Energy situation of world}

The total primary energy demand of the world in 2007. was realized as 12,013 Mtep in 2007. This energy demand in the Reference Scenario is projected to increase by $1.5 \%$ per year between 2007. and 2030., reaching 16,790 Mteo-an overall increase of 40\% (World Energy Outlook, 2009). This increase is smaller than previous prediction due to the impact of financial and economic crisis on demand growth in early of the projection period. The demand declines by $0.2 \%$ per year in 2007.-2010., because of a significant drop in 2009. The fossil fuels remain the dominant sources of primary energy worldwide, accounting for almost $77 \%$ of the overall increase in energy demand between 2007. and 2030. Oil that is a pollution fuel was the largest fuel in primary energy sources in 2007. Coal was also second largest fuel this energy sources in 2007. Renewables' share in the energy mixing was realized as 1514 Mteo in 2007. The contribution of renewable sources will be increased in future, especially wind energy.

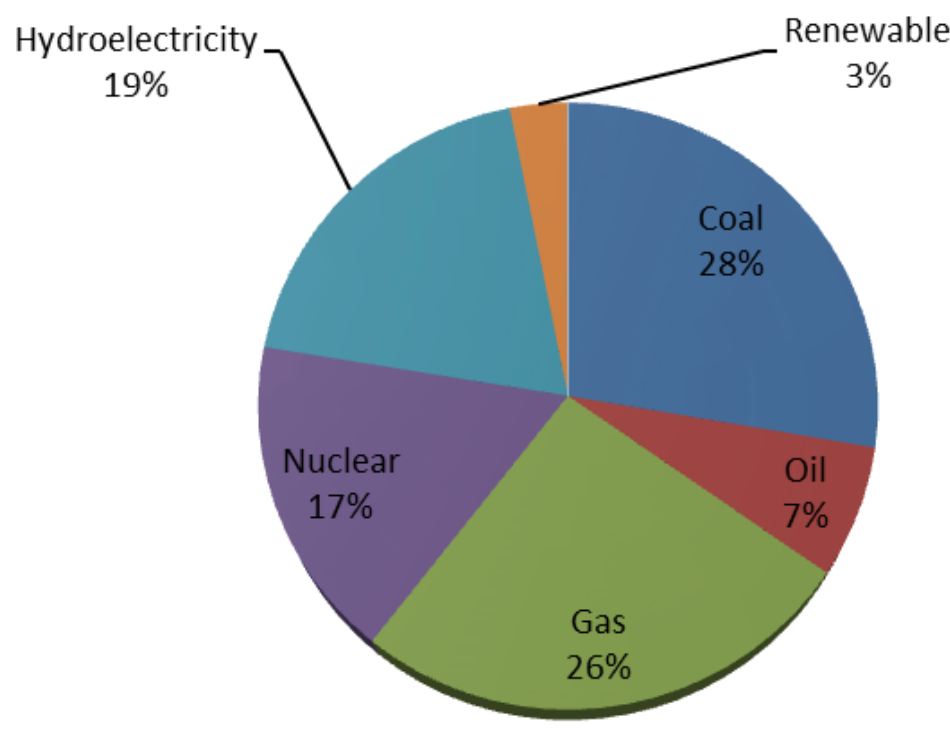

Fig. 1. Global electricity production according to the source distribution in 2007.

The electrical energy production of the world in 2007. was 19,756 TWh and it is estimated that the world will consume 34,292 TWh in 2030. The wind share of the total energy production was also $173 \mathrm{TWh}$ in 2007. It is expected that wind electricity production will have 1535 TWh in 2020. (World Energy Outlook, 2009.). Figure 1 shows the electricity production from different sources in 2007. 


\section{Energy situation of Turkey}

The main purpose of energy policy in Turkey is to supply the sufficient energy to the utilization taking to account environmental and economic aspects by supporting the economical growing and social development (EÜAŞ Sector Report, 2008). Mainly components of Turkey's energy policy are given as follows;

- Raising of security of energy and kinds of energy

- Maintaining of the reform studies that is need for sector

- Supplying of increase for the investments in the all areas of the energy sector by taking into account the environmental aspects

- Playing an active role for trading and carrying of hydrocarbons by complying with concept of energy terminal and passage

Turkey purposes the realization of the development targets, rising of national advancement, international achievement of industrial sector. To do this, energy demand in Turkey is gradually growing. In future, to be continuing the trend of growing has been calculating.

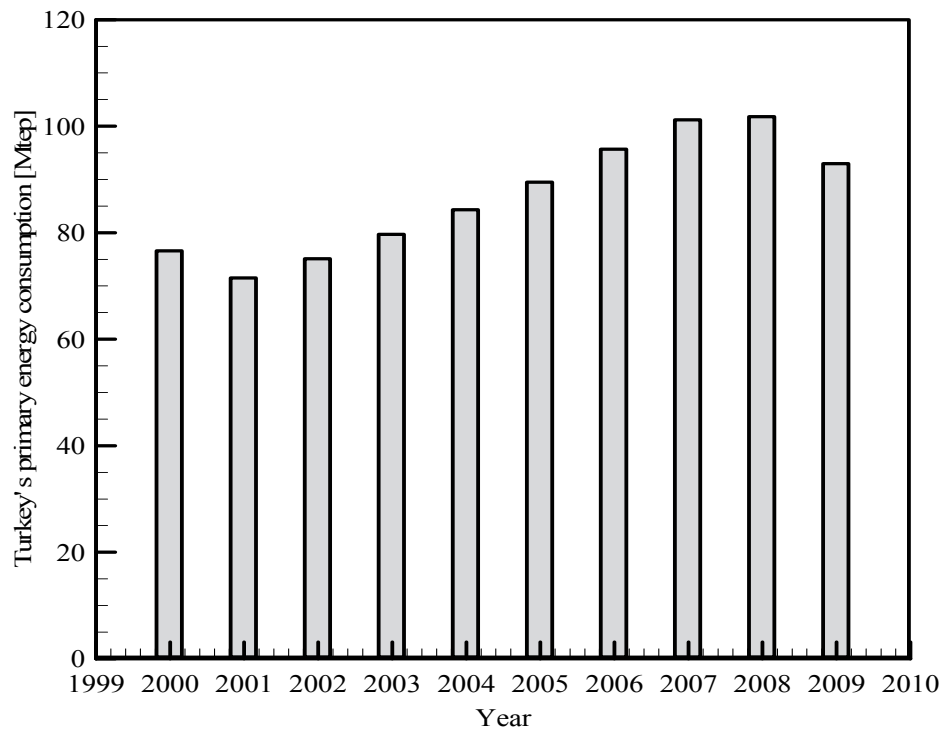

Fig. 2. The annual variation of primary energy consumption in Turkey

Turkey's gross electricity consumption in 2008. was realized as 191.8 billion $\mathrm{kWh}$. It was realized as 193.3 billion $\mathrm{kWh}$ with a decrease about $2.42 \%$ in 2009. when compared to 2008 . Electricity production was also realized as 194.1 billion $\mathrm{kWh}$ with a decrease about $2.02 \%$ in 2009. when compared to the values of 2008. that is 198.4 billion $\mathrm{kWh}$. It is expected that consumption of electricity in 2020. will be 488 TWh according to higher demand scenario and 406 TWh according to the lower demand scenario. The installed power of electricity capacity in Turkey has reached $44600 \mathrm{MW}$ in the end of 2009. (MENR, 2010).

Turkey' s primary energy sources include natural gas, coal, oil, hydraulic, geothermal, wood, waste, solar and wind. The primary energy consumption of Turkey was realized as about 93 Mtep (Oil 31\%, Natural gas 31\%, Coal 29\%, Hydroelectric 9\%) in 2009 (BP Statistical Review of World Energy, 2010). The annual variation of primary energy consumption in Turkey is shown in Fig.2. 


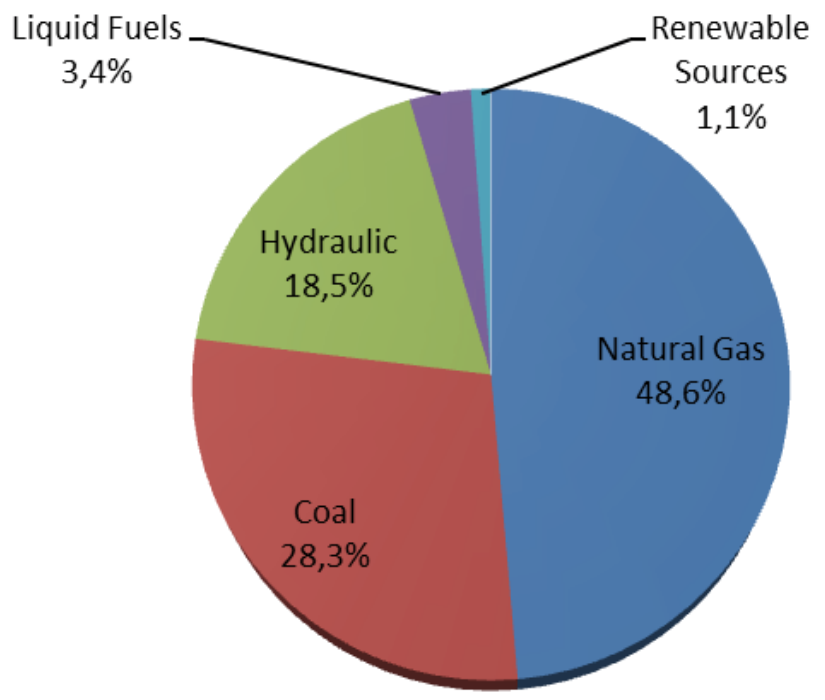

Fig. 3. Share of energy sources for electricity production in Turkey in 2009.

Turkey' s primary energy consumption is shown in Fig. 3 (MENR, 2010.). As shown in the figure, mainly primary energy source to generate electrical energy in 2009. is natural gas that is imported.

\section{Global status of wind energy usage}

Total installed wind power capacity reached up to $157,899 \mathrm{MW}$ at the end of 2009. in the world (GWEC, 2010.).

\begin{tabular}{|c|c|c|}
\hline Countries & Capacity (MW) & $\%$ \\
\hline US & 35,159 & 22.3 \\
\hline Germany & 25,777 & 16.3 \\
\hline China & 25,104 & 15.9 \\
\hline Spain & 19,149 & 12.1 \\
\hline India & 10,926 & 6.9 \\
\hline Italy & 4,850 & 3.1 \\
\hline France & 4,492 & 2.8 \\
\hline United Kingdom & 4,051 & 2.6 \\
\hline Portugal & 3,535 & 2.2 \\
\hline Denmark & 3,465 & 2.2 \\
\hline Total top 10 & 136,508 & 86.5 \\
\hline Rest of the world & 21,391 & 13.5 \\
\hline World total & 157,899 & 100 \\
\hline
\end{tabular}

Table 1. Top 10 cumulative capacity in the world in 2009.

Fig. 4. shows installed wind power capacity in the world between 2000. and 2009. There is a tremendous increasing trend in installed wind energy over this period. It is estimated that installed wind power will be reached in $600 \mathrm{GW}$ in 2030. (GWEC, 2010.). US has the highest 
installed wind capacity with $35,159 \mathrm{MW}$ which is equal the $22 \%$ of world installed capacity as shown in Table 1 (GWEC, 2010.). The new additions to the global wind capacity are being continuously made in the aware of clean energy production. $34.7 \%$ of these new additions were made in China. The US with $26.5 \%$ addition ratio is in the second order. Germany being the member of Europe Union among the countries in world Top 10 has the biggest installed capacity whose is $25,777 \mathrm{MW}$. The biggest share of global wind energy capacity is held by Europe at $48 \%$. The bulk of Europe's wind energy capacity has been concentrated in three countries, Germany, Spain and Italy, which are now home to 39 per cent of all capacity in Europe. Turkey had a share of $0.01 \%$ in Europe' s installed capacity at the end of 2009 . By the end of 2009 global wind energy installation as continental is shown in Fig. 5.

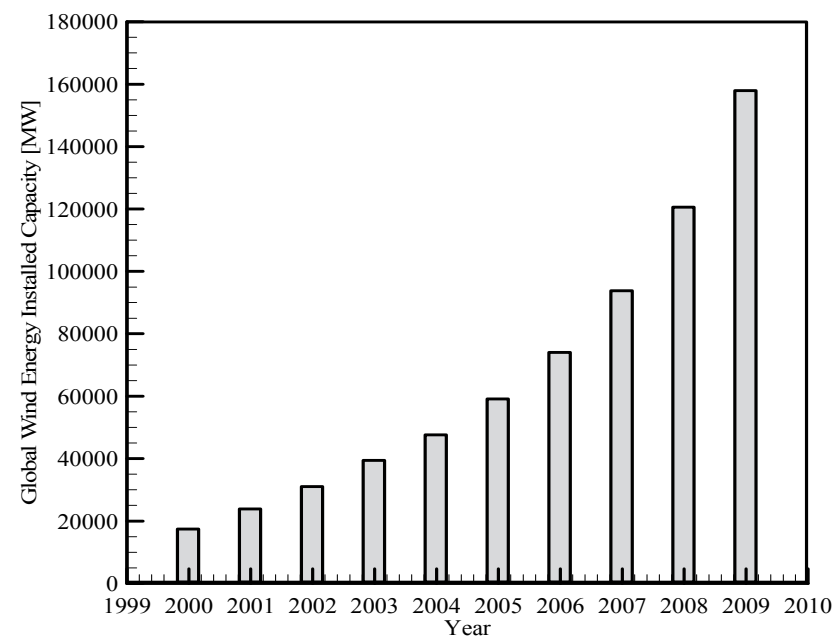

Fig. 4. The annual variation of global cumulative installed wind capacity

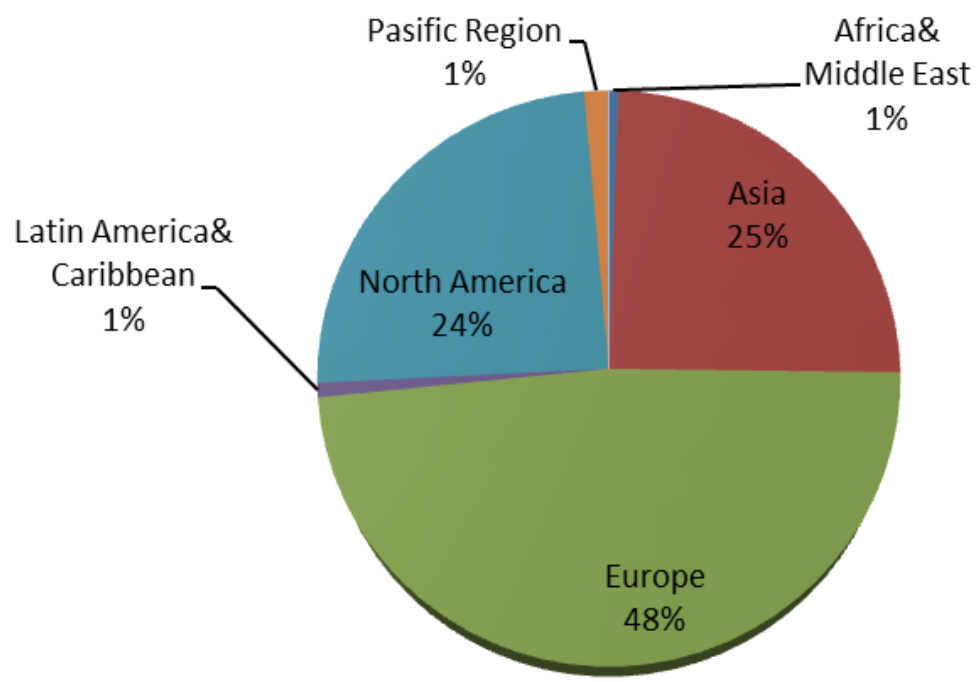

Fig. 5. Usage of wind power as continental. 
Wind energy is now an important player in the world's energy markets. The growth of the Europe wind energy sector has also recently been reflected in other continents, most particularly in China, India and the US. In 2008., over 11 GW of new wind capacity was installed outside Europe, bringing the global total up to about $158 \mathrm{GW}$. In terms of economic value, the global wind market was worth about $€ 25$ billion in 2007. in terms of new generating equipment (EWEA, 2009.). China was the world's largest market in 2009., nearly doubling its wind generation capacity from $12.104 \mathrm{GW}$ in 2008 to $25.104 \mathrm{GW}$ at the end of 2009. with new capacity additions of 13 GW (GWEC, 2010.).

\section{Wind energy potential and its usage in Turkey}

Turkey is a country that is located between Europe and Asia like a bridge and surrounded by seas around three sides. The large part of the land of Turkey is in Asia and the small part called as Thrace is in Europe (Gökçek et al., 2007.). Turkey possesses neither large fossil fuel nor natural gas reserves. Therefore, Turkey to meet the energy necessity is the sources importing country and almost all of the petroleum and natural gas needed is imported. Energy consumption in Turkey is increasing parallel to the technological development as became a developing country. Electricity is produced by hydro power plants and thermal power plants used fossil fuels in Turkey.

\begin{tabular}{|c|c|c|}
\hline Region & $\begin{array}{c}\text { Annual mean } \\
\text { wind speed }(\mathrm{m} / \mathrm{s})\end{array}$ & $\begin{array}{c}\text { Annual mean } \\
\text { power density } \\
\left(\mathrm{W} / \mathrm{m}^{2}\right)\end{array}$ \\
\hline Marmara & 3.29 & 51.91 \\
\hline Aegean & 2.65 & 23.47 \\
\hline Mediterranean & 2.45 & 21.36 \\
\hline Middle Anatolia & 2.46 & 20.14 \\
\hline Black Sea & 2.38 & 21.31 \\
\hline Eastern Anatolia & 2.12 & 13.19 \\
\hline South-Eastern Anatolia & 2.69 & 29.33 \\
\hline
\end{tabular}

Table 2. Average wind power densities and speeds on a regional basis

Hydro electricity production is varied whether became dry of weather. Wind energy that is a renewable energy source is also among the other sources that must be investigated very seriously. Turkey has an important wind energy potential especially in the Aegean region, the Marmara region coasts of western and southern Anatolia. The study of geographical distribution of wind speeds, characteristic parameters of the wind, topography and local wind flow and measurement of the wind speed are very essential in wind resource assessment for successful application of the wind energy systems (Herbert et al., 2007.). According to the data of the General Directorate of State Meteorological Studies, Turkey's annual mean wind speed is $2.58 \mathrm{~m} / \mathrm{s}$ and wind power density is $25.82 \mathrm{~W} / \mathrm{m}^{2}$ (Kaygusuz, 2010.). Mean wind speed and annual power density for Turkey are listed in Table 2.

One of the foundations to fulfill the studies related to determination of wind energy potential in Turkey is EIEI (Electrical Power Resources Survey and Development 
Administration). Studies on determining wind energy potentials of windy areas are gaining importance. Table 3 is listed the wind speeds at $10 \mathrm{~m}$ height above the ground level taken from wind observation station of EIEI for various locations (EIEI, 2010.). According to the "Turkey Wind Map", prepared by EIEI, wind speed at $50 \mathrm{~m}$ height and outside the residential areas, at Marmara, West Black sea, and East Mediterranean coasts and inner parts of these regions are 6.0-7.0, 4.5-5.0 m/s, respectively. Fig. 6. shows the wind speed scattering in $30 \mathrm{~m}$ high in Turkey (Illkılıç \& Turkbay, 2010.). Yearly mean power density for $50 \mathrm{~m}$ is shown in Fig.7. (Akdağ \& Güler, 2010.). Compared to seven regions of the country, wind power densities are seemed to be higher at Marmara, Aegean and South-East Anatolia. Wind speeds are therefore higher at these three regions. In addition, meteorological data by the US space studies have been shown that Turkey has high wind capacity.

\begin{tabular}{|c|c|c|c|c|c|c|c|c|c|c|c|c|c|}
\hline Location & $\mathrm{J}$ & $\mathrm{F}$ & $\mathrm{M}$ & $\mathrm{A}$ & $\mathrm{M}$ & $\mathrm{J}$ & $\mathrm{J}$ & $\mathrm{A}$ & $\mathrm{S}$ & $\mathrm{O}$ & $\mathrm{N}$ & $\mathrm{D}$ & Mean \\
\hline Bababurnu & 6.1 & 6.2 & 5.9 & 5.1 & 4.3 & 5.5 & 5.7 & 6.2 & 4.9 & 5.0 & 5.3 & 6.1 & 5.5 \\
\hline Belen & 5.6 & 5.6 & 5.6 & 5.8 & 6.6 & 8.5 & 10.4 & 10.5 & 7.8 & 5.0 & 4.8 & 5.1 & 6.8 \\
\hline Datca & 5.1 & 5.8 & 5.8 & 5.3 & 5.1 & 6.3 & 7.1 & 7.0 & 6.3 & 5.4 & 4.2 & 5.1 & 5.7 \\
\hline Kocadag & 8.8 & 9.1 & 9.1 & 7.2 & 7.0 & 7.8 & 8.9 & 8.6 & 7.4 & 7.9 & 7.9 & 10.0 & 8.3 \\
\hline Karabiga & 7.5 & 6.7 & 7.0 & 5.1 & 5.4 & 5.2 & 6.8 & 7.1 & 6.4 & 7.4 & 7.3 & 6.9 & 6.7 \\
\hline Nurdag1 & 4.0 & 4.7 & 5.5 & 6.3 & 6.7 & 9.7 & 13.4 & 12.0 & 8.9 & 4.7 & 3.6 & 3.5 & 7.3 \\
\hline Senkoy & 7.1 & 7.5 & 8.9 & 8.0 & 6.7 & 8.1 & 9.8 & 7.9 & 6.9 & 6.3 & 7.6 & 6.5 & 7.7 \\
\hline Gokceada & 7.5 & 7.5 & 7.6 & 6.2 & 6.0 & 5.5 & 6.7 & 7.1 & 5.6 & 6.9 & 6.7 & 8.4 & 7.0 \\
\hline Akhisar & 5.4 & 6.0 & 6.4 & 4.9 & 5.5 & 7.1 & 8.5 & 8.4 & 5.7 & 5.6 & 5.3 & 6.1 & 6.2 \\
\hline Foca & 5.2 & 5.6 & 5.4 & 4.5 & 4.7 & 5.5 & 5.5 & 6.0 & 4.9 & 5.1 & 4.7 & 6.2 & 5.3 \\
\hline Gelibolu & 7.1 & 7.0 & 6.9 & 5.2 & 5.6 & 5.8 & 6.0 & 7.3 & 6.2 & 6.4 & 6.5 & 7.8 & 6.5 \\
\hline Bodrum & 5.7 & 6.9 & 7.0 & 6.4 & 5.7 & 6.2 & 6.1 & 6.2 & 5.9 & 5.8 & 5.1 & 6.6 & 6.1 \\
\hline
\end{tabular}

Table 3. Monthly and annual mean wind speeds $(\mathrm{m} / \mathrm{s})$ from the observation station of EIE.

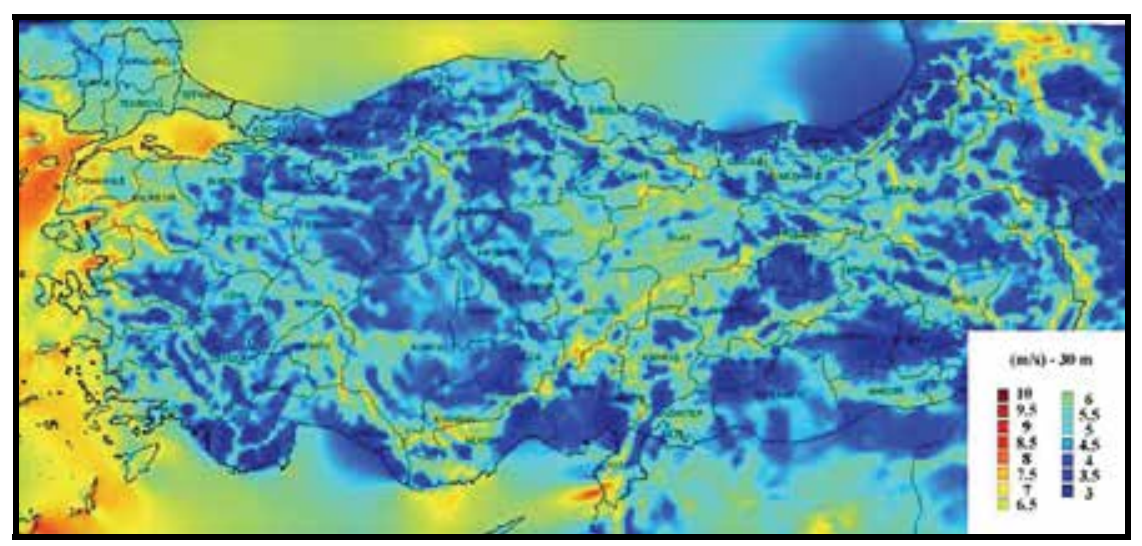

Fig. 6. Distribution of wind velocity in $30 \mathrm{~m}$ high. 
It is estimated that Turkey' s technical wind energy potential is $88,000 \mathrm{MW}$, economical potential is approximately $10,000 \mathrm{MW}$ depending on the technical condition. The EIE' $\mathrm{s}$ wind atlas reported that, Turkey' s technical wind energy potential was 83,000 MW, production potential was $166 \mathrm{TWh}$ /year.

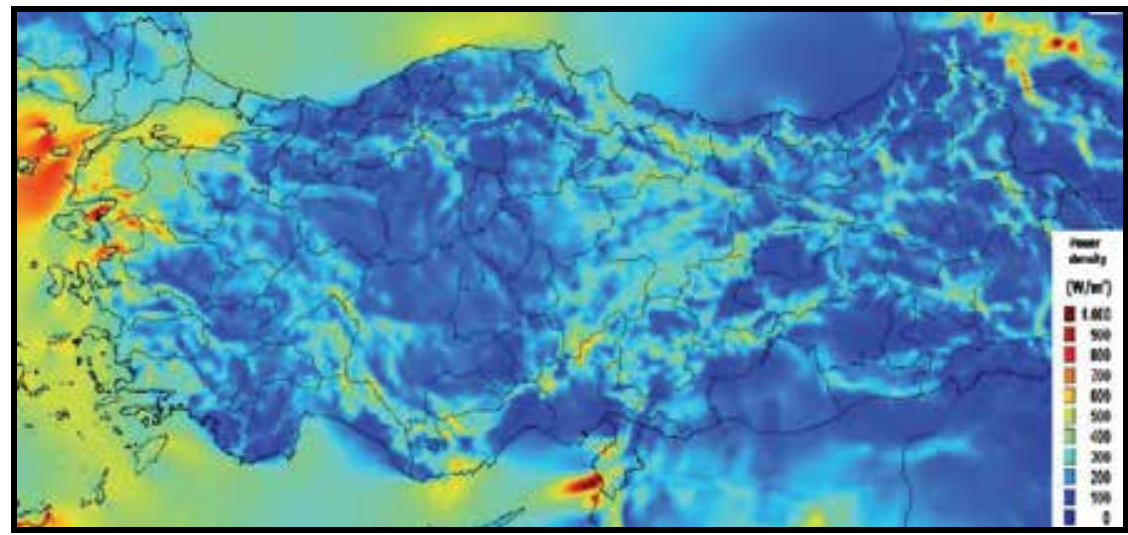

Fig. 7. Yearly mean power density for $50 \mathrm{~m}$.

The first law on the use of Renewable Energy Resources for the Generation of Electrical Energy was enacted in May 2005. Electricity produced by renewable sources is supported by this law. Tariff of the law was increased slightly to $€ 5-5.5 \mathrm{ct} / \mathrm{kWh}$ by a revision of the law in May 2007. (Saidur et al., 2010.). Although the level of support is low in comparison with other European countries, the production licence to the private sector companies is given by EPDK the ARES wind farm was built in Cesme-Alacatı and it includes $12 \times 600 \mathrm{~kW}$ wind turbines.

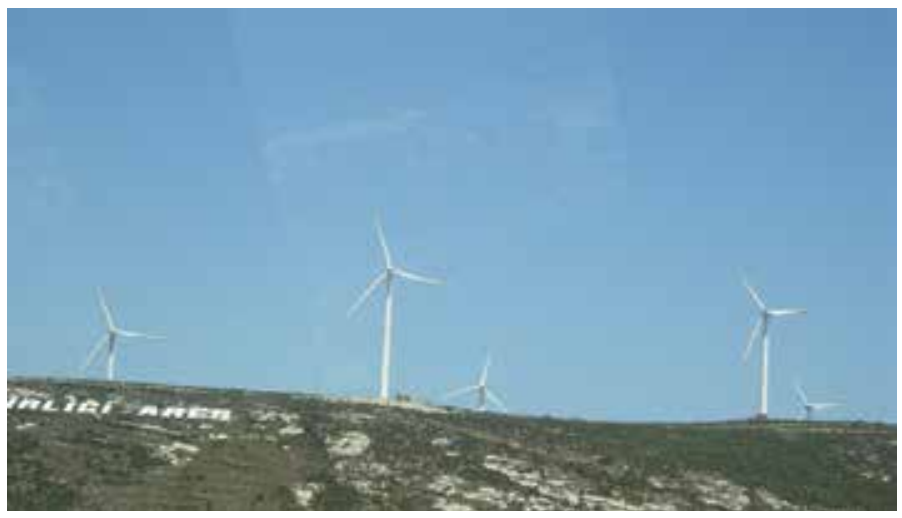

Fig. 8. A wind power plant in Çeşme-Alaçatı

First small-scale application to generate electrical energy in Turkey was started with a plant that has $55 \mathrm{~kW}$ installed power at Altinyunus Hotel in Izmir - Cesme in the Aegean region in 1986. The first power plant in large-scale was also installed in 1998. Cesme- Germiyan with 1.74 MW capacity. In 1998, the ARES wind farm was built in Cesme-Alacat and includes $12 \times 600 \mathrm{~kW}$ wind turbines. Fig. 8. shows the wind power plant in Cesme-Alacat . The biggest wind energy power plant that is constructed in Osmaniye-Bahçe in Turkey in 2009. has 95 MW capacitiy. Current wind energy project in Turkey is listed in Table 4. 
Wind power projects under operation in Turkey

\begin{tabular}{|c|c|c|c|c|c|}
\hline \multicolumn{6}{|c|}{ Wind power projects under operation in Turkey } \\
\hline Location & Company & $\begin{array}{c}\text { Installed } \\
\text { Capacity(MW) }\end{array}$ & $\begin{array}{l}\text { Commissio- } \\
\text { ning Date }\end{array}$ & \begin{tabular}{|c|} 
Turbine \\
Manufacturer
\end{tabular} & $\begin{array}{c}\text { Turbine Capacity } \\
\text { and Number }\end{array}$ \\
\hline İzmir-Çeşme & Alize Corp. & 1.50 & 1998 & Enercon & $0.5 \times 3$ \\
\hline İzmir-Çeşme & Ares Corp. & 7.20 & 1998 & Vestas & $0.6 \times 12$ \\
\hline İstanbul-Hadımköy & Sunjüt Corp. & 1.20 & 2003 & Enercon & $0.6 \times 2$ \\
\hline Balıkesir-Bandırma & Yapisan Corp. & 30.00 & 2006 & GE & $1.5 \times 20$ \\
\hline İzmir-Çeşme & Mare Corp. & 39.20 & 2006 & Enercon & 49 \\
\hline İstanbul-Silivri & Teperes Corp. & 0.85 & 2007 & Vestas & $0.85 \times 1$ \\
\hline Çanakkale-İntepe & Anemon Corp. & 39.40 & 2007 & Enercon & $0.8 \times 38$ \\
\hline Manisa-Akhisar & Deniz Corp. & 10.8 & 2007 & Vestas & $1.8 \times 6$ \\
\hline Çanakkale-Gelibolu & Doğal Corp. & 14.90 & 2007 & Enercon & $0.8 \times 13$ and $5 \times 0.9$ \\
\hline Manisa-Sayalar & Doğal Corp. & 34.20 & 2008 & Enercon & $0.9 \times 38$ \\
\hline İstanbul-Çatalca & Ertürk Corp. & 60.00 & 2008 & Vestas & $3 \times 20$ \\
\hline İzmir-Aliağa & İnnores Corp. & 57.50 & 2008 & Nordex & $2.5 \times 23$ \\
\hline İstanbul-GOP & Lodos Corp. & 24.00 & 2008 & Enercon & $2 \times 12$ \\
\hline Muğla-Datça & Dares Corp. & 29.60 & 2008 & Enercon & $0.9 \times 37$ \\
\hline Hatay-Samandağ & Deniz Corp. & 30.00 & 2008 & Vestas & $2 \times 15$ \\
\hline Aydın-Didim & Ayen Corp. & 31.50 & 2009 & Suzlon & $2.1 \times 15$ \\
\hline Balıkesir-Şamlı & Baki Corp. & 90.00 & 2009 & Vestas & $3 \times 30$ \\
\hline Hatay-Belen & Belen Corp. & 30.00 & 2009 & Vestas & $3 \times 10$ \\
\hline Tekirdağ-Şarköy & Alize Corp. & 28.80 & 2009 & Enercon & $2 \times 14$ and $1 \times 0.8$ \\
\hline İzmir-Urla & Kores Corp. & 15.00 & 2009 & Nordex & $2.5 \times 6$ \\
\hline Çanakkale-Ezine & Alize Corp. & 20.80 & 2009 & Enercon & $2 \times 10$ and $0.8 \times 1$ \\
\hline Balıkesir-Susurluk & Alize Corp. & 20.70 & 2009 & Enercom & $0.9 \times 23$ \\
\hline İzmir-Çeşme & Maz1-3 Corp. & 30.00 & 2009 & Nordex & $2.5 \times 12$ \\
\hline Balıkesir -Bandırma & Akenerji Corp. & 15.00 & 2009 & Vestas & $3 \times 5$ \\
\hline Balıkesir -Bandırma & Borasco Corp. & 45.00 & 2009 & Vestas & $3 \times 15$ \\
\hline Osmaniye-Bahçe & Rotor Corp. & 95.00 & 2009 & GE & $2.5 \times 55$ \\
\hline Manisa-Soma & Soma Corp. & 49.50 & 2010 & Enercom & $0.9 \times 55$ \\
\hline Balıkesir -Bandırma & As MaksanCorp. & 24.00 & 2010 & Nordex & $3 \times 8$ \\
\hline Mersin-Mut & Akdeniz Corp. & 33.00 & 2010 & Vestas & $3 \times 11$ \\
\hline Çanakkale-Bozcada & Bores Corp. & 10.20 & 2000 & Enercon & $0.6 \times 17$ \\
\hline İzmir-Aliağa & Bergama Corp. & 90.00 & 2010 & Nordex & $2.5 \times 36$ \\
\hline Edirne-Enez & Boreas Corp. & 15.00 & 2010 & Nordex & $2.6 \times 6$ \\
\hline \multicolumn{2}{|c|}{ Total Operating Capacity } & 1029.85 & & & \\
\hline \multicolumn{6}{|c|}{ Projects Under Construction and to be Commmissioned in 2010} \\
\hline Balıkesir-Havran & Alize Corp. & 16.00 & 2010 & Enercon & $2.0 \times 8$ \\
\hline Manisa-Kırkağaç & Alize Corp. & 25.60 & 2010 & Enercon & $0.8 \times 32$ \\
\hline Osmaniye-Bahçe & Rotor Corp. & 45.50 & 2010 & GE & $2.5 \times 18$ \\
\hline Osmaniye-Bahçe & Rotor Corp. & 60.00 & 2010 & GE & $2.5 \times 24$ \\
\hline Osmaniye-Bahçe & Rotor Corp. & 50.00 & 2010 & GE & $2.5 \times 20$ \\
\hline Manisa-Soma & Soma Corp. & 90.90 & 2010 & Enercon & $0.9 \times 33,2 \times 29,0.8 \times 4$ \\
\hline İzmir-Aliağa & Doruk Corp. & 30.00 & 2010 & Enercon & $2.0 \times 15$ \\
\hline Manisa-Soma & Bilgin Corp. & 90.00 & 2010 & Nordex & $2.5 \times 36$ \\
\hline Hatay-Samandağ & Ziyaret Corp. & 35.00 & 2010 & GE & $2.5 \times 14$ \\
\hline İzmir-Bergama & Ütopya Corp. & 15.00 & 2010 & GE & $2.5 \times 6$ \\
\hline Balıkesir- Bandırma & Kapıda ğ Corp. & 34.85 & 2010 & & \\
\hline \multicolumn{2}{|c|}{ Total Operating Capacity } & 492.85 & & & \\
\hline
\end{tabular}

Table 4. Wind Power Plant Projects in Turkey in 2010. 
There are also some wind power projects established by private sector to supply their electrical energy needs. Table 1. is listed the wind power plant projects in Turkey in 2010. Installed wind power capacity for electrical energy production is shown in Fig. 9. It is expected that total wind energy installed capacity will have reached $1522.7 \mathrm{MW}$ by the end of 2010 .

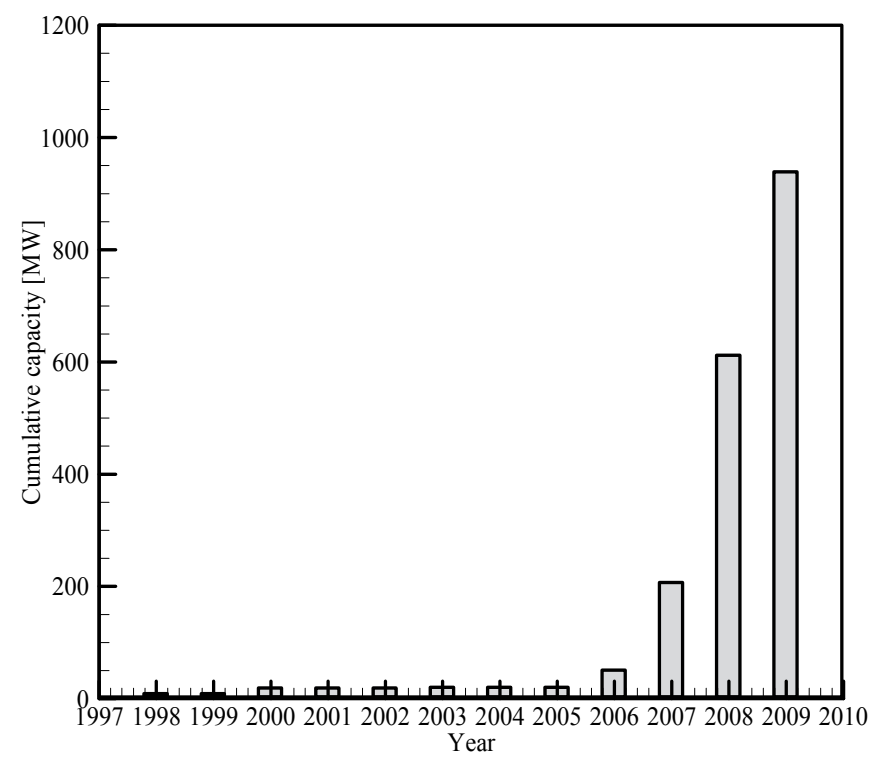

Fig. 9. Installed wind power capacity for electrical energy production in Turkey

\section{Prediction of the wind characteristics}

Determining of wind energy potential for the selected site is made by investigating detailed knowledge of the wind characteristics, such as speed, direction, continuity, and availability. Thus, proper wind turbine selection and micrositting process for the wind power plants are obtained. Knowledge of the wind speed distribution is a very important factor to evaluate the wind potential in the windy areas. In addition to speed distribution, meteorological data and topographical information for considered site have same importance. If ever the wind speed distribution in any windy site is known, the power potential and the economic feasibility belonging to the site can be easily obtained. Wind data obtained with various observation methods has the wide ranges. Therefore, in the wind energy analysis, it is necessary to have only a few key parameters that can explain the behavior of a wide range of wind speed data. The simplest and most practical method for the procedure is to use a distribution function. There are several density functions, which can be used to describe the wind speed frequency curve. The most common two are the Weibull and Rayleigh functions (Gökçek et al., 2007.a).

\subsection{Weibull and Rayleigh distribution function}

The Weibull distribution function that is a special case of generalized gamma distribution for wind speed is expressed with Eq. (1) 


$$
f_{w}(v)=\frac{k}{c}\left(\frac{v}{c}\right)^{k-1} \exp \left[-\left(\frac{v}{c}\right)^{k}\right]
$$

where $\mathrm{v}$ is the wind speed, $\mathrm{c}$ is a Weibull scale parameter in $\mathrm{m} / \mathrm{s}$ and $\mathrm{k}$ is a dimensionless Weibull shape parameter. Besides, the cumulative probability function of the Weibull distribution is calculated as below

$$
F_{w}(v)=1-\exp \left[-\left(\frac{v}{c}\right)^{k}\right]
$$

There are several methods of determining Weibull $\mathrm{k}$ and c parameters, such as least-square fit to observed distribution method, mean wind speed-standard deviation method etc. In this study, the two parameters, k and c, are obtained using Eq. (3) and (4), namely using mean wind speed-standard deviation method (Justus et al., 1977.).

$$
\begin{gathered}
k=\left(\frac{\sigma}{\bar{v}}\right)^{-1.086}(1 \leq \mathrm{k} \leq 10) \\
c=\frac{\bar{v}}{\Gamma\left(1+\frac{1}{k}\right)}
\end{gathered}
$$

where $\bar{v}$ is the mean wind speed and is calculated using Eq. (5), $\sigma$ is the standard deviation and is calculated using Eq. (6)

$$
\begin{gathered}
\bar{v}=\frac{1}{n}\left(\sum_{i=1}^{n} v_{i}\right) \\
\sigma=\left[\frac{1}{n-1} \sum_{i=1}^{n}\left(v_{i}-\bar{v}\right)^{2}\right]^{0.5}
\end{gathered}
$$

where $\mathrm{n}$ is the number of hours in the period of the considered time such as month, season or year. Another distribution function used in determination of the wind speed potential is Rayleigh distribution. This distribution is a special case of Weibull distribution and validate situation where the dimensionless shape parameter $\mathrm{k}$ of the Weibull distribution is assumed to be equal to 2. Probability density and cumulative function of the Rayleigh distribution are given by Eq. (7) and Eq. (8), respectively,

$$
\begin{aligned}
& f_{R}(v)=\frac{\pi v}{2 v^{-2}} \exp \left[-\left(\frac{\pi}{4}\right)\left(\frac{v}{\bar{v}}\right)^{2}\right] \\
& F_{R}(v)=1-\exp \left[-\left(\frac{\pi}{4}\right)\left(\frac{v}{\bar{v}}\right)^{2}\right]
\end{aligned}
$$




\subsection{Calculation of wind power}

The wind power per unit area in any windy site is of importance in assessing of the wind power projection for the power plants. The wind power density of the considered site per unit area based on any probability density function can be expressed as (Gökçek et al., 2007.)

$$
P_{m}=\frac{1}{2} \rho \int_{0}^{\infty} v^{3} f(v) d v
$$

where $\rho$ is the standard air density, $1.225 \mathrm{~kg} / \mathrm{m} 3, \mathrm{v}$ is the wind speed, $\mathrm{m} / \mathrm{s}$. In the current study, the power of the wind was calculated using Weibull function and observed data. When the Weibull function is chosen as distribution function $f(v)$, the average wind power density is calculated as below

$$
P_{m w}=\frac{1}{2} \rho v^{-3} \frac{\Gamma(1+3 / k)}{[\Gamma(1+1 / k)]^{3}}
$$

\section{Calculation of electrical power output from a wind turbine}

Annual energy production (AEP, Ep) for the potential site can be calculated using the wind speed data belongs to that site and the power curves regarding the wind turbines that selected $[1,20]$. The method of calculation requires combining the power curve of turbine considered with the wind speed data prepared in the form of time-series. An algebraic equation of degree $\mathrm{n}$ according to the power curve of the wind turbine between cut-in and rated speed or cut-in speed and cut-out speed can be formed as shown Eq. (11), to predict the wind energy output from the wind turbine (Gökçek et al. 2007.b).

$$
\mathrm{P}_{\mathrm{i}}(\mathrm{v})=\left\{\begin{array}{lc}
0, & \mathrm{v}<\mathrm{v}_{\mathrm{ci}} \\
\left(\mathrm{a}_{\mathrm{n}} \mathrm{v}^{\mathrm{n}}+\mathrm{a}_{\mathrm{n}-1} \mathrm{v}^{\mathrm{n}-1}+\ldots+\mathrm{a}_{1} \mathrm{v}+\mathrm{a}_{0}\right), & \mathrm{v}_{\mathrm{ci}} \leq \mathrm{v}<\mathrm{v}_{\mathrm{R}} \\
\mathrm{P}_{\mathrm{R}}, & \mathrm{v}_{\mathrm{R}} \leq \mathrm{v}<\mathrm{v}_{\mathrm{co}} \text { or } \\
\left(\mathrm{a}_{\mathrm{n}} \mathrm{v}^{\mathrm{n}}+\mathrm{a}_{\mathrm{n}-1} \mathrm{v}^{\mathrm{n}-1}+\ldots+\mathrm{a}_{1} \mathrm{v}+\mathrm{a}_{0}\right), & \mathrm{v}_{\mathrm{ci}} \leq \mathrm{v}<\mathrm{v}_{\mathrm{co}} \\
0, & \mathrm{v} \geq \mathrm{v}_{\mathrm{co}}
\end{array}\right.
$$

where $\mathrm{a}_{\mathrm{n}}, \mathrm{a}_{\mathrm{n}-1}, \mathrm{a}_{1}$ and $\mathrm{a}_{0}$ are regression constants, $\mathrm{v}_{\mathrm{ci}}$ is the cut-in speed, $\mathrm{v}_{\mathrm{R}}$ is the rated speed, $\mathrm{v}_{\mathrm{co}}$ is the cut-out speed and $\mathrm{P}_{\mathrm{R}}$ is the rated power and also $\mathrm{P}_{\mathrm{i}}(\mathrm{v})$ is the power generating in the related wind speed.

Energy corresponding to a specific wind speed is calculated by the product of the power delivered by the turbine at the wind speed $\mathrm{v}$ and the time for which the wind speed $\mathrm{v}$ prevails at the investigated site. The total energy generated by the turbine over a period can be computed by adding up the energy corresponding to all possible wind speeds in the related conditions, at which the system is operational. In this study, the hourly mean wind speed is used in order to obtain the energy output from a turbine. Thus, energy output from the turbine can be calculated by Eq. (12)

$$
E_{p}=\sum_{i=1}^{n} P_{i}(v) \cdot t
$$


where $\mathrm{n}$ is the number of hours in the period of the considered time such as year, season or month, $t$ is one hour time duration. Capacity factor is one of the important indicators for assessing the field performance of a wind turbine. The capacity factor of a turbine at a given location is defined as the ratio of the energy actually produced by the system to the energy that could have been produced by it, if the machine would have operated at its rated power throughout the time period. The capacity factor for the wind turbine can be investigated based on monthly, seasonal and annual values. Annual value of the capacity factor can be calculated as given below;

$$
C f=\frac{E_{\mathrm{p}}}{E_{\text {rated }}}
$$

\section{A case study for western anatolia}

Turkey has an important wind energy potential especially in the Marmara region, coasts of western and southern Anatolia. The main purpose in the case study is to investigate the wind energy potential of Kirklareli province in the northwestern Marmara region, Turkey (Gökçek et al, 2007. a, Gökçek et al. 2007. b). In addition to this, electrical energy production was calculated by considering a wind turbine with $2300 \mathrm{~kW}$ rated power in the related site Wind data at $10 \mathrm{~m}$ height above the ground level related to the selected site were taken from EIEI for the year 2004.

\subsection{Probability density functions}

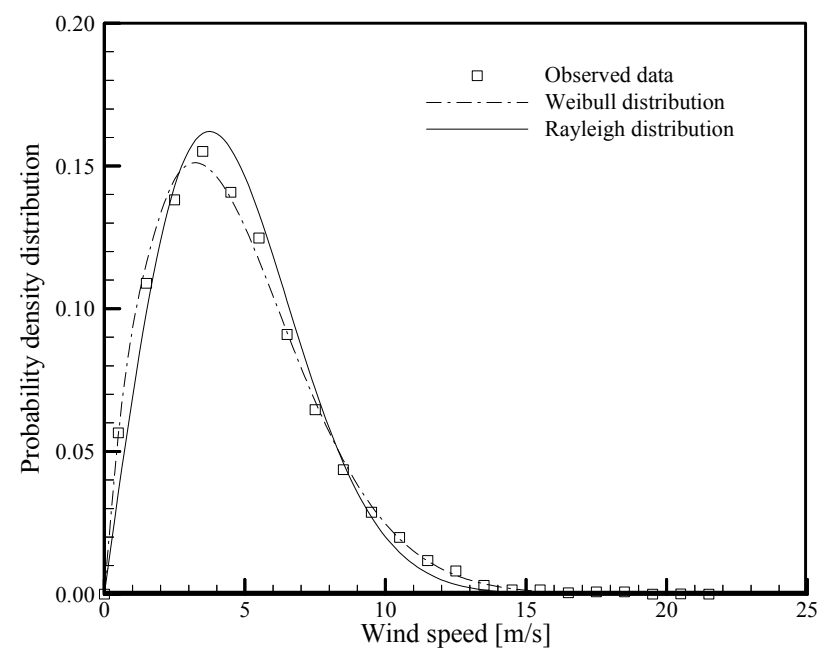

Fig. 10. Wind speed frequency distributions in the site for the year 2004.

Probability density functions such as Weibull or Rayleigh function are usually used to determine the wind speed distribution of a windy site in a period of time. In the current study, determination of wind speed distributions for the investigated site was made using Weibull and Rayleigh probability density functions. Fig. 10. reveals Weibull with the two parameters and Rayleigh distributions derived from observed data for the year 2004. As seen in this figure, the top point of the curve is the most frequent wind speed. The peak 
probability values vary between 0.15 and 0.165 depending on the wind speeds for the considered distribution functions (Weibull, Rayleigh and Actual probability distribution). Shape (k) and scale (c) parameters of the Weibull function were calculated using the method mentioned in the earlier section. The results of the calculation show that dimensionless shape parameter $\mathrm{k}$ is 1.75 while scale parameter $\mathrm{c}$ is $5.25 \mathrm{~m} / \mathrm{s}$ for the site analyzed in the year 2004 .

\subsection{Wind power density}

Fig. 11. shows monthly variations for the mean power density that is calculated using both observed data and Weibull function for the year 2004.

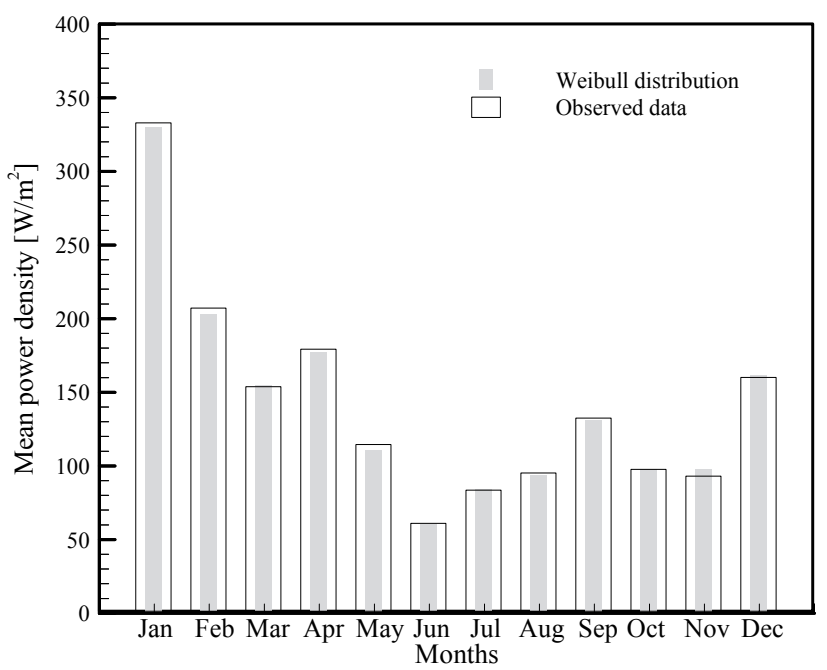

Fig. 11. Monthly variation of the mean power densities depending on Weibull function and observed data

As seen from Fig.11, the mean wind power densities decrease from January to June. In the second half of the year 2004., the changes of the mean power density show almost similar characteristics. The highest mean power density of $332.88 \mathrm{~W} / \mathrm{m}^{2}$ regarding actual data is calculated in the month of January while the lowest is in the month of June with the value of $60.83 \mathrm{~W} / \mathrm{m}^{2}$.

\subsection{Electrical energy production}

The factors influencing the energy produced by the turbine at the considered site during the related time period are the power response of the turbine to different wind velocities, wind regime and wind speed distribution. In this study, annual energy production is calculated by the time-series approach for all turbines considered at the site using the wind data of the year 2004. Fig. 12. shows power curve of the wind turbine considered in this study.

In the result of the case study, annual capacity factor for wind turbine considered is calculated as $27.08 \%$. In January, electrical energy produced by turbine is about $728 \mathrm{MWh}$. This production is highest energy production when considering monthly production. In addition to this, capacity factor for the related month is calculated as $42.52 \%$. In June, electrical energy produced by turbine is calculated about $254 \mathrm{MWh}$. Energy production in the June contrast to January is poor. Capacity factor for the June is also calculated as $15.33 \%$. 
In power generating, the load duration curves are used to illustrate the relationship between generating capacity requirements and capacity utilization. In Fig. 13., the load duration curve for the wind energy production related to turbine considered is shown. As it can be seen in this figure, turbine is operated 6153 hours at the related year.

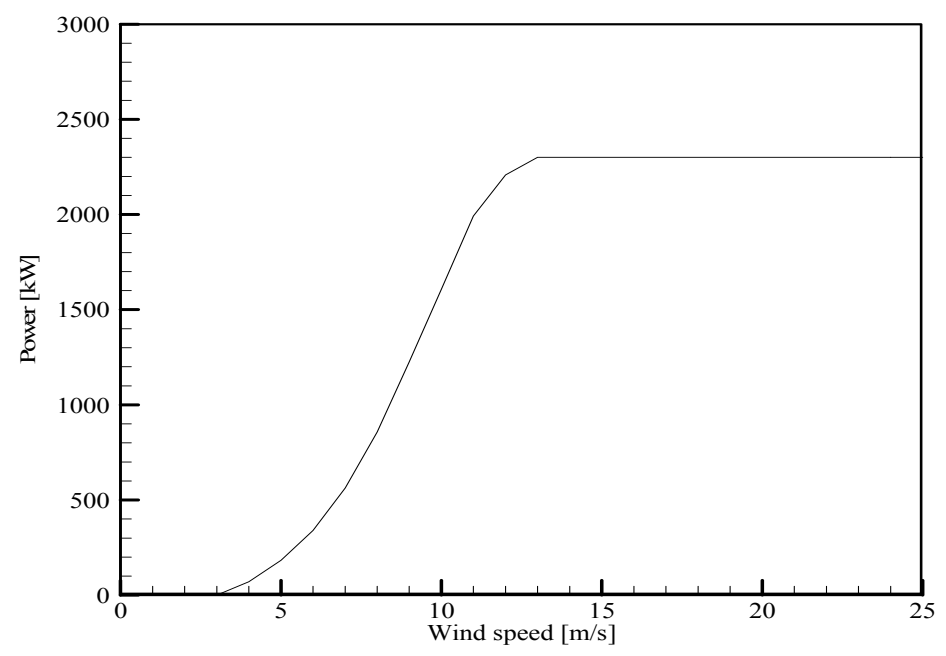

Fig. 12. Power curve for a turbine of $2300 \mathrm{~kW}$ rated power

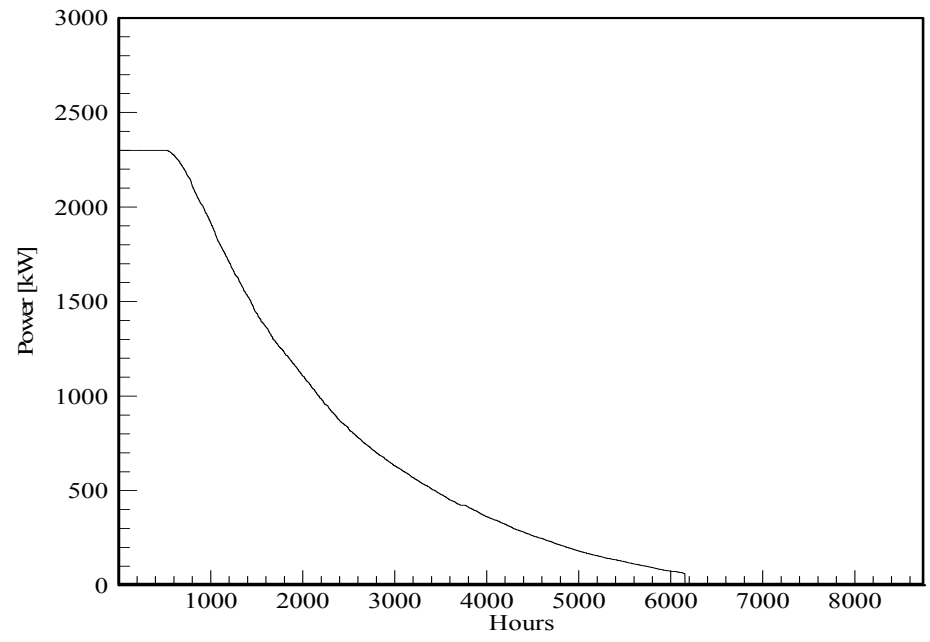

Fig. 13. Load duration curve for the wind turbine

\section{Conclusion}

In this study, wind-electricity status of Turkey was considered according to the recent developments on wind utilization in the world and wind Turkey' $\mathrm{s}$ wind energy potential is reviewed. In addition, a case study was carried out for both wind characteristics and wind energy production. Turkey has a significantly high poetantial of wind energy. This potential can be utilized to satisfy a part of the total energy demand in the country. Turkey has about 
83,000 MW wind energy potential. By the end of 2009., the wind power plants of $802 \mathrm{MW}$ capacity was constructed in Turkey. Wind energy maps of Turkey have been presented and the potential areas are identified with the emphasis on their significance. The potential windy areas in Turkey lie in northern parts and the Northwestern parts, at locations along the Aegean Sea and Marmara Sea coast. The case study shows that there is an important potential to use wind energy in Western Marmara, Turkey.

\section{References}

Akdağ, S.A. \& Güler, Ö. (2010.). Evaluation of wind energy investment interest and electricity generation cost analysis for Turkey, Applied Energy Vol. 87, page numbers $(2574-2580)$.

Burton, T.; Sharpe, D.; Jenkins, N. \& Bossanyi, E., (2001.). Wind Energy Handbook, John Wiley \& Sons, Ltd. Chichester.

BP Statistical Review of World Energy (2010.), http://www.bp.com/statisticalreview

EIEI (2010.), http://www.eie.gov.tr, Electrical Power Resources Survey and Development Administration.

EÜAŞ Sector Report (2008.). Electrical Energy Production Sector Report.

EWEA (2009.), Wind Energy-The Facts, European Wind Energy Agency.

Gökcek, M.; Bayülken, A. \& Bekdemir, Ş. (2007. a). Investigation of Wind Characteristics and Wind Energy Potential in Kirklareli, Turkey, Renewable Energy, Vol. 32, page numbers (1739-1752).

Gökcek, M.; Erdem, H.H. \& Bayülken A. (2007. b). A Techno-economical Evaluation for Installation of Suitable Wind Energy Plants in Western Marmara, Turkey. Energy Exploration $\mathcal{E}$ Exploitation, Vol. 25 (6) Energy Exploration $\mathcal{E}$ Exploitation, page numbers (1739-1752).

GWEC (2010.), Global Wind Energy Council

Herbert, J.G.M.; Iniyan, S.; Sreevalsan, E. \& Rajapandian, S. (2007.). A review of wind energy technologies, Renewable and Sustainable Energy Reviews, Vol.11, page numbers (11171145).

İlkilic, C. \& Türkbay, İ. (2010.). Determination and utilization of wind energy potential for Turkey, Renewable and Sustainable Energy Reviews,Vol.14, page numbers (2202-2207).

Kaygusuz, K., (2010.). Wind energy status in renewable electrical energy production in Turkey, Renewable and Sustainable Energy Reviews,Vol.14, page numbers (2104-2112).

MENR (2010.), http://www.ruzgarenerjisibirligi.org.tr, Turkish Ministry of Energy and Natural Resources.

Saidur, R.; Islam, M.R.; Rahim, N.A. \& Solangi K.H. (2010). A review on global wind energy policy, Renewable and Sustainable Energy Reviews, Vol. 14, page numbers (17441762).

TWEU (2010.), http:/ / www.ruzgarenerjisibirligi.org.tr

Justus, C.G.; Hargraves, R.; Mikhail A. \& Graber D. (1977.) Methods for estimating wind speed frequency distributions. Journal of Applied Meteorology Vol.17, page numbers (350-353).

World Energy Outlook 2009., (2009.). International Energy Agency, ISBN: 9789264061309. 


\section{Part 3}

Energy Storage and Efficient Use of Energy 



\title{
Understanding the Vanadium Redox Flow Batteries
}

\author{
Christian Blanc and Alfred Rufer \\ Laboratoire d'Electronique Industrielle, Ecole Polytechnique Federale de Lausanne
}

Switzerland

\section{Introduction}

Vanadium redox flow batteries (VRB) are large stationary electricity storage systems with many potential applications in a deregulated and decentralized network. Flow batteries (FB) store chemical energy and generate electricity by a redox reaction between vanadium ions dissolved in the electrolytes. FB are essentially comprised of two key elements (Fig. 1): the cell stacks, where chemical energy is converted to electricity in a reversible process, and the tanks of electrolytes where energy is stored.

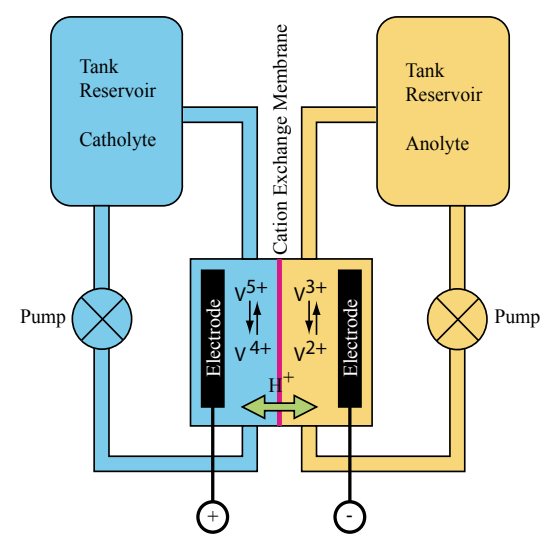

(a)

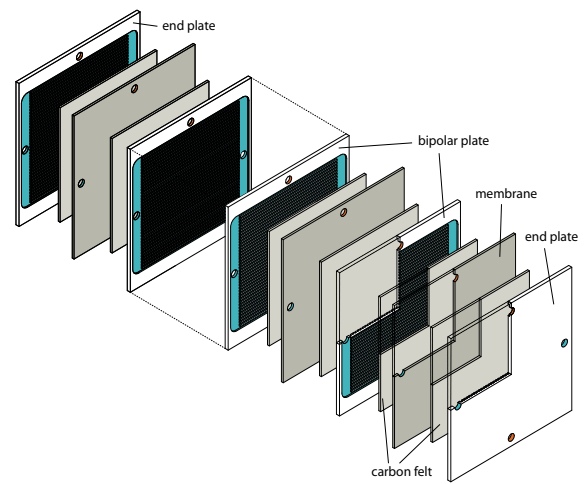

(b)

Fig. 1. (a) The schematics of the vanadium redox flow battery. (b) View of the different components composing a VRB stack. The surfaces in contact with the catholyte are coloured in blue and in orange for the anolyte.

The most significant feature of the FB is maybe the modularity of their power $(\mathrm{kW})$ and energy $(\mathrm{kWh})$ ratings which are independent of each other. In fact, the power is defined by the size and number of cells whereas the energetic capacity is set by the amount of electrolyte stored in the reservoirs. Hence, FB can be optimized for either energy and/or power delivery.

Over the past 30 years, several redox couples have been investigated (Bartolozzi, 1989): zinc bromine, polysulfide bromide, cerium zinc, all vanadium, etc. Among them, VRB has the best chance to be widely adopted, thanks to its very competitive cost, its simplicity and because it contains no toxic materials. 
In order to enhance the VRB performance, the system behaviour along with its interactions with the different subsystems, typically between the stack and its auxiliaries (i.e. electrolyte circulation and electrolyte state of charge), and the electrical system it is being connected to, have to be understood and appropriately modeled. Obviously, modeling a VRB is a strongly multidisciplinary task based on electrochemistry and fluid mechanics. New control strategies, based on the knowledge of the VRB operating principles provided by the model, are proposed to enhance the overall performance of the battery.

\section{Electrochemistry of the vanadium redox batteries}

Batteries are devices that store chemical energy and generate electricity by a reduction-oxidation (redox) reaction: i.e. a transformation of matter by electrons transfer. VRB differ from conventional batteries in two ways: 1) the reaction occurs between two electrolytes, rather than between an electrolyte and an electrode, therefore no electro-deposition or loss in electroactive substances takes place when the battery is repeatedly cycled. 2) The electrolytes are stored in external tanks and circulated through the stack (see Fig. 1). The electrochemical reactions occur at the VRB core: the cells. These cells are always composed of a bipolar or end plate - carbon felt - membrane - carbon felt - bipolar or end plates; they are then piled up to form a stack as illustrated in Fig. 1.

In the VRB, two simultaneous reactions occur on both sides of the membrane as illustrated in Fig. 2. During the discharge, electrons are removed from the anolyte and transferred through the external circuit to the catholyte. The flow of electrons is reversed during the charge, the reduction is now taking place in the anolyte and the oxidation in the catholyte.

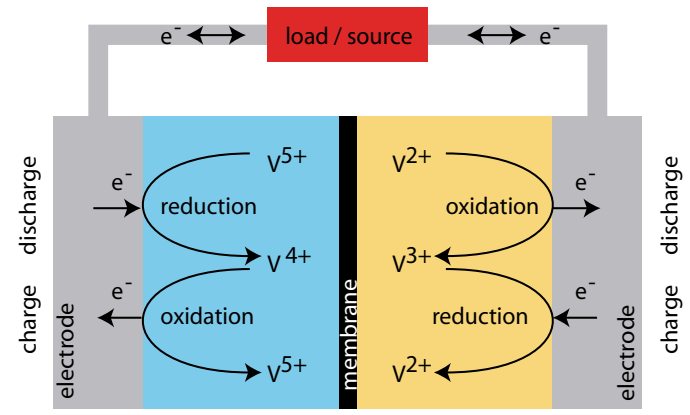

Fig. 2. VRB redox reaction during the charge and discharge

The VRB exploits the ability of vanadium to exist in 4 different oxidation states; the vanadium ions $V^{4+}$ and $V^{5+}$ are in fact vanadium oxide ions (respectively $\mathrm{VO}^{2+}$ and $\mathrm{VO}_{2}^{+}$). Thus, the VRB chemical equations become (Sum \& Skyllas-Kazacos, 1985; Sum et al., 1985):

$$
\begin{gathered}
\mathrm{VO}_{2}^{+}+2 \mathrm{H}^{+}+e^{-} \rightleftarrows V \mathrm{O}^{2+}+\mathrm{H}_{2} \mathrm{O} \\
V^{2+} \rightleftarrows V^{3+}+e^{-} \\
V^{2+}+\mathrm{VO}_{2}^{+}+2 \mathrm{H}^{+} \rightleftarrows V \mathrm{O}^{2+}+V^{3+}+\mathrm{H}_{2} \mathrm{O}
\end{gathered}
$$

where the water $\left(\mathrm{H}_{2} \mathrm{O}\right)$ and protons $\left(\mathrm{H}^{+}\right)$are required in the cathodic reaction to maintain the charge balance and the stoichiometry. 


\subsection{Equilibrium potential}

The stack voltage $U_{\text {stack }}$ depends on the equilibrium voltage $U_{e q}$ and on the internal losses $U_{\text {loss }}$; the equilibrium conditions are met when no current is flowing through the stack. In that case, there is no internal loss and $U_{\text {stack }}$ equals $U_{\text {eq }}$; otherwise, the internal losses modify $U_{\text {stack }}$. The internal losses ${ }^{1} U_{\text {loss }}$ will be discussed in section 3.3. Hence $U_{\text {stack }}$ is given by:

$$
U_{\text {stack }}(t)=U_{e q}(t)-U_{\text {loss }}(t)[V]
$$

The equilibrium voltage $U_{e q}$ corresponds to the sum of the equilibrium potential $E$ of the individual cells composing the stack. This potential is given by the Nernst equation and depends on the vanadium species concentrations and on the protons concentrations (Blanc, 2009):

$$
E=E^{\ominus^{\prime}}+\frac{R T}{F} \ln \left\{\left(\frac{c_{V O_{2}^{+}} \cdot c_{H^{+}}^{2}}{c_{V O^{2+}}}\right)\left(\frac{c_{V^{2+}}}{c_{V^{3+}}}\right)\right\} \quad[V]
$$

where $R$ is the gas constant, $T$ the temperature, $F$ the Faraday constant, $c_{i}$ the concentration of the species $i$ and $E^{\ominus^{\prime}}$ the formal potential. If we assume that the product/ratio of the activity coefficients is equal to 1 , the formal potential $E^{\ominus^{\prime}}$, an experimental value often not available, can be replaced by the standard potential $E^{\ominus}$.

\subsubsection{Standard potential from the thermodynamics}

The standard potential $E^{\ominus}$ is an ideal state where the battery is at standard conditions: vanadium species at a concentration of $1 \mathrm{M}$, all activity coefficients $\gamma_{i}$ equal to one and a temperature of $25^{\circ} \mathrm{C}$. The standard potential is an important parameter in the Nernst equation because it expresses the reaction potential at standard conditions; the second term in the Nernst equation is an expression of the deviation from these standard conditions. Together, they determine the equilibrium cell voltage under any conditions.

The standard potential $E^{\ominus}$ can be found from thermodynamical principles, namely the Gibbs free enthalpy $\Delta G$ and the conservation of energy, and empirical parameters found in electrochemical tables. We introduce here the standard Gibbs free enthalpy of reaction $\Delta G^{\ominus}$ which represents the change of free energy that accompanies the formation of $1 \mathrm{M}$ of a substance from its component elements at their standard states: $25^{\circ} \mathrm{C}, 100 \mathrm{kPa}$ and $1 \mathrm{M}$ (Van herle, 2002):

$$
\Delta G^{\ominus}=\Delta H_{r}^{\ominus}-T \Delta S_{r}^{\ominus} \quad[k J / m o l]
$$

where the standard reaction enthalpy $\Delta H_{r}^{\ominus}$ is the difference of molar formation enthalpies between the products $\Delta H_{f, \text { product }}^{\ominus}$ and the reagents $\Delta H_{f, \text { reagent }}^{\ominus}$ :

$$
\Delta H_{r}^{\ominus}=\sum_{\text {products }} \Delta H_{f, \text { product }}^{\ominus}-\sum_{\text {reagents }} \Delta H_{f, \text { reagent }}^{\ominus}[\mathrm{kJ} / \mathrm{mol}]
$$

and the standard reaction entropy $\Delta S_{r}^{\ominus}$ is the difference of molar formation entropies between the products $S_{f, \text { product }}^{\ominus}$ and the reagents $S_{f, \text { reagent }}^{\ominus}$ :

$$
\Delta S_{r}^{\ominus}=\sum_{\text {products }} S_{f, \text { product }}^{\ominus}-\sum_{\text {reagents }} S_{f, \text { reagent }}^{\ominus} \quad[J / m o l \cdot K]
$$

\footnotetext{
${ }^{1}$ Note that the sign of $U_{\text {loss }}$ depends on the operating mode (charge or discharge).
} 
Then, when we introduce the thermodynamical data from Tab. 1 into (5), the standard reaction enthalpy $\Delta H_{r}^{\ominus}$ of the VRB reaction (1) becomes:

$$
\begin{aligned}
\Delta H_{r}^{\ominus}= & \Delta H_{f, V O^{2+}}^{\ominus}+\Delta H_{f, V^{3+}}^{\ominus}+\Delta H_{f, H_{2} O}^{\ominus} \\
& -\Delta H_{f, V^{2+}}^{\ominus}-\Delta H_{f, V O_{2}^{+}}^{\ominus}-2 \Delta H_{f, H^{+}}^{\ominus} \\
= & -155.6 \mathrm{~kJ} / \mathrm{mol}
\end{aligned}
$$

and similarly, the standard reaction entropy $\Delta S_{r}^{\ominus}$ is obtained when these thermodynamical data are introduced into (6):

$$
\begin{aligned}
\Delta S_{r}^{\ominus}= & S_{f, V O^{2+}}^{\ominus}+S_{f, V^{3+}}^{\ominus}+S_{f, H_{2} O}^{\ominus} \\
& -S_{f, V^{2+}}^{\ominus}-S_{f, V O_{2}^{+}}^{\ominus}-2 S_{f, H^{+}}^{\ominus} \\
= & -121.7 \mathrm{~J} / \mathrm{mol} \cdot K
\end{aligned}
$$

\begin{tabular}{lcccc}
\hline Formula & State & $\Delta H_{f}^{\ominus}[\mathrm{kJ} / \mathrm{mol}]$ & $\Delta G_{f}^{\ominus}[\mathrm{kJ} / \mathrm{mol}]$ & $S_{f}^{\ominus}[\mathrm{J} / \mathrm{mol} \cdot \mathrm{K}]$ \\
\hline$V^{2+}$ & aq & $(-226)$ & -218 & $(-130)$ \\
$V^{3+}$ & aq & $(-259)$ & -251.3 & $(-230)$ \\
$V O^{2+}$ & aq & -486.6 & -446.4 & -133.9 \\
$V \mathrm{O}_{2}^{+}$ & aq & -649.8 & -587.0 & -42.3 \\
$\mathrm{H}_{2} \mathrm{O}$ & aq & -285.8 & -237.2 & 69.9 \\
$\mathrm{H}^{+}$ & $\mathrm{aq}$ & 0 & 0 & 0 \\
\hline
\end{tabular}

Table 1. Thermodynamical data for some vanadium compounds at $298.15 \mathrm{~K}$. Values in parentheses are estimated (Van herle, 2002; Bard et al., 1985).

The conservation of energy relates the change in free energy resulting from the transfer of $n$ moles of electrons to the difference of potential $E$ :

$$
\Delta G=-n F E \quad[J / m o l]
$$

Therefore, we obtain the standard potential $E^{\ominus}$ when we introduce $\Delta G^{\ominus}$ (4) with the values of the standard reaction enthalpy (7) and entropy (8) into the reformulated (9):

$$
E^{\ominus}=-\frac{\Delta G^{\ominus}}{n F}=-\frac{\Delta H_{r}^{\ominus}-T \Delta S_{r}^{\ominus}}{n F} \quad[V]
$$

So, we have determined from the thermodynamical principles that the standard potential $E^{\ominus}$ is $1.23 \mathrm{~V}$ at $25^{\circ} \mathrm{C}$.

The characteristic curve of the equilibrium potential $E$ is illustrated in Fig. 3 for a single cell as a function of the state of charge $S o C$. We can also observe the relation between $E, S o C$ and the protons and vanadium concentrations. 


\begin{tabular}{lcccc}
\hline & Salt & Charge & Discharge & Electrolyte \\
\hline$V^{2+}$ & $V^{2} O_{4}$ & $\uparrow$ & $\downarrow$ & Anolyte \\
$V^{3+}$ & $0.5 \mathrm{~V}_{2}\left(\mathrm{SO}_{4}\right)_{3}$ & $\downarrow$ & $\uparrow$ & Anolyte \\
$V^{4+}$ or $\mathrm{VO}^{2+}$ & $\mathrm{VOSO}_{4}$ & $\downarrow$ & $\uparrow$ & Catholyte \\
$V^{5+}$ or $\mathrm{VO}_{2}^{+}$ & $0.5\left(\mathrm{VO}_{2}\right)_{2} \mathrm{SO}_{4}$ & $\uparrow$ & $\downarrow$ & Catholyte \\
\hline
\end{tabular}

Table 2 . The different vanadium ions with their corresponding salt, their concentration variation during the charge and discharge of the VRB, and the electrolyte where they are dissolved.

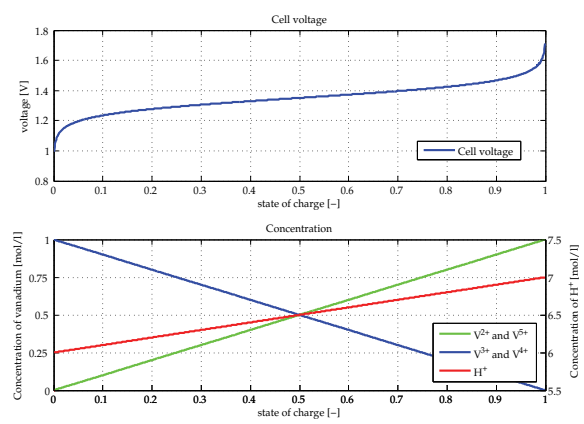

(a)

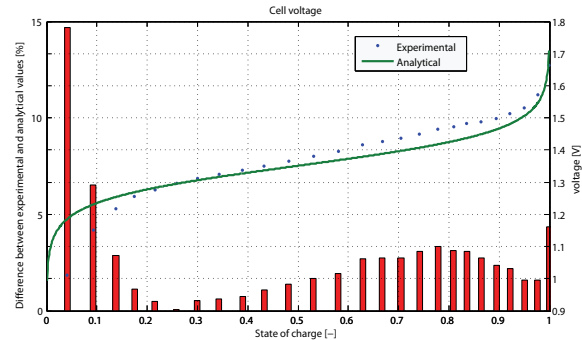

(b)

Fig. 3. (a) Top: Cell voltage versus the state of charge at $25^{\circ} \mathrm{C}$. Bottom: Protons $H^{+}$and vanadium concentrations. (b) Comparison between the Nernst equation (3) and the experimental data published in (Heintz \& Illenberger, 1998). The red bars represent the difference between the analytical and experimental data.

\section{Electrochemical model}

The main electrochemical relations governing the equilibrium voltage where introduced in the previous section. In order to have an electrochemical model of the VRB, it is now necessary to describe how the vanadium concentrations vary during the battery operation.

\subsection{Concentration of vanadium ions}

We see clearly from (1) that during the redox reactions, the vanadium ions are transformed and that some protons $\mathrm{H}^{+}$are either produced or consumed. Therefore, the ion concentrations must change in the electrolyte to reflect these transformations which depend on how the battery is operated.

For example, when the battery is charged, $V^{2+}$ and $\mathrm{VO}_{2}^{+}$are produced and their concentrations increase; and $\mathrm{V}^{3+}$ and $\mathrm{VO}^{2+}$ are consumed and thus their concentrations diminish. This process is reversed when the battery is discharged. Tab. 2 summarizes the direction of the change for each species. 


\subsubsection{Electron exchange rate}

Obviously, the concentration changes are proportional to the reaction rate; and from (1) we also know that an electron is involved each time a redox reaction occurs. Therefore, the concentration changes are also proportional to the electrical current. Thus, the pace of the concentration variation is set by the electrical current flowing through the cell:

$$
Q_{c}=n_{e^{-}}=\int i(t) d t \quad[C]
$$

where $Q_{c}$ is the charge, $i$ the current, $t$ the time, $n_{e^{-}}$the number of electrons and $e$ the elementary charge. Therefore, the number of electrons $n_{e^{-}}$involved for a given current ${ }^{2}$ is:

$$
n_{e^{-}}=\frac{1}{e N_{A}} \int i(t) d t \quad[m o l]
$$

where $N_{A}$ is the Avogadro number. Then (12) leads to the definition of a molar flowrate of electrons $\dot{N}_{e^{-}}$:

$$
\dot{N}_{e^{-}}(t)=\frac{1}{e N_{A}} i(t) \quad[\mathrm{mol} / \mathrm{s}]
$$

Physically, an electron is released by the oxidation of a vanadium ion, travels through the electrodes and is captured by the reduction of another vanadium ion in the opposite half-cell. In the case of a stack composed of $N_{\text {cell }}$ cells, the electrons travel through the bipolar electrode to the adjacent cell (Fig. 4). Thus, for one electron flowing through the external electrical circuit, $N_{\text {cell }}$ redox reactions have occurred. Therefore, the total molar flowrate of electrons $\dot{N}_{e_{t o t}^{-}}$for a stack is obtained by multiplying (13) by the number of cells:

$$
\dot{N}_{e_{\text {tot }}^{-}}(t)=\frac{N_{c e l l}}{e N_{A}} i(t)=\frac{N_{c e l l}}{F} i(t) \quad[\mathrm{mol} / \mathrm{s}]
$$

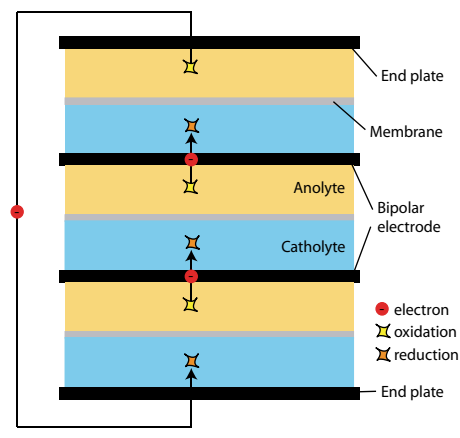

(a)

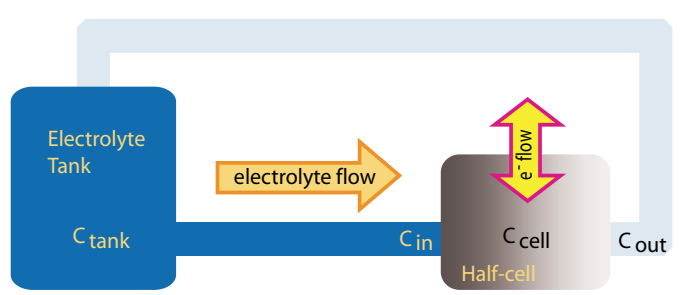

(b)

Fig. 4. (a) Illustration of the redox reactions required to produce a one electron flow in a 3 elements stack during the discharge. When the battery is charged, the flow and the reactions are inverted. (b) Illustration of the hydraulic circuit (half cell) where the concentrations are shown.

\footnotetext{
${ }^{2}$ By convention, the current is positive during the VRB discharge in order to have a positive power delivered by the battery.
} 


\subsubsection{Input, output and average concentrations of vanadium ions}

We know now that the vanadium concentrations change within the cells when the battery is operating. Therefore, the concentrations are not uniformly distributed through the electrolyte circuit (Fig. 4). Indeed, four concentrations are located in the VRB: the tank concentration $c_{\text {tank }}$, the concentration at the cell input $c_{\text {in }}$, the concentration inside the cell $c_{c e l l}$ and the concentration at the cell output $c_{\text {out }}$.

Usually, the size of the reservoir is large compared to the electrolyte flowrate; thus the change in concentrations due to the flow of used electrolyte is so small that the tank concentrations are considered homogeneous. And therefore, the input concentrations $c_{\text {in }}$ correspond exactly to $c_{\text {tank }}$.

The tank concentration $c_{\text {tank }}$ reflects the past history of the battery; indeed the change in $c_{\text {tank }}$ is proportional to the quantity of vanadium that has been transformed in the stack: this value corresponds to the quantity of electrons involves in the reaction. Therefore, $c_{\text {tank }}$ is defined by the initial ion concentrations $c_{\text {tank }}^{\text {initial }}$, the size of the reservoir $V_{\text {tank }}$ and the total molar flowrate of electrons $\dot{N}_{e_{t o t}^{-}}$:

$$
\begin{aligned}
c_{\text {in }}(t)=c_{\text {tank }}(t) & =c_{\text {tank }}^{\text {initial }}+\frac{1}{V_{\text {tank }}} \int b \dot{N}_{e_{\text {tot }}^{-}}(t) d t \\
& =c_{\text {tank }}^{\text {initial }}+\frac{1}{V_{\text {tank }}} \int \frac{b}{F} i(t) d t \quad[\mathrm{~mol} / \mathrm{l}]
\end{aligned}
$$

where $b$ is a sign factor that reflects the direction of the reaction in accordance with Tab. 2:

$$
b=\left\{\begin{array}{c}
-1 \text { for } V^{2+} \text { and } V^{5+} \text { ions } \\
1 \text { for } V^{3+} \text { and } V^{4+} \text { ions }
\end{array}\right.
$$

The description of the output concentration $c_{\text {out }}$ is difficult because it depends on the electrolyte flowrate $Q$, the length of the electrolyte circuit and on the current $i$ that the electrolyte encounters during the cell crossing. Since the distribution of the vanadium ions inside the cell is unknown, we consider that the model has no memory and reacts instantly to a change in the operating conditions. In that case, $c_{\text {out }}$ is related to the electrons molar flowrate $\dot{N}_{e_{\text {tot }}^{-}}$, the electrolyte flowrate $Q$ and on the input concentration $c_{i n}$ :

$$
c_{\text {out }}(t)=c_{i n_{i}}(t)+b \frac{\dot{N}_{e_{\text {tot }}^{-}}(t)}{Q(t)}=c_{i n_{i}}(t)+\frac{b N_{\text {cell }}}{F} \frac{i(t)}{Q(t)} \quad[\mathrm{mol} / \mathrm{l}]
$$

where: $\quad c_{i}=$ concentration of the different vanadium ions

$$
Q(t)=\text { flowrate of the electrolyte }
$$

For a quasi steady state, where the current and the flowrate are almost constant, the model predicts accurately the output concentrations. Unfortunately, it is not able to predict the transient behaviour when the system encounters extreme conditions such as the combination of a low flowrate, few active species and sudden current change. But when these conditions are avoided, (17) offers a very good insight of the battery behaviour.

We still have to establish the most important concentration: the concentration inside the cell $c_{c e l l}$ that is necessary to solve the Nernst equation (3). Because the ion concentrations are not uniformly distributed inside the cell, we will make an approximation to determine $c_{c e l l}$ from the mean value of $c_{\text {in }}$ and $c_{\text {out }}$ :

$$
c_{\text {cell }}(t)=\frac{c_{i n_{i}}(t)+c_{\text {out }}(t)}{2} \quad[\mathrm{~mol} / \mathrm{l}]
$$




\subsection{Concentration of protons}

Unfortunately, (1) does not reflect exactly the phenomena happening in the cells. Indeed, the VRB electrolytes contain not only vanadium ions at different oxidation states, but also protons $\mathrm{H}^{+}$and sulphate ions $\mathrm{SO}_{4}^{2-}$ that are only partially represented in the chemical equations; these ions are called spectator ions and do not take an active part in the reaction. But these spectator ions are important to respect the law of conservation of mass and the charge balance in both electrolytes (Blanc, 2009). The complete ionic equation, illustrated in Fig. 5, is useful to understand how the protons concentration $c_{H^{+}}$changes and why the protons cross the membrane to balance the charge.

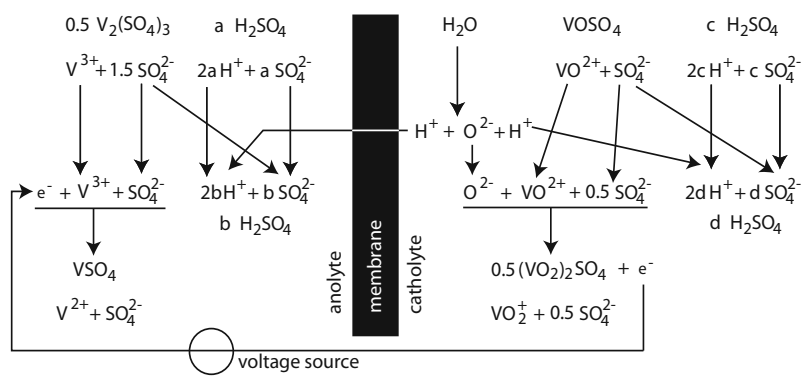

Fig. 5. Illustration of the full ionic equations of the VRB during the charge.

Hence, the protons concentration in the catholyte depends on the electrolyte composition and varies with the state of charge:

$$
c_{H^{+}}=c_{H^{+}, \text {discharged }}+c_{V O^{2+}}[M]
$$

where $c_{H^{+}}$,discharged is the protons concentration when the electrolyte is completely discharged.

\subsection{Internal losses}

When a net current is flowing through the stack, the equilibrium conditions are not met anymore and the stack voltage $U_{\text {stack }}$ is now given by the difference between the equilibrium potential $U_{e q}$ and the internal losses $U_{\text {loss }}$. These losses are often called overpotentials and represent the energy needed to force the redox reaction to proceed at the required rate; a list of the variables affecting this rate is given in Fig. 6.

$$
U_{\text {loss }}(t)=\eta_{\text {act }}(t)-\eta_{\text {conc }}(t)-\eta_{\text {ohm }}(t)-\eta_{\text {ion }}(t)[V]
$$

The activation $\eta_{a c t}$ and the concentration $\eta_{c o n c}$ overpotentials are electrode phenomena and are respectively associated with the energy required to initiate a charge transfer and caused by concentration differences between the bulk solution and the electrode surface; in addition, the ohmic $\eta_{\text {ohm }}$ and ionic $\eta_{\text {ionic }}$ losses also alter the stack voltage. The ohmic losses $\eta_{\text {ohm }}$ occur in the electrodes, the bipolar plates and the collector plates and the ionic losses $\eta_{\text {ionic }}$ occur in the electrolytes and the membranes. But these overpotentials are seldom found in the literature and often applicable only to peculiar conditions. Therefore, an equivalent resistance is introduced instead:

$$
U_{\text {loss }}(t)=R_{\text {eq, charge/discharge }} i(t)[V]
$$

where $R_{\text {eq, charge }}$ is the equivalent charge resistance and $R_{\text {eq, discharge }}$ corresponds to the discharge resistance; these values are found experimentally (Skyllas-Kazacos \& Menictas, 1997) and depends on the electrolyte, electrode materials and stack construction. 


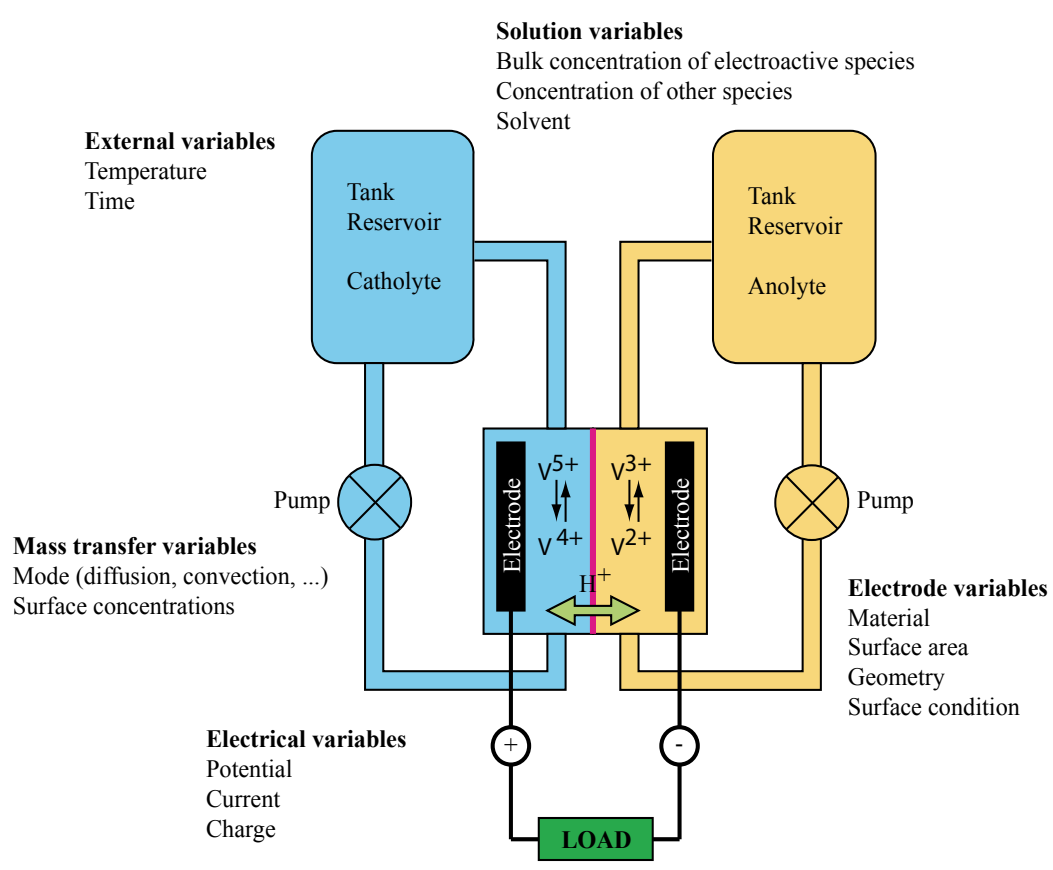

Fig. 6. Schematic representation of VRB with a list of variables affecting the rate of the redox reaction (Bard \& Faulkner, 2001). Note that only one cell is represented on this figure.

\subsection{State of charge}

The state of charge $\mathrm{SoC}$ indicates how much energy is stored in the battery; it varies from 0 (discharged state) to 1 (charged) and is defined by the following relation:

$$
\operatorname{SoC}=\left(\frac{c_{V^{2+}}}{c_{V^{2+}}+c_{V^{3+}}}\right)=\left(\frac{c_{V O_{2}^{+}}}{c_{V O^{2+}}+c_{V O_{2}^{+}}}\right)[-]
$$

\subsection{Electrochemical model}

From the principles explained in the previous section, it is now possible to introduced the electrochemical model that describes the behaviour of the stack, mainly how the stack voltage $U_{\text {stack }}$ depends on the operating conditions: the current $I$, the vanadium concentrations in the electroactive cells $c_{c e l l}$, the protons concentration $c_{H^{+}}$, the electrolyte flowrate $Q$ and the temperature $T$; furthermore, it also describes how the electrolyte compositions change as the battery is operating. The schematic representation of this model is shown in Fig. 7.

\subsection{Efficiencies}

Efficiencies are parameters used to assess the performance of storage system. Basically, the definition of efficiency is simple, the energy efficiency $\eta_{\text {energy }}$ is the ratio of the energy furnished by the battery during the discharge to the energy supplied during the charge:

$$
\eta_{\text {energy }}=\frac{\int P_{V R B, \text { discharge }}(t) d t}{\int\left|P_{V R B, \text { charge }}\right|(t) d t} \quad[-]
$$




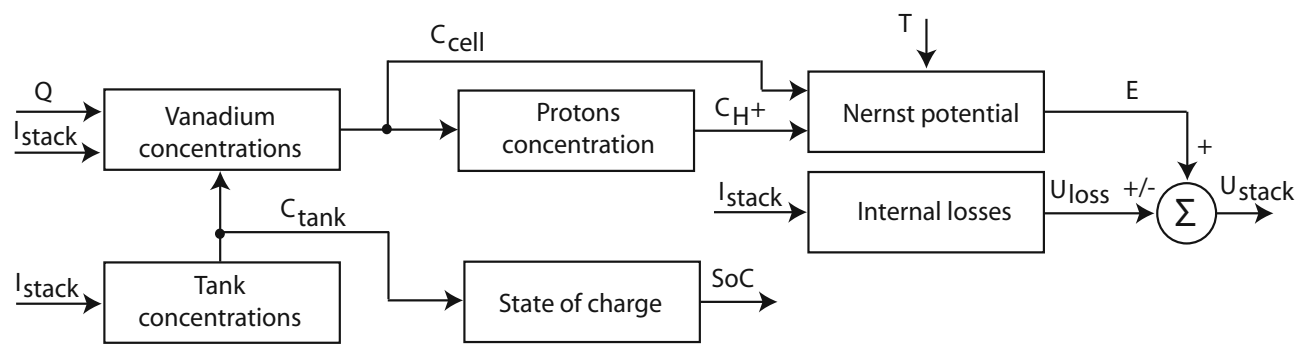

Fig. 7. Schematic representation of the electrochemical model

\begin{tabular}{lclc}
\hline Name & Value & Name & Value \\
\hline number of cells $N_{\text {cells }}$ & 19 & electrolyte vanadium concentration & $2 \mathrm{M}$ \\
$R_{\text {charge }}$ & $0.037 \Omega$ & tank size $V_{\text {tk }}$ & 831 \\
$R_{\text {discharge }}$ & $0.039 \Omega$ & initial concentration of vanadium species & $1 \mathrm{M}$ \\
electrolyte flowrate $Q$ & $21 / \mathrm{s}$ & & \\
\hline
\end{tabular}

Table 3. The characteristics of the VRB stack.

But difficulties quickly arise when different technologies or products are compared because the operating mode has a significant impact on the performance: a quick charge produces more losses than a gentle one. The coulombic efficiency $\eta_{\text {coulombic }}$ is a measure of the ratio of the charge withdrawn from the system $Q_{\text {discharge }}$ during the discharge to the charge $Q_{\text {charge }}$ supplied during the charge:

$$
\eta_{\text {coulombic }}=\frac{Q_{\text {discharge }}}{Q_{\text {charge }}}=\frac{\int i_{\text {discharge }}(t) d t}{\int\left|i_{\text {charge }}(t)\right| d t} \quad[-]
$$

The voltage efficiency $\eta_{\text {voltage }}$ is defined for a charge and discharge cycle at constant current. It is a measure of the ohmic and polarisation losses during the cycling. The voltage efficiency is the ratio of the integral of the stack voltage $U_{\text {stack,discharge }}$ during the discharge to that of the voltage $U_{\text {stack, } \text {,harge }}$ during the charge:

$$
\eta_{\text {voltage }}=\frac{\int U_{\text {stack,discharge }}(t) d t}{\int U_{\text {stack,charge }}(t) d t} \neq \frac{\eta_{\text {energy }}}{\eta_{\text {coulombic }}} \quad[-]
$$

Note that when the mechanical losses $P_{\text {mech }}$ are taken into account, $\eta_{\text {voltage }}$ is not equal to the ratio of $\eta_{\text {energy }}$ to $\eta_{\text {coulombic }}$.

\subsection{Charge and discharge cycles at constant current}

The electrochemical model of the vanadium redox battery is compared in this section to experimental data. To determine the performance, a VRB composed of a 19 elements stack and two tanks filled with 831 of electrolytes will be used. The total vanadium concentration in each electrolyte is $2 \mathrm{M}$. The characteristics of the stack are summarized in Tab. 3 and correspond to an experimental stack built by M. Skyllas-Kazacos and co-workers (Skyllas-Kazacos \& Menictas, 1997). The electrochemical model is used to assess the stack efficiencies during a series of charge and discharge cycles at constant currents. 


\begin{tabular}{cccccccc}
\hline $\begin{array}{c}\text { Current } \\
{[\mathrm{A}]}\end{array}$ & $\begin{array}{c}\eta_{\text {energy }} \\
{[\%]}\end{array}$ & $\begin{array}{c}\eta_{\text {voltage }} \\
{[\%]}\end{array}$ & $\begin{array}{c}\eta_{\text {coulombic }} \\
{[\%]}\end{array}$ & $\begin{array}{c}\text { Current } \\
{[\mathrm{A}]}\end{array}$ & $\begin{array}{c}\eta_{\text {energy }} \\
{[\%]}\end{array}$ & $\begin{array}{c}\eta_{\text {voltage }} \\
{[\%]}\end{array}$ & $\begin{array}{c}\eta_{\text {coulombic }} \\
{[\%]}\end{array}$ \\
\hline \multicolumn{7}{c}{ SIMULATION RESULTS } \\
\hline 10 & 97.0 & 97.0 & 100 & & & & \\
20 & 94.1 & 94.1 & 100 & & & & \\
40 & 88.6 & 88.6 & 100 & 60 & 78.3 & 82.8 & 94.6 \\
60 & 83.3 & 83.3 & 100 & 100 (cycle 1) & 68.0 & 72.3 & 94.0 \\
80 & 78.4 & 78.4 & 100 & 100 (cycle 2) & 70.8 & 73.0 & 96.1 \\
100 & 73.7 & 73.7 & 100 & 100 (cycle 3) & 73.1 & 74.0 & 98.7 \\
\hline
\end{tabular}

Table 4 . Efficiencies at various currents. The cycle starts at $2.5 \% \mathrm{SoC}$, the battery is charged until a $97.5 \%$ SoC and then discharged until a $2.5 \%$ SoC. Experimental data are from (Skyllas-Kazacos \& Menictas, 1997).

At the beginning of the cycle, the battery state of charge SoC is $2.5 \%$ (discharged); the battery is charged at constant current until a $S o C$ of $97.5 \%$ and then discharged until it reached its initial SoC. The resulting stack voltages $U_{\text {stack }}$ and power $P_{\text {stack }}$ are illustrated in Fig. 8 and the efficiencies are summarized in Tab. 4 along with experimental data. We observe quickly that the efficiencies decrease as the current increases.
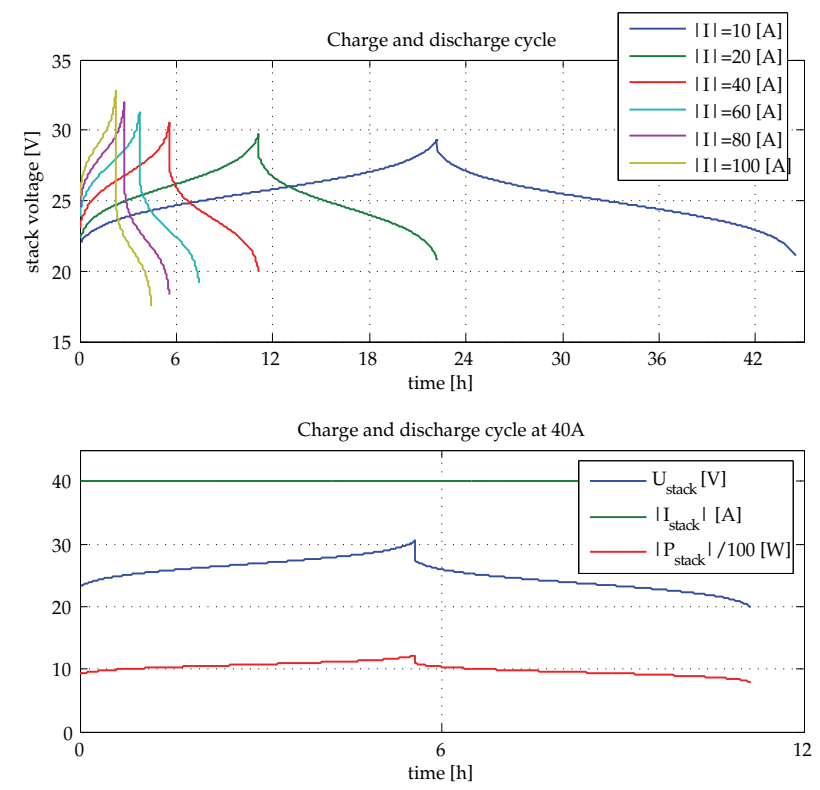

Fig. 8. Stack voltages during charge/discharge cycles at diverse currents. Below: stack voltage, current and power at $40 \mathrm{~A}$.

The voltage efficiencies $\eta_{\text {voltage }}$ are accurately determined by the model; the difference with the experimental data always stays below $2 \%$. The losses in coulombic efficiency $\eta_{\text {coulombic }}$ can be caused by side reactions or cross mixing of electrolyte through the membrane which are not taken into account in the model; note that $\eta_{\text {coulombic }}$ has improved as the battery becomes conditioned. When $\eta_{\text {coulombic }}$ is close to $100 \%$, as it is the case for the last cycle, 


\begin{tabular}{cccc}
\hline $\begin{array}{c}\text { Solution } \\
\text { of vanadium }\end{array}$ & $\begin{array}{c}\text { Density } \\
{\left[\mathrm{g} / \mathrm{cm}^{3}\right]}\end{array}$ & $\begin{array}{c}\text { Viscosity } \\
{[\mathrm{cP}]}\end{array}$ & $\begin{array}{c}\text { Vanadium / sulphuric acid } \\
\text { concentration }[\mathrm{M}]\end{array}$ \\
\hline$V^{2+}$ & $1.2-1.3$ & $1.7-2.4$ & $1-2 / 2$ \\
$V^{3+}$ & $1.2-1.5$ & $1.7-9.6$ & $0.5-3 / 2$ \\
$V^{4+}$ & & $(3.6-33.7)$ & $0.25-3 / 3$ \\
$V^{4+}$ & $1.2-1.5$ & & $1-2 / 1-9$ \\
$V^{5+}$ & $1.2-1.5$ & & $1-2 / 1-9$ \\
$V^{5+}$ & & $3.2-22.3$ & $0.5-3 / 4-7$ \\
\hline
\end{tabular}

Table 5. Density and viscosity of vanadium species solutions (Mousa, 2003; Wen et al., 2006; Oriji et al., 2004; Kausar, 2002). The numbers in brackets are estimations made from the kinematic viscosity.

the experimental and simulated energy efficiencies $\eta_{\text {energy }}$ are almost the same, the difference being less than $1 \%$. In the worst case, cycle 1 , the difference is around $8.3 \%$.

\section{Electrolyte properties}

The electrolyte properties are important parameters in the mechanical model; the density indicates its inertia, or resistance to an accelerating force, and the viscosity describes its fluidity, it may be thought of as internal friction between the molecules. They are both related to the attraction forces between the particles; thus they depend on the electrolyte composition.

The VRB electrolytes are composed of vanadium ions dissolved in sulphuric acid; we have seen previously that their composition changes as the battery is operating (see Fig. 3). Therefore, the electrolyte properties must change accordingly to the composition; but for simplicity reasons, these properties are maintained constant in this work. Tab. 5 gives the density and the viscosity for some vanadium solutions.

\section{Fluid mechanics applied to the vanadium redox flow batteries}

We introduce in this section the mechanical model that determines the power $P_{\text {pump }}$ required to flow the electrolytes from the tanks through the stack and back in the tanks (see Fig. 1). This model is composed of an analytical part that models the pipes, bends, valves and tanks and a numerical part that describes the more complex stack hydraulic circuit.

\subsection{Hydraulic circuit model (without the stack)}

The analytical hydraulic model describes the pressure drop $\Delta p_{\text {pipe }}$ in the pipes, the valve and the tank; it is based on the extended Bernoulli's equation that relates $\Delta p_{\text {pipe }}$ to the fluid velocity $V_{s}$, the height $z$, the head loss $h_{f}$ due to the friction and the minor losses $h_{m}$ :

$$
\Delta p_{\text {pipe }}=-\gamma\left(\frac{\Delta V_{s}^{2}}{2 g}+\Delta z+h_{f}+h_{m}\right) \quad[\mathrm{Pa}]
$$

where $\gamma$ is the specific weight and $g$ the gravitational acceleration.

The head losses are obtained by dividing the hydraulic circuit into smaller sections where $h_{f, i}$ or $h_{m, i}$ are easily determined with the Darcy-Weisbach equation (Munson et al., 1998):

$$
h_{f, i}=f_{i} \frac{L_{i}}{D_{i}} \frac{V_{s, i}^{2}}{2 g}, \quad h_{m, i}=k_{L, i} \frac{V_{s, i}^{2}}{2 g} \quad[m]
$$




\begin{tabular}{cc}
\hline geometry & Loss coefficient $k_{L, i}$ \\
\hline from a reservoir into a pipe & $0.04-0.9$ \\
from a pipe into a reservoir & 1 \\
bends and elbows & $0.2-1.5$ \\
valves & $0.15-10$ \\
\hline
\end{tabular}

Table 6. Loss coefficients (Munson et al., 1998; Candel, 2001).

where $f_{i}$ is the friction factor, $k_{L, i}$ the loss coefficient given in Tab. 6, $L_{i}$ and $D_{i}$ are the length and diameter of the conduit.

When the flow is laminar, the friction factor $f_{i}$ is derived from the Poiseuille law (28) and for a turbulent flow, it is obtained from the Colebrook equation (29) (Candel, 2001):

$$
\begin{array}{r}
f_{i}=\frac{64}{R e_{i}} \quad[-] \\
\frac{1}{\sqrt{f_{i}}}=-2 \log \left(\frac{\epsilon_{i}}{3.7 D_{i}}+\frac{2.51}{R e_{i} \sqrt{f_{i}}}\right)
\end{array}
$$

where $\epsilon_{i}$ is the equivalent roughness of the pipe and $R e_{i}$ is the Reynolds number:

$$
R e=\frac{\rho V_{s} D}{\mu}=\frac{V_{s} D}{v} \quad[-]
$$

where $\rho$ is the density, $\mu$ the dynamic viscosity and $v$ the kinematic viscosity.

\subsection{Stack hydraulic model}

The stack geometry is too complex to be analytically described (Fig. 9), therefore the stack hydraulic model can only be numerically obtained with a finite element method (FEM).

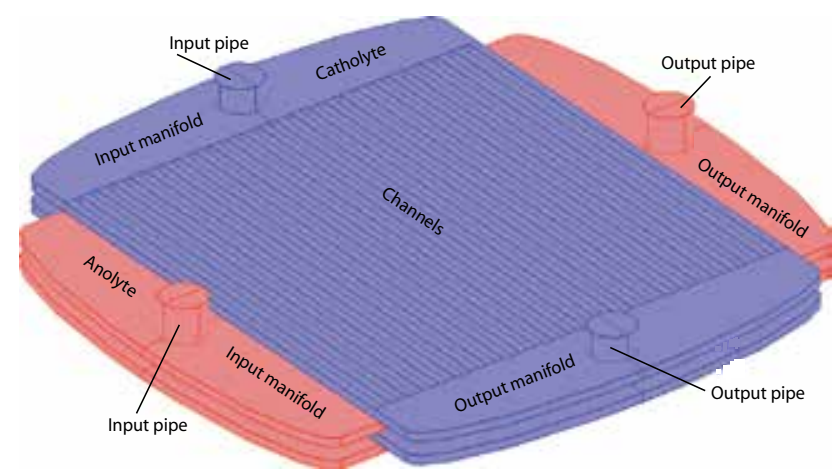

Fig. 9. Hydraulic circuit of a 2 cells stack. Note that the frame is not represented and that the colored segments represented the electrolytes (liquid).

It was assumed that the flow stays laminar in the stack; although the flow might be turbulent in the manifold at high velocity. In this example, the flow stays laminar in the distribution channels where the major part of the pressure drop $\Delta p_{\text {stack }}$ occurs; therefore, the pressure drop in the stack $\Delta p_{\text {stack }}$ is proportional to the flowrate:

$$
\Delta p_{\text {stack }}=Q \widetilde{R} \quad[P a]
$$

where $\widetilde{R}$ is the hydraulic resistance obtained from FEM simulations. 


\subsection{Mechanical model}

Finally, the sum of the pressure drop in the pipes $\Delta p_{\text {pipe }}$ and the pressure drop in the stack $\Delta p_{\text {stack }}$ determines the hydraulic circuit pressure drop $\Delta p_{\text {system }}$ :

$$
\Delta p_{\text {system }}=\Delta p_{\text {pipe }}+\Delta p_{\text {stack }} \quad[\mathrm{Pa}]
$$

The pump power $P_{\text {pump }}$, a determinant variable that influences the battery performance is related the head rise $h_{p}$ supplied by the pump, to the fluid density $\gamma$ and to the flowrate $Q$; we can also relate it to the pressure drop $\Delta p$ (Wilkes, 2005):

$$
P_{\text {pump }}=\gamma h_{p} Q=\Delta p Q \quad[W]
$$

The efficiency of the pump $\eta_{\text {pump }}$ is affected by the hydraulic losses in the pump, the mechanical losses in the bearings and seals and the volumetric losses due to leakages inside the pump. Although $\eta_{p u m p}$ is not constant in reality, it is assume in this work. Therefore, the effective power required by the pump $P_{\text {mech }}$ is given by:

$$
P_{\text {mech }}=\frac{P_{\text {pump }}}{\eta_{\text {pump }}} \quad[W]
$$

Thus, the relations introduced in this section can be combined to form the mechanical model of the VRB as illustrated in Fig. 10. Remember that the VRB needs two pumps to operate.

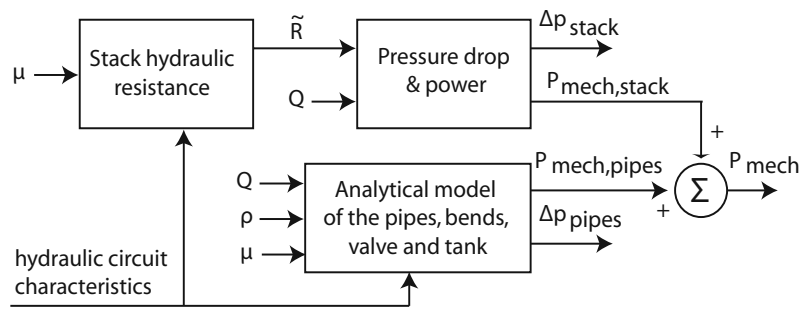

Fig. 10. Flowchart of the VRB mechanical model.

\section{Multiphysics model and energetic considerations}

The combination of the electrochemical model and the mechanical model leads to the multiphysics VRB system model. The functions that determine the vanadium concentrations in the tank $c_{\text {tank }}$ and the state of charge SoC have been separated from the electrochemical model in order to be incorporated into a new model named reservoir and electrolyte model. A system control has also been added to supervise the battery operation; this system controls the flowrate $Q$ and the stack current $I_{\text {stack }}$. This multiphysics system model, illustrated in Fig. 11, is a powerful means to understand the behaviour of the VRB, identify and quantify the sources of losses in this storage system; thus this multiphysics model is a good means to enhance the overall VRB efficiency.

\subsection{Power flow}

In order to optimize the performance of the VRB, it is important to understand the power flows within the VRB storage system. The power converters represented in Fig. 12 are necessary to adapt the stack voltage $U_{\text {stack }}$ to the power source $U_{\text {grid }}$ or to the load voltage $U_{\text {load }}$ and to supply the mechanical power required to operate the pumps. Since power 


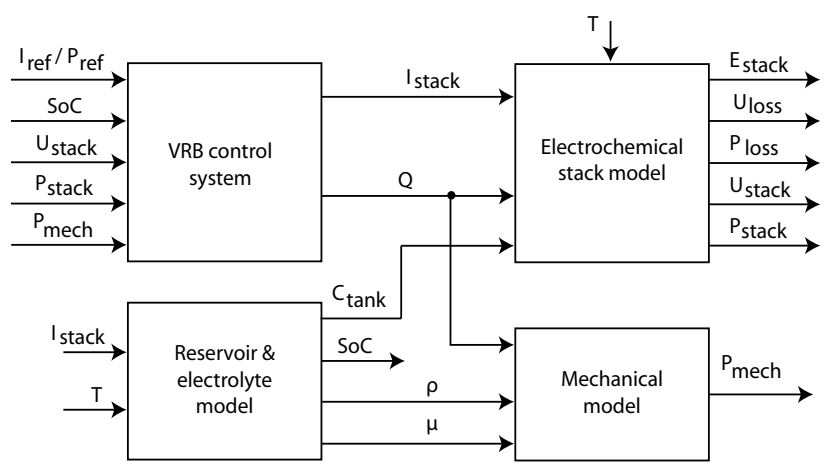

Fig. 11. Structured diagram of the multiphysics VRB system model.

converters are very efficient, with efficiencies around 98 to $99 \%$ (Wensong \& Lai, 2008; Burger \& Kranzer, 2009), they are considered, for simplicity, lossless in this work. Therefore, they are two sources of losses: the internal losses that are already included in the stack voltage $U_{\text {stack }}$ (2), and the mechanical losses $P_{\text {mech }}$. Hence, $P_{\text {mech }}$ is provided from the external power source during the charge and from the stack during the discharge. By convention, the battery power $P_{V R B}$ and the stack power $P_{\text {stack }}$ are positive during the discharge and negative during the charge; $P_{\text {mech }}$ is always positive. Thus, $P_{V R B}$ is given by:

$$
P_{V R B}=P_{\text {stack }}-P_{\text {mech }} \quad[W]
$$

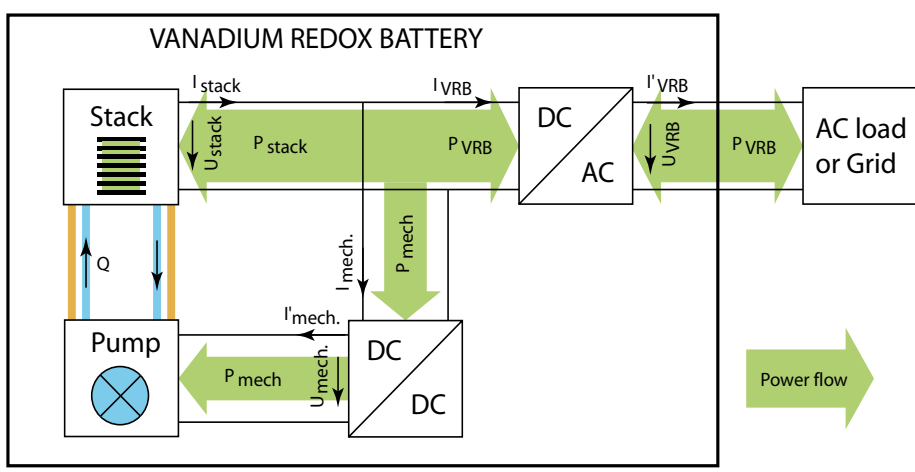

Fig. 12. Power flow in the VRB storage system. In this example, the power converters only adapt the currents and voltages, and are lossless.

In the rest of this section, we will discuss the battery performance under different operating strategy with a strong focus on the battery power $P_{V R B}$, the stack power $P_{\text {stack }}$ ant the mechanical power $P_{\text {mech }}$. Intuitively, we feel that there should be an optimal control strategy that maximizes the battery performance. In these circumstances, the power delivered to the battery at any operating point is minimized during the charge and the power supplied by the battery is maximized during the discharge.

\section{Operation at maximal and minimal flowrates}

First, we will discuss the battery operation at maximal and minimal flowrates. We must keep in mind that an efficient control strategy must maximize the power exchanged with the battery 


\begin{tabular}{lc}
\hline Name & Value \\
\hline number of cells $N_{\text {cells }}$ & 19 \\
$R_{\text {charge }}$ & $0.037 \Omega$ \\
$R_{\text {discharge }}$ & $0.039 \Omega$ \\
flow resistance $\widetilde{R}$ & $14186843 \mathrm{~Pa} / \mathrm{m}^{3}$ \\
electrolyte vanadium concentration & $2 \mathrm{M}$ \\
tank size $V_{\text {tank }}$ & 831 \\
initial concentration of vanadium species & $1 \mathrm{M}$ \\
\hline
\end{tabular}

Table 7. the parameters of the simulation.

while minimizing the losses; there is no point to have a battery that consumes more power than necessary. To illustrate this discussion, we will use a $2.5 \mathrm{~kW}, 6 \mathrm{kWh}$ VRB in the rest of this chapter; its characteristics are summarized in Tab. 7.

\subsection{Maximal flowrate}

The simplest control strategy operates the battery at a constant flowrate set to provide enough electroactive species to sustain the chemical reaction under any operating conditions. Therefore, this flowrate $Q_{\max }$ is determined by the worst operating conditions: low state of charge $\mathrm{SoC}$ during the discharge and high $\mathrm{SoC}_{\mathrm{C}}$ during the charge at high current in both cases. For the battery described in Tab. 7, $Q_{\max }$ is around $1.97 \mathrm{l} / \mathrm{s}$ : in that case, the mechanical power $P_{\text {mech }}$ is $1720 \mathrm{~W}$. In order to assess the performance, an instantaneous battery efficiency $\eta_{b a t t e r y}$ is defined as follow:

$$
\eta_{\text {battery }}=\frac{\left|P_{\text {stack }}\right|}{\left|P_{\text {stack }}\right|+P_{\text {mech }}} \quad[-]
$$

Clearly, the battery performance is poor as it can be observed in Fig. 14 where $\eta_{\text {battery }}$ is illustrated as a function of the stack current $I_{\text {stack }}$ and the state of charge SoC. Indeed, the battery often consumes more power than necessary; therefore, constantly operating the battery at $Q_{\max }$ is not a wise strategy. Nevertheless, it is possible to improve this efficiency by limiting the operating range of the battery (smaller current and/or narrower state of charge); thus the flowrate $Q_{\max }$ and the mechanical power $P_{\text {mech }}$ are reduced. But this also reduces the power rating and/or the energetic capacity while it increases the cost.

\subsection{Minimal flowrate}

The low efficiency at constant flowrate $Q_{\max }$ is due to the large mechanical losses $P_{\text {mech }}$; therefore, a second control strategy is proposed to minimize $P_{\text {mech }}$. In that case, the battery is operating at a minimal flowrate $Q_{\min }$ that is constantly adapted to the actual operating conditions ( $S o C$ and $I_{\text {stack }}$ ) in order to supply just enough electroactive materials to fuel the electrochemical reactions. Since the vanadium concentrations $c_{V}$ change proportionally to $I_{\text {stack }}$, there are critical operating points where $c_{V}$ is close to its boundary. In some cases, the variations of vanadium concentrations tend toward the limit values (Fig. 13). In these critical regions, the electrolyte flowrate $Q$ must be larger to palliate the scarcity of electroactive vanadium ions.

Hence, the minimal flowrate $Q_{\min }$ depends on the required amount of electroactive species, and in consequence on $I_{\text {stack }}$, and on the input vanadium concentrations $c_{\text {in }}$ that are either 


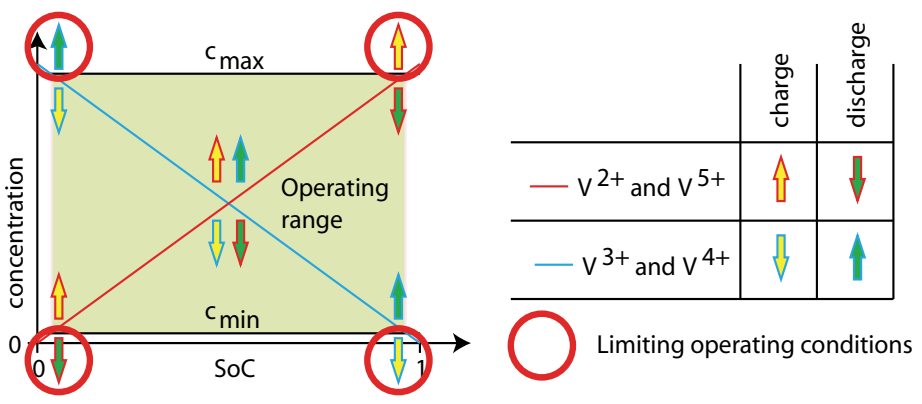

Fig. 13. Operating range and limiting operating conditions. The arrows represent the direction of the vanadium concentrations change as a function of the battery operating mode. The critical operating regions are highlighted in red; they represent the regions where the vanadium concentration $c_{\text {vanadium }}$ tends to its limiting concentrations $\left(c_{\max }\right.$ or $\left.c_{\min }\right)$.

being depleted $(\downarrow)$ or augmented ( $\uparrow)$. $Q_{\min }$ can be derived from (17):

$$
\begin{aligned}
& Q_{\min , \downarrow}(t)=\frac{b N_{\text {cell }} i(t)}{F\left(c_{\text {out }, \text { min }}-c_{\text {in }, \downarrow}(t)\right)} \quad[l / s] \\
& Q_{\text {min }, \uparrow}(t)=\frac{b N_{\text {cell }} i(t)}{F\left(c_{\text {out }, \text { max }}-c_{\text {in }, \uparrow}(t)\right)} \quad[l / s]
\end{aligned}
$$

where $c_{\text {out,min }}$ and $c_{\text {out,max }}$ are constant minimal and maximal output concentrations. The limiting species depends on the operating mode (charge or discharge); thus $Q_{\text {min }}$ is given by the maximal value of (37) and (38):

$$
Q_{\min }(t)=\max \left(Q_{\min , \downarrow}(t), Q_{\min , \uparrow}(t)\right) \quad[l / s]
$$

$Q_{\min }$ is illustrated in Fig. 14 for a wide spectrum of operating points; clearly, $Q_{\min }$ is larger in the critical regions that were highlighted in Fig. 13. Moreover, $Q_{\min }$ is, in comparison, very small in the other operating regions; therefore, there must be a large benefit to operate the battery at $Q_{\text {min }}$.

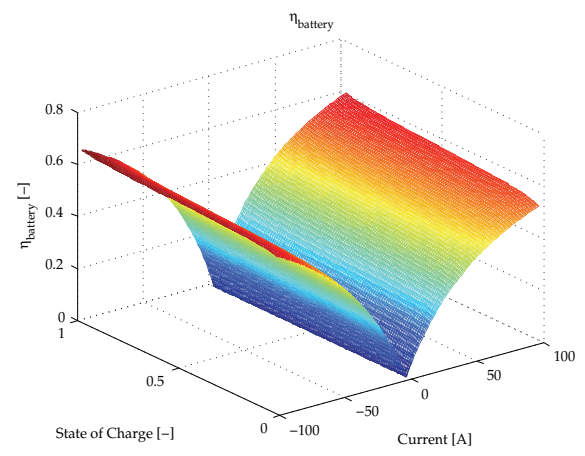

(a)

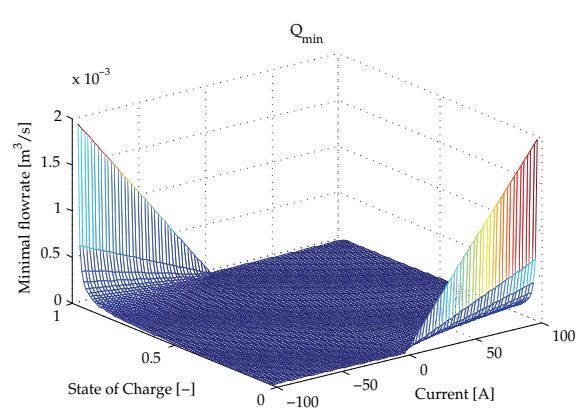

(b)

Fig. 14. (a) The battery efficiency $\eta_{\text {battery }}$ at constant flowrate $Q_{\max }$ as a function of the state of charge $S o C$ and current $I$. (b) Minimal flowrate $Q_{\min }$ as a function of the stack current $I_{\text {stack }}$ and the state of charge $S o C$. 
But a change in the flowrate $Q$ also modifies the vanadium concentrations $c_{\text {cells }}$ within the cells according to (18), and in consequence the stack voltage $U_{\text {stack }}$ and power $P_{\text {stack }}$ according to (2) and (3). This phenomenon is illustrated in Fig. 15 where the equilibrium voltage $E$ at $Q_{\max }$ and $Q_{\min }$ is shown: an increase of the flowrate has always a beneficial effect on $E$. Furthermore, the equivalent state of charge $S_{o} C_{e q}$ which represents the $S o C$ of the electrolyte within the cells is also illustrated as a function of $Q$. Clearly, $S o C_{e q}$ tends toward the battery SoC at high $Q$. Therefore, the change in $c_{c e l l s}$ is maximal at $Q_{m i n}$; and consequently a large variation of $U_{\text {stack }}$ and $P_{\text {stack }}$ is expected between the operations at $Q_{\min }$ and $Q_{\text {max }}$ as it can be observed in Fig. 16. From the strict point of view of $P_{\text {stack }}$, it is more interesting to operate the battery at $Q_{\max }$; indeed, more power is delivered during the discharge and less is consumed during the charge. But it will be shown in the next sections that the mechanical power greatly deteriorates the performance and that the energy efficiency at $Q_{\max }$ is unacceptable.
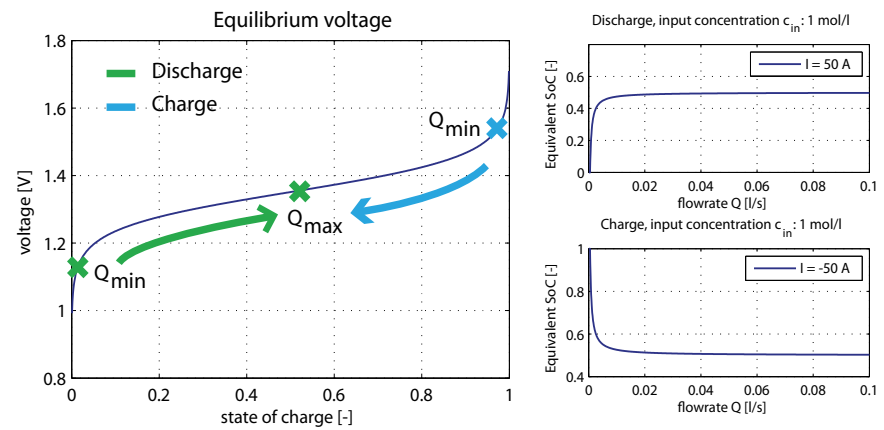

Fig. 15. Effect of the flowrate $Q$ on the equilibrium voltage $E$. On the right, the variation of the equivalent state of charge $S o C$ as a function of $Q$ during the discharge and the charge. In this example, the battery $S o C$ is 0.5 , i.e. the input concentrations are $1 \mathrm{M}$ for each vanadium species.

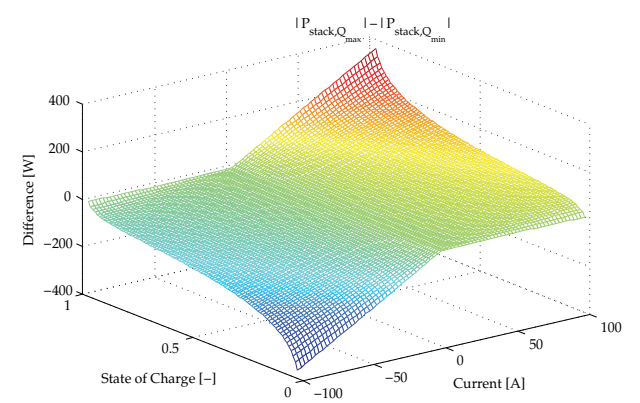

Fig. 16. The difference between the stack power $\left|P_{\text {stack,Qmax }}\right|$ at $Q_{\max }$ and the stack power $\left|P_{\text {stack,Qmin }}\right|$ at $Q_{\text {min }}$.

\section{Optimal operating point at constant current}

In the previous sections, the advantages and disadvantages of operating the battery at either $Q_{\max }$ and $Q_{\min }$ were discussed. At $Q_{\max }$, the stack power $P_{\text {stack }}$ has the highest possible value but the mechanical power $P_{\text {mech }}$ is also very large and consequently deteriorates the performance. At $Q_{\text {min }}, P_{\text {mech }}$ is reduced to the minimum, but $P_{\text {stack }}$ is negatively affected. 
Therefore, it should exist an optimal flowrate $Q_{\text {opt }}$ somewhere between $Q_{\min }$ and $Q_{\max }$ that increases $P_{\text {stack }}$ while maintaining $P_{\text {mech }}$ at a small value.

\subsection{Optimal flowrate during the discharge}

In this section, the battery is controlled by the reference current $I_{\text {stack, ref }}$; therefore there is only one control variable: the flowrate $Q$. Indeed, the stack power $P_{\text {stack }}$ depends on $I_{\text {stack }}, Q$ and the state of charge $S o C$ whereas the mechanical power depends on $Q$ and the electrolyte properties: the density $\rho$ and the viscosity $\mu$ that are maintained constant in this work. During the discharge, the optimal operating point is found when the flowrate $Q_{o p t}$ maximizes the power delivered by the stack $P_{\text {stack }}$ while minimizing the mechanical power $P_{\text {mech }}$. When these conditions are met together, the power delivered by the battery $P_{V R B}$ is optimized:

$$
\max (\underbrace{P_{V R B}}_{f\left(U_{\text {stack }}, I_{V R B}\right)})=\max (\underbrace{P_{\text {stack }}}_{f\left(I_{\text {stack }}, Q, S o C\right)}-\underbrace{P_{\text {mech }}}_{f(Q, \mu, \rho)})
$$

In Fig. 17, $P_{V R B}$ is represented during the discharge as a function of $Q$ at different states of charge for a current of $100 \mathrm{~A}$. Clearly, an optimal flowrate $Q_{o p t}$ exists between $Q_{\min }$ and $Q_{\max }$ that maximizes $P_{V R B}$. The shape of the curves can be generalized to other discharge currents $I_{\text {stack }}>0$; although in some cases where $I_{\text {stack }}$ is low, $P_{V R B}$ might become negative at inappropriately high flowrate $Q$.

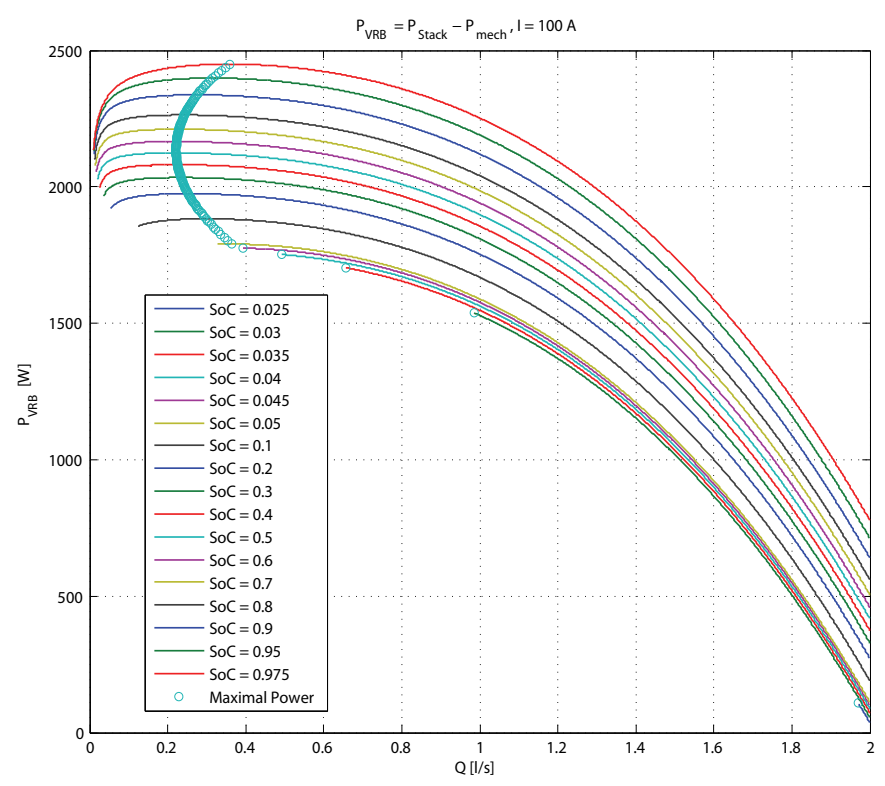

Fig. 17. Optimal flowrate $Q_{o p t}$ as a function of the flowrate $Q$ and the state of charge SoC. Note that when $S o C$ is low, $Q_{o p t}$ is equal to the minimal flowrate $Q$, and the discharge current is equal to $100 \mathrm{~A}$.

\subsection{Optimal flowrate during the charge}

At constant current $I_{\text {stack,ref }}$, the quantity of electrons $e^{-}$stored in the electrolyte does not depend on the stack power $P_{\text {stack }}$ but solely on the stack current $I_{\text {stack }}$; therefore, there is no reason to have a high $P_{\text {stack }}$. Hence, the optimal flowrate $Q_{\text {opt }}$ during the charge is found 
when the sum of $P_{\text {stack }}$ and $P_{\text {mech }}$ is simultaneously minimal. This condition is expressed by the following relation ${ }^{3}$ :

$$
\min (\underbrace{\left|P_{V R B}\right|}_{f\left(U_{\text {stack }}, I_{V R B}\right)})=\min (\underbrace{\left|P_{\text {stack }}\right|}_{f\left(I_{\text {stack }}, Q, S o C\right)}+\underbrace{P_{\text {mech }}}_{f(Q, \mu, \rho)})
$$

The optimal flowrate $Q_{o p t}$ is illustrated in Fig. 18 where $P_{V R B}$ is shown as a function of $Q$ and $S o C$. At very high $S o C, Q_{o p t}$ is equal to $Q_{\min }$ because the electrolyte carries a very small amount of electroactive vanadium ions. Again, the shape of the curves can be generalized to other charge currents $I_{\text {stack }}<0$.

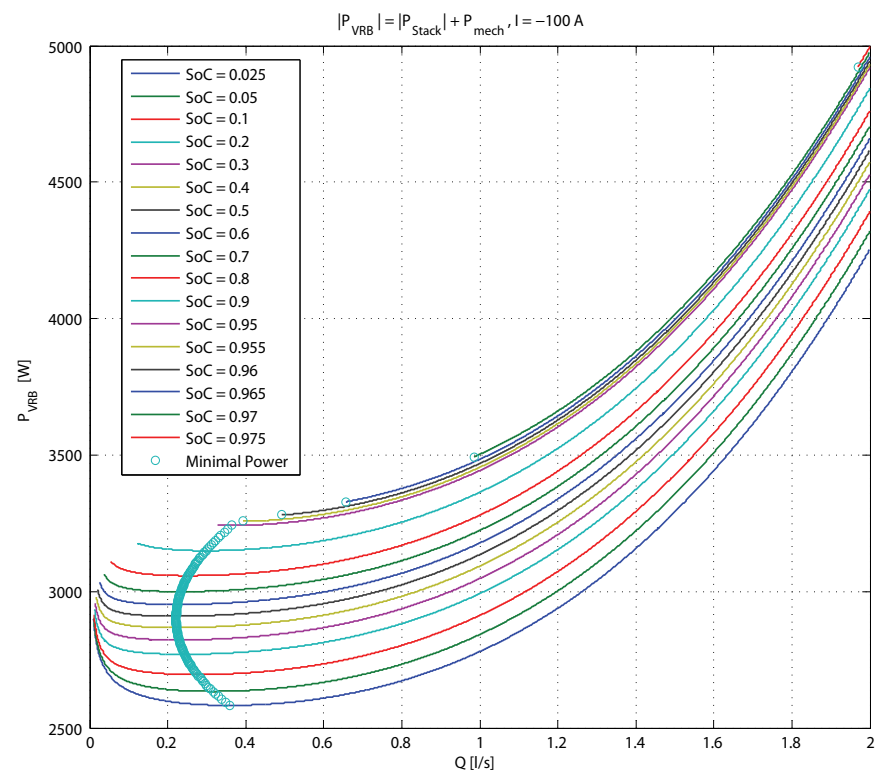

Fig. 18. Optimal flowrate $Q_{o p t}$ as a function of the flowrate $Q$ and the state of charge SoC. Note that when $S o C$ is high, $Q_{o p t}$ is equal to the minimal flowrate $Q$, and that the charge current $I_{\text {stack }}$ is equal to $-100 \mathrm{~A}$.

\subsection{Charge and discharge cycles}

It is always difficult to assess the performance of a battery because it often depends on the operating conditions. In this section, a series of charge and discharge at constant current is performed at minimal flowrate $Q_{m i n}$, at maximal flowrate $Q_{m a x}$ and at optimal flowrate $Q_{o p t}$ in order to assess the performance of this new control strategy.

The voltage $\eta_{\text {voltage }}$ and energy $\eta_{\text {energy }}$ efficiencies are summarized in Tab. 8 and 9; the coulombic efficiency $\eta_{\text {coulombic }}$ is in all cases equal to $100 \%$ because the model does not take into account any side reactions such as oxygen or hydrogen evolution nor any cross mixing of the electrolyte.

Both $\eta_{\text {voltage }}$ and $\eta_{\text {energy }}$ decrease when the current increase; this is mainly due to the internal losses $U_{\text {losses }}$ that are proportional to the current $I_{\text {stack }}$, although the flowrates $Q_{\min }$ and $Q_{o p t}$ increases to supply enough electroactive species. The highest voltage efficiencies occur

\footnotetext{
${ }^{3} \mathrm{~A}$ close look at this relation reveals that it is the same as (40), but (41) is more intuitive for the charge.
} 


\begin{tabular}{cccc}
\hline $\begin{array}{c}\text { Current } \\
{[\mathrm{A}]}\end{array}$ & $\begin{array}{c}\eta_{\text {voltage,Qmax }} \\
{[\%]}\end{array}$ & $\begin{array}{c}\eta_{\text {voltage,Qmin }} \\
{[\%]}\end{array}$ & $\begin{array}{c}\eta_{\text {voltage,Qopt }} \\
{[\%]}\end{array}$ \\
\hline 10 & 97.02 & 87.74 & 96.69 \\
20 & 94.13 & 85.11 & 93.70 \\
40 & 88.58 & 80.09 & 88.03 \\
60 & 83.33 & 75.31 & 82.69 \\
80 & 78.37 & 70.78 & 77.68 \\
100 & 73.65 & 66.46 & 72.94 \\
\hline
\end{tabular}

Table 8. Stack voltage efficiency $\eta_{\text {voltage }}$ at constant maximal flowrate $Q_{\max }$, at minimal flowrate $Q_{\min }$ and at optimal flowrate $Q_{o p t}$.

\begin{tabular}{ccccc}
\hline $\begin{array}{c}\text { Current } \\
{[\mathrm{A}]}\end{array}$ & $\begin{array}{c}\text { Time } \\
{[\mathrm{h}]}\end{array}$ & $\begin{array}{c}\eta_{\text {energy,Qmax }} \\
{[\%]}\end{array}$ & $\begin{array}{c}\eta_{\text {energy,Qmin }} \\
{[\%]}\end{array}$ & $\begin{array}{c}\eta_{\text {energy,Qopt }} \\
{[\%]}\end{array}$ \\
\hline 10 & 44.49 & -73.42 & 87.73 & 96.54 \\
20 & 22.24 & -53.34 & 85.10 & 93.51 \\
40 & 11.12 & -25.65 & 80.04 & 87.77 \\
60 & 7.41 & -8.17 & 75.31 & 82.34 \\
80 & 5.56 & 3.24 & 70.78 & 77.26 \\
100 & 4.45 & 10.81 & 66.24 & 72.43 \\
\hline
\end{tabular}

Table 9. Overall VRB energy efficiencies $\eta_{\text {energy }}$ at constant maximal flowrate $Q_{\text {max }}$, at minimal flowrate $Q_{\min }$ and at optimal flowrate $Q_{o p t}$. 
at $Q_{\max }$ because of its positive effect on the stack voltage $U_{\text {stack }}$ highlighted in section 7.2; consequently, the worst voltage efficiencies occur at $Q_{\min }$. Moreover, the voltage efficiencies at $Q_{\text {opt }}$ are very close to the maximal efficiencies obtained at $Q_{\max }$. In fact, the stack voltages $U_{\text {stack,Qmax }}$ and $U_{\text {stack,Qopt }}$ are very close as it can be observed in Fig. 19.
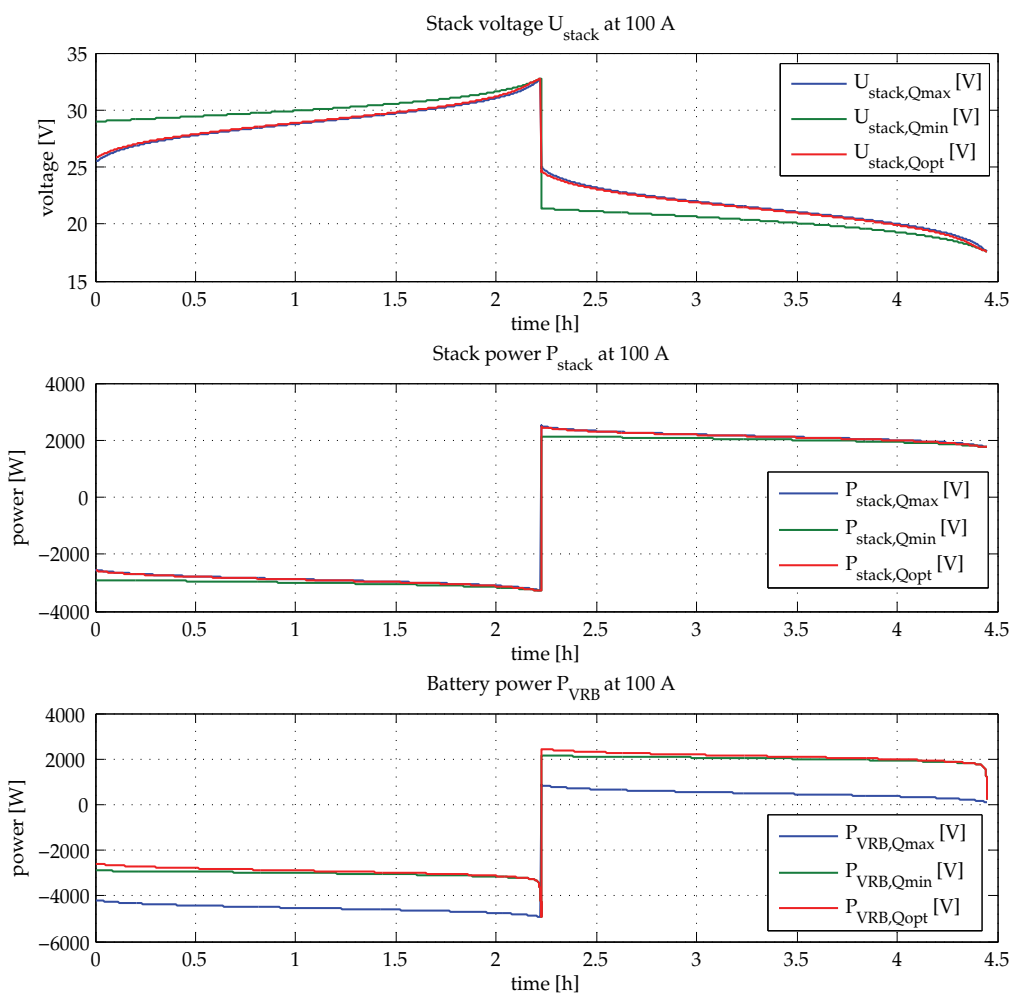

Fig. 19. Stack voltage $U_{\text {stack }}$, stack power $P_{\text {stack }}$ and battery power $P_{V R B}$ during a charge and discharge cycle at $100 \mathrm{~A}$.

Obviously, operating the battery at $Q_{\max }$ is a problematic strategy as $\eta_{\text {energy, }} \mathrm{Qmax}$ is very small or even negative: at small currents, the battery does not deliver any power to the load but consumes more power to operate the pumps than the stack is furnishing. When $P_{\text {mech }}$ is minimized, the energy efficiencies already become interesting at $Q_{\text {min }}$, but they are increased by a further $10 \%$ when the battery is operating at $Q_{o p t}$.

In order to compare the model with experimental data, the stack characteristics were defined to match the stack presented in section 3.7. The experimental results of M. Skyllas-Kazacos and al. are summarized in Tab. 4 (Skyllas-Kazacos \& Menictas, 1997); note that they do not take into account the mechanical power required to operate the pumps and that the flowrate was constant $\left(2 \mathrm{l} / \mathrm{s}\right.$ which correspond to $\left.Q_{\max }\right)$. The losses in coulombic efficiency $\eta_{\text {coulombic }}$ can be caused by side reactions or cross mixing of electrolyte through the membrane which are not taken into account in the model; but $\eta_{\text {coulombic }}$ improves as the battery becomes conditioned. In that case, the energy efficiency $\eta_{\text {energy, Qopt }}$ at optimal flowrate is very close to the maximal electrochemical energy efficiency. Finally, a very good concordance is observed between the voltage efficiencies at $Q_{\max }$ and the experimental results. 


\section{Optimal operating point at constant power}

In practice, the battery must often deliver a certain amount of power to the load: the battery is controlled by a reference power $P_{\text {ref }}$. In that case, a second control variable is available in supplement of the flowrate $Q$ : the stack current $I_{\text {stack }}$. The optimal operating point is the couple $Q_{o p t}$ and $I_{o p t}$ that maximizes the amount of charge that are stored within the electrolyte during the charge and minimizes the amount of charge that are consumed during the discharge. These conditions can be related to $I_{\text {stack }}$ :

$$
\begin{aligned}
& \underbrace{P_{V R B}}_{\text {constant }}=\underbrace{P_{\text {stack }}}_{f\left(I_{\text {stack }}, Q, S o C\right)}-\underbrace{P_{\text {mech }}}_{f(Q, \mu, \rho)} \quad[W] \\
& \text { during the charge: } \max \left(\left|I_{\text {stack }}\right|\right) \quad[A] \\
& \text { during the discharge: } \min \left(I_{\text {stack }}\right) \quad[A]
\end{aligned}
$$

Again, an optimal operating point exists in between the maximal $Q_{\max }$ and minimal $Q_{\min }$ flowrates as it can be observed in Fig. 20 where operating points are represented for different battery power $P_{V R B}$ during the discharge at a $S o C$ equal to 0.5 . At the optimal flowrate $Q_{o p t}$, the battery delivers the same power $P_{V R B}$ but consumes less active vanadium ions; therefore, the battery will operate longer and deliver more power. $Q_{o p t}$ increases with $P_{V R B}$ until it reaches a plateau due to the transition between the laminar and the turbulent regime.

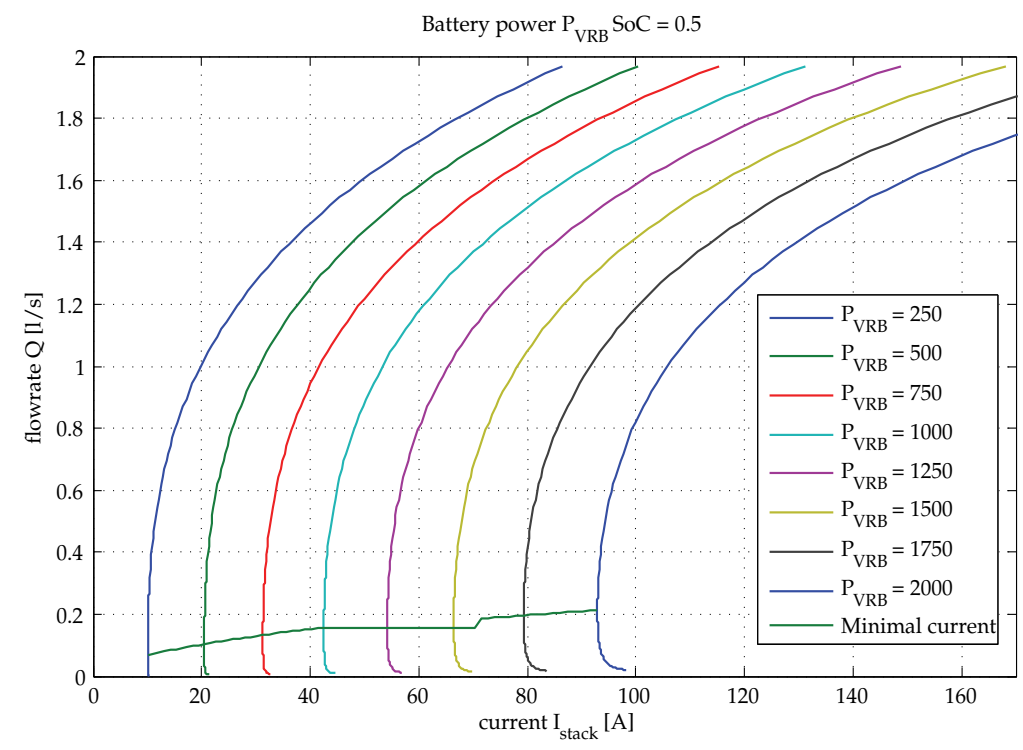

Fig. 20. Battery power $P_{V R B}$ as a function of the discharge current $I_{\text {stack }}$ and the electrolyte flowrate $Q$ at a state of charge $S o C$ equal to 0.5 . The optimal operating points occurs when the current $I_{\text {stack }}$ is minimal for a given battery power $P_{V R B}$.

In fact, $I_{\text {stack }}$ increases above the optimal flowrate to compensate the higher mechanical loss: the stack must deliver more power. Below $Q_{o p t}, I_{\text {stack }}$ increases this time to compensate the lower stack voltage $U_{\text {stack }}$ due to the lower concentrations of active species. The shape of the curves can be generalized for other states of charge SoC.

The optimal operating points during the charge are illustrated in Fig. 21 where the battery power $P_{V R B}$ is shown as a function of the current $I_{\text {stack }}$ and the flowrate $Q$ at a state of charge 
of 0.5. The optimal operating point maximizes the current $\left|I_{\text {stack }}\right|$ delivered to the stack in order to store the maximum amount of electroactive species at a given power $P_{V R B, r e f}$; again, the optimal flowrate $Q_{o p t}$ increases with the battery power $P_{V R B}$ until it reaches the plateau due to the flow regime transition.

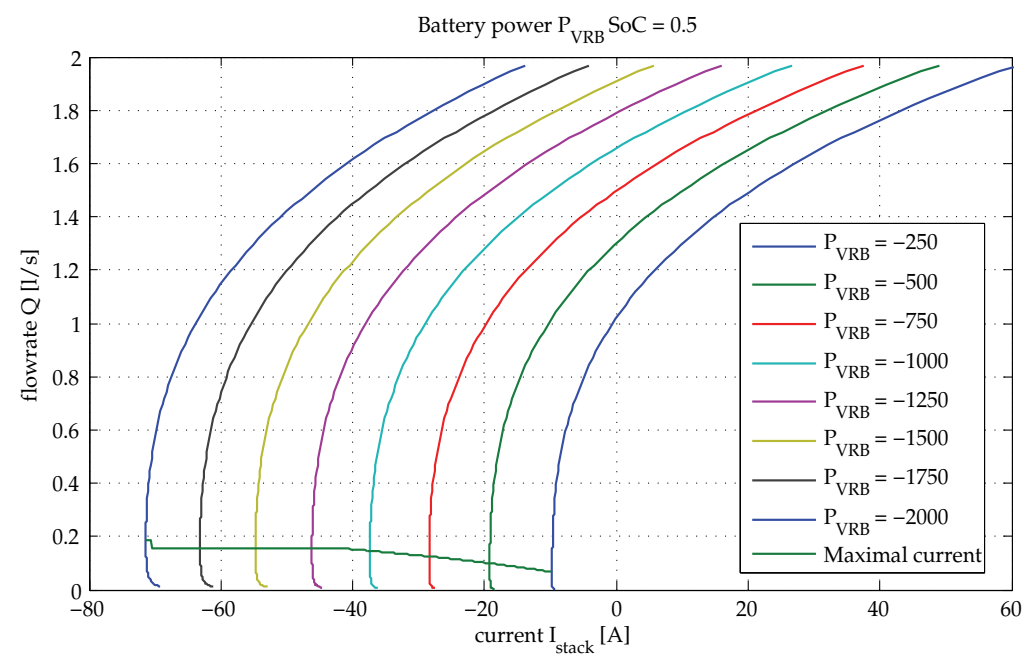

Fig. 21. Battery power $P_{V R B}$ as a function of the charge current $I_{\text {stack }}$ and the electrolyte flowrate $Q$ at a state of charge $S o C$ equal to 0.5 . The optimal operating points occurs when the current $\left|I_{\text {stack }}\right|$ is maximal for a given battery power $P_{V R B}$.

Interestingly, we observe in Fig. 21 that the stack current $I_{\text {stack }}$ changes its sign at high flowrate $Q$; in these unacceptable conditions, the stack is discharged while the battery is being charged. During the charge, the stack current $\left|I_{\text {stack }}\right|$ decreases above the optimal flowrate $Q_{\text {opt }}$ to compensate the higher mechanical loss $P_{\text {mech }}$; in consequence, less power is available to charge the stack (see (42)). Below the optimal flowrate $Q_{\text {opt }}$, the stack current $\left|I_{\text {stack }}\right|$ also decreases because the stack voltage $U_{\text {stack }}$ increases due the change in electroactive species concentrations within the cells $c_{\text {cell }}$; note that the mechanical power $P_{\text {mech }}$ is also reduced below $Q_{o p t}$. Furthermore, the shape of the curves in Fig 21 might be generalized to other states of charge $\mathrm{SoC}$.

\subsection{Charge and discharge cycles}

A new series of charge and discharge cycles at constant power was performed to determine the energy efficiencies at minimal flowrate $Q_{\min }$ and at the optimal operating point: $I_{o p t}$ and $Q_{\text {opt }}$. This optimal point is constantly determined as a function of the actual conditions. The energy efficiencies are given in Tab. 10. The energy efficiency at optimal flowrate $\eta_{\text {energy,Qopt }}$ is increased by $10 \%$ at maximal power when compared to battery operations at minimal flowrate $Q_{\min }$.

\section{Epilogue}

Today, the electricity industries are facing new challenges as the market is being liberalized and deregulated in many countries. Unquestionably, electricity storage will play, in the near future, a major role in the fast developing distributed generations network as it has 


\begin{tabular}{ccc}
\hline $\begin{array}{c}\text { Power } \\
{[\mathrm{W}]}\end{array}$ & $\begin{array}{c}\eta_{\text {energy,Qmin }} \\
{[\%]}\end{array}$ & $\begin{array}{c}\eta_{\text {energy,Qopt }} \\
{[\%]}\end{array}$ \\
\hline 500 & 87.07 & 93.59 \\
1000 & 81.04 & 87.78 \\
1500 & 75.47 & 82.09 \\
2000 & 69.91 & 76.39 \\
2500 & 63.97 & 70.48 \\
\hline
\end{tabular}

Table 10. Overall VRB energy efficiencies $\eta_{\text {energy }}$ for a charge and discharge cycle at constant power at either optimal flowrate $Q_{o p t}$ and minimal flowrate $Q_{\min }$.

many advantages to offer: management of the supply and demand of electricity, power quality, integration of renewable sources, improvement of the level of use of the transport and distribution network, etc. Over the years, many storage technologies have been investigated and developed, some have reached the demonstrator level and only a few have become commercially available. The pumped hydro facilities have been successfully storing electricity for more than a century; but today, appropriate locations are seldom found. Electrochemical storage is also an effective means to accumulate electrical energy; among the emerging technologies, the flow batteries are excellent candidates for large stationary storage applications where the vanadium redox flow battery (VRB) distinguishes itself thanks to its competitive cost and simplicity.

But a successful electricity storage technology must combine at least three characteristics to have a chance to be widely accepted by the electrical industry: low cost, high reliability and good efficiency. A lot of works have already been done to improve the electrochemistry of the VRB and to reduce its overall manufacturing cost. With the multiphysics model proposed in this chapter, we are able to address primarily the battery performance and indirectly its cost; indeed, a good efficiency enhances the profitability and consequently reduces the operating cost.

This ambitious model encompasses the domains of electricity, electrochemistry and fluid mechanics, it describes the principles and relations that govern the behaviour of the VRB under any set of operating conditions. Furthermore, this multiphysics model is a powerful means to identify and quantify the sources of losses within the VRB storage system; indeed, we are now able to understand how the VRB operates and to propose strategies of control and operation for a greater effectiveness of the overall storage system.

Another important feature of this multiphysics model is to facilitate the integration of the VRB into the electrical networks. Indeed, power converters, whose properties and characteristics are known and efficient, are required in practice to interface the VRB with the network; the overall performance might improve if their control strategy takes into account the VRB characteristics.

\section{References}

Bard, A. \& Faulkner, L. (2001). Electrochemical Methods, Fundamentals and Applications, 2nd edn. Bard, A., Parsons, R. \& Jordan, J. (1985). Standard Potentials in Aqueous solution.

Bartolozzi, M. (1989). Development of redox flow batteries. a historical bibliography, Journal of Power Sources 27.

Blanc, C. (2009). Modeling of a Vanadium Redox Flow Battery Electricity Storage System, Ph. D. dissertation, EPFL. 
Burger, B. \& Kranzer, D. (2009). Extreme high efficiency pv-power converters, EPE 2009 Barcelona .

Candel, S. (2001). Mcanique des Fluides.

Heintz, A. \& Illenberger, C. (1998). Thermodynamics of vanadium redox flow batteries electrochemical and calorimetric investigations, Ber. Bunsenges. Phys. Chem. 102.

Kausar, N. (2002). Studies of V(IV) and V(V) species in vanadium cell electrolyte, PhD thesis, UNSW, Australia .

Mousa, A. (2003). Chemical and electrochemical studies of V(III) and V(II) solutions in sulfuric acid solution for vanadium battery applications, PhD thesis, UNSW, Australia .

Munson, B., Young, D. \& Okiishi, T. (1998). Fundamentals of Fluid Mechanics, third edn.

Oriji, G., Katayama, Y. \& Miura, T. (2004). Investitgation on V(IV)/V(V) species in a vanadium redox flow battery, Electrochimica Acta 49.

Skyllas-Kazacos, M. \& Menictas, C. (1997). The vanadium redox battery for emergency back-up applications, Intelec 97 .

Sum, E., Rychcik, M. \& Skyllas-Kazacos, M. (1985). Investigation of the V(V)/V(VI) system for use in the positive half-cell of a redox battery, Journal of Power Sources 16.

Sum, E. \& Skyllas-Kazacos, M. (1985). A study of the V(II)/V(III) redox couple for redox flow cell applications, Journal of Power Sources 15.

Van herle, J. (2002). Electrochemical Technology, Fuel Cells and Batteries, postgrade course.

Wen, Y., Zhang, H., Qian, P., Zhao, P., Zhou, H. \& Yi, B. (2006). Investigation on the electrode process of concentrated $\mathrm{V}(\mathrm{IV}) / \mathrm{V}(\mathrm{V})$ species in a vanadium redox flow battery, Acta Physico-Chimica Sinica 22.

Wensong, Y. \& Lai, J.-S. (2008). Ultra high efficiency bidirectional dc-dc converter with multi-frequency pulse width modulation, IEEE Applied Power Electronics Conference and Exposition, APEC 2008 .

Wilkes, J. (2005). Fluid mechanics for chemical engineers. 


\title{
Desing of Multiphase Boost Converter for Hybrid Fuel Cell/Battery Power Sources
}

\author{
Dr Miroslav Lazić1, Dr Miloš Živanov² and Boris Šašić3 \\ Iritel.AD Beograd, \\ ${ }^{2}$ FTN Novi Sad, \\ 3Spellman New York \\ 1,2Serbia \\ 3USA
}

\section{Introduction}

Alternative energy sources are becoming less and less "alternative". Recent decade has been underlined with worldwide efforts in finding suitable long term alternatives to the carbon based energy sources. There is a multitude of very compelling reasons for investing extra effort - limited supply of natural resources, environmental, geopolitical and even economical reasons.

Sun, wind and oceans are all being harnessed to provide stable and reliable energy. That energy is converted for immediate use or for storage in supercapacitors, chemical energy sources or as a derived chemicals (Hydrogen is produced, for instance).

Next link in the alternative energy chain is efficient use. New supercapacitors are being developed and there are many different battery types already available on the market, each with its own unique application that optimizes efficiency of chemical conversion and number of charge/discharge cycles with minimum of capacity loss.

Fuel cells are being used to efficiently reclaim energy stored in Hydrogen. The process has been well known for decades and is being used in power generation industry in high power systems. As the technology advanced, lower power applications were found - chemical industry was a big benefactor: most of the exhaust gasses could be reclaimed and have Hydrogen extracted in a simple, cost effective manner, ensuring a free energy supply once initial investment in fuel cells and regenerators has been made.

Development of new materials helped further reduce costs and increase efficiency, and even low power fuel cells are now widely available. Even though there are still many new and exciting ongoing developments, the technology is now considered mature and ready for prime time. Fuel cells have a good history in many applications (chemical industry, power generation, transportation) and is considered a serious contender in many other industries.

In some of these industries fuel cells will gain faster acceptance than in others. Material handling industry is among those where benefits of fuel cells can be easily documented and increased cost of initial implementation justified. A fuel cell based system that replaces standard forklift battery pack has many advantages, such as: fast refueling, longer run time between refueling, longer life of the energy source and low maintenance requirements. 
In a typical electric vehicle fuel cells are augmented by an energy storage element, such as a supercapacitor, flywheel or battery. Such hybrid system makes some of the fuel cell deficiencies (high output impedance, for example) transparent to the final user. The typical systems used in industrial vehicles use battery as the energy storage component.

A critical part of such fuel cell system is the load regulator. Its main role is to enable controlled current draw from the fuel cell. It also needs to maintain the auxiliary batteries in a fully charged state and to regulate load current.

This thesis illustrates work on overcoming major challenges of fuel cell load regulator design and offers an illustration in the form of a practical realization of a $5 \mathrm{~kW}$ unit with application in industrial electric vehicles.

\section{Fuel cell systems}

A fuel cell is an electrochemical power source that converts chemical fuel into electrical energy. The electricity is generated via reactions between the fuel and an oxidant (so called reactants) in the presence of an electrolyte. The reactants flow into the cell, and the reaction products flow out of it, while the electrolyte remains within it. The electrolyte is a substance specifically designed so ions can pass through it, but the electrons cannot.

Unlike conventional electrochemical batteries, fuel cells consume reactant from an external source, and it must be replenished, as long as the reactant is available the power can be generated, there are no other restrictions on the fuel cell "capacity". By contrast, batteries store electrical energy chemically and have limited capacity.Hydrogen based fuel cells are the most common. They use Hydrogen as the fuel and Oxygen as the oxidant. Oxygen is most commonly used from air. Many other combinations of fuels and oxidants are possible, but they are not widely utilized.

\subsection{Principle of fuel cell operation}

The core of a fuel cell consists of a membrane electrode assembly, which is placed between two flow-field plates. The assembly consists of two electrodes, the anode and cathode, separated by a Proton Exchange Membrane (PEM). The block diagram of a fuel cell is shown in Figure 1.

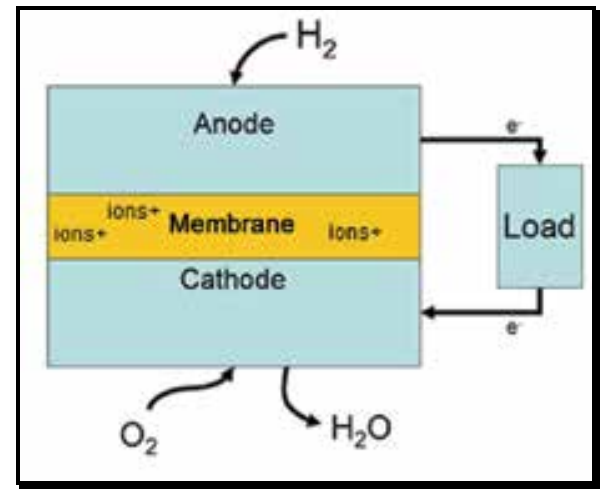

Fig. 1. Fuel cell block diagram

The two electrodes are coated with thin layer of Platinum that acts as a catalyst. At the anode, the catalyst oxidizes the fuel (Hydrogen), turning it into a positively charged ion and a negatively charged electron. The membrane (PEM) is designed so that ions can pass 
through it, but the electrons cannot. The freed electrons travel through a wire creating the electrical current. The ions travel through the electrolyte to the cathode. Once reaching the cathode, the ions are reunited with the electrons and the two react with a third chemical, usually oxygen, to create water and heat.

A typical fuel cell produces a voltage of $0.6-0.7 \mathrm{~V}$ at full rated load. Voltage decreases as current increases, due to several factors:

- Activation loss (activation polarization)

- Ohmic Polarization (voltage drop due to resistance of the cell components and interconnects)

- Gas transport loss (depletion of reactants at catalyst sites under high loads, causing rapid loss of voltage).

A typical fuel cell load curve is shown in Figure 2.

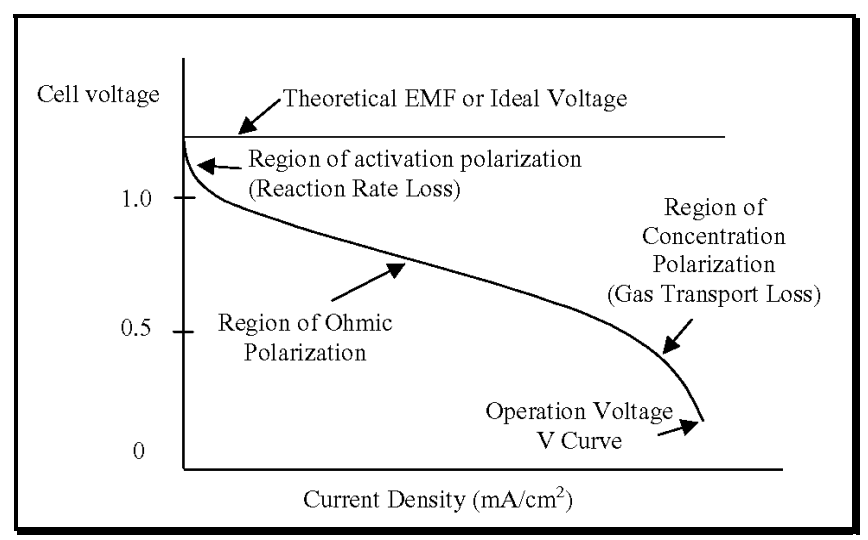

Fig. 2. A typical fuel cell load curve

To deliver the desired amount of energy, the fuel cells can be combined in series and parallel circuits. Such a design is called a fuel cell stack.

A few different fuel stacks are shown in Figure 3.

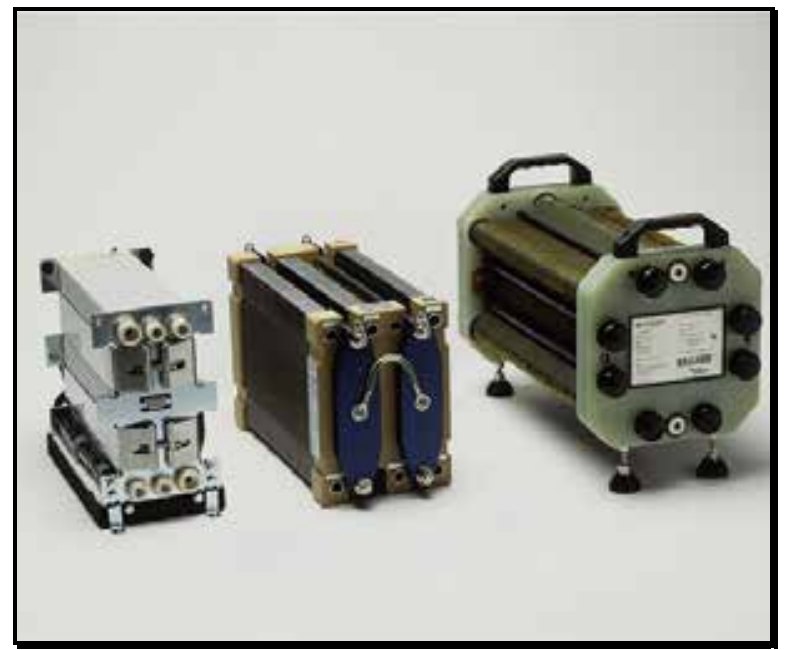

Fig. 3. Examples of fuel cell stacks 


\subsection{Fuel cell systems}

As discussed in the Introduction, the thesis will concentrate on fuel cell applications for industrial off road vehicles. Electric forklifts (Figure 4) are especially interesting due to the problems with existing battery packs.

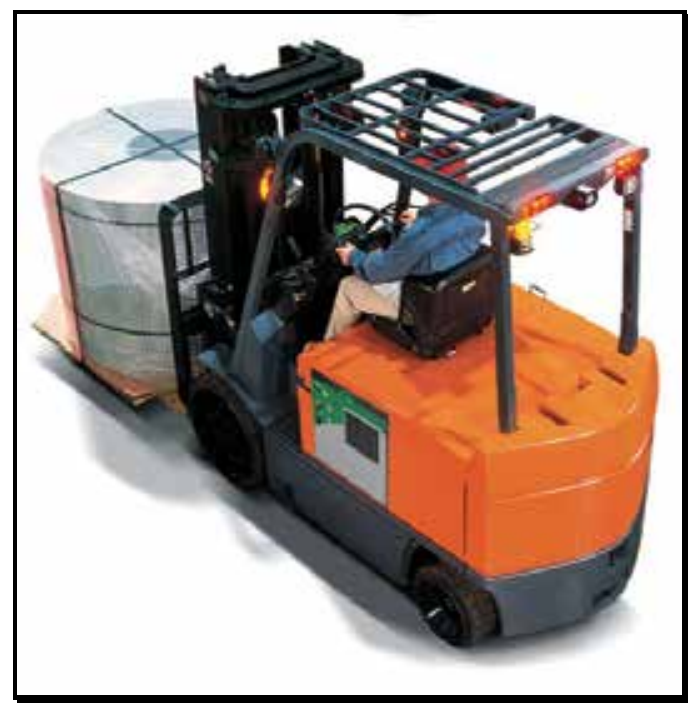

Fig. 4. Electric forklift

A fuel cell based system that replaces standard forklift battery pack has many advantages, such as: fast refueling, longer run time between refueling, longer life of the energy source and low maintenance requirements.

In a typical electric vehicle fuel cells are augmented by an energy storage element, such as supercapacitor, flywheel or battery. Such hybrid system makes some of the fuel cell deficiencies (the most important one being high output impedance) transparent to the final user.

Hybrid systems with a small lead acid battery have many advantages in material handling applications. The most significant two are: (1) battery provides peak current handling capabilities and (2) it ensures reserve power to drive the vehicle to refueling station should hydrogen tank be completely depleted.

Block diagram of a hybrid fuel cell system using auxiliary Sealed Lead-Acid (SLA) battery is shown in Figure 5.

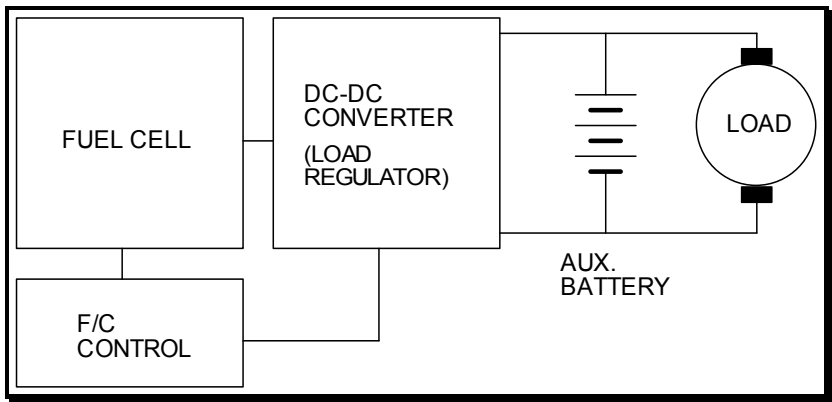

Fig. 5. Block diagram of a hybrid fuel cell system 
Fuel cell is used as a main energy source, controlled by a dedicated electronics (F/C Control) that controls main aspects of fuel cell operation - Hydrogen flow and pressure, monitors output voltage and current and sets operating parameters of a fuel cell regulator. The load regulator processes raw power from the fuel cell, converting it into levels suitable for the load, while keeping auxiliary battery charged and providing adequate protections of the fuel cell, load and self-protection against overvoltage, overtemperature and overload. Auxiliary battery is a small (70Ah) Sealed lead-Acid battery with the main purpose to provide peak power when demanded by the load. Typical peak loads are during vehicle's rapid acceleration and lifting heavy loads. If the Hydrogen tank goes empty, the battery also provides backup power sufficient to drive the vehicle to the refueling station. Finally, the system's load comprises forklift's traction motor, hydraulic pumps, lift motors and various communication and control electronics: new generations of forklifts bear very little resemblance to the noisy and slow vehicles of the past - typical rider vehicle (Class I or Class II) in a larger fleet has a sophisticated joystick controls, very informative displays, radio communication equipment, GPS and tracking devices, and the total power draw is not negligible.

\subsection{Specification requirements}

There are two main factors influencing every design: electrical specifications and application based details. Electrical specifications are straightforward and require little explanation. For our particular design, a fuel cell regulator, electrical specifications are fairly simple:

- Maximum power: $5,5 \mathrm{~kW}$

- Input voltage range: $24-36 \mathrm{~V}$

- Output voltage range: $36-60 \mathrm{~V}$

- Maximum output current: $150 \mathrm{~A}$

Specification parameters related to this particular application add more clarity regarding expected performance of the final product. The parameters are not always clearly defined by numbers and physical values - most common examples are "small size", "low cost", etc. Regardless of their ambiguity or lack of definition, they are still valuable information that is specific to the application and affects the design process.

In this case application specific requirements are summarized as:

- Continuously variable control with automatic crossover:

- Input current controlled in the range 0-220A

- Low input current ripple: $<1 \%$ of output current, measured with $0-10 \mathrm{kHz}$ bandwidth (critical for longevity of the fuel cell)

- High efficiency: $94 \%$ min at $2 \mathrm{~kW}$ and $96 \%$ above $2.5 \mathrm{~kW}$

- Protection against reverse current (which may cause temperature rise and hazardous pressure build up)

- Ability to sustain peak load currents of up to $800 \mathrm{~A}$ for short period of time (1-5 seconds)

- Operating ambient temperature -30 to $+60^{\circ} \mathrm{C}$

- Low physical profile (load regulator needs to fit into a predefined space)

- Low cost

\section{Multiphase boost converters}

Boost converter belongs to the family of basic power conversion topologies (the other two being buck and buck-boos derivative). Boost converters are probably the most versatile 
power converters today. They cover power range from fraction of a Watt (for example raising a single cell battery voltage to a 3.3 or $5 \mathrm{~V}$ logic levels in portable equipment) to tens of $\mathrm{kW}$ (alternative energy sources and distributed power). Extremely popular and almost exclusively used in Power Factor Correction (PFC) applications, they are being manufactured in millions of units.

Unlike buck converter, boost topology is somewhat more difficult to control, due to the Right Half Plane (RHP) Zero in the control transfer function. RHP Zero sets practical limits on the control loop bandwidth but.

Another comparative disadvantage is no inherent short circuit protection: if the output terminals are shorted there is nothing (other than circuit parasitic) to limit or interrupt short circuit current.

Over time, designers have learned how to deal with the two major drawbacks mentioned above and today there are very few restrictions for practical use of this topology.

The boost converter is well understood and successfully used in the multitude of applications. It is typically used when output voltage needs to be higher than the input voltage.

Introduction of multiphase topologies has expanded field of practicality for the converters by offering many advantages that will be discussed below. The simplest way of describing a multistage converter is to see it as consisting of several power stages (converter "phases") with inputs and outputs connected in parallel and drive signals shifted to ensure uniform distribution over a switching period - this techniques is also known as "interleaving" and the term will be used throughout this work.

Input inductance of the boost converter helps control current ripple and has positive effects on reducing electromagnetic emissions. However, the size of the inductor is proportional to the inductance and the square of the peak current and for high power applications its size is considerable.

For high power converters operating from relatively low input voltages, inductor current can be limiting factor due to the fairly large size and lack of space or even availability of adequate core sizes.

One way to reduce the inductor's size would be running the converter at high frequency. Unfortunately, for high power converters, practical considerations such as core's eddy current losses, switching losses in the power switch and rectifier and electromagnetic emissions severely limit the maximum switching frequency.

Output capacitor in the boost converter is subjected to large variations of the current through them. Capacitors' peak-to-peak current is equal to the sum of the input inductor peak current and load current. Consequently, the RMS value of the capacitor current is high resulting in high stress, heating and reduced life and overall reliability of the unit.

One way to deal with the problems is by designing multiphase, interleaved power stages. In a typical interleaved converter several power stages are connected in parallel and driven with signals shifted by $360^{\circ} /$ (number of phases). Effective switching frequency is, thus, increased proportionally to the number of phases with several important benefits:

- For the same value of inductance (compared to an equivalent single-phase boost), current ripple is significantly reduced, helping reduce size of the inductor;

- For the same ripple current, individual inductors can have lower inductance, again reducing their size;

- $\quad$ Reduced ripple current helps relieve stress on the output filter capacitors and increased effective switching frequency makes capacitors running closer to their optimum (most of the aluminum electrolytic capacitors have increased RMS current rating as frequency increases). 


\subsection{Single-phase boost converter}

This is the standard boost converter. Simplified schematic of the power train is shown in Figure 6.

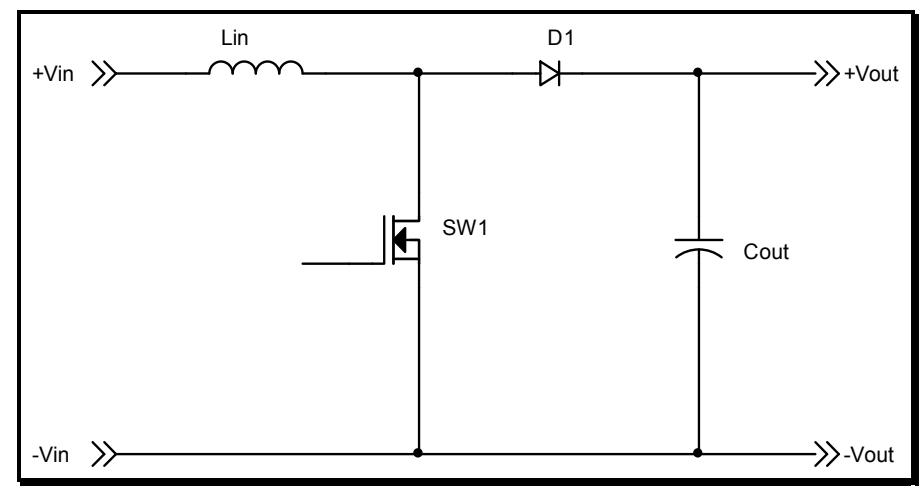

Fig. 6. Boost converter schematic

This is the basic and most commonly used variation, typical for low power converters as well as medium to high power PFC designs. The reason for its popularity is obvious simplicity with low parts count makes this an inexpensive and reliable solution. Additionally, the topology has typically high conversion efficiency thanks to its simplicity and principle of operation: in normal operation, at any moment within a switching cycle current flows through only one semiconductor part (it alternates between the switch and the rectifier). This is can be seen in Figure 7 that shows main waveforms.

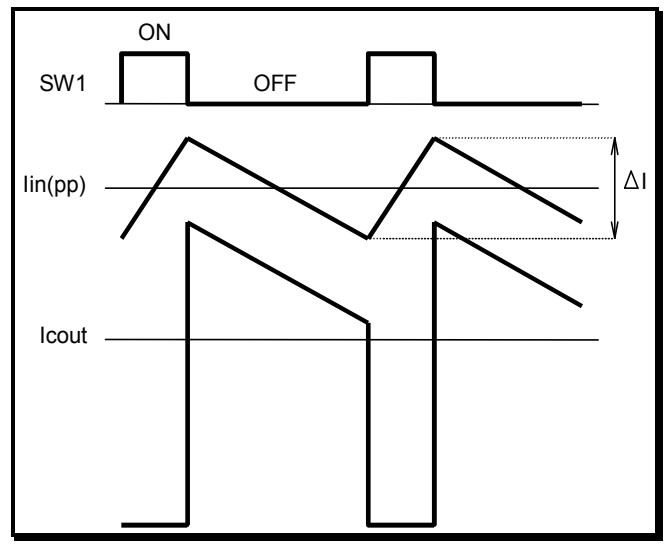

Fig. 7. Boost converter input current and output capacitor waveforms

Basics of the boost converter operation are well known and easily accessible so they will be omitted from this work.

Specific requirements of the application which can be described in simplest terms as "low voltage- high current", dictate that special attention is paid to the current loading of components. As seen in Figure 6, there are only four components employed by the basic topology, two semiconductor switches, inductor and capacitor. Naturally, there will be a lot more parts in the final design, but properly defining critical parameters for the four components will make a selection process for the rest pretty straightforward. 
Semiconductor switches, shown in the schematics (Figure 6) as MOSFET and a diode are less critical of the four indicated components. Modern semiconductor have high current density in miniature packaging and major constraint is not their current handling capacity rather it is power dissipation that small package can conduct to the ambient. Starting with power loss budget, derived from desired efficiency, it will be fairly easy to make proper selection of the component type and quantity.

Unlike semiconductors, where achieving adequate design margins is not a difficult process, inductors and capacitors present a bigger challenge. Even though material science has brought new materials, inductors and capacitors have seen slower progress.

Relationship between power dissipation and saturation characteristics is still a limiting factor for an inductor design, directly affecting its size and operating temperature. Electrolytic capacitors are still the best part for controlling output voltage ripple, but their life is severely limited by temperature rise due to high ripple currents.In order to make proper selection of adequate parts, the work will concentrate on defining input inductor and output capacitor current ripple and defining a method for their optimization.

\subsubsection{Input current ripple}

For a single phase boost converter input current $\left(\mathrm{I}_{\mathrm{in}}\right)$ is same as the input inductor current

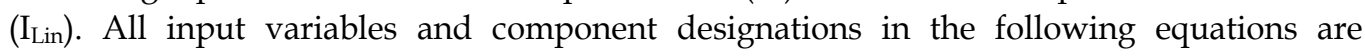
referenced to Figure 6 , and $\delta$ is operating duty cycle of the active switch, defined as turn-on time $\left(\mathrm{T}_{\mathrm{on}}\right)$ divided by switching period $(\mathrm{T})$.

Rising slope of the inductor current is given as

$$
k_{\text {Lin }}=\frac{V_{\text {in }}}{L_{\text {in }}}
$$

Inductor peak-to-peak current ripple is

$$
\Delta I_{\text {Lin }}=k_{\text {Lin }} \delta T=\frac{V_{\text {in }}}{L_{\text {in }}} \delta T
$$

where $\delta$ represents main switch duty cycle and $\mathrm{T}=\mathrm{T}_{\mathrm{on}}+\mathrm{T}_{\text {off }}$ is the switching period.

$$
\delta=\frac{T_{\text {on }}}{T_{\text {on }}+T_{\text {off }}}
$$

Substituting $\mathrm{V}_{\text {in }}$ from the equation for the boost converter's DC gain (Eq. (4) below) into Eq. (2)

$$
\frac{V_{\text {out }}}{V_{\text {in }}}=\frac{1}{1-\delta}
$$

the final equation for the inductor ripple current is derived as

$$
\Delta I_{\text {Lin }}=\delta(1-\delta) \frac{V_{\text {out }} T}{L_{\text {in }}}
$$




\subsubsection{Output capacitor RMS current}

Most commonly used method for calculating RMS values of typical power converter waveforms is by splitting it into piecewise segments and then adding squared RMS values of each individual segment. That is the method that will be used for multiphase converters. The method certainly works for single phase converters as well, but there is a more elegant alternative: we can resort to a Kirchoff's Law's equivalent for RMS currents and calculate output capacitor current by considering all RMS currents inside a boost converter:

$$
I_{\text {CoRMS }}^{2}=I_{\text {inRMS }}^{2}-I_{\text {swRMS }}^{2}-I_{o u t}^{2}
$$

Where,

$$
\begin{gathered}
I_{\text {inRMS }}=I_{\text {LinRMS }}=I_{\text {inAVG }} \sqrt{1+\frac{1}{3}\left(\frac{\Delta I_{\text {Lin }}}{2 I_{\text {inAVG }}}\right)^{2}} \\
I_{\text {swRMS }}=I_{\text {inAVG }} \sqrt{\delta\left(1+\frac{1}{3}\left(\frac{\Delta I_{\text {Lin }}}{2 I_{\text {inAVG }}}\right)^{2}\right)}
\end{gathered}
$$

then, finally,

$$
I_{\text {CoRMS }}^{2}=(1-\delta) I_{\text {inAVG }}^{2}\left(1+\frac{1}{3}\left(\frac{\Delta I_{\text {Lin }}}{2 I_{\text {inAVG }}}\right)^{2}\right)-I_{\text {out }}^{2}
$$

The average input current for an ideal, lossless converter can be calculated by starting with a premise that input power equals the output power:

$$
I_{\text {in } A V G}=\frac{V_{\text {out }} I_{\text {out }}}{V_{\text {in }}}=\frac{V_{\text {out }} I_{\text {out }}}{V_{\text {out }}(1-\delta)}=\frac{1}{(1-\delta)} I_{\text {out }}
$$

Substituting equations (5) and (10) into (9), we are getting the closed form equation for the output capacitor RMS current as follows:

$$
I_{\text {CoRMS }}^{2}=\frac{\delta}{1-\delta} I_{\text {out }}^{2}+\frac{1}{12} \delta^{2}(1-\delta)^{3}\left(\frac{V_{\text {out }} T}{L_{\text {in }}}\right)^{2}
$$

As $\delta$ is always less than one, the right hand side of the equation can be neglected with only a small negative effect on overall accuracy. Practical illustration of this simplification is that the AC ripple component is neglected, i.e. considered negligible when compared to the average value of the input inductor current, which is a meaningful and common practice in everyday engineering. This simplification will pay large dividends when multiple phases are analyzed, as the complete closed form equations would otherwise be difficult to manage and understand. Also the practical measurements will show that, in an optimized multiphase converter, the ripple is indeed very small when compared to the average input current. The identical simplification will be used for deriving RMS capacitor current equations for multiphase converters. It should be noted, though, that this simplification will 
result in capacitor ripple current being zero at specific values for duty cycle. In reality, the ripple current will never reach zero but the actual value will be equal to the neglected factor in the above equation.

Simplified Eq. (11) is then:

$$
I_{\text {CoRMS }}^{2}=\frac{\delta}{1-\delta} I_{\text {out }}^{2}
$$

\subsection{Two-phase interleaved boost converter}

By adding another power stage, connecting inputs and outputs in parallel and shifting drive signals by $180^{\circ}$ a two phase interleaved boost converter is created. Principle schematics is shown in Figure 8.

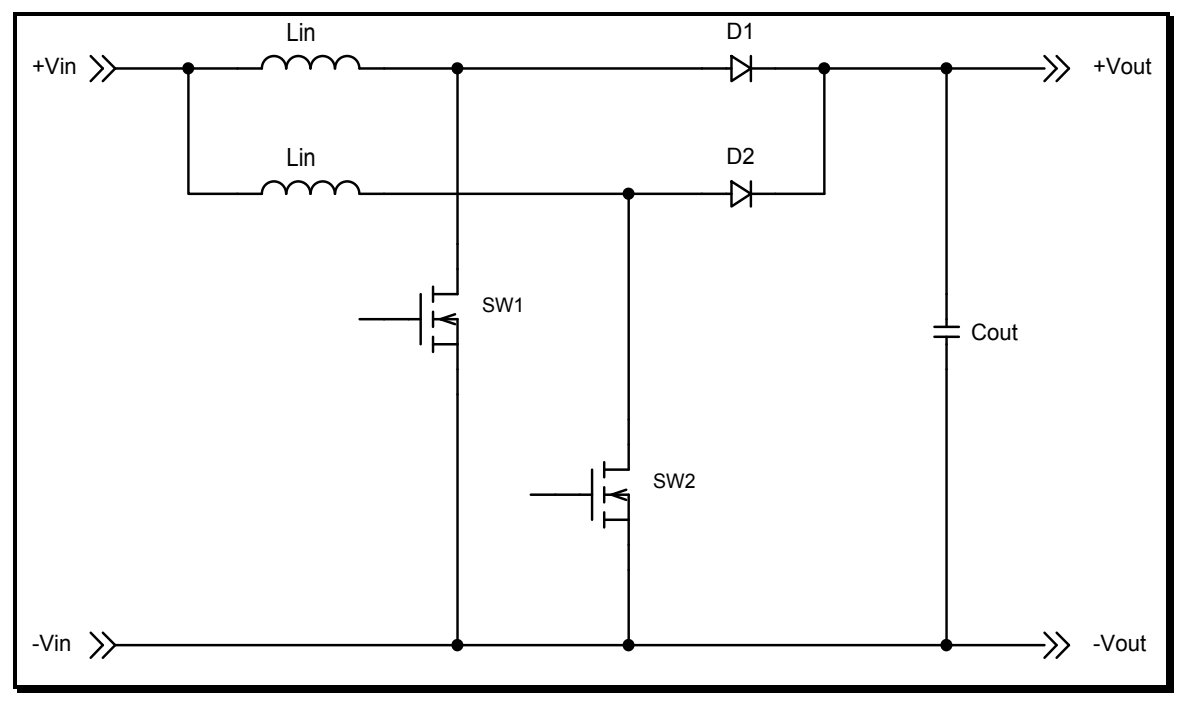

Fig. 8. Two phase boost converter

For a two-phase interleaved boost converter, two distinct modes of operation can be analyzed. One is for duty cycles lower than $0.5(50 \%)$ and the other one for duty cycles above 0.5 . At exactly 0.5 the converter benefits from ripple cancellation and input current ripple is zero, while output capacitor ripple is at minimum (although not exactly zero, as explained in 3.2). The two modes of operation are illustrated in Figures 9 and 10.

\section{- Input current ripple}

The input current ripple, $\Delta \mathrm{I}_{\text {in }}$ will be analyzed for the two cases, $\delta<0.5$ and $\delta>0.5$.

- $\quad \delta<0.5$

Input current and input inductor current waveforms for a duty cycle below 0.5 are shown in Figure 9. For the sake of clarity, designations for ripple currents and duty cycles are removed from the graphs, as they are similar to the single stage boost diagrams.

The duration of the rising slope of the input current equals the rising time of an individual inductor's current, i.e. $\delta$ T. The input current ripple's rising slope in this interval is a difference of the rising current slope of one inductor and falling slope of the other one: 


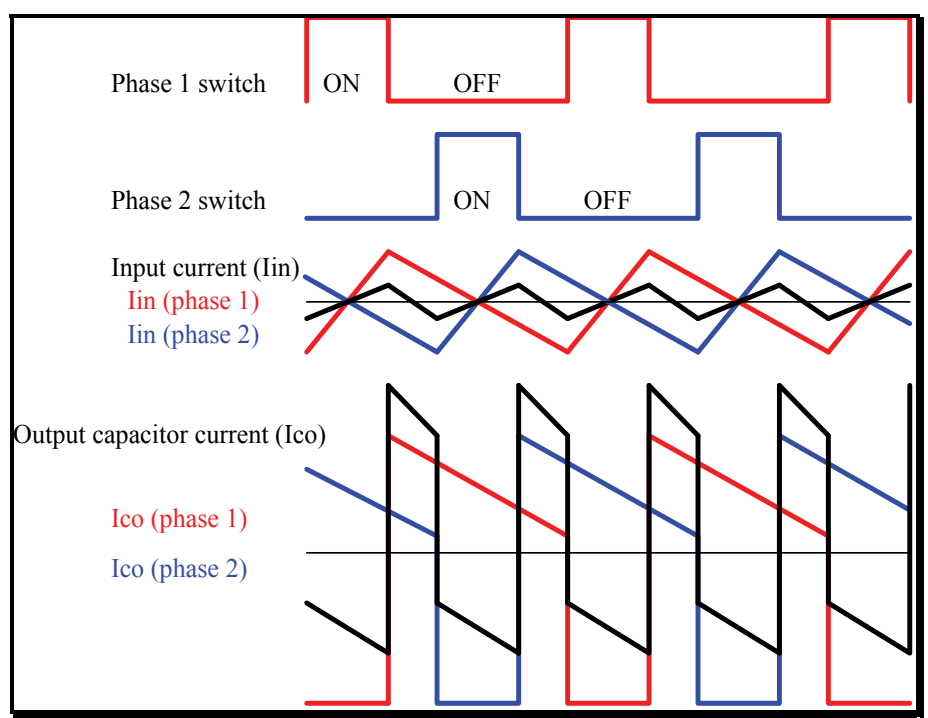

Fig. 9. Two phase boost converter $w$-forms for $\delta<0.5$

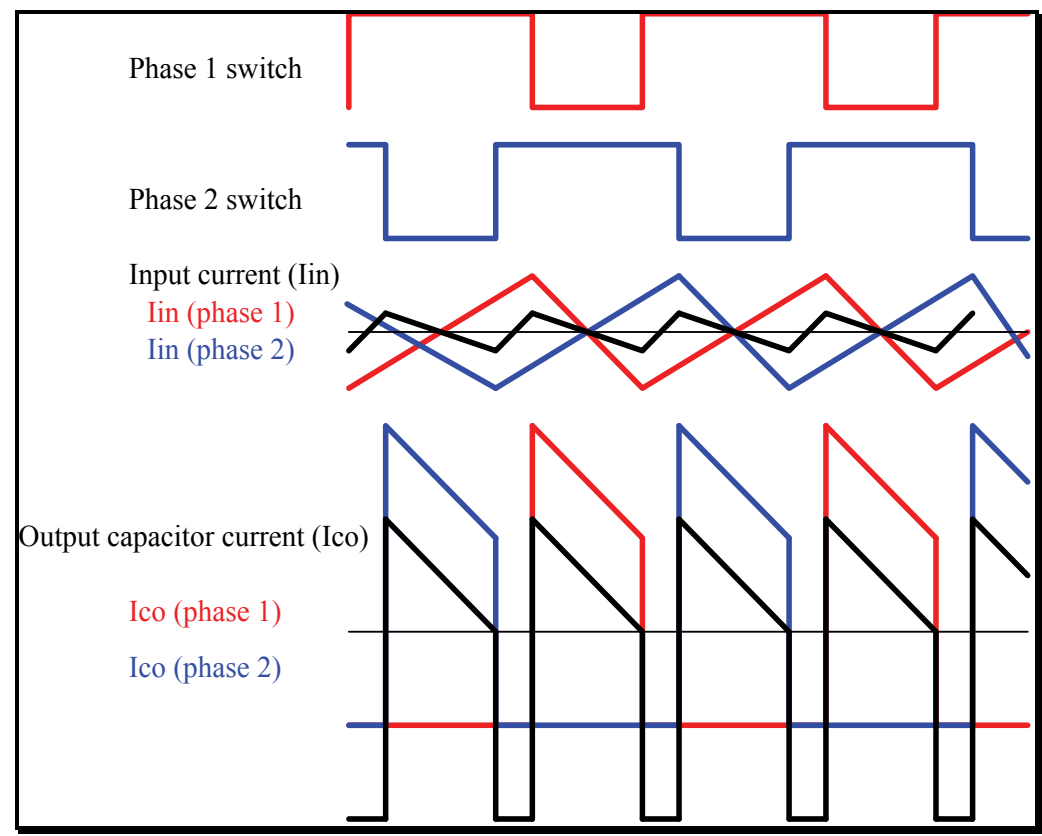

Fig. 10. Two phase boost converter $w$-forms for $\delta>0.5$

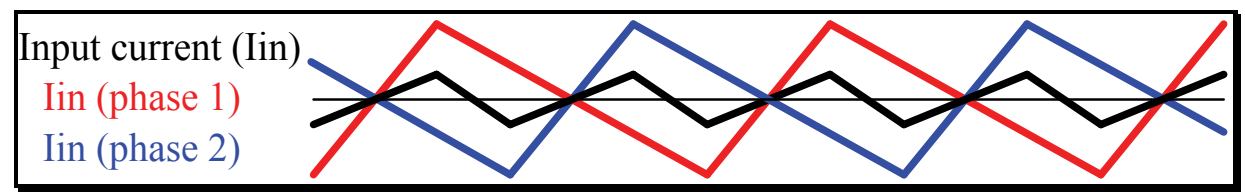

Fig. 11. Two-phase boost converter - input current waveforms, $\delta<0.5$ 


$$
k_{\text {in }}=k_{\text {on }}-k_{\text {off }}=\frac{V_{\text {in }}}{L_{\text {in }}}-\frac{\left(V_{\text {out }}-V_{\text {in }}\right)}{L_{\text {in }}}
$$

Peak-to-peak input current ripple is:

$$
\Delta I_{\text {in }}=k_{\text {in }} \delta T
$$

Substituting $V_{\text {in }}$ from (4) the input current ripple for $\delta<0.5$ is derived as:

$$
\Delta I_{\text {in }}=\delta(1-2 \delta) \frac{V_{\text {out }} T}{L_{\text {in }}}
$$

- $\quad \delta>0.5$

Input current waveforms for $\delta>0.5$ are shown in Fig. 12.

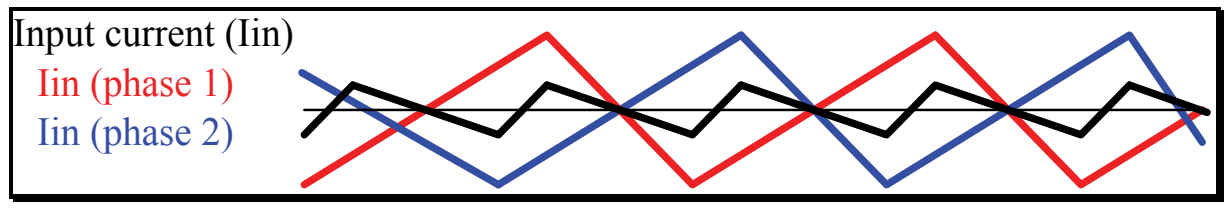

Fig. 12. Two-phase boost converter - input current waveforms, $\delta>0.5$

The duration of the input current rising slope in this case equals $\mathrm{T} / 2-(1-\delta) \mathrm{T}$, or $(\delta-1 / 2) \mathrm{T}$. The slope equals:

$$
k_{\text {in }}=2 k_{\text {onoff }}=2 \frac{V_{\text {in }}}{L_{\text {in }}}
$$

And the input current is:

$$
\Delta I_{\text {in }}=k_{\text {in }}\left(\delta-\frac{1}{2}\right) T=\left(\delta-\frac{1}{2}\right)(2-2 \delta) \frac{V_{\text {out }} T}{L_{\text {in }}}
$$

- Output capacitor RMS current

Similar process will be followed in analyzing current ripple in the output filter capacitor.

- $\quad \delta<0.5$

Output capacitor current waveform for $\delta<0.5$ is shown in Fig. 13.

By neglecting the input inductor ripple, the waveform gets the rectangular shape. This approximation (discussed in 3.2) is acceptable as it helps get results which are easier to understand and interpret. Loss of accuracy is negligible when compared to tolerances and required design margins. Positive amplitude of the waveform equals ( $\left.\mathrm{I}_{\text {inAvG }}-\mathrm{I}_{\text {out }}\right)$ and negative amplitude is $\left(\mathrm{I}_{\text {out }}-\mathrm{I}_{\text {inAVG }} / 2\right)$. The signal is negative during time that equals $\delta \mathrm{T}$ and positive during time $(1 / 2-\delta) \mathrm{T}$. RMS current is then calculated starting with:

$$
I_{C o R M S}{ }^{2}=\delta\left(I_{\text {out }}-\frac{I_{\text {inAVG }}}{2}\right)^{2}+\left(\frac{1}{2}-\delta\right)\left(I_{\text {inAVG }}-I_{\text {out }}\right)^{2}
$$




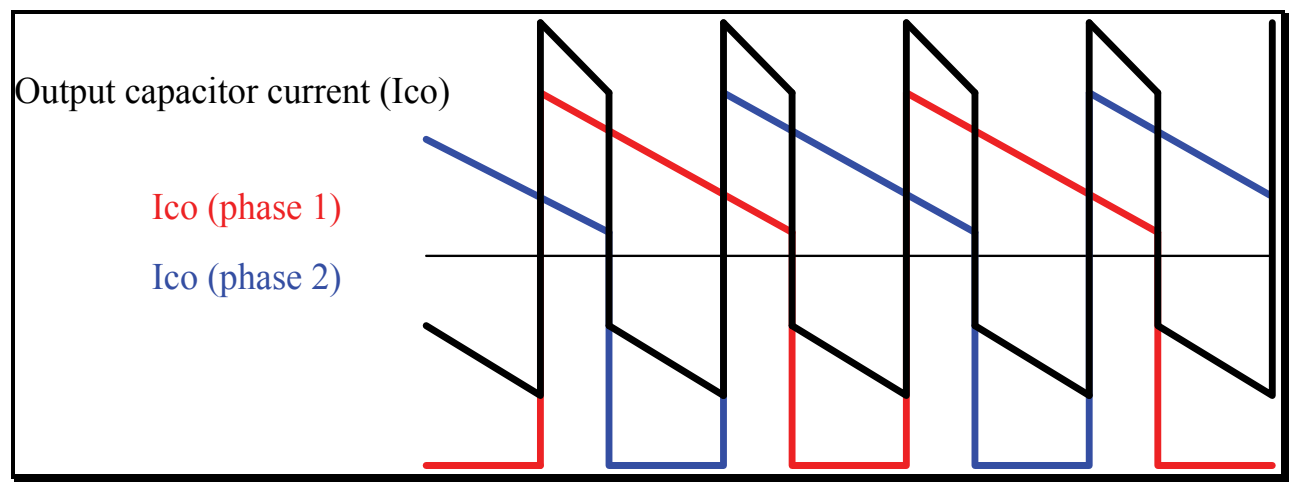

Fig. 13. Two-phase boost converter - output capacitor current waveforms, $\delta<0.5$

Substituting Eq. (10), the final result is derived as

$$
I_{\text {CoRMS }}=\frac{I_{\text {out }}}{2(1-\delta)} \sqrt{\delta(1-\delta)}
$$

- $\quad \delta>0.52$

The output capacitor's current waveform is shown in Figure 14.

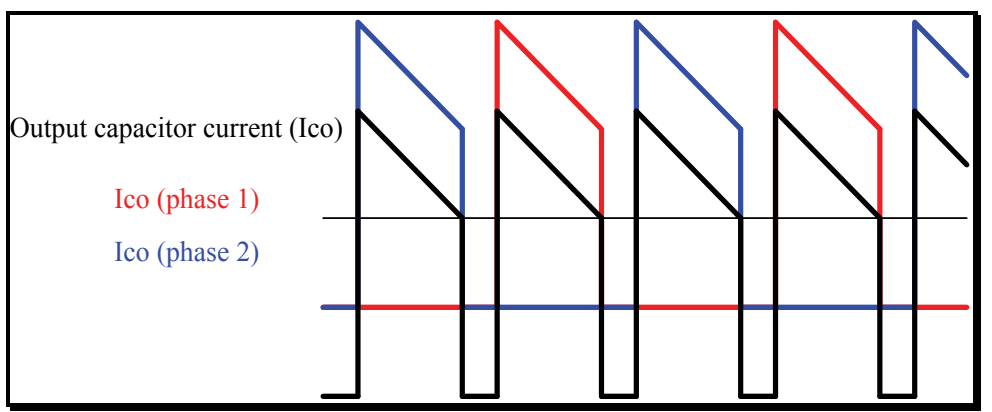

Fig. 14. Two-phase boost converter - output capacitor current waveforms, $\delta>50 \%$

Positive amplitude of the simplified waveform is now ( $\left.\mathrm{I}_{\text {inAVG }} / 2-\mathrm{I}_{\mathrm{out}}\right)$, duration is $(1-\delta) \mathrm{T}$. Negative amplitude equals $\mathrm{I}_{\mathrm{out}}$ and duration is $(\delta-1 / 2) \mathrm{T}$. RMS current is, therefore,

$$
I_{\text {CoRMS }}^{2}=\left(\delta-\frac{1}{2}\right) I_{\text {out }}^{2}+(1-\delta)\left(\frac{I_{\text {in } A V G}}{2}-I_{\text {out }}\right)^{2}
$$

Final equation is derived as

$$
I_{\text {CoRMS }}=\frac{I_{\text {out }}}{2(1-\delta)} \sqrt{\frac{1}{2}(2 \delta-1)(2-2 \delta)}
$$

\subsection{Three-phase interleaved boost converter}

Current state of research and industry applications indicates that most commonly used number of phases in multiphase converters is two, three, or multiple of either one $(4,6$, etc.). 
or that reason and in order to make it easier to derive generalized equations for multiphase converters the three phase boost will also be addressed in more detail.

Basic schematic is shown in Figure 15 and it represents three interleaved stages with drive signals shifted by $120^{\circ}$.

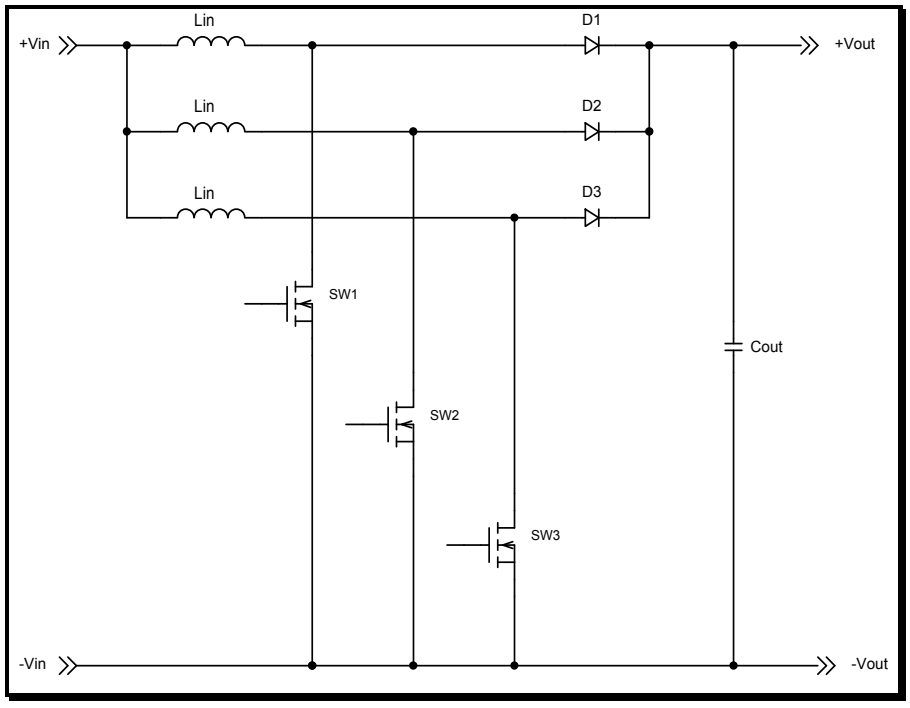

Fig. 15. Three phase boost converter

Similarly to the analysis of a two phase interleaved converter, for the three phase boost converter there are three modes of operation of interest: $(1) \delta<1 / 3$; (2) $1 / 3<\delta<2 / 3$ and (3) $\delta>2 / 3$. Input current waveforms of a three-phase boost converter with duty cycles within the described ranges are shown in Figures 16, 17 and 18.

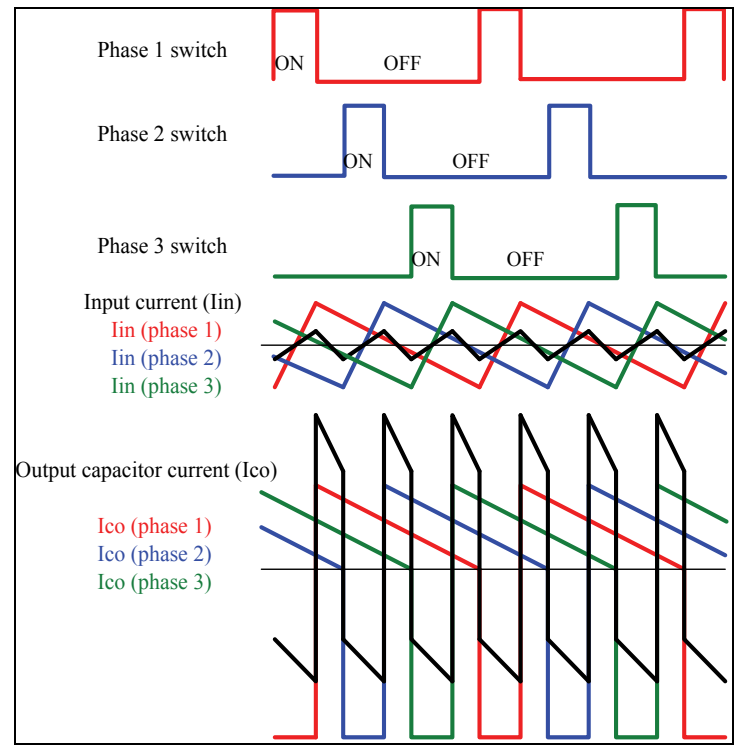

Fig. 16. Three-phase boost converter $\mathrm{w}$-forms for $\delta<1 / 3$ 


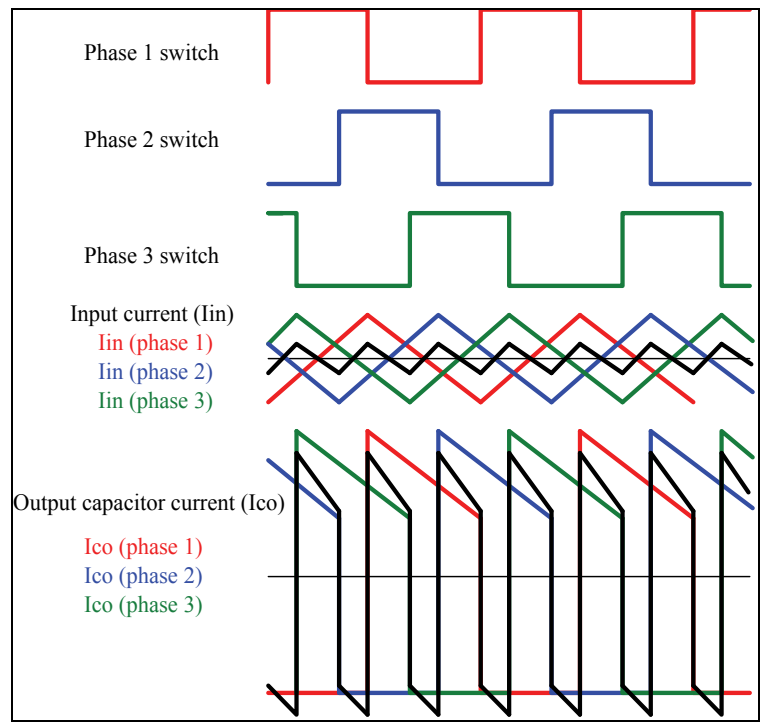

Fig. 17. Three phase boost $w$-forms for $1 / 3<\delta<2 / 3$

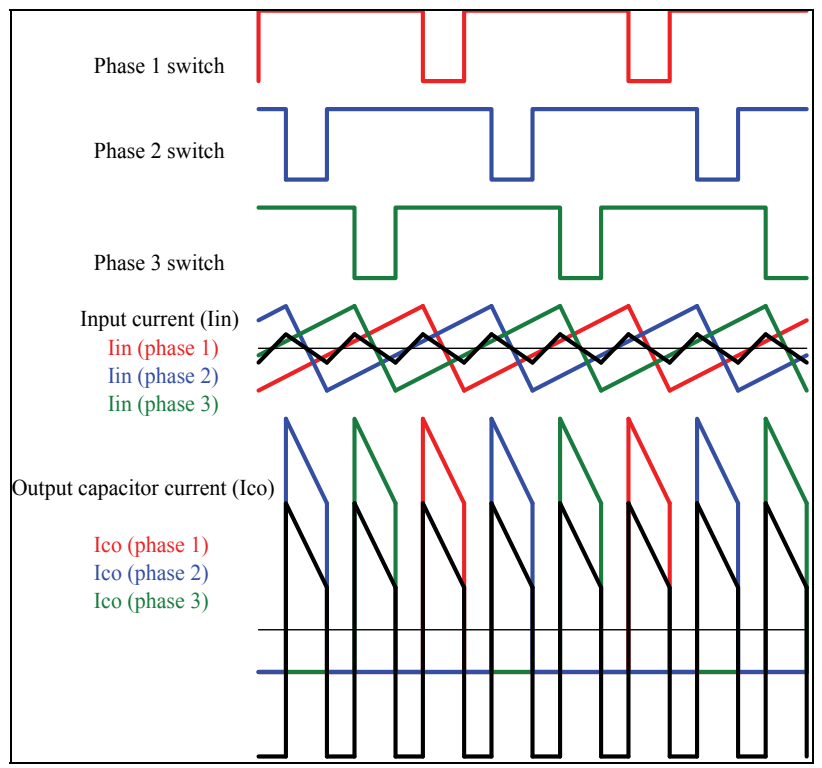

Fig. 18. Three phase boost $w$-forms for $\delta>2 / 3$

\subsubsection{Input current ripple}

\section{- $\delta<1 / 3$}

Input current and input inductor current waveforms for a duty cycle below $1 / 3$ are shown in Figure 19.

In this case the duration of the input current's rising slope coincides with the ON time of the main switch, $\delta T$. The slope itself can be calculated in the similar manner as in the two phase configuration: 


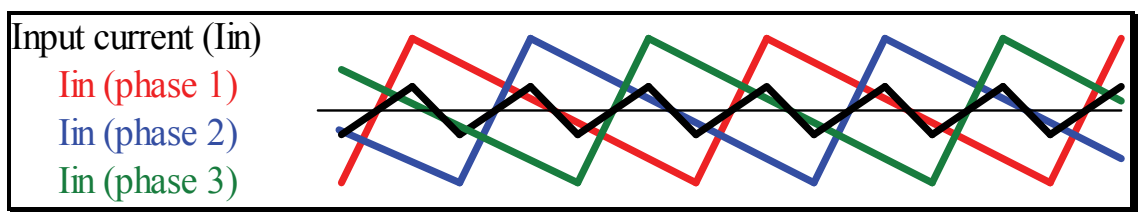

Fig. 19. Three-phase boost converter - input current waveforms, $\delta<1 / 3$

$$
k_{\text {in }}=k_{\text {on }}-2 k_{\text {off }}=\frac{V_{\text {in }}}{L_{\text {in }}}-2 \frac{\left(V_{\text {out }}-V_{\text {in }}\right)}{L_{\text {in }}}
$$

Peak-to-peak current ripple is:

$$
\Delta I_{\text {in }}=k_{\text {in }} \delta \mathrm{T}
$$

Following procedure outlined in 2.1, the value of current ripple for $\delta<1 / 3$ is derived as:

- $\quad 1 / 3<\delta<2 / 3$

$$
\Delta I_{\text {in }}=\delta(1-3 \delta) \frac{V_{\text {out }} T}{L_{\text {in }}}
$$

Figure 20 illustrates input current waveforms for $1 / 3<\delta<2 / 3$.

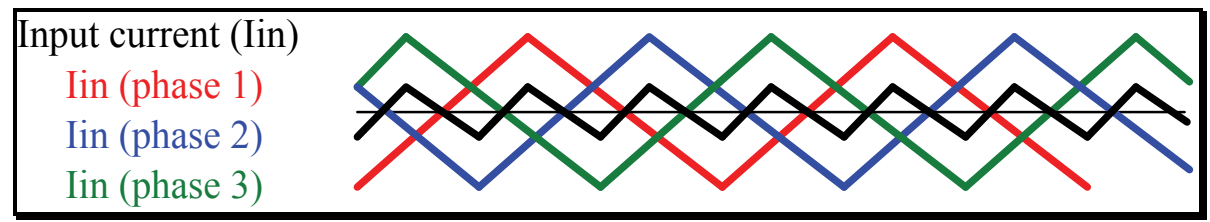

Fig. 20. Three-phase boost converter - input current waveforms, $1 / 3<\delta<2 / 3$

In this case the input current's rising slope duration is $(\delta-1 / 3) \mathrm{T}$ and the value is

$$
k_{\text {in }}=2 k_{\text {on }}-k_{\text {off }}=2 \frac{V_{\text {in }}}{L_{\text {in }}}-\frac{\left(V_{\text {out }}-V_{\text {in }}\right)}{L_{\text {in }}}
$$

Input current ripple is:

$$
\Delta I_{\text {in }}=k_{\text {in }}\left(\delta-\frac{1}{3}\right) T=\left(\delta-\frac{1}{3}\right)(2-3 \delta) \frac{V_{\text {out }} T}{L_{\text {in }}}
$$

- $\delta>2 / 3$

Figure 21 illustrates input current waveforms for $\delta>2 / 3$.

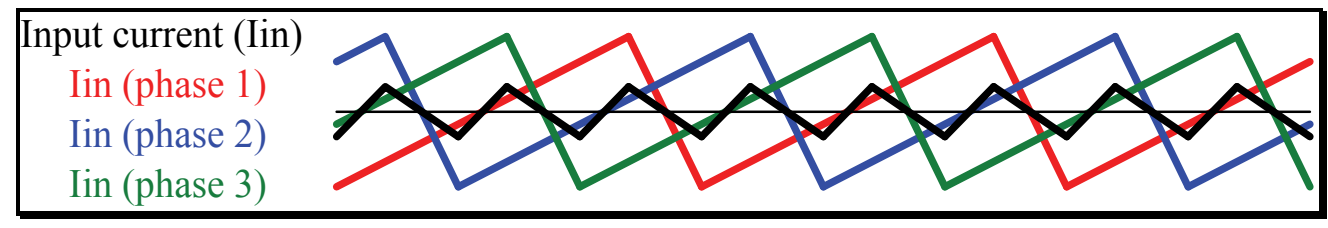

Fig. 21. Three-phase boost converter - input current waveforms, $\delta>2 / 3$ 
The input current ripple slope duration is $(\delta-2 / 3) \mathrm{T}$ and

$$
\begin{gathered}
k_{\text {in }}=3 k_{\text {on }}=3 \frac{V_{\text {in }}}{L_{\text {in }}} \\
\Delta I_{\text {in }}=k_{\text {in }}\left(\delta-\frac{2}{3}\right) T=\left(\delta-\frac{2}{3}\right)(3-3 \delta) \frac{V_{\text {out }} T}{L_{\text {in }}}
\end{gathered}
$$

\subsubsection{Output capacitor RMS current}

\section{- $\delta<1 / 3$}

Figure 22 illustrates filter capacitor current for $\delta<2 / 3$.

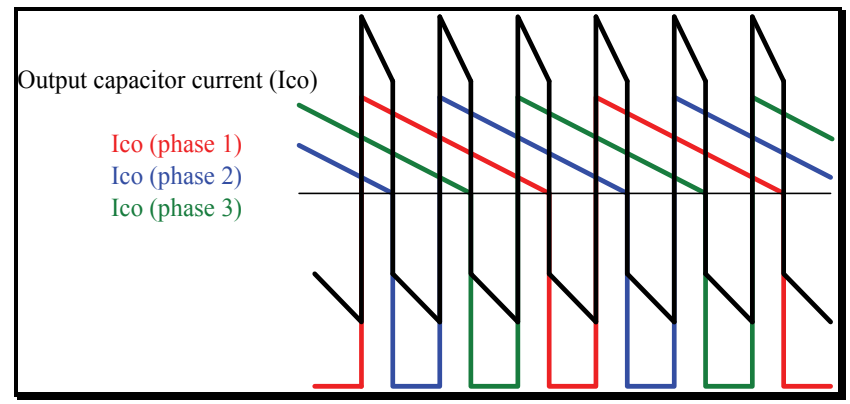

Fig. 22. Three-phase boost converter - output capacitor current waveform, $\delta<1 / 3$

- Positive amplitude: $\left(\mathrm{I}_{\text {inAVG }}-\mathrm{I}_{\text {out }}\right)$, duration: $(1 / 3-\delta) \mathrm{T}$

- Negative amplitude: $\left(\mathrm{I}_{\text {out }}-2 \mathrm{I}_{\text {inAVG }} / 3\right)$, duration: $\delta \mathrm{T}$

RMS current:

$$
\begin{gathered}
I_{\text {CoRMS }}^{2}=\delta\left(I_{\text {out }}-\frac{2}{3} I_{\text {inAVG }}\right)^{2}+\left(\frac{1}{3}-\delta\right)\left(I_{\text {inAVG }}-I_{\text {out }}\right)^{2} \\
I_{\text {CoRMS }}=\frac{I_{\text {out }}}{3(1-\delta)} \sqrt{\delta(1-3 \delta)}
\end{gathered}
$$

- $\quad 1 / 3<\delta<2 / 3$

Figure 23 illustrates filter capacitor current for $1 / 3<\delta<2 / 3$.

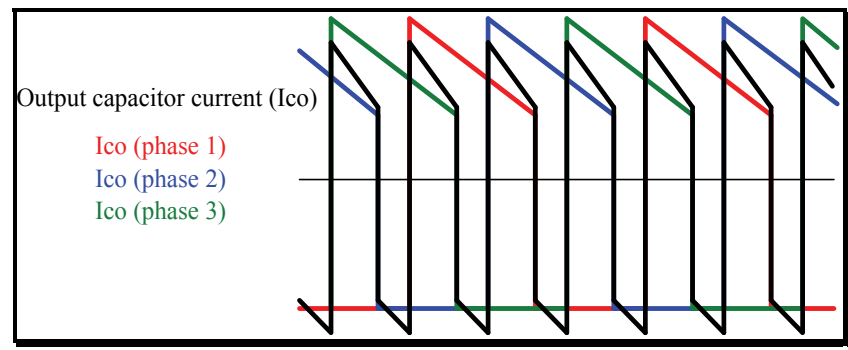

Fig. 23. Three-phase boost converter - output capacitor current waveform, $1 / 3<\delta<2 / 3$ 
- Positive amplitude: $\left(2 \mathrm{I}_{\text {inAVG }} / 3-\mathrm{I}_{\text {out }}\right)$, duration: $(2 / 3-\delta) \mathrm{T}$

- Negative amplitude: $\left(\mathrm{I}_{\text {out }}-\mathrm{I}_{\text {inAVG }} / 3\right)$, duration: $(\delta-1 / 3) \mathrm{T}$

RMS current:

$$
\begin{gathered}
I_{\text {CoRMS }}^{2}=\left(\delta-\frac{1}{3}\right)\left(I_{\text {out }}-\frac{1}{3} I_{\text {inAVG }}\right)^{2}+\left(\frac{2}{3}-\delta\right)\left(\frac{2}{3} I_{\text {inAVG }}-I_{\text {out }}\right)^{2} \\
I_{\text {CoRMS }}=\frac{I_{\text {out }}}{3(1-\delta)} \sqrt{\frac{1}{3}(3 \delta-1)(2-3 \delta)}
\end{gathered}
$$

- $\delta>2 / 3$

Figure 24 illustrates filter capacitor current for $\delta>2 / 3$.

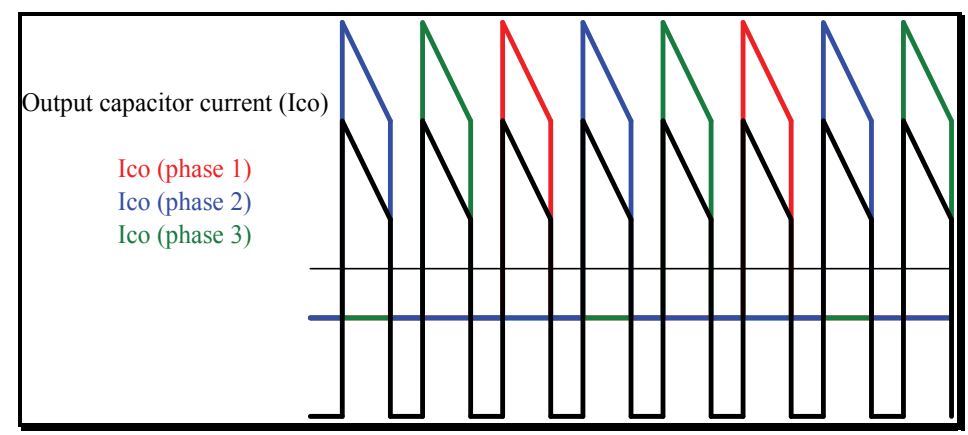

Fig. 24. Three-phase boost converter - output capacitor current waveform, $\delta>2 / 3$

- Positive amplitude: $\left(\mathrm{I}_{\text {inAVG }} / 3\right.$ - $\left.\mathrm{I}_{\text {out }}\right)$, duration: $(1-\delta) \mathrm{T}$

- Negative amplitude: $\mathrm{I}_{\text {out }}$ duration: $(\delta-2 / 3) \mathrm{T}$

RMS current:

$$
\begin{gathered}
I_{\text {CoRMS }}^{2}=\left(\delta-\frac{2}{3}\right) I_{\text {out }}^{2}+(1-\delta)\left(\frac{1}{3} I_{\text {inAVG }}-I_{\text {out }}\right)^{2} \\
I_{\text {CoRMS }}=\frac{I_{\text {out }}}{3(1-\delta)} \sqrt{\frac{1}{3}(3 \delta-2)(3-3 \delta)}
\end{gathered}
$$

\subsection{Generalization for $\mathrm{n}$ phases}

\subsubsection{Input current ripple}

All the results obtained in the previous sections are summarized in the table below. Equations for the 4-phase boost converters are added to the table as they will be used in the following sections. Finally, the general forms of the equations for an n-phase converter are listed in the last row.

Having all relevant equations in one place makes it easy to illustrate benefits of interleaving by graphing input current ripple vs. duty cycle.

Figure 25 shows normalized graphs of the input current ripple for 1, 2, 3 and 4-phase boost converters as a function of duty cycle. 


\begin{tabular}{|c|c|c|c|c|c|}
\hline 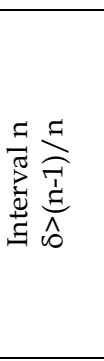 & & & & & 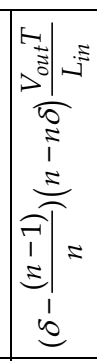 \\
\hline $\bar{\vdots}$ & & & & & $\begin{array}{l}\vdots \\
\end{array}$ \\
\hline 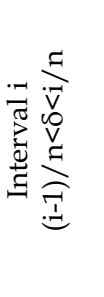 & & & & & 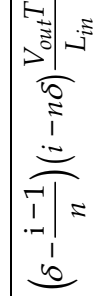 \\
\hline$\vdots$ & & & & & \begin{tabular}{|l}
$\vdots$ \\
\end{tabular} \\
\hline 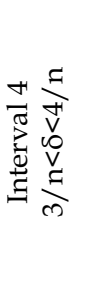 & & & & 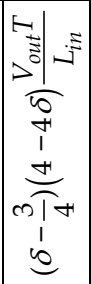 & 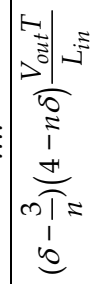 \\
\hline 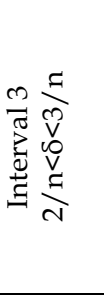 & & & 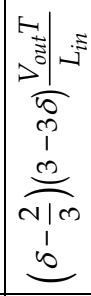 & 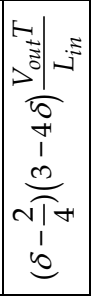 & 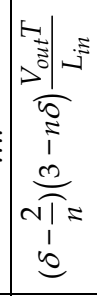 \\
\hline 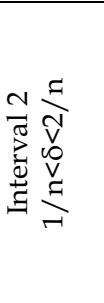 & & 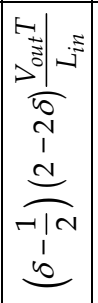 & 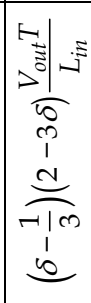 & 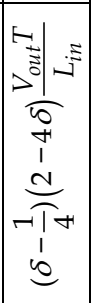 & 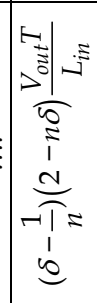 \\
\hline 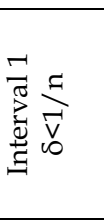 & 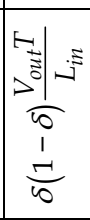 & 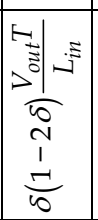 & 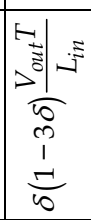 & 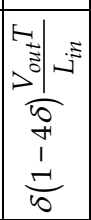 & 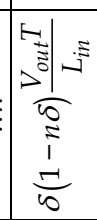 \\
\hline 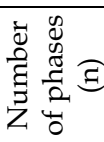 & -1 & $N$ & $\infty$ & $\theta$ & $\approx$ \\
\hline
\end{tabular}




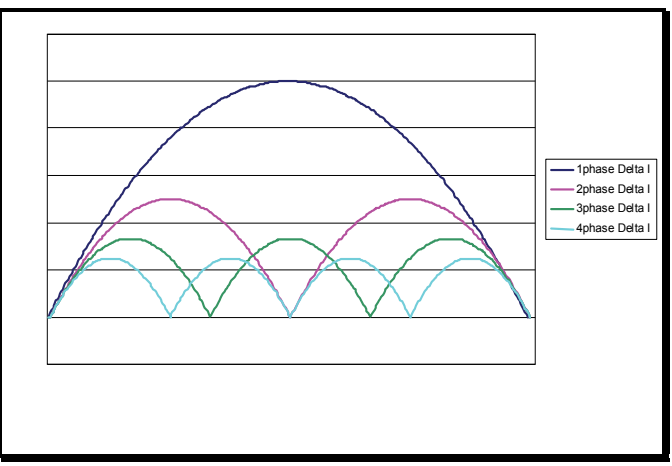

Fig. 25. Input current ripple current vs. duty cycle

The effects of multiphase converters become clearly visible as the maximum current ripple becomes progressively smaller and ripple cancellation effects occur ( $\mathrm{n}-1)$ times (n being the number of phases). Note that duty cycles of zero (0) and one (1.0) are of theoretical value only and ripple cancellation at those duty cycles is of no practical consequence.

Peak value of the ripple current can be found by searching for the maximum of the function for $\mathrm{n}$ phases and interval 1 (in the table above):

$$
\Delta I_{\text {in }}=\delta(1-n \delta) \frac{V_{\text {out }} T}{L_{\text {in }}}
$$

The maximum is then found as:

$$
\Delta I_{\text {in }(\max )}=\frac{1}{4 n} \frac{V_{\text {out }} T}{L_{\text {in }}}
$$

Normalized graphical representation of Eq (36) is simple and shown in Figure 26.

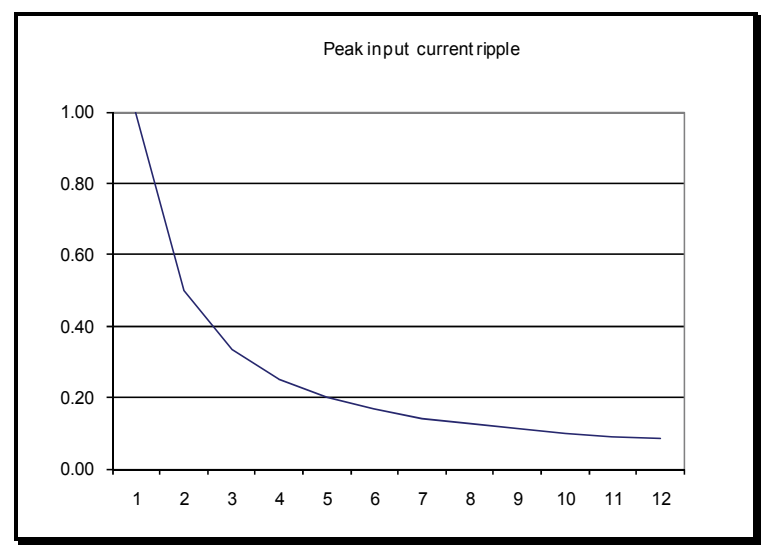

Fig. 26. Peak input current ripple vs. number of phases

\subsubsection{Output capacitor RMS current}

The results for the closed form equations are sorted in the table below. The table is expanded to show 4-phase inverter equations and the general case of an n-phase boost converter. 


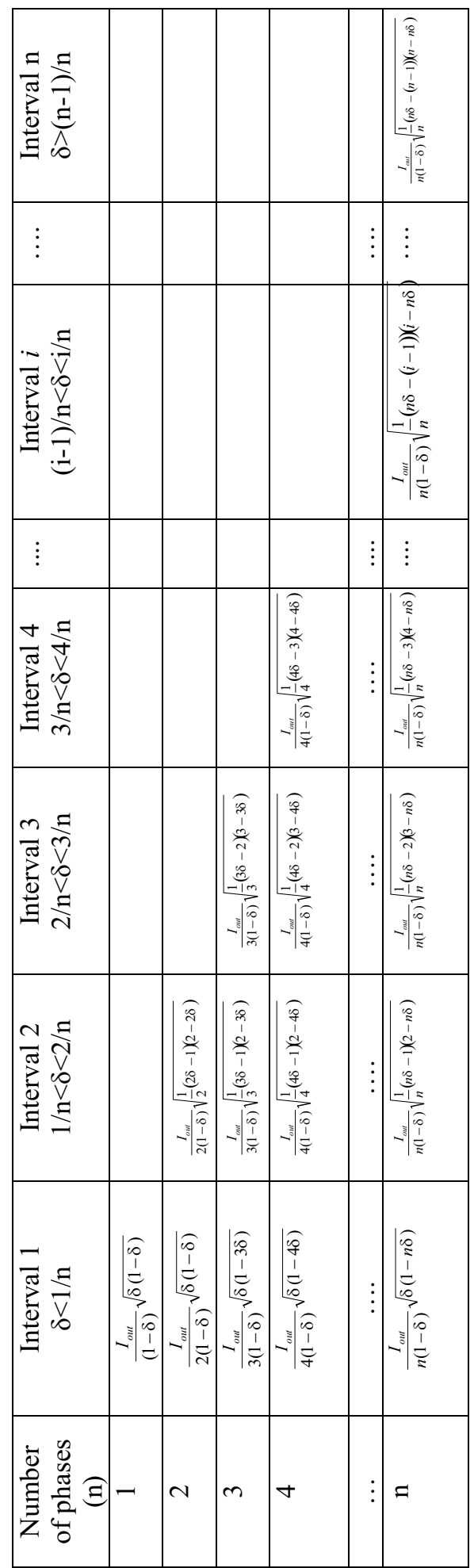


Figure 27 shows graphs of the normalized RMS current for 1, 2, 3 and 4-phase boost converters as a function of duty cycle.

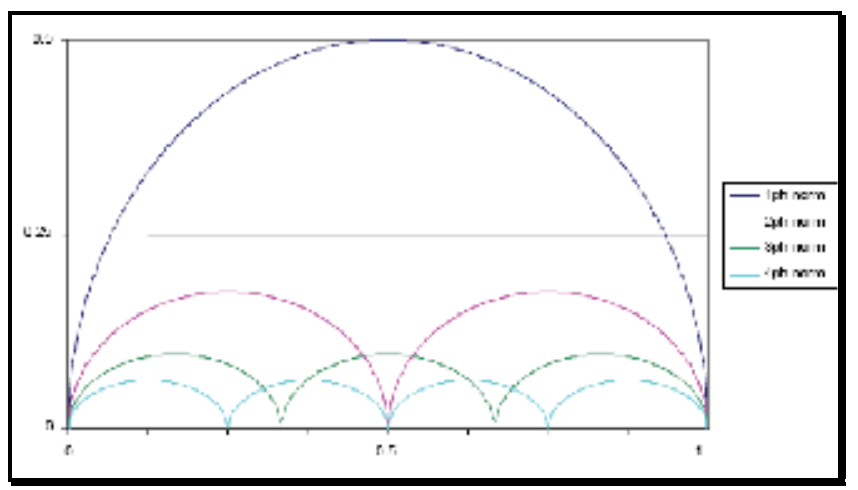

Fig. 27. Normalized output capacitor RMS current vs. duty cycle

The ripple cancellation effects are also very pronounced, but it should be noted once again that, on the output capacitors, there is no complete cancellation - there is always a ripple current present. In our analysis the inductor ripple current was neglected. Even though it is relatively small it never cancels at the output and zero values in Figure 27 should be considered points with the minimum, not zero, ripple.

Peak value of the ripple current can again be found by searching for the maximum of the function for $\mathrm{n}$ phases and interval 1 (in the table above):

$$
I_{\text {CoRMS }}=\frac{I_{\text {out }}}{n(1-\delta)} \sqrt{\delta(1-n \delta)}
$$

The peak RMS current (maximum of the function represented by Eq 37 is then found as

$$
I_{\operatorname{CoRMS}(\max )}=\frac{I_{\text {out }}}{(2 n-1) \sqrt{n}}
$$

Normalized graphical representation of Eq (38) is shown in Figure 28

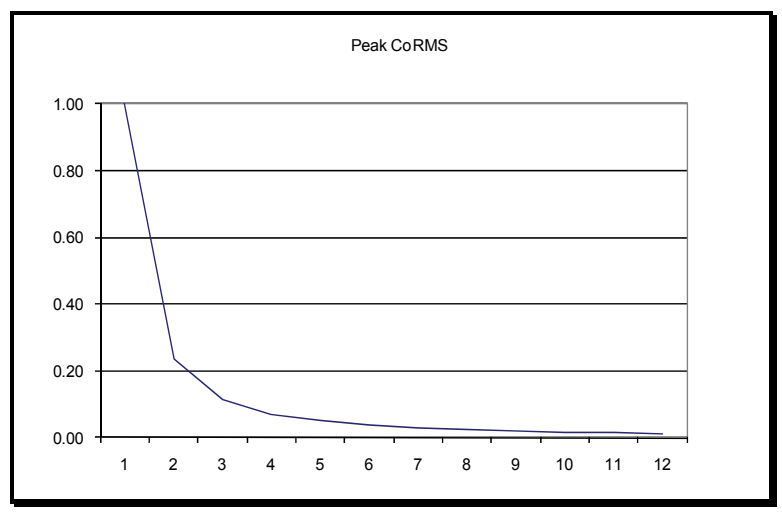

Fig. 28. Normalized output capacitor RMS current vs. number of phases 
It is interesting to see effects of multiple phases on reduction of peak inductor and capacitor currents, when normalized to the same value. Such interpretation is shown in Figure 29.

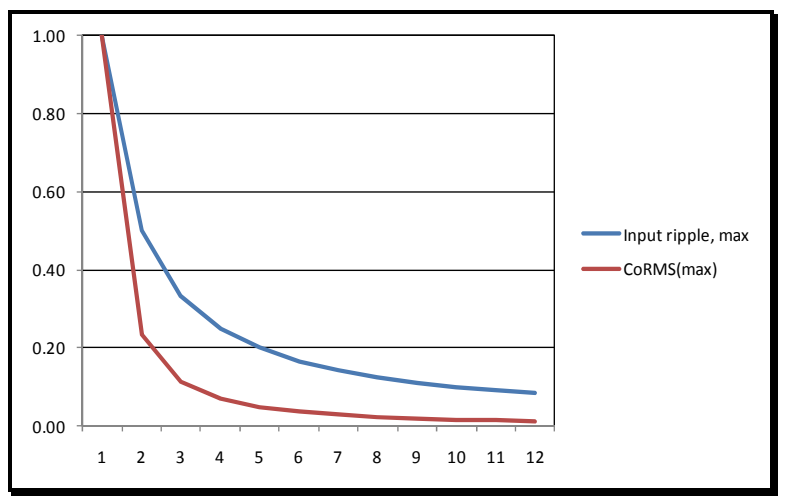

Fig. 29. Comparison of normalized capacitor and inductor (input) current

Capacitor RMS current gets reduced faster as the number of phases in an interleaved converter increases. This is a very good news indeed, as capacitors represent one of the components with shortest life time. Most components typically used in a power train have life span that measures in tens or even hundreds of thousands of hours, and electrolytic capacitors have life expectation of well below 10000 hours under full load.

\section{Optimizing number of phases}

Figure 29 as previously derived (and, for convenience, copied below as Figure 30) can serve as an indication that arbitrary increase of the number of phases in an interleaved configuration may quickly invoke the law of diminishing returns, starting with relatively low number of phases.

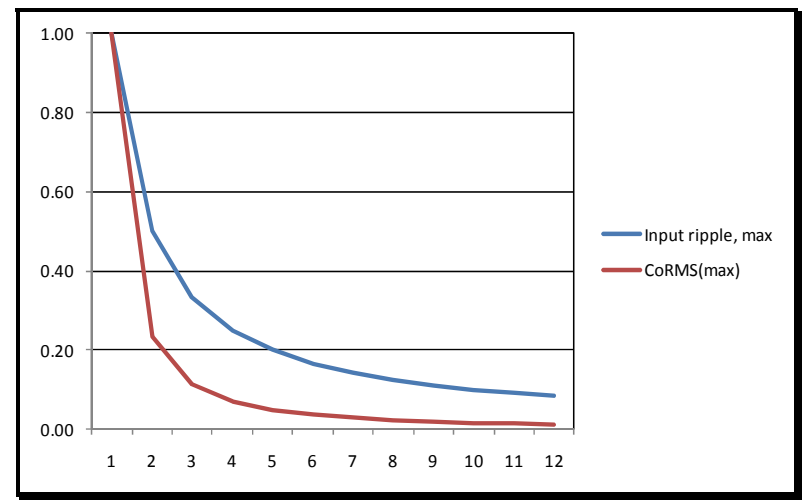

Fig. 30. Comparison of normalized capacitor and inductor (input) current

The process of selection of the number of phases has not been adequately addressed in literature. Most of the time it is selected as a compromise between benefits of an interleaved design and increased cost and complexity. Two phase designs are starting to be popular in PFC designs, although their wide acceptance is yet to be seen. 
However, taking a closer look into design requirements and utilizing work done in previous sections can help illustrate a simple optimization method applicable in practice. Understanding the application and specific requirements outlined in Chapter 2.1 proves to be crucial.

\section{1 "Real World" operating condition}

A good specification is designed to cover all possible operating conditions and adds small margins to ensure safety and reliability. Such specification assigns equal importance to all listed parameters over the whole specified range. Optimization for an infinite number of operating points is often impossible. Luckily, considering actual, "real world" operating conditions, it can be seen that the list of critical parameters and their ranges indicate much narrower operating conditions, and chances of successful optimization are much greater. The "real world" conditions, in the context of this work, are considered operating parameters where converter works most of the time - in other words, this would be an average loading if extreme peak loads (that are infrequent and short in duration) are neglected. For example - even though input voltage range is specified $24-36 \mathrm{~V}$, converter will see steady input voltage of $28 \mathrm{~V}$ during normal operation. It is understood that the regulator must operate within specifications over full operating range, but it still makes a lot of sense to optimize critical parameters for a situation that will apply for most of the unit's serviceable life. Minimizing output capacitor ripple for "real world" operating point will extend their life and life of the unit. Optimum efficiency will result in less heat and smaller, less expensive thermal design.

Chapter 2.1, Specification requirements, lists that the $5 \mathrm{~kW}$ boost converter used as a fuel cell voltage regulator needs to operate over the following voltage ranges:

- Input voltage range: $24-36 \mathrm{~V}$

- Output voltage range: $37-60 \mathrm{~V}$

Starting with the equation for the boost converter DC gain (Eq 4) it is easy to calculate that such a converter will operate over an extremely wide duty cycle between 0.03 and 0.6 . This is a nominal duty cycle range. Designing the converter to cover this wide range at full power would present a challenge regarding driver circuits and containment of electromagnetic emissions.

Considering positive impact of interleaving it is obvious that higher number of phases will help reduce input current ripple as well as the output capacitor's RMS current. Due to the very wide operating range it is not easy to qualify those perceived benefits. A closer look at the application and converter's operating conditions is a necessary step toward circuit optimization:

Wide input voltage range: $24 \mathrm{~V}$ is the fuel cell's "knee" voltage (Region of Concentration Polarization in Figure 31 below) - the fuel cell is in overload and output impedance is rising sharply. Clearly, this is not normal operation, as the system's current limits need to protect both the fuel cell and the regulator. On the other side of the range, $36 \mathrm{~V}$ is the fuel cell's noload (ideal) voltage and the only practical implication is ensuring that the voltage ratings of the associated equipment are adequately selected. In normal steady-state operation the output voltage varies very little and is typically around $28 \mathrm{~V}$.

Wide output voltage range: the actual system operates with $36 \mathrm{~V}$ batteries and the $40-60 \mathrm{~V}$ range is specified for possible future expansion to $48 \mathrm{~V}$ system. In the $36 \mathrm{~V}$ system, the converter's output voltage is set to keep batteries charged to $41 \mathrm{~V}$ (slightly below the fully charged level to ensure that batteries can absorb recuperative braking energy). Therefore, 
$41 \mathrm{~V}$ is the output voltage that will be maintained for all operating conditions except for peak loads that exceed $5.5 \mathrm{~kW}$ rating of the regulator.

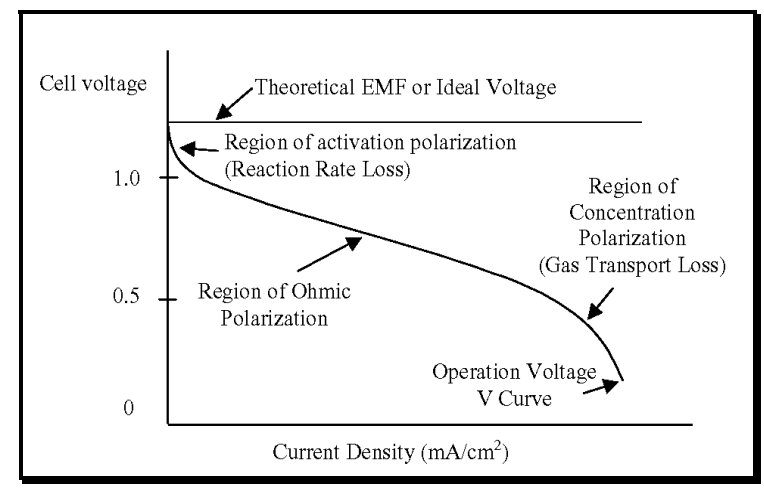

Fig. 31. A typical fuel cell load curve

\subsection{Optimization}

With the practical considerations listed above, the regulator's operating point is:

- Input voltage: $28 \mathrm{~V}$

- Output voltage: 41V

- $\quad$ Operating duty cycle: 0.32

A useful visual representation can be obtained by starting with normalized graphs ( $\Delta$ Iin and I CoRMs vs. duty cycle) and superimposing nominal and operating duty cycles.

Figure 32 shows normalized input ripple current with nominal duty cycle range (0.03-0.60) and operating range (centered around $\delta=0.32$ ) superimposed. Figure 33 shows normalized output capacitor ripple current and nominal and operating duty cycles.

Contrary to the generalized statement that current levels decrease with the number of interleaved phases, examination of Figures 32 and 33, considering a narrow duty cycle range centered around 0.32 shows that the input current ripple, as well as the output capacitor RMS current are significantly lower in the three-phase design than in the higher order, four phase design. Counterintuitive on the first sight, but easily understood considering that operating duty cycle is located very close to the zero-current duty cycle. Therefore, for the real-life, application specific operating conditions the three-phase interleaved converter offers significant benefits compared to the four-phase design: it yields lower cost unit with reduced complexity and, at the same time, results in the lower stress of the output capacitors and, quite likely, lower emissions as a result of reduced input current ripple.

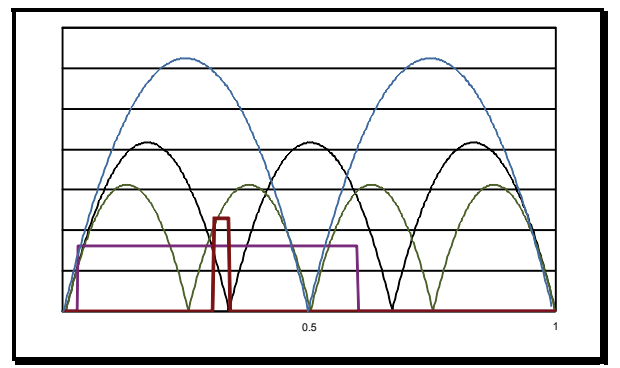

Fig. 32. Input current ripple with nominal and operating duty cycle 


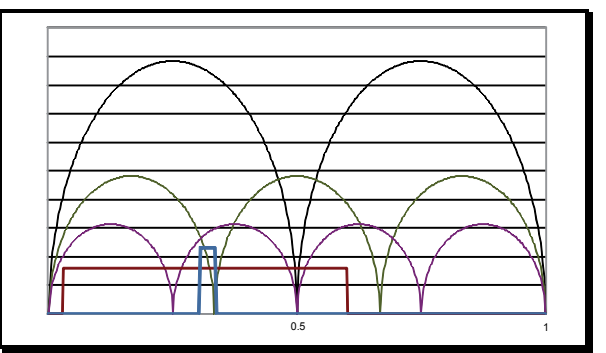

Fig. 33. Output capacitor RMS current with nominal and operating duty cycle

During certain events - system start, initial battery charging, overvoltage or overload transients, the converter will work over the much wider range of input and output voltages, departing from this narrowly defined area. During those events, the converter will work in a suboptimal mode. However, those events are rare (overvoltage conditions are an abnormal situation, system starts once per work shift and the initial battery charging is done only when a new system is initialized) and short in duration (system start is in $~ 30$ seconds, initial battery charging is $\sim 1 \mathrm{hr}$ or less, overload transients may last few seconds). As such, these still regular but suboptimal modes of operation will not overstress the unit for any significant amount of time that would significantly reduce the regulator's service life.

\section{Regulator design}

At this point the electrical specification and application requirements are known (Chapter 4) and three phase interleaved boost converter was proven to be optimum topology for the application. Next step is regulator design, which can be divide into two major sections power stage and control section.

\subsection{Power stage}

Simplified representation of the three-phase boost converter power stage is shown in Fig. 34 .

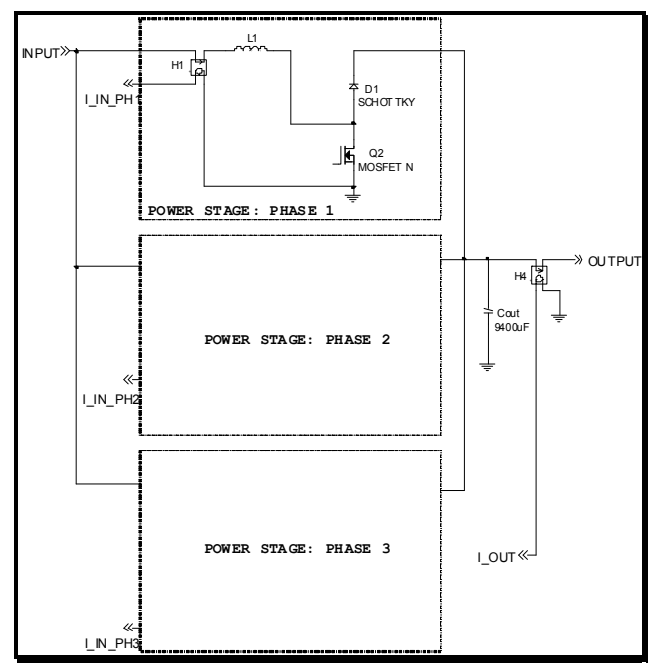

Fig. 34. Block schematic of the three phase boost converter 
The concept is identical to the basic topology shown in Figure 34, but this representation adds more details. Input current is measured at each phase in order to ensure current sharing. Output current is also measured in order to provide accurate monitoring and battery charging.

\subsection{Switching frequency selection}

Electromagnetic compatibility (EMC) issues are typically addressed at the end of a design cycle, when components selection, board layout and mechanical packaging are finalized. However, keeping in mind the EMC at the very beginning of a design pays large dividends when the finalized product is submitted for radiated and conductive emissions testing. Switching frequency was selected based on minimal anticipated electromagnetic emissions. Alternative approach could be starting with efficiency requirements and losses, but it requires that all components are selected which limits options early in the design.

Input inductor current has a triangular ac component (high frequency ripple). Most of the other waveforms have shapes that include part of a triangle. It is not surprising, therefore, that third harmonic is typically the most dominant in the electromagnetic spectrum of a power converter.

Two major groups of standards dominate regulations of the emissions that can be tolerated. FCC, part 15 is mandatory in the US and EMC Directive (required in order for units to carry the CE mark) must be complied with in European Union and many other countries (notably Japan, Australia and China). The emission limits dictated by FCC and CE are very similar, major difference being that FCC limits start at $450 \mathrm{kHz}$, while CE limits start at a lower frequency $-150 \mathrm{kHz}$. Meeting CE requirements automatically means complying with FCC as well.

Safe approach to selecting switching frequency is to ensure that the most dominant third harmonic of the switching frequency falls just at or slightly below the frequency that matters for certification. For CE compliance, the frequency of the third harmonic should, therefore, be $150 \mathrm{kHz}$, which automatically yields maximum switching frequency of $50 \mathrm{kHz}$, or $16.6 \mathrm{kHz}$ per phase.

Unfortunately, $16.6 \mathrm{kHz}$ falls into the audible range and using this frequency may not be ergonomically feasible. As a compromise, the $25 \mathrm{kHz}$ is chosen for the final application as it is not audible and still it seems to be far enough below the mandated test frequency of $150 \mathrm{kHz}$. Since the initial production is planned for the US market where FCC rules apply (minimum frequency is $450 \mathrm{kHz}$ which is the $6^{\text {th }}$ harmonic of our switching frequency, therefore not critical) the we can be reasonably confident in meeting the required specs without major modifications at the time of regulatory approvals.

\subsection{Inductor design}

Compact high power inductors are difficult to make without specialized equipment. Many manufacturers also offer design services. However, it is still beneficial to go through initial parts of the design in order to define basic inductor parameters to ensure that the final design makes perfect sense for the application.

Requirements for small size dictate use of powder cores. There are many variations available, from iron powder, MPP, Cool $\mu$, etc. each with slightly different characteristics and optimum use.

Considering price and availability in the adequate core size, iron powder cores offer the widest selection. This type of core is available at lowest cost, however, it suffers from 
thermal aging problem. If exposed to increased operating temperature, over time its permeability drops and losses increase causing potentially hazardous situations.

Fortunately, new materials were recently developed, enabling operation of up to $200^{\circ} \mathrm{C}$ which increase capabilities beyond those possible even with ferrite cores. Those are 200C Series High Temperature Powder Cores from Micrometals.

Material designated as -60 was among the first ones available in wide spectrum of shapes and sizes, and it was chosen for our design. For anyone with experience in designing with powder cores, the process is straightforward. Thanks to soft saturation characteristics of powder cores, high accuracy and numerous iterations requiring optimization are not required. This type of cores typically operates in the saturation region where permeability drops to $30-70 \%$ of the initial permeability.

The design starts with finding worst case average inductor current $\left(\mathrm{I}_{\text {Lin }}\right)$ :

$$
I_{\text {in }}=\frac{P_{\text {out }}}{\eta V_{\text {in }(\min )}}=\frac{5500 \mathrm{~W}}{0.96 \cdot 24 \mathrm{~V}}=239 \mathrm{~A}
$$

Output power $\left(\mathrm{P}_{\text {out }}\right)$, efficiency $(\eta)$ and minimum input voltage $\left(\mathrm{V}_{\mathrm{in}(\min )}\right)$ are input data defined in the electrical specification.

In the three phase design, each input inductor will see $1 / 3$ of the total input current, or $\mathrm{I}_{\mathrm{L}}=80 \mathrm{~A}$.

Considering ripple attenuation effects, allowable worst case inductor current ripple can be selected as $30 \%$ of the average inductor current, for $\Delta \mathrm{I}_{\mathrm{L}}=24 \mathrm{~A}$. Peak inductor current $\mathrm{I}_{\mathrm{Lpk}}$ is then

$$
\begin{gathered}
I_{L p k}=I_{L}+\frac{\Delta I_{L}}{2}=92 A \\
\Delta I_{L}=\frac{V_{i n(\min )} \delta}{f_{s w} L} \Rightarrow L=\frac{V_{i n(\min )} \delta}{f_{s w} \Delta I_{L}}
\end{gathered}
$$

Switching frequency $\left(\mathrm{f}_{\mathrm{sw}}\right)$ is $25 \mathrm{kHz}$ and worst case duty cycle $(\delta)$ was calculated as 0.6 . Therefore, inductance of the input inductor is calculated as

$$
L=24 \mu \mathrm{H}
$$

Material -60 was the only $200^{\circ} \mathrm{C}$ material available without long wait times. This is material designed for most common application and can be used in variety of applications, hence wide range of available core sizes. For our design an E305-60 core was selected. The main parameters of the core are:

- Initial (reference) permeability $\mu=55$

- $\quad$ Inductance factor $A_{\mathrm{L}}=222 \mathrm{nH} / \mathrm{N}^{2}$

- Equivalent length of magnetic path $\mathrm{l}_{\mathrm{e}}=18.5 \mathrm{~cm}$

- Equivalent cross section $\mathrm{A}_{\mathrm{e}}=5.62 \mathrm{~cm}^{2}$

- $\quad$ Equivalent core volume $\mathrm{V}_{\mathrm{e}}=139 \mathrm{~cm}^{3}$

Initial number of turns $\left(\mathrm{N}_{\mathrm{i}}\right)$ is calculated as

$$
N_{i}=\sqrt{\frac{L}{A_{l}}}=10.4 \text { turns }
$$


The initial number of turns will later be corrected to account for partial saturation of the core, so it may stay as the decimal number, rather than being rounded up.

Owing to the fact that all major iron powder core manufacturers come from the USA, size parameters and material characteristics are given in the CGS units of measure, rather than in the SI units - cm instead of $m$, Öersted (Öe) instead of A/m, Gauss (G) instead of Tesla (T), etc. Even though equations get to be little more cumbersome, in the end it is easier to work with them than to make double conversions.

Magnetizing force is calculated next:

$$
H=\frac{0.4 \pi N_{i} I_{L p k}}{l_{e}}
$$

Substituting previously listed and calculated values yields magnetizing force

$$
H=65 \ddot{O} e
$$

Figure 35 details soft saturation characteristics of $200^{\circ} \mathrm{C}$ iron powder cores. Permeability change (in \%) is given as function of magnetizing force.

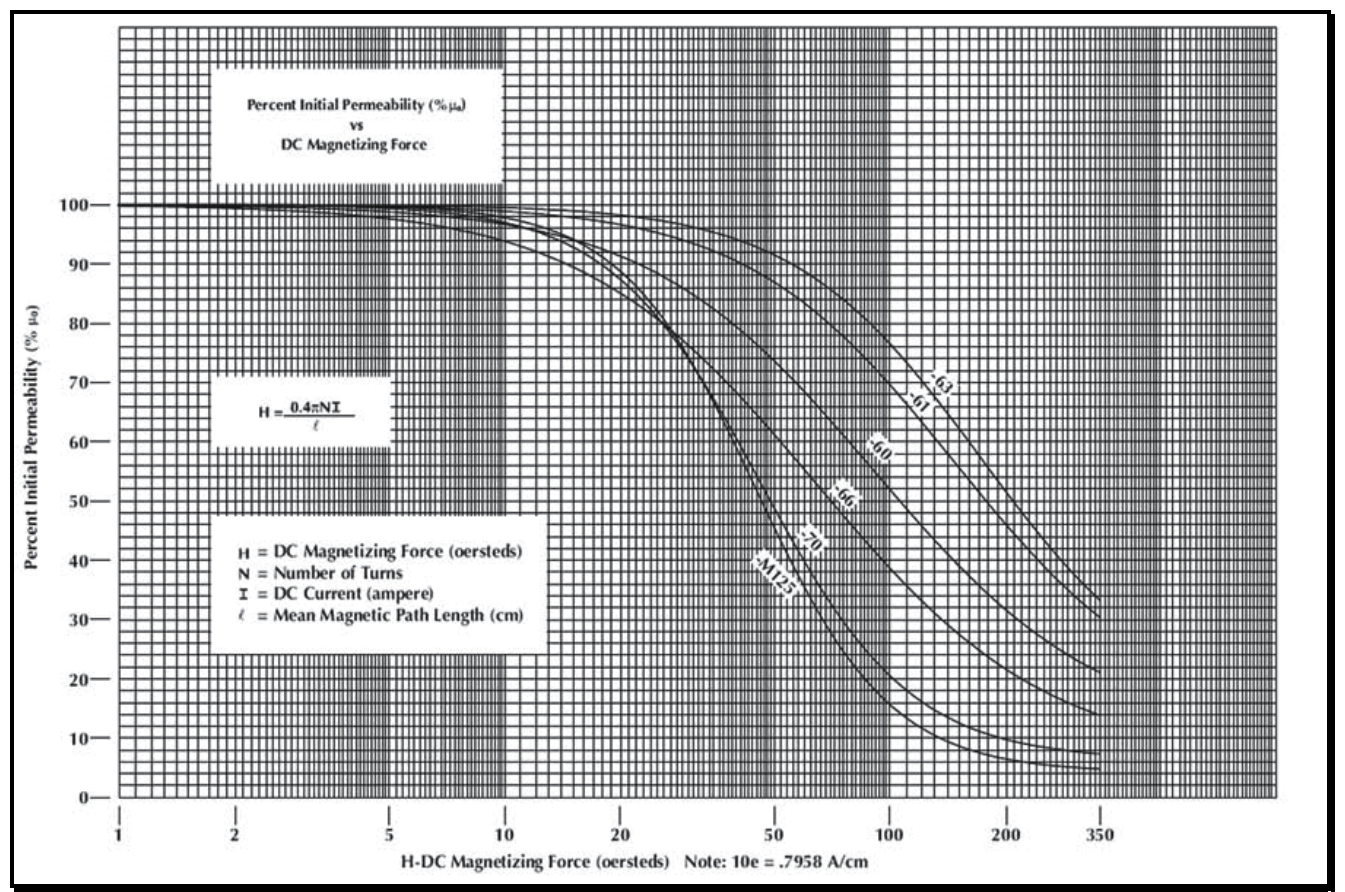

Fig. 35. Permeability change vs. magnetizing force

For magnetizing force of 65 Öe permeability of -60 material will drop to $66 \%$ of the initial permeability. In order to compensate for drop in permeability, initial number of turns $\mathrm{N}_{\mathrm{i}}$ needs to be corrected to get final number of turns $\mathrm{N}$ :

$$
N=\frac{N_{i}}{0.66}=15.76 \text { turns, rounded up to } 16 \text { turns }
$$


In order to confirm feasibility of the selected core, a quick look at losses is required. Based on similar size cores for which the information is available, thermal resistance for this core can be estimated at $\mathrm{R}_{\Theta}=1.5^{\circ} \mathrm{C} / \mathrm{W}$ (assuming some air is being circulated around the inductors). Considering maximum operating ambient of $60^{\circ} \mathrm{C}$, there is about $70^{\circ} \mathrm{C}$ of temperature rise before inductors become too hot for quick safety approvals. Considering the above, our power loss budget is about $47 \mathrm{~W}$ per inductor.

Two main components of inductor loss are core loss and copper loss (in the windings). Core loss is easy to find from the graph showing core loss versus flux density (Figure 36).

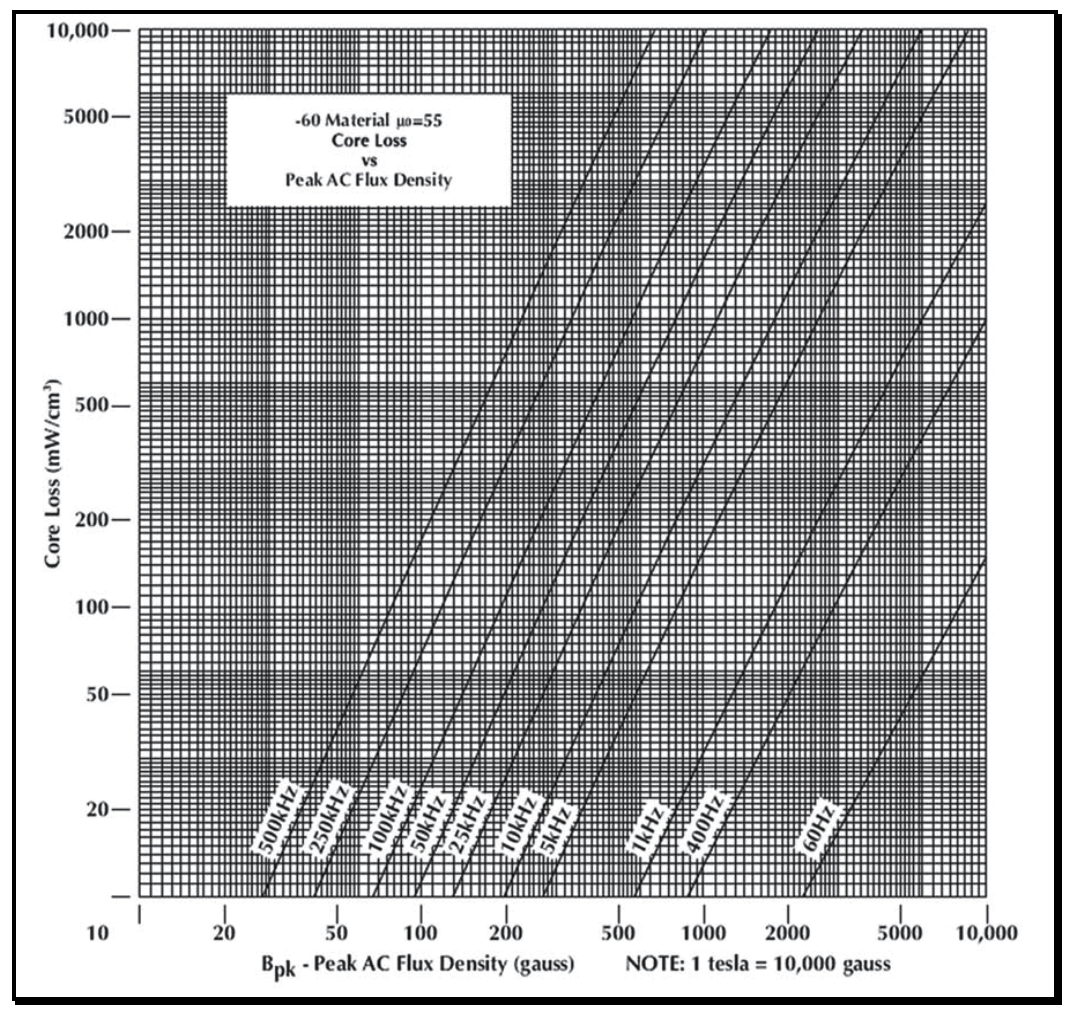

Fig. 36. Specific core loss vs. flux density

In our design, worst case peak flux density is calculated as

$$
B_{p k}=\frac{V_{i n} \delta}{f_{s w} A_{e} N}
$$

Worst case, high power operation will occur when input voltage is $V_{\text {in }}=24 \mathrm{~V}$, output voltage $\mathrm{V}_{\text {out }}=41 \mathrm{~V}$ and resulting duty cycle $\delta=0.41$. substituting these values into Equation 45 will yield peak flux density of $B_{\mathrm{pk}}=44 \mathrm{mT}=440 \mathrm{G}$.

At switching frequency of $25 \mathrm{kHz}$, specific core loss is about $180 \mathrm{~mW} / \mathrm{cm}^{3}$. Considering core volume of $139 \mathrm{~cm}^{3}$, the core loss comes to $25 \mathrm{~W}$. With total power loss budget of $47 \mathrm{~W}$ and core loss of $25 \mathrm{~W}$, copper loss can be as high as $22 \mathrm{~W}$. Reviewing the numbers, the core loss and copper loss are close which indicates adequate inductor design (very often the starting goal in a magnetic design is to make core loss equal to the copper loss). 
Information regarding core type and size, number of turns and power budget was relayed to inductor manufacturer who designs windings based on available conductor type (wire of foil) suitable for their manufacturing process. Photograph of the finished inductor is shown in Figure 37.

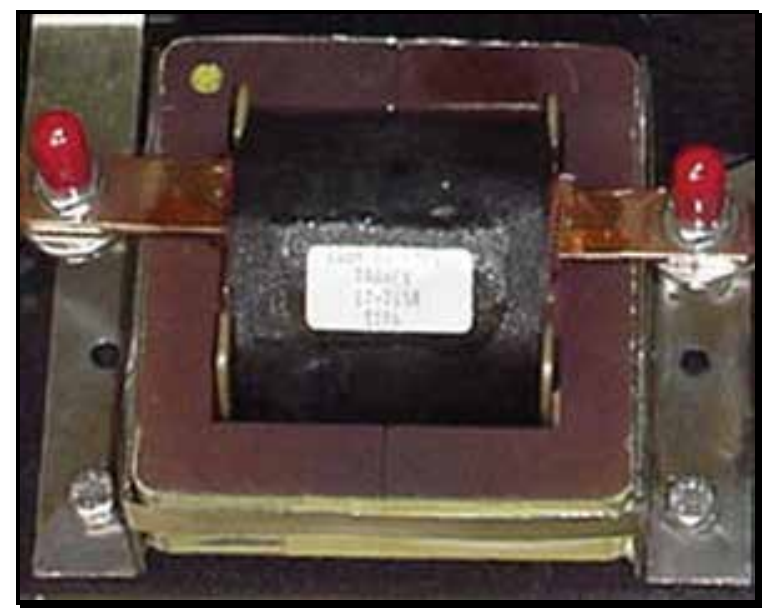

Fig. 37. Photo of the finished input inductor

\subsection{Power switch selection}

Power MOSFETs are the most suitable parts to be used as high frequency switches, thanks to their high switching speed, low cost and low losses. High current MOSFETs are readily available. In high power designs, MOSFET selection needs to be done based on design's ability to dissipate heat generated due to power loss. Switch current waveform is shown in Figure 38 .

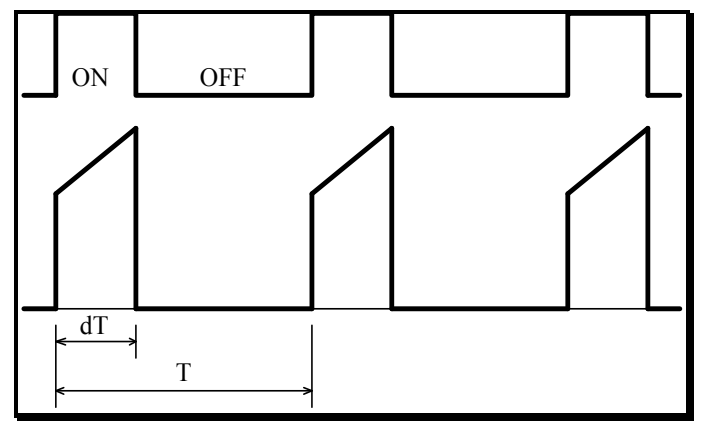

Fig. 38. Switch current waveform

RMS current through the switch in one phase can be calculated as:

$$
I_{s w(R M S)}=\frac{I_{\text {out }}}{1-\delta} \sqrt{\delta\left(1+\frac{\left(\Delta I_{L} / I_{L}\right)^{2}}{12}\right)}
$$

Substituting worst case situation as determined for input inductor calculations $\mathrm{I}_{\text {out }}=150 \mathrm{~A} / 3$ (per phase), $\Delta \mathrm{I}_{\mathrm{L}}=24 \mathrm{~A}, \mathrm{I}_{\mathrm{L}}=80 \mathrm{~A}$ and $\delta=0.41$, switch RMS current is found to be 


$$
\mathrm{I}_{\mathrm{sw}(\mathrm{RMS})}=55 \mathrm{~A}
$$

Low input voltage and low switching frequency indicate that switching loss in power MOSFETs is going to be negligible when compared to the conduction loss due to the high RMS current and $\mathrm{R}_{\mathrm{ds}(\mathrm{ON})}$ characteristic of the part. MOSFET channel resistance, $\mathrm{R}_{\mathrm{ds}(\mathrm{ON})}$ is the parameter we can use in order to minimize the loss in the converter switch.

In order to ensure good thermal management, it was decided to use multiple components in parallel in order to spread generated heat over larger equivalent cooling area. Surface mounted components make it possible to use automated assembly and significantly reduce manufacturing time and errors. D2PAK package, shown in Figure 39 proves to be optimal for the application.

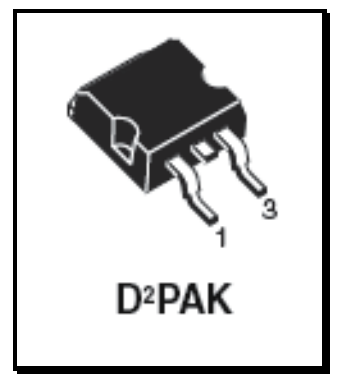

Fig. 39. D2PAK package

After close examination of several usable MOSFETs from International Rectifier, Fairchild Semiconductor, Vishay and ST Microelectronics, an ST part STB160N75F3 was chosen for the application thanks to its low $\mathrm{R}_{\mathrm{ds}(\mathrm{ON})}$ and input capacitance, fast turn-on and turn-off, high maximum operating temperature, low cost and availability on the market. Critical specifications for the MOSFET are:

- Open channel resistance: $\mathrm{R}_{\mathrm{ds}(\mathrm{ON}) 25}=3.7 \mathrm{~m} \Omega \max \left(\right.$ at $\left.25^{\circ} \mathrm{C}\right)$

- $\quad$ Maximum drain-source voltage: $\mathrm{V}_{\mathrm{DS}}=75 \mathrm{~V}$

- $\quad$ Maximum drain current: $\mathrm{I}_{\mathrm{D}}=120 \mathrm{~A}$ (limited by package)

- Input capacitance: $\mathrm{C}_{\mathrm{iss}}=6750 \mathrm{pF}$

- $\quad$ Maximum operating junction temperature: $T_{j}=175^{\circ} \mathrm{C}$

MOSFETs have positive temperature coefficient, indicating that $\mathrm{R}_{\mathrm{ds}(\mathrm{ON})}$ increases with temperature. For STB160N75F3, normalized ON resistance change with temperature is shown in Figure 40.

In order to comply with safety requirements, thermal design will need to ensure that maximum component temperature does not exceed $105^{\circ} \mathrm{C}$. Junction temperature can be estimated to be approximately $20^{\circ}$ higher. Assuming junction temperature of $125^{\circ} \mathrm{C}$, actual operating $\mathrm{R}_{\mathrm{ds}(\mathrm{ON})}$ will be 1.7 times higher than at $25^{\circ} \mathrm{C}$. Therefore, for loss calculations

$$
R_{d s(\mathrm{ON})}=1.7 R_{d s(\mathrm{ON}) 25}=6.3 \mathrm{~m} \Omega
$$

Assuming only one MOSFET per phase, conduction loss would be

$$
P_{c}=R_{d s(O N)} I_{s w(R M S)}{ }^{2}=0.0063 \cdot 55^{2}=19 \mathrm{~W}
$$

This seems excessive considering size of the package and need to dissipate the power in high ambient temperature. In order to keep dissipation per MOSFET low and converter efficiency high, it was decided to use six (6) MOSFETS in parallel for each phase. 


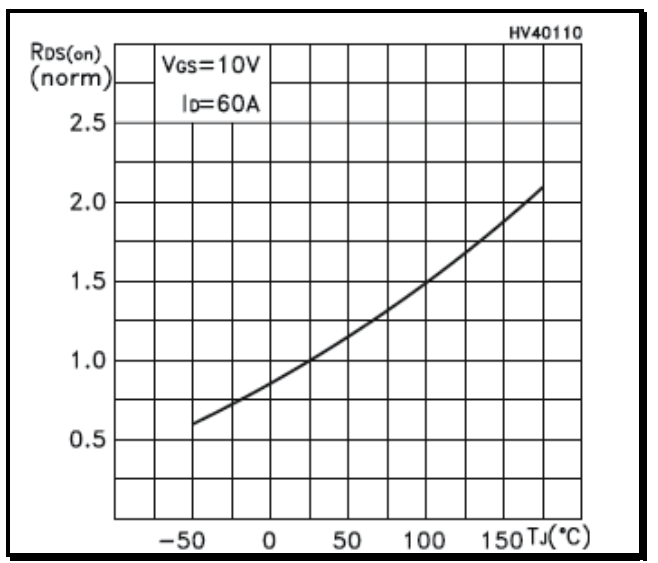

Fig. 40. Normalized ON resistance vs. temperature

\subsection{Rectifier selection}

Reverse recovery time of a diode rectifier is major contributor to power loss in the boost converter's power switch. That loss is directly proportional to switching frequency. Low switching frequency here helps minimize this type of loss. To practically eliminate the loss, Schottky diodes can be used. They will also minimize loss in the diode rectifier.

Average current through the boost rectifier is equal to the load current. Maximum load current is specified as 150A. Split between three phases will yield 50A per phase. In order to ensure healthy margin in the design a 100V Schottky diode from ST Microelectronics was selected. Package is again D2PAK, part number is STPS30SM100S and the most important specifications for the diode are:

- $\quad$ Repetitive peak reverse voltage: $\mathrm{V}_{\mathrm{RRM}}=100 \mathrm{~V}$

- $\quad$ Average forward current $(\delta=0.5): \mathrm{I}_{\mathrm{F}(\mathrm{AV})}=30 \mathrm{~A}$

- Forward voltage drop $\left(\mathrm{I}_{\mathrm{F}}=10 \mathrm{~A}\right.$ and $\left.\mathrm{T}_{\mathrm{j}}=125^{\circ} \mathrm{C}\right): \mathrm{V}_{\mathrm{F}}=560 \mathrm{mV}$

- Maximum operating junction temperature: $\mathrm{T}_{j}=175^{\circ} \mathrm{C}$

In order to ensure adequate cooling with sufficient margins for asymmetrical current sharing, six (6) diodes will be used in parallel. Total power loss per phase can be estimated as

$$
P_{d}=V_{F} \cdot I_{\text {out }} / 3=0.56 \cdot 150 / 3=28 \mathrm{~W}
$$

Diode loss is much higher than MOSFET loss and will be major contributor to overall losses. However, at less than $5 \mathrm{~W}$ per diode, in worst case operating conditions, it will be easily manageable.

\subsection{Output capacitors}

Output filter capacitors are selected based on two criteria: (1) allowable high frequency output voltage ripple at maximum load determines acceptable minimum capacitance and (2) maximum capacitor RMS current determines type and number of capacitors used. Very often this second criteria drives the capacitor selection and minimum capacitance is easier to achieve with modern parts.

Equation 38 defines maximum capacitor RMS current as 


$$
I_{C o R M S(\max )}=\frac{I_{\text {out }}}{(2 n-1) \sqrt{n}}
$$

Output current, $\mathrm{I}_{\text {out }}=150 \mathrm{~A}$

Number of interleaved phases $n=3$

$$
I_{\text {CoRMS }(\max )}=17.3 \mathrm{~A}
$$

The hybrid fuel cell system has lead-acid battery connected at the output and it will help smooth the ripple at high loads. The main concern is, therefore current handling capacity of the output capacitors.

Aluminum electrolytic capacitors VZ series from Nichicon offer low profile, reasonably price and 10000 hours life at $105^{\circ} \mathrm{C}$ temperature rating.

Value of $470 \mu \mathrm{F} / 63 \mathrm{~V}$ has rated RMS current of $640 \mathrm{~mA}$ at $120 \mathrm{~Hz}$. Typically, at higher frequencies capacitor current rating increases and for this capacitor and above $10 \mathrm{kHz}$, frequency multiplier is specified as 1.5, resulting in capacitor's current rating of $960 \mathrm{~mA}$.

In order to satisfy worst case RMS current of $17.3 \mathrm{~A}$ we need minimum of 18 capacitors.

Control circuit, as the name implies, ensures optimum driving of the power stage and provides protections and communications with the outside world. It has the following functions:

- $\quad$ Generation of interleaved PWM signals and MOSFET drivers

- $\quad$ Ensuring stable operation and current sharing between the phases

- $\quad$ Communication with the fuel cell system controller

- Protections:

- Output current limit

- Overvoltage protection

- Reverse current protection

- Overload protection

- Thermal protection

\section{Interleaved PWM signals}

In recent years some dedicated controllers were developed for multiphase applications. Advantages of a highly integrated solution are in simplicity, reliability and shorter development. Disadvantages are that these converters are developed for very specific applications such as PFC or low voltage converters, operation at very high frequencies, lack of flexibility and uncertain future of the part - most semiconductor manufacturers have habit of discontinuing parts if they do not meet sales projections. In other words, if the part does not get designed in a high volume product that results in sales of few million pieces, it is likely that it will be discontinued and replaced with something else. This is the risk that is unacceptable for industrial products that have design life of 10 years or more and being unable to find parts results in very costly redesigns.

Instead of using a dedicated multiphase controller, a safer solution, standard, readily available PWM controller was selected. UCC2581 from Texas Instruments has all the functions that are required. There will be one controller used per phase.

UCC2581 controller has SYNC input, which can be used to synchronize several controllers in order to help reduce EMI. In this application the controller is synchronized to one output of the simple three phase oscillator as shown in the block diagram, Figure 41. 


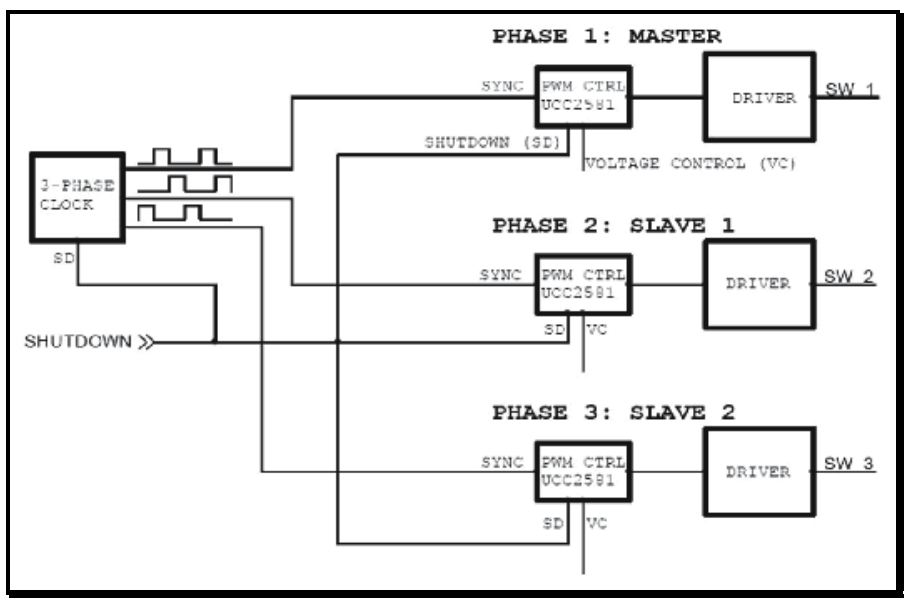

Fig. 41. PWM control block diagram

Another aspect of control can also be seen from the block diagram - current sharing between the three phases will be actively managed in master-slave configuration. In this arrangement, master phase is set to maintain the output voltage regulation and slave phases are designed to closely follow input current of the master slave. This ensures that all three input inductors operate with the same input current, regardless of the load conditions. Even though not the simplest method, the master-slave current sharing offers the most accurate load distribution. Load sharing to within $1 \%$ can typically be expected. This is especially important in high power design where over-rating components carries significant price tag. Schematics of the three phase oscillator is shown in Figure 42.

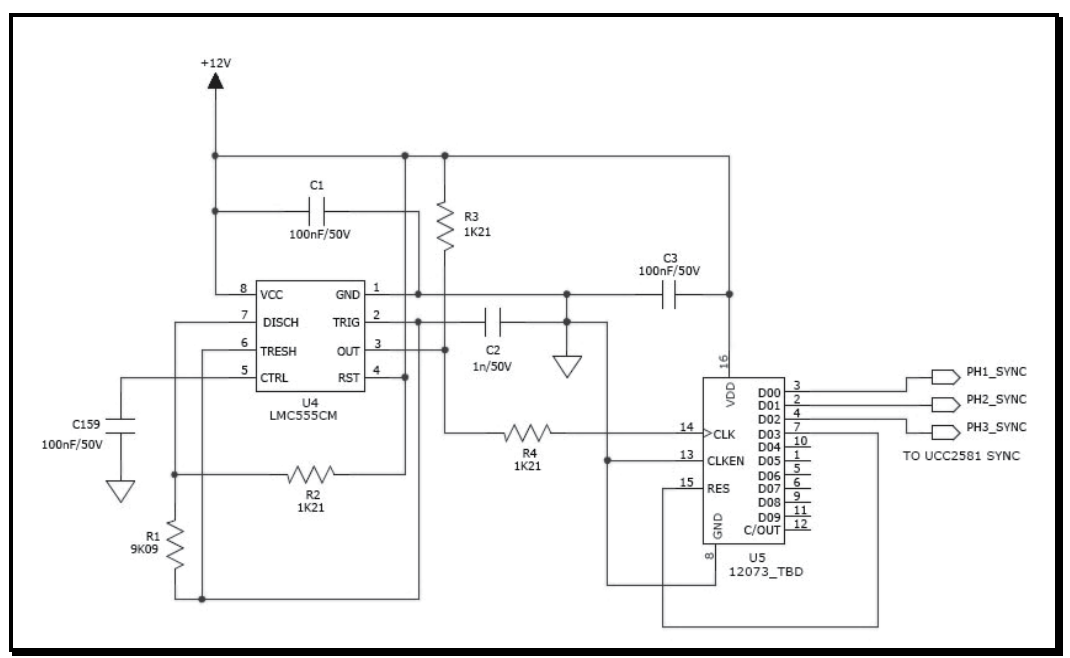

Fig. 42. Schematics of the three phase oscillator

The three SYNC outputs are spaced at $120^{\circ}$ and fed to their respective PWM controllers. This not only synchronizes switching frequencies of the three phases but also interleaves driving pulses equally distributing them over the full switching period. Schematics of an implemented PWM controller is shown in Figure 43. 


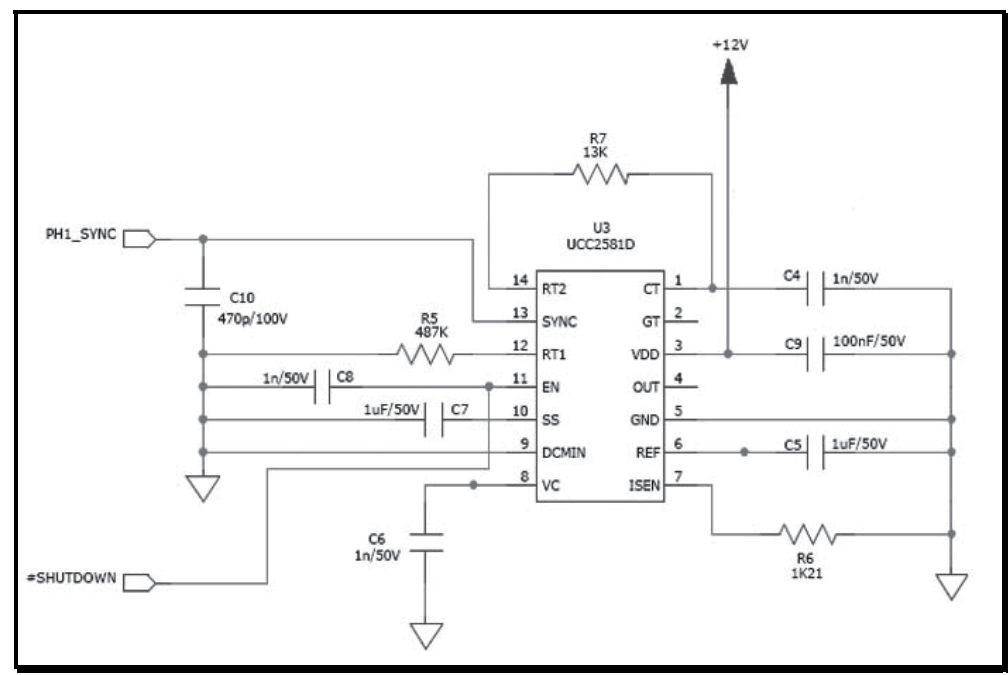

Fig. 43. PWM controller schematics

PWM controller output is fed to a MOSFET driver in order to ensure adequate drive and fast transitions during turn on and turn off of the MOSFETs.

\subsection{Control strategy}

Negative feedback (NFB) loop ensures stable operation of the fuel cell regulator over the full range of operating conditions. For effective control of the fuel cell system, the following variables need to be controlled:

- $\quad$ Output voltage (needs to be adjustable)

- Input current (this is fuel cell output current and also needs to be adjustable)

- Output current (current limit - when the output current reaches certain level, above normal operating current, the regulator needs to switch to the constant current mode operation)

- Current sharing (in master-slave configuration, as previously mentioned, slave phases need to closely follow input current of the master phase).

Every parameter requires its own NFB loop and there will be several error amplifiers (E/A), as illustrated by Figure 44.

Master error amplifiers (E/A) respond to control signal for input current and output voltage (analog inputs). Their outputs are OR-ed together to ensure that, at any point in time, only one error amplifier is controlling the operation, and that is an error amplifier with the lowest output (error) voltage. Third error amplifier (lowest one in Figure 44) sets output current limit and has fixed reference signal. If the output current reaches preset value defined by the reference voltage REF-I_OUT_MAX, its output will become the lowest of the three and output current will be kept constant regardless of the other two variables (ANALOG_I_IN_CTRL and ANALOG_V_OUT_CTRL)

Input current of the master phase is fed as a reference to the two error amplifiers controlling input current of the slave phases (top two E/A Figure 44). Error voltage of the slave E/A becomes control voltage for the slave phases and that ensures very accurate current sharing among all three phases. 


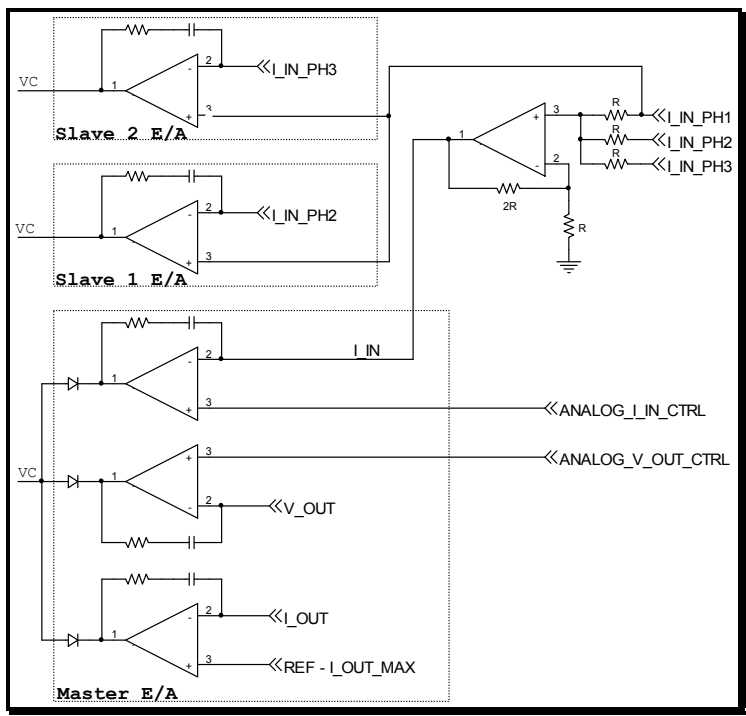

Fig. 44. Simplified error amplifier section

\subsection{Analog control}

The regulator requires two alternative methods of control - manual (local) control and ability to accept analog signals coming from fuel cell controller. This fairly simple circuit is shown in Figure 45.

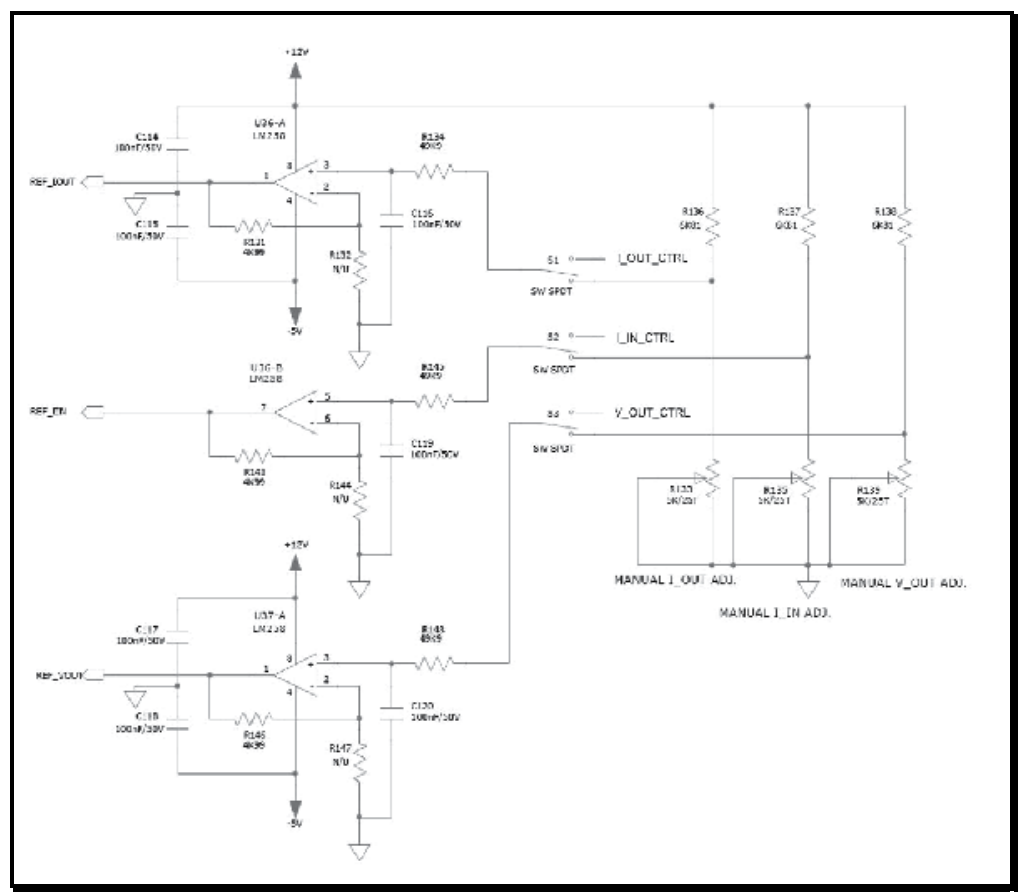

Fig. 45. Analog control section 
Single-Pole-Dual-throw (SPDT) switches are used to select potentiometers for manual control or analog signals. Input and output current and output voltage are parameters that need to be regulated. In finished system only analog signals will be used in order to be able to dynamically change settings depending on the current state of the fuel cell system. In the future it is possible that this will evolve in a digital communication via serial interface.

\subsection{Circuit protections}

As indicated in Chapter 4.2, there are three major protections making sure that regulator always stays within the safe operating area:

- Output current limit

- Overvoltage protection

- Reverse current protection

- Overload protection

- Thermal protection

Output current limit circuit sets absolute maximum output current. When the limit is reached, the regulator will start reducing the output voltage in order to keep output current at the limit. The circuit is designed as a separate error amplifier with fixed reference voltage, as seen in the Figure 44 above. This limit is set at maximum specified output current, $150 \mathrm{~A}$.

Overvoltage protection is derived as a simple comparator monitoring output voltage relative to the fixed reference voltage. The circuit schematic is shown in Figure 46.

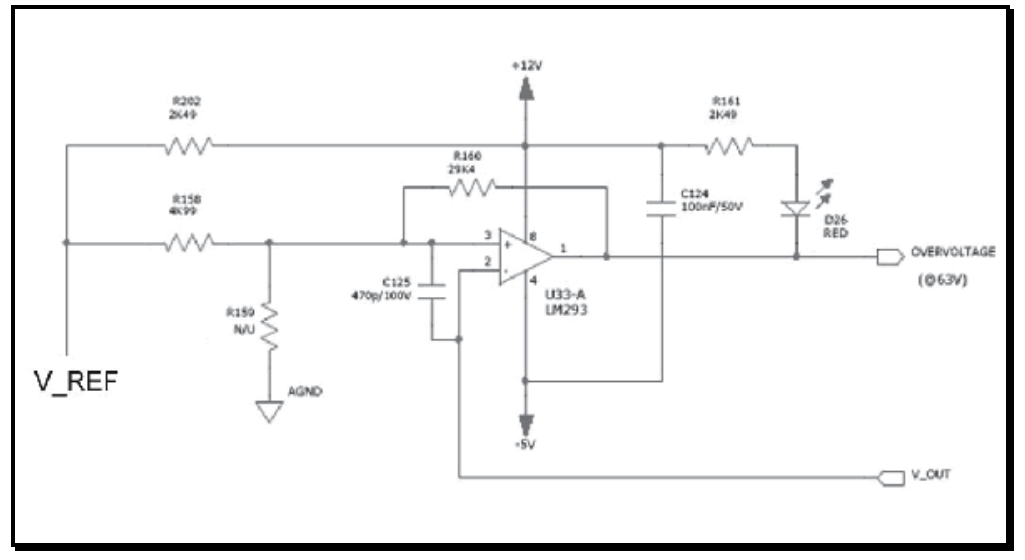

Fig. 46. Overvoltage protection circuit

The limit is set to $63 \mathrm{~V}$. If the output voltage exceeds the limit, unit will shut down and generate fault signal to inform the fuel cell regulator of an abnormal condition.

Reverse current protection is required to prevent current flowing into the fuel cell. This is potentially hazardous condition - the current flowing into the fuel cell will cause Hydrogen pressure and temperature to increase with possibility of damaging fuel cell membrane and overstressing Hydrogen tank. The protection is set to detect negative output current and to shut down the unit while simultaneously flagging the fuel cell controller of an error that requires an immediate attention.

Overload protection circuit reacts when the output current increases above the level of the output current limit (such as in short circuit situation). The goal is to shut down the 
regulator, but also to send signal to the fuel cell controller to quickly turn off input power via the main system contactor. This is necessary as boost converter does not have inherent short circuit protection and overload will cause uncontrolled output current limited only by circuit parasitics.

If there is a short circuit at the output, current will flow through regulator's rectifier diodes, all 18 of them (6 per phase). Surge current rating for the chosen diode (STPS30SM100S) is 530A (non-repetitive for $10 \mathrm{~ms}$ ) and 18 diodes will have theoretical capacity of over 9500A. Even considering less than perfect current sharing, this is way above maximum current that the fuel cell can support in a short period of time, therefore contactor's reaction time of few milliseconds will be sufficiently fast to prevent damage to the regulator and fuel cell.

Finally, thermal protection ensures that the maximum circuit temperature never exceeds safe ratings. Temperature is measured by an NTC resistor (NTC signal) which is located on the IMS board hosting power semiconductors (MOSFET switches and Schottky rectifiers). Considering possibility of very heavy loads at elevated ambient temperature and tight packaging, it is likely that, at times, the regulator circuitry will operate at high temperature. In order to provide adequate warning that critical temperature is being approached, the thermal protection operates as follows:

- When unit's temperature reaches $75^{\circ} \mathrm{C}$, which is the lowest threshold, a warning light will come on and maximum output current will be reduced by $25 \%$. This helps reduce thermal load and slight loss of power gives operator warning without significantly affecting product's functionality.

- If temperature increases to $85^{\circ} \mathrm{C}$ a warning light comes on and power is reduced by $50 \%$ (TEMP_MED signal on the schematics). This more significant power loss indicates to the operator to change operating regime, perhaps to reschedule loads by moving on to lighter loads. The system still operates but functionality is somewhat limited.

- Further increase of temperature, to $95^{\circ} \mathrm{C}$ indicates approaching dangerous levels. Warning light is on and power drops to 25\% (TEMP_MED_HIGH signal). At this point, the vehicle can still move easily but lifting power is severely limited. Operators are advised to allow sufficient time for unit to cool down.

- $\quad$ Finally, if the temperature reaches $100^{\circ} \mathrm{C}$ a shutdown signal is generated (TEMP_HIGH) and the regulator immediately stops. Thanks to thesystems storage battery, the vehicle can still move for a limited time, which is sufficient to complete the operation and relocate to a safe location.

Schematics of the thermal protection circuit is shown in Figure 47.

As the temperature of the unit starts going down, the regulator will be first enabled to work with $25 \%$ of power and then slowly the available power will increase to $50 \%, 75 \%$ and full power $(100 \%)$, when temperature falls $3-5^{\circ} \mathrm{C}$ below the respective threshold.

\section{Test results}

The prototype unit was built to verify circuit and demonstrate regulator's operation. It was made in the form that resembles form factor of the final product. This will result in more accurate measurements than if a typical laboratory breadboard prototype was used. The prototype of the three phase boost fuel cell regulator is shown in Figure 48. 


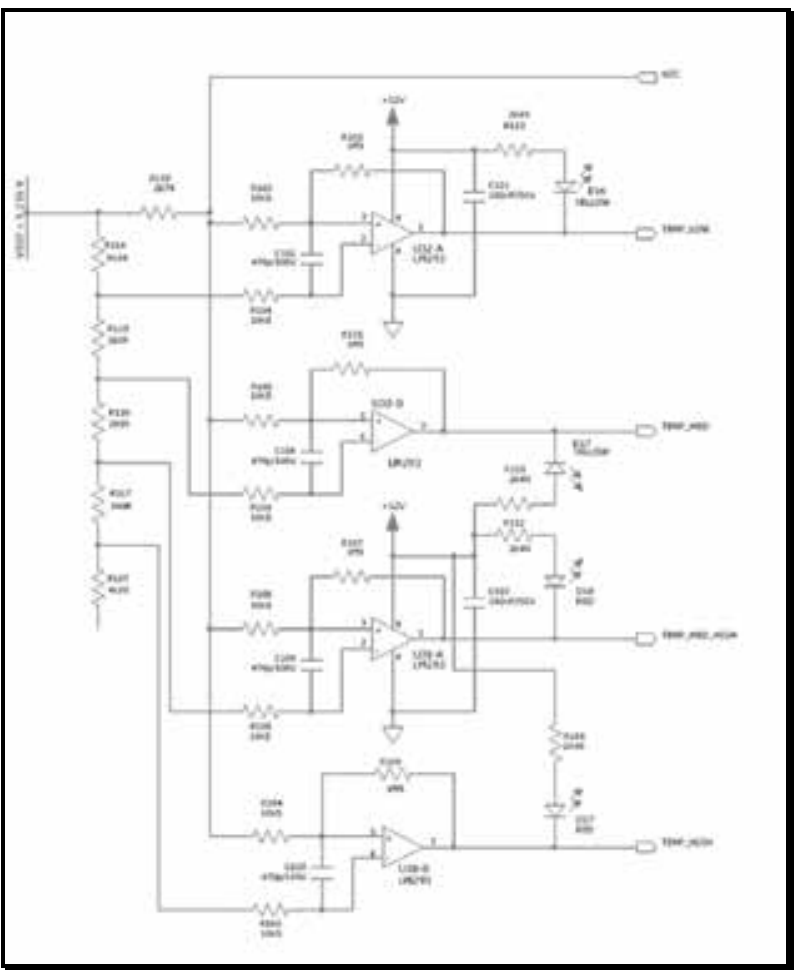

Fig. 47. Thermal protection circuit

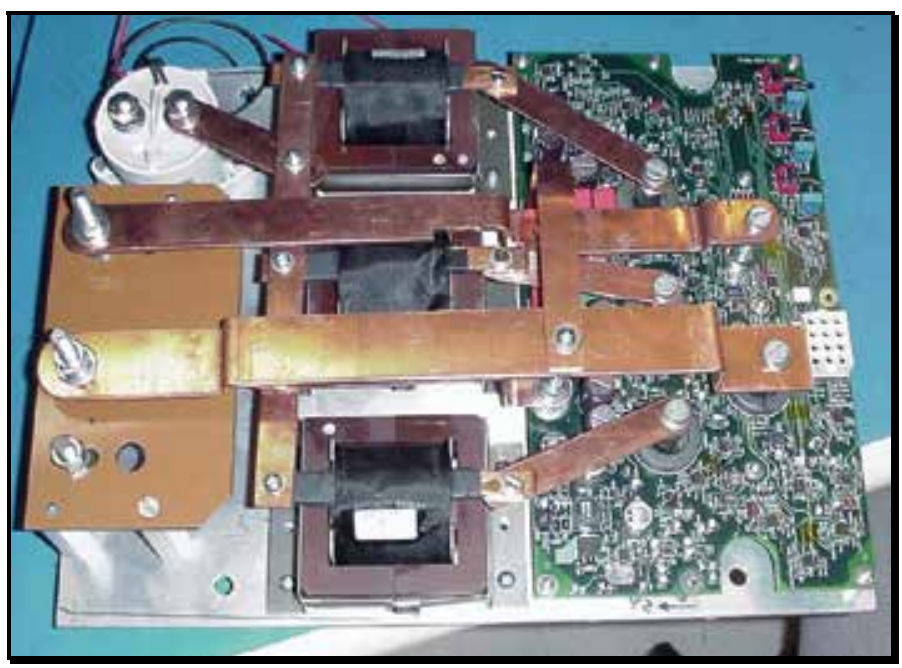

Fig. 48. Photograph of the prototype unit

Base plate of the prototype is a heatsink hosting all the major parts of the regulator. Three input inductors occupy central location. Control board is located on the right side and underneath the board (not visible in the picture) is an IMS board with power semiconductors. 


\subsection{Measurements}

The converter was tested over the full operating range. There were no significant problems found. Some improvements are possible and they will be considered for the future work. They will be described in more details later. Most importantly, testing confirmed that input inductors perform adequately, efficiency meets requirements and circuit waveforms are clean indicating low level of electromagnetic emissions.

For the waveforms captured below, the converter operated with the following nominal conditions (which are representative of the real operation in a fuel cell system):

- Input voltage: $28 \mathrm{~V}$

- $\quad$ Output voltage: $41 \mathrm{~V}$

- $\quad$ Input current: 149.8A

- $\quad$ Output current: 100A

In this mode of operation efficiency was calculated as $97.7 \%$ which is an excellent number, in compliance with the original specification requirement.

Input inductor current of each individual phase is shown in Figure 49.

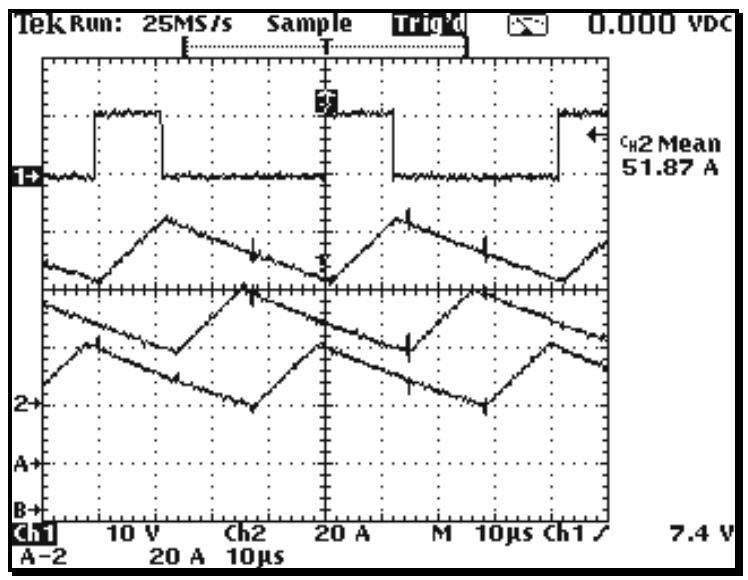

Fig. 49. Input inductor current waveforms of each individual phase

The upper waveform shows gate signal of the Phase 1 MOSFET, which is used as a timing reference. Input inductor current of Phase 2 and Phase 3 is shifted by $120^{\circ}$ and $240^{\circ}$, respectively. Peak-to-peak value of the current is $\sim 20 \mathrm{~A}$, (worst case ripple current of $24 \mathrm{~A}$ ).

Regulator's input current is sum of the three input inductor currents. The waveform is shown in Figure 50.

The effects of ripple attenuation are clearly visible: peak-to-peak input current ripple is less than $4 \mathrm{~A}$, compared to $20 \mathrm{~A}$ for each individual phase. The waveform is very clean indicating stable operation.

The input current ripple being clean, low in amplitude and having $75 \mathrm{kHz}$ frequency is very benign and easy to deal with. A small capacitance at the input of the regulator will further reduce it without stressing the capacitors. Four capacitors, identical to those used in the output filter $(470 \mu \mathrm{F} / 63 \mathrm{~V})$ were added and input current ripple further reduced, to $~ 1 \mathrm{App}$ (Figure 51). 


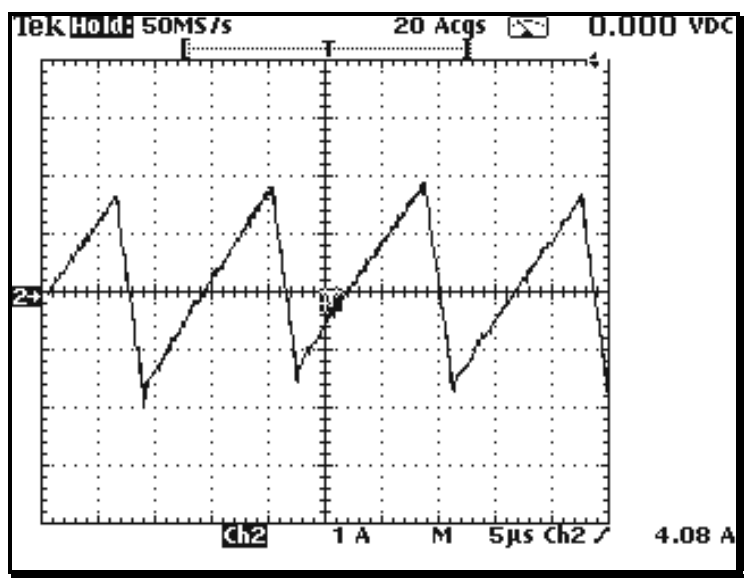

Fig. 50. Input current waveform

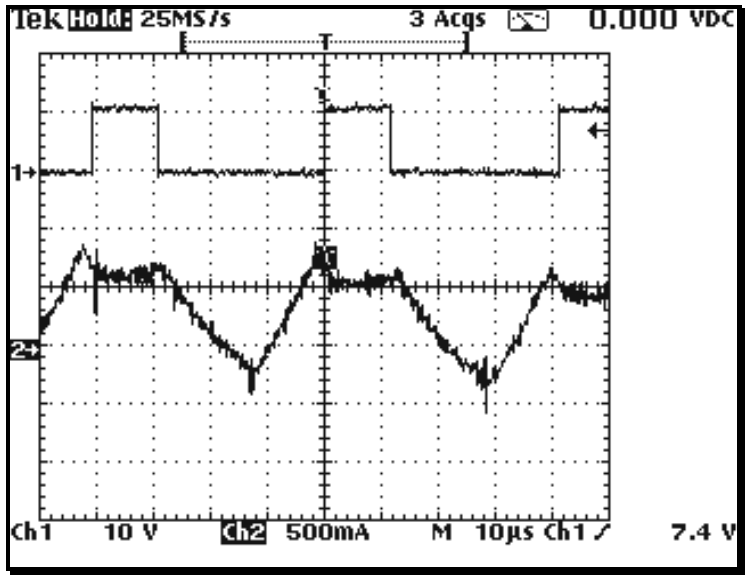

Fig. 51. Input current ripple with $4 \times 470 \mu \mathrm{F}$ filter capacitance

Top waveform is again Phase 1 drive signal. By adding a small (for this power and current level) capacitance $(1,880 \mu \mathrm{F})$ across the input terminals, input ripple current is now reduced to $0.7 \%$ of the input current and is deemed perfectly acceptable for use with fuel cells which are normally very sensitive to the ripple content (typical spec for the ripple current is an RMS value of $1 \%$ or less).

Output current ripple was measured under the same operating conditions. Peak-to-peak value was approximately $0.5 \mathrm{~A}$, which is an excellent result. Waveform of the output current ripple is show in Figure 52.

This level of filtration is achieved with only $8460 \mu \mathrm{F}$ of output capacitance (18 capacitors of $470 \mu \mathrm{F}$ each). This is an excellent figure ensuring high quality battery charging and maintenance and no any negative effect on the load. 
Finally, the conversion efficiency was calculated over the wide range of output power, and the plot is shown in Figure 53.

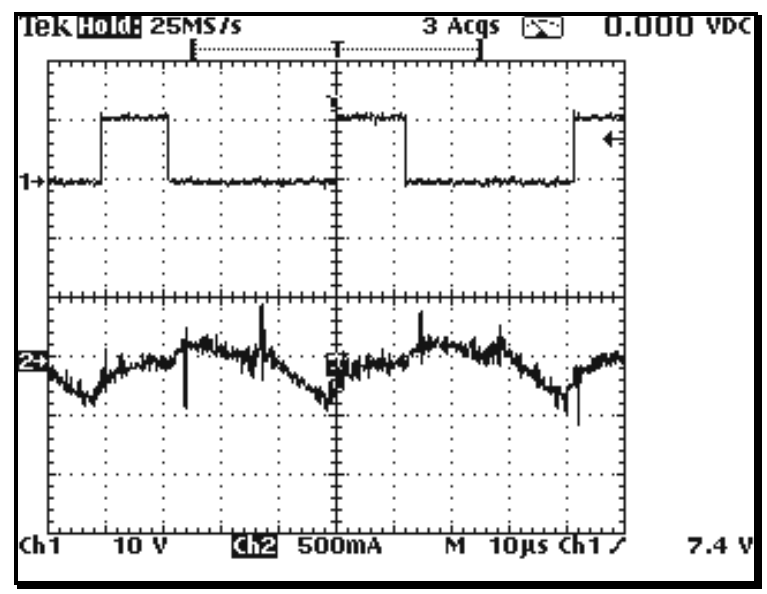

Fig. 52. Output current ripple

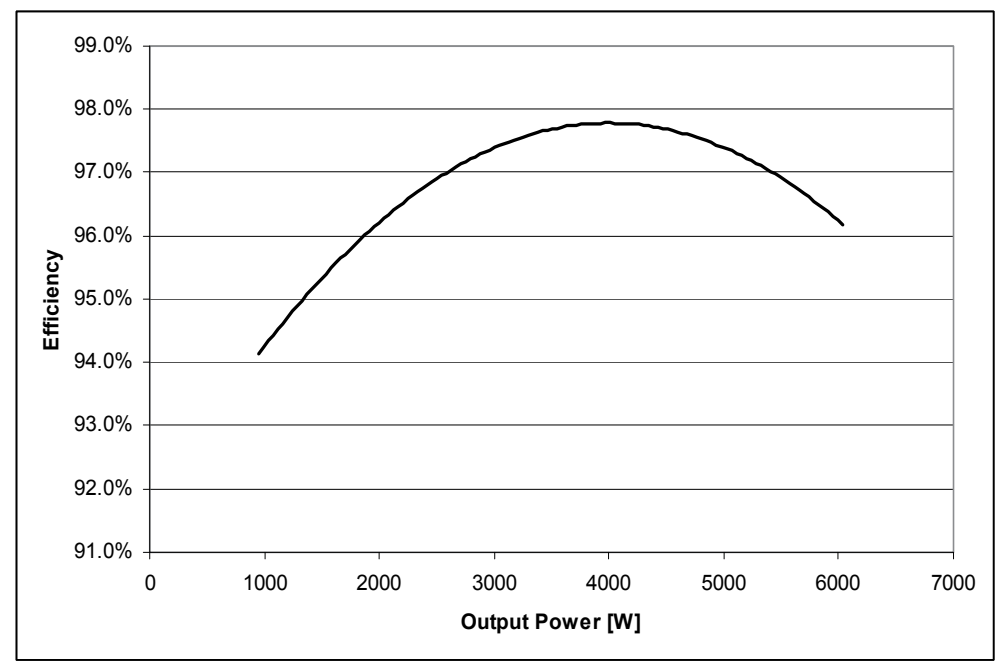

Fig. 53. Efficiency plot

Specification (Section 2.1) mandates efficiency of $94 \%$ minimum at $2 \mathrm{~kW}$ output power and $96 \%$ above $2.5 \mathrm{~kW}$. As the efficiency plot illustrates, this requirement is met and exceeded by a reasonable margin. 


\section{Future work}

During development and evaluation testing of the prototype, certain aspects were considered for possible improvement. Future work will address the following:

Synchronous rectification for increased efficiency. Replacing Schottky rectifier diodes with synchronously driven MOSFETS should, at least in theory, further reduce losses by substituting diode conduction loss $\left(\mathrm{V}_{\mathrm{F}} \cdot \mathrm{I}_{\text {out }}\right)$ for MOSFET conduction loss $\left.\left(\mathrm{R}_{\mathrm{ds}(\mathrm{on})} \cdot \mathrm{I}_{(\mathrm{RMS})}\right)^{2}\right)$. This requires more thorough analysis than simple component replacement, but the control circuit is designed to allow synchronous rectification, by providing complementary aoutputs.

Current sharing circuit also requires detailed analysis in order to ensure equal loading of all three phases during dynamic load changes. In order to perform the evaluation, a better understanding of the nature of the real life load is required. Relevant information is expected to be acquired during prototype testing in the field.

Circuit response to fast current transients will also need to be evaluated during field tests, once the typical values and operating regime is established.

Accuracy of current measurement is critical to ensure safe and reliable operation of the fuel cell, but also for regulator's operation. Measuring high DC current is quite a challenge, especially when the circuit needs to have very low cost. Proposed circuit based on a Hall effect sensors, but detailed evaluation over the wide load and temperature changes is required.

Microprocessor control shows promise of simplifying the circuit complexity by integrating supervisory functions of the regulator. Digital communication via serial interface will also be considered however, this aspect will be mainly driven by requirements and capabilities of the fuel cell controller, who is on the other end of the communication link.

Finally, digital control loop may also make sense in order to simplify the circuit and offer some unique benefits such as adaptive feedback and active current sharing. Development of a digital control loop is probably the most uncertain at the moment, considering state of the art and required multidisciplinary support.

\section{Conclusions}

The boost converter is one of the most commonly used power converter topologies covering wide range of input and output voltages, power levels and applications. Development of high performance and low cost semiconductors helped commercialize multiphase topologies offering multiple benefits at only a small price premium.

This paper addresses two of the most critical aspects of a multiphase boost converter: (1) input current ripple and (2) output capacitor RMS current. The basic equations for both parameters are derived in the first part of the paper. Building on this work a method for optimization of the number of phases is outlined in the second part.

By analyzing one practical application - a $5 \mathrm{~kW}$ fuel cell regulator, interesting and somewhat surprising conclusion is reached: a three-phase converter operates with lower stress than an equivalent four-phase design. Simply increasing a number of phases does not always yield reduced component stress.

The fuel cell regulator has been thoroughly tested and some critical waveforms are shown in the last section as a practical illustration of the work done. 


\section{References}

B. Fahimi, "Automotive Fuell Cell Power Electronic Converters", IEEE APEC Conference Seminar workbook, Vol. 3, February 2007.

B. Sasic, M. Zivanov, L. Nagy, M. Lazic, "Power Regulator Design for Fuel CellApplications", Electronics Journal, Vol. 11, No. 1-2, 2007, pp. 31-35.

B. Sasic, M. Zivanov, M. Lazic, "Design of a Multiphase Boost Converter for HybridFuel Cell/Battery Power Sources", Proc. of the XIV International Simposium on Power Electronics, Ee2007, December 2007, pp 1-5.

D. Liu and H. Li, "A ZVS Bi-Directional DC-DC Converter for Multiple Energy StorageElements", IEEE Transactions on Power Electronics, Vol. 21, No. 5, September 2006, pp.1513-1517

D. Liu at al., "Design of a $6 \mathrm{~kW}$ Multiple-Input Bi-Directional Dc-Dc Converter WithDecoupled Current Sharing for Hybrid Energy Storage Elements", Proc. IEEE APECConference, February 2007, pp. 509-513.

J. Betten and R. Kollman, "Interleaving DC/DC Converters Boost Efficiency and Voltage", EDN Magazine, pp. 77-86, October 13, 2006.

J. Gavlik, “Fuel Cell Basics", Nuts and Volts magazine, May 2010, pp 47-55

J. L. Duarte, M. Hendrix and M. G. Simoes, "Three-Port Bidirectional Converter for

Hybrid Fuel Cell Systems", IEEE Transactions on Power Electronics, Vol. 22, No. 2, March2007, pp. $480-487$

J. Tsai et al., "Interleaving Phase Shifters for Critical-Mode Boost PFC", IEEE Transactions on Power Electronics, Vol. 23, No. 3, pp. 1348-1357, May 2008.

K. Jin, X. Ruan, " Hybrid Full Bridge Three-Level LLC Resonant Converter - A Novel DC-DC Converter Suitable for Fuel-Cell Power System", IEEE Transactions on Industrial Electronics, Vol. 53, No. 5, October 2006, pp. 1492-1503.

M. O'Loughlin, "Advantages of Interleaved Boost Converters for PFC", EDN Magazine,March 30, 2006, pp. 75-78.

M. Zhang, M. Jovanovic, F. Lee, "Analysis and Evaluation of Interleaving Techniques in Forward Converters", IEEE Transactions on Power Electronics, Vol. 13, No. 4, Luly 1998, pp. 690-698.

N. D. Benavides and P. L. Chapman, "Mass-Optimal Design Methodology for DC-DCConverters in Low-Power Portable Fuel Cell Applications", IEEE Transactions on PowerElectronics, Vol. 23, No. 3, May 2008, pp. 1545-1555

S. R. Moon at al., "Multiphase Isolated Dc-Dc Converters for Low-Voltage High-PowerFuel Cell Applications", Proc. IEEE APEC Conference, February 2007, pp. 101-1016.

T. Nussbaumer, M. Baumann, J. Kollar, “Comprehensive Design of a Three-PhaseThree-Switch Buck-Type PWM Rectifier", IEEE Transactions on Power Electronics, Vol. 22,No. 3, March 2007, pp. 551-562

X. Kong and A. M. Khambadkone, "Analysis and Implementation of a High Efficiency,Interleaved Current-Fed Full Bridge Converter for Fuel Cell System", IEEE Transactions on Power Electronics, Vol. 22, No. 2, March 2007, pp. 543-550

Y. Yang and M. Jovanovic, "Interleaved PFC Boost Converter with Intrinsic Voltage-Doubler Characteristic", Proc. IEEE Power Electronics Specialist Conference (PESC), 2006. 
Z. Jiang and R. A. Dougal, "A Compact Digitally Controlled Fuel Cell/Battery HybridPower Source", IEEE Transactions on Industrial Electronics, Vol. 53, No. 4, August 2006, pp.1094-1104

Micrometals, " $200^{\circ} \mathrm{C}$ Series - High Temperature Powder Cores For PowerApplications", Databook, 2007. 


\title{
Non-Isolated High-Gain DC-DC Converter Using Charge Pump and Coupling Inductor
}

\author{
Kuo-Ing Hwu and Yeu-Torng Yau \\ National Taipei University of Technology \\ Department of Electrical Engineering
}

Taiwan

\section{Introduction}

As generally acknowledged, the high-gain DC-DC converter is widely used in the sustainable energy system as the front-stage of the DC-AC converter. Therefore, it is indispensable for low voltage to be boosted to high voltage. In general, the boost converter or the buck-boost converter is widely used in such applications. However, it is not easy for such converters to achieve high voltage ratio. In theory, the voltage ratios of these two converters can reach infinity, but in actuality about three or four, limited by parasitic component effect and controller capability. Consequently, if the voltage ratio of the converter is desired to be over five, then two-stage converter based on the boost converter or the buck-boost converter is utilized, or different converter topologies [1-18] are created.

In [1-10], the Luo converter and its derivatives are presented, whose voltage lift technique is similar to that of the Cuk converter or the SEPIC converter, based on the energy transfer from one inductor via the intermediate capacitor then to the other inductor. Therefore, the transferred energy is mainly determined by the capacitance, thus causing the current stress on the capacitor to be serious. In [11][12], the voltage-boosting converter with very high voltage ratio also uses a capacitor as an energy-transferring medium, similar to the behavior of the Cuk converter or the SEPIC converter, and hence the current stress on the capacitor is also serious. In [13], the voltage-boosting converter, specified with input voltage, output voltage and rated output current being $24 \mathrm{~V}, 200 \mathrm{~V}$ and $2 \mathrm{~A}$, respectively, is presented. Such a converter combines the characteristics of the boost converter and the characteristics of the bootstrap scheme to achieve voltage boosting. The higher the voltage ratio is, the more the number of bootstraps and hence the more the number of diodes and capacitors. However, the surge current occurs as the energy is transferred via large capacitance, and hence the value of the capacitor can not be too large and the corresponding equivalent series resistance (ESR) is relatively large. In [14], the voltage-boosting converter has the voltage ratio of $1 /(1-$ 2D) in the continuous conduction mode (CCM), where $\mathrm{D}$ is the duty cycle of the main switch. And as compared with the boost converter, this converter is complicated due to four switches required. In [15], the KY converter is presented, but the maximum voltage ratio of such a converter is only two. As for [16-18], the coupled-boost converter is presented, which uses a coupling inductor as an energy-transferring medium. In [18], this converter has the voltage ratio of $1+\mathrm{nD} /(1-\mathrm{D})$. However, in this converter, suppressing the voltage spike created due to the leakage inductance of the coupling inductor is taken into account by 
adding an active voltage-clamping circuit which pumps part of the leakage inductance energy to the input. However, for the multi-phase to be considered, the more the number of phases is, the more the number of active voltage-clamping circuits.

Consequently, a new voltage-boosting converter, combining the charge pump and the coupling inductor, is presented herein, together with a passive voltage clamping circuit. There are four main merits in this converter. The first is this converter with high voltage ratio required is simpler in structure than any converter mentioned above. The second is that the primary inductor is magnetized under double the input voltage, thereby causing the input current to be reduced and hence the efficiency to be improved at light load, which is similar to the behavior of the KY converter [19]. The third is that the passive voltageclamping circuit pumps part of the energy stored in the leakage inductance to the output. The four is that, for the multi-phase to be considered, if the number of phases is $\mathrm{N}$, then only additional N-1 diodes are added. However, there is mainly one demerit in this converter. Since there is one right half-plane zero, the corresponding phase margin is reduced and hence the high-performance control of this converter is not so easy to obtain. In this paper, some mathematical derivations, and simulated and experimental results are offered to demonstrate the effectiveness of the proposed voltage-boosting converter topology.

\section{Proposed converter configuration}

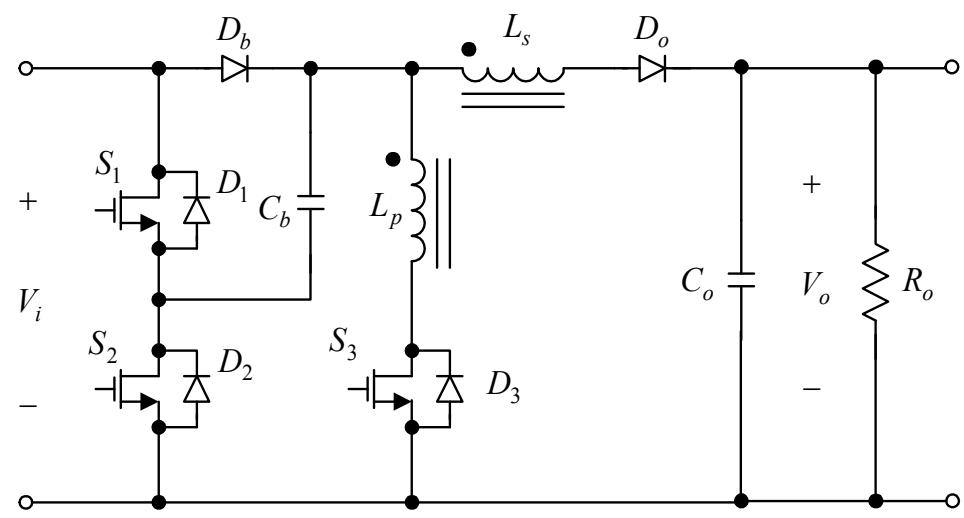

Fig. 1. Proposed voltage-boosting converter without leakage inductance considered.

Fig. 1 shows the proposed voltage-boosting converter. Such a converter contains two cells. One is the charge-pumping cell and the other is the inductance-coupling cell. The former consists of two MOSFET switches $S_{1}$ and $S_{2}$ with two body diodes $D_{1}$ and $D_{2}$ connected in parallel respectively, one diode $D_{b}$, and one capacitor $C_{b}$. The latter is comprised of one main switch $S_{3}$ with one body diode $\mathrm{D}_{3}$ connected in parallel, and one coupling inductor made up of two inductances $\mathrm{L}_{\mathrm{p}}$ and $\mathrm{L}_{\mathrm{s}}$, which are coupled together and put at the primary and the secondary, respectively, with the turns ratio $n$ set to $N_{s} / N_{p}$, where $N_{s}$ is the number of turns in the secondary winding and $\mathrm{N}_{\mathrm{p}}$ is the number of turns in the primary winding. The remainder are one output diode $D_{o}$, one output capacitor $C_{o}$, and one output resistor $R_{o}$. However, there is the leakage inductance existing in this coupling inductor, especially for the leakage inductance $L_{L K}$ at the primary, as shown in Fig. 2. Consequently, in Fig. 3, one passive voltage-clamping circuit, containing one inductor $\mathrm{L}_{\mathrm{sn}}$, one capacitor $\mathrm{C}_{\mathrm{sn}}$, and one diode $\mathrm{D}_{\mathrm{sn}}$, is added to this converter, so as to avoid the voltage spike occurring due to $\mathrm{L}_{\mathrm{LK}}$ and hence destroying the MOSFET switch $\mathrm{S}_{3}$ eternally. Besides, if the multi-phase concept is 
applied to the proposed converter, say, N-phase, then the required passive voltageclamping circuit is the same as that for the single-phase converter except that the number of additional diodes $\mathrm{D}_{\mathrm{sn}}$ is $\mathrm{N}-1$.

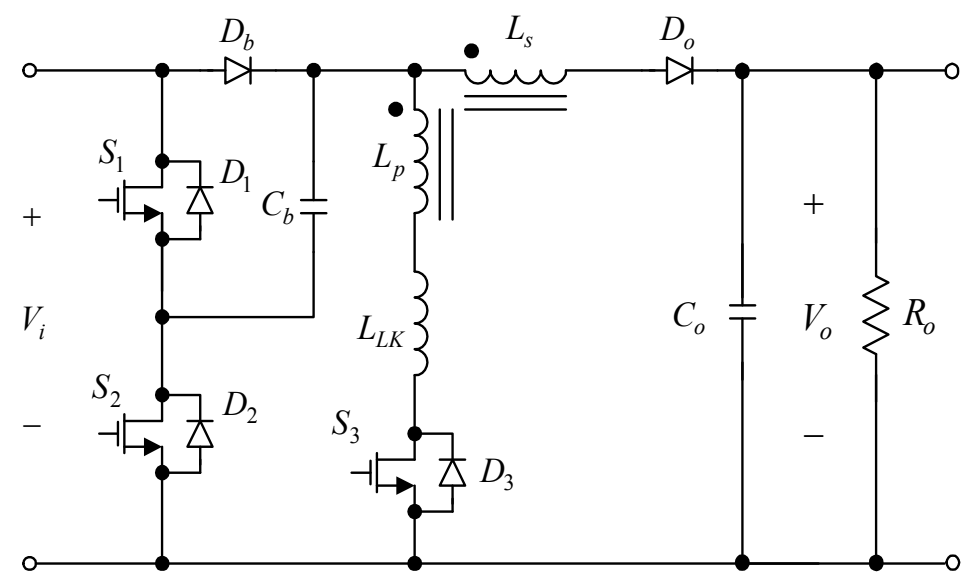

Fig. 2. Proposed voltage-boosting converter with leakage inductance considered.

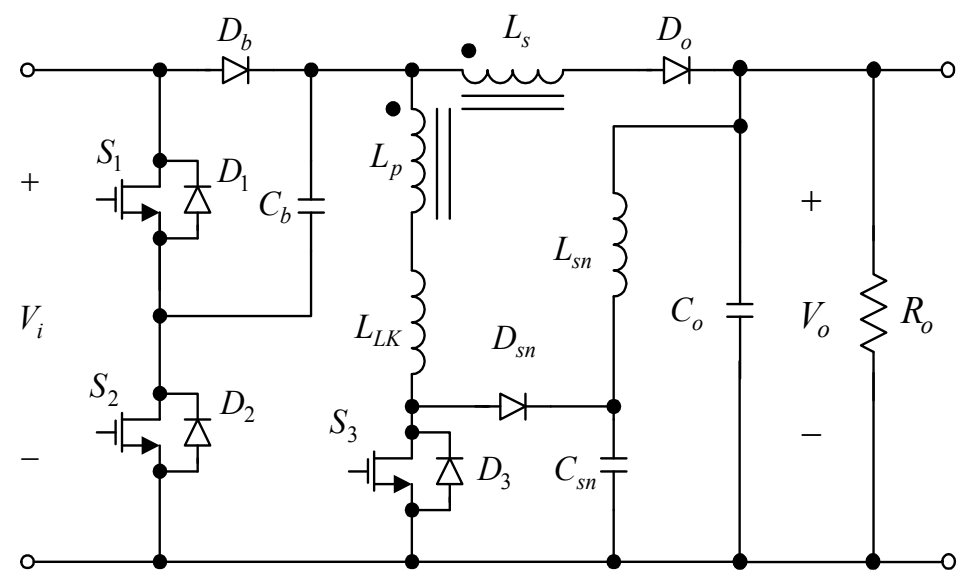

Fig. 3. Proposed voltage-boosting converter with passive voltage-clamping circuit considered.

\section{Basic operating principles}

Before this section is taken up, it is assumed that the voltage across any MOSFET or diode during the turn-on interval is negligible, there are no blanking times between $S_{1}$ and $S_{2}$, the voltage across the capacitor $\mathrm{C}_{\mathrm{b}}$ is equal to $v_{i}$, and the operating mode of this converter is in CCM. As shown in Fig. 4, where $T_{s}$ is the switching period and the gate driving signals $M_{1}$, $M_{2}$ and $M_{3}$ are used to drive $S_{1}, S_{2}$ and $S_{3}$ respectively, the turn-on type of three MOSFET switches is (D, 1-D, D), where $D$ is for $S_{1}$ and $S_{3}, 1-D$ is for $S_{2}$, and $D$ is the duty cycle of the pulse-width-modulated (PWM) control signal for $S_{1}$. First of all, the basic operating principles for the proposed converter without the passive voltage-clamping circuit are described, and next the basic operating principles of the proposed passive voltage-clamping circuit are illustrated. There are two modes for the former and two modes for the latter. 


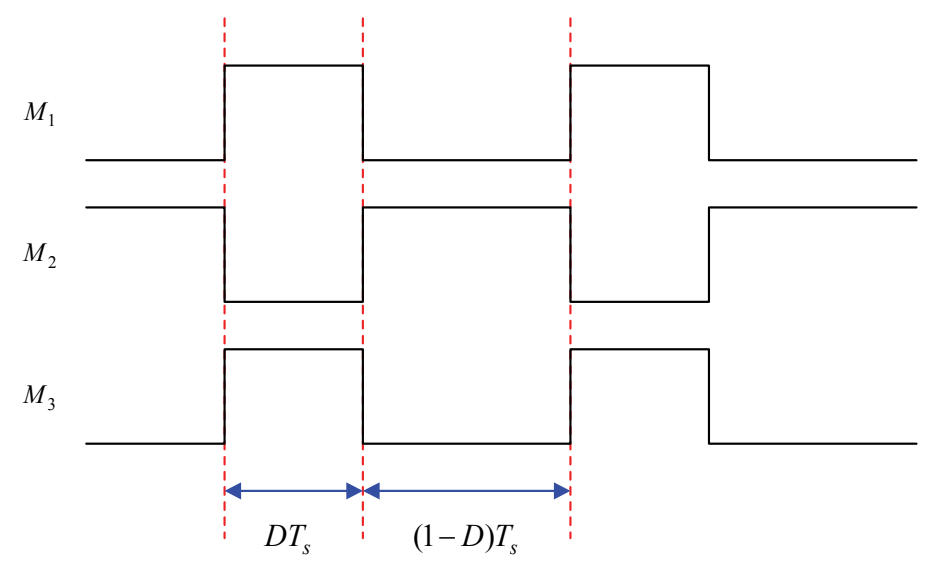

Fig. 4. Ideal timing sequence of gate driving signals $M_{1}, M_{2}$ and $M_{3}$ to drive $S_{1}, S_{2}$ and $S_{3}$ respectively, without blanking times considered.

\section{A. Basic operating principles of converter}

1) Mode 1: In Fig. 5, $S_{1}$ and $S_{3}$ are turned on, but $S_{2}$ is turned off. There are two power flows in this mode. One is from the input through $S_{1}$ via $C_{b}$ and then to $L_{p}, S_{3}$ and the ground. The other is from $\mathrm{C}_{\mathrm{o}}$ to the ground. Therefore, the voltage across $\mathrm{L}_{\mathrm{p}}$ is the input voltage $v_{i}$ plus the voltage $v_{i}$ across $\mathrm{C}_{\mathrm{b}}$, thereby causing $\mathrm{L}_{\mathrm{p}}$ of the coupling inductor to be magnetized. Besides, $C_{b}$ is discharged. Also, $C_{o}$ releases energy into the output. And hence, the corresponding differential equations are:

$$
\left\{\begin{array}{l}
L_{p} \frac{\partial i_{p}}{\partial t}=2 v_{i} \\
C_{o} \frac{\partial v_{o}}{\partial t}=\frac{-v_{o}}{R_{o}} \\
i_{i}=i_{p}
\end{array}\right.
$$

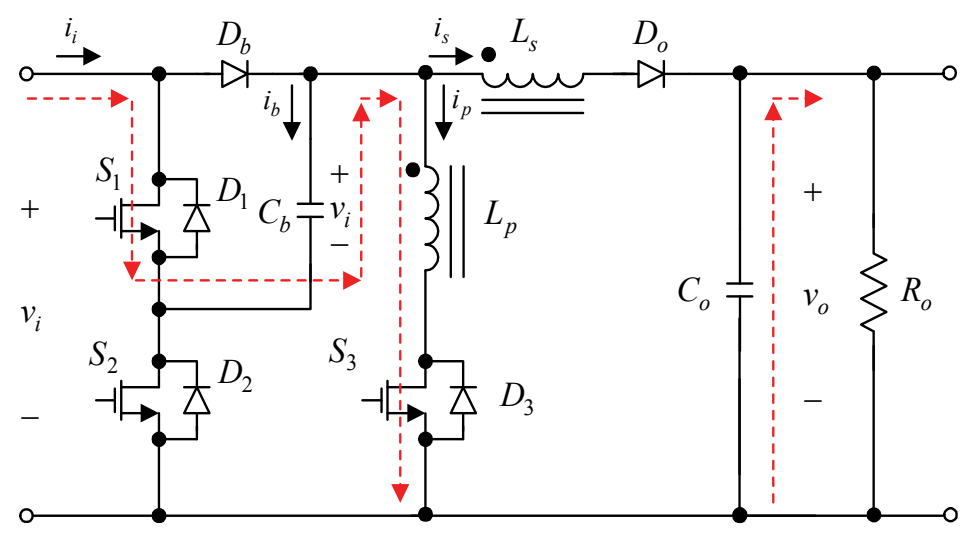

Fig. 5. Power flow of mode 1 without passive voltage-clamping circuit. 
2) Mode 2 : In Fig. 6, $S_{1}$ and $S_{3}$ are turned off, but $S_{2}$ is turned on. There are two power flows in this mode. One is from the input through $C_{b}$ via $S_{2}$ and then to the ground. The other is from the input through $D_{b}$ via $L_{s}$ and then to $D_{o}$ and the output. Therefore, the voltage across $\mathrm{L}_{\mathrm{s}}$ is the input voltage $v_{i}$ minus the output voltage $v_{0}$, thereby causing $\mathrm{L}_{\mathrm{s}}$ of the coupling inductor to be demagnetized. Besides, $C_{b}$ is charged. Also, $C_{o}$ is energized. And hence, the corresponding differential equations are:

$$
\left\{\begin{array}{c}
L_{s} \frac{\partial i_{s}}{\partial t}=v_{i}-v_{o} \\
C_{o} \frac{\partial v_{o}}{\partial t}=i_{s}-\frac{v_{o}}{R_{o}} \\
i_{i}=i_{s}+i_{b}
\end{array}\right.
$$

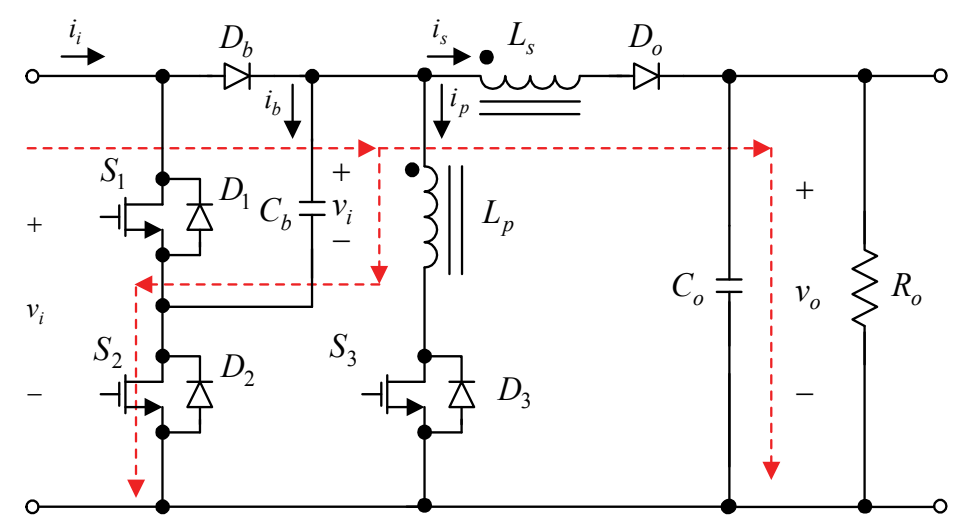

Fig. 6. Power flow of mode 2 without passive voltage-clamping circuit.

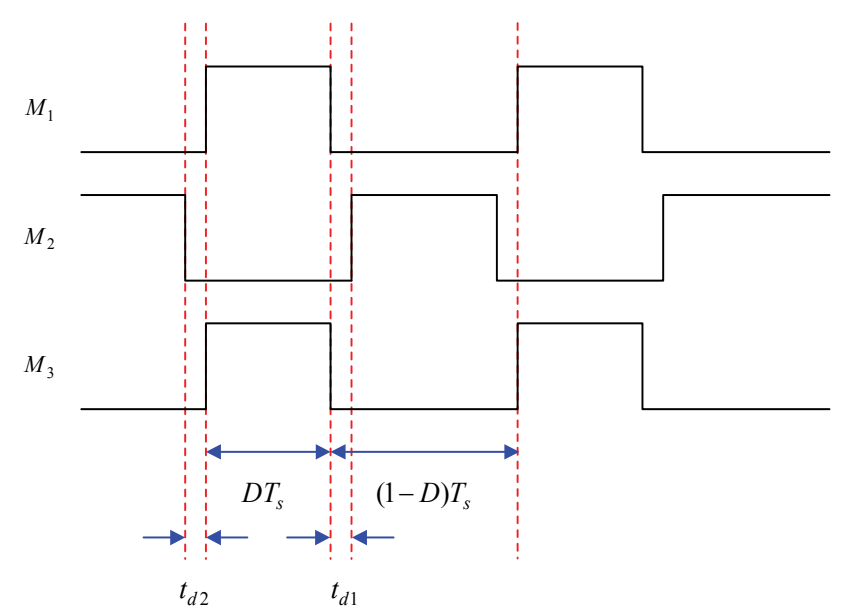

Fig. 7. Ideal timing sequence of gate driving signals $M_{1}, M_{2}$ and $M_{3}$ to drive $S_{1}, S_{2}$ and $S_{3}$ respectively, with blanking times considered. 
However, in practice there are blanking times between $S_{1}$ and $S_{2}$, as shown in Fig. 7. And hence, there exist additional two modes. One mode, mode 3 , locates between mode 1 and mode 2 , with the blanking time of $t_{d 1}$ considered. The other mode, mode 4 , locates after mode 2 before mode 1 , with the blanking time $t_{d 2}$ considered. These two are to be described as follows.

Applying the voltage-second balance to (1) and (2), the voltage conversion ratio can be obtained to be:

$$
\frac{V_{o}}{V_{i}}=\frac{(2 n-1) D+1}{1-D}
$$

3) Mode 3: In Fig. 8, $S_{1}, S_{2}$ and $S_{3}$ are all turned off, with the delay time of $t_{d 1}$ considered. There is only one power flow that is from the ground through $C_{b}$ via $L_{s}$ and then to $D_{o}$ and the output. Therefore, the voltage across $\mathrm{L}_{\mathrm{s}}$ is the voltage $v_{i}$ across $\mathrm{C}_{\mathrm{b}}$ minus the output $v_{0}$, thereby causing $L_{s}$ of the coupling inductor to be demagnetized. Besides, $C_{b}$ is discharged. Also, $C_{o}$ is energized.

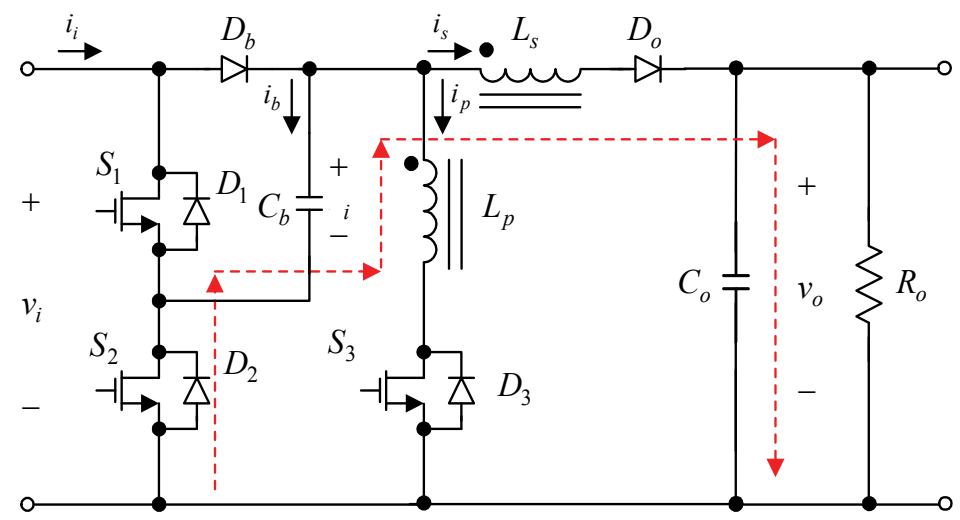

Fig. 8. Power flow of mode 3 without passive voltage-clamping circuit.

4) Mode 4: In Fig. 9, $S_{1}, S_{2}$ and $S_{3}$ are all turned off, with the delay time of $t_{d 2}$ considered. There is only one power flow that is from the input through $D_{b}$ via $L_{s}$ and then to $D_{o}$ and the

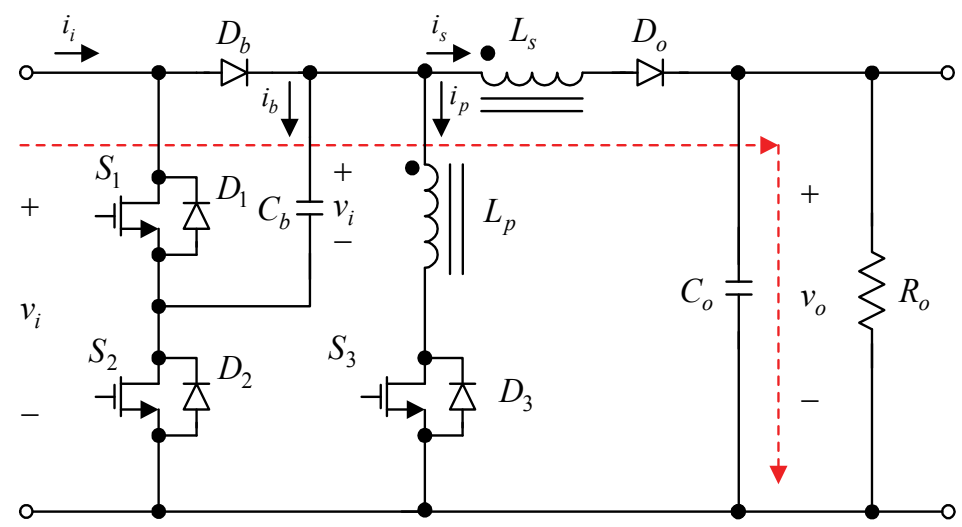

Fig. 9. Power flow of mode 4 without passive voltage-clamping circuit. 
output. Therefore, the voltage across $\mathrm{L}_{\mathrm{s}}$ is the input voltage $v_{i}$ minus the output $v_{o}$, thereby causing $\mathrm{L}_{\mathrm{s}}$ of the coupling inductor to be demagnetized. Besides, $\mathrm{C}_{\mathrm{b}}$ lies idle. Also, $\mathrm{C}_{\mathrm{o}}$ is charged.

\section{B. Operating principles of passive voltage-clamping circuit}

In this subsection, the main description focuses on the behavior of the passive voltageclamping circuit instead of the behavior of the main power stage.

1) Mode 1: In Fig. 10, the moment $S_{3}$ is turned off, the energy stored in $L_{L K}$ is released to $C_{s n}$ via $\mathrm{D}_{\mathrm{sn}}$.

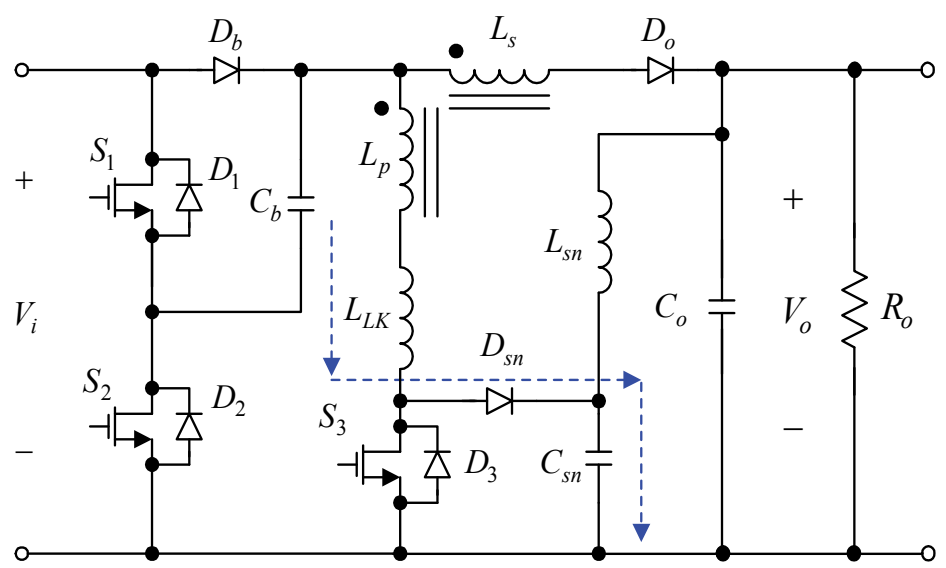

Fig. 10. Power flow of passive voltage-clamping circuit in mode 1.

2) Mode 2: In Fig. 11, as soon as $S_{3}$ is turned on, the energy stored in $C_{s n}$ is pumped into the output via $\mathrm{L}_{\mathrm{sn}}$.

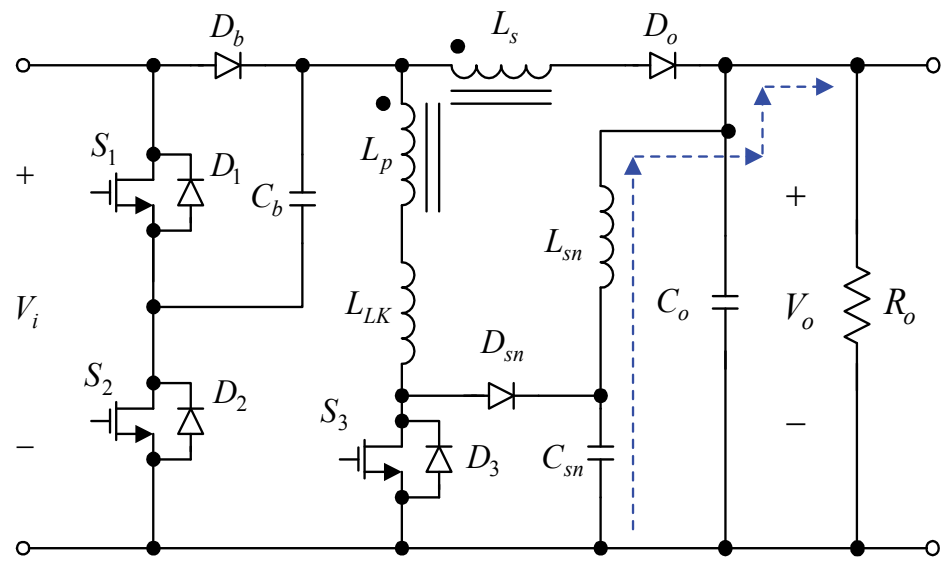

Fig. 11. Power flow of passive voltage-clamping circuit in mode 2.

\section{Applied control method}

Fig. 12 shows the proposed overall system block diagram for the proposed converter. The one-comparator counter-based PWM control without any analog-to-digital converter (ADC) 
based on the field programmable gate array (FPGA) [20][21] is employed herein, and the parameters of the proportional integral (PI) controller, including the proportional gain $k_{p}$ and the integral gain $k_{i}$, are tuned at rated load. In addition, the output voltage information after the voltage divider is obtained through the comparator, and then sent to FPGA having a system clock of $100 \mathrm{MHz}$ to create the desired PWM control signals to drive the MOSFET switches after the gate drives.

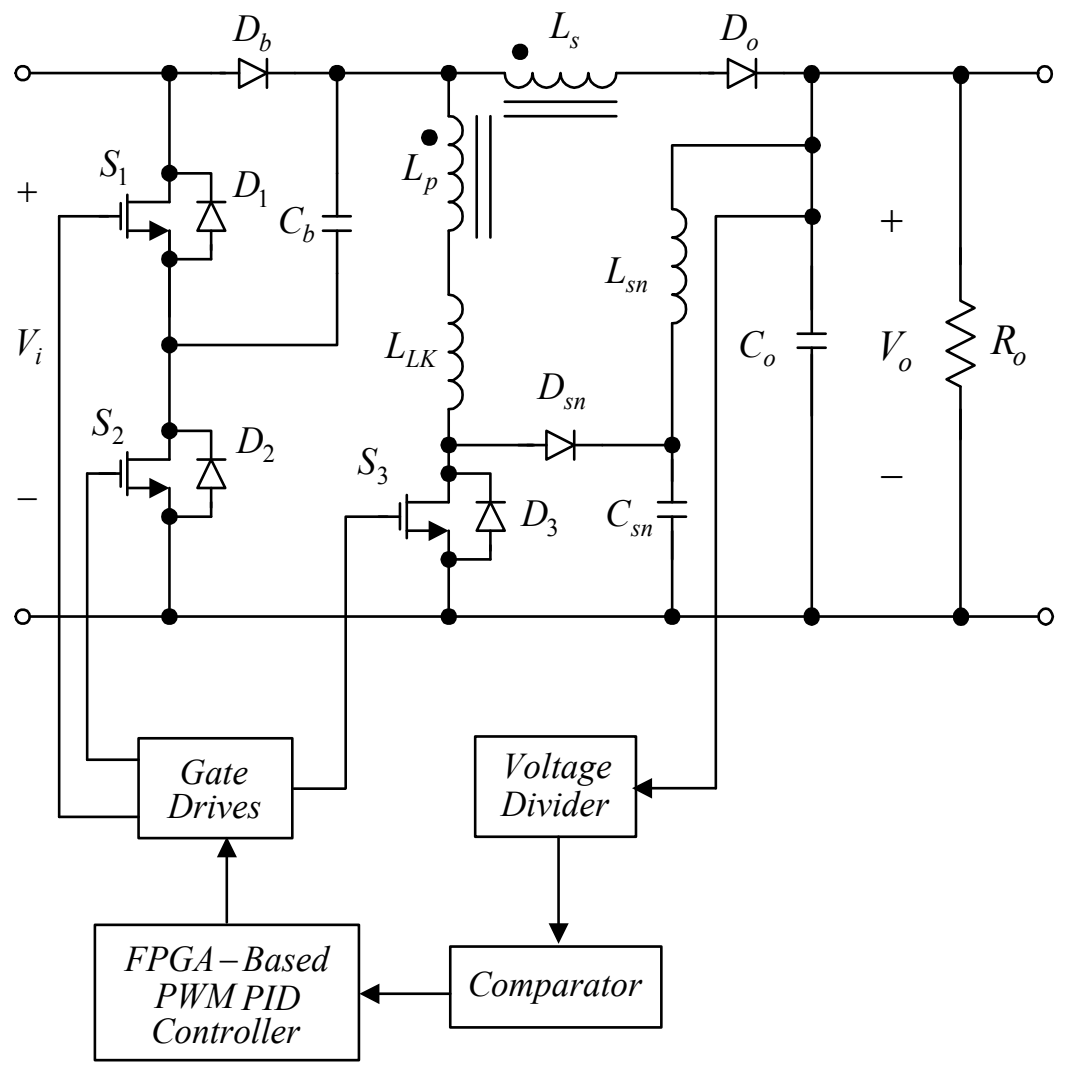

Fig. 12. Overall system block diagram for the proposed converter.

\section{Key parameter considerations}

Before this section is discussed, there are some specifications to be given as follows: (i) rated DC input voltage $V_{i}$ is set to $5 \mathrm{~V}$; (ii) rated DC output voltage $V_{o}$ is set to $48 \mathrm{~V}$; (iii) rated DC output power $P_{o \text {-rated }}$ is set to $48 \mathrm{~W}$; (iv) minimum DC output current $I_{o-\min }$ in the boundary conduction mode $(\mathrm{BCM})$ is $0.15 \mathrm{~A}$; (v) switching frequency $f_{s}$ is chosen to be $195 \mathrm{kHz}$; (vi) turns ratio $\mathrm{N}_{\mathrm{s}} / \mathrm{N}_{\mathrm{p}}$ of the coupling inductor is set to 5; (vii) one $1000 \mu \mathrm{F}$ electrolytic capacitor is chosen for $C_{o}$; (viii) product names of $D_{b}, D_{s n}$ and $D_{o}$ are STPS20L25, 3CTQ100 and 3CTQ100, respectively; (ix) product names of $S_{1}, S_{2}$ and $S_{3}$ are PHD96NQ03LT, PHD96NQ03LT and IRL3705ZS, respectively; (x) product name of the control IC is EPIC3T100; (xi) PI controller parameters $k_{p}$ and $k_{i}$ are set to 0.25 and 0.0625 , respectively; and (xii) blanking times $t_{d 1}$ and $t_{d 2}$ are both set to 100ns. 


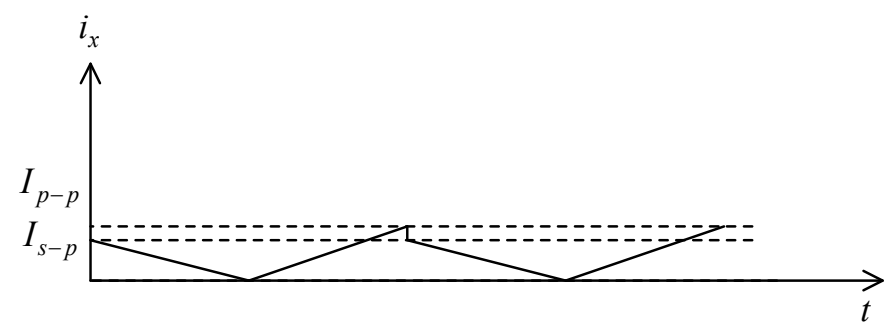

(a)

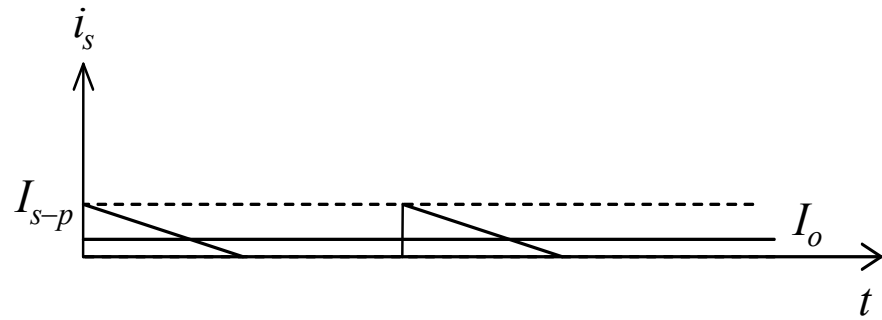

(b)

Fig. 13. Current waveforms in BCM: (a) primary-side current plus secondary-side current, $i_{x}$; (b) secondary-side current $i_{\text {s. }}$.

\section{A. Design of main power stage}

In the main power stage, there are three key parameters to be designed. One is the value of $\mathrm{C}_{b}$ in the charge-pumping cell and the other two are the values of $L_{p}$ and $L_{s}$ in the inductance-coupling cell. On condition that this converter works in BCM, corresponding to the minimum load current $I_{o-m i n}$, the peak value $I_{p-p}$ of the current flowing through $\mathrm{L}_{\mathrm{p}}$, shown in Fig. 13, can be expressed to be:

$$
I_{p-p}=n I_{s-p}=\frac{2 n I_{o-\min }}{1-D}
$$

where $I_{s-p}$ is the peak value of the current flowing through $L_{s}$.

Consequently, the minimum energy stored in $\mathrm{L}_{\mathrm{p}}$ under $\mathrm{BCM}, E_{\mathrm{L}-\mathrm{min}}$, can be represented as:

$$
E_{L-\min }=\frac{1}{2} L_{p} I_{p-p}^{2} \geq \frac{1}{2} V_{i} D T_{s} I_{p-p}
$$

Based on (4) and (5), the value of $\mathrm{L}_{\mathrm{p}}$ can be expressed to be:

$$
L_{p} \geq \frac{V_{i} D(1-D) T_{s}}{2 n I_{o-\min }}
$$

According to the given specifications and (3) and (6), the value of $\mathrm{L}_{\mathrm{p}}$ is calculated to be larger than $4.3 \mu \mathrm{H}$, and eventually one coupling inductor is chosen with $\mathrm{L}_{\mathrm{p}}$ set to $5 \mu \mathrm{H}$ using one T106-18 core with five turns and $L_{s}$ set to $80 \mu \mathrm{H}$ using the same core with twenty turns. Besides, there are some assumptions used to obtain the value of $C_{b}$ as follows: (i) this converter operates at rated load; (ii) $\mathrm{C}_{\mathrm{b}}$ is charged to $V_{i}$ in mode 2; (iii) maximum percentage 
of decreased variation in voltage on $C_{b}$ in discharge, $\varepsilon$, is set to $0.5 \%$ in mode 1 ; (iv) input voltage is an infinite bus, i.e., the input voltage is kept constant and can be represented as infinite capacitance which is much larger than the value of $\mathrm{C}_{b}$; and (v) converter efficiency $\eta$ is initially set to $80 \%$ at rated load. It is noted that the efficiency is assumed to be $80 \%$ at rated load is based on the following reason. Since this coupling inductor behavior is similar to the transformer in the flyback converter and the efficiency of the flyback converter under the traditional control technique is generally about $80 \%$, this is why the efficiency of the proposed converter operating at rated load is roughly chosen to be $80 \%$ for the convenience of design of $\mathrm{C}_{\mathrm{b}}$.

Therefore, in mode 1 , the energy $E_{e}$ is extracted from $V_{i}$ and $C_{\mathrm{b}}$, and can be expressed as:

$$
\begin{aligned}
E_{e} & =\frac{1}{2} C_{b}\left\{\left(2 V_{i}\right)^{2}-\left[(2-\varepsilon) V_{i}\right]^{2}\right\} \\
& =\frac{1}{2}\left(4 \varepsilon-\varepsilon^{2}\right) C_{b} V_{i}^{2}
\end{aligned}
$$

Also, in mode 2, the energy $E_{s}$ is sent to the load, and can be represented as:

$$
E_{s}=\frac{P_{o-r a t e d}(1-D) T_{S}}{\eta}
$$

According to conservation of energy, $E_{e}$ is not less than $E_{s}$, and hence the value of $C_{b}$ can be expressed to be:

$$
C_{b} \geq \frac{2 P_{o-\text { rated }}(1-D) T_{s}}{\left(4 \varepsilon-\varepsilon^{2}\right) V_{i}^{2} \eta}
$$

Based on the given specifications and assumptions and (3) and (9), the value of $C_{b}$ is calculated to be larger than $362 \mu \mathrm{F}$, and finally two paralleled $330 \mu \mathrm{F}$ OSCON capacitors connected in parallel with one $22 \mu \mathrm{F}$ MLCC capacitor are selected for $\mathrm{C}_{\mathrm{b}}$ to compensate the effect of frequency on the capacitance and the reduction of the equivalent series resistance (ESR).

\section{B. Design of passive voltage-clamping circuit}

There are two key parameters to be designed in the passive voltage-clamping circuit. One is the value of $C_{s n}$, and the other is the value of $L_{s n}$. Before doing these, we need to measure the value of $\mathrm{L}_{\mathrm{LK}}$ and set the maximum value of the voltage across $\mathrm{C}_{\mathrm{sn}}, V_{\max }$, during the turn-off period for $S_{3}$ without the voltage spike considered. And hence, based on the following, the minimum value of $\mathrm{C}_{\mathrm{sn}}$ can be obtained to be:

$$
\frac{1}{2} C_{s n} V_{\max }^{2} \geq \frac{1}{2} L_{L K} I_{p-\max }^{2}
$$

By rearranging (10), the resulting value of $C_{\mathrm{sn}}$ can be obtained to be:

$$
C_{s n} \geq \frac{L_{L K} I_{p-\max }^{2}}{V_{\max }^{2}}
$$


where $I_{p-m a x}$ is the maximum value of the current flowing through $\mathrm{L}_{p}$ at rated load.

As for the value of $L_{s n}$, the relationship between the time required for the voltage across $C_{s n}$ to fall from the maximum value to zero without the voltage spike considered and the turnoff period for $\mathrm{S}_{3}$ can be expressed as

$$
(1-D) T_{s} \geq 0.5 \pi \sqrt{L_{s n} C_{s n}}
$$

By rearranging (12), the resulting value of $L_{s n}$ can be found to be

$$
L_{s n} \leq \frac{4(1-D)^{2} T_{s}^{2}}{\pi^{2} C_{s n}}
$$

Based on (13), the measured value of $1.8 \mu \mathrm{H}$ for $\mathrm{L}_{\mathrm{LK}}, V_{\max }$ set to double the input voltage, and other given and calculated values, the resulting minimum value of $\mathrm{C}_{\mathrm{sn}}$ is worked out to be $1.98 \mu \mathrm{F}$ and finally the value of $\mathrm{C}_{\mathrm{sn}}$ is set to $2.2 \mu \mathrm{F}$ whereas the resulting maximum value of $\mathrm{L}_{\mathrm{sn}}$ is figured out to be $1.42 \mu \mathrm{H}$ and eventually the value of $\mathrm{L}_{\mathrm{sn}}$ is set to $1 \mu \mathrm{H}$.

\section{Simulated and experimental results}

Before some experimental results are provided, a simulated result at startup based on MATLAB/SIMULINK/SIMPOWERSYSTEMS for the proposed converter operating under the open loop are provided to verify its feasibility, and after this, some experimental results under the closed loop are utilized to demonstrate the effectiveness of this converter. Therefore, Fig. 14 shows the simulated output voltage of the proposed converter under open-loop control during startup. It can be seen that the output voltage of this converter can stably rise to the neighborhood of the prescribed value.

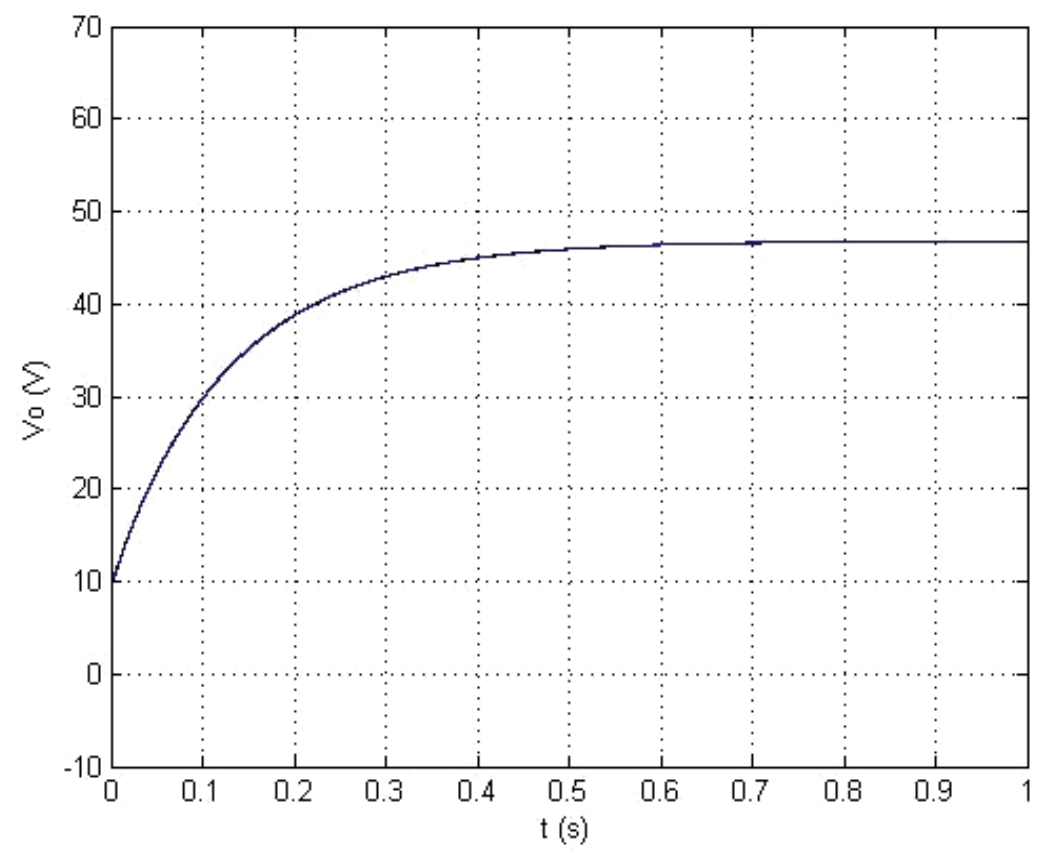

Fig. 14. Simulated output voltage during startup. 


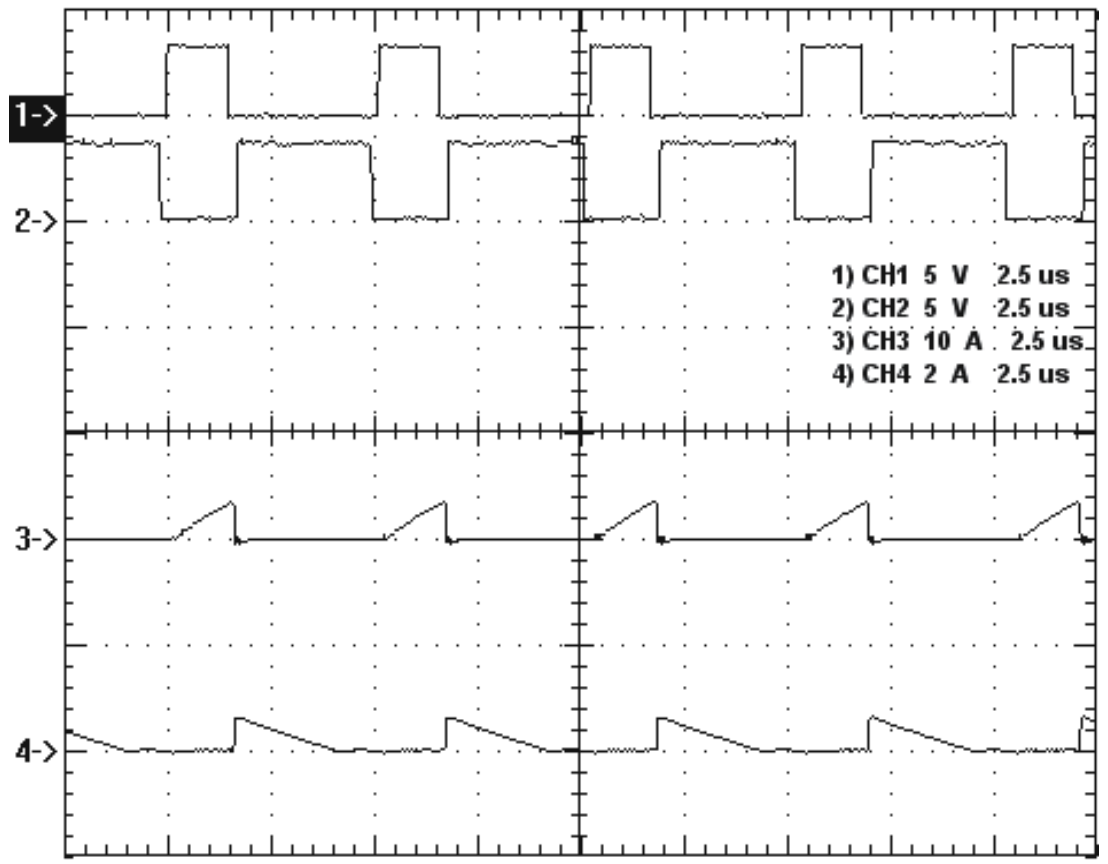

Fig. 15. Under $15 \%$ of the rated load: (1) gate driving signal for $\mathrm{S}_{3}$; (2) gate driving signal for $\mathrm{S}_{2}$; (3) current in $\mathrm{L}_{\mathrm{p}}$; (4) current in $\mathrm{L}_{\mathrm{s}}$.

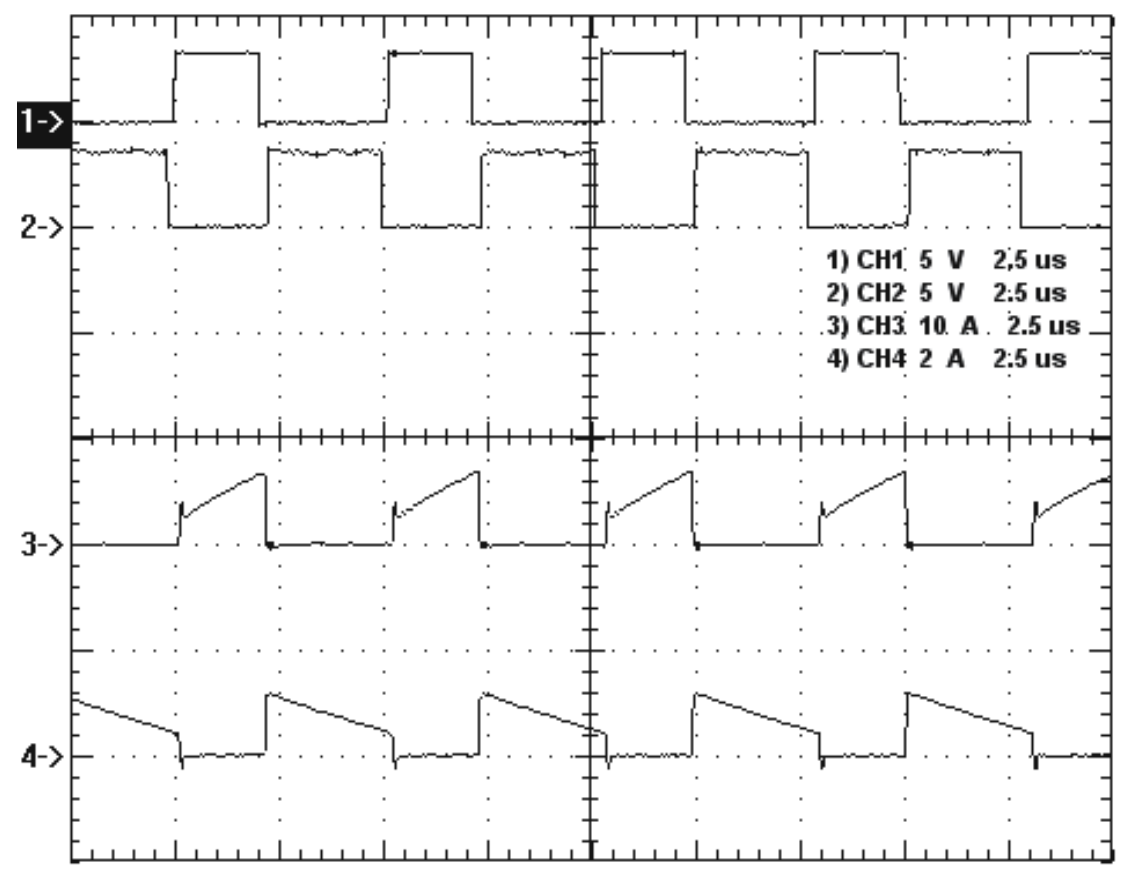

Fig. 16. Under $50 \%$ of the rated load: (1) gate driving signal for $\mathrm{S}_{3} ;(2)$ gate driving signal for $\mathrm{S}_{2}$; (3) current in $\mathrm{L}_{\mathrm{p}}$; (4) current in $\mathrm{L}_{\mathrm{s}}$. 


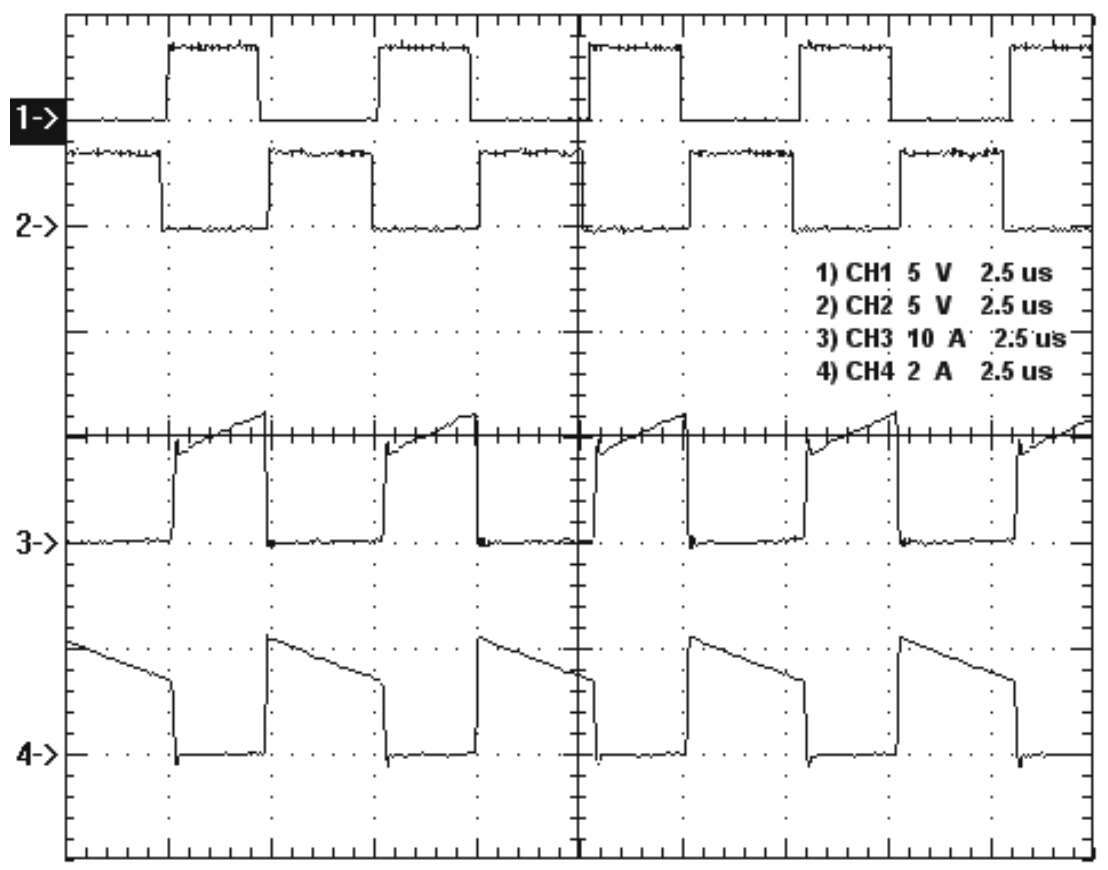

Fig. 17. Under the rated load: (1) gate driving signal for $S_{3}$; (2) gate driving signal for $S_{2}$; (3) current in $\mathrm{L}_{\mathrm{p}}$; (4) current in $\mathrm{L}_{\mathrm{s}}$.

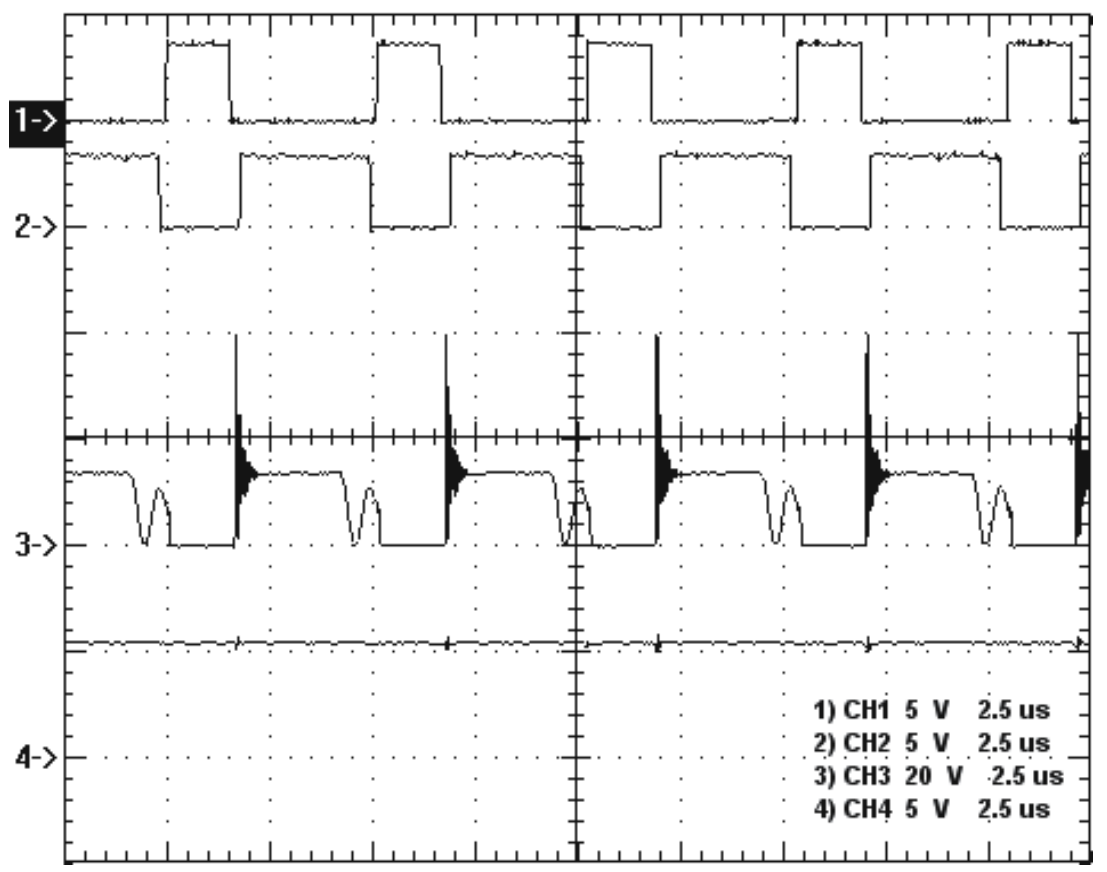

Fig. 18. Under $15 \%$ of the rated load: (1) gate driving signal for $\mathrm{S}_{3}$; (2) gate driving signal for $S_{2} ;(3)$ voltage on $S_{3} ;(4)$ voltage on $C_{b}$. 


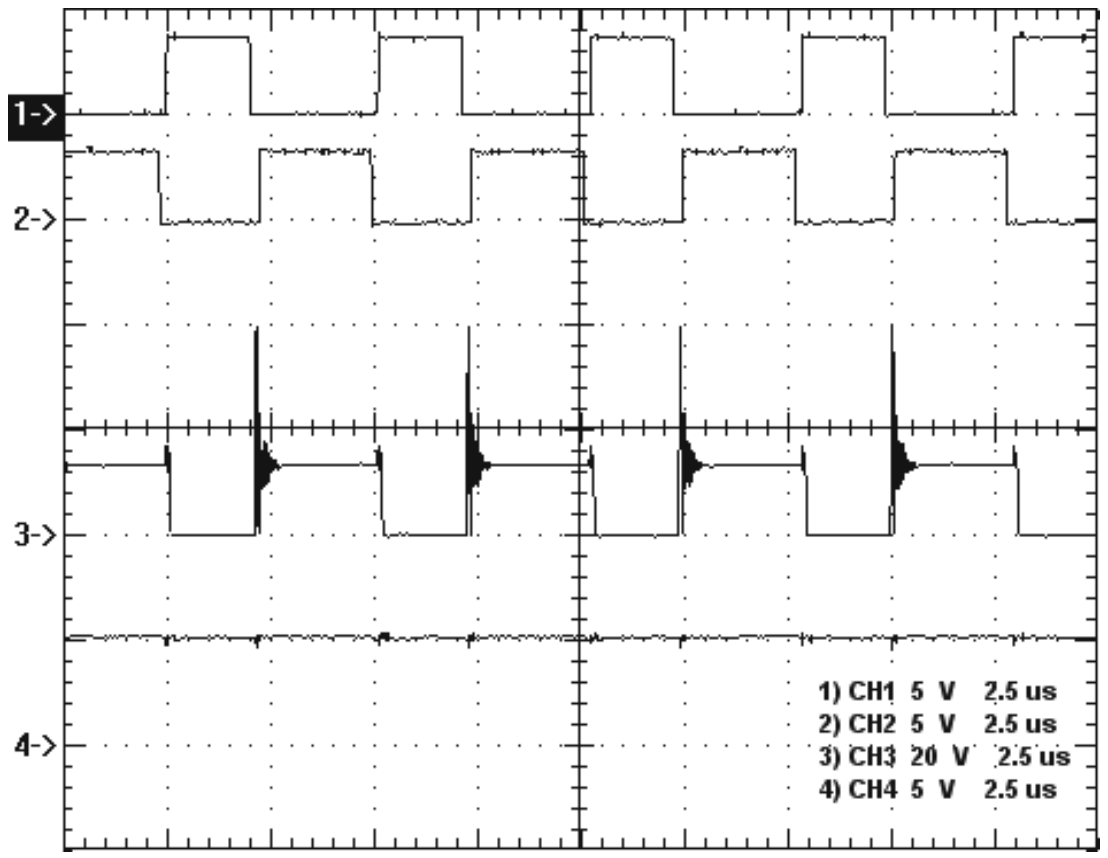

Fig. 19. Under $50 \%$ of the rated load: (1) gate driving signal for $\mathrm{S}_{3}$; (2) gate driving signal for $\mathrm{S}_{2} ;(3)$ voltage on $\mathrm{S}_{3} ;(4)$ voltage on $\mathrm{C}_{\mathrm{b}}$.

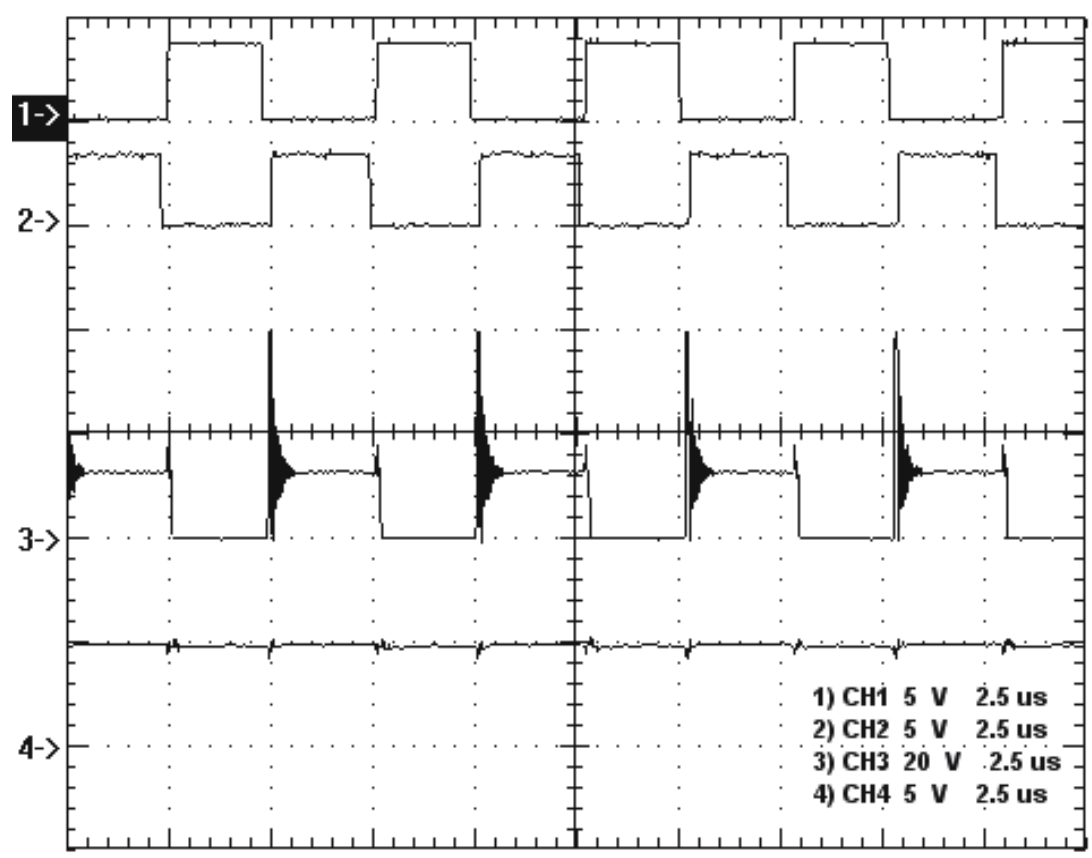

Fig. 20. Under the rated load: (1) gate driving signal for $\mathrm{S}_{3}$; (2) gate driving signal for $\mathrm{S}_{2}$; (3) voltage on $S_{3} ;(4)$ voltage on $C_{b}$. 


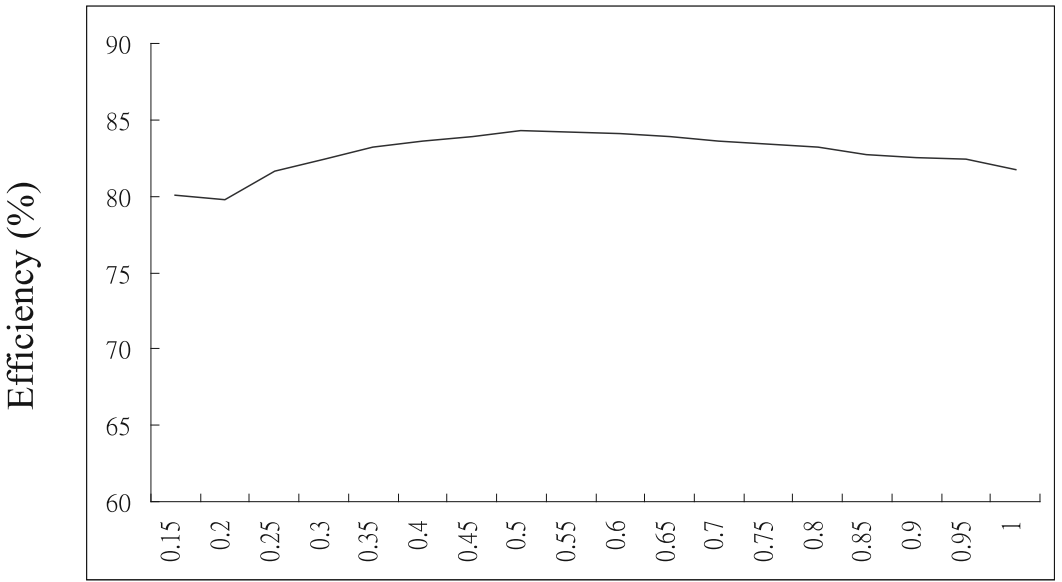

Load current (A)

Fig. 21. Efficiency versus load current.

Afterwards, some experimental waveforms shown in Figs. 15 to 21 are provided to verify the performance of the proposed circuit topology. Figs. 15 to 17 depict the PWM gate driving signals for $S_{3}$ and $S_{2}$ and the currents in $L_{p}$ and $L_{s}$, under $15 \%, 50 \%$ and $100 \%$ of the rated load respectively. It is noted that the converter under $15 \%$ of rated load operates in DCM, which does not correspond to the design specifications. This is because the inductance is reduced due to the high switching frequency. Figs. 18 to 20 show the gate driving signals for $S_{3}$ and $S_{2}$, the voltage on $S_{3}$ and the voltage on $C_{b}$, under $15 \%, 50 \%$ and $100 \%$ of the rated load respectively. It is noted that the more the load current, the lower the voltage on $S_{3}$. As for the voltage spike on $S_{3}$, it is due to the turn-on delay created from the diode $\mathrm{D}_{\mathrm{sn}}$. Besides, the voltage across $\mathrm{S}_{3}$ is larger than double the input voltage prescribed. This is because the value of $\mathrm{C}_{\mathrm{sn}}$ is reduced due to high frequency or there exists capacitance tolerance in $\mathrm{C}_{\mathrm{sn}}$. According to the mention above, it is evident that the proposed voltageboosting converter can stably operate under closed-loop control.

On the other hand, Fig. 21 displays the curve of efficiency versus load current. It is noted that unlike the traditional voltage-boosting converter, the proposed voltage-boosting possesses an almost flat range of the efficiency from minimum load to rated load. This is because the charge-pumping cell is used. To explain lucidly, the primary inductance of the coupling inductor is magnetized by double the input voltage, thereby causing the input current to be reduced, and this behavior is similar to the KY converter.

\section{Conclusion}

A new voltage-boosting converter, combining the charge pump and the coupling inductor, is proposed herein, together with a passive voltage-clamping circuit. Conclusions are summarized as follows:

1. This converter with high voltage ratio required is simpler in structure than any other converter mentioned in Sec. I.

2. The primary inductor is magnetized under double the input voltage, thereby causing the input current to be reduced and hence the efficiency to be upgraded at light load, and this behavior is similar to the KY converter.

3. The passive voltage-clamping circuit pumps part of the energy stored in the leakage inductance to the output. 
4. For the multi-phase to be considered, if the number of phases is $\mathrm{N}$, then only additional $\mathrm{N}-1$ diodes are added.

\section{References}

[1] F. L. Luo, Ye Hong and M. H. Rashid, "Four quadrant operating Luo-converters," IEEE PESC'00, vol. 2, pp. 1047-1052, 2000.

[2] Fang Lin Luo, "Luo-converters, voltage lift technique," IEEE PESC'98, vol. 2, pp. 1783$1789,1998$.

[3]Xiaofan Chen, Fang Lin Luo and Ye Hong, "Modified positive output Luo converters," IEEE PEDS'99, vol. 1, pp. 450-455, 1999.

[4] F. L. Luo, H. Ye and M. H. Rashid, "Multiple-quadrant Luo-converters," IEE Proc. Electr. Power Appl., vol. 149, no. 1, pp. 9-18, 2002.

[5] F. L. Luo and H. Ye, "Positive output cascade boost converters," IEE Proc. Electr. Power Appl., vol. 151, no. 5, pp. 590-606, 2004.

[6] F. L. Luo and H. Ye, “Ultra-lift Luo-converter," IEE Proc. Electr. Power Appl., vol. 152, no. 1, pp. 27-32, 2005.

[7] F. L. Luo, "Seven self-lift DC-DC converters, voltage lift technique," IEE Proc. Electr. Power Appl., vol. 148, no. 4, pp. 329-338, 2001.

[8] F. L. Luo and H. Ye, "Negative output super-lift converters," IEEE Trans. Power Electron., vol. 18, no. 5, pp. 1113-1121, 2003.

[9] F. L.Luo and H. Ye, "Positive output super-lift converters" IEEE Trans. Power Electron., vol. 18, no. 1, pp. 105-113, 2003.

[10] F. L. Luo and H. Ye, "Positive output multiple-lift push-pull switched-capacitor Luoconverters" IEEE Trans. Ind. Electron., vol. 51, no. 3, pp. 594-602, 2004.

[11] Wai Rong-Jong and Duan Rou-Yong, "High step-up converter with coupled-inductor," IEEE Trans. Power Electron., vol. 20, no. 5, pp. 1025-1035, 2005.

[12] Wai Rong-Jong and Duan Rou-Yong, "High step-up coupled-inductor-based converter using bi-direction energy transmission," IEEE PESC'05, pp. 406-412, 2005.

[13] R.Gules, L. L. Pfitscher and L. C. Franco, "An interleaved boost DC-DC converter with large conversion ratio," IEEE ISIE '03, vol. 1, pp. 411-416, 2003.

[14] G. Yao, A. Chen and X. He, "Soft switching circuit for interleaved boost converters," IEEE Trans. Power Electron., vol. 22, no. 1, pp. 80-86, Jan. 2007.

[15] K. I. Hwu and Y. T. Yau, "A novel voltage-boosting converter: KY converter," IEEE APEC'07, vol. 1, pp. 368-372, 2007.

[16] Rong-Jong Wai, Chung-You Lin, Rou-Yong Duan and Yung-Ruei Chang, "Highefficiency DC-DC converter with high voltage gain and reduced switch stress," IEEE Trans. Ind. Electron., vol. 54, pp. 354-364, Feb. 2007.

[17] Tsai-Fu Wu, Yu-Sheng Lai, Jin-Chyuan Hung and Yaow-Ming Chen, "Boost converter with coupled inductors and buck-boost type of active clamp," IEEE Trans. Ind. Electron., vol. 55, pp. 154-162, Jan. 2008.

[18] Qingbo Hu and Zhengyu Lu, "A novel step-up VRM-Two-phase interleaved coupledboost converter," IEEE PESC'06, pp. 1-5, 2006.

[19] K. I. Hwu and Y. T. Yau, "KY converter and its derivatives," IEEE Trans. Power Electron., vol. 24, no. 1, pp. 128-137, 2009.

[20] K. I. Hwu and Y. T. Yau, "Applying a counter-based PWM control scheme to an FPGAbased SR forward converter," IEEE APEC'06, vol. 3, pp. 1396-1400, 2006.

[21] K. I. Hwu and Y. T. Yau, "Improvement of one-comparator counter-based PWM control by applying a sawtoothed wave injection method," IEEE APEC'07, vol. 1, pp. 478-481, 2007. 


\title{
Advanced Power Generation Technologies: Fuel Cells
}

\author{
Farshid Zabihian and Alan S. Fung \\ Ryerson University, \\ Toronto, Ontario, \\ Canada
}

\section{Introduction}

Dependency of the current sophisticated society and the standard of living on energy infrastructure development is going to continue in the future. According to the World Energy Outlook published by the International Energy Agency (IEA), the world's total electricity consumption will double between 2003 and 2030, growing at an average rate of $2.7 \%$ per year (IEA, 2006). Conventionally, the majority of electricity is generated by thermal fossil fuel power stations. However, global climate change and natural resource pollution as well as decline of fossil fuel resources cause significant worldwide concerns about the current trend in energy system development.

As a result of the aforementioned issues, sustainability considerations should be involved in all major energy development plans around the world. There are various definitions for sustainability. Probably the simplest one is that sustainable activities are the activities that help the existing generation to meet their needs without destroying the ability of future generations to meet theirs.

The IEA stated that global energy-related $\mathrm{CO}_{2}$ emission would increase by $55 \%$ between 2003 and 2030 (IEA, 2006). This shows that conventional power plants using current technologies cannot address current environmental constraints. Therefore, they should be replaced by new and more environmentally benign technologies.

Ultimately, renewable energies are environmentally friendly candidates for sustainable electricity generation. But their applications have been limited by some major drawbacks, such as availability, reliability, and cost, at least in the short- and mid-term future. According to IEA, the share of renewable electrical energy in the world will experience a slight decrease from $23 \%$ in 2003 to $22 \%$ in 2030 . On the other hand, the same report predicted that the share of fossil fuels as energy supplies for electricity generation would remain constant at nearly $65 \%$. Global energy-related greenhouse gas (GHG) emissions would increase by $1.7 \%$ per year and would reach $40 \mathrm{Gt}$ in 2030, a 54\% increase over the 2004 level (IEA, 2006; Gale, 2002; Bauer, 2005).

Thus, both fossil and non-fossil forms of energy will be needed in the foreseeable future to meet global energy demand. That is why IEA has commented that "numerous technology solutions offer substantial $\mathrm{CO}_{2}$-reduction potentials, including renewable energies, more efficient power generation, fossil-fuel use with $\mathrm{CO}_{2}$ capture and storage, nuclear fission, 
fusion energy, hydrogen, biofuels, fuel cells and efficient energy end use. No single technology can meet this challenge by itself. Different regions and countries will require different combinations of technologies to best serve their needs and best exploit their indigenous resources. The energy systems of tomorrow will rely on a mix of different advanced, clean, efficient technologies for energy supply and use" (IEA, 2003a, p. 5).

Fuel cells are a promising technology for electricity generation with high efficiency and minimal environmental impacts. The idea is to directly convert fuel chemical energy to electrical and thermal energy via electrochemical reactions. This section outlines the basic operation of a fuel cell and its essential components as well as the main subsystems of fuel cell plants. It also provides a brief overview of the different types of fuel cells and their applications. Then, the solid oxide fuel cell (SOFC), as a main candidate for stationary power generation, is investigated in detail. Also, some advanced power generation technologies that can be potentially integrated into SOFCs to form hybrid systems are explained. Finally, SOFC and hybrid SOFC cycle computer modeling are presented.

\section{Introduction to fuel cells}

Fuel cells are a very interesting alternative for conventional power generation technologies because of their high efficiency and very low environmental effects. In conventional power generation systems, fuel is to be combusted to generate heat and then heat is converted to mechanical energy before it can be used to produce electrical energy. The maximum efficiency that a thermal engine can achieve is when it operates at the Carnot cycle. The efficiency of this cycle is related to the ratio of the heat source and sink absolute temperatures. On the other hand, fuel cell operation is based on electrochemical reactions and not fuel combustion. Bypassing this conversion of chemical energy to thermal and then mechanical energy enables fuel cells to achieve efficiency potentially much higher than that of conventional power generation technologies.

A fuel cell can be considered as a "cross-over" of a battery and a thermal engine. It resembles an engine because theoretically it can operate as long as fuel is fed to it. However, similar to a battery, its operation is based on electrochemical reactions. This combination provides significant advantages for fuel cells. On the other hand, batteries are energy storage devices and when their chemical energy is depleted, they need to be replaced or recharged, whereas fuel cells can generate electricity continuously. Actually, in principle, a fuel cell resembles an instantly rechargeable battery. Mench (2008) explained the differences between a fuel cell and a battery based on the thermodynamic definition of a closed system and control volume. According to his description, a battery is a thermodynamically closed system, whereas a fuel cell is a thermodynamically control volume, and fuel and oxidizer can flow across the system's boundaries.

The main advantages of fuel cells can be summarized as follows. It should be noted that this list is not exhaustive and just enumerates general attributes of all types of fuel cells.

Direct energy conversion (no combustion): Most fuel cell attributes stem from direct electrochemical power generation. In conventional power plants, most irreversibilities, more than 30\%, take place in the combustion process (Campanari \& Macchi, 1998).

Potential for high efficiency: Stand alone fuel cell electrical efficiency is in the range of $40 \%$ to $60 \%$, based on the lower heating value (LHV) (Young, 2007). For hybrid and cogeneration fuel cell systems, efficiency of around 70\% (LHV) and higher than $80 \%$ have been predicted, respectively (EG\&G Services, 2004; Larminie \& Dicks, 2003). 
Lower pollution: Fuel cells can generate electricity with very low amounts of pollutants, such as $\mathrm{GHG}, \mathrm{NO}_{\mathbf{x}}$, and $\mathrm{SO}_{\mathrm{x}}$. This is due primarily to their high efficiency. Also, since there is no combustion in the power generation process, the emissions associated with combustion are eliminated. Moreover, since most fuel cells should be operated on desulfurized fuels, they do not emit any $\mathrm{SO}_{\mathrm{x}}$.

Scalability: The unique characteristic of fuel cells is that their high efficiency and other attributes are nearly unaffected by the size of the plant. That means fuel cells are scalable to all sizes with, more or less, the same high efficiency, low emissions and costs. In addition, modular installations of fuel cells can help them to match load and increase their reliability (EG\&G Services, 2004).

No moving parts in the energy converter: A fuel cell generates electricity by the movement of mobile ions and electrons. Therefore, there are no moving parts in the fuel cell itself. However, some compressors and/or fans are required to supply oxidizer and fuel to the system.

Quiet operation: Due to minimal moving parts, fuel cells can be operated with minimal noises and vibrations. This is very important for some applications such as residential distributed electricity generation.

Fuel flexibility: The ideal fuel for a fuel cell is hydrogen. If fueled by hydrogen, there are no emissions by the fuel cell and the only emissions are for hydrogen generation. However, fuel cells can operate on a wide range of fuels, from conventional fuels, such as natural gas, petroleum, and coal, to renewable fuels, like biogas and ethanol, to landfill gas. This fuel flexibility can provide smoother transition to future power generation infrastructures. Fuel cells can operate, directly or indirectly, based on the fossil fuel, until renewable hydrogen is available commercially. In other words, fuel cells are power generators of today and tomorrow.

Easier carbon capture: In the fuel cell operation, fuel and air streams are not mixed, making $\mathrm{CO}_{2}$ capture easier and less energy intensive.

Possibility for water production: If pure hydrogen and oxygen are used as a fuel and oxidizer, respectively, the only products of the fuel cell operation are electricity, heat, and potable water.

Hybrid systems and cogeneration: Most fuel cells, especially high operating temperature ones, can be used in hybrid systems to produce further electricity and/or in cogeneration systems to produce heating and/or cooling as well as electricity.

Moreover, at least some types of fuel cells have demonstrated the following characteristics: fast response to load changes, unattended operation, good off-design load operation, reliability, and high availability.

All these attributes and characteristics make fuel cells ideal candidates for some major applications. However, before this commercialization can be realized, some significant improvements are required. The most important barrier is cost. In order to reduce the cost of fuel cells, new construction methods and materials must be developed. Mass production and the economy of scale can reduce cost significantly, but some mass markets have to be in place to support it. Also for each application, suitable durability, endurance, reliability, longevity, specific power, and power density need to be achieved, especially for high temperature fuel cells. This includes transient operation and operation in extreme ambient conditions. In addition, the performance of the balance of plant (ancillary system) should be improved to meet the technical and economic requirements of fuel cell systems. Other obstacles to overcome can be enumerated as follows: lack of familiarity of markets with fuel cell technology (especially the power generation industry) and the lack of hydrogen production, storage, and distribution infrastructure for hydrogen fueled fuel cells. 
Fuel cell technology is highly multidisciplinary and its development requires engagement and embrace most of the engineering fields, from electrochemistry to manufacturing and from thermodynamic to material science and control, and is experiencing a tremendous growth. For instance, it has been shown that the number of registered patents related to fuel cells has increased exponentially in the United States in recent years (Mench, 2008). However, any claim regarding the future of fuel cells should be considered cautiously, because a quick review of literature over the past few decades shows that fuel cells have always been seen, and still are being seen, to be a few years away from commercialization.

\section{Fuel cell basic operation}

Since the operation of fuel cell is, in principle, a reverse of the operation of an electrolyzer, the electrolysis process will be briefly explained. Electrolysis is a process to separate substances into their elements by means of the passage of a direct electric current. This process requires three main components: an electrolyte and two electrodes. The external source of direct electric current is supplied to electrodes, where electrons are removed from or added to atoms to generate ions. The electrolyte provides a site to carry mobile ions. Negatively-charged ions (anions) lose electrons at the anode and positively-charged ions (cations) receive electrons at the cathode to become an uncharged atom separated from the electrolyte.

The same principle is true for fuel cells, but the objective is to combine substances to generate electricity. Actually, the concept of fuel cells was discovered when water electrolysis was reversed. In a fuel cell, the reductant (fuel) flows across the anode and is oxidized by removal of electrons. Similarly the oxidant (usually oxygen from air) flows across the cathode, where it is reduced by gaining electrons. Then either positively-charged or negatively-charged ions, depending on the fuel cell type, flow through the electrolyte to participate in electrochemical reactions. The excessive electrons in the anode and lack of electrons in the cathode generate the desired product of the system, electricity. Fig. 1 illustrates a sketch of the basic operation of a typical fuel cell fueled by hydrogen and oxygen. The exact reactions in the electrodes and the type of ions transferred through the electrolyte depend on the fuel cell type and the type of inlet fuel.

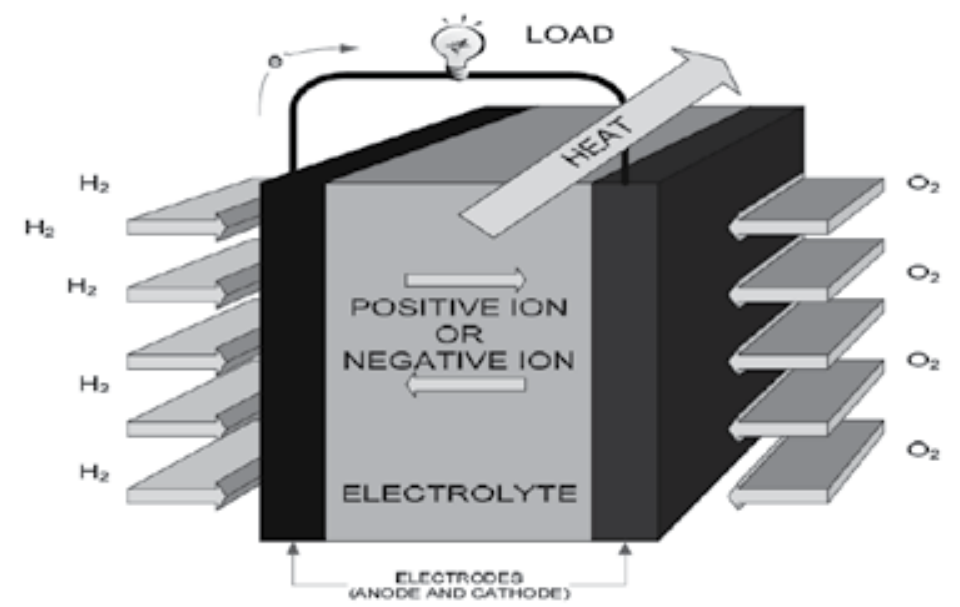

Fig. 1. Sketch of the basic operation of a typical fuel cell fueled by hydrogen and oxygen (Suther, 2006) 


\section{Fuel cell components}

As noted earlier, every fuel cell requires an electrolyte, two electrodes, and interconnections. In order for a material to be suitable for these components, it should have high mechanical strength and thermal conductivity. Furthermore, it should be chemically stable in air and/or fuel as well as with other cell components at operating temperature and during the fabrication. Also, for overall mechanical strength of the fuel cell, the thermal expansion of all components must match. These are the minimum general requirements of fuel cell components. This section provides a brief discussion of the tasks of these components and required characteristics of candidate materials.

Electrolyte: The electrolyte is the most important component of a fuel cell. The properties, operating conditions, and potential applications of each type of fuel cell are dictated by the electrolyte. The functions of the electrolyte, which in turn determine its characteristics, can be enumerated as follows:

- To transfer ionic charges between electrodes;

- To block direct transformation of electrons from the anode to the cathode so that the electric current conducts through an external load;

- To prevent physical mixing of the reductant and oxidant streams.

Electrodes: The electrodes should be able to perform the following functions:

- To provide a surface for electrochemical reactions;

- To supply reactant streams to the site of electrochemical reactions and distribute the streams over the cells as equally as possible;

- To collect and carry away electrons from the anode, and supply and distribute electrons to the cathode (which requires a good electrical conductor);

- To collect and carry away electrochemical reaction products from the site of the reactions.

In order for a substance to be able to perform the tasks mentioned above, it should typically be porous and electrically conductive and have sufficient electro-catalytic activity. Using porous materials for electrodes also significantly increases the contact between the electrode, the electrolyte, and streams. For low temperature fuel cells, few expensive materials can provide the required electro-catalytic activity. Therefore, to reduce the cost of the fuel cell, a small amount of these materials are deposited to the interface of the electrodes and electrolyte. However, for high temperature fuel cells, relatively inexpensive materials can provide sufficient electro-catalytic activity and the electrodes can be manufactured out of such.

Interconnections: The main purpose of interconnections in fuel cells is to conduct electrons from or to the electrodes. These electrons can be transferred either between the cells or between cells and the external circuit. Depending on the type of fuel cell and its configuration, interconnections may have other tasks as well. For instance, in a flat plate design, the interconnections separate the oxidizer and fuel by providing flow channels for streams in the anode and cathode. The material of the interconnections must have high electric conductivity and low ionic conductivity. Both properties are essential for an efficient interconnection.

\section{Configuration of fuel cells}

Although current and power output of a fuel cell, to some extent, can be controlled by its size and reactants flow rate, the voltage of electricity that can be generated by a single fuel 
cell unit is limited to a theoretical maximum of about $1.2 \mathrm{~V}$ at $298 \mathrm{~K}$ and $0.9 \mathrm{~V}$ at $1273 \mathrm{~K}$ for hydrogen oxidation (Campanari \& Macchi, 1998). This is due to the limited electrochemical potential of the reacting agents. Since actual operating voltage is generally lower than $1 \mathrm{~V}$, several fuel cell units should be connected to generate a considerable amount of electricity. The combination of fuel cells is known as a fuel cell stack and gives fuel cells size flexibility. The fuel cell stacking is one of the reasons for the development of various fuel cell configurations, which are the subject of the rest of this subsection.

The configuration of a fuel cell is an important parameter in the fuel cell design that determines the shape of components, stacking of the fuel cell, and the system supporting mechanism. The common configuration of fuel cells can be categorized into two main groups: the planar and the tubular configurations. At the beginning of fuel cell development, there was monolithic design as well but due to its high fabrication costs, its development was not pursued (Singhal, 2000b).

Planar fuel cells: In this design, the fuel cell's flat plate electrolyte and electrodes are located parallel to each other and the individual cells are connected in series (bipolar plates). The planar fuel cells enjoy high power density and their fabrication is simpler. But their structural integrity and sealing at high operating temperatures are serious challenges.

In order to distribute air and fuel evenly within each cell, flow channels can be integrated into the interconnections. Also, there are two more functions for the interconnections:

- To separate fuel and oxidant of two adjacent unit cells;

- To provide electrical connection between adjacent unit cells.

In terms of the flow direction of the reductant and oxidant, there are three common configurations:

- Co-flow: Two streams are parallel and in the same direction;

- Counter-flow: Two streams are parallel and in opposite directions;

- Cross-flow: Two streams are perpendicular.

Also, manifolds are required to distribute fresh air and fuel between cells and collect depleted streams from cells. These manifolds can be either external or integrated in the fuel cell stack design. Further information and illustration about various configurations of fuel cells can be found in Larminie and Dicks (2003).

In solid state electrolyte fuel cells, in order to provide mechanical strength for a planar cell, each cell should be self-supported or supported by an external support. In a self-supported cell, either the electrodes or electrolyte should be thick enough to support other components. The three types of self-supported fuel cells are electrolyte supported, anode supported, and cathode supported. The problem with electrolyte supported cells is the high ionic resistance in the electrolyte due to its greater thickness, requiring a high operating temperature of the system. In electrode supported cells, due to their thinner electrolyte and lower ionic resistance, the operating temperature can be reduced significantly. Alternatively, cells can be externally supported by the interconnections, which results in stronger structure and thinner cell components, but cell support requirements may impose some limitations in flow channel design. Recently, anode supported fuel cells have been receiving the most attention due to their better thermal and electrical conductivity, mechanical strength, and minimal chemical interaction with the electrolyte (Singhal, 2002).

Tubular fuel cells: In this design, a whole cell is in the form of a tube, the cathode being the inner layer, and the electrolyte and anode are deposited on top of the cathode. Since this configuration is mainly used in solid oxide fuel cells, the detailed description of the design will be presented in subsection 12 . 


\section{Balance of plant}

The balance of plant (BoP) is a significant portion of a fuel cell system's weight, volume, and cost. The fuel processor is required to provide fuel in proper conditions for the fuel cell and increase the fuel flexibility of the system. Also, the generated electricity in the fuel cell cannot be directly used by end users and has to be adjusted to meet the load requirements. The inlet fuel type, system application, and operating conditions can affect the type and configuration of the balance of plant. The BoP can include all or some of the following subsystems:

- Feed stream conditioning: the fuel preparation and storage; and the fuel and oxidant supply (compressors or blowers as well as filters);

- Thermal management equipment (to manage the fuel cell stack temperature);

- Water management;

- Electric power conditioning (to convert variable DC fuel cell output to usable electricity);

- Residual fuel recirculation and/or consumption (due to a lower than $100 \%$ fuel utilization factor in fuel cells, residual fuel should be recycled or combusted before being discharged to the environment);

- Start-up equipment (to initiate start of components and preheating of the system);

- Cooling subsystem;

- Control subsystem.

Some of these subsystems will be discussed in more detail in subsection 15.

\section{Fuel cell classification}

Fuel cells can be classified based on various parameters. The most popular categorization is based on the type of electrolyte. The electrolyte can be either solid or liquid with the operating temperatures ranging from $80^{\circ} \mathrm{C}$ to over $1000^{\circ} \mathrm{C}$. According to this classification fuel cells can be categorized into five groups;

1. Polymer electrolyte fuel cell (PEFC);

2. Alkaline fuel cell (AFC);

3. Phosphoric acid fuel cell (PAFC);

4. Molten carbonate fuel cell (MCFC); and

5. Solid oxide fuel cell (SOFC).

Fuel cells can also be grouped based on the charge of ions that are carried between the electrodes. In some fuel cells, positive ions move from the anode to the cathode to produce water and heat by reacting with oxygen (such as PEFC and PAFC). In others, however, negative ions move from the cathode to the anode (such as AFC, MCFC, and SOFC). Some fuel cells are classified by their fuel. The most important and well know fuel cells in this categorization are direct methanol fuel cells (DMFC) and direct carbon fuel cells (DCFC). For instance, the DCFC is a concept of which solid carbon is used directly in a SOFC, MCFC, or AFC with exceptionally high efficiency, due to the thermodynamics of the reactions.

As noted, the type of electrolyte determines the operating temperature of a fuel cell, which in turn dictates the material for other components. Different operating temperatures provide characteristics for each type of fuel cell, making them suitable for various applications.

Low temperature fuel cells: The low operating temperature of this type of fuel cells, usually lower than $200^{\circ} \mathrm{C}$, including PEFC, AFC, and PAFC, provides them with some advantages, most important of which are faster start-up and usually higher efficiency. However, the low temperature fuel cells require expensive electro-catalysts (mostly platinum). Therefore, they 
should be fueled with hydrogen with high purity (with some exceptions, such as DMFC), since some fuel gases, like carbon monoxide, can poison platinum.

High temperature fuel cells: The operating temperature of high temperature fuel cells, SOFC and $\mathrm{MCFC}$, is between $500^{\circ} \mathrm{C}$ and $1000^{\circ} \mathrm{C}$. Unlike low temperature fuel cells, they can operate with less expensive electro-catalysts and require minimal processing of conventional fuels. Some fuel components, like $\mathrm{CO}$ and $\mathrm{CH}_{4}$, not only do not poison the fuel cell, but also can be internally reformed to produce hydrogen rich streams or even directly participate in the electrochemical reactions. The high temperature fuel cells are particularly suitable for stationary power generation, although they have been proposed for other applications as well. In addition, the high temperature exhaust stream of this type of fuel cells contains a considerable amount of energy, which can be used to generate further power and/or thermal energy by integrating bottoming cycle, such as a gas turbine or a waste heat recovery subsystem.

The following sections present a brief introduction to different types of fuel cells based on the type of the cell's electrolyte.

\subsection{Polymer electrolyte fuel cell (PEFC)}

The electrolyte in this type of fuel cell is an acidic solid proton exchange membrane (PEM), such as perfluorinated sulfonic acid polymer, which is an excellent positive ion conductor. Due to a restriction in the operating temperature of the membrane, the fuel cell operates at a low temperature, typically between $60^{\circ} \mathrm{C}$ and $100^{\circ} \mathrm{C}$. Sometimes the PEFC are called proton exchange membrane fuel cells or polymer electrolyte membrane fuel cells (PEMFC) or solid polymer electrolyte fuel cells (SPEFC).

Both anode and cathode electrodes are made of porous carbon with impregnated platinum as electro-catalyst. Interconnections can be made of carbon or metals. The PEFC can be directly fueled either by hydrogen or methanol. For other fuels, however, an extensive fuel reforming is essential because the anode can be easily poisoned by $\mathrm{CO}$ (even with a concentration of as low as 10 ppm (Young, 2007)), sulfurs, and ammonia. A critical point in the PEFC design and operation is water management to provide sufficient water to hydrate membranes and avoid their flooding. Low operating temperature, high current density, low start-up time, compactness, and light weight make this type of fuel cell an ideal candidate for transportation applications. These attributes also suit other applications, such as stationary, combined heat and power cogeneration (CHP), and portable applications.

The main challenges for commercialization of PEFC are water management, thermal management, fuel processing, and durability in severe ambient conditions. The amount of required platinum as electro-catalysts has been reduced significantly in the past two decades, from $28 \mathrm{mg} / \mathrm{cm}^{2}$ to $0.2 \mathrm{mg} / \mathrm{cm}^{2}$ (Larminie \& Dicks, 2003).

A specific type of PEFCs is direct methanol $\left(\mathrm{CH}_{3} \mathrm{OH}\right)$ fuel cells (DMFC). This fuel cell, which is sometimes called a direct alcohol fuel cell (DAFC), is a PEFC directly fed by methanol or other alcohols. Due to its simplicity and compactness, the main application for DMFC is in portable application to replace lithium ion batteries.

\subsection{Alkaline fuel cell (AFC)}

In AFCs, the electrolyte is a corrosive mixture of potassium hydroxide $(\mathrm{KOH})$ in water. The concentration of the mixture determines the operating temperature of the fuel cell. For low operating temperature (less than $120^{\circ} \mathrm{C}$ ), low concentration of the mixture (between 35 and 
$50 \mathrm{wt} \%$ ) is required, whereas a concentration of $85 \mathrm{wt} \%$ is more suitable for high operating temperature (around $250^{\circ} \mathrm{C}$ ). The electrodes are metallic and usually an asbestos matrix is required to retain the liquid electrolyte. The AFCs' flexible choice of electro-catalyst (from nickel and metal oxides to noble metals) is one of their advantages. The development of AFCs began in the 1960s and resulted in their application in the Apollo Space missions to generate electricity and water. The system's performance with hydrogen as fuel and oxygen as oxidizer was remarkable. However, the system can be strongly poisoned by carbon monoxide and carbon dioxide, which prevent the system from operating with air and conventional fuels. Due to this problem, their development has nearly been ceased.

\subsection{Phosphoric acid fuel cell (PAFC)}

The electrolyte of PAFC is corrosive 100\% concentrated phosphoric acid, and the electrodes are mainly made of porous carbon and graphite. In order for phosphoric acid to exhibit satisfactory ionic conductance, an operating temperature of above $150^{\circ} \mathrm{C}$ is required. In PAFC, similar to PEFC, protons are the charge carriers in the electrolyte, and platinum is used as an electro-catalyst for both the anode and the cathode. Thus, the electrochemical reactions in PAFCs are the same as PEFCs, but they occur at a higher temperature. This type of fuel cell can tolerate temperatures up to $220^{\circ} \mathrm{C}$ due to the stable nature of phosphoric acid (unlike other acids). This relatively high operating temperature reduces the sensitivity of these fuel cells to $\mathrm{CO}$ poisoning, while common construction materials can still be used in the balance of plant construction. However, the corrosive nature of the electrolyte necessitates application of special material in the fuel cell stack construction. The water and thermal management are relatively easy in the PAFC. Other major technical challenges are slow start-up, loss of the electrolyte, and expensive electro-catalyst. PAFC is one of the few fuel cells that are currently commercially available, especially for stationary applications. However, their development suffered a slowdown due to their high costs (Young, 2007).

\subsection{Molten carbonate fuel cell (MCFC)}

In MCFC, the electrolyte is usually a corrosive mixture of molten alkali carbonates retained in a porous ceramic matrix, which can conduct negative ions $\left(\mathrm{CO}_{3}{ }^{\circ}\right)$ at high temperature (about $600^{\circ} \mathrm{C}$ to $700^{\circ} \mathrm{C}$ ). The electrodes are commonly made of nickel and nickel oxide and due to sufficient activity of the electrodes, there is no need for noble metal as an electro-catalyst. Due to their high operating temperature, MCFCs have relatively large size, weight, and slow startup. Thus, they are more suited for stationary and marine applications. In fact, commercial MCFCs are available in the market for stationary applications and several multi-megawatt demonstration power stations were installed. Because of the high operating temperature, $\mathrm{CO}$ is not harmful for system operation, but along with other conventional fuels, can be internally reformed to provide a hydrogen rich stream for the anode. MCFCs also can be combined with a bottoming cycle to make use of waste exhaust heat to generate further power and/or heat. The corrosive nature of the electrolyte, loss of the electrolyte, and low power density are the main challenges for this type of fuel cell. Moreover, the system requires a $\mathrm{CO}_{2}$ injection to the cathode to produce carbonate ions, which increase system complexity and cost.

\subsection{Solid oxide fuel cell (SOFC)}

In SOFCs, the electrolyte is a solid ceramic (nonporous metal oxide), which demonstrates sufficient ionic conduction for oxygen ions at a high operating temperature, between $500^{\circ} \mathrm{C}$ 
and $1000^{\circ} \mathrm{C}$. The electro-catalyst is non-noble metal or other less expensive material, and the electrolyte, cathode, and anode are typically made of $\mathrm{Y}_{2} \mathrm{O}_{3}$-stabilized $\mathrm{ZrO}_{2}$, Sr-doped $\mathrm{LaMnO}_{3}$, and $\mathrm{Ni}-\mathrm{ZrO}_{2}$ cermet, respectively.

Major technical challenges are relatively expensive construction material, long start-up time, durability, and sealing of the cells. These problems can be intensified at higher temperatures. That is why lower operating temperature is desired, and there have been numerous studies to reduce the operating temperature even as low as around $500^{\circ} \mathrm{C}$ by using a thinner electrolyte. Stationary power generation, mobile power, and auxiliary power for vehicles are considered as potential applications of SOFCs. Similar to MCFC, SOFC can be integrated to bottoming cycles or heat and power cogeneration plants to increase the overall efficiency of the plant, up to $70 \%$ (Calise et al., 2006). A detailed review of the SOFC will be presented in subsection 10 .

\section{Application of fuel cells}

There are many potential applications for fuel cells. However, in order to recognize the specific fuel cell type for each application, the attribute of the desired system should match the specifications required for particular applications. Most likely, it is not possible to find a system that perfectly satisfies all preferences for an application; therefore, the parameters should be ranked based on their priorities. The desired attributes can be one or several of the following characteristics: cost, efficiency, durability, power density, simplicity, rapid start-up, compactness, robustness, etc. This list is not exhaustive, and for every application other parameters may be added. In the following section, the main potential applications of fuel cells will be investigated.

Stationary and distributed power generation: For the stationary electricity generation, the main desired characteristics are high efficiency and long lifetime. Therefore, compactness, simplicity, and weight are not major constraints for this application. Their power generation capacity ranges from a few hundred $\mathrm{kW}$ to several $\mathrm{MW}$ for the following potential applications:

- $\quad$ Residential power generation;

- On-site industrial electricity generation;

- Backup power supply;

- Combined heat and power cogeneration (CHP);

- Continuous and uninterrupted electricity production.

Fuel cells are particularly suitable for distributed power generation, because the capital costs and efficiency are almost unaffected by the plant size. This means the cost of generated electricity for small power generation plants is close to that of the larger ones and is relatively insensitive to scale. With a well developed natural gas distribution network in urban and industrial regions, this characteristic provides a unique opportunity for residential and industrial on-site and distributed power generation. Fuel cells' modular nature can help them to match demand load specifications. In addition, high efficiency at partial loads, low air pollution, and quiet operation are other important positive attributes of fuel cells, especially for residential applications. Also, coal gasifier requirements closely match the high temperature fuel cell operational conditions. Thus, an integrated system can be developed to use inexpensive coal to generate electricity with high efficiency.

Transportation applications: Due to their high efficiency and low emissions, applications of fuel cells, especially PEFCs, to power light- and heavy-duty vehicles have been a very 
attractive concept. There have been tremendous investments to develop such vehicles, and hundreds of demonstration vehicles are in different stages of development and tests; however, technical and economic constraints and lack of hydrogen infrastructure slow down the progress in this field. The successful introduction of hybrid electric and combustion engine cars and more recently plug-in electric cars has intensified the competition. It seems that the application of fuel cells as the primary power source of vehicles could not be realized, and utilization of fuel cells as a backup power source for plug-in electric cars is more probable.

Portable applications: In this application, DMFCs are employed for powering portable devices, such as laptop computers and cell phones. This is most likely the first application in which fuel cells can be utilized. This is due to the comparable cost of current fuel cells and lithium ion batteries and uninterrupted operation of fuel cell powered devices with replaceable fuel cartridges.

Other applications: Fuel cells are potential candidates wherever electricity is required; however, some applications fit the characteristics of fuel cells more closely. A few of these niche applications are auxiliary power units (APUs) for vehicles, electricity storage by regenerative (reversible) fuel cells, space applications, and military applications. Moreover, some innovative applications have been proposed in the literature.

\section{Comparison of fuel cells}

Table 1 summarizes the characteristics of various types of fuel cells, including the suitable material for different components, operating temperature, and potential applications.

Fuel cells were invented in the 19th century; however, it took more than a century before the first operational fuel cell was made. Over the past two decades, there have been tremendous R\&D activities and dramatic improvements in this field. As noted in Table 1, most types of fuel cells, especially SOFC and MCFC, can be used for stationary power generation. For this work, SOFC will be further investigated for power generation application, which reflects the present level of interests in the field.

\section{Solid oxide fuel cells}

In the 1890s, Walther Nernst, a German scientist, was the first to observe the ion conductivity of stabilized zirconia at high temperature. His observation was used to build the first SOFC in the 1930s. The SOFC's actual development started in the 1950s, which gave SOFC the longest continuous development period among different types of fuel cells. An excellent historical and technical review of SOFCs can be found in Singhal \& Kendall (2006), and also in Williams et al. (2006) and Singhal (2002). Moreover, Dokiya (2002) studied materials and fabrication technologies deployed for manufacturing of different cell components, investigated the performance of the fuel cells manufactured using these materials, and reviewed efforts to reduce fuel cell costs.

As noted in the previous section, among different types of fuel cells, high temperature fuel cells, SOFC and MCFC, are very attractive for stationary power generation. Because of high operating temperature, their application can lead to some advantages such as:

- ability to incorporate bottoming cycles to generate further power and/or thermal energy;

- co-production of hydrogen and electricity (Williams et al., 2006); 


\begin{tabular}{|c|c|c|c|c|c|}
\hline & PEFC & AFC & PAFC & MCFC & SOFC \\
\hline $\begin{array}{l}\text { Electrolyte } \\
\text { material }\end{array}$ & $\begin{array}{l}\text { Acidic solid } \\
\text { proton } \\
\text { exchange } \\
\text { membrane }\end{array}$ & $\begin{array}{c}\text { Potassium } \\
\text { hydroxide } \\
(\mathrm{KOH})\end{array}$ & $\begin{array}{l}\text { Phosphoric } \\
\text { acid }\end{array}$ & $\begin{array}{l}\text { Molten alkali } \\
\text { carbonates }\end{array}$ & Ceramic \\
\hline $\begin{array}{c}\text { Electrode } \\
\text { material }\end{array}$ & $\begin{array}{l}\text { Porous } \\
\text { carbon }\end{array}$ & Metals & $\begin{array}{c}\text { Porous carbon } \\
\text { or graphite }\end{array}$ & $\begin{array}{c}\text { Nickel or } \\
\text { nickel oxide }\end{array}$ & Ceramic \\
\hline Catalyst material & Platinum & $\begin{array}{c}\text { Nickel, metal } \\
\text { oxides, or } \\
\text { noble metals }\end{array}$ & Platinum & $\begin{array}{l}\text { Electrode } \\
\text { material }\end{array}$ & $\begin{array}{c}\text { Electrode } \\
\text { material }\end{array}$ \\
\hline $\begin{array}{c}\text { Interconnections } \\
\text { material }\end{array}$ & $\begin{array}{l}\text { Carbon or } \\
\text { metals }\end{array}$ & Metal & Graphite & $\begin{array}{c}\text { Nickel or } \\
\text { stainless steel }\end{array}$ & $\begin{array}{c}\text { Nickel, } \\
\text { ceramic, or } \\
\text { stainless steel }\end{array}$ \\
\hline $\begin{array}{c}\text { Prime cell } \\
\text { components }\end{array}$ & Carbon & Carbon & Graphite & Stainless steel & Ceramic \\
\hline Mobile ion & $\mathrm{H}^{+}$ & $\mathrm{OH}^{-}$ & $\mathrm{H}^{+}$ & $\mathrm{CO}_{3}=$ & $\mathrm{O}^{=}$ \\
\hline $\begin{array}{c}\text { Operating } \\
\text { temperature }\end{array}$ & $60^{\circ} \mathrm{C}$ to $100^{\circ} \mathrm{C}$ & $50^{\circ} \mathrm{C}$ to $220^{\circ} \mathrm{C}$ & $\begin{array}{l}200^{\circ} \mathrm{C} \text { to } \\
220^{\circ} \mathrm{C}\end{array}$ & $\begin{array}{l}600^{\circ} \mathrm{C} \text { to } \\
700^{\circ} \mathrm{C}\end{array}$ & $\begin{array}{l}500^{\circ} \mathrm{C} \text { to } \\
1000^{\circ} \mathrm{C}\end{array}$ \\
\hline $\begin{array}{c}\text { Electrolyte } \\
\text { poisons }\end{array}$ & $\mathrm{CO}$ & $\begin{array}{l}\mathrm{CO}, \mathrm{CH}_{4} \\
\mathrm{CO}_{2}, \mathrm{H}_{2} \mathrm{~S}\end{array}$ & $\mathrm{CO}, \mathrm{H}_{2} \mathrm{~S}$ & $\mathrm{H}_{2} \mathrm{~S}$ & $\mathrm{H}_{2} \mathrm{~S}$ \\
\hline $\begin{array}{c}\text { Internal fuel } \\
\text { reforming }\end{array}$ & No & No & No & Yes & Yes \\
\hline Applications & $\begin{array}{c}\text { Vehicles, } \\
\text { mobile, small } \\
\text { CHPs } \\
\text { (DMFC: } \\
\text { portable } \\
\text { electronic } \\
\text { systems) }\end{array}$ & $\begin{array}{c}\text { Space } \\
\text { vehicles }\end{array}$ & $\begin{array}{c}\text { Medium-scale } \\
\text { stationary and } \\
\text { CHPs }\end{array}$ & $\begin{array}{c}\text { Medium- and } \\
\text { large-scale } \\
\text { stationary, } \\
\text { hybrid, and } \\
\text { CHPs }\end{array}$ & $\begin{array}{l}\text { All sizes of } \\
\text { stationary } \\
\text { stand alone } \\
\text { and hybrid } \\
\text { systems, } \\
\text { CHPs, and } \\
\text { APUs }\end{array}$ \\
\hline
\end{tabular}

Table 1. Summary of the characteristics of various types of fuel cells

- ability to reform hydrocarbons, including pipeline and liquefied natural gas, diesel, biogas, gasoline, coal syngas, etc., which results in fuel flexibility;

- capability to consume CO as fuel;

- $\quad$ no need for noble metal as electro-catalysts due to high reaction rates.

And in the case of SOFC:

- high oxide-ion conductivity;

- high energy conversion efficiency due to high rate of reaction kinetics;

- $\quad$ solid electrolyte and existence of only solid and gas phases resulting in:

- $\quad$ simplicity in concept;

- ability to be cast into various forms and configurations (that is why a wide range of cell and stack geometries have been proposed for SOFC);

- accurate and appropriate design of the reaction sites;

- no electrolyte management constraints.

Stationary and distributed power generation and auxiliary power units (APUs) for vehicles are the main potential applications of SOFCs, the latter being most likely the first real 
market for such. However, before power generation with SOFCs can be commercialized, some technical challenges should be addressed, including the cost of materials and manufacturing, system life, thermal cycling, limited power density, mismatch of thermal expansion coefficient of different components and sealing problem in planar configuration, materials selection at high temperature especially metal interconnections (Williams et al., 2006), and corrosion in some components.

In the following sections, SOFC components, stack configurations, and balance of plant will be briefly introduced.

\section{SOFC components}

Fig. 2 illustrates the schematic of a typical planar SOFC, including its components and flow paths. Similar to other fuel cells, a SOFC can be broken down into four main components: the electrolyte, anode, cathode, and interconnections.

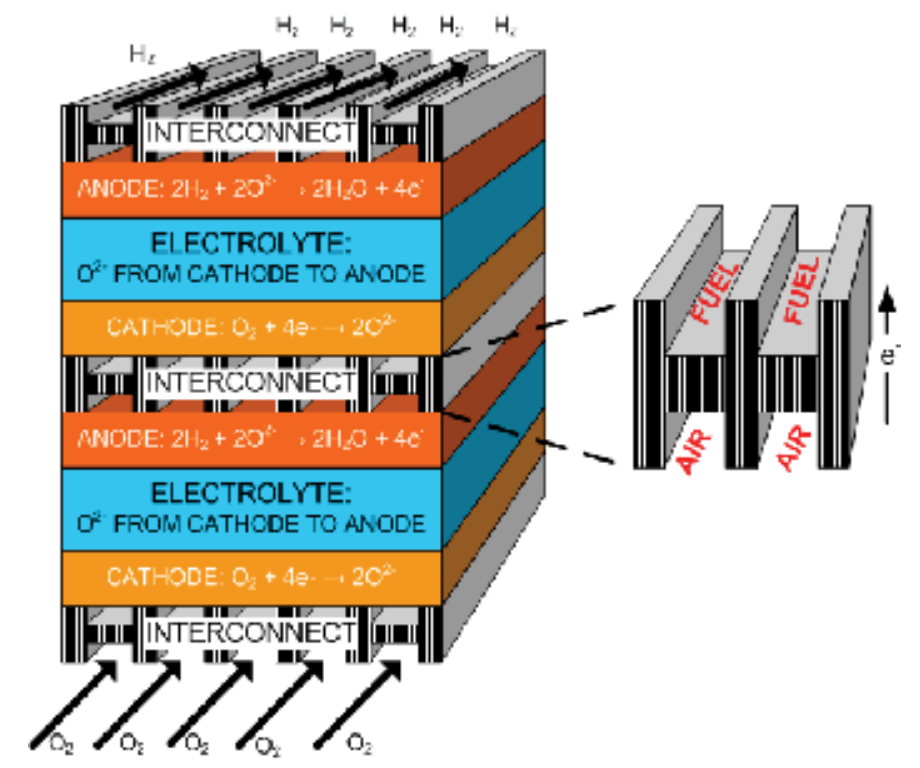

Fig. 2. Schematic of a typical planar SOFC (Suther et al., 2010)

In SOFCs, oxygen is reduced and gains electrons to produce free negatively charged oxygen ions. The electrons required for oxygen reduction are provided from the anode and via external electric load. The oxygen ions immigrate across the oxide-ion conducting electrolyte to the anode. In the anode, the negative ions participate in reactions with fuel to generate steam or carbon dioxide. The actual electrochemical reactions and the products depend on the reductant agents: hydrogen, carbon monoxide, or even methane (these reactions are presented in Fig. 2 for hydrogen as fuel). The reactions in the anode release electrons, which in turn are collected and transferred by the interconnections to generate external electric current.

The electrolyte of SOFC must have high ionic conductivity for the oxygen negative ions as well as low electrical conductivity. Several electrolytes have been proposed for SOFCs, which can be grouped in two categories based on their molecular structure: fluoritestructured and perovskite-structured. All these materials show sufficient ionic conductivity at high temperature, and that is the reason for the high operating temperature of SOFCs. 
The oxygen ions conduction in fluorite-structured materials is due to oxide ion vacancies and interstitial oxide ions. Zirconia- and ceria-based materials are the two most common fluorite-structured electrolytes. In order for zirconia to exhibit sufficient ionic activity at reasonable temperature, it should be doped with other substances, such as yttria and scandia. Both yttria-stabilized zirconia (YSZ) and scandia-stabilized zirconia (SSZ) have been used as electrolytes for SOFCs, the former being the most favored. The ceria-based electrolytes, with many different dopants, have been proposed and utilized mainly for low temperature SOFCs.

Perovskites are compounds of the form $\mathrm{ABO}_{3}$, ( $\mathrm{A}$ and $\mathrm{B}$ are cations with very different sizes) and few of such structure materials have an ionic conduction property. The most common perovskite compound suitable for the electrolyte in SOFCs is $\mathrm{LaAlO}_{3}$.

Among many compounds which have been investigated for use as electrolytes in SOFC, zirconia-based compounds are still the most suitable ones due to their stability, low electric conductivity, and high ion conductivity above $800^{\circ} \mathrm{C}$ (Singhal \& Kendall, 2002).

For electrodes, the material should be highly catalytic for the specific reaction at the particular electrode and good electrical conductor. Also, they should not react with electrolyte material during not only the fuel cell operation, but also manufacturing process, and have thermal expansion coefficient close to the other components.

In early stages of SOFC development, noble metals, such as platinum and gold, were used for the anode and cathode. However, due to high cost as well as physical and chemical instability of these precious metals, they were replaced with other less expensive materials with more desirable properties. The most common material for anode is cermet of nickel and YSZ and for cathode are lanthanum-based perovskite materials such as Sr- or Ca-doped $\mathrm{LaMnO}_{3}$ (Singhal, 2002). Because of some undesirable characteristics of these materials, such as sensitivity to some contaminants, mismatch of thermal expansion coefficient with other cell components, poor activity for direct electrochemical reactions of hydrocarbons, and potential carbon formation (EG\&G Services, 2004), the research of finding better options for the electrodes is ongoing.

For interconnections, at high temperature SOFCs perovskite-based materials, such as Ca- or Sr-doped $\mathrm{LaCrO}_{3}$ and at lower temperature SOFCs inexpensive metallic alloys are very common (Singhal, 2002). It should be noted that the requirements of interconnections are the most severe among SOFC components, because they are exposed to both air and fuel (Singhal, 2000b).

\section{Configurations of SOFCs}

Due to the solid state electrolyte in SOFCs, there are fewer limitations in their design. That is why wide range of cell and stack geometries have been proposed for SOFCs. As noted earlier, the configuration of SOFCs can be categorized into two main groups: the flat plate and the tubular configurations.

Tubular fuel cells were specifically designed for SOFC and most progress in SOFC design has been achieved for this type (Singhal, 2000b). This design solved the sealing problem and provides excellent mechanical integrity for the stack. In this design, the electrodes and electrolyte are in the form of different layers on a tube. In earlier designs, these layers were deposited over a cylindrical tube that did not participate in the electrochemical process (Bevc, 1997). But in current designs, the tube is made of lanthanum manganite and functions as the cathode as well as mechanical support (Singhal \& Kendall, 2002). In any case, for 
operation of this type of SOFC, fuel is passed outside the tube, while air is passed inside the inner cathode tube. Siemens Westinghouse has been historically the pioneer in the tubular SOFC design and manufacturing since 1984 (Singhal, 2000a). The latest development in this design is flat-tube design, which is less expensive and has higher power density (Young, 2007). This design is similar to tubular design only with flattened tubes which incorporates ribs inside the cell. The ribs reduce the current path, like a bridge for electrons, decreasing the cell internal resistance. They can also help to reduce the thickness of cathode and its overpotential (Singhal, 2000a). Another innovative design, developed by Rolls-Royce and called integrated-planar SOFC (IP-SOFC), is a combination of the two aforementioned designs. This type of SOFC enjoys the lower fabrication cost of the planar SOFC and thermal-mechanical strength of the tubular SOFC (Young, 2007).

However, the tubular SOFCs suffer both low specific power density $\left(\mathrm{W} / \mathrm{cm}^{2}\right)$ and volumetric power density $\left(\mathrm{W} / \mathrm{cm}^{3}\right)$ due to longer current path and thus higher electrical resistance (Singhal, 2002). Also, their fabrication cost is high, and there is not much potential to reduce this cost. Last but not least, due to the relatively high thickness of the electrolyte, their operating temperature is high. These problems are partially solved in planar SOFCs. They can achieve high power density. Their manufacturing cost is relatively lower due to the possibility of using a boarder set of materials, and can be significantly reduced by mass production and the economy of scale. Also, the electrode-supported planar SOFCs can be made of very thin electrolyte, which means they can operate at lower temperature (as low as $500^{\circ} \mathrm{C}$ ). This is very important for some applications such as APUs for vehicles. Furthermore, lower operating temperature results in simpler BoP, easier thermal management, less degradation of the components, and faster start-up and cool down. However, the temperature gradient and heat cycles as well as slight mismatch in thermal expansion coefficient between cell components can cause huge thermal stress, as high as several tens of MPa (Yakabe et al., 2001), which makes the sealing of the stack more challenging.

For the tubular SOFC, a power density of about $0.3 \mathrm{~W} / \mathrm{cm}^{2}$ with degradation rate of less than $0.1 \%$ per 1000 hours of operation and fuel utilization factor of about $85 \%$ and for the planar SOFC a power density of about $2 \mathrm{~W} / \mathrm{cm}^{2}$ with fuel utilization factor of about $95 \%$ has been reported (Singhal, 2002, 2000a; Williams et al., 2006).

\section{Hybrid SOFC cycles}

As mentioned earlier, one of the advantages of high temperature fuel cells is their capability to be integrated to a bottoming cycle, so that exhaust thermal energy can be used to generate further useful energy in the form of electricity and/or heat. Singhal (2000a) reported that due to higher efficiency and availability as well as low maintenance costs, the hybrid SOFC plants could compete with conventional power generation systems. In a fuel cell hybrid cycle, both SOFC and MCFC can be utilized in the fuel cell stack, but the focus of this work is only on SOFC hybrid cycles, which reflects current trend in the field.

The high temperature of SOFC products provides very good potential for hybrid SOFC systems, especially for distributed generation (DG). The outlet temperature of SOFCs perfectly matches the requirement of modern gas turbines (Calise et al., 2007). Rajashekara (2005) classified the hybrid fuel cell systems as Type-1 and Type-2 systems. They are mainly suited for combined cycles power generation and backup or peak shaving power systems, respectively. An example of Type-1 hybrid systems is hybrid fuel cell and gas turbine (GT) 
cycle, where high temperature of fuel cell off-gas is used in GT to increase the efficiency of combined system. Another example of this type of combined cycle is designs that combine different fuel cell technologies. Examples of Type-2 hybrid systems are designs that combine a fuel cell with wind or solar power generation systems which integrate the operating characteristics of the individual units such as their availability of power.

By definition, proposed by Winkler et al. (2006), any combination of a fuel cell and a heat engine can be considered as fuel cell hybrid system. Therefore, a hybrid cycle can be any combination of SOFC and gas turbine, steam and gas turbine combined cycle power plant (CCPP), steam turbine, coal integrated gasification (IG), integrated gasification combined cycle (IGCC), and application in combined cooling and/or heating, and power (CCHP/CHP) cycles. These power cycles are investigated later in subsection 14 .

The operating pressure of SOFC affects the types of bottoming cycle that can be integrated into the system. In Type- 1 hybrid systems, if the fuel cell is operated at atmospheric pressure, the exhaust gases can be passed through series of heat exchangers to generate hot water and/or low pressure steam for industrial applications (Riensche \& Fedders, 1993) or high pressure steam for a Rankine power cycle. The latter scheme was proposed as early as 1990 (Dunbar et al., 1990). The fuel cell may also be operated at elevated pressure. In this case, the pressurized hot combustion gases exiting combustor at the bottom of SOFC can be used to drive a gas turbine with or without a bottoming steam cycle. This scheme was proposed in 1991 (Donitz et al., 1991).

Among various hybrid schemes proposed for pressurized fuel cells, probably SOFC-GT hybrid cycles are the most popular systems being studied theoretically and the only one being studied experimentally. There are two main designs to combine SOFC and GT. The difference between these designs is how they extract heat from fuel cell exhaust. In the first design, fuel cell off-gas directly passes through GT. That means the gas turbine combustor is replaced by the fuel cell stack. But in the second scheme, the fuel cell off-gas passes through a high temperature recuperator, which, in fact, replaces the combustor of the gas turbine cycle (Roberts et al., 2006). From operational point of view, these designs are distinguished by the operating pressure of the fuel cell. Their operating pressure is equal to operating pressure of the gas turbine and slightly above atmospheric pressure, respectively. It should be mentioned that in all cases a steam cycle (Campanari \& Macchi, 1998) and CHP plants can be integrated into the hybrid system to recover more energy from exhaust.

So far, to the authors' best knowledge, there have been three proof-of-concept and demonstration SOFC-GT power plants installed in the world. Siemens Westinghouse claimed that it successfully demonstrated its pressurized SOFC-GT hybrid system and has two units, a $220 \mathrm{~kW}$ at the University of California, Irvine and a $300 \mathrm{~kW}$ unit in Pittsburgh (Veyo et al. 2002a). Also, in 2006 Mitsubishi Heavy Industries, Ltd. (MHI, Japan) claimed that it succeeded in verification testing of a $75 \mathrm{~kW} \mathrm{SOFC-Micro} \mathrm{gas} \mathrm{turbine} \mathrm{(MGT)} \mathrm{hybrid}$ cycle (http://www.mhi.co.jp/en/news/sec1/200608041128.html). These experiences prove the possibility of integrating SOFC and gas turbine. However, they showed that this integration was not necessarily straightforward, and finding a GT with operational condition close to SOFC exhaust condition and coupling them could be extremely challenging (Calise et al., 2007).

The advanced cycles that can be used as bottoming cycle for SOFCs are briefly explained in the following subsection. 


\section{Advanced power generation cycles}

Power cycles are thermodynamic cycles of which their objective is to generate power. The power cycles can be categorized based on several characteristics from thermodynamic point of view:

Gas and vapor cycles: In this categorization the cycles are distinguished based on the phase of the working fluid of the cycle. If the working fluid phase remains unchanged (gaseous phase), it is called gas cycle. On the other hand, in a vapor cycle, the working fluid can be in both gaseous and liquid forms in different parts of the cycle.

Open and closed cycles: If working fluid is recycled and returned to its initial condition, the cycle is called closed cycle. But in an open system, in each cycle, the working fluid is discharged to the surrounding and replaced by a fresh feed. The open system is mechanically, but not thermodynamically, a cycle.

Internal and external combustion engines: Unlike previous cases, this categorization is based on the source of heat and not the cycle's working fluid. In internal combustion cycles, the required heat for the cycle is provided from combustion of fuel in the system, as in gas turbines. But in external combustion engines, the heat should be transferred from an external source, as in steam cycles.

It should be noted that there are power generation cycles that do not fit into some of these categorizations, such as fuel cells. In this subsection, some basic and advanced power generation systems, namely gas turbines, steam cycles, combined cycles, and integrated gasification combined cycles as well as some technologies to improve performance of the cycles, such as gas turbine inlet air cooling and $\mathrm{CO}_{2}$ capture and storage technologies are briefly introduced. In this section, there is not enough space to explain the thermodynamic principles of the cycles, so it is advisable that readers review these topics in a basic thermodynamic book.

\subsection{Carnot cycle}

The Carnot cycle is the most efficient and simplest thermodynamic cycle. It consists of two isentropic (and adiabatic) and two isothermal processes. Fig. 3 shows the temperatureentropy diagram of a Carnot cycle (blue dashed line) that operates between a heat source and sink with temperatures of $1572 \mathrm{~K}$ and $293 \mathrm{~K}$, respectively. All processes are reversible and cycle efficiency can be estimated by following equation:

$$
\eta=1-\frac{T_{L}}{T_{H}}
$$

where $\mathrm{T}_{\mathrm{H}}$ and $\mathrm{T}_{\mathrm{L}}$ are the absolute temperatures of heat source and sink, respectively. For the cycle in Fig. 3, this efficiency is about $81 \%$.

\subsection{Gas turbine}

A gas turbine theoretically operates based on a Brayton cycle. However, real gas turbines are usually operated based on an open cycle and consist of three main components: compressor, combustor, and gas turbine. Fig. 4 shows a schematic of basic gas turbine components in a simple gas turbine cycle model developed in Aspen Plus ${ }^{\circledR}$. The temperature-entropy diagram of this simple GT cycle is shown in Fig. 3 (gray solid line). In this cycle, air flow rate $=145 \mathrm{~kg} / \mathrm{sec}$, fuel (natural gas) flow rate $=2.7 \mathrm{~kg} / \mathrm{s}$, compressor 
pressure ratio $=34$, efficiency $=36.8 \%$ (based on lower heating value), and efficiency $=33.2 \%$ (based on higher heating value).

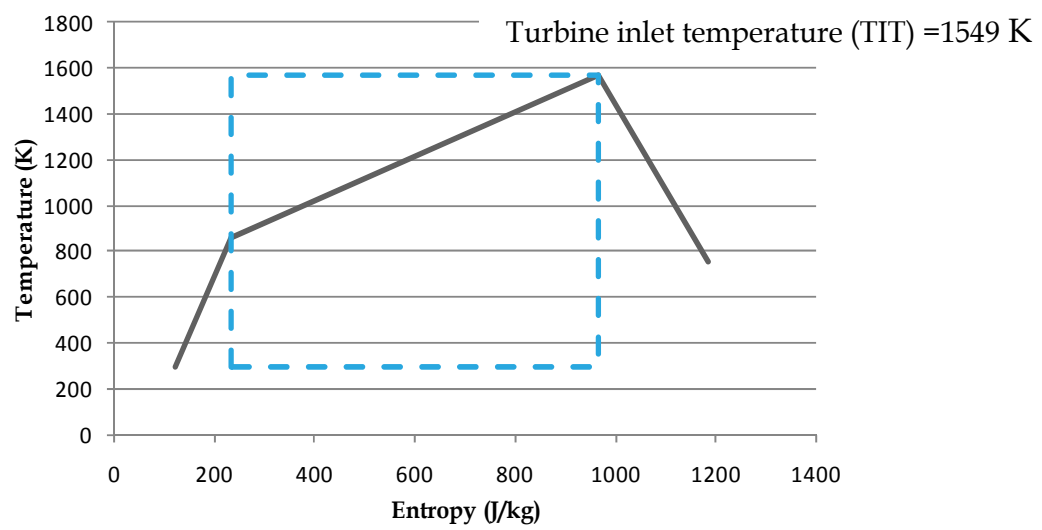

Fig. 3. T-S diagram of a Carnot cycle and a gas turbine cycle

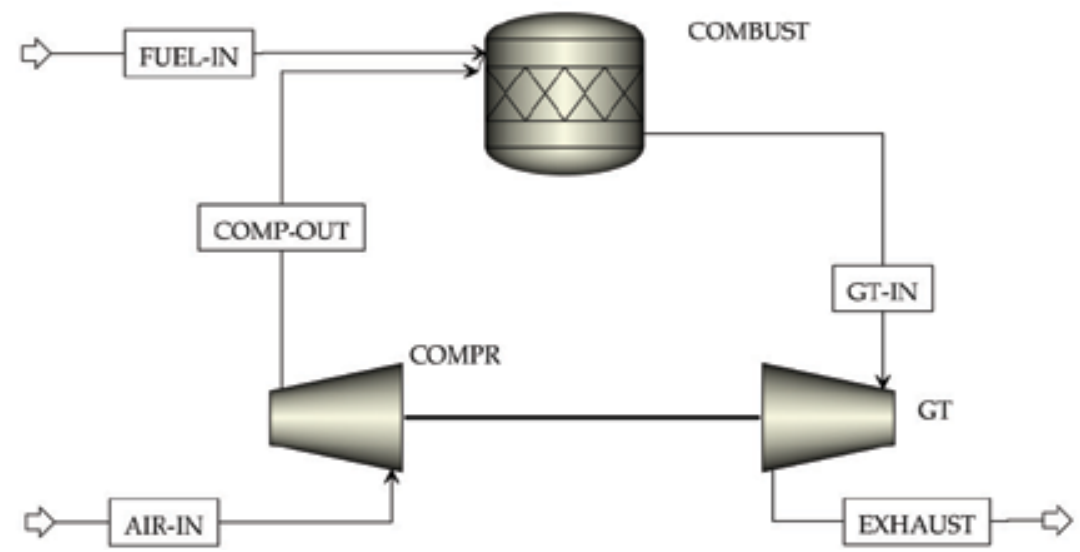

Fig. 4. Schematic of a simple gas turbine cycle in Aspen Plus ${ }^{\circledR}$

The turbine inlet temperature is an important parameter for GT design and operation, because it is the highest temperature throughout a specific gas turbine. The turbine inlet temperature (TIT) is limited by turbine blade material and the maximum permitted $\mathrm{NO}_{x}$ emission.

Gas turbines have been used in power generation industry for more than a century due to their low capital cost and short installation time. Also the short start-up and shut-down time of gas turbines make them a suitable option for peak load operation. Due to their widespread utilization, their technology is mature and very well developed.

Despite their wide application, there are two main problems in using simple gas turbines for power generation. First, the exhaust temperature of GTs is very high, which means highgrade energy is wasted and results in low efficiency of the system. Second, the output and efficiency of GTs and other cycles based on gas turbines strongly depend on ambient temperature and are reduced with higher ambient temperature. These two issues will be investigated in the following subsections (14.3 and 14.4). 


\subsection{Combined cycle power plant (CCPP)}

In order to improve efficiency of GTs, combining the gas turbine with a steam cycle is a suitable option. A schematic diagram of a steam cycle, working based on the Rankine cycle, is illustrated in Fig. 5.

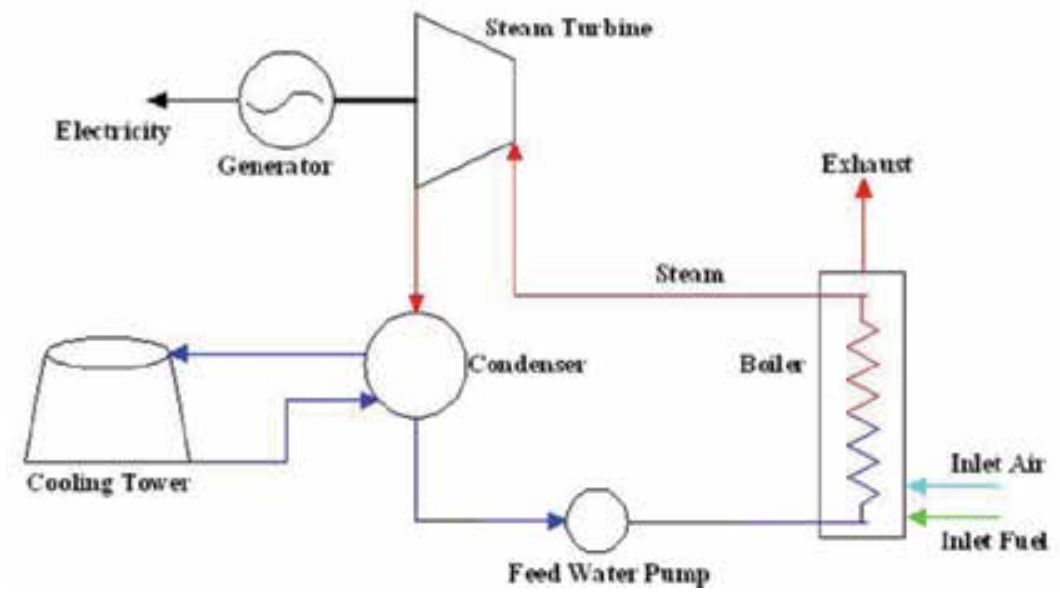

Fig. 5. Schematic of a simple steam power generation (Rankine) cycle

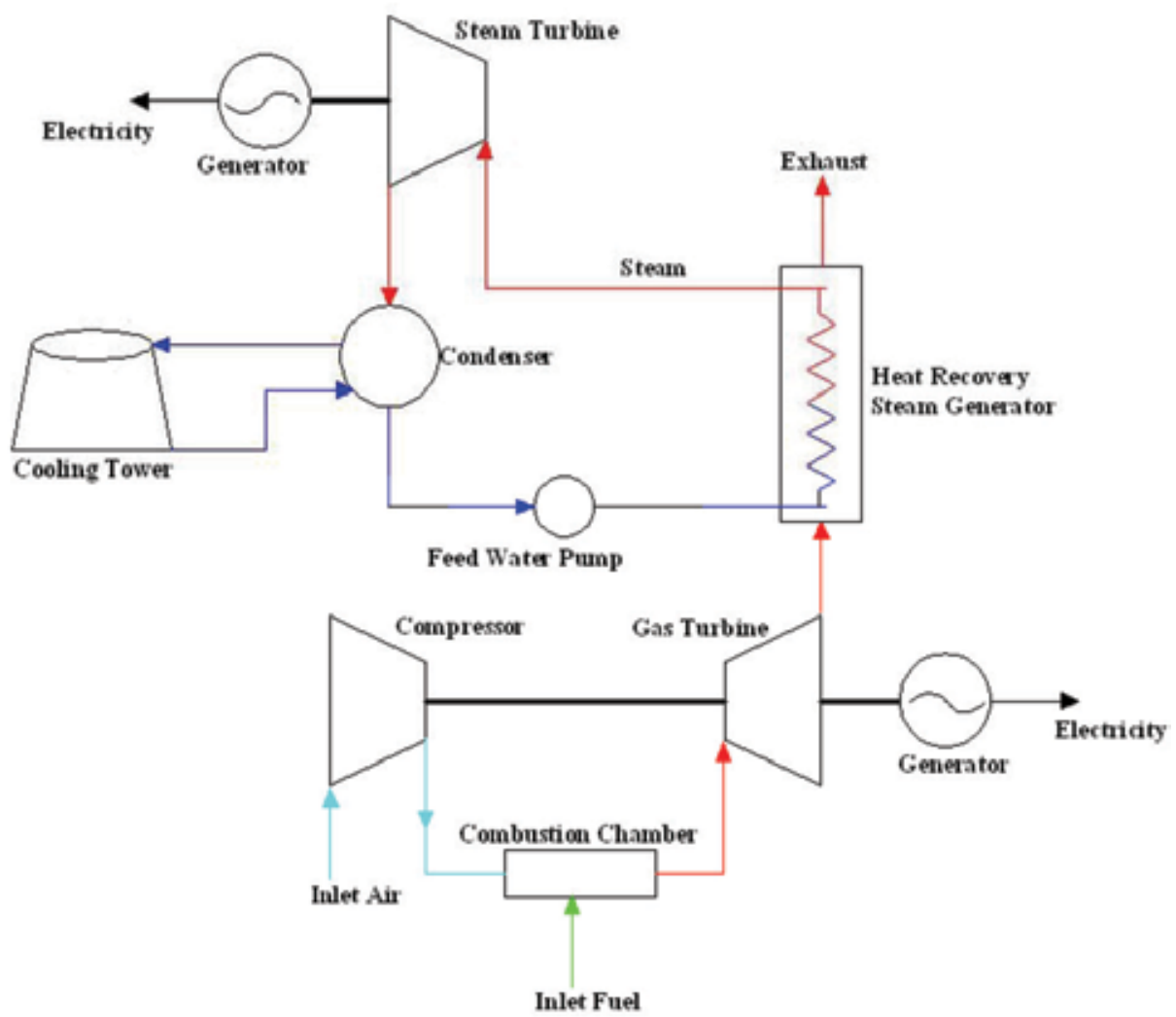

Fig. 6. Schematic of a simple combined cycle power plant 
In a combined cycle power plant, high temperature exhaust stream of the gas turbine is used to generate required steam for the steam cycle in a heat recovery steam generator (HRSG). This is possible because the inlet temperature to the turbine in a gas turbine, higher than $1400{ }^{\circ} \mathrm{C}$ for modern GTs, is much higher than that for steam turbine, around $600{ }^{\circ} \mathrm{C}$. A unit of CCPP consists of several GTs, usually two or three, a heat recovery steam generator, and a single steam cycle (Fig. 6). Very high efficiency, above $60 \%$, has been reported for recent modern CCPPs (Cengel \& Boles, 1998).

HRSG can be designed with or without additional firing. Additional firing is used to increase the inlet temperature of HRSG and as a result the output power of steam cycle; although the overall efficiency of the cycle reduces. In earlier CCPPs, this configuration was very common due to low temperature of the GT exhaust. However, due to simplicity of construction and the higher temperature of the exhaust stream of modern GTs, CCPP with no additional firing in HRSG, where all fuel is combusted in the GT cycle, is more common nowadays. In CCPP without additional firing, the efficiency and power output of the bottoming steam cycle is limited by the temperature and flow rate of gas turbine off-gas and the temperature of the exhaust stream at the stack. The stack temperature is bounded by the exhaust stream dew point to prevent acid corrosions.

Based on the HRSG arrangement, CCPP can be single-, two-, or three-pressure cycle. In the simplest configuration, the single-pressure cycle, HRSG can consist of either an economizer, an evaporator, and a superheater or an once-through boiler to generate steam with one pressure. The disadvantage of this configuration is its poor waste heat recovery efficiency. To improve this efficiency, a multi-pressure HRSG can be used to produce steam with

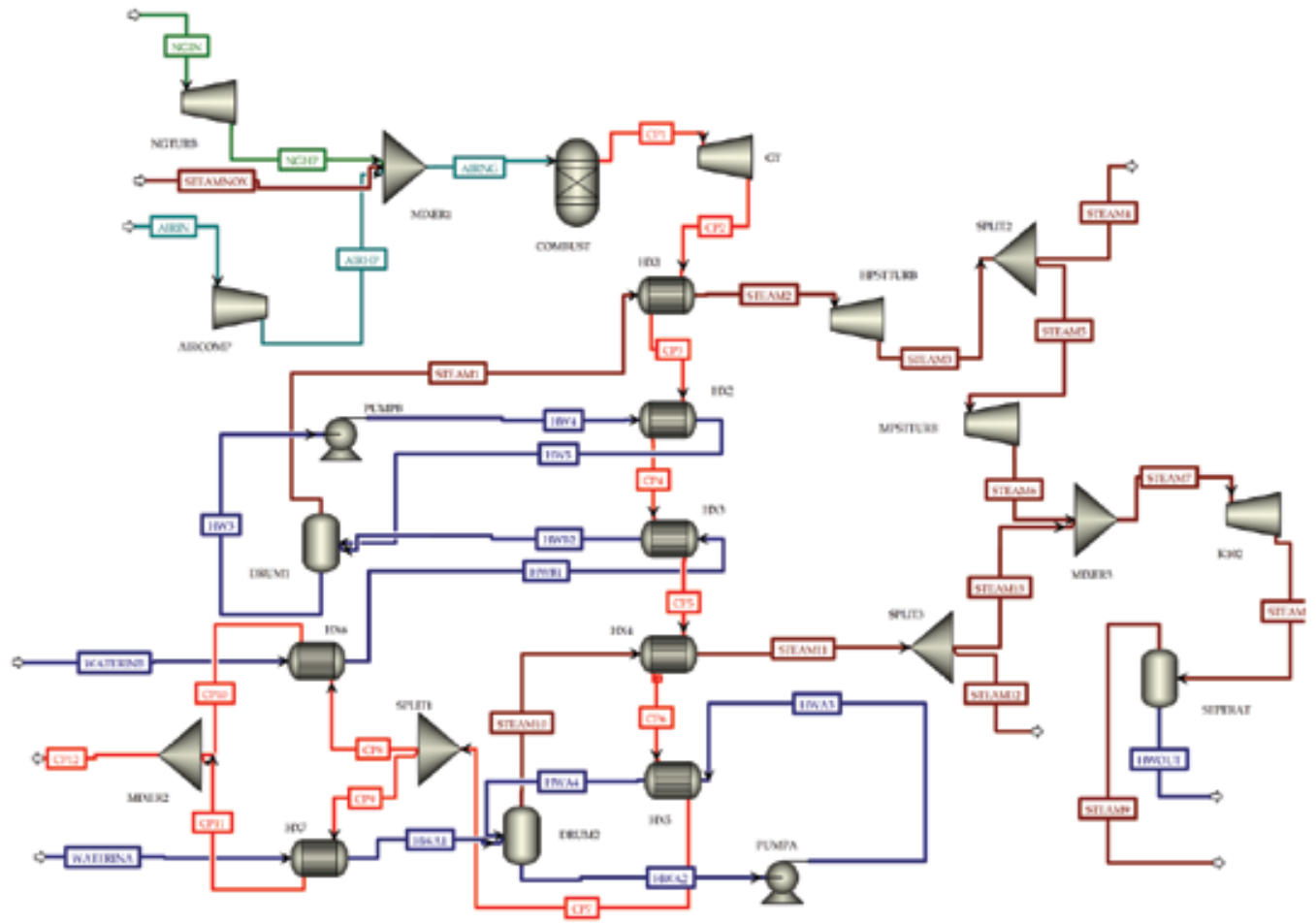

Fig. 7. Schematic of an Aspen Plus ${ }^{\circledR}$ model of a two-pressure CCPP 
different pressures. These multiple-pressure steams can drive high and low-pressure (and possibly medium-pressure) steam turbines with much higher efficiency. Fig. 7 illustrates an Aspen Plus ${ }^{\circledR}$ model of a two-pressure CCPP.

\subsection{Augmentation of gas turbine power output}

The power output and efficiency reduction with higher ambient temperature is a major problem for gas turbine-based cycles, especially in hot climate. Because the peak load in these areas is during summer hot days, and GT-based power plants cannot produce their maximum power output (rated power) when it is most needed. This issue has been intensified with the recent global climate change. The reason for this problem can be explained based on the fact that in a single-shaft gas turbine, the rotational speed of the shaft and as a result the volumetric flow rate of the air are constant. On the other hand, high ambient temperature reduces air density. These two facts, constant volumetric air flow rate and lower air density, cause air mass flow rate reduction with increased ambient temperature. This means lower power output from the gas turbine and higher power requirement in the compressor. Obviously, cooling the inlet air to the compressor can solve the problem. Several methods have been proposed and/or employed to decrease inlet air temperature to the cycle. Generally, these systems can be divided into two main groups: evaporative and non-evaporative systems.

\subsubsection{Evaporative cooling}

In this system, water evaporates in the inlet air stream to the compressor. The heat required for this phase change (the latent heat of evaporation) is achieved by cooling down the air. It should be noted that at constant ambient temperature, increase in relative humidity results in stream with lower density and higher specific heat, which usually the latter overcomes the former. The problem for evaporative systems is that once the air relative humidity reaches $100 \%$, no extra water can be added to the air. Therefore, the cooling capacity of the system is limited by the relative humidity of the air. The evaporative systems are ideal for hot arid regions. The advantages of these systems are their low capital, operating, and maintenance costs, and quick installation. But their operational capacity is limited and highly affected by ambient wet bulb temperature. Also, they require relatively great amount of water, which is usually precious commodity in arid regions.

There are two main types of compressor inlet air evaporative cooling: media evaporative cooler and inlet fogging.

Media evaporative cooler: In this design, the compressor inlet air passes over a film of water in a carefully designed wetted media, such as honey-comb-like medium. This is the first technology employed for gas turbine inlet cooling. The system has the lowest cost among all cooling systems partially because it can operate with less treated water. The system also acts as air washer that cleans air, which in turn can increase the longevity of the gas turbine's filters. However, the water consumption of the system is high, because in each cycle, water is partially evaporated and the remaining water should be partially recycled, with proper control of its chemistry, and the rest should be rejected from the system as blow down. Another disadvantage of the system is that it cannot achieve very high air relative humidity and take advantage of full cooling capacity.

Inlet fogging: In this design, atomized demineralized water is sprayed in the compressor inlet air by high pressure (100 to 200 bar) nozzles, mostly impaction pin type. The GT inlet 
temperature can be controlled by the amount of water sprayed into the stream. The fogging system can increase the air relative humidity to almost $100 \%$. If more water is sprayed, the excessive water will carry over to the compressor in the form of water droplets. These droplets can provide intercooling for the compressor by evaporating while the air temperature increases due to compression. This latter system is called overspraying or wet compression.

Also there are other gas turbine power augmentation methods, such as injection of water or steam to combustion chamber. The main objective of most of this type of GT augmentation is $\mathrm{NO}_{\mathrm{x}}$ emission control and reduction. However, due to increase in GT mass flow rate, higher output power can be achieved as well.

\subsubsection{Mechanical refrigeration system cooling}

Alternatively, mechanical refrigeration systems can be used to decrease gas turbine cycle inlet air temperature. These systems are not limited by ambient conditions and can reduce air temperature lower than that of evaporative systems. The refrigeration system can be either compressor chiller or absorption chiller. The former suffers from high operation cost due to high electricity consumption, and the latter suffers from high capital cost partially due to required waste heat recovery system.

In order to reduce the cost of electricity and take advantage of low night time tariff, thermal energy storage systems can be used. In these systems, ice or chilled water are generated during off-peak hours, usually in the night time, and then used to cool down inlet air in peak hours (Wang, 2007).

\section{$\mathbf{1 4 . 5}$ Integrated gasification combined cycle (IGCC)}

Coal has been used as a fuel for power generation for a long time. This utilization has been mostly in steam power plants, where coal is combusted in a conventional boiler to produce steam for the power plant. These types of coal-fired power plants are mainly pulverized fuel-fired stations and fluidized bed combustion-based plants. The utilization of coal as fuel in GTs was possible only in externally or indirectly fired gas turbines, where coal is burned in an external combustor and then the heat was transferred to air via a heat exchanger to pass through the gas turbine. On the other hand, coal gasification is a well-developed technology to produce synthesis gas (syngas, mainly hydrogen and carbon monoxide) by gasifying coal with steam, oxygen, or air.

Integrated gasification combined cycle is the combination of coal gasification technology with a gas turbine and steam cycle to generate electricity. The advantages of the technology can be summarized as:

- Higher efficiency, around $40 \%$, in comparison to other coal-fired power generation technologies (Ratafia-Brown et al., 2002);

- Feedstock flexibility, since coal, heavy petroleum products, petroleum coke, biomass, etc. can be used as inlet fuel to the system;

- Very low pollutant, such as $\mathrm{CO}_{2}, \mathrm{CO}, \mathrm{NO}_{x}, \mathrm{SO}_{x}$, emissions in comparison to other coalfired power generation technologies. IGCCs can meet the requirements of the most strict air control regulations (Elseviers et al., 1996);

- Various potential products, such as electricity, high and low pressure steam, hot water, hydrogen, syngas fuel, other chemicals, sulphur by-products, even valuable solid wastes (Ratafia-Brown et al., 2002), can be generated; 
- Capability to be adapted for repowering of old coal-fired power plants.

The main additional equipment in IGCC, compared to CCPP, is the gasifier and gas clean up components. In the gasifier, the inlet fuel is converted to high temperature and normally high pressure syngas. The reaction in the gasifier is endothermic, and the required heat can be supplied by fuel partial oxidation. The reactions and their attributes will be explained in the subsection 15.1. The pollutants, such as minerals, ash, slag, particulate, nitrogen, sulphur compounds, and gaseous mercury are then separated from syngas in different stages of gas clean up. Different carbon dioxide capture technologies can be used to significantly reduce greenhouse gas (GHG) emissions. These $\mathrm{CO}_{2}$ capture technologies will be briefly explained in following subsections.

\section{$14.6 \mathrm{CO}_{2}$ capture and storage technologies}

As noted in the introduction, power generation industry is responsible for the majority of GHG emissions from industrial activities. Thus, it is essential to try to reduce such in light of climate change and environmental concerns. One of the methods to achieve this goal is to increase efficiency in power generation, which has been a main topic of this section. Another method is the utilization of $\mathrm{CO}_{2}$ capture and storage systems in power plants. Potentially, $\mathrm{CO}_{2}$ capture technology has already existed for all of the aforementioned power generation technologies, although in most cases it has not been developed particularly for that system. For different types of power plants fueled by oil, natural gas, and coal, there are three main techniques that could be applied (Riahi et al., 2003; Metz et al., 2005):

- $\mathrm{CO}_{2}$ capture after combustion (post-combustion);

- $\mathrm{CO}_{2}$ capture after concentration of flue gas by using pure oxygen in boilers and furnaces (oxy-fuel power plant);

- $\mathrm{CO}_{2}$ capture before combustion (pre-combustion).

These technologies will be explained in the following subsections.

\subsection{1 $\mathrm{CO}_{2}$ capture after combustion (post-combustion)}

This method treats plants' flue gases to remove $\mathrm{CO}_{2}$. This methodology can be easily applied in the near future. Post-combustion $\mathrm{CO}_{2}$ capture in conventional power plants is currently too costly and energy consuming. Several methods to capture $\mathrm{CO}_{2}$ from thermal power stations flue gas are as follows:

Solvent scrubbing systems: This method is suitable for $\mathrm{CO}_{2}$ separation for low concentration of carbon dioxide ( 5 to $15 \%$ by volume) in a stream at low pressure. This low concentration of $\mathrm{CO}_{2}$ and low pressure is very similar to condition in the flue gas of conventional power plants. In this method, the solution of amines is used as solvents to separate $\mathrm{CO}_{2}$. Using this process, $90 \%$ of $\mathrm{CO}_{2}$ in the flue gas can be captured. The separation process of carbon dioxide by chemical absorption consists of two steps:

- the absorption of $\mathrm{CO}_{2}$ by chemical solvents at a low temperature $\left(40-65^{\circ} \mathrm{C}\right)$;

- the recovery of $\mathrm{CO}_{2}$ from chemical solvents by using low temperature $\left(100-150{ }^{\circ} \mathrm{C}\right)$ heat sources usually from power plants.

The details of the mechanisms of $\mathrm{CO}_{2}$ absorption into an amine solution are quite complex (Danckwerts \& Sharma, 1966; Versteeg et al., 1996). At present, a few coal- and gas-fired power plants utilize this technology to capture $\mathrm{CO}_{2}$ (IEA, 2003b). However, scrubber-based systems require considerable capital investment as well as remarkable reduction in the overall plant efficiency. 
Cryogenics: $\mathrm{CO}_{2}$ can be separated from other gaseous compounds in the flue gas by cooling and condensation. This method is suitable for high concentration of $\mathrm{CO}_{2}$ (more than $90 \%$ ), and the technology is not applied to typical power generation plant exhaust stream. Obviously, a disadvantage of the process is that it requires a significant amount of energy.

Membranes: In this method, a separation membrane is used to allow one component to pass more speedily through the membrane. A range of membranes is available for this purpose in which all of them are complex and energy consuming with low degree of separation.

Adsorption: Some solids can separate $\mathrm{CO}_{2}$ from gas mixtures. They are not yet considered to be applicable for power plant application because the capacity and $\mathrm{CO}_{2}$ selectivity of adsorbents is not acceptable yet.

In practice, the most popular technology for $\mathrm{CO}_{2}$ capture from power generation plants and other industries is the scrubber-based system.

\subsection{2 $\mathrm{CO}_{2}$ capture after concentration in the flue gas (oxy-fuel power plants)}

As mentioned, the removal of $\mathrm{CO}_{2}$ from the exhaust stream of power plants is very energy demanding. The oxy-fuel process is proposed to increase the $\mathrm{CO}_{2}$ concentration in the flue gas by burning fuel with pure oxygen instead of air. If oxygen is used for combustion process, the exhaust stream will be mainly composed of $\mathrm{CO}_{2}$ and steam. An air separation unit (ASU) is required to provide pure oxygen. Also, flue gas should be recycled to reduce temperature in the boiler. With this technology, a $\mathrm{CO}_{2}$ concentration of above $90 \%$ is achievable which in turn lowering the energy requirement for the separation process. In order to reduce impurities in the off-gas, reduction of excess oxygen from $17 \%$ to $5 \%$ is proposed (Kather et al., 2007).

\subsection{3 $\mathrm{CO}_{2}$ capture before combustion (pre-combustion)}

In this method, first fuel is gasified and then $\mathrm{CO}_{2}$ is removed. The product fuel gas is almost pure hydrogen. This method is very attractive for the mid-term future in the hydrogen economy. There are different methods to produce hydrogen from decarbonization of fossil fuels, for instance, methane partial oxidation, methane steam reforming, and coal gasification, which will be explained in subsection 15.1. The latter is mostly being used in IGCC plants. In all these methods after preparation of hydrogen rich stream, $\mathrm{CO}_{2}$ is usually removed by chemical absorption method. In all of the above processes, the incorporation of power plants and these systems is complex.

\subsection{4 $\mathrm{CO}_{2}$ liquefaction and sequestration}

After $\mathrm{CO}_{2}$ separation, it is stored as liquid. The liquefaction is implemented in various steps by compressing and cooling of the stream. This process is very energy intensive. The use of geologic formations, gas and oil underground fields, old coal seams, and deep-sea sediments, etc. is all possible methods for $\mathrm{CO}_{2}$ sequestration. Further research and development is required to confirm suitability of which.

\section{Balance of plant in hybrid SOFC systems}

In previous section, the general BoP for fuel cell systems was briefly presented. In this subsection, some of these subsystems that are more important for hybrid SOFC systems' performance will be considered in more details. It should be noted that a great number of 
configurations have been proposed in the literature for hybrid SOFC systems. These layouts have combined some of the following equipment: various SOFC stacks with different configurations, gas turbines, fuel and air compressors, heat exchangers, anode recirculation, water pump, heat recovery steam generators, pre-reformers, internal reformers, mixers, (catalytic) burners, bypasses, electric generators, invertors, etc.

\subsection{Fuel processing}

Theoretically, every fluid that can be chemically oxidized can be used as a fuel in a fuel cell (Appleby \& Foulkes, 1998). SOFCs can be directly fuelled by hydrogen. In this case, the fuel processing system is only hydrogen storage and handling system. For fuels other than hydrogen, generally the first step in fuel preparation process is removal of species, such as sulfur and ammonia, that can degrade fuel cell and/or auxiliary systems. Sometimes it is required to remove some components at the end of fuel processing, such as removal of $\mathrm{CO}$ in PEFC, but this is not the case for SOFCs. The fuel cleaning is a well-developed process and existing technologies can be employed for this purpose.

A SOFC can directly use conventional fuels, such as methane, in electrochemical reactions, at least theoretically. However, this is not currently feasible (Peters et al., 2000). Therefore, in order to increase fuel flexibility, a fuel cell system should be able to use commercially available fuels to produce hydrogen rich stream, a chemically preferred fuel for fuel cells.

At present, three fuel conversion technologies are commercially available, namely steam reforming, partial oxidation, and autothermal reforming.

\subsubsection{Steam reforming}

In this technique, the vaporized hydrocarbon fuel and superheated steam react to create hydrogen and carbon monoxide. To increase concentration of hydrogen, $\mathrm{CO}$ participates in the water-gas shift reaction, where carbon monoxide and steam react to create hydrogen and carbon dioxide. Stream reforming has the highest efficiency and hydrogen concentration at the product among various fuel preparation techniques. For methane, the steam reforming and water-gas shift reactions are as follows:

$$
\begin{array}{ll}
\text { Steam reforming reaction: } & \mathrm{CH}_{4}+\mathrm{H}_{2} \mathrm{O}+\text { heat } \leftrightarrow 3 \mathrm{H}_{2}+\mathrm{CO} \\
\text { Water-gas shift reaction: } & \mathrm{CO}+\mathrm{H}_{2} \mathrm{O} \leftrightarrow \mathrm{H}_{2}+\mathrm{CO}_{2}+\text { heat }
\end{array}
$$

For higher hydrocarbons, the steam-reforming reaction produces a stream of combination of hydrogen, methane, and carbon oxides. This reaction can be simplified in Equation 3 (total reaction including the steam reforming of generated methane but not water-gas shift reaction):

$$
\mathrm{C}_{\mathrm{n}} \mathrm{H}_{\mathrm{m}}+\mathrm{SCRnH} \mathrm{H}_{2} \mathrm{O} \leftrightarrow \mathrm{nCO}+\left(\frac{\mathrm{m}}{2}+\mathrm{n}\right) \mathrm{H}_{2}+(\mathrm{SCR}-1) \mathrm{nH}_{2} \mathrm{O}
$$

where $\mathrm{n}$ and $\mathrm{m}$ define the composition of the fuel and SCR represents the fraction of steamto-carbon of the mixture.

Although the steam reforming reaction does not require catalyst, a catalyst can improve reaction efficiency at lower temperature. The steam reforming process is endothermic and the reaction is slow by nature; therefore, it needs large reactor. Also, this technology is not suitable for rapid start-up and its response to load change is slow. 
The water-gas shift reaction is exothermic; however, the overall reaction, both steam reforming and water-gas shift simultaneous reactions, is endothermic. In a fuel cell system, the required heat can be provided from the electrochemical reactions in fuel cell (which can help to cool down the cell), or from a furnace that burns some of the inlet fuel, or the fuel effluent from the fuel cell. It has been shown that the heat generated in the electrochemical reactions is greater than heat required for steam reforming reaction and excessive heat is removed from fuel cell by exhaust streams. Ahmed and Forger (2000) reported that, under typical operating conditions, the rate of heat generation in the electrochemical reactions was about twice as the thermal energy consumption in steam reforming reaction.

In a steam reforming process, there is possibility of carbon formation by the following reactions (Van Herle et al., 2003):

$$
\begin{gathered}
\mathrm{CH}_{4} \leftrightarrow \mathrm{C}+2 \mathrm{H}_{2} \\
2 \mathrm{CO} \leftrightarrow \mathrm{C}+\mathrm{CO}_{2} \\
\mathrm{CO}+\mathrm{H}_{2} \leftrightarrow \mathrm{C}+\mathrm{H}_{2} \mathrm{O}
\end{gathered}
$$

The carbon formation can be suppressed by providing sufficient steam. The steam-to-carbon molar ratio of higher than 2 is common to prevent soot formation and to force the reaction to completion (EG\&G Services, 2004; Achenbach, 1994).

As Equations 1 and 2 show, these reactions require steam. This steam can be provided from an external water or steam source. In case of water, the water can be converted to steam in a heat recovery steam generator (HRSG) by recovering the waste heat of the system exhaust. Alternatively, the steam can be provided by recycling steam rich anode products. The mixing of the fuel and anode exhaust stream can be performed by means of an ejector. Obviously, during the start-up, the plant requires an external boiler that produces steam for the reactions.

\subsubsection{Partial oxidation (POX)}

Unlike the steam reforming reaction, the partial oxidation does not require any steam. In this process, the fuel is partially combusted with substoichiometric amount of air or oxygen:

$$
\mathrm{CH}_{4}+\frac{1}{2} \mathrm{O}_{2} \leftrightarrow 2 \mathrm{H}_{2}+\mathrm{CO} \text { theat }
$$

Due to the exothermic fuel combustion, the temperature of the reaction is high, but can be reduced by steam injection during water-gas shift reaction. Since there is no need for indirect heat, the equipment is simpler, lighter, and smaller. Its response to load change is fast and start-up time is shorter. However, the concentration of hydrogen in the products is lower. There are different opinions regarding its efficiency. Some references, like EG\&G Services (2004), reported higher efficiency for the partial oxidation process, but widely-held opinion is that the efficiency of steam reforming process is higher. Due to higher temperature of POX, most liquid fuels are reformed in POX reformers (Petruzzi et al., 2003). If air is used for the process (opposed to pure oxygen), nitrogen from air is introduced to the product, which reduces the partial pressure of hydrogen in the product stream and thus the fuel cell power output. In addition, since available heat from the fuel cell is not used in this system and the fuel is directly combusted for this purpose, the effectiveness of the system is lower. 


\subsubsection{Autothermal reforming}

The autothermal reforming is a combination of steam reforming and partial oxidation reactions, where the heat generated by the latter reaction is consumed by the former reaction, resulting in a slightly exothermic reaction. The technique results in a simpler, smaller, and faster responding system than the steam reformer and in higher hydrogen concentration and lower temperature than partial oxidation processor.

A generic equation that covers all aforementioned techniques (the total reaction including water-gas shift reaction) can be summarized as follows (EG\&G Services, 2004):

$$
\mathrm{C}_{\mathrm{n}} \mathrm{H}_{\mathrm{m}} \mathrm{O}_{\mathrm{p}}+\mathrm{x}\left(\mathrm{O}_{2}+3.76 \mathrm{~N}_{2}\right)+(2 \mathrm{n}-2 \mathrm{x}-\mathrm{p}) \mathrm{H}_{2} \mathrm{O} \leftrightarrow \mathrm{nCO}_{2}+\left(2 \mathrm{n}-2 \mathrm{x}-\mathrm{p}+\frac{\mathrm{m}}{2}\right) \mathrm{H}_{2}+3.76 \times \mathrm{N}_{2}
$$

For instance, for $\mathrm{x}=0, \mathrm{p}=0, \mathrm{n}=1$, and $\mathrm{m}=4$, this equation reduces to the steam reforming of methane (Equations 1 and 2).

The efficiency of a fuel processor can be defined based on Equation 9 (EG\&G Services, 2004):

$$
\text { Efficiency }=\frac{\text { LHV of anode fuel produced }}{\text { LHV of inlet fuel }}
$$

Both steam reforming and partial oxidation can be utilized in SOFC plants. However, only a few experimental and modeling works, such as Finnerty et al. (2000) and Petruzzi et al. (2003), used POX and great majority of the SOFC systems in the literature applied the steam reformer. It is suggested that, for small units, where compactness is important, POX process is applied and for applications, where high efficiency is desired, steam reformer is used (Peters et al. 2002). Also, POX is used when the fuel cell is fueled with liquid fuel, for example, for auxiliary power units (APUs) in vehicles, where the system should use same fuel as the vehicle to avoid a second fuel tank (Petruzzi et al. 2003; Steffen et al., 2005).

In the high temperature fuel cells, the fuel, especially methane, can be internally reformed. Although a few SOFC systems with the external reformer have been reported in the literature (Harvey \& Richter, 1994; Palsson et al., 2000; Massardo \& Lubelli, 2000; Van Herle et al., 2003), due to the considerable benefits of internal reformers, most systems make use of this capability of high temperature fuel cells. The internal reforming of fuel can significantly decrease the system cost and increase its efficiency. Also, the endothermic internal steam reforming process can help to provide additional cooling for the cells, which otherwise should be provided by flowing excess air through the cathode. This can cause even distribution of hydrogen, which can potentially result in more even temperature distribution in the stack (Ahmed \& Foger, 2000). However, the complete internal reforming can result in some problems, such as carbon formation in the anode and the exposure of stack to large temperature gradients as a result of the cooling effects of the endothermic reforming reaction (Peters et al., 2000). Existence of heavier hydrocarbons in natural gas, which at high temperatures have a tendency to produce unwanted materials, such as carbon, can intensify the problem. Therefore, to avoid aforementioned problems, it is suggested that the fuel cell system to be equipped with a compact pre-reformer (Peters et al., 2000, 2002; Ahmed \& Foger, 2000; Calise et al., 2007; Dicks et al., 2000).

\subsubsection{Internal reformer}

As noted earlier, high operating temperature of SOFC can eliminate or at least minimize the fuel reforming process by internal reforming of the fuel. There are two designs for internal 
reforming in SOFCs; direct internal reforming (DIR) and indirect internal reforming (IIR). The difference between these two techniques is the actual place that fuel reforming takes place. In DIR, the fuel is reformed while it flows over the catalyst particles in the anode. While in IIR, the reforming reactions take place over the paths close to the stack before the fuel reaches the anode. In both cases, the reformer is integrated to the stack and the heat required for the reforming reaction is provided by the electrochemical reactions in the fuel cell and some kind of catalyst, such as the nickel content, is required to promote the reforming reaction.

\subsection{Combustor}

The fuel cannot be completely consumed in a fuel cell and the fuel utilization factor of fuel cell is always less than $100 \%$. Therefore, in order to avoid unnecessary air pollution and the loss of fuel energy, the remaining fuel should be burned before the SOFC exhaust can be discharged to the environment or a bottoming cycle. This can be done by combusting the anode exhaust with depleted air in the cathode outlet stream. The available fuels in the combustor are hydrogen and lower percentage of carbon monoxide and methane. The cathode air mass flow rate is much higher than the fuel flow rate in order to control stack temperature. Thus, there is enough air in the cathode outlet for the combustion process. The extra heat generated in the combustor can help improve the performance of bottoming cycle and/or heating inlet air as well as fuel to the fuel cell.

\subsection{Heat exchangers}

Heat exchangers are an important part of a hybrid fuel cell system. Although electrochemical reaction in fuel cell is highly exothermic, the inlet air and fuel should be preheated before they are fed to the fuel cell to prevent high temperature gradient and thermal stress in the stack.

\section{Fuel cell modeling}

Simulation and mathematical models are certainly helpful for the development of various power generation technologies; however, they are probably more important for fuel cell development. This is due to the complexity of fuel cells and systems based on them, and the difficulty in experimentally characterizing their internal operation. This complexity can be explained based on the fact that within the fuel cell, tightly coupled electrochemical reactions, electrical conduction, ionic conduction, and heat transfer take place simultaneously. That is why a comprehensive study of fuel cells requires a multidisciplinary approach. Modeling can help to understand what is really happening within the fuel cells (EG\&G Services, 2004).

Understanding the internal physics and chemistry of fuel cells are often difficult. This is due to the great number of physical and chemical processes in the fuel cells, difficulty in independent controlling of the fuel cell parameters, and access limitations to inside of the fuel cells (Bove \& Ubertini, 2006).

In addition, fuel cells simulation can help to focus experimental research and to improve accuracy of interpolations and extrapolations of the results. Furthermore, mathematical models can serve as valuable tools to design and optimize fuel cell systems. On the other hand, dynamic models can be used to design and test fuel cell systems' control algorithms. 
Finally, models can be developed to evaluate whether characteristics of specific type of fuel cell can meet the requirements of an application and its cost-effectiveness (EG\&G Services, 2004).

Due to its importance, in the past 2 decades, there has been tremendous progress on numerical and computational tools for fuel cells and energy systems based on them, and virtually unlimited number of papers has been published on fuel cells modeling and simulation. With this large amount of literature, it is very difficult to keep track of the development in the field. This problem can be intensified for new researchers as they can be easily overwhelmed by this sheer volume of resources. That is why there have been many review papers on the modeling of different types of fuel cells, especially for modeling and simulation of PEFC (Biyikoglu, 2005; Haraldsson \& Wipke, 2004; Sousa \& Gonzalez, 2005; Tao et al., 2006; Young, 2007; Wang, 2004), SOFC (Young, 2007; Wang, 2004; Kakac et al., 2007; Bove \& Ubertini, 2006) and to a lesser extent MCFC (Baker, 1984).

As mentioned previously, although both SOFC and MCFC can be used in hybrid cycles, due to the cell reactions and the molten nature of the electrolyte and lower efficiency of MCFC (Song et al., 2005), vast majority of research in this field are in SOFC hybrid cycles. There have been some steady state (Massardo \& Bosio, 2002; Iora \& Campanari, 2007) and dynamic (Ghezel-Ayagh et al., 2004) modeling on the hybrid MCFC-GT cycles. However, the number of papers and diversity of such are not comparable with papers on the SOFC hybrid cycle modeling.

The complex nature of interaction between the already complicated fuel cell and bottoming cycle makes simulation and modeling an essential tool for researchers in this field. In the next section, the ways to categorize the modeling of SOFC hybrid cycles will be discussed.

\subsection{SOFC hybrid systems modeling categorization}

Haraldsson and Wipke (2004) summarized the key features of the fuel cells models as follows:

- modeling approach (theoretical or semi-empirical);

- $\quad$ model state (steady state or transient);

- $\quad$ system boundary (atomic/molecular, cell, stack, or system);

- $\quad$ spatial dimension (zero to three dimensions);

- complexity/details (electrochemical, thermodynamic, or fluid dynamic relationships);

- $\quad$ speed, accuracy, and flexibility;

- $\quad$ source code (open or proprietary);

- graphical representation of model;

- library of models, components, and thermodynamic properties;

- validation.

Although they provided the above list for PEFC, it could equally be applicable for SOFC modeling. They described the approach of a model as being either theoretical (mechanistic) or semi-empirical. The mechanistic models are based upon electrochemical, thermodynamic, and fluid dynamic relationships, whereas the semi-empirical models use experimental data to predict system behaviors. The state of the model, either steady state or transient, shows whether the model can simulate system only at single operating condition or it can be used in dynamic conditions, including start-up, shut-down, and load changes too. Spatial dimension of a model can be zero to three dimensions. Zero-dimension models only consider current-voltage (I-V) curves. On the other hand, mechanistic approaches address 
governing laws, including mass, momentum, and energy balances, and the electrochemical reactions and need the explicit treatment of geometry (Beausoleil-Morrison et al., 2004).

Singhal and Kendall (2006) categorized the resolution of SOFC models in four levels: atomic/molecular, cell, stack, and system. As Singhal and Kendall pointed out, "the appropriate level of modeling resolution and approach depended upon the objectives of the modeling exercise". For instance, the recommended approach for IEA Annex 42, model specifications for a fuel cell cogeneration device, is system level approach. It is because the Annex 42 cogeneration models include the models of associated plant components, such as hot-water storage, peak-load boilers and heaters, pumps, fans, and heat exchangers. In addition, the systems models should be able to couple to the building models. These models simulate the building to predict its thermal and electrical demands (Beausoleil-Morrison et al., 2004).

On the other hand, the models can be categorized based on their SOFC type rather than modeling approach. For instance,

- Fuel cell type:

- Planar;

- Tubular;

- $\quad$ Monolithic (MSOFC);

- Integrated Planar (IP-SOFC);

- Cell and stack design (anode-, cathode-, electrolyte-supported and co-, cross-, and counter- flow types)

- Temperature level:

- $\quad$ Low temperature (LT-SOFC, $500-650{ }^{\circ} \mathrm{C}$ );

- Intermediate temperature (IT-SOFC, $650-800^{\circ} \mathrm{C}$ );

- High temperature (HT-SOFC, $800-1000^{\circ} \mathrm{C}$ );

- Fuel reforming type:

- External steam reforming;

- Internal steam reforming;

- Partial oxidation (POX);

- Anode recirculation;

- Fuel type.

They can even be categorized by the cycles, such as GT, CCPP, IGCC, and CHP, that are used to form hybrid system with SOFC. Alternatively, the purpose of modeling such as parametric sensitivity analysis, optimization, exergy analysis, economical analysis, configuration analysis, feasibility studies, partial load and transient conditions analysis can be considered for categorizing SOFC hybrid models.

\subsection{Modeling steps}

Before starting modeling of a hybrid system, it is very important to define the purpose of desired model and then determine the key features of the model. The best modeling approach and the characteristics of the model are dependent on the application. Although this is a vital step, there is high tendency to be overlooked. After finalizing these criteria, details of the model can be identified (Haraldsson \& Wipke, 2004).

Similar to modeling of other thermal systems, the first step in the modeling of a SOFC hybrid system is to understand the system and translate it into mathematical equations and statements. The common steps for model development are as follows: 
- $\quad$ specifying a control volume around desired system;

- writing general laws (including conservation of mass, energy, and momentum; second law of thermodynamics; charge balance; and so on);

- $\quad$ specifying boundary and initial conditions;

- $\quad$ solving governing equations by considering boundary and initial conditions (analytical or numerical solution);

- $\quad$ validating the model.

Unlike the actual fuel cell operation which is three dimensional and time dependent, fuel cell simulation can be simplified to a steady state, 2-D, 1-D, or 0-D problem by proper assumptions, based on the application of the modeling. Many of the SOFC hybrid system simulations in the open literature are 0-D models. In this type of modeling, series of mathematical formulations are utilized to define output variables based on input ones. In this approach, fuel cell is treated as a dimensionless box and that is why some authors referred it as box modeling. Despite the large numbers of assumptions and simplifications in this method, it is useful to analyze the effects of various operational parameters on the cycles' overall performance, perform sensitivity analysis, and compare different configurations. When the objective of modeling is to investigate the inner working of SOFC, 0-D approach is not appropriate. However, for hybrid SOFC system simulation, where emphasis is placed on the interaction of fuel cell and the rest of the system and how fuel cell can affect the overall performance of the system, this approach can be suitable. In this level of system modeling, there are a variety of assumptions and simplifications. For instance, Winkler et al. (2006) developed a hybrid fuel cell cycle model and assumed that the fuel cell was operated reversibly, representing any fuel cell type, and the heat engine was a Carnot cycle, representing any heat engine.

Different software and programming languages have been used in hybrid SOFC system simulation. Since there is no commercially available model for SOFC stack, all modelers should prepare their own model with appropriate details and assumptions. Therefore, from this point of view, what differentiates models is how they simulate the other components of the system. Generally, they can be divided into two categories. In the first approach, whole models can be developed in programming languages such as Fortran or high level software such as MATLAB/Simulink ${ }^{\circledR}$ platform to solve governing equations of the system. In the second approach, the modelers can take advantage of commercial software such as Aspen Plus ${ }^{\circledR}$ to model conventional components of the cycle.

Due to the nature of numerical modeling, its results should be used carefully. In every modeling, the physical realities of the system should be translated into mathematical equations and solution of these equations is used to express behavior of the system. In case of fuel cells, the physical realities are extremely complex and some of which are completely unknown. Therefore, in order to extract these governing equations, high level of assumptions and simplifications should be considered which in turn introduce inaccuracy to the final results. This means fuel cell models are a "simplified representation of real physics" and even with appropriate validation, accuracy of their results cannot be guaranteed (Bove \& Ubertini, 2006). For instance, one should be aware of the possible problems that can arise when local equations are considered as global. Bove et al. (2005) highlighted such problem in their paper. They described the main problem of using 0-D approach for modeling was the negligence of variation in the fuel, air, and exhaust gas compositions through the fuel 
cell. As a result of this problem, when the inlet, outlet, or an average value of the gas composition was used in the modeling, different results could be obtained. In particular, it was shown that it was impossible to evaluate effects of fuel utilization variation through the fuel cell when inlet gas composition was considered. On the other hand, considering output streams composition could result in underestimating cell voltage and power output.

However, Magistri et al. (2004) studied simplified versus detailed SOFC models and how this affected the predictions of the design-point performance of the hybrid systems. They emphasized the usefulness of the simplified model for hybrid system design and off-design analysis and detailed model for complete description of the SOFC internal behavior.

Judkoff and Neymark (1995) classified the sources of simulation errors into three groups (these were provided for building simulation programs, but they were equally applicable to SOFC hybrid system simulation):

- Errors introduced due to assumptions and simplifications;

- Errors or inaccuracies in solving mathematical equations;

- Coding errors.

They also proposed a pragmatic, three-step approach to identify these errors. In the first approach, comparative testing, the results of the model should be compared with the results of other models for the same problem with similar initial and boundary conditions. If the results of the models match with acceptable error, it means the implementations are acceptable. However, this does not guarantee the correctness of the results because they all can be incorrect. In the second approach, analytical validation, the results of the model for a simple case are compared with the results of available analytical solution. Finally, in empirical validation, the results of the simulation are compared with real data from the actual system under laboratory or field conditions.

Finally, the validation of a model is important because a model must be validated to be a credible tool. Appropriate data are needed for validation. With limited resources, this can be difficult because most data cannot be found in the open literature. Although performance data from an entire hybrid power generation systems are usually proprietary and are not available in the literature, this information from a single system is easier to find. Therefore, a way to resolve the problem of limited performance data is to develop and validate welldefined subsystem models, and then integrate them to have a complete model of a large hybrid power generation system.

\subsection{A detailed example of SOFC-GT hybrid cycle}

The purpose of this section is to explain the general steps discussed earlier in the context of a real modeling example (Suther et al., 2010). A steady state thermodynamic model of a hybrid SOFC-GT cycle is developed using the commercial process simulation software, Aspen Plus ${ }^{\circledR}$. Aspen Plus ${ }^{\circledR}$ is a computerized process simulation tool that can be used for realistic steady state simulation of thermodynamic cycles. In this software, built-in and userdefined models can be connected with material, work, and heat streams to form a model of an actual system. The user-defined models can be created using Fortran, Aspen Custom Modeler ${ }^{\circledR}$, or Microsoft Excel ${ }^{\circledR}$. There are various physical property models that can be selected for the flow sheet calculations (Aspentech, 2010). One of the inherent characteristics of Aspen Plus ${ }^{\circledR}$ is its sequential modular approach to modeling. That means each 
component, either built-in or user-defined models, is treated independently and calculation results for each block are considered the input for the next block (Bove et al., 2005).

The hybrid cycle model incorporated a 0-D macro level SOFC model. As noted earlier, there is no built-in SOFC model available in this software. Therefore, first, the 0-D model of a SOFC stack was developed using Fortran programming language as user-defined model in Aspen Plus ${ }^{\circledR}$. Therefore, the model consisted of two main parts; the cycle model with various equipments and the SOFC model. The cycle model included all required system equipment such as fuel reformer, compressors, combustor, heat exchangers, mixing chambers, pump, and the fuel cell stack which were linked together with material and energy streams. The SOFC stack model was developed using fundamental equations of thermodynamics, chemical reactions, and electrochemistry. For chemical reactions, it was assumed that three reactions taking place within the SOFC: reaction of $\mathrm{H}_{2}$ with $\mathrm{O}_{2}$ forming $\mathrm{H}_{2} \mathrm{O}$, methane steam reforming reaction, and water-gas shift reaction. The electrochemical calculations were used to estimate the power output of the SOFC. In order to estimate actual operating voltage of the SOFC, the open-circuit voltage was first calculated, and then the three overpotentials (losses), namely the activation, ohmic, and concentration losses were deducted. The thermodynamics equations were also applied to estimate the heat output from the stack and the outlet temperature.

The model constants were determined by using the data from Siemens-Westinghouse SOFC systems (Veyo et al., 2002a, 2002b) as well as considering the ranges available in the literature. As a last step for stack modeling, the model was validated using experimental data from Siemens-Westinghouse SOFC (Veyo et al., 2002a, 2002b). After integrating all equipment, it was possible to investigate two configurations with the same model: with the anode exhaust recirculation and with the heat recovery steam generator, both for maintaining the steam-to-carbon ratio of the reformer. The model was used to carry out parametric study (Suther et al., 2010).

\section{Conclusion}

The power generation industry is responsible for significant portion of industrial GHG and other emissions. Thus, sustainability considerations should be involved in all major energy development plans around the world. Fuel cells are an interesting alternative for conventional power generation technologies because of their high efficiency and low environmental effects. Their operation is based on the electrochemical reactions (and not combustion) of fuel and air. They can directly convert the chemical energy of many types of fuels to electrical energy. Scalability, quiet operation, easier carbon capture, and possible water production are some of their attributes. Based on the type of electrolyte, fuel cells can be categorized into five groups: polymer electrolyte fuel cell (PEFC), alkaline fuel cell (AFC), phosphoric acid fuel cell (PAFC), molten carbonate fuel cell (MCFC), and solid oxide fuel cell (SOFC). Each type of fuel cells is suitable for certain application. Stationary and distributed power generation, transportation, and portable applications are the main candidates for fuel cell utilization. Among these fuel cells, due to their high operating temperature, solid oxide fuel cells are specially suited for stationary electricity generation. They can internally reform some of hydrocarbon fuels and do not need noble metals as electro-catalysts. Also a bottoming cycle, such as gas turbine, steam and gas turbine combined cycle power plant (CCPP), steam turbine, coal integrated gasification, integrated gasification combined cycle (IGCC), and combined cooling and/or heating, and power 
(CCHP/CHP) cycles, can be integrated to the SOFC to generate further power and/or thermal energy and increase the system efficiency. Energetic and/or environmental performance of these bottoming cycles can be improved by some methods, such as augmentation of gas turbine power output and $\mathrm{CO}_{2}$ capture and storage technologies. However, some technical challenges, such as the cost of materials and manufacturing, system life, thermal cycling, limited power density, mismatch of thermal expansion coefficient of different components, sealing problem, materials selection at high temperature especially metal interconnections, and corrosion in some components, should be addressed before SOFCs can be commercialized. The stand alone and hybrid SOFC cycle modeling is an important tool for their developments, due to their complexity and difficulties in conducting experiments on the fuel cell.

\section{References}

Achenbach, E. (1994). Three-dimensional and time-dependent simulation of a planar solid oxide fuel cell stack. Journal of Power Sources, 49 (1-3), 333-348

Ahmed, K. \& Foger, K. (2000). Kinetics of internal steam reforming of methane on Ni/YSZbased anodes for solid oxide fuel cells. Catalysis Today, 63 (2-4), 479-487

Appleby, A. J. \& Foulkes, F.R. (1989). Fuel Cell Handbook, Van Nostrand Reinhold, New York Aspentech. (2010). Aspen Plus ${ }^{\circledR}$ user guide, www.aspentech.com (August 2, 2010)

Baker, B. S. (1984). Molten carbonate fuel cell technology - the past decade. The Electrochemical Society Proceedings, 84-13: 2-19

Bauer, N. (2005). Carbon capturing and sequestration a option to buy time?, Doctor Politicarum, University Potsdam Faculty of Economics and Social Sciences

Beausoleil-Morrison, I.; Weber, A.; Mare'chal, F.; Griffith, B. (2004). Model specifications for a fuel cell cogeneration device. IEA / ECBCS Annex 42 working document

Bevc, F. (1997). Advances in solid oxide fuel cells and integrated power plants. Proceedings of the Institution of Mechanical Engineers, Part A (Journal of Power and Energy), 211 (A5), 359-366

Biyikoglu, A. (2005). Review of proton exchange membrane fuel cell models. International Journal of Hydrogen Energy, 30, 1181-1212

Bove, R.; Lunghi, P.; Sammes, N. M. (2005). SOFC mathematic model for systems simulations. Part one: from a micro-detailed to macro-black-box model. International Journal of Hydrogen Energy, 30, 181-187

Bove, R. \& Ubertini, S. (2006). Modeling solid oxide fuel cell operation: Approaches, techniques and results. Journal of Power Sources, 159, 543-559

Campanari, S. Macchi, E. (1998). Thermodynamic analysis of advanced power cycles based upon solid oxide fuel cells, gas turbines and Rankine bottoming cycle, Proceedings of International Gas Turbine \& Aeroengine Congress, Sweden, Stockholm

Calise, F.; Palombo, A.; Vanoli, L. (2006). Design and partial load exergy analysis of hybrid SOFC-GT power plant. Journal of Power Sources, 158: 225-244

Calise, F.; Dentice d' Accadia, M.; Vanoli, L.; Von Spakovsky, M. R. (2007). Full load synthesis/design optimization of a hybrid SOFC-GT power plant. Energy, 32, 446458 
Cengel, Y. A. \& Boles, M. A. (1998). Thermodynamics: An engineering approach (third ed.). McGraw-Hill, ISBN 0-07-011927-9

Danckwerts, P. V. \& Sharma, M.M. (1966). The absorption of carbon dioxide into solutions of alkalis and amines, The Chemical Engineer, 244-280

Dicks, A. L.; Pointon, K. D.; Siddle, A. (2000). Intrinsic reaction kinetics of methane steam reforming on a nickel/zirconia anode. Journal of Power Sources, 86 (1-2), 523-30

Dokiya, M. (2002). SOFC system and technology. Solid State Ion,152-153, 383-392

Donitz, W.; Erdle, E.; Schafer, W.; Schamm, R.; Spah, R. (1991). Status of SOFC development at dornier. In Proceeding of 2 nd int. on SOFCs. Athens, Greece

Dunbar, W. R.; Lior, N.; Gaggioli, R. (1990). Exergetic advantages of topping rankine power cycles with fuel cell units. American Society of Mechanical Engineers, Advanced Energy Systems Division (AES), 21, 63-68

EG\&G Services. (2004). Fuel Cell Handbook (7th Edition), Parsons, Inc.

Elseviers, W. F.; Van, M. T.; Van, D. V. M. J. F.; Verelst, H. (1996). Thermodynamic simulations of lignite-fired IGCC with in situ desulfurization and $\mathrm{CO}_{2}$ capture. Fuel, 75 (12), 1449-1456

Finnerty, C.; Tompsett, G. A.; Kendall, K.; Ormerod, R. M. (2000). SOFC system with integrated catalytic fuel processing. Journal of Power Sources, 86 (1), 459-463

Gale, J. (2002). Overview of sources, potential, transport and geographical distribution of storage possibilities, IPCC workshop on carbon capture and storage, Regina, Canada, 15 $-29$

Ghezel-Ayagh, H.; Lukas, M. D.; Junker, S. T. (2004).Dynamic modeling and simulation of a hybrid fuel cell/gas turbine power plant for control system development. Fuel Cell Science, Engineering and Technology, 325-329

Haraldsson, K. \& Wipke, K. (2004). Evaluating PEM fuel cell system models. Journal of Power Sources, 126: 88-97

Harvey, S. P. \& Richter; H. J. (1994). Gas turbine cycles with solid oxide fuel cells. Part II: A detailed study of a gas turbine cycle with an integrated internal reforming solid oxide fuel cell. Journal of Energy Resources Technology, 116, 312-318

IEA. (2006). World energy outlook, International Energy Agency

IEA. (2003a). Energy technology: facing the climate challenge, Meeting of the governing board at ministerial level

IEA. (2003b). $\mathrm{CO}_{2}$ capture at power stations and other major point sources, Working party on fossil fuels international energy agency, zero emissions technologies for fossil fuels

Iora, P. \& Campanari, S. (2007). Development of a three-dimensional molten carbonate fuel cell model and application hybrid cycle simulations. Journal of Fuel Cell Science and Technology, 4, 501-510

Judkoff, R. D. \& Neymark, J. S. (1995). Procedure for testing the ability of whole building energy simulation programs to thermally model the building fabric. Journal of Solar Energy Engineering, 117: 7-15

Larminie, J. \& Dicks, A. (2003). Fuel cell systems explained (2nd Edition), John Wiley \& Sons Ltd, ISBN 047084857 X, England

Kakac, S.; Pramuanjaroenkij, A.; Zhou, X. Y. (2007). A review of numerical modeling of solid oxide fuel cells. International Journal of Hydrogen Energy, 32, 761-786 
Kather, A.; Mieske, K.; Hermsdorf, C.; Klostermann, M.; Eggers, R.; Kopke, D. (2007). Oxyfuel process for hard-coal power plants with $\mathrm{CO}_{2}$ removal. Clean Air, 8 (3), 273286

Magistri, L.; Bozzo, R.; Costamagna, P.; Massardo, A. F. (2004). Simplified versus detailed solid oxide fuel cell reactor models and influence on the simulation of the design point performance of hybrid systems. Journal of Engineering for Gas Turbines and Power, 126, 516-523

Massardo, A. F. \& Bosio, B. (2002). Assessment of molten carbonate fuel cell models and integration with gas and steam cycles. Journal of Engineering for Gas Turbines and Power, 124, 103-109

Massardo, A. F. \& Lubelli. F. (2000). Internal reforming solid oxide fuel cell- gas turbine combined cycles (IRSOFC-GT): Part A- Cell model and cycle thermodynamic analysis. Journal of Engineering for Gas Turbines and Power, 122, 27-35

Mench, M. M. (2008). Fuel cell engine, John Wiley \& Sons, Inc. ISBN 978-0-471-68958-4, USA, New Jersey

Metz, B.; Davidson, O.; de Coninck, H. C.; Loos, M.; Meyer, L. A. (2005). IPCC Special report on carbon dioxide capture and storage. Working Group III of the Intergovernmental Panel on Climate Change. Cambridge University Press, UK

Palsson, J.; Selimovic, A.; Sjunnesson, L. (2000). Combined solid oxide fuel cell and gas turbine systems for efficient power and heat generation. Journal of Power Sources, 86, 442-448

Peters, R; Riensche, E.; Cremer, P. (2000). Pre-reforming of natural gas in solid oxide fuel-cell systems. Journal of Power Sources, 86 (1-2), 432-441

Peters, R.; Dahl, R.; Kluttgen, U.; Palm, C.; Stolten, D. (2002). Internal reforming of methane in solid oxide fuel cell systems. Journal of Power Sources, 106 (1-2), 238-244

Petruzzi, L.; Cocchi, S.; Fineschi, F. (2003). A global thermo-electrochemical model for SOFC systems design and engineering. Journal of Power Sources, 118 (1-2), 96-107

Rajashekara, K. (2005). Hybrid fuel-cell strategies for clean power generation. IEEE Transactions on Industry Applications, 41, 682-689

Ratafia-Brown, J. A.; Manfredo, L. M.; Hoffmann, J.M.; Ramezan, M.; Stiegel, G. J. (2002). An environmental assessment of IGCC power systems. Proceedings of Nineteenth Annual Pittsburgh Coal Conference, USA

Riahi K.; Rubin E. S.; Schrattenholzer L. (2003). Prospects for carbon capture and sequestration technologies assuming their technological learning. Proceedings of 6th International Greenhouse Gas Control Technologies, Kyoto, Japan

Riensche, E. \& Fedders, H. (1993). Parameter study on SOFC plant operation for combined heat and power generation. Proceedings of SOFC Int. Symp. Honolulu

Roberts, R.; Brouwer, J.; Jabbari, F.; Junker, T.; Ghezel-Ayagh, H. (2006). Control design of an atmospheric solid oxide fuel cell/gas turbine hybrid system: Variable versus fixed speed gas turbine operation. Journal of Power Sources, 161: 484-491

Singhal, S. C. (2000a). Advances in solid oxide fuel cell technology. Solid State Ionics, 135, 305-313

Singhal, S. C. (2000b). Science and technology of solid oxide fuel cells. MRS Bulletin, 25, 1621 
Singhal, S. C. (2002). Solid oxide fuel cells for stationary, mobile, and military applications. Solid State Ionics, 152-153, 405-410

Singhal, S. C. \& Kendall, K. (2006). High temperature solid oxide fuel cell, fundamental, design and applications, Elsevier, ISBN: 1-85617-387-9, UK

Song, T. W.; Sohn, J. L.; Kim, J. H.; Kim, T. S.; Ro, S. T.; Suzuki., K. (2005). Performance analysis of a tubular solid oxide fuel cell/micro gas turbine hybrid power system based on a quasi-two dimensional model. Journal of Power Sources, 142, 30-42

Sousa, J. R. \& Gonzalez, E. R. (2005). Mathematical modeling of polymer electrolyte fuel cells. Journal of Power Sources, 147, 32-45

Steffen, Jr. C. J.; Freeh, J. E.; Larosiliere, L. M. (2005). Solid oxide fuel cell/gas turbine hybrid cycle technology for auxiliary aerospace power. Proceedings of the ASME Turbo Expo. Reno-Tahoe, United States

Suther, T. (2006). Simulation of a solid oxide fuel cell-gas turbine system using Aspenplus. Master of Applied Science thesis, Dalhousie University

Suther, T.; Fung, A. S.; Koksal, M.; Zabihian, F. (2010). Effects of operating and design parameters on the performance of a solid oxide fuel cell-gas turbine system. International Journal of Energy Research, Articles online in advance of print

Tao, W. Q.; Min, C. H.; Liu, X. L.; He, Y. L.; Yin, B. H.; Jiang, W. (2006). Parameter sensitivity examination and discussion of PEM fuel cell simulation model validation. Part I. Current status of modeling research and model development. Journal of Power Sources, 160, 359-373

Van Herle, J. ; Mare'chal, F.; Leuenberger, S.; Favrat, D. (2003). Energy balance model of a SOFC cogenerator operated with biogas. Journal of Power Sources, 118, 375-383

Versteeg, G. F.; Van Dijck, L. A. J.; Van Swaaij, W. P. M. (1996). On the kinetics between $\mathrm{CO}_{2}$ and alkanolamines both in aqueous and non-aqueous solutions. An overview, Chemical Engineering Community, 144, 113-158

Veyo, S. E.; Shockling, L. A.; Dederer, J. T.; Gillett, J. E.; Lundberg, W. L. (2002a). Tubular solid oxide fuel cell/gas turbine hybrid cycle power systems: Status. Journal of Engineering for Gas Turbines and Power, 124, 845-849

Veyo, S. E.; Vora, S. D.; Litzinger, K. P.; Lundberg, W. L. (2002b). Status of pressurized SOFC/GAS turbine power system development at Siemens Westinghouse. Proceedings of the ASME Turbo Expo. Amsterdam, Netherlands

Wang, C. Y. (2004). Fundamental models for fuel cell engineering. Chemical Reviews, 104, $4727-4765$

Wang, P. Y. (2007). Combined cycle power augmentation study, PhD thesis, National Tsing Hua University, Taiwan

Williams, M. C.; Strakey, J. P.; Surdoval, W. A; Wilson, L. C. (2006). Solid oxide fuel cell technology development in the U.S. Solid State Ionics, 177, 2039-2044

Winkler, W.; Nehter, P.; Williams, M. C.; Tucker, D.; Gemmen R. (2006). General fuel cell hybrid synergies and hybrid system testing status. Journal of Power Sources, 159, 656666

Yakabe, H.; Ogiwara, T.; Hishinuma, M.; Yasuda, I. (2001). 3-D model calculation for planar SOFC. Journal of Power Sources, 102 (1-2), 144-154 
Young, J. B. (2007). Thermofluid modeling of fuel cells. Annual Review of Fluid Mechanics, 39, 193-215

http://www.mhi.co.jp/en/news/sec1/200608041128.html (May, 2008) 


\section{Part 4}

\section{Making Fossil Fuels Sustainable}





\title{
Carbon Capture and Storage Technology for Sustainable Energy
}

\author{
Dr (Mrs.) Malti Goel \\ Jawaharlal Nehru University, Centre for Studies in Science Policy, New Delhi, \\ India
}

\section{Introduction}

Carbon capture and storage (CCS) is amongst the range of energy technology strategies for addressing concerns of increasing greenhouse gas emissions in the atmosphere and achieving sustainable energy from fossil fuel use. In the long run its potential to reduce $\mathrm{CO}_{2}$ concentrations is second to the contribution expected from energy efficiency improvement (ETA, 2008). The main focus of this chapter is to describe the processes and techniques of CCS technology as well as challenges and policy concerns. Large-scale deployment of CCS however, raises issues of permanency and safety of storage. Consequently, enormous research efforts are directed worldwide in testing its efficacy. Results are summarized in the Indian context from the International Workshop on R\&D Challenges in Carbon Capture and Storage Technology.

\section{The CCS technology}

Carbon dioxide is most prominent natural and biogenic greenhouse gas that trap heat in the atmosphere. Its presence at a concentration of 0.03 per cent by volume in the atmosphere is critical in maintaining the planet earth at a temperature suitable for human beings. A natural carbon balance is maintained through 'carbon cycle' in the earth system. It involves exchanges of carbon dioxide in the Atmosphere with the Hydrosphere, Biosphere and Lithosphere.

Post industrialization long-term increase in carbon dioxide content in the air is seen to be of the order of $30 \%$ since 1850, increasing from $280 \mathrm{ppm}$ to $374 \mathrm{ppm}$ in 2005 . As the concentration of $\mathrm{CO}_{2}$ in the atmosphere is building-up, natural carbon cycle is getting disturbed and global warming is being caused. Intergovernmental Panel for Climate Change (IPCC) provides evidence that the average earth's temperature has risen by $0.74^{\circ} \mathrm{C}$, in 2005 from what it was in 1906. The rising concentrations of $\mathrm{CO}_{2}$ are mainly ascribed to the use of fossil fuels - coal, oil and gas for energy production and consumption.

Carbon capture and storage (CCS) is amongst the range of energy technology strategies for addressing concerns of increasing greenhouse gas emissions in the atmosphere and achieving sustainable energy from fossil fuel use. The $\mathrm{CO}_{2}$ sequestration - Carbon Capture and Storage (CCS), may be subdivided into three systems.

- $\mathrm{CO}_{2}$ capture and compression system. This system may also comprise conditioning units for transport 
- Transport system for taking the captured $\mathrm{CO}_{2}$ to appropriate locations.

- Injection and storage system for its permanent storage away from the atmosphere. The injection system comprises wellhead(s) and the injection wells. The storage system comprises the geological formation (reservoir) in which $\mathrm{CO}_{2}$ is injected as well as its surrounding medium (cap-rock, overburden, etc).

The various components of CCS are depicted in Fig. 1.

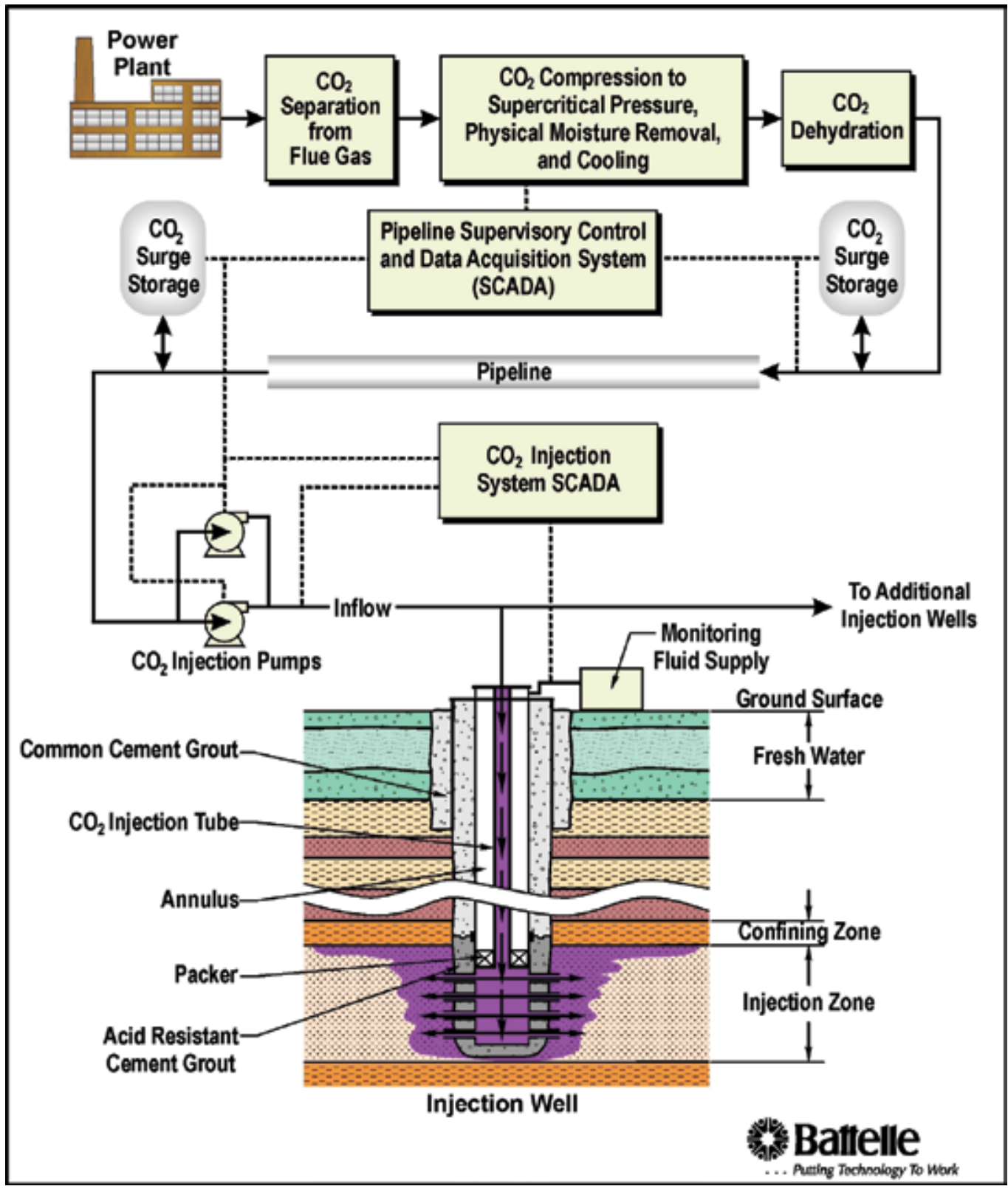

Fig. 1. Carbon Capture and Storage Technology Systems (Dooley, et al, 2006) 


\section{$2.1 \mathrm{CO}_{2}$ capture technology}

The carbon dioxide in the atmosphere can most appropriately be captured at locations where it is produced, such as thermal power plants or industrial units (Herzog and Drake, 1996). Global point sources emitting more than $0.1 \mathrm{Mt}$ of $\mathrm{CO}_{2}$ from 4492 power sources added to $10.5 \mathrm{Bt}$ of $\mathrm{CO}_{2}$ per year and 2953 energy consuming outfits added to $3.5 \mathrm{Bt}$ of $\mathrm{CO}_{2}$ in 2005 (Metz et al 2005). The $\mathrm{CO}_{2}$ capture using chemical, physical and biological techniques can be adapted to power plant flue gas as well as to steel plants, cement works, ammonia, gas processing industries, and refineries as its other point sources. The main considerations in $\mathrm{CO}_{2}$ capture application to a point source, besides technology are; cost and efficiency penalty. The captured $\mathrm{CO}_{2}$ is compressed to liquid form.

\subsection{1 $\mathrm{CO}_{2}$ capture from the flue gas of a coal power plant}

Coal is having relatively highest carbon-to-hydrogen ratio among other fossil fuels and therefore its use results in higher $\mathrm{CO}_{2}$ emissions per unit heat output than oil or natural gas. Three basic options for $\mathrm{CO}_{2}$ capture are distinguished as post-combustion capture, precombustion capture, and modified combustion (oxy fuel and chemical looping) processes. A schematic of $\mathrm{CO}_{2}$ capture process is presented in the Fig. 2. Chemical and physical separation using: absorption in solvents, adsorption on solid sorbents, membrane separation and cryogenic processes, are developed or developing.

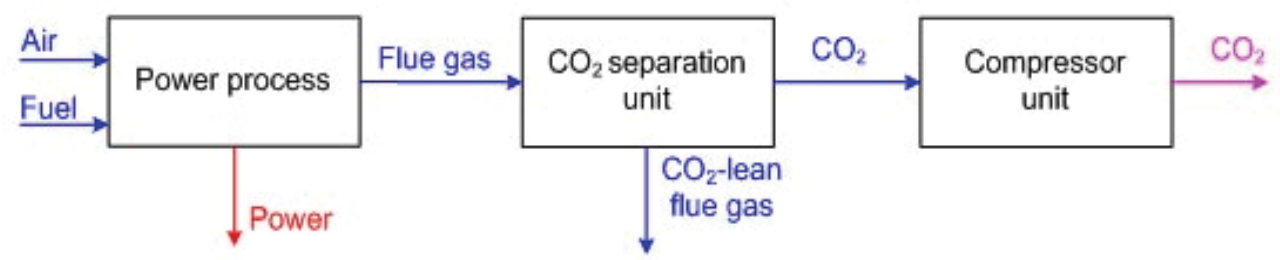

Fig. 2. Schematic of $\mathrm{CO}_{2}$ capture process.

Post-combustion flue gas from a coal based thermal power plant comprises of $8-14 \% \mathrm{CO}_{2}$. At such low concentrations of $\mathrm{CO}_{2}$, chemical absorption processes are more reasonable. Amine based $\mathrm{CO}_{2}$ separation technologies are commercially proven and are industrial bench mark. The power plant flue gas reacts with amines at 40 to $60^{\circ} \mathrm{C}$, but the process of $\mathrm{CO}_{2}$ separation from the $\mathrm{CO}_{2}$ rich solvent needs higher temperature. The solvent can be recycled after use. The advantage is that $\mathrm{CO}_{2}$ is recovered up to $90 \%$ purity and recovery rates are 98\% (Yamasaki, 2003). This process is also known as scrubbing or absorption-stripping of flue gas stacks.

Monoethanol amine (MEA) and diethanol amine (DEA) impregnated activated carbon, zeolites and alumina have been studied for adsorption, desorption and thermo-gravimetric evolved gas analysis of $\mathrm{CO}_{2}$ saturated samples with further optimization in progress (Jadhav, et al, 2008). Amine processes have high energy penalty and the cost of electricity increases by as much as $70 \%$. Low partial pressure, high temperature of flue gas and presence of other gases are some of the other key problems encountered in their use. Polymer system amines like amine functional polystyrene perform better and can be regenerated at a lower temperature of the order of $60^{\circ} \mathrm{C}$ temperature (Chakma, 1997). Amine functionalized materials including natural biopolymers and synthesized nitrogenous activated carbon offer vast scope in reducing energy penalty for $\mathrm{CO}_{2}$ capture (Gattuso, 
2007). Activated carbon offers useful sites for $\mathrm{CO}_{2}$ absorption at atmospheric temperature as well as at high temperatures (temperature of the flue gas).

To offset some of other limitations of solvent based separation i.e. high solvent losses by evaporation and high rate of corrosion of the equipment, search for novel solvents is on. The approach to develop immobilizing liquids disposed upon different solids has been studied (Mahosan, et al, 2008). Enhanced absorption studies carried out for gas separation using multi-phased absorbents that are composed of porous solid support having a liquid phase in $\mathrm{CO}_{2}$ capture are reported.

Commercially proven as gas purification technology, membrane technology for $\mathrm{CO}_{2}$ separation is under development. Membrane separation process can perform in two ways; either a membrane filters $\mathrm{CO}_{2}$ or it filters gases other than $\mathrm{CO}_{2}$ by a solution-diffusion mechanism. Materials for membranes with preferential $\mathrm{CO}_{2}$ transport include functionalized polymers, metal organic framework and polymer composites. These operate close to ambient temperatures. Powell and Qiao, 2006 presented a review on performance of $\mathrm{CO}_{2} / \mathrm{N}_{2}$ gas separation polymeric membranes, their permeability and selectivity properties. Porous and non-porous inorganic nano-membranes offer new possibility of integration with power plants to provide cost-effective $\mathrm{CO}_{2}$ capture solutions. Recent developments include polymer-inorganic hybrid membranes and nanostructures for higher efficiency and reduction of total cost for $\mathrm{CO}_{2}$ capture. Pyrolysis of thermosetting polymers can lead to carbon molecular sieve membranes with pore size distribution below the molecular dimensions. These materials can be supported on alumina to improve their mechanical stability. Ionic transport membranes are also under development.

Application of Pressure Swing Adsorption (PSA) to separate $\mathrm{CO}_{2}$ from other impurities would reduce the energy consumption of $\mathrm{CO}_{2}$ separation by $25-30 \%$. Moreover, Pressure Swing Cycle can be applied for both post-combustion and pre-combustion capture, if $\mathrm{CO}_{2}$ concentration is high. The adsorbent gets saturated with $\mathrm{CO}_{2}$ and subsequently regenerated yields very high purity $\mathrm{CO}_{2}(90 \%)$. A recovery up to $78 \%$ is expected. Simulation of this cycle with a hydrotalcite adsorbents of $0.85 \mathrm{~mol} / \mathrm{kg} \mathrm{CO}_{2}$ capacity at $575 \mathrm{~K}$, shows promising results and potential of PSA processes for still higher $\mathrm{CO}_{2}$ recovery (Goswami, et al, 2008). Recent studies on carbon dioxide adsorption over $\mathrm{Ca} / \mathrm{Al}$ hydrotalcite and $\mathrm{Mg} / \mathrm{Al}$ hydrotalcite have been reported in the temperature range 40 to $800^{\circ} \mathrm{C}$, at different pressures and mol ratio (Gaikwad, 2010). Further work is required in development of nonconventional PSA cycles for $\mathrm{CO}_{2}$ separation and study of behavior of Hydrotalcite materials.

\subsubsection{Advanced $\mathrm{CO}_{2}$ capture options}

New Class of nano-materials, which selectively attract $\mathrm{CO}_{2}$ molecules at $220^{\circ} \mathrm{C}$, i.e. nearer the temperature at which water gas shift reaction occurs in IGCC are being developed. Zeolites as crystalline luminium silicates are effective membranes for a wide range of $\mathrm{CO}_{2}$ separation applications. In the advanced Integrated Gasification Combined Cycle (IGCC) "synthesis gas" (mainly $\mathrm{CO}+\mathrm{H}_{2}$, plus some $\mathrm{CO}_{2}$ ) produced from coal gasification process undergoes a further catalytic "gas-shift" process with water vapour transforming most of the $\mathrm{CO}$ into additional $\mathrm{CO}_{2}$ and $\mathrm{H}_{2}$. The capture of $\mathrm{CO}_{2}$ is then combined with the necessary purification of hydrogen. Hydrogen, together with the non-shifted $\mathrm{CO}$ acts as the feed for a combustion gas turbine for producing electricity. The cost analysis of adding $\mathrm{CO}_{2}$ capture to various options viz., a IGCC plant, pulverized coal fired plant and supercritical coal combustion has been studied (Narain, 2008). 
Zeolites are crystalline aluminum silicates as effective membranes for a wide range of $\mathrm{CO}_{2}$ separation applications. New class of nano-materials, which selectively attract $\mathrm{CO}_{2}$ molecules at $220^{\circ} \mathrm{C}$, i.e. nearer the temperature at which water gas shift reaction occurs in IGCC are being developed. In order to identify possible options, binding energy estimates and thermo gravimetric analysis are used as screening tools. Nanostructures for the abatement of carbon dioxide $\left(\mathrm{CO}_{2}\right)$ at the pre-combustion stage of gasification-based power generation include lithium silicate nanoparticles and membranes that consist of $\mathrm{CO}_{2}$-philic ionic liquids encapsulated into a polymeric substrate (Pennline, et al, 2008).

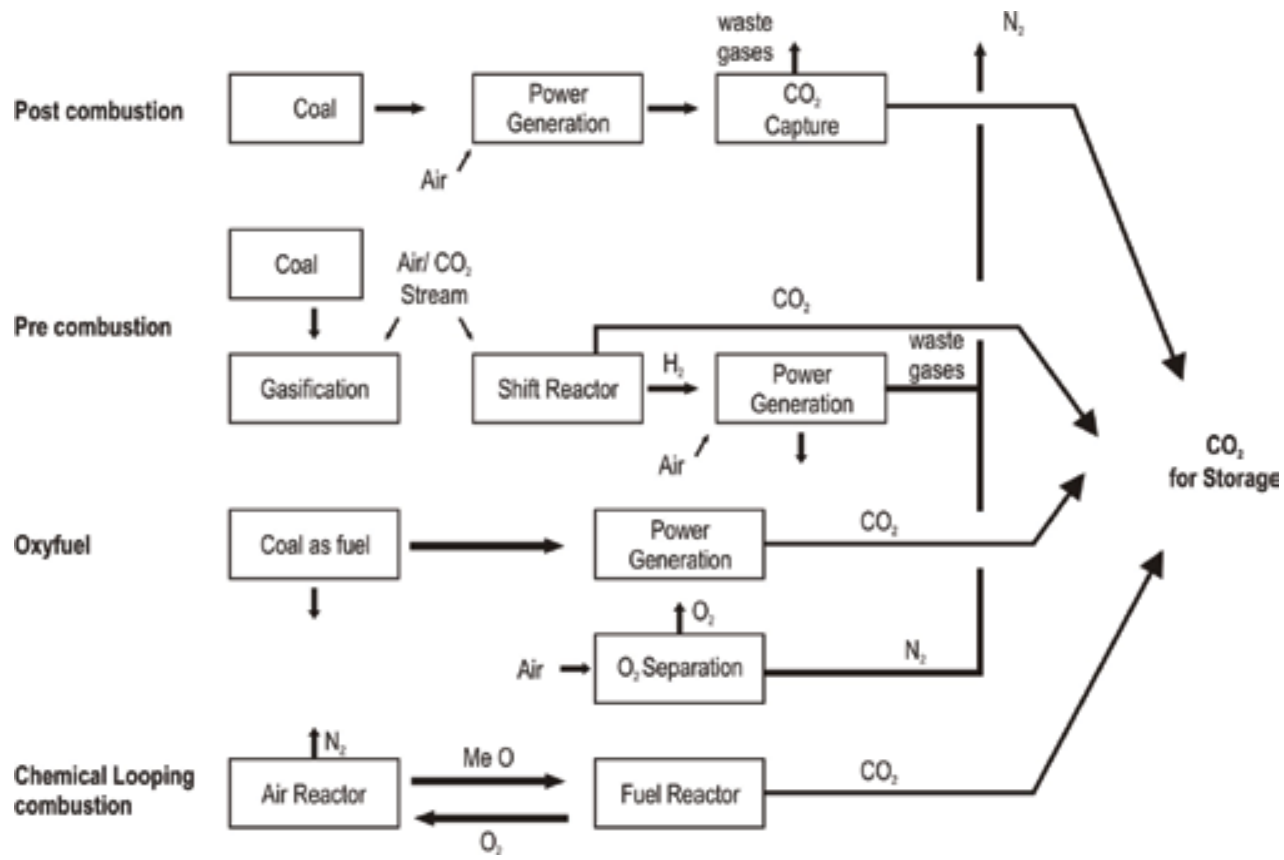

Fig. 3. $\mathrm{CO}_{2}$ capture; pre combustion, post combustion, oxy-fuel combustion and chemical looping combustion (Goel, 2008)

Modified combustion processes are the other options being developed to increase the efficiency of coal based generation and concentration of $\mathrm{CO}_{2}$ in the flue gas. In a highly oxygen enriched atmosphere used in oxy fuel combustion, the thermal ballast is recycled $\mathrm{CO}_{2}$. The other advantage is that the flue gas in this case is essentially composed of $\mathrm{CO}_{2}$ and water instead of nitrogen from air. It does not require separation of inert gases normally present. The energy penalty in this case comes from the additional cost of the air separation process, which is necessary to produce oxygen for combustion.

First CCS power plant based on oxy fuel combustion is Sask Power project, using Saskatchewan lignite. Low sulphur content in coal/ lignite does not required internal desulphurization in the fuel gas recycle loop of an oxy fuel plant. A 0.3MW pilot scale project capture ready power plant planned near Ottawa has been started to demonstrate oxy fuel combustion with $\mathrm{CO}_{2}$ capture. Another oxy coal combustion pilot plant facility of 30MW has been demonstrated in Germany (Vattenfall and Alstom) in 2008. Oxy-fuel Firing is expected to develop for high ash coals as one of the best solution for carbon capture among other options (Timms, 2007). 
Research is also being conducted in advanced coal based technologies like molten carbonate fuel cell, chemical looping combustion etc. for mitigating $\mathrm{CO}_{2}$ emissions. The chemical looping combustion (CLC) has advantage of inherent $\mathrm{CO}_{2}$ capture. The CLC has two reactors, one for air and one for fuel as depicted in Fig. 3. In the air reactor carrier is oxidized by oxygen and in the fuel reactor metal oxide is reduced by the fuel. Flue gas from air reactor contains $\mathrm{N}_{2}$ and unreacted $\mathrm{O}_{2}$. Exit gases from fuel reactor contain $\mathrm{CO}_{2}$ and $\mathrm{H}_{2} \mathrm{O}$, pure $\mathrm{CO}_{2}$ can be separated, whereas $\mathrm{H}_{2}$ is combusted (Mattison and Lyngfelt, 2001).

\section{$2.2 \mathrm{CO}_{2}$ transport}

Once the $\mathrm{CO}_{2}$ is captured and compressed, it can be transported to storage sites. The transport of $\mathrm{CO}_{2}$ is not a scientific problem. Pipelines and ships are considered the most likely means of long distance $\mathrm{CO}_{2}$ transport. Using existing oil pipelines facilities is the most feasible transportation option for distances up to $1000 \mathrm{~km}$. Shipping of $\mathrm{CO}_{2}$ for longer distances or overseas would be similar to shipping liquefied natural gas. In the absence of oil pipeline networks, new high pressure pipelines are major infrastructure costs. The pressurization energy requirement and recycling of $\mathrm{CO}_{2}$ at the receiving end also add to the cost.

\section{$2.3 \mathrm{CO}_{2}$ storage}

For geological storage $\mathrm{CO}_{2}$ is injected underground in a variety of geological environment in sedimentary basins. Within these basins oil \& gas reservoirs and empty fields; unmineable coal seams; and saline formations are possible sites. Other potential storage sites for sequestration of carbon dioxide include caverns, basalt rocks and organic shales. These kind of geological formations are found both on and offshore in various locations around the world. To achieve successful storage in terms of mitigating the damaging environmental effects of $\mathrm{CO}_{2}$ accumulations in the atmosphere, such storage must be relatively permanent. Permanence would means that the $\mathrm{CO}_{2}$ does not leak back into the atmosphere at any significant rate for hundreds to thousands of years. To achieve this injection of $\mathrm{CO}_{2}$ must take place at depths in excess of 800 metres so that geological cap rock can prevent the gas from migrating back to the surface.

Injection of $\mathrm{CO}_{2}$ is done using infrastructure and experience of oil industry. Innovation is also taking place. Carbon micro-bubbles can be injected as atomized foam and this allows dispersal deep into tiny pores of different underground structures and makes it a stable and leak proof process (Koide and $\mathrm{Xiu}, 2009$ ). The R\&D needs with respect to injectivity, reactive fluid, transport reservoir monitoring etc. for $\mathrm{CO}_{2}$ sequestration, (which are likely to become an important part of exploration \& production operation in oil fields) have been identified based on results obtained from the FRIO project (Hovorka et al, 2005). where in 600 tonnes $\mathrm{CO}_{2}$ was injected in geological formations and has been monitored.

The carbon dioxide exists in gas, liquid, solid and supercritical phase. The pressuretemeperature phase diagram is depicted in Fig. 4. The $\mathrm{CO}_{2}$ is normally stored underground in super-critical phase, which is attained at $31.1^{\circ} \mathrm{C}$ temperature and at pressure greater than 73.9 bars. It has properties in between gas and solid with following characteristics.

- Dense gas

- Physico - chemical properties between those of liquid and gas.

- Solubility approaching liquid phase

- Diffusivity approaching gas phase 


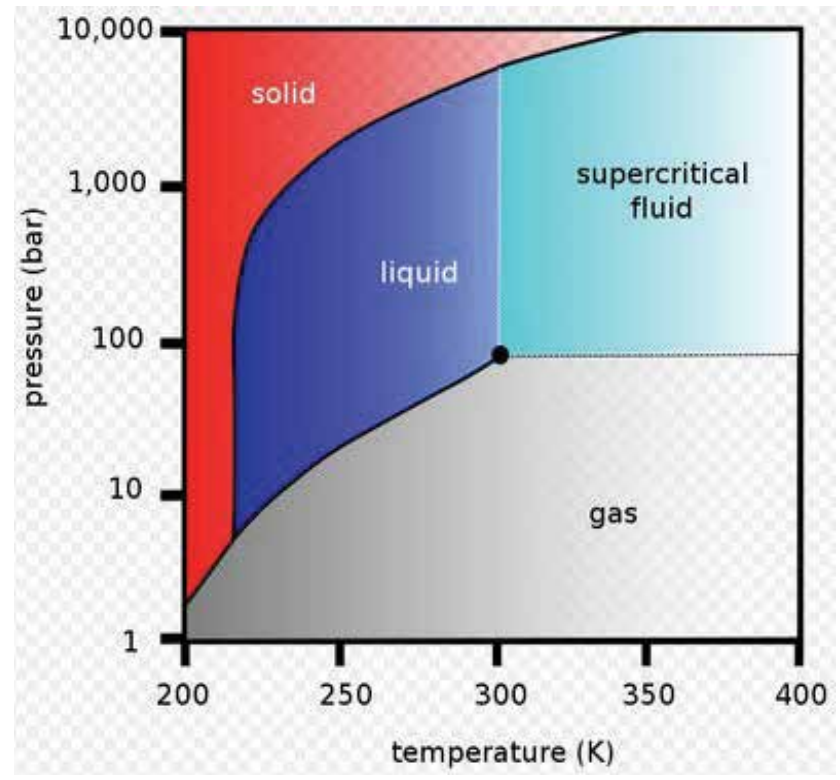

Fig. 4. Pressure-temperature phase diagram of $\mathrm{CO}_{2}$

\subsubsection{Trapping mechanisms}

Inside the earth, pore space between the rock grains or minerals is occupied by fluids. Open fracture and cavities are also filled with fluid. These act as trapping sites. Depending on the permeability and thickness of the formation, $\mathrm{CO}_{2}$ injection raises the pressure near an empty reservoir the well, allows the liquid gas to enter pore spaces. The $\mathrm{CO}_{2}$ may either dissolve in or mix with the fluid, displace the in-situ fluid or react with mineral grains or combination of the processes may occur. In case of saline aquifers, $\mathrm{CO}_{2}$ solubility in formation water decreases as temperature and salinity increases. The $\mathrm{CO}_{2}$ dissolved in water can form $\mathrm{CaCO}_{3}$ and it also reacts with sodium, potassium, silicates, magnesium etc. Reaction can be rapid in case of carbonate materials, but slow in case of silicate materials. Once formation fluid is saturated with $\mathrm{CO}_{2}$, its absorption slows down and is controlled by diffusion and convection. The $\mathrm{CO}_{2}$ storage process changes the reservoir properties. Thus different trapping mechanisms for injected $\mathrm{CO}_{2}$ are expected to occur.

Structural / Stratigraphic trapping - When $\mathrm{CO}_{2}$ is pumped under low permeable rock conditions it rises up until it reaches top of the formation. Below the impermeable cap rock trapping occurs in the structural faults and in between two stratified layers. The drilling wells are resealed with steel and cement caps.

Hydrodynamic / Residual trapping - Residual trapping occurs when liquid $\mathrm{CO}_{2}$ becomes stuck within the pore spaces of the rock, which has sponge like structure. It remains confined to an immobile phase.

Geochemical / Solubility Trapping - Injected $\mathrm{CO}_{2}$ forms a bubble around the injection well, displacing mobile water laterally and vertically. The interaction between fluids or salty water contained in the pore spaces of the formations allows geochemical trapping mechanism to take effect. Geochemical trapping is relatively permanent but slow process. $\mathrm{CO}_{2}$ undergoes sequence of geo-chemical reactions, first reacts with water and then residual $\mathrm{CO}_{2}$ trapping may occur with in-situ fluid. 
Mineral Trapping - Over time $\mathrm{CO}_{2}$ that is not immobilized by residual trapping, can react with in-situ fluid to form carbonic acid $\left(\mathrm{H}_{2} \mathrm{CO}_{3}\right)$ that dominates for tens to hundred years. Dissolved $\mathrm{CO}_{2}$ can eventually react with surrounding minerals, if the appropriate mineralogy is encountered. It forms carbon bearing ionic species $\mathrm{HCO}_{3}{ }^{-1}$ and $\mathrm{CO}_{3}{ }^{-2}$ also known as ionic trapping. It dominates for hundred to thousand years (Fig. 5).

Further breakdown of the ionic minerals could precipitate in carbonates $\left(\mathrm{CaCO}_{3}\right)$ that could fix injected $\mathrm{CO}_{2}$ over thousand to million years. Multiple trappings can lead to rock formation through conversion into carbonates, magnesite and Kaolins etc, which are the main components of natural rocks. This being most permanent fixation of $\mathrm{CO}_{2}$, the reaction rate can be enhanced and the kinetics of reaction mechanism can be understood. Preferred storage mechanisms for different geo-environments are depicted in Table 1.

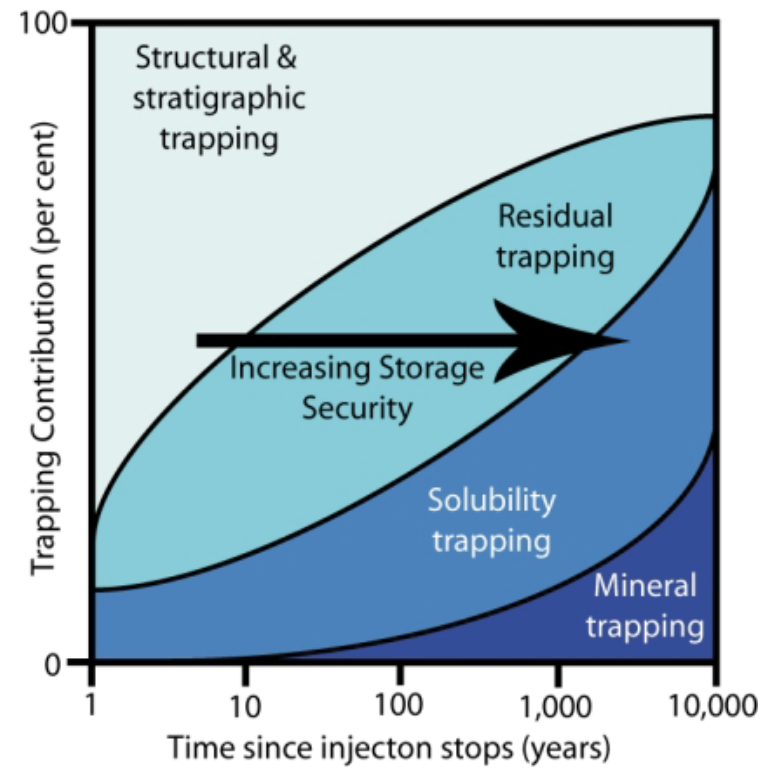

Fig. 5. $\mathrm{CO}_{2}$ underground trapping as a function of time (source - IPCC 2005)

\begin{tabular}{|l|l|l|}
\hline S. No. & \multicolumn{1}{|c|}{$\mathrm{CO}_{2}$ Subsurface reactions } & \multicolumn{1}{c|}{ Preferred Geo-environment } \\
\hline 1. & Structural \& Stratigraphic & In Natural gas reservoirs \\
\hline 2. & Hydro dynamic trapping & In saline aquifers, gas reservoirs \\
\hline 3. & Solvability trapping & In oil reservoirs \\
\hline 4. & Mineral trapping & In brines, Basalt rocks \\
\hline
\end{tabular}

Table 1. $\mathrm{CO}_{2}$ underground trapping mechanisms and preferred environment

Technologies such as Geographical Information System (GIS) are useful tool for mapping of $\mathrm{CO}_{2}$ sources and analyzing potential for its storage sites (Holloway et al, 2008). Storage 
capacity in possible underground locations has been assessed. The process of Enhanced Oil Recovery (EOR) using $\mathrm{CO}_{2}$ is an active process and how it can help sequester the carbon dioxide at a low net cost is being tested in Canada's Weyburn Oil Fields. In the coal beds, enhanced coal bed methane (ECBM) process can increase the recovery from $\mathrm{CO}_{2}$ injection up to $90 \%$.

\subsection{2 $\mathrm{CO}_{2}$ storage possible sites - basalts, saline, empty gas fields, empty oil fields}

Basalt formations are solidified lava and have unique chemical properties. In Basalts, carbonation rate at equilibrium with supercritical $\mathrm{CO}_{2}$ in pore water is higher as compared to other sedimentary rocks such as day feldspar (McGrail el.al. 2006). Subsurface reactions with minerals to from carbonate precipitations are being looked as possible long-term fixation. Research carried out in Columbia River Basalts suggests that lateral dispersions and vertical transport of $\mathrm{CO}_{2}$ to overlaying basalt flows are expected to be important limiting factor controlling in-situ process. Pacific Northwest National Laboratory, USA has identified carbon dioxide sequestration research priorities in flood basalts in Columbia river region. Simulation of gas phase saturation is depicted in Fig. 6. Considerable further research is needed to understand the kinetics of rapid mineralization reaction rates that may occur in different basalts across the world.

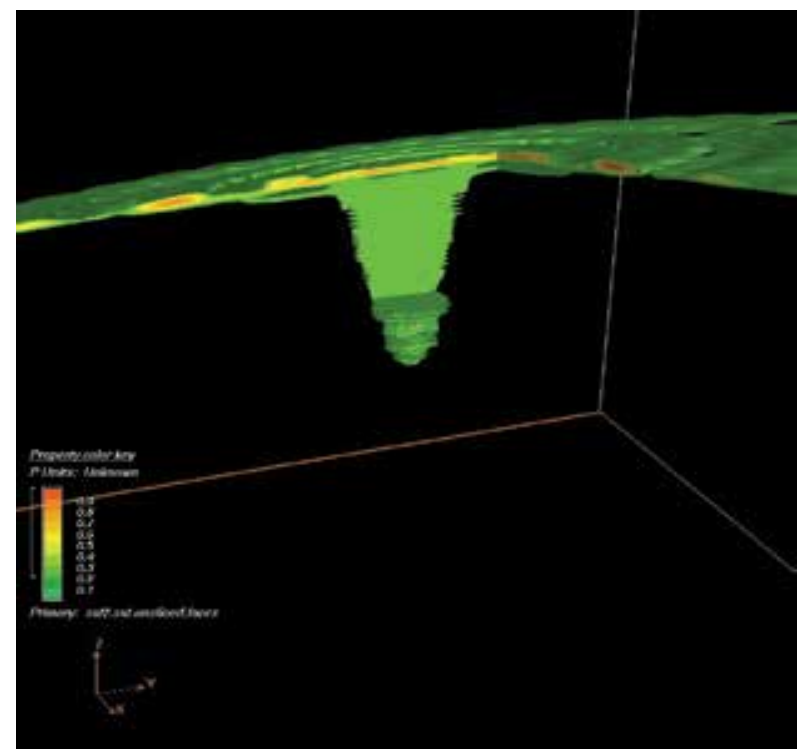

Fig. 6. Simulation of gas phase saturation in Basalts (source - Pacific Northwest National Laboratory, McGrail, et al, 2008)

Deccan Province in West India is one of the continental flood basalts covering an area of $500 \times 10^{3}$ sq. $\mathrm{km}$ and one amongst the largest flood eruption in the world. Thickness varies from a few hundred $\mathrm{m}$ to $1.5 \mathrm{~km}$ consisting of the thick Mesozoic sediments, below which could show accelerated reaction with $\mathrm{CO}_{2}$ and its conversion into mineral carbonates (Kumar, et al, 2008; Prasad et al, 2009). Similar to Columbia river basalts in composition, the basalts are expected to form a good cap rock to the reservoir. However, this region is seismically opaque and therefore difficult to monitor. One of the research areas is identified as role of vesicles in vertical carbon flows and enhanced reactivity. 
Saline aquifers provide large $\mathrm{CO}_{2}$ storage capacity. Major bottlenecks are; lack of knowledge about their structure and physical properties as well as the behavior of $\mathrm{CO}_{2}$ in the subsurface saline reservoirs aquifers. The studies so far are site specific and need to be evaluated on case to case basis. Considerable additional geological investigation would be needed to create data base for effective mapping of such reservoirs. One of the first saline aquifer storage projects is in Norway. $\mathrm{CO}_{2}$ from Sleipner Vest field is being sequestered in the North Sea into a shallow subsurface aquifer below seabed in Utsia. About $3000 \mathrm{t} \mathrm{CO}_{2}$ per day (1Mt/year) has been injected into an aquifer at a depth of $1000 \mathrm{~m}$ just above the production reservoir since 1996 . Total $20 \mathrm{Mt}$ of $\mathrm{CO}_{2}$ is expected to be sequestered at this site. The $\mathrm{CO}_{2}$ flow is constantly monitored to see its impact.

New experiments are under planning. A large commercial sequestration project is under planning stages at Gorges fields of NW of Australia. It is proposed that 10,000 tons of $\mathrm{CO}_{2}$ per day could be injected into the deep saline aquifer. Empty gas fields and empty oil fields are other underground storage options.

\subsection{3 $\mathrm{CO}_{2}$ utilization in recovery of energy fuels}

An important aspect of carbon sequestration is recovery of value added products while $\mathrm{CO}_{2}$ is injected in oil or coal fields.

\subsubsection{Oil reservoirs}

In geological storage of $\mathrm{CO}_{2}$ in Enhanced Oil Recovery (EOR) project, injection wells are most critical areas requiring study of mechanisms to determine the potential of oil recovery. To assess oil displacement various mechanisms are involved; oil swelling, viscosity reduction, miscibility generation and reduction in residual oil saturation. Relative contribution of various parameters depends on the reservoir conditions and crude oil quality. The $\mathrm{CO}_{2}$ in oil well can be either miscible or immiscible phase depending primarily on the pressure of injection gas into the reservoir. In miscible phase injected $\mathrm{CO}_{2}$ can mix with the viscous crude causing it to swell. It reduces viscosity while increasing reservoir pressure thus helping to produce more oil. In immiscible phase $\mathrm{CO}_{2}$ does not dissolve in crude, the pressure is raised and helps to sweep the oil towards production well. A combination of both miscible and immiscible phases can occur for $\mathrm{CO}_{2}$ sequestration.

First $\mathrm{CO}_{2}$ - EOR scientific research project was started way back in 1972 in USA with the objective to recover more oil using different approaches. In this $\mathrm{CO}_{2}$ from Natural gas fields was used. In 1986, $\mathrm{CO}_{2}$ purchased from ExxonMobil was injected in an oil field in Colorado. This experiment also provided a test for efficacy of $\mathrm{CO}_{2}$ sequestration, as it was mentioned that Weber Sandstone reservoir has good cap rock, making this oil field a high quality longterm sequestration site, beside enhanced oil recovery. The injection of $\mathrm{CO}_{2}$ for its sequestration from a syn-fuel power plant has been established at Weyburn oil fields in Southern Saskatehewan, Canada while obtaining enhanced oil recovery. Weyburn field projections have suggested that $\mathrm{CO}_{2}$ flooding has proved more effective in oil recovery as compared to water flooding. In addition, injecting about 6000 tons of $\mathrm{CO}_{2}$ per day, 20Mt of $\mathrm{CO}_{2}$ is expected to be sequestered (Vargas, 2009).

Another international project on $\mathrm{CO}_{2}$ sequestration for enhanced oil recovery is In Salah, Algeria. It is expected that $17 \mathrm{Mt}$ of $\mathrm{CO}_{2}$ could be injected in the gas leg of the reservoir into the oil field till the project completion in 2020. Laboratory scoping studies have also been carried out in India in a mature oil field of Ankleshwar and preliminary results from application of $\mathrm{CO}_{2} \mathrm{EOR}$ have revealed that incremental oil recovery by $\mathrm{CO}_{2}$ injection is 
possible over water-flooding under immiscible displacement conditions, which may lead to enhanced recovery of up to $4.5 \%$ over the project life span of 35 years. By one estimate 7.5 $\mathrm{Mt}$ of $\mathrm{CO}_{2}$ could be sequestered over the project life. A study on thermal EOR monitoring in heavy oil fields of Oil and Natural Gas Commission (ONGC) was conducted (Dimri, et al, 2008) under NGRI-NTNU project (Indo-Norwegian collaboration). Time lapse analysis for monitoring of fluid flow dynamics may help in optimizing the production and injection strategy.

Some of the future EOR projects are; Joint projects of Monash Energy and Shell for $35,000 t /$ day $\mathrm{CO}_{2}$ sequestration project in Australia, and $\mathrm{BP} \mathrm{CO}_{2}$ sequestration project envisaging $\mathrm{CO}_{2}$ injection form a gas based power plant into North Sea Miller Oil field for oil recovery operation. In addition to these, Shell oil and Statoil have announced two large $\mathrm{CO}_{2}$ EOR projects and BP plans to have another project on gasification of petroleum coke, an abundant byproduct of the oil refining process. It is envisaged that $90 \% \mathrm{CO}_{2}$ emissions will be captured and injected for enhanced oil recovery. EOR operations and $\mathrm{CO}_{2}$ injection rates need a balance for optimizing the delivery and vary from site to site.

\subsubsection{Coal beds}

Coal and lignite may act as permanent storage for $\mathrm{CO}_{2}$ in view of its affinity to coal molecules. Research in this area is in infancy. In a recent study conducted in USA, 90t of $\mathrm{CO}_{2}$ injected into a Burke Country coal $3 \mathrm{~m}$ thick seam at a depth of $300 \mathrm{~m}$, remained contained for 3 months. Although there were no results presented in the workshop on technical feasibility of enhanced coal bed methane recovery, some of the preliminary analysis made for enhanced gas recovery from coal beds in India, suggested that deep seated unmineable coal beds could have storage capacity of up to $120 \mathrm{Mt}$ (Singh, 2008). Stimulated gas production profile for gas recovery through $\mathrm{CO}_{2}$ injection in a laboratory simulation on coal samples from Southern Part of Raniganj Coalfield has been carried out (Mendhe, et al, 2008). Stratigraphic horizon of coal deposits in India and possibility of further research on coal bed methane from $\mathrm{CO}_{2}$ storage in coal seams need to be demonstrated. In depth studies on geological, geo-morphological and physio-chemical studies of reservoirs and cap rocks are required to address the questions like; whether carbon dioxide will remain entrapped, for how long and what coal types are suitable?

\section{Future challenges}

Huge amounts of natural gas are expected to be trapped in condensed form in the gas hydrates. The gas hydrates are non stiochiometric inclusion compounds in gaseous molecules, which exist as a solid phase at high gas pressures and low temperatures deep inside the oceans. The gaseous molecule can be methane or carbon dioxide or any other. Recovery of hydrocarbons from methane gas hydrates is yet a challenging task. Formation of carbon dioxide clathrates in fluid inclusions can be a mechanism of $\mathrm{CO}_{2}$ sequestration (Prasad, 2008) while recovering methane.

Other challenges in sustainable energy lie in production of hydrogen based power with carbon dioxide capture and storage (Wright, 2008). First industrial demonstration of $475 \mathrm{MW}$ capacity using hydrogen as fuel to generate low carbon power is in planning stage. Green Power generation using hydrogen from Natural gas with $\mathrm{CO}_{2}$ capture \& storage up to $1.8 \mathrm{Mt}$ / year is expected. Carson Hydrogen project is another industrial scale 500 MW project of hydrogen manufacture from Petroleum Coke with CCS facility. It is estimated that $4 \mathrm{Mt} /$ year of $\mathrm{CO}_{2}$ will be injected underground, while hydrogen will be used to produce power. 
A number of other breakthrough ideas and innovative concepts have been suggested for mitigating carbon dioxide in the atmosphere. A pilot integrated converter has been conceived in which magnesium can be recycled partly for energy and partly utilized for value added products. The oxygen is produced as a by-product. A magnesium carbon dioxide $\left(\mathrm{Mg}-\mathrm{CO}_{2}\right)$ reactor could reduce $44 \mathrm{~g}$ of $\mathrm{CO}_{2}$ to $12 \mathrm{~g}$ elemental carbon (Chandra, 2008). Elemental carbon has versatile applications ranging from laser research to produce exotic materials like fullerenes and carbon nanotubes (Goel, 2009).

Oil-shale is another possible option for $\mathrm{CO}_{2}$ sequestration and is also an alternate energy source to deal with the oil crisis. In oil shale production when oil shale kerogen is pyrolyzed, $\mathrm{CO}_{2}$ is co-produced. Colorado School of Mines has estimated that World oil shale resources are likely to consist 15 trillion barrels of hydrocarbon products. The Green River valley has $3,000,000$ barrels resource. In an effort to control release of $\mathrm{CO}_{2}$ from an in-situ oil shale industry, a model for $\mathrm{CO}_{2}$ separation and sequestration has been developed (Boak, 2008). Studies have been carried out to reduce the fraction of $\mathrm{CO}_{2}$ and develop $\mathrm{CO}_{2}$ sequestration schemes along with production of oil shale. More work is needed not only to define its potential energy resource from underground, but also in defining the rock potential for storage. As the oil shale production grows it will be necessary to identify, secure and link large-scale target formations for these volumes of $\mathrm{CO}_{2}$ sequestration.

\section{Infrastructure issues}

\section{$4.1 \mathrm{CO}_{2}$ capture}

A thermal power plant as a point source has a long lead time of 5-6 years for putting in place the necessary infrastructure. Planning for $\mathrm{CO}_{2}$ capture should be done in advance. This would require proper site selection and adequate space for capture components. Adequate infrastructure is required for the success of the operation. Cost-effective technologies and engineering systems are needed to capture $\mathrm{CO}_{2}$ emissions. $\mathrm{CO}_{2}$ Capture can become an industry standard only after technology is proven and necessary regulations are in place.

A conceptual journey on how to make a transition towards capture ready power plants has been suggested (Lucquiaud and Gibbins, 2009). Major requirements for $\mathrm{CO}_{2}$ Capture Ready plant regardless of the CCS technology chosen for the retrofit are identified as:

i. A study of options for $\mathrm{CO}_{2}$ capture retrofit and potential pre-investments;

ii. Sufficient space and access for the additional facilities that would be required;

iii. Identification of reasonable route(s) to storage of $\mathrm{CO}_{2}$.

\section{$4.2 \mathrm{CO}_{2}$ transport}

Taking part in $\mathrm{CO}_{2}-\mathrm{EOR}$ is considered a way forward for the future survival of fossil fuels based energy industry. Initially thought as an option to mitigate $\mathrm{CO}_{2}$ emissions using existing infrastructure of oil \& Gas industry (storage in depleted oil \& gas reservoirs and transportation of $\mathrm{CO}_{2}$ using existing pipelines) the experience suggests that new infrastructure would be required not only in power plant construction, but also in transport and at the appropriate location of storage.

\section{$4.3 \mathrm{CO}_{2}$ storage}

\subsubsection{Geo-modeling}

Geo-modeling studies are carried out to model the reservoir in terms of its various parameters such as depths, size cap rock characteristics as well as $\mathrm{CO}_{2}$ behavior in the 
reservoir. Although oil \& gas fields offer promising energy fuel opportunities it is saline aquifers, which have highest storage capacity. Performance prediction of $\mathrm{CO}_{2}$ behaviour in these reservoirs can be made by using theoretical models. A range of models have been developed to study $\mathrm{CO}_{2}$ geochemistry, leakage pathways and trapping mechanisms, such as CO2PENS, STOMP, FEHM, PNLCARB, TOUGH and others, which can predict the ability of a geologic formation to sequester $\mathrm{CO}_{2}$ as follows (Jain, 2010).

- GEO-SEQ is aimed at improved prediction of injectivity and capacity of saline formations.

- CO2PENS takes a broader view and analyzes the entire CCS operation from capture of $\mathrm{CO}_{2}$ through transportation to injection and trapping in the reservoir.

- The STOMP-CO $\mathrm{CO}_{2}$ is numerical multiphase $\mathrm{CO}_{2}$ flow and transport simulator for modeling behavior at $\mathrm{CO}_{2}$ of in different geo-environments. Phase behavior algorithms for physiochemical properties of $\mathrm{CO}_{2}$ in supercritical region were added to stimulate deep well injection.

- TOUGH is a simulator development of fluid dynamics, geochemistry and geomechanics to track multiphase flows of water $/ \mathrm{CO}_{2} / \mathrm{NaCl}$ mixtures for application to studies of reservoir dynamics, storage capacity, $\mathrm{CO}_{2}$ leakage, mineral trapping \& cap rock integration.

- PNLCARB adopted a semi-analytical modeling framework to simulate deep-well injection of $\mathrm{CO}_{2}$ for geological sequestration. Studies were conducted on radial injection of supercritical $\mathrm{CO}_{2}$ in deep well formations, and tracking its multiphase flows.

\subsubsection{Measurement, monitoring \& verification}

The $\mathrm{CO}_{2}$ injected beneath the ground is to be carefully tracked through measurement, monitoring and verification (MMV). As many as twenty parameters have been identified for monitoring to achieve safe $\mathrm{CO}_{2}$ storage using physical and chemical characterization techniques starting from the site selection. Site location and its characterization require scientific study in following domains.

- Sub surface domain- characterization of reservoirs and well bores to study deep migration and behavior of stored $\mathrm{CO}_{2}$.

- Near surface domain - geological site description, seal properties, study of water quality samples to verify non seepage into shallow aquifers and soil.

- Atmospheric or surface domain -to characterize the atmospheric monitoring of gases in the area before injection and after injection.

Surface characterization is done to know about future possible leakages into atmosphere. After injection of $\mathrm{CO}_{2}$ at a depth of $800 \mathrm{~m}$ or so, seismic surveys by electromagnetic and gravitation sensors distributed on the surface of boreholes for storage integrity studies are carried out. The $\mathrm{CO}_{2}$ flow and transport process in porous media, and how the cap rock seal behaves over very long time scales are the other parameters to be investigated.

Various geophysical tools such as seismic for imaging the acoustic velocity structure, gravity for imaging the density distribution, and electromagnetic (EM) methods for imaging the electrical resistivity structure are available. Electromagnetic methods are particularly useful for imaging the fluid contents of potential reservoir rocks, because electrical resistivity is largely controlled by pore fluids, porosity, pore connectivity, and, to some extent, by temperature. Different EM methods have previously been used for characterizing reservoirs. Electrical resistivity tomography (ERT) is widely used for shallow investigations. Passive 
magnetotelluric (MT) methods utilize natural electromagnetic fields, are typically applied for deep crustal-scale investigations. However, because of their sensitivity to electrical conductivity, noise levels are very high. Controlled-source electromagnetic (CSEM) prospecting techniques have received considerable attention for land-based imaging of different exploration targets (Sreitch, Becken and Ritter, 2010)

Well completion integrity such as cementing, injection equipment completion, are important parameters for safety of storage. At present no wells are proved to be leak tight, when exposed to supercritical $\mathrm{CO}_{2}$ over a period of 1,000 years. Seal Integrity of cap rock is most important issue in $\mathrm{CO}_{2}$ storage (Sengul, 2008). Well completion integrity such as cementing, injection equipment completion, and accessories are important parameters for characterization. All cement based materials are vulnerable to the attack of atmospheric or subsurface $\mathrm{CO}_{2}$. Proper completion of an injection well should be planned initially as longterm storage requires well completion design to be safe and strong.

Otway Basin Pilot Project has been the first structured monitoring and verification project launched as geo sequestration project in Australia. Up to 100,000 tonnes of $\mathrm{CO}_{2}$ is expected to be injected into a depleted gas fields (Sharma and Rodds, 2008). Predictive modeling studies have been developed for the sub-surface movement of stored $\mathrm{CO}_{2}$ for many years into the future. Injection of $\mathrm{CO}_{2}$ began in OTWAY basin of Australia in April 2008 and in the first year $4000 \mathrm{mt}$ of $\mathrm{CO}_{2}$ was injected.

Geophysical, geochemical and geo-mechanical characterization and modeling studies of heterogeneities in different types of geological formations ranging from deep saline aquifers, unmineable coal beds and mature gas and oil fields are necessary for identification of suitable storage sites. Geo-statistical behavior of reservoir and fluid flow simulations are made to test efficiency of possible storage in deep aquifers. The mineralization rate and the process in the cap rock as well as in underlying rock formation have greater capacity for mineralization and can sometime breakdown cap rock integrity. Multistage monitoring data integration would form the basis of successful $\mathrm{CO}_{2}$ project site selection and safe storage. New tools for monitoring enhanced oil recovery using time lapsed 4D seismography are developing.

\section{Geo-engineering approaches}

In addition to underground $\mathrm{CO}_{2}$ storage, geo-engineering approaches have been suggested for finding low cost solutions for $\mathrm{CO}_{2}$ sequestration. Three ways to accelerate the natural process of $\mathrm{CO}_{2}$ absorption are; (i) enhanced mineralization of olivine / silicate rocks (Schulings and Krijgsman, 2006). (ii) in the biosphere through enhanced genetically modified bio-sequestration, and (iii) in the oceans as artificial iron fertilization. Biochar strategy for bioenergy production with $\mathrm{CO}_{2}$ sequestration is also proposed.

\subsection{Stimulated weathering of mineral rocks}

The $\mathrm{CO}_{2}$ fixation by mineral carbonation is a process of chemical weathering in the silicates rocks of magnesium and calcium. These metal oxides and silicates are present in the earth's crust as serpentine $\left[\mathrm{Mg}_{3} \mathrm{Si}_{2} \mathrm{Os}(\mathrm{OH})\right]$ and olivine $\left.\left[\mathrm{Mg}, \mathrm{FeSio}_{4}\right)\right]$. They are also present in small quantity in some industrial wastes. $\mathrm{CO}_{2}$ reaction with such calcium, magnesium or iron bearing alkaline silicate rich rocks in a two step process to produce carbonates, is as follows:

$$
\text { (Mg. Ca })_{x} \mathrm{Si}_{\mathrm{y}} \mathrm{O}_{\mathrm{x}+2 \mathrm{y}}+\mathrm{H}_{2} \mathrm{O}+\mathrm{CO}_{2}----(\mathrm{Mg}, \mathrm{Ca}) \mathrm{CO}_{3}+\mathrm{yCO}_{2}
$$


The cations $\left(\mathrm{CO}^{-2}\right)$ react with $\mathrm{HCO}_{2}$ to form carbonates. Mafic and Ultramafic rock minerals, olivine, pyroxene and anorthile are present in large quantity in the subsurface environment. These minerals play an important role in the natural carbon cycle and natural weathering occurs over geological time scales. To test efficacy of artificial weathering, pilot experiments are being carried out to study mineral reactivity, energy balance, type of $\mathrm{CO}_{2}$ injection and dynamics of $\mathrm{CO}_{2}$ in pores.

Naturally occurring silicate materials like forsterite, wollastonite and synthetic magnesium silicates have been studied by intense grinding in presence of gaseous $\mathrm{CO}_{2}$ (Zhana et al, 2010). In a biomimetic process (Liu et al, 2005) enzyme carbonic anhydrase as catalyst was used to accelerate the rate of precipitation of mineral carbonate with industrial wastewater as cation source. Biomimetic approach helps to develop on-site scrubber that could provide a plant-by-plant solution to $\mathrm{CO}_{2}$ sequestration and would eliminate transportation cost. Rock-Eval analysis (Garcial et al, 2010) to quantify carbonation yields has revealed that high reactivity of system will rapidly obstruct pore space volume in an ultramafic formation with important consequences in terms of reactivity and injectivity. Effects of $\mathrm{CO}_{2}$ fugacity and salinity impact on the kinetics of olivine diffusion have been investigated. Results suggested no inhibition effect of these parameters. Dissolution kinetics depends on $\mathrm{pH}$ at any temperature and would control effective mineralization process.

Mineral carbonation process is an interesting concept which involves storage of $\mathrm{CO}_{2}$ as stable environmentally safe material. Chemical reactions produce carbonate minerals, which are stable and can be deposited on earth. The advantages are that fixation is permanent and the potential is large as the material, either manmade or natural, is freely available. The carbonation process is however energy intensive and need more field studies on the ways to assess its technical feasibility.

\subsection{Enhanced bio-sequestration}

Biological routes of $\mathrm{CO}_{2}$ fixation offer new breakthrough concepts as cost-effective options. It provides an opportunity for both active and passive storage. Enhanced $\mathrm{CO}_{2}$ absorption rate in vegetation and cropland can lead to active storage. It can be a passive storage in wetlands, mined or un-mined forest sites and high way construction sites. Microalgae act as biocatalyst for the photosynthetic conversion of flue gas $\mathrm{CO}_{2}$ to hydrocarbons or biofuels. Enzyme based hollow fiber contained liquid membranes and carbonanic anhydrase membranes from various microbial sources predict higher efficiency in $\mathrm{CO}_{2}$ sequestration. Strategies for $\mathrm{CO}_{2}$ fixation include solar energy capture; carbonic anhydrase enzymes, carbon assimilation and detoxification of soils by employing algae to remove heavy metal contaminants. New possibilities exist in bio-fixation of $\mathrm{CO}_{2}$ from industrial waste gases through microbial and micro-algae processes, and development of nano-material compositions. The process efficiencies are however low.

Enhanced biological $\mathrm{CO}_{2}$ capture is possible by increasing the rate of photosynthesis in photo-bioreactors. It is proposed to construct open and closed photo-bioreactors. Open bioreactors are large ponds of $10 \times 10 \mathrm{~km}$ and $150 \mathrm{~m}$ deep conceived to develop new stains of micro-organisms, which can grow faster than normal rate of photosynthesis. The $\mathrm{CO}_{2}$ introduced as bubbles is made to reach algae in shaded areas. Such ponds can produce liquid (lipid) fuel, which can be converted to biodiesel. The advantage of this method is that it does not require pure $\mathrm{CO}_{2}$ and saves on cost of capture as well as compression. Solar bioreactor has been proposed for warm and sunny climatic regions (Stewart and Hessami, 
2005). It combines solar energy use through a fibre optic system to stimulate the growth of biological organisms. The efficiencies are low because of non-uniform distribution of light throughout the bioreactor. Triangular Air-lift bioreactor has been designed to obtain experimental data for two different algal species. In a pilot-scale unit supplied with flue gases from a small power plant, removal efficiency of $\mathrm{CO}_{2}$ was seen to be 80 per cent. Preliminary cost analysis suggested that micro algae biofixation from a $550 \mathrm{MW}$ coal-fired power plant could sequester 25 per cent of the $\mathrm{CO}_{2}$ cost-effectively, if the value recovered from the harvested algae could be priced at approximately $\$ 100$ per ton. Membrane photo bioreactor technology has been reported to have potential to increase $\mathrm{CO}_{2}$ fixation rate significantly using algal biomass.

Genome analysis of green algae has uncovered hundreds of genes associated with $\mathrm{CO}_{2}$ capture. Photo-autotrophic organisms ranging from bacterial to higher plants have been evolved as unique Carbon Concentrating Mechanisms (CCMs). Besides enhanced $\mathrm{CO}_{2}$ capture, genetic manipulation of crop plants by engineering $C_{4}$ genes into $C_{3}$ plants could lead to $\mathrm{C}_{4}$ like environment in them and help to achieve optimal crop yield under predicted global climate change (Reddy et al, 2010).

\subsection{Ocean geochemical fertilization}

In a natural course oceans absorb and emit large quantity of $\mathrm{CO}_{2}$ and there is no net exchange of $\mathrm{CO}_{2}$ between the oceans and atmosphere. But as a result of anthropogenic built up of $\mathrm{CO}_{2}$ in the atmosphere, a net flow of $\mathrm{CO}_{2}$ from atmosphere to the upper layers of ocean is estimated to be $2 \mathrm{Bt} /$ year. It is estimated that ocean can take up to $400 \mathrm{Bt}$ of $\mathrm{CO}_{2}$. The $\mathrm{CO}_{2}$ can be dispersed on the sea surface as dry ice. The $\mathrm{CO}_{2}$ is soluble in ocean water and its sequestration efficiency in ocean is determined from how long the gas will remain in the ocean before returning to the atmosphere. The ocean waters as active media for $\mathrm{CO}_{2}$ storage are however, not preferred because of their prominent role in carbon cycle and threat of increasing $\mathrm{CO}_{2}$ to the survival of marine species.

Geo-engineering approach of sprinkling iron would stimulated the growth of phytoplankton in the areas of deficit, sinking of organic matter and ultimate $\mathrm{CO}_{2}$ sequestration in deep sea sediments (Lempitt et al, 2008). Various side effects of Ocean Iron Fertilization (OIF) can however occur such as fate of planktons, ration of iron to be added to $\mathrm{CO}_{2}$ sequestered need monitoring and verification studies. First feasibility study reported in the Southern Ocean Iron Experiment (SOFeX) suggested 900 tons of carbon sequestered for 1.26 tons of iron added. Long-term $\mathrm{CO}_{2}$ sequestration effect was not understood (Zeebe and Archer, 2005). The contamination from other trace gases on air-sea fluxes is also not identified (Sarma, 2010). To experimentally test efficacy of iron fertilization in Southern Ocean for $\mathrm{CO}_{2}$ sequestration an experiment has been conducted in 2009 jointly by Alfred Wegener Institute, Germany and National Institute of Oceanography, India as LOHAFEX (LOHA - iron, FEX - Fertilization EXperiment).

The concentration disposal in deep oceans has been proposed (Sorai and Ohosumi, 2005) to inject liquid $\mathrm{CO}_{2}$ at a depth greater than 3,000 $\mathrm{m}$ below sea level. At this depth, density of $\mathrm{CO}_{2}$ exceeds the density of sea water. It sinks to the bottom and stays there, leading to formation of relatively immobile $\mathrm{CO}_{2}$ hydrates or dry ice, also known as Chlatharets. The $\mathrm{CO}_{2}$ hydrate $\left(\mathrm{CO}_{2}-\mathrm{nH}_{2} \mathrm{O}, \mathrm{C}>\mathrm{n} \sim 6\right.$ or 7$)$ have density of $1.04-1.07 \mathrm{~g} / \mathrm{cm}^{3}$. It is thus captured as a stable entity, at the temperatures below $10^{\circ} \mathrm{C}$ and pressure of 44.5 atmospheres (Elwell and Grant 2006). Possibilities of storage of $\mathrm{CO}_{2}$ below permafrost layers to form gas hydrates $/ \mathrm{CO}_{2}$ Clatharets are also being investigated (Prasad, 2010). 


\subsection{Biochar}

Biochar addition to soil to enhance $\mathrm{CO}_{2}$ absorption capacity involves photosynthetic carbon capture by crop biomass, which is thermally decomposed in the absence of oxygen to biochar. In addition the soil fertility is expected to enhance. Life cycle assessment of different biochar systems has been carried out (Roberts, 2010). Crop yield may increase up to $10 \%$. Economic viability of pyrolysis-biochar depends on the cost of feedstock production, pyrolysis and value of carbon credits. The energy balance studies are also reported (Gaunt and Laehman, 2008).

Farm waste through pyrolysis can be used to produce biodiesel and it can sequester carbon dioxide as well. Low temperature slow pyrolysis ofFers an energetically efficient strategy for bio-energy production and land addition of black carbon material as biochar reduces emissions to a great extent than when biochar is used only to effect emissions. Benefits of biochar returned to soil are many, it leads to (i) long-term carbon sequestration (ii) renewable energy generation (iii) biochar as a soil amendment and (iv) biomass waste management. However, many uncertainties remain and further research is needed to understand these $\mathrm{CO}_{2}$-biochar-soil-plant interactions.

\section{International policy perspectives - networking}

In an international perspective, networking / collaboration is an important aspect of CCS research. The $\mathrm{CO}_{2}$ GeoNet presented a Network of Excellence having thirteen partner countries with a common aim to integrate $\mathrm{CO}_{2}$ storage research between the network members (Christian et al, 2008). This multi-national project has many priorities research areas, viz., predictive modeling experiments, enhanced hydrocarbon recovery, monitoring \& verification, risks analysis and geological modeling. Predictive modeling studies have been developed for the sub-surface movement of $\mathrm{CO}_{2}$ for many years into the future. Joint activities have been carried out between networking partners to form durable 'virtual' and unique research centers within Europe to fulfill the need for creation of infrastructure for CCS research and providing knowledge support to policy makers.

Worldwide fossil fuels are having $85 \%$ share in total energy consumed contributing to two third of global $\mathrm{CO}_{2}$ emissions. Carbon Sequestration Leadership Founder (CSLF) began in 2003 as multi-country initiative of Department of Energy, USA. The CSLF Technical Roadmap addresses to individual technical issues and suggest the pathways toward commercial deployment of CCS technology. It aims to collaborate on development of improved cost-effective technologies for the separation and capture of $\mathrm{CO}_{2}$ for its transport and long-term storage. India became a founder member to CSLF in 2003 among 16 other countries. Research capabilities in India have been developed in $\mathrm{CO}_{2}$ capture materials, lithium silicate nano-particles and membrane technology.

Multiplicity of data and role of multiple organizations has been highlighted in storage projects. The $\mathrm{CO}_{2}$ Sequestration Initiative, a multi-national programme at Pacific Northwest National Laboratory, USA having two main components; (i) In situ Supercritical Suite (IS3), (ii) Geological sequestration software suit $\left(\mathrm{GS}^{3}\right)$, is another step in this direction. It integrates in-situ supercritical suite IS 3 in an investigative approach to probe geochemical reactions under supercritical pressures and temperatures. It uses advanced techniques of optical spectroscopy, nuclear magnetic resonance, atomic force microscopy and high pressure XRD instruments to study supercritical $\mathrm{CO}_{2}$ geochemistry of the cap rock and monitoring of boreholes (Murphy et al, 2010). Geological sequestration software suit GS$^{3}$ has been 
designed for modeling of geological sites for sequestration using advance scientific programming and benchmarking of scientific simulators for different geo-environment. In collaborative $R \& D$ mode this initiative aims at advancing our scientific knowledge of both aqueous and supercritical $\mathrm{CO} 2$ in the subsurface and incorporating this knowledge into simulators that are used to assess the performance of storage reservoirs. More such scientific investigations if conducted for enhanced oil recovery and enhanced coal bed methane can lead not only to additional fuels, but also to better understanding of earth processes.

International Energy Agency has been taking lead in developing policy guidelines for CCS projects and bench marking of storage projects. A Global Institute of Carbon Capture and Storage (GCCSI) has come up in Australia to provide thrust towards research and demonstration of industrial scale projects on CCS technology.

\section{Conclusions}

Various international initiatives in abatement of greenhouse gas emissions and recent developments towards implementation of Carbon Capture and Storage (CCS) technology are geared to achieve the sustainable energy development in fossil fuel based economies. This article describes developments in $\mathrm{CO}_{2}$ capture technologies, various options of precombustion and post combustion $\mathrm{CO}_{2}$ capture processes and underground $\mathrm{CO}_{2}$ storage. The CCS technology is developing but not proven. Each of the options for $\mathrm{CO}_{2}$ capture, disposal and storage in closed or open reservoirs has some unresolved challenges. There are no fullscale plants in operation of $\mathrm{CO}_{2}$ capture yet. Increasing geo-modelling research is being carried out to prove the feasibility in large-scale operations and address the issues about permanency of $\mathrm{CO}_{2}$ storage as well as environment safety. The R\&D challenges with respect to $\mathrm{CO}_{2}$ injection, reaction with the fluid and monitoring of transport in reservoir for $\mathrm{CO}_{2}$ sequestration form an important part of such assessment. More attention is also required to be given to development of cost-effective geo-engineering approaches, which aim to accelerate the natural process of $\mathrm{CO}_{2}$ absorption in the biosphere, lithosphere and in the oceans.

\section{Acknowledgements}

The author expressed her thanks to Chairman, Center for Studies in Science Policy and Dean, School of Social Sciences, Jawaharlal Nehru University for the encouragement. The financial support from, Council of Scientific \& Industrial Research is gratefully acknowledged. The views expressed need not necessarily represent these organizations.

\section{References}

Boak Jeremy (2008), Carbon Balance for the In-Situ Production of Shale Oil from Green River Formation in Western Colorado, in Carbon Capture and Storage : R\&D Technology for Sustainable Energy Future, Eds. Malti Goel, B. Kumar and S. N. Charan, Narosa Publishing House, Delhi, p.163.

Chakma A. (1997), CO2 Capture process opportunities for improved energy efficiency Energy Conser. \& Mgmt, 38, pp 51-56.

Chandra K. (2008), Carbon Dioxide Sequestering Technologies Magnesium-Carbon Dioxide Reactor, in Carbon Capture and Storage : R\&D Technology for Sustainable Energy 
Future, Eds. Malti Goel, B. Kumar and S. N. Charan, Narosa Publishing House ,Delhi, p.133.

Dimri V. P., Srivastava R. P. and Vedanti N. (2008), Tools for Enhanced Oil Recovery, ibid, p.23.

Dooley J. J., Davidson C. L., Dahowski R. T., Wise M. A., Gupta N., Kim S. H., Malone E. L., "Carbon Dioxide Capture and Geologic Storage: A Key Component of a Global Energy Technology Strategy to Address Climate Change, Joint Global Change Research Institute, Battelle Pacific Northwest Division. May 2006. PNWD-3602. College Park, MD.

Energy Technology Analysis (2008), $\mathrm{CO}_{2}$ Capture and Storage, A key carbon abatement option, International Energy Agency (IEA).

Fouillac Christian, Czernichowski-Lauriol Isabelle, Persoglia Sergio and Riley Nick (2008), The Research Activities of the CO2GeoNet European Network of Excellence on CO2 Geological Storage, in Carbon Capture and Storage : R\&D Technology for Sustainable Energy Future, Eds. Malti Goel, B. Kumar and S. N. Charan, Narosa Publishing House ,Delhi, p.3, p.219.

Gaikwad A. G. (2010), Carbon Dioxide Sequestration over mixed metal oxide adsorbents at Higher temperature, in CO2 Sequestration Technologies for Clean Energy, Eds. S. S. Qasim and Malti Goel, Daya Publishing House, Delhi, p. 53-74.

Garcia B., Beaumont V., Perfetti E., Rouchon V., Blanchet D., Oger P., Dromart G., Huc A. Y. and Haeseler F. (2010), Experiments and geochemical modelling of CO2 sequestration by olivine : Potential, quantification - Applied Geochemistry, 25, (9), pp 1383-1396.

Gattuso S. A. (2007), Ph.D thesis, University of Pitsburry, $\mathrm{CO}_{2}$ Capture by tertiary amidine functional absorbent.

Gaunt J. L. and Lehmann J. (2008), Energy balance and emissions associated with biochar sequestration and pyrolysis bioenergy production, Environmental Science and Technology, 42 (11), pp. 4152-4158.

Gibbins Jon (2008), Making the Transition to Carbon Capture and Storage, in Carbon Capture and Storage : R\&D Technology for Sustainable Energy Future, Eds. Malti Goel, B. Kumar and S. N. Charan, Narosa Publishing House ,Delhi, p. 81.

Goel Malti (2008), Carbon Capture and Storage, Energy Future and Sustainable Development: Indian Perspective, ibid, p.3-14.

Goel Malti (2009), Recent approaches in $\mathrm{CO}_{2}$ fixation research in India and future perspective towards zero emission coal based power generation, Current Science, Vol. 97, pp1625-1633.

Goswami A. N., Nanoti A., Gupta P., Dasgupta S., and Garg M. O. (2008), An Overview of PSA Processes for CO2 Recovery from Power Plant Flue Gas, ibid, p.67.

Herzog H. J. and Drake E. M. (1996), Carbon dioxide recovery and disposal from large energy systems, Annual Review of Energy and the Environment, 21 : 145-166.

Holloway S., Garg A., Kapshe M., Singh A. Kumar, Mahmood M. A., Khan S. R., Kirk K. L., Vincent C. J., Williams J. and Gale J. (2008), GIS as a Tool for Mapping CO2 Sources and Storage Sites, in Carbon Capture and Storage : R\&D Technology for Sustainable Energy Future, Eds. Malti Goel, B. Kumar and S. N. Charan, Narosa Publishing House, Delhi, p.97. 
Hovorka Susan. D. and research team, (2005), Field Experiment for CO2 Sequestration, Update on the Frio Brine Pilot Experiment - six months after injection, http://www.beg.utexas.edu/environqlty/co2seq/fieldexperiment.htm

IPCC 2005: IPCC Special Report on Carbon Dioxide Capture and Storage. Prepared by Working Group III of the Intergovernmental Panel on Climate Change, Figure 5.9. Cambridge University Press.

Jain P., (2010), Geo-modeling studies of carbon fixation in Indian context, Research internship Student Project, personal communication.

Jadhav P. D., Labhsetwar N. K., Balek V. and Rayalu S. S. (2008), Study of CO2 Adsorption on Aminated Activated Carbons using TG-EGA Technique, Carbon Capture and Storage : R\&D Technology for Sustainable Energy Future, Eds. Malti Goel, B. Kumar and S. N. Charan, Narosa Publishing House,Delhi, p.3, p.49.

Koide H. and Xue Z. (2009), Carbon Microbubbles Sequestration : A novel technology for stable underground emplacement of greenhouse gases into a wide vanity of saline aquifers, fractured rock and tight reservoirs Energy Presidia, (i), (ii), p. 3655-3662.

Kumar B., Charan S. N., Menon R. \& Panicker Smitha K. (2008), Geological CO2 Sequestration in the Basalt Formations of Western India: A Feasibility Study, in Carbon Capture and Storage : R\&D Technology for Sustainable Energy Future, Eds. Malti Goel, B. Kumar and S. N. Charan, Narosa Publishing House ,Delhi, p.105.

Lampitt R. S., Achterberg E. P., Anderson T. R., Hughes J. A., Iglesias-Rodriguez M. D., Kelly-Gerreyn B. A., Lucas M., Popova E. E., Sanders R. Shepherd J. G., SmytheWright D. and Yool A. (2008), Ocean fertilization: A potential means of geoengineering, Philosophical Transactions of the Royal Society A: Mathematical, Physical and Engineering Sciences - 366, (1882), pp 3919-3945.

Liu N., Bond G. M., Abel A., McPherson B. J. and Stringer J. (2005), Biomimetic sequestration of $\mathrm{CO} 2$ in carbonate form: Role of produced waters and other brines, Fuel Processing Technology, 86: 1615-1625.

Lucquiaud M. and Gibbins J. (2009), Retrofitting CO2 capture ready fossil plants with postcombustion capture. Part 1: requirements for supercritical pulverized coal plants using solvent-based flue gas scrubbing, Proc. IMechE Vol. 223 Part A: J. Power and Energy, pp 213-26.

Masohan Asha, Deswal Mohan, Ahmed Mamshad, Suneja Vipin, Ali Shareka and Garg Madhukar Onkarnath (2008), Enhanced Absorption Studies for Gas Separation at IIP: CO2 Capture Perspective, in Carbon Capture and Storage : R\&D Technology for Sustainable Energy Future, Eds. Malti Goel, B. Kumar and S. N. Charan, Narosa Publishing House ,Delhi, p. 57.

Mattison T. and Lyngfelt A (2001), Application of Chemical Looping with Capture of CO2, Second Nordic Mini-symposium on Carbon Capture and Storage, Gutenberg, Oct 26.

McGrail B. Peter, Schaef H. Todd, and Spane Frank A (2008), New Findings Regarding Carbon Dioxide Sequestration in Flood Basalts, Carbon Capture and Storage : R\&D Technology for Sustainable Energy Future, Eds. Malti Goel, B. Kumar and S. N. Charan, Narosa Publishing House ,Delhi, p.15.

Mendhe V. A., Singh A. K. and Singh H (2008), Enhanced Coalbed Methane Recovery through CO2 Sequestration: A Laboratory and Simulation Investigation in Southern Part of Raniganj Coalfield, West Bengal; ibid, p.153. 
Metz, B. Davidson, O. Coninck, H., Loos, M. Meyer, L. Eds. (2005), IPCC Special Report on Carbon Capture and Storage, Working Group III.

Murphy E., Bonneviller A., Rosso K. and White M. (2009), Carbon Sequestration Initiative, September Issue, (http://stomp.pnl.gov/gs3/CSIOverviewNewsletter.pdf).

Myers C. R., Morsi, B. I., Heintz Y. J., Ilconich J. B. (2008), Progress in carbon dioxide capture and separation research for gasification-based power generation point sources, Fuel Processing Technology 89 (9), pp. 897-907.

Narain Mudit (2008), MIT Study on the Future of Coal, Carbon Capture and Storage : R\&D Technology for Sustainable Energy Future, Eds. Malti Goel, B. Kumar and S. N. Charan, Narosa Publishing House ,Delhi, p.209.

Pennline H. W. Luebke, D.R., Jones, K.L., Myers, C.R., Morsi, B.I., Heintz, Y.J., Ilconich, J.B. (2008), Progress in carbon dioxide capture and separation research for gasificationbased power generation point sources, Fuel Processing Technology 89 (9), pp. 897907

Powell C. E. and Qiao G. G (2006), Polymeric CO2 / N2 gas separation membranes for the capture of carbon dioxide for power plant flue gases, J. of Membrane Science, 279 (1-2), pp. 1-49.

Prasad P. S. R. (2008), Carbon Dioxide Clathrates in Quartz Veins: FTIR Spectroscopic Investigations, ibid, p.127.

Prasad P. S. R., D. Srinivasa Sarma, L. Sudhakar, U. Basavaraju, Ravi S. Singh, Zahida Begum, K. B. Archana, C. D. Chavan and S. N. Charan (2009), Geological sequestration of carbon dioxide in Deccan basalts: preliminary laboratory study, Current Science, 96, no.2, pp288-92.

Prasad P. S. R. (2010), Sequestering Carbon dioxide into Clathrate Hydrates: Laboratory Studies, in Awareness and Capacity Building in Sustainable Energy (ACBSE 2010) IIC, New Delhi.

Reddy A. R., Rasineni G. K. and Raghavendra A. S. (2010), The impact of global elevated $\mathrm{CO} 2$ concentration on photosynthesis and plant productivity, Current Science, Vol. 99, No. 1, 10 July 2010 pp. 46-54.

Sarma N. S. (2010), Oceans : a ready solution or a last frontier in carbon dioxide mitigation in $\mathrm{CO} 2$ sequestration technologies for Clean Energy, Eds. Qazim S. Z. and Goel Malti, Daya Publishing House, Delhi, pp. 155-162.

Schuling R. D. and Kigjsman P. (2006), Enhanced Weathering: an effective and cheap tool to sequester $\mathrm{CO}_{2}$, Climate Change, 74, pp 349-354.

Sengul Mahmut (2008), Reservoir-Well Integrity Aspects of Carbon Capture and Storage, in Carbon Capture and Storage : R\&D Technology for Sustainable Energy Future, Eds. Malti Goel, B. Kumar and S. N. Charan, Narosa Publishing House ,Delhi, p. 187.

Sharma S. and Dodds K. (2008), Challenges in Developing a Monitoring and Verification Scheme for Australia's first Geosequestration Project; ibid, p.179.

Singh A. K. (2008), R\&D Challenges for $\mathrm{CO}_{2}$ Storage in Coal Seams, ibid, p.139.

Sorai M. and Ohsumi T. (2005), Ocean uptake potential for carbon dioxide sequestration, Geochemical Journal, 39 (1), pp. 29-45.

Sreitch R., Becken M. and Ritter O. (2010), Imaging of $\mathrm{CO}_{2}$ storage sites, geothermal reservoirs and gas shales using controlled - source magnetotellurics : Modeling studies, chewie der Ercle - Geochemistry, 70 (3), pp. 63-75. 
Timms A. (2007), Oxy-fuel firing of coal, International Workshop On R\&D Challenges In Carbon Capture \& Storage Technology For Sustainable Energy Future (IWCCS-07), January 12 - 13th 2007, Hyderabad.

Vargas K. J. (2009), Multiple tasks finalize Weyburn $\mathrm{CO}_{2}$ injection modification Oil \& Gas Journal 107 (44), 44-49.

Wright Iain (2008), Hydrogen Power with Carbon Dioxide Capture and Storage: BP.s Experience to Date and Future Challenges, Carbon Capture and Storage : R\&D Technology for Sustainable Energy Future, Eds. Malti Goel, B. Kumar and S. N. Charan, Narosa Publishing House ,Delhi p.203.

Yamasaki A. (2003), An overview of $\mathrm{CO}_{2}$ mitigation options for global warming Emphasizing $\mathrm{CO}_{2}$ sequestration options. Journal of Chemical Engineering of Japan, 36(4): 361-375.

Zeebe R. E. and Archer D. (2005), Feasibility of Ocean fertilization and its impact on future atmospheric CO2 levels, Geophysical Research Letters, 32, (9), pp 1-5.

Zhana J., Zhana R., Geerlings H. and Bi J. (2010), A novel indirect wallastonite carbonation route for $\mathrm{CO} 2$ sequestration, Chemical Engineering and Technology, 33 (7), pp. 1177-1183. 


\title{
CaO-based $\mathrm{CO}_{2}$ Capture Technology and Its Application in Power Plants
}

\author{
Rongrong Zhai and Yongping Yang \\ North China Electric Power University
}

China

\section{Introduction}

Carbon dioxide $\left(\mathrm{CO}_{2}\right)$ emission causes many environmental problems, such as global warming, which results in the rise of sea level. Currently, it is a mission for the whole world to control and reduce the emission of $\mathrm{CO}_{2}$. There is a great amount of $\mathrm{CO}_{2}$ being released from coal-fired power plants. Coal is expected to continue to be a prominent fuel for electricity production in the future (IEA, 2003; Thitalamol et al., 2007). $\mathrm{CO}_{2}$ mitigation options include energy efficiency improvements, the switch to less carbon-intensive fuels, nuclear power, renewable energy sources, enhancement of biological sinks, reduction of non- $\mathrm{CO}_{2}$ greenhouse gas emissions and $\mathrm{CO}_{2}$ capture and storage (CCS). CCS has the potential to reduce overall mitigation costs and increase flexibility in achieving greenhouse gas emission reductions. The widespread application of CCS would depend on technical maturity, costs, overall potential, diffusion and transfer of the technology to developing countries and their capacity to apply the technology, regulatory aspects, environmental issues and public perception (IPCC, 2005).

In order to mitigate the $\mathrm{CO}_{2}$ emission from coal-fired power plants, there are three main methods of CCS technologies such as post-combustion capture, pre-combustion capture and oxy-fuel combustion. Among them, the post-combustion method is the easiest method for the retrofitting of the current existing power plants. Limestone has been viewed as a potential sorbent for $\mathrm{CO}_{2}$ capture process because of its low-cost and easy access. The basic process of $\mathrm{CO}_{2}$ capture systems using lime was first outlined by Shimizu et al. (1999).

\section{Related work}

\subsection{Modeling of $\mathrm{CaO}$ based $\mathrm{CO}_{2}$ capture process}

There have been extensive researches on the post-combustion systems incorporated with carbonation/calcinations looping cycle, involving the reaction kinetics, modeling and so on. Microscopic modeling mainly focuses on the particle or a small group of particles. The random pore model (RPM) (Khinast et al., 1996; Adanez et al., 2000; Stanmore and Gilot, 2005), grain model (Garcia-Labiano et al., 2002; Stanmore and Gilot, 2005; Garea et al., 2005) and homogeneous particle model (Garcia-Labiano et al., 2002; Abanades et al., 2004) all belong to this catalogue. On the other hand, the macroscopic modeling focuses on the reactors where those processes take place. The core reactors used for calcination and 
carbonation are either bubbling fluidized bed reactors or circulating fluidized bed reactors. It is therefore necessary to examine the models of those reactors in order to analyze the lime based $\mathrm{CO}_{2}$ capture system. The first approximation to the modeling of a fluidized bed carbonator reactor has been proposed and the efficiency of $\mathrm{CO}_{2}$ capture is analyzed (Alonso et al., 2009). The KL fluid bed model (Kunii and Levenspiel, 1990) has been used to interpret the experimental $\mathrm{CO}_{2}$ concentration profiles measured inside the bed during the fast reaction period in literatures (Abanades et al., 2004; Romano, 2009).

\subsection{Integration of $\mathrm{CaO}$ based $\mathrm{CO}_{2}$ capture process with power plants}

Experiments in a pilot-scale fluidized-bed reactor have been carried out to investigate the carbonation reaction of $\mathrm{CaO}$, as a potential method for $\mathrm{CO}_{2}$ capture from combustion flue gases at high-temperatures. The heat requirements for calcium looping cycle have been developed (Rodriguez et al., 2008). The carbonate looping processes of post-combustion $\mathrm{CO}_{2}$ capture for coal-fired power plants have been studied (Strohle et al., 2009; Hawthorne et al., 2009). The carbonate looping process was integrated after the flue gas desulphurization unit of an existing power plant. The energy penalty is about $2.75 \%$, much lower than that of other $\mathrm{CO}_{2}$ capture technologies (Strohle et al., 2009). The retrofitted steam cycle which includes an air separation unit (ASU) and integrated $\mathrm{CO}_{2}$ conditioning unit with interstage cooling increases the net generated power from 1052 MWe to $1533 \mathrm{MWe}$, resulting in an overall electric efficiency of 39.2\% (Hawthorne et al., 2009). One kind of possible integrations of a power plant with $\mathrm{CaO}$-based $\mathrm{CO}_{2}$ capture process has been studied by Romeo et al. (2008).

\subsection{Contributions of our work}

For the modeling of carbonator, the parameters that may affect the carbonation process haven't been fully analyzed in the previous research. We built the model of carbnator which can be used to examine the effects of the parameters on the carbonation process. For the integrations of $\mathrm{CO}_{2}$ capture process and power plants, few papers have been focused on the effects of the $\mathrm{CaO}$-based $\mathrm{CO}_{2}$ capture process to the reference plant which vents its $\mathrm{CO}_{2}$ to the atmosphere. We examined the possible integrations of the power plant with the $\mathrm{CO}_{2}$ capture process.

In this chapter, a one-dimension model of $\mathrm{CaO}-$ based $\mathrm{CO}_{2}$ capture process has been built. Based on this model, the effects of superficial gas velocity, the particle diameter and the calcinations/carbonation cycle on the carbonation process have been discussed. In addition, five cases for the possible integration with the reference plant which vents its $\mathrm{CO}_{2}$ to the atmosphere are considered. Three possible methods for the utilization of the recovered heat from the $\mathrm{CO}_{2}$ capture process are used in these integrations. In addition, thermal performance evaluation of these cases has been investigated.

\section{Carbon capture process based on $\mathrm{CaO}$}

\subsection{System description}

$\mathrm{CO}_{2}$ capture plant as shown in Fig.1 is composed of two fluidized bed reactors. One reactor is the calciner, operating at about $900{ }^{\circ} \mathrm{C}$, using oxygen obtained from the air separation unit (ASU); the other one is the carbonator, operating at around $650{ }^{\circ} \mathrm{C}$. For the simplicity of the study, sulphation has been taken as undesirable reaction and been neglected in our analysis. 


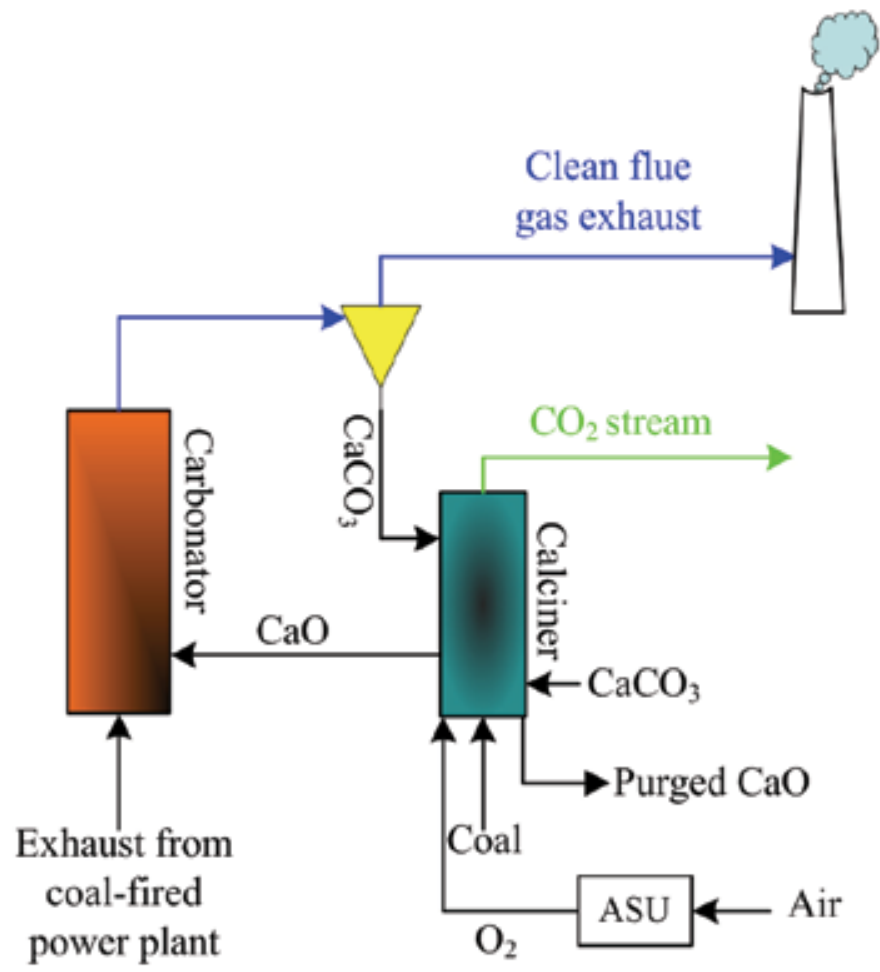

Fig. 1. General layout of $\mathrm{CaO}-$ based $\mathrm{CO}_{2}$ capture cycle

In the carbonator the main reaction is:

$$
\mathrm{CaO}+\mathrm{CO}_{2} \rightarrow \mathrm{CaCO}_{3}
$$

In the calcinator the main reaction is:

$$
\mathrm{CaCO}_{3} \rightarrow \mathrm{CaO}+\mathrm{CO}_{2}
$$

Pipes and cyclones are used to exchange particles between the calciner and carbonator. Ideally, the process can take place continuously without refilling fresh limestone. However, the reactivity of the sorbent decays as the process goes on. Therefore, used lime needs to be purged out of the carbonator and new lime needs to be added to maintain these reactions.

\subsection{Modeling of the carbonator}

The carbonator as shown in Fig.1 is one key reactor in the $\mathrm{CO}_{2}$ capture process, where the carbonation takes place. The dense bed height of the carbonator is about $1.5 \mathrm{~m}$. In order to interpret the carbonation process, the model of the carbonator has been built. It is composed of three sub-models: the $\mathrm{CO}_{2}$ mass balance sub-model, the hydrodynamics sub-model and the microscope carbonation sub-model. The $\mathrm{CO}_{2}$ mass balance sub-model (KL fluid bed model) was first proposed by (Kunii and Levenspiel, 1990), and then it has been used in literatures (Abanades et al., 2004; Romano, 2009). The main equations for hydrodynamics sub-model are semi-experimental equations from previous research. The microscopic carbonation sub-model describes the carbonation rate of the process. 


\section{The $\mathrm{CO}_{2}$ mass balance sub-model}

Assumptions have been made for the $\mathrm{CO}_{2}$ mass balance sub-model. It is assumed that there are two phases in the reactor as the bubble phase and the emulsion phase. The carbonation reaction takes place only in the emulsion phase, assuming that the bubble phase is particle free.

Equilibrium $\mathrm{CO}_{2}$ concentration in the carbonation/calcination process $C_{\mathrm{CO} 2 \text {,eq }}$ at about $650^{\circ} \mathrm{C}$ was given by (Baker, 1962).

$$
C_{\mathrm{CO} 2, e q}=\frac{1.46210^{11}}{T} \exp (-19130 / T)
$$

Where, $\mathrm{T}$ is the temperature of carbonation.

$\mathrm{CO}_{2}$ mass balance in bubble phase (Kunii and Levenspiel, 1990):

$$
-u_{b}{ }^{*} \frac{d C_{b \mathrm{CO} 2}}{d z}=\gamma_{b} f_{a} K_{r}\left(C_{b \mathrm{CO} 2}-C_{\mathrm{CO} 2, e q}\right)+K_{b e}\left(C_{b \mathrm{CO} 2}-C_{e \mathrm{CO} 2}\right)
$$

$\mathrm{CO}_{2}$ mass balance in emulsion phase (Kunii and Levenspiel, 1990):

$$
-(1-\delta) u_{m f} \frac{d C_{e \mathrm{CO} 2}}{d z}=(1-\delta)\left(1-\varepsilon_{m f}\right) f_{a} K_{r}\left(C_{e \mathrm{CO} 2}-C_{\mathrm{CO} 2, e q}\right)-\delta K_{b e}\left(C_{b \mathrm{CO} 2}-C_{e \mathrm{CO} 2}\right)
$$

Where, $\mathrm{C}_{b \mathrm{CO} 2}$ is $\mathrm{CO}_{2}$ concentration in the bubble phase; $\mathrm{C}_{e \mathrm{CO} 2}$ is $\mathrm{CO}_{2}$ concentration in the emulsion phase; $u_{m f}$ is Minimum fluidization velocity; $\varepsilon_{m f}$ is Bed porosity at minimum fluidization; $\delta$ is Bubble fraction in the fluidized bed; $\gamma_{b}$ is Volume of solids in bubble phase divided by the volume of bubbles.

\section{The hydrodynamics sub-model}

As mentioned before, the hydrodynamics sub-model has been built based on previous semi-experimental equations. The main factors to describe the hydrodynamics are minimum fluidization velocity, the equivalent volume diameter, the absolute velocity of the bubble, bubble fraction in the fluidized bed and effective gas velocity in bubble phase.

The minimum fluidization velocity can be defined as the velocity at which the bed just becomes fluidized. The minimum fluidization velocity can be obtained by solving the following equations (Grace, 1992; Basu, 2006):

$$
\operatorname{Re}_{m f}=\frac{U_{m f} d_{p} \rho_{g}}{\mu}=\left[27.2^{2}+0.0408 A r\right]^{0.5}-27.2
$$

The bubble diameter $d_{b}$ can be estimated using the expression given by Darton et al.

(Darton et al., 1977):

$$
d_{b}=0.54\left(U-U_{m f}\right)^{0.4}\left(Z+4 \sqrt{A_{0}}\right)^{0.8} g^{-0.2}
$$

The absolute velocity of the bubble $U_{b}$ has been developed by Davidson and Harrison (Davidson and Harrison, 1963) as

$$
U_{b}=\left(U-U_{m f}\right)+0.711 \sqrt{g d_{b}}
$$


Bubble fraction in the fluidized bed $\delta$ (Kunii and Levenspiel, 1990):

$$
\delta=\frac{u_{0}-u_{m f}}{u_{b}+2 u_{m f}}
$$

Effective gas velocity in bubble phase $u_{b}{ }^{*}$ (Kunii and Levenspiel, 1990):

$$
\begin{gathered}
u_{b}{ }^{*}=\frac{u_{0}-(1-\delta) u_{m f}}{\delta} \\
u_{b}{ }^{*}=u_{b}+3 u_{m f}
\end{gathered}
$$

The microscopic carbonation sub-model

In the microscopic carbonation sub-model, the key parameters are: the overall gas interchange coefficient between bubble and emulsion phases, carbonation reaction rate constant, overall carbonation rate constant of particles in the emulsion phase, fraction of active $\mathrm{CaO}$ in the carbonator and maximum carbonation conversion of $\mathrm{CaO}$ to $\mathrm{CaCO}_{3}$ in the $\mathrm{N}^{\text {th }}$ cycle.

Overall gas interchange coefficient between bubble and emulsion phases $\mathrm{K}_{\mathrm{be}}$ (Kunii and Levenspiel, 1990):

$$
K_{b e}=4.5 u_{m f} / d_{b}
$$

Carbonation reaction rate constant $K_{r i}$ (Kunii and Levenspiel, 1990):

$$
K_{r i}=k_{s} \frac{X_{b, N} S_{0} \rho_{\mathrm{CaO}}}{M_{\mathrm{CaO}}}(1-X)^{2 / 3}
$$

The correlation for the Sherwood number Sh (Turnbull and Davidson, 1984) has been listed as Eq.12, in which the $\mathrm{CO}_{2}$ mass transfer coefficient towards the carbonating particles $k_{g}$ can be estimated.

$$
S h=\frac{D_{\mathrm{CO} 2}}{k_{g} d_{p}}=2 \varepsilon_{m f}+0.95 \operatorname{Re}_{m f}^{0.5} S c^{0.3}
$$

Overall carbonation rate constant of particles in the emulsion phase $\kappa_{r}$ (Abanades et al., 2004):

$$
K_{r}=\frac{1}{\frac{d_{p}}{6 k_{g}}+\frac{1}{K_{r i}}}
$$

Fraction of active $\mathrm{CaO}$ in the carbonator $f_{a}$ :

$$
f_{a}=X_{b, N}-X
$$

With the development of research, the equation for the maximumum carbonation conversion of $\mathrm{CaO}$ to $\mathrm{CaCO}_{3}$ in the $\mathrm{N}^{\text {th }}$ cycle has been improved.

Firstly, Abanades (Abanades, 2002) fitted an empirical model: 


$$
X_{N}=f^{N+1}+b
$$

Where $\mathrm{f}=0.782$ and $\mathrm{b}=0.174$ are constant.

Then, Abanades and Alvarez (Abanades and Alvarez, 2003) developed an analytical model in terms of change in porosity, as:

$$
X_{b, N}=f_{m}^{N}\left(1-f_{w}\right)+f_{w}
$$

Where, $f_{m}=0.77, f_{w}=0.17$.

Later, Wang and Anthony (Wang and Anthony, 2005) presented a model based on only one parameter:

$$
X_{N}=\frac{1}{1+k N}
$$

Finally, considering a residual conversion, $\mathrm{Xr}$, of about 7-8\%, Grasa and Abanades (Grasa and Abanades, 2006) proposed a semi-empirical model based on one parameter:

$$
X_{N}=\frac{1}{\frac{1}{1-X_{r}}+k N}+X_{r}
$$

$\mathrm{N}$ is defined as the number of calcination/carbonation cycle, with $\mathrm{N}=1$ the first carbonation reaction using fresh $\mathrm{CaO}$. The fresh $\mathrm{CaO}$ is obtained from the calcination of limestone.

\section{Integration and evaluation of a power plant with a $\mathrm{CaO}$ based $\mathrm{CO}_{2}$ capture process}

\subsection{System description}

The basic layout of $\mathrm{CaO}-$ based $\mathrm{CO}_{2}$ capture process has been shown in Fig. 1. Table 1 shows the main variable of the capture plant.

\begin{tabular}{lc}
\hline Oxygen mass flow $(\mathrm{kg} / \mathrm{s})$ & 78.5 \\
$\mathrm{CaCO}_{3}$ mass flow $(\mathrm{kg} / \mathrm{s})$ & 89.7 \\
Coal mass flow $(\mathrm{kg} / \mathrm{s})$ & 38.4 \\
\multicolumn{2}{c}{ Coal composition (\% wet basis) } \\
Carbon & 66.9 \\
Ash & 13.9 \\
Hydrogen & 3.7 \\
Nitrogen & 1.6 \\
Oxygen & 6.5 \\
Sulphur & 0.7 \\
Moisture & 6.8 \\
LHV $(\mathrm{kJ} / \mathrm{kg})$ & 25200 \\
Purge mass flow (kg/s) & 64.5 \\
Low $\mathrm{CO}_{2}$ concentration flue gases $(\mathrm{kg} / \mathrm{s})$ & 540.1 \\
$\mathrm{CO}_{2}$ to compression, captured $(\mathrm{kg} / \mathrm{s})$ & 230 \\
\hline
\end{tabular}

Table 1. Capture process main variables 


\begin{tabular}{ll}
\hline Gross power output (MW) & 600 \\
Flue gases mass flow (kg/s) & 647.6 \\
Flue gases composition (\% vol) & \\
$\mathrm{CO}_{2}$ & 12 \\
$\mathrm{~N}_{2}$ & 73.7 \\
$\mathrm{H}_{2} \mathrm{O}$ & 8.3 \\
$\mathrm{O}_{2}$ & 5.5 \\
$\mathrm{SO}_{2}$ & 0.5 \\
Coal composition (\% wet basis) & \\
Carbon & 42.2 \\
Ash & 23.5 \\
Hydrogen & 2.7 \\
Nitrogen & 0.7 \\
Oxygen & 7.0 \\
Sulphur & 4.8 \\
Moisture & 19.1 \\
LHV(kJ/kg) & 15854 \\
\hline
\end{tabular}

Table 2. Main operating conditions of Reference plant which vents its $\mathrm{CO}_{2}$ to the atmosphere

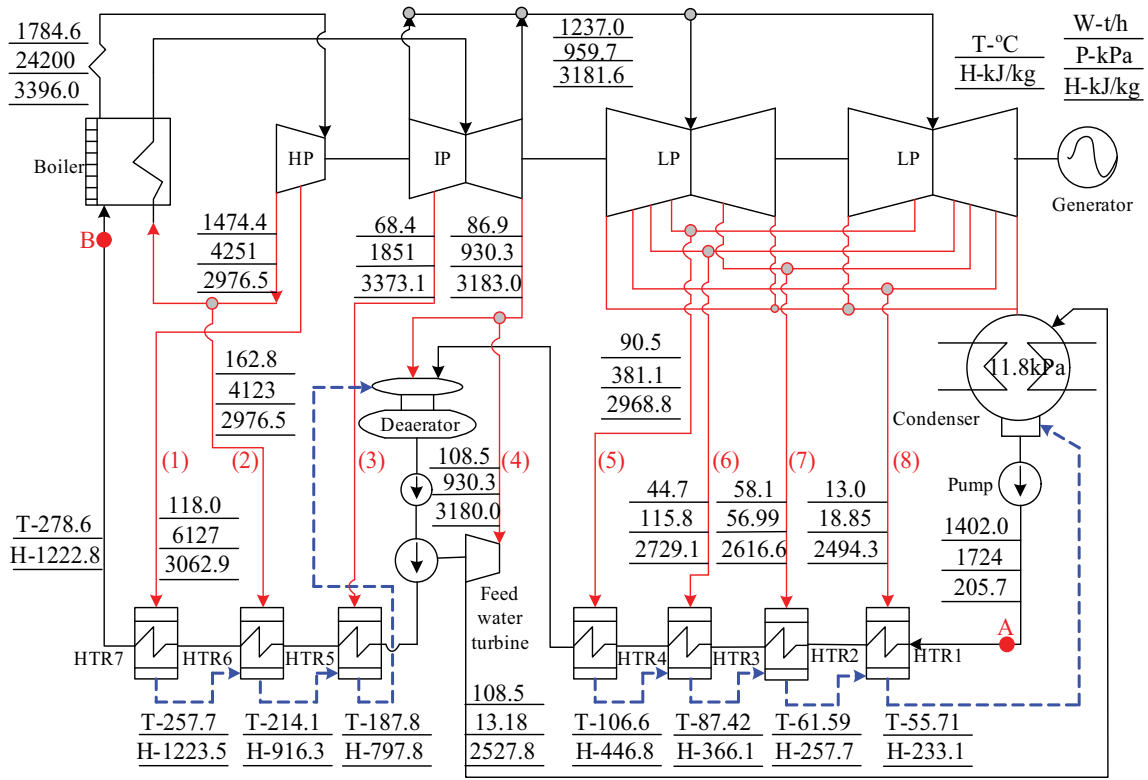

* (1)-(8) denote the stream conditions.

Fig. 2. Steam layout of a 600MW supercritical power plant

The main operating conditions of the existing power plant are shown in Table 2 with the typical composition of flue gas and coal composition referred to that in the literature (Romeo et al., 2008). The typical widely used 600MW reheated steam cycle system in recent power industry has been shown in Fig. 2. The combustion of coal takes place in the boiler. The unsaturated boiler feedwater from the condenser enters into the boiler after going through four low-pressure reheaters (HTR1, HTR2, HTR3, HTR4), three high pressure 
reheaters (HTR5, HTR6, HTR7) and a deaerator (Deaerator). The outlet superheated steam from the boiler is transported to the high pressure cylinder to produce power, and then the exhaust steam drives intermediate pressure and lower pressure cylinders after being reheated in the boiler. In the end, the final exhaust is condensed in the condenser. It can be seen from Figure 2 that the extractions from different positions of the cylinders ((1)-(8)) are used to heat the feedwater via feedwater reheaters.

\subsection{Integration methods}

The carbonation process is exothermic, i.e. a great amount of heat will be released during this reaction. It can be seen from Figure 1 that there are mainly three parts of recoverable heat from the $\mathrm{CO}_{2}$ capture process as heat from the carbonator $\left(\mathrm{Q}_{1}\right)$, heat from $650{ }^{\circ} \mathrm{C}$ clean flue gas $\left(\mathrm{Q}_{2}\right)$ and heat from $900{ }^{\circ} \mathrm{C} \mathrm{CO}_{2}$ stream $\left(\mathrm{Q}_{3}\right)$. Theoretically, these three parts of heat can be recovered and utilized. In the carbonator, $\mathrm{Q}_{1}$ is related to three items: reaction heat released from the carbonation with about $168.5 \mathrm{~kJ}$ per mol $\mathrm{CaCO}_{3}$ produced; heat recovery from the $900{ }^{\circ} \mathrm{C}$ solid particles of $1227 \mathrm{~kg} / \mathrm{s}$ and heat consumed by heating the flue gas to 650 ${ }^{\circ} \mathrm{C}$. $\mathrm{Q}_{1}$ can be calculated by adding the first two items and deducting the last item. The maximum $\mathrm{Q}_{1}$ is calculated to be about $389 \mathrm{MW}$ with flue gas temperature of $150^{\circ} \mathrm{C}$.

There are three possible methods for the utilization of the recovered heat from the $\mathrm{CO}_{2}$ capture process, as follows (Yang et al., 2010):

1. Use the recovered heat to produce steam in order to replace the extracted steam from turbines (as shown (1)-(8) in Figure 2). The produced steam will be used to provide heat for the high-pressure heaters, deaerator or low-pressure heaters as the original extracted steam does;

2. Use the recovered heat to provide part of the boiler heat load;

3. Use the recovered heat to produce superheated steam, which can be then used to generate electricity in the turbines.

Based on the above three methods of heat utilization, five possible cases have been considered to integrate the $\mathrm{CO}_{2}$ capture process with the power plant.

The basic heat transfer equation used in the calculation is as follows:

$$
Q=C_{p} M\left(T_{2}-T_{1}\right)
$$

Where, $C_{p}$ is the specific heat capacity, depending on the temperature, pressure and composition of the gas. Once the temperature, pressure and composition of the gas are defined, $C_{p}$ can be calculated using MTDATA software which predicts the phases forming at equilibrium in systems containing many components and many phases.

\section{Case 1: Use the recovered heat to replace extracted steam from the turbines}

It can be seen from Figure 2 that there are eight steam extraction streams from turbines ((1)(8)) used to heat the feedwater. In Case 1, the feedwater is initially pressurized via a series of pumps to the defined pressure values of the original extractions from the turbines. If the total mass flow of the extracted steam from the turbines decreases, there will be more electricity generated.

In Case 1, the condensed water from Point A (as seen in Figure 2) is divided into eight streams respectively. The recovered heat from the $650{ }^{\circ} \mathrm{C}$ clean flue gas is used to heat six feedwater streams; while the recovered heat from the $900{ }^{\circ} \mathrm{C} \mathrm{CO}_{2}$ stream is used to heat two feedwater streams. The total recovered heat from the $\mathrm{CO}_{2}$ capture process is about $498.3 \mathrm{MW}$ with $342.3 \mathrm{MW}$ from the $650^{\circ} \mathrm{C}$ clean flue gas and $156 \mathrm{MW}$ from the $900{ }^{\circ} \mathrm{C} \mathrm{CO}_{2}$ stream. The parameters of the steam heating system in Case 1 are the same with those in Figure 2. The 
total increased power output for the power system due to having less steam extractions is about 148.8MW.

\section{Case 2: Use the recovered heat to replace part of the boiler heat load}

It has been calculated that the recovered heat can account for about $50 \%$ of the boiler load. However, it should be pointed out that the quantity of fuel for the boiler, the $\mathrm{CO}_{2}$ releasing and the operating load for the $\mathrm{CO}_{2}$ capture process will all reduce with part of the boiler's load replaced by the recovered heat. Therefore, the above factors should be considered when designing the heat recovery method in this case study.

It is assumed that the load of the $\mathrm{CO}_{2}$ capture process is linear with the $\mathrm{CO}_{2}$ emission. The heat replacement ratio is defined as:

$$
X=\frac{Q_{1}+Q_{2}+Q_{3}}{Q_{1}+Q_{2}+Q_{3}+Q_{0}}
$$

Where $Q_{1}$ is recoverable heat from the carbonator;

$Q_{2}$ is recoverable heat from the clean flue gas;

$Q_{3}$ is recoverable heat from $\mathrm{CO}_{2}$ stream;

$Q_{0}$ is heat consumed by the boiler in the original steam system;

Based on the data from Table $1 \& 2$, the heat replacement ratio for the system is about $43.1 \%$ if all recovered heat is used to assume part of the boiler's load.

In Case 2, the $650{ }^{\circ} \mathrm{C}$ clean flue gas is used to heat the feedwater of $438.6 \mathrm{t} / \mathrm{h}$ from $278.6^{\circ} \mathrm{C}$ to $566{ }^{\circ} \mathrm{C}$, while its own temperature decreases from $650{ }^{\circ} \mathrm{C}$ to $279{ }^{\circ} \mathrm{C}$. The $900{ }^{\circ} \mathrm{C} \mathrm{CO}_{2}$ stream is used to heat the feedwater of $145.5 \mathrm{t} / \mathrm{h}$ from $278.6{ }^{\circ} \mathrm{C}$ to $566{ }^{\circ} \mathrm{C}$, while its own temperature decreases from $900{ }^{\circ} \mathrm{C}$ to $279{ }^{\circ} \mathrm{C}$. The recovered heat from the carbonator is used to heat the feedwater of $366.6 \mathrm{t} / \mathrm{h}$ from $278.6^{\circ} \mathrm{C}$ to $566^{\circ} \mathrm{C}$. The total recovered heat is about $1008.8 \mathrm{MW}$, in which $465.4 \mathrm{MW}$ is from the $650{ }^{\circ} \mathrm{C}$ clean flue gas, $154.4 \mathrm{MW}$ from the $900{ }^{\circ} \mathrm{C} \mathrm{CO}_{2}$ stream and $389 \mathrm{MW}$ from the carbonator.

Case 3: Use the recovered heat to replace the extracted steam from the turbines and part of the boiler heat load

It can be found that in Case 1, when the extractions from turbines are all replaced by the recovered heat, there is still part of the recoverable heat not being utilized. In addition, when the heat is all used to replace part of the boiler's load in Case 2, it is not desirable for the stable operation of the system. Therefore, in this case, the recovered heat will be utilized to replace the steam extractions from the turbines and part of the boiler heat to make full use of the recoverable heat from the $\mathrm{CO}_{2}$ capture process.

It is assumed that the load of the $\mathrm{CO}_{2}$ capture process is linear with the $\mathrm{CO}_{2}$ emission. The new heat replacement ratio is defined as:

$$
X=\frac{Q_{1}+Q_{2}+Q_{3}-Q_{4}}{Q_{1}+Q_{2}+Q_{3}+Q_{0}}
$$

Where, $Q_{4}$ is the heat used to replace the extractions from turbines.

In Case 3, the condensed water from Point $\mathrm{A}$ is divided into eight streams respectively. Approximately, $25 \%$ of the boiler heat load is assumed by the recovered heat from the carbonator and $\mathrm{CO}_{2}$ stream. The recovered heat from the carbonator can replace part of the 
boiler load, and the $900{ }^{\circ} \mathrm{C} \mathrm{CO}_{2}$ stream is used to replace the other part of the boiler load. The $650{ }^{\circ} \mathrm{C}$ clean flue gas is used to produce steam with the same parameters as the eight extractions ((1)-(8)) in Figure 2. The total recovered heat is about $905.8 \mathrm{MW}$, in which 498.3MW is from the $650{ }^{\circ} \mathrm{C}$ clean flue gas, $115.8 \mathrm{MW}$ from the $900{ }^{\circ} \mathrm{C} \mathrm{CO}_{2}$ stream and 291.8MW from the carbonator. The output power increase due to less steam extractions is about 148.8MW.

Case 4: Use the recovered heat to build a heat recovery steam generator and produce steam to drive new turbines

In Case 4, a new steam driven process is built to generate electricity based on the amount of the recoverable heat. It has been calculated that the heat recovered from the $\mathrm{CO}_{2}$ capture process is able to heat the feedwater of $1255 \mathrm{t} / \mathrm{h}$ from $278.6^{\circ} \mathrm{C}$ to $566{ }^{\circ} \mathrm{C}$, which is enough for a 400MW steam turbine cycle.

In this case, the $650{ }^{\circ} \mathrm{C}$ clean flue gas is used to heat the feedwater of $726.5 \mathrm{t} / \mathrm{h}$ from $278.6^{\circ} \mathrm{C}$ to $566{ }^{\circ} \mathrm{C}$, while its own temperature decreases from $650{ }^{\circ} \mathrm{C}$ to $279{ }^{\circ} \mathrm{C}$. In addition, the recovered heat from the carbonator is used to heat the feedwater of $528.5 \mathrm{t} / \mathrm{h}$ from $278.6^{\circ} \mathrm{C}$ to $566{ }^{\circ} \mathrm{C}$. The $900{ }^{\circ} \mathrm{C} \mathrm{CO}_{2}$ stream is used to reheat the steam from the high-pressure turbine. The total recovered heat is about $906.6 \mathrm{MW}$, in which $438.6 \mathrm{MW}$ is from the $650{ }^{\circ} \mathrm{C}$ clean flue gas, $149 \mathrm{MW}$ from the $900^{\circ} \mathrm{C} \mathrm{CO}_{2}$ stream and $319 \mathrm{MW}$ from the carbonator.

Case 5: Use part of the heat to build a heat recovery steam generator and produce steam to drive new turbines, the other part to replace the extracted steam in the new steam cycle In Case 5, a new steam driven process is built to generate electricity with all the extractions from the turbines replaced by recovered heat. It has been calculated that the heat recovered from the $\mathrm{CO}_{2}$ capture process is able to heat the feedwater of $1025 \mathrm{t} / \mathrm{h}$ from $248.8^{\circ} \mathrm{C}$ to $537^{\circ} \mathrm{C}$, which is enough for a $300 \mathrm{MW}$ turbine cycle, while all the extractions from the turbines are replaced by steam generated via recovered heat.

In this case, the $650{ }^{\circ} \mathrm{C}$ clean flue gas of $204 \mathrm{~kg} / \mathrm{s}$ is used to provide the desired steam to replace the extractions from the turbines and the $650^{\circ} \mathrm{C}$ clean flue gas of $336.1 \mathrm{~kg} / \mathrm{s}$ is used to heat the feedwater of $502.7 \mathrm{t} / \mathrm{h}$ from $248.8^{\circ} \mathrm{C}$ to $537^{\circ} \mathrm{C}$. Additionally, and the recovered heat from the carbonator is used to heat the feedwater of $522.3 \mathrm{t} / \mathrm{h}$ from $248.8^{\circ} \mathrm{C}$ to $537^{\circ} \mathrm{C}$. The 900 ${ }^{\circ} \mathrm{C} \mathrm{CO}_{2}$ stream is used to reheat the steam from the high-pressure turbine. The total recovered heat is about $777.5 \mathrm{MW}$, in which $303.5 \mathrm{MW}$ is from the $650{ }^{\circ} \mathrm{C}$ clean flue gas, 158.8MW from the $900^{\circ} \mathrm{C} \mathrm{CO}_{2}$ stream and 315.3MW from the carbonator.

\subsection{Thermal performance evaluation}

Power output, thermal efficiency, heat consumption rate and coal consumption rate are used as the four indicators in this evaluation, as follows:

1. Power output

The turbine can be divided into different stages, and the real power delivered excluding losses is:

$$
W_{\text {out }}=F_{\text {in }} \times e_{\text {stage }} \times \Delta H=F_{\text {in }} \times e_{\text {stage }} \times\left(H_{\text {in }}-H_{\text {out }}\right)
$$

Where, $H_{\text {in }}$ is the inlet steam enthalpy; $H_{\text {out }}$ is the outlet stream enthalpy; $W_{\text {out }}$ is the outlet power per unit; and $\Delta H$ is the enthalpy change in the stages. 


\section{Thermal efficiency}

Thermal efficiency is defined as the ratio of net power generated to the total lower heating value of the consumed fuel.

3. Heat consumption rate

The heat consumption rate is defined as the heat needed to generate one $\mathrm{kWh}$ of electricity. In all the above cases, the heat needed can be calculated based on the heat supplied by the boiler and the heat consumed in the carbonator.

4. Coal consumption rate

The coal consumption rate is defined as the quantity of coal consumed to generate one $\mathrm{kWh}$ of electricity. There are various kinds of coal with different heat values, for example, the lower heating values of the two kinds of coal shown in Table $1 \& 2$ are different. In order to analyzed and compare the total amount of coal consumed, the standard coal needs to be defined. It is defined here that the lower heating value of the standard coal is $29306 \mathrm{~kJ} / \mathrm{kg}$ $(7000 \mathrm{kcal} / \mathrm{kg}$ ) (Tian, 2001; You and $\mathrm{Xu}, 2008)$. This definition is especially useful when calculating the cost of the different fuel later in the paper. In all the above cases, the coal consumed should take into account the coal consumption for both the boiler and the calciner.

The conditions of $\mathrm{CO}_{2}$ streams after heat recovered can be seen from Figures 3. to 7 . In all the cases, $\mathrm{CO}_{2}$ streams will be compressed from atmospheric pressure, at which point it exists as a gas, up to a pressure suitable for pipeline transport (110bar), at which point it is in either the liquid or 'dense phase' regions, depending on its temperature. Therefore, $\mathrm{CO}_{2}$ undergoes a phase transition somewhere between these initial atmospheric pressure and final pressure (110bar). Compression of the $\mathrm{CO} 2$ to 110 bar will require around 0.4 GJ/tCO2 (IEA GHG, 2004; IPCC, 2005). In this study, the energy consumption for $\mathrm{CO} 2$ is assumed to be the same for the cases, about 92 MW.

In Table 3, the reference plant which vents its $\mathrm{CO}_{2}$ to the atmosphere refers to the $600 \mathrm{MW}$ power plant without any $\mathrm{CO}_{2}$ capture process and the reference plant with $\mathrm{CO}_{2}$ capture but no heat recovery refers to the power plant with a $\mathrm{CO}_{2}$ capture process but without recovering heat from the $\mathrm{CO}_{2}$ capture process. The gross power output refers to the power output without deducting the power consumed by the $\mathrm{O}_{2}$ separation and $\mathrm{CO}_{2}$ compression processes; while the net power output is the power output excluding the power consumed by the $\mathrm{O}_{2}$ separation and $\mathrm{CO}_{2}$ compression processes. The coal consumption rate results in Table 3 are based on the standard coal's heating value.

It can be seen from Table 3 that Case 4 has the most power output, the highest efficiency, lowest heat consumption and lowest total coal consumption rate. Case 2 has the lowest power output. If cases 1 to 5 are compared with the reference plant with $\mathrm{CO}_{2}$ capture but no heat recovery, their efficiencies increase by $30.4 \%, 75.8 \%, 80.4 \%, 89.7 \%$ and $87.1 \%$ respectively; while their heat consumptions and their total coal consumptions reduce by $30.4 \%, 75.8 \%, 80.4 \%, 89.7 \%$ and $87.1 \%$ respectively. The same trend is because there are fixed links among the efficiency, the heat consumption and total coal consumption rate. However, the efficiencies of cases 1 to 5 are much lower than that of the reference plant which vents its $\mathrm{CO}_{2}$ to the atmosphere due to the large amount of energy consumed by the oxygen separation and $\mathrm{CO}_{2}$ compression processes. Even for the highest efficiency case among the five cases (Case 4), its efficiency is still 3.8\% lower than that of the reference plant which 
vents its $\mathrm{CO}_{2}$ to the atmosphere. The net power outputs of cases 4 and 5 are higher than that of the reference plant which vents its $\mathrm{CO}_{2}$ to the atmosphere.

\begin{tabular}{lcccccccc}
\hline & $\begin{array}{l}\text { Reference plant } \\
\text { which vents its } \\
\mathrm{CO}_{2} \text { to the } \\
\text { atmosphere }\end{array}$ & $\begin{array}{c}\text { Reference plant } \\
\text { with } \mathrm{CO}_{2} \\
\text { capture but no } \\
\text { heat recovery }\end{array}$ & Case 1 & Case 2 & Case 3 & Case 4 & Case 5 \\
\hline $\begin{array}{l}\text { Gross power } \\
\text { output (MW) }\end{array}$ & 600 & 600 & 748.8 & 600 & 748.8 & 1000 & 989.3 \\
$\begin{array}{l}\text { Net power } \\
\text { output }\end{array}$ & 600 & 446 & 594.8 & 446 & 594.8 & 846 & 835.3 \\
$\begin{array}{l}\text { Efficiency (\%) } \\
\begin{array}{l}\text { Heat consumption } \\
\text { rate }(\mathrm{MJ} / \mathrm{kWh})\end{array}\end{array}$ & 40.6 & 19.4 & 25.3 & 34.1 & 35 & 36.8 & 36.3 \\
$\begin{array}{l}\text { Total coal } \\
\text { consumption } \\
\text { rate }(\mathrm{g} / \mathrm{kWh})\end{array}$ & 8.87 & 18.56 & 14.21 & 10.56 & 10.28 & 9.78 & 9.91 \\
\hline
\end{tabular}

Table 3. Comparison of the thermal evaluation results from different cases

\subsection{Conclusions}

Five cases for the possible integration of a power plant with $\mathrm{CaO}$-based $\mathrm{CO}_{2}$ capture process have been considered in this paper. Several main conclusions can be drawn as follows:

1. If cases 1 to 5 are compared with the reference plant with $\mathrm{CO}_{2}$ capture but no heat recovery, their efficiencies increase by $30.4 \%, 75.8 \%, 80.4 \%, 89.7 \%$ and $87.1 \%$ respectively; their heat consumptions and total coal consumptions share the same trend with the efficiencies, because of the fixed links between the efficiency, the heat consumption and total coal consumption rate.

2. Case 4 has the most net power output of $846 \mathrm{MW}$, the highest efficiency of $36.8 \%$.

3. Case 2 recovers the most total heat, about $1008.8 \mathrm{MW}$ but it has the lowest net power output of 446MW and the second lowest of efficiency of $34.1 \%$. This implies that the integrated system's performance depends both on the amount of heat recovery and the type of heat utilization.

4. Case 2 recovers the most heat from the carbonator, while Case 1 recovers the least heat from the carbonator. Case 3 recovers the most heat from the clean flue gas, while Case 5 recovers the least heat from the clean flue gas. Case 5 recovers the most heat from the $\mathrm{CO}_{2}$ stream, while Case 3 recovers the least heat from the $\mathrm{CO}_{2}$ stream.

Although the cases in this paper might not be the optimal one in their own category, theoretical factors have been considered in the design of the heat recovery in each case. The optimization of the integration will be included in further study.

\section{Conclusions and future work}

In this chapter, firstly, $\mathrm{CO}_{2}$ capture processes based on $\mathrm{CaO}$ has been analyzed from the microscopic angle. Secondly, the integrations of $\mathrm{CO}_{2}$ capture processes based on $\mathrm{CaO}$ with 
power plants have been discussed. Five cases for the possible integration of a 600MW power plant with $\mathrm{CaO}$-based $\mathrm{CO}_{2}$ capture process have been discussed. When the system is configured so that recovered heat is used to replace part of the boiler heat load (Case 2), modeling shows that this is the system recovering the most heat of $1008.8 \mathrm{MW}$ but also results in the system with the lowest net power output of $446 \mathrm{MW}$ and the second lowest of efficiency of $34.1 \%$.

In future work, a dynamic model of the carbonator will be built to analyze the effect of reaction time. The analysis of the integrations has been performed only on a 600MW power plant under base load in this chapter. Power plants with different capacities, for example, $300 \mathrm{MW}$ and $1000 \mathrm{MW}$ will be taken as the base cases in future research. In addition, the integrations under different working conditions of power plants will be studied as well.

\section{Acknowledgement}

The work presented here is funded by the Program for 973 Project 'Spatio-temporal Distribution \& Evaluation Method \& System Integration of Energy Consumption at Overall Working Conditions for Large-scale Coal-fired Power Generating Unit' (No.2009CB219801), China National Natural Science Fund Project (No. 50776028 and No.50606010). Program for Changjiang Scholars and Innovative Research Team in University (IRT0720).

\section{References}

Abanades, JC., 2002. The maximum capture efficiency of $\mathrm{CO}_{2}$ using a carbonation/calcination cycle of $\mathrm{CaO} / \mathrm{CaCO}_{3}$. Chem. Eng. J.. 90, 303-306.

Abanades, JC. and Alvarez, D., 2003. Conversion limits in the reaction of $\mathrm{CO}_{2}$ with lime. Energy and Fuels. 17, 308-315.

Abanades, JC., Anthony, EJ., Lu, DY., Salvador, C. and Alvarez, D., 2004.

Capture of CO2 from Combustion Gases in a Fluidized Bed of CaO. AIChE J.. 50, 1614-1622.

Abu-Zahra, M.R.M., Schneider, L.H.J., Niederer, J.P.M., Feron, P.H.M., Versteeg, G.F., 2007. $\mathrm{CO}_{2}$ capture from power plants Part I. A parametric study of the technical performance based on monoethanolamine. International journal of greenhouse gas control. 1, 37 - 46 .

Adanez, J., Garcia-Labiano, F. and Fierro, V., 2000. Modelling for the high-temperature sulphation of calcium-based sorbents with cylindrical and plate-like pore geometries. Chem. Eng. Sci.. 55, 3665-3683.

Abanades, J.C., Grasa, G., Alonso, M., Rodriguez, N., Anthony, E.J., Romeo, L.M., 2007. Cost structure of a Postcombustion $\mathrm{CO}_{2}$ capture system using $\mathrm{CaO}$. Environmental Science Technology. 41(15), 5523-5527.

Alonso, M., Rodriguez, N., Grasa, G. and Abanades, JC., 2009. Modelling of a fluidized bed carbonator reactor to capture $\mathrm{CO}_{2}$ from a combustion flue gas. Chem. Eng. Sci.. 64, 883-891.

Baker, EH., 1962. The calcium oxide-carbon dioxide system in the pressure range 1-300 atmospheres. J. Chem. Soc.. 3, 464-701. 
Basu, P., 2006. Combustion and gasification in fluidized beds. Taylor \& Francis Group, CRC Press, United States.

Darton, RC., LaNauze, RD., Davidson, JF.and Harrison, D., 1977. Bubble growth due to coalescence in fluidized beds. Trans. Instn chem. Engnrs.. 55, 274-280.

Davidson, JF. and Harrison, D., 1963. Fluidised particles. Cambridge University Press, New York.

Dennis, JS. and Hayhurst, AN., 1987. The effect of $\mathrm{CO}_{2}$ on the kinetics and extent of calcination of limestone and dolomite particles in fluidised beds. Chem. Eng. Sci.. 42, 2361 - 2372.

Desideri, U., Paolucci, A., 1999. Performance modelling of a carbon dioxide removal system for power plants. Energy Conversion Management. 40, 1899-1915.

Garcia-Labiano, F., Abad, A., de Diego, LF., Gayan, P. and Adanez, J., 2002. Calcination of calcium-based sorbents at pressure in a broad range of $\mathrm{CO}_{2}$ concentrations. Chem. Eng. Sci.. 57, 2381-2393.

Garea, A., Marques, JA. and Irabien, A., 2005. Modelling of in-duct desulfurization reactors. Chem. Eng. J.. 107, 119-125.

Grace, JR., 1992. Fluidized bed hydrodynamics. In: G. Hetsroni, Editor, Handbook of multiphase systems. Washington Hemisphere Publishing, Washington.

Grasa, GS. and Abanades, JC., 2006. $\mathrm{CO}_{2}$ capture capacity of $\mathrm{CaO}$ in long series of carbonation/calcination cycles. Ind. Eng. Chem. Res.. 45, 8846 - 8851.

Grasa, GS., Abanades, JC., Alonso, M. and Gonzalez, B., 2008. Reactivity of highly cycled particles of $\mathrm{CaO}$ in a carbonation/calcination loop. Chem. Eng. J.. 137, 561-567.

Hawthorne, C., Trossmann, M., Galindo Cifre, P., Schuster, A. and Scheffknecht, G., 2009. Simulation of the carbonate looping power cycle. Energy Procedia. 1, 1387-1394.

Huilin, L., Guangbo, Z., Rushan, B., Yongjin, C., Gidaspow, D., 2000. A coal combustion model for circulating fluidized bed boilers. Fuel. 79, 165-172.

IEA. Annual Energy Outlook 2003. DOE/IEA-0383, January 2003.

IEA GHG, 2004: Improvements in power generation with postcombustion capture of $\mathrm{CO}_{2}$, report PH4/33, Nov. 2004, IEA Greenhouse Gas R\&D Programme, Cheltenham, UK.

IPCC Special report on carbon dioxide capture and storage, 2005.

Kakaras, E., Doukelis, A., Giannakopolous, D., Koumanakos, A., 2007. Economic implication of oxyfuel application in a lignite-fired power plant. Fuel. 86, 2151-2158.

Khinast, J., Krammer, GF., Brunner, Ch. and Staudinger, G., 1996. Decomposition of limestone: the influence of $\mathrm{CO}_{2}$ and particle size on the reaction rate. Chem. Eng. Sci.. 51, 623 - 634 .

Kunii, D. and Levenspiel, O., 1990. Fluidized reactor models. 1. For bubbling beds of fine, intermediate, and large particles. 2. For the lean phase: freeboard and fast fluidization. Ind. Eng. Chem. Res.. 29, 1226-1234.

Mimura, T., Simayoshi, H., Suda, T., Iijima, M., Mituoka, S., 1997. Development of energy saving technology for flue gas carbon dioxide recovery in power plant by chemical 
absorption method and steam system. Energy Conversion and Management. 38, S57- S62.

Porta, F.L., 2006. Technical and economical analysis of future perspectives of solar thermal power plants, Università di Padova.

Rao, A.B. and Rubin, E.S., 2002. A technical, economic and environmental assessment of amine-based $\mathrm{CO}_{2}$ capture technology for power plant greenhouse gas control. Environmental Science Technology. 36(20), 4467-4475.

Rodriguez, N., Alonso, M., Grasa, G., Abanades, J.C., 2008. Heat requirements in a calciner of $\mathrm{CaCO}_{3}$ integrated in a $\mathrm{CO}_{2}$ capture system using $\mathrm{CaO}$. Chemical Engineering Journal. 138, 148-154.

Romano, M., 2009. Coal-fired power plant with calcium oxide carbonation for postcombustion $\mathrm{CO}_{2}$ capture. Energy Procedia. 1, 1099-1106.

Romeo, LM., Abanades, JC., Escosa, JM., Pano, J., Gimenez, A., Sanchez-Biezma, A. and Ballesteros, JC., 2008. Oxyfuel carbonation/calcination cycle for low cost $\mathrm{CO}_{2}$ capture in existing power plants. Energy Convers. Manage.. 49, 28092814.

Rubin, E.S., Chen, C., Rao, A.B., 2007. Cost and performance of fossil fuel power plants with $\mathrm{CO}_{2}$ capture and storage. Energy Policy. 35, 4444-4454.

Shimizu, T., Hirama, T., Hosoda, H., Kitano, K., Inagaki, M. and Tejima, K., 1999. A twin fluid-bed reactor for removal of $\mathrm{CO} 2$ from combustion processes. Trans. IChemE.. 77, 62- 68 .

Silcox, GD., Kramlich, JC.and Pershing, DW., 1989. A mathematical model for the flash calcination of dispersed $\mathrm{CaCO}_{3}$ and $\mathrm{Ca}(\mathrm{OH})_{2}$ Particles. Ind. Eng. Chem. Res.. 28, $155-160$.

Stanmore, BR. and Gilot, P., 2005. Calcination and carbonation of limestone during thermal cycling for $\mathrm{CO}_{2}$ sequestration. Fuel Processing Technology. 86, 1707-1743.

Strohle, J., Galloy, A., Epple, B., 2009. Feasibility Study on the Carbonate Looping Process for Post-Combustion $\mathrm{CO}_{2}$ Capture from Coal-Fired Power Plants. Energy Procedia. $1,1313-1320$.

Sun, P., Grace, JR., Lim, CJ. and Anthony, EJ., 2007. The effect of $\mathrm{CaO}$ sintering on cyclic $\mathrm{CO}_{2}$ capture in energy systems. Environmental and Energy Engineering. 53(9), 24322442.

Thitakamol, B., Veawab, A. and Aroonwilas, A., 2007. Environmental impacts of absorption-based $\mathrm{CO}_{2}$ capture unit for post-combustion treatment of flue gas from coal-fired power plant. Int. J. Greenhouse Gas Control. 1, 318-342.

Tian, J., 2001. Economic feasibility of heat supply from simple and safe nuclear plants. Annals of Nuclear Energy. 28, 1145-1150.

Turnbull, E. and Davidson, J.F., 1984. Fluidized combustion of char and volatiles from coal. AIChE J.. 30, 881-889.

Wang, J. and Anthony, E.J., 2005. On the decay behavior of the $\mathrm{CO}_{2}$ absorption capacity of CaO-based sorbents. Ind. Eng. Chem. Res.. 44, 627 - 629. 
Yang Y.P., Zhai R.R. and et al. 2010, Integration and evaluation of a power plant with a CaObased $\mathrm{CO}_{2}$ capture system, International Journal of Greenhouse Gas Control, 4(4), 603-612;

You, C. and Xu, X., 2008. Utilization of ventilation air methane as a supplementary fuel at a circulating fluidized bed combustion boiler. Environment Sci Technology. 42, 25902593. 


\title{
MEA-Based $\mathrm{CO}_{2}$ Capture Technology and Its Application in Power Plants
}

\author{
Yongping Yang and Rongrong Zhai \\ North China Electric Power University
}

China

\section{Introduction}

$\mathrm{CO}_{2}$ emission has the greatest negative impact on the observed greenhouse effect, causing approximately $55 \%$ of the global warming (IPCC, 2005). Currently, it is a mission for the whole world to control and reduce the emission of $\mathrm{CO}_{2}$. There is a great amount of $\mathrm{CO}_{2}$ being released from coal-fired power plants. Coal is the most abundant fossil fuel, and its resources are more evenly distributed all over the world than those of oil or natural gas. Coal is expected to continue to be a prominent fuel for electricity production in the future (Thitakamol et al., 2007; Romeo et al., 2008; IEA, 2003).

For coal-fired power plants, $\mathrm{CO}_{2}$ capture technologies can be divided into pre-combustion, oxyfuel and post-combustion method based on the position of $\mathrm{CO}_{2}$ captured. Meanwhile, it can also be divided into chemical absorption method, adsorption method, membrane separation method and so on.

$\mathrm{CO}_{2}$ capture based on monoethanolamine (MEA) is one of the most mature chemical absorption methods of post-combustion technologies. There has been extensive research on $\mathrm{CO}_{2}$ capture system based on MEA. But MEA based $\mathrm{CO}_{2}$ capture system needs thermal energy to regenerate MEA, which leads to the energy penalty to the power plant.

\section{Related work}

\subsection{Research progress on MEA based $\mathrm{CO}_{2}$ capture system}

It has been concluded that the energy penalty is about $2.57-4.2 \mathrm{GJ} / \mathrm{tCO}_{2}$, based on the simulation in software Aspen plus (Romeo et al., 2008; Mimura et al., 1997; Desideri et al., 1999). Recently, outstanding studies have analyzed different alternatives to reduce the heat duty on the reboiler and the thermal integration requirements on the power cycle (Mimura et al., 1997; Desideri et al., 1999; Mohammad et al., 2007; Ali, 2004; Bozzuto et al., 2001; Singh et al., 2003). There are mainly two ways to reduce the energy penalty. One is to optimize $\mathrm{CO}_{2}$ capture system based on MEA, while the other is to optimize the integration of $\mathrm{CO}_{2}$ capture system and power plant. The thermal efficiency reduction for the power plant is about $6.82 \%$ with the energy supplied by steam extractions from the turbines (Romeo et al., 2008). Besides the method of steam extractions, building new reboilers or gas turbines have also been discussed (Romeo et al., 2008). The parameters that affect the energy penalty of the system have been analyzed and optimized (Mohammad et al., 2007). It has been found that the thermal energy requirement for MEA process is a major part of the process overall 
operating cost (Singh et al., 2003). By modeling the MEA process for a $400 \mathrm{MWe}$ coal fired power plant, a specific thermal energy requirement equal to $3.8 \mathrm{GJ} /$ ton $\mathrm{CO}_{2}$ has been found. Other studies have focused on the location of turbine steam extractions and the re-injection of condensate from stripper to steam cycle. Power reduction around $17 \%$ has been reported, for a $90 \mathrm{MW}$ coal-fired power plant (Mimura et al., 1997), where $611 \mathrm{t} / \mathrm{h}$ of $\mathrm{CO}_{2}$ are captured and compressed, using $737 \mathrm{t} / \mathrm{h}$ of steam, which is the $54 \%$ of the steam leaving the boiler. Some researchers have calculated power reduction up to $26 \%$, with a decrease in power plant efficiency of 11.6 points for a 320MW coal-fired power plant (Desideri \& Paolucci, 1999).

However, in the previous research, MEA based $\mathrm{CO}_{2}$ capture system itself has been given too much concentration, and power plants are usually treated as black boxes. Although the effects on the power plant due to installing $\mathrm{CO}_{2}$ capture have been mentioned, the effects have not been fully discussed. It has been proposed that a typical range of energy required is between 0.72 and 1.74 MWt per MWe generated in a coal-fired power plant (Ali, 2004).

\subsection{Contributions of our work}

In this chapter, $\mathrm{CO}_{2}$ capture process based on MEA will be introduced firstly. Then a $600 \mathrm{MW}$ coal fired power plant will be taken as the base case, and the integrations of this plant with MEA-based $\mathrm{CO}_{2}$ capture processes will be discussed.

\section{Carbon capture process based on MEA}

\subsection{System description}

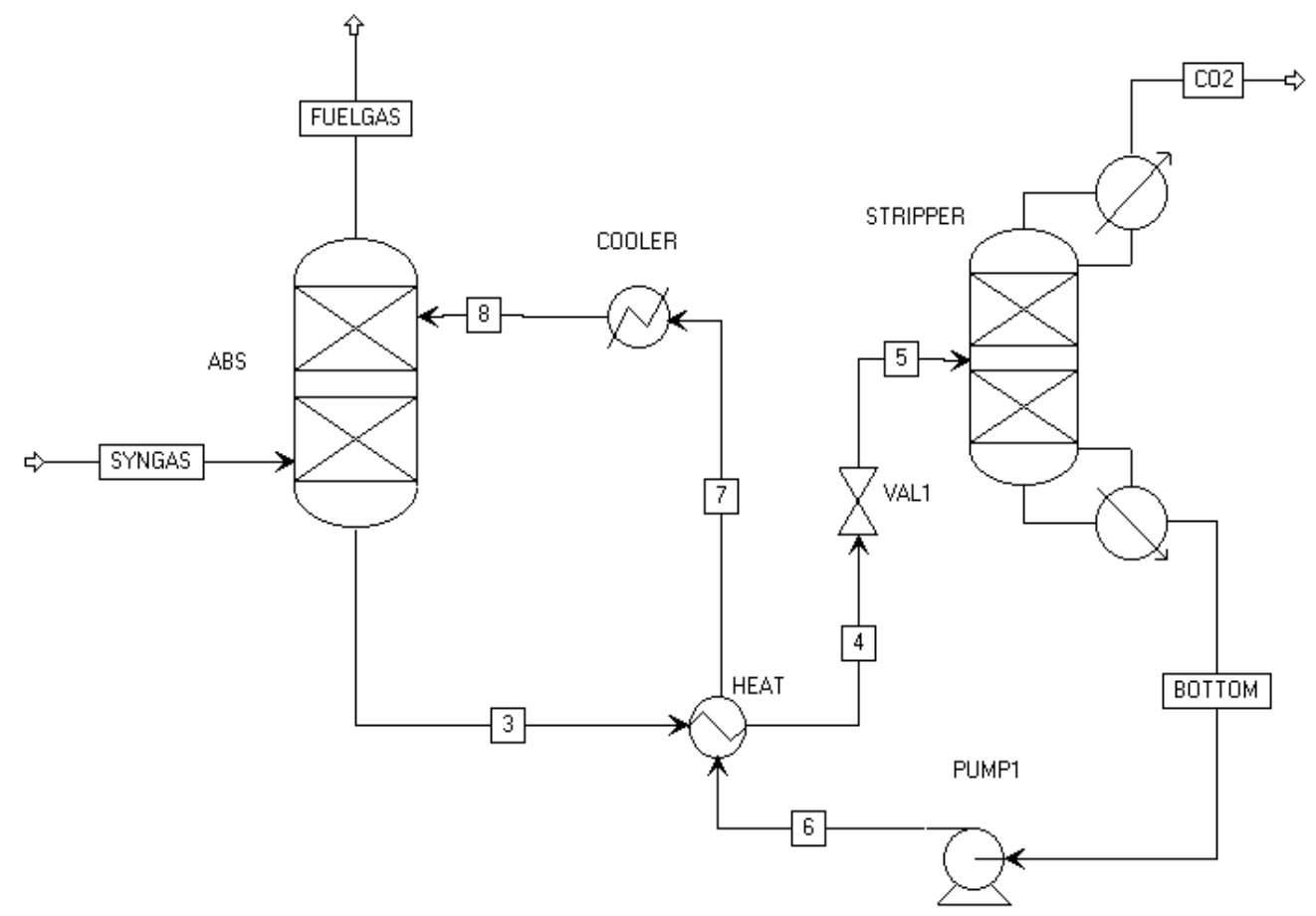

Fig. 1. Diagram of MEA based $\mathrm{CO}_{2}$ capture system 
MEA based $\mathrm{CO}_{2}$ capture system has been shown in Fig.1 (Zhai et al., 2008; Zhai et al., 2009). The main components are the absorber, stripper, pump, heat exchangers and so on. The flue gas from the power plant enters the absorber to have $\mathrm{CO}_{2}$ absorbed, and then the untreated gases go out from the top of the absorber. The rich solution with $\mathrm{CO}_{2}$ is pumped into the stripper to separate $\mathrm{CO}_{2}$ from the rich solution. The $\mathrm{CO}_{2}$ stream will be pressurized, while the lean solution without $\mathrm{CO}_{2}$ will go back to the absorber to form a cycle. Besides, there is a heat exchanger between the rich solution and lean solution to recovery the heat.

\subsection{Modeling and evaluation}

The flowsheet in Fig.1 can be simulated by ASPEN PLUS. The ELECNRTL physical property option set was selected. This was done to enable more accurate predictions of ionization equilibrium and the heats of solution. The absorber with 7 equilibrium stages is modeled in ASPEN using RadFrac, a rigorous, 'plate-to-plate' equilibrium stage model that allows for chemical reactions as well as phase equilibrium at each stage. The stripping column is modeled using RadFrac and contains 15 equilibrium stages.

The main reactions taking place in aqueous systems of $\mathrm{MEA}$ and $\mathrm{CO}_{2}$ are:

$$
\begin{aligned}
& 2 \mathrm{H}_{2} \mathrm{O} \Leftrightarrow \mathrm{H}_{3} \mathrm{O}^{+}+\mathrm{OH}^{-} \\
& \mathrm{CO}_{2}+2 \mathrm{H}_{2} \mathrm{O} \Leftrightarrow \mathrm{H}_{3} \mathrm{O}^{+}+\mathrm{HCO}_{3}^{-} \\
& \mathrm{HCO}_{3}{ }^{-}+\mathrm{H}_{2} \mathrm{O} \Leftrightarrow \mathrm{H}_{3} \mathrm{O}^{+}+\mathrm{CO}_{3}{ }^{2-} \\
& 2 \mathrm{MEA}+\mathrm{CO}_{2} \Leftrightarrow \mathrm{MEAH}^{+}+\mathrm{MEACOO}^{-} \\
& M E A^{+}+H_{2} \mathrm{O} \Leftrightarrow M E A+H_{3} O^{+} \\
& \mathrm{MEACOO}{ }^{-}+\mathrm{H}_{2} \mathrm{O} \Leftrightarrow \mathrm{MEA}+\mathrm{HCO}_{3}^{-}
\end{aligned}
$$

The component of the SYNGAS is showed in Table 1. And the main assumptions made for the $\mathrm{CO}_{2}$ recovery process is showed in Table 2 .

\begin{tabular}{ccc}
\hline \multicolumn{2}{c}{ Temperature ${ }^{\circ} \mathrm{C}$} & 37.8 \\
\multicolumn{2}{c}{ Pressure $\mathrm{MPa}$} & 1.7 \\
& $\mathrm{CO}$ & 0.44 \\
& $\mathrm{CO}_{2}$ & 24.6 \\
Mole & $\mathrm{H}_{2}$ & 31.9 \\
Fraction (\%) & $\mathrm{H}_{2} \mathrm{O}$ & 0.35 \\
& $\mathrm{~N}_{2}$ & 41.5 \\
& Others & 1.21 \\
\hline
\end{tabular}

Table 1. The composition of syngas 
The methodology 'Specific Consumption Analysis' based on the second law of thermodynamics was proposed by Prof. Song Zhiping in 1992. In this paper, the raw material consumption for the unity end product is referred to as 'specific consumption'. Unless otherwise stated it is always defined with respect to the 'total energy system' from the very input of primary energy until it reaches the end-users.

\begin{tabular}{lc}
\hline \multicolumn{1}{c}{ Parameters } & Value \\
\hline Absorber's inlet temperature ${ }^{\circ} \mathrm{C}$ & 38 (gas) $/ 38$ (liquid) \\
Absorber's outlet temperature ${ }^{\circ} \mathrm{C}$ & 70 (top) $/ 77$ (bottom) \\
Absorber's pressure $\mathrm{MPa}$ & 1.7 \\
Stripper's inlet temperature ${ }^{\circ} \mathrm{C}$ & 83 \\
Stripper's outlet temperature ${ }^{\circ} \mathrm{C}$ & 38 (top) $/ 112$ (bottom) \\
Stripper's pressure $\mathrm{MPa}$ & 0.1 \\
Stripper's reflux ratio & 0.54 \\
$\mathrm{CO}_{2}$ recovery rate $\%$ & 95 \\
\hline
\end{tabular}

Table 2. Assumptions made for the $\mathrm{CO}_{2}$ absorption

As can be seen in Table 3, the AspenPlus flow sheet does, reasonably well, predict the plant data.

\begin{tabular}{cccc}
\hline Stream & & Field data & AspenPlus \\
\hline Gas & $\mathrm{CO}_{2}$ in & $24.6 \%$ & $24.6 \%$ \\
& $\mathrm{CO}_{2}$ out & $93.5 \%$ & $93.2 \%$ \\
\hline \hline
\end{tabular}

Table 3. Validation of AspenPlus flow sheet

In accordance with the advanced exergo-economic approach, specific consumption is composed of the theoretically minimum specific consumption $\left(b_{\min }\right)$ and the specific consumption accruals $\left(b_{I}\right)$, where subscript $I=1,2, \ldots, n$ is the order number of the subsystem in question. The theoretically minimum specific consumption $b_{\text {min }}$ arises in a hypothetical ideal energy system which is conceived as an entirely reversible energy system with an infinite lifetime and without any fixed costs. It follows that the theoretically minimum specific consumption for a system can be shown as

$$
b_{\min }=\left(F / e_{F}\right) /\left(P / e_{P}\right)=e_{P} / e_{F}
$$

Where $e_{P}$ and $e_{F}$ refer to the exergy for per unit product and the exergy for per unit material respectively.

Any irreversibility results in a raw material accrual and a relevant accrual of specific consumption $b$. Consider an energy system consisting of $n$ subsystems and $m$ streams. The specific consumption accruals in terms of a column vector due to irreversibility are 


$$
\mathbf{b}=\left[\begin{array}{llll}
b_{1} & b_{2} & \ldots . & b_{n}
\end{array}\right]^{\tau}=\left(b_{\min } / P\right) \mathrm{A} \mathbf{E}
$$

where, $P$ the total exergy amount of the end product

E the column vector of $m$ stream exergies

$A=\left[a_{i j}\right]$ the incident matrix with elements $a_{i j}=1$ (if stream $j$ flows into subsystem $i$ ); $a_{i j}=-1$ (if stream $j$ flows out of subsystem $i$ ); $a_{i j}=0$ (if stream $j$ has no direct connection with subsystem $i$ )

The specific consumption of the end product equals its theoretically minimum specific consumption plus the sum of the specific consumption accruals, i.e.

$$
b=b_{\min }+\sum_{0}^{n} b_{I}
$$

The specific consumption of the $\mathrm{CO}_{2}$ recovery process can be identified as the MEA mole needed for the absorption of $1 \mathrm{~mol} \mathrm{CO}_{2}$.

The degree of carbonation in the absorber refers to the mole of $\mathrm{CO}_{2}$ that can be absorbed by 1 mol MEA, i.e. the $\mathrm{CO}_{2}$ solubility in 1 mol MEA.

The ideal degree of carbonation refers to the maximum mole of $\mathrm{CO}_{2}$ that can be absorbed by 1 mol MEA in the absorber. And the minimum specific consumption is the reciprocal of the ideal degree of carbonation. In this paper, the ideal degree of carbonation is 0.16 $\mathrm{molCO}_{2} / \mathrm{molMEA}$, i.e. the minimum specific consumption is $6.25 \mathrm{molMEA} / \mathrm{molCO}_{2}$.

In addition, based on the definition above, the specific consumption of the system is the mole of MEA needed for absorbing $1 \mathrm{~mol} \mathrm{CO}_{2}$, taking the component losses into consideration. And the reciprocal of the specific consumption is defined as the nominal degree of carbonation, which is the nominal mole of $\mathrm{CO}_{2}$ that can be absorbed by $1 \mathrm{~mol}$ MEA in the absorber. According to the flowsheet in Fig.1, the relationship between

\begin{tabular}{|c|c|c|c|c|c|c|c|c|c|c|c|}
\hline & SYNGAS & 3 & 4 & 5 & 6 & 7 & 8 & FLUEGAS & ВОTTOM & $\mathrm{CO}_{2}$ & Heat stream \\
\hline Absorber & 1 & -1 & 0 & 0 & 0 & 0 & 1 & -1 & 0 & 0 & 0 \\
\hline Heat exchanger & 0 & 1 & -1 & 0 & 1 & -1 & 0 & 0 & 0 & 0 & 0 \\
\hline Condenser & 0 & 0 & 0 & 0 & 0 & 1 & -1 & 0 & 0 & 0 & 0 \\
\hline Pump & 0 & 0 & 0 & 0 & -1 & 0 & 0 & 0 & 1 & 0 & 0 \\
\hline Valve & 0 & 0 & 1 & -1 & 0 & 0 & 0 & 0 & 0 & 0 & 0 \\
\hline Stripper & 0 & 0 & 0 & 1 & 0 & 0 & 0 & 0 & -1 & -1 & 1 \\
\hline
\end{tabular}
components and streams can be depicted in Table 4 .

Table 4. The incident matrix between components and streams

$$
\text { The incident matrix } A=\left[\begin{array}{lllllllllll}
1 & -1 & 0 & 0 & 0 & 0 & 1 & -1 & 0 & 0 & 0 \\
0 & 1 & -1 & 0 & 1 & -1 & 0 & 0 & 0 & 0 & 0 \\
0 & 0 & 0 & 0 & 0 & 1 & -1 & 0 & 0 & 0 & 0 \\
0 & 0 & 0 & 0 & -1 & 0 & 0 & 0 & 1 & 0 & 0 \\
0 & 0 & 1 & -1 & 0 & 0 & 0 & 0 & 0 & 0 & 0 \\
0 & 0 & 0 & 1 & 0 & 0 & 0 & 0 & -1 & -1 & 1
\end{array}\right]
$$


According to the calculations based on Eq.2, the specific consumption accruals in components are showed in Tab.V. The total exergy amount of the end product $\mathrm{P}$, the exergy of the $\mathrm{CO}_{2}$, is $277000 \mathrm{~kW}$.

\begin{tabular}{lcccccc}
\hline & Absorber & Cooler & Pump & Heat exchanger & Valve & Stripper \\
\hline Exergy loss kW & 14089.5 & 22040.3 & 580.0 & 1845.0 & 12006.5 & 69044.8 \\
Specific consumption & 0.32 & 0.50 & 0.01 & 0.04 & 0.27 & 1.56 \\
accruals kW & $11.78 \%$ & $18.43 \%$ & $0.48 \%$ & $1.54 \%$ & $10.04 \%$ & $57.73 \%$ \\
Ratio &
\end{tabular}

Table 5. Specific consumption accruals in components

It can be seen in Table 5, the stripper has the highest specific consumption accruals, accounting for more than $57.73 \%$ of the total specific consumption accruals. The salt formed in the reaction between $\mathrm{CO}_{2}$ and MEA is relatively stable, which needs great heat to depose, about $4.25 \mathrm{MJ} / \mathrm{kgCO}_{2}$. And the cooler has the second highest specific consumption accruals, about $18.43 \%$ of the total specific consumption accruals. The specific consumption accruals for the heat exchanger, pump and valves are relatively small, because there are no chemical reactions in these components.

The specific consumption for the system is $8.95 \mathrm{molMEA} / \mathrm{molCO}{ }_{2}$, calculated by Formula 3, increasing by about $43.18 \%$ of the theoretically minimum specific consumption. And the normal degree of carbonation is $0.11 \mathrm{molCO}_{2} / \mathrm{molMEA}$, lower than the ideal degree of carbonation, which is caused by the component losses. Based on the analysis above, the components should be improved to reduce the specific consumption of the system, especially the stripper.

\subsection{Discussions and conclusions}

A novel method for chemical process evaluation was proposed in this paper. The specific consumption analysis is now accessible to perform optimizing studies using exergy analysis for amine based $\mathrm{CO}_{2}$ removal technology. It can be used to find leads to lower the energy consumption, either by optimization of the current flow sheet or by more structural improvements.

\section{Integration and evaluation of a power plant with a MEA based $\mathrm{CO}_{2}$ capture process}

\subsection{System description}

The layout of MEA-based $\mathrm{CO}_{2}$ capture process has been shown in Fig.1. It is assumed that the fraction of $\mathrm{CO}_{2}$ captured is about $65 \%$. The energy required for $\mathrm{CO}_{2}$ capture is calculated to be around $3.5 \mathrm{GJ} / \mathrm{tCO}_{2}$ in Aspen plus.

The base power plant used is shown in Fig.2. The combustion of coal takes place in the boiler. The unsaturated boiler feedwater from the condenser enters into the boiler after going through four low-pressure reheaters (HTR1, HTR2, HTR3, HTR4), three high pressure reheaters (HTR5, HTR6, HTR7) and a deaerator (Deaerator). The outlet superheated steam from the boiler is transported to the high pressure cylinder to produce power, and then the exhaust steam drives intermediate pressure and lower pressure cylinders after being reheated in the boiler. In the end, the final exhaust is condensed in the condenser. The extractions from different positions of the cylinders ((1)-(8)) are used to heat the feedwater via feedwater reheaters. 


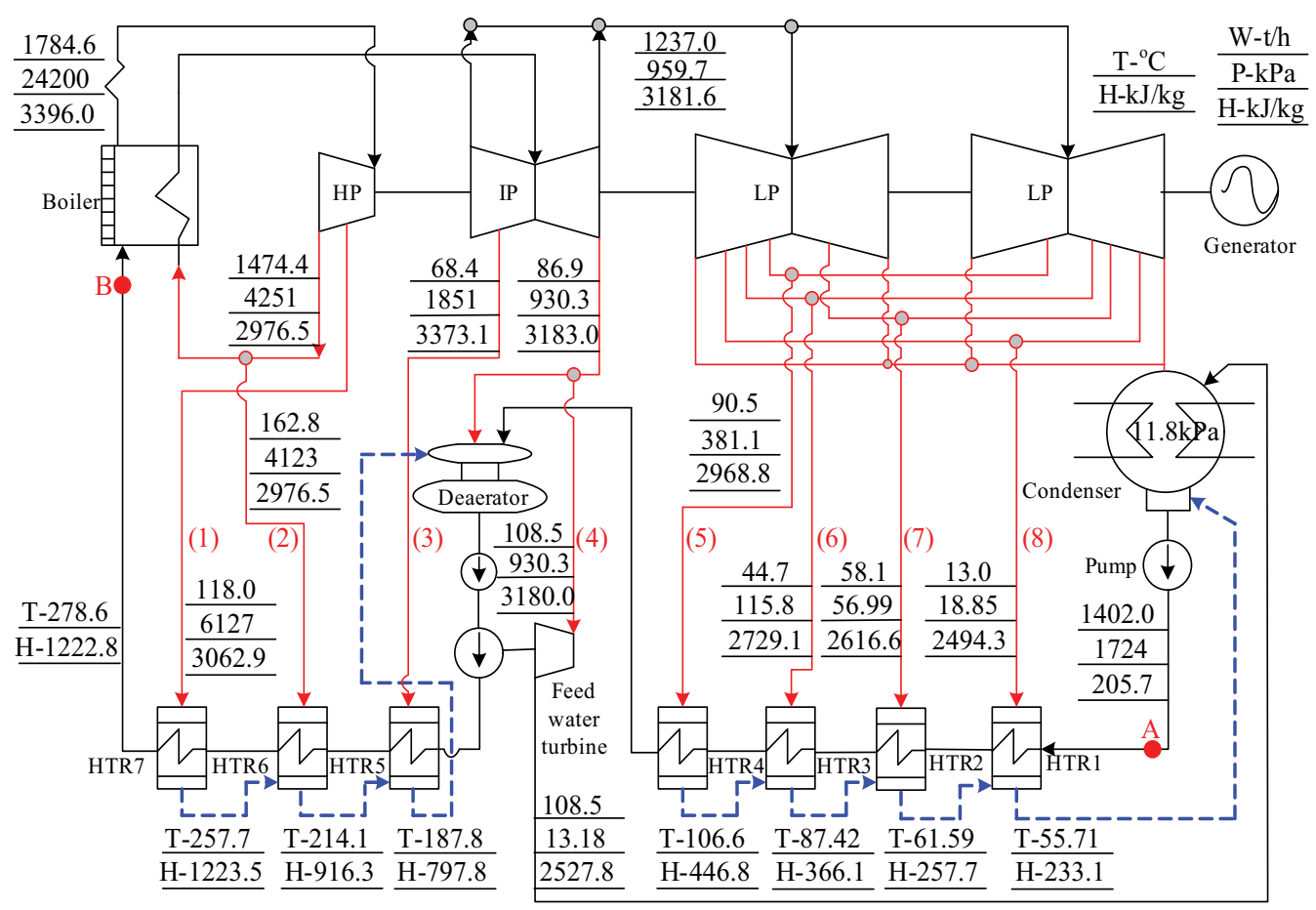

* (1)-(8) denote the stream conditions.

Fig. 2. Steam layout of a $600 \mathrm{MW}$ supercritical power plant

\subsection{Integration methods}

It has been stated that the MEA regeneration process in the stripper needs thermal energy. Integration based on power plant internal streams has been discussed in this section. As can be seen in Fig.2, there are eight extractions from the turbines. In order to extract steam for MEA regeneration, there are two kinds of methods. One method is called Power Output Reduction Method (PORM). In this method, more steam is extracted from the original one or more original steam extractions, as shown in Fig.3(a). The other method is called Coal Consumption Rate Increase Method (CCRIM). In this method, the original extractions from the turbines are kept unchanged, and part of the original steam is allocated for MEA regeneration, as shown in Fig.3(b) (Zhai, 2010).

However, not all the steam extractions from the turbines are suitable for MEA regeneration. Bounded to the chemical restrictions of MEA, the regeneration temperature needs to be below $122{ }^{\circ} \mathrm{C}$. If the temperature is above $122{ }^{\circ} \mathrm{C}$, MEA will decay rapidly and may cause corrosion to the reactor (Ali, 2004). If the approach temperature is set to be $10{ }^{\circ} \mathrm{C}$, ideally the saturated temperature of the steam should be $132{ }^{\circ} \mathrm{C}$. However, none of the original eight steam extractions' saturated temperate is $132{ }^{\circ} \mathrm{C}$. The saturated temperatures of extractions (6) to (8) are too low to be suitable for MEA regeneration. But the steam of extractions (1) to (5) can be used supply the heat for MEA regeneration. Valves need to be used to reduce the pressures of the extractions (1)-(5) first. Therefore, the extractions (1) to (5) can be used to supply the heat for MEA regeneration and extractions after heat transferring will return to the reheat system. 


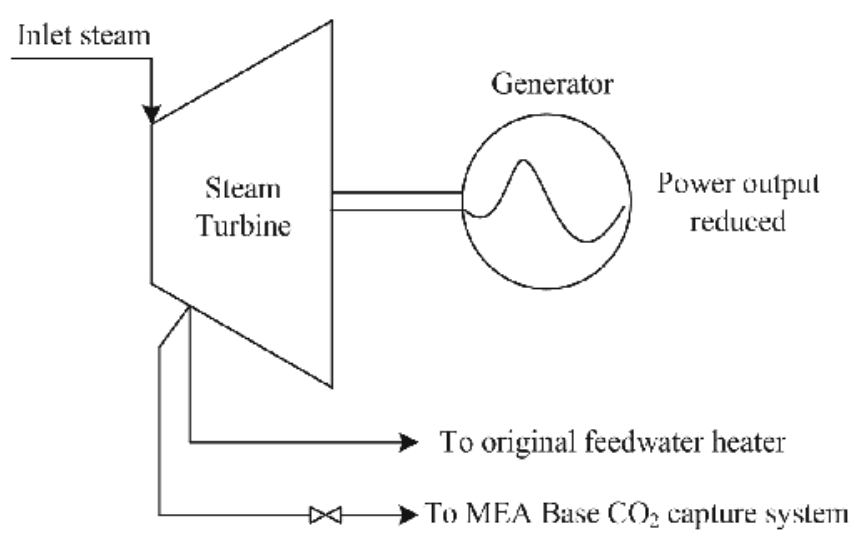

(a) Schematic diagram of Power Output Reduction Method

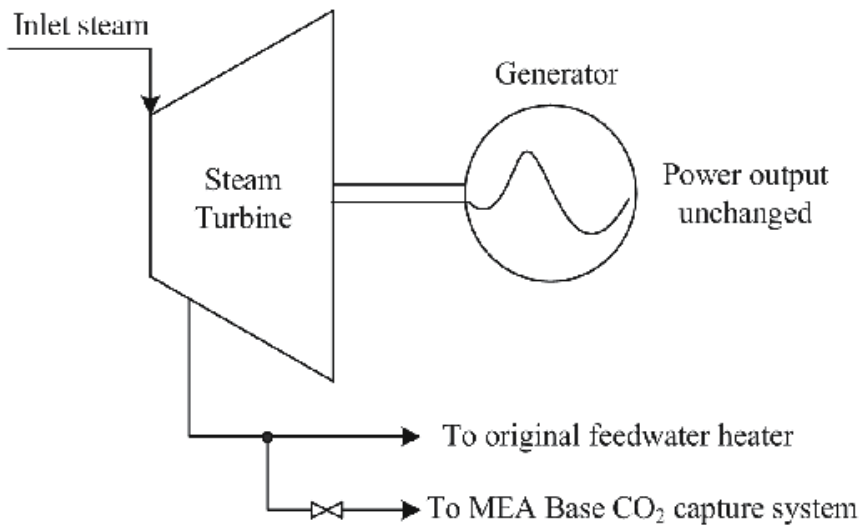

(b) Schematic diagram of Coal Consumption Rate Increase Method

Fig. 3. Integrations using internal energy flows

Based on the above two kinds of methods, nine possible cases have been considered as follows:

Case 1: Increasing the steam extraction of stream (1) to supply heat for MEA regeneration;

Case 2: Increasing the steam extraction of stream (2) to supply heat for MEA regeneration;

Case 3: Increasing the steam extraction of stream (3) to supply heat for MEA regeneration;

Case 4: Increasing the steam extraction of stream (4) to supply heat for MEA regeneration;

Case 5: Increasing the steam extraction of stream (5) to supply heat for MEA regeneration;

Case 6: Keeping all the steam extractions from the turbines unchanged and using the extractions (2)(3)(5) \& part of extraction (1) to supply heat for MEA regeneration;

Case 7: Keeping all the steam extractions from the turbines unchanged and using the extractions (1)(3)(5) \& part of extraction (2) to supply heat for MEA regeneration;

Case 8: Keeping all the steam extractions from the turbines unchanged and using the extractions (1)(2)(5) \& part of extraction (3) to supply heat for MEA regeneration;

Case 9: Keeping all the steam extractions from the turbines unchanged and using the extractions (1)(2)(3) \& part of extraction (5) to supply heat for MEA regeneration.

Cases 1 to 5 belong to the Power Output Reduction Method, while cases 6 to 9 belong to the Coal Consumption Increase Method. 


\subsection{Evaluation methodology}

Thermal performance evaluation is going to be used in this analysis. Power output, thermal efficiency, heat consumption rate and coal consumption rate are used as the four indicators in this evaluation, as follows:

\section{(1) Power output}

The turbine can be divided into different stages, and the real power delivered excluding losses is:

$$
W_{\text {out }}=F_{\text {in }} \times e_{\text {stage }} \times \Delta H=F_{\text {in }} \times e_{\text {stage }} \times\left(H_{\text {in }}-H_{\text {out }}\right)
$$

Where, $H_{\text {in }}$ is the inlet steam enthalpy; $H_{\text {out }}$ is the outlet stream enthalpy; $W_{\text {out }}$ is the outlet power per unit; and $\Delta H$ is the enthalpy change in the stages.

\section{(2) Thermal efficiency}

The thermal efficiency is defined as the ratio of net power generated to the total lower heating value of the consumed fuel.

\section{(3) Coal consumption rate}

The coal consumption rate is defined as the quantity of coal consumed to generate one $\mathrm{kWh}$ of electricity. There are various kinds of coal with different heat values. In order to analyzed and compare the total amount of coal, the standard coal needs to be defined. It is defined that the lower heating value of the standard coal is $29306 \mathrm{~kJ} / \mathrm{kg}(7000 \mathrm{kcal} / \mathrm{kg})$ (Tian, 2001; You \& $\mathrm{Xu}, 2008)$.

\subsection{Results and discussions}

Figures 4 to 6 show the results for the cases, including the power outputs, coal consumption rates and efficiencies.

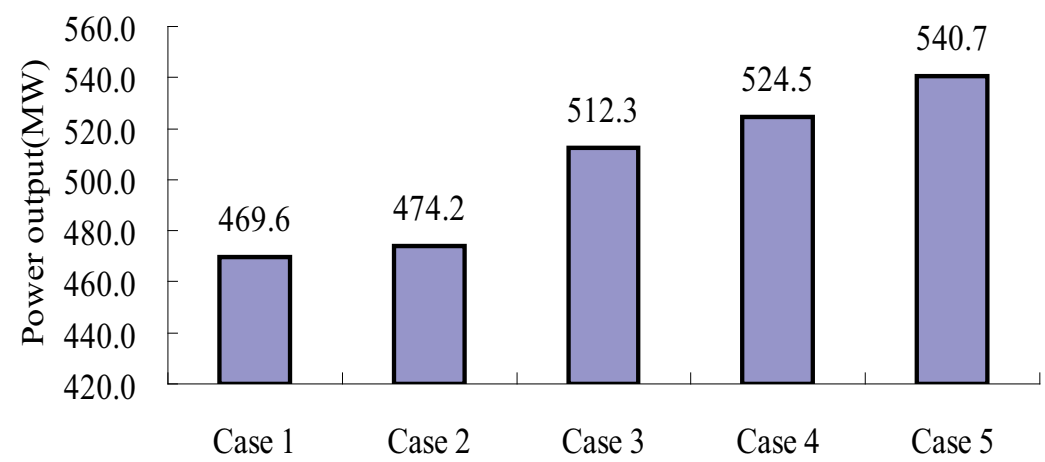

Fig. 4. Power outputs for cases 1 to 5

Fig. 4 shows the power outputs for cases 1 to 5 . The power outputs for cases 1 to 5 increase from $469.6 \mathrm{MW}$ to $540.7 \mathrm{MW}$, indicating that the effects of $\mathrm{MEA}$ based $\mathrm{CO}_{2}$ capture system on the power unit for the five cases reduce. There will be smaller power output reduction if the extractions are from low pressure turbines rather than those from high pressure turbines. For example, the power output reduces about 59.57MW with steam extracted from stream (5) (Case 5). The reduction is $54.4 \%$ lower compared to the case stream extracted from (1). However, the power output's difference between case 3 and 2 are the highest among all the abut cases, about 38.1MW. 


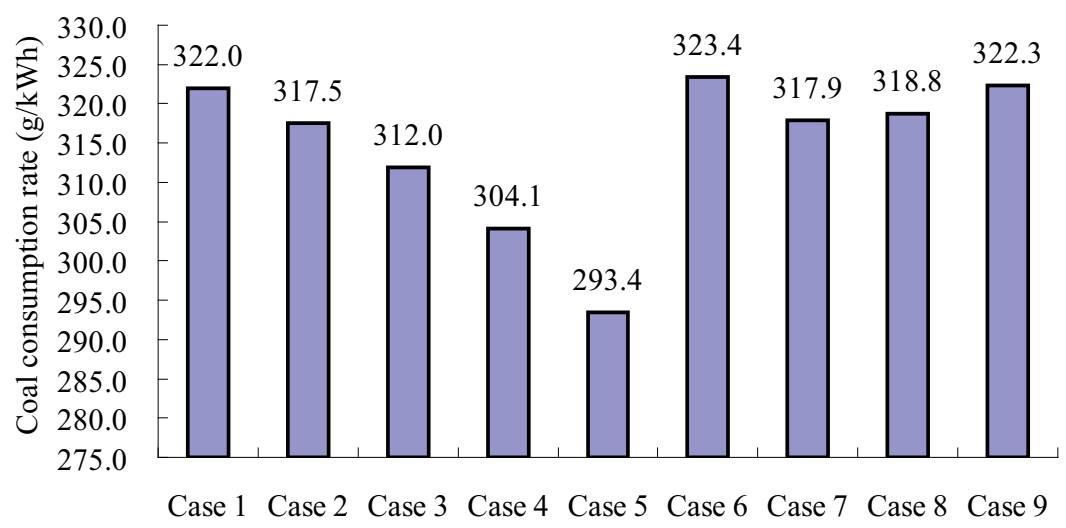

Fig. 5. Coal consumption rates for cases 1 to 9

Fig. 5 shows the coal consumption rates for cases 1 to 9 . Although cases 1 to 5 are Power Output Reduction Method, the coal consumptions still change. It is because the main steam flowrate reduces due to more steam extracted from the turbines. The coal consumption rates for cases 1 to 5 reduce. For example, the coal consumption rate of Case 5 reduces by about $8.88 \%$, compared to that of Case 1 . However, the coal consumption rate's difference between case 4 and 5 are the highest among all the abut cases, about $10.7 \mathrm{~g} / \mathrm{kWh}$.

Cases 6 to 9 belong to the Coal Consumption Rate Increase Method, and the power output is 600.27MW unchanged. The coal consumption rate of Case 7 is the lowest among cases 6 to 9 . However, the average coal consumption rate of cases 6 to 9 is higher than that of cases 1 to 5 . Coal consumption rate of Case 7 (the lowest coal consumption rate among the Coal Consumption Rate Increase Method) is still $24.5 \mathrm{~g} / \mathrm{kWh}$ higher than the coal consumption rate of Case 5 (the lowest coal consumption rate among the Power Output Reduction Method). The coal consumption rates of cases 7 and 8 are lower than that of Case 1. It is further indicated that it is not reasonable to extract steam from high pressure turbines. The coal consumption rates for cases 1 to 9 can be sequenced as follows: Case $5<$ Case $4<$ Case $3<$ Case $2<$ Case $7<$ Case $8<$ Case $1<$ Case $9<$ Case 6 .

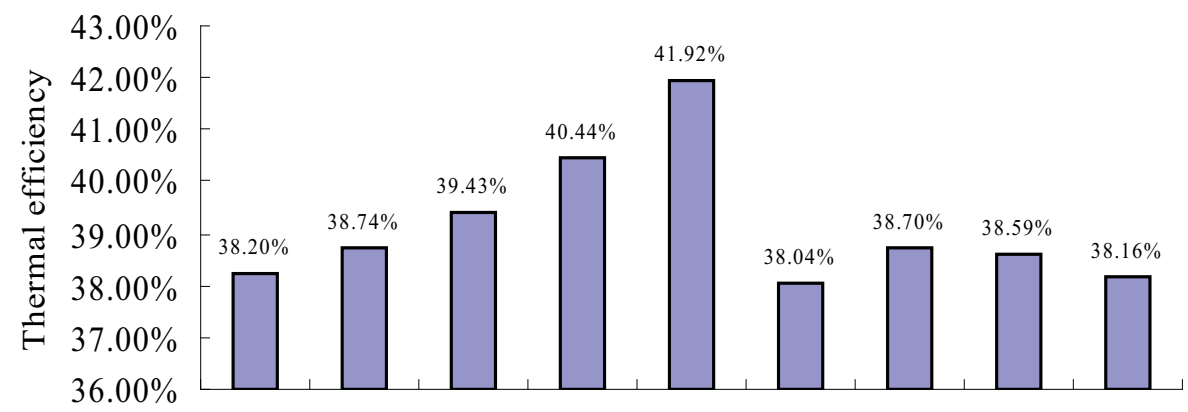

Case 1 Case 2 Case 3 Case 4 Case 5 Case 6 Case 7 Case 8 Case 9

Fig. 6. Thermal efficiencies for cases 1 to 9

Fig. 6 shows the efficiencies for cases 1 to 9 . Case 5 has the highest thermal efficiency while Case 6 has the lowest thermal efficiency among the cases. Compared with the thermal 
efficiency of the original power plant $45.14 \%$, the thermal efficiency reduction for cases 5 and 6 are $3.22 \%$ and $7.1 \%$, respectively. The efficiencies for cases 1 to 9 can be sequenced as follows: Case $5>$ Case $4>$ Case $3>$ Case $2>$ Case $7>$ Case $8>$ Case $1>$ Case $9>$ Case 6 . This trend is the reversed trend of coal consumption rates for the cases. That's because there is a certain relationship between coal consumption rate and efficiency.

Based on the analysis above, Case 5 is the optimal case. The difference between Case 5 and the reference plant as shown Figure 1 lies in that extra steam of 337.4t/h has been extracted from the original stream (5). The extra steam is used to regenerate MEA, and it then goes back to the deaerator. The parameters of the feedwater heaters have all changed.

After $\mathrm{CO}_{2}$ stream has been separated, it needs to be compressed from atmospheric pressure, at which point it exists as a gas, up to a pressure suitable for pipeline transport (110bar), at which point it is in either the liquid or 'dense phase' regions, depending on its temperature. Therefore, $\mathrm{CO}_{2}$ undergoes a phase transition somewhere between these initial atmospheric pressure and final pressure (110bar). Compression of the $\mathrm{CO}_{2}$ to 110 bar will require around $0.4 \mathrm{GJ} / \mathrm{tCO}_{2}$ (IPCC, 2005; IEA, 2004).

The analysis above doesn't take $\mathrm{CO}_{2}$ compression. The average thermal efficiency reduction of the nine cases is about $6 \%$, while it is only $3.22 \%$ for the optimal case (Case 5). If $\mathrm{CO}_{2}$ compression is taken into consideration, energy of $30.16 \mathrm{MW}$ will be consumed for the compression process. The thermal efficiency reduction of Case 5 will increase to $5.56 \%$. The thermal efficiency reduction for the power plant is about $6.82 \%$ with the energy supplied by steam extractions from the turbines (Mimura et al., 1997). Therefore, the calculations in this paper are reasonable.

\section{Conclusions and future work}

In this chapter, firstly, $\mathrm{CO}_{2}$ capture processes based on monoenthomal (MEA) have been analyzed from the microscopic angle. Secondly, the integrations of $\mathrm{CO}_{2}$ capture processes (based on MEA) with power plants have been discussed. The main research findings are as follows:

(1) The MEA based $\mathrm{CO}_{2}$ capture process has been shown in Fig.1. The performance of the MEA based $\mathrm{CO}_{2}$ capture process has direct connection with stripper pressure, MEA inlet flowrate and weight percentage, distillate rate and reflux ratio. Based on the specific consumption analysis, the energy consumption is $4.25 \mathrm{MJ} / \mathrm{kgCO}_{2}$, and the stripper accounts for the most energy loss. Measures can be taken to lower the energy consumption.

(2) The integration of a $600 \mathrm{MW}$ supercritical power plant with a MEA based $\mathrm{CO}_{2}$ capture process has been discussed. When the system is configured so that more steam is extracted from the low turbine, modeling shows that this system has the highest thermal efficiency, about $41.92 \%$ reducing $3.22 \%$ compared with the thermal efficiency of the original power plant.

In future work, the optimization of MEA-based capture process integrated with power plants will be examined. The MEA-based capture process needs to be optimized for the operation as well.

\section{Acknowledgement}

The work presented here is funded by the Program for 973 Project 'Spatio-temporal Distribution \& Evaluation Method \& System Integration of Energy Consumption at Overall 
Working Conditions for Large-scale Coal-fired Power Generating Unit' (No.2009CB219801), China National Natural Science Fund Project (No. 50776028 and No.50606010). Program for Changjiang Scholars and Innovative Research Team in University (IRT0720).

\section{References}

Bozzuto CR, Nsakala N, Liljedahl GN, Palkes M, Marion JL.,2001. Engineering feasibility of $\mathrm{CO}_{2}$ capture on an existing US coal-fired power plant, Final Report, vol. I, ALSTOM Power Inc.;

C. Ali.,2004. Simulation and optimisation of a coal-fired power plant with integrated $\mathrm{CO}_{2}$ capture using MEA scrubbing, Master Thesis, University de Waterloo;

Desideri U, Paolucci A., 1999. Performance modelling of a carbon dioxide removal system for power plants. Energy Conversion \& Management. 40, 1899-1915;

IEA, 2003. Annual Energy Outlook 2003. DOE/IEA-0383;

IEA GHG, 2004. Improvements in power generation with postcombustion capture of $\mathrm{CO}_{2}$, report PH4/33. IEA Greenhouse Gas R\&D Programme, Cheltenham, UK;

IPCC, 2005. Special report on carbon dioxide capture and storage;

Mimura T, Simayoshi H, Suda T, Iijima M, Mituoka S., 1997. Development of energy saving technology for flue gas carbon dioxide recovery in power plant by chemical absorption method and steam system. Energy Conversion and Management. 38, $57-62$;

Mohammad RM. Abu-Zahra, Le'on H.J. Schneider, John P.M. Niederer, Paul H.M. Feron, Geert F. Versteeg., 2007. $\mathrm{CO}_{2}$ capture from power plants Part I. A parametric study of the technical performancebased on monoethanolamine. International Journal of Greenhouse Gas Control. 1, 37 - 46;

Romeo LM, Bolea I, Escosa JM, 2008. Integration of power plant and amine scrubbing to reduce $\mathrm{CO}_{2}$ capture costs. Applied Thermal Engineering. 28, 1039-1046;

Singh D, Croiset E, Douglas PL, Douglas MA., 2003. Techno-economic study of $\mathrm{CO}_{2}$ capture from an existing coal-fired power plant: MEA scrubbing vs. $\mathrm{O}_{2} / \mathrm{CO}_{2}$ recycle combustion. Energy Conversion and Management. 44, 3073-3091;

Thitakamol B, Veawab A, Aroonwilas A., 2007. Environmental impacts of absorption-based $\mathrm{CO}_{2}$ capture unit for post-combustion treatment of flue gas from coal-fired power plant. International Journal of Greenhouse Gas Control. 1, 318-342;

Tian, J., 2001. Economic feasibility of heat supply from simple and safe nuclear plants. Annals of Nuclear Energy. 28, 1145-1150;

You $\mathrm{C}$ and $\mathrm{Xu} X ., 2008$. Utilization of ventilation air methane as a supplementary fuel at a circulating fluidized bed combustion boiler. Environment Sci Technology. 42, 25902593;

Zhai R.R., Yang Y.P., Duan L.Q., 2008. Exergy Analysis of $\mathrm{CO}_{2}$ Recovery Process by Specific Consumption, IEEE International Conference on Sustainable Energy Technologies ICSET2008 Singapore, 182-185;

Zhai R.R., Yang Y.P., Duan L.Q., Yan Q., 2009. Modeling and simulating of GTCC system with $\mathrm{CO}_{2}$ removal plant using Aspen Plus, International Journal of Modeling, Identification and Control. 8(7)-4, 365-370;

Zhai R.R., 2010. Study on the Mechanism of $\mathrm{CO}_{2}$ Capture Technologies and Its Coupling Effect with Power Plants, North China Electric Power University; 


\title{
High Renewable Energy Penetration Diesel Generator Systems
}

\author{
Professor Chemmangot V. Nayar \\ Curtin University of Technology \\ Australia
}

\section{Introduction}

Most small Island and remote communities around the world today are dependent on imported fossil fuels for most of their energy requirements. These communities are exposed to diesel fuel price volatility, frequent fuel spills and high operation and maintenance costs including fuel transportation and bulk storage. In addition to remote area power systems, commercial and residential customers in urban areas are also seeking new sources of backup power located on their premises. Diesel generators are a major source of backup power due to ease of transportation, installation and removal, as well as the mature and stable nature of the diesel industry with reliable suppliers. Having said this however, in the past decade, diesel prices have more than doubled. High fuel costs have translated into tremendous increases in the cost of energy generation. Diesel generators also a major source of pollution.

Renewable energy sources such solar photovoltaic (PV) and wind power are clean, affordable, readily available, and sustainable and can supplement generators in both grid connected and off-grid residential and commercial applications. Hybrid energy systems integrate these renewable energy technologies with diesel generators, inverters and batteries to provide grid quality power in remote areas not connected to a utility grid. Such an isolated grid is known as a Stand-alone Micro-Grid and is widely recognised as the remote area electrification technology for the $21^{\text {st }}$ century.

The author has been involved in the development of off-grid remote area power systems over the past two decades. This paper presents case studies of micro-grid distributed generation systems using wind turbines, photovoltaic modules and details how an innovative variable speed diesel/bio-diesel generator (HybridGen ${ }^{\mathrm{TM}}$ ) can be integrated into such systems.

\section{Remote area power supply options}

There are two general methods of supplying electricity to remote areas: grid extension and the use of diesel generators. Grid extension can be very expensive in many locations. Diesel generators are therefore the only viable option for remote area electrification. However, remote areas with relatively small communities generally show significant variation between the daytime peak loads and the minimum night-time loads. A typical example of a load profile of a remote community in Western Australia is shown below in Figure 1. 


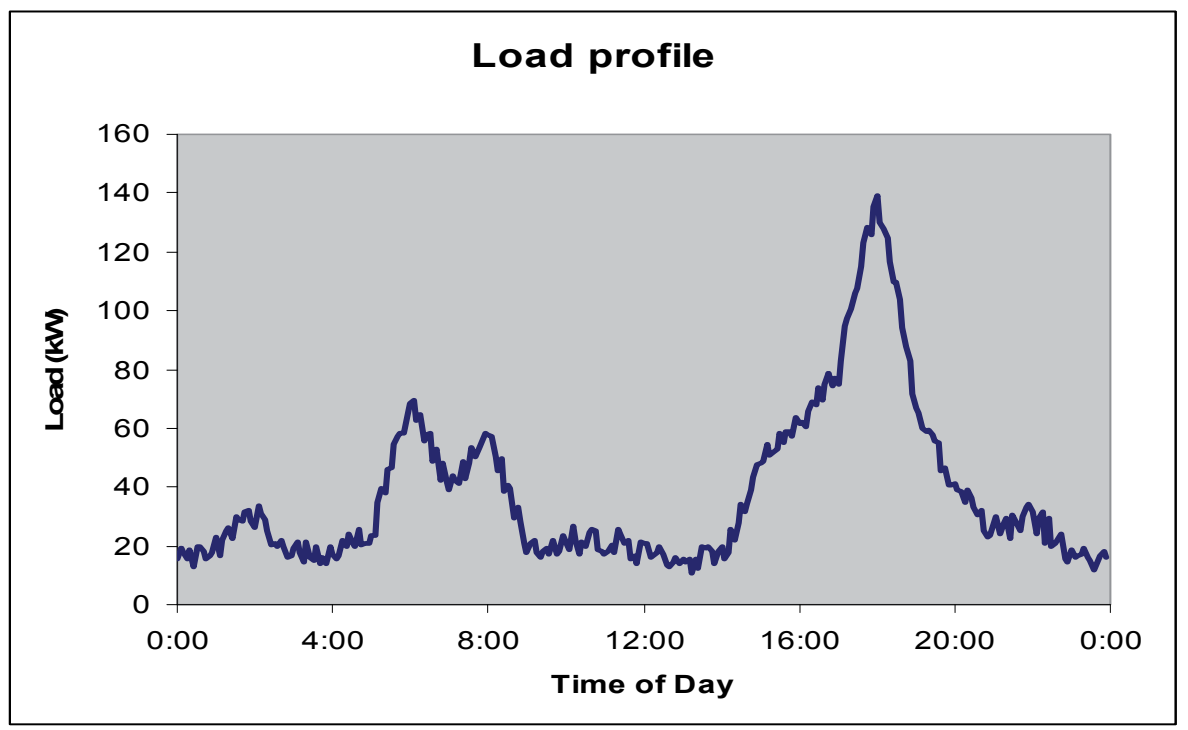

Fig. 1. Typical load profile of a remote community

Diesel-powered electric generators are typically sized to meet the peak demand during the evening but must run at very low loads during "off-peak" hours during the day and night. This low-load operation results in poor fuel efficiency and increased maintenance. The main problems of remote area power generation using diesel generators are:

- High cost of electricity due to increasing fuel and transportation cost.

- Air and noise pollution.

- Loss in diesel fuel efficiency and increased operation and maintenance cost due to incomplete combustion of fuel during light loads

The typical fuel consumption characteristic of a 50kVA diesel generator is shown in Fig. 2:
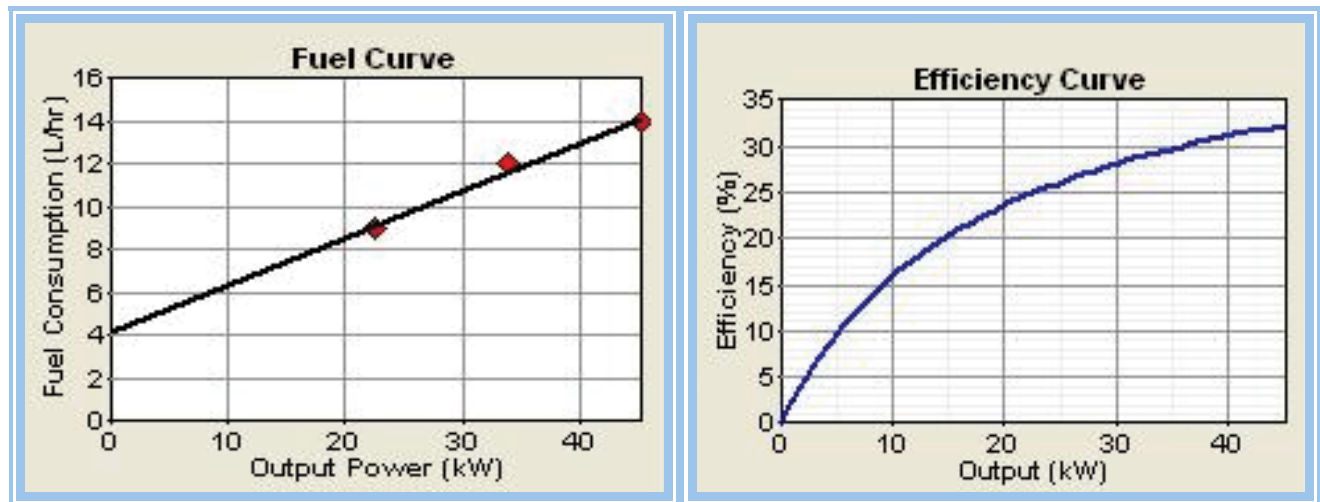

Fig. 2. Typical fuel consumption characteristics of diesel generator

In some remote locations, a dual diesel generator system is employed. When the load is light, the smaller generator is used; as the load increased, the manual switch is transferred to the larger generator. This approach results in some fuel savings, however managing this dual system is time consuming and impractical. 
Another solution proposed and implemented in many parts of the world involves a battery/diesel/inverter hybrid system as shown in Figure 3. This hybrid system configuration allows all energy sources to supply the load separately at low or medium load demand, as well as supplying peak loads from combined sources by synchronising the inverter with the constant speed driven alternator output waveform. The bi-directional inverter can charge the battery bank (rectifier operation) when excess energy is available from the diesel generator, as well as acting as a DC-AC converter (inverter operation) when the diesel generator is switched off. The inverter may provide 'peak shaving' as part of a control strategy when the load demand exceeds the supply capacity of the diesel generator.

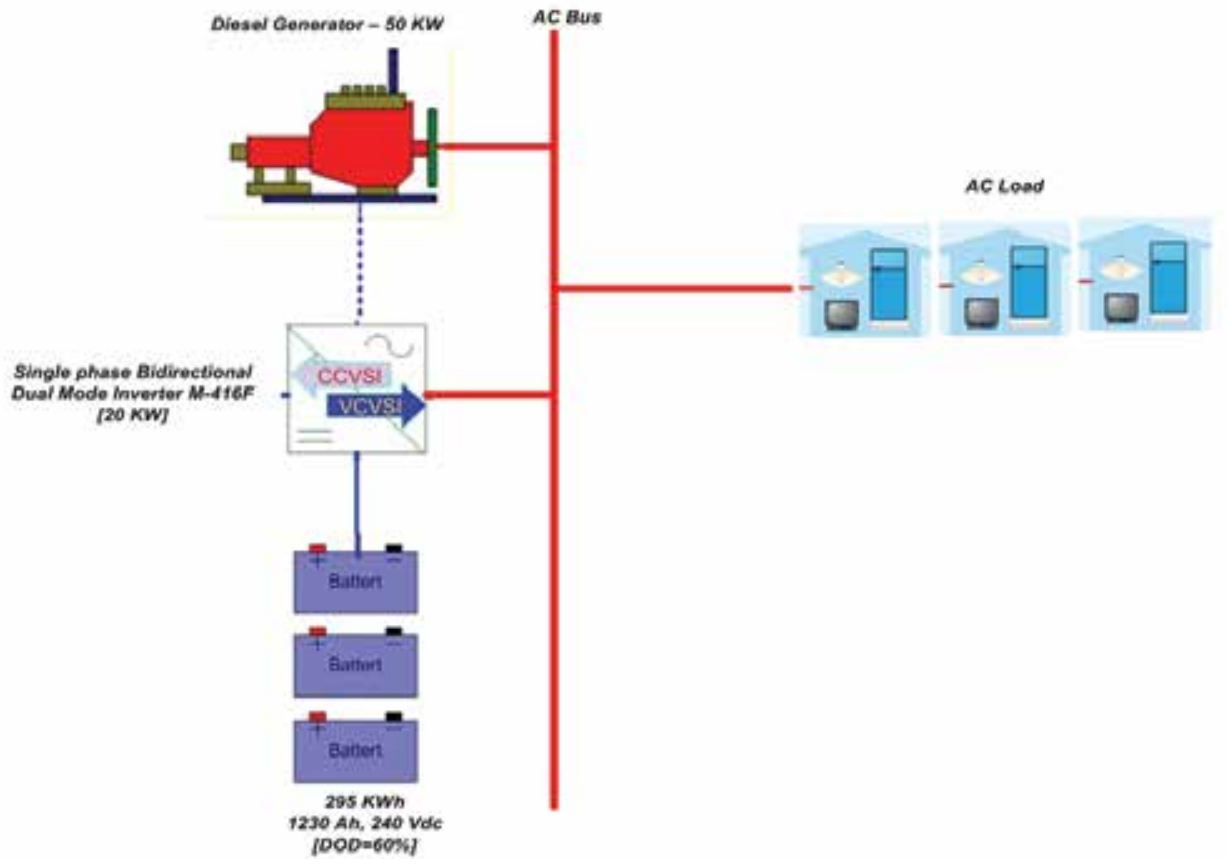

Fig. 3. Battery/Inverter/Diesel Generator hybrid system

The author was involved in the design and implementation of hybrid energy systems in many parts of the world. Two such case study examples are summarised in the following sections.

\section{Case studies of Micro-Grid Systems}

\subsection{Case Study 1: Wind/PV/Diesel Micro Grid System implemented in remote islands in the Republic of Maldives}

The Republic of Maldives is an island nation consisting of 1,192 islands with a land area of about $300 \mathrm{~km}^{2}$, formed on a chain of 26 coral reef atolls in the Indian Ocean. The exact location of the country is to the west of Sri Lanka and south-west of India between latitudes $7^{\circ} 06^{\prime} 35^{\prime \prime}$ North to $00^{\circ} 42^{\prime} 24^{\prime \prime}$ South and longitudes $72^{\circ} 33^{\prime} 19^{\prime \prime}$ East to $73^{\circ} 46^{\prime} 13^{\prime \prime}$ East. The size of the archipelago is $753.6 \mathrm{~km}$ length and $118.2 \mathrm{~km}$ width of total area 999,702 km2 including territorial sea. There are only 199 inhabited islands. Of the inhabited islands, 78 have populations less than 1,000 and 118 have populations between 1,000 and 4,000. Only four islands have populations in excess of 4,000 . Around 80 percent of the total landmass of 
the Maldives is less than 1 meter above sea level. Out of the 199 inhabited islands, just 24 islands including Male' have 24-hour, reliable and continuous power supply which is provided by the Government owned, State Electric Company (STELCO). On 26 December 2004 the Maldives experienced the worst natural disaster in the nation's history, when the disaster in the form of tsunami washed over the entire country claiming 82 lives and leaving 26 people missing and 15,000 homeless and displaced. The recovery and reconstruction work with the kind assistance of various donor agencies is being carried out by the Government of Maldives. After the tsunami, the state of electricity supply has changed because many power houses and generators were among the destroyed infrastructure. Some islands with 24-hour supply before tsunami are now supplying only for 12 hours from 6.00PM to 6.00AM.

The electricity in the Maldives is exclusively produced by diesel generators run on every inhabited island. With the rising price of fuel, the production of electricity has become prohibitively expensive; making the renewable energy sources an appropriate alternative for the authorities to reduce the dependency on fossil energy as they are also concerned about global warming impact on sea level. Trade winds and abundant sun are two energy sources on which Maldivian authorities are focusing for electricity production in the islands. A renewable energy power plan was proposed to implement through a program of deployment of solar and wind systems in stand-alone systems and with mini-grid distribution village power for the islands in the Republic of Maldives. The Plan will cover approximately 120 islands in the Northern and Central atolls, servicing a total of around 100,000 persons. The systems will augment diesel AC distribution grids with wind energy of approximately $80 \%$ energy offset for village power. Off-grid systems will provide electricity to individual homes supplying them with $100 \%$ of their electricity needs and the entire program will roll out over about a 7 year period.

The author led a feasibility study in 2007. to examine the technical, socioeconomic and financial factors concerning island electrification, in accordance with the objectives of the Maldives Renewable Energy Power Plan, by concentrating initially on 3 islands. The scope of work of the feasibility included:

- To assess and map the available renewable energy resources (wind and solar) and evaluate their potential as options for remote island electrification in Maldives.

- Undertake a technical study

- to confirm power and energy requirements

- $\quad$ determine sites for the wind turbines

- Specify equipment requirements.

- determine how the small wind power generators could be integrated to the grids

- determine the foundation aspects of the wind turbines

- determine the voltage and frequency window of the power electronic interface of the wind generators and any impact of voltage and frequency fluctuations on the stability of the system

- $\quad$ how the surplus power could be utilised

- height and size or approximate quantity of turbines needed

- where batteries and the mini grid to be located on the island

- likely capital, and operation and maintenance costs

- life cycle cost of the hybrid system versus diesel power

- technical personnel required to operate and maintain the system 
- Investigate Demand Side Management options (use of energy saving devices, load limiting devices and consumer education so that energy inputs are minimized and cost savings maximized. This can be carried out with sensitivity to the consumer needs whilst preventing energy wastage and excess consumption.

- Design and predict performance of the proposed combined small wind generator, photovoltaic , battery, diesel hybrid system

- Prepare detailed specifications including remote monitoring and communication

- To conduct feasibility studies in three selected islands considering the technical, economic and financial, social and environmental impacts of solar/wind based hybrid electrification systems in order to undertake successful implementation of a sustainable energy rollout plan covering a number of islands.

The three islands selected for the preliminary study were:

\begin{tabular}{|c|c|c|c|}
\hline Location & Atoll & Latitude & Longitude \\
\hline Uligam Island & HA Uligam & $7^{\prime} 05^{\prime \prime} \mathrm{N}$ & $72^{\prime} 55^{\prime \prime} \mathrm{W}$ \\
\hline Raimandhoo Island & S. Meemu Atoll & $3^{\prime} 05^{\prime \prime} \mathrm{N}$ & $73^{\prime} 40^{\prime \prime} \mathrm{W}$ \\
\hline Kondey Island & South Huvadhoo Atoll & $0^{\prime} 40^{\prime \prime} \mathrm{N}$ & $73^{\prime} 50^{\prime} \mathrm{W}$ \\
\hline
\end{tabular}

A standard approach was made at each site for the collection of the necessary data to assess what was possible at each of the sites. The methodology use is listed below.

- Meet with the island chief and community leaders, discuss island issues, development plans and other aspects relevant to the energy consumption of the island

- Undertake power quality measurement at the power house to measure voltage, frequency and harmonics over a period of time

- Measure the instantaneous load to identify any problematic loads with high starting currents or large demands

- Survey buildings for the potential of supporting PV arrays on the roof. This includes checking orientation, slope and potential shading issues.

- Survey the island for locations of the wind turbines taking into account the most prevalent wind direction onto the island, the distance from the power house, and the height of vegetation around the turbines.

- Undertake renewable energy system planning using the software tool HOMER and to analyse the various options paying particular attention to the cost per unit of electricity consumed, fuel saved and initial capital requirements.

Based on the above study, it was decided to implement a micro-grid hybrid distributed generation system combining several small scale wind generators, solar photovoltaic panels, battery storage, advanced power electronics equipment and existing diesel generators. The system architecture employed in the hybrid micro-grid system is "AC Coupled" whereby the renewable energy sources and the conventional diesel generators all feed into the AC side of the network as shown in Figure 4.

Figure 5 shows an aerial view of the northern island known as Uligam. The wind resource information was sourced from a report prepared by the National Renewable Energy Laboratories (NREL) in the USA which gives various maps of the Maldives showing the wind resource potential [4]. Figure 6 shows the wind resource map of the three locations selected for the pilot installation in the country. The wind map shows the highest resource in the north-central part of the Maldives just north of the capital of Male, from $4.5^{\circ}$ north 
latitude to $6.5^{\circ}$ north latitude. The level of resource in these areas is considered good for small-scale village applications. The wind resource gradually decreases from Male southwards with the lowest resource found on the atolls south of $1^{\circ}$ north latitude. Figure $7 \mathrm{a}$ gives an overview of the wind resource at the three locations. The solar resource for this study is obtained from NREL and NASA data and is shown in Figure 7b.

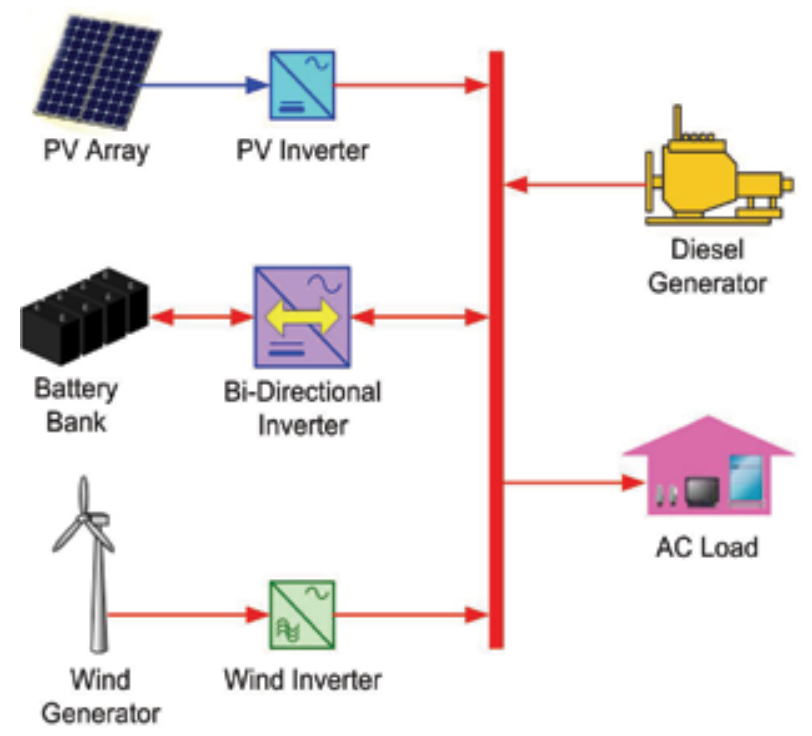

Fig. 4. Hybrid system schematic diagram showing renewable energy sources coupled to the ac side

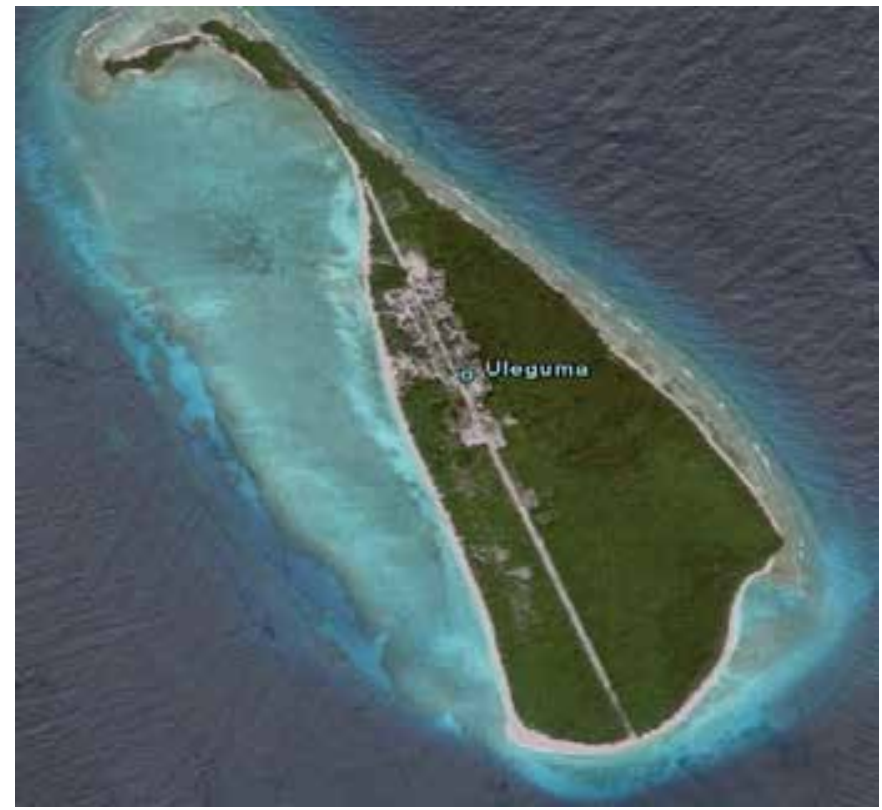

Fig. 5. Aerial view of the Uligam island 


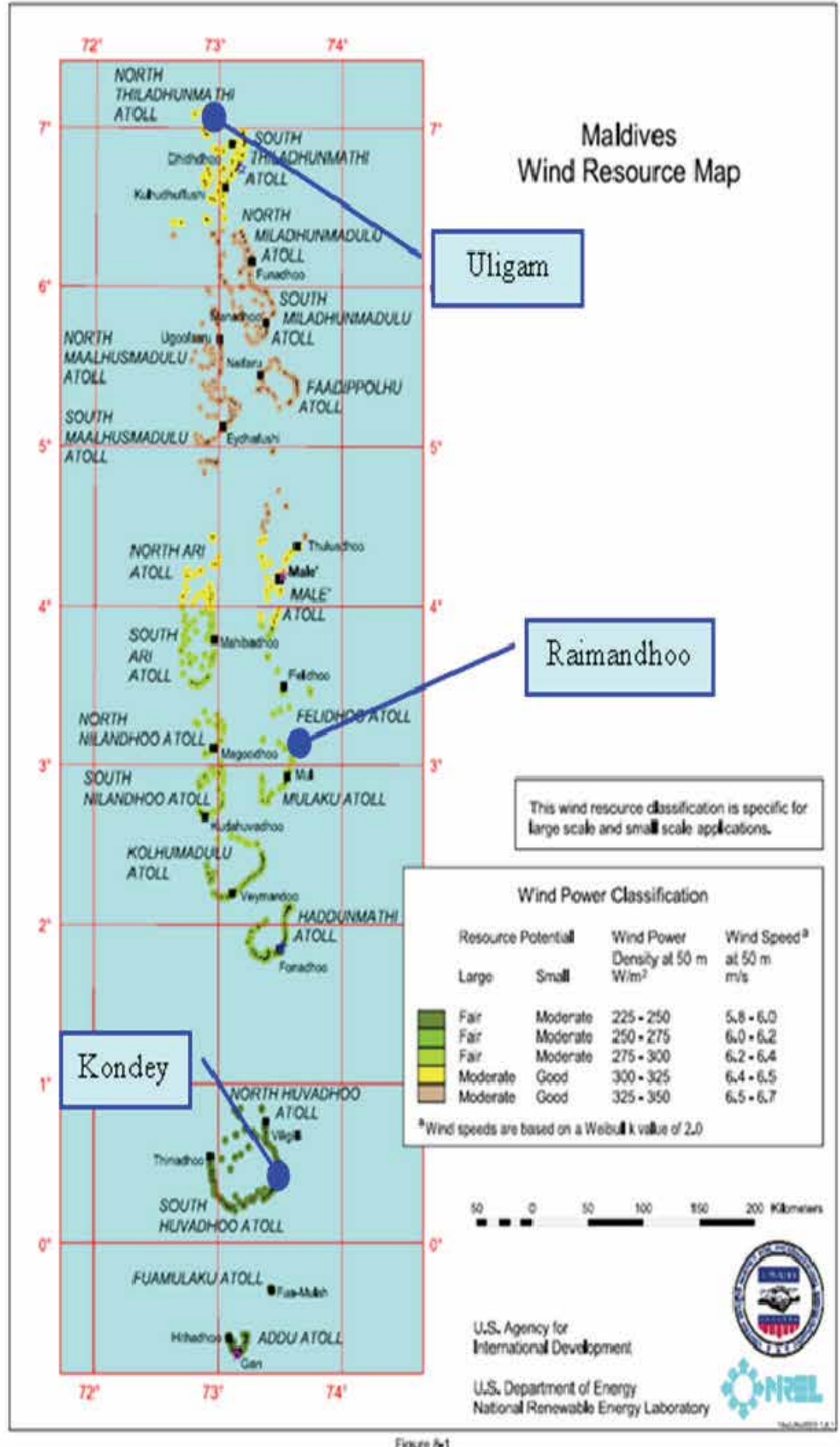

Fig. 6. Wind power resource and the selected islands 


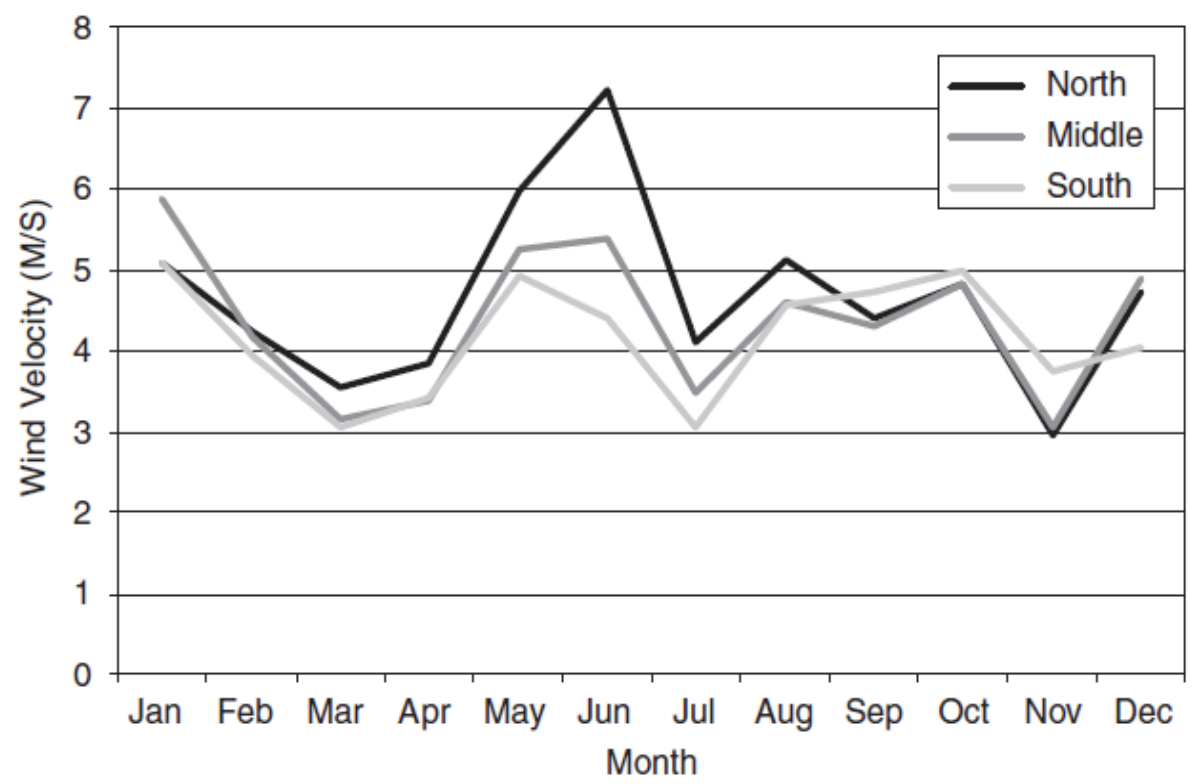

Fig. 7.a Wind resource map for selected locations for pilot installations in Maldives

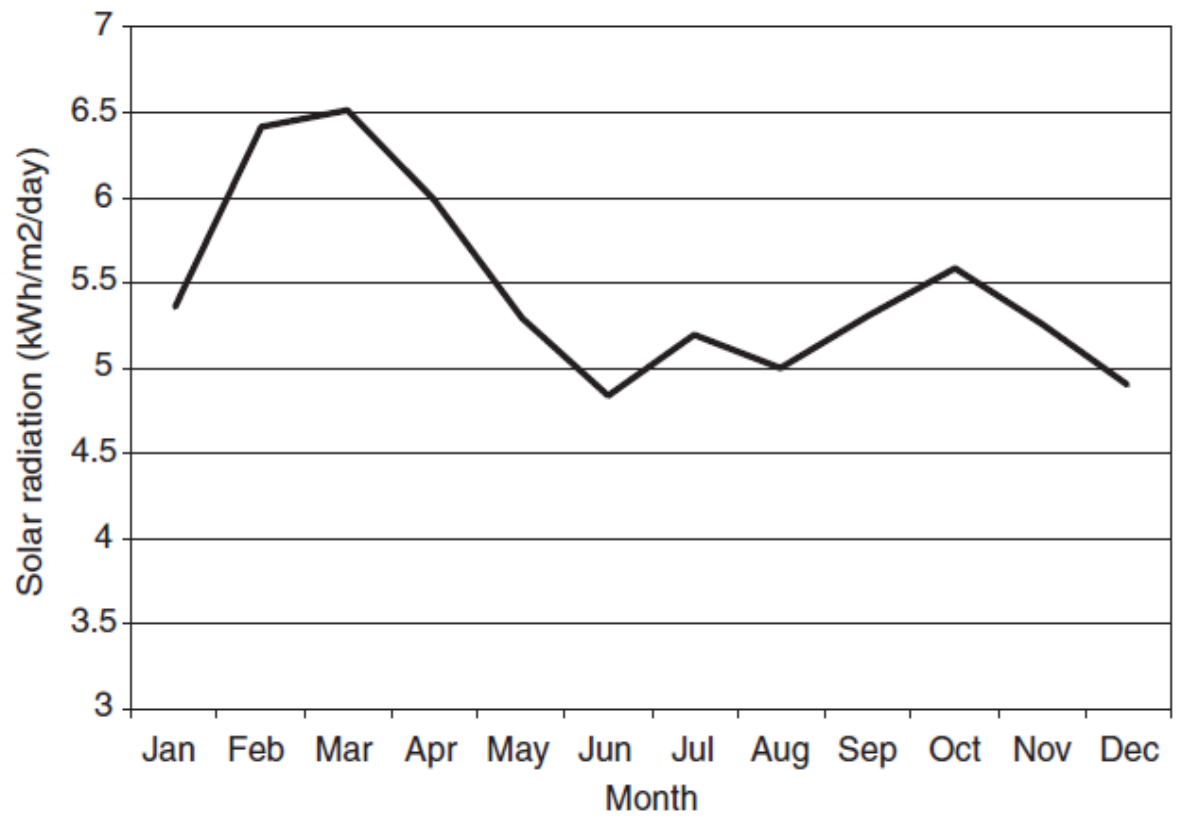

Fig. 7.b Solar radiation levels for locations of pilot installations in Maldives

The existing electricity power generation using diesel generators in every island was reviewed. The intention was to establish how much if any upgrade to the local island power station or its distribution system would be required for the implementation of a renewable energy system on the island. Fig. 8 shows photographs of the diesel power stations in two of the islands. 


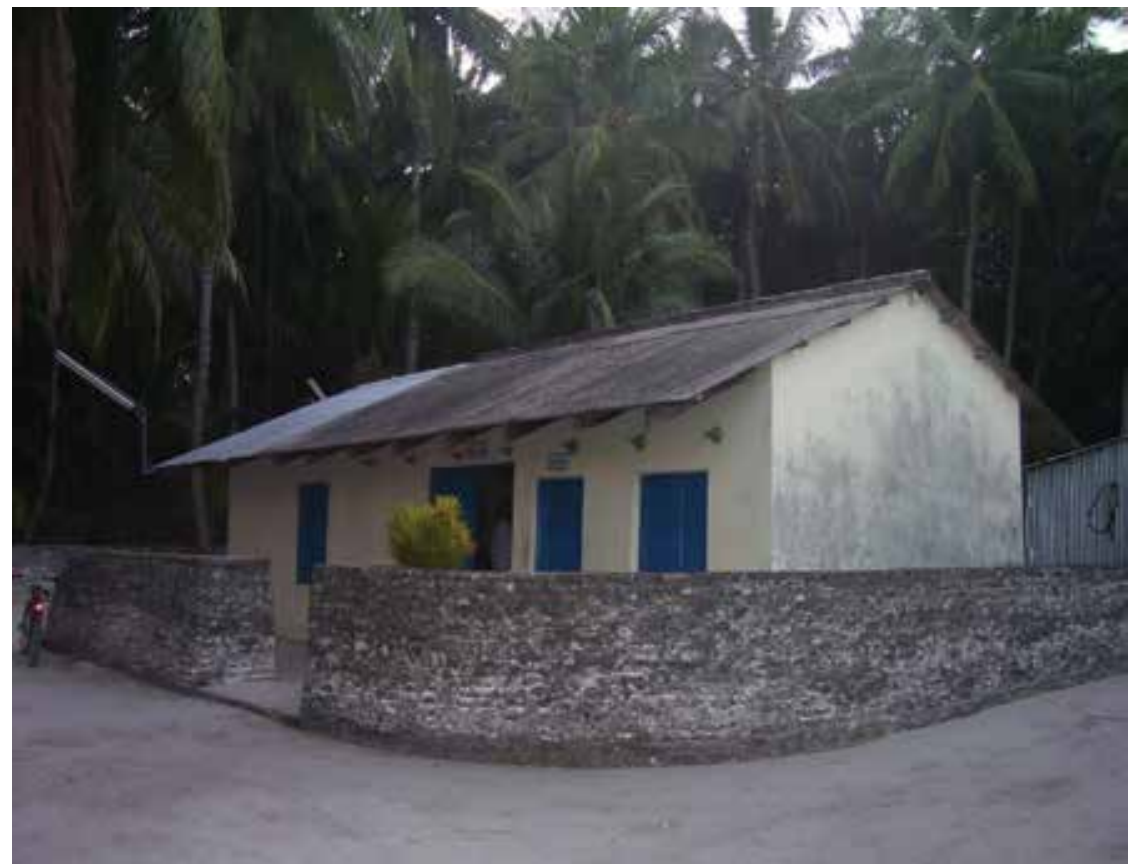

Fig. 8.a - Uligam power house

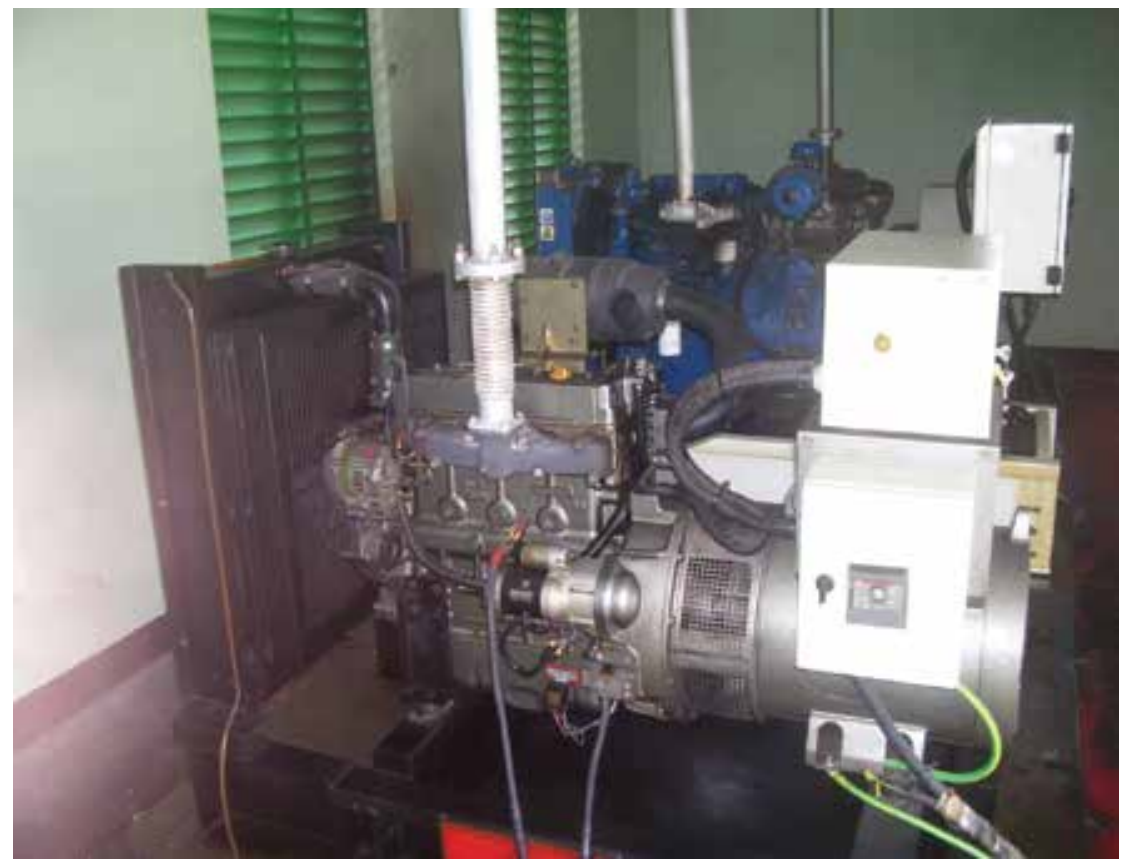

Fig. 8.b - Raimandhoo power house

Detailed power quality monitoring was carried out using Fluke Power Quality Analyser and storing the data in a computer. The system voltage and frequency variation were 
determined as well as any peak demand requirement that may highlight problematic loads. The results show that the power system is typical of small diesel generated electricity supplies with voltage variations at the main bus of $+10 \%$ to $-12 \%$ and frequency variations of as much as $\pm 3 \mathrm{~Hz}$. Figure 9a shows the voltage and line current of the diesel generator measured by the power quality meter. Figure $9 \mathrm{~b}$ and $\mathrm{c}$ shows the variation of frequency and voltage .

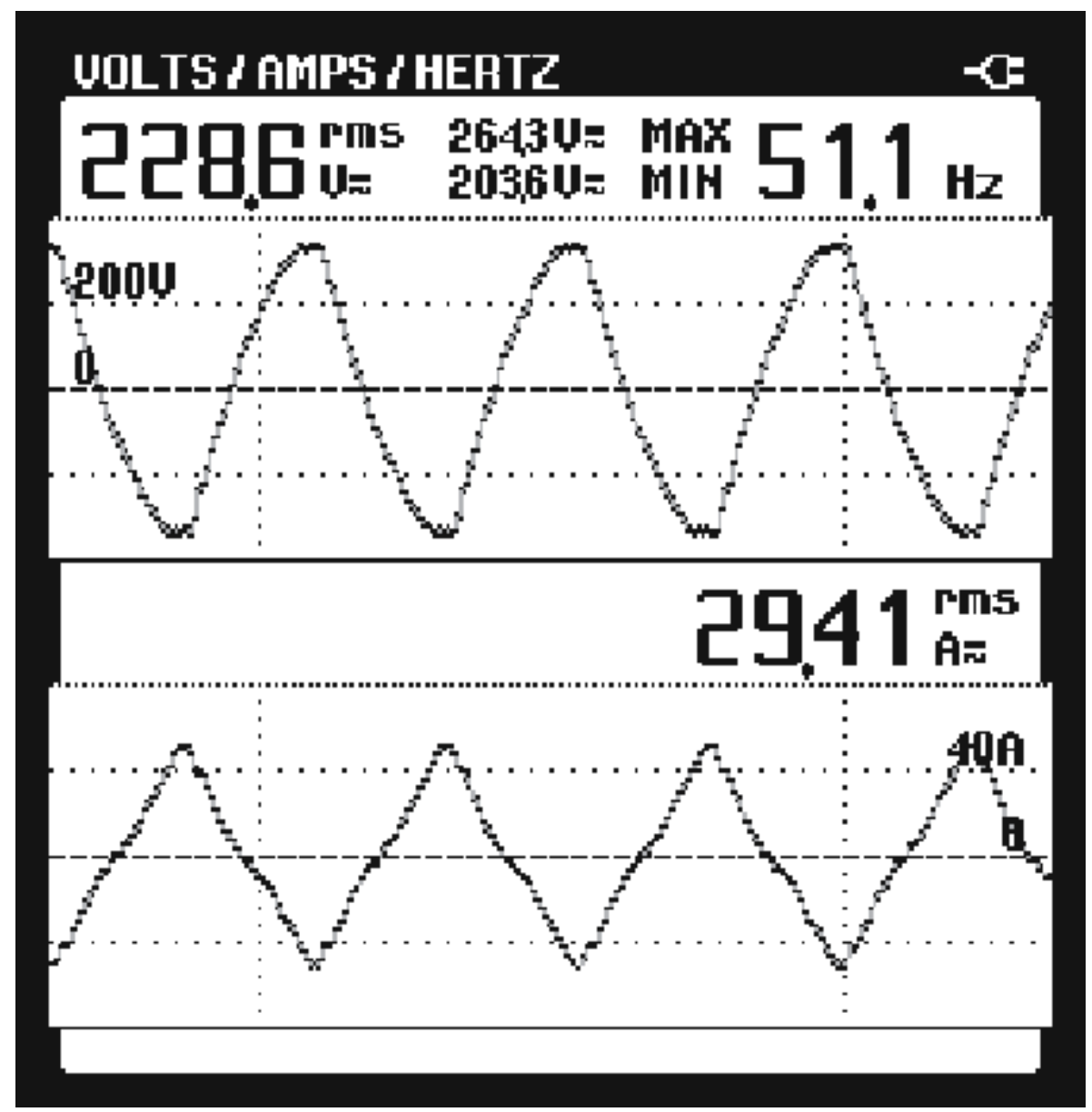

Fig. 9.a - Typical voltage and current waveforms

Most of the islands in the Maldives have basic infrastructure such as a school, health clinic, island administration office and mobile phone communication tower. The three selected islands have 24 hour power supply using diesel generators. The electrical loads in the islands were classified as: residential, govt .buildings (such as the island office, school, health centre etc), street lighting and commercial (such as mobile telephone towers etc).

Electrical load profiles were developed for each island using assembled data and other information (electricity metering bills for different consumers). For the pilot phase three load profiles baseline (existing), conservative growth and higher growth scenarios were developed and used as inputs for the Homer simulation software. The "Baseline" scenario was estimated from the existing use of electricity, and a long term demand function model, 
which takes into account socio-economic circumstances such as population growth, personal income growth, electricity price and intensity of use. The growth scenario assumes increased consumption due to increased use of appliances and takes into account economic factors such as population growth, personal income, intensity of use, and tariff. Possibility of load growth due to the construction additional infrastructure such as health centre with air conditioning load, and income generation activities were also evaluated. The load demand profiles of most of the outer islands (excluding the capital, Male) have a similar profile with peak load occurring in the night, as shown in Figure 8 [8].

Uligam Frequency

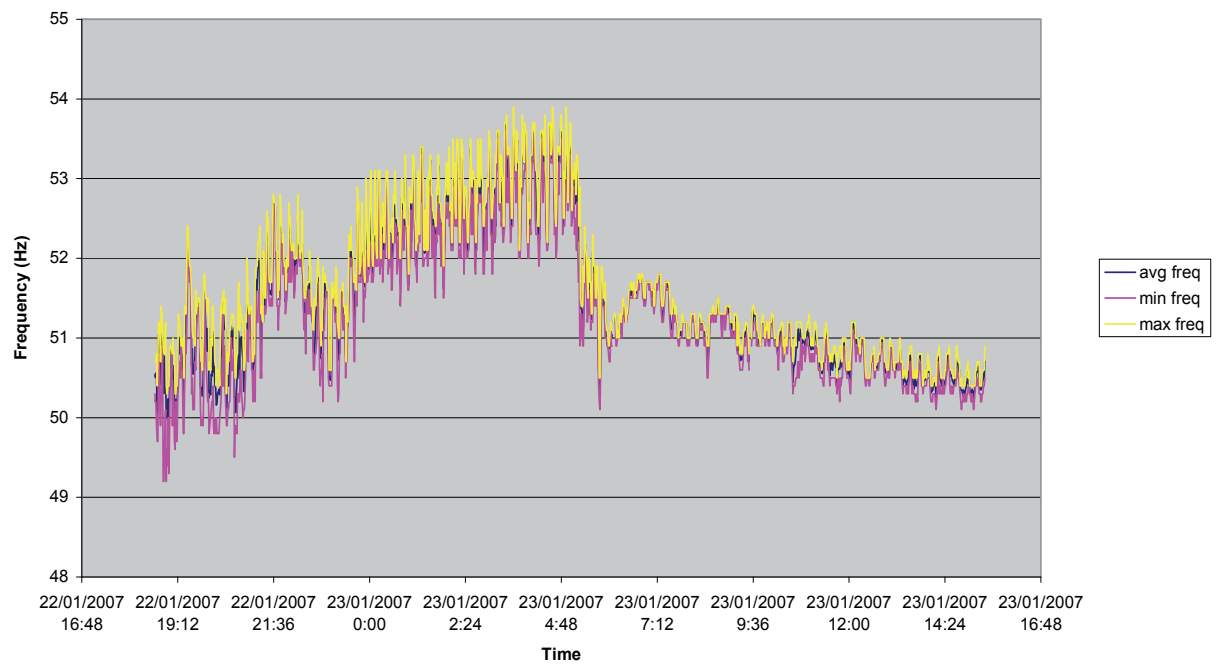

Fig. 9.b - Typical frequency data

Uligam Voltage Red Phase

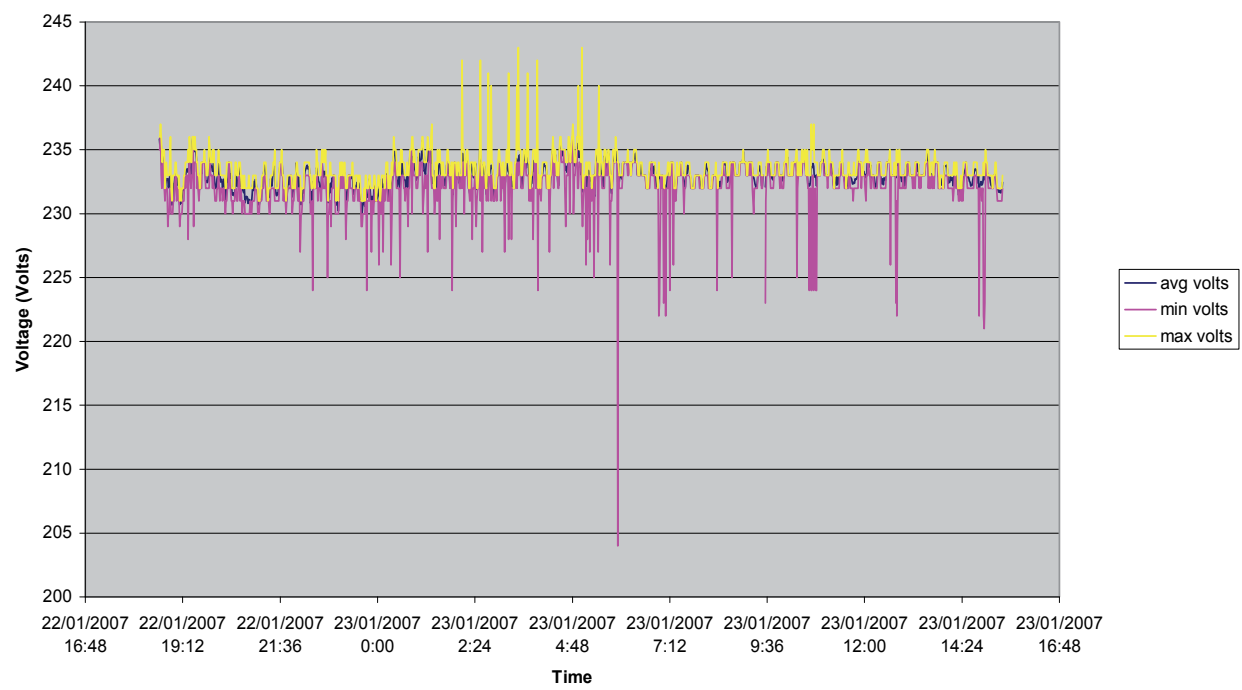

Fig. 9.c- Typical voltage data 


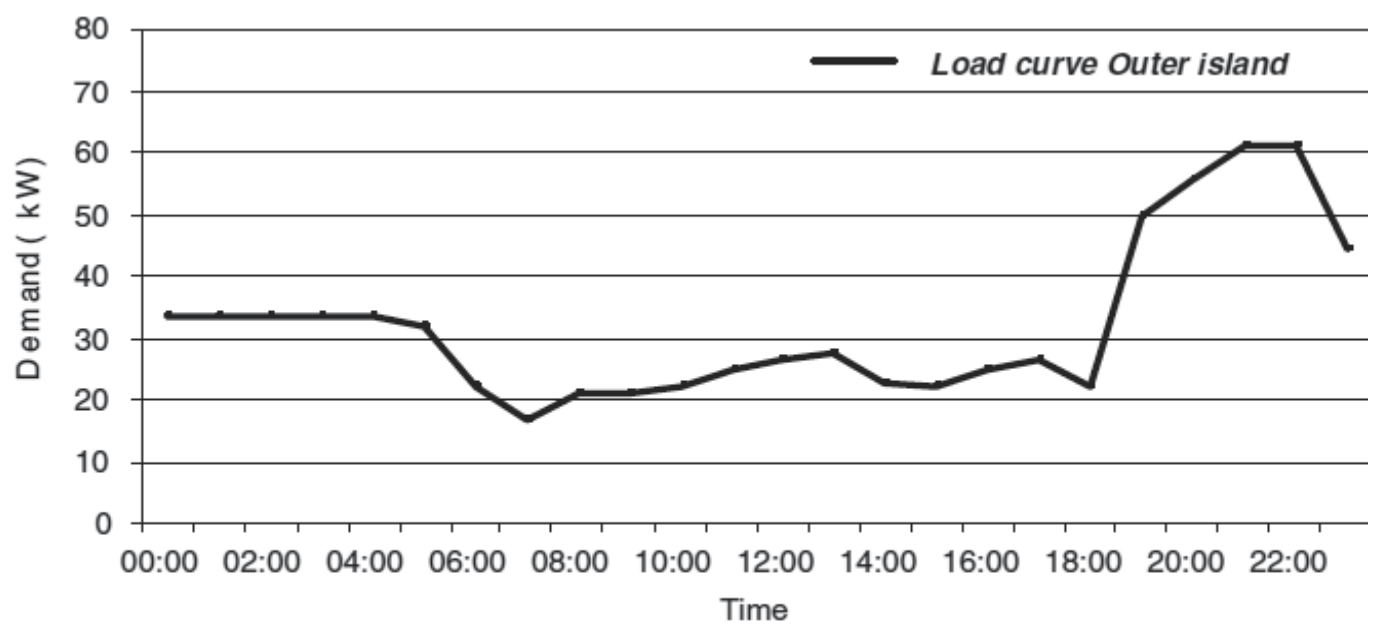

Inhabitants: 1290

Peak load (AC): $90 \mathrm{~kW}$

Households: 240

Total demand: $765 \mathrm{kWh} /$ day

Fig. 10. Typical daily load profile

In this pilot study, the consultants investigated the possibility of siting the optimum number of the Skystream 3.7 manufactured by Southwest wind turbines, USA. Skystream is a new generation all-inclusive wind generator (with controls and inverter built in) designed to provide quiet, clean electricity in very low winds. The rated capacity is $1.8 \mathrm{~kW}$ and the estimated energy production is $400 \mathrm{KWh}$ per month at $5.4 \mathrm{~m} / \mathrm{sec}$. Having surveyed the various islands, the consultants feel that this turbine is ideally suited for the conditions in Maldives due to its ease of erection, ease of integration and suitable low wind regime power curve.

Methodology involved in selecting the number of wind turbines include:

- $\quad$ The prevailing wind resource ( wind speed and direction)

- Land area available

- Obstructions such as trees

- Distance from the power station

Figure 11 - Typical layout of the proposed systems, shows the proposed structure of the power system.

A wide range of possible combinations of diesel generators, number of skystream wind turbines, photovoltaics (PV), batteries and inverters have been studied for the existing load profile, conservative growth and high growth scenarios. The computer program "HOMER" ranks the combinations according to long term cost per $\mathrm{kWh}$. At these same points the key input parameter of diesel fuel price was varied around a base value, to give a sensitivity analysis. Fig. 12 shows a screen shot of the Homer output.Using the highest ranked plant combinations for the probable load forecast, a low cost, logical plant augmentation program was developed for each island, for the 20 year study period. This program included plant replacement (replacement of the batteries and diesel generators) and the capacity upgrades necessary to best meet the load. 


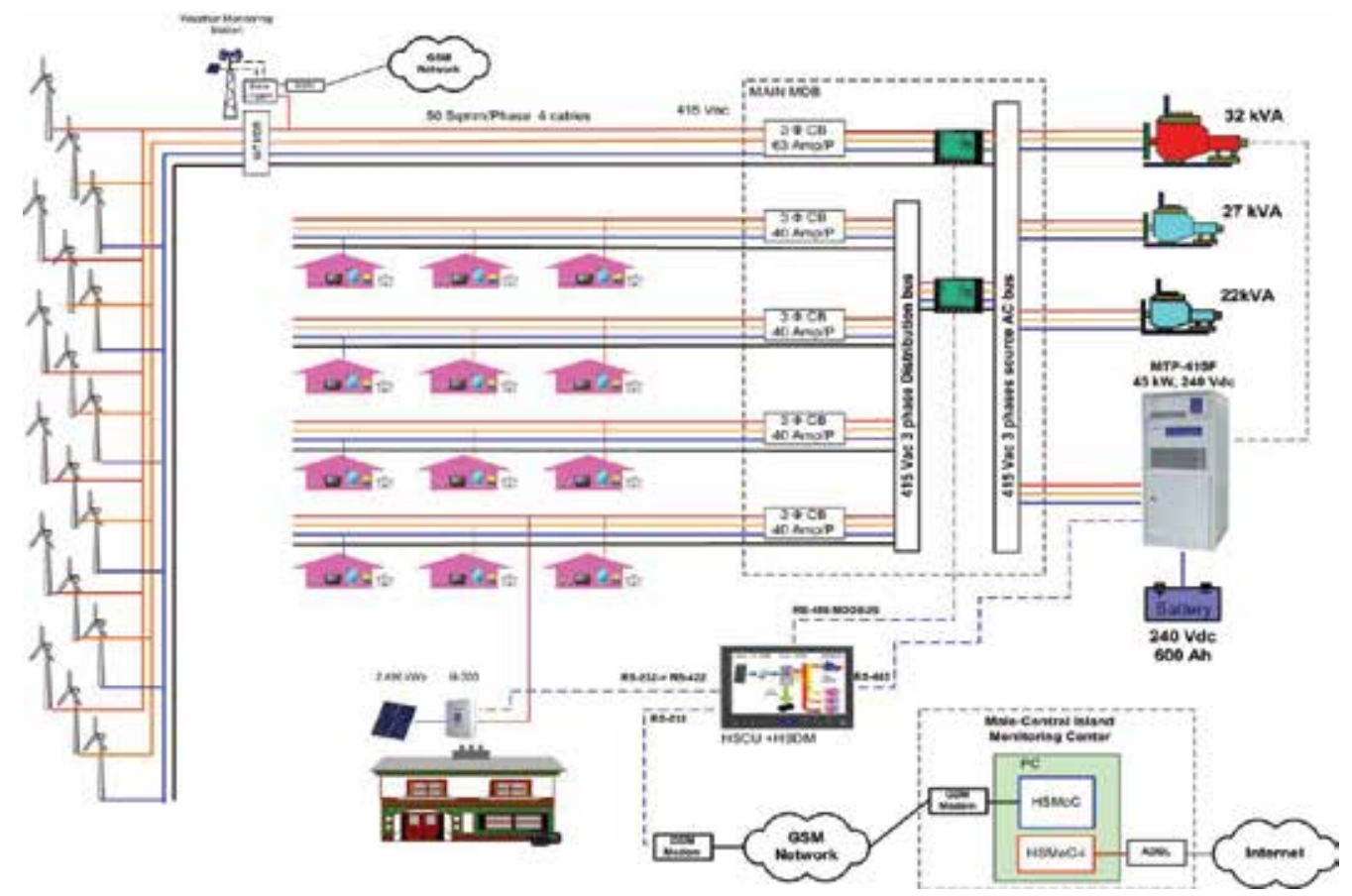

Fig. 11. Typical layout of the hybrid system

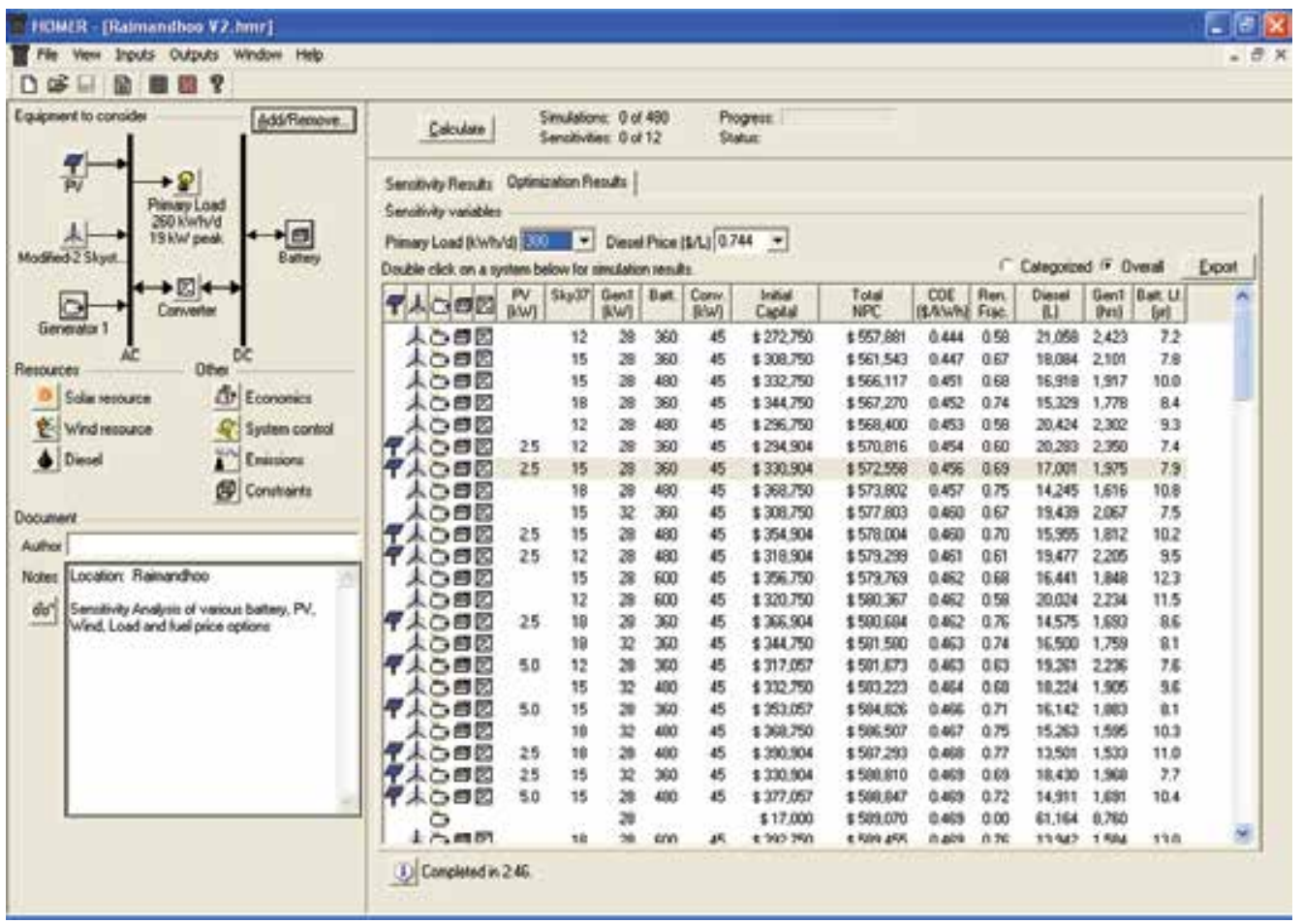

Fig. 12. Homer program output 
The economic analysis was done using HOMER. HOMER takes inputs regarding system component sizes and costs, fuel prices, load data and produces cost and fuel estimates for the various scenarios. Table 3 summarise the input data for each system.

\begin{tabular}{|l|c|c|c|}
\hline Load Profile Data File & Uligam & Raimandhoo. & Kondey \\
\hline Average Energy Consumption 2006 (kWh/day) & 215 & 200 & 127 \\
\hline December 2006 consumption (kWh/day) & 250 & 214 & 141 \\
\hline Medium Growth (kWh/day) & 300 & 260 & 170 \\
\hline Fast Growth (kWh/day) & 450 & 400 & 260 \\
\hline
\end{tabular}

Table 3. Load data scenarios

\begin{tabular}{|l|c|c|c|}
\hline & Uligam & Raimandhoo. & Kondey \\
\hline Cost of Diesel Fuel per litre & $\$ 1.11$ & $\$ 1.22$ & $\$ 1.11$ \\
\hline
\end{tabular}

Table 4. Diesel fuel price scenarios

The output from Homer includes financial and technical information. The key parameters reviewed in the feasibility of a system were:

- Cost per unit of electricity - This was examined to see at what point there was a significant change in price for a change of system. In many cases the PV/Wind/Diesel combination was more expensive than just Wind/Diesel, but the difference was very small so as part of the pilot study it has been included for completeness.

- Fuel Saved - In the cases mentioned above, for a small increase in price, there was significant reduction in fuel used. This was considered a valuable result beyond the small increase in cost.

- Capital cost - the project does have financial constraints and these were considered in the final selection

- $\quad$ Battery Life - The target life was greater than 7 years.

\begin{tabular}{|c|c|c|c|c|c|}
\hline & Diesel Generator & Wind Turbines & Solar & Battery & Inverter \\
\hline & & $1.8 \mathrm{~kW}$ units & $\mathrm{kW}$ & $\begin{array}{c}\mathrm{kWh} \\
(400 \mathrm{Ah})\end{array}$ & $\mathrm{kVA}$ \\
\hline Uligam & $\begin{array}{c}32 \mathrm{kVA}+32 \mathrm{kVA}+60 \mathrm{kVA} \\
\text { proposed } \\
\end{array}$ & 24 & 2.5 & 96 & 45 \\
\hline Raimandhoo & $22 \mathrm{kVA}+27 \mathrm{kVA}$ & 18 & 2.5 & 192 & 45 \\
\hline Kondey & $17 \mathrm{kVA}+32 \mathrm{kVA}$ & 6 & 5 & 96 & 25 \\
\hline
\end{tabular}

Table 5. Optimised equipment selection

Hybrid systems consisting of a cluster of small wind turbines, photovoltaic modules, a bidirectional grid forming mini grid inverter (which can also work as a battery charger), battery storage and the existing diesel generators were installed and commissioned in the three islands in July/August 2007. Figure 13 shows a photograph of the micro-wind farm and solar panels installed on the Uligam Island. 


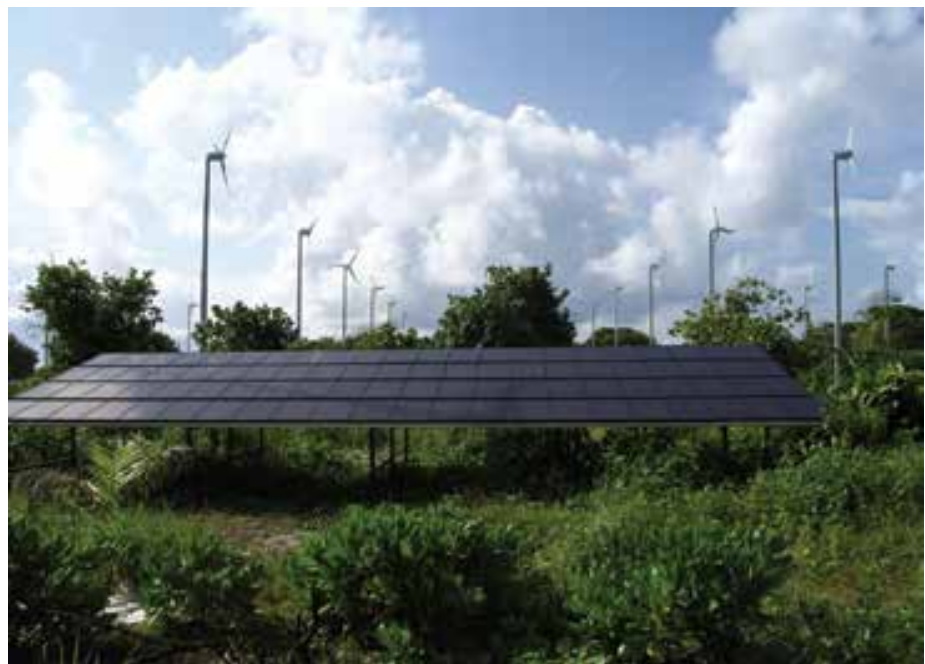

Fig. 13. Micro-wind farm and photovoltaic panels as installed in the Uligam island

Performance data of this system in each island can be accessed through a remote monitoring system. Figure 14 shows real-time captured information of the system on 29th October 2007. It can be seen that the combined of the output of the wind farm on the morning of the day is around $34.2 \mathrm{~kW}$, out of which $15.3 \mathrm{~kW}$ goes into the island load and $19.3 \mathrm{~kW}$ goes into the battery. The grid is provided by the bi-directional inverter when the diesel generator is not running.

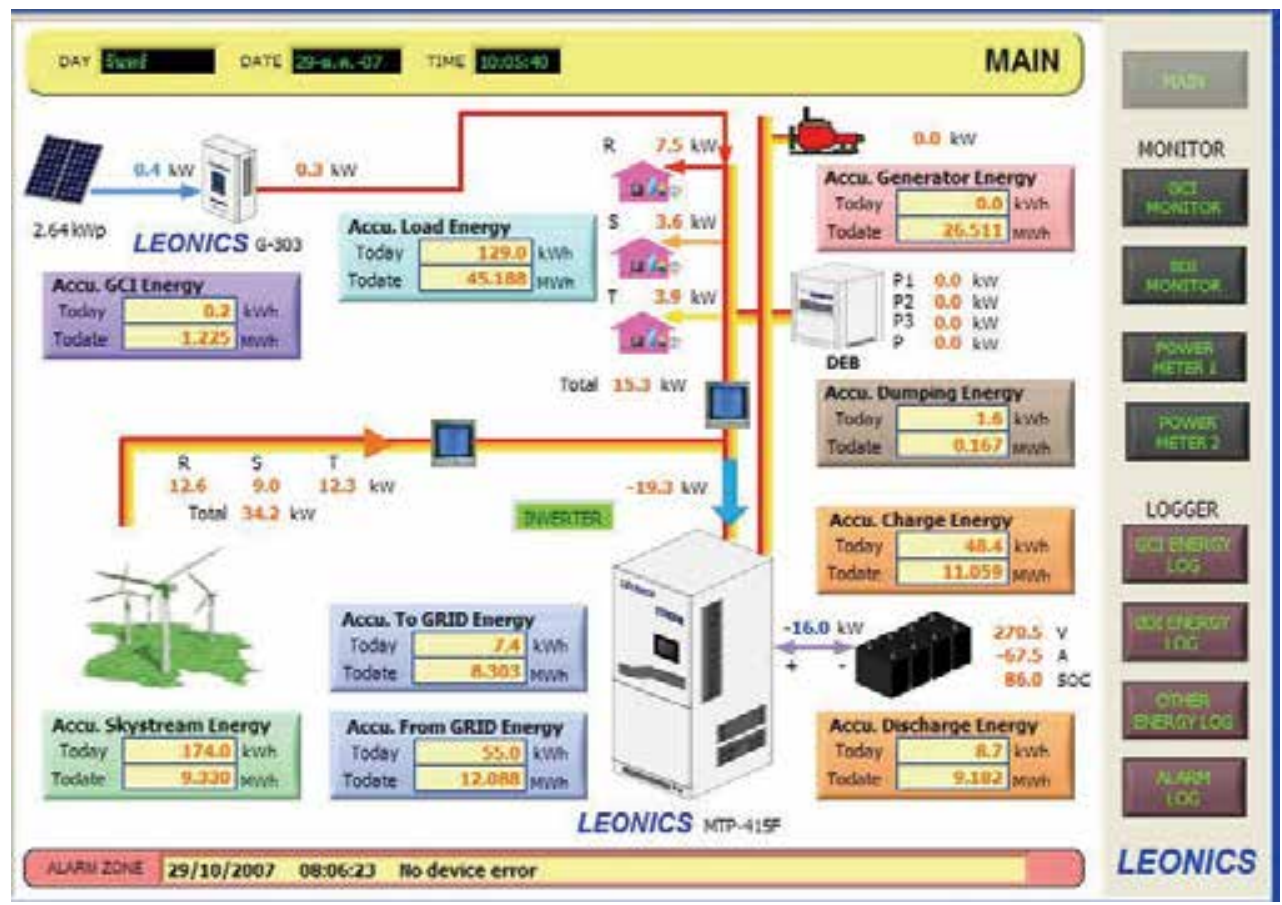

Fig. 14. Real time monitoring of Uligam Island power system. 
Figure 15 shows measurements of the power contribution from solar, wind and diesel generator over a four day period.

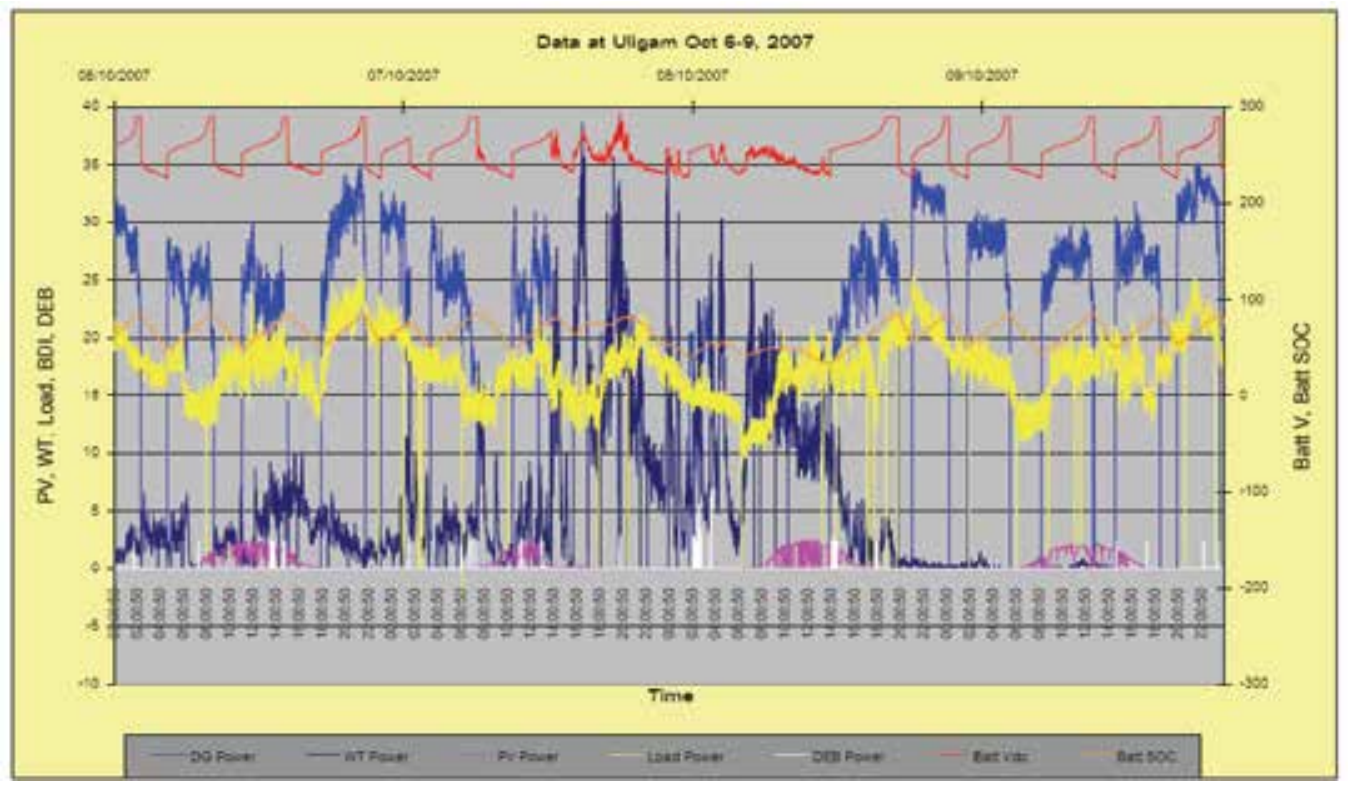

Fig. 15. Recording of the power contribution from solar, wind and diesel generator.

\subsection{Case Study 2: PV/Diesel Micro Grid System implemented in a remote tourist resort in Western Australia}

The Eco Beach Wilderness Retreat is located amongst a pristine, untouched environment about $2000 \mathrm{~km}$ north of Perth, the capital of Western Australia. An aerial view of the resort is shown in Figure 16. Western Australia (WA) is blessed with ample solar radiation and wind resources as shown in Figure 17.

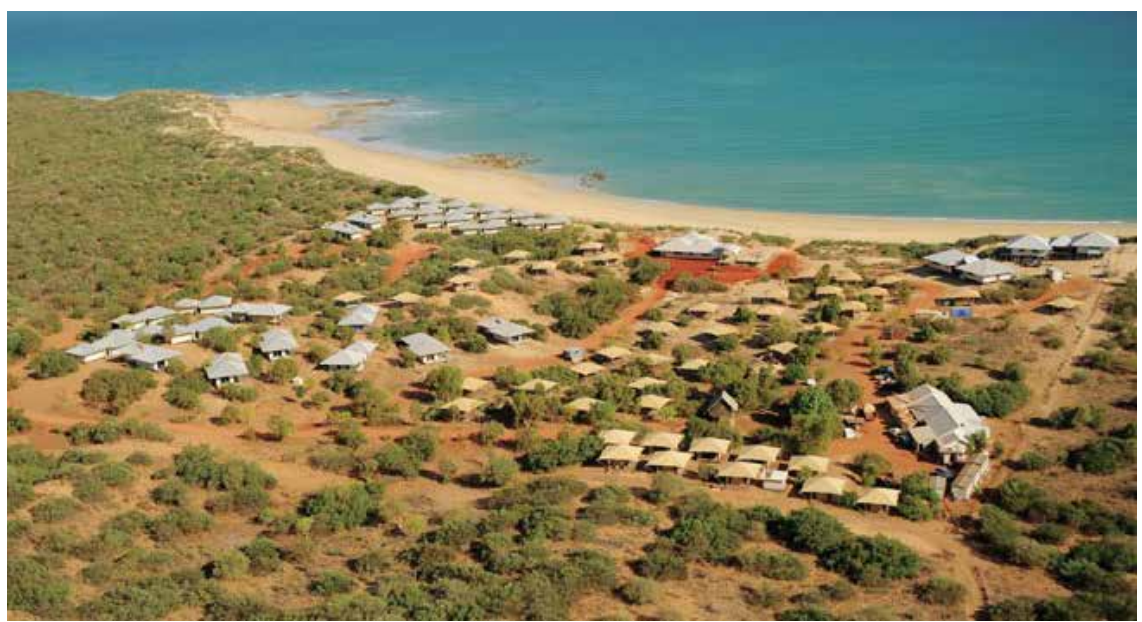

Fig. 16. Aerial view of the Eco Beach Resort 


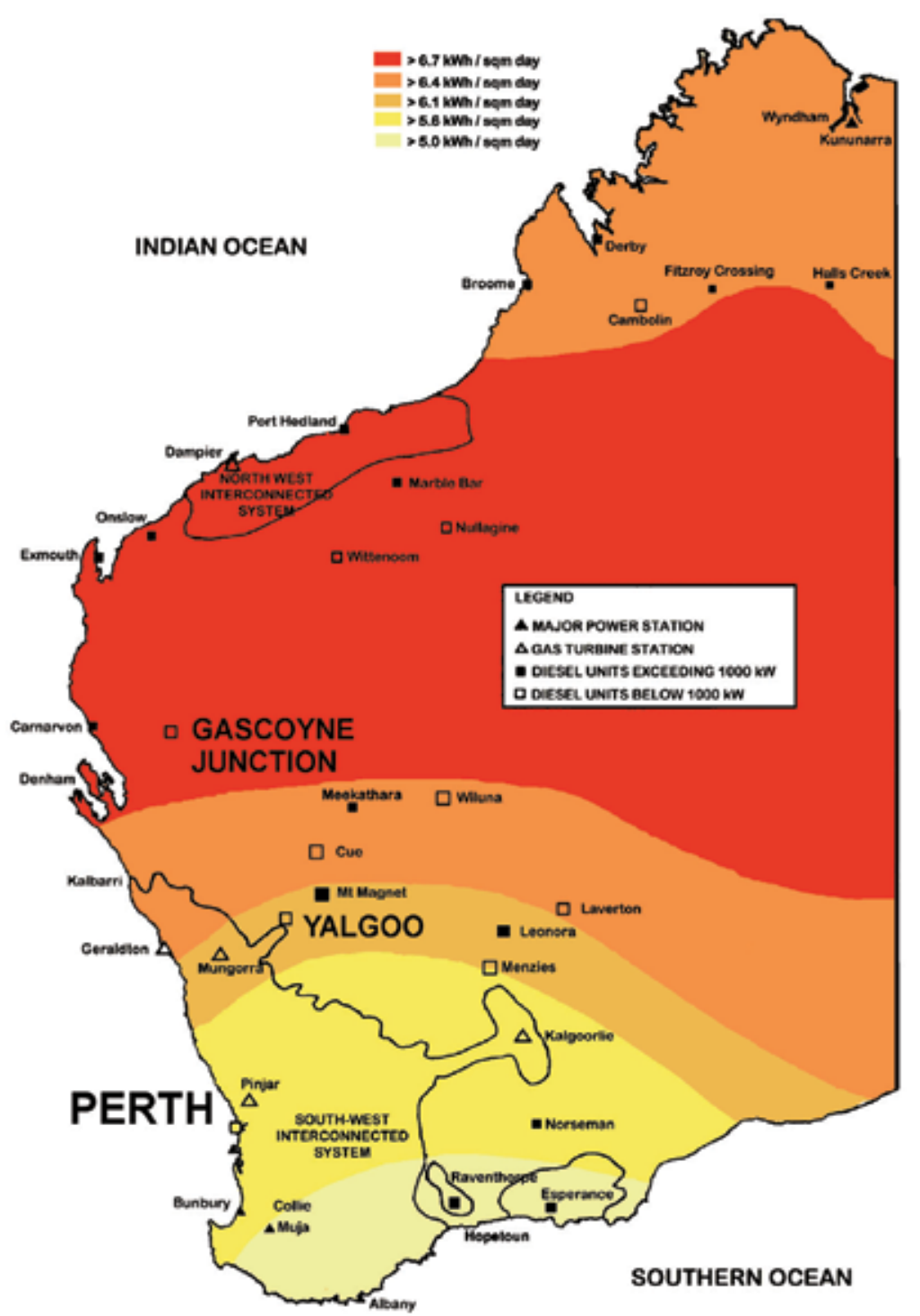

Fig. 17. Annual solar radiation in Western Australia

The author was approached in June 2008 to undertake a feasibility study to implement a renewable energy based hybrid power system for the Eco Beach Wilderness resort in Broome, WA. As the resort was under construction during the project inception stage, the power and energy requirements were unknown. Hence, a detailed energy audit was carried out, and the system loads were predicted. From this analysis, a peak load of $120 \mathrm{~kW}$ and a daily energy consumption of $600 \mathrm{kWh}$ were predicted. The resort occupancy was factored to create seasonal and monthly load profiles.

The entire project including installation, testing and commissioning was carried out within a period six months and the resort was operational by May 2009. The system installed consists of $24 \times 2 \mathrm{~kW}$ PV arrays, a $120 \mathrm{~kW}$ central bi-directional inverter with a 360V, 1500Ahr battery 
bank and $4 \times 50 \mathrm{~kW}$ diesel generators. Each villa had a power monitoring device installed which tracks the renewable energy generated and the actual energy used in the villa. This allows energy conscious guests to audit their usage during occupancy. Each villa has a $2 \mathrm{~kW}$ PV array installed on its north-facing side of the roof, as shown in Figure 18.

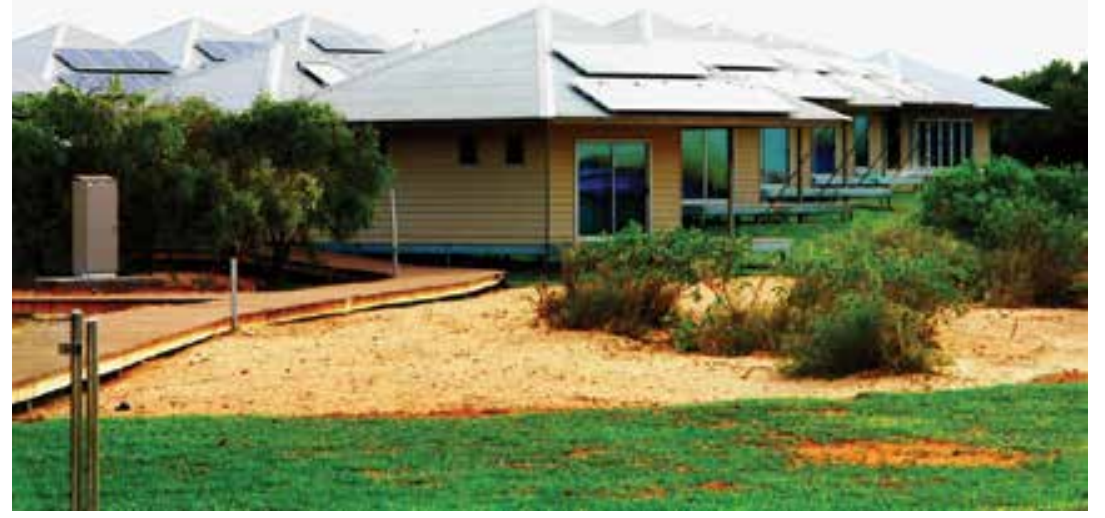

Fig. 18. Eco resort villas with photovoltaic panel installation

Two main considerations were adhered to while designing the system. One was to minimize the use of diesel fuel, as it was an eco resort and the second was the need to switch off the generators at night, so that the 'sounds of nature' could be heard. In addition to the capability to monitor the entire resort, the performance of each villa with solar PV on the roof, can also be individually monitored.

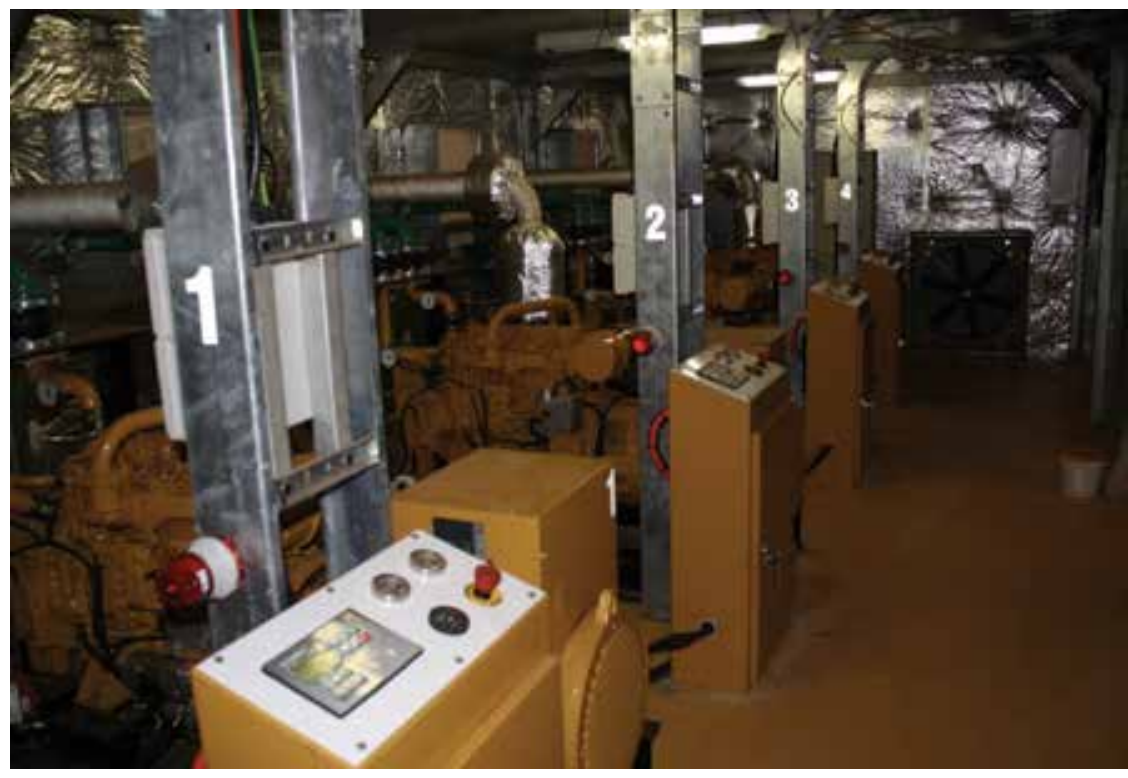

Fig. 19. Diesel Room at Eco Beach Resort 


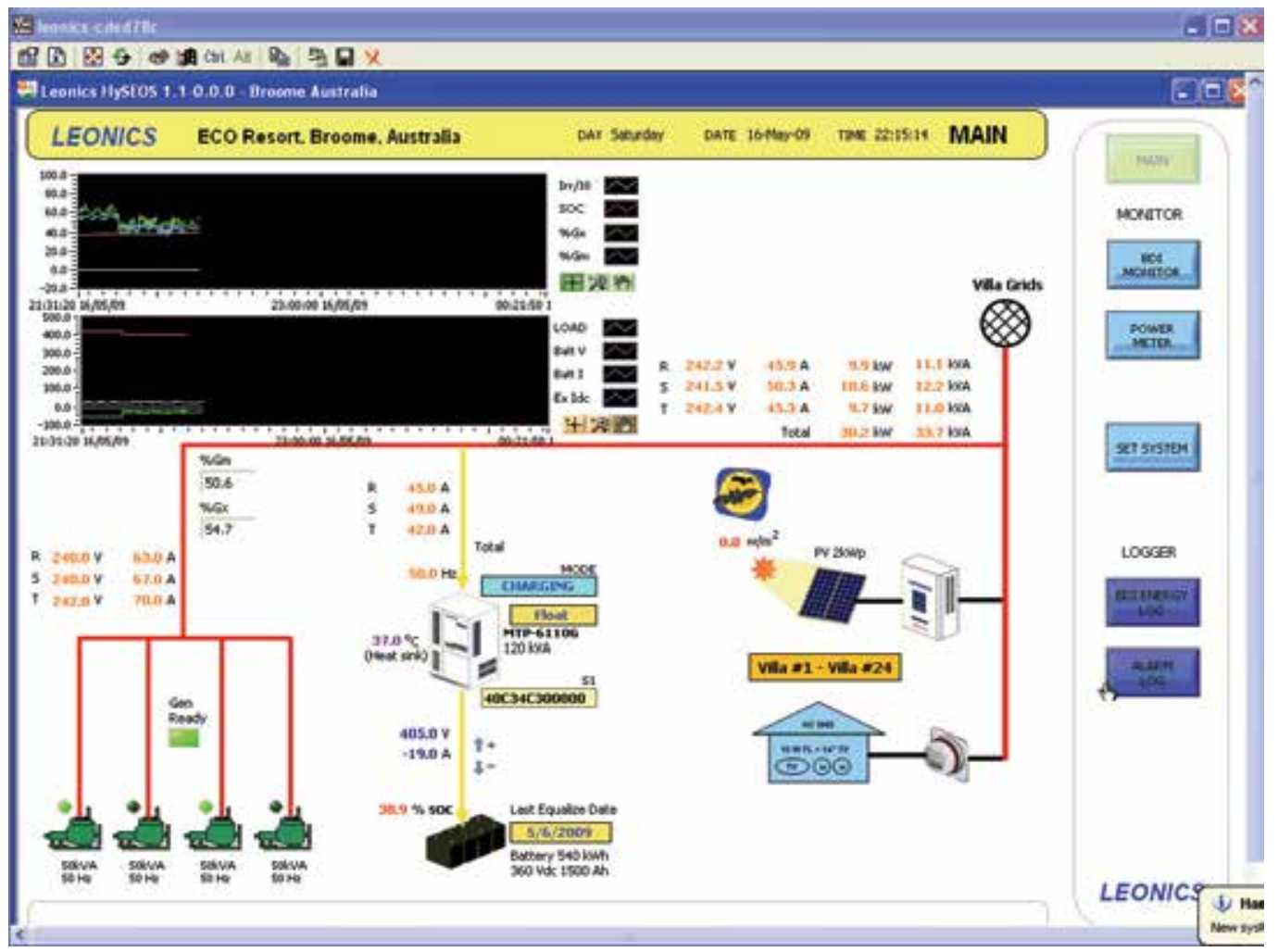

Fig. 20. Remote monitoring display

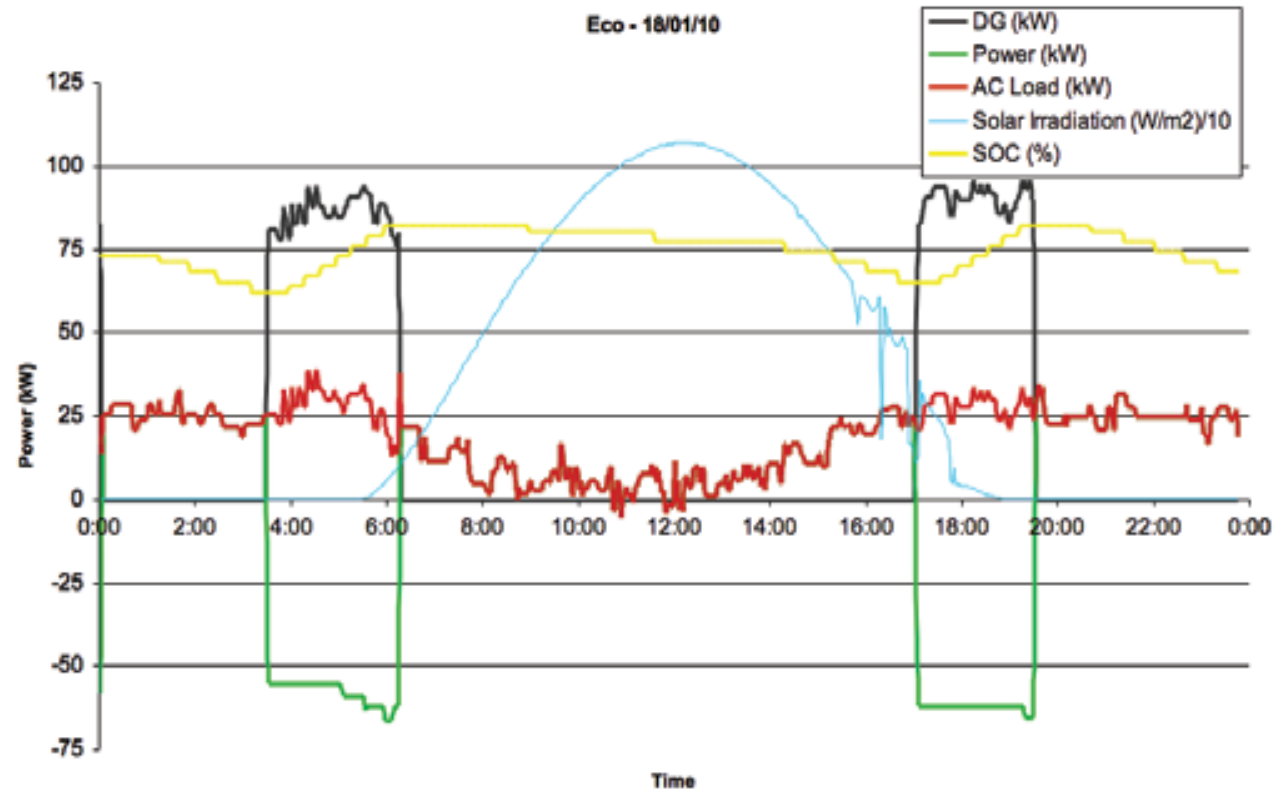

Fig. 21. System operation on a clear sunny day 


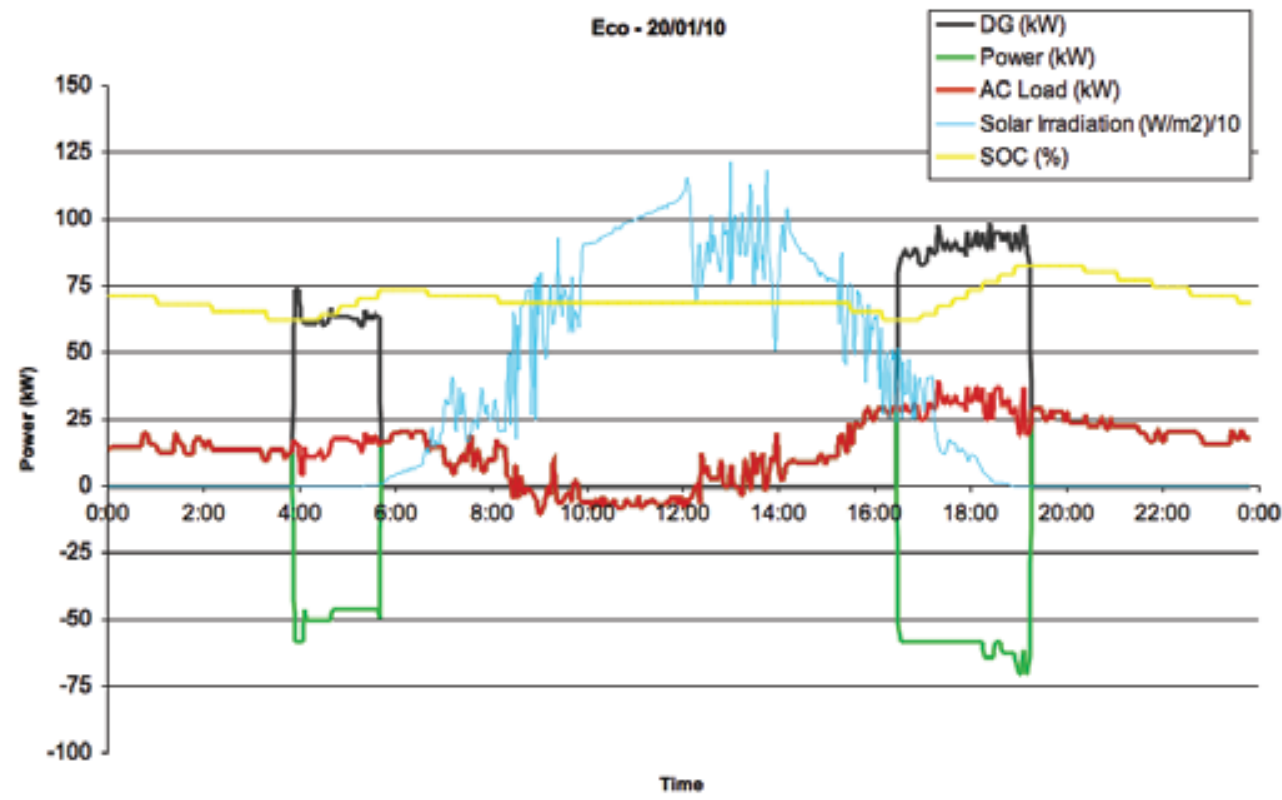

Fig. 22. System operation on a cloudy day

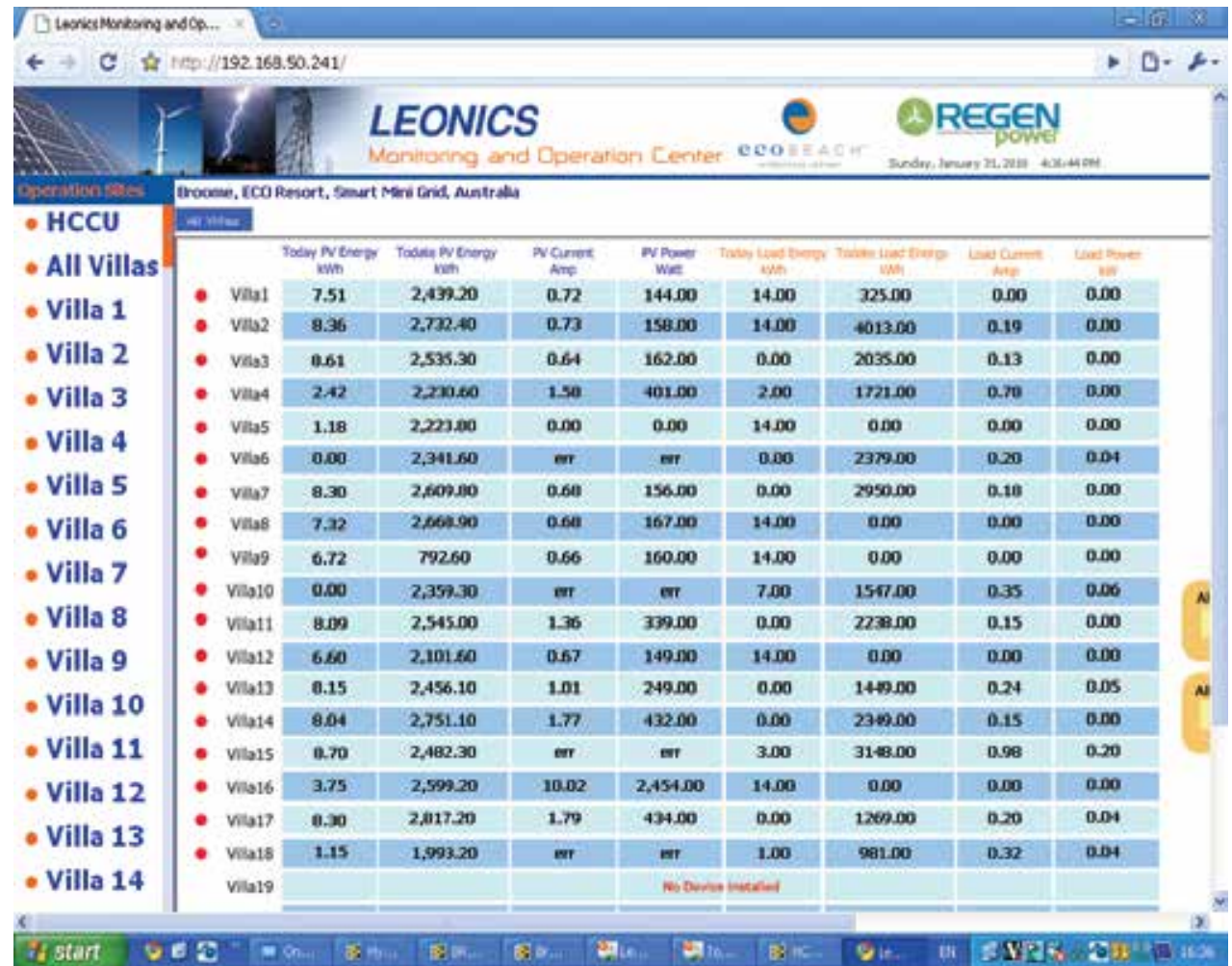

Fig. 23. Monitoring of energy generation and consumption in villas 


\section{Variable speed operation of a diesel generator}

A conventional diesel generator consists of an engine connected directly to a synchronous alternator to produce electricity. Since the electricity produced must be at a fixed frequency, normally $50 \mathrm{~Hz}$ or $60 \mathrm{~Hz}$, the engine must rotate at a constant speed (typically $1500 \mathrm{rpm}$ for $50 \mathrm{~Hz}$ or $1800 \mathrm{rpm}$ for $60 \mathrm{~Hz}$ ), regardless of the power demand. One solution to save fuel in a diesel generator is to enable the engine to operate at variable speeds in direct relation to the electrical load demand.

There are a number of applications for which the power demand varies greatly that can benefit from this technology which include:

- Staff accommodation on oil, gas and mineral exploration sites

- Construction sites where electrical demand fluctuates day and night

- $\quad$ Remote villages, islands, houses, cabins

- Telecom towers with air conditioning units that start and stop

The use of a variable speed generator has many advantages compared to a standard diesel generator, as outlined below.

\subsection{Fuel savings}

A variable speed generator can save fuel in two ways. First, running the engine at its most efficient speed for a given power demand allows for considerable fuel savings. A comparison of the fuel efficiency of a constant speed diesel generator and a variable speed generator is shown in Figure 24. Estimation of the real saving in fuel consumption would depend on the load curve in a particular application.

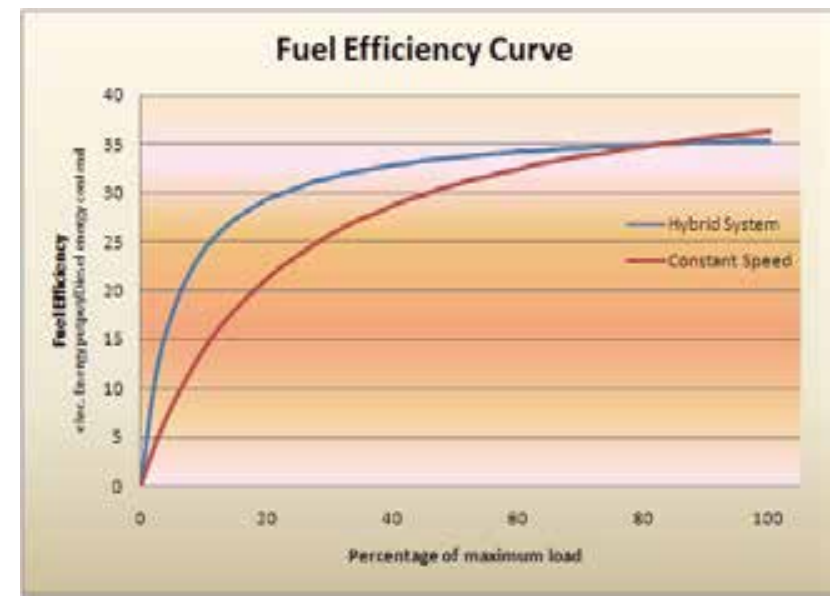

Fig. 24. Typical Fuel Efficiency curve of a diesel engine in Variable Speed (HybridGen) and constant speed genset

Fuel savings can also be achieved, as a variable speed genset requires smaller engine compared to a fixed speed generator of the same power rating. A standard engine power curve (shown in Figure 25) illustrates why the engine on a variable speed generator can be smaller. On a standard fixed speed generator, the engine can only operate at $1500 \mathrm{rpm}$. This means all the power above the nominal rated speed (Figure 25 - red area) is unavailable. A variable speed generator can use the engine over its full speed range, allowing a smaller engine to be used as compared to a fixed speed generator of the same power rating. Depending on the engine, its application, normally $50 \mathrm{~Hz}$, and its power curve, a variable 
speed generator can extract up to $30 \%$ more power from the engine. It is worth noting that since generators rarely run at their rated capacity full time, the average operating speed of the engine will be below 1500 RPM.

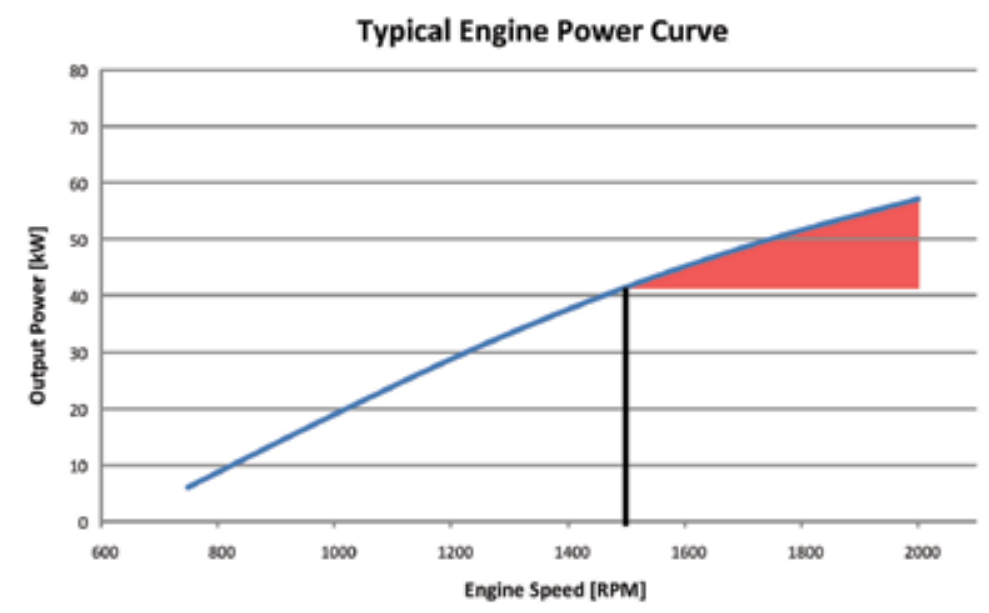

Fig. 25. Typical Diesel Engine Power Curve (Red Area: Engine power available above 1500 RPM)

\subsection{Reduced noise}

Almost all the noise produced by a generator is due to the engine and the speed of revolution. When the engine speed is reduced, noise is also greatly reduced, which means that in power saving mode, when the engine is at a low speed, a variable speed generator is much quieter.

\subsection{Prolonged engine life}

Variable speed generator in remote area applications will mostly run at lower speeds. This can prolong engine life. The moving parts in an engine are subjected to a "load cycle" every time the engine rotates. A reduction in speed results in a reduction of the number of load cycles resulting in extended engine life.

The second advantage is the elimination of a common problem in engines called cylinder glazing or wet stacking. Cylinder glazing usually occurs when an engine runs too cold and combustion is inefficient. This happens in fixed speed diesel engines when operating at low load. At low loads, the engine runs colder, which results in deposits on the cylinder walls of the combustion chamber. When the engine is continuously at its most efficient point, it remains hot and bore glazing is greatly reduced and/or eliminated, resulting in prolonged engine life.

\subsection{Reduced emissions}

Results from testing variable speed generators indicate that emissions are reduced proportionally to the fuel economy generated by the variable speed generating system.

\section{HybridGenTM - An innovative variable speed generator}

HybridGen is based on a Doubly Fed Induction Generator (DFIG) system which uses a wound rotor induction machine with the rotor's voltage controlled by two converters in a back to back configuration [9]. The basic system topology for a DFIG is shown in Figure 26. 


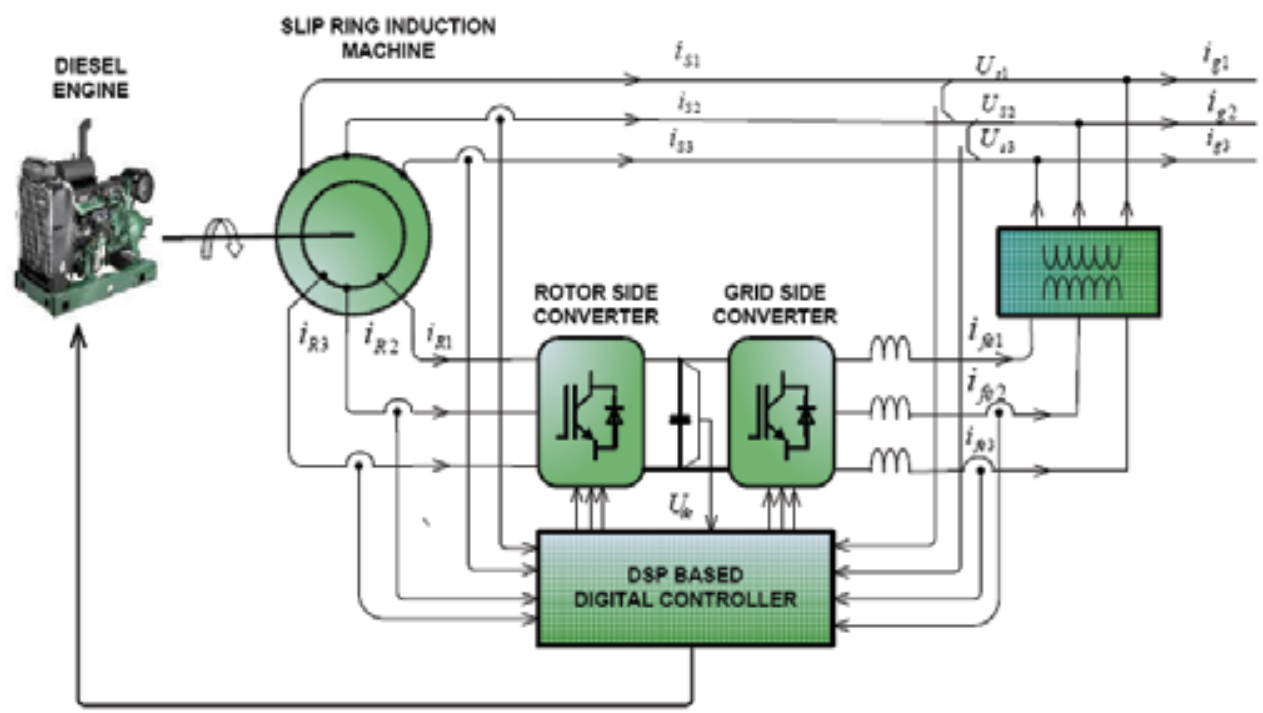

Fig. 26. Diesel powered Variable speed Doubly Fed Induction Generator

In this scheme, the Rotor Side Converter produces variable voltage at rotor frequency. Grid Side Converter controls the DC-link voltage and provides independent control of active and reactive power. In order to control the machine, the voltage impressed on the rotor must be capable of varying its voltage magnitude, phase shift, frequency and phase sequence. A voltage source for the rotor that is capable of meeting these requirements is created by connecting two PWM converters back to back. One of the inverters in the configuration is connected to the stator which is ultimately connected to the grid. This inverter is known as the stator side converter. The other inverter in the configuration is connected to the rotor's slip rings; this inverter is known as the rotor side converter. A DC bus is formed where the stator side converter connects to the rotor side converter. The stator and rotor side converters work together to create a frequency changing circuit. On the grid-side the frequency is fixed normally at $50 \mathrm{~Hz}$, and on the rotor side the frequency will vary depending on the rotor speed. HybridGen is designed for maintaining rated output voltage and output frequency of the wound rotor generator irrespective of the 1 engine shaft speed. Diesel engines will be operated at the optimum speed depends on the load to reduce the fuel consumption. By utilising state of the art technology a high efficient, easy to use, variable speed generator has been designed with good dynamic performance.

Salient features are:

- Constant voltage/constant frequency output irrespective of the prime-mover speed

- Programmable voltage and frequency

- Engine to operate at optimum efficiency at different to load conditions

- Capable of producing higher power output (more than the rated power) at higher speeds to meet the higher load demand without overloading the system

- Less maintenance cost / down time of prime mover

- $\quad$ Ease of synchronizing with grid without additional synchronising relay

- Wide operating range (750 RPM to $2000 \mathrm{RPM})$

- Programmable PI controllers for optimum transient response and steady state regulation 
- Sophisticated PLC based supervisory control

- $\quad$ Advanced DSP based digital control and IGBT based inverter

- Flexible operating modes either as a stand- alone or grid connected generator

- Programmable output power at grid connected mode

- Programmable operating power factor

- Multi-data display: displays voltage, current power, and power factor

- Advanced protection systems to limit over voltage, short circuit and, over current

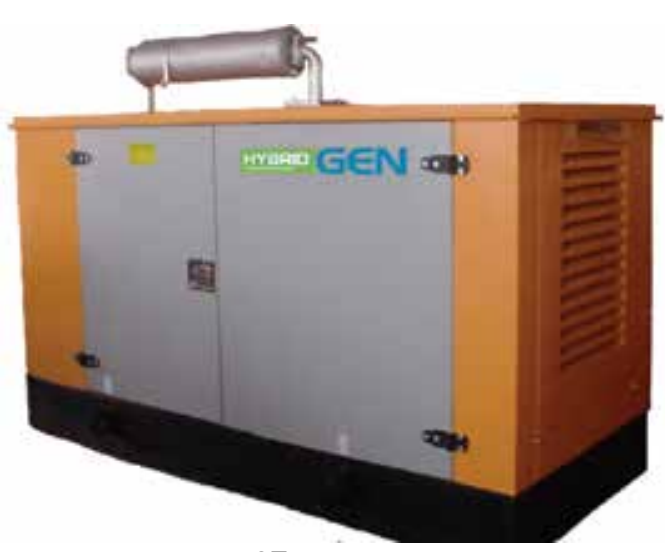

27.a

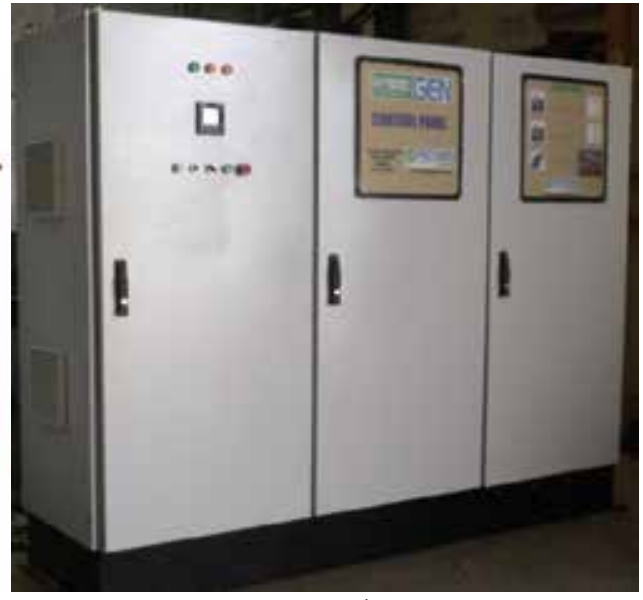

27.b

Fig. 27.a A HybridGen (40kVA) consisting of diesel engine, generator and electronic fuel regulator

Fig. 27.b Power conditioning unit

\section{Fuel Consumption of HybridGen and Constant Speed}

\section{Diesel Generator}

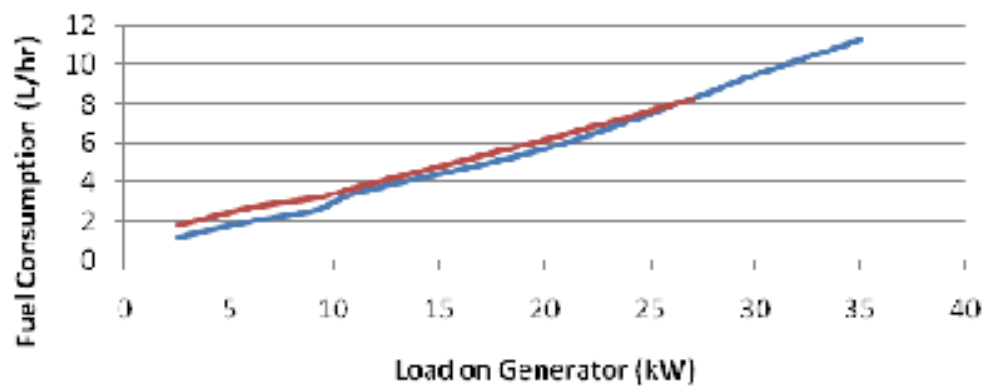

- HybridGir Constant Spead Generator (15c0rom)

Fig. 28. Fuel consumption of a constant speed generator and HybridGen.

Figure 29 shows a schematic diagram showing multiple variable speed diesel generators with AC-coupled wind generators and photovoltaic generators. Future hybrid energy systems will be using variable speed generators instead of conventional constant speed diesel generators. 


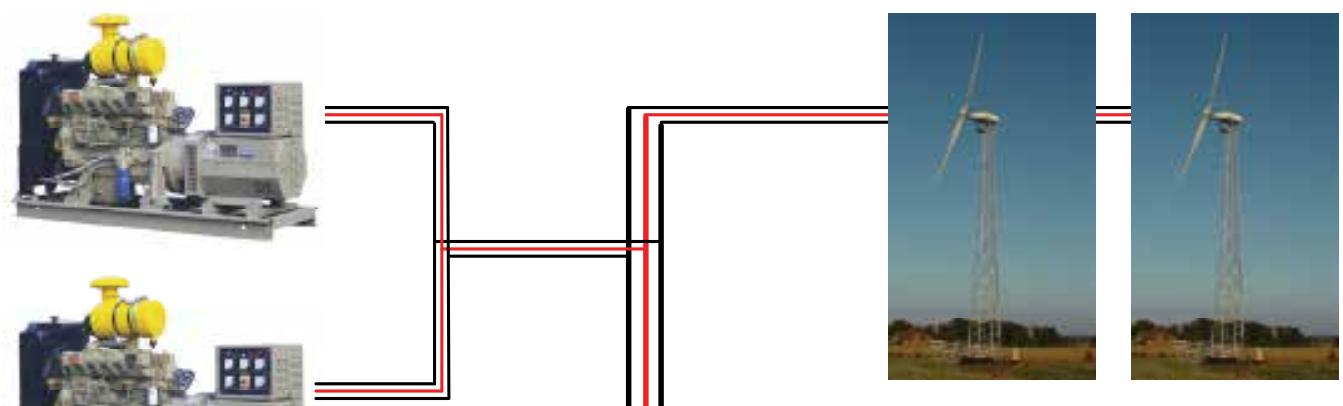

Wind Turbines

Variable Speed

Diesel Generators

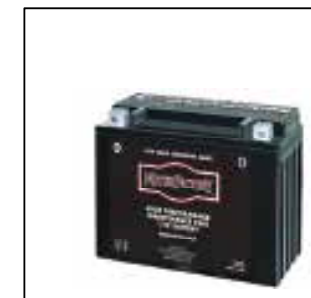

Battery

Bi-directional Inverter

Solar Panels

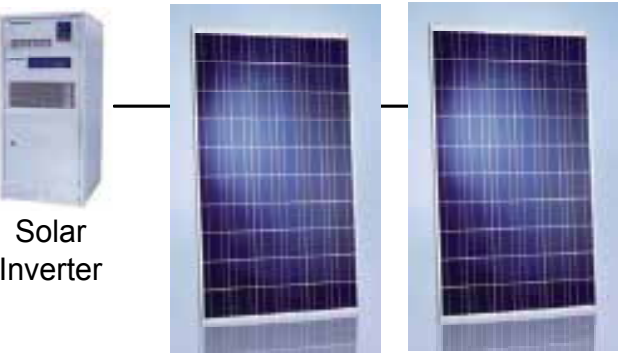

Optional:

Dynamic Energy Balancer

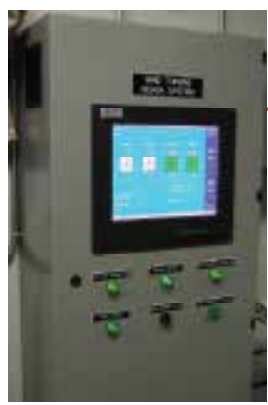

Communication Bus System

Hybrid System

Supervisory Controler and

Web based Monitor

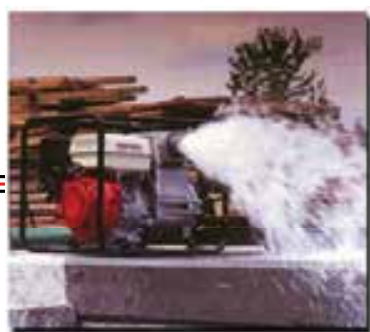

Secondary Load

Water pumping, Ice Making
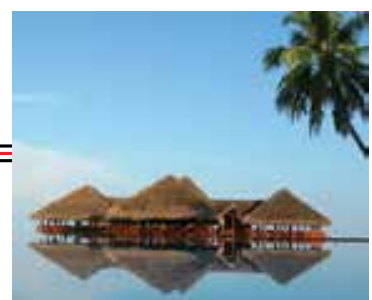

Local primary Load

Fig. 29. Multiple variable speed generators with AC-coupled wind turbines and solar panels 


\section{Conclusion}

Islands and remote communities represent a big niche market for the application of renewable energy technologies and are very important when it comes to the promotion of renewable energy worldwide. From the experience learned from the implementation of several remote area power systems, it is clearly evident that hybrid, renewable micro grids are a reality and the right step towards making resorts and remote islands self sufficient. It also opens up the potential for tourism, apart from making the earth a cleaner place to live. The newly developed variable speed diesel generator system is expected to provide very good opportunities to showcase high penetration of renewable energies using state-of-theart wind turbines and photovoltaic modules. The new hybrid system configuration offers several advantages such as maximised diesel efficiency, minimised maintenance of diesel generators and a reduction in the required capacities of diesel fuel and battery storage.

\section{References}

Alphen, Klann van et al (2007) Renewable energy technologies in the Maldives - determining the potential, Renewable and Sustainable Energy Reviews, Vol 11, 1650-1674.

Bull, S.R. (August 2001) Renewable Energy Today and Tomorrow, Proceedings of the IEEE, Vol. 89, No. 8.

Burges, K. , Hemert, B. Van (2000) "Market Introduction of Hybrid Power Supply Systems," Paper for PV Hybrid Power Systems conference, Aix en Provence, pp. 1-4.

Darbyshire, J. (unpublished) Multi-Function Power Electronic Interface for Hybrid Mini-Grid Systems, PhD Thesis.

Datta,M., Senjyu, T., Yona, A. \& Funabashi, T. (2009) A Frequency Control Method for Isolated Photovoltaic-diesel Hybrid Power System with Use of Full Renewable Energy, PEDS, pp. 1.

Lowe, D. \& Lloyd, C.R. (February 1999) Renewable energy systems for remote areas in Australia, Paper for the World Renewable Energy Congress, Murdoch University, pp. 1-4.

Luiz, R., Osvaldo, S. L., Shigeaki \& Jose, D. (November 2009) Isolated Micro-Grid with Renewable Hybrid Generation, IEEE Transactions on Sustainable Energy, pp. 1-2.

Nayar, C. (Nov. 2008) Remote area micro-grid system using diesel driven doubly fed induction generators, photovoltaics and wind generators,Sustainable Energy Technologies, 2008. ICSET 2008. IEEE International Conference , 1081 - 1086, 24-27.

Nayar, C.; Tang, M.; \& Suponthana,W. (December 2007) An AC Coupled PV/Wind/Diesel Microgrid System Implemented in a Remote Island in The Republic Of Maldives, AUPEC Conference proceedings, pp. 1-4.

Nayar, C., et al July 2006) Power Conversion System and Method of Converting Power, US Patent US7,072,194B2. 


\title{
Facts about Producer Gas Engine
}

\author{
G. Sridhar ${ }^{1}$ and Ravindra Babu Yarasu ${ }^{2}$ \\ ${ }^{1}$ Siemens Corporate Research and Technologies, Bangalore, \\ ${ }^{2}$ Govt. College of Engineering, Amravati, Maharashtra, \\ India
}

\section{Introduction}

Reciprocating internal combustion engines have integrated into society service since the middle of $20^{\text {th }}$ century. Their use has improved the quality of life substantially, but at the cost of degradation to the environment as well as depletion of fossil fuels, certainly due to insufficient environmental consciousness in several countries. Therefore, large impetus is being given to reduce the emissions by two approaches namely, increasing the engine efficiency and the use of alternate fuels in place of fossil fuels. In present chapter, the use of alternate fuels has been addressed along with modeling and simulation of engine combustion. In the domain of alternative fuels, gaseous fuels receive more prominence because of the possibility of cleaner combustion. Among the gaseous fuels, producer gas derived from biomass gasification is a better option as an environment friendly fuel. This fuel gas, in addition to being $\mathrm{CO}_{2}$ neutral, generates lesser quantity of undesirable emissions. Even though the merits of producer gas have been recognized earlier, the technological capitalization has remained in infancy.

The thermo-chemical conversion of biomass leads to generation of a gas generally termed as producer gas. The process is termed as gasification implies that a solid fuel is converted to a gaseous fuel. Gasification is not a new technology but is known ever since World War II. During this period a number of vehicles in Europe were powered with charcoal gasifiers (ANON-FAO Report, 1986). It is estimated that over seven million vehicles in Europe, Australia, South America and Pacific Islands were converted to run on producer gas during World War II. These engines were spark ignition (SI) engines, mostly operating in the lower compression ratio (CR) range and based either on charcoal or biomass derived gas.

At the far end of $20^{\text {th }}$ century, there was a renewed interest in biomass gasification technology, which had stimulated interest in producer gas operated engines. Prior to 21st century, the work reported in this area had been limited to lower CR (less than 12.0) engine due to perceived limitation of knock at higher CR. A short review of some of earlier studies, related to producer gas engine is presented in the following section in order to explain the context for this topic.

\section{Literature review}

Literature survey in the field of producer gas based engines reveals modest research work to have been carried out since the inception of biomass/charcoal gasification systems. This 
could be attributed to two reasons, namely non-availability of standard gasification system that could generate consistent quality producer gas and the other relating to misconceptions about producer gas fuel.

It was reported that Europe exploited the most of gasification technology during petroleum oil crisis of World War II. Among the European nations, Sweden accounts for a large amount of work in the area of wood and charcoal gasification. National Swedish Testing Institute of Agricultural Machinery, Sweden (ANON-FAO Report, 1986) has reported extensive work on the design and development of closed top charcoal and wood gasifiers for use with the reciprocating engines. These engines were however in the lower compression ratio $(\mathrm{CR})$ - 10, either adapted from petrol engines or modified diesel engine. Martin et al., (1981) reported work using charcoal gas and biomass based producer gas on a SI engine with a de-rating of $50 \%$ and $40 \%$ respectively at a CR of 7 . They also claimed $20 \%$ de-rating when worked with producer gas at a CR of 11. They indicate an upper limit of CR of 14 and 11 for charcoal and biomass based producer gas, respectively.

American sub-continent also claims experimental work relating to producer gas engines. Tatom et al., (1976) reported work on a gasoline truck engine with a simulated pyrolysis gas at a de-rating of $60-65 \%$. It was also emphasized that that the optimum ignition timing is a function of engine speed. Parke et al., (1981) worked on both naturally aspirated and super charged gas engines. The de-rating of $34 \%$ was claimed compared to gasoline operation and a lesser de-rating in a supercharged mode.

In the Indian sub-continent, work in the area of producer gas engine has been reported by the biomass gasification group of Indian Institute of Technology, Mumbai. They have reported work on a gas engine converted from a naturally aspirated diesel engine at CR of 11.5 (Shashikantha et al. 1993, 1999; Parikh et al. 1995). The reason given for limiting the CR was knocking tendency. However, no experimental evidence was provided in support of it. If one were to summarize the findings of earlier studies (prior to 2000), it becomes evident that no systematic investigation had been attempted in identifying the existence of knock limitation, if any, with producer gas operation at CR comparable to that of diesel engine operation. On the contrary producer gas with large fraction of inert (> 50\%) and with laminar burning velocity being high (due to the presence of $\mathrm{H}_{2}$ ), smooth operation at higher CR must be definitely possible.

A systematic investigation on producer gas operation at CR comparable to that of diesel engine was carried out and reported by one of the present authors (Sridhar et al., 2001; Sridhar, 2003; Sridhar et al., 2006). The source of producer gas fuel used was from an open top re-burn down draft gasifier system (Mukunda et al., 1993 \& 1994) using Casuarina wood pieces as the fuel. The compression ratio limits were tested up to 17:1 without any audible knocking. It was demonstrated that the comparable power to that of diesel engine (with a lesser extent of de-rating $\sim 15-20 \%$ ) could be achieved with producer gas by operating engine at higher $\mathrm{CR}$. The outcome of the experimental work along with simulation tools to predict the engine performance is explained in the following sections.

\section{Scope of the chapter}

Based on the review of the published work (prior to 2000), there is no positive evidence for the presence of knock with producer gas fuel in spark ignition (SI) engines at higher CR than 14. This restriction in compression ratio (CR) was simply a matter of presumption rather 
than fact. One of the primary objectives of this chapter is to present the results of producer gas based SI engine operating at the higher possible CR. The results of a systematic investigation, which includes the in-cylinder pressure measurements are presented. Assessing the thermodynamic behaviour of the engine, nitric oxide emissions and also validation of the engine simulation models with help of the measured in-cylinder pressure data are discussed.

The in-cylinder processes in a reciprocating engine are extremely complex in nature. While much is known about these processes, they are not adequately understood at a fundamental level, especially the combustion process. Tools used for prediction of in-cylinder processes in a reciprocating engine operating on producer gas are mentioned. The comparisons of results of two different combustion models against experimental data are presented. A Zerodimensional thermodynamic model can give quick results. However, it fails to predict the results accurately at wide range of varied ignition timings. It is due to the varying degree of favorable or adverse effect of reverse squish flow on burning of mixture inside the cylinder, particularly at high CR. Whereas a multi-dimensional combustion model, based on Flame surface density can give a better prediction of engine performance. The objective of including the engine simulation work is to predict the burn rate in a producer gas fuelled SI engine under the influence of varying ignition timing and compression ratio.

The first model, i.e., a Zero-dimensional model was used to simulate the complete thermodynamic cycle. Eddy entrainment and laminar burn-up (EELB) postulated by Keck (1982), was adopted to compute burn rate with parameters of turbulence properly accounted for engine geometry under study. A curve fit equation of laminar burning velocity of Producer gas at pressures and temperature relevant to engine operation is presented which can be used in combustion simulation models. The second model, based on Flame surface density, for multi-dimensional combustion simulation was used with wall correction. The limitations and capabilities of these models are explained.

\section{Properties of Producer gas}

Some of the fundamental data relating to producer gas along with pure gases is given in Table 1. The comparison of producer gas with methane is more vital with regard to the internal combustion engine operation. This is because most of the engines operating on gaseous fuels are either close to pure methane (natural gas) or diluted methane (bio-gas, land-fill gas). The fuel-air mass equivalence ratio, i.e., (actual fuel to air ratio)/(stoichiometric fuel to air ratio) at the flammability limits compares closely for both the gases, but the laminar burning velocity for producer gas at the lean limits is much higher. The laminar burning velocity for producer gas (at $0.1 \mathrm{MPa}, 300 \mathrm{~K}$ ) is about $0.5 \mathrm{~m} / \mathrm{sec}$ which is about $30 \%$ higher than methane. This feature demand lower advancement in the ignition timing for the engine based on producer gas fuel.

Like any other gaseous fuel, producer gas can be used for internal combustion engine operation provided that the gas is sufficiently clean and contaminant does not accumulate in the intermediary passages to the engine cylinder. But this fuel has largely been left unexploited due to additional perceptions, namely (1) auto-ignition tendency at higher CR, (2) large de-rating in power due to lower calorific value. However, these perceptions were re-examined (Sridhar et al., 2001). Firstly, as the laminar burning velocity being high due to the presence of hydrogen (more so, with the gasifier system adapted) might reduce the tendency for the knock. Secondly, the presence of inert in the raw gas $\left(\mathrm{CO}_{2}\right.$ and $\left.\mathrm{N}_{2}\right)$ might 
suppress the pre-flame reactions that are responsible for knocking on account of increased dilution. Also the maximum flame temperature attainable with the producer gas being lower compared to conventional fuels like methane, one could expect better knock resistivity.

Furthermore, there is a general perception that producer gas being a low-energy density fuel, the extent of de-rating in power would be large when compared to high- energy density fuels like natural gas and Liquefied petroleum gas. This could be misleading because what needs to be accounted for comparison is the charge mixture energy density (Fleischer et al., 1981) and not the fuel energy density per se. On comparison with $\mathrm{CH}_{4}$, the mixture energy density for producer gas is lower by $23 \%$ as reflected in Table 1 . The product to reactant mole ratio for producer gas is less than one. These two parameters could contribute to de-rating of engine output. However, it might be possible to reduce de-rating by working with engines of higher $\mathrm{CR}$, perhaps higher than what has been examined using natural gas at $\mathrm{CR}=15.8$ (Das \& Watson, 1997).

\begin{tabular}{|c|c|c|c|c|c|c|c|c|c|c|}
\hline \multirow{2}{*}{$\begin{array}{c}\text { Fuel } \\
+ \\
\text { Air }\end{array}$} & \multirow{2}{*}{$\begin{array}{c}\text { Fuel } \\
\mathrm{LCV}, \\
\mathrm{MJ} / \mathrm{kg}\end{array}$} & \multirow{2}{*}{$\begin{array}{c}\text { Air/Fuel } \\
@(\Phi=1)\end{array}$} & \multirow{2}{*}{$\begin{array}{c}\text { Mixture, } \\
\mathrm{MJ} / \mathrm{kg}\end{array}$} & \multicolumn{2}{|c|}{$\Phi$, Limit } & \multicolumn{2}{|c|}{$\begin{array}{c}S_{L} \text { (Limit) } \\
\mathrm{cm} / \mathrm{s}\end{array}$} & \multirow{2}{*}{$\begin{array}{c}S_{L} \\
\Phi=1, \\
\mathrm{~cm} / \mathrm{s}\end{array}$} & \multirow{2}{*}{$\begin{array}{c}\text { Peak } \\
\text { Flame } \\
\text { Temp, } \\
\text { K }\end{array}$} & \multirow{2}{*}{\begin{tabular}{|c} 
Product/ \\
Reactant \\
Mole \\
Ratio
\end{tabular}} \\
\hline & & & & Lean & Rich & Lean & Rich & & & \\
\hline $\mathrm{H}_{2}$ & 121 & 34.4 & 3.41 & 0.01 & 7.17 & 65 & 75 & 270 & 2400 & 0.67 \\
\hline $\mathrm{CO}$ & 10.2 & 2.46 & 2.92 & 0.34 & 6.80 & 12 & 23 & 45 & 2400 & 0.67 \\
\hline $\mathrm{CH}_{4}$ & 50.2 & 17.2 & 2.76 & 0.54 & 1.69 & 2.5 & 14 & 35 & 2210 & 1.00 \\
\hline $\mathrm{C}_{3} \mathrm{H}_{8}$ & 46.5 & 15.6 & 2.80 & 0.52 & 2.26 & - & - & 44 & 2250 & 1.17 \\
\hline $\mathrm{C}_{4} \mathrm{H}_{10}$ & 45.5 & 15.4 & 2.77 & 0.59 & 2.63 & - & - & 44 & 2250 & 1.20 \\
\hline PG & 5.00 & 1.35 & 2.12 & $\begin{array}{c}0.47 \\
\mathrm{a}\end{array}$ & $\begin{array}{c}1.60 \\
b\end{array}$ & 10.3 & 12 & $\begin{array}{c}50 \\
C\end{array}$ & $\begin{array}{c}1800 \\
\mathrm{~d}\end{array}$ & 0.87 \\
\hline
\end{tabular}

PG: $\mathrm{H}_{2}-20 \%, \mathrm{CO}-20 \%, \mathrm{CH}_{4}-2 \%$; a: $\pm 0.01, \mathrm{~b}: \pm 0.05, \mathrm{c}: \pm 5.0, \mathrm{~d}: \pm 50$; LCV: Lower Calorific Value

Table 1. Properties of Producer Gas (PG) Compared with Pure Combustible Gases

\subsection{Laminar burning velocity $\left(\mathrm{S}_{\mathrm{L}}\right)$ of Producer gas}

The laminar combustion properties of gaseous fuels at high temperatures and pressures are of fundamental importance for analyzing and predicting the performance of internal combustion engines and power plant burners. Experimental laminar burning velocity can also be used to check theoretical combustion models and calculate apparent activation energies.

Laminar burning velocity $\left(\mathrm{S}_{\mathrm{L}}\right)$ of a gaseous fuel is function of reactant mixture pressure and temperature. For Producer gas, Laminar burning velocity is also function of its composition. To establish the $S_{L}$ values of producer gas, efforts were made by few researchers at ambient and higher pressure and temperature conditions. Experimental and theoretical calculation works made by the researchers to determine the laminar burning velocity of producer gasair mixtures are presented below.

Kanitkar et al., (1993) determined the laminar flame speed $\left(\mathrm{S}_{\mathrm{L}}\right)$ at ambient conditions $(0.96$ bar, $300 \mathrm{~K}$ ) by conducting experiments using flame tube apparatus for producer gas-air mixture. These experiments were conducted at laboratory reference conditions using producer gas generated from IISc's on-line open top re-burn gasification system. The gas 
consisted of $18-23 \% \mathrm{H}_{2}, 17-20 \% \mathrm{CO}, 3-4 \% \mathrm{CH}_{4}, 13-14 \% \mathrm{CO}_{2}$ and rest $\mathrm{N}_{2}$. A wide range of mixture ratios were considered within the flammability limits of rich and lean mixtures, namely equivalence ratio from 0.47 (26\% fuel on volume basis) to 1.65 (56\% fuel) for lean and rich limits, respectively. The physical values of burning velocity varied from 0.10 and $0.13 \mathrm{~ms}^{-1}$ at lean and rich limits, to the peak value of $0.50 \pm 0.05 \mathrm{~ms}^{-1}$ around stoichiometry (45\% fuel).

Experimental laminar burning velocity $\left(S_{L}\right)$ values of producer gas at high pressures and temperatures were reported by Keshavamurthy et al., (2004). The experiments were conducted in a spherical combustion vessel. Synthetic mixtures of producer gas with a composition of $22 \% \mathrm{H}_{2}, 22 \% \mathrm{CO}, 4 \% \mathrm{CH}_{4}, 10 \% \mathrm{CO}_{2}$ and $42 \% \mathrm{~N}_{2}$ were used to determine $\mathrm{S}_{\mathrm{L}}$ at initial pressures of 0.5 to 5 bar and ambient temperature. With these initial pressures and temperature a peak pressure of 30 bar during combustion and a maximum unburnt gas temperature of $450 \mathrm{~K}$ were obtained. The unburnt gas temperatures were obtained by assuming isentropic compression of unburnt gases as the combustion progresses. The experiments were conducted at equivalence ratios (ratio of actual fuel-air mass ratio to the stoichiometric fuel-air mass ratio) in the range of 0.8 to 1.4. The laminar burning velocity values have been deduced from the pressure-time measurements. The variation of $S_{L}$ values with respect to pressure, temperature and equivalence ratio was presented. The experimental data points were fitted with a power law equation of the form $S_{L}=a P^{b}$ where $a$ and $b$ were curve fit coefficients. Different sets of $a$ and $b$ values for different initial temperatures were specified. The burning velocity values were extrapolated from higher pressures and temperatures to ambient conditions to arrive at a value of $0.47 \mathrm{~ms}^{-1}$ at stoichiometric conditions.

Sridhar et al. (2005) reported computational results concerning the laminar burning velocity of a biomass-derived producer gas and air mixture at pressures and temperatures typical of the unburned mixture in a reciprocating engine. Based on a number of calculations at varying pressures (5-50 bar) and temperatures (630-1082 K), and equivalence ratios (0.91.07), an expression for estimating the laminar burning velocity with the residual gas (RG) mass fraction $(0-10 \%)$ was obtained. Also, the effects of varying residual gas in the engine cylinder, $\mathrm{H}_{2}$ and $\mathrm{CO}$ mass fraction in the fuel on $\mathrm{S}_{\mathrm{L}}$ were estimated. This work on $\mathrm{S}_{\mathrm{L}}$ is useful in predicting the burn rate in a spark ignition engines fuelled with a producer gas. The expression for estimating the laminar burning velocity, $\mathrm{S}_{\mathrm{L}}$ in $(\mathrm{cm} / \mathrm{s})$ is as follows.

$$
S_{L}(\mathrm{~cm} / \mathrm{s})=\left(\frac{p}{p_{0}}\right)^{0.2744} 94.35(0.96+1.2(\Phi-1))(1-2.4 \psi)
$$

where $\mathrm{p}$ is the pressure of the mixture in engine cylinder in $\mathrm{kPa}, \mathrm{p}_{0}$ is the reference pressure, i.e., $100 \mathrm{kPa}, \Phi$ is the equivalence ratio of the mixture, $\Psi$ is the residual gas (RG) mass fraction in the engine cylinder. The burning velocity dependence upon the initial temperature is built into the pressure term in Eq. (1).

Natarajan et al., (2007) reported laminar flame speeds of lean $\mathrm{H}_{2} / \mathrm{CO} / \mathrm{CO}_{2}$ (syngas) fuel mixtures, which have been measured over a range of fuel compositions (5-95\% for $\mathrm{H}_{2}$ and $\mathrm{CO}$ and up to $40 \%$ for $\mathrm{CO}_{2}$ by volume), reactants preheat temperatures (up to $700 \mathrm{~K}$ ), and pressures (1-5 atm). Two measurement approaches were employed: one using flame area images of a conical Bunsen flame and the other based on velocity profile measurements in a 
one-dimensional stagnation flame. These data were compared to numerical flame speed predictions based on two established chemical mechanisms: GRI Mech 3.0 and the Davis $\mathrm{H}_{2} / \mathrm{CO}$ mechanism with detailed transport properties. For room temperature reactants, the Davis mechanism predicted the measured flame speeds for the $\mathrm{H}_{2} / \mathrm{CO}$ mixtures with and without $\mathrm{CO}_{2}$ dilution more accurately than the GRI mechanism, especially for high $\mathrm{H}_{2}$ content compositions. This work was more about the checking ability of mechanism to predict the $S_{\mathrm{L}}$ values of Syngas.

Ratnakishore et al., (2008) reported the laminar burning velocity values of producer gas from computations of spherical outwardly propagating flames and planar flames. Different reaction mechanisms were assessed for the prediction of laminar burning velocities of $\mathrm{CH}_{4}$, $\mathrm{H}_{2}, \mathrm{H}_{2}-\mathrm{CO}$, and $\mathrm{CO}-\mathrm{CH}_{4}$ and results showed that the Warnatz reaction mechanism with $\mathrm{C} 1$ chemistry was the smallest among the tested mechanisms with reasonably accurate predictions for all fuels at 1 bar, $300 \mathrm{~K}$. Unstable flames due to preferential diffusion effects were observed for lean mixtures of fuel with high hydrogen content. On accounting the Soret effect, the variation in burning velocity was at least $5 \%$ even with $5 \%$ of hydrogen (by volume) in the binary fuel of $\mathrm{H}_{2}-\mathrm{CO}$.

\section{Engine experimental results at varied compression ratios}

Experimental results of a systematic investigation on producer gas operated internal combustion engine at higher compression ratio (CR) for the first time was reported by Sridhar et al., (2001). The primary investigation was conducted on an engine of $24 \mathrm{~kW}$ capacity. Experiments were conducted on a spark ignition (SI) engine converted from a naturally aspirated, three-cylinder, direct injection diesel engine (RB 33 model) of compression ratio (CR) 17. The knock sensitivity identifies the Highest Useful Compression Ratio (HUCR) for most of the fuels having higher octane number. For higher-octane fuels, it has been experimentally established that the upper limit of CR is 17 beyond which there is a fall in efficiency (Caris \& Nelson, 1959).

The salient features of the diesel engine chosen for conversion to SI engine are shown in Table 2. The naturally aspirated engine of 3.3 litre capacity is designed at a $C R=17$, to operate at an air-to-fuel ratio of 20 - 21 (with diesel) at rated conditions. The combustion chamber of the engine is formed of a flat cylinder head and slightly offset bowl-in piston as shown in Fig.1. The bowl is hemispherical in shape and has a squish area of $70 \%$ (percentage of piston area closely approaching the cylinder head). The engine was characterized using diesel fuel prior to conversion. The trial result database obtained was consisting of incylinder pressure, and the specific fuel consumption at the rated speed of $1500 \mathrm{rev} / \mathrm{min}$. The engine delivered a peak power of $21 \mathrm{kWe}$, which is equivalent to a net brake (shaft) output of $24.0 \mathrm{~kW}$ against the rated output of $28.0 \mathrm{~kW}$ (at sea level). The loss in power is attributed to lower air density at Bangalore, due to its elevation ( $1000 \mathrm{~m}$ above sea level).

The diesel engine was modified to work as SI engine by insertion of spark plug in place of fuel injector and adapting distributor type battery based ignition system. However, the combustion chamber was left unchanged. The combustion chamber comprised of a flat cylinder head and slightly offset bowl-in-piston was retained (Fig. 1). The compression ratio was varied (17, 14.5, 13.5 and 11.5) by changing the thickness of cylinder head gasket, thereby altering the clearance volume. 


\begin{tabular}{|l|l|}
\hline Parameter & Specification \\
\hline Make and Model & Kirloskar, RB-33 Coupled to a 25kVA Alternator \\
\hline Engine Type & In-Line, 3 Cylinder, 4-Stroke, Naturally Aspirated \\
\hline Rated Output - Diesel & $28 \mathrm{~kW} @ 1500 \mathrm{rev} / \mathrm{min}$ \\
\hline Net Output - Diesel & $24 \mathrm{~kW}(21 \mathrm{kWe}) @ 1500 \mathrm{rev} / \mathrm{min}$ \\
\hline Type of Cooling & Water Cooled with Radiator \\
\hline Bore x Stroke & $110 \times 116 \mathrm{~mm}$ \\
\hline Swept Volume & 1.1 Litre \\
\hline Compression Ratio & $17: 1$ \\
\hline Bumping Clearance & $1.5 \mathrm{~mm}$ \\
\hline Combustion Chamber & Flat Cylinder Head and Hemispherical Bowl-in Piston Type \\
\hline Squish Area & $70 \%$ \\
\hline
\end{tabular}

Table 2. Engine Configuration Details

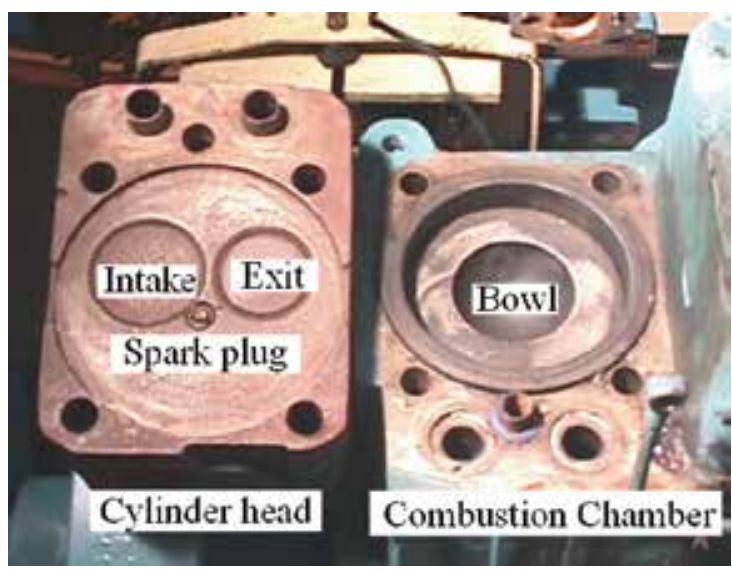

Fig. 1. Engine's combustion chamber

\subsection{Instrumentation on the engine}

Fig. 2 depicts the instrumentation scheme adopted for the experiments. For combustion diagnostics, the in-cylinder pressure was measured using a Piezo sensor (PCB make) mounted on the cylinder No. 1 of the engine. The sensor is hermitically sealed (model No. HS 111A22) with a built-in charge amplifier, the other specifications being: resolution - 0.69 $\mathrm{kPa}$, rise time $<1$ micro second, discharge time constant $>500$ second, natural frequency of the crystal $=550 \mathrm{kHz}$. The in-cylinder pressure measurement synchronized with the crank angle measurement (sensed using an optical sensor) was acquired on a PC (Personal Computer, $600 \mathrm{MHz}$ processor) at time intervals of one-degree crank angle. 


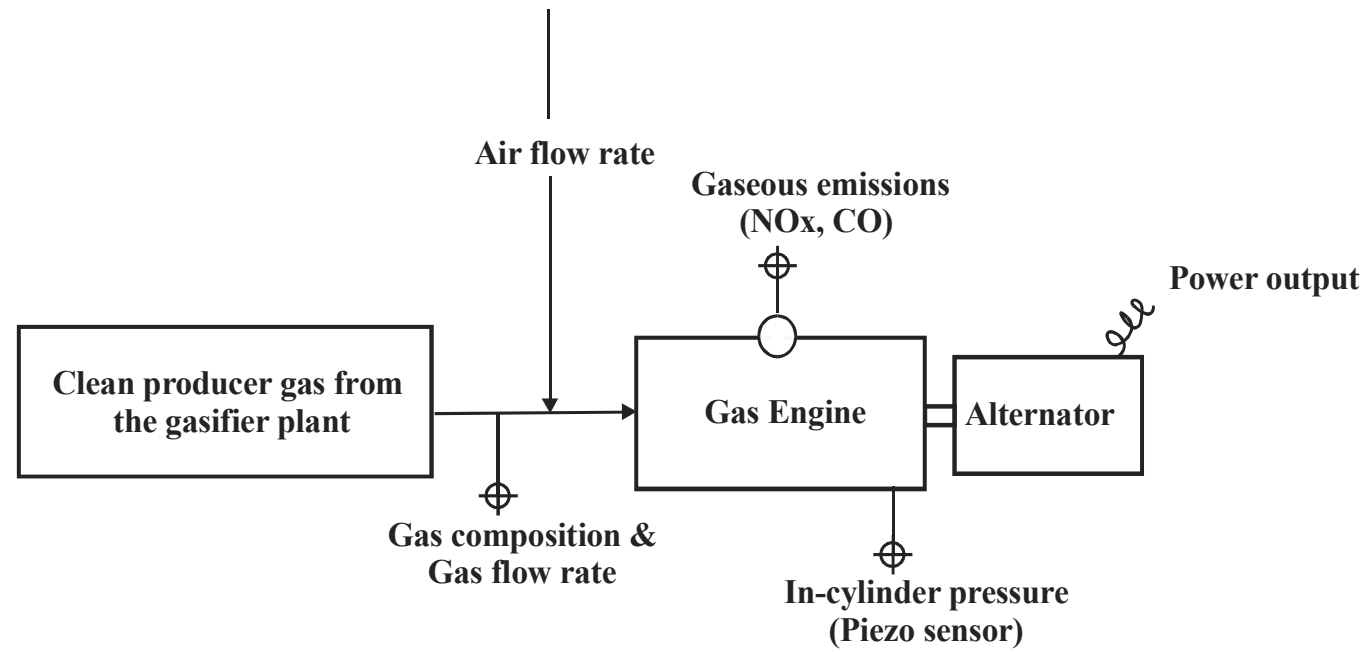

Fig. 2. Scheme for instrumentation

\subsection{Engine's performance}

The power developed and other important performance parameters of an engine operating on biomass generated producer gas at varied compression ratio results are presented below.

\subsubsection{Power and efficiency}

The first and the foremost result of these tests is that the engine worked smoothly without any sign of knock at the CR of 17. There was no sign of audible knock during the entire load range. Moreover, the absence of knock is clear from the pressure-crank angle $(p-\theta)$, which does not show any pressure oscillations, either at part load or at full load (wide open throttle) conditions. A comparison of normal and abnormal (due to knock) combustion is shown in Fig. 3. The normal performance (without pressure oscillations) shown as (i) and (ii) in Fig. 3 (a) corresponds to two firing cycles at ignition advance of $26^{\circ}$ and $12^{\circ}$ BTC respectively. These correspond to operations with producer gas on the converted gas engine
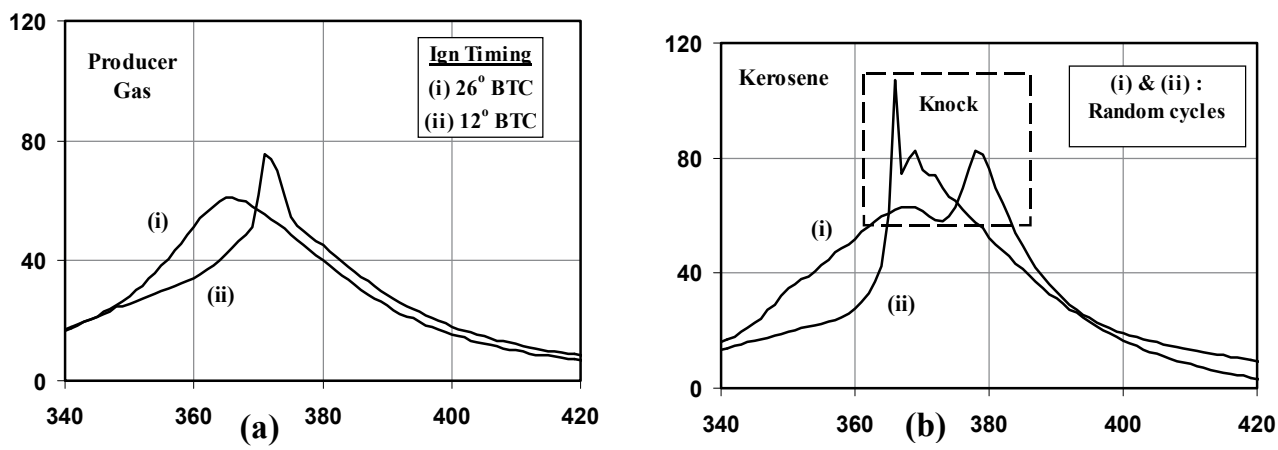

Fig. 3. (a) Normal combustion under wide open throttle condition with Producer Gas at different ignition timings at $C R=17$, (b) Incipient knock with Kerosene at No-Load condition with ignition timing of $30^{\circ} \mathrm{BTC}$ at $\mathrm{CR}=16.5$. 
at $\mathrm{CR}=17$ under wide open throttle conditions. Whereas, performance with incipient knock (with pressure oscillations) shown as (i) and (ii) in Fig. 3 (b) corresponds to two random firing cycles. These correspond to operations with kerosene fuel on a single cylinder SI engine (converted from a diesel engine) at $\mathrm{CR}=16.5$ under no-load conditions. The piezo sensor employed for $\mathrm{p}-\theta$ recording was the same in either case.

The results of the power output with producer gas are shown in Table 3 . At $C R=17$, the engine delivered a maximum net brake output of $20 \mathrm{~kW}(17.5 \mathrm{kWe})$ at an efficiency of $30.7 \%$ compared to $24 \mathrm{~kW}(21 \mathrm{kWe})$ brake output at 33\% efficiency with diesel (compression ignition mode). The efficiency calculation is based on the ratio of net brake output to the energy content of the air and gas mixture (gas-to-shaft power). The useful output and efficiency decreased with the lowering of CR. A maximum net brake output of $17.6 \mathrm{~kW} \mathrm{(15.3}$ $\mathrm{kWe}$ ) at an efficiency of $27.5 \%$ was obtained at CR of 11.5 . The power output at intermediate CR of 14.5 and 13.5 were 18.8 and $18.6 \mathrm{~kW}$ respectively and with efficiencies around $29 \%$. The efficiency at $\mathrm{CR}=13.5$ was comparable to that at 14.5 probably due to relatively leaner operation. The extent of de-rating in brake power was about $16.7 \%$ at $\mathrm{CR}=17$ and increased to as high as $26 \%$ at $\mathrm{CR}=11.5$ compared with baseline operations in diesel mode.

\begin{tabular}{|c|c|c|c|c|c|c|}
\hline CR & $\begin{array}{c}\text { IGN, } \\
\text { BTC }\end{array}$ & $\Phi$ & $\begin{array}{c}\text { Net Elec. } \\
\text { Power, kWe }\end{array}$ & $\begin{array}{c}\text { Net Brake } \\
\left.\text { Power } \mathbf{( B P}_{\text {Net }}\right), \\
\mathbf{k W}\end{array}$ & $\begin{array}{c}\text { Mixture } \\
\text { Energy } \\
\text { Density, } \\
\text { MJ/kg }\end{array}$ & $\begin{array}{c}\text { Efficiency : } \\
\text { Gas-to- } \\
\text { Shaft, \% }\end{array}$ \\
\hline 17.0 & 06 & 1.10 & 17.5 & 20.0 & 2.20 & 30.7 \\
\hline 14.5 & 10 & 1.10 & 16.4 & 18.8 & 2.20 & 29.0 \\
\hline 13.5 & 14 & 1.06 & 16.2 & 18.6 & 2.10 & 29.3 \\
\hline 11.5 & 15,17 & 1.07 & 15.3 & 17.6 & 2.20 & 27.5 \\
\hline
\end{tabular}

$\Phi=$ Equivalence Ratio: (Actual fuel- to- air ratio)/(Stoichiometric fuel- to- air ratio)

Table 3. Maximum net engine output at varying CR

\begin{tabular}{|c|c|c|c|c|c|c|c|}
\hline $\begin{array}{l}\text { IGN, } \\
\text { BTC }\end{array}$ & $\Phi$ & $\mathbf{B P} \mathbf{P}_{\text {net }}, \mathbf{k W}$ & $\eta, \%$ & $\begin{array}{l}\text { IGN, } \\
\text { BTC }\end{array}$ & $\Phi$ & $\mathbf{B} \mathbf{P}_{\text {net}}, \mathbf{k W} *$ & $\eta, \%$ \\
\hline \multicolumn{4}{|c|}{$\mathrm{CR}=17.0$} & \multicolumn{4}{|c|}{$\mathrm{CR}=14.5$} \\
\hline 06 & 1.10 & 20.0 & 30.8 & 08 & 1.20 & 18.6 & 25.0 \\
\hline 12 & 1.00 & 19.8 & 31.0 & 10 & 1.10 & 18.8 & 29.0 \\
\hline 17 & 1.09 & 18.4 & 29.0 & 16 & 1.11 & 17.9 & 27.5 \\
\hline 22 & 1.03 & 17.9 & 28.0 & 20 & 1.11 & 17.7 & 27.2 \\
\hline 26 & 1.10 & 16.2 & 25.3 & & & & \\
\hline 33 & 1.25 & 14.0 & 19.0 & & & & \\
\hline \multicolumn{4}{|c|}{$\mathrm{CR}=13.5$} & \multicolumn{4}{|c|}{$\mathrm{CR}=11.5$} \\
\hline 08 & 1.05 & 18.2 & 28.6 & 06 & 1.07 & 17.0 & 27.0 \\
\hline 14 & 1.06 & 18.6 & 29.0 & 15,17 & 1.07 & 17.6 & 27.5 \\
\hline 18 & 1.07 & 17.0 & 27.8 & 27 & 1.09 & 15.6 & 25.5 \\
\hline 25 & 1.06 & 17.0 & 28.0 & 38 & 1.07 & 13.3 & 20.0 \\
\hline
\end{tabular}

* Excluding Radiator Fan Power

Table 4. Maximum net engine output as a function of ignition timing at varying $\mathrm{CR}$ 
The net brake output with producer gas at varying ignition timing for the four different CRs tested is shown in Table 4. It is evident from the above data that ignition timing had to be retarded with the increase in $\mathrm{CR}$ in order to obtain higher output. This is because the thermodynamic conditions in terms of pressures and temperature are more severe at higher $\mathrm{CR}$ and thereof the combustion is faster thus calling for the optimum ignition timing to be located close to TC. The maximum output was recorded at an ignition advance of $6^{\circ} \mathrm{BTC}$ at $\mathrm{CR}=17$ and increased to about $15-17^{\circ} \mathrm{BTC}$ at a $\mathrm{CR}=11.5$. At intermediate $\mathrm{CR}$ of 14.5 and 13.5 the ignition advance was 10 and $14^{\circ} \mathrm{BTC}$ respectively. The fuel-air equivalence ratio was about $1.06 \pm 0.5$ in most of the cases, with efficiency of 30.7 and $27.5 \%$ corresponding to maximum output at higher and lower CRs respectively (Sridhar et al., 2001).

The incremental gain in maximum power and efficiency per unit $C R$ is well within the range quoted in literature. The gain in power was between 2.2 and 2.6 per unit CR, but the gain in efficiency was marginally lower. However, these figures are well within the range of 1 to $3 \%$ gain per unit increment of CR reported by Heywood (1988).

\subsubsection{In-Cylinder pressure measurements}

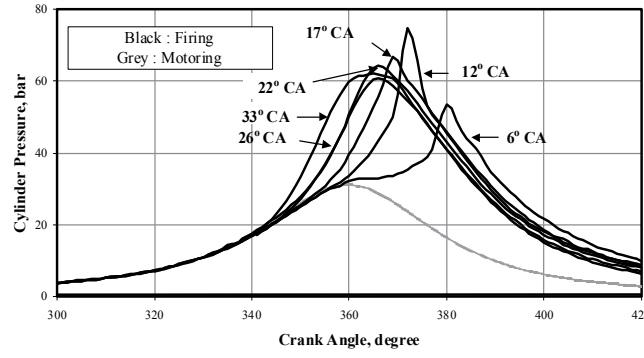

$\mathrm{CR}=\mathbf{1 7}$

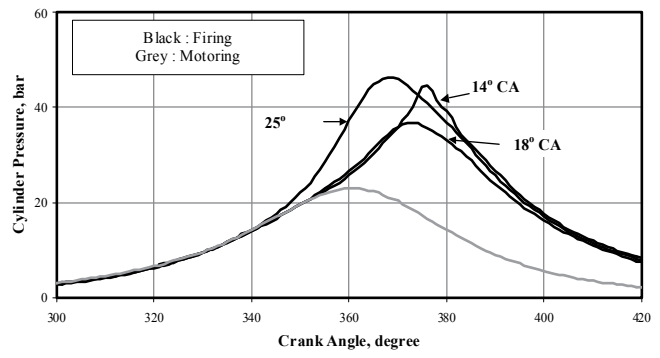

$\mathrm{CR}=\mathbf{1 3 . 5}$

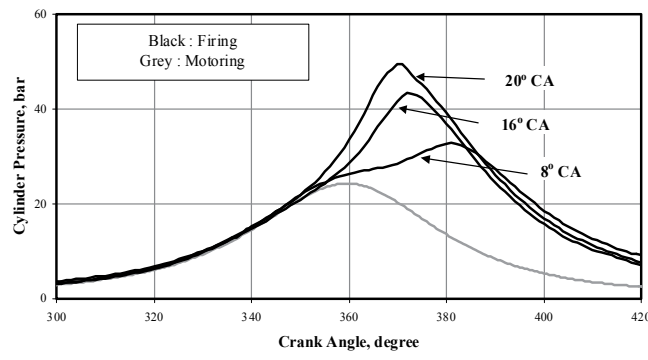

$\mathrm{CR}=\mathbf{1 4 . 5}$

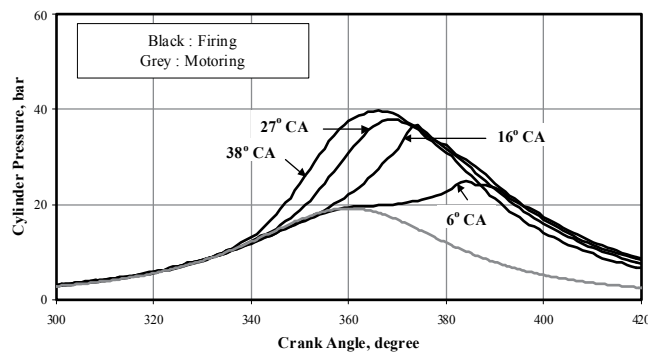

$\mathrm{CR}=\mathbf{1 1 . 5}$

Fig. 4. p- $\theta$ Recording corresponding to maximum brake output at different ignition advance and varying CRs. (Ensemble-averaged data over 30 consecutive cycles)

The pressure-crank angle $(p-\theta)$ recording is shown in Fig. 4 at different CRs, none of these show any trace of knock for all ranges of load inclusive of peak. These figures contain ensemble average data over thirty consecutive cycles. It is clear from these curves that smooth and normal combustion seemed to occur even at advanced ignition timing of $33^{\circ} \mathrm{CA}$ corresponding to CR of 17. Faster burn rate due to presence of hydrogen in the fuel gas could be the principal factor for the no-knock performance. The effect of the ignition 
advance on the pressure history is evident from the above curves. There are substantial differences in the maximum cylinder pressure and their point of occurrence. The ratio of maximum cylinder pressure between the highest and the lowest $\mathrm{CR}$ at corresponding ignition timing is about 2 .

The net work delivered over a complete cycle can be found by integrating the pressurevolume $(\mathrm{p}-\mathrm{v})$ data over the four processes. This had also helped in identifying the optimum ignition timing for a given CR - commonly referred as MBT (Maximum Brake Torque). The net indicated mean effective pressure (IMEP) obtained from the integrated $p-v$ data is a measure of effectiveness with which an engine of a given volumetric displacement converts the input energy into useful work. The IMEP obtained from ensemble average $p-v$ data $(\sim 30$ cycles) at varying $C R$ as a function of ignition timing is shown in Figure 5. At $C R=17$, the maximum IMEP recorded is 5.98 bar corresponding to a ignition timing of $6^{\circ} \mathrm{CA}$ and this declined to 4.85 bar with ignition timing being $15^{\circ} \mathrm{CA}$ at $\mathrm{CR}$ of 11.5 . These values are obtained at $\Phi=1.08 \pm 0.2$ and fall within the anticipated value of $\Phi=1.0$ to 1.1 (Heywood, 1988). It is also evident from the plot that variations in the IMEP values are modest between ignition timings of 6 and $12^{\circ} \mathrm{CA}$ corresponding to $\mathrm{CR}=17$.

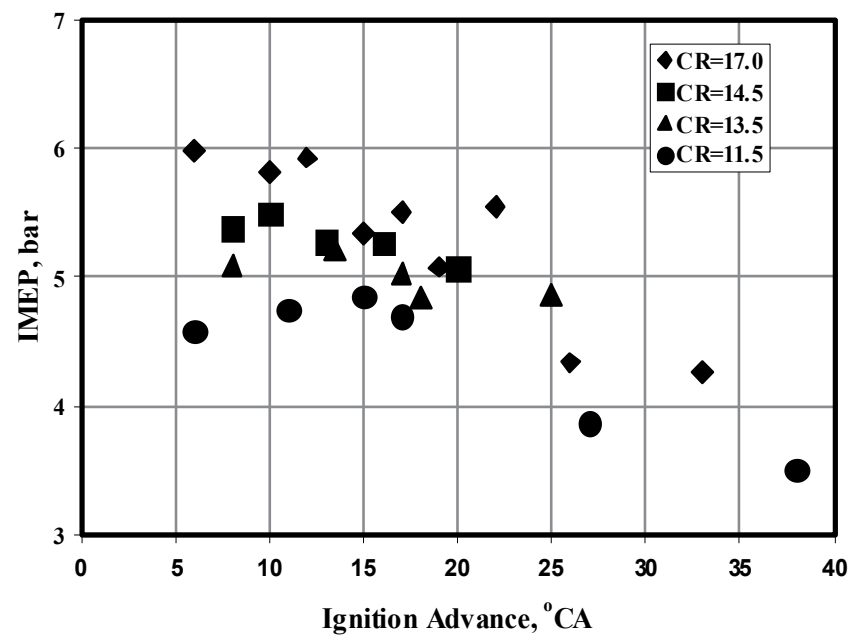

Fig. 5. Variation of IMEP (Net) with ignition advance at various CRs

Exploring further the $\mathrm{p}-\theta$ data, the peak pressure and the point of occurrence at ignition timings close to MBT are listed in Table 5. These measurements are accurate within $-1.0^{\circ}$ CA (due to possible lag in the signal and error in TC identification). The coefficient of variation of the IMEP at all CRs and ignition settings occurred well within 3-3.5\%, implying low cycle-to-cycle variation. The reason for low cyclic variation is the faster rate of combustion occurring inside the engine cylinder. The faster rate of combustion is attributed to higher flame speeds due to the presence of hydrogen in the gas and also to the combustion chamber design.

\subsubsection{Nitric oxide emission from the engine}

The Nitric oxide (NO) emission from the engine was measured. The variation of $\mathrm{NO}$ in gas mode at varying $\mathrm{CR}$ with ignition advance is shown in Fig. 6 . The NO level reduced with 


\begin{tabular}{|c|c|c|c|}
\hline CR & Ign. Advance, ${ }^{\circ}$ CA & Peak pressure, bar & Occurrence, $^{\circ}$ ATC \\
\hline 17.0 & 6 & 55.00 & 20 \\
\hline 14.5 & 10 & 43.30 & 19 \\
\hline 13.5 & 14 & 45.00 & 17 \\
\hline 11.5 & 15,17 & $33.00,38.00$ & 17,12 \\
\hline
\end{tabular}

Table 5. Cylinder Peak Pressures and Their Occurrence

the retardation of ignition timing and this feature is observed for all CRs. The NO level is observed to be maximum at the highest $\mathrm{CR}$ with advanced ignition timings, whereas in the MBT range of 6 to $20^{\circ} \mathrm{BTC}$ the NO is lower and comparable in almost all the cases. It is well known that $\mathrm{NO}$ generation is strongly dependent on the temperature, oxygen availability and residence time in the combustion chamber. With the flame speed of the gas mixture being high, the ignition setting is retarded whereby the residence time in the high temperature combustion chamber is automatically reduced. Therefore the low NO levels at retarded ignition setting are an expected and consistent behavior. The above results match well with those quoted by Heywood [1988], which shows small to modest variation of NO with CR.

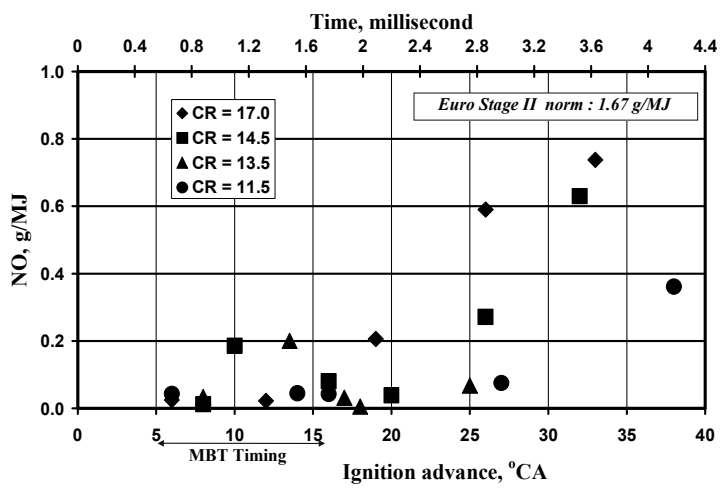

Fig. 6. Variation of NO with Ignition Advance at Various CRs

\subsection{Summary of the experimental work}

Performance of the engine at higher $C R$ is smooth and it has been established that the engines using producer gas in SI mode at CR up to 17 is feasible. This is obvious from the p$\theta$ curve, which shows a smooth rise in pressure without any pressure oscillations. A shorter duration of combustion has been observed with producer gas fuel, requiring retardation of the ignition timing to achieve MBT. These faster burning cycles are corroborated by low cyclic pressure fluctuations with coefficient of variation $\sim 3 \%$. The faster burning process is due to higher flame speed of the fuel - air mixture and this is attributed to the hydrogen content in the gas. The MBT arrived from this study is much retarded than claimed by the earlier researchers. The MBT in the current case are in the range between 6 and $17^{\circ} \mathrm{CA}$ for CR range between 17 and 11.5 against $30-45^{\circ} \mathrm{CA}$ (for a CR of 11.5 and below) claimed by the earlier researchers. This change in ignition advance in the present study can only be attributed to the improved producer gas composition.

The maximum de-rating in power is observed to be $16.7 \%$ in gas mode compared to diesel operations at comparable CR. The extent of de-rating is much lower when compared to any 
of the previous studies (Parke et al., 1981; Ramachandra, 1993; Martin et al., 1981). This value matches with a similar kind of de-rating reported (Das \& Watson, 1997) with natural gas operation. However, the brake thermal efficiency drops down by $5 \%$ compared to normal diesel mode of operation. This is related to excessive heat loss to the coolant at all CRs. The emission in terms of NO is found to be much lower.

\section{Modeling of engine processes}

The ability to utilize experimental data in new situations and conditions other than those where experiments are conducted is truly enhanced by using mathematical modeling. Modeling is classified as thermodynamic or fluid dynamic either based on energy conversation or on a complete analysis of fluid flow (Heywood, 1988). The thermodynamic models are more popularly known as zero-dimensional, phenomenological or quasidimensional models. The fluid-dynamic based models are often multidimensional due to their inherent ability to provide detailed information of the flow field and involves solving of governing equations of flow. Both the approaches are presented here. Initially the zero dimensional modeling results are validated against the experimental results; the limitations are identified and further a three dimensional CFD based modeling results are presented. Both the zero dimensional and three dimensional modeling require certain fuel related properties as input to the model. One among them is the laminar burning velocity $\left(S_{\mathrm{L}}\right)$ of a gaseous fuel, which is function of fuel composition, reactant pressure and temperature. Laminar burning velocity for fuel-air mixture can be determined either from experiments or theoretical calculations. The data relating to laminar burning velocity $\left(S_{\mathrm{L}}\right)$ of typical producer gas is given in Sec. 4.1

\subsection{Zero dimensional modeling}

The model comprises of sub-models to simulate the four processes of reciprocating engine cycle namely intake, compression, heat release followed by expansion and exhaust. The various sub-models used in the above simulation are (a) the filling and emptying technique for intake and exhaust processes (Heywood, 1988) as outlined, (b) Eddy Entrainment and Laminar Burn-up (EELB) model (Keck, 1982) for simulation of heat release, and (c) the heat loss due to convection based on Annand's convective heat transfer correlations (Annand, 1963; Baruah, 1986). The flame propagation (or heat release) is modelled as a two-zone model, where a thin wrinkled multi-connected laminar flame separates the burned and the unburned mixture. The EELB model (Keck, 1982) is represented by two equations namely,

$$
\begin{aligned}
& \frac{d m_{b}}{d t}=\rho_{u} A_{f} S_{l}+\frac{\mu}{\tau_{b}} \\
& \frac{d \mu}{d t}=\rho_{u} A_{f} u_{T}-\frac{\mu}{\tau_{b}}
\end{aligned}
$$$$
\text { Where } \quad \mu=\rho_{u} \ell_{T}\left(A_{\ell}-A_{f}\right)
$$

Eq. (2a) represents the mass burn rate, whereas Eq. (2b) represents the rate of change of mass of unburned mixture within the flame front. In these equations, there are two quantities, namely the characteristic speed $\left(u_{T}\right)$ and length $\left(\ell_{T}\right)$, which could be related to the turbulence parameters namely $u^{\prime}$ and $l_{I}$. Turbulence parameters namely turbulence intensity and length scales are extracted from the CFD results and used as a 0-D model 
input. It was further assumed that during combustion, the unburned mixture undergoes isentropic compression sufficiently rapidly for the simple distortion process to occur. These are given as follows:

$$
u^{\prime}=u_{0}{ }^{\prime}\left(\rho_{u} / \rho_{0}\right)^{1 / 3} ; l_{I}^{\prime}=l_{I, 0}^{\prime}\left(\rho_{u} / \rho_{0}\right)^{-1 / 3}
$$

where $\rho_{u}$ refers to the density of the unburned gas, $\rho_{0}$ refers the state at the start of combustion, $u^{\prime}$ and $u_{0}^{\prime}$ refers to turbulence intensity under reacting and non-reacting conditions respectively, similarly $l_{I}^{\prime}$ and $l_{I, 0}^{\prime}$ refers to integral length scale under reacting and non-reacting conditions respectively.

\subsubsection{Zero Dimensional modeling results}

In these computations, appropriate fuel-air mixture recorded during experiments constituted the input energy (IE). The recycled gas fraction in the total air + fuel mixture was calculated in the gas exchange process of the thermodynamic cycle simulating firing conditions. In the Table 6, Case No. 1 (in italics) corresponding to an ignition advance of $26^{\circ}$ $\mathrm{CA}$ at $\mathrm{CR}=17.0$ was used as a trial case for choosing the coefficients for the heat loss equation. The computed $\mathrm{p}-\theta$ curves and their comparison with experimental results are given below.

\begin{tabular}{|c|c|c|c|c|c|c|c|c|}
\hline $\begin{array}{c}\text { Case } \\
\text { no. }\end{array}$ & \multirow{2}{*}{$\mathbf{C R}$} & \multicolumn{3}{|c|}{ Composition, Vol \% } & \multirow{2}{*}{$\boldsymbol{T}$} & \multirow{2}{*}{$\mathbf{I}^{*}$} & $\begin{array}{c}\text { Ign, } \\
{ }^{\circ} \mathbf{C A}\end{array}$ & $\begin{array}{c}\text { Ign delay, } \\
{ }^{\mathbf{C}} \mathbf{C A}\end{array}$ \\
\hline & & $\mathbf{H}_{\mathbf{2}}$ & $\mathbf{C O}$ & $\mathbf{C H}_{\mathbf{4}}$ & & & & \\
\hline 1 & 17.0 & 20.8 & 16.2 & 2.0 & 1.10 & 1.70 & 26 & 12 \\
\hline 2 & 17.0 & 21.0 & 18.6 & 2.0 & 1.03 & 1.70 & 22 & 9 \\
\hline 3 & 17.0 & 21.5 & 16 & 2.5 & 1.09 & 1.69 & 17 & 9 \\
\hline 4 & 17.0 & 2.10 & 19.2 & 2.0 & 1.00 & 1.69 & 12 & 9 \\
\hline 5 & 17.0 & 20.0 & 20.0 & 2.0 & 1.10 & 1.73 & 6 & 6 \\
\hline 6 & 13.5 & 20.0 & 15.0 & 2.5 & 1.06 & 1.62 & 25 & 9 \\
\hline 7 & 13.5 & 20.0 & 15.0 & 2.5 & 1.07 & 1.63 & 18 & 9 \\
\hline 8 & 13.5 & 20.0 & 15.7 & 2.5 & 1.06 & 1.63 & 14 & 9 \\
\hline 9 & 11.5 & 18.0 & 18.0 & 2.5 & 1.09 & 1.63 & 27 & 9 \\
\hline 10 & 11.5 & 21.0 & 20.0 & 2.0 & 1.07 & 1.70 & 17 & 9 \\
\hline 11 & 11.5 & 19.5 & 20.0 & 2.0 & 1.07 & 1.66 & 6 & 6 \\
\hline
\end{tabular}

* I=Input Energy/cycle, kJ

Table 6. Principal Parameters of the Test Cases Used in the 0-D Computations

\subsubsection{Computational results at advanced ignition setting}

The results of five test cases (Case Nos. 1, 2, 6, 7, 9 in Table 6) are discussed here. The ignition settings of these cases are between 18 and $27^{\circ} \mathrm{CA}$. All the five cases are computed with the well-observed phenomenon of a spherical flame propagating into the unburned mixture. With the ignition occurring at the pre-set time, a flame kernel forms at the ignition site. During the ignition delay period, the flame kernel is assumed to move vertically downward due to the surrounding turbulent fluid flow. Subsequent to the ignition delay period, the EELB model of flame propagation is invoked wherein a spherical flame is assumed to propagate into the unburned mixture, with continued movement of the flame 
due to local fluid velocities. This spherical flame propagation continues till the flame encounters a wall, further the entrained unburned mixture is assumed to burn exponentially. During the quasi-steady flame propagation, typical turbulent burning velocities are of the order of $7-9 \mathrm{~m} / \mathrm{s}($ at $C R=17.0)$ and time scale of the order of $0.5-0.6 \mathrm{~ms}$ during the initial stages of flame propagation, and once the flame reaches the wall, time scale for exponential burning is of the order of 0.8 to $1.0 \mathrm{~ms}$ and somewhat similar to the value $(0.6$ to $1.0 \mathrm{~ms}$ ) reported (Keck, 1982). The computations one each for every CR is shown in Fig. 7 a - c. The computed results at all CRs matched reasonably well with the experimental data.

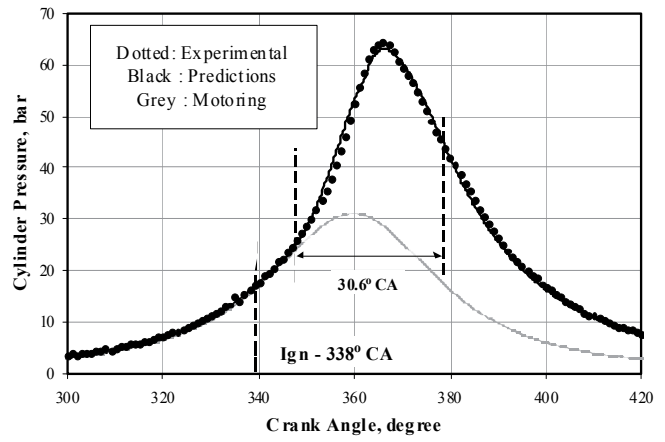

(a) $\mathrm{CR}=17 ; \operatorname{Ign}=22^{\circ} \mathrm{CA}$

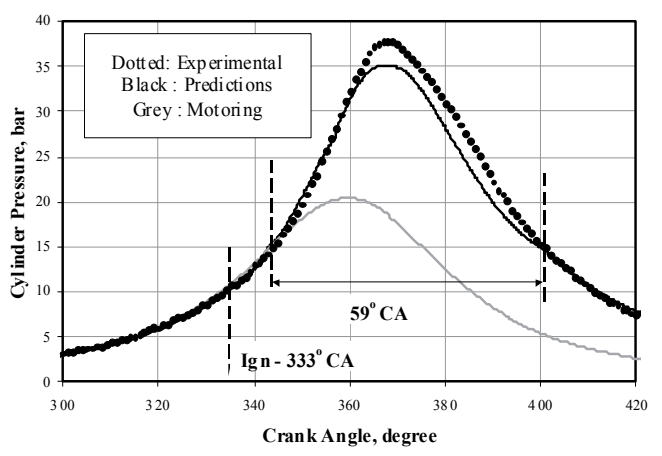

(c) $\mathrm{CR}=11.5 ; \operatorname{Ign}=27^{\circ} \mathrm{CA}$

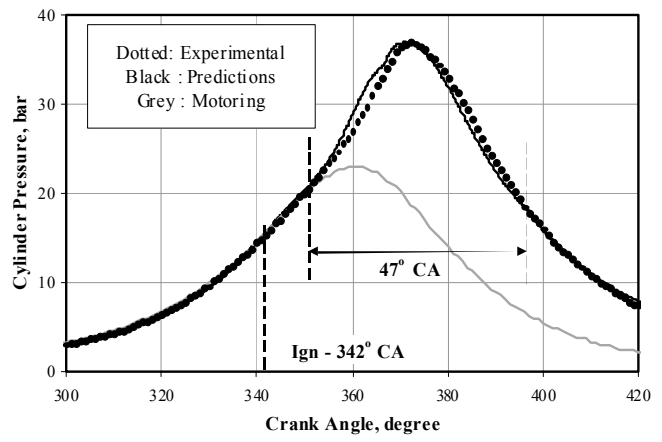

(b) $\mathrm{CR}=13.5 ; \operatorname{Ign}=18^{\circ} \mathrm{CA}$

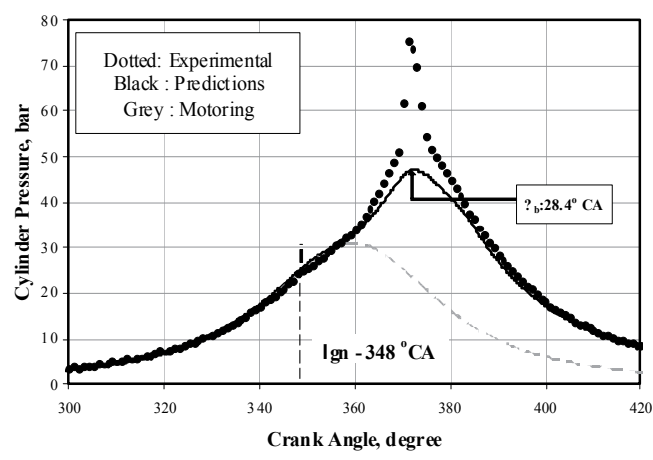

(d) $\mathrm{CR}=17 ; \operatorname{Ign}=12^{\circ} \mathrm{CA}$

Fig. 7. p- $\theta$ Computation at varied CRs and with different Ignition Advances

\subsubsection{Computational results at less advanced ignition setting}

The results of six test cases corresponding to less advanced ignition setting (Case Nos. 3, 4, $5,8,10,11$ in Table 6) are discussed here. Computations using spherical flame assumption were made for all the six test cases, one test result corresponding to $\mathrm{CR}=17$ at $12^{\circ} \mathrm{CA}$ ignition advance is shown in Fig. 7 (d). From the figure it is evident that there is deviation in the computed pressures beyond a certain crank angle (CA). At careful look at the experimental curve shows that there is a steep rise in the cylinder pressure. Therefore, at less advanced ignition setting the enhanced fluid dynamics due to reverse squish flow could be modifying the burn rate to such an extent that there is a steep rise in cylinder pressure. The cold flow CFD studies (Sridhar et al., 2004) clearly indicate high velocity jets coming out of 
the bowl and reentering the cylinder during reverse squish period. And whenever major part of the combustion occurred during this time, there appears to be abrupt increase in the burn rate leading to steep pressure rise. This effect is observed to be more severe at higher CR of 17 and 13.5 as compared to $C R=11.5$. This could be true because, the peak reverse squish velocities (without combustion) with $C R=17$ is of the order of $31 \mathrm{~m} / \mathrm{s}$ as against 6 $\mathrm{m} / \mathrm{s}$ for $\mathrm{CR}=11.5$ (Sridhar et al., 2004). Therefore, the deviations in the computed results at $\mathrm{CR}=11.5$ is lower compared to $\mathrm{CR}=17$ and 13.5.

Furthermore, the 0-D model is used to estimate the work produced in a completed thermodynamic cycle by integrating the pressure-volume data over a complete cycle resulting in indicated power (IP). At advanced ignition timing, the 0-D model is able to make reasonably good predictions by assuming the conventional spherical flame propagation model. The IP is under-predicted by about $3 \%$ for $C R=17.0$ and 11.5 , and between 5 and $8 \%$ for the other two cases at $C R=13.5$. In all the eleven test cases that were discussed, for higher CR of 17 and 13.5 the error in the $0-\mathrm{D}$ prediction is large in around ignition advance of 6 and $12^{\circ} \mathrm{CA}$ respectively. Whereas, for lower $\mathrm{CR}=11.5$ the error in 0 -D prediction is of the order of $5-6 \%$. This under- predication is attributed to the strong complex fluid flow-flame interaction occurring during the reverse squish period, which requires a detailed 3-D CFD modelling to understand the phenomenon. The results of one such study are given in the following section.

\subsection{Multi-dimensional modeling}

Combustion problems involve strong coupling between chemistry, transport and fluid dynamics. Multi-dimensional turbulent combustion models are expected to simulate turbulent flames and to provide an estimation of mean production or consumption rates of chemical species. They need to be based on known quantities (mean flow characteristics, for example) or on quantities that may be easily modelled or obtained from closed balance equations. Three main types of approaches are; scalar dissipation rate estimation, geometrical analysis, and statistical method (Veynante \& Vervisch, 2002). In the geometrical analysis, the flame is described as a geometrical surface. This analysis is generally linked to the assumption of a sufficiently thin flame, viewed as an interface between fresh and burnt gases in premixed combustion. Two formalisms of geometrical analysis are; G-field equation and flame surface density (FSD) concept. The FSD approach is explained below.

\subsubsection{Flame surface density model}

In this model, the flame is identified as a surface and the flame surface density $(\Sigma)$ is the available flame area per unit volume. The mean burning rate of an $i^{\text {th }}$ specie $\left(\overline{\dot{\omega}}_{i}\right)$ is modelled as:

$$
\overline{\dot{\omega}}_{i}=\dot{\Omega}_{i} \Sigma
$$

where $\dot{\Omega}_{i}$ is the mean local burning rate per unit flame area integrated along the normal direction to the flame surface. The main advantage of this formulation is to decouple the chemical description from the flame/turbulence interaction. The mean consumption rate per unit volume at a point in the flow is determined as the product of flame surface density at that point and the volume consumption rate per unit of flame area, obtained from the 
analysis of local strained laminar flamelets. Thus the mean burning rate of an $i^{\text {th }}$ species, $\overline{\dot{\omega}}_{i}$ in a stretched laminar flamelet regime is given as,

$$
\overline{\dot{\omega}}_{i}=\rho_{u} Y_{u, i} I_{0} S_{L} \Sigma
$$

where $\rho_{u}$ is the density of unburnt reactant mixture ahead of flame front,

$Y_{u, i}$ is the mass fraction of the $i$ th species,

$I_{0}$ is the mean stretch factor of stretched laminar flamelet in turbulent mixture,

$S_{L}$ is the laminar burning velocity of the fuel.

The flame surface density $(\Sigma)$ is estimated by solution of a balance equation. The balance equation for flame surface density $(\Sigma)$ can be written as:

$$
\frac{\partial \Sigma}{\partial t}+\nabla \cdot(U \Sigma)=\nabla \cdot\left(\frac{v_{t}}{\sigma_{\Sigma}} \nabla \Sigma\right)+S-D
$$

where $S$ is the production rate of flame surface density $(\Sigma)$ by turbulent rate of strain, and $D$ is the annihilation rate of flame surface density by mutual collision. $v_{t}$ is the turbulent kinematic viscosity, and $\sigma_{\Sigma}$ is the flame surface turbulent Schmidt number. The above

\begin{tabular}{|c|c|c|}
\hline Model & $S$ & $D$ \\
\hline Cheng model (Cheng et al., 1991) & $\alpha \sigma \frac{\varepsilon}{k} \Sigma$ & $\frac{\beta S_{L} \Sigma^{2}}{\left(\bar{Y} / Y_{0}\right)}$ \\
\hline CFM-2 model (Choi \& Huh, 1998) & $\alpha \frac{u^{\prime}}{l_{t c}} \Sigma$ & $\frac{\beta S_{L} \Sigma^{2}}{\left(\bar{Y} / Y_{0}\right)\left[1-\left(\bar{Y} / Y_{0}\right)\right.}$ \\
\hline $\begin{array}{l}\text { Modified FSD model (Yarasu, } \\
\text { 2009) }\end{array}$ & $\alpha \frac{u^{\prime}}{l_{t}} \Sigma \quad$ where $\quad l_{t} \geq l_{t w}$ & $\frac{\beta S_{L} \Sigma^{2}}{\left(\bar{Y} / Y_{0}\right)\left[1-\left(\bar{Y} / Y_{0}\right)\right.}$ \\
\hline
\end{tabular}
equation is an exact balance equation with unclosed terms, $S$ and $D$.

Table 7. Production term, $S$ and Annihilation, $D$ of flame in Eq. (6)

The main focus of modelling is the production and annihilation terms, $S$ and $D$. The summary of available closures of $S$ and $D$, are given in the literature (Veynante \& Vervisch, 2002). Formulation of $S$ and $D$ used in present simulations is explained.

\section{- $\quad$ Production term $S$}

The term $S$ is proportional to $\Sigma$ in all models as shown in Table 7. It is given as a product of the average rate of strain and the flame surface density. The average rate of strain may be estimated as $1 / \tau_{t}$ from the rate of strain of large energy-containing eddies. The symbol $\varepsilon$ represents the dissipation rate of turbulent kinetic energy, $k$. In CFM-2 model (Choi \& Huh, 1998), the average rate of strain is given proportional to $u^{\prime}$ and production term $S$ is given as:

$$
S=\alpha \frac{u^{\prime}}{t_{t c}} \Sigma
$$

where $l_{t c}$ is an arbitrary length scale which was introduced for dimensional consistency. $l_{t c}$ value $1.26 \mathrm{~mm}$ was suggested for constant volume combustion in a closed vessel (Choi \& 
Huh, 1998). Also, it was suggested to combine this constant value with the model tuning constant $\alpha$. A particular value of $l_{t c}$ will be suitable only for a particular value of turbulent length scale in a closed vessel of isotropic turbulence. If $l_{t c}$ is replaced with turbulent integral length scale $l_{t}$ and specifying a limiting cut off value near the wall, the model would be suitable for simulation of both the constant volume combustion in a closed vessel and engine combustion of varied turbulent length scales. Hence in the modified FSD model (Yarasu, 2009), production term $S$ is used as;

$$
S=\alpha \frac{u^{\prime}}{l_{t}} \Sigma \text { where } \quad l_{t} \geq l_{t w}
$$

where $l_{t w}$ is cut-off turbulent integral scale near the wall. The limiting value near the wall prevents the unphysical flame generation and acceleration along the wall. The cut-off value $l_{t w}$ to be determined with help of a plot (Yarasu \& Paul, 2007) of $l_{t}$ in the domain or it may also be taken as an average integral length scale of entire domain.

\section{- Annihilation or Destruction term, D:}

The term $D$ is proportional to $\Sigma^{2}$ in almost all models (see Table 7). This is reasonable, since annihilation occurs due to collision between flame surfaces. In CFM-2 (Choi \& Huh, 1998) model, it is given as;

$$
D=\beta \frac{S_{L}}{\left(\bar{Y} / Y_{0}\right)\left[1-\left(\bar{Y} / Y_{0}\right)\right]} \Sigma^{2}
$$

where $\beta$ is model tuning constant. $\mathrm{S}_{\mathrm{L}}$ - Laminar burning velocity, $\bar{Y}=$ mean fuel mass fraction, and $Y_{0}=$ fuel mass fraction in the fresh mixtures. The denominator in the $D$ term of Cheng model is $\bar{Y} / Y_{0}$ (Cheng \& Diringer, 1991) while CFM-2 use $\left(\bar{Y} / Y_{0}\right)\left[1-\left(\bar{Y} / Y_{0}\right)\right]$. The EBU model is limiting form of the CFM-2 model for infinitely fast chemistry and steady balance between production and annihilation of flames. Hence, in the present model, the term $D$ is taken same as that of CFM-2 model. The predictions of CFM-2 model were tested in constant volume combustion chamber with hydrocarbon flames and the limitations were identified (Choi \& Huh, 1998; Yarasu et al., 2005). The modified FSD model was validated for constant volume combustion of producer gas-air mixture with initially induced turbulence. It was observed that there is a delay in development of initial flame kernel (Yarasu, 2009). Once the flame kernel is developed, the combustion rate is predicted well. The delay also depends on initial turbulent intensity in the domain. The delay decreases as the initial turbulent intensity increases. The delay was suitably compensated by offsetting ignition timing in the computations compare to experimental setting by advancing it about $3-4^{\circ} \mathrm{CA}$. The modified FSD model predictions for a critical case of CR 17 and varied ignition timing of $26^{\circ}, 12^{\circ}$ and $6^{\circ} \mathrm{CA}$ are given in the following section.

\subsubsection{Engine combustion simulation}

CFD simulation of producer gas engine combustion process was carried out using ANSYSCFX-10 software. The flame surface density (FSD) based combustion models are not available in ANSYS-CFX. Hence, it was implemented in ANSYS-CFX with user FORTRAN code for the source terms in transport equation of $\Sigma$, which is Eq.(6). During the 
compression and combustion process simulations, structured meshes having 0.04 to 0.1 million cells were used. K-epsilon turbulence model was used for flow simulation. Initial flame kernel was given by providing high flame surface density in a small volume comparable to the spark size at the time of ignition and location. The integral length scales in the domain along the line normal to the cylinder head surface at spark location was plotted in Fig. 8. This graph was used for determining the limiting value of $1_{\mathrm{tw}}$ near the wall of the domain, refer $\mathrm{Eq}(8)$. The slope of the curve near the wall at point $\mathrm{A}$, about $5 \mathrm{~mm}$ away from the wall, is growing steeper. A tangent drawn at point $\mathrm{A}$ intersects the ordinate at point $B$. The cut-off integral length scale value $l_{t w}$ near the wall is the value of $l_{t}$ at point $B$ which is equal to $3.4 \mathrm{~mm}$ for the computational domain considered. The point $\mathrm{A}$ was located intuitively. A more scientific method is required to fix the $1_{t w}$ value for a particular domain.

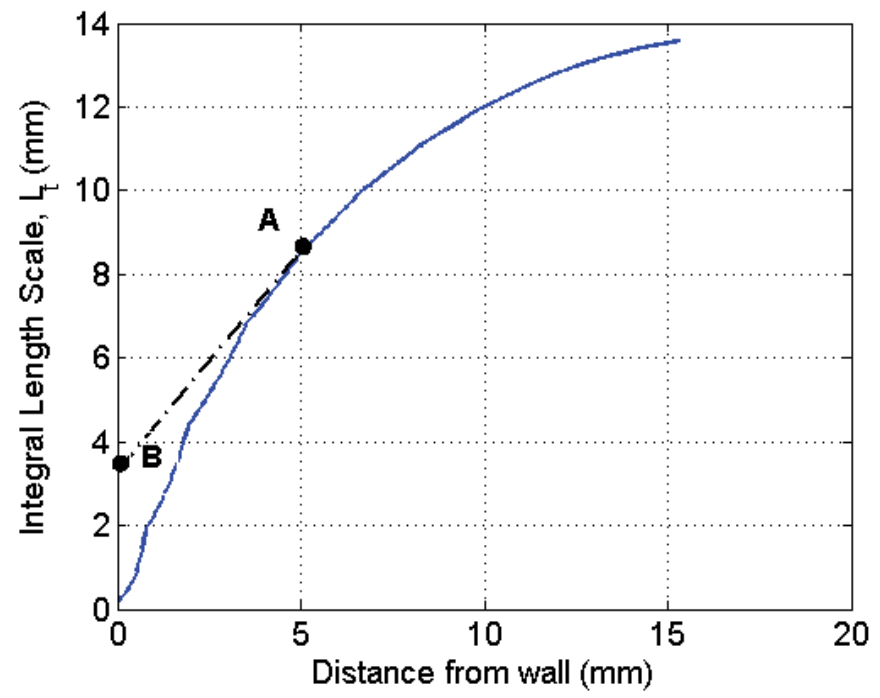

Fig. 8. Integral length scale plot

The modified FSD model prediction for a critical case of CR 17 and ignition timings of $26^{\circ}$, $12^{\circ}$ and $6^{\circ} \mathrm{CA} \mathrm{BTC}$ were compared below. The progress rate of combustion with different ignition timings was analyzed. The ignition timing in the simulation was advanced by $3-4^{\circ}$ $\mathrm{CA}$ in order to compensate initial flame kernel development (this was not so with the 0-D modelling). For ignition at $26^{\circ}$ BTC case, the simulated ( $3-\mathrm{D}$ and $\left.0-\mathrm{D}\right)$ and experimental p- $\theta$ values are compared in Fig. 9a. The products mass fraction profile is shown in the Fig. $9 \mathrm{~b}$. The flame front was touching bowl walls. The simulated 3-D pressure curve follows the experimental curve up to $351^{\circ} \mathrm{CA}$. During the combustion process, the shape of the flame remained very close to the spherical flame front and it was propagating in slightly suppressed turbulent flow field compared to the flow field that prevailed during the motoring operation. Thereafter, the 3-D model pressure values were over-predicted. The reason for over-predicting the pressure value could be due to higher flame generation near the walls, which is related to cut off value of $l_{\mathrm{tw}}$ near the wall (Fig.8). It also suggests that $\mathrm{l}_{\mathrm{tw}}$ value need to be increased with suitable criteria. However, the zero dimensional predictions are much closer to experimental values in this particular case. 


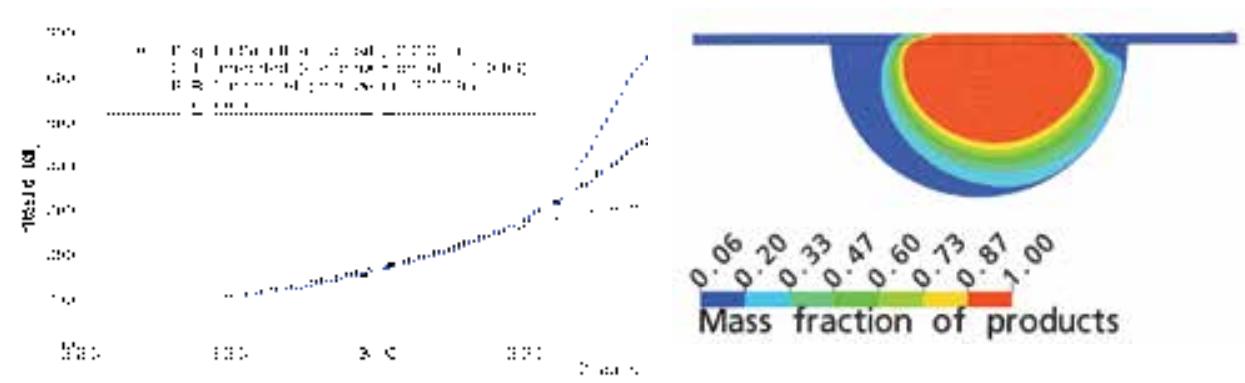

(a)

(b)

Fig. 9. Results at ignition advance of $26^{\circ} \mathrm{CA}$ (a) p- $\theta$ diagram comparison; (b) Product mass fractions profile at $354^{\circ} \mathrm{CA}$

For ignition at $12^{\circ}$ BTC case, comparison of the simulated (3-D and 0-D) with the experimental p- $\theta$ diagram of the engine is shown in Fig. 10a. The simulated pressure curve follows the experimental curve up to $363^{\circ} \mathrm{CA}$. Thereafter, the pressure values were slightly over predicted by FSD model. In this case, the flame approached the bowl walls by $363^{\circ} \mathrm{CA}$. The products mass fraction profile is shown in the Fig. 10b. The flame front was touching bowl walls. The burn rate was slightly over-predicted. It also suggests that $1_{t w}$ value need to be increased with suitable criteria. The FSD model under-predicted the peak pressure by $18 \%$ (Yarasu, 2009). However, it has the inherent ability to predict the higher burn rate during reverse squish period for this complex case. FSD model predicted pressure values have better matching compared to zero dimensional prediction.

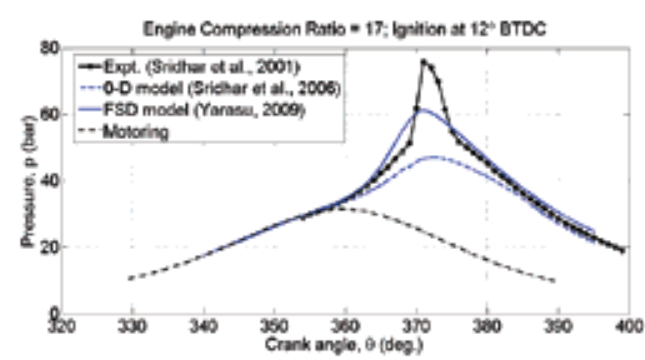

(a)

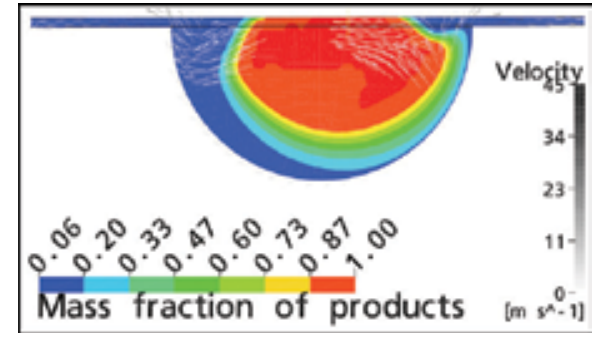

(b)

Fig. 10. Results at ignition advance of $12^{\circ} \mathrm{CA}$ (a) p- $\theta$ diagram comparison; (b) Product mass fractions profile at TC

For the ignition at $6^{\circ}$ BTC case, comparison of simulated (3-D and 0-D) and experimental p$\theta$ diagram of the engine is shown in Fig. 11a. The products mass fraction profile is shown in the Fig. $11 \mathrm{~b}$ when the flame front was touching bowl walls. Predicted pressure values were again, low compared to the experimental values. The simulated pressure curve matched well up to $370^{\circ} \mathrm{CA}$. Thereafter, the pressure values were slightly over-predicted by FSD model. The reason could be due to the slight higher burn rate predicted by the model when the flame surface is near the wall. However, the simulated curve still under-predicted the peak pressure by $9 \%$, but there is better match of predicted pressure values of FSD model compared to zero dimensional prediction. 


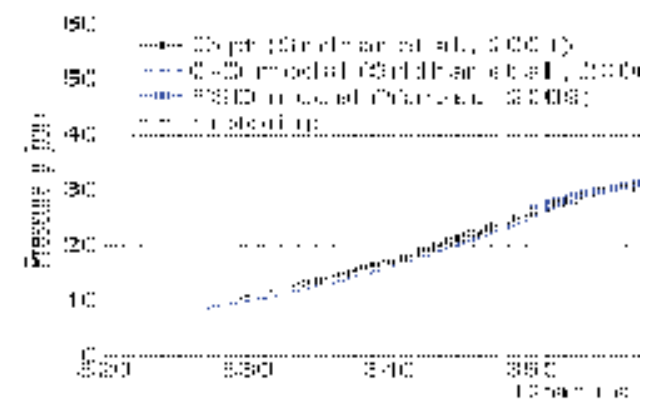

(a)

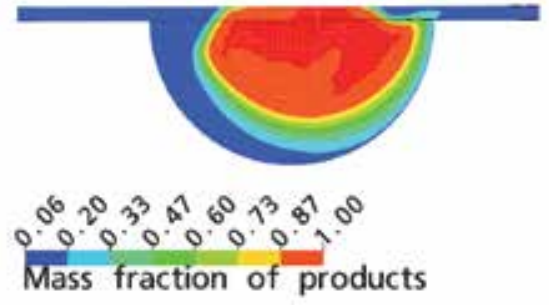

(b)

Fig. 11. Results at ignition advance of $6^{\circ} \mathrm{CA}$ (a) p- $\theta$ diagram comparison; (b) Product mass fractions profile at $370^{\circ} \mathrm{CA}$

\section{Conclusions}

The research findings have broken the compression ratio (CR) barrier and it is shown that the engine runs smoothly at CR of 17:1 without any tendency of knock or auto-ignition. Experiments at varying CRs have established the benefits of operating the engine at higher $\mathrm{CR}$ in terms of lower de-rating and better efficiencies. A simplified zero-dimensional model is able to predict the engine cylinder pressure versus time cycle and thereof the power output to reasonable accuracy for certain conditions but under-predicts the peak cylinder pressure at less advanced ignition timing or close to optimum ignition timing, in particular at higher CR. These were attributed to the complex fluid flow interaction, which is not possible to account using zero-dimensional modeling. Therefore, a turbulent combustion model based on flame surface density (FSD) approach with wall correction has been used for combustion simulations. The simulations with FSD model for these test cases are much improved compared to zero dimensional results but still falls short of the experimental results. It is however difficult to identify precise reason for these under-predictions until better understanding prevails on the existing models.

It is further anticipated that the knowledge accrued as a consequence of this research activity would help the gas engine community in better understanding of the complex combustion process using producer gas as the fuel; thereof serve as a basis in identifying the optimum operating conditions and also probably the combustion chamber design.

\section{Acknowledgement}

The work reported in this chapter is a consolidation of research work carried out by the authors between 1996 and 2009. Even though the research was carried out at different time periods, the authors have made a sincere attempt to present an integrated version of the work. The research work was entirely carried out at Combustion Gasification and Propulsion Laboratory, Indian Institute of Science, Bangalore, India under the supervision of Prof. H.S. Mukunda and Prof. P.J. Paul. The authors sincerely thank them. 


\section{Notations}

\begin{tabular}{|c|c|c|c|}
\hline$A_{f}, A_{l}$ & $\begin{array}{l}\text { Spherical flame and Laminar } \\
\text { burning area, } \mathrm{m}^{2}\end{array}$ & $\sigma_{\Sigma}$ & $\begin{array}{l}\text { flame surface turbulent Schmidt } \\
\text { number }\end{array}$ \\
\hline$l_{I}, l_{I, 0}^{\prime}$ & $\begin{array}{l}\text { Integral length under reacting \& } \\
\text { non-reacting condition, } m\end{array}$ & $k$ & turbulent kinetic energy, $\mathrm{m}^{2} / \mathrm{s}^{2}$ \\
\hline$\ell_{T}$ & Characteristic length, $\mathrm{m}$ & $\varepsilon$ & $\begin{array}{l}\text { dissipation rate of turbulent } \\
\text { kinetic energy, } \mathrm{m}^{2} / \mathrm{s}^{3}\end{array}$ \\
\hline$m_{b}$ & Mass of mixture burned, $\mathrm{kg}$ & $l_{t c}$ & arbitrary length scale, mm \\
\hline$p, p_{\mathrm{o}}$ & $\begin{array}{l}\text { Actual cylinder pressure and } \\
\text { reference pressure, bar }\end{array}$ & $l_{t}$ & turbulent integral length scale, $\mathrm{m}$ \\
\hline$S_{L}$ & Laminar burning velocity, m/s & $l_{t w}$ & cut-off value of $l_{t}$ near wall \\
\hline $\begin{array}{l}u^{\prime} \\
u_{0}^{\prime}\end{array}$ & $\begin{array}{l}\text { Turbulence Intensity under } \\
\text { reacting \& non-reacting condition, } \\
\mathrm{m} / \mathrm{s}\end{array}$ & $\beta$ & model tuning constant \\
\hline$u_{T}$ & Characteristic speed, $\mathrm{m} / \mathrm{s}$ & $\bar{Y}$ & mean fuel mass fraction \\
\hline$\rho_{u}$ & Unburned gas density, $\mathrm{kg} / \mathrm{m}^{3}$ & $Y_{0}$ & $\begin{array}{l}\text { fuel mass fraction in the fresh } \\
\text { mixtures }\end{array}$ \\
\hline$\rho_{0}$ & $\begin{array}{l}\text { Unburned gas density at the start } \\
\text { of combustion, } \mathrm{kg} / \mathrm{m}^{3}\end{array}$ & LCV & Lower Calorific Value, MJ/kg \\
\hline$\mu$ & Parametric mass, kg & CA & Crank Angle \\
\hline$\tau_{b}$ & Characteristic time, sec & $\mathrm{TC}$ & Top Dead Centre \\
\hline$\Phi$ & Fuel-air equivalence ratio & BTC & Before Top Dead Centre \\
\hline$\Psi$ & Recycled gas fraction & $\theta$ & Crank Angle \\
\hline $\bar{\theta}$ & Crank Angle & $p$ & Pressure, bar \\
\hline $\bar{\Sigma}$ & flame surface density, $\mathrm{m}^{-1}$ & $\mathrm{CR}$ & Compression Ratio \\
\hline$\dot{\Omega}_{i}$ & $\begin{array}{l}\text { mean local burning rate per unit } \\
\text { flame area integrated along the } \\
\text { normal direction to the flame } \\
\text { surface, } \mathrm{kg} / \mathrm{m}^{2} \mathrm{~s}\end{array}$ & $\tau_{t}$ & Turbulent time scale, s \\
\hline$\overline{\dot{\omega}}_{i}$ & $\begin{array}{l}\text { mean local burning rate of } i \text { th } \\
\text { species per unit volume, } \mathrm{kg} / \mathrm{m}^{3} \mathrm{~s}\end{array}$ & $\alpha$ & model tuning constant \\
\hline$Y$ & mass fraction & $\mathrm{CR}$ & Compression Ratio \\
\hline$I_{0}$ & mean stretch factor & MBT & $\begin{array}{l}\text { Minimum Advance for Brake } \\
\text { Torque }\end{array}$ \\
\hline$S$ & $\begin{array}{l}\text { production rate of flame surface } \\
\text { density }\left(\mathrm{m}^{-1} \mathrm{~s}^{-1}\right)\end{array}$ & IP & Indicated Power, kW \\
\hline$D$ & $\begin{array}{l}\text { Annihilation rate of flame surface } \\
\text { density }\left(\mathrm{m}^{-1} \mathrm{~s}^{-1}\right)\end{array}$ & $\mathrm{BP}$ & Brake Power, kW \\
\hline$v_{t}$ & $\begin{array}{l}\text { turbulent kinematic viscosity } \\
\left(\mathrm{m}^{2} / \mathrm{s}\right)\end{array}$ & IMEP & $\begin{array}{l}\text { Indicated Mean Effective } \\
\text { Pressure, bar }\end{array}$ \\
\hline FSD & Flame Surface Density, $\mathrm{m}^{-1}$ & PG & Producer gas \\
\hline
\end{tabular}




\section{References}

Annand, W. J. D. (1963). Heat Transfer in the Cylinders of Reciprocating I.C. Engines, Proc. Institution of Mechanical Engineers, Vol. 177, pp. 973-990

Anon, (1986). Wood gas as engine fuel, A Report of the Mechanical Wood Products Branch of FAO Forestry Paper No. 72, FAO of United Nations, Rome

Baruah, P.C. (1986). Combustion and Cycle Calculations in Spark Ignition Engines, in the Thermodynamics and Gas Dynamics of I.C. Engines, Vol. 2, pp. 823-865

Caris, D.F. \& Nelson, E.E. (1959). A New Look at High Compression Engines, SAE Transactions, Vol. 67, pp. 112-124

Cheng,W.K.\& Diringer, D. J. A. (1991). Numerical modelling of SI engine combustion with a flame sheet model. SAE paper 910268

Choi, C. R. \& Huh, K. Y. (1998). Development of coherent flamelet model for a spark-ignited turbulent premixed flame in a closed vessel. Combustion and flame, Vol. 114, pp. 336-348

Das, A. \& Watson, H.C. (1997). Development of a Natural Gas Spark Ignition Engine for Optimum Performance, Proc Institution of Mechanical Engineers, Part D, Vol. 211, pp. 361-378

Fleischer, F.; Grosse, W. \& Zapf H. (1981). Fuels From Biomass and Their Rational Utilisation in I.C. Engines, Proc International Conference - New Energy Conversion Technologies and Their Commercializations, Vol. 2, pp. 1334-1340

Heywood, J.B. (1988). I.C. Engine Fundamentals, International edition. McGraw-Hill

Kanitkar, S.; Chakravarthy, P.; Paul, P.J. \& Mukunda, H.S. (1993). The flame speeds, temperature and limits of flame propagation for producer gas-air mixturesexperimental results. Proc. of 4th meet on Biomass Gasification and combustion, pp. 50-62, Mysore, 6-8th Jan. 1993, Bangalore, India

Keck, C.J. (1982). Turbulent Flame Structure and Speed in Spark Ignition Engines, Proc Ninetieth International Symposium on Combustion, The Combustion Institute, Vol. pp. 1451-1466

KeshavaMurthy, T.V.; Ravi, M.R. \& Anjan Ray. (2004). Investigation of burning velocity of laminar premixed producer gas/air mixtures at various pressures and temperatures. Proc. of 17th National and 6th ISHMT/ASME Heat and Mass Transfer Conference, pp. 538-543, IGCAR, Kalpakkam, India.

Martin, J. \& Wauters, P. (1981). "Performance of Charcoal Gas I.C. Engines, Proc of International Conference - New Energy Conversion Technologies and Their Commercialization, Vol. 2, pp. 1415-1424

Mukunda, H.S.; Dasappa, S. \& Shrinivasa, U. (1993). Open-Top Wood Gasifiers, Renewable Energy - Sources for Fuels and Electricity, Island press, pp. 699-728

Mukunda, H.S.; Paul, P.J.; Dasappa, S.; Shrinivasa, U. \& Sharan, H. (1994). Results of an Indo-Swiss Programme For Qualification and Testing of a 300-kW IISc-Dasag Gasifier, Energy for sustainable development, Vol. 4, pp.46-49

Natarajan, J.; Lieuwen, T. \& Seitzman, J. (2007). Laminar flame speeds of h2/co mixtures: Effect of $\mathrm{co} 2$ dilution, preheat temperature, and pressure. Combustion and flame, Vol. 151, pp. 104-119

Parikh, P.P.; Banerjee, P.K.; Shashikantha \& Veerkar, S. (1995). Design Development and Optimisation of a Spark Ignited Producer Gas Engine, Proceedings of XIV National Conference on IC engines and Combustion, Vol. 14, pp. 97-107, Pune, India 
Parke, P.P.; Stanley, S.J. \& Walawnder, W. (1981). Biomass Producer Gas Fuelling of I.C. Engines, Energy From Biomass and Wastes V, pp. 499 -516, Florida

Parke, P.P. \& Clark, S.J. (1981). Biomass Producer Gas Fuelling of IC Engines - Naturally Aspirated and Supercharged Engines, American Society of Agricultural Engineers, Michigan, pp. 1-35

Ramachandra, A. (1993). Performance Studies on a Wood Gas Run IC engine Recent advances in biomass gasification and combustion. Proc. of 4th meet on Biomass Gasification and combustion, pp. 213-218, Bangalore, India

Ratnakishore, V.; Ravi, M.R. \& Anjan Ray. (2008). Effect of hydrogen content and dilution on laminar burning velocity and stability characteristics of producer gas air mixtures Int. Journal of Reacting flows, Vol. 2008, 1-8

Shashikantha; Banerjee, P.K.; Khairnar, G.S.; Kamat, P.P. \& Parikh, P.P. (1993). Development and Performance Analysis of a $15 \mathrm{kWe}$ Producer Gas Operated SI Engine, Proceedings of $4^{\text {th }}$ National Meet on Biomass Gasification and Combustion, Vol. 4, pp. 219-231 Mysore, India

Shashikantha \& Parikh, P.P. (1999). Spark Ignited Producer gas and Dedicated CNG Engine - Technology Development and Experimental Performance, SAE paper, 1999-013515 (SP-1482)

Sridhar, G.; Paul, P.J. \& Mukunda, H.S. (2001). Biomass Derived Producer Gas as a Reciprocating Engine Fuel - An Experimental Analysis, Biomass \& Bioenergy, Vol. 21, pp. $61-72$

Sridhar, G. (2003). Experiments and Modeling Studies of Producer Gas based Spark-Ignited Reciprocating Engines. PhD Thesis, Indian Institute of Science, Bangalore, India

Sridhar, G.; Paul, P.J. \& Mukunda, H.S. (2004). Simulation of fluid flow in a high compression ratio reciprocating internal combustion engine, Proc. IMechE Vol. 218 Part A: J. Power and Energy, No. 218, pp.403-416

Sridhar, G.; Paul, P.J. \& Mukunda, H.S. (2005). Computational studies of the laminar burning velocity of a producer gas and air mixer under typical engine conditions. Proc.IMechE Vol.Part A: Journal of Power and Energy, Vol.219, pp. 195-201

Sridhar, G.; Paul, P.J. \& Mukunda, H.S. (2006). Zero-dimensional modelling of a producer gas-based reciprocating engine, Proc. IMechE Vol. 220 Part A: J. Power and Energy, No. 220, pp.923-931

Tatom, J. W.; Colcord, A.R.; Williams, W.M.; Purdy, K.R. \& Beinstock, D. (1976). Development of a Prototype System for Pyrolysis of Agricultural and Forestry Wastes into Fuels and Other Products, Prepared for EPA

Veynante, D \& Vervisch, L. (2002). Turbulent combustion modeling. Progress in Energy and Combustion Science, Vol. 28, pp.193-266

Yarasu, R. B.; Nadkarni, V. \& Paul, P. J. (2005). Laminar and turbulent burning velocities of premixed hydrocarbon-air flames in closed cubical vessel. Proc. of 19th NCICEC, Chidambaram, India, pp.335-341

Yarasu, R. B. \& Paul, P. J. (2007). Simulation of Premixed Turbulent Combustion of Producer Gas in S. I. Engine. Proc. of Int. Conf.\&20th NCICEC, Hyderabad, India, pp.714-723

Yarasu, R. B. (2009). Premixed turbulent combustion of Producer gas in closed vessel and engine cylinder. PhD Thesis, Indian Institute of Science, Bangalore, India 


\section{Part 5}

Role of Technological Innovations and Emerging Technologies 



\title{
Electric Power from Rice Paddy Fields
}

\author{
Kazuya Watanabe and Koichi Nishio \\ The University of Tokyo \\ Japan
}

\section{Introduction}

One of the largest innovations in the twentieth century is the use of petroleum (and other fossil fuels, such as, coal, and natural gases) for the energy source that supports the human society. Petroleum is an easy-to-use, energy-intensive fuel as well as a material for a variety of chemical products. It is produced by pumping-up from natural underground reservoirs. In 2006, petroleum and other fossil fuels support $86 \%$ of the total energy supply for the human society (Energy Information Administration 2007), indicating that they are currently indispensable for us.

Recently, however, humans face problems associated with the use of fossil fuels. One of such problems is the limitation in fossil fuels stored in our planet. It is known that fossil fuels (as the name indicates) had been mostly generated by long-term geochemical reactions with ancient plants and algae as original resources and accumulate in underground reservoirs. Such reactions may also occur currently, while the recent consumption of fossil fuels is much faster than that, resulting in the rapid decrease in the amounts of fossil fuels in underground reservoirs. In addition, a large fraction of petroleum stored in easily accessible reservoirs is considered to have already been consumed, and engineers predict that the cost for producing petroleum will dramatically increase in the 21th century. Another problem results from the combustion of fossil fuels; this process generates carbon dioxide that is released and accumulates in the air, resulting in the green-house effect and global warming. According to an assessment report in 2007 by the Intergovernmental Panel on Climate Change (IPCC), global surface temperature increased $0.74 \pm 0.18^{\circ} \mathrm{C}$ during the 20th century (IPCC 2007). This increase corresponds to an increase in the carbon dioxide concentration in the atmosphere (from $0.03 \%$ to $0.037 \%$ ) in the 20th century (Global Warming Art 2007). We therefore consider that the use of fossil fuels is such a process that converts underground carbons into carbon dioxides and release them into the atmosphere.

Under such circumstances, energy sources alternative to fossil fuels are strongly desired for supporting human activities in the 21th century, particularly those that are renewable and not associated with the global warming. The primary important is the solar energy. It has been estimated that the amount of solar energy that strikes the Earth every hour $\left(\sim 4.3 \times 10^{20}\right.$ $\mathrm{J})$ is approximately equal to the total amount of energy consumed by human society every year (Donohue \& Cogdell 2006). Hence, global energy needs can be substantially satisfied even with a small fraction of the available solar energy, and the use of photovoltaic solar cells (Fahrénbruch \& Bube 1983) is currently expanding. We also consider that biomass is another important renewable energy source. Biomass includes all biologically synthesized 
chemicals, primary by photosynthetic organisms using sun light as the energy source and carbon dioxide as the raw material (i.e., the biological primary production). It is also known that the geochemical energy is also available for the synthesis; this process involves bacteria, called chemolithotrophs, that use the chemical energy conserved in reduced inorganic chemicals to synthesize organic compounds from carbon dioxide. Biomass is the most abundant carbonaceous material at the surface of our planet, and the total amount has been estimated to be approximately 75 billion tons. Although the combustion of biomass also generates carbon dioxide, this is considered to be a part of carbon cycling on our planet along with the biological primary production. In this sense, the use of biomass as an energy source is regarded as the "carbon neutral process". The history of using biomass as our energy source is long, starting from the finding of fire on woods that ancient people used for heating and cooking, while recent technical achievements include the conversion of raw biomass into convenient forms of energy (e.g., liquid fuels, and electricity), and the use of biomass that is difficult to use (e.g., those that contain a large amount of water). Accordingly, scientists and engineers are recently keen in developing technologies for utilizing energies conserved in biomass; these include the production of bio-ethanol (Gray et al. 2006), bio-hydrogen (Levin et al. 2004), and bio-electricity (Logan et al. 2006; Watanabe 2008).

As described, we expect that the solar light and biomass will become important energy sources in the 21th century, and biological energy conversion (BEC) processes will be widely used in association with this energy shifts. In such processes, organisms (in particular, microbes) are catalysts that convert energy forms (e.g., the solar energy into the chemical energy) and chemical species (e.g., biomass into ethanol). A representative example is a photosynthetic organism that conserves the light energy as organic compounds (rich in the chemical energy) (Gust et al. 1993). In another case, bacteria ferment biomass chemicals, such as starch, to produce bio-ethanol (Gray et al. 2006). Besides, recent studies have found that some bacteria convert chemical energies in organic compounds into electricity (McConnell et al. 2010). Accordingly, we can say that we have a large repertoire of energy conversion processes, if biological systems are used. There are advantages of BEC processes over chemical processes; these include (i) they are environmentally friendly, (ii) the diversity of catabolic capacities expands a range of chemicals that can serve as fuels, and (iii) they are self-sustaining. Based on these advantages, BES processes are also able to use waste biomass as energy sources to generate fuel gases (hydrogen, and methane) and electricity. Such a process must be impossible, when we use chemical catalysts.

This chapter introduces technologies for generating bio-electricity from the sun light, and/or biomass, particularly those that use in rice paddy fields (RPFs). Since electricity generation in RPFs is a process that is a combination of microbial solar cells (MSCs) and microbial fuel cells (MFCs), these BEC processes are explained before describing RPF electricity generation.

\section{Microbial solar cells (MSCs) and Microbial fuel cells (MFCs)}

\subsection{MFCs}

MFCs are devices that exploit microbial catabolic activities to generate electricity from a variety of materials, including complex organic waste and renewable biomass. In MFCs, microbes utilize organic compounds as energy and carbon sources. In order to generate energy for growth, organics are decomposed, and chemical energy is released (i.e., 
fermentation). In addition, high-energy electrons released from organics are transferred to oxidized chemicals (i.e., electron acceptors, such as molecular oxygen) to conserve electrochemical energy (i.e., respiration). In microbial cells, electrons released from organics are initially accepted by intercellular electron-shuttling compounds (e.g., nicotinamide adenine dinucleotide [NAD]), and subsequently transferred to electron acceptors via respiratory electron-transport chains. If a mechanism is present by which electrons released from organics can be transferred from any step in the intercellular electron-transfer pathway to an extracellular electrode (i.e., anode), then microbial oxidation of organics can be coupled to electricity generation (i.e., an MFC).

Fig.1 illustrates typical structures of MFCs. Fig. 1A shows a membrane-type oxygendiffusion cathode that is frequently used in recent studies (Watanabe 2008). This type of reactor is called "a single-chamber MFC reactor", while two-chamber MFCs are also used, which are comprised of anode and cathode chambers separated by proton-exchange membranes (Ishii et al. 2008a). As shown in this figure, electrons released by microbes are captured by an anode and transferred to a cathode according to the potential gradient between them. The electrons are used in cathode chemical reactions, in which protons released at the anodes and diffusively transferred to the cathodes are also utilized, thereby completing an electric circuit. Cathode reactions are dependent on the species of electron acceptor and catalyst (see below). Ambient oxygen is the most commonly used electron acceptor, while other oxidants, such as ferricyanide, can also be used (Logan et al. 2006). As a cathode catalyst, platinum is widely used for oxygen reduction.

It has been suggested that MFCs have many possible future applications; these include water treatments coupled to energy recoveries, portable fuel cells, biosensors, and in-situ energy sources. Among them, the first one, waste treatments, is considered to be the most promising, and MFCs may be able to work as energy- and cost-saving options for waste treatments (Watanabe 2008). The MFC technology has however not yet been applied to practical waste treatments. This is primarily because it is an emerging technology and more time is required for technical maturation. Another reason is that its process performance is considered low when compared to its competitors (e.g., methanogenic anaerobic digesters). On average, modern methanogenic anaerobic digesters treat organic wastes at efficiencies of $\sim 8-20 \mathrm{~kg}$ chemical oxygen demand (COD) units per $\mathrm{m}^{3}$ of reactor volume per day (Lettinga 1995), equivalent to $\sim 1,200-3,000$ watts per $\mathrm{m}^{3}$. Given that waste-to-gas, and gas-toelectricity conversion efficiencies are typically $80 \%$, and $40 \%$, respectively, these methanogenic digesters generate electricity at $\sim 380-960$ watts per $\mathrm{m}^{3}$. On the other hand, a recent MFC study reported a power density of 130 watts per $\mathrm{m}^{3}$ with a model organic waste (comprised of starch, peptone, and fish extract) as the fuel (Shimoyama et al. 2008), suggesting that $\sim 7$-fold increases in power output may be necessary for MFCs to exceed performances of anaerobic digesters. Approaches to how power outputs of MFCs can be increased have been summarized in a literature (Watanabe 2008).

Recent studies have identified that there exist bacteria that can use self-sustaining extracellular electron transfer mechanisms to respire MFC anodes (Lovley 2008; Watanabe et al. 2009). Some bacteria excrete water-soluble electron-shuttling compounds that are reduced by bacterial cells and oxidized by transferring electrons to MFC anodes (Watanabe et al. 2009). Other bacteria use secreted and/or cell-surface electron-transporting proteins (e.g., cytochromes) for the electron transfer toward MFC anodes (Lovley 2008). An important point is that they have self-sustaining anode-respiring mechanisms without the need of artificial assistance, e.g., the supplementation of MFC with artificial electron 

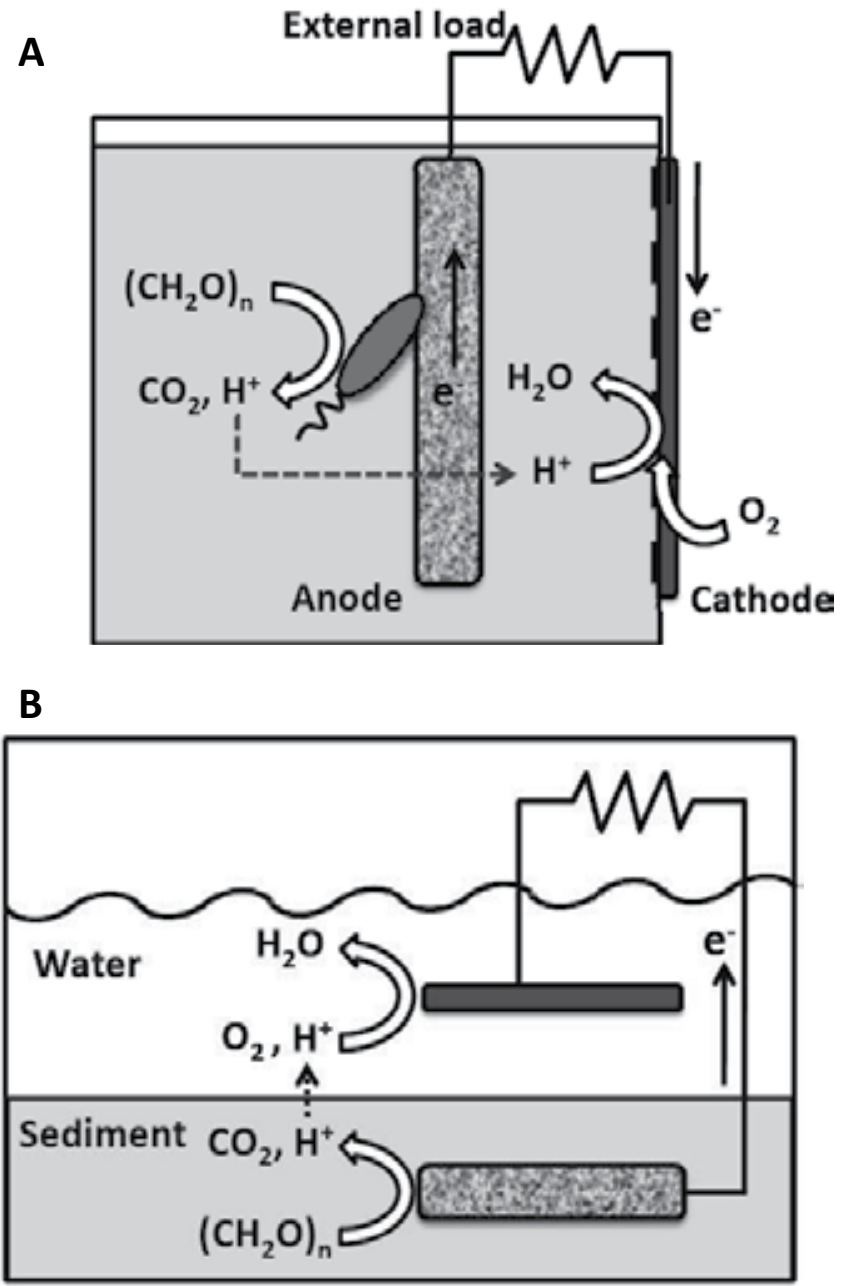

Fig. 1. Schematic diagrams for a single-chamber MFC (A) and sediment MFC (B).

shuttles. This finding is really important, when one consider the application of MFC to waste treatment. Furthermore, with such bacterial self-sustaining electron-transfer mechanisms, sediment MFC (this includes RPF electricity generation) can also be constructed (Fig. 1B). We consider that deeper understanding of bacterial self-sustaining electron-transfer mechanisms will facilitate more efficient MFCs.

Here we also explain sediment MFCs (sMFCs) as the final part in the MFC section (Fig. 1B). In sMFCs (Reimers et al. 2001), anodes are submerged in freshwater and marine sediments, while cathodes are placed in water phases above the sediments. Since sediment and water are anaerobic and aerobic, respectively, potential gradients are generated between them. It is therefore possible to generate electricity between them, if anode microbes have selfsustained extracellular electron transfer mechanisms (Lovley 2006). So far, sMFCs have mostly been set in shallow marine coasts, since the high ionic strength in the sea water is beneficial to the electron transfer. Researchers aim at applying sediment MFCs to on-site power sources for environmental monitoring systems (Donovan et al. 2008). 


\subsection{MSCs}

As the name of MSC represents its function, MSC is a type of solar cells used for the light/electricity conversion with living phototrophic microbes serving as catalysts for the conversion (Rosenbaum et al. 2010). In one work, a phrase, photosynthetic MFCs (photoMFCs), is used for biological light/electricity conversion processes (Rosenbaum et al. 2010). In MSCs, photosynthetic microbes, such as microalgae and cyanobacteria, use the light energy to liberate high energy-level electrons from water molecules, and these electrons are transferred through photosynthetic electron-transport chains and finally used to fix carbon dioxides and synthesize organic molecules (Gust et al. 1993). Fig. 2 shows two representative types of MSCs, namely, mediator-type MSCs (Fig. 2A), and syntrophic MSCs.

A
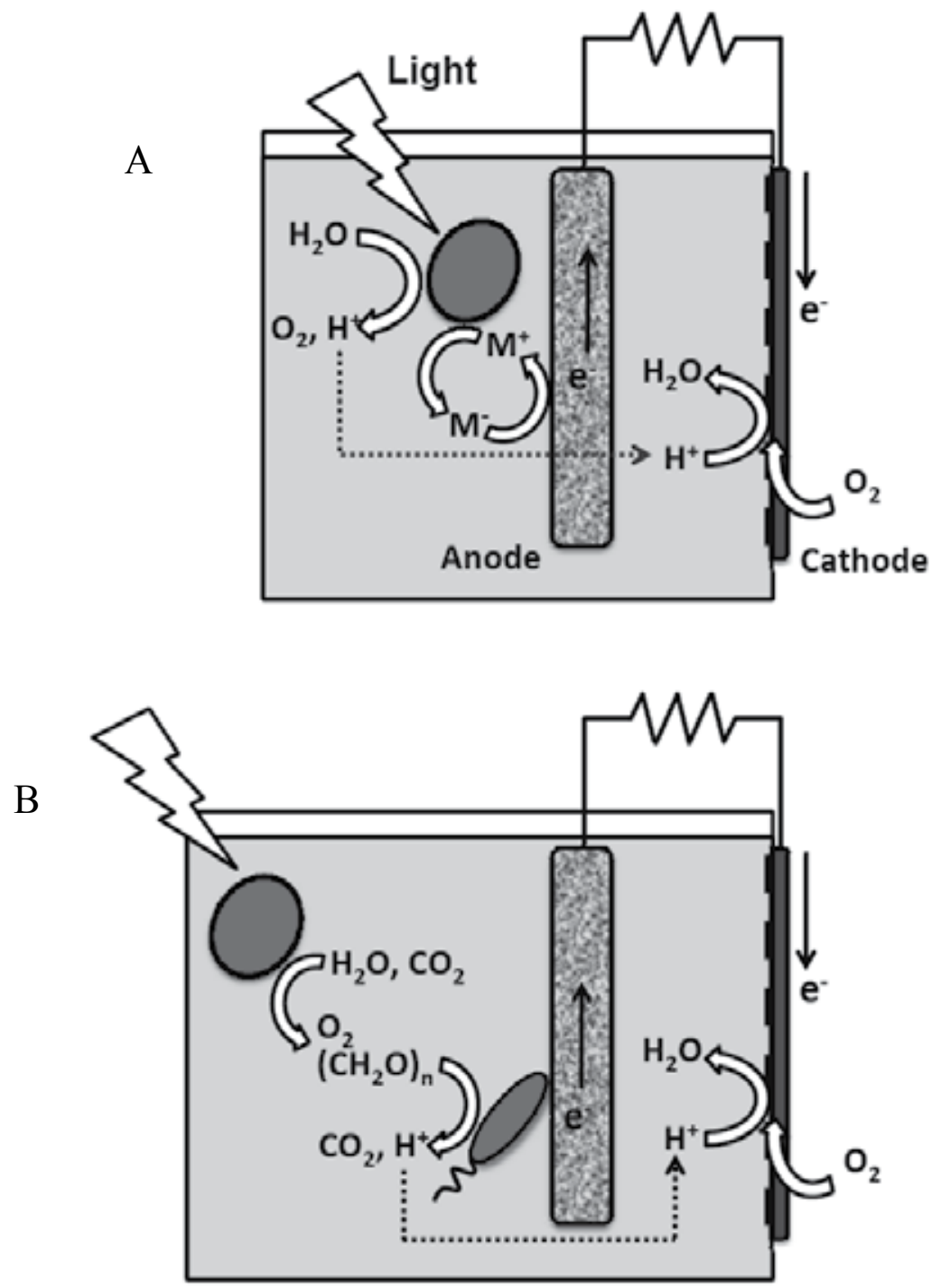

Fig. 2. Systematic diagrtams for a mediator-type MSC (A) and syntrophic MSC (B). 
In mediator-type MSCs (Fig. 2A), electron-shuttling compounds (also called as electron mediators; " $\mathrm{M}$ " in Fig. 2A) are supplemented. These compounds are reduced (accept electrons) at anywhere in electron-transport chains in photosynthetic microbes and are oxidized (release electrons) at the surface of MSC anodes. Subsequently, electrons are transferred to cathodes according to the potential gradient between them. The electrons are used in cathode chemical reactions, in which protons released at the anodes and diffusively transferred to the cathodes are also utilized, thereby completing an electric circuit. This cathode reaction is the same with MFCs. Mediator-type MSCs are possible only by supplementing with artificial mediators, since there has been no known photosynthetic microbe that is able to produce mediator compounds; in this sense, mediator-type MSCs are not self-sustaining processes. This type of MSCs was actively investigated $\sim 10$ years ago (Rosenbaum et al. 2010). In that period, cyanobacteria (e.g., Anabaena and Synechocystis) were mainly used as biocatalysts with 2-hydroxy-1,4-naphtoquinone (HNQ) as an artificial mediator (Tanaka et al. 1985; Yagishita et al. 1997; Tanaka et al. 1988; Yagishita et al. 1999). Most of these studies however observed the increases in power outputs in association with the dark reaction, where intracellular carbon storages were oxidized, and electrons were liberated. On the other hand, oxygen production limited power outputs in the light (Tanaka et al. 1985; Yagisgita et al. 1998). Such researches are not actively performed in recent years, since it has been realized that artificial mediators are toxic and costly, and mediator-type MSCs are thereby not sustainable and practical.

The idea of syntrophic MSCs (Fig. 2B) has recently been proposed (Nishio et al. 2010). Since the addition of artificial mediator compounds is not sustainable, researchers have been looking for ways that make MSCs sustainable. In the research performed by Nishio et al. (2010), single-chamber MFC reactors were inoculated with natural microbial communities (those in fresh water samples and hot-spring green mats), irradiated, and investigated for their electric outputs. They found that, with some natural inoculants, light-dependent electric outputs were observed when anodes were covered with green biofilms. Analyses of anode biofilms established from a hot-spring green mat revealed that they included microalgae and hetertrophic bacteria closely related to those found in MFCs (Nishio et al. 2010). It was therefore suggested that these two types of microbes had syntrophic relationships, in which microalgae produced organic compounds by photosynthesis, and bacteria used them to generate electricity. Although a power conversion efficiency (PCE; conversion of light into electricity) was low (approximately 0.03\%), the concept of syntrophic MSCs is considered to be widely applicable, and further researches are awaited to find strategies to increase PCEs.

A self-sustained biological process for the light/electricity conversion has also been reported recently (He et al. 2009). In that report, when a sediment MFC was irradiated, photosynthetic microbes grew in the water phase and subsequently deposited on the sediment, serving as substrates for heterotrophic bacteria in the sediment to generate electricity (He et al. 2009). They suggested that self-sustained phototrophic microbial fuel cells could be constructed based on the synergistic cooperation between photosynthetic microorganisms and heterotrophic bacteria. A difference between these two studies was that electricity was generated only under dark conditions in the latter study. Although authors of that study speculated that oxygen molecules evolved by photosynthesis in the light may have been inhibitory to electricity generation, clear mechanisms are still unclear, partially because microbes involved in the light/electricity conversion have not yet been analyzed. Despite such a difference in the condition for electricity generation, these two studies are 
outstanding examples for self-sustained MSCs with a common feature that microbial communities were used rather than pure cultures of photosynthetic microbes. This feature is important, since it suggests a possibility for constructing syntrophic MSCs in natural environments. On the other hand, complex community structures could cause difficulties in analyzing conversion mechanisms and improving PCEs. We therefore consider that it will also be necessary to construct simple models of syntrophic MSCs using defined mix cultures of photosynthetic microbes and electricity-generating bacteria and to examine syntrophic relationships between these organisms.

\section{Plant-assisted sMFCs}

In 2008, three reports have been published, which describe sMFCs (Fig. 1B) in the presence of plants (Kaku et al. 2008; Strik et al. 2008; De Schamphelaire et al. 2008). Among them, two studies used rice plants (Kaku et al. 2008; De Schamphelaire et al. 2008), while the other used reed mannagrass (Strik et al. 2008). Two studies used laboratory pot-culture systems (Strik et al. 2008; De Schamphelaire et al. 2008), while the other used a real rice paddy field (RPF; Kaku et al. 2008). This section initially explains a concept of these plant-assisted sMFCs, followed by detailed explanations for two pot-culture sMFCs.

Fig. 3 illustrates conceptual models for plant-associated sMFCs. A RPF sMFC system is shown in Fig. 3A, while a pot-culture sMFC is illustrated in Fig. 3B. An original idea for RPF sMFC was that rice paddy soil was rich in organics, including residues of past rice plant bodies, and self-sustained electricity-generating bacteria in soil use these organics for generating power using sMFC systems. However, Kaku et al. (2008) and other groups have found that organics excreted from rice roots (i.e., root exudates) largely contributed to electricity generation. Since these organics are photosynthesized by plants using the solar energy, these systems can be called "plant-assisted sMFCs". Plant-assisted sMFCs can also be considered as solar cells in which plants and microbes establish syntrophic relationships. In this sense, a RPF sMFC should be included in syntrophic MSCs, in which rice plants are used rather than microalgae. In RPF SMFC, cathodes are placed in flooded water above the anode-submerged soil, and oxygen dissolved in the water is used for the cathode reaction. In a pot-culture sMFC (Fig. 3B), the anode system is the same with a RPF sMFC, while the two studies (Strik et al. 2008; De Schamphelaire et al. 2008) prepared additional cathode chambers that were connected to the anode pots via proton-exchange membranes. In one system reported by Strik et al. (2008), oxygen was used for the cathode reaction, while ferricyanide was also used in the other study (De Schamphelaire et al. 2008). The use of ferricyanide could improve power outputs, although the system was no longer sustainable.

Among the three studies, I first introduce that done by Strik et al. (2008). In that study, Reed mannagrass (Glyceria maxima), also named Reed sweetgrass, was used, because it is an abundant grass species in America, Europe, and Asia, and it is one of the few local species in the Nederland that can grow in anaerobic freshwater sediments. These anaerobic conditions were considered necessary for an anode compartment to function. To start a pot-culture sMFC, an anode chamber was filled with graphite granules that contained microorganisms pre-grown on acetate under electricity-generating conditions and inoculated with Reed mannagrass. Graphite granules were used to fill the anode pot, because they were conductive and could serve as the plant support as well as electrode. The pot-culture sMFCs were operated for 118 days, and substantial increases in cell voltages (over $100 \mathrm{mV}$ ) were observed after day 50 only in MFCs inoculated with plants. This level of cell voltage was 
A

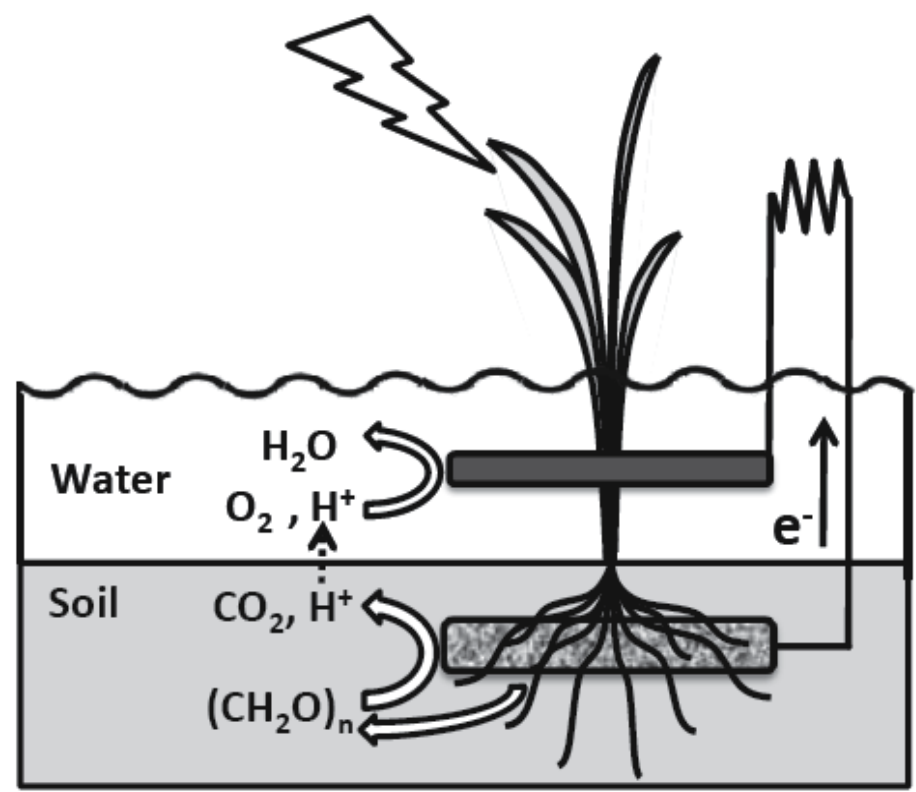

$\mathrm{B}$

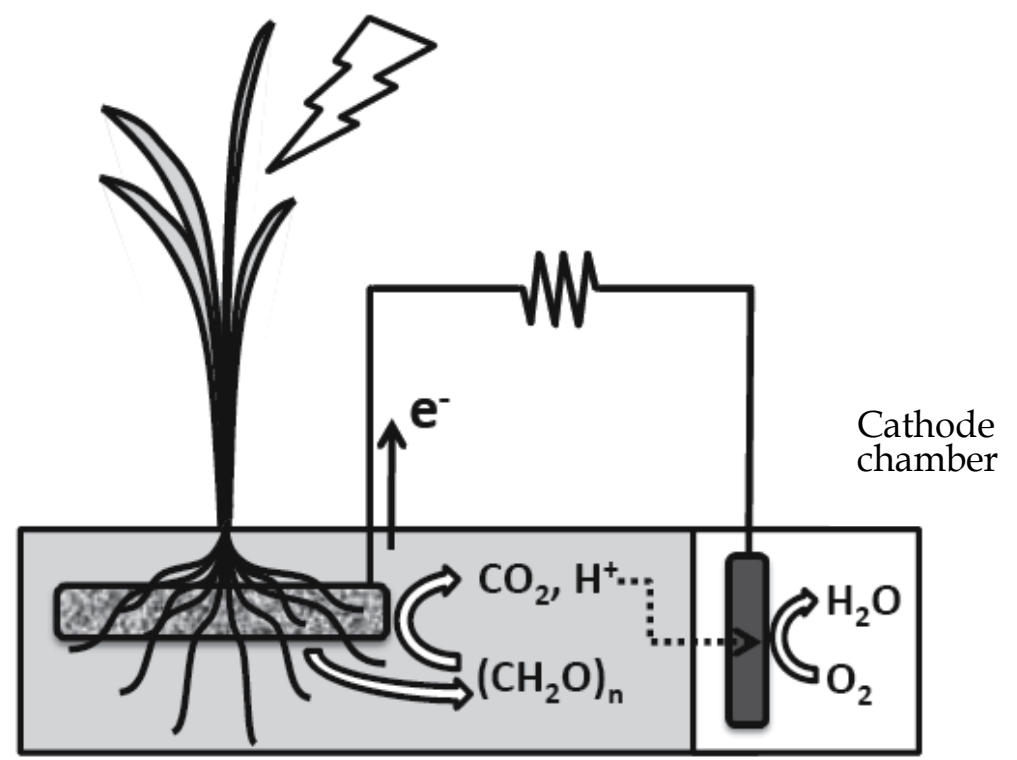

Fig. 3. Systematic diagrams for a rice paddy-field MFC (A) and plant pot-culture MFC (B).

continued for 50 days afterward, followed by an unexpected drop down to below $50 \mathrm{mV}$. Polarization-curve analyses (refer to Watanabe 2008 for methods) on day 90 estimated a maximum power density (per anode surface) of $67 \mathrm{~mW}$ per $\mathrm{m}^{2}$. They deduced that the voltage drop resulted from the decline of plant vitality. They also reported that the cell voltage showed oscillatory behavior which was most pronounced between days 50 and 60 and was probably related to the daily light cycle. The photosynthates produced during the 
day time may have led to increased exudate production and substrate availability in the MFC thereby increasing the cell voltage. The simultaneous daily temperature fluctuations of $4^{\circ} \mathrm{C}$ probably affected the microbial activity as well, and thus the cell voltage. From day 60 on, the electricity production continued at night, which means that the plant-MFC has the equivalent of a battery built into its system.

In their subsequent study (Timmers et al. 2010), the plant used was changed to a salt marsh species, Spartina anglica, and it was reported that electricity was generated for 119 days or more. A maximum power density was increased up to $100 \mathrm{~mW}$ per $\mathrm{m}^{2}$ (geometric anode area); they described that it was the highest reported power output for a plant-assisted sMFC. Electrochemical analyses revealed that cathode overpotential was the main potential loss in the period of oxygen reduction due to slow oxygen reduction kinetics at the cathode. Ferricyanide reduction improved the kinetics at the cathode and improved electricity generation with a maximum of $254 \%$. In the period of ferricyanide reduction, the main potential loss was transport loss of hydrogen between the anode and cathode. It is likely that a salt-rich condition for the growth of Spartina anglica was favorable for electron transfer in the MFC system, resulting in the increased electric output. It is therefore reasonable to deduce that marine sediment MFCs can be coupled to plants for getting more powers.

A study done by De Schamphelaire et al. (2008) used pot cultures of rice plants (Oryza sativa ssp. indica). In their pot-culture sMFCs, natural soils, vermiculites, or graphite granules were used as plant supports, graphite mats were used as anodes, and cathodes were set either as indicated in Fig. 3A (graphite rods floating in water above the plant support) or Fig. 3B (graphite granules set in cathode chambers filled with $100 \mathrm{mM}$ ferricyanide). The primary aim of these experiments was to identify experimental settings that generate more electricity than others. They initiated pot-culture sMFCs experiments by inoculating the MFCs with microbes obtained from an acetate-fed MFC and those from a methanogenic tank. Besides, a cathode culture in pre-operated sediment MFC was also inoculated to the floating graphiterod cathode. These MFCs were operated over 100 days, and they confirmed that plant inoculation substantially (typically 7 folds) enhanced electricity generation, when the plants were actively grew (in summer). Concerning plant support media, soil was the best among them in term of electric output. In contrast, there were no substantial differences in MFC performances between these two cathode settings, while, in some pots, the leakage of ferricyanide solutions into anode pots resulted in decreases in the plant vitality and electric output. Consequently, the highest power output achieved in that study was reported to be $33 \mathrm{~mW}$ per $\mathrm{m}^{2}$ geometric anode area, equivalent to $330 \mathrm{~W}$ per ha, while it should be noted that this is not a value based on land area. They also reported that start-up periods of 50 to 100 days were needed to produce electric powers with the aid of living plants. They assumed that the time delay could be due to one or some of following reasons, such as the life cycle dependency of the exudate release, both qualitatively and quantitatively (Grayston et al. 1997), the omission of nutrients (which can induce exudation) (Marschener 1998), the release of oxygen, conducted through the aerenchyma (Neue et al. 1996), scavenging the electrons otherwise collected at the anode, and the lack of an adapted anodic microbial consortium. Another important point shown in that study was that there was a certain level of positive relationship between the concentration of organics in vermiculite support media and the electric output, suggesting that rhizodeposits (organics excreted from roots) were fuels used to generate electricity in the pot-culture MFCs.

In their subsequent study (De Schamphelaire et al. 2010), microbial communities established on anode graphite mats in rice pot-culture sMFCs containing vermiculite or natural soils as 
support media were analyzed using molecular ecological tools (including, clone-library analyses, denaturating gradient gel electrophoresis [DGGE], and terminal restriction fragment length polymorphism [T-RFLP]) for the domain Bacteria and Archaea. They focused their analyses on microbial communities on anodes, because these were considered responsible for the generation of electrical current and hence fulfilled pivotal roles in MFCs. Furthermore, they compared community structures between open-circuit and closed-circuit MFCs to more clearly identify microbial species involved in electricity generation. As a result, they found that closing the electrical circuit, allowing a capture of electrons by the anode, resulted in clear shifts in the bacterial community of soil MFCs, while shifts were not clear in vermiculite MFCs; reasons for this phenomenon is not clear. It was also found that the electrical circuit also influenced the archaeal community, despite that the Archaea were less influenced than the Bacteria were. They concluded that closed-circuit anodes in potting soil were enriched with Desulfobulbus-like species, members of the family Geobacteraceae, and as yet uncultured representatives of the domain Archaea, suggesting that they were involved in electricity generation. Future studies will be performed to isolated and characterize bacteria and archaea that were detected by the molecular ecological analyses.

\section{Rice paddy-field sMFC}

As described above, rice paddy-field (RPF) SMFC is a type of plant-assisted sMFCs, and uses a real RPF rather than a pot-culture system. RPF-sMFC experiments have been performed only by our research group (Kaku et al. 2008; Takanezawa et al. 2010), and here we explain experimental settings and results obtained in these studies.

A paddy field is a flooded parcel of arable land used for growing rice and other semiaquatic crops. In Japan, rice paddy fields cover 2.5 million ha and occupy more than $50 \%$ of the total arable land areas (Ministry of Agriculture, Forestry and Fisheries 2006). When a paddy field is flooded, the soil immediately below the surface becomes anaerobic (Takai 1969), and a community of anaerobic microbes (comprised mainly of sulfate-reducing bacteria, ironreducing bacteria, fermenting bacteria and methanogenic archaea) is established (Grosskopf et al. 1998; Chin et al. 1999). Since a potential gradient is known to be formed between the soil and the flooded water, it was anticipated that an sMFC system could operate in a paddy field.

In order to demonstrate this idea, electrodes were set in RPF as presented in Fig. 3A concomitant with the transplantation of rice seed cultures (in May 2007) (Kaku et al. 2008). In the experiment in 2007, Oryza sativa L. cv. Sasanishiki was used as a rice plant, while the experimental RPF in the university farm of Yamagata University (Tsuruoka, Japan) was the experimental field. Anode and cathode electrodes were made of graphite felts without any modification. Monitoring of the cell voltage (the potential difference between the anode and cathode) was initiated immediately after the electrodes were set in the RPF, and an electric output of approximately $0.05 \mathrm{~V}$ was immediately detected after that, which then increased to more than $0.2 \mathrm{~V}$ (measured in the daytime) within 7 days. It was also found that the electric output increased in the daytime and decreased at night. These observations implied that the electric output was dependent on the sunlight. Such circadian oscillation was observed throughout the experiment. A similar trend of electric output was also observed in experiments performed in 2008 using a RPF of the Kanagawa Agricultural Technology Center in Hiratsuka, Japan (Takanezawa et al. 2010). A typical trend was presented in Fig. 4, 
in which the experiment was initiated in June. In this case, the increase in electric output was somewhat slow compared to that observed in the 2007 experiment, while the clear circadian oscillation was also observed. The difference in the start-up period was likely ascribable to differences in field manipulations, nutrients in soil, and microorganisms in soils. The oscillation suggested that sunlight affected the electric output, although effects of temperature should have also been considered. This is because we also found that the electric output was influenced by whether and temperature. In the 2007 experiment, the polarization-curve analysis in June and August showed that the RPF sMFC could generate the power as much as $6 \mathrm{~mW}$ per $\mathrm{m}^{2}$ anode geometric area. This value was low compared to those reported for the pot-culture sMFCs. This was in part because the anode was large in area and covered not only rice rhizospheres but also soils between rice hills.

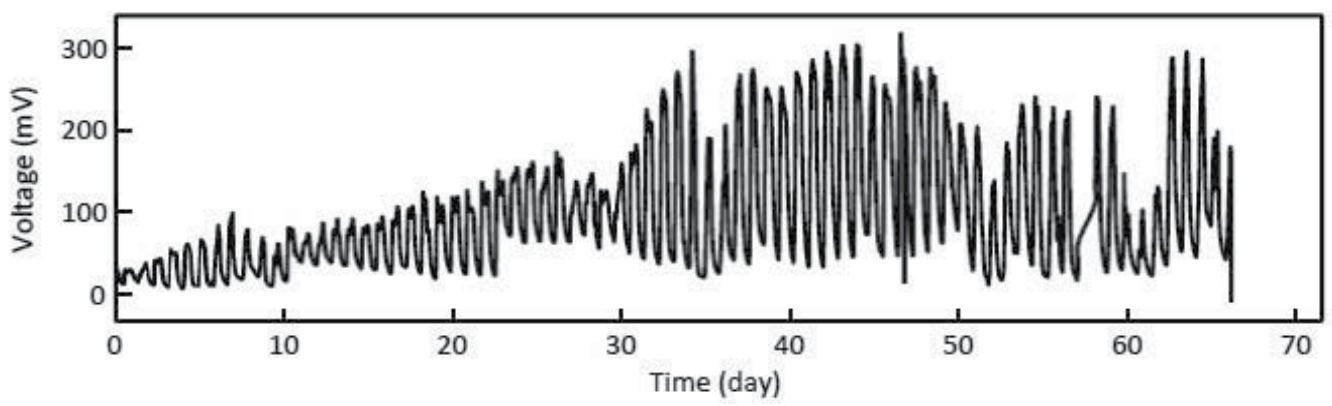

Fig. 4. A trend of electric output from an RPF sMFC set in the Hiratsuka field in 2008, showing the presence of a circadian oscillation in the electric output.

In order to examine how sunlight influenced the electric output (in August, 2007), we shaded either rice plants or the surface of the cathode and then monitored the electric output (Kaku et al. 2008). This experiment revealed that the shading of rice plants largely reduced the output, while there was no significant effect when only the cathode surface was shaded. This result suggested that plant photosynthesis enhanced the electricity generation. Nest, we examined if sunlight could stimulate rice plants to exhaust photosynthesized organic compounds from their roots (Kaku et al. 2008). It has been reported that plants exhaust photosynthesized organic compounds from their roots (Jones 1998; Walker et al. 2003), and organic acids and sugars are the main components (Jones 1998). In the experiment, rice plants were pulled from the paddy field and incubated them under the light and dark conditions by soaking their roots in water supplemented with the antibiotics. Total organic concentration (TOC), organic acids, and sugars in the root-soaked water were analyzed $2 \mathrm{~h}$ after commencing the incubation and compared with values at hour 0 . It was found that the TOC value increased only under sunlight, indicating that sunlight largely enhanced the amounts of organics exhausted from the roots. Among the organic compounds analyzed, acetate was the most abundant, followed by glucose, and their production was also found to be sunlight dependent. Since we also found that rice roots penetrated the anode graphite felt and occasionally entwined with the graphite fibers, it is reasonable to conclude that these organics can serve as fuels in PRF sMFCs.

In MFCs, bacteria are considered to be responsible for electricity generation (Logan and Regan 2006; Lovley 2006). In the 2007 experiment (Kaku et al. 2008), bacterial populations 
attaching onto the anode and cathode of the RPF sMFCs were analyzed by DGGE of PCRamplified 16S rRNA gene fragments (refer to Watanabe et al. 2001 for methods). The DGGE profiles were compared with those of bacteria associated with the graphite felts in the control system (electricity not generated) and also those in soil, allowing us to identify bacteria that specifically occurred in response to electricity generation. This electrophoresis analysis detected several intense bands that specifically occurred on the anode or cathode of the power-generation system; sequence analyses revealed that bands from the anode were related to Natronocella acetinitrilica (Sorokin et al. 2007) and Rhizobiales bacterium A48 (Satoh et al., 2002), while that from the cathode was related to Rhodobacter gluconicum (Do et al. 2003). Among them, A48 was isolated from a rice root surface (Satoh et al., 2002), and its taxonomy has recently been described as the genus Rhizomicrobium gen nov. (Ueki et al. 2010). In addition, closely related bacteria were detected in laboratory MFCs operated with cellulose as the sole fuel (Ishii et al. 2008a; Ishii et al. 2008b). It is therefore considered that bacteria related Rhizomicrobium was involved in the electricity generation. Information concerning roles of other bacteria detected by the DGGE analysis is to date not sufficient.

All together, these results suggest the RPF electricity-generation system was an ecological solar cell in which the plant photosynthesis was coupled to the microbial conversion of organics to electricity. In our next study (Takanezawa et al. 2010), we identified factors affecting electric outputs from RPF sMFCs. According to that study, in the next section, we discuss factors that can affect electric outputs from RPF sMFCs.

\section{Factors affecting electric outputs from rice paddy-field sMFCs}

\subsection{System configurations}

In the study done by Takanezawa et al. (2010), sMFC systems were set under different experimental conditions (Table 1) based on our knowledge on laboratory MFC reactors, and power outputs from these RPF sMFCs were evaluated by the polarization-curve analyses. Among these conditions (Table 1a), a number of anode felt was changed (one versus five [vertically aligned]; compare conditions 1 and 2), since it had been considered that more organic exudates from roots could be utilized for microbial anode respiration, if the roots were contacted with more anode felts. The anode position (a depth of the anode) corresponded to a distance between the anode and cathode that was placed at the surface of the soil (conditions 1 and 3); an anode/cathode distance is known to influence MFC performances, since it affects the proton diffusion from the anode to cathode (Cheng et al. 2006). We also examined several different external loads (conditions 1,5 , and 6), since it has been reported that external loads influenced the electric output from laboratory MFC reactors (Jadhav, G.S. \& Ghangrekar 2009). In these experiments, it was found that the anode depth and external load largely affected the electric output, while the anode number did not (Table 1). Among them, the result for the anode/cathode distance was unexpected, since it suggests that the proton-transfer efficiency (from the anode to cathode) did not limit the electric output. Two possible reasons are conceivable for the high performance with the anode at $5 \mathrm{~cm}$ in depth: (i) a zone at the depth of $2 \mathrm{~cm}$ was not sufficiently anaerobic, resulting in the presence of oxygen that served as an alternative electron sink; (ii) more riceplant roots could access to the anode at $5 \mathrm{~cm}$ in depth than that at $2 \mathrm{~cm}$, resulting in the larger amounts of organics supplied for the anode at $5 \mathrm{~cm}$. We consider that the second possible reason is more likely, since oxidation/reduction potentials (vs. a standard 
hydrogen electrode) for zones at $2 \mathrm{~cm}$ and $5 \mathrm{~cm}$ in depth were not largely different $(-158 \mathrm{mV}$ and $-165 \mathrm{mV}$, respectively).

\begin{tabular}{|c|c|c|c|c|}
\hline Condition & $\begin{array}{l}\text { Anode GF-felt } \\
\text { number }\end{array}$ & $\begin{array}{l}\text { Anode depth below } \\
\text { the soil surface }(\mathrm{cm})\end{array}$ & $\begin{array}{c}\text { External resister } \\
(\Omega)\end{array}$ & $\begin{array}{l}\text { Maximum power } \\
\left(\mathrm{mW} \text { per } \mathrm{m}^{2}\right)\end{array}$ \\
\hline 1 & 5 & 2 & 100 & 3.52 \\
\hline 2 & 1 & 2 & 100 & 3.96 \\
\hline 3 & 5 & 5 & 100 & 9.82 \\
\hline 4 & 5 & 2 & 100 & 2.32 \\
\hline 5 & 5 & 2 & 10 & 2.16 \\
\hline 6 & 5 & 2 & 1000 & 14.44 \\
\hline
\end{tabular}

Table 1. Experimental conditions of RPF sMFCs to identify factors affecting electric outputs.

\subsection{Electrode materials}

Studies on MFC reactors have indicated that electrode modification, both for anode and cathode, substantially improves MFC performances (Watanabe 2008). It is therefore reasonable to deduce that electrode modification is also beneficial for RPF sMFCs. In our study (Takanezawa et al. 2010), it was found that the modification of cathode with platinum catalysts (originally developed for hydrogen fuel cells) largely improved the electric output. This is in accordance with previous studies showing that the catalyst can largely accelerate oxygen reduction (Lefebvre et al. 2008).

A substantial amount of studies have been done to modify MFC anodes (Watanabe 2008), and these studies have suggested that the surface area and electrochemical properties are important factors for efficiently capturing electrons released by microorganisms. To cite an instance, Zhao et al. reported that the modification of graphite anodes with nano-porous conductive polymers substantially ( 10 folds) improved the electric outputs from laboratory single-chamber MFCs (Zhao et al. 2010). In another example, carbon electrodes were coated with a composite of conductive polymers and carbon nanotubes and successfully used for MFC anodes (Qiao et al. 2007). It should however be noted that it is difficult to sustain improved anode performances for a long time, since these materials are not sufficiently resistant to microbial attacks (Niessen et al. 2004). In some cases, such as organic polymers, microorganisms use these materials as substrates for their growth. This would be particularly true in RPF sMFCs, since the soil contains very diverse microorganisms with a wide variety of catabolic abilities. It is desired to develop materials that are electrochemically active and persistent in rice paddy-field soil.

\subsection{Root exudates}

On average, $30-60 \%$ of photosynthesized organics are allocated by plants to roots, and a substantial portion of these organics are released from or secreted by roots into the rizosphere (Marschner 1995). The RPF sMFC experiments indicates that the electricity generation was dependent on root exudates (Kaku et al, 2008), suggesting that better understanding of root exudates will allow RPF sMFCs to function more efficiently. In 
addition, it is also necessary to understand effects of allelopathic compounds produced by rice roots (Olofsdotter et al. 2002) to electricity generation by rhizosphere bacteria.

\subsection{Microbes in rhizosphere}

A large amount of studies has been carried out concerning microorganisms inhabiting RPF soil (Liesack et al. 2000), particularly those associated with rice rhizosphere. There may be two reasons for the active research on RPF microorganisms. First, they are considered to influence (positively and negatively) the rice production. Second, these microorganisms are responsible for the methane emission from RPFs; methane is known to exert strong green house effects (Prinn 1994). Since these studies have revealed that RPF soils harbor surprisingly diverse microbial species, we deduce that a variety of bacteria capable of transfer electrons to anodes may also be present there. Actually, MFCs were successfully developed using RPF soils as inocula (Ishii et al. 2008a; Ishii et al. 2008b). It is also important to note that the electric output was relatively rapidly (within 7 days) increased in our 2007 experiment (Kaku et al. 2007), while the pot-culture sMFC experiments needed substantially longer times ( $\sim 50$ days) despite that these sMFCs were inoculated with microbial communities sufficiently acclimatized in MFCs (Strik et al. 2008; De Schamphelaire et al. 2008). This fact supports the idea that PRF soils harbor substantial amounts of electricitygenerating bacteria that adapt to the soil environment. A bacterial strain was isolated from RPF soil which is capable of electricity generation in pure-culture MFCs (Kodama \& Watanabe 2008), and a novel species (Rhizomicrobium electricum) has been proposed for this bacterium (Kodama \& Watanabe 2010). This organism is the first isolate of electricitygenerating bacteria inhabiting RPFs, and further studies on this organism will provide valuable information concerning the physiology and genetics of microbial electricity generation in the rhizosphere.

\section{Conclusions}

The RPF sMFC is a representative of BEC processes that clearly demonstrates the concept of self-sustainable biological systems. The fact that rice is the world's most important agronomic plant with 143 million ha under cultivation globally suggests a great possibility for the future contribution of the RPF sMFC to global energy issues. In addition, similar systems may also be applicable to wetland ecosystems. Besides, it is also important to suggest that the sMFC systems may possibly reduce methane emission from rice paddy fields and natural wetlands. This is currently under investigation in our laboratory.

RPF sMFCs are also interesting from the scientific viewpoint, since the electric output enables the real-time monitoring of ecosystem functions in the rhizosphere; for instance, the circadian oscillation of root deposition was for the first time observed using the RPF sMFC system (Fig. 4). This would leads to deeper understanding of ecological interactions between plants and rhizoshere microorganisms.

\section{References}

Cheng, S.; Liu, H. \& Logan, B.E. (2006). Environ. Sci. Technol. 40, 2426-2432. 
Chin, K.J.; Hahn, D.; Hengstmann, U.; Liesack, W. \& Janssen, P.H. (1999). Characterization and identification of numerically abundant culturable bacteria from the anoxic bulk soil of rice paddy microcosms. Appl. Environ. Microbiol. 65, 5042-5049.

De Schamphelaire, L.; Van den Bossche, L.; Dang, H.S.; Hofte, M.; Boon, N.; Rabaey, K. \& Verstraete, W. (2008). Microbial fuel cells generating electricity from rhizodeposits of rice plants. Environ. Sci. Technol. 42, 3053-3058.

De Schamphelaire, L.; Cabezas, A.; Marzorati, M..; Friedrich M.W.; Boon, N. \& Verstraete, W. (2010). Microbial community analysis of anodes from sediment microbial fuel cells powered by rhizodeposits of living rice plants. Appl. Environ. Microbiol. 76, 2002-2008.

Do, Y.S.; Schmidt, T.M.; Zahn, J.A.; Boyd, E.S. de la Mora, A. \& DiSpirito, A.A. (2003). Appl. Environ. Microbiol. 69, 1710-1720.

Donohue, T.J. \& Cogdell, R.J. (2006). Microorganisms and clean energy. Nat. Rev. Microbiol. 4,800 .

Donovan, C.; Dewan, A.; Heo, D. \& Beyenal, H. (2008). Batteryless, wireless sensor powered by a sediment microbial fuel cell. Environ. Sci. Technol. 42, 8591-8596.

Energy Information Administration. (2007). http:/ / www.eia.gov.

Fahrénbruch, A.L. \& Bube, R.H. (1983). Fundamentals of solar cells: photovoltaic solar energy conversion. Academic, New York.

Global Warming Art. (2007). http:/ / www.globalwarmingart.com.

Gray, K.A.; Zhao, L. \& Emptage, M. (2006) Bioethanol. Curr. Opin. Chem. Biol. 10, 141-146.

Grayston, S.J.; Vaughan, D. \& Jones, D. (1997). Rhizosphere carbon flow in trees, in comparison with annual plants: The importance of root exudation and its impact on microbial activity and nutrient availability. Appl. Soil Ecol. 5, 29-56.

Grosskopf, R.; Janssen, P.H. \& Liesack, W. (1998). Diversity and structure of the methanogenic community in anoxic rice paddy soil microcosms as examined by cultivation and direct $16 \mathrm{~S}$ rRNA gene sequence retrieval. Appl. Environ. Microbiol. 64, 960-969.

Gust, D.; Moore, T.A. \& Moore, L.A. (1993). Molecular mimicry of photosynthetic energy and electron transfer. Accounts Chem. Res. 26, 198-205.

He, Z.; Kan, J.; Mansfeld, F.; Angenent, L.T. \& Nealson, K.H. (2009). Self-sustained phototrophic microbial fuel cells based on the synergistic cooperation between photosynthetic microorganisms and heterotrophic bacteria. Environ. Sci. Technol. 43, 1648-1654.

IPCC. (2007). Summary for Policymakers" (PDF). Climate Change 2007: The Physical Science Basis. Contribution of Working Group I to the Fourth Assessment Report of the Intergovernmental Panel on Climate Change. ICPP.

Ishii, S.; Shimoyama, T.; Hotta, Y. \& Watanabe, K. (2008a). Characterization of a filamentous biofilm community established in a cellulose-fed microbial fuel cell. BMC Microbiol. 8,6 .

Ishii, S.; Hotta, Y. \& Watanabe, K. (2008b). Methanogenesis versus electrogenesis: morphological and phylogenetic comparisons of microbial communities. Biosci .Biotechnol. Biochem. 72:286-294.

Jadhav, G.S. \& Ghangrekar M.M. (2009). Bioresour. Technol. 100, 717-723. 
Jones, D.L. (1998). Organic acids in the rhizosphere-a critical review. Plant soil 205:25-44.

Kaku, N.; Yonezawa, N.; Kodama, Y. \& Watanabe, K. Plant/microbe cooperation for electricity generation in a rice paddy field. Appl. Microbiol. Biotechnol. 79, 43-49.

Kodama, Y. \& Watanabe, K. (2008). An electricity-generating prosthecate bacterium strain Mfc52 isolated from a microbial fuel cell. FEMS Microbiol. Lett. 288, 55-62.

Kodama, Y. \& Watanabe, K. (2010). Rhizomicrobium electricum sp. nov., a facultatively anaerobic, fermentative, prosthecate bacterium isolated from a cellulose-fed microbial fuel cell. Int. J. Syst. Evol. Microbiol. in press.

Lefebvre, O.; Al-Mamun, A.; Ooi, W.K.; Tang, Z.; Chua, D.H. \& Ng, H.Y. (2008). Water Sci. Technol. 57, 2031-2037.

Lettinga, G. (1995). Anaerobic digestion and wastewater treatment systems. Antonie Van Leeuwenhoek. 67, 3-28.

Levin, D.B.; Pitt, L. \& Love, M. (2004). Biohydrogen production: prospects and limitations to practical application. Int. J. Hydrogen Energy 29, 173-185.

Logan BE, Regan JM (2006) Electricity-producing bacterial communities in microbial fuel cells. Trends Microbiol. 14, 512-518.

Logan, B.E.; Hamelers, B.; Rozendal, R.; Schröder, U.; Keller, J.; Freguia, S.; Aelterman, P.; Verstraete, W. \& Rabaey, K. (2006). Microbial fuel cells: methodology and technology. Environ. Sci. Technol. 40, 5181-5192.

Lovley. R.D. (2006). Microbial fuel cells: novel microbial physiologies and engineering approaches. Curr. Opin. Biotechnol. 17, 327-332.

Lovley, D.R. (2008). The microbe electric: conversion of organic matter to electricity. Curr. Opin. Biotechnol. 19, 564-571.

Marschener, H. (1995). Mineral nutrition of higher plants, 2nd edition. Academic press, London.

Marschener, H. (1998). Role of root growth, arbuscular mycorrhiza, and root exudates for the efficiency in nutrient acquisition. Field Crops Res. 56, 203-207.

McConnell, I.; Li, G. \& Brudvig, G. W. (2010). Energy conversion in natural and artificial photosynthesis. Chem. Biol. 17, 434-447.

Ministry of Agriculture, Forestry and Fisheries. (2006). Statistics of agriculture, forestry and fisheries. Ministry of Agriculture, Forestry and Fisheries, Japan

Neue, H.U.; Wassmann, R.; Lantin, R.S.; Alberto, M.; Aduna, J.B. \& Javellana, A.M. (1996). Factors affecting methane emission from rice fields. Atmos. Environ. 30, 1751-1754.

Niessen, J.; Schröder, U.; Rosenbaum, M.; \& Scholz, F. (2004). Fluorinated polyanilines as superior materials for electrocatalytic anodes in bacterial fuel cells. Electrochem. Commun. 6, 571-575.

Nishio, K.; Hashimoto, K. \& Watanabe, K. (2010). Light/electricity conversion by a selforganized photosynthetic biofilm in a single-chamber reactor Appl. Microbiol. Biotechnol. 86, 957-964.

Olofsdotter, M.; Jensen, L.B. \& Courtois B. (2002). Improving crop competitive ability using allelopathy - an example from rice. Plant Biol. 121, 1-9.

Qiao, Y.; Li, C.M.; Bao, S.J. \& Bao, Q.L. (2007). Carbon nanotube/polyaniline composite as anode material for microbial fuel cells. J. Power Sources 170, 79-84.

Reimers, C.E.; Tender, L.M.; Fertig, S. \& Wang, W. (2001). Harvesting energy from the marine sediment-water interface. Environ. Sci. Technol. 35, 192-195. 
Prinn, R.G. (1994). Global atmospheric-biospheric chemistry. Global atmospheric-biospheric chemistry. 1-18. Plenum, New York.

Satoh, A.; Watanabe, M.; Ueki, A. and Ueki, K. (2002). Physiological properties and phylogenetic affiliations of anaerobic bacteria isolated from roots of rice plants cultivated on a paddy field. Anaerobe 8, 233-246.

Sorokin, D.Y.; van Pelt, S.; Tourova, T.P.; Takaichi, S. \& Muyzer, G. (2007). Acetonitrile degradation under haloalkaline conditions by Natronocella acetinitrilica gen. nov., sp. nov. Microbiology 153, 1157-1164.

Strik, D.P.B.T.B.; Hamelers, H.V.M.; Snel, J.F.H. \& Buisman, C.J.N. (2008) Green electricity production with living plants and bacteria in a fuel cell. Int. J. Energy Res. 32, 870876.

Takanezawa, K.; Nishio, K.; Kato, S.; Hashimoto, K. \& Watanabe, K. (2010). Factors affecting electric output from rice-paddy microbial fuel cells. Biosci. Biotechnol. Biochem. 74, 1271-1273.

Takai, Y. (1969). The mechanism of reduction in paddy soil. Jpn. Agri. Res. 4, 20-23.

Tanaka, K.; Tamamushi, R. \& Ogawa, T. (1985). Bioelectrochemical fuelcells operated by the cyanobacterium, Anabaena variabilis. J. Chem. Technol. Biotechnol. 35B, 191-197.

Tanaka, K.; Kashiwagi, N. \& Ogawa, T. (1988). Effects of light on the electrical output of bioelectrochemical fuel-cells containing Anabaena variabilis M-2: mechanism of the post-illumination burst. J. Chem. Technol. Biotechnol. 42, 235-240.

Timmers, R.A.; Strik, D.P.B.T.B.; Hamelers, H.V.M. \& Buisman, C.J.N. (2010) Long-term performance of a plant microbial fuel cell with Spartina anglica. Appl. Microbiol. Biotechnol. 86, 973-981.

Ueki, A.; Kodama, Y.; Kaku, N.; Shiromura,T.; Satoh, A.; Watanabe,K. \& Ueki, K. (2010). Rhizomicrobium palustre gen. nov., sp. nov., a facultatively anaerobic, fermentative stalked bacterium in the class Alphaproteobacteria isolated from rice plant roots. J. Gen. Appl. Microbiol. 56, 193-203.

Walker, T.S.; Bais, H.P.; Grotewold, E. \& Vivanco, J.M. (2003). Root exudation and rhizosphere biology. Plant Physiol. 132, 44-51.

Watanabe, K.; Kodama, Y. \& Harayama, S. (2001). Design and evaluation of PCR primers to amplify bacterial $16 \mathrm{~S}$ ribosomal DNA fragments used for community fingerprinting. J. Microbiol. Methods 44, 253-262.

Watanabe, K. (2008). Recent developments in microbial fuel cell technologies for sustainable bioenergy. J. Biosci. Bioeng. 106, 528-536.

Watanabe, K.; Manefield, M.; Lee, M. \& Kouzuma, A. (2009) Electron shuttles in biotechnology. Curr. Opin. Biotechnol. 20, 633-641.

Yagishita, T.; Sawayama, S.; Tsukahara, K.I. \& Ogi, T. (1997). Behavior of glucose degradation in Synechocystis sp. M-203 in bioelectrochemical fuel cells. Bioelectrochem. Bioenerg. 43, 177-180.

Yagishita, T.; Sawayama, S.; Tsukahara, K.I. \& Ogi, T. (1998). Performance of photosynthetic electrochemical cells using immobilized Anabaena variabilis M-3 in discharge/culture cycles. J. Ferment. Bioeng. 85, 546-549. 
Yagishita, T.; Sawayama, S.; Tsukahara, K. \& Ogi, T. (1999). Effects of glucose addition and light on current outputs in photosynthetic electrochemical cell using Synechocystis sp. PCC6714. J. Biosci. Bioeng. 88, 210-214.

Zhao, Y.; Watanabe, K.; Nakamura, R.; Mori, S.; Liu, H.; Ishii, K. \& Hashimoto, K. (2010). Three-dimensional conductive nanowire networks for maximizing anode performance in microbial fuel cells. Chemistry 16, 4982-4985. 


\title{
Switching from Renewable to Renewable - A Case Study from Nordic Perspective
}

\author{
Alemayehu Gebremedhin \\ Gjøvik University College \\ Norway
}

\section{Introduction}

Human beings have been using energy in its different forms since early times and the use of energy has been increasing since then. Though the degree of energy utilisation varies from country to country as a result of different conditions, energy is being used for different purposes within different sectors as for example household (residential), industry, transport, service, agriculture etc. Within the household, industrial and the service sector energy is used commonly for lighting, heating, cooling, tap water heating and running different devices. A large portion of the world's energy is used within the household and service sectors. According to International Energy Agency (IEA, 2009a), the energy consumption of these two sectors alone accounted for $37 \%$ of the world's total final energy consumption in 2006. In terms of $\mathrm{CO}_{2}$ emissions, these sectors make up about $32 \%$ of end-use sectors $\mathrm{CO}_{2}$ emissions during the same period.

Though mankind enjoy the benefit of energy in its diverse forms, the extraction and utilisation of energy has not been harmless. Our planet is facing today one of the most serious problems due to greenhouse gas (GHG) emissions coming from different kinds human activities. Being aware of the issue of climate change, different kinds of researches are going on around the world. For instance, based on report from the Intergovernmental Panel on Climate Change (IPCC) the developed nation alone would need to cut their emissions by $10-40 \%$ in 2020 and $40-95 \%$ in 2050 compared to the level of 1990 to limit the temperature increase to $2^{\circ} \mathrm{C}$ above pre-industrial levels (IPCC, 2007)

Today, the issue of climate change is highlighted as one of the political agenda in many nations. For instance, the European Union has through what is known as 20-20-20 targets set different targets to be met by 2020 . These targets mean $20 \%$ reduction of GHG, $20 \%$ renewable energy in the EU energy consumption and 20\% reduction of primary energy (EC 2008). Within the EU some national and continental measures are introduced to achieve the targets. Emission trading system for $\mathrm{CO}_{2}$ and different type of subsidy to promote power generation from renewable sources are some examples in this direction. These policies will affect the energy sector.

Power consumption in Norway is mostly considered to be $\mathrm{CO}_{2}$ neutral due to the fact that power production is almost entirely based on hydropower. However, this would be correct if and only if the power system of Norway is considered as an isolated system. As it is known, the conditions for the electricity market in northern European countries have changed step by step beginning in 1996. Today it can be said that the Nordic power market 
is more or less fully deregulated with cross-border trading at Nordpool, a platform for electricity market within the Nordic countries. Consumer's power price is determined based on supply and demand curve. However, there are still some discrepancies in spot prices within the market area due to capacity limits and other regulations. Weekly Spot prices for the different price area are shown in Fig.1 (Nordpool, 2010). As it can be seen from the figure, Norway and Denmark have more than one price area. The peak prices in the figure were caused by the rather cold winter in 2010. Peak prices can be also expected during periods of low precipitation. Furthermore, the Nordic market is to some extent connected to markets in the continental Europe and also Russia.

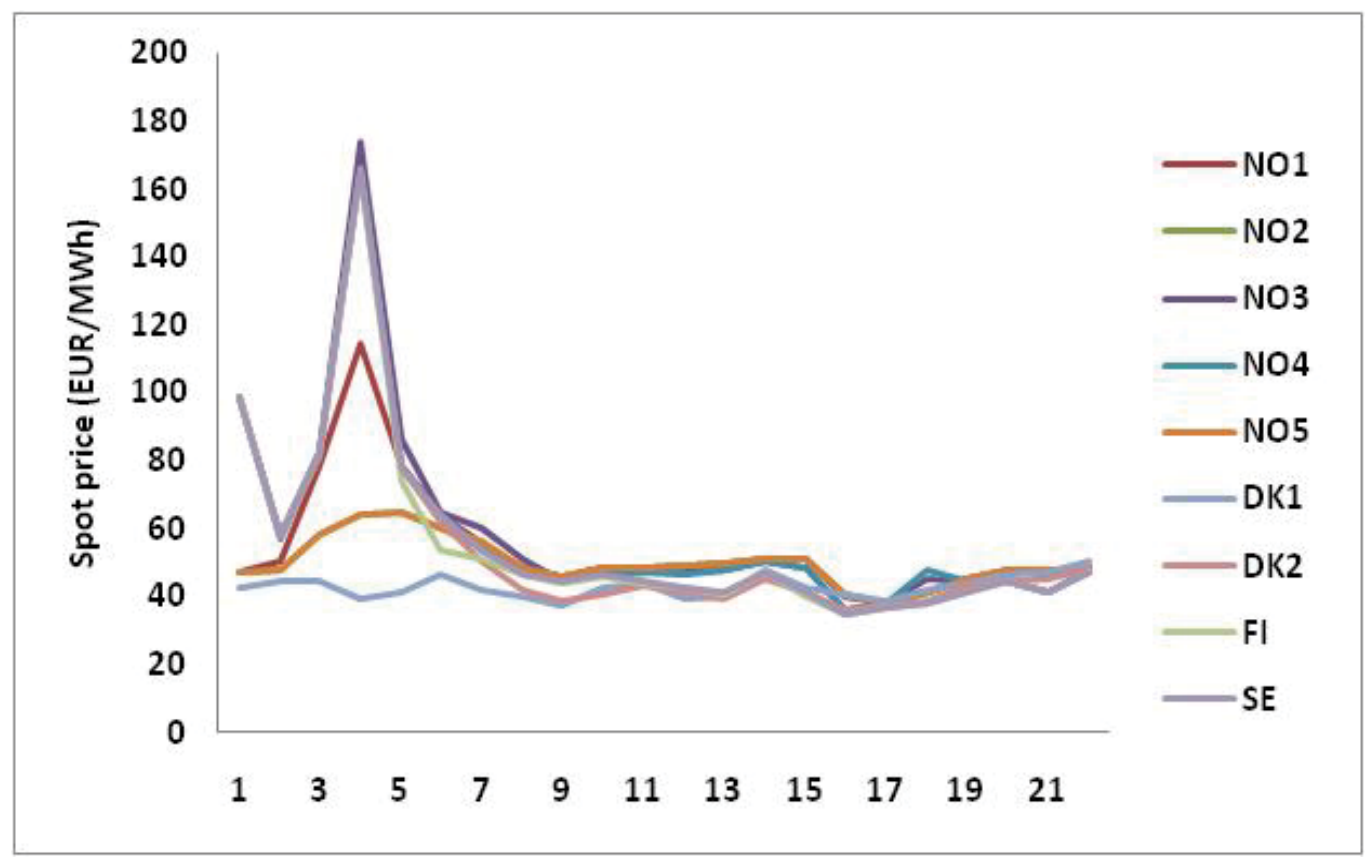

Fig. 1. Weekly spot prices at Nordpool (NO = Norway, DK= Denmark, SE= Sweden, FI= Finland).

According to annual report from Nordel (Nordel, 2008), the total installed capacity for electricity generation for the Nordic countries (excluding Iceland) was 94. $624 \mathrm{GW}$. Hydropower (mainly available in Norway and Sweden) has the largest share with $52 \%$ followed by thermal power (31\%), nuclear (12\%) and wind (ca 5\%). The shares in terms of energy sources are renewable (62\%), fossil fuels (25\%) and nuclear $(12 \%)$. Statistics on power generation from 2008 (Nordel, 2008) shows that renewable alone (including hydropower) accounted for $65 \%$ of total generation (398 TWh) followed by nuclear $(21 \%)$ and fossil fuels (13\%). These figures vary from year to year depending on among other things precipitation and other external conditions. The high dependency on hydropower means that Norway can be either a net exporter or importer of electricity.

Based on the above figure, it can be stated that a major part of power production in the Nordic region (mainly Norway and Sweden) is basically $\mathrm{CO}_{2}$ emissions free (taking into account hydro, nuclear and other renewable). Though the share of renewable energy is high in these regions, the power system still emits $\mathrm{CO}_{2}$ when fossil fuel based plants become 
marginal producer. This can happen during high power demand or during other periods of the year depending on different circumstances.

It is estimated that energy corresponding to 45-50 TWh is used for heating purposes in Norway (NVE, 2003). A total domestic heat market in the order of about 55 TWh is also mentioned in another study (Trømborg et al, 2008). About 30 TWh of the total heat demand is supplied by electricity while the rest comes from oil and firewood. There is also a limited use of district heating (see section 4) and other energy sources. The availability of high hydropower resources together with other factors like settlement structure and favourable tax on power have directly or indirectly encouraged the deployment of power for heating. As a result of this, the share of electricity is quite high within the household and service sector. From the Nordic perspective and based on production data from 2008, the amount of electricity that is used for space heating in Norway corresponds to about $12 \%$ of the total generation from renewable sources (hydropower, wind, etc.), $36 \%$ of the total generation from nuclear and $56 \%$ of the total generation from fossil fuel. It is worth to mention that about 20 TWh of the total heat demand in Sweden (one of the Nordic countries with a highest share of district heating in the heat market) is supplied by electricity (Swedish Energy Agency, 2009). Based on these figures, it is clear that any measure that will contribute to the reduction of power consumption within the heating sector is beneficial from a widened system perspective. According to data from State of the Environment Norway (State of the Environment Norway, 2010), the total GHG emissions were 53.7 million tonnes of $\mathrm{CO}_{2}$ equivalents in 2008. The distribution of the emissions by source is shown in Fig.2. In the figure below, the group "others" represents emission contributions from agriculture, household, service and others (where the contribution from household and service sectors is between 10-15\%). According to Fig. 2, the transport, the petroleum and the industry sectors are the ones where

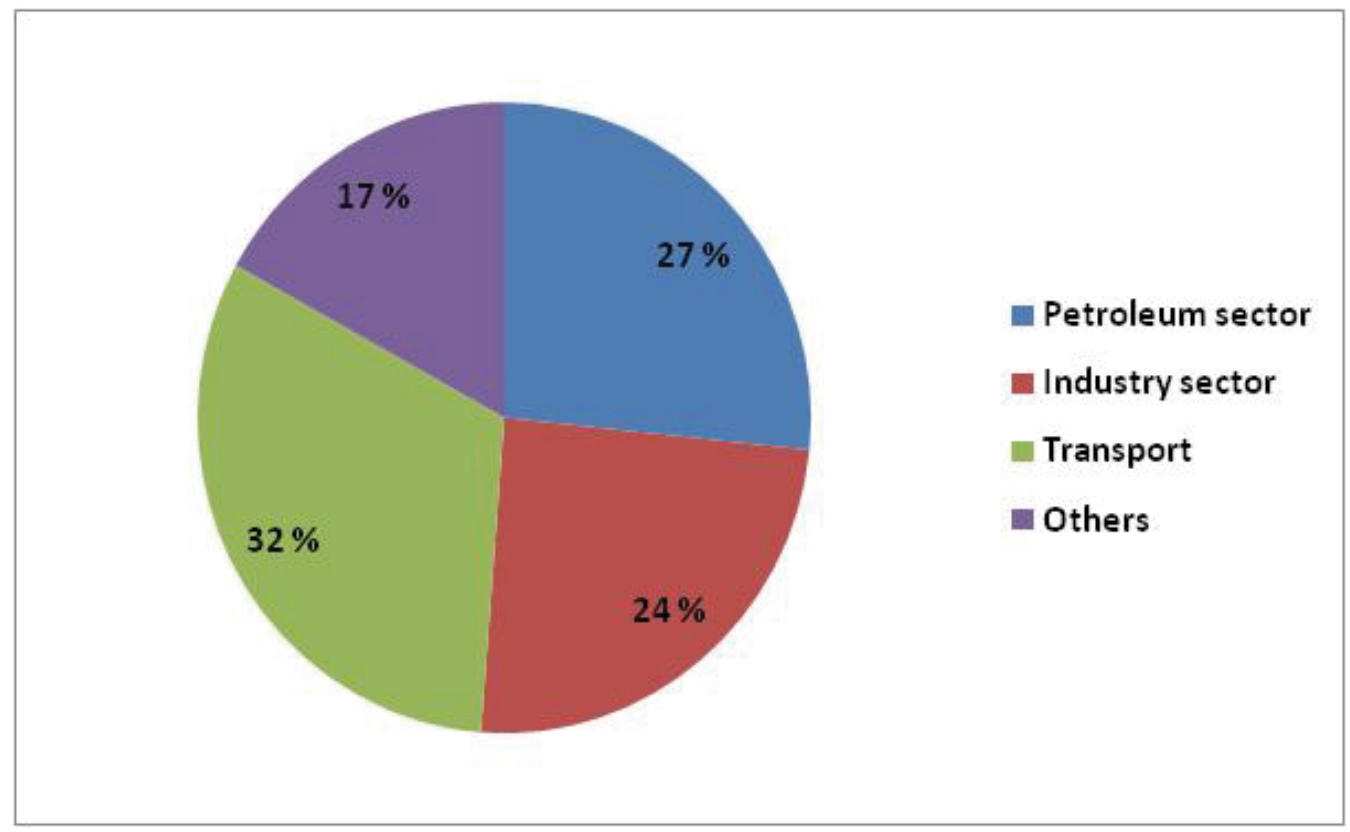

Fig. 2. GHG emissions in Norway by sector (based on figures from State of the Environment Norway) 
major attention should be given to reduce emissions. However, this does not mean that nothing needs to be done in the heating sectors. The Norwegian government is much aware of the climate change issue and it has therefore set some targets along this line. The targets proposed by the government are: carbon neutral Norway by 2050, global GHG emission reduction corresponding to $30 \%$ of its own emission by 2020 and strengthening the Kyoto commitment (Norwegian Ministry of the Environment, 2008). The electricity dominated heating sector may therefore play a significant role in achieving the climate target.

Since Norway is part of the internal energy market of European economic area (EC 2008) the EU renewable energy target where $20 \%$ of the energy use should come from renewable energy sources (EC 2009) is also relevant for Norway. The less utilized biomass potential together with hydropower based power system offer a tremendous opportunity to reduce the global GHG.

The purpose of this study is to present the result of a simplified model study where the impact of the measure of energy-carrier switching (from electricity/fossil fuel to biomass based district energy (DE) or other forms of biomass based heating) on $\mathrm{CO}_{2}$ emission reduction from the local and global perspectives are highlighted. The county of Oppland in Norway is used as a study object.

\section{Sustainable energy}

Terms like "sustainable", "sustainable development" and "sustainable energy" are words and phrases that are used frequently in our society. Since the book deals with sustainable energy, a brief definition of the term is given here. According to Wikipedia, sustainable energy is the provision of energy such that it meets present demand without compromising the ability of future generations to meet their need (http://en.wikipedia.org). This definition is actually similar to the definition of sustainable development as formulated by Brundtland Commission in 1987 (United Nation, 1987).

Based on the above definition, the supply of energy should have to be based on energy sources that are renewable if we desire to have a sustainable energy system. All energy sources that will not run out can therefore be considered as renewable energy. For instance, energy from the sun can be used to meet present demand without affecting future generations (future generations will still have the ability to extract the same or more quantity of energy to meet their needs). A list of renewable energy sources include: hydro, wind, biomass, solar, wave, tidal, and geothermal.

According to IEA statistics from 2007, fossil fuels accounted for about $80 \%$ of the world's total primary energy supply and almost all $\mathrm{CO}_{2}$ emission caused by fuel combustion (IEA 2009b). Since fossil fuels are limited and their use has negative impact on the environment, a shift toward sustainable energy will play a substantial role in reducing global GHG emission. A large proportion of the world energy is used today within the building sector. It is therefore of vital importance to design a supply system based on sustainable energy sources.

As mentioned earlier, the power system in Norway and Sweden is characterised by a large share of hydropower (a renewable energy source). The abundance in hydropower has on the other hand in one way or another encouraged the use of electricity for non-electricity specific purposes in the household, service and also quite often in the industry sectors. It would be, however, important to be reminded that a major part of the electricity in Europe is generated based on fossil fuels and with low efficiency. Thus, electricity, which is high quality energy, should not be used for non-electricity specific purposes (like heating, cooling 
etc.). If electricity has to be used then it is wise to use it for electricity-specific processes (such as driving motors, lighting and other similar processes). Hence, energy-carrierswitching measures, in this case, from electricity to district heating or other biomass based supply system will have a pivotal role in developing sustainable system. For instance, a study from Sweden shows that there is a significant potential of reduced power consumption in the industry sector if such measures are implemented (Henning, 2005).

\section{Bioenergy}

The term bioenergy is widely used across the world and it refers to energy extracted from biomass. Using biomass one can generate heat energy (for space heating and water heating), electricity and steam (for industrial processes). Biomass can be also used to produce vehicle fuels. Biomass can be considered as a resource that will not deplete (if managed properly). Bioenergy is in general $\mathrm{CO}_{2}$ neutral but one should take into consideration if the production process is $\mathrm{CO}_{2}$ neutral or not.

From the Nordic perspective, bioenergy has a significant role in the entire energy system. However, the degree of utilisation of this energy varies much within the countries, with Finland and Sweden having the highest share. According to a report from a Nordic energy research, Finland has the highest share of bioenergy in its total energy consumption followed by Sweden, Denmark and Norway (ECON Pöyry 2008). In terms of potential biomass availability, Sweden has the largest potential. The Nordic countries have ambitious plan to increase the use of bioenergy. Current and potential supply of bioenergy in Finland, Norway and Sweden is shown in Fig.3. The application of bioenergy varies much within the Nordic countries, where Finland has a leading position in terms of power production and Sweden in terms of heat generation (ECON Pöyry 2008).

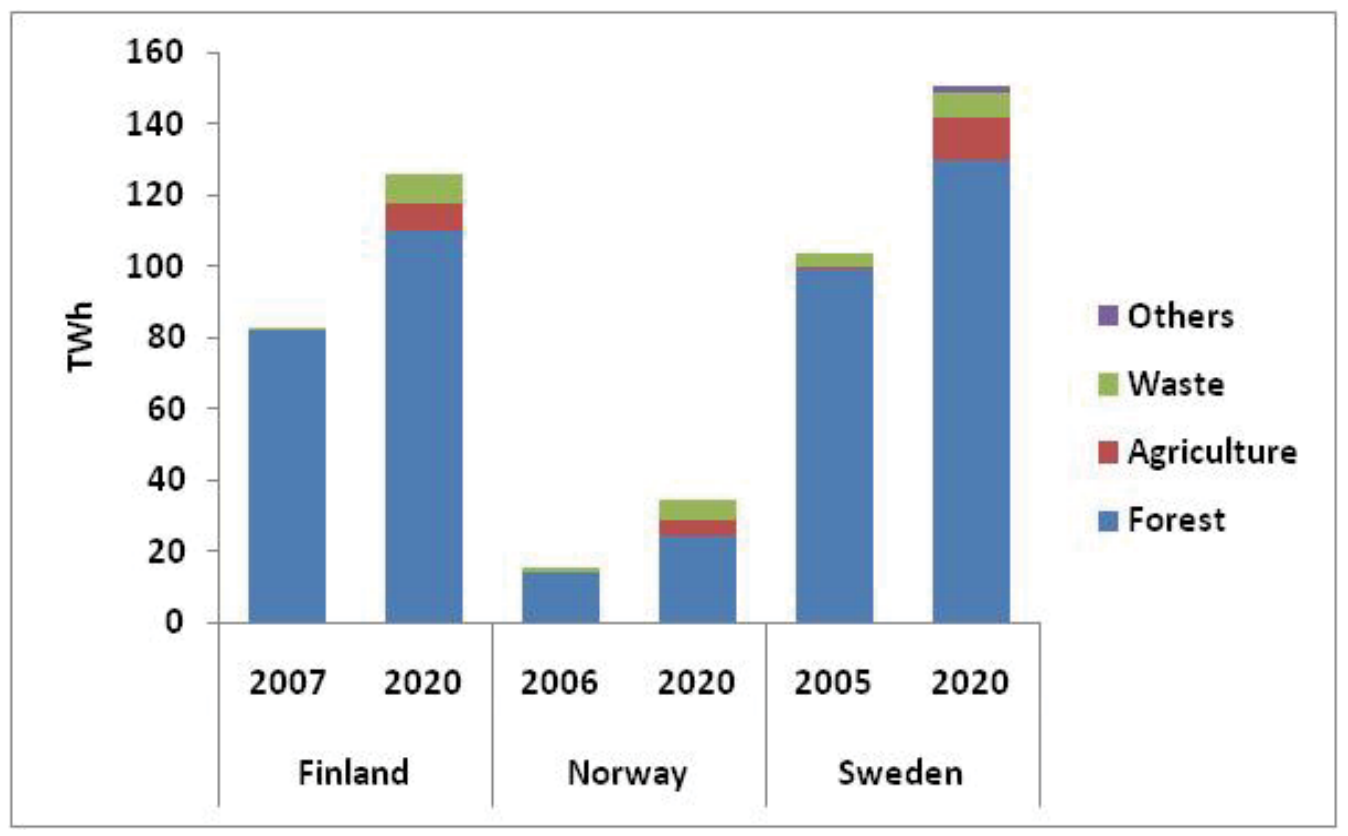

Fig. 3. Current and potential supply of bioenergy (Nordic Council of Minsters, 2009) 
According to a report from NVE, the total biomass potential for energy purposes is around 47 TWh of which only $34 \%$ is in use currently (NVE 2004). At current status, bioenergy accounts for only $5 \%$ of the total net domestic energy consumption. The use of bioenergy in Norway is currently about $14 \mathrm{TWh} /$ annually where about 8-9 TWh is used within the heating sector (Trømborg et al, 2008). The potential of bioenergy is however much more higher than the current use. One of the measures that are proposed by the Norwegian government to reduce emissions from the energy sector is to increase the use of bioenergy with 14 TWh (Norwegian Ministry of the Environment, 2008) by 2020.

Though hydropower is a dominating energy source in Norway, technologies that use biomass can provide a significant possibility to shape the energy system towards a more sustainable system not only on national level but also on international level.

\section{District energy}

A district energy scheme (DES) is a system where hot/cold water is generated centrally. The product is then distributed through pipeline to different types of customers that are connected to the network. Some of the advantages of DES are:

- Flexible production

- With sufficient base load, it allows the use of combined heat and power production (CHP). This means less use of primary energy.

- It allows the use of larger boilers with higher conversion efficiency

- The specific cost of larger boilers are in general cheaper

- Better possibility of heat utilisation from waste heat and other surplus heat and also the use of waste as a fuel

Flexible production means that DES offers a great opportunity to incorporate different types of production units and energy sources. This means it is possible to incorporate renewable energy sources like bioenergy and thereby offer a better opportunity for the use of sustainable energy sources. The technology of district heating is today well established and district heating systems are widely spread in many European countries even though the degree of penetration in the heat market varies from country to country due to a number of reasons as for instance climate, natural resources, infrastructure for energy and so on.

From the Nordic perspective, district heating has become an important part of the energy system (mainly Sweden, Finland and Denmark). The share of district heating in the total domestic heat market is shown in Fig. 4.

The total supply of district heating varies from about 3 TWh in Norway (Norwegian district heating association, 2010) to 48 TWh in Sweden (Swedish Energy Agency, 2009). The type of energy carriers that are used for district heating production varies also depending on the market and resource condition existing in each country. Fig. 5 shows production by type of energy carriers. As it can be seen from the figure, a highest share of biomass is seen in Sweden while Denmark and Finland have a significant share of fossil fuels. It should be, however, mentioned here that both Denmark and Finland have a very high share of combined heat and power production within the district heating sector (DEA, 2010; Statistics in Finland, 2007). According to current heat market share of district heating in the Nordic countries, Norway seems to have a substantial potential for increased application of district heating. 


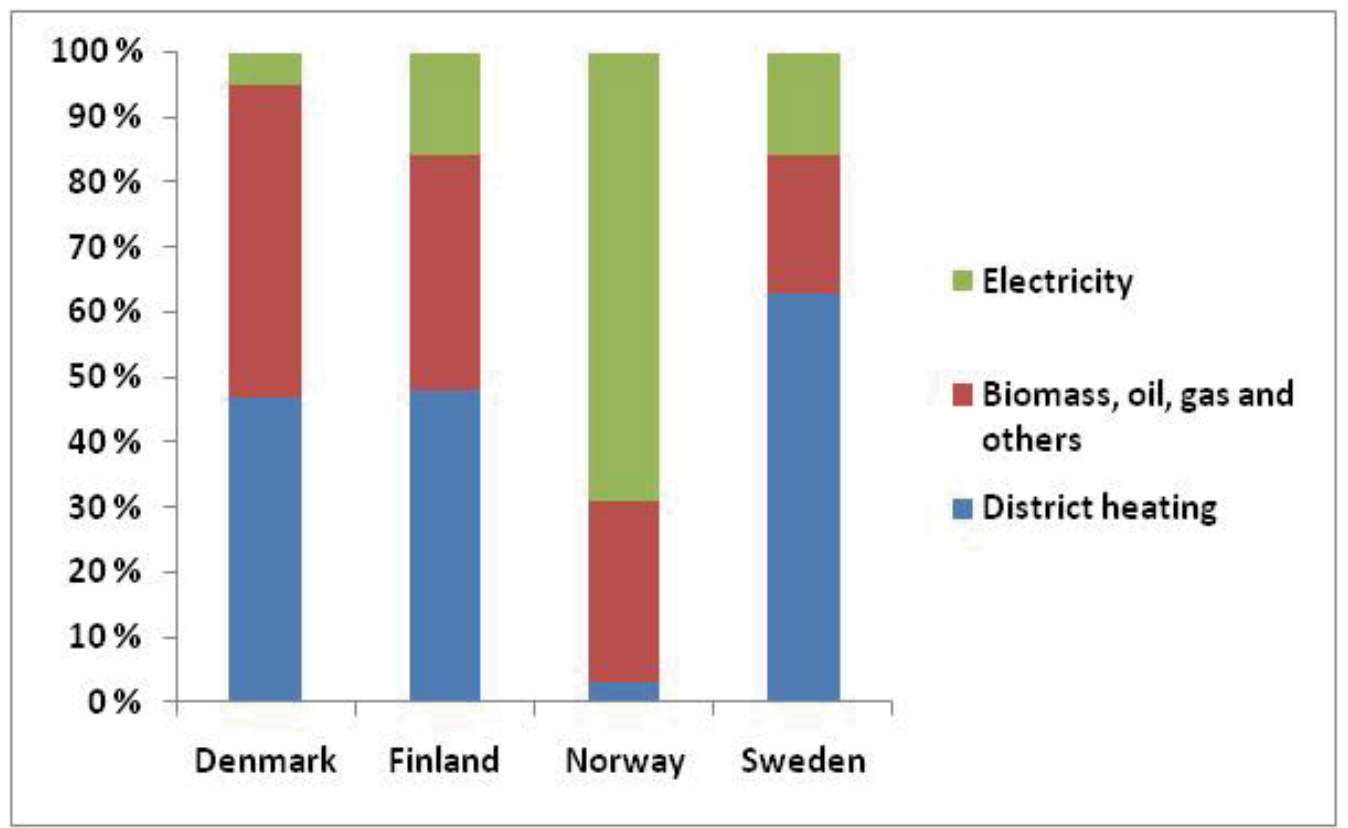

Fig. 4. Share of district heating (modified, Energigården, 2007)

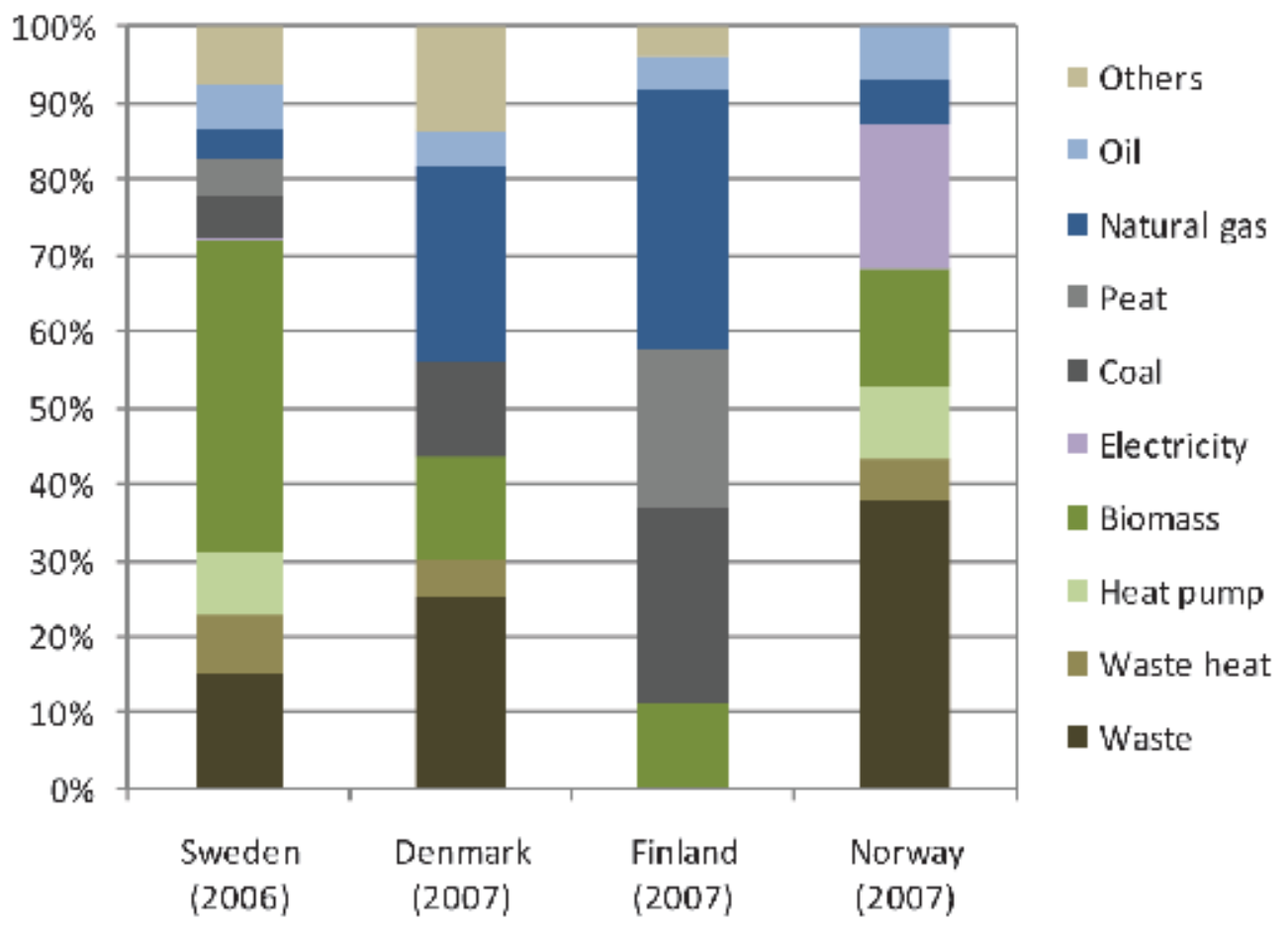

Fig. 5. District heating production by type of production (NEP, 2010) 
Though Norway has a similar climate condition as neighbouring countries, the share of district heating in the heat market is quite low. The share of district heating in the total net domestic energy consumption was only 1\% in 2008 (SSB, 2010) while corresponding figure for Sweden was 12 \% (Swedish Energy Agency, 2009). Abundance in hydropower in general and to some extent settlement pattern have made it difficult for the expansion of district heating compared to the rest of the Nordic countries. Even though the share in the heat market is low, district heating systems in Norway are increasing gradually. Based on statistics from Norwegian district heating association, the net production increased by $6.3 \%$ compared to 2007 (Norwegian district heating association, 2010). Production by type is more or less similar to that of Fig.5, but compared to 2007 a 5 and $16 \%$ increase is noticed in biomass and waste respectively. The share of electricity is still high. The contribution from biomass may increase if a switch from electricity and fossil fuels are encouraged.

Though the share of district heating in the domestic heat market is low, there is still significant potential for increased use of it. It will also offer a better condition to incorporate biomass (renewable source) in the heating sector. District heating may not be attractive in heat sparse areas due to cost and other aspects but it could offer a tremendous opportunity of heat/cold supply in areas with densely population (high heat intensity).

\section{Current heating system in the county}

The county of Oppland is located in the centre of southern Norway. With about 185216 inhabitants (SSB, 2010), Oppland is one of the largest counties. The county has in total 26

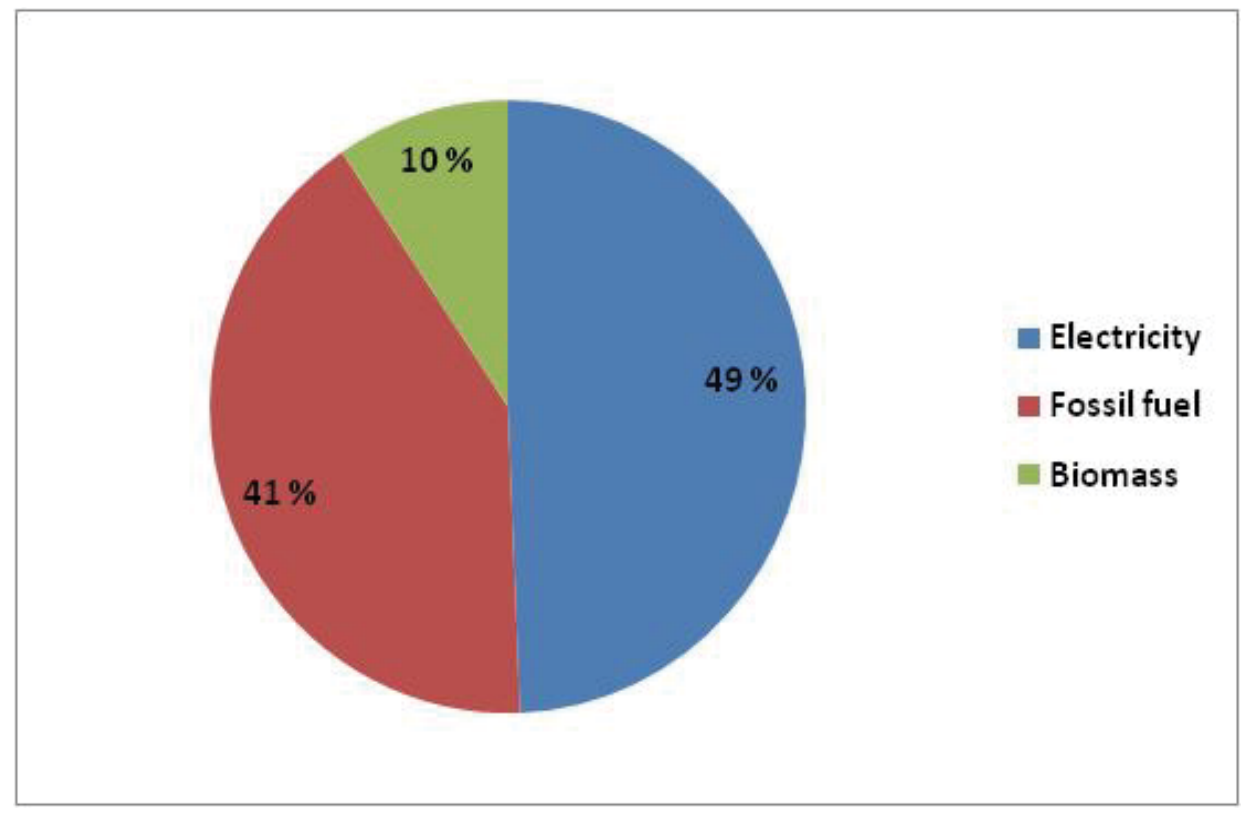

Fig. 6. Total energy use in the county of Oppland (SSB, 2008) 
municipalities where only five of them have population higher than 10000 . For the entire county as a whole, there were 67931 detached houses, 8423 semi-detached houses, 6252 row houses, 5906 apartment buildings, 2043 residence for communities and 2400 other buildings in 2009 (SSB, 2010). According to statistics from 2008, the total energy use was about 7 TWh. Energy use by type is shown in Fig. 6. As it can be seen from the figure, electricity is the dominating energy source in the county followed by fossil fuels (the transport sector accounts for a major part of the fossil fuel use) and biomass.

The household and the service sector accounted for more than $70 \%$ of the total electricity consumption in the county. The heat demand for the different building stock is covered individually (in some cases collectively) mainly by electricity followed by firewood and fossil fuel. Not much is known about the use of district heating in the region (few small scale supply system are available in some areas), but there are plans and projects underway in some places. It is quite difficult to quantify the amount of electricity used for space heating purposes. According to statistics from ENOVA, $43.6 \%$ of the total energy used in the residential sector in Norway is electricity for space heating. Corresponding figure for service sector is $35.7 \%$ (ENOVA, 2004).

\section{Method}

In order to carry out this particular analysis, an energy modelling tool known as MODEST (Henning, 1999; Gebremedhin, 2003) is used. MODEST is an acronym for Model for Optimisation of Dynamic Energy Systems with Time-dependent components and boundary conditions and the tool is suitable for such a study and it has been used to study the electricity and district heating supply of about 50 Swedish municipalities. For instance, the entire Stockholm was studied using MODEST (Danestig, et al, 2007). With MODEST it is possible to describe any energy system (heat supply system, power supply system or both) on local, regional and national level. Linear programming (Bazaraa, 1990) is used to optimise the total system cost (sum of all costs for fuel, maintenance, investment and other costs like taxes and fees). One of the strength of the MODEST tool is that it can provide good information on optimal investment and thereby helps in decision making process.

\section{Input data}

As the aim of this study is to present the impact of introducing energy-carrier-switching on the environment, it is of good importance to describe the current and future supply system as good as possible. This depends however on the availability of data. The most important data in this study are electricity price, fuel prices (oil and biomass) and heat demand. As it is mentioned earlier the power price is determined by market price from NordPool. Besides power price consumers have to pay for transmission cost. The transmission cost includes grid owner's cost, consumption fee and other official fee. There is also what is known as primary and secondary transmission cost agreement for consumers of various category. This means that large consumers who have electric boiler are privileged to buy electricity with a lower transmission cost (secondary transmission cost). The precondition for such favourable price is that the consumer must have alternative unit to replace the electric boiler when the net owner due to critical condition on the grid switch off the supply (this is the risk the 
consumer take when signing such a contract). It should be mentioned here that such a favourable price have in some way or another encouraged and is still encouraging the use of electricity for generation of heat and steam and thereby hampered the deployment of other resources like for instance bioenergy.

It is quite difficult to know the actual price paid by different consumers for electricity and fuels. Fuel and energy prices are therefore estimated roughly based on data from Norwegian statistics bureau (SSB), Norwegian Petroleum institute (NP) and Norwegian bioenergy association (Nobio). The fuel prices that are used in this study are presented here as the ratio of oil prices (prices are from 2009). Since the price relations given in the figure below are based on estimation, it should be viewed with caution when interpreting results.

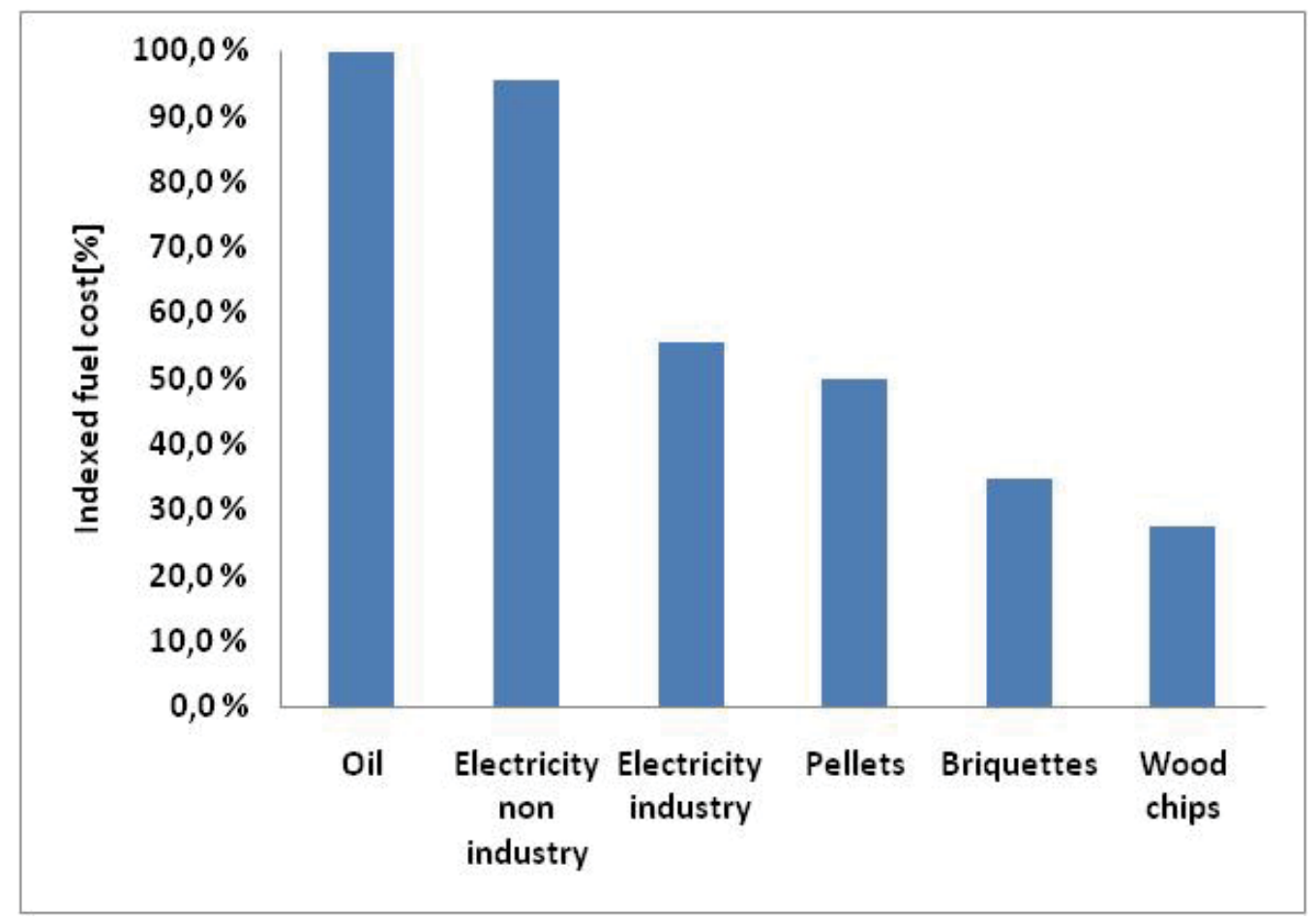

Fig. 7. Fuel costs as a ratio of oil cost

Based on the statistics from ENOVA, it is assumed in this study that about $40 \%$ of the total electricity consumption in the household and service sector is used for space heating. In total it is assumed that there is a total heat demand of about $1700 \mathrm{GWh}$ within these sectors. Besides this, the industry sector uses about $20 \%$ of the total electricity used in the county. However, it is not known how much electricity is used for generation of thermal energy within this sector. It is therefore assumed in this study a thermal energy demand of about $100 \mathrm{GWh}$. In total there is an estimated thermal energy demand of $1800 \mathrm{GWh}$. The energy 
demand is largely concentrated around some of the larger municipalities. However, the demand is not concentrated in densely populated areas due to a rather dispersed settlement pattern. It is therefore assumed that at least $20 \%$ of the total demand can be supplied from a possible DES. Other options like individual heating based on biomass and small scale heating systems are also considered.

As far as production units are concerned, the model contains different types of production units, both existing and future units. There are electricity boilers, oil fired boilers and other individual heating systems that use electricity, biomass and oil. Biomass fired combined heat and power (CHP) unit and other energy-carrier-switching measure (an option to switch from electricity and oil based heating to biomass based system) also included as a potential unit in the model.

Besides the data that are estimated or assumed so far, some data on emission factors are also needed. This will be useful to make some statement based on the outcome of the optimisation. The $\mathrm{CO}_{2}$ emission for oil is assumed to be $280 \mathrm{~kg} / \mathrm{MWh}$ while biomass is considered as $\mathrm{CO}_{2}$ neutral. The problem is here how to assess the environmental impact of electricity production and use. If one considers the electricity production mix of Norway alone, one would tend to conclude that production and use of power have more or less no negative effect on climate. However, the fact that the Norwegian power system is connected with power systems of Nordic countries and even some nations of continental Europe gives us another picture. This situation makes it difficult to clearly asses the environmental impact of power production and use in the Nordic countries. A number of approaches on $\mathrm{CO}_{2}$ accounting, as for instance, marginal electricity and average electricity are discussed in (Dotzauer, 2010). For simplification reason, emission factors in the interval of $0-1000 \mathrm{~kg}$ $\mathrm{CO}_{2} / \mathrm{MWh}$ are used (In this way one can cover the different approaches).

\section{Results}

This section presents some of the results obtained from modelling and optimisation of two cases, the current (no energy-carrier-switching) and the future (with energy-carrierswitching) system. Total system cost, heat and (power) generation and $\mathrm{CO}_{2}$ emissions are used to roughly compare the two alternatives.

A simplified model of the heat supply of the county of Oppland has been built with both existing and future components. The system has been then optimised with and without introduction of energy-carrier-switching measure to evaluate the impact of the new measure on the energy system as a whole and the environment. The model and the optimisation focus on the system perspective.

\subsection{Existing and future system}

Simulation of the existing system does not give any new solution than what is described in section 5 . However, new solutions are obtained when the system is simulated by including biomass based energy-carrier-switching measure. According to the optimisation based on the applied data and with no restriction, a DES that can handle an aggregated heat demand of about $1400 \mathrm{GWh}$ is theoretically possible (this would mean about $80 \%$ of the total demand). Such a base load concentrated in one municipality or area with reasonable 
distance to production plant would give an opportunity to generate a total of $400 \mathrm{GWh}$ electricity simultaneously. This is, however, unrealistic from the geographical point of view. As mentioned earlier, it would be unrealistic to have a DES with the above size. Based on the settlement pattern and the distribution of heat density areas in the county, it would be more reasonable to assume a DES that can handle a heat demand corresponding to $25 \%$ of the total demand. The optimisation is therefore performed based on this assumption. Use of fuel and electricity to supply the thermal energy demand for the existing/future system is shown in Fig. 8. According to the figure, there is a significant shift from high electricity share to a high biomass share. The use of oil will totally disappear (electricity will still be needed as a compliment during colder periods). Since the DES included in the model is limited to supply only $25 \%$ of the total demand, the rest of the demand will have to be supplied using biomass based heating systems individually or in group (where briquettes and pellts could be used). Since the heat generated within the DES comes from biomass based CHP, there will be also a potential power production of about $100 \mathrm{GWh}$ (provided that all heat demand is available within a reasonable distance).

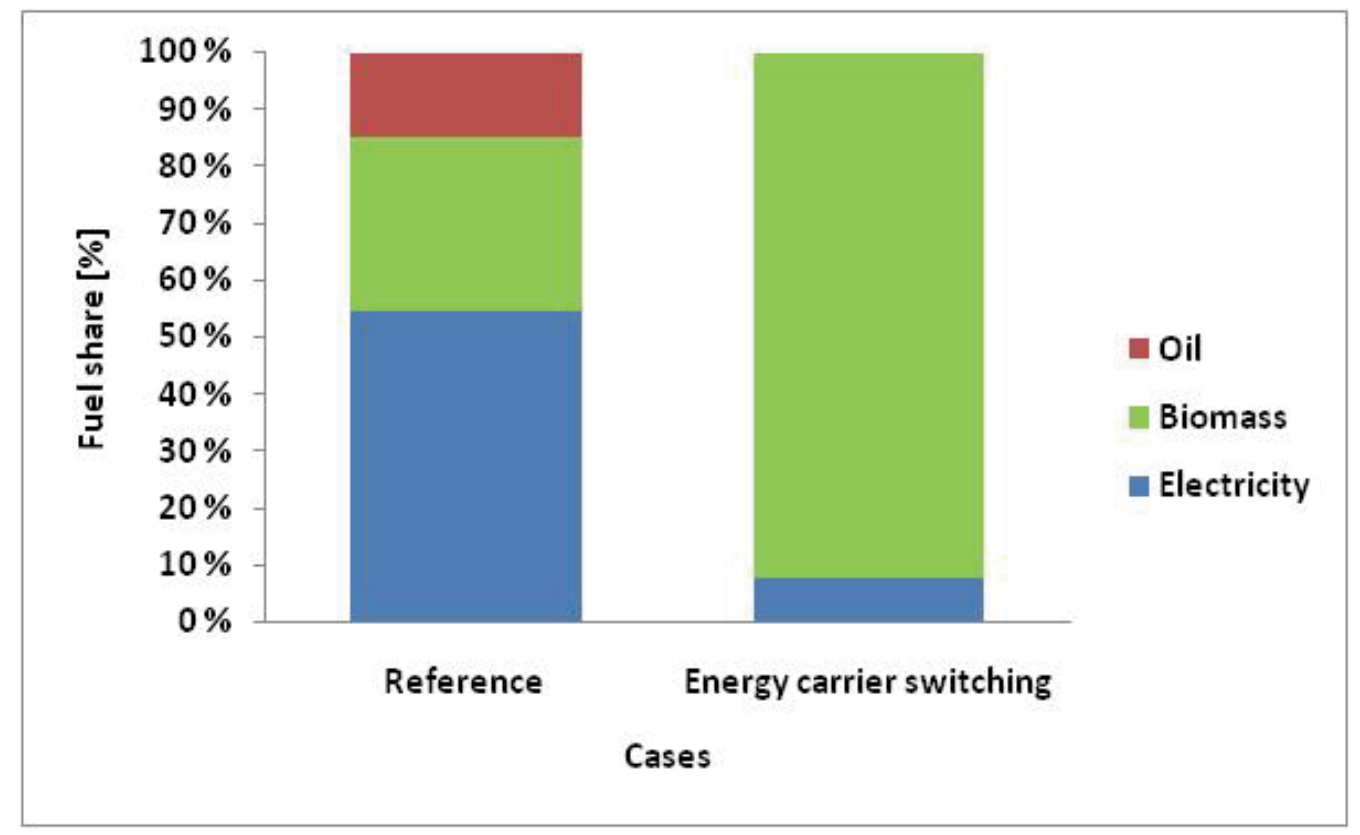

Fig. 8. Fuel used for heat supply

Since most data are approximation and relevant investment costs could not be found, it would be quite difficult to make a proper comparison between the two alternatives in terms of cost. However, based on given data and without including investments, the alternative with energy-carrier-switching has a system cost about $50 \%$ lower than the reference system. 
This implies that there is a significant investment potential for financing the energy-carrierswitching measure (biomass based DES and other forms of biomass based heating systems).

\section{$8.2 \mathrm{CO}_{2}$ emissions}

The quantity of $\mathrm{CO}_{2}$ emissions for these two alternatives depends on how one defines the environmental impact of using electricity. The $\mathrm{CO}_{2}$ emissions for the alternatives are calculated for a variety of emission factors as mentioned in section 7 . The result is presented in Fig.9. The environmental benefit of the combined measure of energy-carrier-switching measure can be seen if power production and use has emission factor higher than zero. The emission reduction resulted from introducing these measures depends on what is assumed to be the marginal producer. The highest reduction can be achieved if conventional power plant based on coal is replaced (which may have emission factors between $800-1000 \mathrm{~kg}$ $\mathrm{CO}_{2} / \mathrm{MWh}$ ). The fact that there is a certain degree of power exchange with continental Europe can to some extent justify this assumption. The measures have positive impact even under assumption based on average electricity where the power production mix has much lower emissions compared to marginal electricity approach.

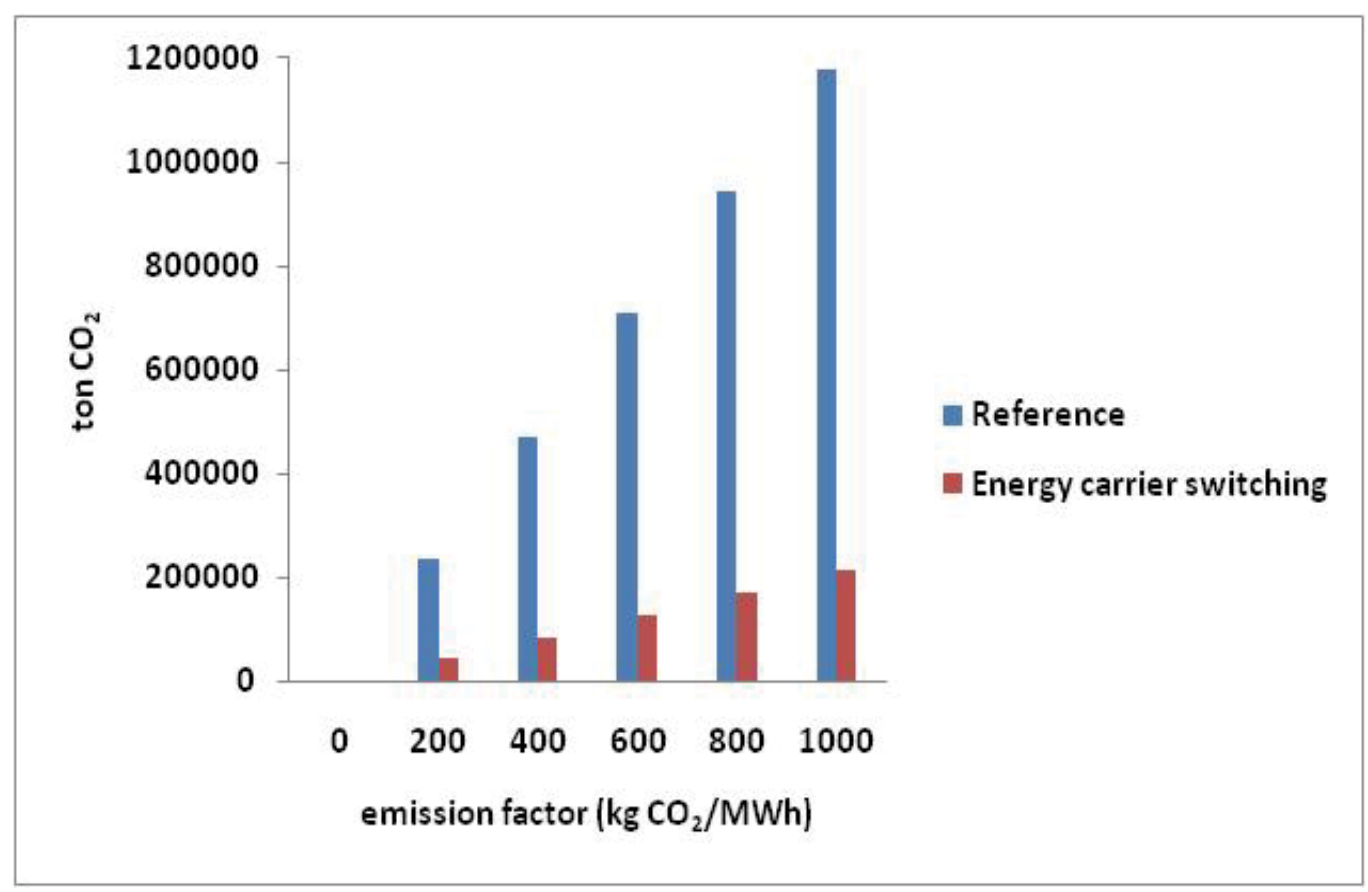

Fig. 9. $\mathrm{CO}_{2}$ emissions for different emission factors 


\section{Conclusion and discussion}

Though many of the data that are used in this study are approximation, the results of the optimisations indicate that energy-carrier-switching measure (from electricity to bioenergy) is an interesting option both in terms of economy and environment. Since the optimisation is carried out from societal perspective, the solution may not be necessarily attractive to individuals. For most consumers, the determining factor is the cost and not the environment (the environment comes second because there is sometimes a strong belief that all electricity is generated on renewable basis). People should be made aware of the advantage of switching from one renewable (hydropower based heating) to another renewable (bioenergy based heating). Production and consumption of power should be seen from broader system perspective, in this case Nordic or continental Europe. Thus, it is only with this thinking in mind that one can see the benefit of switching to bioenergy clearly.

The investment potential is clearly significant but since the cost aspect is the determining factor for any development in this direction, a support from authorities is needed to implement such a project. Besides, an in-depth cost benefit analysis by incorporating environmental aspects would be also necessary to further assess this measure. A cost effective production and distribution of bioenergy is essential to better compete with the well established renewable energy source.

The combination of hydropower and bioenergy is one of the best nature-given solutions to the climate issue both locally and internationally. Energy-carrier-switching measure will make a significant amount of electricity available and this energy can be used for other purposes where it is well needed locally or globally. Since the emissions from the transport sector is much higher than that of the heat sector, energy-carrier-switching measures in the heating sector could offer a tremendous opportunity for similar measure in the transport sector and thereby reduce GHG emissions. Using bioenergy will also offer a good opportunity for employment in the region (provided that the production and the conversion process of bioenergy will take place within the region).

Since most of the data that are used in this study are assumed values, the results should be viewed with carefulness.

\section{References}

DEA, 2010. Danish Energy Authority. Energy statistics, /http:// www.ens.dk accessed July 2010

Dotzauer, E. (2010). Greenhouse gas emissions from power generation and consumption in a nordic perspective, Energy Policy, 38(2010)701-704

Energigården (2007). http://www.energigarden.no/engelsk/index.html accessed July 2010 ENOVA (2004). Bygningsnettverkets energistatistikk. ENOVA. Available at

/http://www.enova.no. accessed July 2010

EC (2008). Second strategic energy review. An EU energy and solidarity action plan. $\operatorname{COM}(2008) 781$ final. accessed July 2010

EC 2009. The promotion of the use of energy from renewable sources. Direc-tive 2009/28/EC. accessed July 2010 
IEA (2009a). Towards a more energy efficient future - Applying indicators to enhance energy policy Available at

/http:/ / www. iea.org. accessed July 2010

IEA (2009b). Key world energy statistics Available at /http:/ / www. iea.org. accessed July 2010

Henning, D. (1990). Optimisation of local and national energy systems: development and use of the MODEST model, dissertation no. 559, Linköping University, Linköping, Sweden.

Henning, D.(2005). El till vad och hur mycket I svensk industri. Available at /http://www. energimyndigheten.se. accessed May 2010

Gebremedhin, A. (2003) A regional and industrial co-operation in district heating systems, dissertation no. 849, Linköping Institute of Technology, Linköping, Sweden.

Danestig, M.;Gebremehdin, A.;Karlsson, B. (2007). Stockholm CHP potential-An opportunity for CO2 reductions?. Energy Policy 35 (2007) 4650-4660

Bazaraa M. S., Jarvis J. J., Sherali H. D. (1990) Linear Programming and Network Flows, Wiley, New York, NY, U.S.A.

IPCC, (2007). Mitigation of Climate Change, IPCC Fourth Assessment report by Working Group III of the Intergovernmental Panel on Climate Change. Available at / http:/ / www. ipcc.ch. accessed June 2010

NVE (2003). Bioenergiressurser i Norge [Biomass resources in Norway]. Norwegian Water Resources and Energy Directorate (NVE). Available at /http:/ / www.nve.no. accessed June 2010

Nordel (2008). Annual report. Available at / http:/ / www.entsoe.eu. accessed June 2010

NEP (2010). Towards a Sustainable Nordic Energy System. Final report for the second phase of the Nordic Energy Perspectives project Available at http://www.nordicenergyperspectives.org/. accessed July 2010

Norwegian district heating association (2010). Available at /http://www. fjernvarme.no. accessed July 2010

Norwegian Minstry of the Environment (2008). Norwegian climate policy No. 34 (2006-2007) to the Storting. Available at /http:/ / www. government.no. accessed July 2010

ECON Pöyry (2008). Status and Potentials of Bioenergy in the Nordic Countries ECON PöyryReport no. 2008-057, Project no. 53160 Public ISSN: 0803-5113, ISBN 82-7645-977-7

Nordic Council of Ministers (2009) Increased biomass harvesting for bioenergy - effects on biodiversity, landscape amenities and cultural heritage values Available at /http:/ / www.norden.org. accessed July 2010

NordPool (2010). Available at http:/ / www.nordpoolspot.com/. accessed July 2010

State of the Environment Norway, 2010 Available at http:/ / www.environment.no/ accessed July 2010

Statistics Norway (2010). Available at / http:/ / www. ssb.no. accessed June 2010

Statistics in Finland, 2007. / http:/ / www.stat.fi. accessed July 2010

Swedish EnergyAgency (2009). Energiläget. Available at / http:/ / www. energimyndigheten.se. accessed June 2010

Trømborg, E.;Bolkesjø, T.; Solberg, B. (2008). Biomass market and trade in Norway: Status and future prospects Biomass and Bioenergy 32 ( 2008 ) 660 - 671 
United Nation (1987). Report of the World Commission on Environment and Development: Our Common Future, Available at http:/ / www.un-documents.net/k-001303.htm accessed June 2010 


\title{
Design and Technology for Efficient Lighting
}

\author{
R. Faranda, S. Guzzetti and S. Leva \\ Department of Energy - Politecnico di Milano, \\ Via la Masa 34, 20156 Milano, \\ Italy
}

\section{Introduction}

The conscientious use of energy resources has become an indispensable prerogative in our society. In the last years the artificial light, that represents a significant amount of the total consumption of electrical electricity, is becoming a significant aspect order to obtain economic and energy savings. Besides, it's important to consider that, over the last decade, global demand for artificial light grew at an average rate of $2.4 \%$ per year and the growth in demand is expected to continue for the foreseeable future (IEA, 2006).

For these reasons, in recent years, several governments have been increasingly deploying a range of policy measures to improve lighting energy savings. These measures include address to the lighting system as a whole (i.e. building codes, as EN 15193, that limit the maximum power demand of the lighting circuit for unit area and mandating the use of controls and zoning in new build and retrofits) and for specific lighting components (i.e. minimum energy efficiency requirements for lamps and ballasts, IEC 62442 or DIN IEC 60294).

Given this, nowadays the lighting systems are developed to use the more efficiency lights and to optimize energy consumption. Specifically, researchers are working, both in private and in public field, on the proper design approach, on the efficiency of light sources, on the performance of lighting equipment and on the development of intelligent control systems ${ }^{1}$; the results obtained give good prospects of success.

\subsection{New concept of lighting design and lighting system}

In this section a new approach to lighting design will be discussed. As a matter of fact, in the last years the lighting concept is moving from a functional point of view, in which the lighting systems are use only to light, to a new point of view, in which the lighting system is an instrument to guarantee comfort and environmental well-being at the end users.

This modern concept of the lighting has had an important benchmark in "CIE Symposium on Lighting Quality" of 1998. In fact, the results of this symposium are used by Engineer, Illuminating Society of North America (IESNA) to develop a new approach to lighting design. This model, proposed in IX Edition of manual lighting (IESNA, 2000) is, schematized in Fig. 1. It states that the quality of lighting design strictly depends on the interaction of

\footnotetext{
${ }^{1}$ Reduce energy consumption is much more complex in most less-developed countries because there are not often reference standards on recommended lighting and because efficient technologies have a selling price higher than the old and inefficient solutions.
} 
three fields: the individual, the light integration with architecture and the ergonomic and environmental implications (Blaso, Pellegrino 2007).

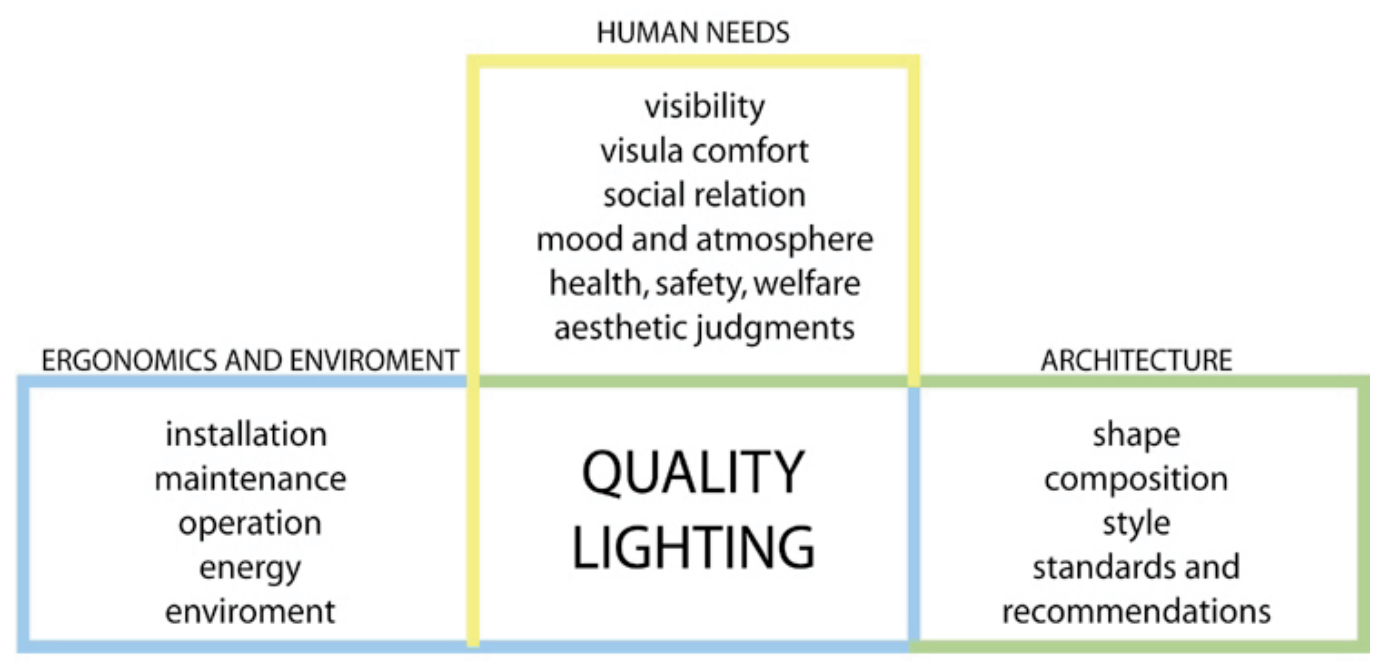

Fig. 1. Schema about quality of lighting design (www.infobuilddossier.it)

Another official confirmation of this new approach to lighting design is the introduction, in the lighting sector, of a new indicator the Ergonomic Lighting Indicator (ELI), about the quality of light.

According to this indicator, the quality of light is classified on a scale based to five criteria:

- Performance (with reference to appropriate standards):

- illuminance (right amount of horizontal illuminance according to required);

- glare control;

- low luminance;

- Appearance:

- $\quad$ space (e.g. bright, open and friendly space);

- $\quad$ colour (e.g. natural colour temperature and rendering);

- Comfort:

- $\quad$ shadows (e.g. soft shadows, neither too harsh nor too diffuse);

- modelling (e.g. cylindrical illuminance, friendly illumination of faces);

- Emotion:

- $\quad$ light distribution (e.g. architectural lighting of surfaces and objects in the room);

- $\quad$ preference (e.g. personal preference for lighting situation);

- Individuality:

- $\quad$ own light (e.g. personal lighting, personal use of switches);

- individual control (e.g. lighting chosen for individual benefit).

These new guidelines for the quality of lighting can be also important tools to improve the energy savings. In fact the light quality, characterized by dynamic light and its ability to create different scenarios, can be achieved only using modern devices, such as efficient sources, luminaries with high performance, systems for integration of natural light and for intelligent control, which, as now known (Benediktsson, 2009.), are also very energyefficient solutions. 
In the following, with reference to the difference fields of lighting and to the energy saving, the most important characteristics of lighting system will be described. Furthermore particular emphasis will be dedicated to the technology and to some case studies.

\section{The fields of lighting}

As mentioned in the introduction, lighting represents a substantial proportion of global electricity consumption, equal to $17,5 \%$ (IEA, 2006). But it is important to know that there are different types of lighting, each with particular characteristics, to properly treat the issue of energy savings.

In particular, regarding energy consumption, the largest amount of energy is used in offices and commercial buildings (43\%), followed by: residential buildings (31\%), industrial buildings (18\%) and outdoor lighting (8\%) (IEA, 2006).

There are many types of lighting designated for different applications and there are significant savings opportunities in each of them. In fact, as estimated by IEA, at least $38 \%$ of global lighting energy consumption could be saved cost-effectively for the end-user by greater use of existing efficient lighting technologies. In the following paragraphs the main field of lighting will be described.

\subsection{Public lighting}

The public lighting is an essential element for our safety. In fact, the term "public lighting", as stated by standard "lighting road" (EN 13201-1), defines all fixed lighting installations which provide user a correct visual perception of the outdoor public traffic areas during periods of darkness, and are designed to ensure the safety of drivers, the proper disposal of traffic and the safety of all people. To ensure safety, it is very important that artificial light has a good quality (e.g. high CRI, Color Rendering Index). In fact, streets and towns pleasantly lighted promote socialization in outdoor public spaces even in the hours of darkness. The presence of people discourages illegal activity and therefore the public safety increases.

But despite their great importance, the most of existing lighting systems are very obsolete and, therefore, they're inefficient. Besides this, speaking about energy consumption, it is also important to consider that the number of street lighting will greatly increase in the coming years (over all in the African countries or in the Chinese countryside, etc.).

Therefore, to save energy will be important both to increase the efficiency of existing lighting and to pay attention in the design of new systems.

Fortunately there are a number of areas in lighting systems where energy saving initiatives can be still implemented in street luminaries. These can broadly be categorized into the following areas:

- the lamp;

- the luminary;

- the ballast;

- 'intelligent' systems;

- $\quad$ remote monitoring devices.

The lamp

The efficiency of lamps has improved significantly in recent years and the type used can have significant impact on the amount of energy required to run them (the specific characteristics of the lamps will be described in the paragraph 3.1). 
Although this, today the most common type of lamp used in street lighting is still highpressure mercury lamp ${ }^{2}$, an extremely inefficient and pollutant source. It is followed by lowpressure sodium (LPS) lamp; it's a very efficient type of source but with a bad quality of light (it glows yellow-orange).

Policies of energy saving gives positive signal so that lamp changing initiatives (re-lamping) have taken place in a number of countries due to political awareness. This initiative is an important first step because, such as recent studies have indicated, "shifting to high-pressure sodium (HPS) or metal halide lamp (from older models) could result in an efficiency improvement in the lamp itself as high as 40\%" (E-Street, Project Report).

Concluding, changing sources can be just considered as a simple and cheap way to save energy.

\section{The luminaire}

Street luminaires of the most existing road lighting are inefficient. In fact, today a typical luminaire installed absorbs more than $50 \%$ of the light emitted by the light-source; this is due to the low-performance of the optical system. Besides this, the lamp installed is often of the old generation, therefore the global lighting system is very inefficient. The importance of both the lamp and luminaire efficiency in street lighting is indicated in Table 1, which reports data from an European study (Eurelectric, 2004) that are generally applicable all around the world.

\begin{tabular}{|l|c|c|c|}
\hline & $\begin{array}{l}\text { Luminous efficacy } \\
\text { of lamp }(\mathrm{lm} / \mathrm{W})\end{array}$ & $\begin{array}{l}\text { Average luminaire } \\
\text { efficiency }(\%)\end{array}$ & $\begin{array}{l}\text { Total efficiency } \\
(\mathrm{lm} / \mathrm{W})\end{array}$ \\
\hline Low-pressure sodium & $68-177$ & 25 & $17-44$ \\
\hline $\begin{array}{l}\text { Tubular high- } \\
\text { pressure sodium }\end{array}$ & $70-150$ & 45 & $32-68$ \\
\hline $\begin{array}{l}\text { Elliptical high- } \\
\text { pressure sodium }\end{array}$ & $59-124$ & 30 & $18-37$ \\
\hline $\begin{array}{l}\text { High-pressure } \\
\text { mercury }\end{array}$ & $34-58$ & $35-40$ & $21-34$ \\
\hline Metal halide & $61-85$ & 45 & $32-34$ \\
\hline Ceramic metal halide & $70-76$ & & \\
\hline
\end{tabular}

Tab. 1. Total efficiency of combinations of lamp and luminaire for outdoor street lighting

Today there is a very large range of luminaires available commercially and these can have significantly different optical properties, which have a large impact on the efficiency of the lighting system. The most efficient optical systems can absorb less than $10 \%$.

In conclusion, "development in lamp size and the characteristics in optical design mean that the efficiency of modern luminaries can be $25-30 \%$ higher that those based on old lamps" (E-Street, Project Report).

2 Among OECD countries, Japan has the highest share of mercury vapour lamp sales at $42 \%$ of all HID High Intensity Discharge lamps, in Europe they account for 30\%, in Australia 18\% and the United States only $8 \%$. In non-OECD countries, mercury vapour lamps account for about $93 \%$ of HID sales in Russia and a more modest $61 \%$ in China (OECD/IAC, 2010). 


\section{The ballast}

Such as said, the most used lamps in street lighting are the discharge lamps (HID). They cannot be connected directly to the supply line, they need a device to obtain the necessary circuit conditions for starting and operating, called ballast.

There are two types of this device: electro-mechanical (traditional power supply system) and electronic (new generation power supply system).

Recent studies have shown the use of electronic ballast allows to save about $7 \%$ of energy and to extend lamp life by $30 \%$ respect to traditional ballast (E-Street, Project Report). Considering also that electronic ballast can control the luminous flux performing and the regulation of the flux emission, the energy savings may be estimated of about $30 \%$ compared to traditional solution (electro-mechanical ballast).

Finally, also recent European and National standards suggest the use of programmable clocks as switching on and off devices and luminous flux reduction, of 30\% from 24.00 to 8.00, to save energy (UNI 11248, 2007 and L.R. n¹7, 2000).

The ballasts will be analyzed more detail in the paragraph 3.2.1, while 'Intelligent' (lighting control) systems and building automation devices will be discussed in the paragraph 3.2.2 and 3.2.3 respectively.

Today, besides to these consolidated systems to save energy, new solutions are beginning to experimentes LED (Light Emitting Diode) solutions. An example is the project implemented by the City of Los Angeles, called Clinton Climatic Initiative (www.clintonfoundation.org). The project will involve the replacement of 140,000 traditional street luminaries with LED lumimaries and it will be executed from 2009 to 2013. The City will install remote monitoring devices on each of its new LED street luminaries, allowing the Los Angeles Bureau of Street Lighting to collect real-time data on its system performance at the fixture level.

Thanks to this project, the designers claim that the City will dramatically reduce its energy consumption due to efficient of the new luminaries and control system and will reduce its street lighting maintenance costs due to the long life of LED lamps and the remote monitoring device (expected payback of the investment should be 7 years). In particular energy savings (post retrofit) should be of $68.640 .000 \mathrm{kWh} /$ year and $\mathrm{CO}_{2}$ savings should be $40.500 \mathrm{t} \mathrm{CO}_{2}$ /year.

In conclusion, today a modern "effective energy-efficient street lighting should use a balance of proper energy-efficient technologies and design layout to meet performance, aesthetic and energy criteria required by pedestrian, motorist, community residents municipalities and utilities" (NYSERDA 2002).

\subsection{Lighting for work-spaces}

Most countries official issue recommend illumination levels that installers of lighting systems are requested to attain in the work-spaces.

These informations are collected in specific standards. They define the performance levels of lighting workstations and their direct environment. They also include tables with lighting requirements in accordance with the type of work and the visual task (e.g. in European countries the standards are EN 12464-1 "Light and lighting - The Lighting of work places" Part 1: Indoor work places", EN 12464-2 "Light and lighting - Lighting of work places - Part 2: Outdoor work places").

But despite this, today most lighting in work-space do not respect guidelines on recommended lighting levels and lighting systems are usually installed via rules of thumb applied by electrical fitters. This way of working means that the light levels guaranteed are often higher than necessary. This causes great waste of energy and discomfort to workers. 
After this general introduction about work-place lighting, in the following only the office will be analyzed. This choice was made because there are many different types of work-places (according to the different economies in different countries) each with specific characteristics and problems, in opposite office is a common reality to all countries.

In the last years, standards that define the maximum power consumption were written to reduce the energy waste in the buildings, so in the offices. For example, in Europe the reference standard is EN 15193 Energy performance of buildings - Energy requirements for lighting - Part 1: Lighting energy estimation, march, 2007.

Specifically, these standards define the energy parameters that lighting systems must follow and how to get them. For example, the European Standard EN 15193 defines the parameter LENI (Lighting Energy Numeric Indicator) that describes the yearly energy consumption for lighting per square meter for the buildings. This indicator changes according to the energy needs required by the visual tasks. For offices LENI is equal to $36 \mathrm{kWh} / \mathrm{m}^{2}$ (EN 15193, 2007).

When possible, the guidelines contained in the standard should be followed by lighting designers. This would lead to an huge energy savings.

Besides this, in this sector, simply the replace of same devices now installed, such as:

- magnetic ballast with electronic ballasts;

- traditional linear fluorescent lamps (LFL) with slimmer fluorescent tubes with efficient phosphors (common known as "super LFL");

- $\quad$ obsolete luminaries with high quality luminaires characterized by efficient optical systems;

produces savings that are just impressive.

Finally, the global lighting system could be made more efficient, $35-40 \%$ typically (IEA, 2006), through the use of sophisticated devices, such as:

- time-scheduled switching;

- occupancy sensors;

- daylight-responsive dimming technologies.

Also, these devices provide ensure great comfort to the worker because they create lighting quality (e.g. light dynamic, customizable lighting performance etc.) and, as already shown by many researches, it positively influences the health and well-being of users (Boyce et al., 2003) and the performance of office work (Newsham, Veitch, 1996).

Concluding, for the lighting office sector there are now great opportunities for saving energy, increasing final-user comfort. This can be achieved thanks to the technologies described. In fact all these devices are already fully mature and ready to be used.

\subsection{Lighting for artistic and architectural buildings}

\subsubsection{Artistic buildings lighting}

Lighting of the art sites has historically always made through incandescent lamps, especially halogen. Because, until not long ago, these luminous sources were the most used in projectors/spotlights to create accent lighting, due to their high color rendering index (CRI $100)$ and their very compact dimensions.

These sources are also highly inefficient $(15-201 \mathrm{~m} / \mathrm{W})$ and they have a short life time (2000$4000 \mathrm{~h}$ ). The lighting systems of these areas consume a lot of energy and the costs of maintenance are very high (it is necessary to replace lamps frequently). Given the cultural importance of these places and that until recently lamp with performance like halogen doesn't exist, the theme of energy saving has always been a secondary thematic in the 
museum system. However recently, although the distrust of museum curators, thanks to new technology performance, either in terms of the qualitative aspects of light and energy, there are first projects according energy-saving.

In summary, the main tools which are available today in order to have good results in energy saving are:

- $\quad$ sources;

- natural light;

- management systems.

Sources

Technological improvements have allowed to get very efficient sources $(\mathrm{lm} / \mathrm{W})$ with a high color rendering index (CRI) in a lot range of correlate color temperature (CCT). Specifically we are specking about fluorescent, ceramic metal halide and LED.

Some examples:

- linear fluorescent lamp (Philips, T8, Master TL-D Graphics 90, 58W): 601m/W, 98 CRI, CCT 5300/6500K (Price list Philips, 2009);

- metal halide lamps with ceramic burner (Philips, CDM-TC Elite Mastercolour, 70W): 1001m/W, 90 CRI, CCT 3000K (Price list Philips, 2009);

- $\quad$ power LED (CREE, XLamp XR-E LED): 56,8-87,4lm/W, CRI 90, CCT 2600-3700K (datasheet, CREE, www.cree.com).

\section{Natural light}

The light of the sun is the best light which our visual system can perceive colors, shades, materials etc.. Therefore give emphasis to the natural light, inside the museum spaces allows the visitors to enjoy the beauty of the exposed works. Besides this, the contribution of natural light, if well managed by the installation of artificial lighting, through detection systems and management, can obviously become a valuable item that reduces energy consumption.

In conclusion, at the planning of lighting systems is important to carefully evaluate the natural light and prepare its integration to maximize the use of energy resources, and even more design new buildings according the guidelines of daylighting.

\section{Management Systems}

Especially in a places like a museums, where the visitors are not the same number all over the day, but it depends on certain time slots, an intelligent lighting system is essential in order to save energy. The main devices which allow an appropriate use of energy resources are presence sensors, daylight sensors, flow regulators and fragmented light. In fact, thanks to these appliances the lighting systems work only when it is necessary, according to the presence of someone and with natural light (see 3.2.2).

An example of modern lighting museum, designed with energy-saving criteria, is the museum of contemporary art "Punta della Dogana" in Italy in Venice (Spotti, 2009).

The lighting system, designed by Studio Ferrara Palladino, has planned to use for the entire lighting system only discharge lamps with high energy efficiency, high color rendering to a colour temperature of $4200 \mathrm{~K}$. These choices have allowed to reduce the consume for a museum, which is calculated at full capacity around $25 \mathrm{~W} / \mathrm{m}^{2}$ walkable levels of illumination that can reach average values of 300 lux. The other factors that have led more savings have been the contribution of natural light provided by skylights, and the use of control systems connected to the DALI controllers throughout the building (the system used DALI allows the adjustment from 0 to $100 \%$ for each unit individually). With these elements in fact it was ascertained through a period of monitoring (the entire period of the inaugural 
exhibition), an energy consumption of the system during the hours of opening to the public less than $10 \mathrm{~W} / \mathrm{m}^{2}$.

\subsubsection{Architectural lighting}

Architectural lighting aims to show buildings' architectural beauty and to make it can enjoyed by people at night. Architectural lighting often makes buildings more beautiful at night than daytime. Ugly buildings, such as old shopping mall or ruins of industrial archaeology, become fascinating architectural volumes through good lighting. As a matter of fact, when the light changes, our perception and our experience also changes. This is the main concept of architectural lighting (Egan, 2002).

On the other side, in this period, in which the energy saving is one of the main goal, light something for only aesthetic reasons can be considered a huge waste, especially if it is done with inefficient lamps or luminaries. Until a few years ago, this was what happened. In fact, architectural lighting, particularly outdoors, was realized by floodlights with halogen lamps.

In the last years the way to realize architectural lighting has very changed. The main change is that buildings are no longer illuminated from the bottom, but they are illuminated from top to bottom to avoid problems of light pollution and to save energy. Another change is that more efficient lamps and luminaries are used: linear fluorescent luminaries (for wall wash lighting) or floodlights with discharge lamps, in particularly metal halide lamps (for accent light).

The use of these sources has led to decreased energy consumption for this particular kind of lighting. In fact, the light efficiency of traditional halogen is equal to $15-201 \mathrm{~m} / \mathrm{W}$ on the contrary fluorescent lamps are characterized by light efficiency of $60-100 \mathrm{~lm} / \mathrm{W}$ and metal halide of $80 \mathrm{~lm} / \mathrm{W}$, more or less. Also maintenance costs are decreased because the life time of the new efficient lighting sources is much longer than halogen lamps (5/6 times).

Finally, in this field the last major innovation is LED device. Thanks to LED, small luminaries, that can easily be hidden in volumes of buildings (inside throats, under the eaves, etc.), have been made. In this way the architecture is not contaminated by any device: only light. Moreover LEDs have introduced another possibility: create bright and dynamic skins on the exterior walls of buildings. In fact, only the LEDs, small and easy to dim, can transform a wall into a big screen.

For this particular type of architectural lighting -"surfaces of light"- the LED is the solution energetically and economically successful. In fact, as shown by recent studies (Gregorius, Siti Handjarinto, 2007), although LED's initial cost is very high, its operational cost, in a long term, is cheapest of all other solutions; also if it is compared to luminaries characterized by discharge lamps.

Concluding, in architectural lighting's field where energy saving is not the main goal, today there is great potential for energy savings. This is very important because architectural lighting is now a factor that characterizes, more and more, our cities. Such as we saw in these few lines, aesthetic choices, technology and energy saving can travel together.

\subsection{Residential lighting}

Globally, residential lighting consumes about $31 \%$ of total world lighting electricity and it constitutes about $18.3 \%$ of residential electricity consumption. High consumption is caused by used of inefficient lamps, in particular incandescent in many countries, and of luminaries with low luminaire output ratio (LOR); this means that only a small amount of source- 
lumens makes a useful contribution to overall illumination. In fact, total system (luminaire and lamps) efficacy is average equal to $16.8 \mathrm{~lm} / \mathrm{W}$ (IEA, 2006).

Another factor that does not help save energy is the absence of standards and the possibility of direct control in this lighting sector.

For all these reasons, residential lighting is thus the least efficient of all grid-based electriclighting end-user sectors and is also the one with the highest theoretical potential for improvement.

In fact, without a palpable change in lighting quality, simply a market shift from inefficient incandescent lamps to CFLs (Compact Fluorescent Lamps) would cut world lighting electricity demand by $18 \%$ (IEA, 2006). About this, fortunately, almost all governments are in the process of phasing-out traditional incandescent lamps (General Lighting Service, GLS). This process began since early 2007 and it will end in 2020. (OECD/IEA, 2010).

In the last years, the conception of residential lighting is changing. In fact, today, the house isn't only a place in which we sleep and eat, but it is seen as a place in which other different activities take place: relaxing, socializing, working etc. For this reason, lighting designers work increasingly to realize installations in private dwellings. In these cases, the welfare of the end-user, pleasant environment and the quality of light, often coincide with the energy savings. This happens because these kinds of lightings are realized with efficient luminaries of new generation (usually characterized by LED or fluorescent lamps) and they are often controlled by home automation systems. Indeed, if the dimmers and devices for on/off lights and for adjusting their intensity are properly managed, lighting scenes best suited to each need and significant reduce consumption can be obtained (Pizzagalli, 2009).

In conclusion, today in the lighting residential sector there are large energy waste, in most situations. Fortunately, the new government policies, the new conception of home, seen by more and more people as comfortable and wellness place, and the new technologies open up interesting prospects.

\section{Technologies for energy saving}

Currently there are already many technologies (eg. efficient lamps, control systems etc.) and as many in development (eg. power LED, O-LED, etc.), which could provide interesting energy savings, if correctly used them. In the following paragraphs the main of these will be described.

\subsection{Light sources: state of the art and development 3.1.1 Traditional light sources}

Lamps have a very important role in determining energy consumption of a lighting system. There are many lamps, each one with very different characteristics both for energy efficiency and for spectral emission. For this reason the right luminous source for each particular application have to be choosen.

In particularly, there are three main families of lamps: incandescent, discharge an combined incandescent-discharge (now a days this kind is very rare).

Complete overview of all different types of lamps is shown in fig. 2.

Regarding to the different fields of application before analyzed, the mainly characteristics of luminous sources with the best quality light and efficiency are:

- for public lighting: HSP (70-120lm/W and average CRI) or Ceramic Metal Halide, CMH (67-104lm/W and very high CRI); 
- for the offices: LFLs (60-1001m/W and very high CRI);

- $\quad$ architecture and museums: LFLs (60-1001m/W and very high CRI), CMH (67-104lm/W and very high CRI) and LED powers (60-901m/W and high CRI);

- $\quad$ for the residential sector: CFLs (35-801m/W and high CRI).

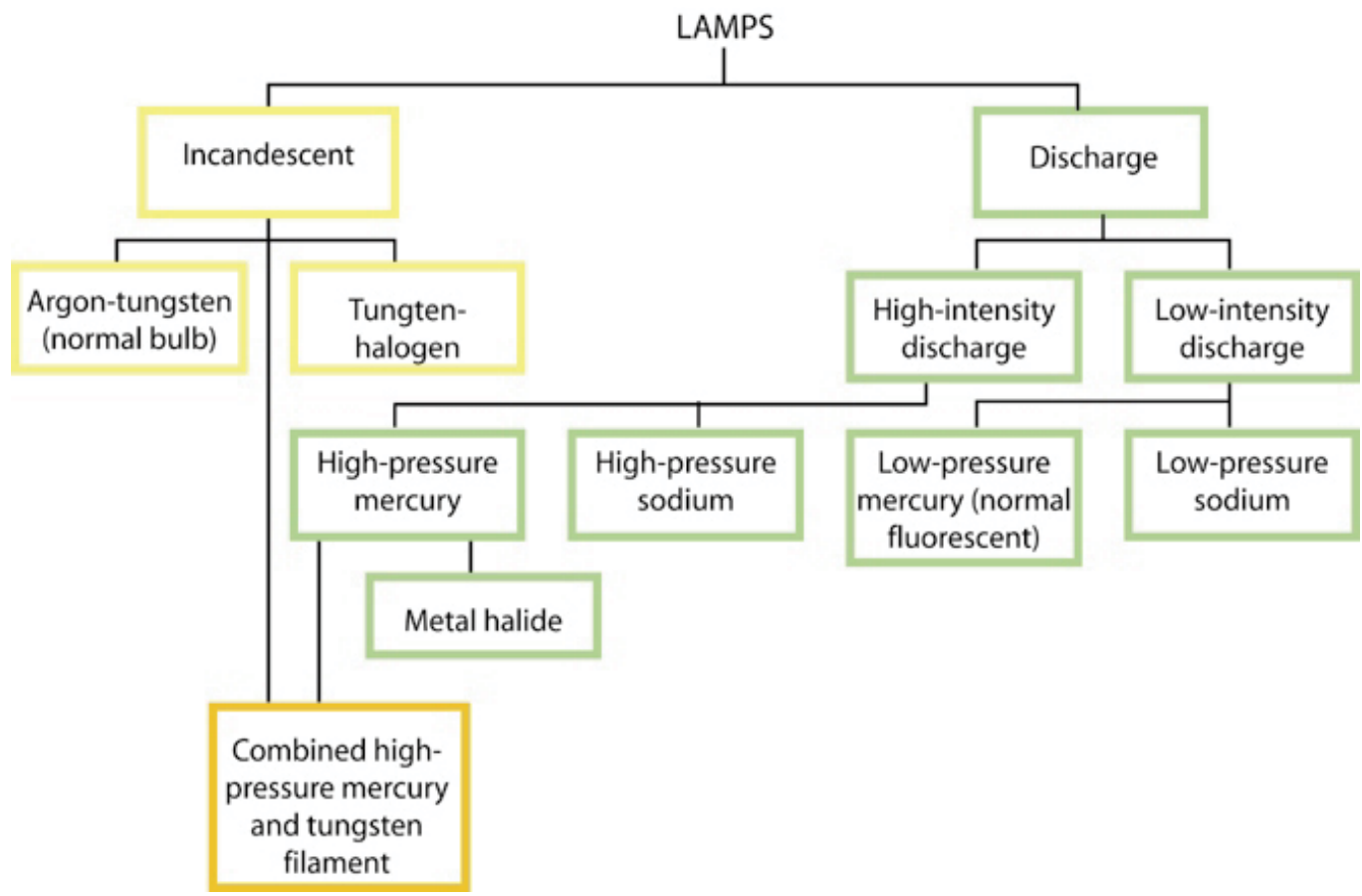

Fig. 2. General schema lamps

Not to dwell much too, all other light sources and their specifications have been collected in the table 2 .

\begin{tabular}{|c|c|c|}
\hline $\begin{array}{c}\text { Lamp } \\
\text { category }\end{array}$ & Characteristics & Applications \\
\hline 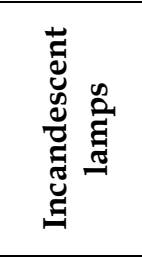 & $\begin{array}{c}\text { Very low efficacy and low life. Low } \\
\text { investment costs, high running costs. } \\
\text { Dimmable. Reflector lamps for } \\
\text { concentrated light beams. 10-15 lm/W } \\
\text { with lamp life of } 1000 \text { h. Very high CRI } \\
\text { and low CCT. }\end{array}$ & $\begin{array}{l}\text { For general, local, ambient and spot } \\
\text { lighting. } \\
\text { Not suitable where high lighting levels } \\
\text { are necessary. }\end{array}$ \\
\hline 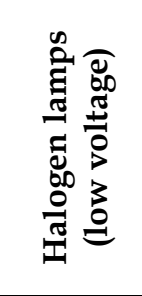 & $\begin{array}{l}\text { Very small lamps, capable of producing } \\
\text { highly directable light beams. Some } \\
\text { losses in the transformer. Low to mid } \\
\text { efficacy with low to mid lifespans. } \\
15-33 \mathrm{~lm} / \mathrm{W} \text { with lamp life of } 2000 \text { to } \\
6000 \mathrm{~h} \text {. Very high CRI and low CCT, } \\
\text { but slightly higher than incandescent. }\end{array}$ & Highly suitable for spotlighting. \\
\hline
\end{tabular}




\begin{tabular}{|c|c|c|}
\hline 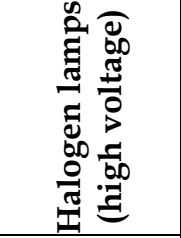 & $\begin{array}{c}\text { Slightly higher efficacies than } \\
\text { incandescent lamps. } \\
\text { 15-25 lm/W with lamp life of } 2000 \text { to } \\
6000 \mathrm{~h} \text {. Very high CRI and low CCT, } \\
\text { but slightly higher than incandescent. }\end{array}$ & $\begin{array}{l}\text { Suitable for spotlighting or illuminating } \\
\text { large areas (floodlighting). }\end{array}$ \\
\hline 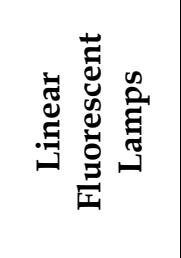 & $\begin{array}{c}\text { Mid to high efficacy depending on } \\
\text { type, with highest efficacy when used } \\
\text { with electronic ballasts. } \\
60-100 \mathrm{~lm} / \mathrm{W} \text { with lamp life of } 7000 \text { to } \\
20000 \mathrm{~h} \text {. High to very high CRI, with } \\
\text { broad range of CCT available. }\end{array}$ & $\begin{array}{l}\text { Wide application. Highly suitable for } \\
\text { general indoor illumination, especially } \\
\text { to provide economic, even illumination } \\
\text { and for all low- and mid-bay lighting. } \\
\text { Not suitable for spot lighting. }\end{array}$ \\
\hline 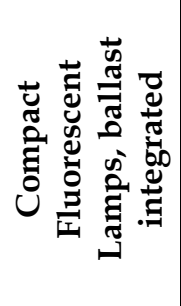 & \begin{tabular}{|} 
Directly interchangeable with \\
incandescent lamps: greater energy \\
efficiency, much longer life expectancy. \\
Not dimmable. Also available as \\
reflector lamps. $35-80 \mathrm{~lm} / \mathrm{W}$ with lamp \\
life of 5000 to $15000 \mathrm{~h}$. High CRI and \\
broad range of CCT available.
\end{tabular} & $\begin{array}{l}\text { For almost all areas where incandescent } \\
\text { lamps are used: general, local and spot } \\
\text { lighting. }\end{array}$ \\
\hline 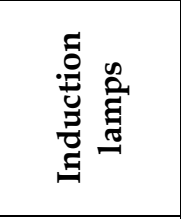 & $\begin{array}{c}\text { Very long life of } 30000 \text { to } 100000 \mathrm{~h} \text { and } \\
\text { mid to high efficacy of } 55-80 \mathrm{~lm} / \mathrm{W} \text {. } \\
\text { High CRI and wide range of CCT } \\
\text { available. }\end{array}$ & $\begin{array}{l}\text { Relatively high first costs mean they are } \\
\text { most economic when used in } \\
\text { inaccessible areas with high } \\
\text { maintenance costs, such as tunnel } \\
\text { lighting. }\end{array}$ \\
\hline 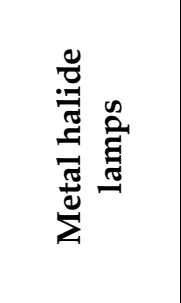 & $\begin{array}{l}\text { Mid- to high-efficacy lamps covering a } \\
\text { broad lumen-package range. Warm-up } \\
\text { time of a few minutes. Dimming } \\
\text { difficult and sometimes suffers from } \\
\text { poor lumen maintenance. } 47-105 \mathrm{~lm} / \mathrm{W} \\
\text { with lamp life of } 6000 \text { to } 20000 \mathrm{~h} \text {. High } \\
\text { CRI and broad range of CCT available. }\end{array}$ & $\begin{array}{l}\text { Suitable for mid and high-bay indoor } \\
\text { lighting and outdoor lighting, } \\
\text { whenever long operating hours apply. } \\
\text { Poor lumen maintenance. Most } \\
\text { commonly used for industrial and } \\
\text { street lighting. }\end{array}$ \\
\hline 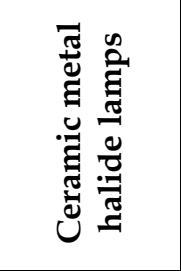 & $\begin{array}{c}\text { High-efficacy lamps covering a low to } \\
\text { high lumen-package range. Warm-up } \\
\text { time of a few minutes. Dimming } \\
\text { difficult. } 67-104 \mathrm{~lm} / \mathrm{W} \text { with lamp life of } \\
6000 \text { to } 15000 \mathrm{~h} \text {. High CRI and low- to } \\
\text { mid-range CCT available. }\end{array}$ & $\begin{array}{c}\text { Suitable for indoor display lighting (as } \\
\text { a substitute for halogen lamps) and for } \\
\text { mid and high-bay indoor lighting. Also } \\
\text { provide street and architectural } \\
\text { lighting. }\end{array}$ \\
\hline 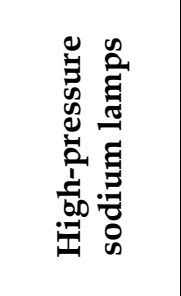 & $\begin{array}{c}\text { High- to very high efficacy lamps } \\
\text { covering a broad lumen-package range. } \\
\text { Poor to moderate CRI and relatively } \\
\text { long warm-up periods } 70-120 \mathrm{~lm} / \mathrm{W} \\
\text { with lamp life of } 5000 \text { to } 30000 \mathrm{~h} \text {. Low } \\
\text { to mid CRIs and low CCTs (orange- } \\
\text { yellow hued light). }\end{array}$ & $\begin{array}{c}\text { Economic street lighting and industrial } \\
\text { lighting where high CRI is not } \\
\text { required. }\end{array}$ \\
\hline
\end{tabular}




\begin{tabular}{|c|c|c|}
\hline 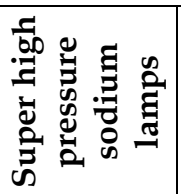 & $\begin{array}{l}\text { Start-up time a few minutes. Not } \\
\text { dimmable. Reasonable efficacy. High } \\
\text { light output per lamp. Colour change } \\
\text { possible at end of useful life. }\end{array}$ & $\begin{array}{l}\text { Suitable for lighting objects (shop } \\
\text { window displays) or as general } \\
\text { downlighting in high-ceilinged rooms. }\end{array}$ \\
\hline 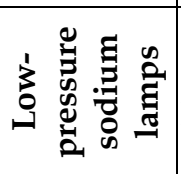 & $\begin{array}{c}\text { Very high efficacy. Monochromatic } \\
\text { light, no colour rendering. } 120-200 \\
\text { Im/W with lamp life of } 10000 \text { to } 16000 \\
\text { h. Zero CRI and very low CCT. }\end{array}$ & $\begin{array}{l}\text { Low-cost outdoor lighting for } \\
\text { applications where colour rendering is } \\
\text { not required. }\end{array}$ \\
\hline 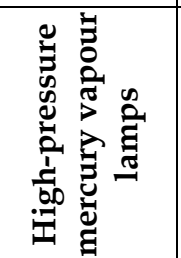 & $\begin{array}{c}\text { Low- to mid-efficacy lamps covering a } \\
\text { broad lumen-package range. Poor to } \\
\text { moderate CRI and relatively long } \\
\text { warm-up periods. } 23-601 \mathrm{~m} / \mathrm{W} \text { with } \\
\text { lamp life of } 6000 \text { to } 28000 \mathrm{~h} \text {. Low- to } \\
\text { mid-range CRI and CCT. }\end{array}$ & $\begin{array}{l}\text { Mostly used for street, security and } \\
\text { industrial lighting. } \\
\text { Low first costs but uneconomic over } \\
\text { the lamp life cycle compared to } \\
\text { equivalent alternatives. }\end{array}$ \\
\hline 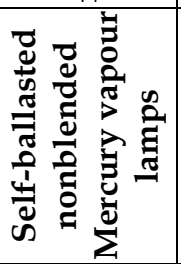 & $\begin{array}{l}\text { Very low to low-efficacy lamps cove- } \\
\text { ring a broad lumen-package range. } \\
\text { Poor to moderate CRI and relatively } \\
\text { long warm-up periods. } 14-29 \mathrm{~lm} / \mathrm{W} \\
\text { with lamp life of } 6000-12000 \mathrm{~h} \text {. } \\
\text { Mid-range CRI and CCT. }\end{array}$ & $\begin{array}{l}\text { Mostly used for street, security and } \\
\text { industrial lighting in non-OECD } \\
\text { countries. Very low first costs but } \\
\text { highly uneconomic over the lamp life } \\
\text { cycle compared to equivalent } \\
\text { alternatives. }\end{array}$ \\
\hline 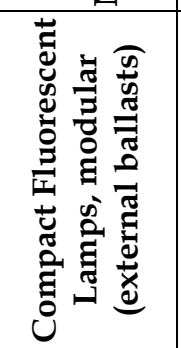 & $\begin{array}{l}\text { Compact lamp with high efficacy. } \\
\text { Longer life and slightly higher efficacy } \\
\text { than equivalent ballast-integrated } \\
\text { CFLs. Dimmable when used with } \\
\text { specially designed electronic ballasts. } \\
60-80 \mathrm{~lm} / \mathrm{W} \text { with lamp life of } 10000 \text { to } \\
20000 \mathrm{~h} \text {. High CRI and broad range of } \\
\text { CCT available. }\end{array}$ & $\begin{array}{l}\text { Alternative to incandescent lamps } \\
\text { (more efficient), but with } \\
\text { (external ballasts) electronic ballasts. }\end{array}$ \\
\hline
\end{tabular}

Source: Adapted and updated from CADDET Energy Efficiency, 1995.

Abbreviations: $\mathrm{CCT}$ = colour correlated temperature; $\mathrm{CRI}=$ colour rendering index;

Tab. 2. Summary of lamp characteristics

\subsubsection{LED in the lighting}

The lighting concept is changing: in particularly, more attention to energy savings policies and to more comfort for users are the new main aims. In order to meet a so complex scenario, luminaries and lighting control system had to increase their performances. Specifically, with regard to the luminaries, the performance of the lamps are became a very important goal.

In this research context LEDs (Light Emitting Diode) are becoming more and more interesting devices. In particularly, the development of power LEDs is more and more an affordable solution to meet the needs of modern lighting product/system.

LEDs have reached interesting features such as (Liu, et al., 2009.):

- $\quad$ high luminous efficiency now a days (at least 90-100lm/W);

- lower losses in the distribution of the controlled luminous flux compared to traditional lamps (emitting only a beam of $120^{\circ}$, whilst traditional have about $360^{\circ}$ );

- $\quad$ extremely small dimensions and consequently extreme flexibility of use; 
- good colour rendition (Colour Rendering Index, CRI $\geq 80$ );

- wide range of colour temperature;

- light-up instantaneously;

- fully dimmable without colour variation;

- coloured light without filters;

- dynamic colour control.

But this new lamp compared to traditional ones has a very high initial cost. Its use today is not so advantageous in all applications, but only in specific situations where the particular characteristics of the LEDs (small size, light coloured or dynamic) are really useful.

Specific areas of virtuous application of these new lamps can be identified in two broad categories, relating to the creation of performance luminaries in a position to communicate with right control systems for the management of lighting contributions and of special optical system, ad hoc, with high lighting performance and small sizes (Liu, et al., 2009).

Concluding, with regard the use of this innovative lighting source, small, efficient and dynamic (colour management, the luminous flux, et.), its application is already introducing benefits in some specific areas (such as implementation of lighting performance able to can communicate with the management daylight systems and implementation of optical systems with high lighting performances and small size). Indeed, about future prospective, considering the technological growth perspectives of this lighting source in the coming years, and its positive results provided over a relatively short time since it came into the light design, in the short- medium-term, its use may be extended to the more traditional areas of illumination.

\subsubsection{O-LED in the lighting: some notes and prospective}

The innovation of technology, electronics and "solid-state light" will be protagonist in the next future: LEDs and O-LEDs (Organic Light Emitting Diode).

Regarding OLEDs, their technology is similar to that of LEDs, the only difference is that the semiconductor used is not inorganic (silicon) but organic (carbon).

Regarding lighting sector, today LEDs are already used in opposite OLED, are not lighting system, but they are only prototypes. They have not yet high performance in order to be on market.

Today, they limits are:

- $\quad$ low efficiency $(231 \mathrm{~m} / \mathrm{W}$ white light $631 \mathrm{~m} / \mathrm{W}$ green light);

- $\quad$ maximum size of $50 \mathrm{~cm}^{2}$;

- $\quad$ very high expensive ( $300 €$ for a device of $\left.20 \mathrm{~cm}^{2}\right)$;

- the time life is not very long $10.000 \mathrm{~h}$ (50\% of initial luminous flux).

But this should be only a momentary situation. In fact, the potential of OLEDs are undoubtedly vast, especially considering their particular shape.

In fact, they will be not lighting sources to put in luminaries, but they will be large lighting areas (e.g. they could be walls and ceilings which will be able to produce diffused, dynamic and variable colour light). They aren't rigid but flexible, they could be opaque or transparent of various forms which will be able to produce white or coloured light, static or dynamic images.

They will be large lighting areas with low luminance and high luminous efficiency, characterized by soft and diffused light.

Besides, OLEDs, once reached the optimal performance, could be more advantageous than LEDs for: 
- lower luminance (no problems with glare);

- $\quad$ no heat (no problem with dissipation);

- $\quad$ spectral emission more rich, Fig. 3. (High CR).

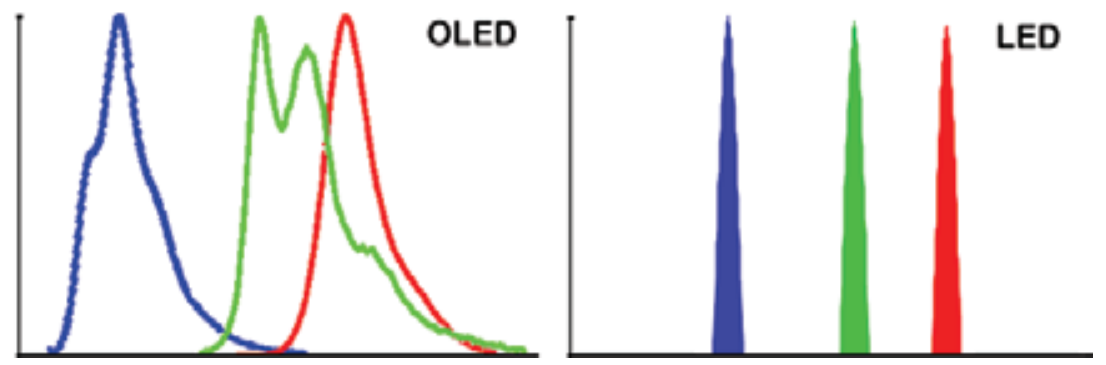

Fig. 3. Spectral emission of OLED and LED (Philips presentation, 2009)

As mentioned, the major current limitations of OLEDs technology, besides cost, are the small size, low luminous efficiency and time life. The following (Fig. 4) charts show, however, as within a short period, 7/8 years (fig.4), those constraints should be overcome, thanks to worldwide and European funding which are allocated to encourage the development of this new technology (eg. projects Olla, Oled100 or TOPLESS).

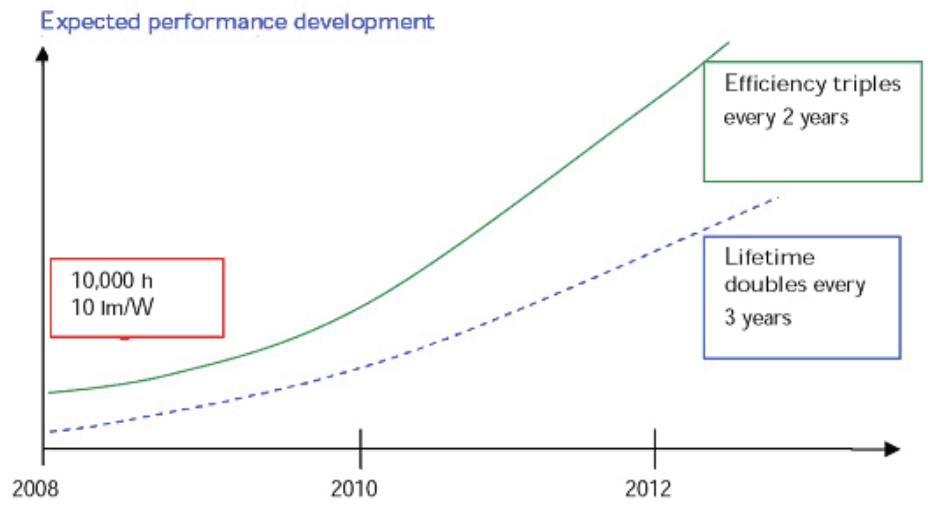

Fig. 4. Expected performance development of OLEDs (Philips presentation, 2009)

The research project OLLA consortium of European companies and universities, which began Oct. 1. 2004 and completed in 2008, was based to produce O-white LED emission and high efficiency lighting to use ( $60 \mathrm{lmW}$, this objective has been achieved in the laboratory). The project Oled100 begins by major successes of OLLA and it has its benchmark, the new international agreement on environmental protection of the European Community. It is called "Packet 20-20-20" which also imposes a 20\% reduction in CO emissions within 2020.

Oled100' s aim is a more durable product with better light and more handsome:

- $\quad$ better light efficiency $(100 \mathrm{~lm} / \mathrm{W})$;

- $\quad$ longer life (100.000 h);

- increased emitting area $\left(100 \times 100 \mathrm{~cm}^{2}\right)$;

- $\quad$ lower cost $\left(100 € / \mathrm{m}^{2}\right)$;

- standardization system. 
Regarding price reduction of OLEDs, today there are another OLED project called TOPLESS (Thin Organic Polymeric Light Emitting Semiconductor Surfaces). It is focusing on commercially viable lighting products.

Concluding OLEDs have achieved interesting results in display applications, but they are not yet competitive in functional lighting.

However the research is moving in this particular sector, on different fronts in order to have a common aim of efficient technology and in the same time competitive about price.

In particular, it is trying either to improve lighting performance of OLED (efficiency, luminance, and life time) or to pay attention to reducing costs (regarding choice of materials, cost of packaging and production process).

Considering the projected development trends of the largest manufacturers Osram, Philips, Siemens and GE and the speed with this technology is developed the achieve of interesting performance appears really near.

\subsection{Intelligent management systems: from ballast to building automation system}

Modern lighting use intelligent management systems, which, if properly integrated, can provide attractive energy savings.

Specifically, there are different lighting control devices, which according to the application layer, capable of handling functions more and more complex in efficient way.

These technologies can be summarized in the following three levels:

- First level: the single lamp manager. The most common is ballast, used by all discharge lamps.

- Second level: lighting control system. It coordinates of all elements of the lighting system based on specific criteria;

- Third level: domotic and building automation system. They manage the last level: it coordinates synergistically all plants present in a building/dwelling.

Considering the importance of these devices, each of these technologies will be analyzed in the following paragraphs.

\subsubsection{Single lamp manager}

In the lighting sector, the main lamp manager is ballast; it is a device that primarily allows the working of discharge lamps. In fact, discharge lamps cannot be connected directly to the supply line, because, to ignite them it is necessary to provide an extra voltage of some $\mathrm{kV}$. In order to limit the current, a ballast in series with the lamp is typically used. Today there are electro-mechanical ballast and electronic ballast, new generation device.

Today, all new generation luminaires are fitted with electronic ballast.

This is because, besides the simple operation of discharge lamps, electronic ballast, compared to electro-mechanical ballast, device has other main advantages, such as:

- to regulate luminous flux;

- to extend lamp life;

- to maintain constant the luminaires' luminous flux.

So, all these factors ensure comfort, energy savings and safety.

In order to better assess the benefits provided by this device is shown comparative analysis of the performances of a 150W HPS (High Pressure Sodium) street luminaire, made by Department of Energy of the Politecnico di Milano, in 2010 (Dolara et al. 2010). The comparative analysis is made supplying the same lamp with an electro-mechanical traditional power supply system (comprehensive of ballast and capacitor) and successively with an electronic ballast. 
In summary, the comparison made shows that:

- $\quad$ electronic ballast can perform luminous flux regulation: this is very important in order to save energy. In fact, a reduction of the luminous flux of $30 \%$, in the period from 24.00 to 8.00, as required by the guidelines for light pollution (UNI 11248, 2007 and L.R. n ${ }^{\circ} 17$, 2000), may result in an average reduction of energy consumption of about $30 \%$;

- electronic ballast ensures lamps greater useful life. This allows a reduction of maintenance costs and an increase road safety;

- electronic ballast allows to maintain constant the luminaires' luminous flux for all the working period: changing the main voltage, the illuminance is constant. It's very important specially in street lighting sector because the RMS voltage value, supplied by mains electricity distribution, varies during a day. In this way the parameters of the lighting design and drivers' safety can be also guaranteed for all the working period of the lighting. Finally, maintain constant the voltage, so the power consumption, allows to save $25 \%$ of energy compared to a electro-mechanical ballast. Considering this factor, it is interesting to know that supply voltage is always higher than the nominal voltage of $230 \mathrm{~V}$ during any day of the year when the street luminaires have to be powered;

- finally, to maintain constant the voltage prevents shutdown of the lamp due to a sharp decrease of the RMS value of voltage supply;

- $\quad$ electronic ballast reduce PQ problems and allows a rational use of the lighting reducing line losses, voltage drop and voltage distortion (electronic ballast can implement the compensation of all the non-active power components. The input current waveform of electronic ballast is mainly a sinusoid in phase with the voltage waveform and the power factor is very close to the fundamental power factor, that is just a little less of unity).

Concluding, for energy savings, these considerations are very interesting for the field of street lighting, considering the amount of energy used for this application and the obsolescence of luminaries in it used (as said, only the replacement of the old electromechanical ballast with new electronic ballast could provide an average savings of about $30 \%$ ), but they are also extensible to all applications that use discharge lamps (offices, industry, commercial buildings etc.).

Further more, all these characteristics have been in general easily implemented in LED power supply.

\subsubsection{Lighting control system}

A lighting control system is a device that manages the operation of the lighting according to specific criteria. These devices, combined with the choice of efficient lamps and luminaries characterized by high LOR (Luminaire Output Ratio), can provide significant energy savings (IEA, 2006).

Currently there are a few common strategies within the lighting control technique. According to different lighting sector, outdoor (in particular street lighting) or indoor (office), there are specific lighting control system.

Outdoor lighting system (for street lighting):

- intelligent systems allow for individual street luminaries to automatically react to external conditions such as traffic density, daylight levels, road works, accidents, or weather circumstances. Thanks to these devices, the parameters of the lighting design and drivers' safety can be also guaranteed for all the working period of the lighting;

- remote monitoring devices on each luminaries of the street lighting allow the operator to collect real-time data on system performance at the fixture level. In this way the 
operator is able to savings and performance of the luminaries, and optimizing equipment maintenance.

Indoor lighting system (Benediktsson, 2009):

- occupancy sensing is intended to limit the use of artificial lighting when the area is not occupied;

- daylight harvesting uses a measurement of available daylight to reduce the use of artificial light sources, usually by dimming them;

- time scheduling can vary the lights based on some time schedule and the task tuning can alter the light scenes in a room based on the current activity;

- personal control devices allow users to control their personal light, from their own panel or even from their computers;

- variable load shedding can be useful in circumstances where some predefined energy maximum is to be avoided (is not as common).

Concluding all this type of device provides high energy savings equal to 54\% (IEA, 2006) because, with these systems, artificial light is provided only when needed and with right lighting levels.

\subsubsection{Domotics and building automation system}

The term "Domotics" is commonly used to designates an practice of increased automation of housing environments to obtain high comfort and safety for final-users with lower power consumption. In fact the main aim of "Domotic" is the intelligent cooperation of several different equipments to manage the housing environments in an efficient, safe and comfortable way. When instead, this practice is applied to buildings it's called Building Automation.

The systems for the integrated management of all technology functions of a building are generically called Building Management Systems (BMS). They manage control systems for lighting, shading, air conditioning, access and security. In particular, for lighting systems, the most common standard protocol, used by the BMS, is the DALI (Digital Addressable Lighting Interface).

Talking about interaction between different equipment of a building, with regard to lighting, the equipment that must mainly cooperate, through a BMS, are the lighting, the air conditioning and the shading to obtain efficient and comfortable solution.

Then, as regards the management of the lighting system, the use of fully or partially automated systems for control and integration of artificial and natural light can contribute to the determination of certain benefits. They are: increased visual and thermal comfort inside buildings, obtaining energy savings due to lower consumption of electricity for lighting and, in the case of air-conditioned buildings, a reduction of thermal loads generated by endogenous sources of light.

But, it's important to use efficient control system for daylighting and for shading devices to optimize this particular type of synergy.

Concluding, today Building Automation Systems to control lighting can concur to energy savings. Besides this, they provide other benefits: the ability to track occupancy and energy use, the ability to monitor and control lighting throughout a large facility, and the ability to minimize peak demand.

\subsubsection{Daylighting}

Daylighting systems are a series of devices capable of delivering or managing the natural light inside the indoors enviroments. To make it, these elements must be integrated or 
added the openings of the building. The resulting combination of the windows and these equipped elements is called "Daylighting Systems" (Sabry, 2006).

There are many kinds of this devices, for example elements adjacent to windows or integrated into their glass panel (they are repetitive planner arrangement of tiny optical devices), reflectors or light shelves (these are systems made of reflectors positioned on either the interior or the exterior part of the windows) etc.. Each one of these systems has different characteristics related to major performance parameters. For this reason, it is important choose them according to visual performance and comfort, building energy use and systems integration.

Also, being daylight, for its nature, a light source that varies constantly in intensity, colour and luminance distribution, in all indoor environments it is necessary to implement the natural light with an electric lighting system to ensure adequate lighting levels to support any visual tasks even during all day. So, the electric lights serve to balance the available daylight and to create a dynamic luminous environment.

Then, it is important that the total lighting system (natural and artificial lighting) meets daylighting controls system (better if it is automated) in order to fully benefit from natural light and to save energy.

In fact, regarding the energy savings, a recent study (De Carli, De Giuli, 2009) has shown that the correct integration of natural light, through the use of automatic daylighting system and BMS system, can reduce building energy consumption. Specifically, this study analyzed energy savings obtained by different lighting and shading control strategies, the dynamic daylight performance parameters and the annual illuminance profiles of an sample office, located in five different latitudes: Stockholm $\left(59^{\circ} 65^{\prime} \mathrm{N}\right)$, Venice $\left(45^{\circ} 50^{\prime} \mathrm{N}\right)$, El Cairo $\left(30^{\circ} 13^{\prime}\right.$ $\mathrm{N})$, Bombay $\left(19^{\circ} 12^{\prime} \mathrm{N}\right)$ and Colombo $\left(6^{\circ} 82^{\prime} \mathrm{N}\right)$. Reducing consumption was from $31 \%$ to $73 \%$, according to latitude. Therefore a significant saving in all cases.

Moreover, as already shown by many studies, the natural light provides for functioning of our body, our mental well-being and to increase our productivity at work. Therefore, it is very important to have interiors characterized by a good natural lighting. Again the daylighting is a great tool.

Concluding, daylighting is able to support health and activities of people and is able to reduce energy demand in the building. But, in order to do this, it must be managed by Automation Building System characterized by automatic lighting and automatic daylighting system.

\section{Case studies. Flexible LED light sources}

LEDs are growing and increasingly widespread technology. To appreciate some of their qualities, in this section will present three case studies of lighting using LED and the relative advantages of this practice.

\subsection{Office}

In this case study will be illustrated lighting design realized by LED solutions of an Edison's headquarter office, in Milan. It was designed by the authors.

In particular, this case study shows the possibility to reduce energy consumption and to increase the visual and environmental comfort through LED solutions, integration of natural light and control lighting systems.

\section{Introduction}

In the paste, in this office there were 9 traditional luminaries with fluorescent lamps without any lighting control system, although there are 4 big windows (fig. 5). The luminaries gave a 
very high average illuminance, equal to $8001 x$ in opposite the (level required from the European Standard is equal to 5001x (UNI 12464-1).

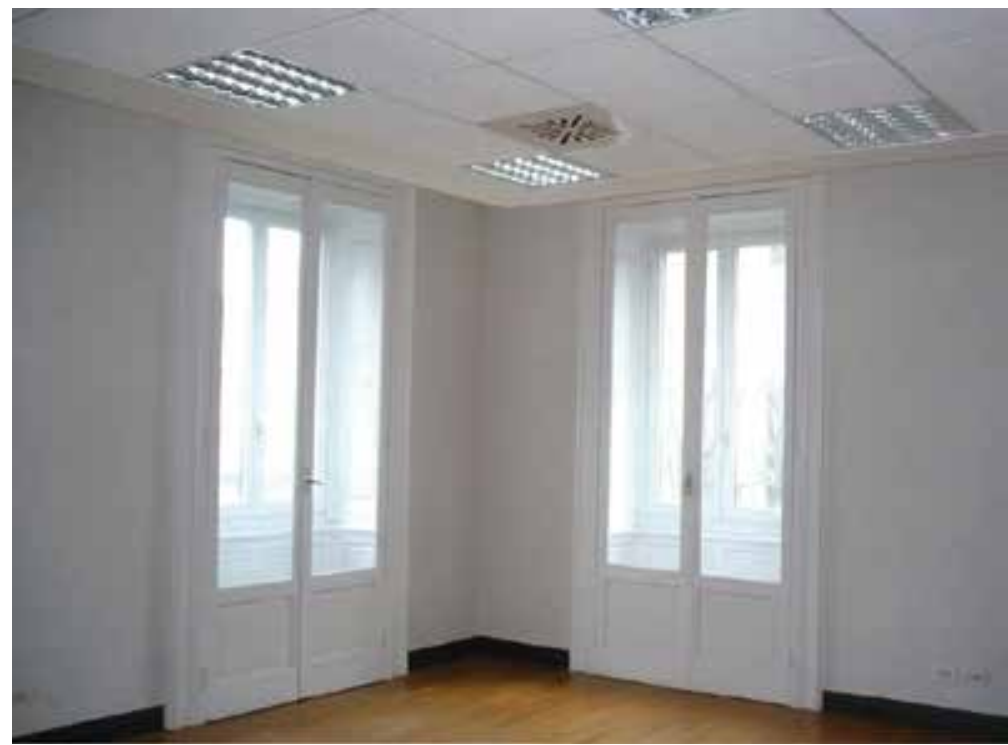

Fig. 5. Old lighting system with fluorescent lamps

\section{Design}

In the new project, the 9 luminaries, with 4 fluorescent tubes to $18 \mathrm{~W}$ each-one, were replaced with 8 polycarbonate lighting panels (Lumisheet, 37W, Fawoo). This polymer layer is characterized by a texture able to extract and restore the environment providing the lumen output with drowned coast LEDs, with an excellent performance. Also, an automatic control system (characterised by natural light sensors for detection and by dimming) was used (Fig. 6).

\section{Results}

The new system, without control system, can provide 500lx ensuring energy saving of 58\%. Moreover this savings increases to $70 \%$, if, as requested by the client, the value of average illuminance is decreased to 350lx. With automatic control system and average illuminance to $3501 x$ the energy saving grow up to $84 \%$.
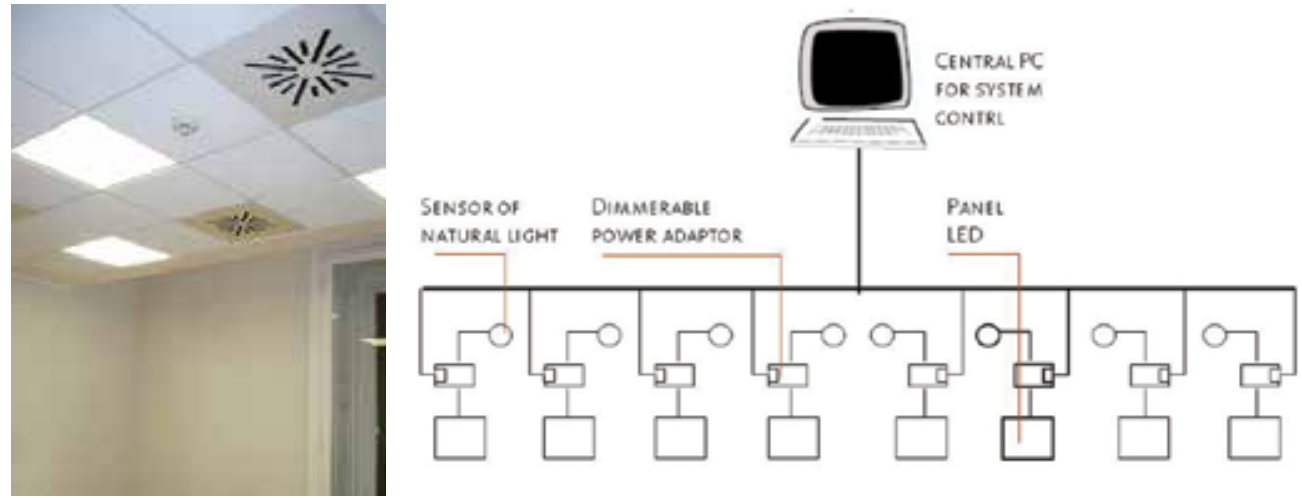

Fig. 6. New lighting system with LED panel and schema of the lighting control system 


\section{Conclusion}

The choice of this particular LED technology has enabled to reduce the installed power, to avoid glaring problems and to manage easily artificial light.

Finally, the control system has allowed to optimize energy savings, to integrate the natural light, so increasing the visual and environmental comfort for workers.

\subsection{Historical building}

In this case study the lighting system refurbishment of a living room in an historical building of Edison, in Milan, will be described. It was designed by the author (Faranda et al. 2010).

In particular, this case study shows the possibility to reduce energy consumption, and to increase the visual and environmental comfort through LED solutions, integration of natural light and control lighting systems. Moreover, it shows the application flexibility of the LED light source in the production of new high performance luminaires

\section{Introduction}

The area of intervention, is defined by a particular architecture and characterized by a very long and narrow plan, from a historical glass vault, and with large windows.

The current lighting of the room is composed by fluorescent lamps both for the back-lighting of the vault and for the desks area, for a total installed power of $19.3 \mathrm{~kW}$.

There is no lighting control system, although there are large windows.

Regarding the lighting performance, it provides a very low average level of illuminance equal to 135lx (even if the level required from the European Standard is equal to 500lx (UNI 12464-1).

Also, the analysis of the technical query performed of the architectural structure showed hazard conditions of the glazing system covering the vault (Fig. 7).
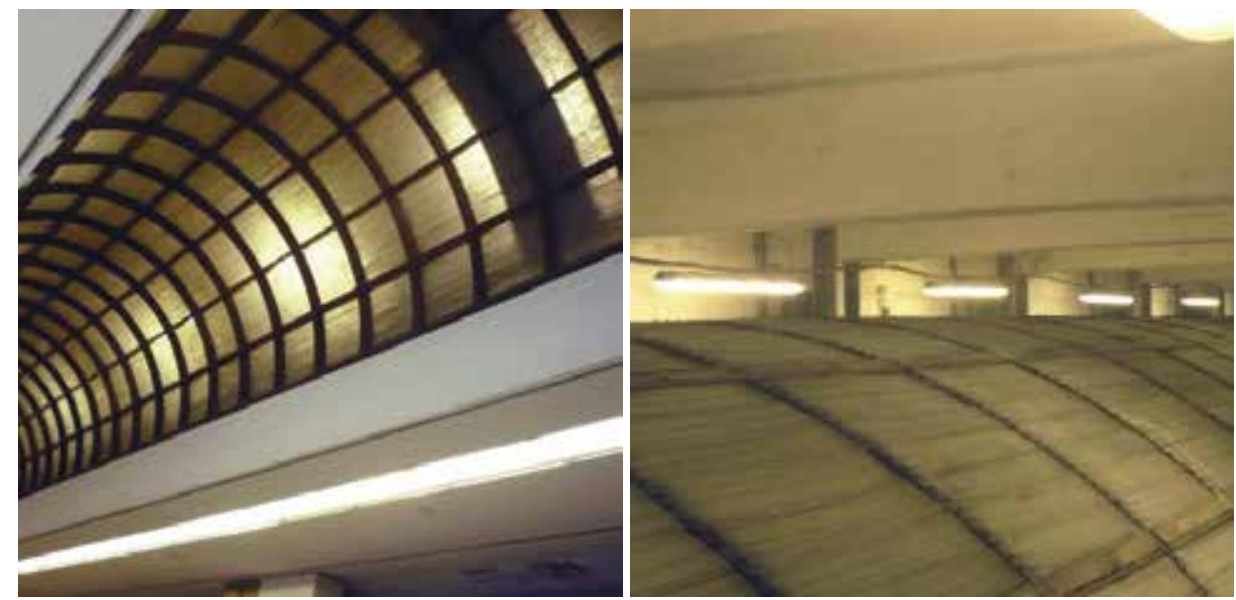

Fig. 7. Actual condition of the vault and back lighting vault (luminaries with fluorescent lamp)

\section{Design}

In order to resolve the problems about the low lighting performance and put in safety the vault, the existing windows are been replaced with 552 polycarbonate lighting panels (Lumisheet, 21W, Fawoo). This polymer layer is characterized by a texture able to extract and restore the environment providing the lumen output with drowned coast LEDs, with an excellent performance. Moreover, to implement the levels of illuminance on the work plans have been proposed 30 luminaries with fluorescent lamps to $49 \mathrm{~W}$ (Fig. 8). Whit this type of 
lighting, total power installed is equal to $16 \mathrm{~kW}$ and the average illuminance is equal to 350 $1 x$, as required by the client.

For lighting management was provided a control system with sensors for detection of natural light and dimming devices.

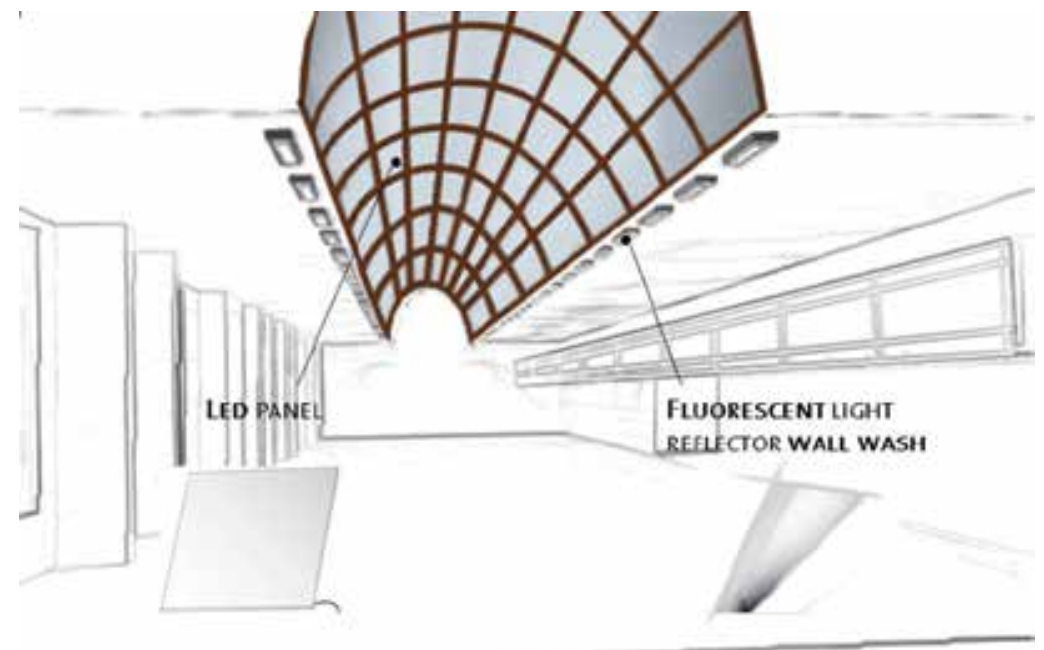

Fig. 8. New lighting concept of the room

\section{Conclusion}

The proposed lighting system, due to the efficiency of the luminaries and to the integration of the light management system, can meet the requirements of the standard (UNI 12464-1), to achieve significant energy savings of about $66 \%$ and a reduction of total costs, for use and management, of about $70 \%$. The increased lighting characteristics associated with the integration of daylight also enhance comfort and environmental well-being for users who work every day in the room.

Finally, the specificities of the light panels solution, only achievable for obvious dimensional features with LEDs sources, allows the safety and upgrading of the vault through the strict respect for the historical identity of the place.

This case, although it is not common, is very important in the countries with a lot of historical buildings.

\subsection{Particular application}

In this case will be presented the idea of a LED lighting system realized for the box of WSB Team Yamaha Sterilgarda designed by the authors. In particular this analysis shows the possibility of increasing the visual and environmental comfort through the use of LED.

\section{Introduction}

Today, the lighting system used in these areas is generally characterized by spotlights with halogen (low efficiency light source with high luminance and high spectral infrared emission), positioned on the supporting structures of the American box (Fig. 9).

This type of solution has two problems: direct/indirect dazzling for operators and heat.

The mechanics work in order to avoid this problem pointing the spots towards the cover of the box. However, this solution generates very low results as regards illumination levels guaranteed average illuminance of $100 \mathrm{~lx}$ to $\mathrm{h} .60 \mathrm{~cm}$. 


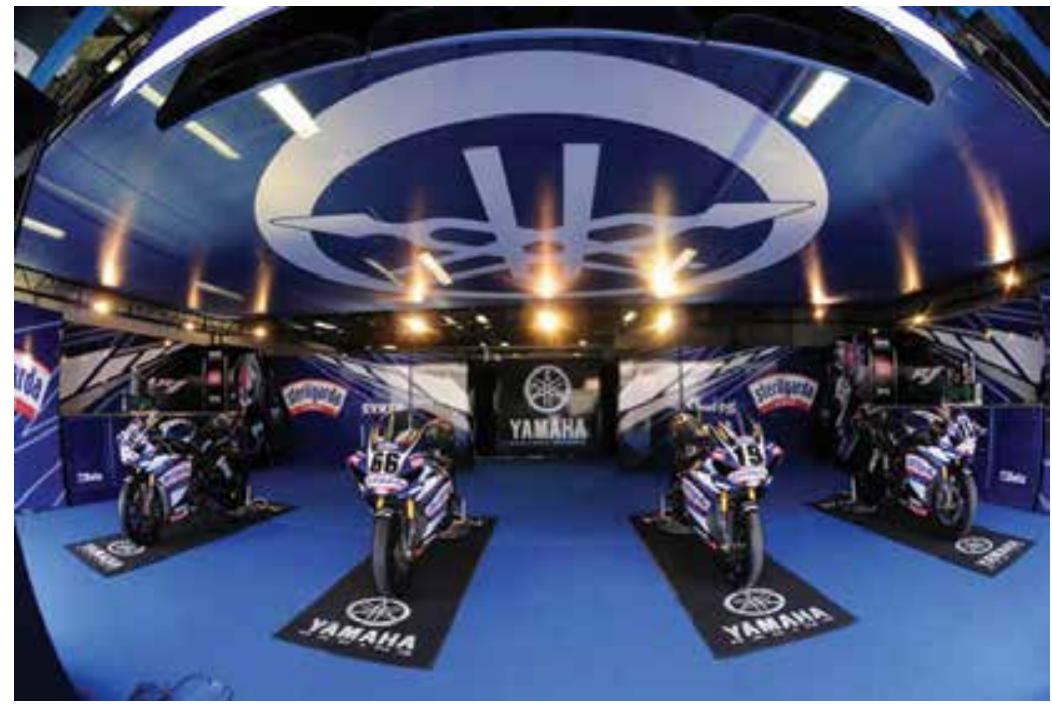

Fig. 9. Old lighting system of the box Yamaha, alogen spots (Photo agency: Alex Photo)

Finally, this type of lighting creates reflections on the phenomena for the body of motorbike and on the walls of the box on the shiny sheet, during photo and television shoots.

\section{Project}

In the planning in order to avoid the problem of the dazzling, it was decided to use a lighting diffuse system. Instead were chosen LED devices (panels with LED drowned coast) in order to avoid the problem of heat.

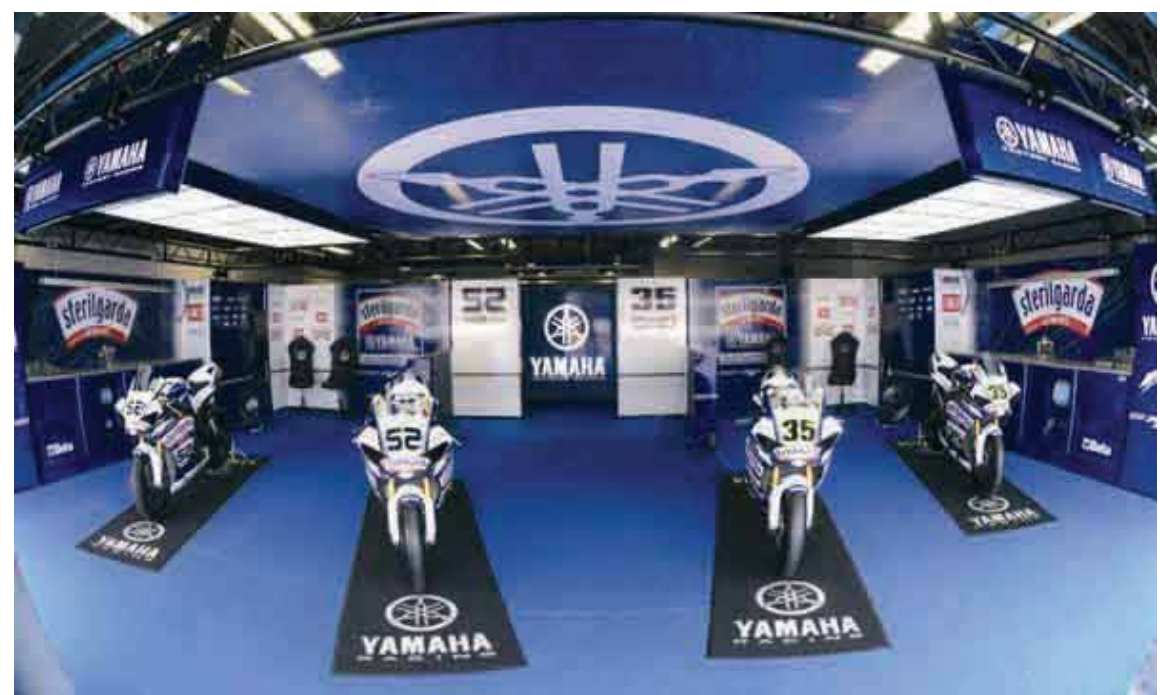

Fig. 10. New lighting system on the box Yamaha, with LED panel (Photo agency: Alex Photo)

Specifically, the lighting system, showen in Fig. 10, was characterized by: 24 LED panels (Lumisheet, 21W, Fawoo) drawed to each other and arranged in two sections of the ceiling, 4 linear suspension elements LED (Linealuce, 37W, Maytag) and 4 LED projectors (Miniwoody, iGuzzini) as. 


\section{Results}

This system has resulted in:

- $\quad$ optimal lighting levels for activities equal to $10001 \mathrm{x}$ at h.60cm ca;

- $\quad$ excellent uniformity 0.8 ;

- $\quad$ pleasant environment (CRI LED> 90);

- a low consume of energy (installed capacity $667 \mathrm{~W}$, approximately $15 \%$ less than the one installed in the old system);

- easy and immediate installation (panels extremely manageable, $60 \times 70 \times 0.8 \mathrm{~cm}$ $5.2 \mathrm{~kg} /$ each one directly supplied by a simple plug).

\section{Conclusions}

The choice to use a particular type of lighting with LED technology has improved dramatically lighting performance guaranteed (average illumination from $100 \mathrm{~lx}$ to $1000 \mathrm{~lx}$ at h.60cm) and to improve workers' visual, environmental comfort and reducing energy consumption.

Whereas, the modular system and the simplicity of power supply have made the solution effective both to installation/operation and to storage/transportation.

Finally, about image, the proposed solution is successful. In fact, the his atypical appearance, compared to lighting of other teams, has become a distinctive and characteristic element for the box.

\section{Conclusion}

Scenarios which characterize the lighting design are nowadays becoming increasingly complex because alongside the technical/functional needs, the comfort condition, user's well being and saving energy have now priority.

The need to find new technological solutions, new languages for lighting systems is witnessed by numerous research projects aimed at studying sophisticated control systems (eg. BMS) and new sources of illumination. Especially and specifically for light source, it is significant the special care with which it is supporting the study and development of power LEDs and OLEDs. The advent of OLEDs technology, in particular, will lead to a conceptual revolution of the light source: cannot longer three dimensional but two dimensional, no single lighting elements point but big lighting sources surface could indeed illuminating, in the near future, our enviroments.

In conclusion, today there are already useful technologies to achieve important energy savings and at the same time to increase the comfort for users. Then, many other devices are developing. Therefore, the efficient tools are there, we just need to learn to integrate them in our traditional contexts.

\section{References}

G. Benediktsson (2009), Lighting Control-possibilities in cost and energy-efficient lighting control techniques, IEA, LTH, December 2009.

L. Blaso, A. Pellegrino, (2007), Sistemi di controllo ed integrazione luce naturale ed artificiale: stato dell'arte e presentazione di un'attività di ricerca sperimentale, www.infobuilddossier.it, 29. July, 2007.

P.R. Boyce, J.A. Veitch, G.R. Newsham, M. Myer, C. Hunter (2003), Lighting Quality and Office Work: A Field Simulation Study, 2003.

M. De Carli, V. De Giuli (2009), Optimization of daylight in buildings to save energy and to improve visual comfort: analysis in different latitudes, Eleventh International IBPSA Conference Glasgow, Scotland, 27-30, July 2009. 
A. Dolara, R. Faranda, S. Guzzetti, S. Leva (2010), Power Quality in Public Lighting System,Proc. 14th International conference on Harmonics and Quality of Power, 2629 Sept. 2010.

M. D. Egan (2002), Architectural Lighting, New York: McGraw-Hill, 2002.

E-Street, Project Report - Intelligent Road and Street Lighting in Europe, E-Street

R. Faranda, S. Guzzetti, S. Leva (2010), LEDs Lighting: Two case studies, U.P.B. Sci. Bull. series $C$, to be published

A.G.A Gregorius, H. Siti (2007), LED Technology in Architectural Lighting of Building's Façade, Proceeding 10th Int'l QIR, 4-6 Dec. 2007.

IESNA (2000), IESNA Lighting Handbook, 9th Edition Illuminating Engineering Society, 01Dec. 2000.

International Energy Agency (2006), Light's Labour's Lost, Policies for Energy-efficient Lighting, 2006.

T. Liu, F.Yang, J. Yu, Y. Wang (2009), Designing of LED Illuminating System and Testing Notice, Proc. WASE International Conference on Information Engineering, Taiyuan, Shanxi, China, Vol. 2, 10-11 Jul 2009, pg. 277-280

L.R. $n^{\circ} 17$ (2000), Misure urgenti in tema di risparmio energetico ad uso di illuminazione esterna e di lotta all'inquinamento luminoso, L.R. $n^{\circ} 17$, Mar. 2000.

NYSERDA (2002), New York State Energy Research and Development Autorhority, How-to guide to Effective Energy-Efficient Street Lighting, Oct. 2002.

OECD/IAC (2006), Light's labour's lost, Policies for Energy-efficient Lighting, 2006.

OECD/IEA (2010), Phase out of incandescent lamps, Implications for international supply and demand for regulatory compliant lamps, pg.9, 2010.

M. Pizzagalli (2009), Domotica per una illuminazione di design, la Casa Futura vista dalla fondazione Politecnico di Milano, Casa future, Apr. 2009.

Philips presentation (2009), OLED Lighting innovation 2009, Politecnico di Milano, 4 Nov. 2009.

Price list Philips (2009), Price list Philips lamps and accessories, 2009.

Eurelectric (2004), Proceeding of annual conference of Eurelectric 2004, 2004.

H. M. K. Sabry (2006), The Impact of Daylighting- Guiding Systems on Indoor Natural Light Penetration: Simulation Analysis for Light-Shelves, PLEA2006 - The 23rd Conference on Passive and Low Energy Architecture, Geneva, Switzerland, 6-8 Sept. 2006.

P. Spotti (2009), Punta della Dogana: un museo elettronico, Luce\&design, pg. 29-36, Nov. 2009.

Standard EN 15193 (2007), Energy performance of buildings - Energy requirements for lighting Part 1: Lighting energy estimation, Mar. 2007.

Standard DIN IEC 60294 (1986), Measurement of the dimensions of a cylindrical component having two axial terminations, Gen. 1986.

Standard IEC 62442 (2007), Energy efficiency of electrical lighting equipment, International Standards Commission, 2007.

Standard UNI EN 11248 (2007), Illuminazione stradale. Selezione delle categorie illuminotecniche, Oct. 2007.

Standard UNI EN 12464-1 (2004), Luce e illuminaizone - Illuminazione dei posti di lavoro - Parte 1: Posti di lavori in interni, Oct. 2004.

Standard UNI EN 13201-1 (2003), Illuminazione pubblica - Parte 1: selezione delle classi di illuminazione, Apr. 2003.

J.A. Veitch, G.R. Newsham, (1996), Determinants of Lighting Quality II: Research and Recommendations, Lighting Research \& Recommendations, National Research Council of Canada, 104th Annual Convention of the American Psychological Association, Canada, ED408543, Aug. 1996.

www.clintonfoundation.org; www.infobuilddossier.it 


\title{
Ground Coupled Heat Pumps in Mixed Climate Areas: Design, Characterization and Optimization
}

\author{
Álvaro Montero', Tatyana Bandos², Julio Martos³, Teresa Magraner4, \\ Nicolás Pardo ${ }^{1}$ and Javier Urchueguía ${ }^{2}$ \\ ${ }^{1}$ Instituto de Ingeniería Energética, Universidad Politécnica de Valencia \\ 2Instituto de Matemática Pura y Aplicada, Universidad Politécnica de Valencia \\ ${ }^{3}$ Departamento de Ingeniería Electrónica, Universidad de Valencia \\ ${ }^{4}$ Energesis Ingeniería S.L. \\ Spain
}

\section{Introduction}

This contribution reviews the research work developed by the authors on the design, characterization and optimization of ground coupled heat pumps in mixed climates areas.

The design of a ground coupled heat pump HVAC system starts with the estimation of the thermal loads that the air-conditioned area demands. The capacity of the ground source airconditioning system is determined from this thermal load estimation. With this value and a proper estimation of the ground thermal properties, the characteristics of the water to water heat pump and the required length and layout of the borehole heat exchangers are estimated.

Determining ground thermal properties is crucial for an accurate design of the air conditioning system. In situ thermal response tests are carried out to have a measurement at site of ground properties. These tests are based on the Kelvin infinite line source model of heat transfer by thermal conduction. Improvements of this technique can be pursued in different ways. One approach consists in refining the model describing the borehole heat exchanger to include effects not taken into account. Finite length effects can be incorporated in the analysis procedure of test in situ outputs as shown in Bandos et al (2008a), Bandos et al (2008b) and Bandos et al (2009a). A filtering technique of the undesired effect produced in temperature measurements by the ambient temperature can be used to improve the estimating of ground thermal properties (Bandos et al (2009b), Bandos et al (2009c), Bandos et al (2009d)).

Another approach to improve the in situ estimation of ground thermal properties is the development of new devices able to measure relevant quantities for the correct characterization of heat transfer between the fluid and the ground. This characterization could be done if the evolution of the fluid temperature along the heat exchanger is known. A sensor probe including a temperature sensor, an acquisition system, temporary storage and wireless communication has been developed to obtain these measurements (Martos et al (2008), Martos et al (2009), Martos et al (2010a), Martos et al (2010b), Martos et al (2010c)). With this new information it will be possible to infer some properties about the ground structure relevant for the design of the ground coupled system. 
Once ground properties are estimated the length and layout of the heat exchanger is determined. After the execution of the ground source air conditioning system, will be desirable to validate the goodness of the design procedure to predict the energy performance of the ground coupled system. For this purpose, the experimental data presented in Urchueguía et al (2006) and Urchueguía et al (2008), characterizing the energy performances of a monitored ground coupled heat pump system, were used to compare with the predictions of a standard design procedure based of nominal heat pump capacities and performances. The achieved result was that this prediction overestimates the energy performances by a percentage between the $15 \%$ and the $20 \%$ (Magraner et al (2009), Magraner et al (2010a), Magraner et al 2010b)). A sensitivity analysis of the energy performance results to the design input parameters showed that heat pump nominal coefficient of performance was the parameter that mostly affects the prediction. The result of this analysis supports the idea that the differences between experimental results and design predictions, are mainly due to heat pump performance degradation for being used at partial load.

Optimizing the energy performance of a ground coupled air conditioning system can also be faced by managing its operation. Note that, in the standard design of an air conditioning system, the references taken to estimate the heating and cooling capacity of the heat pump to be installed are usually based on the coldest and the warmest day along the year. Therefore, the thermal energy required by the thermal load is under the design point of the air conditioning system during most part of the time. In this context, the development of strategies for the operation of the air conditioning system based on the ground coupled heat pumps, allowing adapting the thermal energy generated by the system with the thermal load is a good way to improve the system energy efficiency while satisfying the thermal comfort. In Pardo et al (2007), Pardo et al (2008) and Pardo et al (2009c), a new management strategy is designed to diminish the consumption of the system while keeping the comfort requirements. In Pardo et al (2009a), Pardo et al (2009b) and Pardo et al (2010), an approach based in combining the ground source system with other production system, and decoupling energy production from energy distribution using a thermal storage device was studied. In both cases substantial energy savings, of the order of the $30 \%$, were achieved.

This chapter is organised as follows. Section 2, determining ground thermal properties, presents the results obtained by the authors on the improving of data analysis tools and experimental techniques to measure ground thermal properties. Section 3, energy performances of a ground coupled heat pump system: experimental characterization, reviews the results obtained for the performances of GeoCool plant. Section 4, predictions of ground coupled heat pump energy performances from standard design procedures, shows a comparison between the energy performances of GeoCool plant and predictions from standard design procedures. Section 5, optimization of ground coupled heat pump systems, studies two ways of improving the efficiency of this system. Finally, section 6 summarizes the conclusions.

\section{Determining ground thermal properties}

A ground coupled heat pump exchanges heat with the ground through a U-tube loop based in the earth. The knowledge of ground thermal properties is crucial for the design of ground coupled heat pump air conditioning systems. Field tests allow performing measurements of effective thermal conductivity in realistic conditions.

In situ tests are based on studying of the thermal response of the borehole heat exchanger (BHE) to a constant heat injection or extraction. The outputs of the TRT are the inlet and 
outlet temperature of the heat carrier fluid as a function of time. From these experimental data, and with an appropriate model describing the heat transfer problem between the fluid and the ground, the thermal conductivity of the surroundings is inferred. The infinite linesource (ILS) model is the most widely used method for evaluation of response test data because of its simplicity and speed (Hellström, 1991; Witte et al, 2002).

This section presents improvements on the data analysis procedure and on the measurement technique of a standard in situ test. On the first subject, improving the analysis procedure, the results of a standard test are compared with the predictions from finite line-source (FLS) model for the average ground temperature with finite-length corrections accounting the actual borehole heat exchanger. In addition, this study also addresses the influence of the diurnal temperature on the estimation of the thermal conductivity of the ground, which was pointed repeatedly (Signorelli et al, 2007). And on the improvement of the measurement technique, a new instrument has been developed able to measure the evolution of the fluid temperature along its way through the borehole heat exchanger.

\subsection{Improving data analysis tools}

Within the infinite line-source (ILS) approach commonly applied for the estimates of thermal response test data, the ground is assumed to be a homogeneous infinite medium characterized by its thermal conductivity. In the surroundings of the borehole the results of the infinite line-source model for sufficiently large time values give:

$$
T(r, t)=T_{0}-\frac{Q_{z}}{4 \pi \lambda} \operatorname{Ei}\left(-\frac{r^{2}}{4 \alpha t}\right) \approx \frac{Q_{z}}{4 \pi \lambda}\left\{\ln \frac{4 \alpha t}{r^{2}}-\gamma+O\left(\frac{r^{2}}{4 \alpha t}\right)\right\}+T_{0}, \text { for } \frac{4 \alpha t}{r^{2}}>1
$$

The function $\operatorname{Ei}(u)$ denotes the exponential integral, $\gamma$ is Euler's constant, $\alpha$ is the ground thermal diffusivity, and $T_{0}$ is identified with the undisturbed ground temperature. It is usually assumed that the heat is released at a constant rate from the borehole heat exchanger (BHE), in the 'radial' direction orthogonal to it, and is transferred by the mechanism of thermal conductivity.

In the frame of the finite line-source (FLS) model in the semi-infinite region, the approximation of the ground temperature, averaged along the $\mathrm{BHE}$, for the times corresponding to the TRT was proposed by Bandos et al. (2009a). The average ground temperature response for $t_{z}>>>>t_{r}=r_{b}^{2} / \alpha$ is given by:

$$
<T(r, z, t)-T_{0}>\approx \frac{Q_{z}}{4 \pi \lambda}\left\{-\gamma-2 \ln \frac{r}{H}+\ln \frac{4 t}{t_{z}}+\frac{3 r}{H}-\frac{3}{\sqrt{\pi}} \sqrt{\frac{4 t}{t_{z}}}-\frac{3}{\sqrt{\pi}} \frac{r^{2}}{H^{2}} \sqrt{\frac{t_{z}}{4 t}}\right\},
$$

Where $t_{z}=H^{2} / \alpha$ the characteristic axial time scale and $\mathrm{H}$ is the borehole depth.

The acquisition system used to monitor the ground thermal response was connected to the borehole heat exchanger by insulated 1-m long tubes. The experiments were performed on a borehole heat exchanger with radius $r_{b}=0.15 \mathrm{~m}$ and depth $H=25 \mathrm{~m}$. Figure 2.1 a illustrates correlation between the changes of the measured fluid temperature and the ambient temperature. To provide the constant heat rate (of $1000 \mathrm{~W}$ as shown in Figure 2.1b), the difference between temperature of the circulating fluid on the input and output of the ground loop were hold constant as well as the volume flow rate of fluid, G. The test parameters were monitored every 3 minutes by a data logger. Figures 2.1 present the plots of 1418 readings after data averaging over 30 points. The following values of model 
parameters in equations $(2.1,2.2)$ are set in the numerical calculations throughout the section: $\alpha=1.2110^{-6} \mathrm{~m}^{2} / \mathrm{s}, \mathrm{T}_{0}=14^{\circ} \mathrm{C}$.

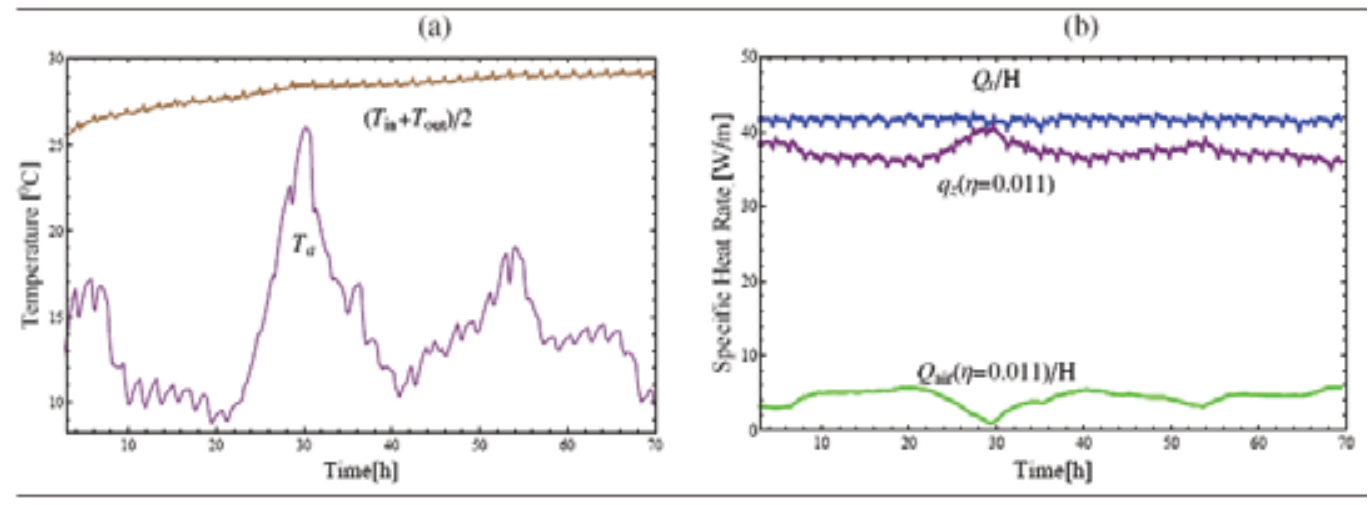

Fig. 2.1. (a) Influence of varying ambient air temperature (purple line) on the average fluid (brown line) temperature in the injection mode. (b) Measured total heat rate $Q_{t}$ (blue line), variable heat rate $q_{z} H$ transferred to ground (purple line), $Q_{\text {air }}$ calculated with the fitting parameter $\eta=0.011$ (green line) as a function of time.

Although pipes connecting the test rig with the borehole are insulated, undesirable correlation between the air temperature and the mean temperature of fluid is usually observed (as shown in figure 2.1a). The heat exchange between the air and the fluid flowing through the pipes changes the actual heat transferred to the BHE because of the heat dissipated to the ambient. Besides diurnal changes of the temperature of the air, the interior temperatures of the test rig affect the efficiency of the system operation. The total heat rate $Q_{t}$ can be written as $Q_{t}=Q_{a i r}+H q_{z}$, where $Q_{a i r}$ is the heat rate transferred to the ambient air, and $q_{z} H$ is the actual heat transferred to the ground.

The fluid temperature changes with coordinate along the plastic pipes outside the borehole due to the heat exchange with the ambient air. At the quasi steady-state case, the heat transport by the fluid along the pipes, accompanied by the transverse heat flux to the air, is governed by the convection equations (Hellström, 1991). To account for this climatic influence, the dimensionless parameter $\eta$ is used thereafter; it appears in the solution of the convection equations for $T_{\text {in }}\left(T_{\text {out }}\right)$, the fluid input (output) temperature at the point of the external pipe on the ground surface level, and can be calculated using physical parameters of the fluid, flow rate of the heat carrier, the thermal resistance for the heat flow from fluid to the air, and the length of the pipe between the point of measurement of the fluid temperature at the test rig and the corresponding point, at which the flow upwards/downwards the subsurface. This parameter influences both the heat rate and mean fluid temperature as:

$$
\begin{gathered}
q_{z}(\eta, t) H=C_{f} G\left(2 T_{a}(t) \sinh \eta-e^{\eta} T_{\text {out }}^{*}+e^{-\eta} T_{\text {in }}^{*}\right), \\
\overline{T_{f}}(\eta, t)=\left(T_{\text {out }}(t)+T_{\text {in }}(t)\right) / 2=T_{a}(t)(1-\cosh \eta)+\left(e^{\eta} T_{\text {out }}^{*}+e^{-\eta} T_{\text {in }}^{*}\right) / 2
\end{gathered}
$$

Where $T_{\text {in }}{ }^{*}\left(T_{\text {out }}{ }^{*}\right)$ corresponds to the fluid temperature at the point of measurement related to the input (output) of the borehole. Fig.1.b shows that $q_{z}(\eta ; t)$ and $Q_{a i r}(\eta ; t)$ change with 
time, but $Q_{t}$ remains the same by keeping the temperature difference $T_{\text {in }}-T_{\text {out }}$ constant during the TRT. Since $Q_{a i r}(\eta ; t)$ is subtracted from the fluid outside of where the temperature measurements are made, the actual heat injection rate to the ground is reduced. To estimate the effective thermal conductivity, time-dependence of the ground temperature approximation is compared with time-dependence of the measured fluid temperature. The parameter $\lambda$ of the ILS model depends on the $\eta$ through the late time slope $k$ of the experimental $T_{f}(\ln (t))$ curve and the heat- flux $q_{z}(\eta ; t)$, equation (2.3), as:

$$
\lambda=\left\langle q_{z}(\eta ; t)\right\rangle_{t} /(4 \pi \mathrm{k}(\eta))
$$

Where $\langle\ldots\rangle_{t}$ denotes time averaging. Here $\mathrm{k}$ is the slope of linear approximation in the semilogarithmic scale, i.e. $\bar{T}_{f}(t)=k \ln (t)+m$ for the time-dependence of the experimental data. A lower heat injection rate results in a lower estimate for thermal conductivity. Notice that if the connecting pipes were ideally insulated, i.e. $\eta=0$, neither $T_{\text {in }}$ nor $T_{\text {out }}$ would depend on the air temperature. The question then arises: how to select parameter $\eta$ for filtering the air temperature variation effect.

On the pre-processing step of the test analysis, model parameter $\eta$ can be evaluated by matching the measured fluid data to equation (2.3). The energy rate balance and equation (2.3) set the correspondence between $\eta$ and the $\mathrm{p}$-th part of the total heat rate transmitted to the air $\left(Q_{a i r}=p Q_{t}\right)$ as:

$$
(p-1+\cosh \eta)\left\langle T_{\text {in }}^{*}(t)-T_{\text {out }}^{*}(t)\right\rangle_{t}=\left\langle T_{\text {out }}^{*}(t)+T_{\text {in }}^{*}(t)-2 T_{\text {air }}(t)\right\rangle_{t} \sinh \eta
$$

If the heat loss to the ambient is a small part of the total injected heat rate $(p<<1)$, the series expansion for $\eta$ in equation (2.3) gives:

$$
\eta=p \frac{\left\langle T_{\text {in }}^{*}(t)-T_{\text {out }}^{*}(t)\right\rangle_{t}}{\left\langle T_{\text {out }}^{*}(t)+T_{\text {in }}^{*}(t)-2 T_{a}(t)\right\rangle_{t}}
$$

Then, the values of $\eta$ turn out to be small as far as $p<<1$. One can use the above equation to select $\eta$. There is some arbitrariness involved in the exact quantity of the total measured heat rate transferred to the ground. The idea behind the proposed method of pre-processing TRT data is to use the freedom in choosing $\eta$ to suppress the influence of the air temperature oscillations, i.e. to select such a value of fitting parameter $\eta$ that the fluid temperature of outward flow from the borehole $T_{\text {out }}(t)$ can be approximated by a sufficiently smooth function of time. In the non ideal test the fluid is exposed to a certain climatic influence when flowing from the test rig to the borehole at the same time as the heat conduction into the ground attenuates $T_{i n}(t)$ oscillations when fluid passing through the borehole as shown in figure 2.2a. The effect of the air temperature variation is mitigated if the fitting parameter $\eta$ is set equal to 0.011 given $p=0.1$ and below it is applied to the parameter estimation analysis of the results of the test.

On the next stage, when fitting $T_{b}=T\left(r_{b} ; t\right)$ to the experimental data of $\bar{T}_{f}$, the thermal resistance $R_{b}$ between the borehole wall and the fluid must be taken into account, $R_{b} C_{f} G\left(T_{\text {in }}-T_{\text {out }}\right)=R_{b} q_{z}=\bar{T}_{f}(\eta, t)-T_{b}(t)$, where $C_{f}$ is the volumetric heat capacity of fluid. Notice that the borehole temperature $T_{b}(t)$ is influenced by the measured fluid temperatures and $T_{a}(t)$ through the $Q_{a i r}(t)$ as: 


$$
Q_{\text {air }}(\mathrm{t}) \approx 2 \eta C_{f} G\left(\left(T_{\text {in }}{ }^{*}+T_{\text {out }}{ }^{*}\right) / 2-T_{a}(t)\right)
$$

For small values of $\eta$. The parameter $R_{b}$ is also obtained from the TRT. Below the proposed formulas for subtraction of climatic influence on the TRT are applied to the parameter estimation analysis.

The assessment of the late-time TRT data allows to estimate, and to obtain a extrapolated value for $T_{0}$ (Hellström, 1991). The data obtained from the 71-h TRT were evaluated and compared by making use of the ILS and FLS models along with the introduced method of account for the heat transfer to the ambient characterized by $\eta$. To find suitable model parameters, equations (2.1) and (2.2) are matched to the heat carrier fluid temperature data by using regression; the average heat rate, $\left\langle q_{z}(t)\right\rangle_{t}$, is applied when the heat rate variations $q_{z}(t)$ are caused by $T_{a}(t)$ fluctuations as described before. Figure $2.2 \mathrm{~b}$ compares the estimated values from both the ILS and FLS models on different length of data interval of the same test, for $\eta=0$ and $\eta=0.011$.

Figure $2.2 \mathrm{~b}$ reveals noticeable oscillations of $\lambda$ caused by small fluid temperature variations due to the air temperature changes (Signorelli et al, 2007). Small changes in the mean fluid temperature curve are significantly amplified for thermal conductivity $\lambda$ that is inversely proportional to the time derivative of the temperature. Figure $2.2 \mathrm{~b}$ also demonstrates that these fluctuations are lowered for $\eta \neq 0, R_{b}=0$ and almost disappear for $\eta \neq 0, \quad R_{b} \neq 0$. Therefore, the developed method successfully removes cyclic distortions caused by the diurnal temperature cycle.

For either procedure of evaluating, when energy loss in the air is absent, the values of thermal conductivity, calculated from both ILS and FLS models are higher than the ones evaluated with the proposed method of decoupling climatic influence from the TRT data; this is the effect of the heat transfer to the ambient.

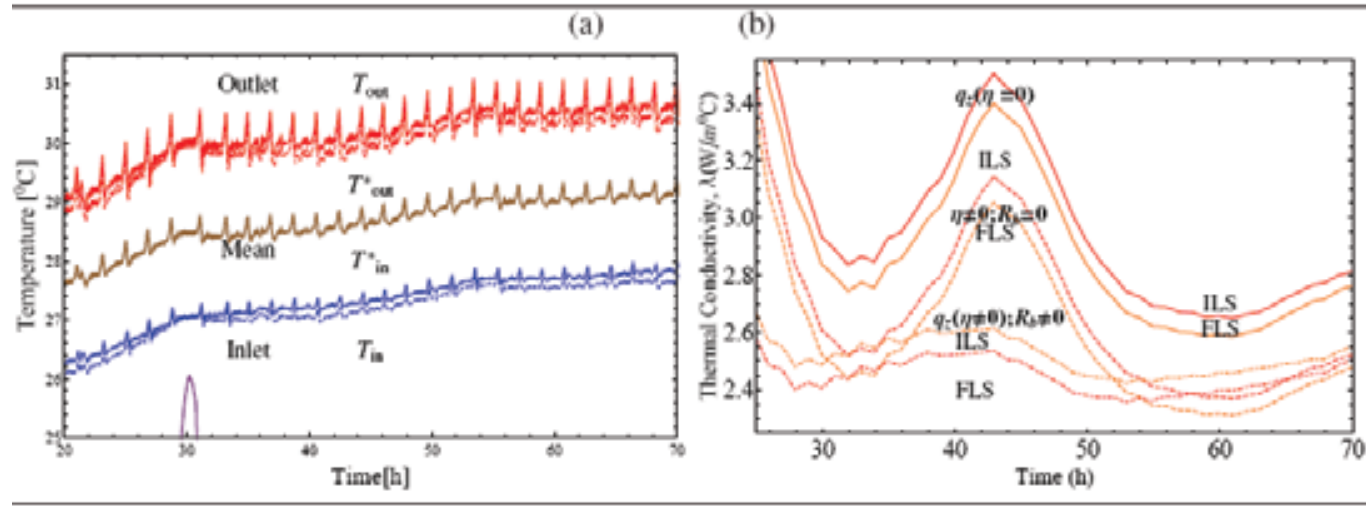

Fig. 2.2. (a) Comparison between measured inlet, $T_{\text {in }}{ }^{*}$, outlet, $T_{\text {out }}{ }^{*}$, temperatures (dashed red, blue lines, respectively) and calculated $T_{\text {in }} ; T_{\text {out }}$ with $\eta=0.011$ (red, blue lines, respectively). Brown line indicates the mean fluid temperature. (b) Comparison between dependence of thermal conductivity from the ILS (red line) and FLS (orange line) model on the time estimation interval for the same test data. Estimates of thermal conductivity based on the ILS and FLS models when the end of the evaluation interval is fixed, while starting time increases: (i) without heat loss to the ambient $(\eta=0)$ - solid lines (ii) with heat loss to the ambient $(\eta=0.011)$ : dashed for $R_{b}=0$, dot-dashed for $R_{b} \neq 0$ lines, respectively. 


\subsection{Improving experimental measurements}

To improve the measurement technique, it has been developed a new measurement instrument that allows obtaining the evolution of the fluid temperature along its way through the borehole heat exchanger (Martos et al (2008), Martos et al (2009), Martos et al (2010a), Martos et al (2010b), Martos et al (2010c)). The characteristics of this equipment are the following: small volume and easy to transport; it is very easy to locate temperature sensor in the borehole head measuring only the heat transfer between the pipes and the ground; allow new methodologies for TRT because gives new information for the fluid temperature evolution.

The aim of this instrument is to determine the spatial and temporal behaviour of the fluid temperature along the $\mathrm{BHE}$, so it is necessary to measure the temperature of the fluid flowing through the pipe along the entire length. To do so, miniature temperature probes are inserted to measure the temperature at specified intervals. The instrument has been divided in three parts: Autonomous sensors, Software for recording and analysis, and the Hydraulic system.

Figure 2.3 presents the logic diagram of the instrument; the hydraulic system comprises a water tank, a circulation pump and two valves for the insertion and extraction of the autonomous temperature probes. A laptop runs the program for thermal response test configuration, acquisition and analysis of the values of measured temperature. Finally, a set of small $25 \mathrm{~mm}$ diameter balls contains the electronic circuitry of the autonomous temperature probes. Also, a set of sensors monitor several variables during the running of thermal response test, such as the flow of water that circulates, the inlet and outlet water temperature, the temperature of the tank, as well as the pressure in the pipes.

The autonomous sensors are key components of the instrument. They are devices that measure the thermal evolution of an elementary volume of water along the BHE pipe. Its sizes must be as small as possible so they can move easily through the pipes carried by the water flow, and at the same time contain an acquisition system, temporary storage and unloading of temperature data. To achieve these functions and capabilities, a circuit has been designed based on the CC1010 transceiver that allows including it in a sphere with diameter smaller than $25 \mathrm{~mm}$. It has been designed a 4-layer PCBs for mounting all the necessary components. The characteristics of each autonomous sensor are: temperature range: $0-40{ }^{\circ} \mathrm{C}$; resolution temperature $:<0.05{ }^{\circ} \mathrm{C}$; accuracy temperature $:<0.05{ }^{\circ} \mathrm{C}$ rank sampling: 0.1-25 s; capacity sampling: 1000 samples.

The mode of operation of the autonomous sensors is as follows: the control system selects an available probe and puts it in the status of test run; transfer the parameters of sampling; insert the probe into the BHE water flow; the probe starts the process of acquiring, storing temperatures at fixed intervals; after the tour, the temperature data are downloaded to the control system; it's going to low-power mode.

The hydraulic subsystem has as many autonomous sensors as necessary to ensure that they are inserted to the programmed rate. The key factor of success in using these autonomous probes lies in the duration of the power supply. Each probe carries a battery type button 3 volts and $230 \mathrm{mAh}$, which guarantees the proper functioning of the probes during more than a year for a duty cycle which they perform. The hydraulic circuit comprises a water tank, as buffer for the thermal fluid, an electronically controlled circulation pump, a flow meter and two valves, one for inserting probes and another for their extraction. The water temperature can be set through an electric heater controlled by the program that runs on the PC, which also controls the flow of water that is injected into the pipe of BHE. The insertion of the probes is performed with selected time intervals in terms of realizing the TRT, 
controlled by the PC. When extracted, the probe is situated at the point of data discharge and, once it is completed, the data contained in the probe is deleted and is prepared for next insertion.

To verify the operation of the instrument a laboratory installation has been built to simulate a borehole heat exchanger. A 5 meters U-pipe has been arranged in spiral layout to perform two tests: transit time verification and response time of the Pt100 sensor. A key point to the proper location on the pipe is ensuring that the sensor is carried by the water flow at the same speed. If the density of the sphere that constitutes the probe is close to the density of the thermal fluid, will be carried both in vertical as horizontal configurations. To verify this, a set of measures of transit time has been completed with a set of spheres throughout the interior of a pipe with a length of $10 \mathrm{~m}$. The result was that this is a technique with small error (smaller than 2\%) allowing to accurately deducing the sensor position. Another relevant point is the response time of the element used as Pt100 temperature sensor. This time has to be precisely known to estimate the accuracy of the sensor measurement with the actual value of the temperature at the measuring point. This response time has been characterized in laboratory, being $0.5 \mathrm{~s}$ the time needed to reach $66 \%$ of the actual temperature and $1.5 \mathrm{~s}$ to reach $90 \%$. These values for the response time allow obtaining a signal that appropriately filtered reproduces the temperature evolution of the fluid along its way through the borehole heat exchanger.

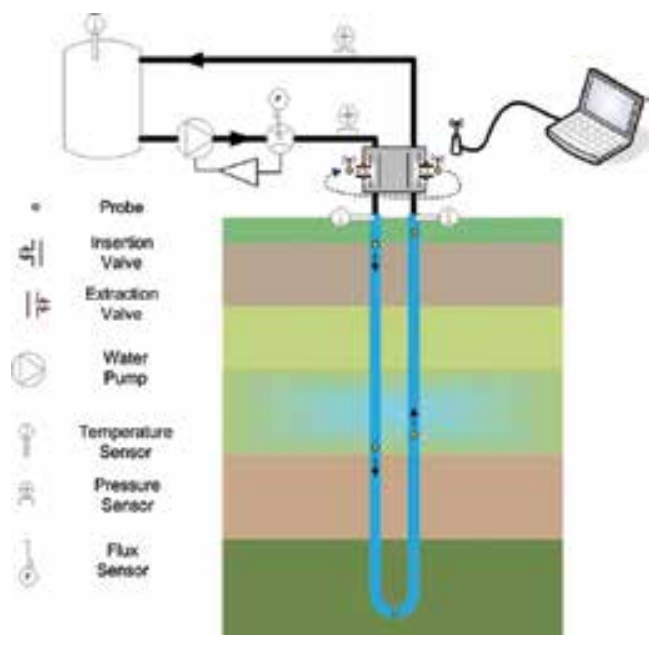

Fig. 2.3. Logic diagram of the instrument

\section{Energy performances of a Ground Coupled Heat Pump: experimental characterization}

This section presents the energy performance characterization of a monitored ground coupled heat pump system (Urchueguía et al (2006), Urchueguía et al (2008)). This plant was the result of a EU project (GeoCool) and air-conditions a set of spaces in the Department of Applied Thermodynamics at the Polytechnic University of Valencia, Spain, with a total surface of approximately $250 \mathrm{~m}^{2}$. This area includes nine offices, a computer classroom, an auxiliary room and a corridor. All rooms, except the corridor, are equipped with fan coils supplied by the experimental system, an air to water heat pump and a ground coupled heat pump working alternately (Figure 3.1). 
The ground coupled system consists of a reversible water to water heat pump $(15.9 \mathrm{~kW}$ of nominal cooling capacity and $19.3 \mathrm{~kW}$ of nominal heating capacity), a vertical borehole heat exchanger and a hydraulic group. The water to water heat pump is a commercial unit (IZE70 model manufactured by CIATESA) optimized using propane as refrigerant. As reported in GeoCool final publishable report (GeoCool 2006), the coefficient of performance of the improved heat pump is $34 \%$ higher in cooling and $15 \%$ higher in heating operation.The vertical heat exchanger is made up of 6 boreholes of $50 \mathrm{~m}$. depth in a rectangular configuration, with two boreholes in the short side of the rectangle and three in the large side, being $3 \mathrm{~m}$. the shorter inter-borehole distance. All boreholes are filled with sand and finished with a bentonite layer at the top to avoid intrusion of pollutants in the aquifers.

A network of sensors allows monitoring the most relevant parameters of these air conditioning systems (Figure 3.1). These sensors measure temperature, mass flow and power consumption. The temperature sensors are four wire PT100 with accuracy $\pm 0.1{ }^{\circ} \mathrm{C}$. The mass flow meters are Danfoss Coriolli meters, model massflo MASS 6000 with signal converter Compact IP 67 and accuracy $<0.1 \%$. The power meters are multifunctional power meters from Gossen Metrawatt, model A2000 with accuracy $\pm 0.5 \%$ of the nominal value. Data from this sensor network is collected by a data acquisition unit Agilent HP34970A with plug-in modules HP34901A.

The geothermal system is characterized by the heat that the ground can absorb or transfer. To record this value inlet and outlet fluid temperature of the water to water heat pump and circulating mass flow are measured. In addition inlet and outlet temperature in each borehole are measured too and in three of the boreholes the temperature at several depths is recorded to acquire ground temperatures. There is a power meter located on the right of figure 3.1 which has two functions: record the consumption of the air to water heat pump including the fan when the air system is working or record the consumption of the water to water heat pump plus the circulation pump when the geothermal system is working.

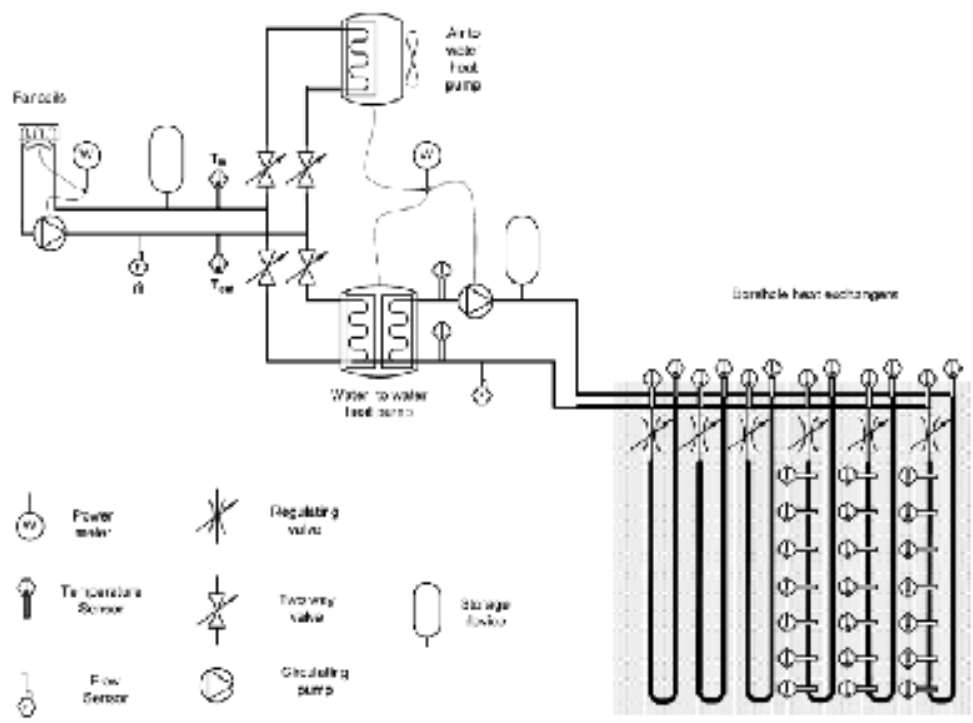

Fig. 3.1. GeoCool schematic diagram. The air to water heat pump and the ground source heat pump are linked in parallel to the internal hydraulic group that transfers the energy to fan-coils. 
The system energy efficiency is calculated from the power consumption readings and the values of the internal thermal loads calculated from experimental measurements. Instantaneous thermals loads are obtained by means of the following expression:

$$
\dot{Q}(t)=\dot{h}_{\text {out }}(t)-\dot{h}_{\text {in }}(t)
$$

Where:

$$
\dot{h}_{\text {in }}(t)=\dot{m} C p T_{\text {in }}(t) ; \dot{h}_{\text {out }}(t)=\dot{m} C p T_{\text {out }}(t)
$$

are the input and output enthalpy flows at the circuit connecting the fan coils and the heat pump. Because of all the measures are taken in one minute intervals, the internal thermal load is defined as the integral of expression (3.1). It represents the cooling or heating load demanded by the building during the time period $\Delta t$ starting at $T_{0}$ time.

$$
Q=\int_{T_{0}}^{T_{0}+\Delta t} \dot{Q}(t) d t
$$

Likewise, the system energy consumption is calculated by integrating numerically the power consumption, $\dot{W}$, measured by the power meter located on the right of figure 3.1, corresponding to the consumption of the water to water heat pump, $\dot{W}_{w w}$, plus the consumption of the circulation pump, $\dot{W}_{c p}$.

$$
W=\int_{T_{0}}^{T_{0}+\Delta t} \dot{W}(t) d t ; \dot{W}(t)=\dot{W}_{w w}(t)+\dot{W}_{c p}(t)
$$

The system energy efficiency is characterized by the energy performance factor, defined as the ratio between the thermal load and the electric energy consumption during a time interval:

$$
P F=\frac{Q}{W}
$$

Depending on the duration of the integration period the energy performance factor can be seasonal, monthly, daily, etc. The most representative one is the seasonal performance factor (SPF) that estimates the system performance in a working mode (heating or cooling).

From the performance factor values it is possible to estimate the energy savings that may be obtained when switching to GCHP technology assuming that the heating/cooling load are the same for both systems. Under this hypothesis, the energy savings can be evaluated as:

$$
\frac{W_{a w}-W_{w w}}{W_{a w}} \times 100=\left(1-\frac{S P F_{a w}}{S P F_{w w}}\right) \times 100
$$

Figures 3.2 present the results of the seasonal and daily evolution the performance factor. The value of the performance factor at the end of each season, defined as the seasonal performance factor (SPF), gives an estimation of the total energy performance. As stated above, from this quantity it can be estimated the energy savings that may be obtained when 
switching to GCHP technology. The performance factor evolution for both AC systems and both operating modes, heating and cooling, is shown in figures 3.2. These numbers are calculated as stated previously, being $\mathrm{T}_{0}$ the starting point of each season and $\delta \mathrm{T}$ the period of time covered from this starting point to the day considered. The top solid line corresponds to the ground source heat pump system and the bottom solid line to the air source heat pump system. At the end of the heating season the value for the performance factor was $\mathrm{SPF}=3.5 \pm 0.6$ for the geothermal system and $\mathrm{SPF}=2.0 \pm 0.3$ for the conventional system. This result represents an averaged efficiency improvement of $73 \%$ in heating mode. At the end of the cooling season the final value of the performance factor was $\mathrm{SPF}=4.3 \pm 0.6$ for the geothermal system and $\mathrm{SPF}=2.7 \pm 0.4$ for the conventional system, with a cooling efficiency improvement of $60 \%$. The conclusion achieved was that the system based on ground coupled heat exchangers uses $43 \pm 7 \%$ less electric energy than the conventional one for the same heating requirements. In cooling mode, the ground coupled heat exchanger based system requires an average of $37 \pm 18 \%$ less energy than the conventional one. These results show that the use of the ground as a heat source allows achieving considerable energy savings in heating mode, and its use as a heat sink also allows to achieve important energy savings in cooling mode.
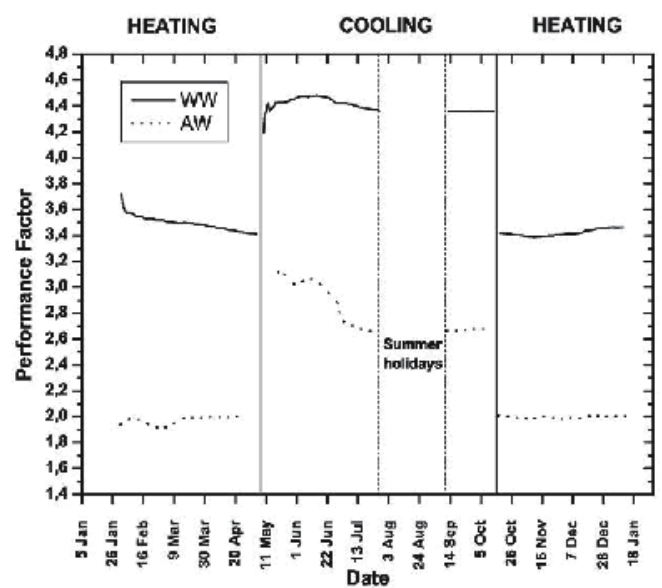
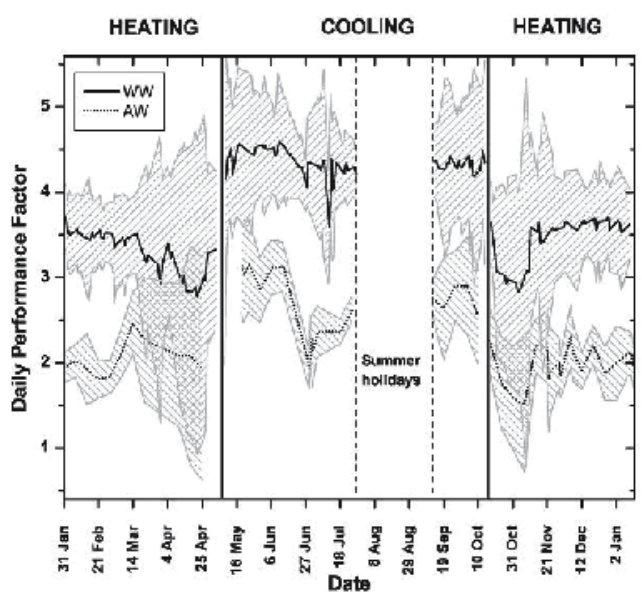

Fig. 3.2. Performance Factor evolution (left figure) for both AC systems and both operating modes, heating and cooling. The top solid lines correspond to the water to water system (WW); the bottom broken lines correspond to the air to water system (AW). Daily

Performance Factor is shown on the right figure for both AC systems, and for both operating modes. The top solid lines correspond to the water to water system (WW); the bottom broken lines correspond to the air to water system (AW). Each value for Daily performance Factor is shown together with its error bandwidth.

Figures 3.3 present the results of the monthly electrical consumption of both AC systems. The contribution corresponding to the energy transport components (fan coils and internal circulation pump) are separated from the energy production ones (water to water heat pump and external circulation pump for the geothermal system, and air to water heat pump for the conventional system) in order to evaluate the impact of these secondary components in the energy balance. From this figures it can be seen that in the case of the geothermal system the consumption of the secondary components exceeds $30 \%$ of the total 
consumption. In heating mode and during warmer periods, when the system use is low, their contribution to the total electrical consumption increases to $50 \%$. For the air to water heat pump system these percentages are lower due to the higher electrical consumption of the heat pump itself, but in any case they are larger than $20 \%$. This analysis points to the need of more intelligent control strategies to attenuate the energy demand of the secondary components.
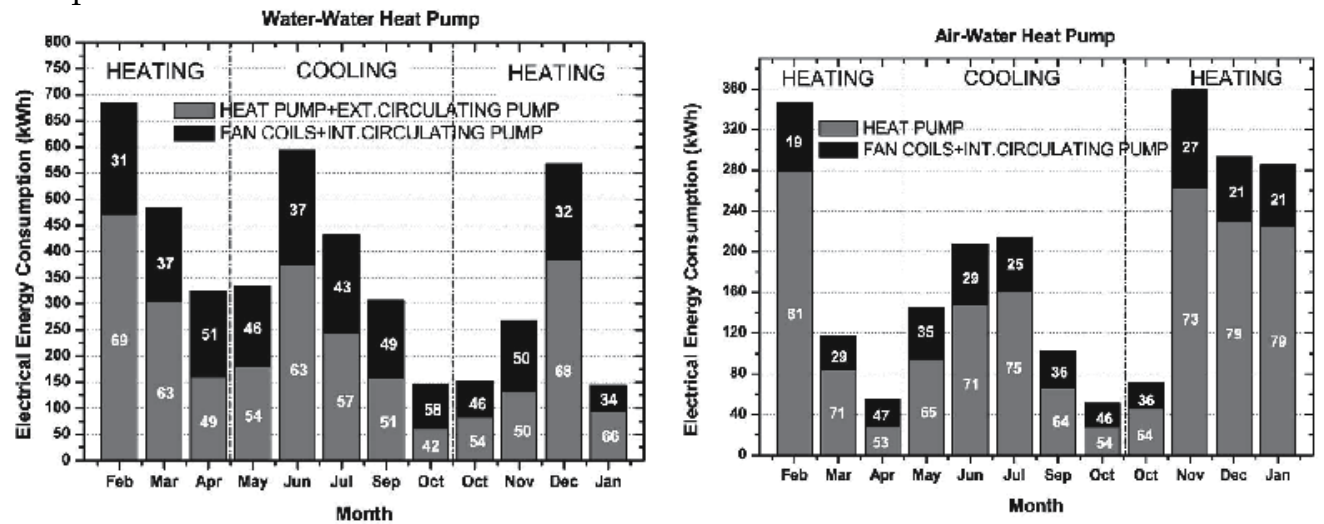

Fig. 3.3. Electrical energy consumption for the water-water system (left figure) and for the air-water system (right figure).

\section{Predictions of Ground Coupled Heat Pump energy performances from standard design procedures}

This section deals with the comparison of energy performances obtained from ground coupled heat pump design methodology based in TRNSYS with the experimental results just presented in previous section ( Magraner et al (2009), (2010a), (2010b) ). TRNSYS is a transient system simulation program with a modular structure that was designed to solve complex energy system problems by breaking the problem down into a series of smaller components (referred to as "Types"). TRNSYS Library includes the components commonly found in a geothermal system (ground heat exchanger, heat pump, circulation pump, etc) and the program allows to directly join the components implemented using other software (e.g. Matlab or Excel).

Figure 4.1 shows the TRNSYS model scheme used to simulate GeoCool plant. The model scheme consists of four components: water to water heat pump, circulation pump, vertical ground heat exchanger and loads. The first three components have been selected from TRNSYS library. And the last component, "Loads", is an Excel file containing the experimental thermal loads.

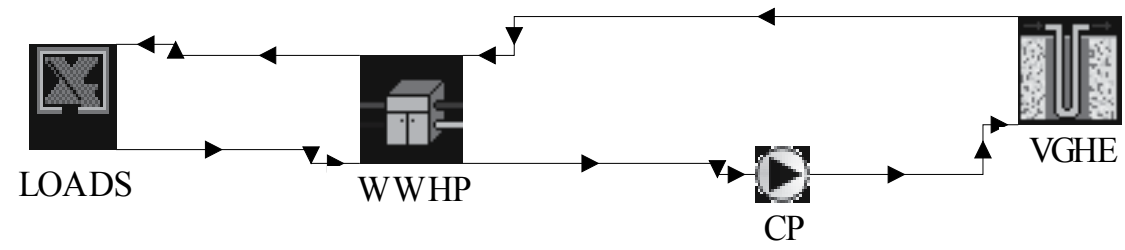

Fig. 4.1. TRNSYS model scheme used to simulate GeoCool plant. 
The water to water heat pump selected component is a reversible heat pump; it supplies the thermal loads absorbing energy from (heating mode) or rejecting energy to (cooling mode) the ground. This type is based on user-supplied data files containing catalogue data for the capacity and power draw, based on the entering load and source temperatures. These files (one for heating and one for cooling) are modified introducing the values of the GeoCool commercial unit (CIATESA IZE-70). The performance improvement coming from using propane as refrigerant instead of R-407c is also included (an increment of $34 \%$ for the Efficiency Energy Rate, EER, and an increment of $15 \%$ for the coefficient of performance, COP, as reported in GeoCool final report (GeoCool (2006))).

The circulation pump component is a simple-speed model which computes mass flow rate using a variable control function, which must have a value between 1 and 0 . The user can fix the maximum flow capacity, in the model established for the heat pump, and the pump power is calculated as a linear function of mass flow rate.

A vertical ground heat exchanger model must analyze the thermal interaction between the duct system and the ground, including the local thermal process around a pipe and the global thermal process through the storage and the surrounding ground. GeoCool ground heat exchanger has been modelled using 'Duct Ground Heat Storage Model' (Hellström (1991)). The user can define ground thermal properties like thermal conductivity and heat capacity and also determine the main heat exchanger characteristics (depth, radius, number of boreholes, etc.). The parameters used in the simulation are shown in Table 4.1. In order to evaluate the ground thermal properties at GeoCool site, laboratory experiments on soil samples were performed. The fill thermal conductivity considered is the average value for wet sand. Also U-tube pipe parameters correspond to the properties of polyethylene pipes DN 32 mm PE 100.

Loads module represents the thermal loads that the air conditioning area is demanding. Normally, these thermal loads are estimated from the building characteristics, occupancies, weather data... obtaining an a priori prediction of the hourly thermal loads that the air conditioning area is demanding. To make a better comparison between the usual design procedure to predict the energy performance of the system and the experimental data measured, the simulation uses the experimental thermal loads measured in GeoCool plant along a whole cooling season and a whole heating season as input values.

\begin{tabular}{|l||l|}
\hline Borehole heat exchanger parameters & Value \\
\hline \hline Number of boreholes & 6 \\
Borehole depth & $50 \mathrm{~m}$ \\
Borehole radius & $0.120 \mathrm{~m}$ \\
Outer radius of u-tube pipe & $0.016 \mathrm{~m}$ \\
Inner radius of u-tube pipe & $0.0131 \mathrm{~m}$ \\
Center to center half distance & $0.035 \mathrm{~m}$ \\
Fill thermal conductivity & $2.0 \mathrm{~W} / \mathrm{m} \mathrm{K}$ \\
Pipe thermal conductivity & $0.42 \mathrm{~W} / \mathrm{m} \mathrm{K}$ \\
\hline Ground parameters & Value \\
\hline Undisturbed ground temperature & $291.15 \mathrm{~K}$ \\
Storage thermal conductivity & $1.43 \mathrm{~W} / \mathrm{m} \mathrm{K}$ \\
Storage Heat Capacity & $2400 \mathrm{~kJ} / \mathrm{m}^{3} / \mathrm{K}$ \\
\hline
\end{tabular}

Table 4.1. Description parameters of the ground and of the borehole heat exchanger. 
The TRNSYS model calculates the energy performance factors which are to be compared with the corresponding experimental values. The simulation program obtains this quantity following the same procedure outlined in section 3 to calculate the experimental value for the energy performance factor. The measured energy performances and the predicted ones are compared in figures 4.2.

In figures 4.2, the accumulated and daily energy performances for both seasons are depicted. In both cases dash-dotted lines correspond to the values obtained from the simulation and solid lines correspond to experimental measured values. The quantity shown in the vertical axis is the performance factor (PF) defined in equation (5), for the corresponding integration period. From these figures it can be seen that the simulation outputs overestimate the experimental measures by a percentage between $15 \%$ and $20 \%$. Taking into account these experimental uncertainties in principle it can be concluded that in most cases experimental values and simulation estimations are compatible. Nevertheless, the tendencies observed are very similar when comparing both curves, pointing to the fact that there may be systematic discrepancies. The main difference between both figures is a higher discrepancy between both values when the heating or cooling demand is very low (close to the dates in which the system changes operation from heating to cooling mode).
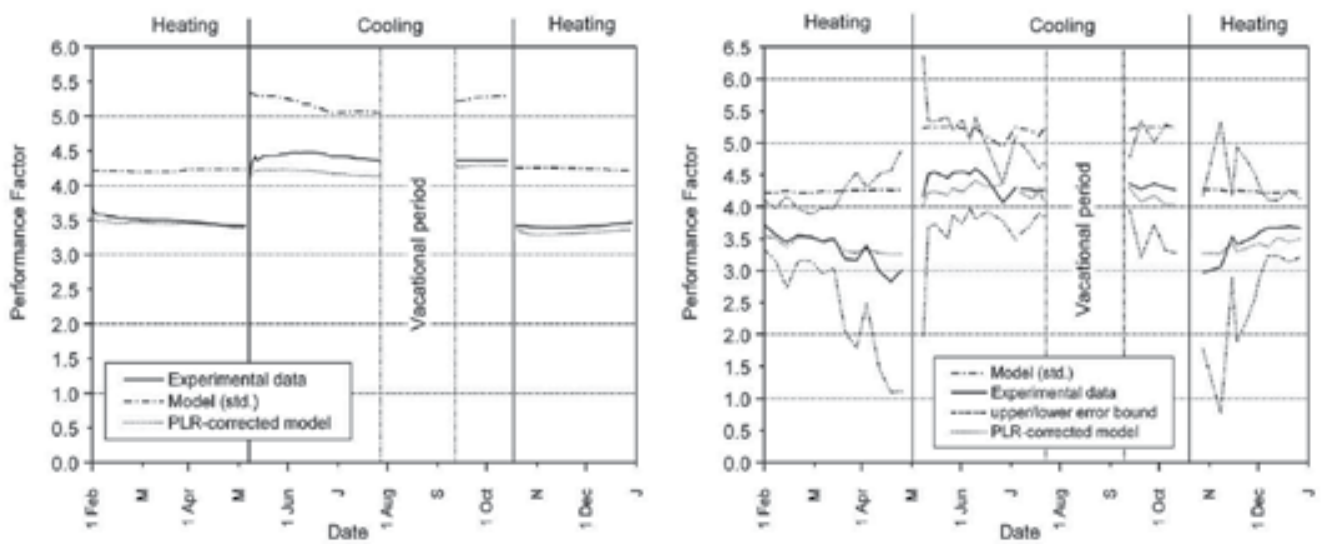

Fig. 4.2. On the left, comparison between experimental measurements (solid lines) and numerical predictions (dash-dotted lines and dotted lines) for the accumulated performance factor of GeoCool plant. On the right, comparison between experimental measurements (solid lines) and numerical predictions (dash-dotted lines and dotted lines) for the daily performance factor of GeoCool plant. Errors for the experimental values of daily performance factor are represented by the distance between the top dash-dot-dotted line and the bottom dash-dot-dotted line (upper/lower error bound).

The discrepancies between simulated and experimental data have been investigated with a sensitivity analysis of the energy performance simulation results to changes of its input parameter values. This analysis showed that the simulated energy performance results are rather insensitive to changes in the main ground parameters such as conductivity and diffusivity. Regarding the heat pump description, a high sensitivity of the simulated results to the heat pump nominal coefficient of performance is observed. The differences between experimental and simulated data could be explained as degradation of the heat pump performance for being used at partial load. ARI recommendations have been followed to 
make an estimation of the impact of heat pump performance degradation in the energy performance results, and an average degradation coefficient is estimated. Energy performances estimated for a time period are multiplied by the average degradation coefficient corresponding to the same period. Accumulated energy performances and daily energy performances have been corrected following this procedure. Dotted lines in figures 3.2 correspond to the accumulated energy performance values obtained from the simulation multiplied by the corresponding average degradation coefficient. With this correction included simulation results match very well with the tendencies described by the experimental measured values, being the differences between both always smaller than $3 \%$ for data belonging to the heating season and always smaller than $7 \%$ for data belonging to the cooling season.

\section{Optimization of Ground Coupled Heat Pumps systems}

In the standard design of an air conditioning system, the references taken to estimate the heating and cooling capacity of the heat pump to be installed are usually based on the coldest and the warmest day along the year. Therefore, the thermal energy required by the thermal load is under the design point of the air conditioning system during most part of the time. In this context, the development of strategies for the system based on the ground coupled heat pumps, allowing adapting the thermal energy generated by the system with the thermal load is a good way to improve the system energy efficiency while satisfying the thermal comfort.

In subsection 5.1 it is studied the efficiency improvements that a new management strategy can produce in a HVAC system composed by a ground coupled heat pump and a central fan coil linked to a standard office space (Pardo et al (2007), Pardo et al (2008) and Pardo et al (2009c) ). In this new management strategy, the air mass flow in the fan, the water mass flow in the internal and external hydraulic system and the set point temperature in the heat pump, usually fixed in conventional strategies, have the possibility of a continuous regulation that allows us to design a more efficient way to achieve the desired thermal comfort. This new management strategy is based on five capacity levels developed from the total electrical power equation of the HVAC system. In our particular case, this equation indicates that to achieve energy savings is desirable to work with low water flows. For this reason, the new management strategy tries to achieve a steady state in which the water mass flow is maintained as low as possible, using first all other possibilities to supply energy.

In subsection 5.2 the efficiency improvements which can be achieved by combining a ground coupled heat pump system with other HVAC system, such as an air to water heat pump is studied. In addition, the impact of incorporating a thermal storage device in an air conditioning system to decouple energy generation from energy distribution is investigated (Pardo et al (2009a), Pardo et al (2009b) and Pardo et al (2010)). This possibility produces two important advantages, it allows a size reduction of the heat pump, and diminishes the effects of the thermal load peaks generating thermal energy when the environmental conditions are more favourable. The purpose of this work is to evaluate the electrical energy consumption and the energy efficiency of several air conditioning layouts in a cooling dominated building, implementing both ideas together. The procedure to evaluate the energy efficiency of the designed HVAC system is as follows. First step in the procedure is the evaluation of the electrical energy consumptions of the air conditioning system when is driven by a pure air to water heat pump (AWHP) system or by a pure ground coupled heat 
pump (GCHP) system. These values are used as a reference for comparison with the consumptions of the implemented layouts. Then, we present an air conditioning configuration composed by a GCHP combined with an AWHP to study the behaviour of both systems working together. Afterwards, we combine a stratified water tank as thermal storage device with a GCHP or with an AWHP to study the behaviour when energy generation and distribution is decoupled. Finally, we present a hybrid configuration which combines both heat pumps and a stratified water tank and we evaluate the efficiency improvement of this combined alternative.

\subsection{Efficiency improvement from energy management}

An office space in a cooling dominated area is modelled to evaluate in these conditions the energy performance of the ground coupled heat pump HVAC system when it is managed by the new management strategy and by a conventional one. The thermal comfort criterion which has to be satisfied is the Predicted Mean Vote index (PMV). The annual electrical energy consumption of the HVAC system when it is managed by our new management strategy and by a conventional one are compared. For both systems, two aspects are fixed: the working period and the heating and cooling seasons. The working period in the office is fixed from 9:00 to 18:00, which is the period when is switched on the air conditioning system. The heating season is considered from November to December and from January to March and the cooling season from April to October.

The objective of the new management strategy is to improve the energy efficiency of the air conditioning system by adapting properly its generated energy to the actual thermal demand in the office. To maintain neutral comfort conditions in the office the PMV value should be zero in the Thermal Comfort Scale. The deviation of the PMV from zero indicates a variation of the thermal demand in the office area. Notice that, to satisfy this thermal demand, there are several configurations of the management variables which are suitable to compensate this PMV deviation. Our management strategy is based on the choice of a particular configuration of these variables. This choice classifies the air conditioning system capacity in five capacity levels given by the steady state value of the management variables. In figure 5.1, we show a diagram illustrating this classification. We now describe each capacity level.

- First capacity level; in steady state conditions the fan capacity is between the $0 \%$ and the $50 \%$ of its maximum capacity and the other devices are switched off. In this level the blown air by the fan modify the convective factor and homogenize the temperature in the office to achieve the thermal comfort.

- Second capacity level; the fan, the hydraulic pumps and the heat pump are switched on. In steady state conditions the air blown by the fan is fixed to the $50 \%$ of its maximum capacity, the water mass flows of the internal and external hydraulic pumps are between the $0 \%$ and the $10 \%$ of its maximum allowed value, and the set point temperature is $0 \%$, which indicates the lowest or highest set point temperature for heating or cooling mode respectively.

- Third capacity level; in steady state conditions the air blown by the fan is fixed to the $50 \%$ of its maximum capacity, the water mass flows of the internal and external hydraulic pumps are fixed to the $10 \%$ of its maximum allowed value and the set point temperature is between $0 \%$ and $100 \%$, meaning that the set point temperature can be any value of its range in heating or cooling mode. 
- $\quad$ Fourth capacity level; in steady state conditions the air blown by the fan is fixed to the $50 \%$ of its maximum capacity, the water mass flows of the internal and external hydraulic pumps are between the $10 \%$ and the $100 \%$ of its maximum allowed value and the set point temperature is $100 \%$ which indicates the highest or lowest set point temperature for heating or cooling mode respectively.

- $\quad$ Fifth capacity level; in steady state conditions the fan capacity is between the $50 \%$ and the $100 \%$ of its maximum capacity, the water mass flows of the internal and external hydraulic pumps are fixed to the $100 \%$ of its maximum allowed value and the set point temperature is $100 \%$.

If the energy supplied by the air conditioning system when all the active devices are given the $100 \%$ of its capacities is not enough to maintain the thermal comfort conditions, the PMV diverts from zero and the thermal demand is not satisfied.

The choice of these five capacity levels is based on a study of the system energy consumption as a function of the operational variables. The conclusion of this study was that to achieve energy savings is desirable to work with low water flows in the air conditioning system. For this reason, the new management strategy tries to achieve a steady state in which the water mass flow is maintained at the lower level that guarantees the production of enough thermal energy to satisfy the thermal demand. A suitable way to implement this new management strategy is through a cascade control structure because allows to quickly achieve the thermal comfort state and, after this, drive the management variables to the steady state of the capacity levels described before without comfort penalties.

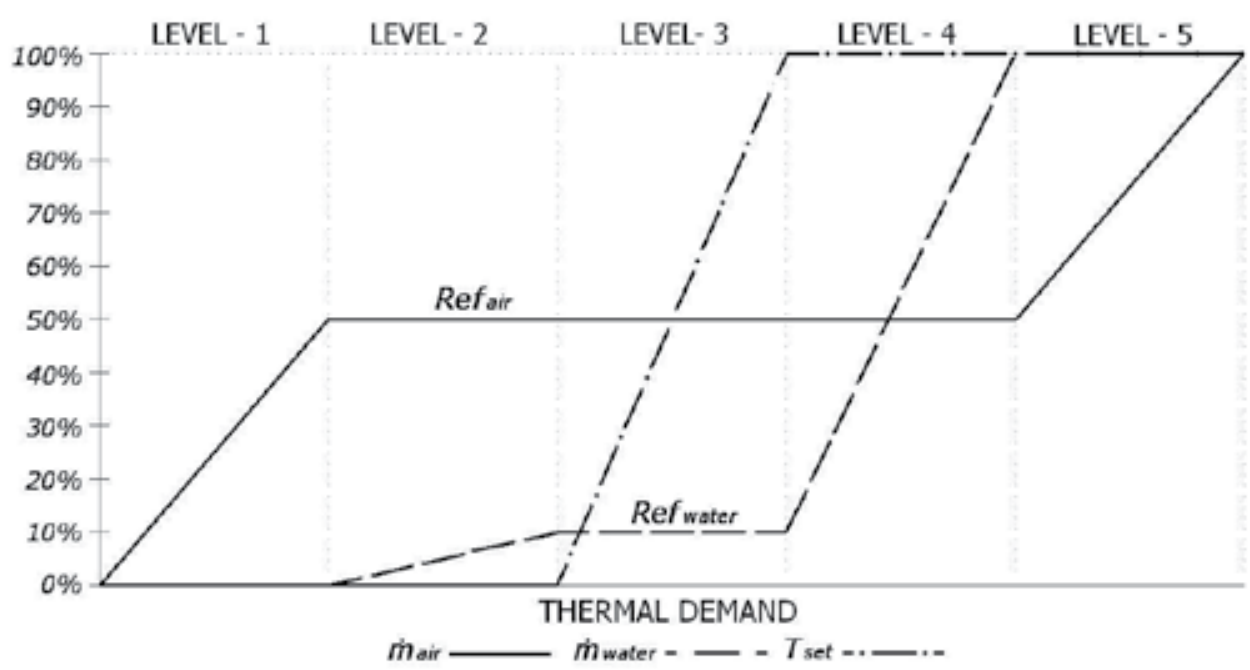

Fig. 5.1. Diagram illustrating the classification in capacity levels of the system capacity given by the steady state values of the management variables. For a given thermal demand there is a unique choice for the operational point of the air conditioning system.

The conventional strategy uses on/off regulators to manage the air conditioning system. This kind of regulators has only two possible operation points. They give its maximum capacity when switched on and nothing when switched off. The on/off regulators are installed in active elements: the heat pump, the electric motor of the fan coil and the internal 
and external water pumps. In this strategy, three aspects are important. First, the difference between the set point temperature and the inlet temperature of fluid in the heat pump from the office area indicates the connection or disconnection of the generator energy system, composed by the heat pump, the external water pump and the ground heat exchanger. Therefore, the internal water pump is always switched on to have a measure of this difference during the working period. Second, to maintain the comfort conditions, the PMV is located in a comfort band between 0.5 and -0.5 , in order to try to avoid an excessive number of connections and disconnections of the system which, in an actual situation, could damage the actuators of the fan coil. Finally, the set point temperature in the heat pump is constant, for the heating season is fixed to $45^{\circ} \mathrm{C}$ and for the cooling season to $7^{\circ} \mathrm{C}$.

In heating mode the conventional management strategy works as follows. When the value of the PMV variable is below the lower limit of the comfort band, PMV equal to -0.5, the electric motor of the fan is switched on. Then, the air goes through the coil, where a constant water mass flow is pumped from the internal circulation pump. This heat exchange produces a variation of the temperature of the water in the internal circuit which is detected by the heat pump; immediately this device and the external water pump are switched on to provide the necessary energy to fix the value of the PMV to the upper limit of the comfort band, PMV equal to 0.5. After achieving this value, the heat pump, the external water pump and the electric motor of the fan are switched off. In cooling mode the conventional management strategy is the same as the previous one except that the references of the comfort band are inverted. The electric motor of the fan is connected when the PMV is above the upper limit, PMV equal to 0.5 , and the air conditioning system stops supplying energy when the PMV arrives to -0.5 .

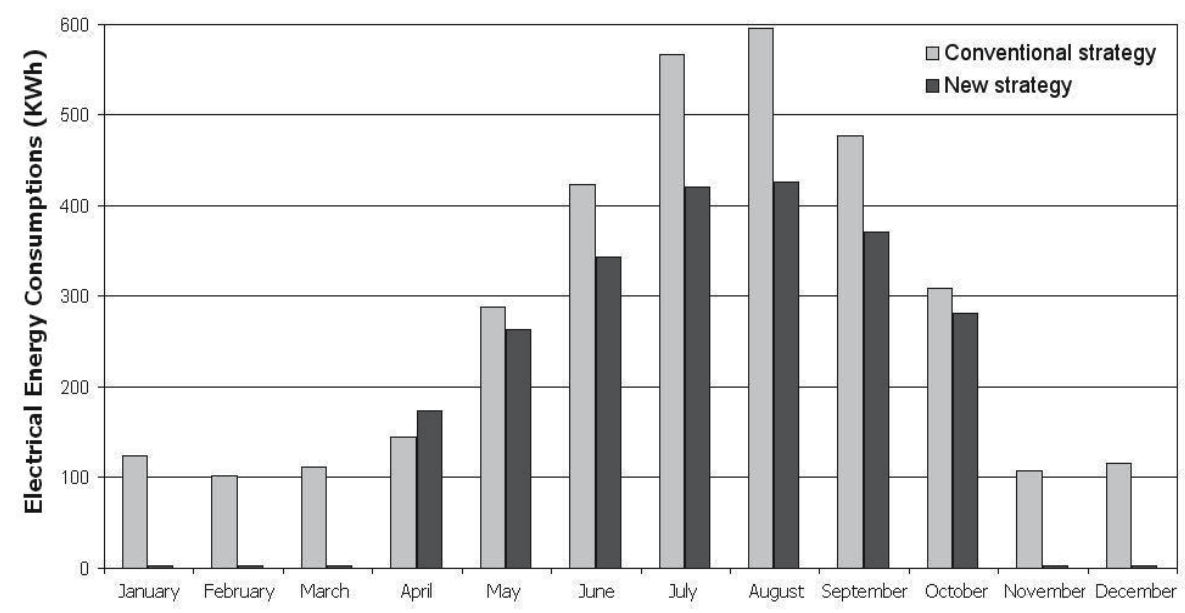

Fig. 5.2. Electrical energy consumptions for both management strategies.

The energy consumption of the air conditioning system for both management strategies are now presented. In the simulation conditions, the weather database employed models the Mediterranean coast weather, which is characterized to have hot summers and warm winters and the working period coincides when the external ambient temperature and the solar radiation is the highest throughout the day. The combination of these two factors 
produces that the energy demand in cooling mode is much higher than in heating mode. In figure 5.2 the monthly electrical energy consumptions of the air conditioning system for the two management strategies are presented. From this figure we can see that in all months, except April, the system consumes less electrical energy when it is managed by the new management strategy.

In winter season, our simulation results show that the influence of the external temperature and the solar radiation in the office area during the working period is enough to maintain the thermal comfort in it during most days of the winter season, therefore the energy provided by the air conditioning system is very low. A remarkable difference between both management strategies exists because the conventional strategy employs the temperature change of the water in the internal hydraulic circuit to communicate the energy demand in the office room to the generator system. As a consequence, the internal water pump is always switched on during the working time and, therefore, consuming electrical energy independently of the air conditioning necessities. Whereas, in the new management strategy, the air conditioning system only consumes electrical energy according with the thermal demand in the office area. Then, the unnecessary electrical consumptions, which can suppose a great energy loss throughout the year, are avoided.

In summer season, the influence of the external temperature and the solar radiation which were an advantage during the winter season are now a disadvantage. Therefore, both management strategies are more active to provide the necessary high cooling power to achieve the thermal comfort. In these conditions is when the new management strategy has more chances to manage the air conditioning system to reduce its electrical consumption. In figure 5.2, the electrical consumption for both strategies grows up in function of the cooling demand, being the maximum electrical consumptions during the warmest months, July and August. In all months during the cooling season, except April, the electrical consumptions of the air conditioning system when is employed the new one are significantly smaller than the ones achieved when using the conventional one. Furthermore, the new strategy improves the efficiency of the air conditioning system as the cooling demand increases.

In April, the electrical consumption of the air conditioning system is smaller when the conventional management strategy is used. This behaviour is because in the first day of this month the air conditioning system changes from heating mode to cooling mode. When the conventional management strategy manages the air conditioning system the value of the PMV index is between 0.0 and 0.5 most of the time belonging to the working periods. In these conditions, this strategy keeps switched off the fan, the heat pump and the external water pump. Meanwhile, the new strategy activates these three devices to supply energy to the office to compensate the small deviation of the PMV from the neutral thermal comfort state.

Finally, the annual electrical consumption of the air conditioning system when it is managed by the conventional management strategy is estimated in $3359 \mathrm{kWh}$, and in $2289 \mathrm{kWh}$ when managed by the new one. Then, the annual energy savings achieved are estimated in a value around the $30 \%$.

\subsection{Efficiency improvement of Ground Coupled Heat Pumps when combined with air source heat pump and thermal storage}

An office building, located in the Mediterranean coast area, is modelled to obtain a thermal load in order to evaluate in these conditions the energy performance of the air conditioning 
configurations to be studied. The thermal comfort criteria employed to obtain an estimation of the thermal loads demanded by the office building is the Predicted Mean Vote (PMV) index. This study is focused in the cooling dominated area of the Mediterranean coast. To estimate the thermal loads demanded by the office building it is considered that the heating season comprises the period from January to March and from November to December, and the cooling season the period from April to October. Daily load in heating or in cooling has to satisfy neutral thermal comfort conditions. The weather database employed describes an average season representing the Mediterranean coast weather for the city of Valencia (Spain).

The model of the office building adopted for this study is chosen to be representative of this kind of buildings in our area. It features three floors with a length of $30 \mathrm{~m}$, a width of $20 \mathrm{~m}$ and a height of $3 \mathrm{~m}$ with eight thermal zones per floor. External walls are defined as ventilated façades composed by four elements: perforated brick, $5 \mathrm{~cm}$ of insulation, air chamber and a Naturex plate cover; its global conductivity is $0.51 \mathrm{~W} / \mathrm{m}^{2} \mathrm{~K}$. The window fraction is approximately $22 \%$ in each façade; the windows are composed by a glass, with solar radiation transmissivity equal to 0.837 and conductivity equal to $5.74 \mathrm{~W} / \mathrm{m}^{2} \mathrm{~K}$, dedicating a $15 \%$ of this area to the frame surface with conductivity equal to $0.588 \mathrm{~W} / \mathrm{m}^{2} \mathrm{~K}$. The internal and external shadow factor for these windows is estimated at 0.7. Gains due to occupancy and lights are as follows. Peak building occupancy is $11 \mathrm{~m}^{2} /$ person. Each office worker contributes $132 \mathrm{~W}$ of internal gain, where $54 \%$ are assumed to be sensible and $46 \%$ latent. The working schedule starts at 7:00 and at 9:30 the occupancy arrives to its peak. The lunch time is from 13:00 to 15:00 in this period the occupancy decrease until a fifty per cent. Finally, people start to leave the office at 18:00 and the office is empty at 20:00. The light system is switched on at 7:00 in the morning and increases progressively until its peak at 8:00. The value of the peak lighting density is $20 \mathrm{~W} / \mathrm{m}^{2}$. This value is constant until 19:00; in this moment starts to decrease and all the lights are switched off at 20:00. Taking into account all these considerations, the daily loads in heating season and in cooling season are calculated.

The air conditioning configurations coupled to the above described office buildings are described in the following paragraphs.

- Air to water heat pump configuration ('Air'), composed by an AWHP, an internal water pump and an air fan. Thermal energy is generated and supplied by the air to water heat pump when it is demanded by the building.

- Ground coupled heat pump configuration ('GCHP'), composed by a water to water heat pump (WWHP), a ground heat exchanger and an internal and an external water pump. Thermal energy is generated and supplied by the ground coupled heat pump when it is demanded by the building.

- $\quad$ Ground coupled heat pump and air to water heat pump configuration ('GCHP + Air'). This configuration combines a GCHP and an AWHP. Thermal energy is generated and supplied to the thermal load by the GCHP and, if this element has not enough capacity to supply the demanded thermal energy, the AWHP is switched on and supplies thermal energy up to satisfy the thermal demand. The GCHP system is switched on first because its coefficient of performance is the higher of both.

- Air to water heat pump with thermal storage device configuration ('Air + S'). This configuration combines an AWHP system with a thermal storage device. A period in the night is dedicated to store thermal energy. This energy is generated by the AWHP 
system. The procedure to supply thermal energy to the load in cooling mode is as follows. The thermal demand is first satisfied by the thermal energy previously stored during the night. If the thermal storage device has not enough capacity, this element is supported by the AWHP until the thermal demand is covered. Finally, the thermal storage device is by-passed when its water outlet temperature is higher than its water inlet temperature. At these conditions only the AWHP supplies thermal energy to the load.

- Ground coupled heat pump with thermal storage device configuration ('GCHP + S'): This configuration combines a GCHP system with a thermal storage device. A period in the night is dedicated to store thermal energy. This energy is generated by the GCHP system.

- Hybrid configuration ('HC'): This configuration comprises a GCHP, an AWHP and a thermal storage device, implementing both ideas, combining two heat pumps and decoupling thermal generation from thermal distribution. The GCHP is used to store thermal energy during the night. The procedure to supply thermal energy to the load in cooling mode is as follows. The energy stored during the night in the storage device is used to satisfy the thermal demand. If the thermal storage device has not enough capacity, the GCHP is switched on to support it. If these two elements are still not enough, the air to water heat pump is switched on. Finally, the thermal storage device is by-passed when its water outlet temperature is higher than its water inlet temperature and only the GCHP and the AWHP supply thermal energy to the load.

The choice of the parameters for each air conditioning configuration considers the nominal coefficient of performance for the WWHP in cooling mode to be 4.5, and the nominal coefficient of performance for the AWHP in cooling mode to be 2.5. For the configuration design it is assumed that the thermal storage device supplies $40 \%$ of the thermal energy demanded by the load and that the water inlet temperature to the thermal load is fixed to the value $T=7^{\circ} \mathrm{C}$ (a typical distribution temperature for these type of systems). To estimate the size of the ground heat exchanger we use the method proposed in (Canada (2005)). The obtained length is normalized to boreholes of one hundred meters depth which are connected in parallel. We consider a ground thermal conductivity and a pipe thermal conductivity of $2 \mathrm{~W} / \mathrm{mK}$ and $0.42 \mathrm{~W} / \mathrm{mK}$ respectively and a borehole radius of $0.1016 \mathrm{~m}$.

\begin{tabular}{|l|cccccccccc|}
\hline & $\begin{array}{c}P_{\text {WWHP }} \\
(\mathrm{kW})\end{array}$ & $\begin{array}{c}\mathrm{P}_{\mathrm{AWHP}} \\
(\mathrm{Kw})\end{array}$ & $\begin{array}{c}\mathrm{P}_{\mathrm{AF}} \\
(\mathrm{Kw})\end{array}$ & $\begin{array}{c}\mathrm{m}_{\mathrm{AF}} \\
\left(\mathrm{m}^{3} / \mathrm{h}\right)\end{array}$ & $\begin{array}{c}\mathrm{P}_{\text {EWP }} \\
(\mathrm{Kw})\end{array}$ & $\begin{array}{c}\mathrm{m}_{\text {EWP }} \\
(\mathrm{Kg} / \mathrm{h})\end{array}$ & $\begin{array}{c}\mathrm{P}_{\text {IWP }} \\
(\mathrm{Kw})\end{array}$ & $\begin{array}{c}\mathrm{m}_{\text {IWP }} \\
(\mathrm{Kg} / \mathrm{h})\end{array}$ & $\begin{array}{c}\text { Number } \\
\text { Boreholes }\end{array}$ & $\begin{array}{c}\mathrm{TSD} \\
\left(\mathrm{m}^{3}\right)\end{array}$ \\
\hline Air & & 45.0 & 4.30 & 18000 & & & 1.70 & 9000 & & \\
GCHP & 45.0 & ------ & ------- & ------ & 0.85 & 9000 & 1.70 & 9000 & 13 & \\
GCHP+Air & 35.0 & 10.0 & 0.74 & 4100 & 0.76 & 7000 & 1.42 & 7000 & 12 & \\
Air+S & ------ & 35.0 & 3.27 & 14000 & ----- & ----- & 1.42 & 7000 & ----- & 40 \\
GCHP+S & 35.0 & ------ & ----- & ------ & 0.76 & 7000 & 1.42 & 7000 & 8 & 40 \\
HC & 24.6 & 9.0 & 0.65 & 3700 & 0.67 & 5000 & 1.14 & 5000 & 7 & 27 \\
\hline
\end{tabular}

Table 5.1. Parameters of the different devices for the air conditioning configurations.

Following these considerations and design procedures we have chosen the parameters for each air conditioning configuration. Table 5.1 shows the values of these parameters. For 
each configuration the nominal cooling capacity of the WWHP (PWWHP), the nominal cooling capacity of the AWHP (PAWHP), the air fan power consumption (PAF), the air volume flow (mAF), the external water pump power consumption (PEWP), the water mass flow in the external circuit (mEWP), the internal water pump power consumption (PIWP), the water mass flow in the internal circuit (mIWP), the number of boreholes and the size of the thermal storage device (TSD), are included. The values of the parameters presented in table 5.1 have been chosen after performing a study of the efficiency of the combined system for different capacities of the heat pumps and for different sizes of the thermal storage device. The most efficient configurations are the ones presented in table 5.1.

In figure 5.3 the total electrical energy consumption of each air conditioning layout during cooling season evaluated using TRNSYS software tool is presented. The total electrical energy consumption is composed by three parts: the electrical energy consumption of the heat pumps (AWHP and WWHP), the electrical energy consumption of the water pumps (IWP and EWP) and the electrical energy consumption of the air fan (AF). We evaluate the energy efficiency for each layout with the Cooling Mode Performance Factor, CMPF, defined as the ratio between the total cooling thermal load and the total electrical energy consumption in cooling mode:

$$
\text { CMPF }=\frac{Q_{\text {load }, \text { cool }}}{W_{\text {elec }, \text { cool }}}
$$

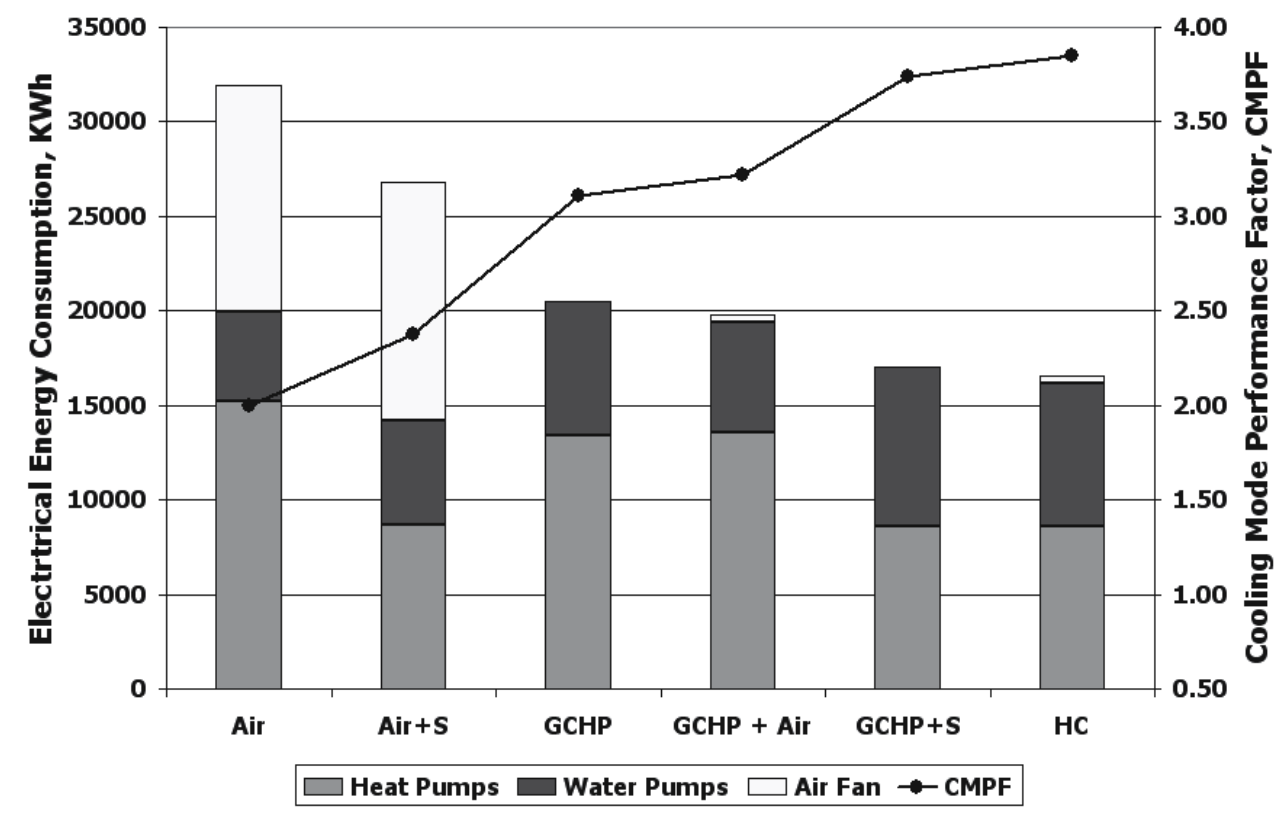

Fig. 5.3. Total electrical energy consumption in cooling mode and Cooling Mode Performance Factor (CMPF) for the air conditioning configurations.

Looking at figure 5.3 we observe the following behaviour of the studied layouts:

- Combination of both heat pumps ('GCHP+Air' configuration). In figure 5.3 it can be seen that the 'GCHP + Air' configuration is more efficient than the sole ground source 
system 'GCHP' because the electrical energy savings achieved by reducing the sizes of the water to water heat pump and water pumps are higher than the electrical energy consumption of the auxiliary system.

- One heat pump and thermal storage ('GCHP+S'or 'Air+S' configuration). An improvement in efficiency is produced in all air conditioning configurations which store cooled water during the night. In these configurations the electrical energy consumption of the heat pumps is reduced in spite of the increase in the electrical energy consumption of the air fan and the water pumps.

- $\quad$ Both heat pumps and thermal storage ('HC' configuration). This layout is the one that takes most advantage of the combination of both heat pumps and the decoupling of energy generation from energy distribution.

\section{Conclusion}

This contribution collects the recent research work of the authors on the subject of design, characterization and optimization of ground coupled heat pump systems. On the area of determining ground thermal properties, the effect of finite size corrections on the evaluation of ground thermal conductivity has been studied on a data set obtained from a standard thermal response test, and a method of subtraction of the influence of outside perturbations has been developed. In addition, an instrument able to measure the temperature evolution of the fluid along its way through the borehole heat exchanger has been designed.

The energy efficiency of an air conditioning system based on ground coupled heat exchangers (GeoCool plant) has been compared to a conventional air source system in heating and cooling modes. The obtained results have demonstrated that a ground source heat pump system is a viable and energy efficient alternative to conventional systems for heating and cooling applications in the South European regions. Predictions of energy performances based in standard design procedures based in TRNSYS have been compared with the actual performances of GeoCool plant. This comparison has allowed to estimate the accuracy of this design procedure.

A new management strategy for the operation of a ground coupled heat pump system has been designed and tested by means of TRNSYS simulation. The conclusion achieved was that management strategies able to adapt the production of thermal energy to the actual thermal demand can produce substantial energy savings (of the order of $30 \%$ in our study). Finally, the energy efficiency improvement of ground coupled heat pump systems when combined with thermal storage and supported by an air to water heat pump has been investigated. The obtained results showed that decoupling thermal energy production from thermal energy distribution, by means of a storage element, and properly combining a ground coupled heat pump with an air to water heat pump, are possible ways to reduce the electrical energy consumption of the system.

\section{Acknowledgements}

This work has been supported by the Spanish Government under projects "Modelado y simulación de sistemas energéticos complejos" (2005 Ramón y Cajal program), "Modelado, simulación y validación experimental de la transferencia de calor en el entorno de la edificación" (ENE2008-00599/CON). 


\section{References}

Bandos, T., Montero, Á., González-Santander, J.L., Isidro, J.M., Fernández, E., Pérez, J., Fernández de Córdoba, P. \& Urchueguía, J.F. (2008a). Geothermal vertical effects in thermal response tests, Proceedings of the XXXIII Workshop Geothermal Reservoir Engineering, pp. 184-191, Stanford (California, USA), January 2008, Stanford University.

Bandos, T., Montero, Á, González-Santander, J.L., Isidro, J.M., Fernández, E., Pérez, J., Fernández de Córdoba, P. \& Urchueguía, J.F. (2008b). Analytical studies of geothermal vertical effects in thermal response tests. Proceedings of the 5 th European Thermal-Sciences Conference, (Eindhoven; 2008).

Bandos, T., Montero, Á., Fernández, E., González-Santander, J.L., Isidro, J.M., Pérez, J., Fernández de Córdoba, P. \& Urchueguía, J.F. (2009a). Finite line source for borehole heat exchangers: effect of vertical temperature variations. Geothermics 38 (2009) 263270.

Bandos, T., Montero, Á., Fernández, E., Reig, A. \& Urchueguía, J.F. (2009b). Improvement in the estimating of ground thermal properties from geothermal response tests. Proceedings of the 11th International Conference on Thermal Energy Storage (Stockholm; 2009).

Bandos, T., Montero, Á., Fernández, E., Reig, A. \& Urchueguía, J.F. (2009c). Effect of finite depth of borehole heat exchanger on the estimate of ground thermal conductivity from field data obtained in conditions of atmospheric influence. Proceedings of the International Conference Engineering, Technologies and Systems, Journal of the Technical University at Plovdiv, "Fundamental Sciences and Applications", Vol. 14 (2009) 575-580.

Bandos, T., Montero, Á., Fernández de Córdoba, P. \& Urchueguía, J.F. (2009d). Improving of Parameter Estimates Obtained from the Thermal Response Tests. Proceedings of the First International Conference on Computational Methods for Thermal Problems (Napoles; 2009).

Canada (2005). Ground-source heat pump project analysis, in: Clean Energy Project Analysis, CANMET Energy Technology Centre - Varennes (CTEC), Minister of Natural Resource Canada 2001-2005.

GeoCool (2006). GeoCool project (EU 5th Framework Programme, NNE5-2001-00847). Publishable version of the Final Report: http://www.geocool.net/ project/results/Publishable-Final-Report.pdf.

Hellström, G., Thermal Analysis of Duct Storage System. Dep. of Mathematical Physics, University of Lund, Lund, Sweden, 1991, 262 pp.

Magraner, T., Montero, Á., Quilis, S. \& Urchueguía, J.F. (2009). Comparison between simulation and experimental results for the energy performance of GeoCool geothermal experimental plant. Proceedings of the 11th International Conference on Thermal Energy Storage (Stockholm; 2009).

Magraner, T., Montero, Á., Quilis, S. \& Urchueguía, J.F. (2010a). Comparison between simulation and experimental results for a monitored ground coupled heat pump system. Proceedings of the World Geothermal Congress (Bali, 2010).

Magraner, T., Montero, Á., Quilis, S. \& Urchueguía, J.F. (2010b). Comparison between design and actual energy performance of a HVAC-Ground Coupled Heat Pump 
system in heating and cooling operation. Energy and Buildings (2010), doi: 10.1016/j.enbuild.2010.03.008.

Martos, J., Torres, J., Soret, J. \& Montero, Á. (2008). Wireless sensor network for measuring thermal properties of borehole heat exchangers. Proceedings of the IEEE International Conference on Sustainable Energy Technologies (Singapore; 2008).

Martos, J., Torres, J., Soret, J. \& Montero, Á. (2009). New miniaturized wireless instrument to characterize thermal properties of borehole heat exchangers. Proceedings of the 11th International Conference on Thermal Energy Storage (Stockholm; 2009).

Martos, J., Montero, Á., Torres, J. \& Soret, J. (2010a). Application of a New Wireless Instrument to Characterize Thermal Properties of Ground Coupled Heat Exchangers. Proceedings of the IFAC Conference on Control Methodologies and Technology for Energy Efficiency (Vilamoura; 2010).

Martos, J., Montero, Á., Torres, J., Soret, J. \& Martínez, G. (2010b). Design and test of a new instrument to characterize borehole heat exchangers. Proceedings of the ASME-ATIUIT Conference on Thermal Environmental Issues in Energy Systems (Sorrento; 2010)

Martos, J., Montero, Á., Torres, J. \& Soret, J. (2010c). Wireless sensor network for monitoring thermal evolution of the fluid traveling inside ground heat exchangers, In: Wireless sensor networks. IntechWeb Ed. (2010), ISBN: 978-3-902613-49-3.

Pardo, N., Martos, J., Sala, A., Montero, Á. \& Urchueguía, J.F. (2007). Energy control system for a HVAC with a geothermal heat pump applied to an office building in the Mediterranean area. Proceedings of the 4 th Mediterranean Congress of HVAC Engineering (Genova; 2007).

Pardo, N., Sala, A., Montero, Á., Urchueguía, J.F. \& Martos, J. (2008). Advanced Control Structures for a HVAC with a Geothermal Heat Pump Applied to an Office Building in the Mediterranean Area. Proceedings of the 17th IFAC world congress (Seul; 2008).

Pardo, N., Montero, Á., Martos, J. \& Urchueguía, J.F. (2009a). Efficiency Study of a Ground Coupled Heat Pump combined with an Air Source Heat Pump and Storage. Proceedings of the 5th Mediterranean Congress of HVAC Engineering (Lisboa; 2009).

Pardo, N., Montero, Á., Martos, J. \& Urchueguía, J.F. (2009b). Energy efficiency study of a hybrid ground coupled heat pump system in several layout combinations. Proceedings of the 11th International Conference on Thermal Energy Storage (Stockholm; 2009).

Pardo, N., Montero, Á., Sala, A., Martos, J. \& Urchueguía, J.F. (2009c). Management strategy for improving the energy efficiency of a ground coupled HVAC system. Proceedings of the 11th International Building Performance Simulation Association Conference (Glasgow; 2009).

Pardo, N., Montero, Á., Martos, J. \& Urchueguía, J.F. (2010). Optimization of hybrid ground coupled and air source - heat pumps in combination with thermal storage. Applied Thermal Engineering 30 (2010) 1073-1077.

Signorelli, S., Bassetti, S., Pahud, D. \& Kohl, T., Numerical evaluation of thermal response tests, Geothermics 36 (2007) 141-166.

Urchueguía, J.F., Zacarés, M., Montero, Á. \& Martos, J. (2006). Experimental comparative analysis of a ground-coupled heat pump system versus a conventional air-to-water 
heat pump in typical conditions of the European Mediterranean coast. Proceedings of the 3rd Mediterranean Congress of HVAC Engineering (Lyon; 2006).

Urchueguía, J.F., Zacarés, M., Corberán, J.C., Montero, Á., Martos, J. \& Witte, H. (2008). Comparison between the energy performance of a geothermal heat pump system and an air to water heat pump system for heating and cooling in typical conditions of the European Mediterranean coast. Energy Conversion and Management 49 (2008) 2917-2923.

Witte, H. J. L., van Gelder, G. J. \& Spitler, J.D., In Situ measurement of ground thermal conductivity: a Dutch perspective. ASHRAE Transactions 108, 2002, pp.1-10. 


\title{
Development of a Boiler for Small Straw Bales Combustion
}

\author{
Branislav Repic, Dragoljub Dakic, Dejan Djurovic and Aleksandar Eric \\ University of Belgrade, Vinca Institute of Nuclear Sciences
}

Serbia

\section{Introduction}

In terms of sustainable energy development in Serbia, as well as in the whole world, there is a growing need for using the alternative energy sources. Alternative energy sources are, in most cases, renewable: biomass, wind power, solar energy, hydro-power and geothermal energy. A need for the utilization of this kind of energy sources is dictated by the market, on one side, as well as by environmental protection, on the other. Prices of fossil fuels grow proportionally to the decreasing of fossil fuel reserves. Since available reserves of fossil fuels in Serbia, especially those of high quality, are relatively limited, this problem becomes even more emphasized. On the other hand, it is necessary to harmonize the energy production legislation and practice in Serbia with the directives of the European Union, in the sense of intensifying the utilization of renewable energy sources and thus reducing pollution and greenhouse effect formation.

Biomass is one of key renewable energy sources (van Dam et al., 2007). This is the reason for the development of cheap thermal devices (boilers and furnaces) burning biomass from agricultural production, as quite available and cheap energy source. These devices could be used primarily in villages, small towns and small businesses processing agricultural goods (greenhouses, dairy farms, slaughterhouses, etc.). The devices could also find use heating schools, hospitals and other institutions.

Boilers and furnaces should utilize baled biomass which has not been adequately used and should have complete combustion control. The most favorable combustion organization for this type of devices is based on the principles of burning of a cigarette. The development of these devices should be simultaneous with the solving of the problem of low ash melting temperature and damaging of boiler metal parts and walls. At the same time, environmental aspect of combustion should be kept in mind.

\section{Basic potentials and characteristics of biomass}

Serbia has ample biomass energy resources, consequently in the total energy balance of the country biomass represents a true energy potential. Usually, biomass is divided into forest and agricultural types. In table 1, the estimate of biomass potential of Serbia is shown (Ilic at al., 2003). Biomass from agricultural production represents about $60 \%$ of this potential.

The potential role that agricultural biomass could play in meeting Serbian energy consumption, can be overviewed by comparing its energy potential to the potential of the 
coal consumed for the production of electricity in the utilities of the Electric Power Industry of Serbia (EPS), shown in table 2. Some basic data on physical characteristics of various types of biomass are given in table 3 (Oka, 1992). It can be seen that the ranges are quite huge for some values, for example for heating value.

\begin{tabular}{|c|l|c|}
\hline No & Biomass residues & TJ/year \\
\hline 1 & Forest & 43000 \\
\hline 2 & Agriculture & 65076 \\
\hline 2.1 & Grain growing & 40000 \\
\hline 2.2 & Fruit and grapevine production & 25000 \\
\hline 2.3 & Cattle breeding & 76 \\
\hline & Total & 108076 \\
\hline
\end{tabular}

Table 1. Energy potential of biomass in Serbia

\begin{tabular}{|c|l|c|c|}
\hline No & \multicolumn{1}{|c|}{ Type of coal } & $\begin{array}{c}\text { Consumption } \\
(\mathrm{t} / \text { year })\end{array}$ & $\begin{array}{c}\text { Energy } \\
\text { potential } \\
(\mathrm{TJ} / \text { year })\end{array}$ \\
\hline 1 & $\begin{array}{l}\text { Lignites (Obrenovac and Kostolac thermal } \\
\text { power stations) }\end{array}$ & 35000000 & 248000 \\
\hline 2 & $\begin{array}{l}\text { Higher quality coals (underground } \\
\text { exploitation) }\end{array}$ & 624000 & 10700 \\
\hline & Total & & 258700 \\
\hline
\end{tabular}

Table 2. The consumption of coal used for electricity production in Serbia

Although biomass is close to local lignite, considering the heating value, relatively low energy density has a great influence on transport, storage space, and fuel feeding equipment costs. Moisture content influences biomass combustion behaviour, causing different adiabatic combustion temperature and volume of gaseous products. In the case of higher moisture the drying process is longer, so volatiles releasing and char combustion are delayed, requiring larger furnace space.

In the process of production of various agricultural crops produced biomass that remains in some kind of residues are up to three times the amount produced culture. These residues can be baled, so today in Serbia producers of baled biomass are mainly farmers who receive baled biomass in the form of a by-product along the main product. In practice there are two

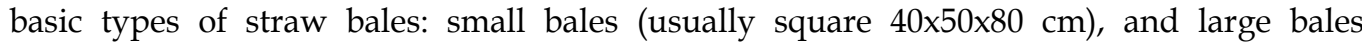

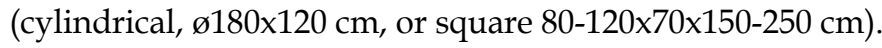

Advantages and disadvantages of some forms of bales are reflected in the following. Small conventional bales have a number of advantages: low cost presses, binders moderate price, the need for a smaller tractor, good storage, a favourable agreement on the means of transport, easy disintegration and fragmentation means lower prices, the possibility of firing whole bales and others. Disadvantages are: manual manipulation, usually by hand using storage aids, relatively high consumption of binders, and lower reliability than other presses. 


\begin{tabular}{|l|l|}
\hline Characteristic & Range \\
\hline Heating value & $5-20 \mathrm{MJ} / \mathrm{kg}$, depending on moisture \\
\hline Density & $400-900 \mathrm{~kg} / \mathrm{m}^{3}$ \\
\hline Heating value per $\mathrm{m}^{3}$ & $700-12000 \mathrm{~kJ} / \mathrm{m}^{3}$ \\
\hline Moisture content & $8-50 \%$ \\
\hline Ash content & $1-10 \%$ \\
\hline Volatile content & $50-70 \%$ \\
\hline Ash sintering temperature & $800-1100^{\circ} \mathrm{C}$ \\
\hline
\end{tabular}

Table 3. Values of physical characteristics for various kinds of biomass

Baled biomass can be used in cattle breeding, as food supplement, or stall cover. There are few boilers and furnaces burning baled biomass at the moment in Serbia, and their technical level could be considered as low (Martinov et al., 2006). Most of the straw is reverted to the fields, burned and ploughed. Although this treatment of biomass residue is unacceptable, it is widespread, because there are no adequate sanctions. The main reason for avoiding straw baling and using it as fuel is that there is no organized market and no sufficient number of users. Additionally, low ash melting temperature causes problems during biomass combustion.

There is a keen interest of agricultural producers in utilizing biomass residues, in order to use it at their own farms, or to find a market for it. It is anticipated that if baled biomass were used close to its source and the problems mentioned above were solved, it would become the most prospective alternative fuel in Serbia. It is perceived that intensive utilization of this kind of biomass would streamline agricultural production, because energy originating from biomass could be used for improving agricultural technologies. At the present level of the market, technology and prices, it is estimated that utilities with direct biomass combustion would be the most efficient.

\subsection{General characteristics of biomass}

Biomass fuel is a very good quality but with specific characteristics that make it different from fossil fuel and cause a variety of ways of its use. There is a big difference in the characteristics of biomass from the viewpoint of the benefits of its application in practice. Burning biomass from the standpoint of convenience, or applications, can be divided into two main groups, namely: a) forest biomass b) biomass from agricultural production. The main difference between these two types of biomass is in the ash characteristics or ash melting temperatures (sintering (shrinkage) temperature, deformation temperature, hemisphere temperature and the flow temperature).

Sintering temperature is very important for the process of biomass combustion. It is the temperature at which ash shows preference for the start gluing. If any fuel is used in installations where drainage of liquid slag is missing, sintering temperature can not be exceeded in the furnace.

Unfavourable circumstance for the application of biomass from agricultural production is that the ashes of that biomass usually has a strong tendency to sticking, and sintering temperature of ash from agricultural biomass production is much lower than the sintering temperature of ash from forest biomass. This phenomenon is not accidental but it is a result 
of application of fertilizers in the cultivation of agricultural crops. The application of fertilizers involves increasing the concentration of the contents of potassium $(\mathrm{Ka})$ in the mineral part of plant (ash). On the other hand, the basic mineral content of plants, or one of the main components, is the $\mathrm{SiO} 2$ silicon dioxide - quartz sand. $\mathrm{SiO}_{2}$ melting temperature is $1400-1500^{\circ} \mathrm{C}$, but with the addition of potassium or sodium the temperature can drop below the $800^{\circ} \mathrm{C}$. Described phenomena are also the cause of the pronounced tendency toward gluing the ashes of biomass from agricultural production.

In addition to the fibrous structure of biomass it is very difficult to cut and prepare it for the mechanized and controlled heating. When it comes to mechanized and controlled heating usually refers to the fragmented biomass burning or combustion of briquettes or pellets that are made of fragmented biomass. With all this before mentioned, biomass also must be dried if the humidity exceeds its limits, and usually exceed. So the classical system implementation of biomass from agricultural production had to be applied: drying, chopper, grinder, briquette (pellet), and a special system for fuel dosage or insufflations. Primarily from the energy point of view, and also from an economic, which are not negligible, it reduces the effects of use biomass from agricultural production. Applied technical solutions must meet all required environmental aspects.

\section{Biomass combustion technologies}

The main problems that occur when burning straw that is biomass from agricultural production are related to (Strehler, 2005): the quality of combustion, combustion efficiency, workload plants, the cost of equipment, applied materials (thermal and chemical stability of the material). Although the straw is widespread fuel it is used negligible compared to other types of biomass. The main reasons for this are the problems caused by physical and chemical characteristics of the straw. Also, the energy density of straw is low so it is not economical to transport it to greater distance, which limits the possibility of securing large quantities of straw in the boilers of greater powers.

For the combustion of straw can be used all developed technologies that are used for solid fuel. One of the main criteria for the selection of combustion technology is the size of plant that is built so that they can distinguish between small plants with thermal power of $15 \mathrm{kWt}$, the average thermal power plants up to $1 \mathrm{MWt}$ power and industrial plants over $1 \mathrm{MWt}$.

Small furnaces (boilers) are used in the household sector for heating water and rooms up to $15 \mathrm{KWt}$. Plants of up to $1 \mathrm{MWt}$ are used for commercial purposes. These are furnaces (boilers) that burn biomass in baled form or another, and where the products of combustion discharge into the environment via the chimney. Thermal power plants over $1 \mathrm{MWt}$ is used for heating, heat or steam production that is used in a technological process or the combined plant for the production of heat and electricity.

The technology for optimal utilization of biomass is determined by biomass characteristics. Reported technologies of biomass conversion are (Obernberger, 1998): fixed bed combustion, combustion on a grate, fluidized bed combustion and, finally, gasification. All these technologies are described in detail in the literature (Merick, 1984), and have their pros and cons. The basic advantages of these technologies are in the fact that they can be used for various types of fossil fuels, and that there is an extensive range of producers (including local ones) of utilities of this kind, etc. The main disadvantages are short life, inflexibility and lack of proved combustion technologies for agricultural biomass. Apart from being used as primary fuel, biomass is often used in co-combustion with fossil fuels, even in large- 
scale utilities (thermal power plants for instance), and experiences with this kind of biomass utilization are reported and described in detail (Leckner, 2007).

Whereas forest biomass utilization is quite simple, the use of agricultural biomass for energy production faces quite a lot of difficulties (Zabanitou et al., 2007). One of the most disadvantageous is that its ash has an excessive inclination towards melting, and problems with slagging and fouling in biomass-fired facilities are present even in case of cocombustion (Tortosa et al., 2003). Low ash sintering temperature is caused by using the chemical fertilizers during plant growth. On the other side, fibrous structure of biomass affects its grinding and preparation in the forms of pellets and briquettes. This leads to conclusion that agricultural biomass should be combusted as collected from the fields - in baled form.

Technologies recommended for various type of the biomass combustion for the heating purposes is presented in table 4. Cigar burner combustion system of baled biomass has also been recognized by the European Union as the most suitable method to be utilized for burning baled agricultural residue (Kavalov \& Peteves, 2004). For straw combustion cigar burner technology is very appropriate and without any reserves (Mladenovic et al., 2009).

\begin{tabular}{|l|c|c|c|c|c|c|}
\hline Technology & Wood & $\begin{array}{c}\text { Wood } \\
\text { chips }\end{array}$ & $\begin{array}{c}\text { Wood } \\
\text { powder }\end{array}$ & Pellets & Briquetess & Straw \\
\hline 1. Open fireplace & 0 & - & - & - & 0 & - \\
\hline 2. Manual stove & + & - & - & - & + & - \\
\hline 3. Automatic burner & -- & + & - & ++ & -- & + \\
\hline 4. Batch combustion & 0 & -- & -- & -- & - & + \\
\hline 5. Fixed inclined grate & -- & + & - & + & - & - \\
\hline 6. Travelling grate & -- & ++ & - & ++ & - & + \\
\hline 7. Vibrating grate & -- & + & - & + & - & + \\
\hline 8. Underfeed stoker & -- & + & - & + & -- & - \\
\hline 9. Dust burner & -- & -- & + & -- & -- & - \\
\hline 10. Cigar burner & -- & -- & -- & -- & -- & ++ \\
\hline
\end{tabular}

Legend: (- -) Not possible; (-) Not appropriate; (0) The penalties are compensated to a given extent by the advantages; $(+)$ Appropriate; $(++)$ Very appropriate

Combustion systems (1-3) are suitable for small-scale applications, while combustion systems (4-10) are appropriate for large-scale facilities.

Table 4. Biomass for the heating purposes

\section{The boiler burning baled biomass}

The experimental boiler burning small soybean, corn or wheat straw bales, with $0.8 \times 0.5 \times 0.4$ $\mathrm{m}$ in size, has been designed and built (Djurovic et al., 2008). The combustion has been organized on the principles of cigarette burning (Kraus, 1985). In Fig. 1, the scheme of the experimental boiler is shown (Repic et al., 2008a). Baled straw is introduced through the inlet (1) into the combustion zone (7). The inlet is supplied by cover (2) to prevent air suction and provide stable combustion conditions (Fig. 2). Furnace walls (4) have been made of 
refractory material - chamotte, with thermal insulation (5). In the combustion zone a mobile chamotte plate (6) has been placed, serving as combustion (air amount) regulator.

The primary and secondary air flows (divided by a screen) are supplied through the mesh (10), which is also used for positioning the bale in the combustion zone. The tertiary air is supplied through the inlet (12), and is previously heated by flowing inside the walls (13). In the zone (14) is carried out the process of final combustion of the bale. The heat produced by combustion of biomass is transferred by the gas-to-water heat exchanger (15). After passing through the channels (16) to the flue gases collector (17), the flue gases leave the boiler through the smokestack (18), equipped with the flap (19), and through the cyclone-type particle precipitator (Fig. 3). Ash is collected in ash collectors (20, 21, and 22). A mobile tube for ash removal (23) has been placed inside the furnace, as well as a tube for pneumatic transport of ash (24). The boiler has a revision opening (25) for manual ash removal.

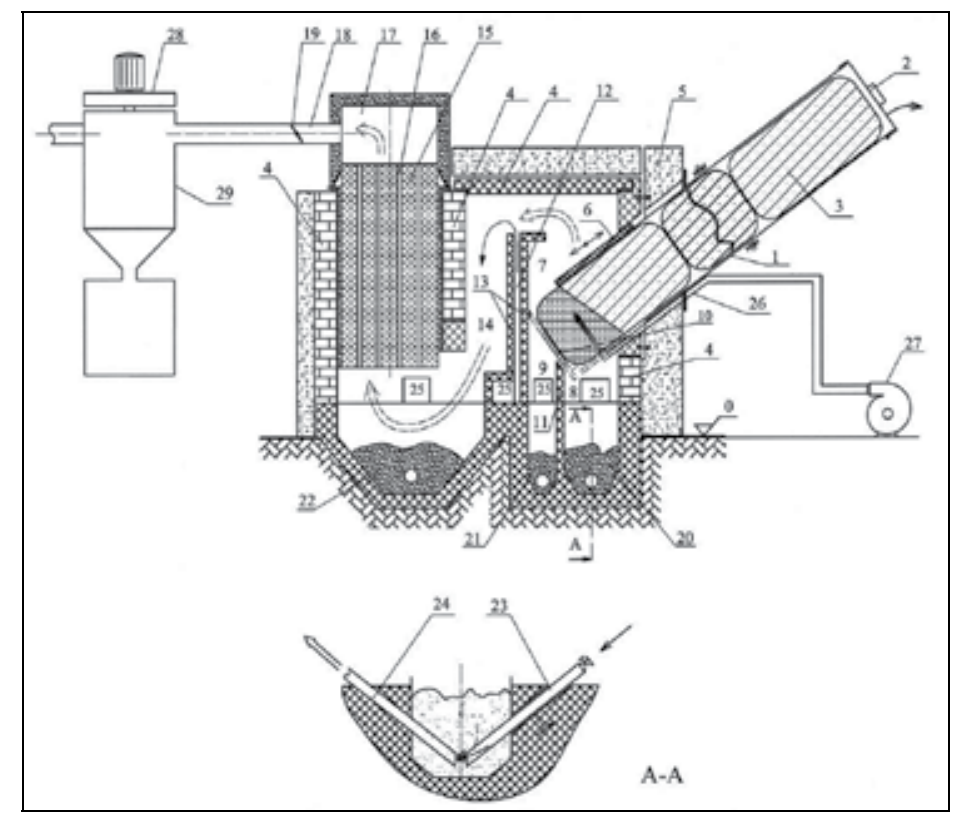

Fig. 1. The scheme of the experimental boiler. 1. fuel feeding, 2-cover, 3-baled biomass, 4insulation, 5-heat insulation, 6-regulation of combustion zone, 7-combustion zone, 8primary air supply, 9-secondary air supply, 10-grate, 11-compartment between primary and secondary air, 12-tertiary air introduction, 13-tertiary air channels, 14-burnout zone, 15-heat exchanger, 16-flue gas channel, 17-flue gases collector, 18-smokestack, 19-flap, 20,21,22-ash collector, 23-air tube for ash removal, 24-ash removal tube, 25-revision opening, 26-air distributor, 27-air fan, 28-flue gases fan, 29-cyclone separator with bunker.

After the first examination of the boiler some changes were carried out in the distribution of air (Repic et al., 2008b, Djurovic et al., 2009), so that after this change the air for combustion is inserted into the space through the distributor (26) which is connected to a fan of fresh air (27). By changing the position of the air distributor (Fig. 2) can be regulated the part of the bale involved in combustion and thus indirectly is regulated the heat output of the boiler. Also, a several types of biomass feedings were made: shorten (Fig. 2), inclined (Fig. 4) and horizontal (Fig. 5). 
In order to obtain to plant work at nominal power, heat accumulator (thermal reservoir, with volume of $5 \mathrm{~m}^{3}$ ) has been installed (Fig. 6). In this way it is ensured that no matter what the current needs for heating buildings, boiler always works with the nominal power (Mladenovic et al., 2008). The transitional periods (spring, autumn), for example, the need for heating usually amount to $20-40 \%$ rated power boiler, which would mean a much lower level of utility plant. Thermal scheme of distribution facilities is shown in Fig. 7. For it can be seen following thermal circles: a) Hot water from the boiler goes directly into a building that is heated, b) Hot water from the boiler goes into heat only tank, c) Hot water from the boiler going at the same time in the building and heat reservoir, d) Hot water tank from the heat goes into the building. Also, the boiler is equipped with appropriate management and control system (Figs. 2 and 3).

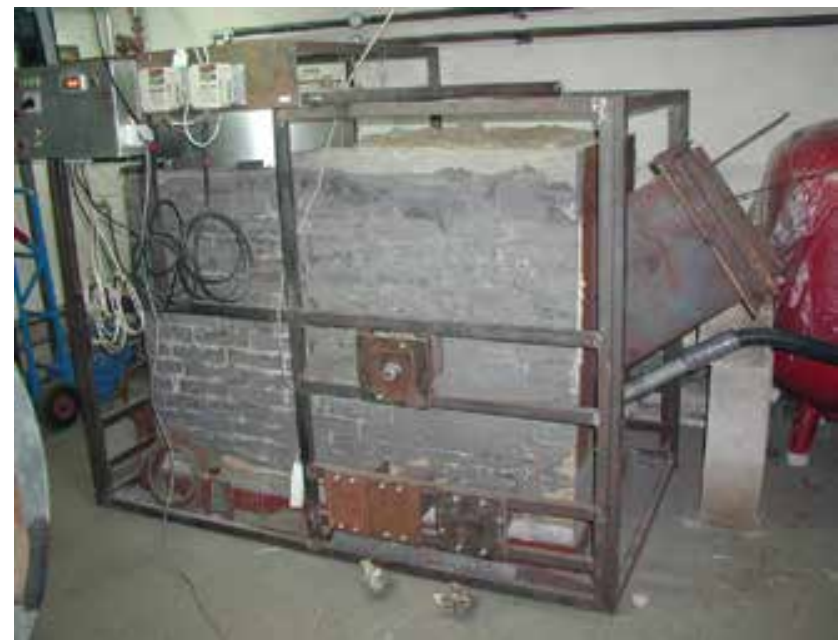

Fig. 2. The picture of the experimental boiler

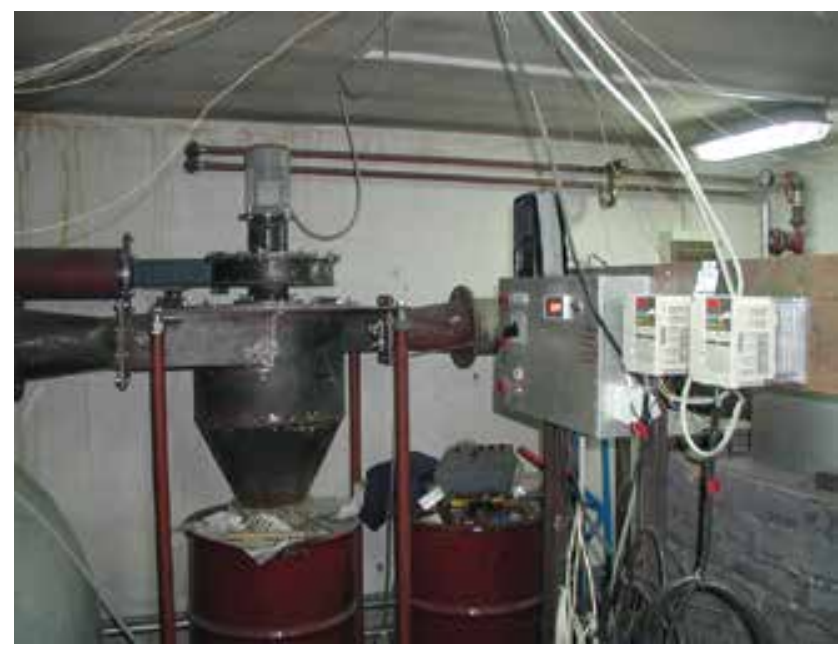

Fig. 3. The cyclone-type particle precipitator 
The thermal power of the boiler has been regulated with: the amount of straw engaged in the combustion process, the air excess and the fuel feeding rate. This experimental boiler could be scaled, since it satisfies the similarity requirements in (Beer, 1966): geometry, flow patterns, thermal load, thermal flux, adiabatic temperature, average temperature and flue gases content.

\section{Some results of the boiler investigation}

Biomass combustion in the boiler has been experimentally investigated. The experiment groundwork consisted of biomass sample preparation. The sample biomass was soybean and wheaten straw. The proximate and ash analysis of straw used in tests is given in table 5 .

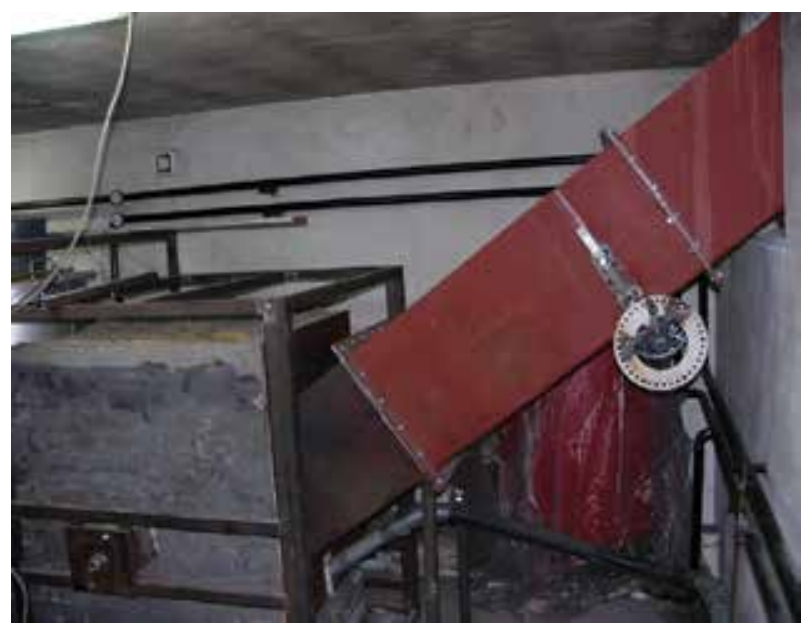

Fig. 4. Inclined fuel feeding

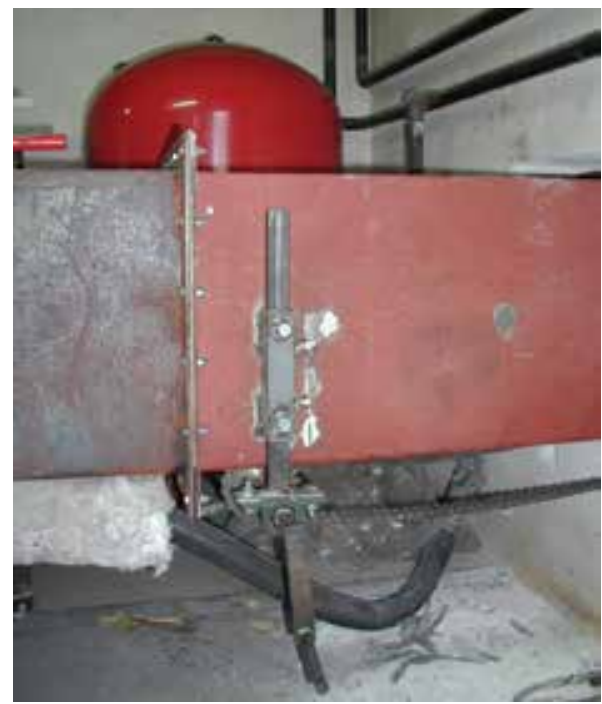

Fig. 5. Horizontal fuel feeding 
The sum of six tests was done. A summary of main test parameters is given in table 6 . Experiments trough 1-5 was performed with inclined bale feeder, and 6 with horizontal feeder. Experiments trough 1-4 was performed using soybean straw, and 5-6 using soybean and wheaten straw as fuel.

Experiments with both type of biomass have been successful, and showed that straw is suitable for cigarette-type combustion technology. Especially, soybean straw is very suitable for this technology of straw combustion because the ash melting temperature is so high (table 5). A picture of the cigarette flame of baled biomass is shown in Fig. 8.

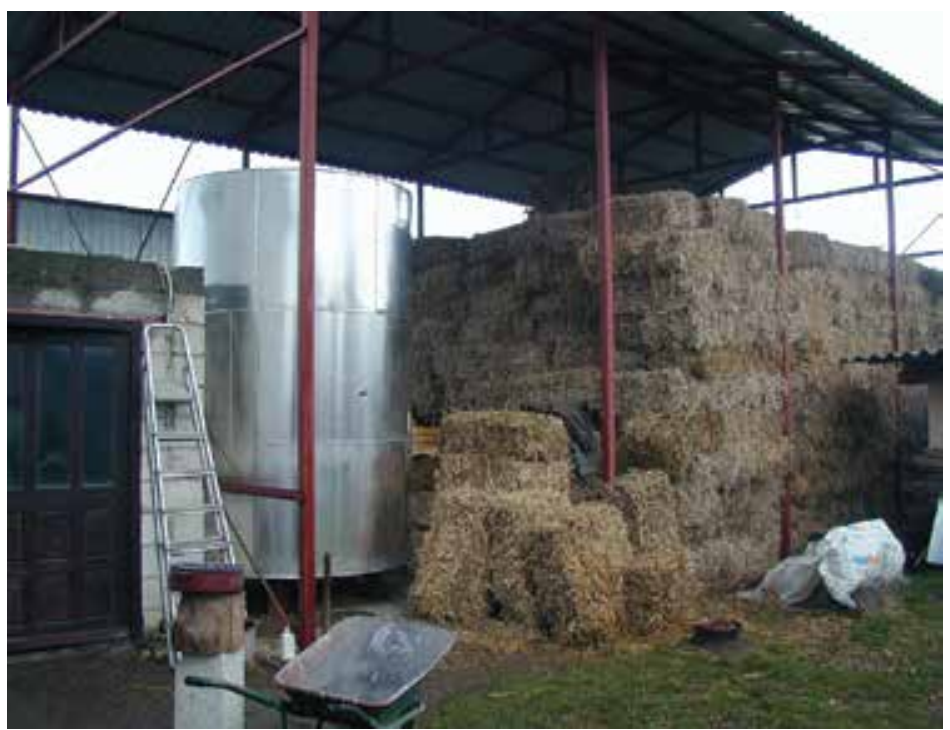

Fig. 6. Heat accumulator (thermal reservoir)

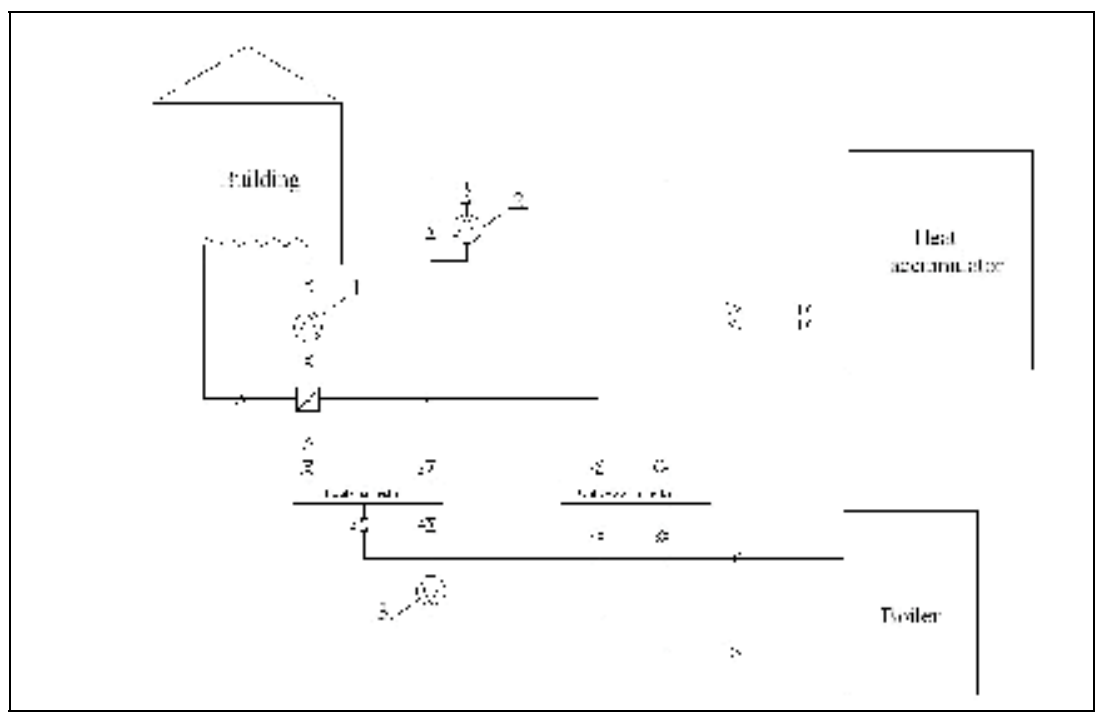

Fig. 7. Thermal scheme of distribution facilities 


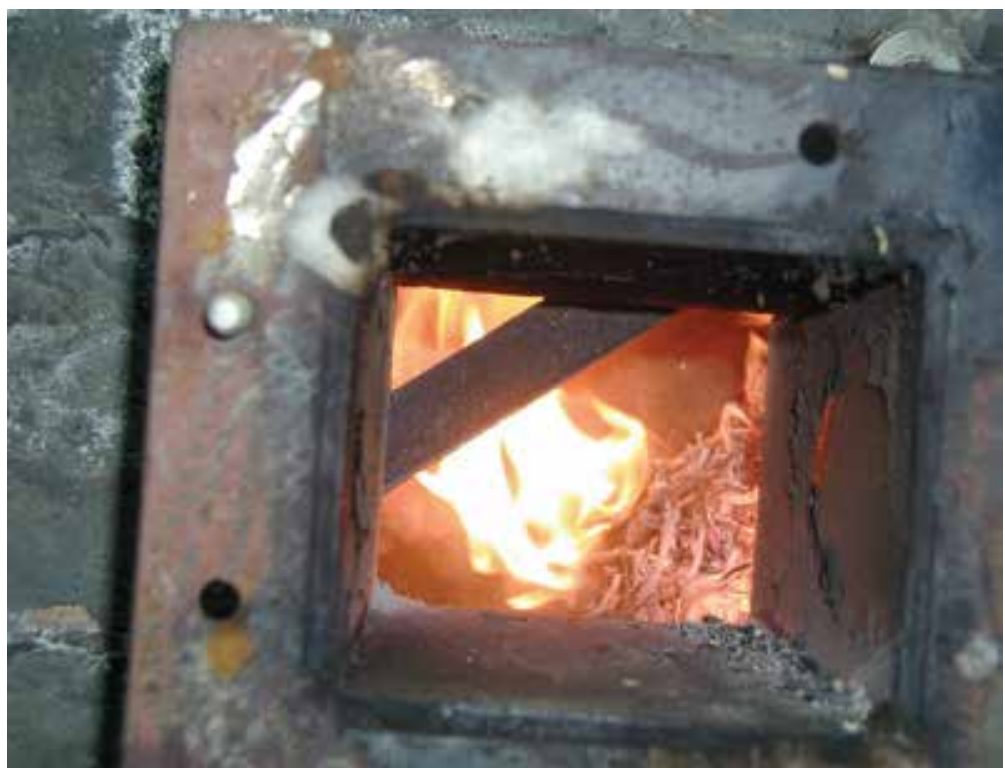

Fig. 8. Cigarette flame of baled biomass

\begin{tabular}{|l|c|c|c|}
\hline Element & Unit & Wheat straw & Soybean straw \\
\hline Proximate analyze & & & \\
\hline Moisture & $\%$ & 9.90 & 18.80 \\
\hline Ash & $\%$ & 11.29 & 5.66 \\
\hline Combustible matter & $\%$ & 78.81 & 75.54 \\
\hline Volatile matter & $\%$ & 62.33 & 59.08 \\
\hline Fixed carbon & $\%$ & 16.48 & 16.46 \\
\hline Char & $\%$ & 27.77 & 22.12 \\
\hline Net calorific value & $\mathrm{kJ} / \mathrm{kg}$ & 14.242 & 14.318 \\
\hline Solubility of the ash & & & 1185 \\
\hline Sintering (shrinkage) strat temperature & ${ }^{\circ} \mathrm{C}$ & 880 & 1310 \\
\hline Deformation temperature & ${ }^{\circ} \mathrm{C}$ & 1020 & 1420 \\
\hline Hemisphere temperature & ${ }^{\circ} \mathrm{C}$ & 1125 & 1170 \\
\hline Flow temperature & ${ }^{\circ} \mathrm{C}$ & & \\
\hline
\end{tabular}

Table 5. The proximate analysis of straw used in tests 


\begin{tabular}{|l|c|c|c|c|c|c|}
\hline Test & 1 & 2 & 3 & 4 & 5 & 6 \\
\hline Number of used bales & 2,0 & 2,0 & 5 & 6 & 12 & 11 \\
\hline Amount of straw $(\mathrm{kg})$ & 24,6 & 27,7 & 61,3 & 75,9 & 166 & 144 \\
\hline Average fuel consumption $(\mathrm{kg} / \mathrm{h})$ & 21,1 & 16,6 & 18,4 & 19,8 & 20,8 & 17,3 \\
\hline Total air flow rate $\left(\mathrm{m}^{3} / \mathrm{h}\right)$ & 169 & 143 & 187 & 173 & 166 & 169 \\
\hline Calculated thermal power $(\mathrm{kW})$ & 71,3 & 49,4 & 53,5 & 57,4 & 60,3 & 50,2 \\
\hline Air excess coefficient measured at & 1,38 & 2,23 & 1,45 & 1,62 & 1,35 & 1,09 \\
the furnace exit $\mathrm{l}(-)$ & $-2,35$ & $-5,35$ & $-4,27$ & $-4,27$ & $-2,52$ & $-2,82$ \\
\hline Test duration $(\mathrm{min})$ & 75 & 100 & 200 & 230 & 480 & 560 \\
\hline
\end{tabular}

Table 6. Test parameters

Short and long tests have been carried out, with average fuel flow rates of 16,6 to $21,1 \mathrm{~kg} / \mathrm{h}$ (table 6). The thermal power of the boiler changed in the range from 49,4 to $71,3 \mathrm{~kW}$. The boiler power has been regulated using the regulatory distributor of air excess. Air excess coefficient measured at the furnace exit varied in the range of 1,09-5,35. This shows that there were significant suctions of air from the outside into the furnace, especially in the period when new bales were led into the channel. There was no ash sticking on boiler walls, as well as on the heat exchanger, which was checked after the experiments (Fig. 9).

In order to obtain valid information on the operation of the facility, the following parameters were measured (Fig. 10):

- flue gas temperatures (in the furnace - $t_{1}$, in the burn-out zone - $t_{2}$, and behind the heatexchanger $-t_{3}$ ),

- $\quad$ water temperatures (at the outlet $-t_{4}$ and at the inlet $-t_{5}$ ), and

- flue gas contents at the boiler outlet (amount of $\mathrm{O}_{2}, \mathrm{CO}$ and NOx). Gas sampling was done with a probe placed in the gas duct. Gas samples were discontinuously analyzed since the gas analyzer used is not meant for continuous measurement.

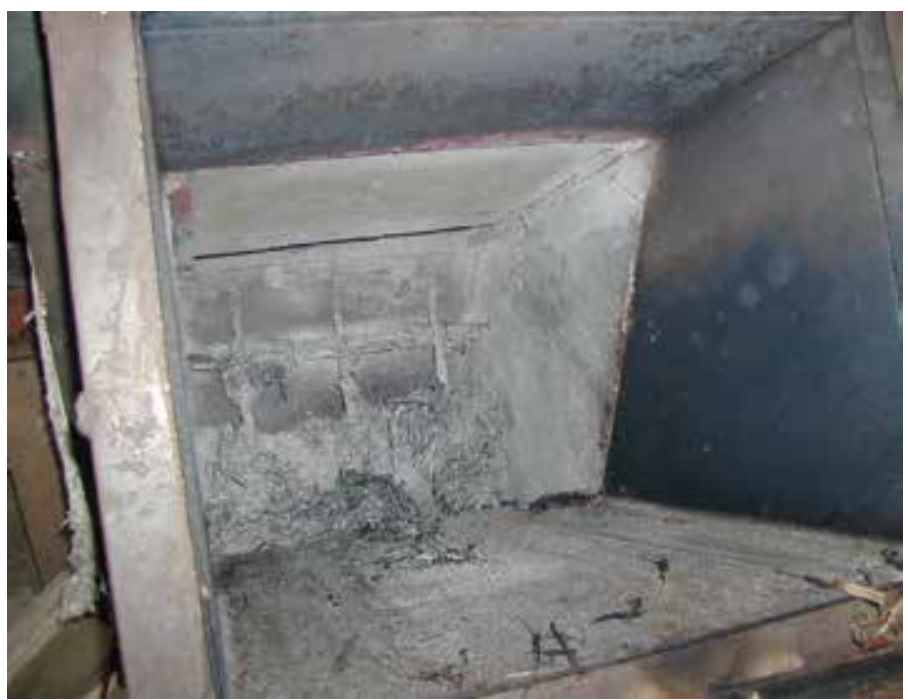

Fig. 9. The view of the furnace inside 


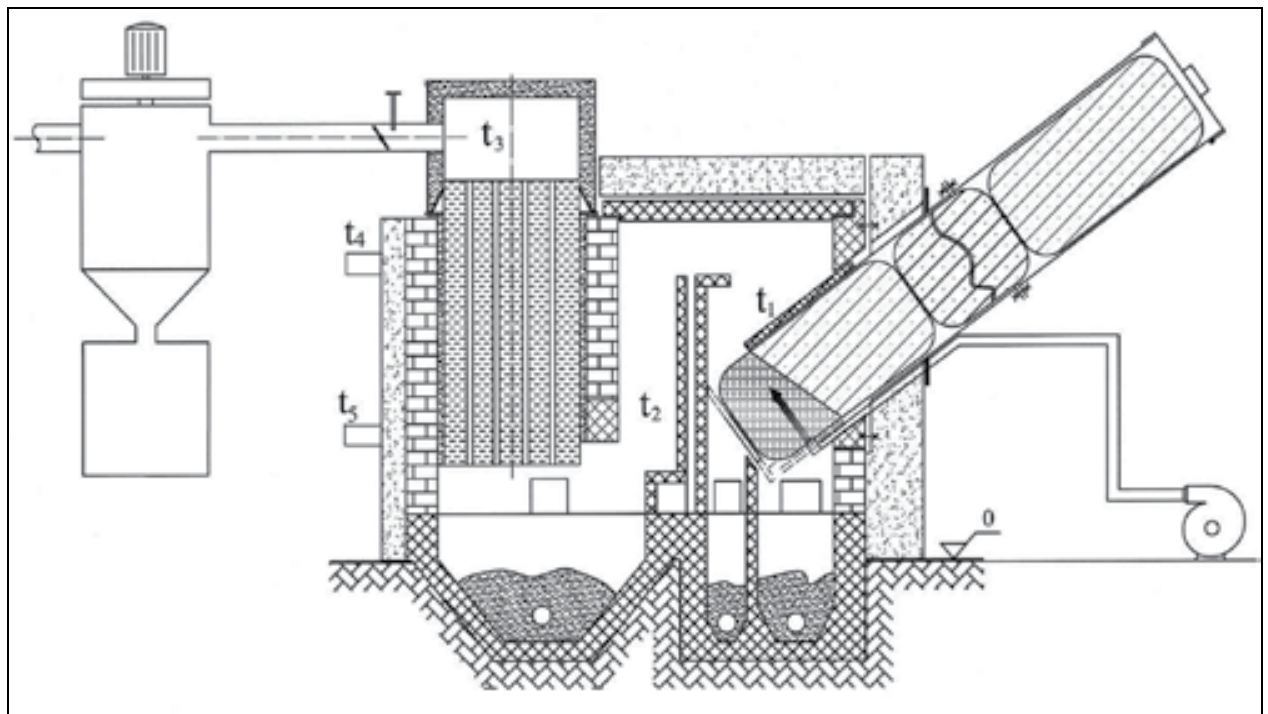

Fig. 10. Measured scheme

In Figs. 11 and 12 flue gas and water temperatures are presented, for two regimes of operation. It can be seen (Fig. 11) that gas temperature in the furnace rose up to $1000^{\circ} \mathrm{C}$, in the burn-out zone up to $850^{\circ} \mathrm{C}$, and on the boiler outlet up to $220^{\circ} \mathrm{C}$, during the operating regime 2. During the operating regime 6 (Fig. 12), the gas temperature in the furnace was about $900{ }^{\circ} \mathrm{C}$, in the burn-out zone up to $800^{\circ} \mathrm{C}$, and at the boiler outlet up to $220^{\circ} \mathrm{C}$. According to the temperature histories, it could be concluded that soybean and wheat straw combustion was satisfactory. Also, the measured water temperatures at the outlet and at the inlet (Figs. 11 and 12) have been in accordance with the values recommended for the heating of objects. The hot water temperature reached values of $95^{\circ} \mathrm{C}$, while the water temperature at the inlet reached $70^{\circ} \mathrm{C}$.

As mentioned earlier, during all experiments the contents of the flue gases at the boiler outlet was measured. For the reason of instrument used (instrument with electrochemical cells), gas samples were discontinuously analyzed - several times for 10-20 minutes - during all regimes of operation. The results obtained for $\mathrm{O}_{2}, \mathrm{CO}$ and $\mathrm{NOx}$ contents in the exit flue gases, for operating regimes 2 and 6, are presented in Figs. 13 to 16. Oscillation in the $\mathrm{O}_{2}$ and $\mathrm{CO}$ contents are a consequence of several influences: unsteady feeding of baled biomass, which is caused by gravitational feeding and introduction of the bales into the furnace space; periodical opening of the cover at the back side of the bale channel, which caused rapid suction of false air into the boiler furnace. Measurement of NOx shows smaller oscillations in measured emission values.

Measurement of the oxygen content in exit flue gases has shown a range of $10-17 \%$, depending on the combustion regime. In Fig. 13, the oxygen content in the flue gases for a chosen sequence of measurement at stable operating conditions, for operating regime 2, is shown. Simultaneously, CO and NOx content in the flue gases have been measured (Figs. 15 and 16). The Book of Regulations on emission limitations, issued by Serbian Ministry of Environmental Protection (1997) recommends that furnaces and boilers burning wood, briquettes and waste biomass should satisfy certain values of $\mathrm{CO}$ and NOx oxides 
limitations. Although the investigated boiler has small capacity, and not subjected to emission limitations (Book of Regulation, 1997), it has been anticipated that in the future small capacity boilers will have to meet some limitation requirements. During the investigations, $\mathrm{CO}$ emission varied in a wide range. When stable regime of operation was established, $\mathrm{CO}$ emission was in the range between $81 \mathrm{mg} / \mathrm{m}^{3}$ and $243 \mathrm{mg} / \mathrm{m}^{3}\left(\right.$ at $11 \% \mathrm{O}_{2}$ in the flue gases), which is below Serbian emission limitation (for furnaces and boilers with power 1-50 MWt it is $250 \mathrm{mg} / \mathrm{m}^{3}$, calculated for $11 \% \mathrm{O}_{2}$ ). Nitrogen oxides emission was in the range between $311 \mathrm{mg} / \mathrm{m}^{3}$ and $384 \mathrm{mg} / \mathrm{m}^{3}$ (at 11\% $\mathrm{O}_{2}$ in the flue gases), which is below the $500 \mathrm{mg} / \mathrm{m}^{3}$ legislative limit.

The experimental investigation of the boiler has provided necessary parameters (ratio of primary $(67-82 \%$ of total air), secondary (12-21\%) and tertiary air (6-12\%), temperatures in the furnace, at the inlet/outlet of the heat exchanger and at the boiler outlet) for the calculation and design of higher capacity boilers, burning baled biomass.

Boiler efficiency was determined according to recommendations (Brkic et al., 1999), and the values of the elements that are of importance for efficiency calculations are given in table 7 .
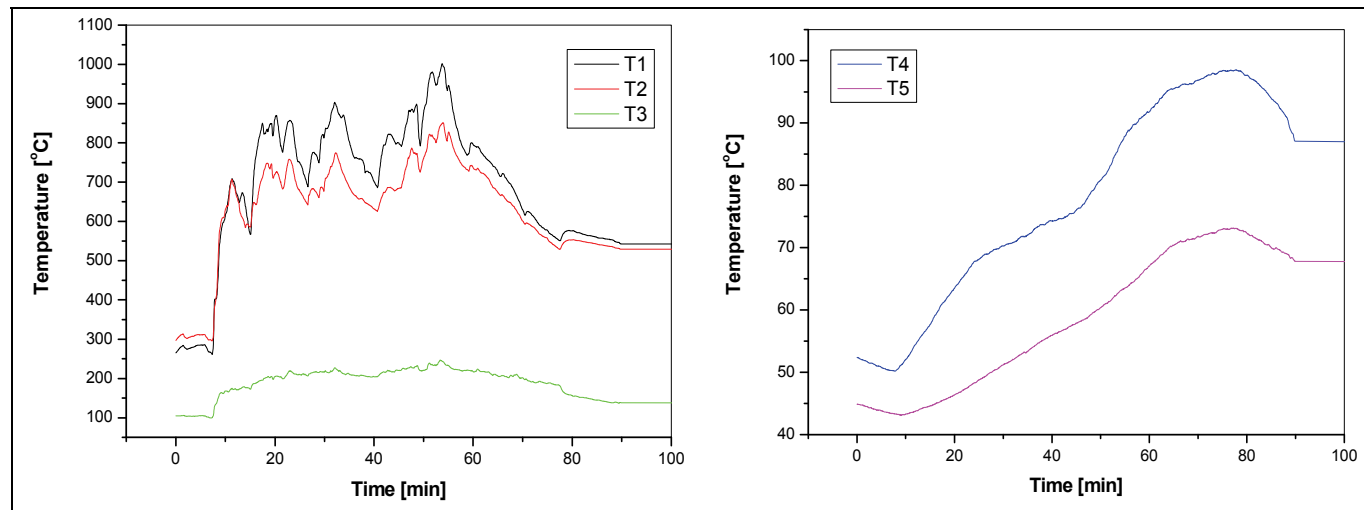

Fig. 11. Measured gas and water temperatures (operating regime 2)
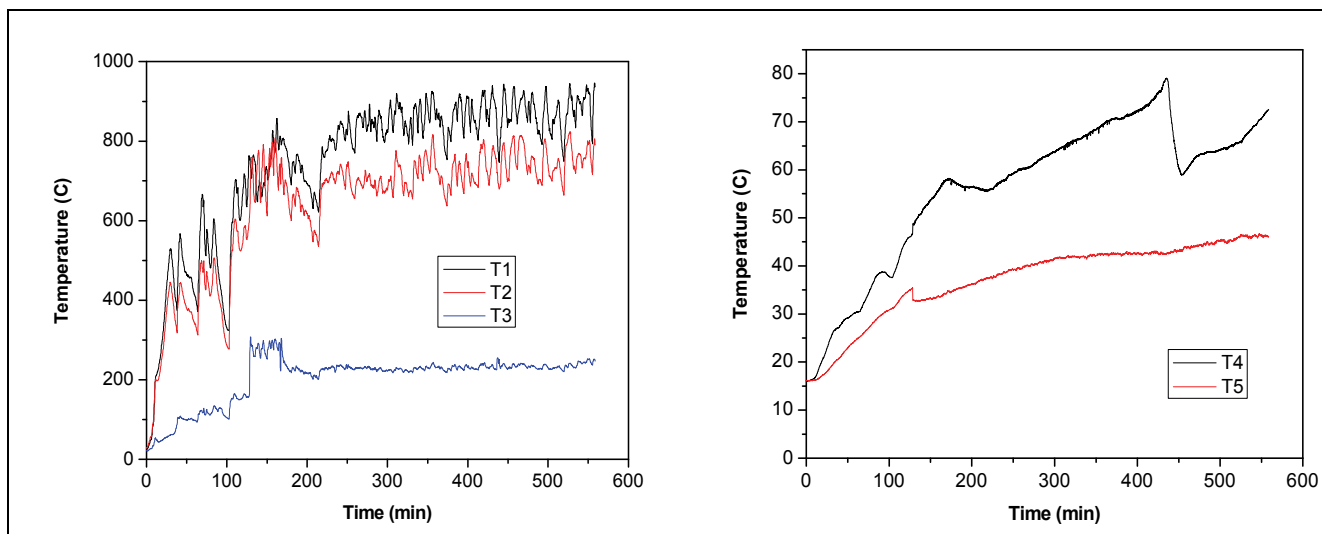

Fig. 12. Measured gas and water temperatures (operating regime 6) 


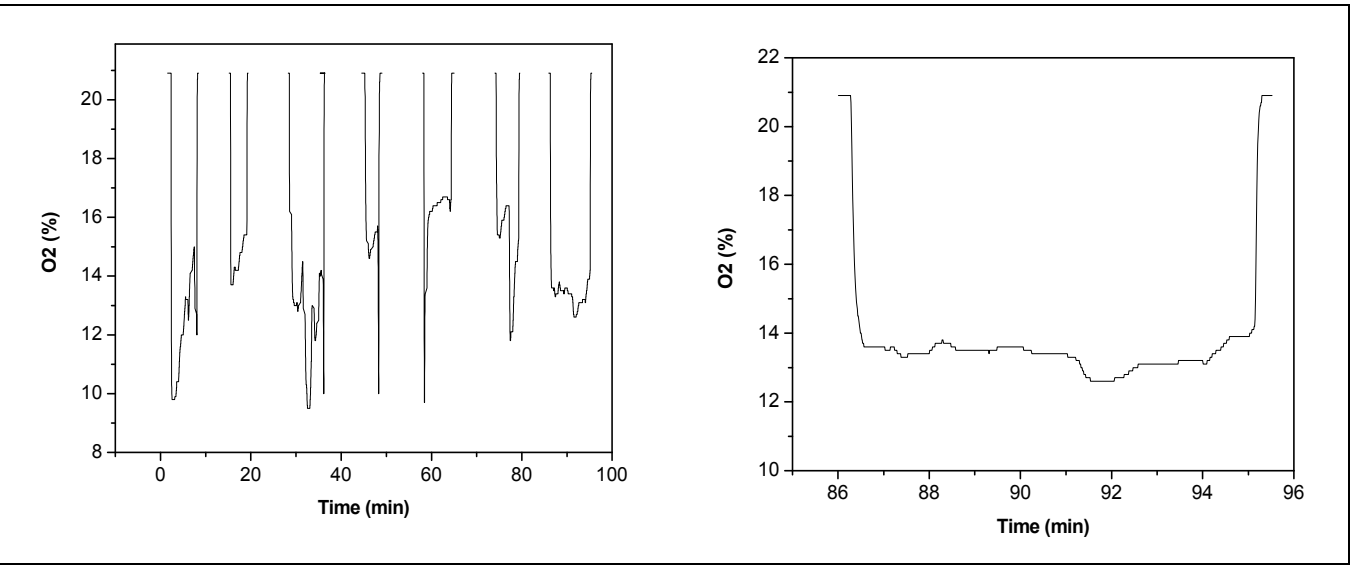

Fig. 13. Change of $\mathrm{O}_{2}$ concentration in exit flue gases - operating regime 2

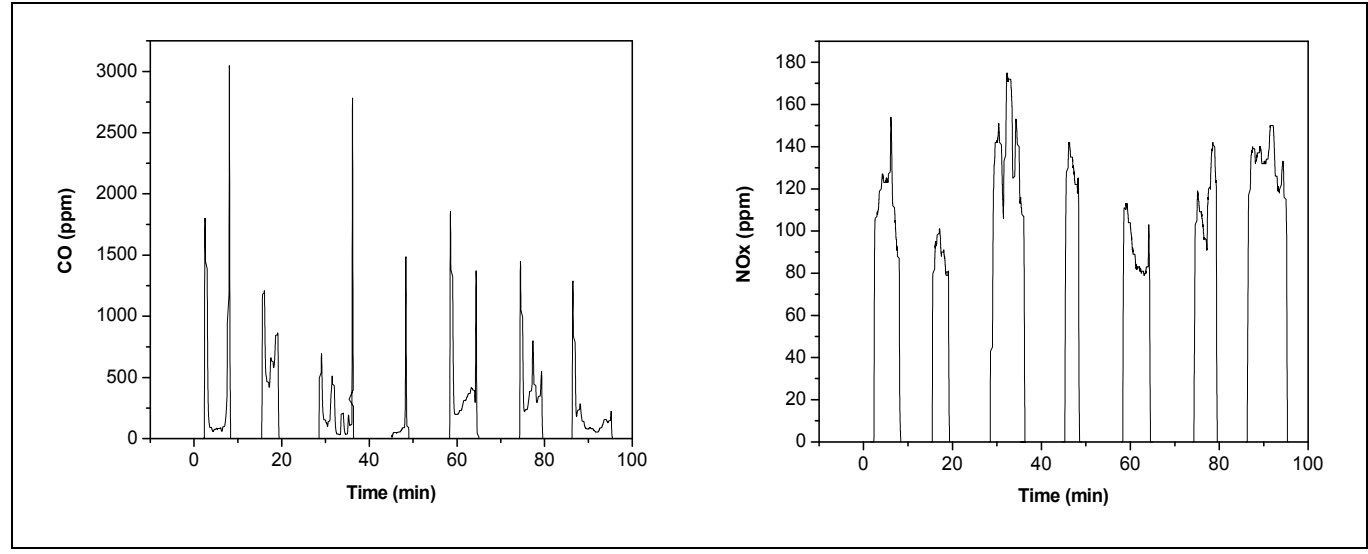

Fig. 14. Emission of the flue gases products (CO and NOx) - operating regime 2

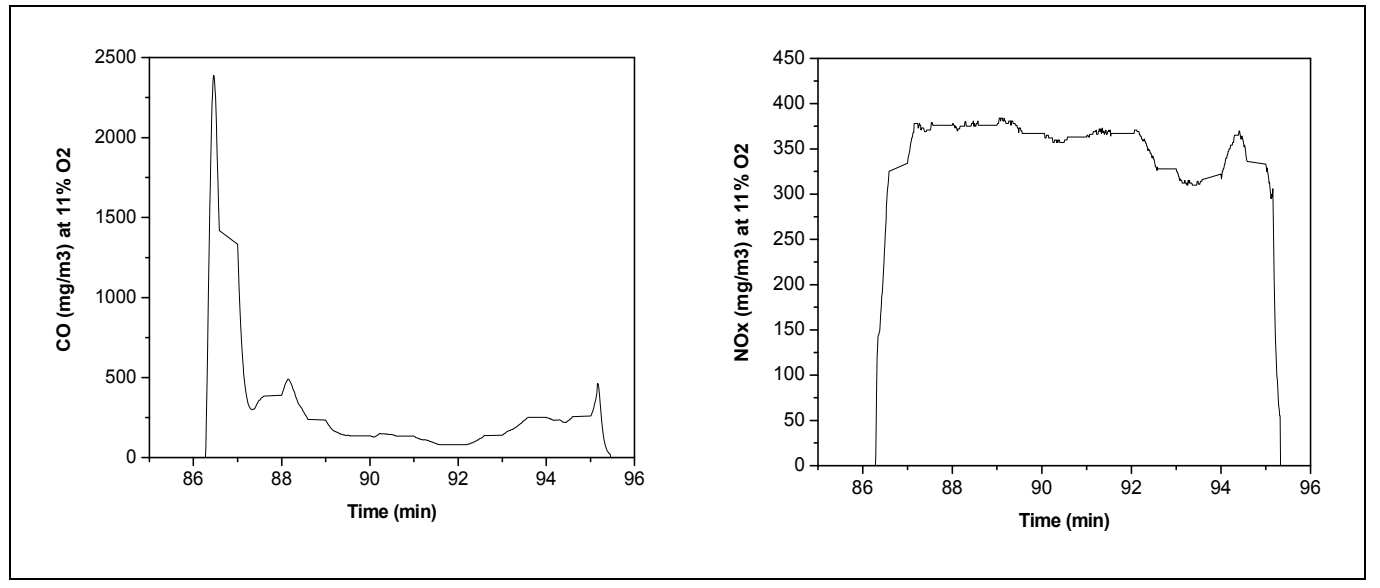

Fig. 15. Emission of the flue gases products $(\mathrm{CO}, \mathrm{NOx})$ - a sequence in operating regime 2 


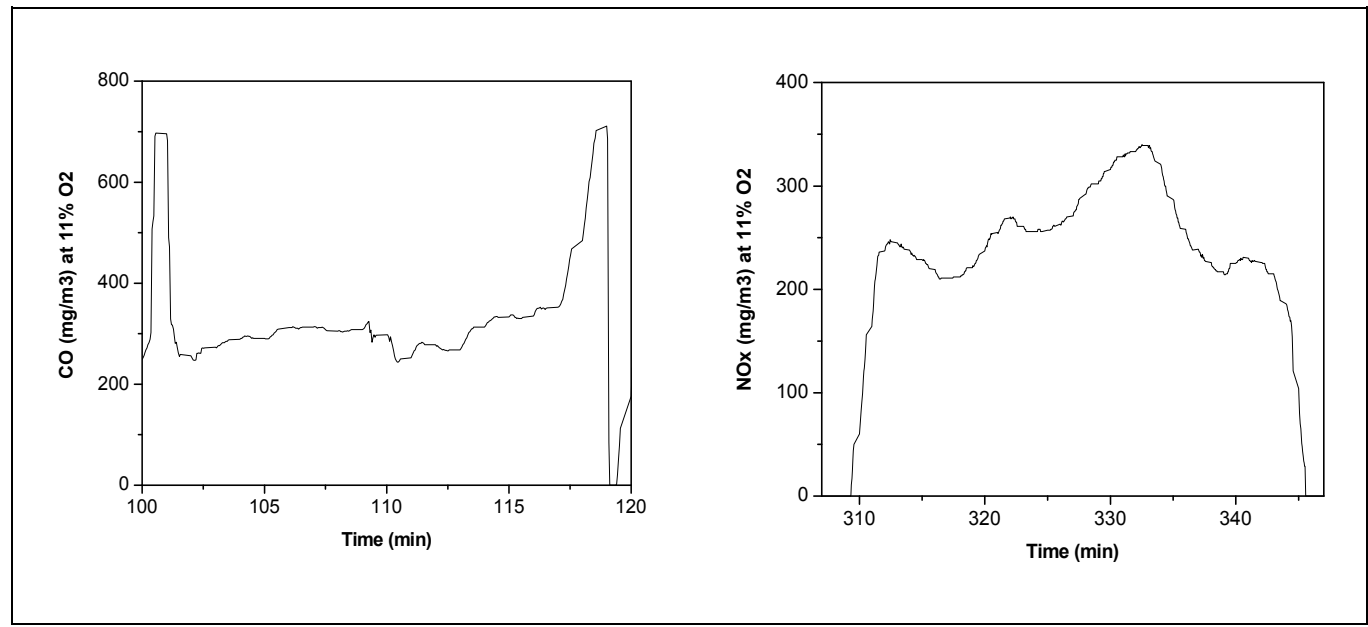

Fig. 16. Emission of the flue gases products $(\mathrm{CO}, \mathrm{NOx})$ - a sequence in operating regime 6

\begin{tabular}{|l|c|c|}
\hline Element & Unit & Value \\
\hline Lower heating value & $\mathrm{kJ} / \mathrm{kg}$ & 13686 \\
\hline Available heat & $\mathrm{kJ} / \mathrm{kg}$ & 13686 \\
\hline Air excess coefficient at the boiler exit & - & 2,8 \\
\hline Combustion (fresh) air temperature & ${ }^{\circ} \mathrm{C}$ & 30 \\
\hline Enthalpy of the theoretical amount of combustion air & $\mathrm{kJ} / \mathrm{kg}$ & 140,61 \\
\hline Exit flue gas temperature & ${ }^{\circ} \mathrm{C}$ & 220 \\
\hline Exit flue gas enthalpy & $\mathrm{kJ} / \mathrm{kg}$ & 3240,97 \\
\hline $\begin{array}{l}\text { Heat loss due to mechanical incompleteness of } \\
\text { combustion }\end{array}$ & $\%$ & 4 \\
\hline Loss with the flue gas & $\%$ & 19,97 \\
\hline Heat loss due to chemical incompleteness of combustion & $\%$ & 0,5 \\
\hline Heat loss due to boiler cooling from the outside & $\%$ & 2 \\
\hline Heat loss due to the physical heat of slag & $\%$ & 0,2 \\
\hline Boiler efficiency & $\%$ & 73,33 \\
\hline
\end{tabular}

Table 7. Calculation of the boiler efficiency 


\section{Conclusions}

The results of the development of the experimental boiler burning baled biomass have been presented in the paper. The combustion has been organized on the principles of cigarette burning. Basic features and advantages of this kind of combustion have been shown, as well as some essential test results. The investigation proved that with agricultural biomass combustion:

- ensures high enough temperatures in the boiler combustion zone,

- $\quad$ water in the heat exchanger can be heated to nominal temperature, and

- $\quad \mathrm{CO}$ and NOx emissions are low enough.

Investigations were performed using soybean and wheaten straw as fuel. Experiments with both type of biomass have been successful, and showed that straw is suitable for cigarettetype combustion technology. Especially, soybean straw is very suitable for this technology of straw combustion because their ash melting temperature is so high. In the next time investigations with other type of straw (corn and rape seed) will be performed. All data collected during these experimental tests were used for designing and building-up of a 1.5 MW hot water boiler for greenhouse heating, also based on cigarette type combustion using large baled biomass.

\section{Acknowledgements}

This work was supported by the Ministry of Science and Technological Development of Serbia, through the project TR18216 “Development of technology for cigarette baled biomass combustion with analyze of possibility of combined production heat and electric energy".

\section{References}

Beer, J.M. (1966). The significance of modelling, J. Inst. Fuel, November, pp.466-473.

Brkic, LJ., Zivanovic, T. \& Tucakovic, D. (1999). Thermal calculation of steam boilers (in Serbian), Faculty of Mechanical Engineering, Belgrade, Serbia.

Djurovic, D., Dakic, D., Repic, B. \& Stojiljkovic, D. (2008). Development of the small scale boiler for combustion of baled biomass from agricultural production, Thermal engineering, Vol.34, No.2-3, pp. 161-173, ISSN 0350 $-218 X$.

Djurovic, D., Dakic, D., Eric, A. \& Repic, B. (2009). Development of the boiler for combustion of agricultural biomass by products, Proceedings on CD ROM of $5^{\text {th }}$ Dubrovnik Conference on Sustainable Development of Energy, Water and Environment Systems, pp.1 -18, Dubrovnik, Croatia, September 29th -October 3th, ISBN 978-953-6313-98-3.

Ilic, M., Oka, S., Grubor, B., Dakic, D. et al. (2003). Energy potential and characteristics of waste biomass and its preparation technologies in Serbia, Report on Project of National Program of Energy Efficiency, NPEE 611-113A (in Serbian), Belgrade. 
Kavalov, B. \& Peteves, S.D. (2004). Bioheat applications in the European Union: An Analysis and Perspective for 2010, European Commission Directorate General Joint Research Centre, Institute for Energy.

Kraus, U. (1985). Test results from pilot plants for firing wood and straw in the Federal Republic of Germany, Energy from biomass, Proceedings $3^{\text {rd }}$ E.C. Conference Energy from Biomass, pp. 799-803, Elsevier Applied Science Publishers, London.

Leckner, B. (2007). Co-combustion - a summary of technology, Thermal Science, Vol. 11, No.4, pp. 5-40.

Martinov, M., Tesic, M. \& Brkic, M. (2006). Efficiency and emission of crop residues combustion facilities in Serbia - status and needed measures for improvement, Thermal Science, Vol. 10, No. 1, pp. 189-194.

Merick, D. (1984). Coal combustion and conversion technology, Macmillan Publishers Ltd., London, UK.

Mladenovic, R., Eric, A., Mladenovic, M., Repic, B. \& Dakic, D. (2008). Energy Production Facilities of Original Concept for Combustion of Soya Strow Bales, Proceedings on CD ROM of 16th European Biomass Conference $\mathcal{E}$ Exibition "From research to industry and markets", pp. 1260-1270, June 2-6, Valensia, Spain.

Mladenovic, R., Dakic, D., Eric, A., Mladenovic, M., Paprika, M. \& Repic, B. (2009). The boiler concept for combustion of large soya straw bales, Enery, Vol. 34, No. 5, pp. 715-723.

Obernberger, I. (1998). Decentralized biomass combustion: state of the art and future development, Biomass and Bioenergy, Vol. 14, No. 1, pp. 33-56.

Oka, S. (1992). Utilization of biomass for energy purposes, Technologies development program and conditions for realization, Professional Advancement Series "Biomass combustion for energy purposes", pp. 9-19, Ed. N. Ninić, S. Oka, Yugoslav Society of Thermal Engineering, Scientific book, Belgrade, Serbia.

Repic, B., Dakic, D., Paprika, M., Mladenovic, R. \& Eric, A. (2008). Soya straw bales combustion in high efficient boiler, Thermal Science, Vol. 12, No. 4, pp.51-60.

Repic, B., Dakic, D., Mladenovic, R., Eric, A. (2008). Development of a boiler based on cigarette combustion principle for straw bales from agricultural production, Proceedings on CD ROM of 18th International Congress of Chemical and Process Engineering CHISA 2008, Paper P5.264., pp. 1-12, August 24-28, Praha, Czech Republic, ISBN 978-80-02-02047-9.

Republic of Serbia, Ministry of environmental protection. (1997). Book of Regulations on emission limitations (in Serbian), Belgrade, Serbia.

Strehler, A. (2005). Results from the research work in heat generation from wood and strow, Energy from Biomass, Elsevier, London, pp.788-792.

Tortosa-Masia Abel, A., Anhert, F., Spliethoff, H. \& Hein, K.R.G. (2003). Slagging and fouling in biomass co-combustion, Thermal Science, Vol. 9, No. 3, pp. 85-98. 
van Dam, J., Faaij, A.P.C., Lewandowski, I. \& Fischer, G. (2007). Biomass production potentials in Central and Eastern Europe under different scenarios, Biomass and Bioenergy, Vol. 31, pp. 345-366.

Zabanitou, A. A., Skoulalou, V. K., Koufodimos, G. S. \& Samaras, Z. C. (2007). Investigation study for technological application of alternative methods for the energy exploitation of biomass-agricultural residues in Northern Greece, Thermal Science, Vol. 11, No. 3, pp. 115-123. 



\section{Edited by Jatin Nathwani and Artie Ng}

The world's reliance on existing sources of energy and their associated detrimental impacts on the environment- whether related to poor air or water quality or scarcity, impacts on sensitive ecosystems and forests and land use - have been well documented and articulated over the last three decades. What is needed by the world is a set of credible energy solutions that would lead us to a balance between economic growth and a sustainable environment.

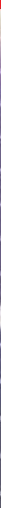

